Arthur Schnitzler

Reigen

Band 1 


\title{
Arthur Schnitzler
}

\author{
Werke \\ in historisch-kritischen Ausgaben
}

Herausgegeben von

Konstanze Fliedl 


\section{Arthur Schnitzler}

\section{Reigen}

Historisch-kritische Ausgabe

Herausgegeben von

Marina Rauchenbacher und Konstanze Fliedl

unter Mitarbeit von

Ingo Börner, Teresa Klestorfer und Isabella Schwentner

Band 1 
Diese Ausgabe entstand im Rahmen der vom österreichischen Fonds zur Förderung der wissenschaftlichen Forschung (FWF) finanzierten Projekte

„Arthur Schnitzler - Kritische Edition (Frühwerk) II“ (P 27138)

und „Arthur Schnitzler - Kritische Edition (Frühwerk) III“ (P 30513).

Für Abdruckgenehmigungen ist der Cambridge University Library, dem Deutschen

Literaturarchiv Marbach, der Fondation Martin Bodmer, Cologny (Genève), dem KHM-Museumsverband - Theatermuseum Wien, dem Niederösterreichischen Landesarchiv,

St. Pölten und der Wienbibliothek im Rathaus (MA 9) zu danken. Für weitere finanzielle Unterstützung ist darüber hinaus dem Referat Wissenschaft und Forschung der Kulturabteilung der Stadt Wien (MA 7) zu danken.

Lektorat: Gregor Gumpert

Es wurde versucht, alle Rechtsnachfolger zu ermitteln,

im Falle unberücksichtigt gebliebener Ansprüche bitten wir, sich an den Verlag zu wenden.

ISBN 978-3-11-065590-2

e-ISBN (PDF) 978-3-11-066158-3

Veröffentlicht mit Unterstützung des Austrian Science Fund (FWF), PUB 648-Z

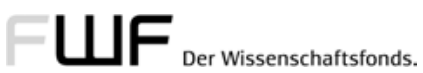

\section{(cc) BY}

Dieses Werk ist lizensiert unter der Creative Commons Attribution 4.0 Lizenz. Weitere Informationen finden Sie unter https://creativecommons.org/licenses/by/4.0/

Library of Congress Control Number: 2019941828

Bibliografische Information der Deutschen Nationalbibliothek

Die Deutsche Nationalbibliothek verzeichnet diese Publikation in der Deutschen

Nationalbibliografie; detaillierte bibliografische Daten sind im Internet über http://dnb.dnb.de abrufbar.

(C) 2019 Marina Rauchenbacher, Konstanze Fliedl, published by Walter de Gruyter GmbH \& Co. KG, Berlin/Boston Dieses Buch ist publiziert Open Access auf www.degruyter.com Einbandgestaltung: Martin Zech, Bremen

Satz: Dörlemann Satz GmbH \& Co. KG, Lemförde Druck und Bindung: Hubert \& Co. GmbH \& Co. KG, Göttingen $\infty$ Gedruckt auf säurefreiem Papier

Printed in Germany

www.degruyter.com 


\section{Inhalt}

0. Vorbemerkung ....................... . . 1

0.1 Entstehungsgeschichte . . . . . . . . . . . . . . . . . . 1

0.2 Provenienz . . . . . . . . . . . . . . . . . . . . . . . . . 1

0.3 Nachlass-Konvolut . . . . . . . . . . . . . . . . . . . . . 2

0.4 Genese. . . . . . . . . . . . . . . . . . . . . . . . . 3

0.5 Genetisches Material . . . . . . . . . . . . . . . . . . . . . . 9

0.6 Zur Handschrift. . . . . . . . . . . . . . . . . . . . . . . . . 11

0.7 Zur Umschrift . . . . . . . . . . . . . . . . . . . . . . . 12

0.8 Druckgeschichte . . . . . . . . . . . . . . . . . 12

0.9 Uraufführung und österreichische Erstaufführung . . . . . . . . 22

0.10 Zum Drucktext . . . . . . . . . . . . . . . . . . . . 23

0.11 Zum Apparat. . . . . . . . . . . . . . . . . . . . . . . . . . . . 24

0.12 Zum Kommentar . . . . . . . . . . . . . . . . . . . . . . . . . . . 29

1. Handschriften und Typoskript . . . . . . . . . . . . . . 31

Umschlag $\cup \ldots \ldots \ldots \ldots$

Entwurfsskizze E . . . . . . . . . . . . . . . . . . . . . 34

Figurenliste $\mathrm{HF} \ldots \ldots \ldots \ldots \ldots$

Szene 1 HSz1 . . . . . . . . . . . . . . . . . . . . . . . . . . 38

Szene $2 \mathrm{HSz2} \ldots \ldots \ldots \ldots \ldots$

Szene 3 HSz3 . . . . . . . . . . . . . . . . . . . . . . . . . . . . 106

Szene 4 HSz4. . . . . . . . . . . . . . . . . . . . . . . . . . . . . . . 144

Typoskript TSz4 . . . . . . . . . . . . . . . . . . . . . . . . . . . . . . 272

Szene 5 HSz5. . . . . . . . . . . . . . . . . . . . . . . . . . . . . 280

Szene 6 HSz6. . . . . . . . . . . . . . . . . . . . . . . . . . . . . 354

Szene 7 HSz7. . . . . . . . . . . . . . . . . . . . . . . . . . . . . . 482

Szene 8 HSz8 . . . . . . . . . . . . . . . . . . . . . . . . . . 576

Textstufe H'Sz9 . . . . . . . . . . . . . . . . . . . . . . . . . . . . . . . . 658

Szene $9 \mathrm{HSz9} \ldots \ldots \ldots$. . . . . . . . . . . . . . . . . . . . 742

Textstufe H'Sz10 . . . . . . . . . . . . . . . . . . . . . . . . 830

Notiz N . . . . . . . . . . . . . . . . . . . . . . . . . . . . . . . 870

Szene 10 HSz10 . . . . . . . . . . . . . . . . . . . . . 872

2. Drucktext. . . . . . . . . . . . . . . . . . . . . 929

2.1 Herausgebereingriffe . . . . . . . . . . . . . . . 1051 
3. Kommentar . . . . . . . . . . . . . . . . . 1053

4. Anhang . . . . . . . . . . . . . . . . . . 1065

4.1 Schenkungsblatt . . . . . . . . . . . . . . . . . . . . 1067

4.2 Schauplätze und Orte . . . . . . . . . . . . . . . . . . . . . 1068

4.3 Stadtplan von Wien (1893) . . . . . . . . . . . . . . . . . . . 1071

4.4 Druckgeschichte . . . . . . . . . . . . . . . . . . . . . . 1072

4.5 Beispielseiten aus dem Privatdruck . . . . . . . . . . . . . . . 1075

4.6 Siglenverzeichnis . . . . . . . . . . . . . . . . . . . . 1087 


\section{0 . Vorbemerkung}

\subsection{Entstehungsgeschichte}

Am 23. November 1896 vermerkte Arthur Schnitzler in seinem Tagebuch: „Einen Hemicyclus von zehn Dialogen begonnen" (Tb II, 226); am 24. Februar 1897 notierte er: „Liebesreigen' beendet.” (Tb II, 239) Diese ,Dialoge' wurden 1900 unter dem Titel Reigen als Privatdruck publiziert und sorgten zwei Jahrzehnte später durch die Uraufführung in Berlin und die erste österreichische Aufführung in Wien für einen der größten Theaterskandale des 20. Jahrhunderts.

\subsection{Provenienz}

Das erhaltene handschriftliche Konvolut zu Reigen schenkte Schnitzler an seinem 68. Geburtstag am 15. Mai 1930 seiner geschiedenen Frau Olga Schnitzler.1 1938, nach dem sogenannten ,Anschluss' Österreichs an das Deutsche Reich, wurde es wie Schnitzlers gesamter Nachlass - nach Großbritannien gebracht und an der Cambridge University Library verwahrt. ${ }^{2}$ Von dort nahm es Olga Schnitzler - zusammen mit anderen ihr überlassenen Materialien - in die USA mit; in einem Brief an den gemeinsamen Sohn Heinrich Schnitzler ist diesbezüglich von den ihr "geschenkten und handschriftlich gewidmeten 3 Manuscripte[n] in bunten Ledermappen: ,Liebelei', "Casanova' und ,Reigen'“3 die Rede. Bereits vor 1938 hatte Olga Schnitzler allerdings an einen Verkauf gedacht und deswegen Raoul Auernheimer kontaktiert. ${ }^{4}$ Erst am 3. Mai 1956 - sie lebte damals in Berkeley/Kalifornien - übernahm der Schweizer

1 Vgl. Handschriftliches Schenkungsblatt: "Dieses Manuscript / Reigen / gehört Olga / Arthur Schnitzler / Wien, 15. Mai 1930" (TMW, HS_Schn 152_12,2; s. Anhang, S. 1067).

2 Zur Geschichte von Schnitzlers Nachlass vgl. LG-HKA 1.

3 Brief v. Olga Schnitzler an Heinrich Schnitzler v. 30.10.1938 (DLA, A:Schnitzler, NZ85.1.5432,2, Mappe 1678); vgl. Wilhelm Hemecker u. David Österle: „... so grundfalsch war alles Weitere“. Zur Geschichte des Nachlasses von Arthur Schnitzler. In: Jahrbuch der Deutschen Schillergesellschaft 58 (2014), S. 3-40, hier S. 18; vgl. ferner den Brief v. Olga Schnitzler an Henry B. Garland v. 14. 2. 1939 (DLA, A:Schnitzler, NZ85.1.5410,1, Mappe 1656); vgl. Rovagnati 2004, 23.

4 Vgl. Briefe v. Raoul Auernheimer an Stefan Zweig v. 1.3.1937 und 10.3.1937; Brief v. Zweig an Auernheimer v. 5.3.1937. In: The Correspondence of Stefan Zweig with Raoul Auernheimer and with Richard B. Berlin. Hrsg. v. Donald G. Daviau, Jorun B. Johns u. Jeffrey B. Berlin. Columbia/South Carolina: Camden House 1983 (= Studies in German Literature, Linguistics, and Culture 20), S. 117-119. - Olga Schnitzlers Anfrage betraf nicht nur Reigen, sondern auch Liebelei und Casanova (vgl. ebd. S. 117); Zweig wies auf die problematische Marktlage hin und empfahl für den Verkauf den Sammler Martin Bodmer - allerdings in Bezug auf Liebelei (vgl. ebd. S. 118; Rovagnati 2004, 21 f.). 
Archivar Erwin Rosenthal das Konvolut "on commission" 5 . Er hatte mit ihr einen Preis von $\$ 1.000$,- vereinbart und bestätigte, für die Versicherung aufzukommen. ${ }^{6}$ Noch im selben Jahr verkaufte Rosenthal die Reigen-Manuskripte über das von ihm 1920 gegründete, damals in Zürich niedergelassene Antiquariat L'Art Ancien ${ }^{7}$ - und zwar direkt an die Fondation Martin Bodmer in Cologny. Dementsprechend vermerkt die archivalische Beschreibung der Fondation handschriftlich: „Rosenthal, Art Ancien, Zch. Mai 56"8; in einem Brief an Heinrich Schnitzler bestätigte Rosenthal die Transaktion "zu dem vereinbarten Preis"9.

\subsection{Nachlass-Konvolut ${ }^{10}$}

Daher befindet sich das Reigen-Konvolut nicht - wie der Großteil des Werknachlasses - an der Cambridge University Library, sondern nach wie vor im Besitz der Fondation Martin Bodmer. Das erhaltene Konvolut besteht aus einem Umschlag (U), einer Entwurfsskizze (E; datiert mit "95"), der finalen Textstufe $(\mathrm{H})$ sowie Textstufen zu den Szenen 9 ( $\mathrm{H}^{\prime} \mathrm{Sz} 9$ ) und 10 ( $\left.\mathrm{H}^{\prime} \mathrm{Sz} 10\right)$, die ebenso wie eine Notiz (N) undatiert sind. ${ }^{11} \mathrm{H}$ umfasst eine Figurenliste (HF), die als Entstehungszeitraum "1896/7" verzeichnet, sowie zehn Umschläge mit je einer Szene (HSz1-HSz10), wobei mehrfach Datierungen vorgenommen wurden: „23/11“ (HSz1 3), "25/11" (HSz2 17), "27/11u 28/11" (HSz4 56), 12 "?29/11?" (HSz5 119), "10/12 96" (HSz6 156) sowie "24/2 97" (HSz10 370). Mit HF setzt eine Paginierung ein, wobei einige beschriebene Seiten unpaginiert geblieben bzw. fehlerhaft gezählt sind; H umfasst insgesamt 379 Seiten. ${ }^{13}$ Die - vermutlich durch fremde Hand - auf HF notierte Zahl "380" hält also den

5 Übernahmebestätigung durch Erwin Rosenthal v. 3.5.1956 (TMW, HS_Schn 152_12,1).

6 Vgl. Lorenzo Bellettini: Auf verschlungenem Pfad in die Bibliothek der Weltliteratur. In: Neue Zürcher Zeitung (10.12.2011). https://www.nzz.ch/auf_verschlungenem_pfad_in_die_bibliothek_der_weltliteratur-1.13583561, aufgerufen am 10.10.2018.

$7 \mathrm{Vgl}$. http://www.galerie20.smb.museum/kunsthandel/K40.html, aufgerufen am 10.10. 2018.

8 Diese Beschreibung wurde dankenswerterweise von der Fondation Martin Bodmer, Cologny (Genève) zur Verfügung gestellt. Vgl. auch Martin Bircher: Katalog der Ausstellung. In: Musik und Dichtung. Handschriften aus den Sammlungen Stefan Zweig und Martin Bodmer, Cologny-Genève. Eine Ausstellung der Fondation Martin Bodmer in Verbindung mit dem Museum Carolino-Augusteum Salzburg. Hrsg. v. Martin Bircher. Cologny: Fondation Martin Bodmer u. München: K. G. Saur Verlag 2002, S. 97-224, S. 219; Rovagnati 2001, 374; Rovagnati 2004, 24.

9 Brief v. Erwin Rosenthal an Heinrich Schnitzler v. 25. 1.1970 (TMW, HS_Schn 46_27,55,1); vgl. die beiden Briefe v. H. Schnitzler an Rosenthal v. 21.1.1970 und 28.1.1970 (TMW, HS_Schn 46_27,54; HS_Schn 46_27,56); H. Schnitzler wusste bis zu diesem Briefwechsel nicht, dass der Verkauf des Reigen-Konvoluts zustande gekommen war.

10 Vgl. Kapitel 0.5, S. 9-11.

11 H'Sz9 und H'Sz10 sind unpaginiert, Seitenzahlen sind daher im Folgenden in eckiger Klammer angegeben.

12 Vgl. Tb II, 227 (27. 11. 1896).

13 Drei - ansonsten unbeschriebene - Blätter mit fragmentarisch ausgeführten bzw. gestrichenen Seitenzahlen sind hierbei nicht berücksichtigt. - Sowohl in der archivalischen Beschreibung (Anm. 8) als auch bei Bircher (Katalog der Ausstellung, Anm. 8) und Rovagnati 2001 (S. 374) sowie Rovagnati 2004 (S. 293) ist der Umfang des Konvoluts falsch angegeben. 
ungefähren Gesamtumfang fest. Ebenfalls Teil des Genfer Konvoluts ist ein undatiertes siebenseitiges Typoskript zu Szene 4 (TSz4). ${ }^{14}$

\subsection{Genese}

Titel. Die Entwurfsskizze E nennt noch nicht den späteren Titel, sondern spricht von einem "Hemicyclus". Dieser Begriff findet sich - neben einem ersten Entwurf zum Figurenensemble - auch in dem (undatierten) Notizbuch (NB) an der Cambridge University Library, in welchem Schnitzler bis etwa 1900 Stoffideen verzeichnete:

$$
\begin{aligned}
& \text { Hemicycle Dirne - Gemeiner - Stubenma - } \\
& \text { Stubenma - junger Herr - Grisette - } \\
& \text { Ehemañ - Frau - Dichter - } \\
& \text { Schauspielerin - Aristokrat - Dirne }{ }^{15}
\end{aligned}
$$

Auf der Figurenliste HF ist der Text mit „Ein Liebesreigen“ benannt, was jedoch einem Rat Alfred Kerrs folgend - geändert wurde. Kerr habe - so heißt es in den Protokollen zum zweiten Berliner Reigen-Prozess - den Text bereits vor 1900 gelesen und Schnitzler zur Veröffentlichung geraten; allerdings habe er die Überschrift beanstandet, sei doch „,Liebe' [...] in dem ganzen Werk nicht geschildert - sondern etwas anderes, also der Geschlechtsakt."16 Dementsprechend trägt der Umschlag U auch nur mehr den Titel "Reigen", der dann seit dem ersten Druck, dem Privatdruck (PD) von 1900, beibehalten wurde. ${ }^{17}$

Figurennamen. Mehrfache Änderungen wurden im Verlauf der Entstehung auch hinsichtlich der Figurenbenennungen vorgenommen, so etwa "Gemeiner" (NB) "der gemeine Soldat" (E) - "Der Soldat" (H) oder "Aristokrat" (NB, E) - "Der Graf" $(\mathrm{H})$. Auch die Bezeichnung für den „Eheman̄" (NB, E) änderte sich mehrmals - „Der

14 Seit 2004 liegt die kritische Edition der Reigen-Handschrift von Gabriella Rovagnati vor (Rovagnati 2004). Diese weist - wie Peter Michael Braunwarth bereits anhand eines Vergleichs von Rovagnatis Transkription mit den wenigen in ihrem Band reproduzierten Faksimiles darlegte - eine Vielzahl von Entzifferungsfehlern auf. (Vgl. Peter Michael Braunwarth: Minutenlang ausgerutscht oder ununterbrochen ausgeglitten? Anmerkungen zu einer neuen Schnitzler-Edition. In: Hofmannsthal-Jahrbuch zur europäischen Moderne 13 (2005), S. 295-300). Ein umfassender Vergleich für die vorliegende Edition bestätigte diesen Befund. Hingewiesen sei an dieser Stelle exemplarisch auf eine Fehllesung mit entscheidenden interpretatorischen Konsequenzen. In H'Sz9 möchte der Graf der Schauspielerin „alle Schätze vom Orient Indien zu Füßen legen“ ([11],7f.). Rovagnati entzifferte statt „Indien" „Judäa” $(2004,221,64)$ und zog daraus den Schluss, dass Schnitzler „auf die verbreiteten Vorurteile gegen die Juden" im zeitgenössischen Wien angespielt habe (Gabriella Rovagnati: Wie ich zur Edition des Ur-Reigen kam. In: Schnitzler's Hidden Manuscripts. Hrsg. v. Lorenzo Bellettini u. Peter Hutchinson. Oxford u.a.: Lang 2010 (= Britische und Irische Studien zur deutschen Sprache und Literatur 51), S. 81-98, hier S. 92). Rovagnati berücksichtigt N nicht (vgl. 2004, 294).

15 CUL, A 193,2, S. [38].

16 Heine 213.

17 Die mit dieser Betitelung assoziierte musikalisch-spielerische Komponente arbeitete vor allem Max Ophüls in der wohl nach wie vor bekanntesten Reigen-Verfilmung, La Ronde (Frankreich 1950), heraus. 
junge Mann" (HF), "Gatte" $(\mathrm{H})$ - und blieb in PD und den Folgedrucken uneinheitlich („Ehegatte" - D 9; „Ehemann“ - D 1273; "Gatte” - passim D 1276-2311). ${ }^{18}$ Bei anderen Figuren wechselten nicht nur die Bezeichnungen, sondern auch die Reihenfolge ihrer Auftritte wurde verschoben: "Grisette" (NB) - "die Grisette" / "Die Frau” (E) - "Die junge Frau” (H); "Frau” (NB) - "seine Frau" / "Frau” / "Das Mädl” (E) "Das süße Mädl" (H). ${ }^{19}$

Sozialtypologie. Die Ehebruchsszenen (HSz4 und HSz6) wurden - wie die schon erläuterten Umbenennungen nachvollziehen lassen - im Laufe der Entstehung verschoben bzw. verändert. Während NB und zuerst auch noch E vorsehen, dass die Frau mit dem Dichter Ehebruch begeht (dort in der siebten Szene), wird ihre Affäre durch eine in E erfolgende Korrektur zur vierten Szene, zum Jungen Herrn, vorgezogen. Der Gatte hingegen, der zuerst mit der Grisette untreu sein sollte (in E in der fünften Szene), ist es dann in der sechsten Szene mit dem Süßen Mädl. Durch diese Verschiebung wird das kulturgeschichtlich und gesellschaftspolitisch so wichtige Gespräch über die Institution ,Ehe' neu positioniert (HSz5); der Ehebruch der Gattin ist nun vorgezogen, ein zentrales Skandalon des Textes.

Bei den Figurenbezeichnungen handelt es sich durchwegs um soziale Rollenzuschreibungen, was auch durch entsprechende Korrekturen verdeutlicht wird. Fast alle Figuren nämlich tragen Namen, die aber nicht als Sprecherangaben eingesetzt werden. So wurde etwa Marie mehrmals durch verschiedene Kürzel für Das Stubenmädchen überschrieben (u. a. „D St”, „D Stub", ,St.., HSz3 39-41 / 43 / 45); „Fra” (Franz) an einer Stelle durch "Soldat" (HSz2 28,3) und "Alfr" (Alfred) einmal durch "Der jung Herr" (HSz4 79,4). Es ist in der Reigen-Forschung hinreichend diskutiert, dass die Figuren verschiedenen sozialen Schichten zugeordnet sind und damit gesellschaftliche Hierarchien um 1900 repräsentieren. Dass die Dirne (Leokadia) den Reigen, den sie mit dem Soldaten (Franz) eröffnet (HSz1), mit dem Grafen wieder abschließt (HSz10), war schon in NB vorgesehen. Die beiden Szenen beziehen sich auch auf die Versuche der Regulation und Registrierung von Prostitution im letzten Drittel des 19. Jahrhunderts. ${ }^{20}$ Daher fürchtet sich die Dirne in der ersten Szene - im Freien - auch vor dem "Wachter" (HSz1 12,3; s. Kommentar). Der Soldat bewegt sich zwar stets außerhalb seiner militärischen Umgebung, doch reglementiert die Zeiteinteilung des Kasernenlebens auch seine privaten Unternehmungen. Das Stubenmädchen (Marie) wiederum dient sowohl ihm als auch dem Jungen Herrn (Alfred) lediglich als Lustobjekt; letzteres spiegelt die nicht unübliche zeitgenössische Ausbeutung von Hausangestellten. ${ }^{21}$ Das ausgewogenere Machtspiel zwischen dem Jungen Herrn und der Jungen Frau (Emma) beruht auf der hierarchischen Ebenbür-

18 Eine Ausnahme bildet hier nur das als Luxusausgabe erschienene 100. Tausend, das einheitlich „Der Gatte" verzeichnet. (Vgl. Reigen. Zehn Dialoge. 100. Tausend. Berlin, Wien: Verlag Benjamin Harz [1927].)

19 In HF verweist eine Überschreibung noch auf die Bezeichnung "Grisette”: „Dieas Єsüße Mädl”.

$20 \mathrm{Vgl}$. Helga Amesberger: Sexarbeit in Wien. Von Regulierungsversuchen, Arbeitsbedingungen und Resistenz. In: Sex in Wien. Lust. Kontrolle. Ungehorsam. Hrsg. v. Andreas Brunner u. a. 411. Sonderausstellung des Wien Museums. Wien: Wien Museum, Metroverlag 2016, S. 176-183, hier S. $176 f$.

21 Vgl. Sabine Fellner u. Katrin Unterreiner: Frühere Verhältnisse. Geheime Liebschaften in der k. u. k. Monarchie. Wien: Amalthea Signum 2010, bes. S. 47-63. 
tigkeit. Schon der Name selbst legt die Typizität dieser Frauenfigur nahe: Auch in der Erzählung Die Toten schweigen, die im Oktober 1897, also kurz nach der Niederschrift von Reigen, erschien, heißt die Ehebrecherin ,Emma';22 darüber hinaus verweist dieser Name jedenfalls auf die Protagonistin von Gustave Flauberts Roman Madame Bovary (1857). Der Gatte (Karl) erhält denn auch den Namen von Emma Bovarys betrogenem Ehemann Charles. Die betreffende fünfte Szene illustriert anschaulich geschlechterspezifische Rollenzuschreibungen innerhalb der bürgerlichen Ehe. Karl wiederum betrügt seine Gattin mit dem (namenlos bleibenden) Süßen Mädl. Diese einflussreiche Figur aus dem Schnitzler'schen Repertoire stellt als erotisches "Wunschbild des Bürgers" 23 eine junge, unverheiratete Frau aus dem vorstädtischen Kleinbürgertum mit leicht zu befriedigenden materiellen Ansprüchen dar. Ein Merkmal der französischen Grisette, nämlich der Verkehr in Künstlerkreisen, bleibt dem Süßen Mädl in der Szene mit dem Dichter (HSz7) erhalten, ${ }^{24}$ der in H den Namen Richard trägt (z. B. HSz7, 225,2a), in PD jedoch Robert heißt (z. B. D 2370). ${ }^{25} \mathrm{Im}$ Verhältnis zur Schauspielerin (HSz8) erscheint der Dichter dann in Status und Prestige unterlegen. In PD wurden dabei gegenüber $\mathrm{H}$ mehrere längere Passagen hinzugefügt, die einen stärkeren Kontrast zwischen dem schwärmerischen Dichter und der pragmatisch-prosaischen Schauspielerin herausarbeiten. ${ }^{26}$ Letztere trägt in H'Sz9 noch den Namen Charlotte bzw. Lotte, ${ }^{27}$ ist aber in $\mathrm{H}$ namenlos. Als einzige Frauenfigur, die ihr sexuelles Begehren offen zum Ausdruck bringt, tritt sie durchwegs mit Geschlechternormen in Konflikt. ${ }^{28}$ Namenlos bleibt in den letzten beiden Szenen auch der Graf als Repräsentant der österreichischen Aristokratie.

Paarkonfigurationen. Für die Dramaturgie von Reigen ist die Ökonomie seiner Zweierkonfigurationen entscheidend. Dritte Figuren treten selten auf und bleiben in $\mathrm{H}$ auch stumm: in HSz2 beispielsweise ein vorbeitanzendes blondes ,Fräulein' und ihr Partner $(35,2-4)$ oder in HSz10 ein Stubenmädchen, das der Graf bezahlt $(370,10 f$.$) . In PD erhält dieses als einzige dritte Figur auch Text, allerdings nur einen$ lapidaren Gruß. Sie erwidert des Grafen "Gute Nacht" mit "Guten Morgen." (D 3997 / 3999)

22 Vgl. TS-HKA.

23 Janz 53; vgl. Ortrud Gutjahr: Im Wechselspiel von Enthusiasmus und Melancholie. Zu Arthur Schnitzlers „Reigen". In: Melancholie und Enthusiasmus. Studien zur Literatur- und Geistesgeschichte der Jahrhundertwende. Eine internationale Tagung, veranstaltet vom Österreichischen Kulturinstitut in Bachotek/Polen, Oktober 1985. Hrsg. v. Karol Sauerland. Frankfurt a. M. u. a.: Lang 1988 (= Akten internationaler Kongresse auf den Gebieten der Ästhetik und der Literaturwissenschaft 5), S. 69-83, hier S. 77; Schneider 87-91.

24 Vgl. Janz 48-50.

25 "Robert" ist in H der Name eines Schauspielerkollegen (HSz8 283,5 / 300,8), der in PD "Benno" heißt (D 2975 / 3193); anstelle von „Robert" war in H zuerst "Walter" vorgesehen (HSz8 283,5).

26 Vgl. D 2856-2861; 2887-2891; 2921-2930; 3039-3047.

27 Vgl. H'Sz9 [14],7 / [22], 12). Bei der ersten Nennung wurde mit "Charl” angesetzt und zu "Lotte” korrigiert, dann wurde der Name gestrichen (vgl. H'Sz9 [14],7); die zweite Nennung, „Lotte“, bleibt.

28 Als biografische Bezugsperson für diese Figur wurde wiederholt auf Adele Sandrock (1863-1937) verwiesen, wofür eine - in PD gestrichene - Stelle in H sprechen könnte (vgl. HSz8 299,4; s. Kommentar zu „Francillon”). 
Ein undatiertes Typoskript zu Szene 4 (TSz4) zeigt den Ansatz einer umfangreicheren Konfiguration: Hier wird die Episode zwischen dem Jungen Herrn und der Jungen Frau durch einen Diener und das Freundespaar Eduard und Max unterbrochen, welches den Jungen Herrn als Sekundanten für ein bevorstehendes Duell Eduards gewinnen will. Zwei - typografisch nicht abgesetzte - Anweisungen verdeutlichen die Überlegungen zur Einbindung in die vierte Szene; auf "Seite 66" (TSz4, 1,2) sollte der Auftritt der drei zusätzlichen Figuren erfolgen und die Junge Frau ins Nebenzimmer flüchten; nach dem Abgang des Freundespaares folgt der Hinweis, dass nun „das Stendal Gespräch" anschließe; "Später, | Seite 75 | verschwinden" die Junge Frau und der Junge Herr "wieder ins Nebenzimmer, die Bühne bleibt eine Weile ganz leer" (TSz4, 6,109-112). Diese Seitenverweise können sich jedoch nicht auf H beziehen, ${ }^{29}$ da dort das ,Stendhal-Gespräch' erst nach S. 75 stattfindet (vgl. HSz4 94-105), und auch nicht auf PD, da dieser Druck unpaginiert ist. In der Erstausgabe im Wiener Verlag (EA) hingegen erfolgt es auf den Seiten 67-75, sodass die ,Anschlussstellen' eindeutig gegeben sind. Dieser Umstand spricht dafür, dass es sich bei dem Typoskript um eine Sekretärinnen-Abschrift eines Entwurfes handelt, die mit der Buchausgabe abgeglichen wurde. In HSz4 kommt dieses - etwa in Liebelei genutzte ${ }^{30}$ - Duellmotiv nicht vor.

Topographien. Von besonderer genetischer Relevanz und sozialer Bedeutung sind in Reigen Schauplätze und topographische Verweise (s. Anhang S. 1068-1071). In der Entwurfsskizze E wurden dem Figurenensemble bestimmte Ortsangaben (mit Bleistift) hinzugefügt; sie entsprechen zum großen Teil - zumindest inhaltlich, wenngleich nicht unbedingt wörtlich - den späteren Angaben in den eröffnenden Nebentexten in H. Die Ortsangaben auf den Umschlägen der einzelnen Szenen wurden indessen konsequent gestrichen - wohl ein Hinweis darauf, dass die Beschriftung der Umschläge vor der Niederschrift der einzelnen Szenen vorgenommen wurde. Die (getilgte) Angabe des Schauplatzes auf dem Umschlag von HSz4 - „Im Absteigquartier" $(55,4)$ - folgt E - "Abstge" (6; s. Kommentar) - und unterscheidet sich damit auffallend vom ersten Nebentext von HSz4, in dem detailliert eine Wohnung "in einem Hause der Schwindgasse" (56,3f.) beschrieben wird. Diese Änderung kann auch als Resultat der bereits beschriebenen Umreihung des Szenenverlaufs verstanden werden: In E war die vierte Szene zuerst für den Jungen Herrn und die Grisette vorgesehen. Die Verschiebung der Figurenkonfiguration (Junger Herr und Junge Frau) erforderte einen anderen Schauplatz; die elegante Schwindgasse im 4. Wiener Gemeindebezirk bot eine plausible Adresse für eine statusgerechte, zu erotischen Zwecken angemietete Wohnung. Wie in vielen anderen Fällen liefern die topographischen Marker im Text konkrete Hinweise auf die Strata der habsburgischen Hauptstadt. ${ }^{31}$ Auch in Hinblick auf die Entstehungsreihenfolge von H'Sz10 und HSz10 sind die Ortsangaben aufschlussreich. Das in E genannte "Tschecherl" (12; s. Kommentar) kommt in H'Sz10 als Begriff ([17],4 / [20],3), wenngleich nicht mehr als Schauplatz, in HSz10 aber gar nicht vor.

29 So aber Rovagnati 2004, 235.

$30 \mathrm{Vgl.} \mathrm{L-HKA,} \mathrm{passim.}$

31 Vgl. Janz, passim. 
Entstehung von Szene 9. Die undatierte Textstufe H'Sz9 setzt - ohne einleitenden Nebentext - mit dem - in HSz9 fast wortidenten ${ }^{32}$ - Beginn des Gesprächs zwischen Schauspielerin und Graf ein;33 sie könnte somit als eine zweite, dann jedoch verworfene Variante gelten, bei der der eröffnende Nebentext gleichgeblieben wäre. Dafür spräche auch, dass es zwischen H'Sz9 und der Notiz (N), die sich ansonsten auf die Entstehung von HSz10 (siehe unten) bezieht, einen auffallenden Bezug gibt. $\mathrm{N}$ und H'Sz9 verbindet nämlich die unbeantwortet bleibende Frage: "Was ist das Leben?" $(N, 11)$ - "Da hab ich mir gedacht: was ist das Leben." (H'Sz9 [22],4 / 6); auch liegt N im Konvolut nach H'Sz9. Dies könnte darauf hinweisen, dass H'Sz9 erst nach HSz10 verfasst wurde. Die thematische Verschiebung - in H'Sz9 nimmt das Eifersuchtsthema ${ }^{34}$ größeren Raum ein, in HSz9 die schärfere Charakterisierung des Grafen ${ }^{35}$ deutet allerdings auf eine Entstehung von H'Sz9 vor HSz9 hin; auch der Umstand, dass der Name Charlotte/Lotte in HSz936 fallengelassen wurde, entspricht Schnitzlers allgemeiner Tendenz zur Typisierung und Entindividualisierung im Lauf des Schreibprozesses und kann daher ebenfalls als Indiz dafür gelten, dass H'Sz9 die frühere Textstufe ist. ${ }^{37}$

Entstehung von Szene 10. Im Gegensatz zu HSz10 ist die ebenfalls undatierte Textstufe H'Sz10 prinzipiell analog zu den anderen Szenen aufgebaut und beginnt mit der Interaktion vor dem Koitus. Dann bricht das Manuskript ab. HSz10 hingegen weicht von dieser Struktur insofern ab, als sie nur mehr das ,Danach' am nächsten Morgen darstellt, eingeleitet durch einen längeren Monolog des Grafen. Eine mögliche Annäherung zum Geschlechtsverkehr findet sich auch in HSz10, wurde jedoch sofort gestrichen (362f.). Das Erwachen des Grafen (HSz10 348-352) wird zudem in N skizziert. Dabei variiert die letzte Zeile - „?Hand? ?Küsse? - - Prinzessin . . Unterschied? ." (14) - eine Sequenz aus H'Sz10. Dort zieht sich die Dirne aus, woraufhin der Graf meint: "So . . und jetzt ... nichts reden, und nichts anhaben . . wo ist dañ noch der Unterschied . . . . Jetzt konnt ich dh für ein Prinzessin halten" ([10],2-5). In HSz10 wird diese Überlegung an markanter Stelle aufgegriffen: Der Graf "(nim̄t die Hand und küsst sie mechanisch - bemerkt es, lacht.) . . Wie einer Prinzessin ....." $(354,6 f$.$) . Aufgrund des Aufbaus von HSz10 ist zu vermuten, dass H'Sz10 eine erste$ Textstufe darstellt, worauf in $\mathrm{N}$ weitere Texteinfälle gesammelt wurden, bis es in HSz10 zur Neukonzeption der Szene kam. Dafür spricht auch die standesangemessenere Charakterisierung des Grafen analog zu HSz9.

Paginierung. Die Paginierung von HF sowie HSz1-HSz10 lässt auf den ersten Blick darauf schließen, dass diese nach der Niederschrift vorgenommen wurde; H'Sz9 und H'Sz10 tragen keine Seitenzahlen. Insgesamt neun unpaginiert gebliebene beschrie-

32 Vgl. HSz9 305,4.

33 Vgl. H'Sz9 [1],1.

34 Vgl. H'Sz9 [15]-[17] / [30] / [36]-[37]. In HSz9 ist dieser thematische Strang stark reduziert (308 / 320 / 334).

35 Vgl. v.a. HSz9 310-319.

36 Vgl. Anm. 27. - Möglicherweise sollte eine Assoziation mit dem Namen der Burgtheater-Tragödin Charlotte Wolter (1834-1897) vermieden werden.

37 Vgl. zur Zurücknahme biografischer Details zuletzt BI-HKA 9. 
bene Blätter (HSz4, HSz6-HSz10) könnten schlicht überblättert worden sein. Zweimal wurde die fehlende Zählung mit Tinte ergänzt (HSz4: "115a”; HSz9: „3411⁄2”). Auch manche deutlich an den Schriftverlauf angepasste Seitenzahlen sprechen für eine nachträgliche Paginierung. Allerdings gibt es auch mehrfache Überschreibungen der Seitenzahlen durch Text, was wiederum auf eine Vorpaginierung der Blätter deutet. Offensichtlich wurden die Seitenzahlen szenen- bzw. partienweise sowohl auf schon beschriebenen als auch auf erst noch zu beschreibenden Blättern eingetragen, wofür auch ein ,Anschlussfehler' spricht: In HSz4 wurde die Seitenzahl ,88' nicht, ,92' jedoch doppelt verwendet.

Vom Manuskript zu den Drucken. Die Veränderungen von H zu PD betreffen etwa die bereits erwähnten Benennungen des Gatten und des Dichters oder die Charakterisierungen des Grafen und des Dichters, die geschärft wurden. Darüber hinaus fällt vor allem eine Regulierung bzw. der Ersatz der in $\mathrm{H}$ häufig und zahlreich gesetzten Gedankenpunkte auf, wodurch der Text gestrafft wird. Zudem waren die in den Drucken notorischen Halb- und Viertelgeviertsstriche - als typographische Substitute des Koitus - in H noch als Punkte, Gedankenstriche und an einer Stelle als Linie wiedergegeben worden.

Daneben kommen zahlreiche stilistische und semantische Korrekturen oder Begriffsklärungen ins Spiel, wie beispielsweise die Ersetzung des Ausdrucks "vielfache Musik" (HSz2 17,5) durch "wirre Musik" (D 177) oder der Attribuierung "eine brutale Polka" (HSz2 17,7) durch "eine ordinäre Polka” (D 178). Nebentexte wurden sowohl hinzugefügt als auch weggelassen; bei den Tilgungen fällt auf, dass sie sich vorwiegend auf das Verhalten vor und nach dem Koitus beziehen: So fehlt in PD etwa die Regieanweisung, dass das Stubenmädchen "rasch ihre Toiltett" ordnet (HSz3 52,8; D 598) oder dass sich der Dichter auskleidet (HSz8 284,10f.; D 2993).

In der Erstausgabe (EA) erfolgen weitere Rücknahmen: Während es in PD etwa noch heißt, dass der Soldat nach der Dirne greift, ist er ihr in EA nur "nahe" (Apparat zu D 34); dass der Gatte den "Schlafrock" abwirft, bevor er sich zu seiner Frau ins Bett begibt, fehlt in EA (Apparat zu D 1362). Getilgt wurde beispielsweise auch ein Nebentext, der beschreibt, wie sich der Dichter entkleidet (Apparat zu D 2581) und wie er das süße Mädel auf "den Divan" drückt (Apparat zu D 2589f.). Diese Änderungen von $\mathrm{H}$ zu PD und dann zu EA - vor allem die Tilgung der auf Körper und Kleidung bezogenen Nebentexte - können als (selbst-)zensierende Eingriffe verstanden werden, verweisen aber auch auf eine zunehmende Fokussierung auf die "kulturelle Überformung" von Sexualität „im Vor- und Nachspiel“. ${ }^{38}$

38 Peter Sprengel: Reigen. Zehn Dialoge. Die ungeschriebenen Regeln der Liebe. In: Interpretationen. Arthur Schnitzler. Dramen und Erzählungen. Hrsg. v. Hee-Ju Kim u. Günter Saße. Stuttgart: Reclam 2007 (= RUB 17532), S. 101-116, hier S. 105. 


\subsection{Genetisches Material}

Die nachgelassenen Materialien zu Reigen befinden sich in einer roten Saffianledermappe, ${ }^{39}$ welche an Vorder- und Rückseite durch Karton mit schwarzem Inlet verstärkt ist. In dieser Mappe liegt das gesamte Konvolut in einem Umschlag (U), der aus dickem, bräunlichem Papier mit deutlich erkennbarer Maserung besteht. In gefaltetem Zustand hat er die Maße $20 \times 25,6 \mathrm{~cm}$ und trägt von Schnitzlers Hand mit Bleistift die Aufschrift "Reigen 1896/7".

Beschreibstoff der Handschriften ist glattes, bräunliches Papier im Format von ca. $17 \times 21 \mathrm{~cm}$. Die einzelnen Blätter tragen Schnittspuren an jeweils zwei benachbarten Kanten. Es wurden also Bogen in ungefähr den Maßen $34 \times 42 \mathrm{~cm}$ verwendet und mittels zweifacher Faltung in jeweils vier Blätter geteilt; die Trennspuren sind unterschiedlich stark ausgeprägt. Das Papier ist teilweise nachgedunkelt und weist wiederholt Knicke und Risse auf. HSz1-HSz10 befinden sich in Umschlägen, die aus dem gleichen Papier bestehen und $34 \times 21 \mathrm{~cm}$ messen. Die größeren Bogen wurden also nur einmal der Länge nach geteilt. Schreibstoff ist Bleistift, mit Ausnahme der Figurenangaben in $\mathrm{E}$, zweier Paginierungen in $\mathrm{H}$ (siehe oben), einer gestrichenen $\mathrm{Pa}$ ginierung („?31?", H'Sz9 [39],1) sowie einer kurzen Linie (HSz6 180,1), die jeweils mit Tinte ausgeführt wurden.

Der Umschlag $(U)$ enthält in folgender Reihenfolge:

Figurenliste (HF): (1 BI.); pag. (1), dat. "1896/7"; am unteren Blattrand sind stärkere Nachdunkelungen sowie Risse und leichte Verschmutzungen zu erkennen.

Szenen 1-10 (HSz1-HSz10): einseitig beschrieben, pag. und beschrieben jeweils ab der ersten Umschlagvorderseite; Pag. beginnend mit 2; unpag. sind jeweils die Umschlagrückseiten, vereinzelt nach den jeweiligen Szenenenden eingefügte unbeschriebene Einlegeblätter sowie einzelne beschriebene Blätter, zwei sind mit Tinte pag. ( „115 a“ und „3411/2”).

Szene 1 (HSz1): (1 Umschlag, 14 Bl.); durchgehend pag. (2-15); letztes Blatt unpag. und unbeschrieben; dat. „23/11“ (HSz1 3). Die Blätter mit der Paginierung 11-15 sowie das unbeschriebene Blatt weisen zusätzlich mittige Längsfalten auf. Szene 2 (HSz2): (1 Umschlag, 19 BI.); durchgehend pag. (16-35); dat. „25/11“ (Hsz2 17).

Entwurfsskizze (E): (1 Bl.); dat. "95"; liegt im Konvolut lose zwischen HSz2 und HSz3; weist starke Nachdunkelungen und insbesondere am rechten, auch aufgerauten Blattrand Verunreinigungen auf; Risse an mehreren Stellen wurden archivalisch repariert.

Szene 3 (HSz3): (1 Umschlag, 18 BI.); durchgehend pag. (36-54), undat.

Szene 4 (HSz4): (1 Umschlag, 63 Bl.); nicht durchgehend pag. (55-117); "115 a“ mit Tinte pag.; Pag. auf der Umschlagrückseite gestrichen; es fehlt die Seitenzahl 88; 92 wurde zweimal verwendet; dat. "27/11 - u 28/11“ (HSz4 56). Der Umschlag ist entlang der Längsfalte gerissen und nachgedunkelt bzw. verschmutzt;

39 Vgl. Archivalische Notiz der Fondation Martin Bodmer. Auch Olga Schnitzler schrieb von „bunten Ledermappen", in denen die ihr überlassenen Manuskripte von Liebelei, Casanova und Reigen verwahrt würden (Brief an Heinrich Schnitzler v. 30. 10. 1938; DLA, A:Schnitzler, NZ85.1.5432,2, Mappe 1678). 
stark beschädigt ist die Umschlagrückseite. Für HSz4 96-112 wurde ein etwas stärkeres und minimal dunkleres, daher weniger durchscheinendes Papier verwendet. Die Blätter weisen an den oberen Rändern saubere, am linken Rand unregelmäßige und grobe Schnittspuren auf.

Szene 5 (HSz5): (1 Umschlag, 37 Bl.); durchgehend pag. (118-154); letztes Blatt unpag. und unbeschrieben; dat. "?29/11?" (HSz5 119).

Szene 6 (HSz6): (1 Umschlag, 63 BI.); nicht durchgehend pag. (155-217); unpag., der Länge nach mittig gefaltetes und beschriebenes Blatt zwischen HSz6 188 und 189; dat. „10/12 96" (HSz6 156). Auf HSz6 170-179 befindet sich eine fleckartige Verunreinigung, die am stärksten auf den Blättern mit den Seitenzahlen 174 und 175 ausgeprägt ist und sich von dort aus vermutlich übertragen hat; ebenfalls verschmutzt ist die äußere Umschlagrückseite. Neben der Seitenzahl „180" befindet sich eine kurze Linie in Tinte.

Szene 7 (HSz7): (1 Umschlag, 46 BI.), nicht durchgehend pag. (218-262); jeweils ein unpag. und beschriebenes Blatt zwischen HSz7 248 und 249 sowie HSz7 249 und 250; undat. Das letzte Blatt weist eine fleckartige Verunreinigung auf, die sich über den Umschlag auf die ersten Seiten der Folgeszene übertrug.

Szene 8 (HSz8): (1 Umschlag, 41 Bl.); nicht durchgängig pag. (263-302); unpag. und beschriebenes Blatt zwischen HSz8 272 und 273; die Paginierungen auf dem letzten, ansonsten unbeschriebenen Blatt $\left({ }_{\text {„303“) }}\right.$ ) und der Umschlagrückseite ( „304") wurden gestrichen; undat.

Szene 9 (HSz9): (1 Umschlag, 43 Bl.); nicht durchgängig pag. (303-344); unpag. und beschriebenes Blatt zwischen HSz9 306 und 307; "3411/2" mit Tinte pag.; undat. Der Umschlag weist am linken Rand Risse und starke Nachdunkelungen auf; die Blätter mit den Seitenzahlen 304, 310 und 312 sind stärker verschmutzt; 312 ist außerdem eingerissen. Auf der Umschlagrückseite sind auffallende Verunreinigungen sowie Kratzer zu sehen. Auf der Rückseite von HSz9 308 befindet sich ein kurzer Bleistiftstrich.

Szene 10 (HSz10): (1 Umschlag, 28 BI.); nicht durchgängig pag. (345-370); jeweils ein unpag. und beschriebenes Blatt zwischen HSz10 355 und 356 sowie HSz10 360 und 361; letztes Blatt unpag. und unbeschrieben; dat. "24/2 97" (HSz10 370). Das Blatt mit der Seitenzahl 353 hat einen auffallenden Knick am rechten Rand. Das unbeschriebene Blatt weist wie die Umschlagrückseite Verunreinigungen auf; diese ist zudem mehrfach gefaltet bzw. geknittert.

Nach HSz10 wurde ein stärkeres weißes Blatt eingefügt.

Textstufe H'Sz9: (42 BI.); unpag.; undat.; eingeschlagen in einen weißen Umschlag aus A4-Papier, der in Bleistift eine Notiz von fremder Hand trägt: „43 n. num Bl. Vorstufe 9". H'Sz9 [33]-[44] weisen am linken Rand gröbere Schnittspuren auf und wurden mittig der Länge nach leicht gefaltet; auf den letzten Blättern ist am linken Rand der Abdruck einer Büroklammer zu erkennen. Auf H'Sz9 [39],1 befindet sich eine gestrichene Paginierung in Tinte $\left({ }^{\text {? }}{ }^{3} 7^{\prime}\right.$ " $)$.

Notiz (N): (1 Bl.), unpag.; undat.; liegt im Umschlag von H'Sz9. Am linken Blattrand befinden sich Spuren einer Büroklammer. 
Textstufe H'Sz10: (20 BI.); unpag.; undat.; eingeschlagen in einen weißen Umschlag aus A4-Papier, der in Bleistift eine Notiz von fremder Hand trägt: „Vorstufe 10". Die Ordnung der Blätter entspricht nicht dem rekonstruierten Textverlauf: Das an vierter Stelle eingeordnete Blatt muss auf H'Sz10 [10] folgen. Auf dem ersten und letzten Blatt ist der Abdruck einer Büroklammer zu sehen.

Auf H'Sz10 folgt ein Blatt (stärkeres Papier, Maße 14,7 × 20,8 cm), das maschinenschriftlich verzeichnet: "Schnitzler, Arthur / Reigen / 1896/97 / Eigenhändiges Manuskript / Mit ungedruckten Materialien / Vermutlich erste Niederschrift"; am rechten unteren Blattrand ist mit Bleistift die Signatur der Fondation Martin Bodmer vermerkt: „F. II. 2".

Typoskript zu Szene 4 (TSz4): (7 BI.);40 Blätter mit den Maßen $17 \times 20,8 \mathrm{~cm}$; bläuliche Schriftfarbe; fortlaufend pag. (TSz4, 1 und 3 mit Bleistift, vermutlich von fremder Hand; TSz4, 2, 4 und 5 maschinenschriftlich; TSz4, 6 und 7 mit Bleistift nach Korrektur maschinenschriftlicher falscher Paginierung); undat.; insbes. TSz4, 1 und 7 sind beschädigt.

Für die Wiedergabe in der historisch-kritischen Ausgabe wurde eine an entstehungsgeschichtlichen und inhaltlichen Kriterien orientierte Umordnung der archivalischen Reihenfolge vorgenommen. Auf $U$ folgt zuerst der mit 1895 datierte Entwurf $\mathrm{E}$, danach HF, HSz1-HSz4, TSz4, HSz5-HSz8, H'Sz9, HSz9, H'Sz10, N und schließlich HSz10. Die Lage der Blätter in H'Sz10 wurde richtiggestellt. H ist - zur besseren Orientierung - auch in den Kolumnentiteln durchnummeriert.

\subsection{Zur Handschrift}

Die Schwierigkeiten, die bei der Entzifferung der Handschriften zu Reigen auftreten, sind dieselben wie die in den bisherigen Bänden der Werke in historisch-kritischen Ausgaben ${ }^{41}$ beschriebenen. Schnitzlers Schrift verschleift nicht nur Wortendungen, auch die einzelnen Buchstaben verlieren ihre distinkten Merkmale, die sie von anderen, im Kurrentschriftsystem ähnlichen, Graphen unterscheiden (Abb. 1).

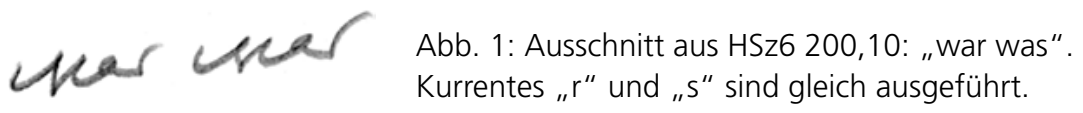

Die Differenz zwischen distinkten und indistinkten, gleichwohl erkennbar intendierten Graphen oder Graphenfolgen wird in der Transkription durch die Verwendung von schwarzer bzw. grauer Schriftfarbe veranschaulicht. Bei grau gesetzten Einheiten handelt es sich also nicht um editorische Ergänzungen, sondern um Auflösungen uneindeutiger graphischer Spuren unterschiedlicher Ausprägung. Im Vergleich mit den in

40 In der archivalischen Notiz der Fondation Martin Bodmer (Anm. 8) wird der Umfang des Typoskripts mit 16 Blatt angegeben.

41 Vgl. u. a. LG-HKA 2f. und St-HKA 5; zum Sonderfall des langen , s' vgl. FBG-HKA $7 f$. 
Originalgröße reproduzierten Faksimiles lässt sich die ,Erschließung' der betreffenden Schriftzeichen überprüfen. Schnitzlers gelegentliche nachträgliche Verdeutlichungen einzelner Graphen (Abb. 2) werden in der Transkription nicht eigens markiert.

4 Abb. 2: Ausschnitt aus HSz8 269,11: "eine"

Vertikale Streichungen, Einfügungszeichen u.ä. werden nachgeahmt, wobei das Transkript aber nicht eine exakte optische Wiedergabe des gesamten Erscheinungsbilds bieten soll.

\subsection{Zur Umschrift}

Xxx Aus indistinkten Graphen erschlossene Zeichen oder Zeichenfolgen erscheinen in grauer Schriftfarbe.

*** Streichungen werden typographisch wiedergegeben; zweifache Streichungen werden dann berücksichtigt, wenn sie zu verschiedenen Textschichten gehören. Dreifache Streichungen werden nicht imitiert.

**xxx Überschriebene Graphe und Graphenfolgen werden durchgestrichen und vor der sie ersetzenden Variante hochgestellt.

$x x x$

xxxxx Ergänzungen und Varianten ober- oder unterhalb der Zeile werden in kleinerem Schriftgrad gesetzt.

$x x x \quad$ Durch Lateinschrift hervorgehobene Einheiten werden kursiviert.

?xxx? Fragliche Entzifferungen werden durch hochgestellte Fragezeichen gekennzeichnet.

[???] Unentziffertes wird durch Fragezeichen in eckigen Klammern markiert.

[xxx] Eintragungen fremder Hand werden in eckige Klammern gestellt.

\subsection{Druckgeschichte}

Die Druckgeschichte von Reigen ist wesentlich beeinflusst von den politischen Entwicklungen des ersten Drittels des 20. Jahrhunderts; sie ist geprägt von Zensur, Beschlagnahmungen, häufigen Verlagswechseln und rechtlichen Problemen. 42

42 Vgl. zur Druckgeschichte insbes.: Richard H. Allen: An Annotated Arthur Schnitzler Bibliography. Editions and Criticism in German, French, and English 1879-1965. Chapel Hill: The University of North Carolina Press 1966, S. 54; Pfoser I, 43-71; Schinnerer 1932/33, 111 f.; Urbach 159f. Zum Teil irrige Angaben der Sekundärliteratur wurden in den folgenden Ausführungen korrigiert. 
Privatdruck. Schnitzler versuchte ursprünglich, den Text beim S. Fischer Verlag unterzubringen, doch Samuel Fischer hatte aufgrund der Zensur "grosse Bedenken"43. Er riet zu einem Privatdruck ${ }^{44}$ und stellte schließlich - nach juristischer Begutachtung 45 - den Kontakt mit der Buchdruckerei Roitzsch her, bei der auch die im S. Fischer Verlag erscheinende Neue Deutsche Rundschau gedruckt wurde. Da weder die Druckvorlage noch Briefe Schnitzlers an Fischer aus diesem Zeitraum erhalten sind, lässt sich der weitere Verlauf nicht exakt rekonstruieren. ${ }^{46}$ Wie aus Fischers Briefen hervorgeht, sollte Schnitzler das Druckmanuskript an die Druckerei senden und die Kosten übernehmen. Fischer selbst wollte zwar "nach außen gar nicht in die Erscheinung treten", aber dennoch unter anderem die "Correctur des Titels resp. der Einleitung" 47 begutachten; er begleitete die Herstellung schließlich durchgehend. ${ }^{48}$ Als Schnitzler zu einem späteren Zeitpunkt noch Korrekturen vorschlug, bat inn Fischer, diese direkt an die Druckerei zu übermitteln. ${ }^{49} \mathrm{Im}$ November 1899 erkundigte sich Fischer, ob "der erste Bogen zum ,Reigen' noch nicht gedruckt" sei; er habe nur den "Titelbogen[]" erhalten. ${ }^{50} \mathrm{Am}$ 12.2. 1900 kündigte Fischer schließlich ein „Expl. des fertig gedruckten Buches (in 200 Expl.)" ${ }^{\prime 51}$ an. Der Privatdruck trägt den Druckvermerk "Als Manuscript gedruckt" 52 und ist mit einem Vorwort versehen:

Ein Erscheinen der nachfolgenden Scenen ist vorläufig ausgeschlossen. Ich habe sie nun als Manuscript in Druck gegeben; denn ich glaube, ihr Wert liegt anderswo als darin, daß ihr Inhalt den geltenden Begriffen nach die Veröffentlichung zu verbieten scheint. Da jedoch Dummheit und böser Wille immer in der Nähe sind, füge ich den ausdrücklichen Wunsch bei, daß meine Freunde, denen ich dieses Manuscript gelegentlich übergeben werde, es durchaus in diesem Sinne behandeln und als ein bescheidenes, ihnen persönlich zugedachtes Geschenk des Verfassers aufnehmen mögen. ${ }^{53}$

43 Brief v. Samuel Fischer an Schnitzler v. 11.1.1898 (Fischer-Bw 60).

44 Vgl. Brief v. Fischer an Schnitzler v. 30. 8. 1899 (CUL B 121a / de Mendelssohn 438).

45 Vgl. u.a. Briefe v. Fischer an Schnitzler v. 11.2. 1898 und 30. 8. 1899 (Fischer-Bw 61 f.; CUL B 121a / de Mendelssohn 438).

46 Vgl. zur Problematik der nicht überlieferten Druckvorlagen bei Schnitzler: Konstanze Fliedl: Arthur Schnitzler. Schrift und Schreiben. In: Die Werkstatt des Dichters. Imaginationsräume literarischer Produktion. Hrsg. v. Klaus Kastberger u. Stefan Maurer unter Mitarbeit v. Georg Hofer u. Bernhard Judex. Berlin, Boston: De Gruyter 2017 (= Literatur und Archiv 1), S. 139-161, hier S. 150.

47 Brief v. Fischer an Schnitzler v. 13. 10. 1899 (Fischer-Bw 63).

$48 \mathrm{Vgl}$. auch die Briefe v. Fischer an Schnitzler v. 3.11.1899, 8.11.1899, 23.11.1899, 5.12.1899 und 12. 2. 1900 (Fischer-Bw 64; CUL B 121a / de Mendelssohn 439f.).

49 Brief v. Fischer an Schnitzler v. 8.11.1899 (CUL B 121a / de Mendelssohn 439).

50 Brief v. Fischer an Schnitzler v. 23.11.1899 (CUL B 121a).

51 Brief v. Fischer an Schnitzler v. 12.2.1900 (CUL B 121a / de Mendelssohn 439f.)

52 Vgl. zu diesem Vermerk Briefe v. Fischer an Schnitzler v. 30. 8. 1899 und 18. 10. 1899 (CUL B 121a / de Mendelssohn 438; CUL B 121a).

53 Arthur Schnitzler: Reigen. Zehn Dialoge. Winter 1896/97. Als Manuscript gedruckt. Buchdruckerei Roitzsch vorm. Otto Noack \& Co. [1900], S. [3] (Exemplar der Wienbibliothek im Rathaus, Signatur: A 123706). - Die hier verzeichneten Reigen-Exemplare werden jeweils mit Bibliothek und Signatur versehen, da sich im Zuge der Recherchen herausgestellt hat, dass es aufgrund der komplizierten Druckgeschichte in Bibliothekskatalogen und Suchmaschinen wiederholt zu falschen Angaben bezüglich Erscheinungsjahr und Auflagenzahl gekommen ist. 
Trotz dieses Appells erschienen mehrere Rezensionen, so etwa noch im Jahr 1900 jene von Alfred Kerr, der erläuterte, dass Reigen nicht „im Handel“ erschienen sei: „Unsere Besten haben kein Vertrauen zu dieser Gegenwart." 54 Die Popularität dieses Druckes wird schließlich auch im Börsenblatt für den deutschen Buchhandel von 1903 bezeugt: Dort ist die Rede vom "Neid aller jener, die nicht vom Autor bedacht worden waren" 55 .

Wiener Verlag. Am 2. April 1903 vermerkte Schnitzler im Tagebuch: „Reigen erscheint." (Tb III, 23) Da sich Fischer nicht zur Publikation hatte entschließen können Schnitzler sollte noch jahrzehntelang mit inm weiterverhandeln ${ }^{56}$-, wurde das Buch vom Wiener Verlag herausgebracht, ${ }^{57}$ worüber Schnitzler auch zuvor schon mit Fischer gesprochen hatte. ${ }^{58} \mathrm{Am} 23$. April wurde der Reigen im Börsenblatt für den deutschen Buchhandel angekündigt; 59 bereits in den ersten vierzehn Tagen waren 4.000 Exemplare verkauft. $60 \mathrm{Im}$ Mai und Juni folgten das 5. und 6. Tausend; 61 in der zweiten Junihälfte war das 6 . Tausend bereits vergriffen und das 7. wurde angekündigt. ${ }^{62}$ Am 28. Juni des Jahres vermerkte Schnitzler im Tagebuch: „8 Auflagen bis jetzt." (Tb III, 33) Der Band hatte eine Deckblatt-Illustration von Otto Friedrich,63 war mit Grafiken Bertold Löfflers ${ }^{64}$ geschmückt und wurde vom Verleger Fritz Freund massiv beworben; in einem Werbetext im Börsenblatt hieß es beispielweise: „Das Buch steht einzig in seiner Art da und macht beispielloses Aufsehen. Einige Firmen haben bereits dreihundert Exemplare dieses Buches verkauft. Buchhandlungen in Sommerfrischen und Badeorten können spielend 100 und mehr Exemplare absetzen." 65 Ende Februar 1904 waren das 11. bis 14. Tausend vergriffen und das 15. bis 20. Tausend wurde für Anfang März angekündigt.66 Schon ab April 1903 - dies zeigen zahlreiche Tagebucheinträge, Rezensionen und öffentliche Stellungnahmen wurde Reigen kontrovers diskutiert; Schnitzler wurde zwar einerseits gelobt, andererseits aber auch massiv angegriffen, wobei deutlich antisemitische Tendenzen zutage traten. ${ }^{67}$ Im März 1904 wurde Reigen schließlich in Deutschland beschlag-

54 Vgl. Alfred Kerr: „Reigen“ von Schnitzler. In: Neue Deutsche Rundschau (Freie Bühne), 11 (1900), 1. u. 2. Quartal, S. 666.

55 Friedrich Schiller: Wiener Brief V. In: BDB (1.9. 1903), Nr. 202, S. 6655-6657, hier S. 6656; vgl. Pfoser I, 212f. - Vgl. weitere Rezeptionszeugnisse bei Schneider 36-39; vgl. auch Schinnerer 1931, 840.

56 Vgl. u.a. Brief v. Fischer an Schnitzler v. 13.2. 1903 (CUL B 121b / de Mendelssohn 440f.) sowie allgemein die Korrespondenz zwischen Schnitzler und Fischer bezüglich Reigen (u.a. CUL B 128a).

57 Reigen. Zehn Dialoge. Geschrieben Winter 1896-97. Buchschmuck von Berthold Löffler. Wien, Leipzig: Wiener Verlag 1903 (Exemplar der Bayerischen Staatsbibliothek München, Signatur: L.sel.I 1591). Ab der zweiten Auflage ist die Auflagen- bzw. Tausenderzahl jeweils verzeichnet.

58 Vgl. u.a. Briefe v. Fischer an Schnitzler v. 8.11.1899 und 12.2.1900 (beide: CUL B 121a / de Mendelssohn 439f.).

59 Vgl. BDB (23.4. 1903), Nr. 92, S. 3206.

60 Vgl. Hall 139.

61 Vgl. BDB (4. 5. 1903), Nr. 101, S. 3539; (27.5. 1903), Nr. 120, S. 4244; vgl. Hall 139.

62 Vgl. BDB (22.6. 1903), Nr. 141, o. S. (Umschlag).

63 Vgl. Pfoser I, 20; Tb III, 107 (17. 12. 1904).

64 Die Ausgaben im Wiener Verlag führen die Schreibweise "Berthold".

65 BDB (27. 5. 1903), Nr. 120, S. 4244, Herv. i. O.; vgl. Hall 139; Schneider 39 f.

66 Vgl. BDB (25.2.1904), Nr. 46, S. 1838; vgl. Hall 140.

67 Vgl. u.a. Pfoser I, 50-53; Schneider 44-58. 
nahmt, 68 woraufhin die Auslieferung gestoppt werden musste. Wie Schnitzler im Tagebuch verzeichnete, wurde der Text im selben Jahr schließlich gerichtlich in Leipzig verboten. ${ }^{69} \mathrm{Am}$ 31. Januar 1905 wurde dann durch das Landgericht I, Strafkammer II Berlin die "Unbrauchbarmachung des Buches"70 angeordnet. Freund und Schnitzler planten zu diesem Zeitpunkt bereits eine neue, billigere Ausgabe, ${ }^{71}$ die auch dazu dienen sollte, die Zensur zu umgehen: Wenn „das Buch in einer neuen Ausstattung und in einem neuen Format erscheint, muss es von Neuem beschlagnahmt werden, was natürlich ein neues Verfahren bedingt." 72

Obwohl das 20. Tausend schon für März 1904 angekündigt worden war, fehlte es noch im Juni des Jahres, ${ }^{73}$ und am 7. Januar 1905 teilte Freund zudem mit, dass die Druckerei einen Fehler gemacht und nicht nur die 21. bis 24. Auflage auf billigerem Papier gedruckt habe, sondern auch schon die 20., weswegen auch diese billiger verkauft werden müsse. ${ }^{74}$ Das 21. bis 25 . Tausend erschien 1905 mit reduziertem Buchschmuck ${ }^{75}$ und in kleinerem Format. ${ }^{76}$ Bereits im März 1906 wurden aber auch diese Auflagen in Berlin beschlagnahmt. 77 Darüber hinaus geriet Freund ab August $1905^{78}$ zusehends in Zahlungsschwierigkeiten, ${ }^{79}$ bis er sich schließlich 1908 "wegen selbstverschuldeter Krida [...] und Exekutionsvereitelung verantworten mußte." 80 Reigen erschien im Wiener Verlag in einer Gesamtauflage von 35.000 Exemplaren, 81 das 31. bis 35. Tausend vermutlich zuletzt 1906.82 Die Ausgaben im Wiener Verlag wurden mit folgendem Vermerk publiziert: „VON DIESEM BUCHE WURDEN 25 NUMERIERTE EXEMPLARE AUF BÜTTENPAPIER ABGEZOGEN UND VOM AUTOR SIGNIERT"; sie sind mit 1903 datiert und verzeichnen die K. U. K. [! ] Hofbuchdrucker Fr. Winiker \& Schickardt, Brünn.83

68 Vgl. BDB (22. 3. 1904), Nr. 67, S. 2669; vgl. Pfoser I, 53; Schinnerer 1931, 844; Schneider 72f.; vgl. Tb III, 64 (16.3. 1904).

69 Vgl. Tb III, 90 (1. 10. 1904).

70 BDB (15.2. 1905), Nr. 38, S. 1584; vgl. Pfoser I, 53.

71 Vgl. u.a. Brief v. Fritz Freund an Schnitzler v. 23.12.1904 (DLA, A:Schnitzler, NZ85.1.3038,12, Mappe 764); Tb III, 114 (19.1.1905).

72 Vgl. Brief v. Freund an Schnitzler v. 7.1.1905 (DLA, A:Schnitzler, NZ85.1.3038,6, Mappe 764).

73 Vgl. u.a. Brief v. Freund an Schnitzler v. 2.6.1904 (DLA, A:Schnitzler, NZ85.1.3038,9, Mappe 764).

74 Vgl. u.a. Brief v. Freund an Schnitzler v. 7. 1. 1905 (DLA, A:Schnitzler, NZ85.1.3038, 16, Mappe 764).

75 Vgl. auch Pfoser I, 54.

76 Vgl. z. B. Reigen. Zehn Dialoge. Geschrieben Winter 1896-97. Buchschmuck von Berthold Löffler. 22. Aufl. Wien, Leipzig: Wiener Verlag [1905] (Exemplar der Wienbibliothek im Rathaus, Signatur: A 120049); 23. Aufl. (Exemplar der Oberösterreichischen Landesbibliothek, Signatur: I 51203) und 25. Aufl. (Exemplar der Universitätsbibliothek Freiburg, Standnummer: E 7135,ni).

77 Vgl. BDB (20.3. 1906), Nr. 65, S. 2920; vgl. Pfoser I, 54.

$78 \mathrm{Vgl}$. Brief v. Freund an Schnitzler v. 3. 8. 1905 (DLA, A:Schnitzler, NZ85.1.3038,21, Mappe 764).

79 Vgl. v.a. Tb III, passim 166-267, z.B. 3.9. 1906: „Freund, der wieder nicht gezahlt hat" (Tb III, 218).

80 Hall 143.

81 Vgl. Hall 140; siehe auch ebenda die Erläuterungen zu anderen, nicht korrekten Auflagenzahlen, die in der Reigen-Forschung genannt werden.

82 In einem Brief vom 8. 12.1905 an Schnitzler erläuterte Freund, dass "noch keine Rede" davon sein könne, dass das 31. bis 35. Tausend gedruckt sei (DLA, A:Schnitzler, NZ85.1.3038,26, Mappe 764).

83 Eingesehen werden konnten folgende Auflagen des Wiener Verlags: [1], 2, 3, 6, 8, 11, 14, 22, 23, 25, 27 sowie das 31.-35. Tausend. 
Singer Verlag. Aufgrund der gerichtlichen Schritte gegen Freund waren bereits zu Beginn des Jahres 1907 die Rechte wieder an Schnitzler gegangen. ${ }^{84}$ Wiederum versuchte er Reigen im S. Fischer Verlag unterzubringen, doch Fischer hatte am Ende immer noch zu große Bedenken;85 eine Anfrage des Hans Bondy Verlags 86 nahm Schnitzler nicht an und überließ die Rechte schließlich dem Verlag J. Singer \& CO. in Berlin. ${ }^{87}$ Dieser verpflichtete sich dazu, „sofort 5 Auflagen à 1000 Exemplare= [!] 5000 Exemplare" 88 zu drucken und zu bezahlen. Das 36. bis 40. Tausend wurde im Dezember 1908 „im größeren Format und besserer Ausstattung" 89 angekündigt; es erschien ohne Jahres- und Verlags-, Orts- und Druckereiangabe. Der Satz entspricht den Ausgaben des Wiener Verlags, übernommen wurde die Titelvignette (nicht mehr farbig), jedoch nicht der sonstige Buchschmuck, auch Löffler wird nicht mehr genannt. Wie einem Schreiben von Freunds Konkursverwalter L. Schönberger zu entnehmen ist, wurde mit dem Verkauf jedoch erst Anfang 1909 begonnen. ${ }^{90}$ Diese Auflage trägt den Druckvermerk: „VON DIESEM BUCHE WURDEN 100 NUMERIERTE EXEMPLARE AUF BÜTTENPAPIER ABGEZOGEN UND VOM AUTOR SIGNIERT"91. Der Singer Verlag ging 1909 in Konkurs, wurde jedoch unter demselben Namen weitergeführt, Geschäftsführer war Arthur Loewe, einer der ursprünglichen Eigentümer. ${ }^{92}$ Trotz der Vertragsverletzungen durch den Verlagg3 erschien 1911 das 41. bis 43. Tausend wieder bei Singer, ${ }^{94}$ ohne Druckvermerk, wiederum mit der (reduzierten) Titelvignette des Wiener Verlags und ohne Angaben zu Jahr, Verlag, Ort und Druckerei. Von zwei eingesehenen Exemplaren trug eines einen Verweis auf den Wiener Verlag auf dem Einband; 95 Singer hatte offensichtlich "auch die Rechte an dem Namen ,Wiener Verlag" mit übernommen"96. Indessen verringerte sich der Absatz des Bandes, was laut Loewe auf die "Zentralstelle zur Bekämpfung der Schmutzliteratur" in Berlin zurückzuführen war. ${ }^{77}$ Trotzdem bereitete der Singer Verlag schließlich eine

84 Vgl. Brief v. Schnitzler an Fischer v. 29. 5. 1908 (Br I, 577f.); Tb III, 235 (26. 11. 1906).

85 Vgl. Brief v. Fischer an Schnitzler v. 1.6.1908 (Fischer-Bw 83).

86 Vgl. Brief v. Schnitzler an Fischer v. 29.5. 1908 (Br I, 577f.); Brief v. Fischer an Schnitzler v. 1.6. 1908 (Fischer-Bw 83).

$87 \mathrm{Vgl.} \mathrm{Tb} \mathrm{III,} \mathrm{358f.} \mathrm{(10.10.1908).}$

88 Brief v. Josef Singer \& CO. an Schnitzler v. 17. 10. 1908 (CUL B 1051a). Die Rede ist in dieser Vereinbarung auch von "100 Exemplare[n] Luxusausgaben auf echt Bütten" (Brief v. J. Singer \& CO. an Schnitzler v. 23. 10.1908, CUL B 1051a).

89 Österreichisch-ungarische Buchhändler-Correspondenz (2.12.1908), Nr. 49, S. 736; vgl. Hall 148/ Anm. 18; Pfoser I, 58.

90 Vgl. Brief v. L. Schönberger an Paul Jonas v. 27.1.1910 (CUL B 1051a).

91 Reigen. Zehn Dialoge. Geschrieben Winter 1896-97. 36.-40. Tausend. [Berlin: Verlag J. Singer \& CO. 1909] (Privatexemplar).

92 Vgl. u.a. Brief v. Jonas u. Max Ehrlich an Schnitzler v. 17. 10.1910 (CUL B 1051a); Brief v. Schönberger an Jonas u. Ernst v. 25. 11. 1910 (CUL B 1051a); Tb IV, 104 (24.11. 1909).

93 Vgl. u.a. Brief v. Jonas an Schönberger v. 17. 10. 1910 (CUL B 1051a).

94 Vgl. Tb IV, 246 (10.6. 1911); Brief v. Schnitzler an Arthur Loewe v. 13.6. 1911 (DLA, A:Schnitzler, NZ85.1.950,1, Mappe 366).

95 Vgl. Reigen. Zehn Dialoge. Geschrieben Winter 1896-97. 41.-43. Tausend. [Berlin: Verlag J. Singer \& CO. 1911]; das Exemplar der Österreichischen Nationalbibliothek (Signatur: 482858-B) nennt den Wiener Verlag nicht; jenes der Wienbibliothek im Rathaus (Signatur: A 238878) schon.

96 Pfoser I, 55.

97 Vgl. Brief v. Loewe an Schnitzler v. 8.7.1912 (CUL, B 1051b). 
weitere Auflage "in Neuer [!] Ausstattung" 98 vor; auch wurde ein Freigabeprozess erwogen. ${ }^{99}$ Das 44. bis 46. Tausend erschien vermutlich 1913, mit neuem Satz, ohne die Titelvignette des Wiener Verlags, ohne Jahresangabe, nun aber unter dem Verlagsnamen J. Singer \& CO. und der Angabe der Druckerei (Spamersche Buchdruckerei in Leipzig). ${ }^{100}$ Schnitzler verpflichtete sich, Reigen bis Oktober 1923 in keine Gesamtausgabe aufzunehmen; der Singer Verlag wiederum dazu, nötigenfalls rechtliche Schritte hinsichtlich einer Freigabe zu setzen. ${ }^{101}$ Am 3. Juli 1913 hatte Jacques Jolowicz, der Rechtsanwalt des Singer Verlages, Schnitzler erkärt, dass "die Rechtslage bedeutend günstiger angesehen werden" könnte, falls er sich dazu entschließen würde, „einige wenige Worte im Text zu ändern."102 Genaueres dazu fehlt; wie der Vergleich der einzelnen Drucke zeigt, dürfte Schnitzler darauf nicht eingegangen sein. ${ }^{103}$ In Hinblick auf den geplanten Freigabeprozess kontaktierte man den Schutzverband deutscher Schriftsteller und holte Gutachten ein. ${ }^{104}$ Vermutlich aufgrund des Krieges wurde dieser Prozess jedoch nie geführt. Im Februar 1917 wandte sich Schnitzler schließlich in einem ausführlichen Brief an den Verlag, forderte die Einhaltung der Vertragsbedingungen und bestand auch auf einer neuen Luxusausgabe. ${ }^{105}$ Es folgten weitere (schriftliche) Verhandlungen, die jedoch ergebnislos blieben. 106

Harz Verlag. Im Mai 1917 erhielt Schnitzler einen Brief des Berliner Verlegers Benjamin Harz, der ihm mitteilte, dass er "von der Firma J. Singer \& co. [!] in Berlin den "Wiener Verlag'" übernommen habe und diesen mit zwei weiteren erworbenen Verlagen „in Wien als österreichischen Verlag” eröffnen wolle. Der erste Titel sollte Reigen sein - "in ganz neuer Ausstattung" 107. Wie ein späterer Brief Schnitzlers an den Singer Verlag belegt, war diese Übernahme ohne sein Einverständnis geschehen. ${ }^{108}$ Noch im selben Monat schloss er jedoch einen Vertrag mit Harz, der einen Neudruck in "neuer Ausstattung" in einer Mindestauflage von 3.000 Exemplaren vorsah und festhielt, dass Schnitzler Reigen bis Ende 1925 nicht in eine Gesamtausgabe übernehmen dürfe. Das Verlagsrecht bleibe "für alle Auflagen in deutscher Sprache" in Harz' Besitz. ${ }^{109}$ Wenig später kam es aber zu kriegsbedingten Schwierigkeiten: Harz

98 Vgl. Brief v. Loewe an Schnitzler v. 5.6. 1913 (CUL, B 1051b); vgl. Pfoser I, 59.

99 Vgl. ebd.; Tb V, 40 (23. 5. 1913); Tb V, 66 (5. 10. 1913).

100 Reigen. Zehn Dialoge. Geschrieben Winter 1896-97. 44.-46. Tsd. Berlin: Verlag J. Singer \& CO.

[1913?] (Exemplar der Wienbibliothek im Rathaus, Signatur: A 301889).

101 Vgl. Brief v. Loewe an Schnitzler v. 5. 6.1913 und 29. 7.1913 (beide: CUL, B 1051b).

102 Brief v. Jacques Jolowicz an Schnitzler v. 3.7.1913 (CUL, B 1051b), Herv. i. O.

$103 \mathrm{Vgl}$. die Ausführungen zum Apparat, S. 27; vgl. Pfoser I, 59.

104 Vgl. u. a. Brief v. Jolowicz an Schnitzler v. 14. 10. 1913 (CUL, B 1051b); Brief v. Schnitzler an Hermann Bahr v. 12. 6. 1914 (Br II, 43); Brief v. Jolowicz an Schnitzler v. 2. 7. 1914 (CUL, B 1051b); vgl. Br II, 847.

$105 \mathrm{Vgl}$. Brief v. Schnitzler an Jolowicz v. 26.2.1917 (Br II, 125-132).

106 Vgl. u.a. CUL B 1051b (Briefe zw. 18.4. 1917 und 30.4. 1917); Brief v. Schnitzler an Jolowicz v. 4. 4. 1917 (DLA, A:Schnitzler, NZ85.1.1116,3, Mappe 389); Briefe v. Schnitzler an J. Singer \& Co v. 23. 4. 1917 und 4. 5. 1917 (DLA, A:Schnitzler, NZ85.1.950,4 / 5, Mappe 366).

107 Brief v. Benjamin Harz an Schnitzler v. 20.5. 1917 (CUL B 1051b); vgl. Tb VI, 49 (23. 5. 1917).

108 Vgl. Brief v. Schnitzler an J. Singer \& CO. v. 26.3.1918 (CUL B 128b); Brief v. Friedrich Geiringer an Schnitzler v. 28.12.1918 (CUL B 1051b).

109 Brief v. Harz an Schnitzler v. 31. 5. 1917 (CUL B 1051b); vgl. Tb VI, 51 (31. 5. 1917). 
musste einrücken und konnte aufgrund des herrschenden Papiermangels die Vertragsbedingungen ohnehin nicht erfüllen. ${ }^{110}$ Am 27. Februar 1918 kündigte er immerhin an, dass er Schnitzler 2.000 Kronen überweisen könne, als Teilhonorar für die 2.000 Exemplare, die in Prag hergestellt würden. ${ }^{111}$ Es handelt sich dabei um das 47. bis 48. Tausend, das - vermutlich 1918 - ohne Angabe von Jahr und Auflage unter dem Verlagsnamen Verlag B. Harz Wien und unter Angabe der Druckerei Heller \& Stransky in Prag erschien. ${ }^{112}$ Für das 49. bis 58. Tausend wurden neue Vereinbarungen getroffen; diese Exemplare sollten bis zum 31. Oktober 1918 auf den Markt kommen. ${ }^{113}$ Harz erfüllte auch diese Vereinbarung nicht, weswegen - so der Anwalt Friedrich Geiringer Ende 1918 - die Rechte an Reigen eigentlich an Schnitzler zurückgefallen waren. ${ }^{114}$ Dennoch folgte am 16. Januar 1919 ein neuerlicher Kontrakt mit Harz. Gegenstand war wieder das 49. bis 58. sowie zusätzlich das 59. bis 68. Tausend; explizit festgehalten wurde, dass die Rechte an Reigen nach dem 1. Juli 1920 wieder an Schnitzler zurückgehen sollten, jedoch blieb die Sperre für eine Gesamtausgabe bis zum 1. Juli 1925 aufrecht. ${ }^{115}$ Das 49. bis 58. Tausend erschien nun erst 1919 ohne Angabe von Jahr und Auflagenzahl unter dem Verlagsnamen B. Harz Verlag, Berlin-Wien in der Druckerei Kurt Hedrich in Wien. ${ }^{116} \mathrm{Ab}$ dem 59. Tausend bis inkl. 99. Tausend - vermerken die Auflagen einheitlich den Verlagsnamen Benjamin Harz=Verlag Berlin Wien sowie die Gesellschaft für Graphische Industrie in Wien als Druckerei; insbesondere aber wurde ab diesem Tausend durchgehend der Urheberrechtshinweis "COPYRIGHT 1914 BY BENJAMIN HARZ VERLAG BERLIN · WIEN" angebracht. Im Januar 1920 musste Harz Schnitzler allerdings mitteilen, dass gegen Reigen wiederum gerichtlich vorgegangen wurde; das Urteil von 1906 sollte nochmals vollstreckt und die Beschlagnahmung verfügt werden; auch habe man die "Unbrauchbarkeit der [Druck-]Platten verlangt" 117 . Harz versicherte, dagegen vorgehen zu wollen, und verwies darauf, dass ungeachtet aller Komplikationen die neue Auflage, das 59. bis 68. Tausend, bereits in Wien gedruckt werde. ${ }^{118}$ Entgegen den vertraglichen Vereinbarungen ${ }^{119}$ erschien sie jedoch nicht bis Anfang 1920. ${ }^{120}$ Harz erklärte am 15. Mai 1920, dass sie zwar "in Wien gedruckt und bereits erschienen",

110 Vgl. die umfangreiche Korrespondenz zwischen Schnitzler und Harz v. a. zW. Juni 1917 und Mai 1918 (CUL B 1051b; DLA, A:Schnitzler, NZ85.1.950, Mappe 366; CUL B 128b); vgl. Pfoser I, 60-66.

111 Vgl. Brief v. Harz an Schnitzler v. 27. 2.1918 (CUL B 1051b).

112 Reigen. Zehn Dialoge. Gesc|hrieben[!] Winter 1896-97. [47.-48. Tausend]. Wien: Verlag B. Harz [1918?] (Privatexemplar).

113 Vgl. Brief v. Harz an Schnitzler v. [21. 5.] 1918 (CUL B 1051b); vgl. zur Datierung dieses Schreibens: Brief v. Geiringer an Schnitzler v. 28.12.1918 (CUL B 1051b).

114 Vgl. Brief v. Geiringer an Schnitzler v. 28.12.1918 (CUL B 1051b).

115 Vgl. Brief v. Harz an Schnitzler v. 16. 1.1919 (CUL B 1051b); vgl. Tb VI, 217 (9. 1. 1919).

116 Vgl. dazu einen Brief v. Schnitzler an Fischer v. 10. 5. 1919: Die "zuletzt erschienenen Auflagen des 'Reigen' 49-58" seien in oben genannter Druckerei ohne Angaben der Auflagenzahl erschienen (Fischer-Bw 125). Vgl. Reigen. Zehn Dialoge. Geschrieben Winter 1896-97. [49.-58. Tausend]. Berlin, Wien: B. Harz Verlag [1919] (Exemplar der Österreichischen Nationalbibliothek, Signatur: 776867-B).

117 Vgl. Brief v. 8.[?]1.1920 (CUL B 1051b).

118 Vgl. ebd.; vgl. Brief v. Harz an Schnitzler v. 31.10.1919 (CUL B 1051b).

119 Vgl. Brief v. Harz an Schnitzler v. 16.1.1920 (CUL B 1051b).

120 Vgl. Brief v. Harz an Schnitzler v. 15. 6. 1920 (CUL B 1051b); Tb VII, 19 (10.2. 1920). 
jedoch noch nicht gebunden worden sei. Sie sei "bedeutend schöner", allerdings habe das Papier nicht "zu einer vollen Ausgabe [...] ausgereicht, sodass ich auch jetzt einige hundert Exemplare weniger erhalten habe." Von der alten Ausgabe seien noch 2.500 Exemplare vorhanden, die vorher abgesetzt werden müssten. ${ }^{121}$ Trotz aller Verzögerungen traf Schnitzler im Januar 1921 eine neuerliche Abmachung mit Harz - dieses Mal bezüglich des 69. bis 73. Tausends, das fertiggestellt werden müsste, sobald "die 64.-68. Auflage zur Herausgabe kommt"122. Am 13. März 1920 war Reigen durch das Landgericht III Berlin "für unzüchtig erklärt und eingezogen worden"123; als die Strafkammer 6 des Landgerichts III Berlin am 22. März 1921 dieses Urteil - zumindest in Bezug auf das Druckwerk - aufhob, nutzte Harz dies, um Werbeeinschaltungen im Börsenblatt vorzunehmen. ${ }^{124}$ Trotz der Kassation wurde Reigen nach wie vor durch das Landgericht I beschlagnahmt; im Mai 1921 erklärte Harz, dass der Börsenverein auf Intervention des Polizeipräsidiums hin keine weiteren Inserate mehr annehmen würde. ${ }^{125}$ Als am 18. November d. J. der zweite Prozess zugunsten von Reigen ausging, betraf dies das Buch und die Berliner Aufführung, ${ }^{126}$ trotzdem wurde die Beschlagnahmung aufgrund älterer Urteile fortgesetzt. ${ }^{127}$ Im März 1921 ging schließlich das 69. bis 78. Tausend in Druck. ${ }^{128}$

Bereits im Juni 1921 hatte Fischer Schnitzler signalisiert, dass er den Reigen nun doch übernehmen wolle, ${ }^{129}$ die betreffenden Verhandlungen blieben jedoch wiederum ergebnislos. ${ }^{130}$ Daher übertrug Schnitzler Anfang 1922 die Rechte für das 79. bis 100. Tausend neuerlich an Harz. ${ }^{131}$ Die ersten 2.000 Exemplare waren bereits im März 1922 im Handel; 132 es war geplant, das 100. Tausend als Luxusauflage auf den

121 Brief v. Harz an Schnitzler v. 15.5.1920 (CUL B 1051b); vgl. Reigen. Zehn Dialoge. Geschrieben 1896-97. 59.-68. Tausend. Berlin, Wien: Benjamin Harz=Verlag [1920] (Exemplar der Staatsbibliothek zu Berlin - Preußischer Kulturbesitz, Signatur: Yz 907959).

122 Brief v. Schnitzler an Harz v. 3.1.1921; vgl. Brief v. Schnitzler an Harz v. 10.2.1921 (beide: CUL B 128b); vgl. zu dieser Aufl. auch Brief v. Harz an Schnitzler v. 10.3.1921 (CUL B 1051c).

123 Heine 434.

124 Vgl. ebd.; vgl. BDB (11.4.1921), Nr. 83, S. 503; Brief v. Harz an Schnitzler v. 12.4.1921 (CUL B 1051c); Pfoser I, 63.

125 Vgl. Brief v. Harz an Schnitzler v. 14. 5. 1921 (CUL B 1051c); Pfoser I, 63.

126 Vgl. v.a. Heine 437-445.

127 Vgl. Brief v. Sammy Gronemann an Harz v. 5. 12.1921; Brief v. Harz an Schnitzler v. 17. 12. 1921 (beide: CUL B 1051c).

128 Vgl. u.a. Brief v. Harz an Schnitzler v. 10.3.1921, v. 23. 5. 1921, v. 19.10. 1921 und v. 30.11. 1921 (alle: CUL B 1051c); vgl. eine Werbeeinschaltung im BDB (16.4. 1921), Nr. 88, S. 4001; vgl. zu dieser Ausgabe auch: Briefe v. Schnitzler an Harz v. 18.4.1921 und 13.5.1921 (beide: CUL B 128b). - Vgl. Reigen. Zehn Dialoge. Geschrieben Winter 1896-97. 69.-78. Aufl. Berlin, Wien: Benjamin Harz=Verlag [1921?] (Exemplar der Sächsischen Landesbibliothek, Signatur: 28.8.4900).

129 Vgl. Brief v. 4.6. 1921 (Fischer-Bw 129).

130 Vgl. u.a. Brief v. Fischer an Schnitzler v. 6.12.1921 (CUL B 121e / de Mendelssohn 840) und v. 7.12.1921 (CUL B 121e / de Mendelssohn 841); Brief v. Schnitzler an Harz v. 12.12.1921 (CUL B 128b); Brief v. Harz an Schnitzler v. 17.12.1921 (CUL B 1051c); Brief v. Fischer an Schnitzler v. 4.7.1922 (CUL B 121e / de Mendelssohn 841).

131 Vgl. Brief v. Schnitzler an Harz v. 12.1.1922 (CUL B 128b). Reigen. Zehn Dialoge. Geschrieben Winter 1896-97. 79.-88. Tausend. Berlin, Wien: Benjamin Harz=Verlag 1922 (Exemplar der Landesbibliothek Coburg, Signatur: SL 4608); Reigen. Zehn Dialoge. Geschrieben Winter 1896-97. 89.-99. Tausend. Berlin, Wien: Benjamin Harz=Verlag [1923/1924?] (Privatexemplar).

132 Vgl. Brief v. Harz an Schnitzler v. 18. 3. 1922 (CUL B 1051c). 
Markt zu bringen. ${ }^{133}$ Aufgrund von Zahlungsrückständen verschlechterte sich das Verhältnis zwischen Harz und Schnitzler aber immer mehr; 1923 kam es schließlich zum Prozess. ${ }^{134}$ Die Luxusausgabe war - ohne Schnitzlers Wissen ${ }^{135}$ - dem Druckvermerk zufolge bereits 1923 gedruckt, 136 erschien jedoch aufgrund des anhängigen Verfahrens erst 1927.137

Frisch - Wilhartitz - Wieland. 1921 wurde auch eine Luxusausgabe im Frisch \& Co. Verlag publiziert; ;38 sie ist mit "zehn Illustrationen nach Radierungen von Stefan Eggeler" versehen und hatte eine Auflagenhöhe von 3.000 Exemplaren;139 noch im selben Jahr wurde sie beschlagnahmt. 1401922 folgte - wie mehrere Quellen vermerken - eine weitere Luxusausgabe bei Ernst Wilhartitz. ${ }^{141}$ Im Deutschen Literaturarchiv Marbach ist für das Jahr 1920 zudem die Kopie eines Verlagsvertrags zwischen Schnitzler und dem Wieland Verlag (O. C. Recht Verlag) verwahrt, in welchem Übereinkünfte bezüglich einer Luxusausgabe (unter 1000 Exemplaren) getroffen werden. Der Vertrag ist mit dem 10.11.1920 datiert und von Schnitzler und dem Verlagsleiter Otto Zoff unterschrieben. ${ }^{142}$ Diese Ausgabe wurde jedoch nie realisiert.

133 Vgl. u.a. Brief v. Harz an Schnitzler v. 12. 10. 1922 (CUL B 1051c).

$134 \mathrm{Vgl}$. u.a. den Briefwechsel zwischen Schnitzler und dem Anwalt Arthur Rosenberger zwischen Mai 1923 und Mai 1927 (CUL B 128b; CUL B 1051c; CUL B 1051d; DLA, A:Schnitzler, NZ85.1.1720, Mappe 453).

135 Vgl. u.a. Briefe v. Schnitzler an Arthur Rosenberger v. 8.3.1924 und 21.7.1924 (beide: DLA A: Schnitzler, NZ85.1.1720, 12 / 16, Mappe 453).

136 Vgl. Brief v. Felix Münzer an das Landgericht I Berlin v. 21. 2. 1924 (CUL B 1051d). Der Druckvermerk lautet: „In Tausend numerierten Exemplaren als hundertstes Tausend dieses Buches für den Verlag Benjamin Harz in Berlin und Wien unter typographischer Leitung von Lazarus Goldschmidt im Sommer 1923 in der Offizin von W. Drugulin in Leipzig hergestellt, von denen dieses ist Exemplar Nr." Reigen, 100. Tausend (Anm. 18).

137 Vgl. u.a. Brief v. Schnitzler an Harz v. 5.3.1927 (CUL B 128b); Tb IX, 101 (2.11.1927).

$138 \mathrm{Vgl}$. Tb VII, 162 (26.3.1921); 170 (19.4.1921); 213 (6.8.1921); 228 (17.9.1921); vgl. Pfoser I, 63-65.

139 Das eingesehene Exemplar trägt den Vermerk: „Dieses Buch wurde im Jahre 1921 vom Frisch \& Co. Verlag in Wien herausgegeben und in der eigenen Anstalt des Verlages in einer einmaligen Auflage von 3000 numerierten Exemplaren hergestellt. Die ersten 150 Exemplare sind in Halbleder gebunden und vom Autor und vom Künstler signiert. Nr. 151-1000 wurden in Ganzleinen ausgegeben. Dieses Exemplar trägt die Nummer". Reigen. Zehn Dialoge, geschrieben Winter 1896/97. Mit zehn Illustrationen nach Radierungen von Stefan Eggeler. Wien, Leipzig, Bern: Frisch \& Co. Verlag 1921 (Privatexemplar).

140 Vgl. BDB (30.11.1921), Nr. 279, S. 1731; Pfoser I, 64. Am 30.11. schaltete der Frisch \& Co. Verlag auch eine Anzeige zu den "Mappenwerke[n]" Stefan Eggelers, darunter Reigen; vgl. BDB (30.11.1921), Nr. 279.

$141 \mathrm{Vgl}$. Tb VII, 309 (19. 5. 1922). Diese Ausgabe konnte nicht eingesehen werden, sie ist jedoch mehrmals verzeichnet: vgl. u. a. Br II, 879; Urbach 159. Laut Schinnerer trug sie den Vermerk "Dieses Buch wurde im Jahre Eintausendneunhundertzweiundzwanzig vom Verlag Ernst Wilhartitz in Wien herausgegeben und in der eigenen Anstalt des Verlags in einer einmaligen Auflage von 50 römisch numerierten Exemplaren hergestellt. - Die Exemplare enthalten Original-Radierungen, sind in Ganzleder gebunden und vom Autor und Künstler signiert." (1932/33, 111) - Ernst Wilhartitz war ab 1916 Gesellschafter und ab 1920 Inhaber des Frisch Verlags (vgl. http://verlagsgeschichte.murrayhall.com, aufgerufen am 4. 10.2018).

142 Vgl. DLA, A:Schnitzler, NZ85.1.4180,7, Mappe 1090. 
Fischer Verlag. Zwar hatte Harz Schnitzler mehrfach zugesichert, dass die Rechte für Reigen ab der 101. Auflage wieder bei inm lägen, doch müssten vor einem Verlagswechsel alle Exemplare verkauft sein. ${ }^{143}$ Neuerlich versuchte Schnitzler, Reigen bei Fischer unterzubringen. ${ }^{144}$ Dieser jedoch hatte nach wie vor Bedenken wegen des Schund- und Schmutzgesetzes. ${ }^{145}$ Schnitzler betonte, dass seines „Wissens keinerlei Verbot mehr" bestehe und unterstrich einmal mehr, wie wichtig ihm die Aufnahme von Reigen in den Fischer Verlag sei. ${ }^{146} 1928$ war Harz jedoch immer noch in Besitz von 4.000 bis 4.500 Exemplaren; ${ }^{147}$ Schnitzler wollte gemeinsam mit Fischer diesen Restbestand aufkaufen, was jedoch nicht zustande kam. 148 Wegen der ungeklärten juristischen Situation hinsichtlich dieser Restexemplare war das Verfügungsrecht weiter blockiert. ${ }^{149}$ Trotzdem hielt Schnitzler an der Idee einer Neuauflage fest, ${ }^{150}$ das Projekt wurde jedoch wieder verschoben. ${ }^{151}$ Am 5. April 1930 richtete Schnitzler schließlich einen ausführlichen Brief an Fischer, rekapitulierte dessen ambivalente Haltung und wiederholte seinen Wunsch, Reigen „endlich an der Seite meiner anderen Werke seinen ihm gebührenden Platz in meinem angestammten Verlage einnehmen zu sehen"152. Im Juni teilte Fischer Schnitzler schließlich mit, dass nun ein Abkommen mit Harz getroffen worden sei. ${ }^{153}$ Nach weiteren Verschiebungen ${ }^{154}$ kamen das 101. bis 104. Tausend im Mai 1931 bei S. Fischer heraus. ${ }^{155}$

Reigen erschien folglich zu Lebzeiten Schnitzlers - abgesehen von den 200 Exemplaren des Privatdrucks sowie den Ausgaben bei Frisch (und Wilhartitz) - in einer Höhe von 104.000 Exemplaren in vier Verlagen.

143 Vgl. u.a. Brief v. Harz an Schnitzler v. 4. 4. 1927 (CUL B 1051d)

144 Vgl. u.a. Brief v. Schnitzler an Fischer v. 2.6. 1927 (CUL B 128a).

145 Vgl. Brief v. Fischer an Schnitzler v. 4.6. 1927 (Regest bei: de Mendelssohn 1218).

146 Vgl. u.a. Brief v. Schnitzler an Fischer v. 11.6.1927 (CUL B 128a).

147 Vgl. Brief v. Schnitzler an Harz v. 3.3. 1928 (CUL B 128a); Brief v. Schnitzler an Fischer v. 7. 6. 1928 (CUL B 128a); Brief v. Harz an Fischer v. 7.11.1928 (CUL B 1051d). - Am 27. Oktober 1928 wurde das 99. Tausend im Börsenblatt für den deutschen Buchhandel beworben; auch Exemplare der Luxusausgabe seien - wie es dort heißt - noch vorhanden (vgl. BDB (27. 10. 1928), Nr. 252, S. 9361).

148 Vgl. u. a. Briefe v. Schnitzler an Fischer v. 22. 1. 1928; 15. 3. 1928; 31. 5. 1928 und 28. 9. 1928 (alle: CUL B 128a); Brief v. Schnitzler an Harz v. 7.6.1928 (CUL B 128a); vgl. Pfoser I, 66.

149 Vgl. u.a. Brief v. Schnitzler an Fischer v. 29.3.1928 (CUL B 128a); Brief v. Fischer an Schnitzler v. 21.9. 1928 (CUL B 128a); Brief v. Harz an Schnitzler v. 26.9.1928 (CUL B 1051d).

150 Vgl. u.a. Briefe v. Schnitzler an Fischer v. 23. 6. 1928, 28. 9. 1928 und 25. 10. 1928 (alle: CUL B 128a); Brief v. Schnitzler an Harz v. 14. 7.1928 (CUL B 128b).

151 Vgl. Brief v. Schnitzler an Fischer v. 26.11.1928 (CUL B 128a).

152 Brief v. Schnitzler an Fischer v. 5. 4. 1930 (Br II, 677).

153 Vgl. Brief v. Fischer an Schnitzler v. 30.6.1930 (de Mendelssohn 1218).

154 Vgl. u.a. Brief v. Schnitzler an Schinnerer v. 8.1.1931 (Br II, 739f.); Brief v. Schnitzler an Olga Schnitzler v. 14.1.1931 ( $\mathrm{Br} I I, 743)$. Schnitzler wünschte sich Schinnerers Aufsatz, The History of Schnitzler's Reigen, als "Vorwort oder Nachwort", was Fischer jedoch u.a. mit Verweis auf die "antisemitische Presse" ablehnte (Brief v. Schnitzler an Otto Schinnerer v. 18. 10. 1930 (Br II, 715); Brief v. Fischer an Schnitzler v. 10.11.1930 (Fischer-Bw 162); vgl. Schinnerer 1931).

155 Vgl. Tb X, 43 (21. 5. 1931); 44 (23. 5. 1931). - Reigen. Zehn Dialoge. 101.-104. Aufl. Berlin: S. Fischer Verlag 1931 (Exemplar der Österreichischen Nationalbibliothek, Signatur: 805275-B). 


\subsection{Uraufführung und österreichische Erstaufführung ${ }^{156}$}

Bezüglich der Uraufführung, ${ }^{157}$ die am 23. Dezember 1920 am Berliner Kleinen Schauspielhaus - unter der Direktion von Gertrude Eysoldt und Maximilian Sladek stattfand, hatte sich Schnitzler schon seit Dezember 1918 mit dem Direktor des Deutschen Theaters, Max Reinhardt, bzw. nach dessen Rücktritt mit seinem Nachfolger Felix Hollaender besprochen. ${ }^{158}$ Reinhardt hatte besonders die ersten drei Szenen bearbeitet und mit zahlreichen Skizzen und Regieanweisungen versehen, wie das entsprechende Regiebuch zeigt. 159 Hubert Reusch, der schließlich die Inszenierung von Reigen übernahm, baute auf Reinhardts Entwürfen auf und arbeitete in enger Abstimmung mit Schnitzler. 160 Die beiden Berliner Reigen-Prozesse im Jahr 1921, die die Rezeptionsgeschichte maßgeblich bestimmen, wurden breit dokumentiert. 161

Die erste österreichische Aufführung fand am 1. Februar 1921 an den Wiener Kammerspielen unter der Direktion Alfred Bernaus statt; Regie führte Heinz Schulbaur. 162 Wie vor allem Schnitzlers Tagebuch belegt, war er selbst an dieser Inszenierung unmittelbar beteiligt. ${ }^{163}$ Zwei Zensurexemplare im Niederösterreichischen Landesarchiv bezeugen indessen die zeitgenössischen politischen Kontexte. Im Exemplar von November $1920^{164}$ sind häufig einzelne Passagen markiert (v.a. Nebentexte zu Körperlichem und Kleidung; Dialoge zu Liebe und Sexualität; Ausführungen zu Religion und religiösen Symbolen; Beschreibungen der Lebensumstände der Dirne). Dem Exemplar von 1921165 ist eine Abschrift der Aufführungsbewilligung vom 12. Januar 1921 durch das Wiener Magistrat, Abteilung 55 beigelegt, in welchem ausführlich darauf hingewiesen wird, dass "die Regie mit ganz besonderem künstlerischem Takte" vorzugehen habe; bezüglich der dramaturgischen Umsetzung der den Koitus markierenden Gedankenstriche solle "dem Zuschauer die Wahrnehmung des sinnlichen Vorganges erspart bleibe[n], alles [...], was geeignet wäre, das gesellschaftlich als anstössig Empfundene etwa noch zu unterstreichen",

156 Vgl. die Informationen zu weiteren - auch zuvor im Ausland unautorisiert stattgefundenen - Aufführungen und Lesungen insbesondere bei: Pfoser I; Pfoser II; Schinnerer 1931; Schneider.

157 Vgl. Pfoser II, 25-58; Schneider 92-104. Am 25. Juni 1903 hatte - vor geschlossener Gesellschaft eine Teilaufführung (vierte bis sechste Szene) des Akademisch-Dramatischen Vereins im Münchner Kaim-Saal stattgefunden. Der Verein wurde daraufhin vom Universitätssenat verboten (vgl. Br I, 983; Pfoser I, 73; Schinnerer 1931, 842f.; Schneider 58-65; u.a. Tb III, 51 (4. 12. 1903)).

158 Vgl. Reinhardt-Bw, 82-95; u.a. Tb VI, 207 (7. 12. 1918).

159 The Max Reinhardt Archives \& Library, Special Collections, Binghamton University Libraries, Binghamton University, State University of New York.

160 Vgl. Pfoser II, 25-58; Schinnerer 1931, 847; Schneider 93. Im Protokoll zum Reigen-Prozess ist nachzulesen, dass Reusch „mit dem Tag der Premiere” seine Tätigkeiten für die Inszenierung beendet hatte (Heine 32); vgl. auch die Stellungnahmen Maximilian Sladeks (ebd., S. 30f.). Vgl. zur Berliner Inszenierung ebd. S. 438-441.

161 Vgl. u. a. Heine; Pfoser II, 40-46 / 59-75; Schinnerer 1931; Schneider 104-106 / 196-215.

162 Vgl. dazu ausführlich Pfoser I, 81-115; Schneider 110-129.

163 Vgl. passim Tb VII (Dezember 1920 und Januar 1921); vgl. u.a. Schinnerer 1931, 850; Schneider 114-117.

164 NÖLA, TB K 575/12.

165 NÖLA, TB K 575/28. 
solle vermieden werden. ${ }^{166} \mathrm{Im}$ Exemplar selbst sind alle Gedankenstrich-Passagen mit „Der Vorhang fällt" überschrieben. Die der Aufführung folgende Instrumentalisierung des Textes in Zusammenhang mit politischer Agitation ist in der Forschungsliteratur umfangreich erschlossen. ${ }^{167}$

\subsection{Zum Drucktext}

Der hier edierte Drucktext (D) folgt dem Privatdruck (PD) von 1900. PD kann aufgrund der Publikationssituation nicht als Erstausgabe im Sinne einer in einem Verlag erschienenen Ausgabe gelten und wurde auch nur in 200 Exemplaren hergestellt.

166 Ebd.

167 Vgl. zuerst v. a. Schnitzlers Briefe an Werner Richter v. 30.12.1920 (Br II, 223-228) und an Otto P. Schinnerer v. 6. 2. 1930 (Br II, 660-664); Nikolaj Beier: „Vor allem bin ich ich ...”. Judentum, Akkulturation und Antisemitismus in Arthur Schnitzlers Leben und Werk. Göttingen: Wallstein 2008, S. 531-552; Pfoser II; Schinnerer 1931; Schneider 110-182. - Intensiv erforscht wurden darüber hinaus u.a. sozial- und kulturgeschichtliche sowie gendertheoretische Fragestellungen; vgl. u.a. Erna Neuse: Die Funktion von Motiven und stereotypen Wendungen in Schnitzlers "Reigen“. In: Monatshefte für deutschen Unterricht, deutsche Sprache und Literatur 64 (1972), 4, S. 356-370; Janz; Johanna Bossinade: „Wenn es aber ... bei mir anders wäre”. Die Frage der Geschlechterbeziehungen in Arthur Schnitzlers Reigen. In: Aufsätze zu Literatur und Kunst der Jahrhundertwende. Hrsg. v. Gerhard Kluge. Amsterdam: Rodopi 1984 (= Amsterdamer Beiträge zur neueren Germanistik 18), S. 273-328; Ludwig Marcuse: Berlin 1920. Sex, Politik und Kunst - im Reigen. In: Ders.: Obszön. Geschichte einer Entrüstung. Zürich: Diogenes 1984, S. 189-240; Konstanze Fliedl: Arthur Schnitzler: Reigen. In: Dramen des 20. Jahrhunderts. Bd. 1. Stuttgart: Reclam 1996 (= RUB 9460), S. 25-39; Wolfgang Koebner: Arthur Schnitzler: Reigen. Erläuterungen und Dokumente. Stuttgart: Reclam 1997 (= RUB 16006); Arthur Schnitzler. Affairen und Affekte. Hrsg. v. Evelyne Polt-Heinzl u. Gisela Steinlechner. Mit Beitr. von Konstanze Fliedl u.a. Wien: Brandstätter / Österreichisches Theatermuseum 2006, passim; Sprengel; Birgit Schuhbeck: Paradise Lost. Das Denkmodell des Tabu/Bruchs in Drama, Theater und Gesellschaft um 1900. Würzburg: Königshausen und Neumann 2018 (= Film Medium - Diskurs 62), S. 328-376. - Eine Vielzahl von filmischen und literarischen Adaptionen zeigt die Möglichkeiten kreativer Aneignung und Aktualisierung von Reigen; vgl. u.a. La Ronde. R.: Max Ophüls. Frankreich 1950; Michael Kehlmann, Carl Merz u. Helmut Qualtinger: Reigen 51. Variationen über ein Thema von Arthur Schnitzler. Wien: Universal-Edition 1951; Ringel-Ringel-Reigen. Parodien von Arthur Schnitzlers „Reigen“. Hrsg. v. Gerd K. Schneider u. Peter Michael Braunwarth. Wien: Sonderzahl 2005; Rhea Krcmárová: REIGEN RELOADED. In: wortstaetten 2. anthologie. das buch zum interkulturellen autorentheaterprojekt wiener wortstaetten 2007. Hrsg. v. Hans Escher u. Bernhard Studlar. Wien: edition exil 2007, S. 63-166; Werner Schwab: DER REIZENDE REIGEN nach dem Reigen des REIZENDEN HERRN ARTHUR SCHNITZLER. In: Ders.: Werke. Hrsg. v. Ingeborg Orthofer. Graz, Wien: Droschl 2007ff., Bd. 8: Coverdramen. Hrsg. v. I. O. u. Lizzi Kramberger. Mit einem Nachw. v. Eckhard Schumacher (2009), S. 5-58. Diese Produktivität heben auch entsprechende Untersuchungen hervor; vgl. u.a. Leonhard Fuest: Nach dem Schwindel. Überlegungen zu Werner Schwabs $D E R$ REIZENDE REIGEN nach dem Reigen des REIZENDEN HERRN ARTHUR SCHNITZLER. In: "Das Schöne soll sein". Aisthesis in der deutschen Literatur. Festschrift für Wolfgang F. Bender. Hrsg. v. Peter Heßelmann, Michael Huesmann u. Hans-Joachim Jakob. Bielefeld: Aisthesis 2001, S. 469-485; Schneider; Gerd K. Schneider: „Ich will jeden Tag einen Haufen Sternschnuppen auf mich niederregnen sehen". Zur künstlerischen Rezeption von Arthur Schnitzlers „Reigen“ in Österreich, Deutschland und den USA. Wien: Praesens 2008; Marianne Wünsch: Wi(e)der die Doppelmoral. Arthur Schnitzlers Reigen (1920) und die Verfilmung von Max Ophüls (1950). In: Literaturskandale. Hrsg. v. Hans-Edwin Friedrich. Frankfurt a. M. u.a.: Lang 2009, S. 113-126. 
Allerdings steht PD H am nächsten und wurde - wie bereits beschrieben - auch öffentlich rezipiert.

PD: Reigen. Zehn Dialoge. Winter 1896/97. Als Manuscript gedruckt. Buchdruckerei Roitzsch vorm. Otto Noack \& Co. [1900]. ${ }^{168}$

Dieser Druck weist eine Reihe von Unregelmäßigkeiten auf, wie etwa die variierende Interpunktion bei Figurennamen und Nebentexten sowie die nicht vereinheitlichte Groß- bzw. Kleinschreibung nach Rufzeichen. Dies wird in D nicht normalisiert, sondern als spezifisches Merkmal dieses Druckes und damit als ein Verweis auf die komplizierte Druckgeschichte verstanden. Nicht eingegriffen wurde auch bezüglich der uneinheitlichen Verwendung von Elisionszeichen, wie sie für die Reigen-Drucke zu Lebzeiten Schnitzlers kennzeichnend ist und die Schwierigkeiten in der Wiedergabe gesprochensprachlicher Elemente um 1900 illustriert. PD ist nicht paginiert, daher werden die Seitenzahlen in $\mathrm{D}$ in eckigen Klammern angegeben; begonnen wurde mit der Zählung beim Titelblatt. Der unruhige Satz des Privatdruckes - v. a. hinsichtlich der Positionierung und Formatierung der Figurennamen und des Nebentextes sowie der Einzüge - wurde vereinheitlicht;169 Nebentexte werden in D durchwegs kursiv gekennzeichnet. Die Frakturschrift von PD wurde nicht übernommen. Ligaturen bei Digraphen in Sperrungen werden in D nicht imitiert. Die einzelnen Szenen schließen in PD jeweils mit einer mittig gesetzten, $2 \mathrm{~cm}$ langen Linie, die in den Folgedrucken wegfällt. Sperrungen sowie die Setzung von Viertelspatien vor Doppelpunkten, Fragezeichen, Rufzeichen und Semikola wurden übernommen. Die Wiedergabe von PD im Drucktext setzt mit dem Figurenverzeichnis ein. ${ }^{170}$ Alle Emendationen werden am Ende des Drucktextes angeführt (s. Herausgebereingriffe, S. $1051 \mathrm{f}$.). Der edierte Text bewahrt den originalen Zeilenfall. In der Marginalspalte werden die Seitenwechsel von PD und EA angegeben:

markiert in D einen Seitenwechsel im Privatdruck;

markiert in D einen Seitenwechsel in der Erstausgabe.

\subsection{Zum Apparat}

Der dem Drucktext D hinzugefügte Einzelstellenapparat verzeichnet die Abweichungen von PD zu der Erstausgabe im Wiener Verlag (EA), dem 44.-46. Tsd. des J. Singer Verlags (JSV), dem 89.-99. Tsd. des Benjamin Harz Verlags (BHV) und der Ausgabe im S. Fischer Verlag (SFV). Fehler in späteren Auflagen werden im Apparat nicht vermerkt; ebensowenig werden dort unterschiedliche Formatierungen der Nebentexte sowie der Wegfall der Viertelspatien in JSV berücksichtigt.

EA (Erstausgabe): Reigen. Zehn Dialoge. Geschrieben Winter 1896-97. Buchschmuck von Berthold Löffler. Wien, Leipzig: Wiener Verlag 1903.171

\footnotetext{
168 Exemplar der Wienbibliothek im Rathaus (Signatur: A 123706).

169 Siehe dazu Anhang, S. 1075-1086: Beispielseiten aus dem Privatdruck.

170 Siehe Zitation des Vorwortes von PD, S. 13.

171 Exemplar der Bayerischen Staatsbibliothek München (Signatur: L.sel.I 1591).
} 
Es handelt sich dabei um die erste in einem Verlag erschienene Ausgabe. EA weist eine Reihe von Abweichungen gegenüber PD auf (vgl. S. 25-27), wobei darauf hinzuweisen ist, dass - wie schon in PD - weder Satz noch Orthografie oder Schreibweisen von Begriffen und Namen sowie die Setzung der Elisionszeichen einheitlich gestaltet sind. Die zahlreichen regelhaften Abweichungen von EA zu PD weisen jeweils eine Reihe von Ausnahmen auf bzw. sind fallweise nur auf einzelne Szenen beschränkt. Auch EA setzt vor Doppelpunkten, Fragezeichen, Rufzeichen und Semikola Viertelspatien. EA zeichnet sich durch aufwändigen Buchschmuck aus: Jeder Szene ist eine Titelvignette vorangestellt; ab der jeweils zweiten Seite gibt es Kopfvignetten; nach jeder Szene wurde eine Schlussvignette gesetzt. Verziert sind auch Titelblatt und Figurenverzeichnis; der Buchschmuck wurde in späteren Auflagen reduziert (vgl. S. 15). Titelei und Impressum vorangestellt ist der Druckvermerk: „VON DIESEM BUCHE WURDEN 25 NUMERIERTE EXEMPLARE AUF BÜTTENPAPIER ABGEZOGEN UND VOM AUTOR SIGNIERT".

Regelhafte Abweichung in EA und den Folgedrucken außer SFV:

- Szenenüberschriften werden im Gegensatz zu PD in Großbuchstaben und ohne abschließenden Punkt geschrieben. Das Eszett bei "süße” wird durch Doppel-s („,süsse ") ersetzt.

Regelhafte Abweichungen in EA und sämtlichen Folgedrucken:

- PD ist in Fraktur gesetzt, Lehn- bzw. Fremdwörter werden durch Antiquaschrift hervorgehoben; dies wird in D kursiviert wiedergegeben - mit Ausnahme einzelner Buchstaben (v.a. „è" in „Portière"). Ab EA wird durchgehend Antiqua verwendet; Lehn- und Fremdwörter wurden folglich nicht mehr gesondert gekennzeichnet.

- Das Figurenverzeichnis samt Überschrift wird ab EA in Großbuchstaben und ohne Interpunktion gesetzt. Das Eszett bei "süße” wird durch Doppel-s ( „süsse”) ersetzt. - Bei Nebentexten weist PD unregelmäßige Interpunktion auf (tlw. fehlende Klammern sowie eine variierende Folge von abschließender Klammer und Satzzeichen). Dies wird in EA mitunter vereinheitlicht: Während in der ersten und zweiten Szene mit einer Ausnahme durchwegs das abschließende Satzzeichen auf die Klammer folgt, wird in den folgenden Szenen inkonsequent vorgegangen, zum Teil erfolgen sogar gegenteilige Korrekturen. JSV, BHV und SFV folgen diesen Korrekturen bzw. nehmen neue vor, bleiben jedoch inkonsequent. SFV tendiert dazu, die Funktion bestimmter Nebentexte als Inquit-Formel hervorzuheben, indem sie mit „::" bzw. an einer Stelle mit Doppelpunkt und ohne Klammer abgeschlossen werden; bei den vorhergehenden Drucken ist dies seltener zu finden.

- Die Anzahl der Gedankenstriche, die im Text an elf Stellen den Koitus markieren, beträgt in PD durchgehend 16. In EA und JSV variiert die Anzahl (zW. 12 und 14 bzw. 14 und 16); BHV vereinheitlicht mit einer Ausnahme zu 17. PD, EA, JSV und BHV setzen Halbgeviertstriche. In SFV fehlen die Gedankenstriche in der ersten Szene; ansonsten vereinheitlicht SFV zu 27 bzw. 28 (Szene 4 und 7) Viertelgeviertstrichen.

- In EA wird anstelle der in PD mittig gesetzten Linie am Ende der einzelnen Szenen eine Schlussvignette gesetzt; in den Folgedrucken fehlen diese grafischen Elemente. - PD weist eine unregelmäßige Verwendung von Elisionszeichen auf - vor allem bei der Imitation gesprochensprachlicher Merkmale. EA nimmt zahlreiche Änderungen 
vor, diese sind jedoch nicht systematisch. Alle Folgedrucke nehmen Änderungen bezüglich der Elisionszeichen vor, wobei SFV am meisten Einheitlichkeit anstrebt und gelegentlich Fehler/Unstimmigkeiten der Drucke ab EA wieder rückgängig macht.

- PD schreibt - mit drei Ausnahmen - Personal- und Possessivpronomina der 2. Person Singular groß. EA korrigiert - mit drei Ausnahmen - zu Kleinschreibung; ISV korrigiert zusätzlich zwei; BHV folgt JSV; SFV berichtigt auch die letzte Ausnahme.

- Die Großschreibung von Personalpronomen der 2. Person Plural in verschiedenen Deklinationsformen in PD wird ab EA zu Kleinschreibung geändert.

- EA eliminiert - mit neun Ausnahmen - die Schreibung von "th" bei allen Deklinationsformen der Substantiva "That", "Thränen" und "Thür", bei allen Konjugationsformen des Verbes "thun" sowie bei dem Adjektiv "räthselhaft"; JSV ändert zusätzlich diese Ausnahmen; BHV und SFV folgen JSV.

- Die Schreibung von "Cigarette", "Cigarre" und "Civilist" wird ab EA zu "Zigarette", "Zigarre" und "Zivilist" geändert.

- Konjugationsformen von "geben" sowie "hingeben", bei welchen sich der Stammvokal zu "i" ändert, werden in PD mit "ie" geschrieben. In EA wird - mit fünf Ausnahmen - zu "i“ korrigiert; JSV berichtigt zusätzlich diese Ausnahmen; BHV und SFV folgen JSV.

- PD schreibt das Adverb "abends" drei Mal groß und einmal klein; JSV korrigiert zwei Mal zu Kleinschreibung; BHV übernimmt dies; SFV ändert vollständig zu Kleinschreibung. PD schreibt das substantivisch gebrauchte und auf Temporaladverbien folgende "Abend" fünf Mal groß und einmal klein; EA korrigiert dabei zu Großschreibung, dem folgt JSV; gleichzeitig werden jene Fälle, in denen in PD Großschreibung verwendet wurde, ab JSV zu Kleinschreibung korrigiert. BHV und SFV machen die Korrektur zu Großschreibung wieder gänzlich rückgängig; SFV korrigiert zusätzlich den einzigen Fall, in dem in PD ein groß geschriebenes "Abend" auf eine Wochentagsangabe folgt, zu Kleinschreibung. PD schreibt darüber hinaus die Adverbien "mittags" und "nachts" groß; EA korrigiert zwei- von dreimal zu Kleinschreibung; SFV führt die letzte Korrektur durch.

- Die Schreibweise von Zahlen ist in PD uneinheitlich; ab EA werden Zahlen ausgeschrieben.

- EA setzt bei beidmaligem Vorkommen des Begriffes "Cotillon" die Schreibweise "Kotillion" (engl. "cotillion", eingedeutschte Schreibweise mit "K"). JSV übernimmt dies. BHV korrigiert zu "Kotillon", dem folgt SFV.

- Ab EA werden Verben auf "-iren" bzw. "-ieren" einheitlich mit „ie" geschrieben. - PD schreibt die Interjektion "Oh" "oh" mit Dehnungs-h. EA ändert an nur zwei Stellen zur Schreibung ohne Dehnungs-h; JSV an 16; BHV korrigiert zahlreiche weitere Fälle, jedoch nicht vollständig, und macht an zwei Stellen Korrekturen von JSV sogar rückgängig. SFV folgt BHV.

- PD tendiert bei substantivierten Adjektiven zu Kleinschreibung, bleibt jedoch uneinheitlich. EA und JSV korrigieren tlw. zu Großschreibung, BHV und insbesondere SFV nehmen weitere, jedoch unvollständige Korrekturen vor.

- PD schreibt adverbiale Komposita mit "einander" uneinheitlich zusammen oder getrennt: "aneinander", „ineinander", "miteinander", aber auch "mit einander", "von einander", "zu einander". EA korrigiert durchwegs zu "miteinander" bzw. 
"zueinander"; nur an einer Stelle zu "voneinander"; dem folgen JSV und BHV; erst SFV ändert vollständig zu "voneinander".

- PD schreibt "Küss'“ bzW. „küss'”, was ab EA zur Schreibung mit Eszett geändert wird.

- PD schreibt "Haus" bzw. "Hause” nach der Präposition "nach" mit zwei Ausnahmen groß; EA korrigiert auch diese beiden Ausnahmen.

JSV: Reigen. Zehn Dialoge. Geschrieben Winter 1896-97. 44.-46. Tausend. Berlin: Verlag J. Singer \& CO. [1913?]. ${ }^{172}$

Es handelt sich dabei nicht um die erste durch den Singer Verlag vertriebene Auflage, sondern - wie oben beschrieben - um die erste, die auch unter dem Verlagsnamen publiziert wurde. Der noch in der vorangehenden Ausgabe ${ }^{173}$ übernommene (reduzierte) Buchschmuck der Wiener Verlags-Ausgaben fehlt; bei Überschriften und Interpunktionszeichen fallen typographische Änderungen auf; ebenso fehlen nun die Viertelspatien. JSV nimmt eine Reihe von - auch regelhaften - Eingriffen vor, die in die Folgedrucke übernommen wurden, wie beispielsweise Änderungen bei der Interpunktion; tIw. wurden Fehler aus EA wieder korrigiert und Sperrungen eliminiert. Auffallend ist ein inhaltlich verfälschender Eingriff, der in den Folgedrucken erhalten blieb. Zu Beginn der vierten Szene wird thematisiert, dass die Junge Frau zwei Schleier trage (D 696-698), die schließlich vom Jungen Herrn abgenommen werden. Während es in PD und EA sowie auch noch in der Vorgängerausgabe im Singer Verlag an der entsprechenden Stelle heißt: „Er nimmt ihr die Schleier ab" (D 725), ändert JSV fälschlicherweise zu "den Schleier" (Apparat zu D 725).

Regelhafte Abweichungen in JSV und Folgedrucken:

- Mit JSV wird die Schreibweise von "Cognac" zu „Kognak" geändert.

- In JSV wird die Schreibweise von "Divan" sechs Mal zu „Diwan” modernisiert; BHV korrigiert auch die restlichen sieben Fälle; dem folgt SFV.

- Mit JSV wird die Schreibweise von "gleichgiltig" in beiden auftretenden Fällen zu "gleichgültig" verändert.

- JSV korrigiert systematisch „Freundinen" zu "Freundinnen".

- Mit JSV wird die Schreibweise des Pronomens "bischen" zu "bißchen" korrigiert.

BHV: Reigen. Zehn Dialoge. Geschrieben Winter 1896-97. 89.-99. Tausend. Berlin, Wien: Benjamin Harz=Verlag [1923/24?]. ${ }^{174}$

Die Auflagen im Harz Verlag folgen bis zum 69. Tausend mit wenigen Änderungen JSV; erst mit dem 69. bis 78. Tausend finden weitere Eingriffe in den Text statt, die im 79. bis 88. Tausend - abgesehen von einigen Fehlern - übernommen wurden, im 89. bis 99. Tausend (BHV) jedoch zum Teil wieder rückgängig gemacht wurden. Auffallend ist etwa die im 69. bis 78. Tausend erfolgende Korrektur eines seit EA bestehen-

\footnotetext{
172 Exemplar der Wienbibliothek im Rathaus (Signatur: A 301889).

173 Reigen, 41.-43. Tausend (Anm. 95).

174 Privatexemplar.
} 
den Fehlers: ${ }^{175}$ In der sechsten Szene heißt es, dass ,der Gatte' aufstehe, sich hinter den Sessel stelle und "das süße Mädel" umarme (D 1697f.); in EA wurde fälschlicherweise zu "daß süße Mädel" (EA 111) geändert, was von den folgenden Ausgaben übernommen wurde. Darüber hinaus handelt es sich insbesondere um Änderungen von Schreibweisen und Interpunktion sowie der Anzahl der den Koitus markierenden Gedankenstriche. Verschiedene Eingriffe wurden durch BHV wieder rückgängig gemacht: So erläutert der Dichter in der siebten Szene etwa gegenüber dem Süßen Mädel, er hege "einen gewissen Verdacht" (D 2660), was zu "einen groBen Verdacht" 176 geändert und in BHV rückkorrigiert wurde. Insgesamt lässt der Vergleich von BHV mit dem 69. bis 78. Tausend sowie JSV darauf schließen, dass diese Ausgabe lektoriert und mit mehreren vorhergehenden Ausgaben verglichen wurde. $\mathrm{BHV}$ verwendet eine andere Schriftart, unterscheidet sich in Format und auch teilweise bzgl. der Seitenumbrüche von den älteren Harz-Ausgaben und ist - dies zeigt die Kollationierung - als Grundlage für die Ausgabe im S. Fischer Verlag (SFV) zu verstehen. Wie alle Harz-Ausgaben - mit Ausnahme des als Luxusausgabe erschienenen 100. Tausend - trägt auch BHV den Vermerk: „COPYRIGHT 1914 BY BENJAMIN HARZ VERLAG BERLIN · WIEN".

SFV: Reigen. Zehn Dialoge. 101.-104. Aufl. Berlin: S. Fischer Verlag 1931. ${ }^{177}$

Diese Ausgabe ist gänzlich überarbeitet; Seitenlayout, Schrift und Hervorhebungen unterscheiden sich signifikant von den ansonsten seit EA ähnlichen Drucken. So werden etwa Sprecherangaben kursiviert und ohne abschließenden Punkt verzeichnet; folgt darauf ein Nebentext, wird dieser in kleinerer Schrift in derselben Zeile angeschlossen; Hervorhebungen werden kursiviert. Die Wiederholung des Titels unmittelbar vor dem Figurenverzeichnis fehlt. Der bei Harz und Singer jeweils als Titelzusatz geführt Hinweis auf den Entstehungszeitraum wurde bei der Fischer-Ausgabe ins Impressum verschoben: „Geschrieben im Winter 1896/97". Wie schon erläutert, zeigt die Kollationierung, dass sich SFV an BHV orientiert, darüber hinaus jedoch eine Reihe von regelhaften Änderungen vornimmt bzw. Ausnahmen von regelhaften Eingriffen der vorhergehenden Drucke korrigiert (siehe oben), wobei beispielsweise bei Elisionszeichen nach wie vor Unregelmäßigkeiten bleiben. Charakteristisch für SFV ist das Fehlen der Gedankenstriche in der ersten Szene - wohl irrigerweise aufgrund des an dieser Stelle erfolgenden Seitenumbruchs.

Regelhafte Änderungen in SFV:

- Figurenbezeichnungen sind kursiv und ohne abschließenden Punkt gesetzt.

- Szenenüberschriften werden im Gegensatz zu EA, JSV und BHV gesperrt und nicht in Großbuchstaben geschrieben und "süße" folglich wieder mit Eszett; jedoch wird auch hier - im Gegensatz zu PD - kein abschließender Punkt gesetzt.

- Die zuvor jeweils stark variierende Anzahl an Gedankenpunkten wird zu drei vereinheitlicht.

\footnotetext{
175 Wie erläutert, werden neue Fehler im Apparat nicht verzeichnet. Vgl. daher Reigen, 69.-78. Tausend (Anm. 128), S. 115.

176 Ebd., S. 171. Dem folgt: Reigen, 79.-88. Tausend (Anm. 131).

177 Exemplar der Österreichischen Nationalbibliothek (Signatur: 805275-B).
} 
- Die Schreibung von "chambre separée" wird zu "Chambre separée" geändert. - Während EA, JSV und BHV nur an einer Stelle das in PD mit "z.B." bzW. "Z. B." abgekürzte "zum Beispiel” bzW. "Zum Beispiel” ausschreiben, nimmt SFV diese Änderung systematisch vor.

- PD schreibt "Gotteswillen" in dem mundartlichen Ausruf ,Um/um Gotteswillen” zusammen; JSV und Folgedrucke ändern an einer Stelle zu "Gottes willen"; nur SFV führt diese Änderung konsequent durch.

- SFV ändert das auf ein Temporaladverb folgende Substantiv „Vormittag" zu Kleinschreibung.

- SFV schreibt "Portière" ohne Gravis.

- PD, EA, JSV und BHV schreiben "hieher"; SFV modernisiert zu "hierher".

\subsection{Zum Kommentar}

Der Einzelstellenkommentar enthält kulturgeschichtliche sowie topografische Hinweise und bietet Erläuterungen zu Austriazismen sowie veralteten, zum Teil fremdsprachlichen Ausdrücken im handschriftlichen Konvolut, dem Typoskript und dem Drucktext. Darüber hinaus werden fehlerhafte Schreibweisen richtiggestellt. Variierende und alphabetisch benachbarte Schreibweisen eines Begriffes werden jeweils zusammengefasst, wobei auf die Wiedergabe spezifischer Kennzeichnungen in der Handschrift (z. B. Gräuungen, Streichungen) verzichtet wird. 

1. Handschriften und Typoskript 


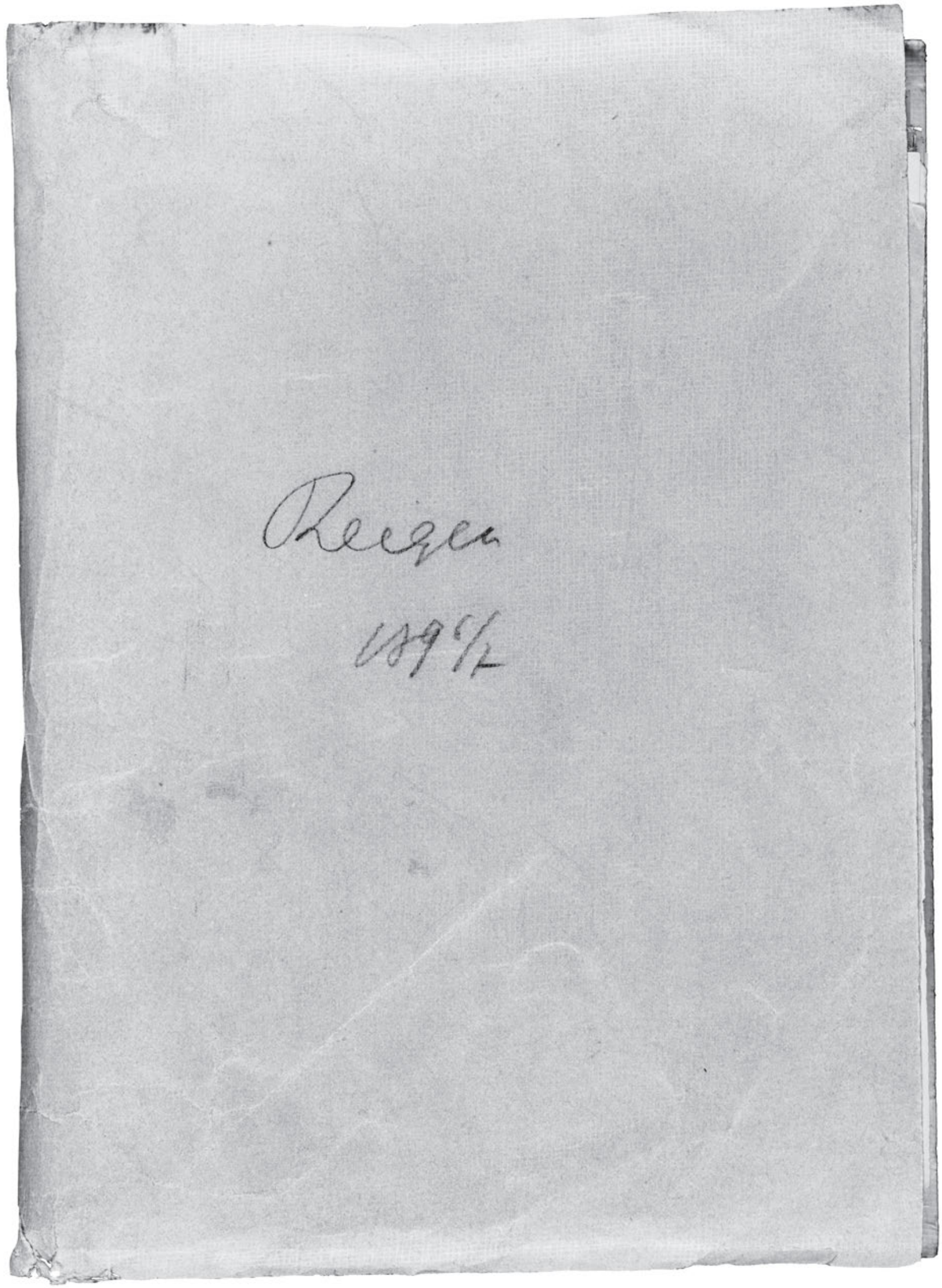

Originalmaße $20 \times 25,6 \mathrm{~cm}$ 


\section{Reigen}

$1896 / 7$ 
E

Handschriften und Typoskript

$+$

er

Gi Lenighlo

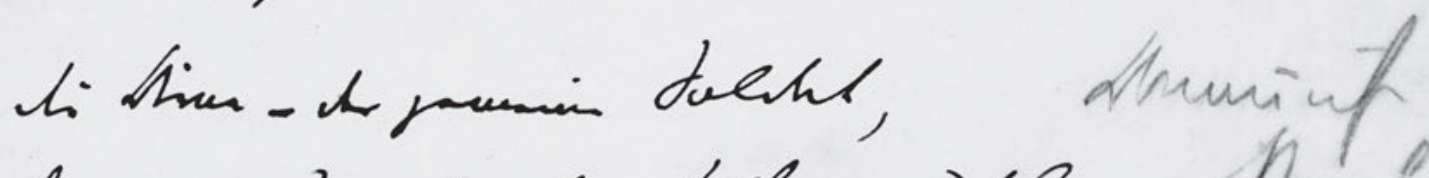

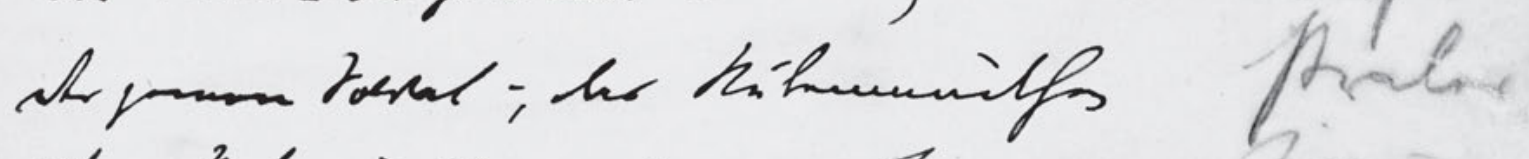
tho histminilfs - L jis Forr

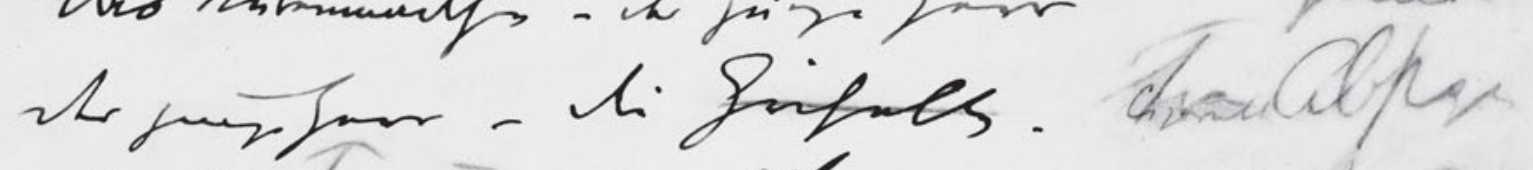

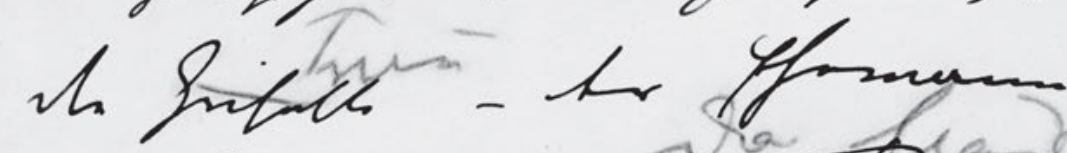

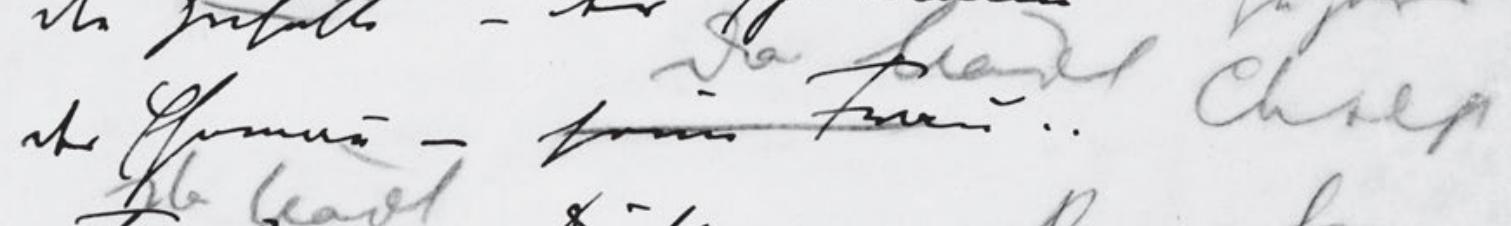
trabcart sifar. Pin - fro

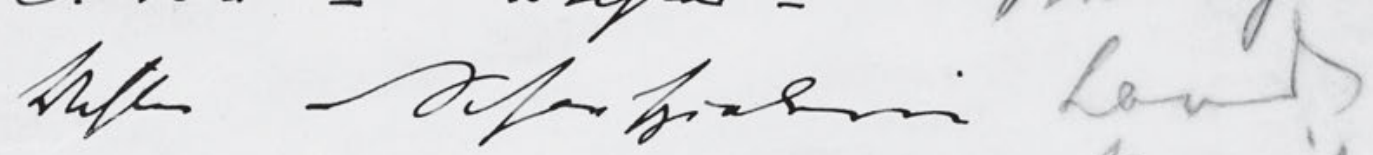
typipasion - An fokel. R. I Anfortant - di Mina.

- If Siabz.

34 
Ein Hemicyclus

Die Dirne - der gemeine Soldat,

Donauufer

Der gemeine Soldat -, das Stubenmädchen Prater

Das Stubenmädchen - der junge Herr

Zimer

Der junge Herr - die Grisette.

${ }^{\text {Fra }}$ Cigarett Abstge

Frau

Die Grisette - der Ehemann

zu haus

Das Mädl

Der Eheman̄ - seine Frau . .

Chsep

Das Mädl

Frau - Dichter -

Bei ihm

10

Dichter - Schauspielerin

Land

Schauspielerin - Aristokrat -

Bei ihr

Aristokrat - die Dirne.

Tschecherl.

Zehn Dialoge. -

Schreibstoff: Tinte; Paginierung und Datierung in Zeile 1, Ortsangaben in der rechten Spalte und Tilgungen bzw. interlineare Einfügungen wurden mit Bleistift vorgenommen.

6 Abstge: Absteige.

8 Chsep: Chambre séparée. 
HF 1

Handschriften und Typoskript

Uu

1

380

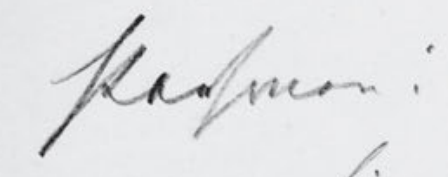

l.

chi Asins

ver Folctul

she fintminger

tivellos 
[380]

1

Ein Liebesreigen.

Vo Arth Sch

Personen:

5

Die Dirne

Der Soldat

Das Stubenmädchen

Der junge Herr

Die junge Frau

10

Der junge Mann

$D^{\text {ie } a s}{ }^{G}$ süße Mädl

Der Dichter

Die Schauspielerin

Der Graf.

15

$1896 / 7$. 
HSz1 2

Handschriften und Typoskript

2

1

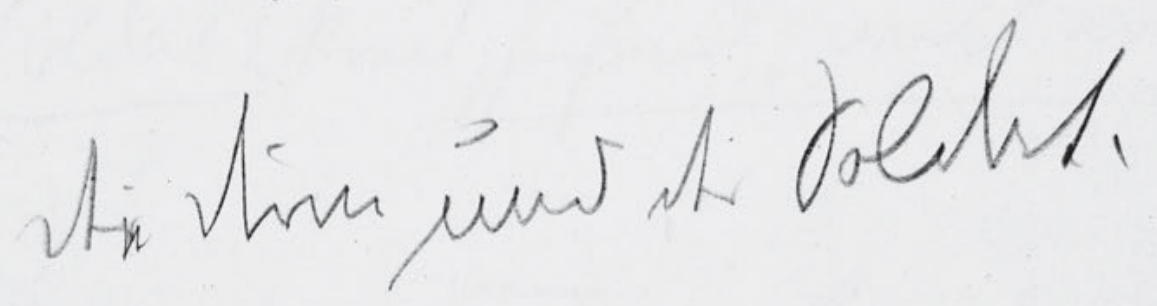

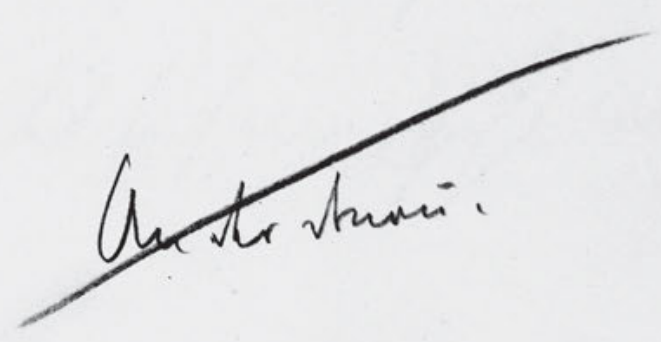

38 
1.

$\mathrm{D}^{\mathrm{er}}$ ie Dirne und der Soldat.

An der Donau. 
HSz1 3

Handschriften und Typoskript

2) 111.

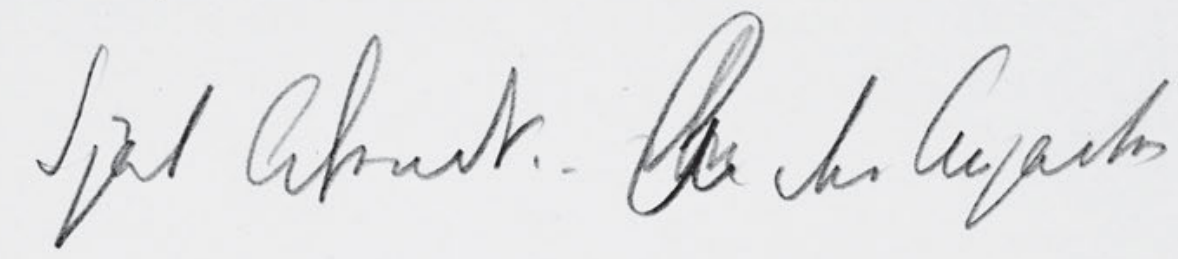

hinctin.-

3

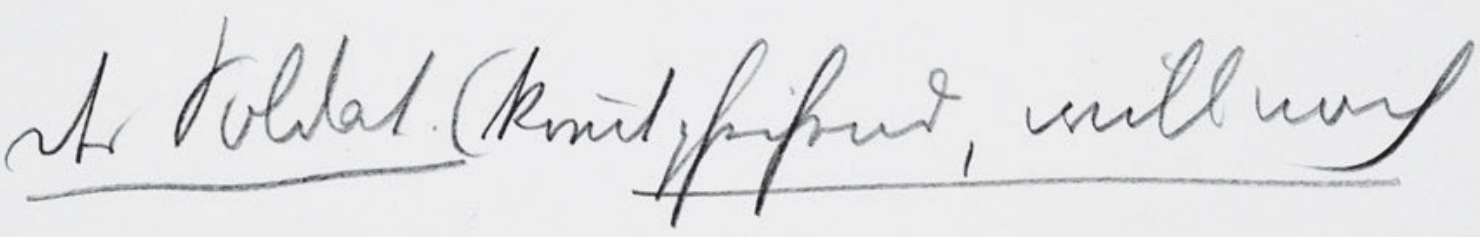

pis)

th thin hom, to topros fugal,

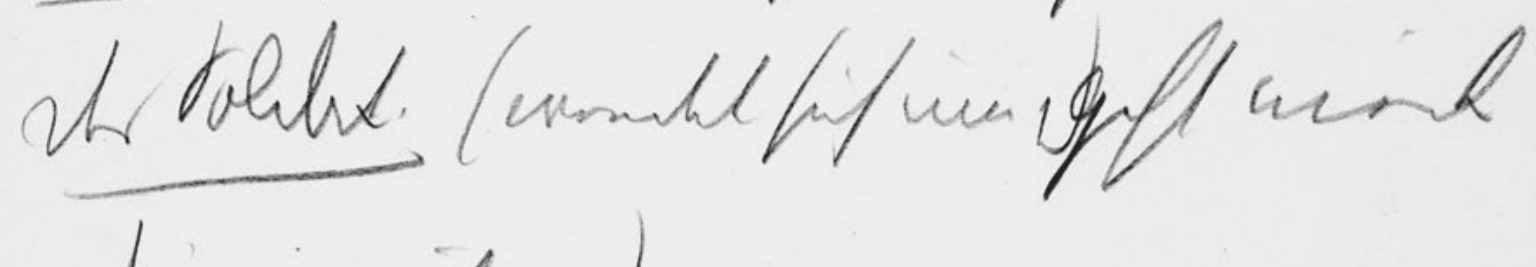

shim. wille ti unft wit mo Rinum

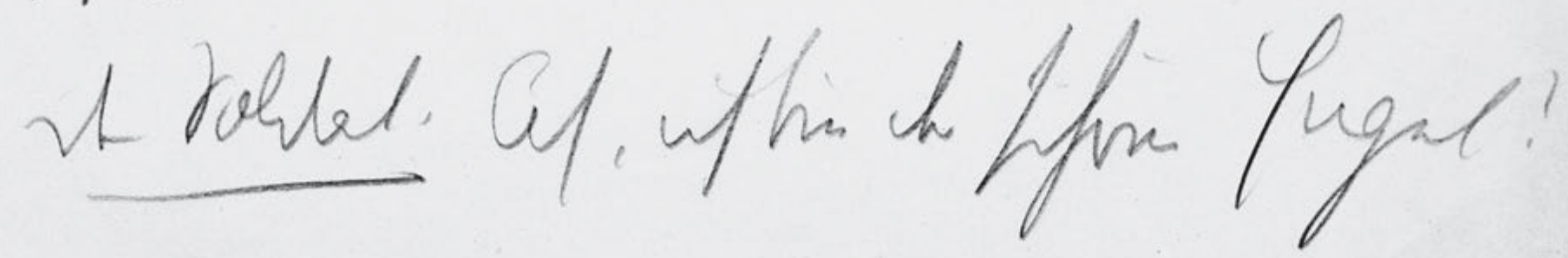

40 
$23 / 11$.

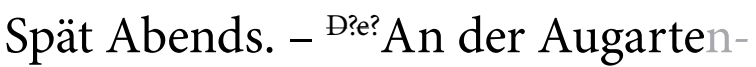

brücke. -

Der Soldat. (kō̄t pfeifend, will nach

$5 \quad$ Hause)

Die Dirne .. Kō̄̄, du schöner Engel.

Der Soldat. (wendet sich um,')geht wieder

Dirne. weiter.)

Die Dirne. Willst du nicht mit mir

10 komen.

Der Soldat. Ah, ich bin der schöne Engel? 
HSz1 4

Handschriften und Typoskript

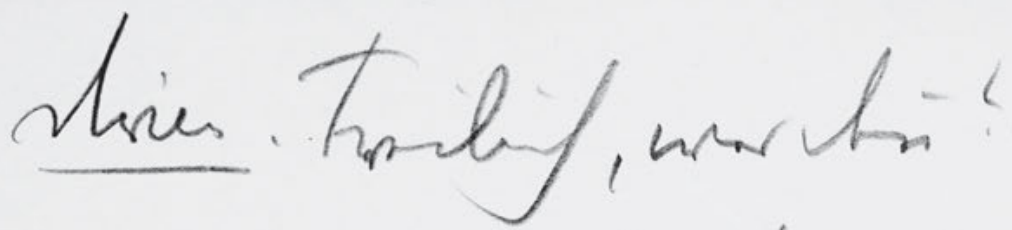

Apthom re

virs.

ipuof paif in

haj.

h

folkum git

Anit

in likafiom

dive. in hafor tarmp u

2

robbl (gontt west fir)

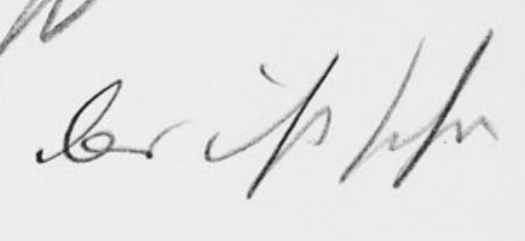

neiglay

Mine kp. Jot ther

42 
4

Dirne . Freilich, wer dē̄? . Geh, kom zu

mir. Ich wohn gleich in der Näh.

Soldat. Ich hab keine Zeit. Ich muss

5 in die Kasern.

Dirne. In die Kasern kō̄st imer noch

zu recht. Bei mir ist besser.

Soldat (greift nach ihr.) Das ist schon

möglich

10 Dirne Pst. Jeden Moment kan ein

Wachmann kō̄en. 
HSz1 5

Handschriften und Typoskript

th dolbat Lafoly! Me funanu' bot ainf urn betroganft? Arm. Gof, thris weil.

rolbet Laf mitu his Gnetpolst anftruis

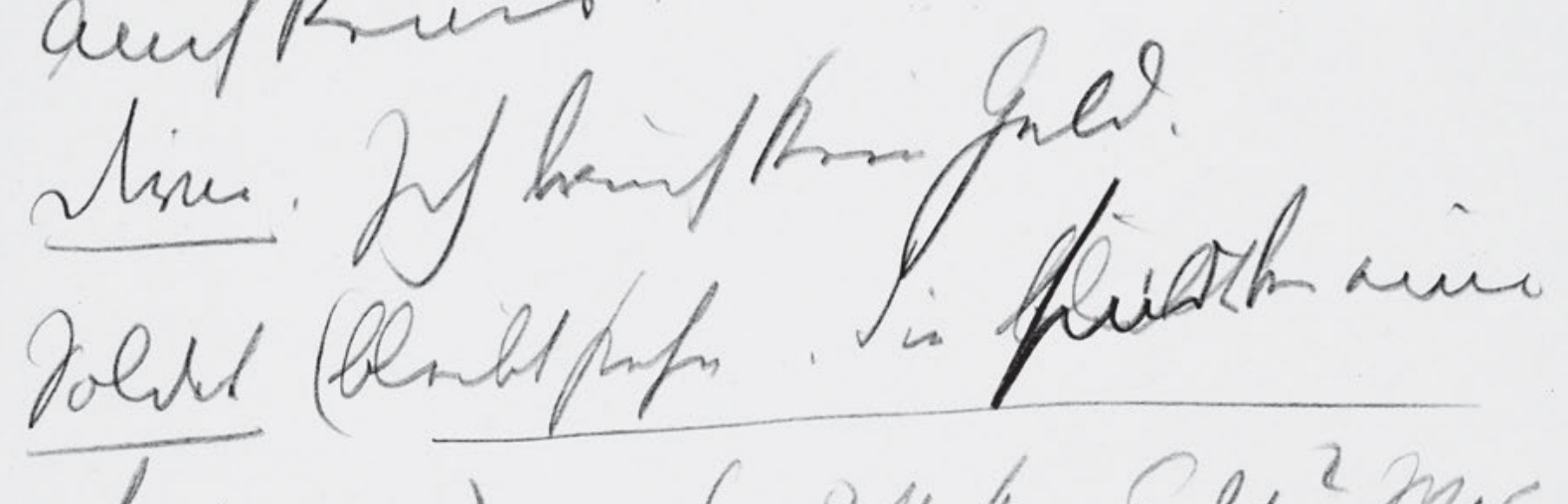

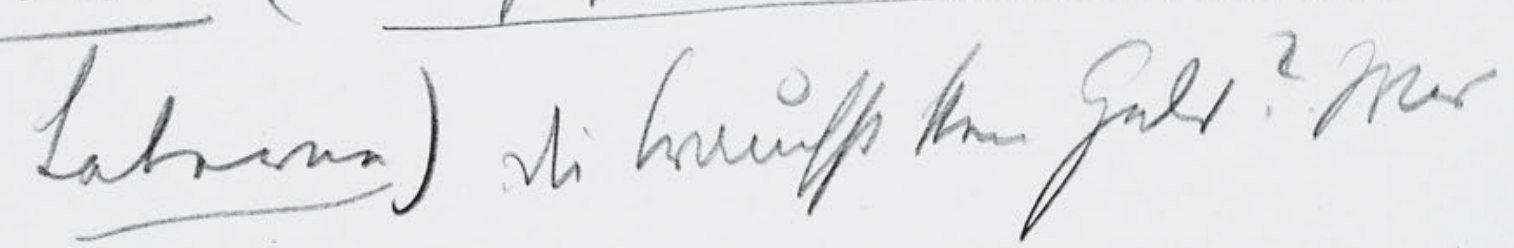
hip tim? tan

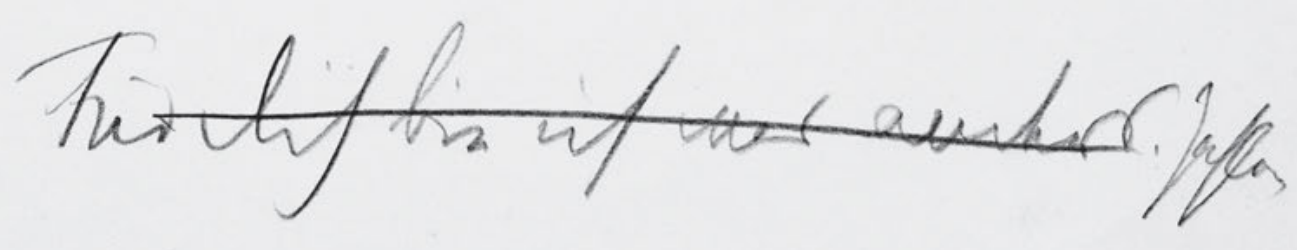

44 
Der Soldat. Lächerlich! Wachmann! Ich

hab auch mein Seitengewehr!

Dirne. Geh, kō̄ mit.

5 Soldat. Laß mich in Ruh. Geld hab ich

auch keins.

Dirne. Ich brauch kein Geld.

Soldat (bleibt stehn. Sie bleibtsind bei einer

Laterne) Du brauchst kein Geld? . Was

bist denn?

Dirne . Für dich bin ich was anders. Zahlen 
HSz1 6

Handschriften und Typoskript

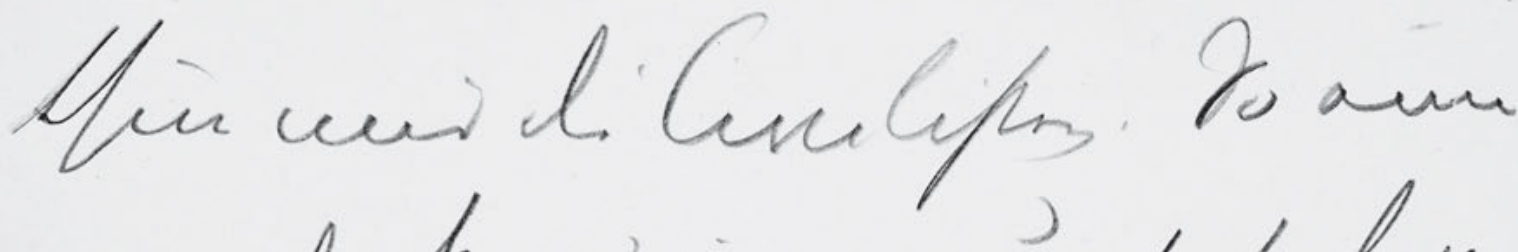
min likañ ine uuppos bu wi fahn.

Moludat. tikf om Ins hi unch wer hjom

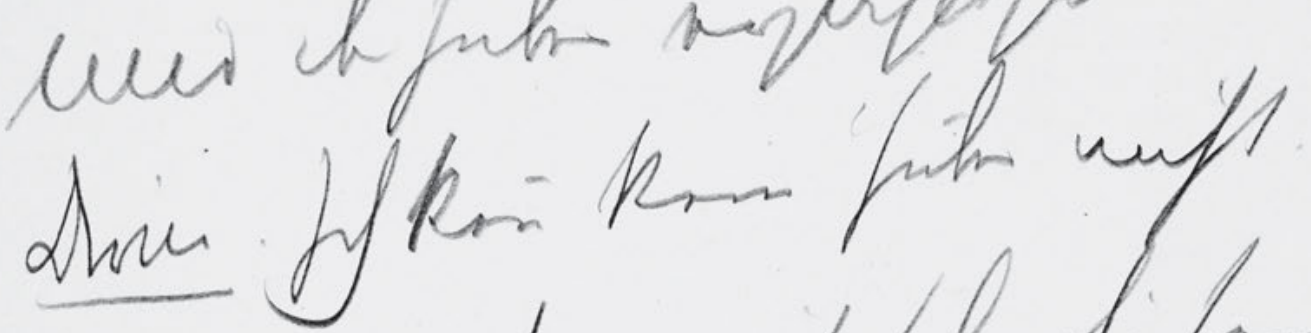

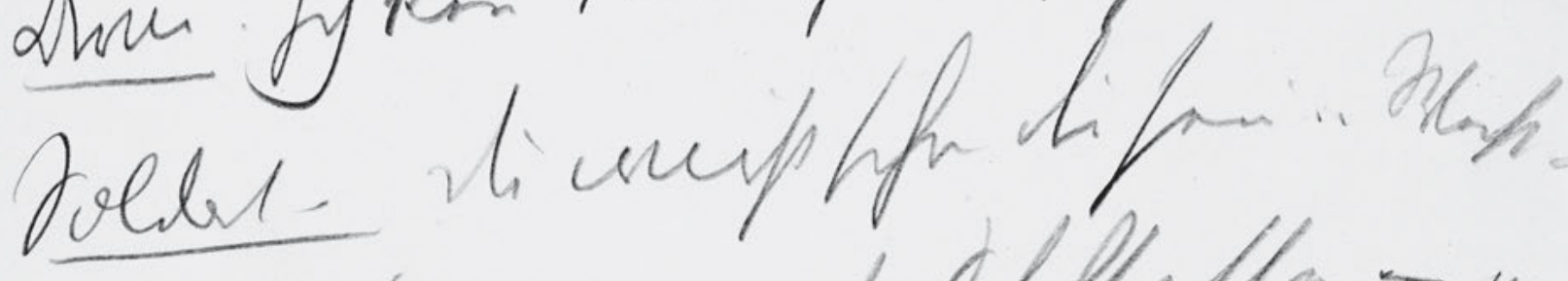

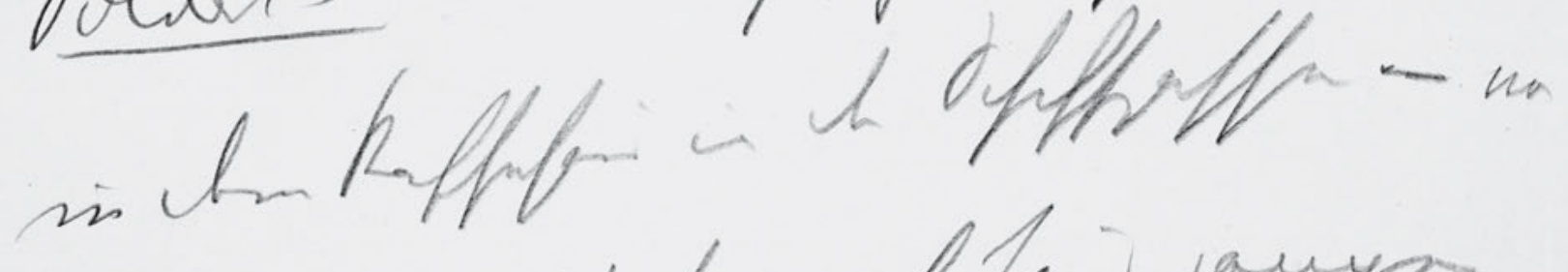

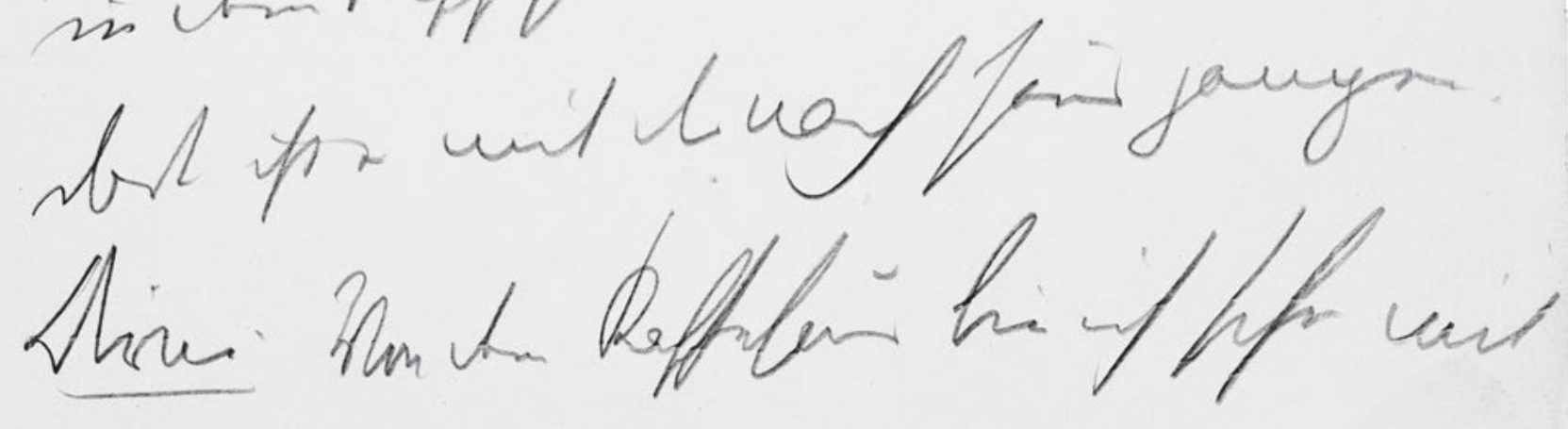

46 
6

thun mir die Civilisten. So einer

wie du kan̄'s imer umsonst bei mir

haben.

5

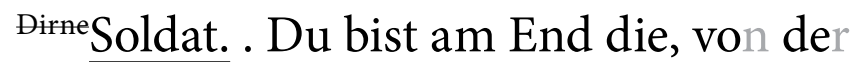

mir der Huber erzählt hat.

Dirne. Ich kē̄ kein Huber nicht.

Soldat. Du wirst schon die sein . . Weißt -

in dem Kaffehaus in der Schiffgassen - von

10 dort ist er mit dir nach Haus gangen.

Dirne. Von dem Kaffehaus bin ich schon mit 
HSz1 7

Handschriften und Typoskript

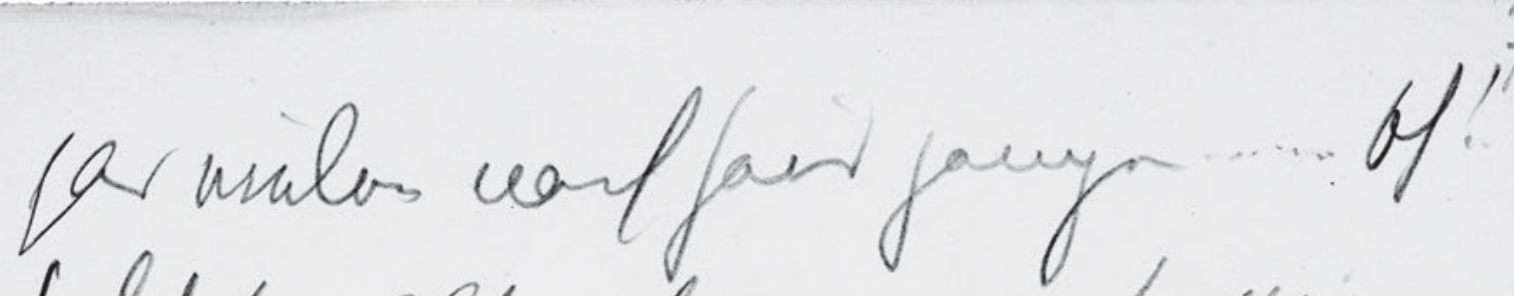
solbes alf gaf nei gof mi.

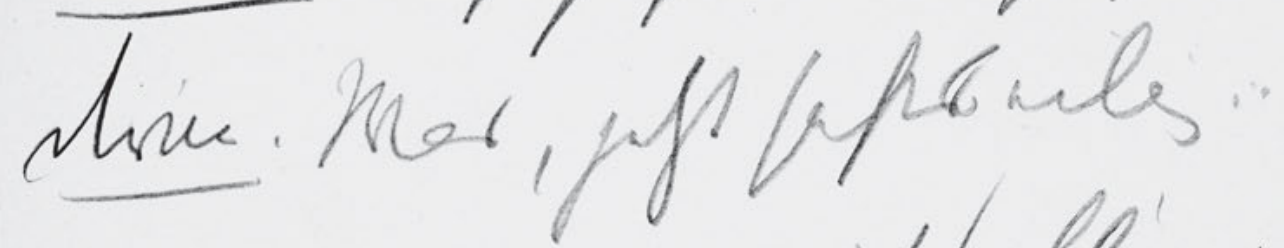
robber. hes, werertfoll'n un unf

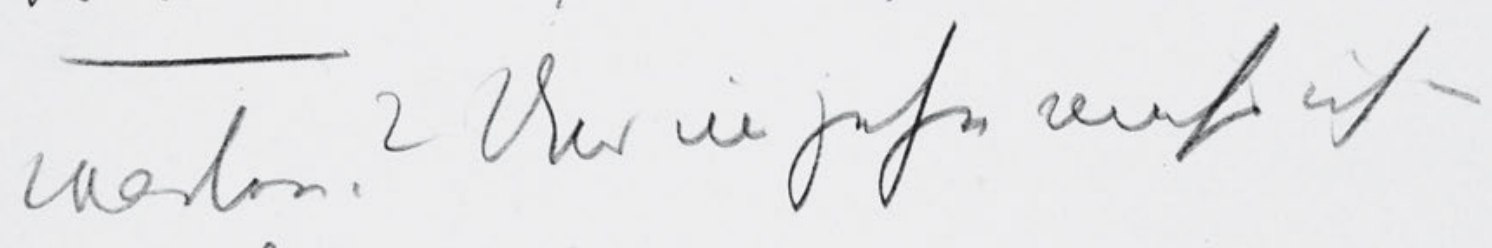
ch Raformpor

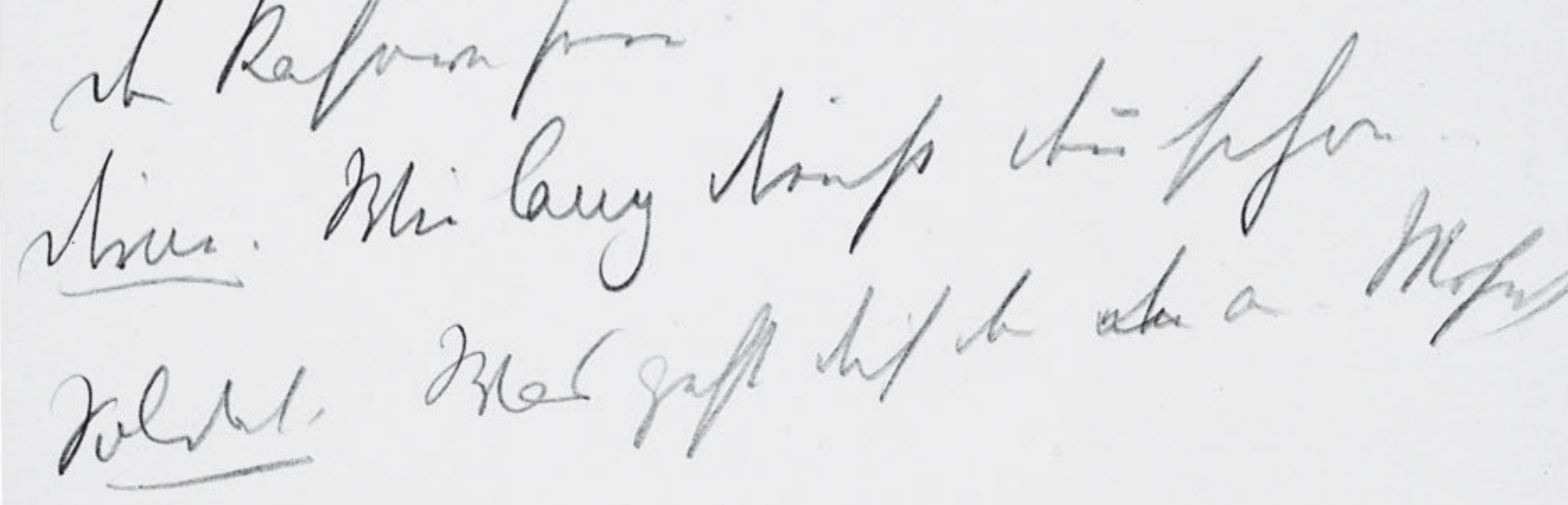
Volve

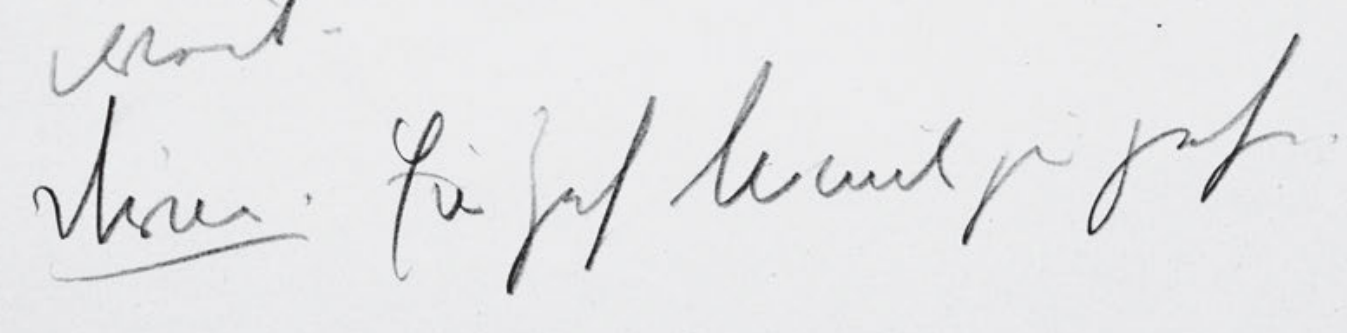

48 
gar vielen nach Haus gangen ...... Oh! Oh! -

Soldat. Also gehn wir - gehn wir ..

Dirne. Was, jetzt hast's eilig ...

5 Soldat. Na, worauf soll'n wir noch

warten? Und um zehn muss ich in

der Kasern sein.

Dirne. Wie lang dienst den̄ schon ..

Soldat. Was geht dich das ${ }^{\text {ei }}$ den an. Wohnst

10 weit -

Dirne. Ein Zeh Minute zu gehn. 
HSz1 8

Handschriften und Typoskript

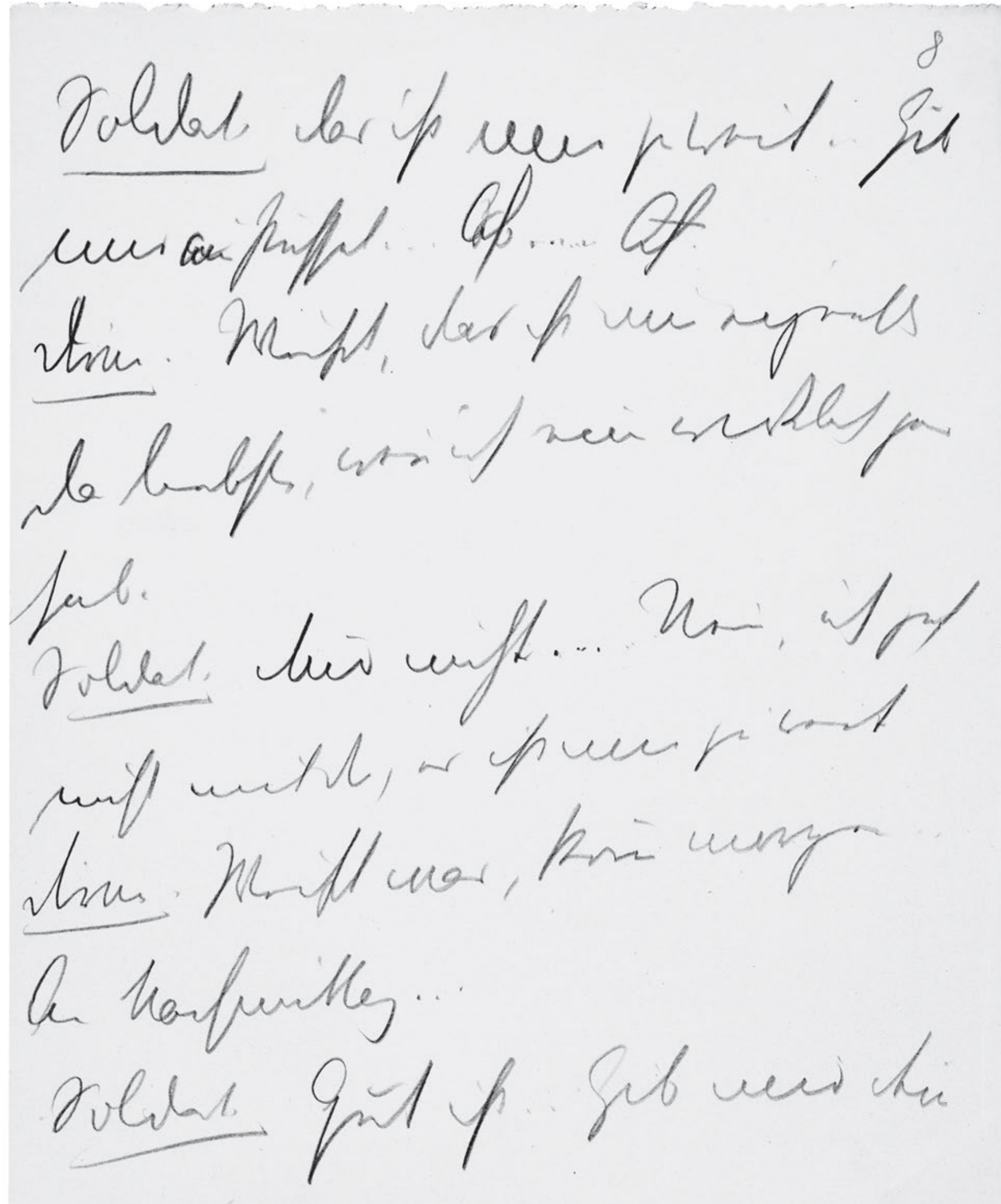

50 
8

Soldat. Das ist mir zu weit . . Gib

mir ${ }^{a}$ ein Pussel ... ${ }^{\text {s}_{\theta}} \mathrm{Ah} . . .$. . Ah.

Dirne. Weißt, das ist mir eigentli

5 das liebste, wen̄ ich einen wirklich ger

hab.

Soldat. Mir nicht ...... Nein, ich geh

nicht mit dir, es ist mir zu weit

Dirne. Weißt was, kō̄ morgen . .

Am Nachmittag...

Soldat. Gut ist . . Gib mir dein 
HSz1 9

Handschriften und Typoskript

Aulall

dimi.

Ah di ku

q

Ane di

intos

le

rip

Polbat. the

thim se if

lebrar wis-

(wrip and hutrei)

rolbat.

A b ip

mf

52 
9

Adress . .

Dirne . Aber du komst am End nicht.

Soldat. Wen̄ ich dir's sag . .

$5 \quad$ Dirne. Du, weißt was, - wen̄s dir

zu weit ist heut Abend zu mir - da

unten .. da . (weist auf die Donau).

Soldat. Was ist da?

Dirne. Da ist auch schön ruhig....geht

jetzt kein Mensch . .

Soldat. Ah .. Das ist nicht das rechte. 
HSz1 10

Handschriften und Typoskript

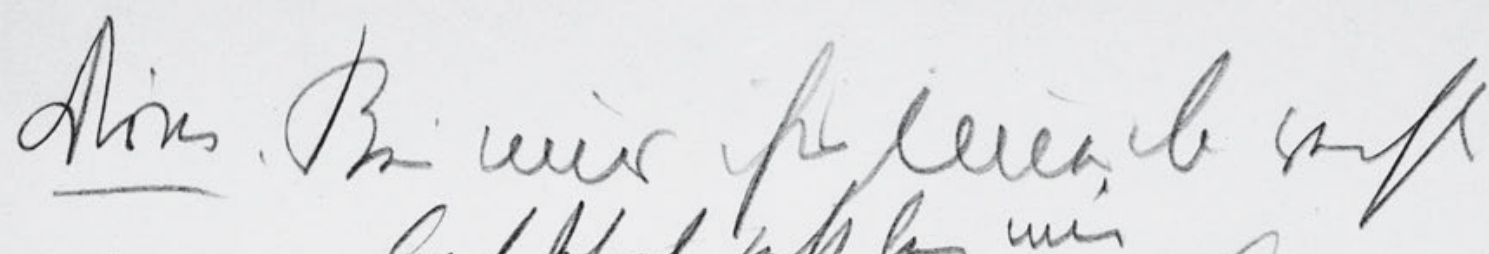

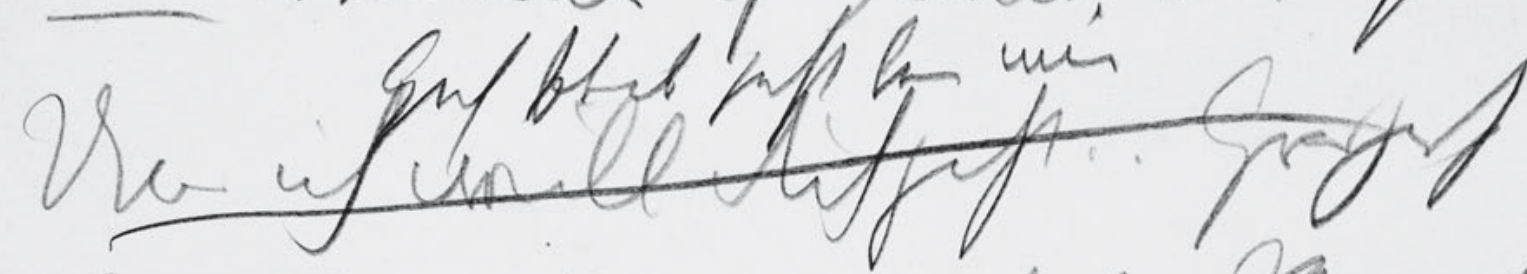

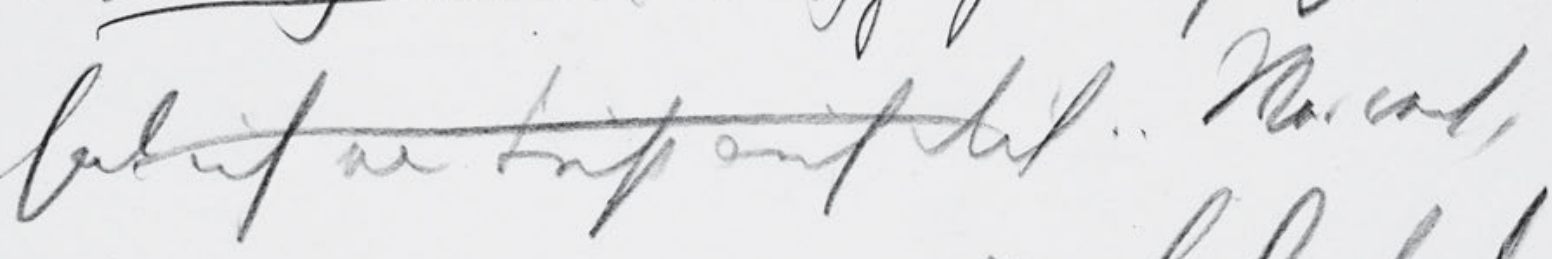
ob unvicungr unfi lahgeh. Tolbe. To hon-ah sthinew tive giloterf... ba sf thum onmp intontty, hiff us stren.

volbt ma of b hp 
Dirne. Bei mir ists imer das rechte. .

Geh bleib jetzt bei mir

Und ich will dich jetzt. . Grad jetz

hab ich eine Lust auf dich .. Wer weis,

5 ob wir morgen noch's Leben haben.

Soldat. So kom - aber gschwind -

Dirne. Gib Obacht..... da ist so dunkel.

Wenst ausrutscht, liegst in der

Donau.

Soldat. Wär eh das beste - 
HSz1 11

Handschriften und Typoskript

xhated

Mer

uner gims.
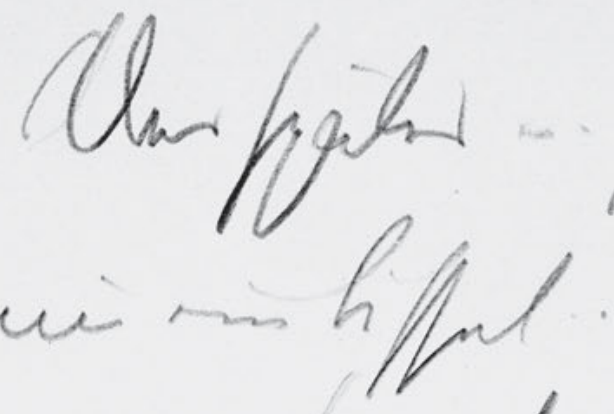
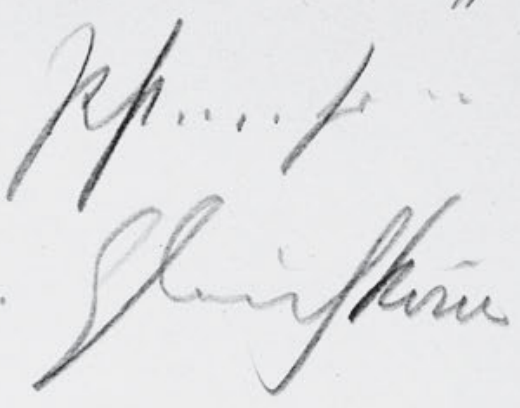

II 
Soldat. Dirne. ${ }^{[?]}$ Und später . . Pst . . . so so . .

Wart nur ein bissel . . Gleich kō̄en

wir zu einer Bank -

$5 \quad$ Soldat. Kennst dich da gut aus.

Dirne. So einen wie dich möcht ich

zum Geliebten.

thät viel eifer

Soldat. Ich wär dir zu eifersüchtig

Dirne. Das möcht ich dir schon abge

10 wöhnen.

Soldat. $\mathrm{Ha}-$ 
HSz1 12

Handschriften und Typoskript

$\frac{\text { din }}{\text { bef }}$

tupl

lent.

12 wer losinta, lef we lunts thelle

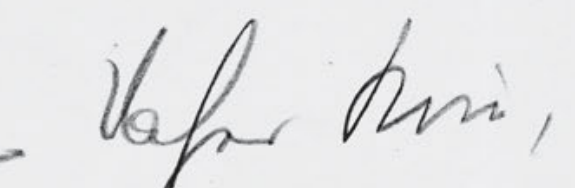

un.

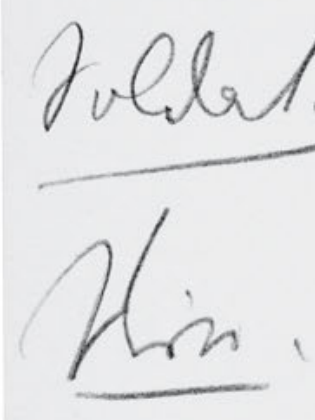

mill andith

lir unes

Mafferit

rublal.

lalpio

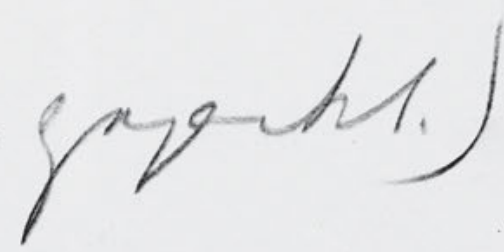

Af. Sh

58 
${ }^{\text {s}}$ Dirn. Nicht so laut ..... manchmal ist doch,

dass sich ein Wachter verirrt.... Sollt

man glauben, dass wir da mitten in

5 der Wiener Stadt sind.

Soldat. Daher kō̄, daher -

$$
\text { deñ }
$$

Dirn. Aber was fallt dir ein . . wenn

wir $\mathrm{da}$ ausgleiten, liegen wir im

Wasser unten.

Soldat. (hat sie gepackt.) Ah .. du .. 
HSz1 13

Handschriften und Typoskript

$\frac{\text { Anim }}{\text { Toldal }}$

13

$\longrightarrow$

Galktipuir fip

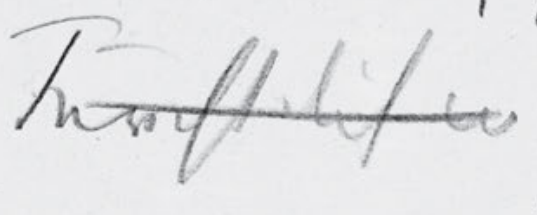

tal ba auph...

of

Dime Gaph kenth

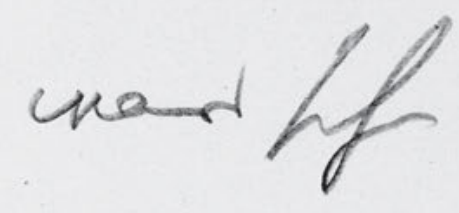

befr purst

Poldat.

la Mt k... ha krall

sifin. ke lonff

Joldet.

hif.

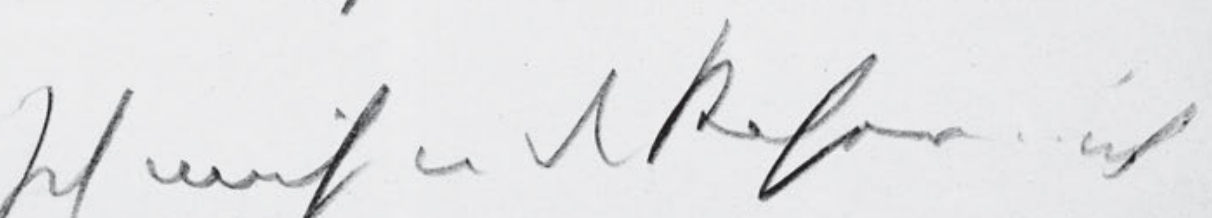

60 
Dirne. Halt dich nur fest an . .

Soldat. Fürcht dich ni hab keine Angst....

..oh...

5

Dirne. Auf der Bank wars schon

besser gewesen.

Soldat. Da oder da ... Na . . krall

aufi -

10 Dirne. Was laufst deñ so -

Soldat. Ich muss in die Kasern .. ich 
HSz1 14

Handschriften und Typoskript
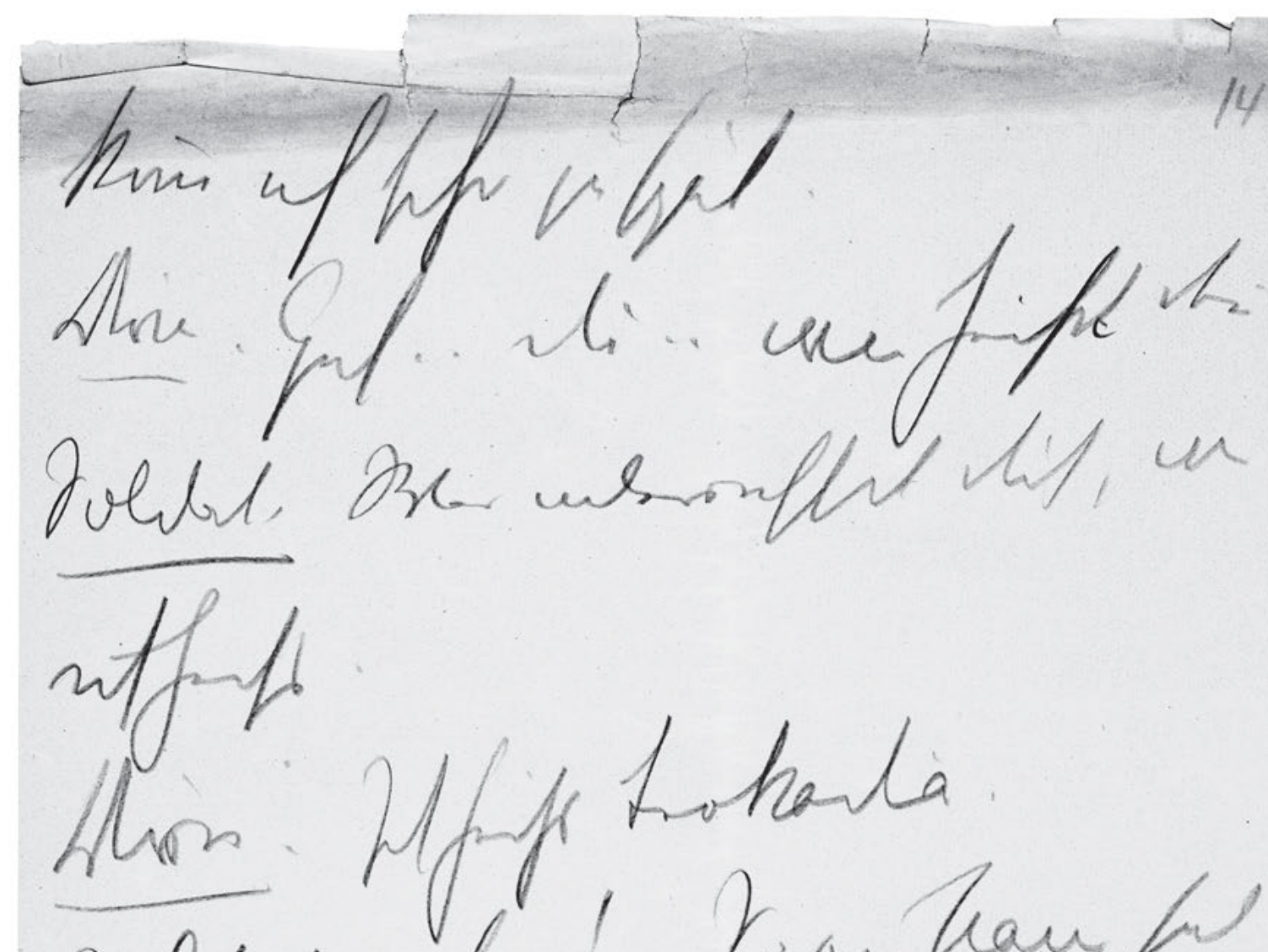

rolidal.

tohala

thin

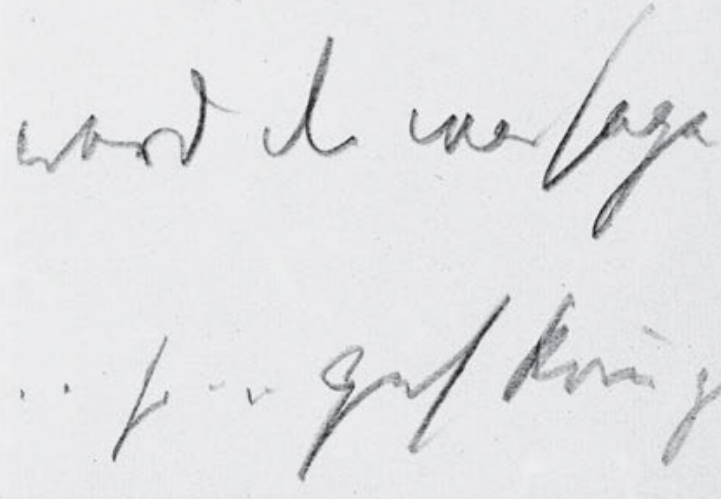

pont

t

M

uni

62 
kō̄ eh schon zu spät.

Dirne. Geh . . du .. wie heißt den̄

Soldat. Was interessirt dich, wie

5 ich heiss.

Dirne. Ich heiss Leokadia.

Soldat. Ha! - So an Nam hab ich

auch noch nie gehort.

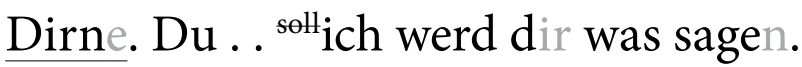

10 so gut .. so .. oh .. so ... geh kom zu

$\operatorname{mir} \ldots .$. 
HSz1 15

Handschriften und Typoskript

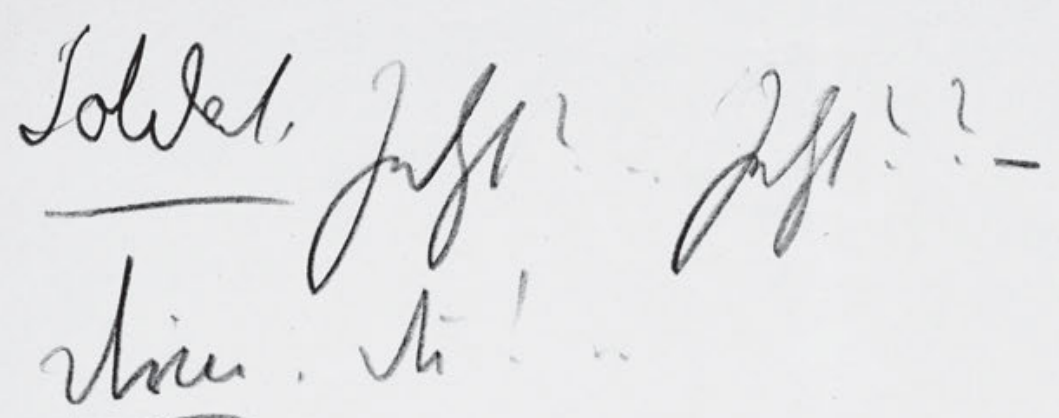

Publat. he uno willf th

15

tim qup

in

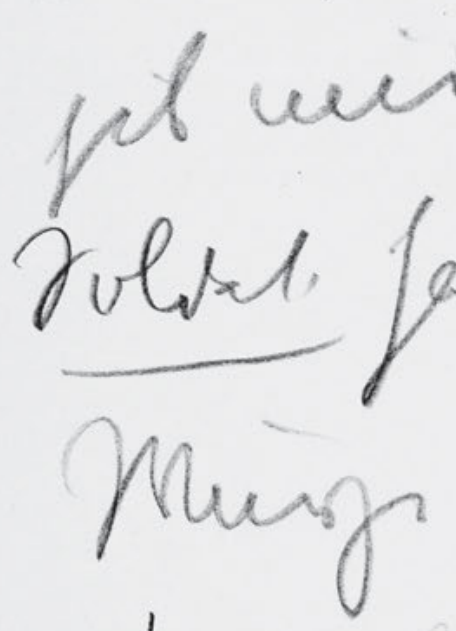

Cyiph it

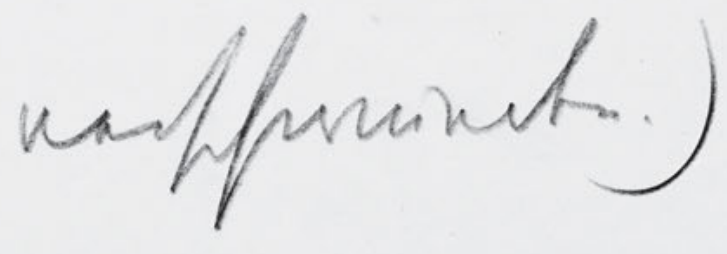

64 
Soldat. Jetzt? . Jetzt? ? -

Dirne . Du! . .

Soldat. Na was willst dē̄?

${ }_{5}$ Dirne. Geh, ein Sechserl für Hausmeist

gib mir wenigstens! -

Soldat. Ha! . . Glaubst, ich bin dei

Wurzn ..... Servus! Leokadia! -

Dirne. Strizi! Fallott! -

10 (Er ist ihr verschwunden.) 
HSz2 16

Handschriften und Typoskript

16

In tolubs nus

dor

Thibumeniys

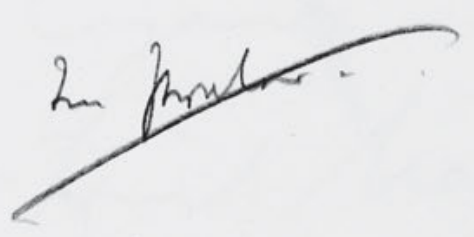

66 


\section{2. \\ Der Soldat und \\ das Stubenmädchen}

Im Prater.

5 punktförmige Verschmutzung nach Prater. 
HSz2 17

Handschriften und Typoskript

2174

Pentar Pontes

What

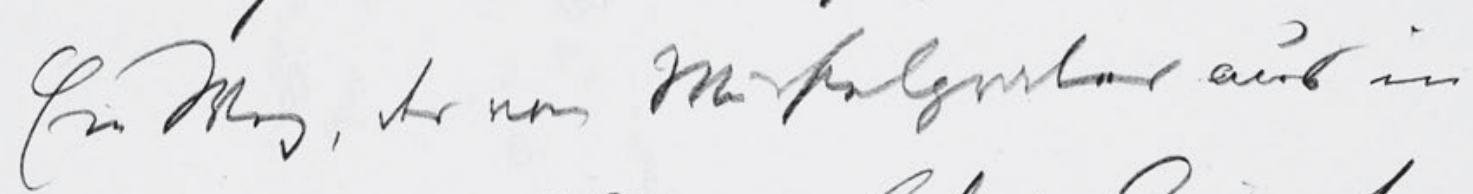

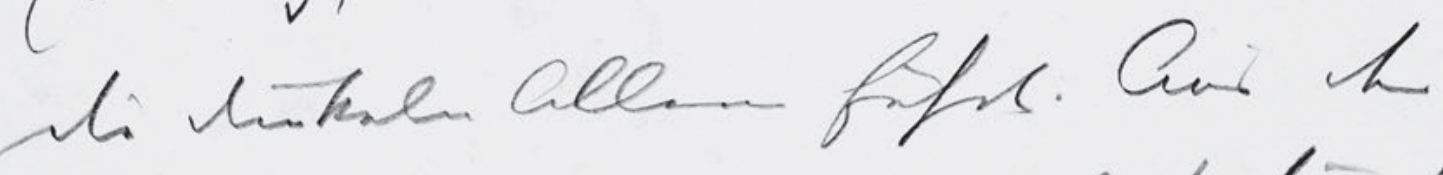

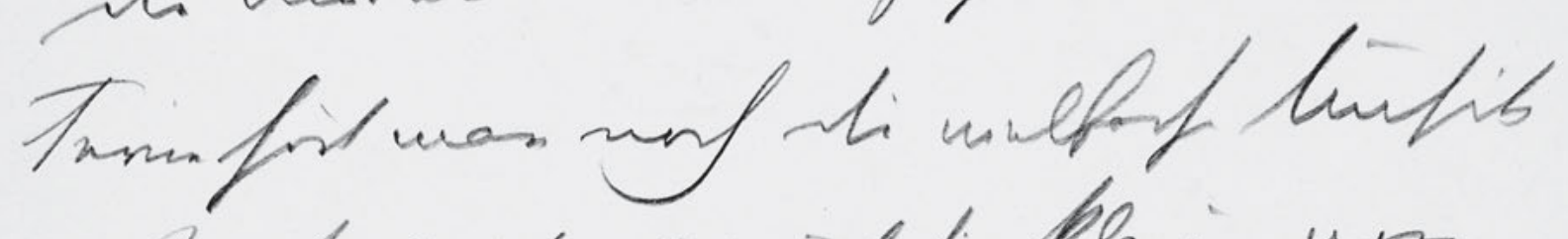

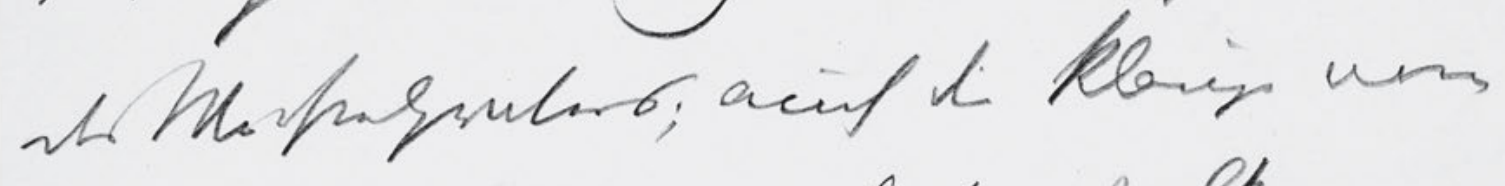

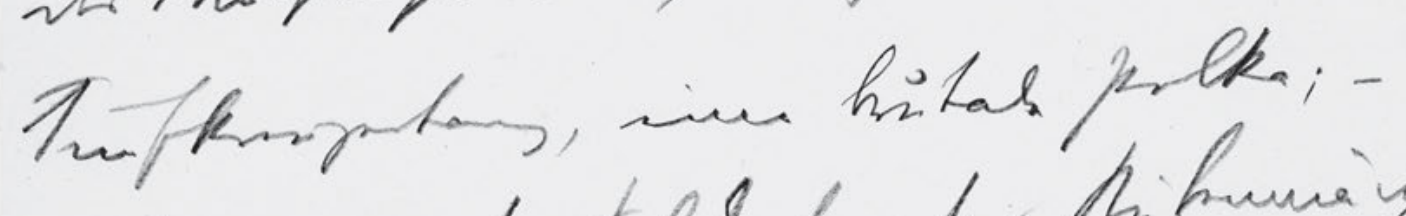
at

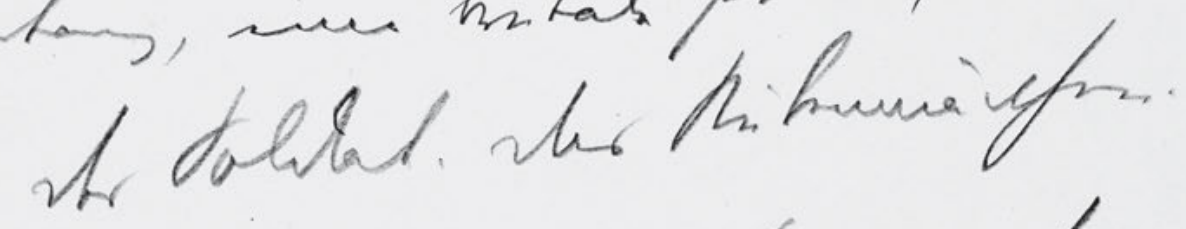

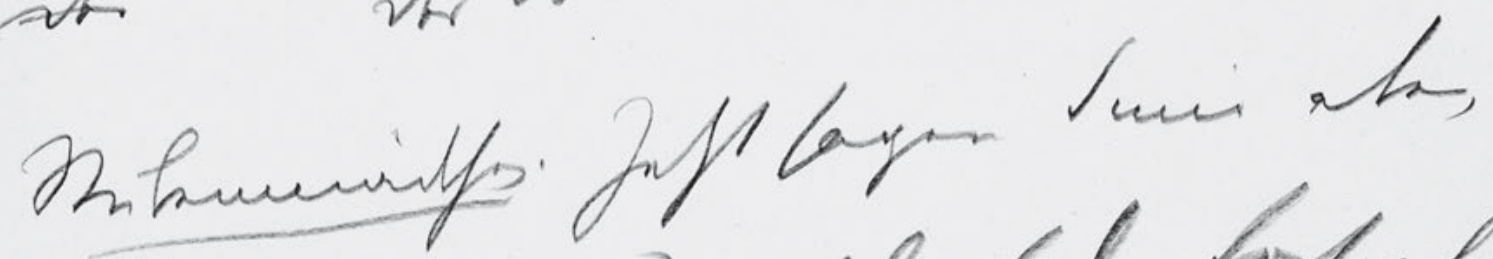

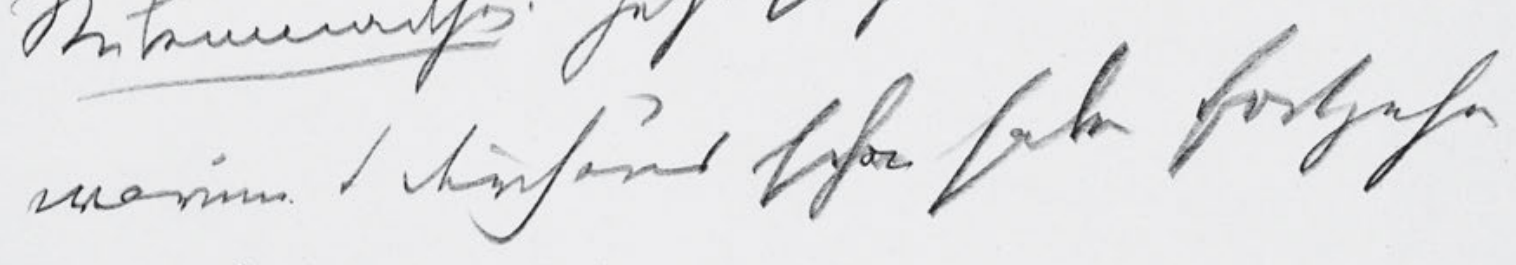
sole, miff.

Dohbl /beft moryon, tiven.)

68 
$25 / 11$

17

Prater. Sontag Abend

Ein Weg, der vom Wurstelprater aus in die dunkeln Alleen führt. Aus der

5 Ferne hört man noch die vielfache Musik

des Wurstelpraters; auch die Klänge vom

Fünfkreuzertanz, eine brutale Polka; -

Der Der Soldat. Das Stubenmädchen . .

Stubenmädchen. Jetzt sagen S mir aber,

10 warum $\mathrm{S}$ durchaus schon haben fortgehen

wollen, müssen.

Soldat. (lacht verlegen, dumm.) 
HSz2 18

Handschriften und Typoskript

18

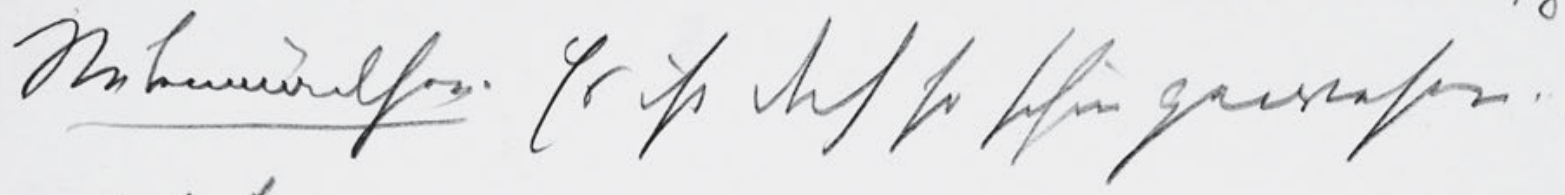

If tong gron.

Poldex. (faff' in min th boles)

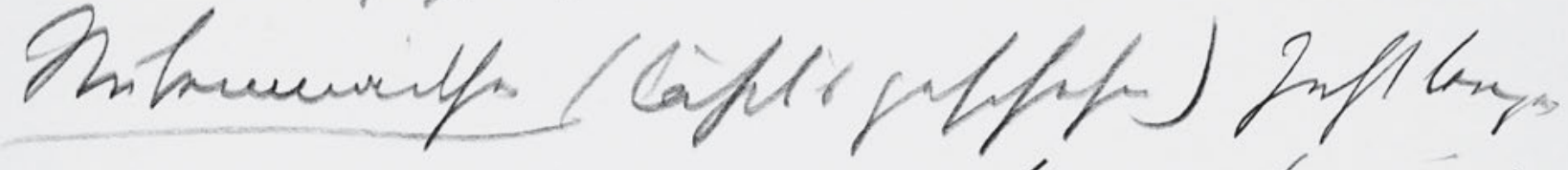

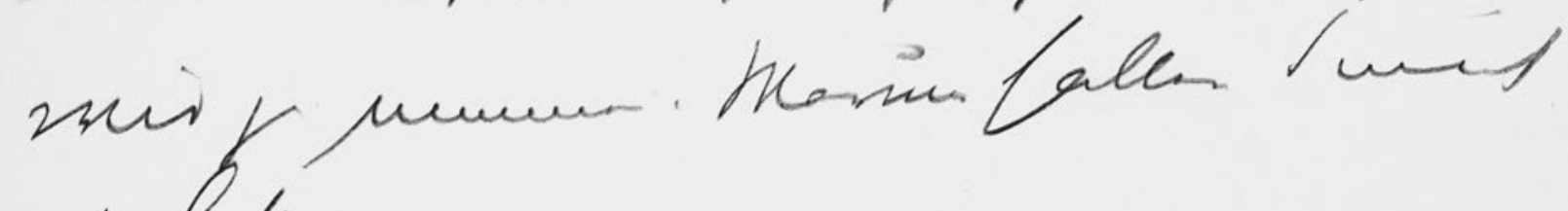

sofip

olat Migripon

Halfi:.

Thinumief Afor. Is min mhall

Af

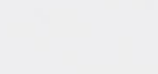

in kof …

Tolbet

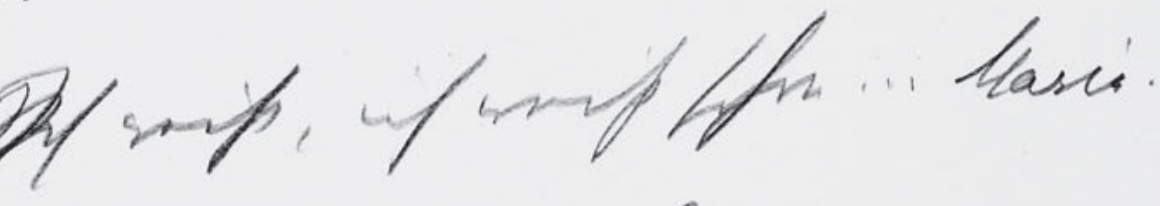

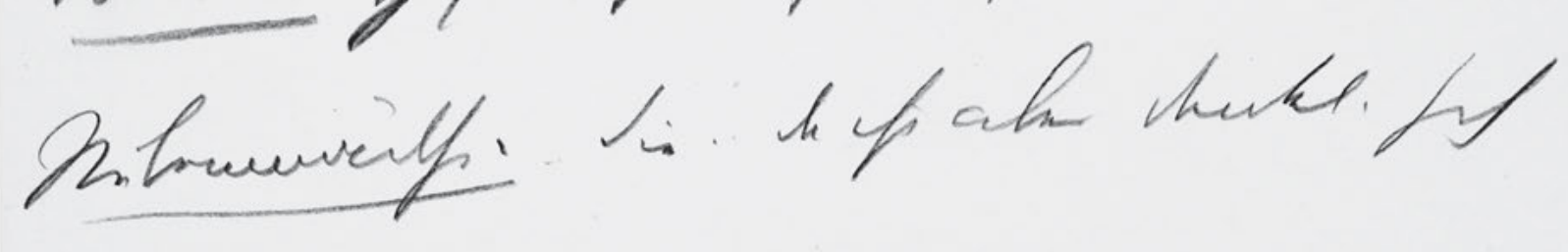

kaisf mu Gusfs

70 
Stubenmädchen. Es ist doch so schön gewesen . .

Ich tanz gern. -

Soldat. (fasst sie um die Taille)

${ }_{5} \quad$ Stubenmädchen (läßt's geschehen) Jetzt tanzen

wir ja nimmer. Warum halten $S$ mich

so ${ }^{\circ}$ fest

Soldat. .. Wie heißen 'S . . . ? Kathi ... ?

Stubenmädchen. . Ihnen ist imer eine Kathi

10 im Kopf ...

Soldat. ${ }^{\text {IIch }}$ weiß, ich weiß schon ... Marie ..

Stubenmädche. .. Sie . . da ist aber dunkel. Ich

krieg so eine Angst. 
HSz2 19

Handschriften und Typoskript

Tolbe. Mni if miffurs his,

19 Dew wefer prings folfa de for neis!

Onfunuirilfa:

kmin

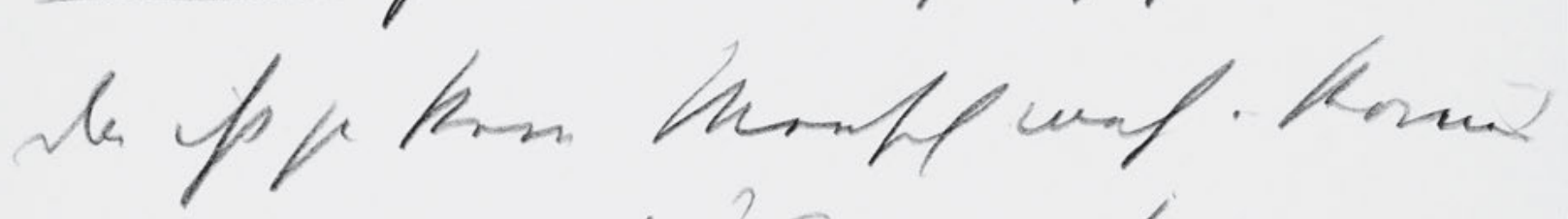
ref une junit.

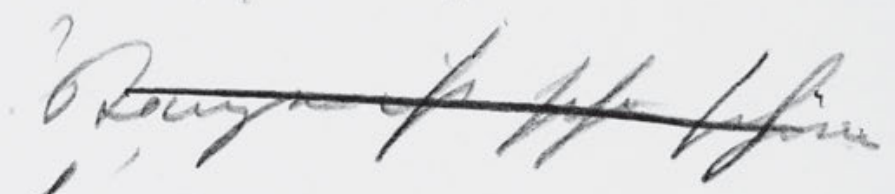

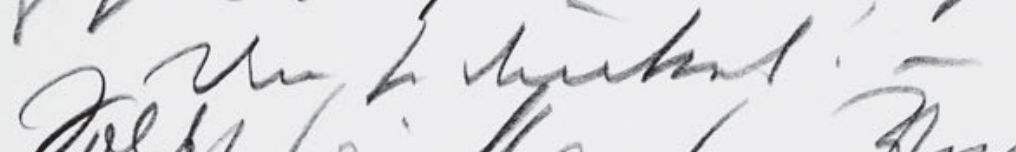

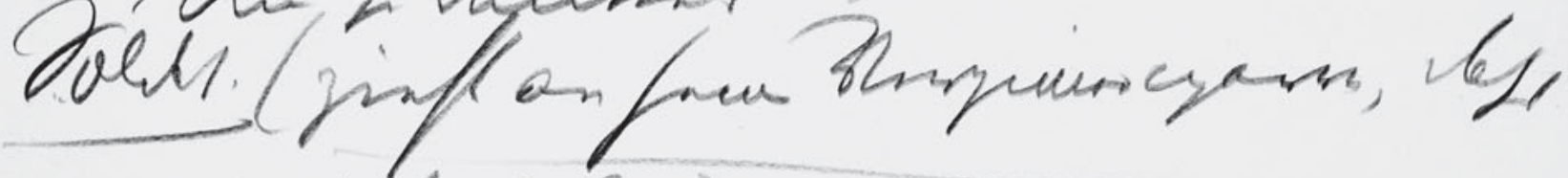
stastolf /unt hinget inur If

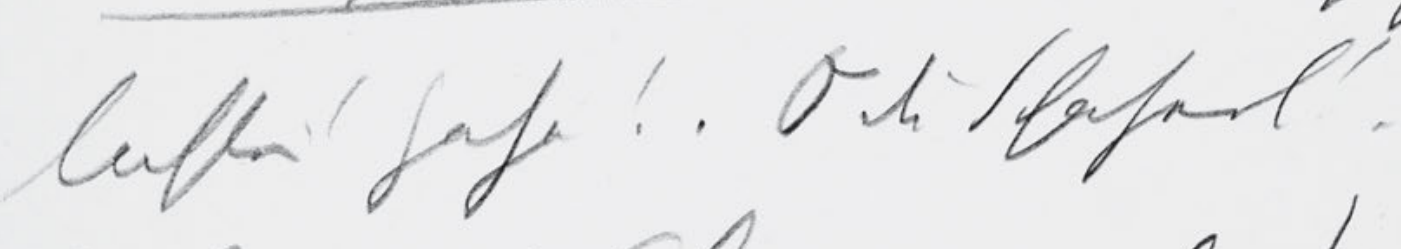

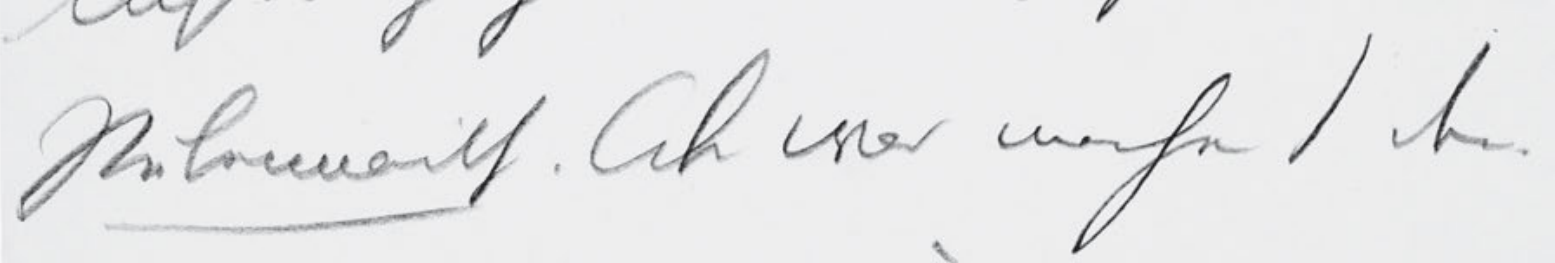
Mring bor gurnts foll.

72 
Soldat. Weñ ich bei Ihnen bin, brauchen S

Ihnen nicht zu fürchten. Gott sei dan

${ }^{\mathrm{W}}$ Mir sein ${ }^{\mathrm{w}} \mathrm{mir}$.

komen

5 Stubenmädchen. . Aber wohin gehn wir denn da ist ja kein Mensch mehr. Komen S gehn wir zurück .. ? s Tanzen ist schon schöner Und so dunkel! -

Soldat. (zieht an seiner Virginiercigarre, dass

$\mathrm{d}^{\mathrm{ie}}$ as ${ }^{[\mathrm{f}]}$ rothe Ende leuchtet) $\mathrm{S}$ wird schon

10 lichter! Haha! . O du Schatzerl! -

Stubenmädchen . Aber was machen $\mathrm{S}$ denn.

Weñ ich das gewußt hätt. 
HSz2 20

Handschriften und Typoskript

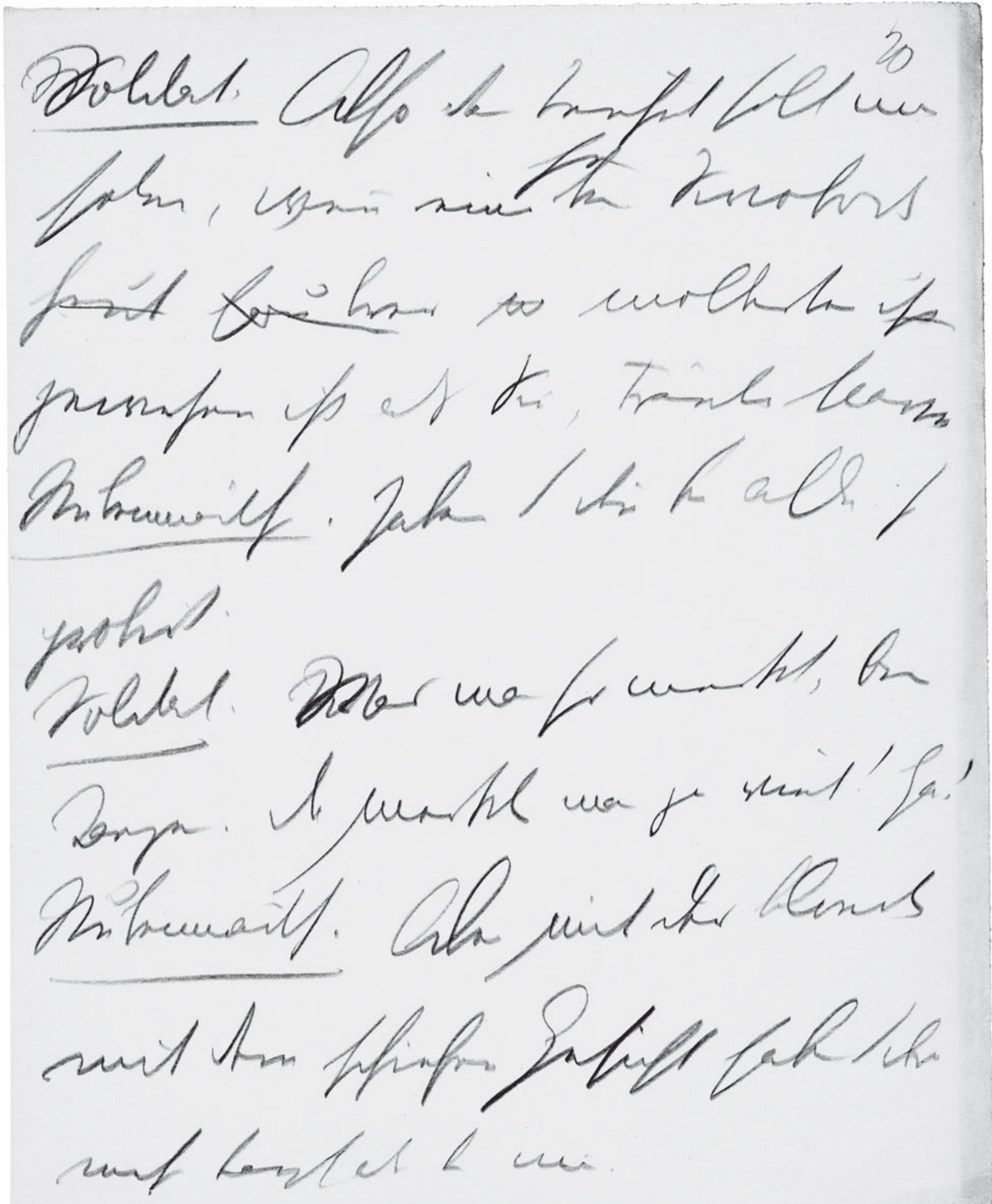

74 


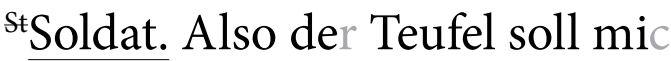
heu holen, weñ eine beim Swoboda heut saubrer [?] mollerter ist 5 gewesen ist als Sie, Fräuln Marie Stubenmädchen. Haben $\mathrm{S}$ deñ bei alle so probirt.

Soldat. ${ }^{N}$ Was man so merkt, beim

Tanzen. Da merkt man 'ja? viel! Ha!

10 Stubenmädch. Aber mit der blonden mit dem schiefen Gesicht haben S ?doc? mehr tanzt als ? $\mathrm{b}$ ? mir. 
HSz2 21

Handschriften und Typoskript

Nold.

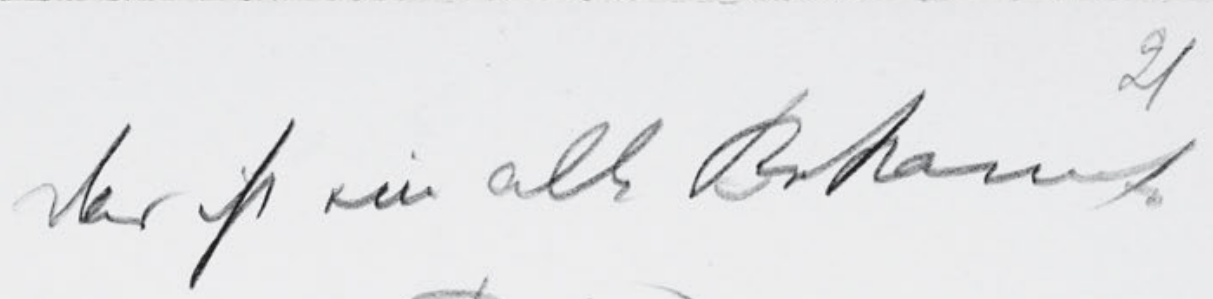

ne mas unery traver

Dhtreeva

golal

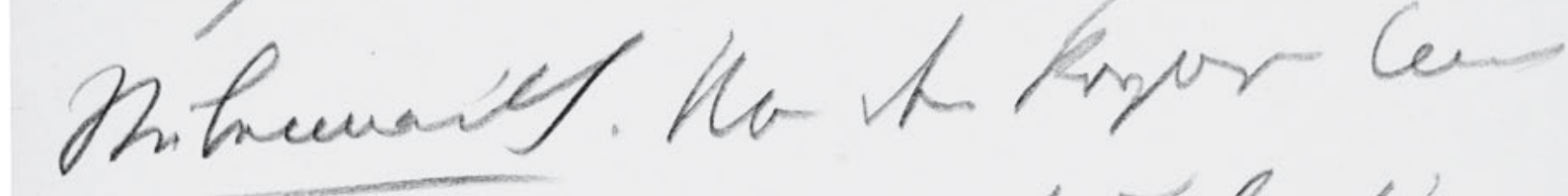

R fapr lea

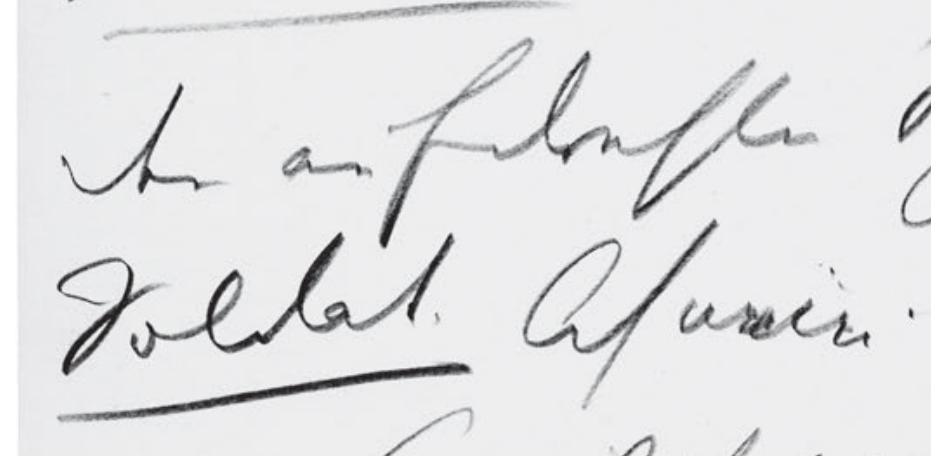

2 funitast.

$\sin$
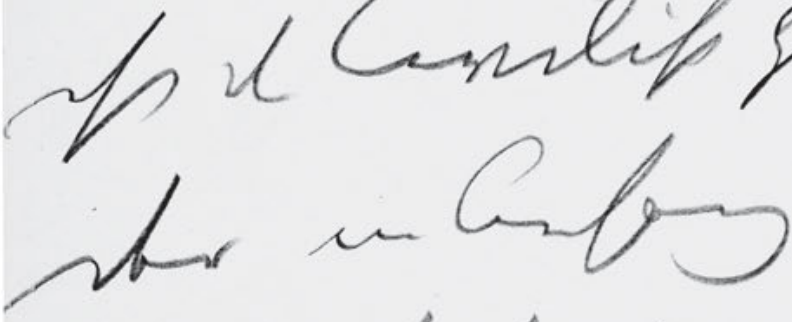

sulf

fot ipt

pinfmuares. At is

m hat witus

Fobat ip

im lenth

hin Lt

76 
21

Soldat. Das ist eine alte Bekannte

vo ein meinig Freund. .

Stubenmädch. Von dem Korporal mit

5 dem aufdrehten Schnurbart?

Soldat. Ah $n^{a}$ ein ... aus der Zeit das

ist der Civilist gwesen, wissen $\mathrm{S}$

der im Anfang am Tisch mit mi

gsessen hat "ist, der so heisrig redt.

10 Stubenmädch. Ah ich weiß scho ..... das

Soldat ist ein keck Mensch. 
HSz2 22

Handschriften und Typoskript

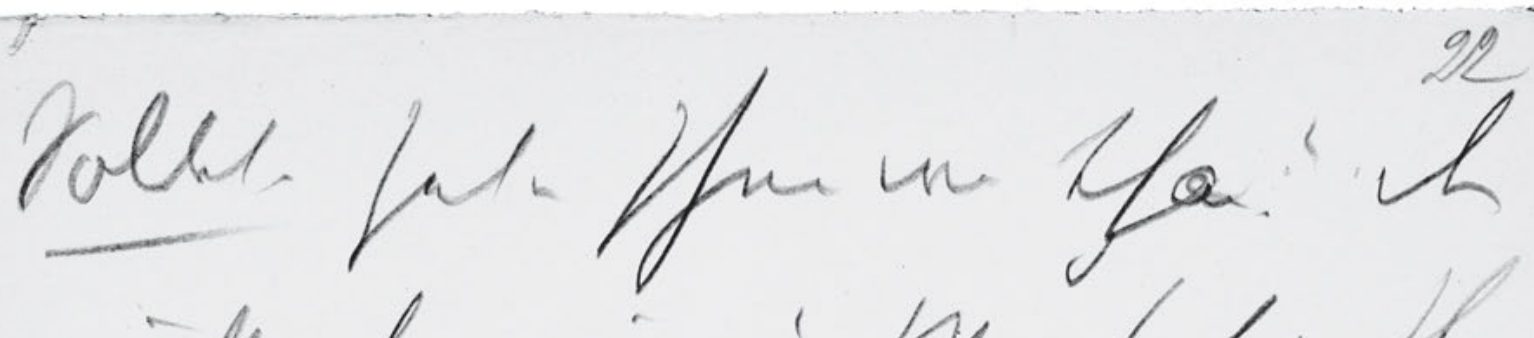
migts of raig : the fort ff. tom.

Antruief G wift

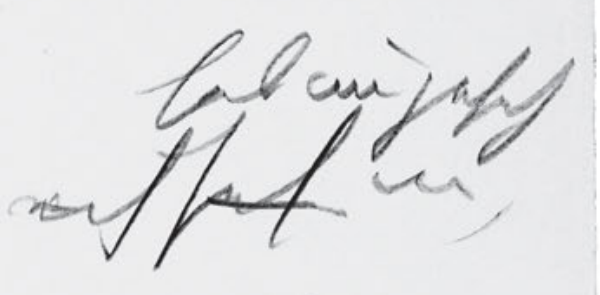
uneror wat $d$ onitom ife poles Payr Itrin's hasis.

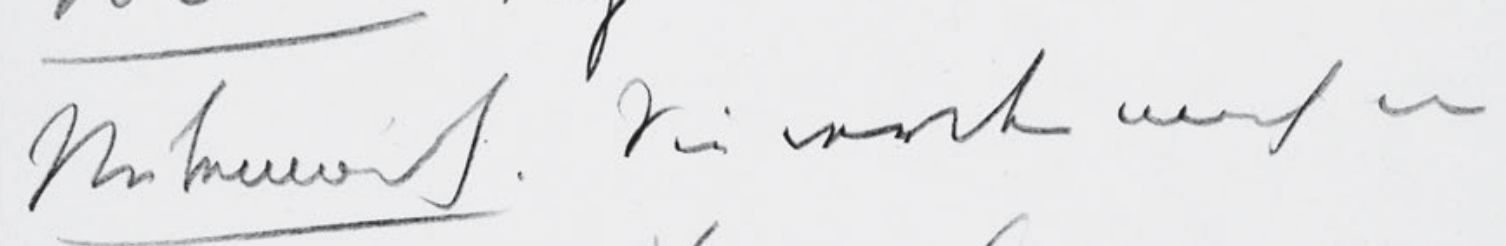
hrom unt furor Gyair

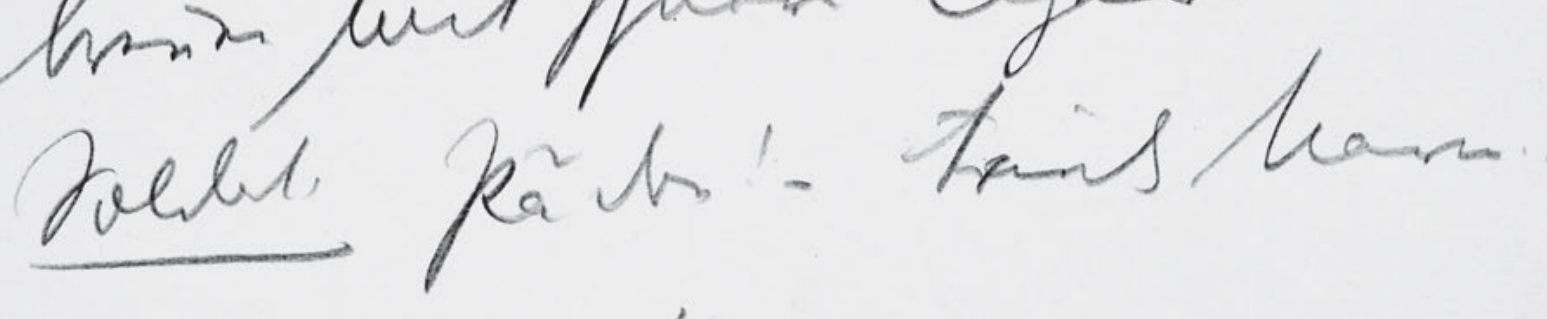
Jagr un wi $h$...

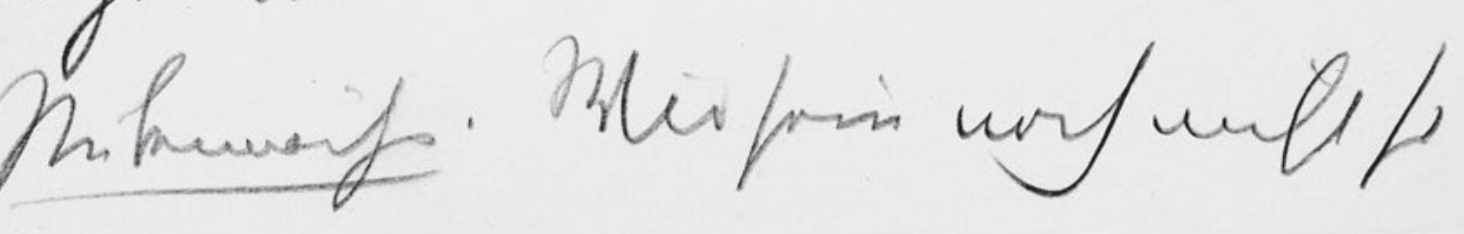

78 
Soldat. Hat er Ihnen wa than. . ? . Dem

möchts ich zeigen! Was hat er Ihnen

than?

hab nur geseh

$5 \quad$ Stubenmädchen. Oh nichts - eiich seh 'nu?, wie er mit $\mathrm{d}$ andern ist.

Soldat. Sagen S Fräuln Marie . .

Stubenmädch. Sie werden mich ?no?

bren̄en mit Ihner Cigarr.

10 Soldat. Pãdon! - Fräuln Marie . .

Sagen wir uns du . .

Stubenmädchen. Wir sein noch nicht so 
HSz2 23

Handschriften und Typoskript

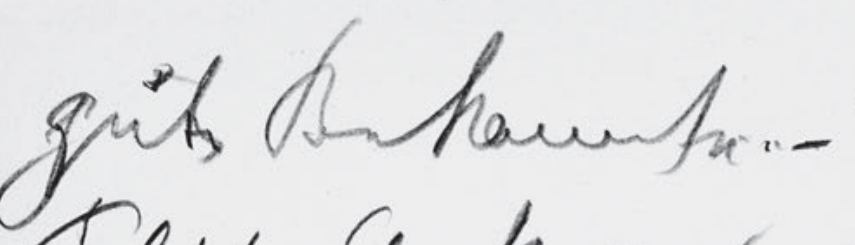

23

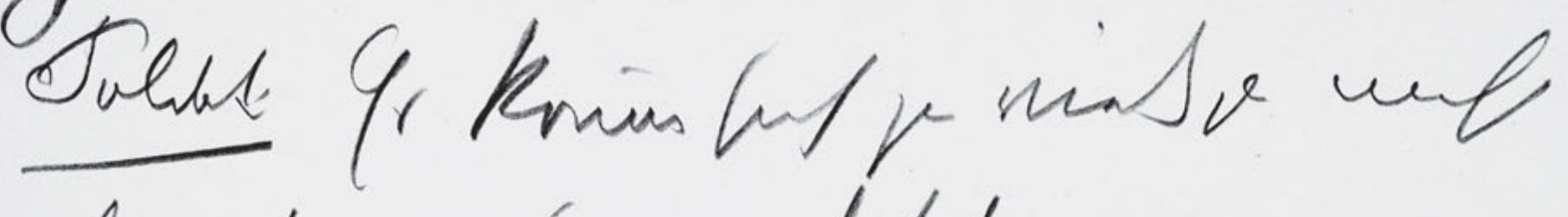

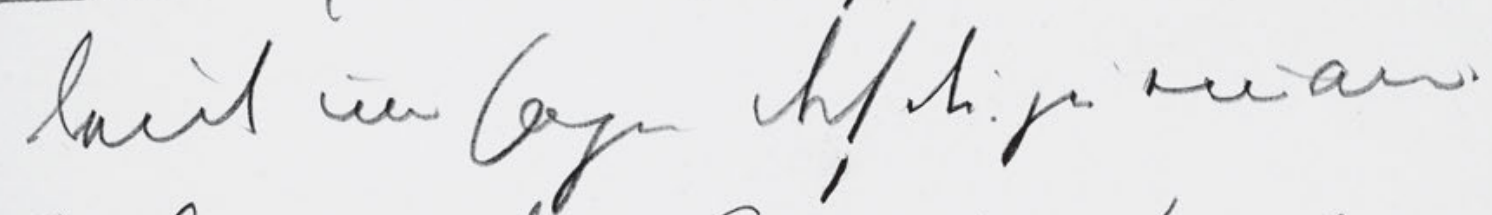

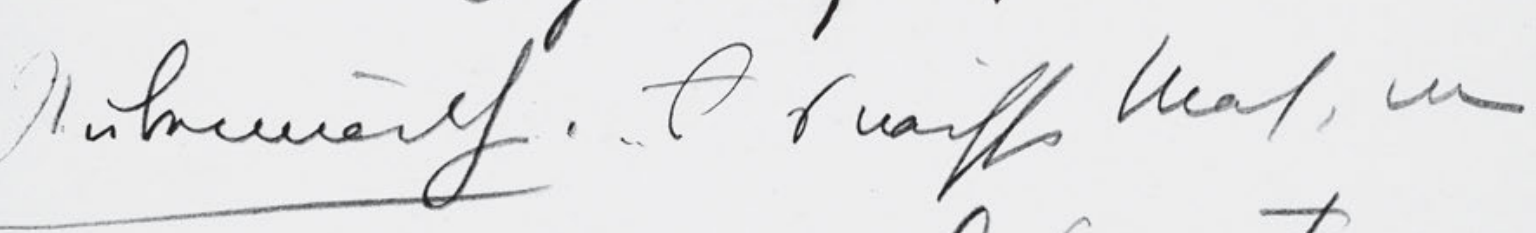
raer un $r$ mual Oh four trovs. velas. have fah

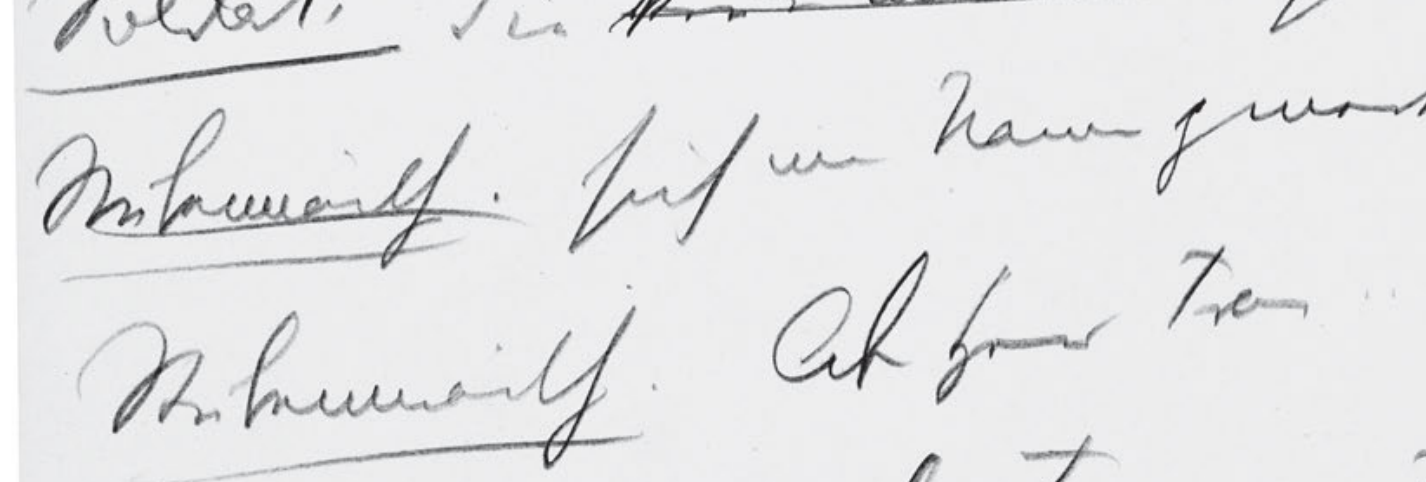

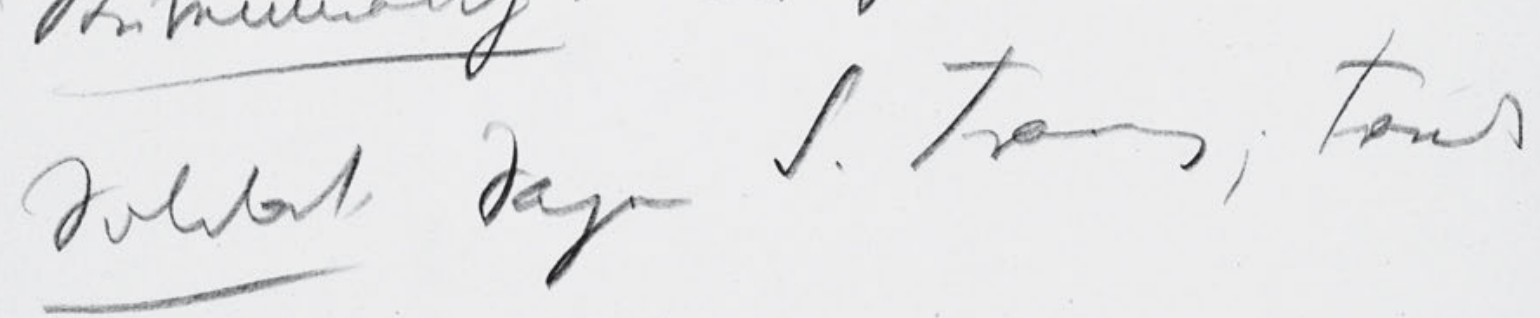
Merin

80 
gute Bekannte .. -

Soldat. Es können sich ja viele ga nicht

leiden und sagen doch du . zu einand.

5 Stubenmädchen. . ? $\ominus$ ?'s nächst Mal, wenn

[?] wir ?uns? ?einmal? .. Aber Herr Franz.

Soldat. Sie ken̄en me Namen. haben

Stubenmädchen. sich mein Namen gmerkt

Stubenmädchen. Aber Herr Franz . .

$10 \quad$ Soldat. Sagen S. Franz; Fräuln

Marie. 
HSz2 24

Handschriften und Typoskript

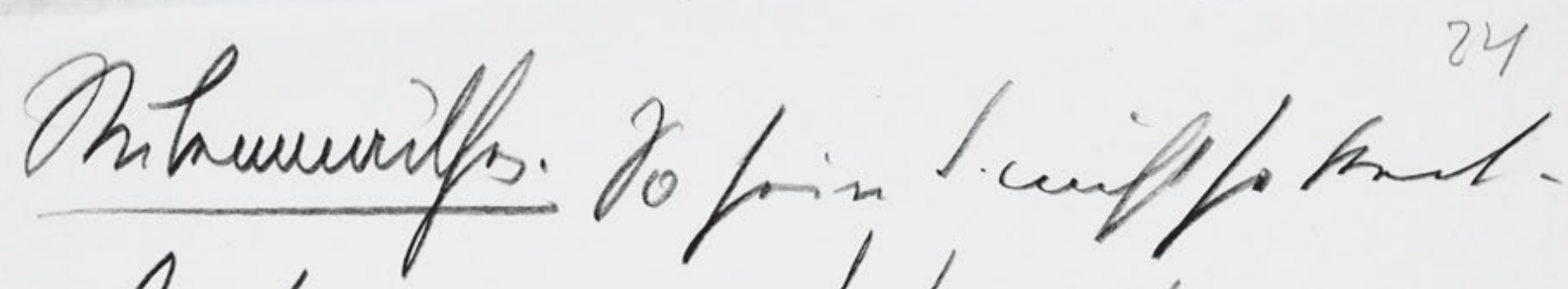
ala sp

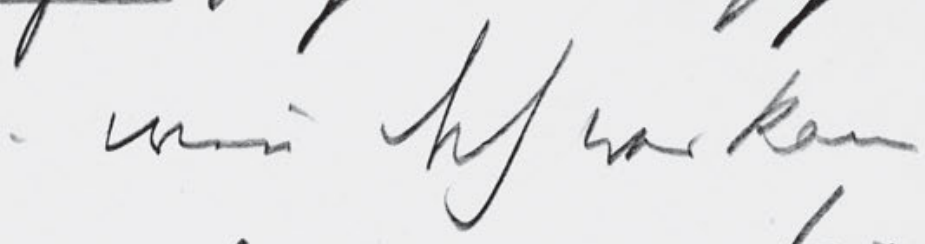

tolbat. U un mi hain ...ma

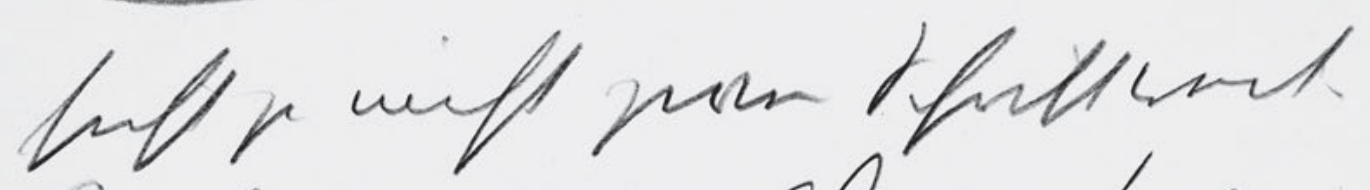

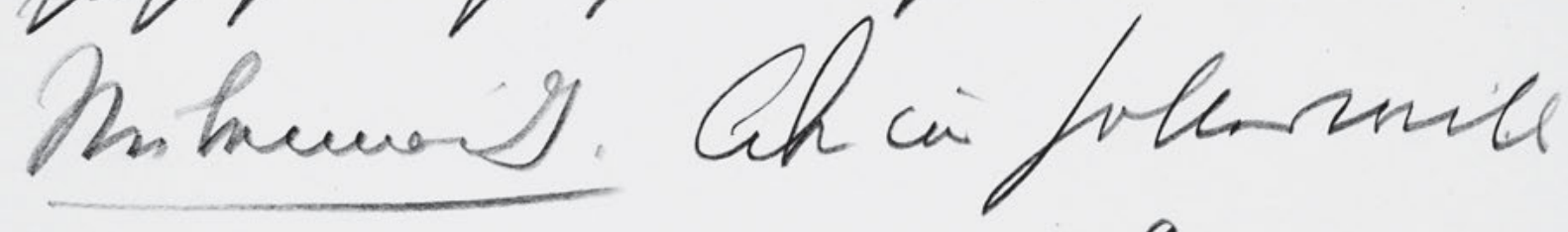
unofir kni un $h$ da...

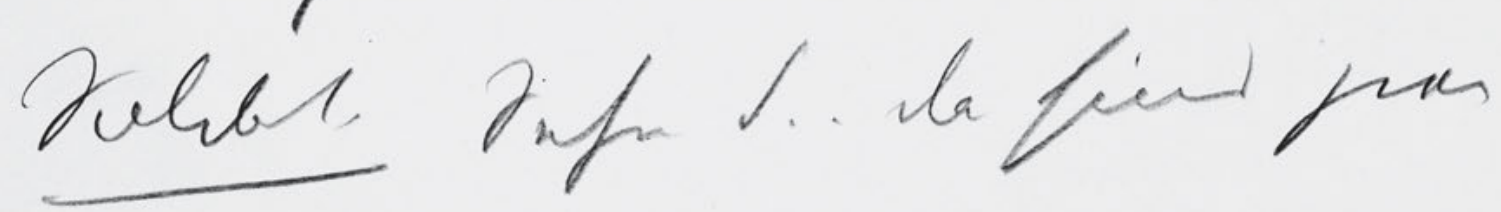
grow wi usir...

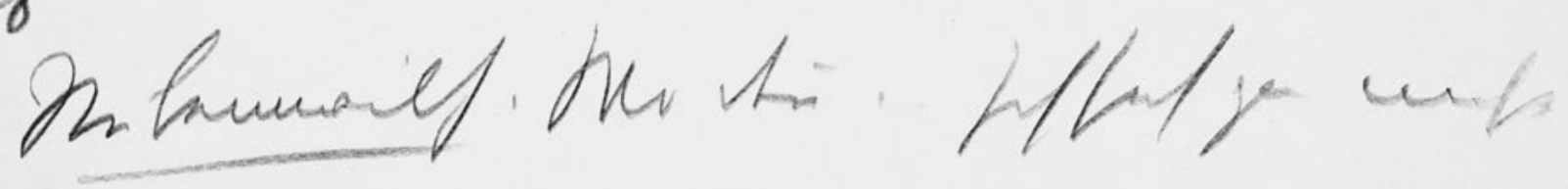
Folet le..nor int...

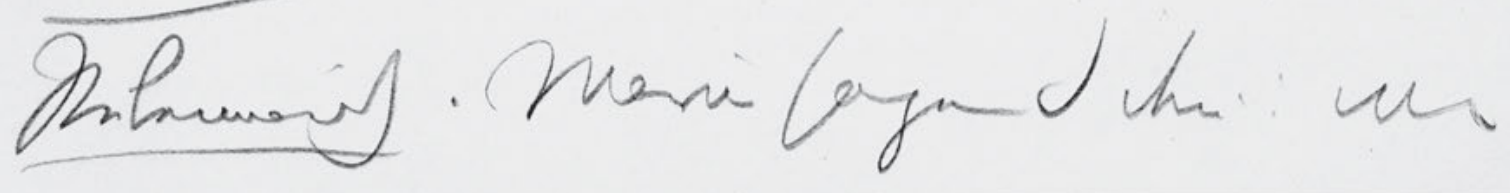

82 
Stubenmädchen. So sein S. nicht so keck aber pst .. weñ doch wer kam

Soldat. . . Und wen̄ einer käm . . . man

$5 \quad$ sieht ja nicht zwei Schritt weit.

Stubenmädh. Aber um Gotteswill

. . wohin kō̄en wir deñ da ........

Soldat. Sehn S . . da sind zwe

grad wie wir...

10 Stubenmädch. Wo dē̄ . . Ich seh gar nicht

Soldat. Da . . vor uns ...

Stubenmädh. Warum sagen S deñ: wie 
HSz2 25

Handschriften und Typoskript

werpur?

rolbt he

tupant

Dnfmuery

Gh
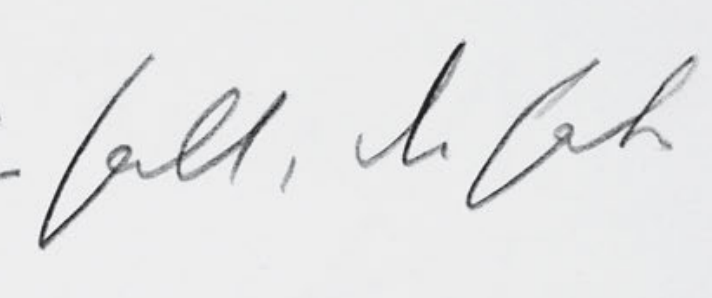

25

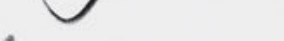

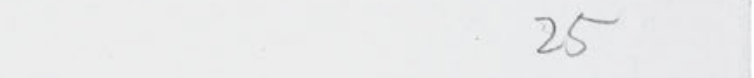

$\frac{\text { ptri } l}{\text { Ooldet }}$

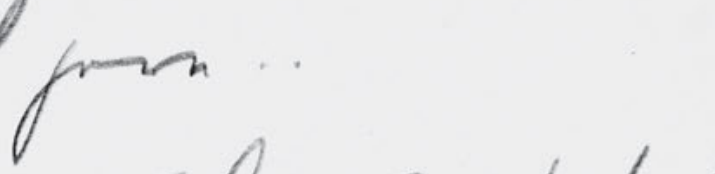

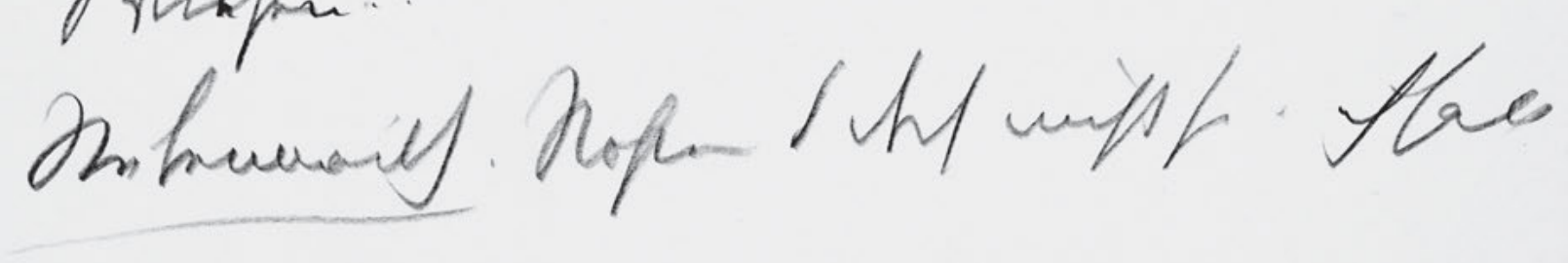

Vin.

Joliat.

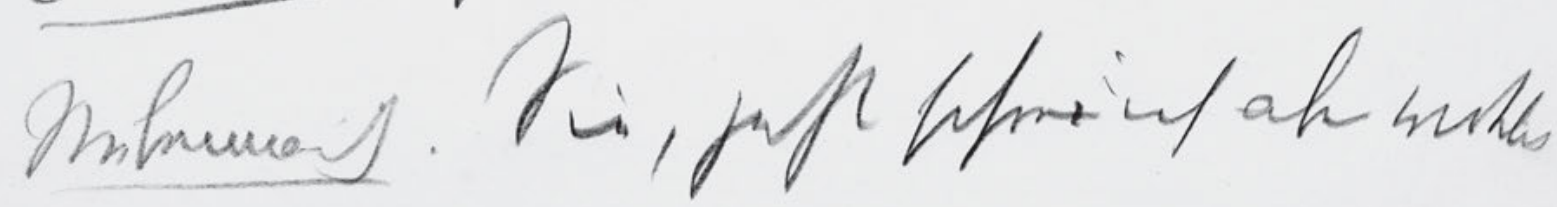

84 
wir zwei?-

Soldat. Na ich mein halt, die haben

sich auch gern ..

$5 \quad$ Stubenmädch. Aber geben $S$ doch acht .. was

ist deñ da . jetzt war ich beinah gfall.

Soldat. Ah, das ist das Gatter um d

Wiesen ....

Stubenmädch. Stoßen S doch nicht so . ich fall

$10 \quad$ ja um..

Soldat. Pst . . nicht so laut ....

$\underline{\text { Stubenmädh }}$. Sie, jetzt schrei ich aber wirklich 
HSz2 26

Handschriften und Typoskript

Ohr mur mung I thi ah

26

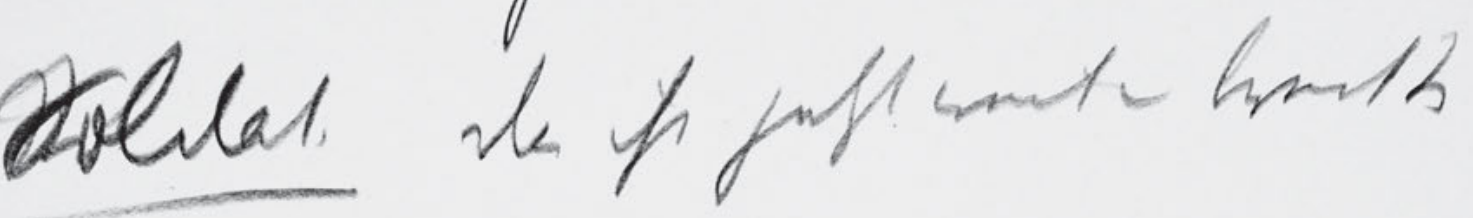

tras

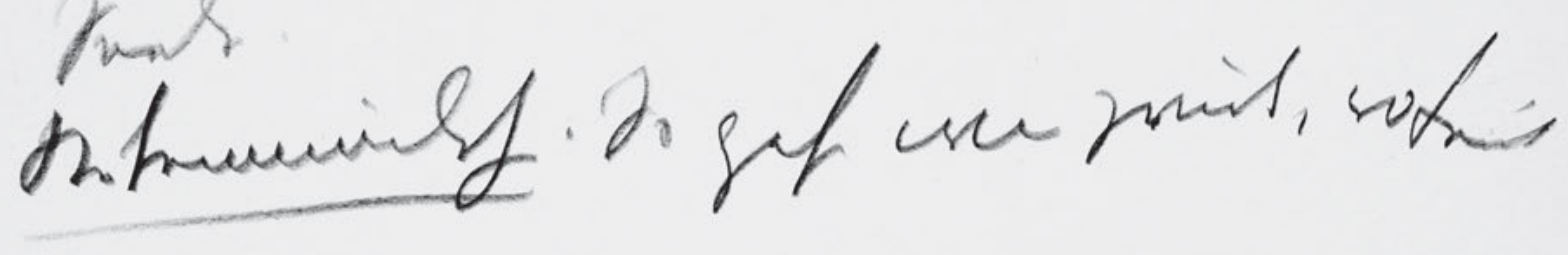

tim

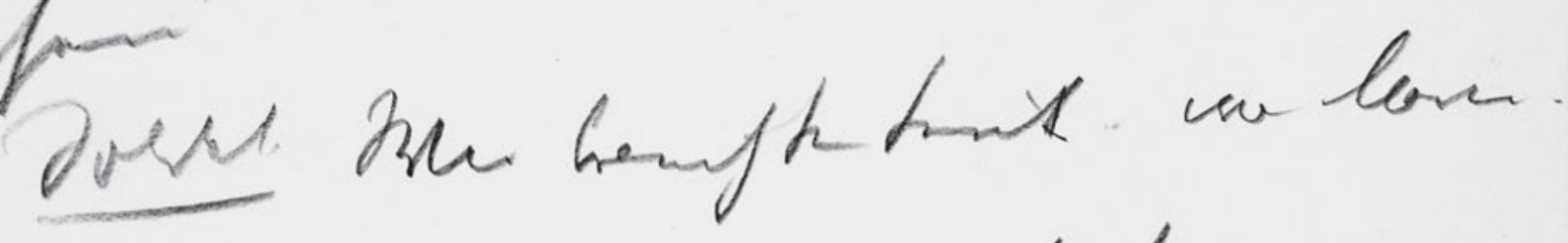
sum banif leg bof

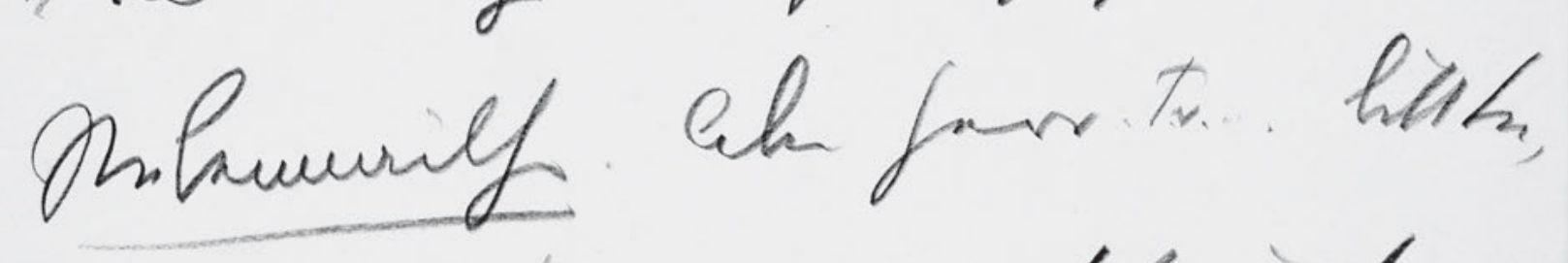

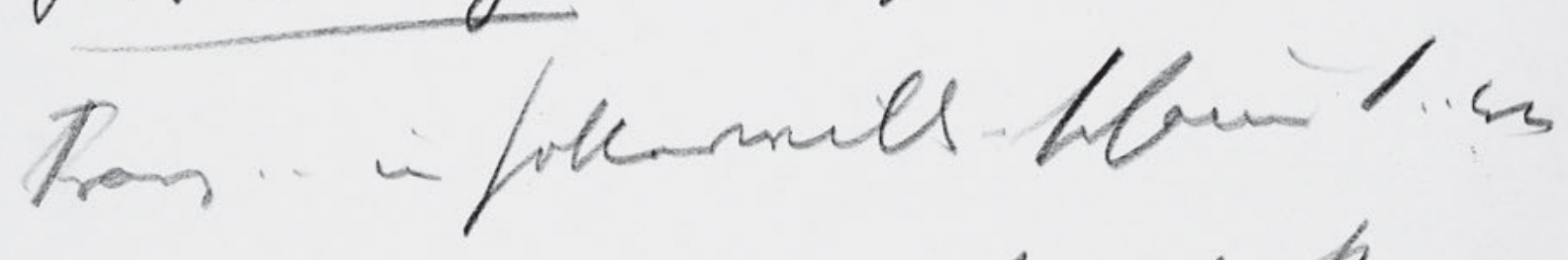

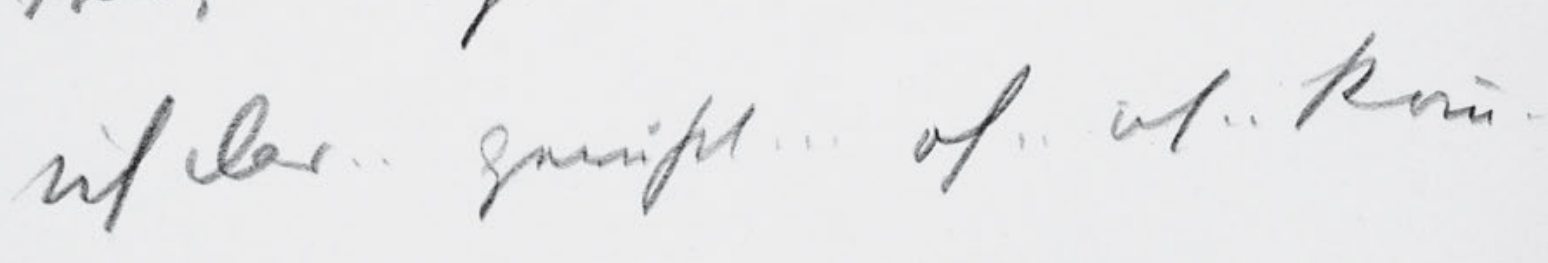

86 
Aber was machen $S$ deñ . . aber.

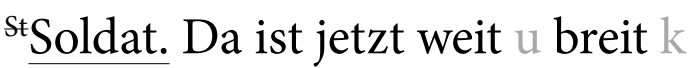

Seele.

5 Stubenmädchen . So gehn wir zrück, wo Leut

sein

Soldat. Wir brauch kein Leut . . was Marie .

wir brauchen .. dazu .. haha.

Stubenmädchen. Aber Herr . Fr . . . bitt Sie,

10 Franz .. um Gotteswillen - schauen S . . wen

ich das . gewußt ... oh . . ich . . kom - 
HSz2 27

Handschriften und Typoskript

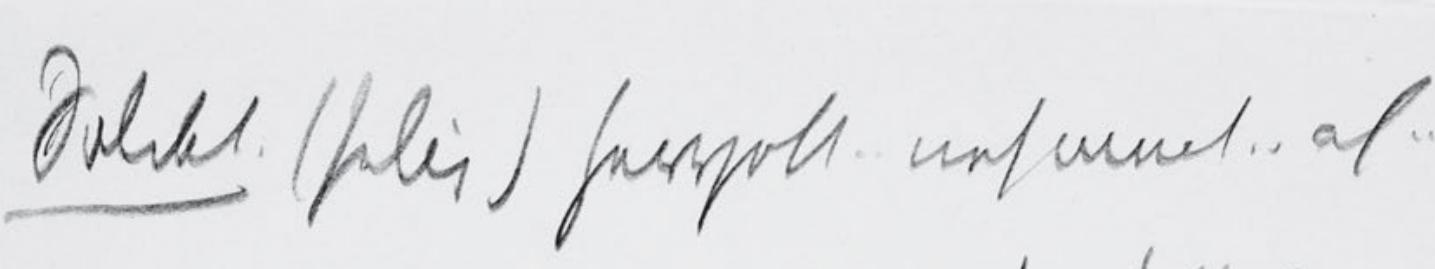

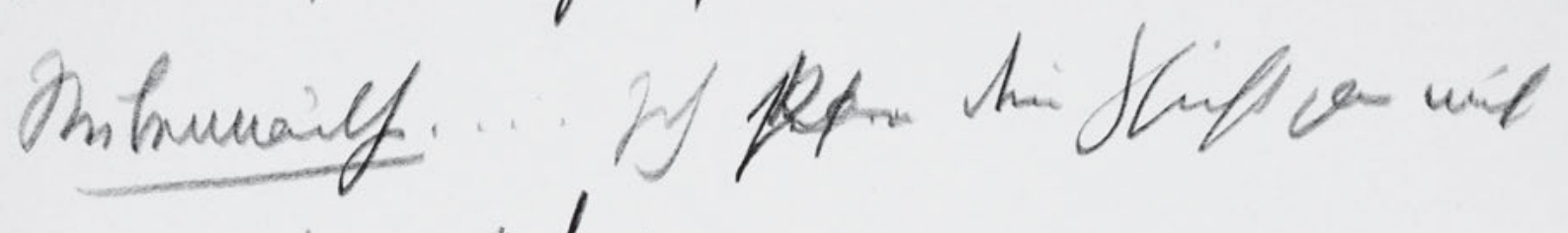
oves atuer. glvif

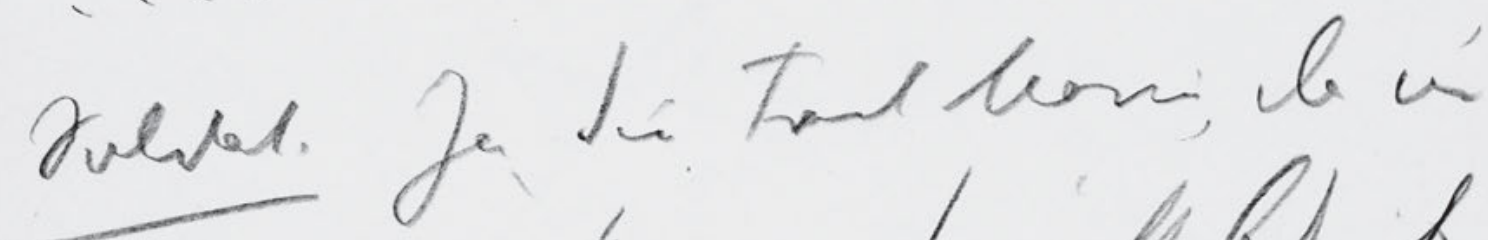

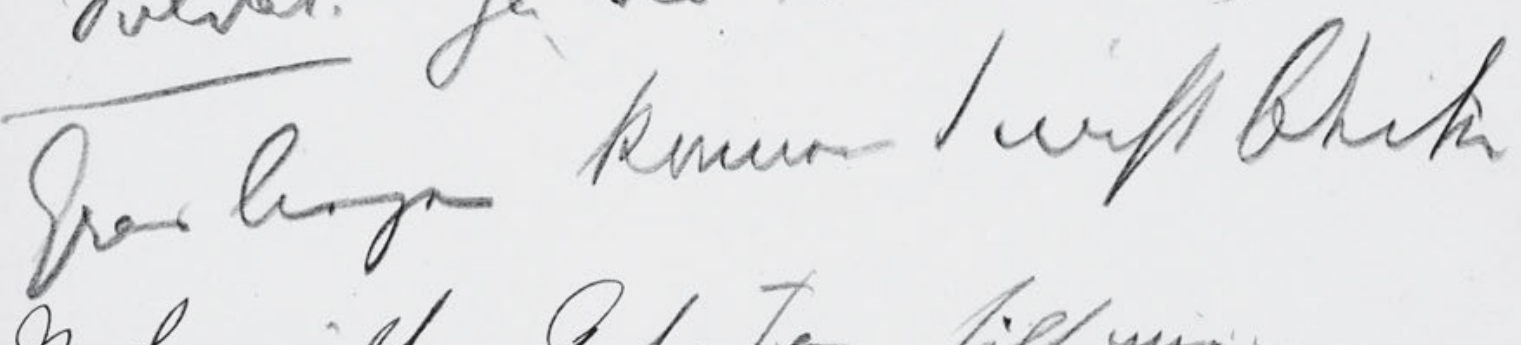
Os ntrumailf. As, tes filf un. roles ha, fainiji Antrumaing of fols. Trons. Polval, hage, we if wut th trons

88 
Soldat. (selig) Herrgott . . noch ?amal? . . ah . .

Stubenmädchen .... Ich ${ }^{\text {seh }}$ kann dein Gsicht gar nicht

ausnehmen sehn.

$5 \quad$ Soldat. Ah was - Gsicht......

Soldat. Ja, Sie Fraul Marie, da im

Gras liegen konnen S nicht bleiben

Stubenmädche. Geh, Franz, hilf mir ...

10 Soldat. Na, kom zugi ..

Stubenmädchen. Oh Gott . . Franz . .

Soldat. Na ja, was ist mit dem Franz.. 
HSz2 28

Handschriften und Typoskript

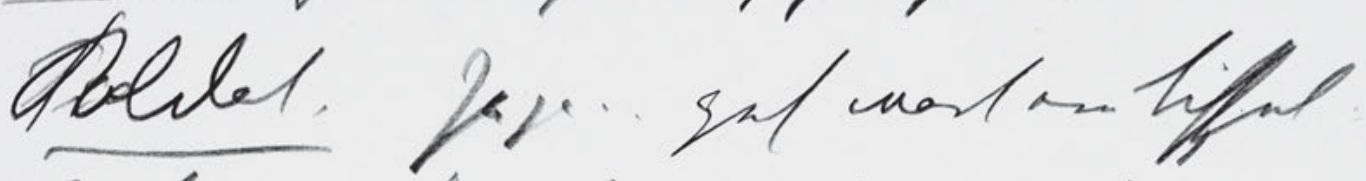

Antrumaifon. Me laft wift oax -

tolet he, sh thrim uns cof un herpinct hiffe

Anbunuse Grift buk

oles horge frit iff cuentar be

Antrumigh.

Tions teassin fo....

Antruminf Mofinmele S

roher he, prich

90 
Stubenmädchen. Du bist ein schlechter Mensch . . Frnz.

Fra Soldat. Ja ja . . geh wart ein bissel . .

Stubenmädhen. Was laßt mich denn ?at? aus -

$5 \quad$ Soldat. ${ }^{[?]} \mathrm{Na}$, die Virgin werd ich mir

doch anzünden dürfen -

Stubenmädhen. Es ist so dunkel . .

Soldat. Morgen früh ist schon wieder licht.

Stubenmädchen. Sag wenigstens, hast mich gern.

10 Soldat. Na, das mußt doch gspürt haben.

Fräuln Marie, ha! ....

Stubenmädhen . Wohin willst denn -

Soldat. Na, zrück . . 
HSz2 29

Handschriften und Typoskript

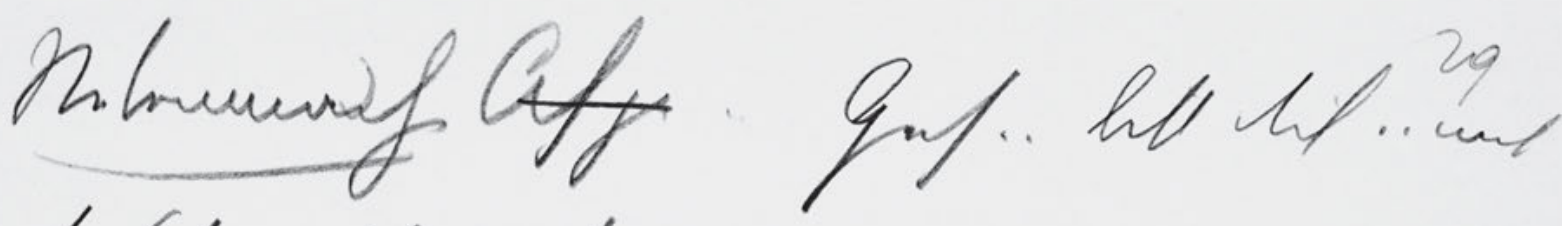

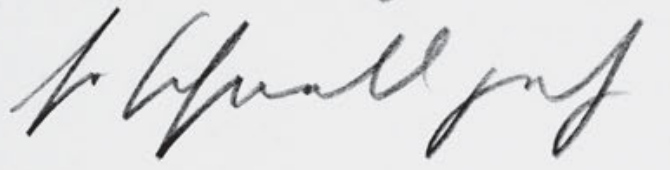

Folve, he wer if th.
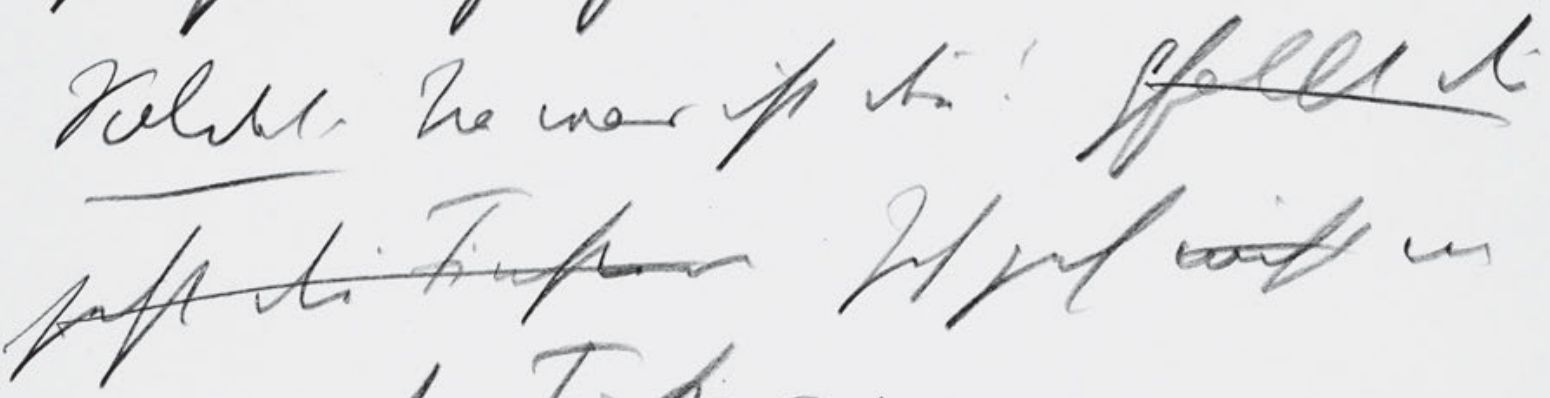
prom in 1 Tizporn.

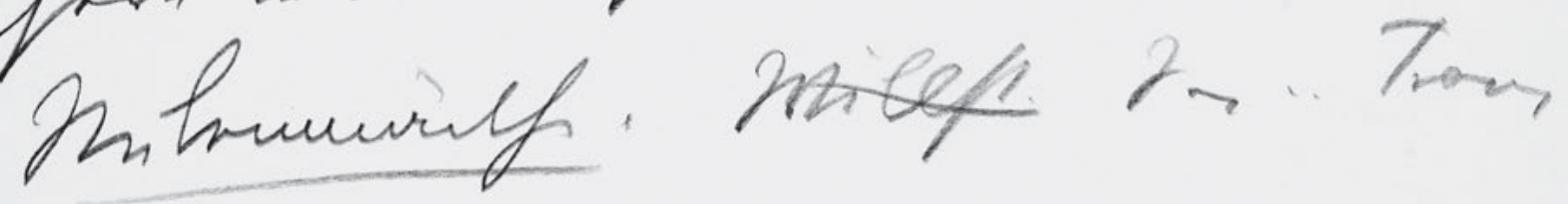
tape mif give

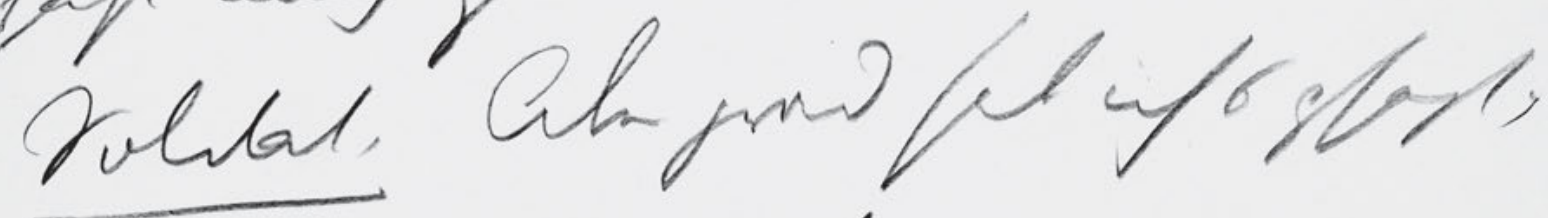
laf if lif pron fath Antrumeng. gn/, wele we unt ma.togh Joblar (quits) \& s.... Xffs al.

92 
Stubenmadchen Ah ja .. Geh . . bitt dich .. nicht

so schnell gehen -

Soldat. Na was ist deñ? Gfallt dir

$5 \quad$ jetzt die Finstern Ich geh nicht un

gern in der Finstern.

Stubenmädchen. Willst. Sag . . Franz . .

hast mich gern.

Soldat. Aber grad hab ich s gsagt",

10 dass ich dich gern habe

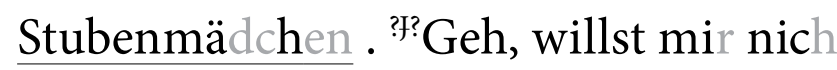

ein Pussel geben.

Soldat. (gnädig) Na da ...... Siehst . a $a h$ - 
HSz2 30

Handschriften und Typoskript

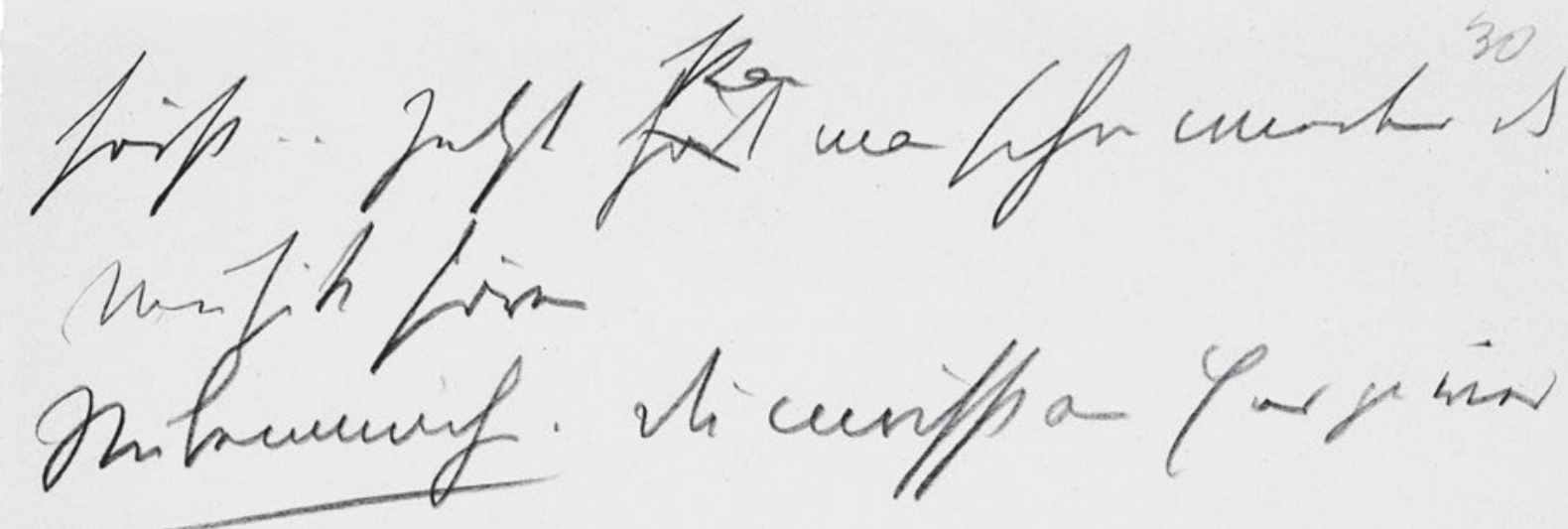

- tar fof

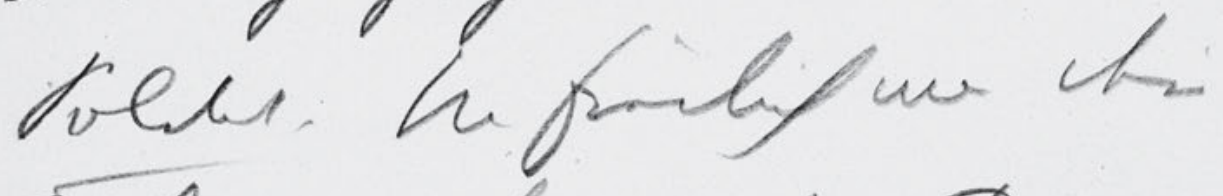

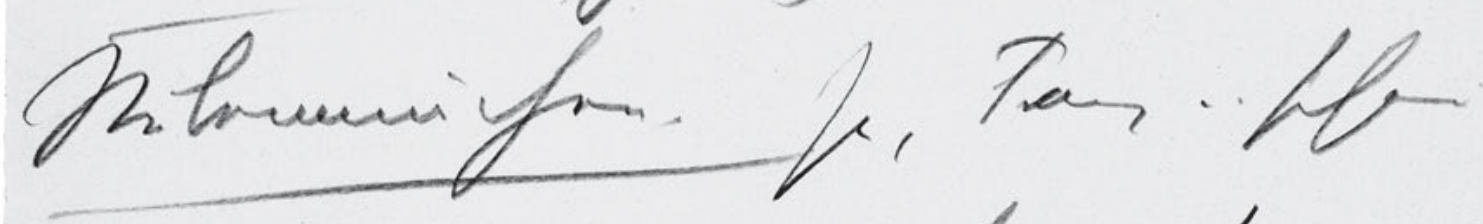

ift witef if .. Si wash

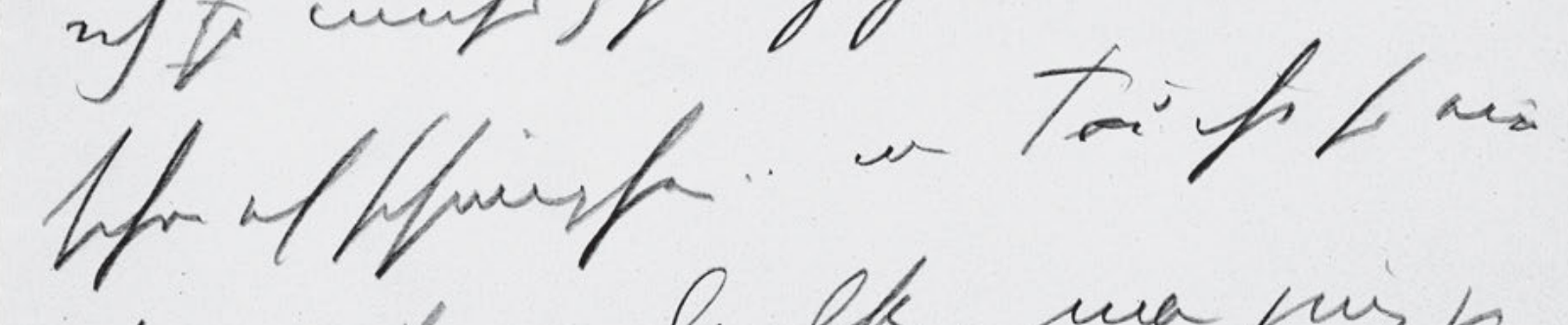

sicunf a babfs, ma pus

uift fort.

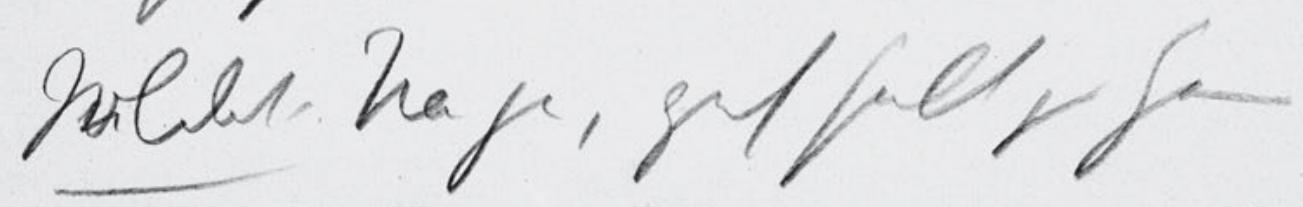

94 
kan

hörst . . Jetzt hört man schon wieder die

Musik hören

Stubenmädhen. Du möchst am End ga wied

[?] tanzen gehn.

$5 \quad$ Soldat. Na freilich was den̄..

Stubenmädhen. Ja, Franz . . schau ..

ich so muss zhaus gehn .. Sie werden

schon eh schimpfen .. mei Frau ist so eine

die möcht am liebsten, man ging ga

10 nicht fort.

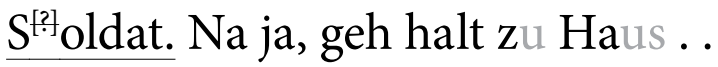


HSz2 31

Handschriften und Typoskript

Alat. Mibusuag

xabaffe,

jortrotablae

sophto

Antruma

y jorifore

Polal

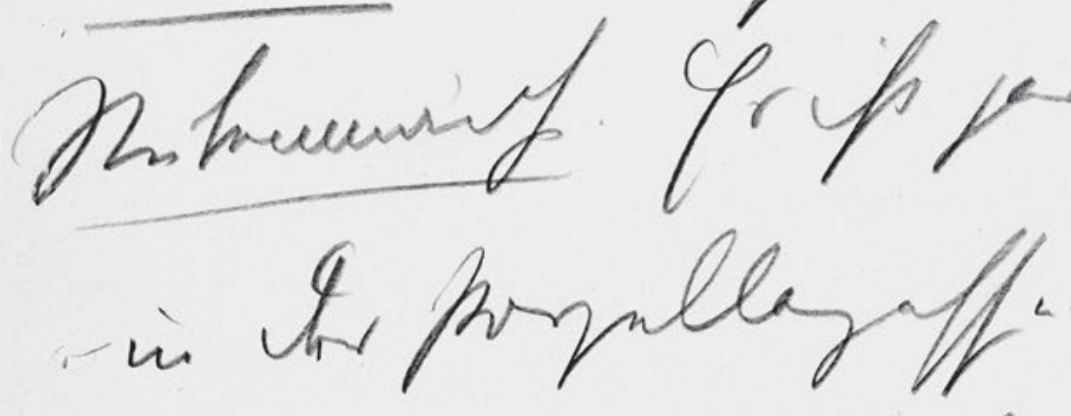

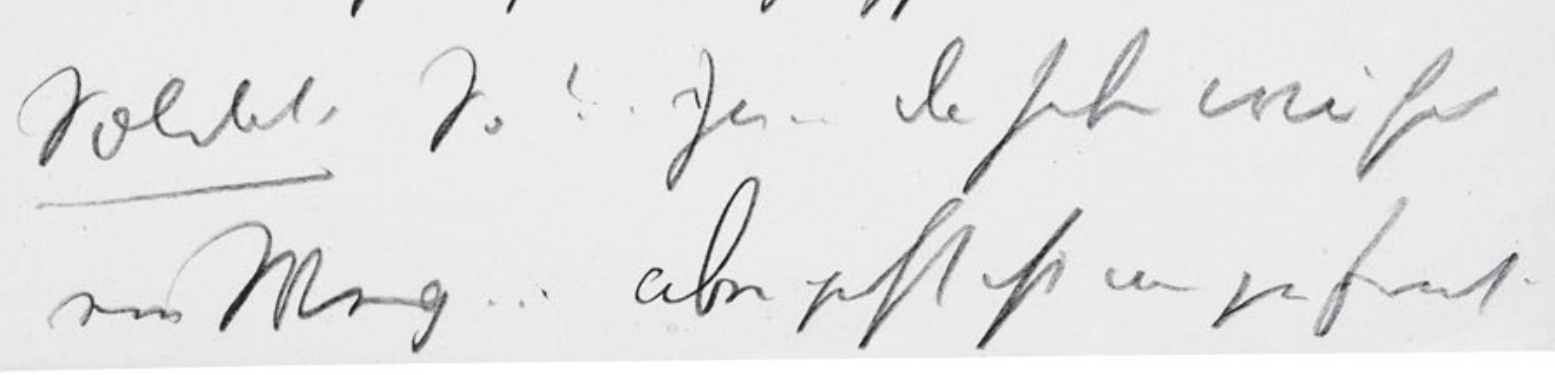

96 
31

Soldat. Stubenmädchen. Ich hab halt

ged $^{\text {acht }}$ enkt, Herr Franz, Sie werden mich

begleiten . zhaus führen.

$5 \quad$ Soldat. Z haus führen? . Ah! .

Stubenmädh. Gehn S . . es ist so [???]

Soldat. traurig, allein zhaus gehn.

Soldat. Wo wohnen $\mathrm{S}$ deñ?

Stubenmädchen. Es ist gar nicht so weit.

10 . - in der Porzellangassen . .

Soldat. So? . ${ }^{[?]} \mathrm{Ja}$ - da haben wir ? fas?

ein Weg... aber jetzt ist mir zu fruh. 
HSz2 32

Handschriften und Typoskript

plimen un

nth

rita sur IL

1

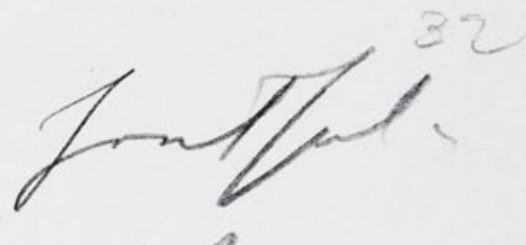

hamifican

in tha
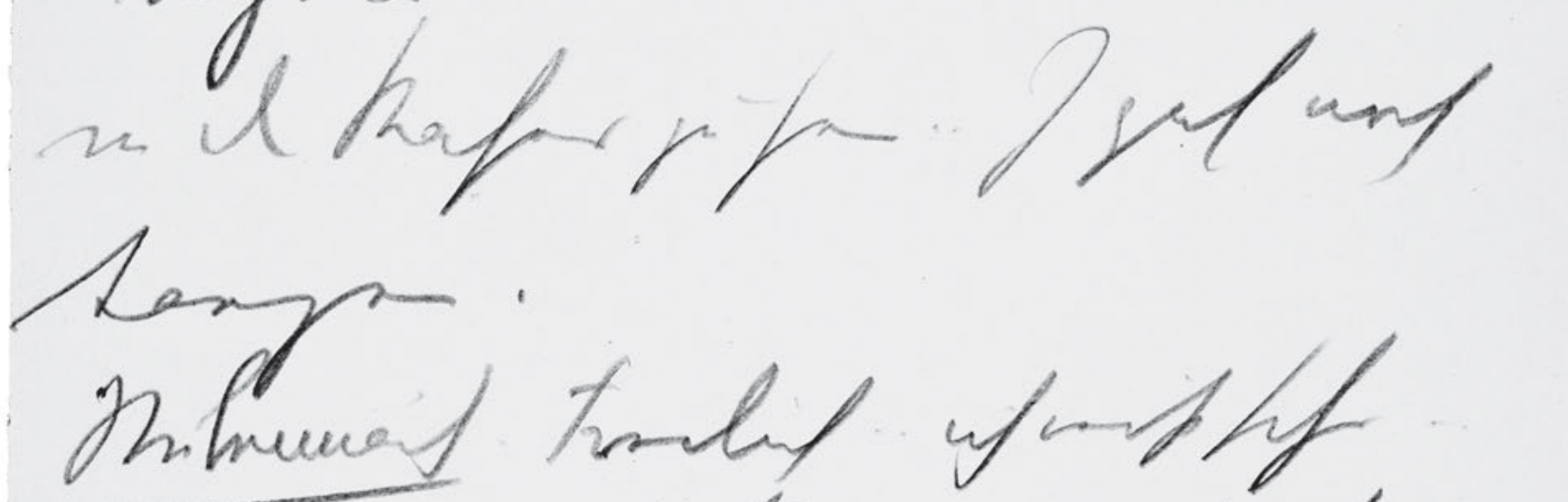

ph

In

trolif

of $n$

if

int tiflonst mut

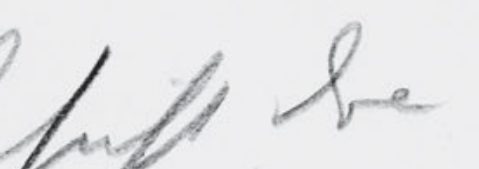

$$
\text { ' }
$$

fa! - sh
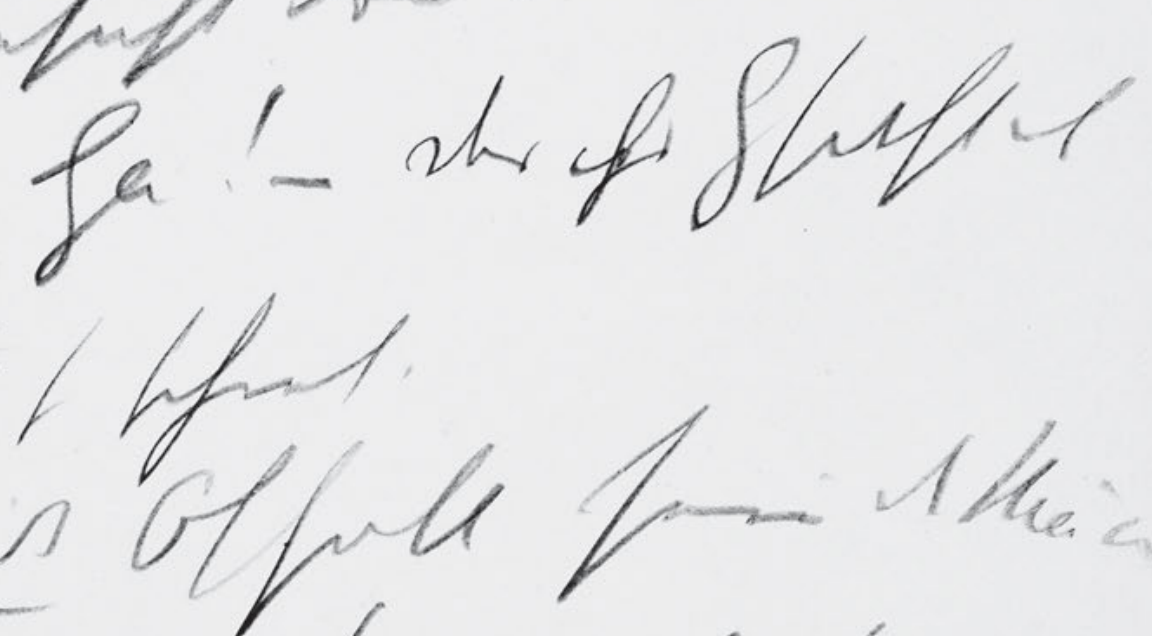

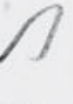

Me
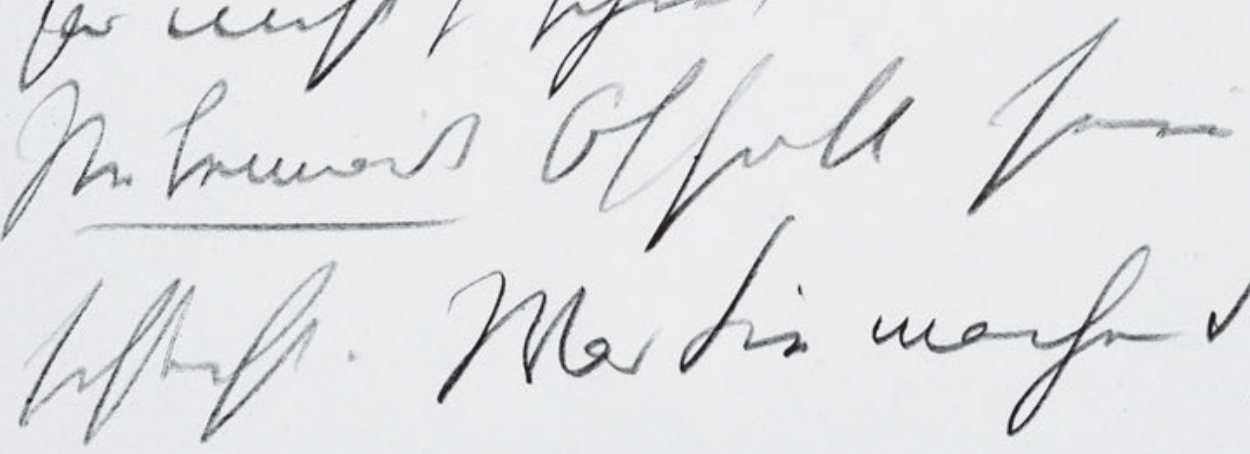

Ata

98 
jetzt wird noch draht . . Heut hab i

über Zeit . . vor 12 brauch i nich

in der Kaser zu sein . I geh noch

$5 \quad$ tanzen.

Stubenmädh . Freilich .. ich weiß scho ..

jetzt kō̄t die blonde mit dem

schiefen Gesicht dran!

Soldat. Ha! - Der ihr Gsicht is

10 gar nicht so schief.

Stubenmädh OhGott sein d Mäner

schlecht. Was Sie machen S sicher mit 
HSz2 33

Handschriften und Typoskript

rier protn fo

33

Polal.

snimenuaifa

tergr uive.

larmar,

Ifom 1.

dolet fef

trous, hithfing ford

sat

golidat... lar

,

frit btik rusta.

ontrumigt the $\mathrm{h}$.

100 
einer jeden so.

Soldat. Das wär z viel! . .

Stubenmädhen. Franz, bitt schön . . heut

$5 \quad \operatorname{tanzen} S$ nimer .. heut bleiben $S^{\text {? }}$ mit? $^{\text {m }}$, schaun S . .

Soldat. Ja ja - ist schon gut . . Aber

tanzen werd ich doch noch dürfen.

Stubenmädhen. Ich tanz heut mit kein'

mehr!

Soldat. ... Das ist er ja schon.

Stubenmädhen. Was den . . 
HSz2 34

Handschriften und Typoskript

Delat

st turbode' Heifuens mirmint la frion... hn/ wirlfiah

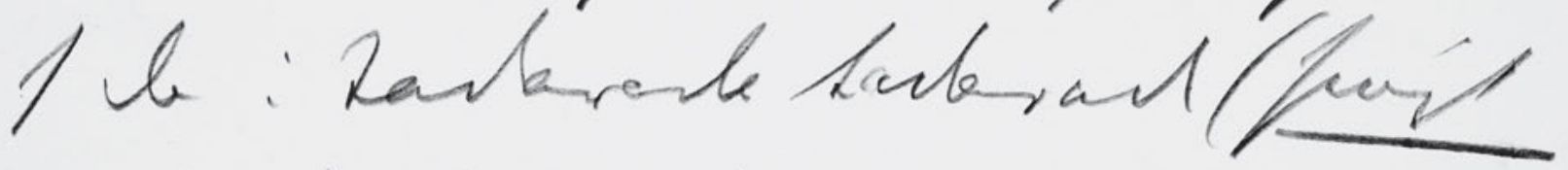
mit) .... Alfe mifts aif wifuas mille, ffof if hy Ja w unft - Jramar wit.

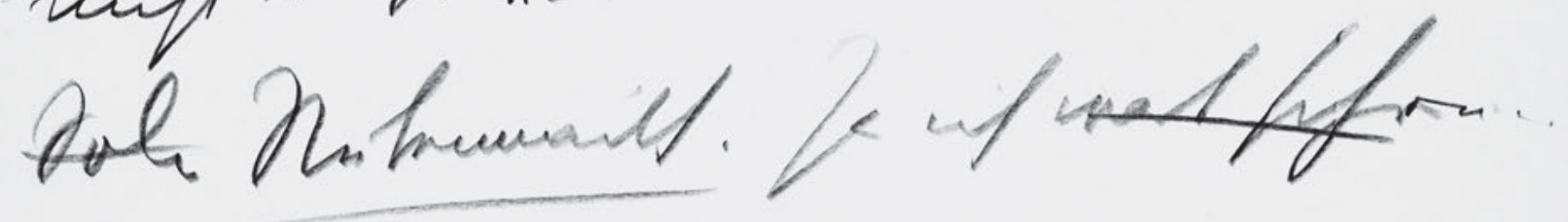

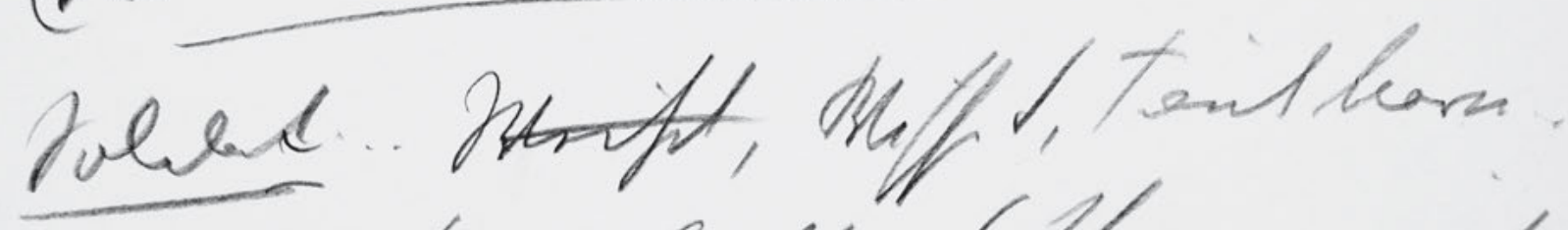

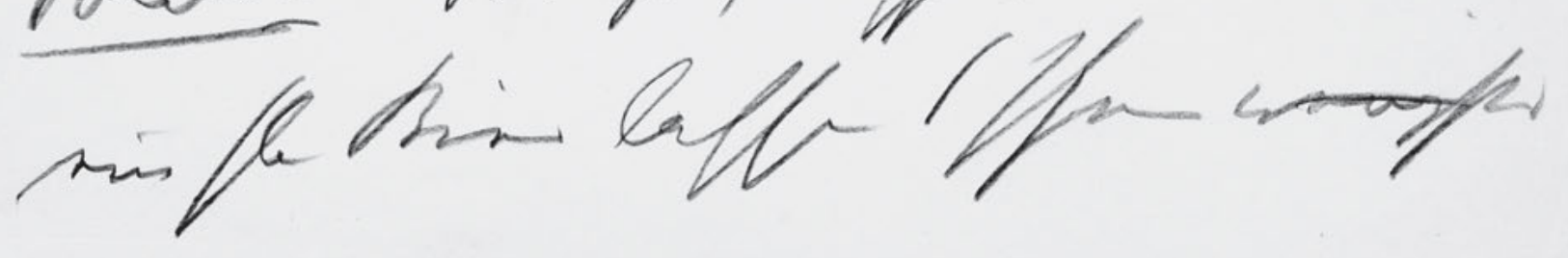

102 
34

Soldat. Der Swoboda! Wie schnell

wir wieder da seïn .... Noch ī̄me spielen

s da : Tadarada tadarad (singt

$5 \quad$ mit) ..... Also weñst auf mich wart

willst, so führ ich dich z Haus - wen̄

nicht - Servas mit . .

Sold Stubenmädch. Ja ich wart schon ...

.... werd warten . .

10 (Sie treten in den Tanzsaal ein.)

Soldat. .. Weißt, Wisse S, Fräul Marie . .

ein Glas Bier lassen S Ihnen wenigstens 


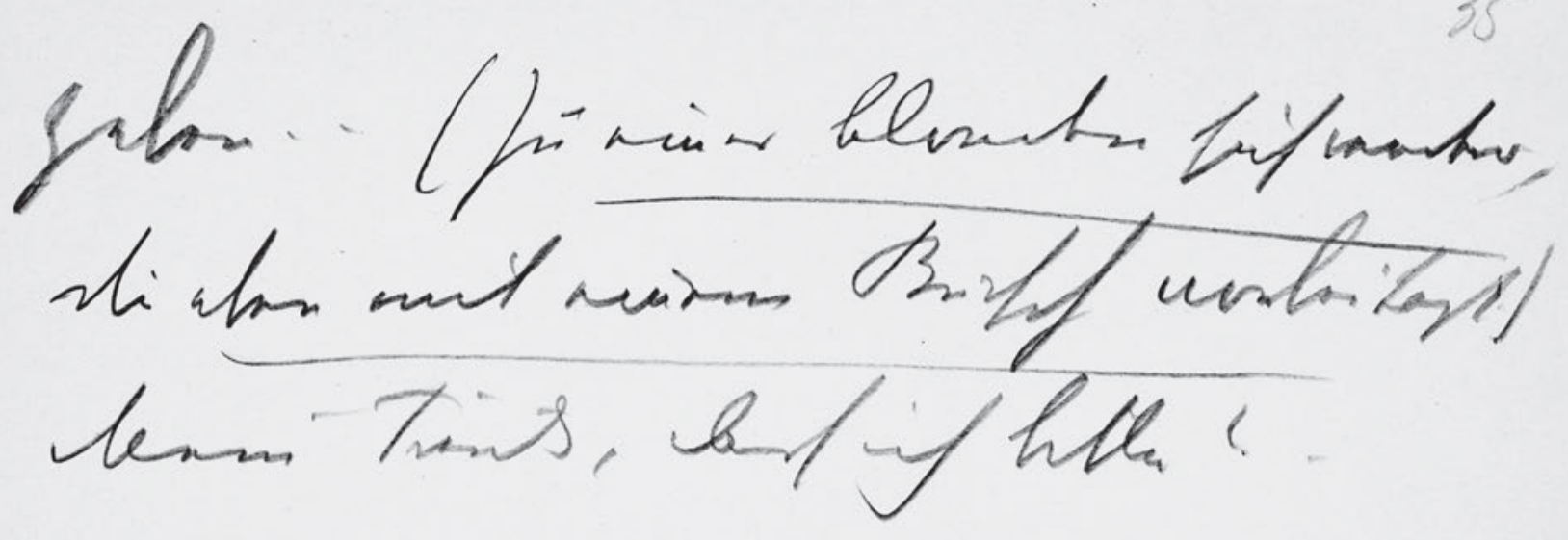


35

geben . . ( $\mathrm{Zu}$ einer blonden sich wendend,

die eben mit einem Burschen vorbeitanzt.)

Mein Fräuln, darf ich bitten? - 
HSz3 36

Handschriften und Typoskript

36
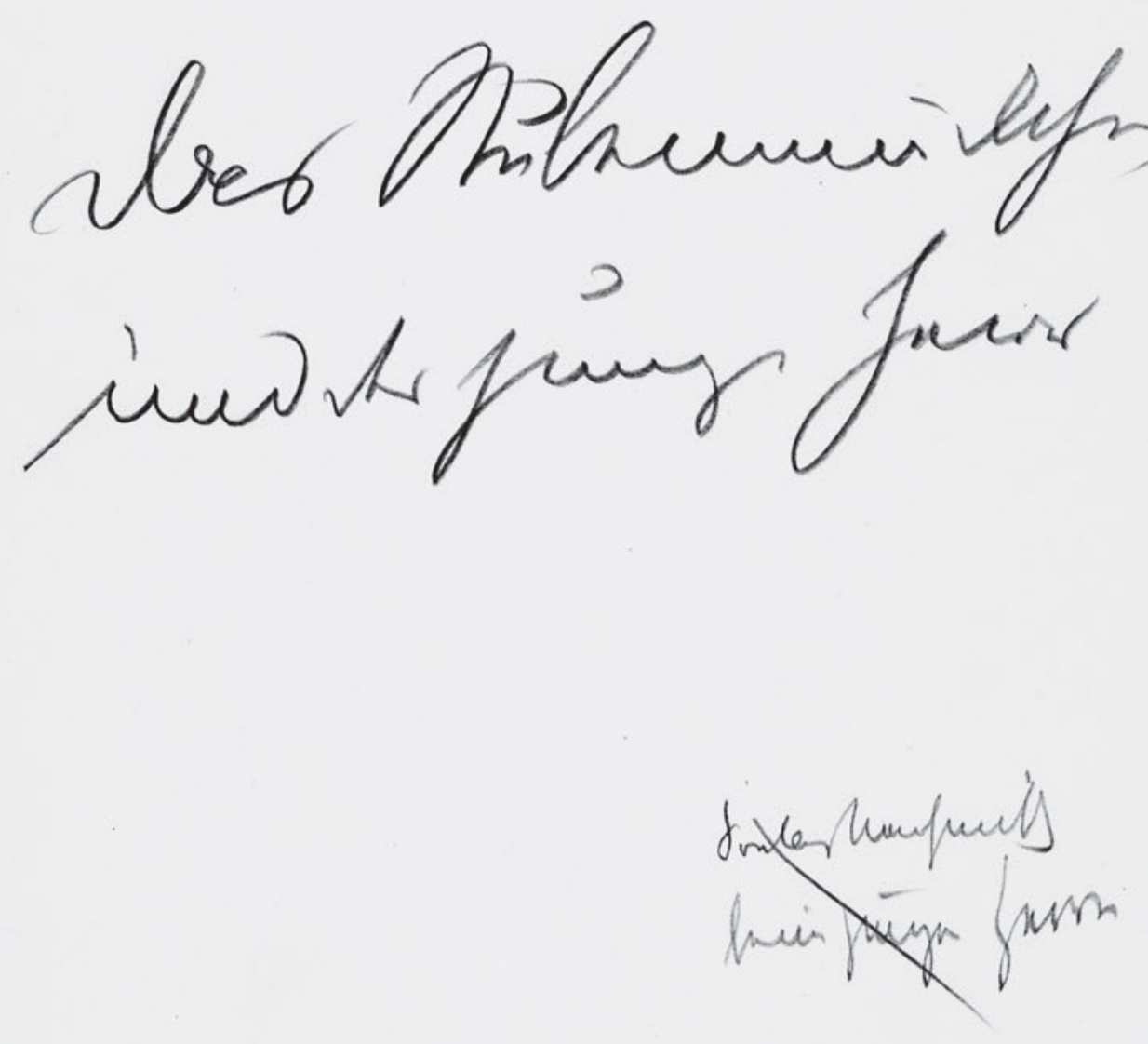

106 
36

3.

Das Stubenmädchen

und der junge Herr

beim jưngen Herrn 
HSz3 37

Handschriften und Typoskript

37

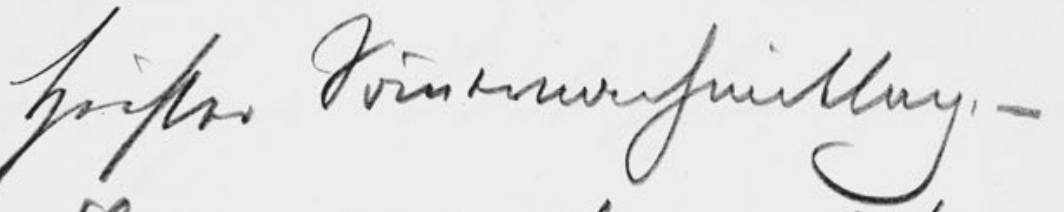

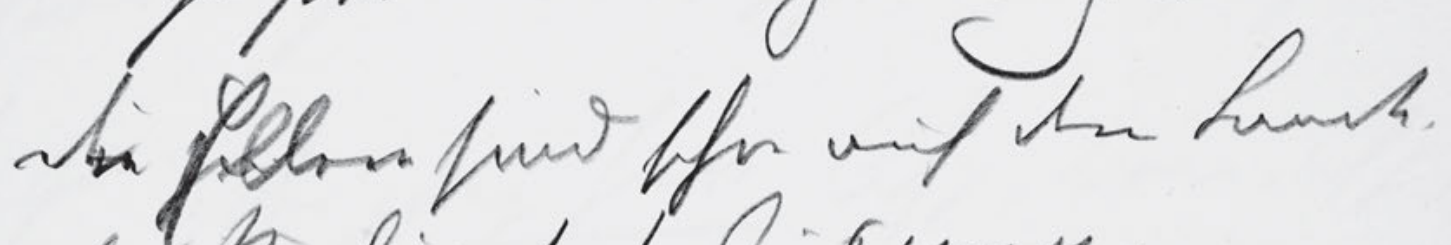
ch Ronfin fat airgeny.

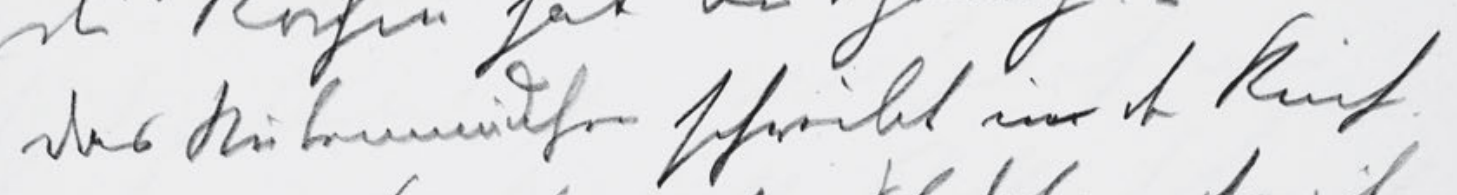

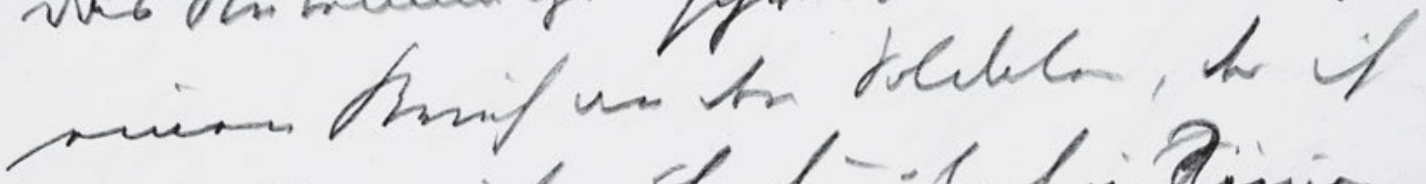

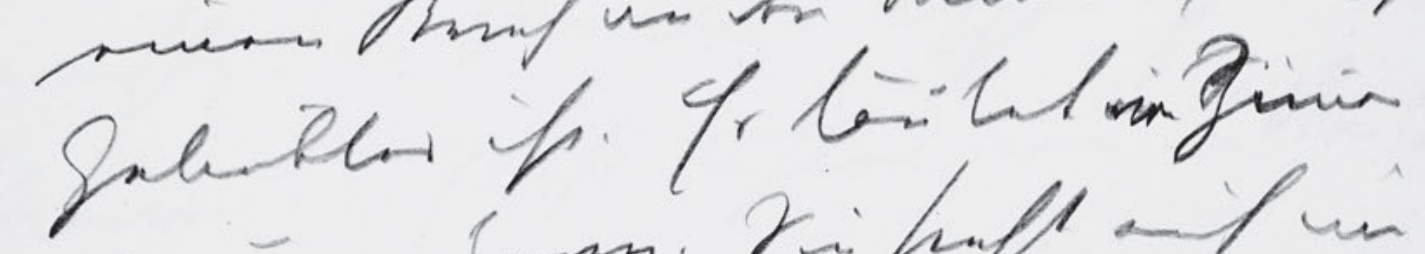
string form. Fifulf if un gafl ins

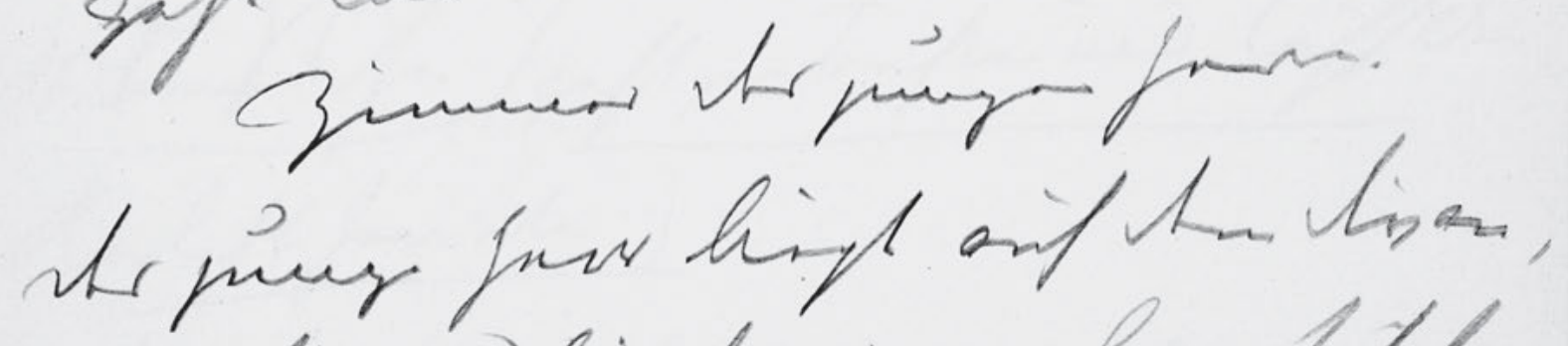

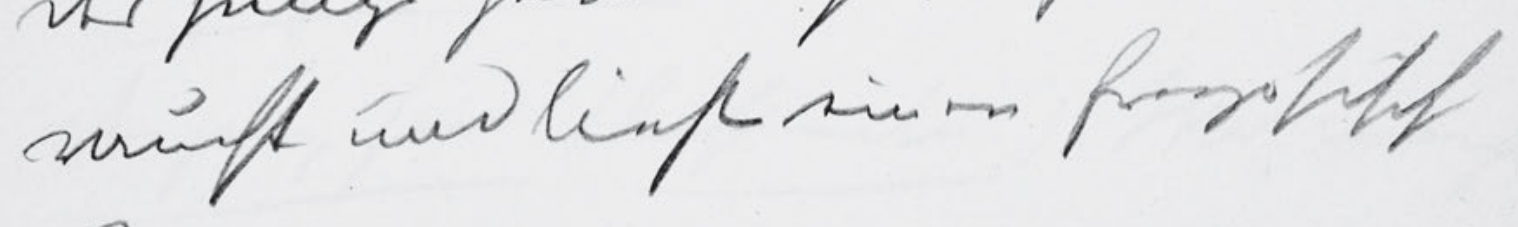
Rinums.

108 
Heißer Sō̄ernachmittag. -

$\mathrm{D}^{\mathrm{er}} \mathrm{ie}^{\mathrm{ju}}$ Eltern sind schon auf dem Lande.

Die Köchin hat Ausgang. -

5 Das Stubenmädchen schreibt $\mathrm{i}^{\mathrm{m}} \mathrm{n}$ der Küche

einen Brief an den Soldaten, der ihr

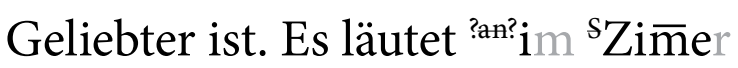

des jungen Herrn. Sie steht auf und

geht ins

Zimmer des jungen Herrn.

Der junge Herr liegt auf dem Divan,

raucht und liest einen franzosischen

Roman. 
HSz3 38

Handschriften und Typoskript

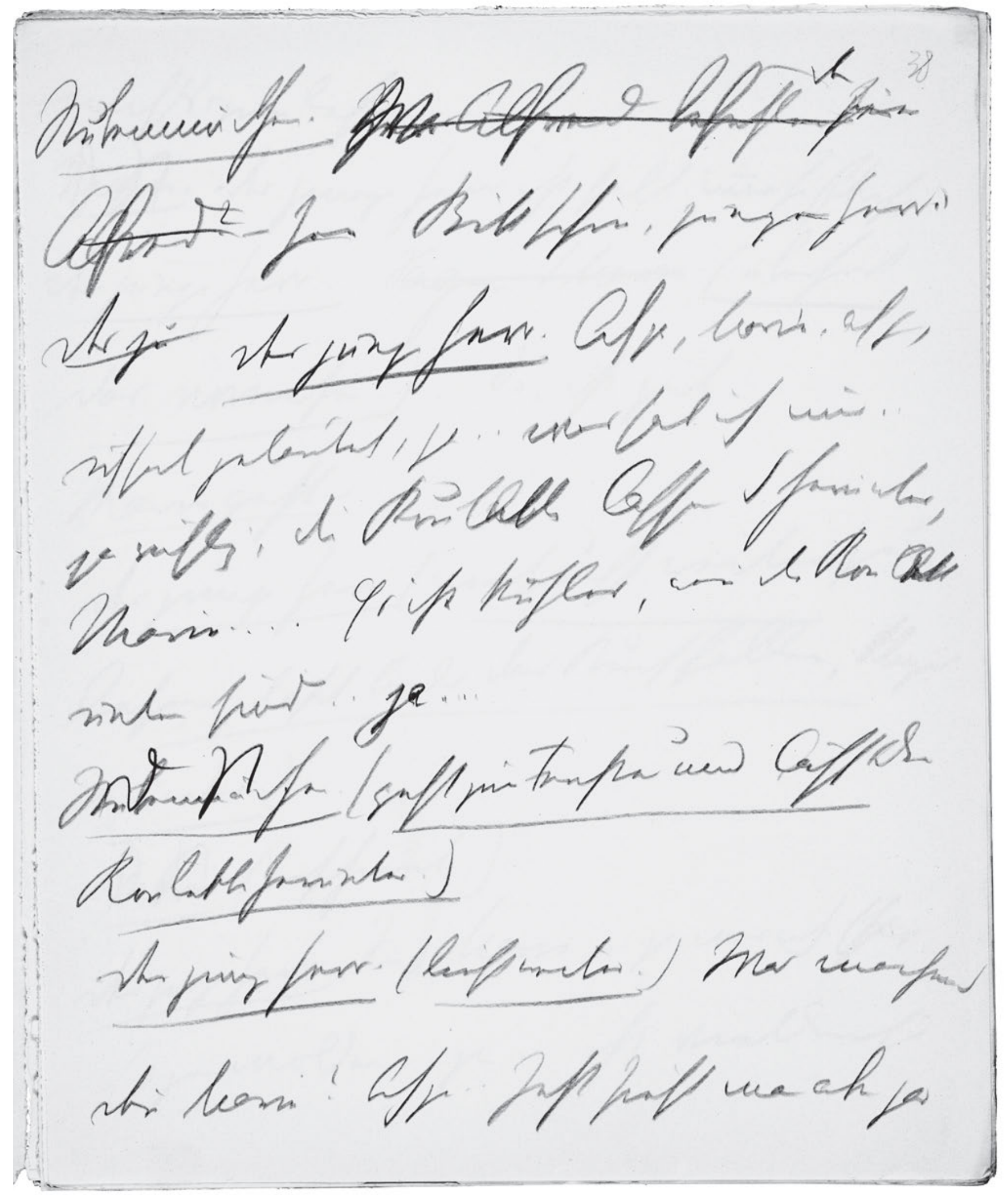




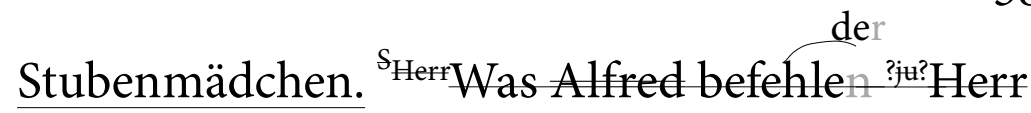

Alfred? - Her Bitt schön, junger Herr . .

Der ju Der junge Herr. Ah ja, Marie, ah ja,

5 ich hab geläutet, ja .. was hab ich nur . .

ja richtig, die Roul ${ }^{l e} e t t e n$ lassen $S$ herunter,

Marie .... Es ist kühler, weñ die Roul' ${ }^{1} e t t$

unten sind . . ja ....

Stubenmäthen. D St. (geht zum Fenster und lässt die

$10 \quad$ Rouletten herunter.)

Der junge Herr. (liest weiter.) Was machen $S$

den̄ Marie? Ah ja . . Jetzt sieht man aber gar 
HSz3 39

Handschriften und Typoskript

mifsing afm.

多

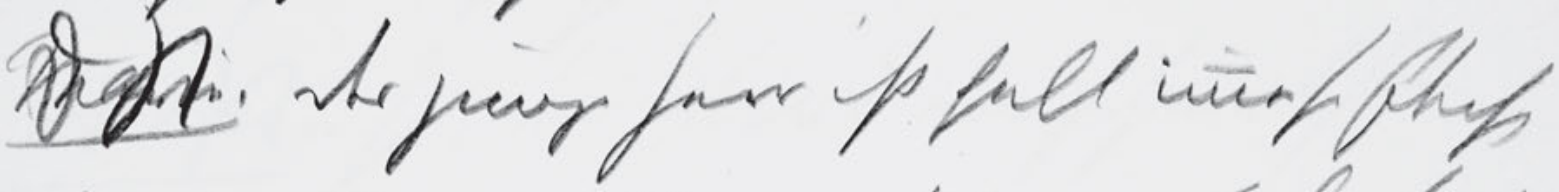
thening far ver unmatin do, spit

hasingafl.

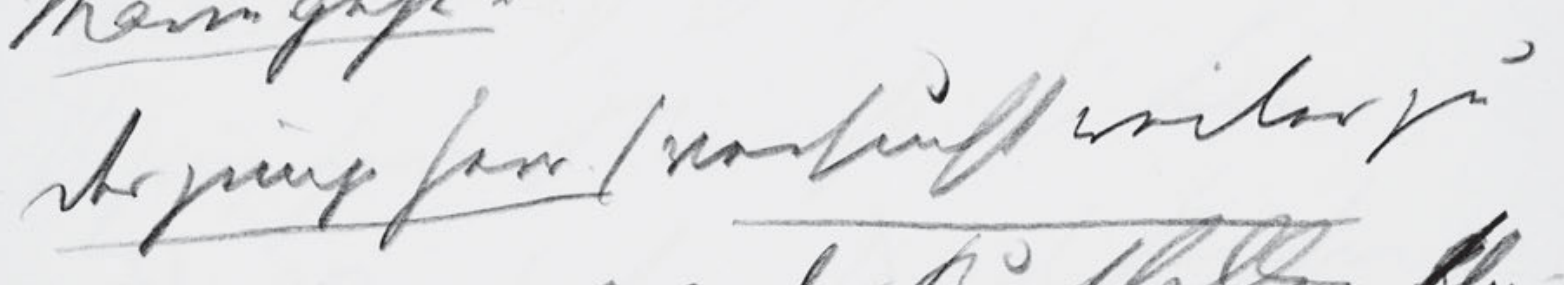
Cafo; laft bal in kinfleter. thai Voinh.s.

intini (nffromis)

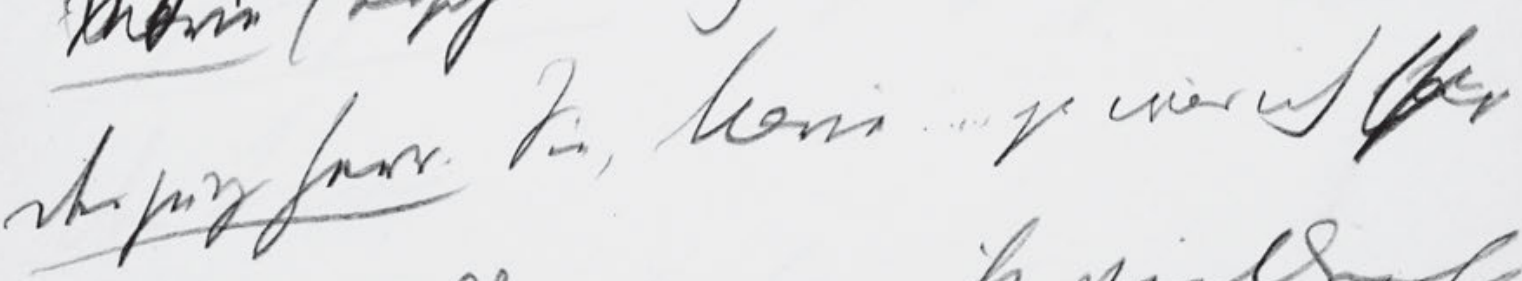

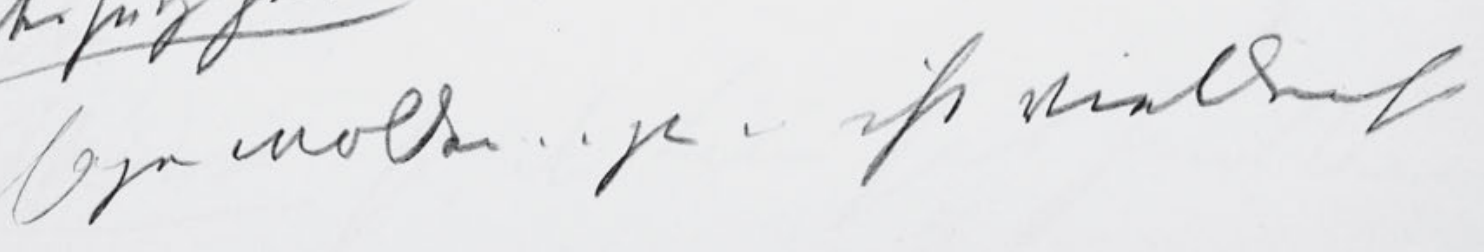

112 
nichts “zum lesen.

Marie. D St Der junge Herr ist halt ime so ?fleiß?

Der junge Herr .... Sagen S Marie “(überhört

5 das vornehm) .. So, ist gut . .

Marie geht.

Der junge Herr. (versucht weiter zu

lesen; läßt bald das Buch fallen, klingel

wieder.)

${ }^{\text {Marie }} \mathrm{D}$ St (erscheint.)

Der junge Herr. Sie, Marie .... . ja was ich sagha

sagen wollen . . ja . . ist vielleicht 
HSz3 40

Handschriften und Typoskript

sincoure

40 wethe.

L

ing mor

Sart.

ylenflas

of 20

Mfing

h

atist.

tis

for Glfins

he

Aa k knjis.

thin.

Ahatin.

Lin

fatponteres.

114 
ein Cognac zu Haus . .

Marie. D St. Ja, der wird eingsperrt sein.

${ }^{[?]}$ Der junge Herr. $\mathrm{Na} \mathrm{w}^{\mathrm{i} e r}$ hat den die

5 Schlussel.

Marie. D. St Die Schlüssel hat die Lini.

De jung Herr Wer ist die Lini?

Marie.D. St Die Lini Na, die Kochin,

Herr Alfred.

10 Der jung Herr. Na so sagen $S$ hal

der Lini . .

Marie. $\underline{\mathrm{D} S t}$ Ja, die Lini hat heut Aus- 
HSz3 41

Handschriften und Typoskript

long... stivg furs.

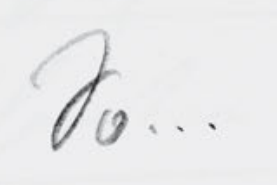

प)

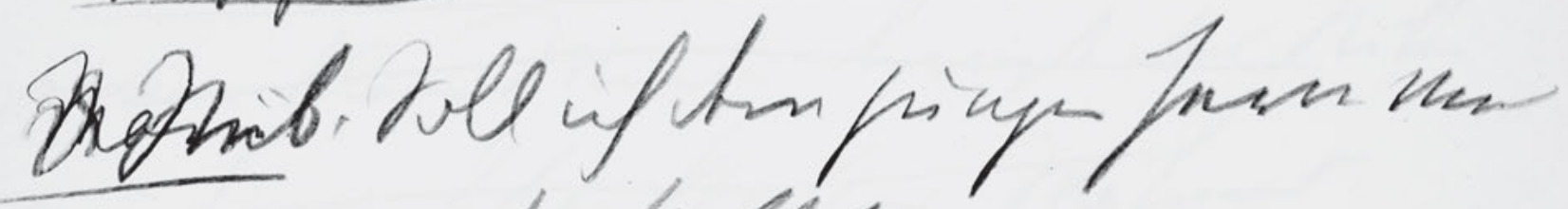
lnaf forp

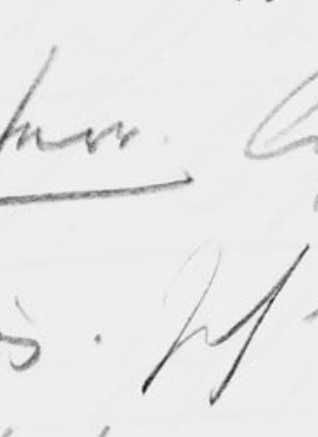

Miffon he

aba

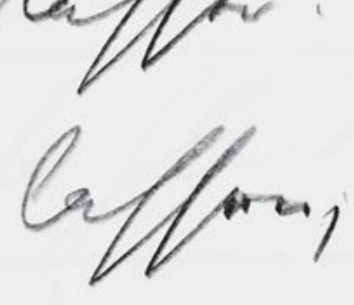

besthidat

theng furs Giaft
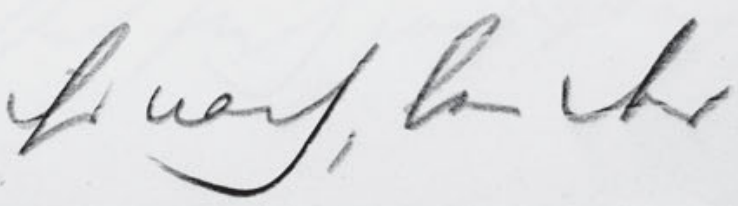

116 
gang...

Der junge Herr. So ...

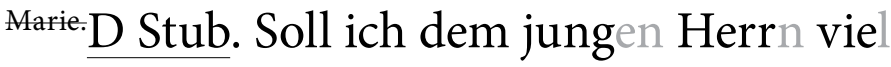

leicht aus dem Kaffehaus.

5 Der junge Herr. Ah nein ... es ist so ? wie?

heiß genug. Ich brauch kein Cognac . .

Wissen S, Marie, bringen Sie mir

ein Glas Wasser . Pst, Marie dass recht ist

aber laufen lassen;, kalt, kalt! .

Marie D Stub ab.

Der junge Herr (sieht ihr nach, bei der 


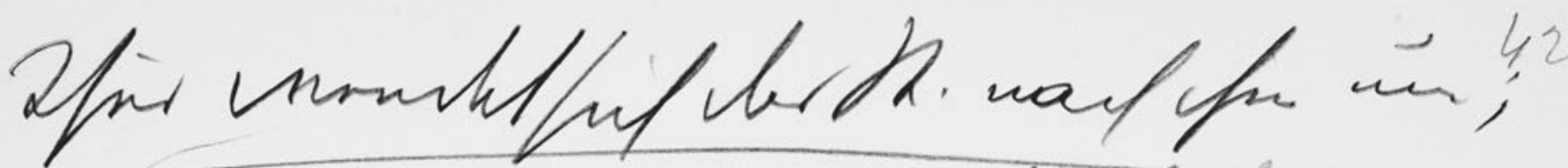

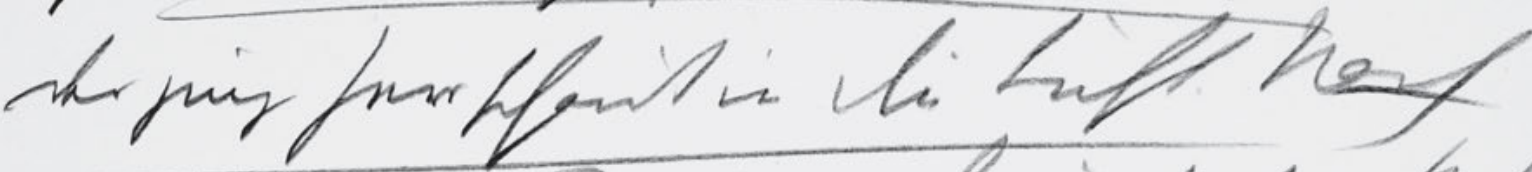

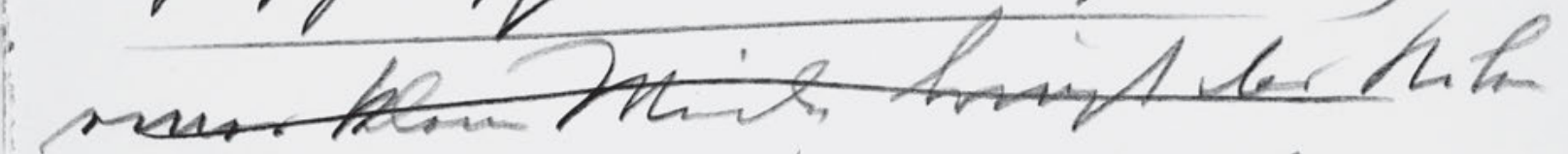

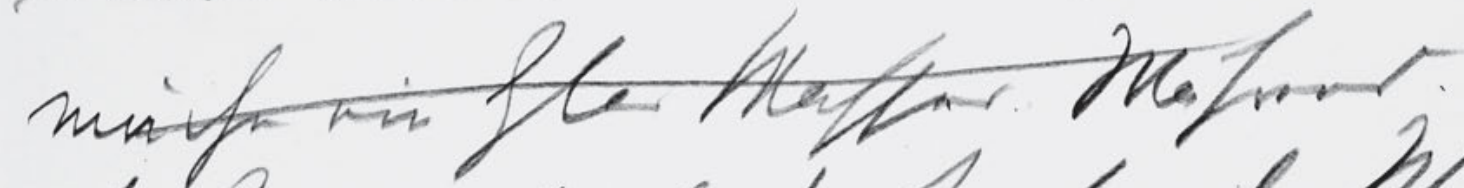
satint. Mreft th fafe thefe hituisant, laft b Mift bof

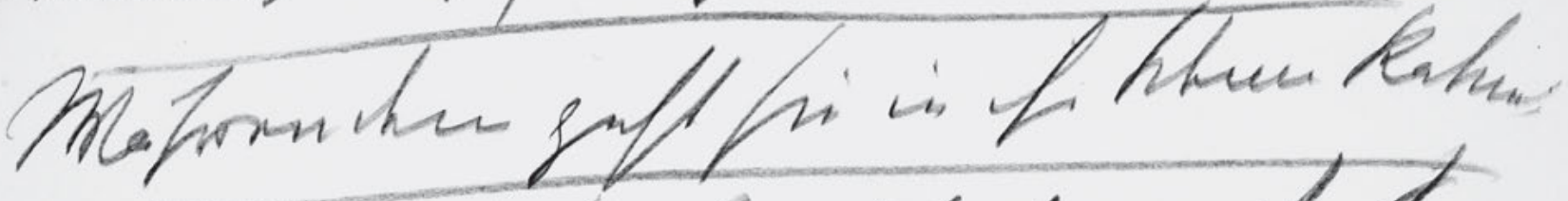

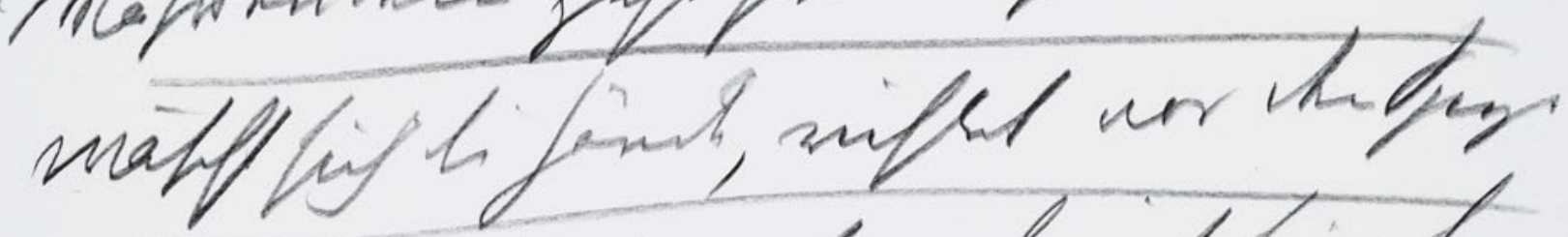

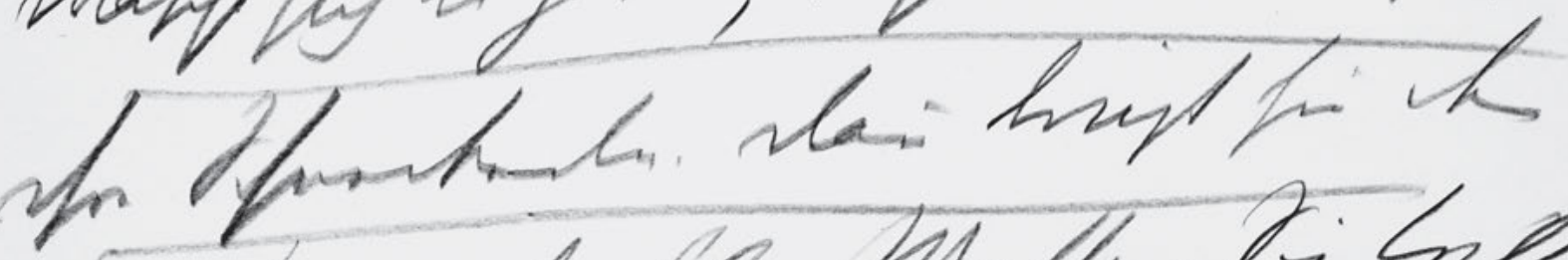
pong garm da fle Maffer zi ine min tran.)

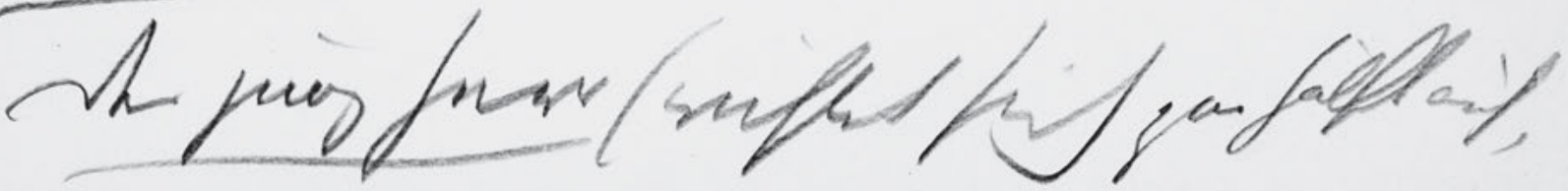


42

Thür wendet sich das St. nach ihm um; der junge Herr schaut in die Luft. Nach einer kleinen Weile bringt das Stuben-

5 mä hen ein Glas Wasser.. Während.

Das Stub. dreht den Hahn der Wasser

leitung auf, läßt das Wasser laufen

Währendem geht sie in ihr kleines Kabinet,

wäscht sich die Hände, richtet vor dem Spiegel

10 ihre Schneckerln. Dan̄ bringt sie dem

jung Herrn das Glas Wasser. Sie tritt

zum Divan.)

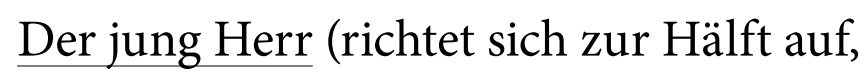


HSz3 43

Handschriften und Typoskript

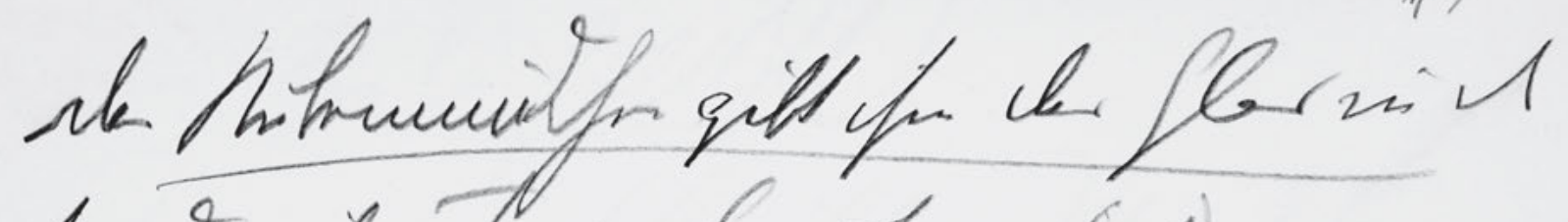

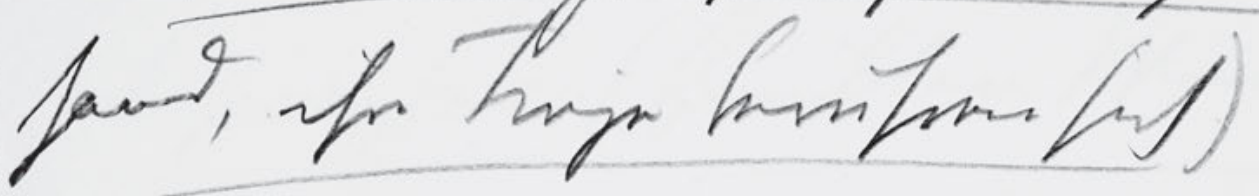

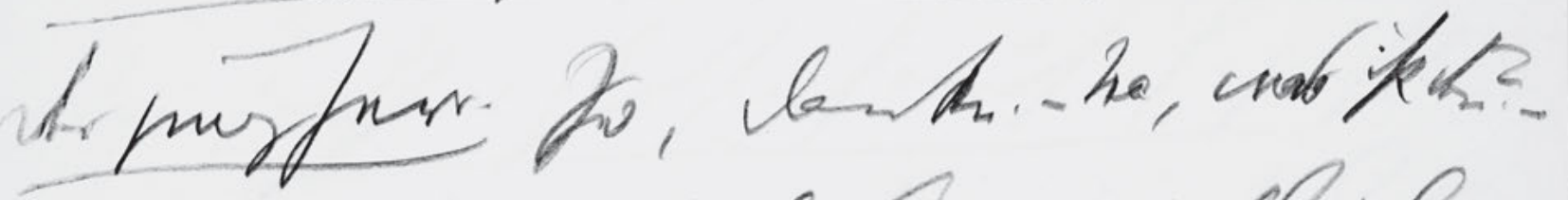

vin

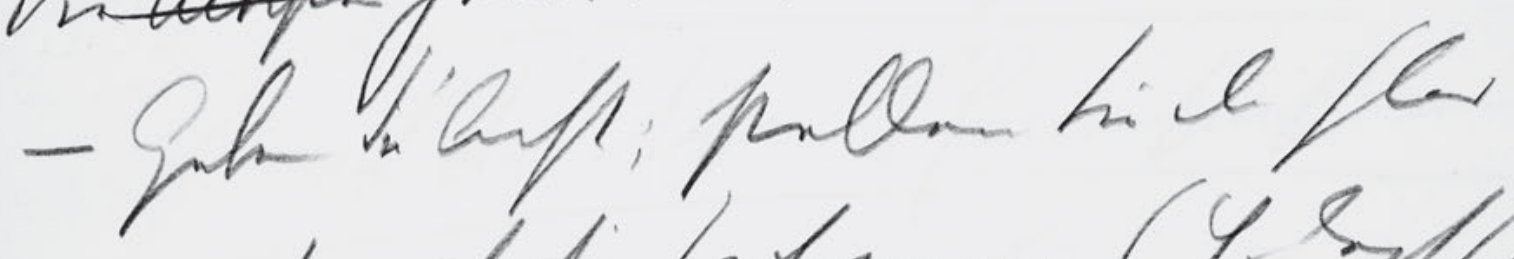

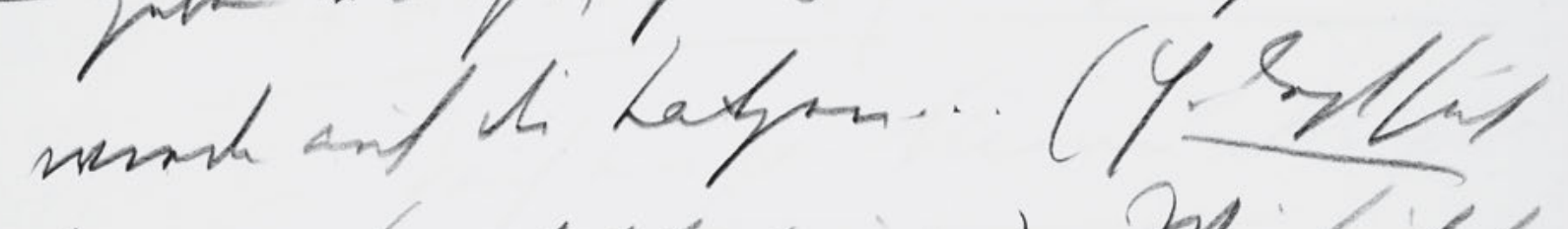

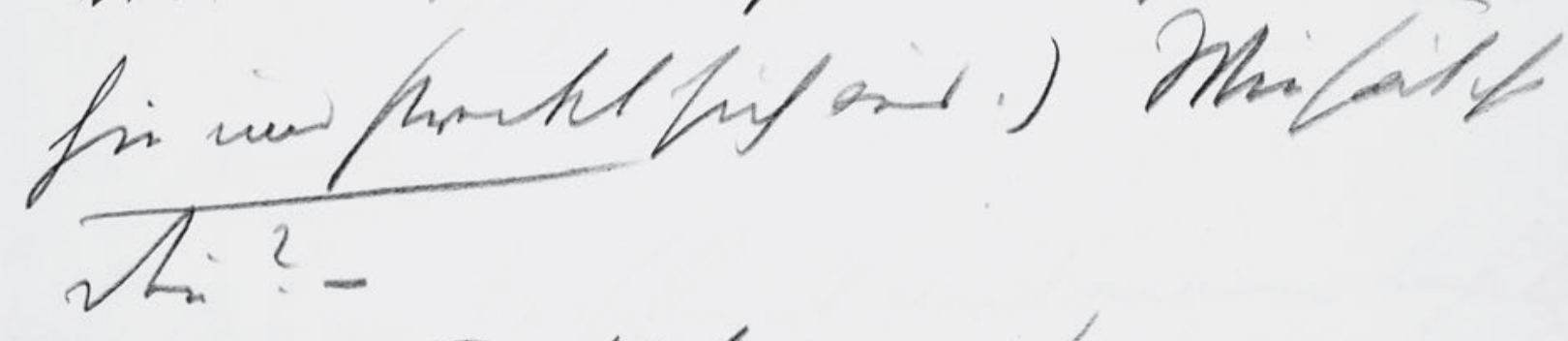

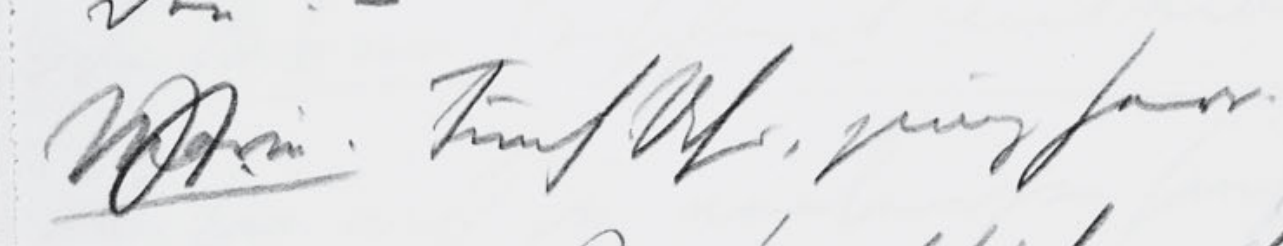

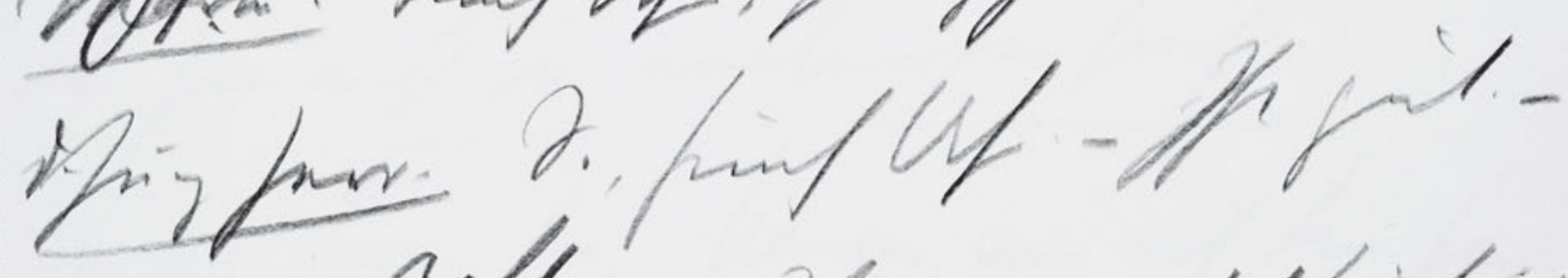

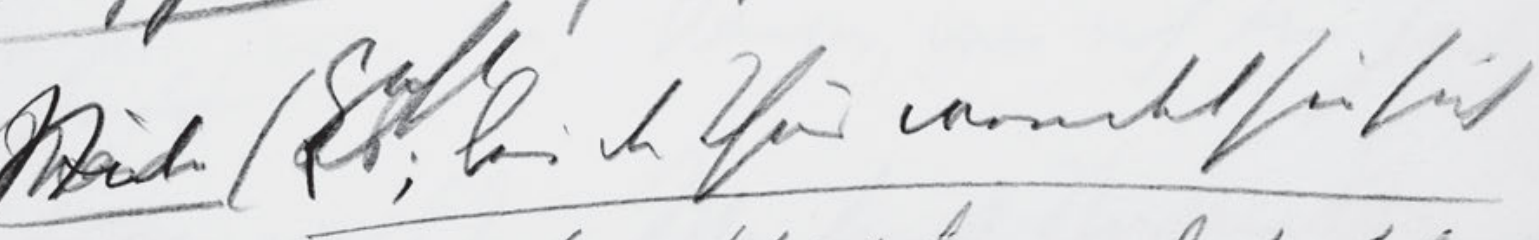

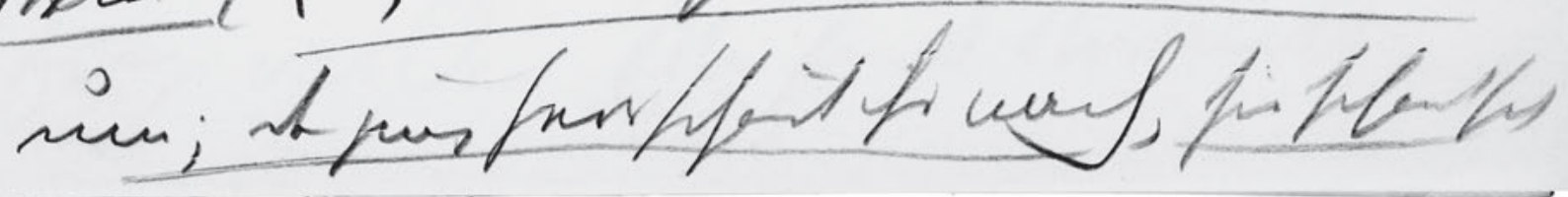

120 
das Stubenmädchen gibt ihm das Glas in d

Hand, ihre Finger berühren sich.)

Der junge Herr. So, danke. - Na, was ist den? -

5 Sie möchten heut lieber Au auch lieber

- Geben Sie Acht ; stellen Sie das Glas

wieder auf die Tatzen ... (Er legt sich

hin und streckt sich aus.) Wie spät ist

den̄? -

Marie.St. Fünf Uhr, junger Herr.

D.

Jung Herr. So, fünf Uhr. - Ist gut. geht

${ }^{\text {MarieStub (ab; bei der Thür wendet sie sich }}$

$\underline{\text { um; der jung Herr schaut ihr nach, sie schaut sich }}$ 
HSz3 44

Handschriften und Typoskript

min, fir bifnlight

44

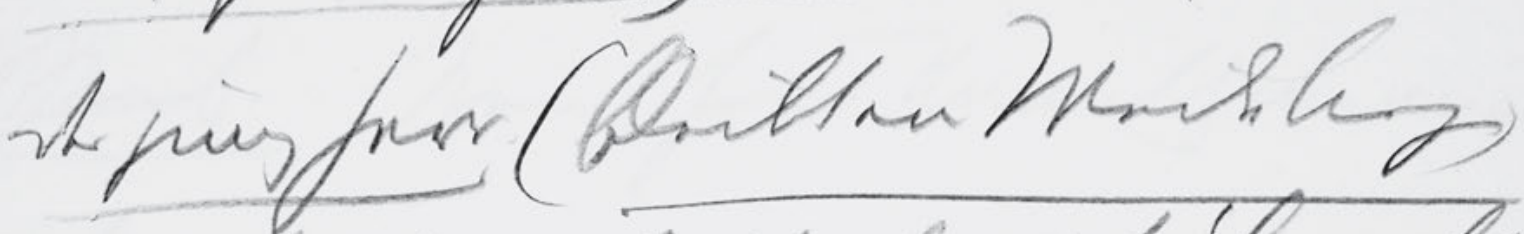

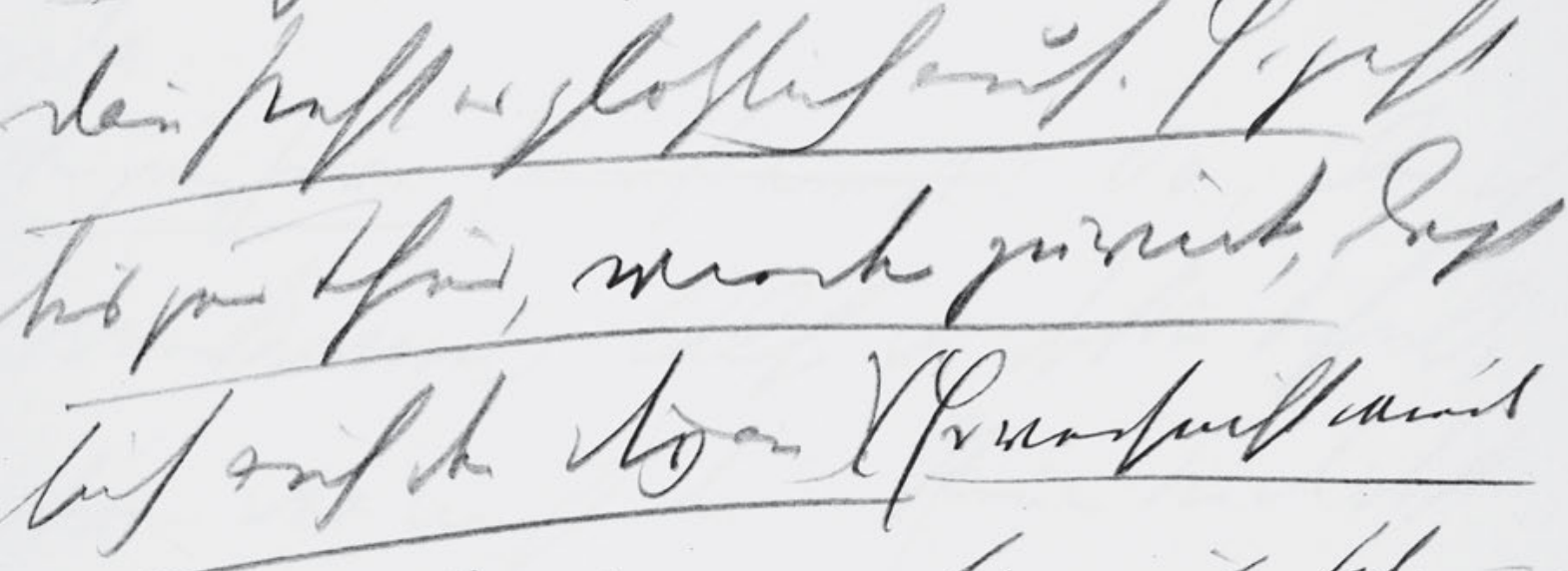

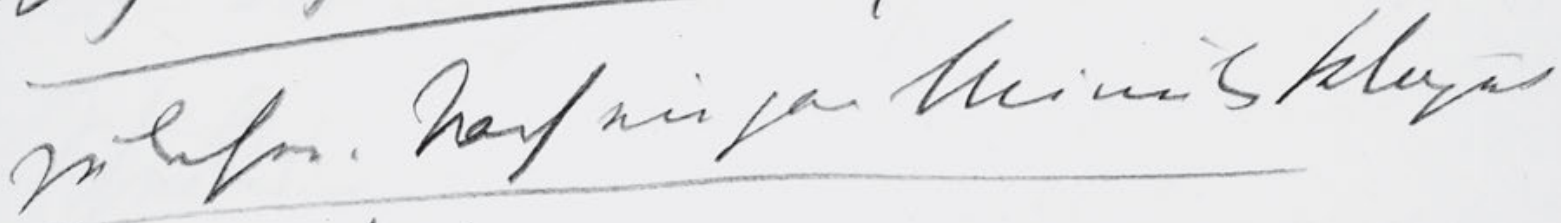

wolinh

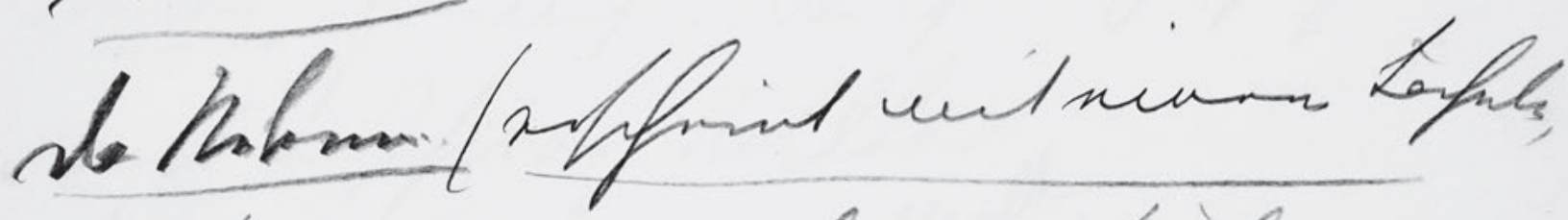

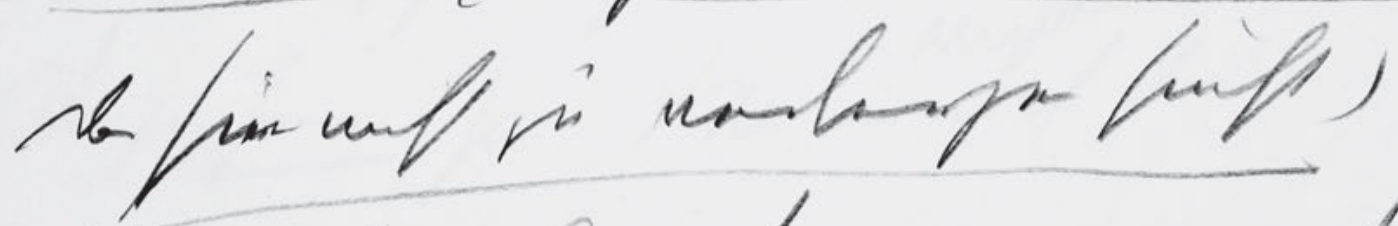

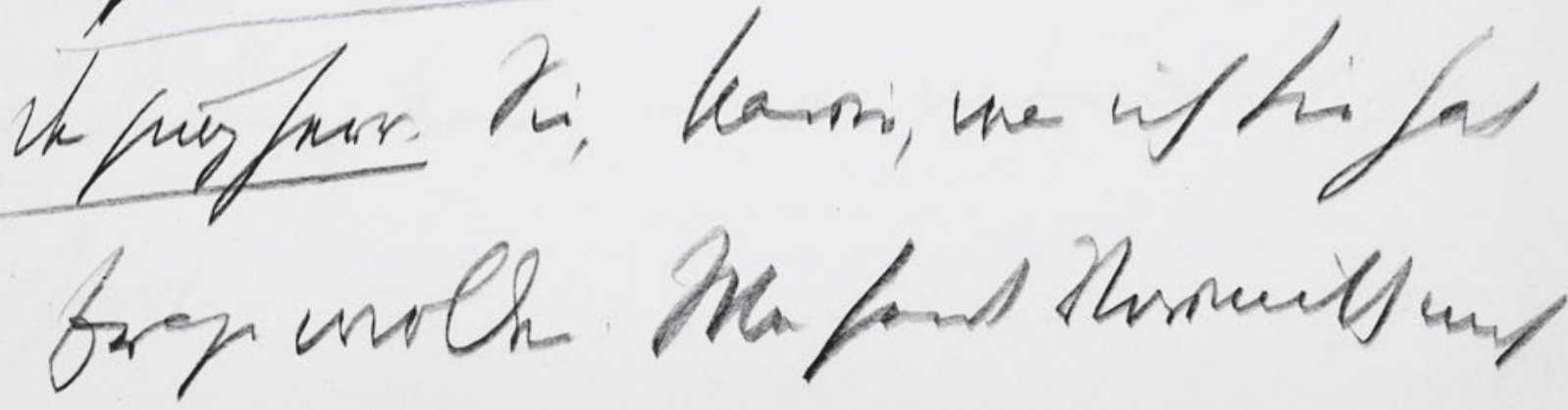

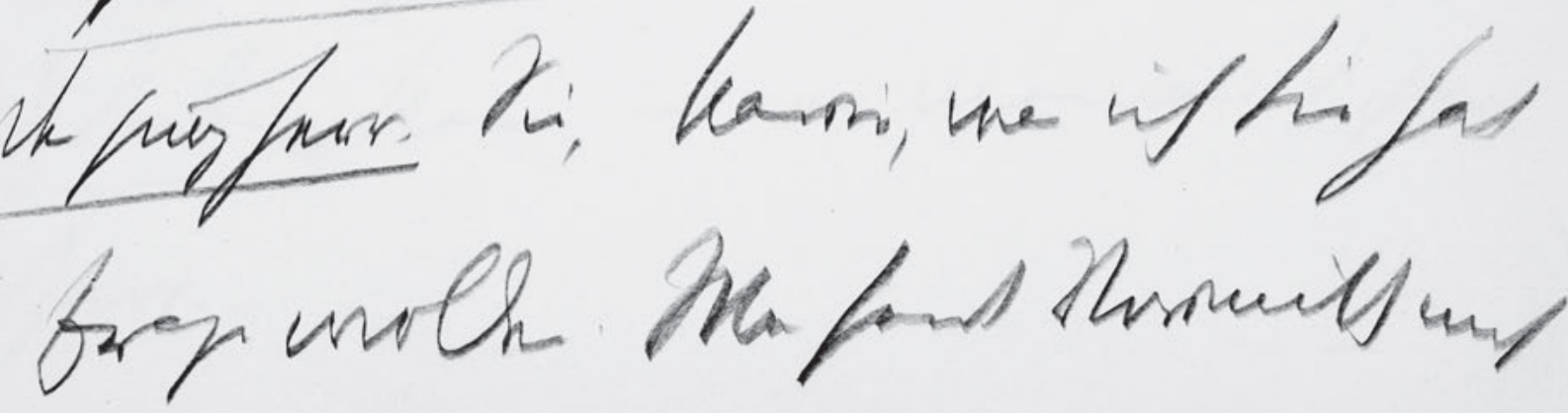

122 
um, sie lächelt.'Ab.)

Der jung Herr. (bleibt eine Weile liegen,

dan̄ steht er plötzlich auf. Er geht

bis zur Thür, wieder zurück, legt

$5 \quad$ sich auf den Divan) ${ }^{*}$ (Er versucht wied

zu lesen. Nach ein paa Minuten klingel

er wieder)

Das Stubenm. . (erscheint mit einem Lächeln,

das sie nicht zu verbergen sucht)

10 Der jung Herr. Sie, Marie, was ich Sie hab

frage wollen. War heut Vormittg nich 
HSz3 45

Handschriften und Typoskript

stor blator Ofill de :

45

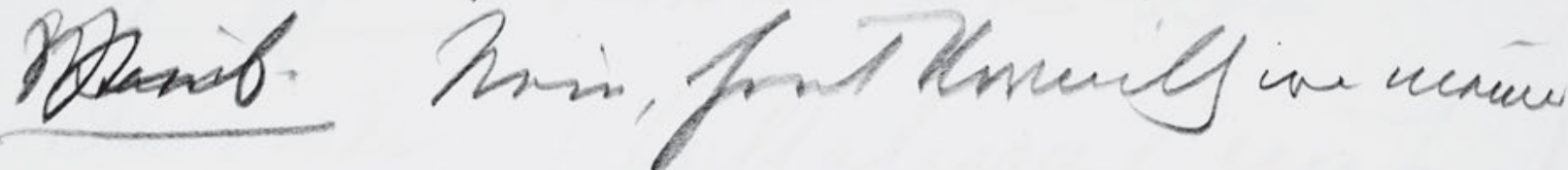
sa..

thrigfurr

unchanion.

Alf

Sh the Silils

the we unff las

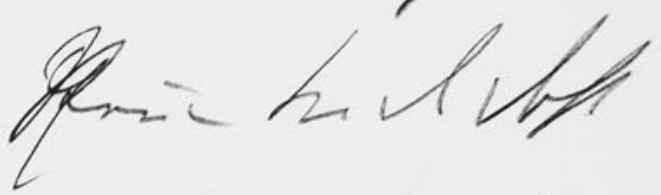

sfribli:

Pribe. Trolif de fic uop

sut LAfinay

it 1 mith

Thesporr fa.. The while

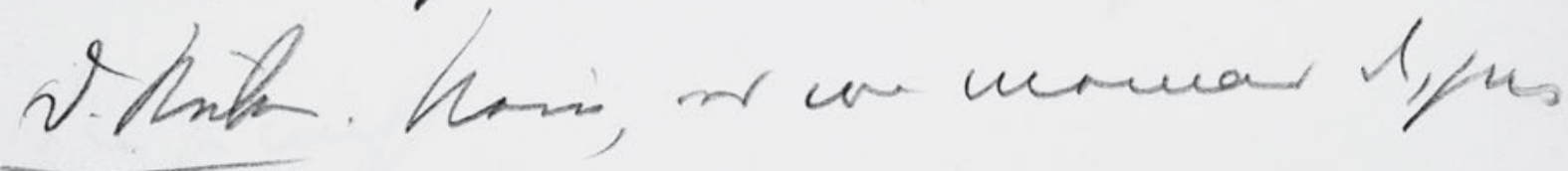

farr.

124 
der Do ${ }^{\left[{ }^{[?]}\right.}$ ktor Schüler da? -

[?] ${ }_{\text {MarieStub. Nein, heut Vormittg war niema }}$

da...

Der jung Herr. (leicht erregt) So, das is

5 merkwürdg . . Also der Dokto Schüller

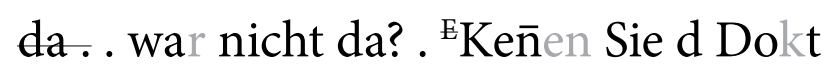
Schüller? -

D

Stuben . Freilich .. das ist der große Herr . mit dem schwarzen Vollbart. viellei

${ }_{10}$ Der jung Herr. Ja ... War er doch da?

D. Stuben. Nein, es war niemand d, jung Herr. - 
HSz3 46

Handschriften und Typoskript

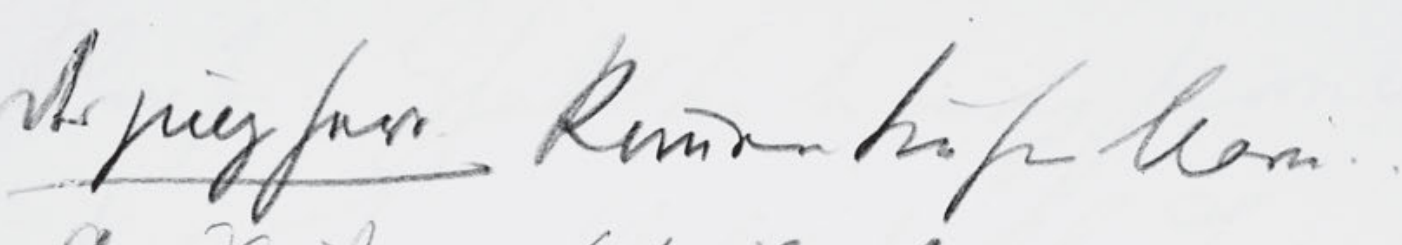

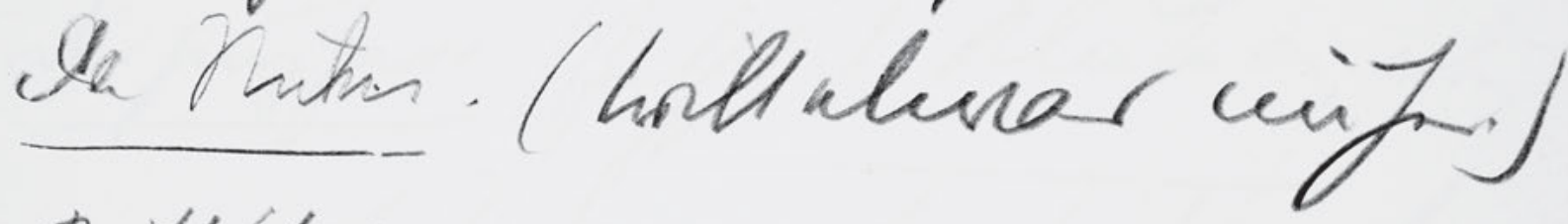

Bitlffini-

huspurs haja to af infw wi phlentl

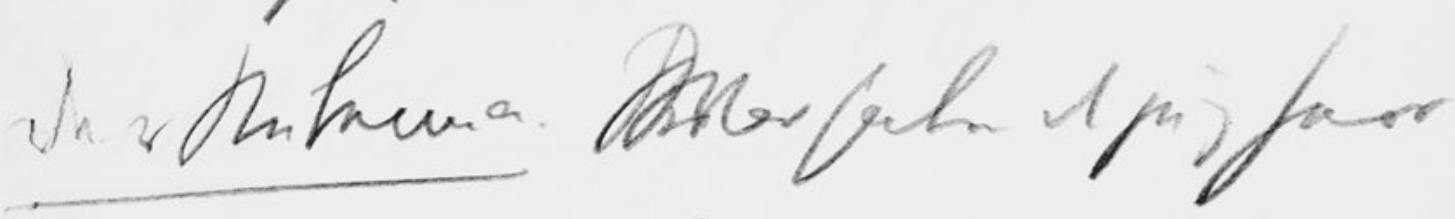

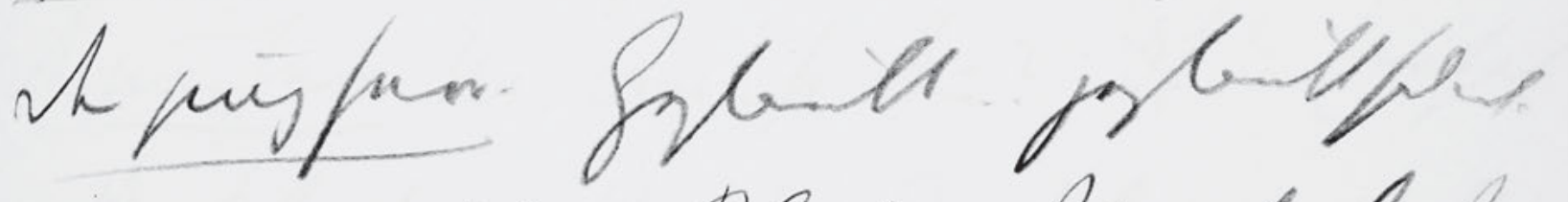

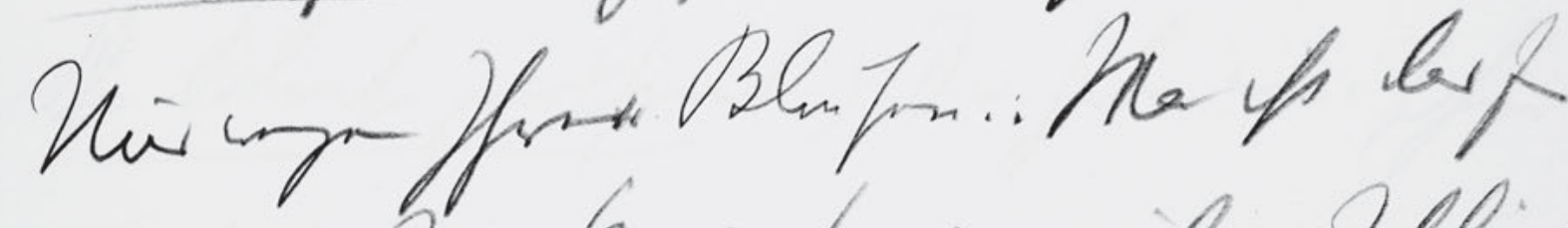
suin he Amum mi nafh. Afthif lin anf

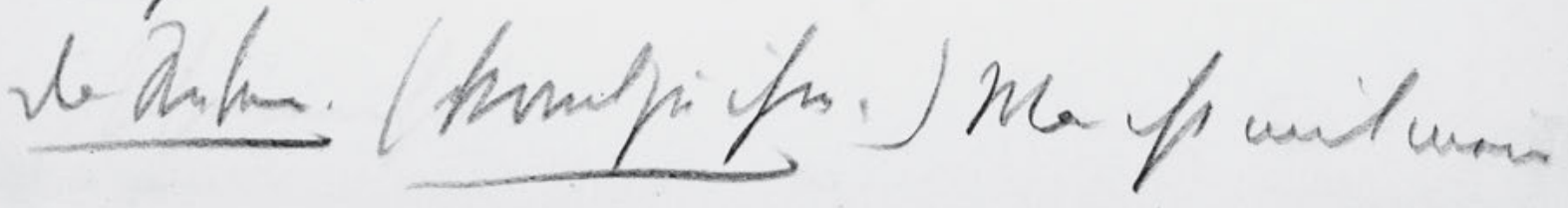

126 
46

Der jung Herr. Kō̄en Sie her Marie . .

Das Stuben . (tritt etwas näher.)

Bitt schön’? -

$5 \quad$ Der jug Herr. Näher - so . . ah .. ich hab

nur geglaubt.

De ?r? Stubenma. ${ }^{\text {Se} W a s ~ h a b e n ~ d e r ~ j u g ~ H e r r . ~}$

Der jung Herr. Geglaubt . . geglaubt hab ich.

Nur wegen Ihrer Blusen. : Was ist das für

ein - Na komen S nur näher. Ich beiß

Sie ja nicht.

Das Stubenm. (komt zu ihm.) Was ist mit mein 
HSz3 47

Handschriften und Typoskript

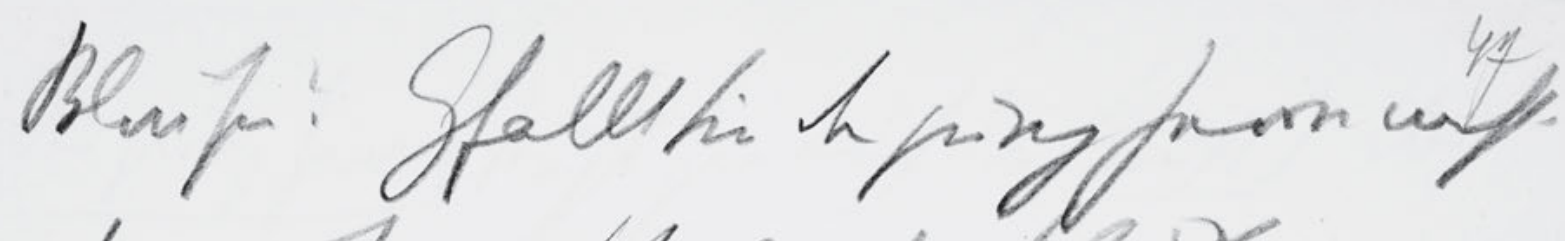

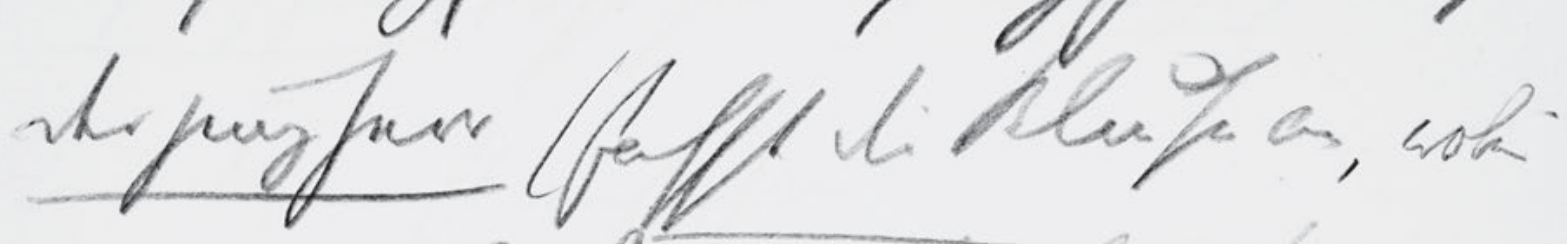

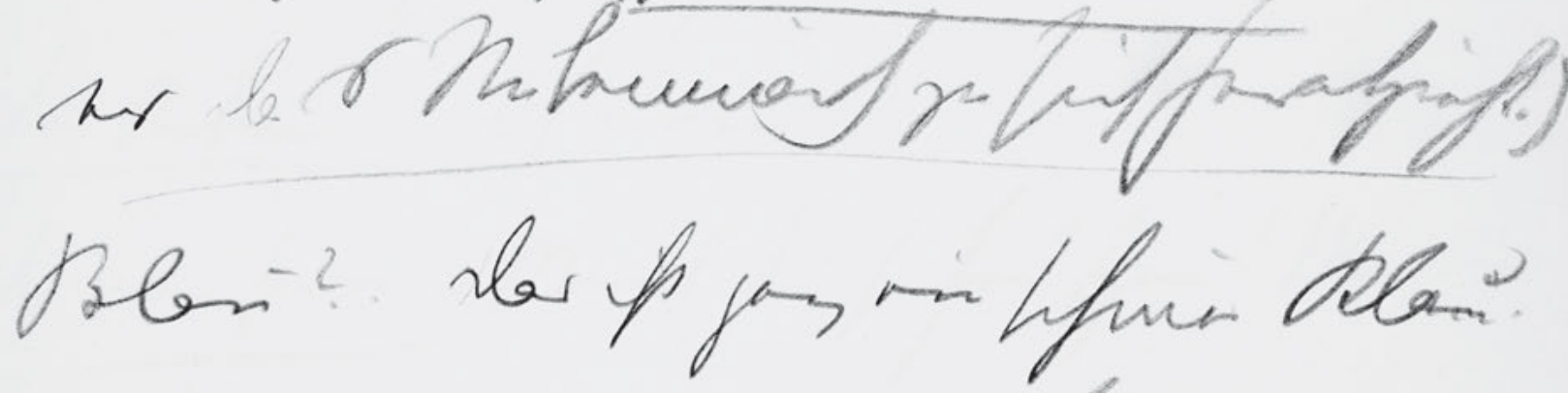

lis furfof unth aygry, Cosi... sher this Chr ping frow.

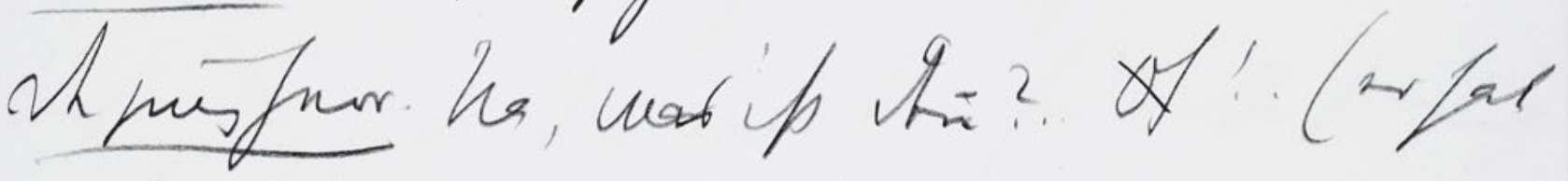

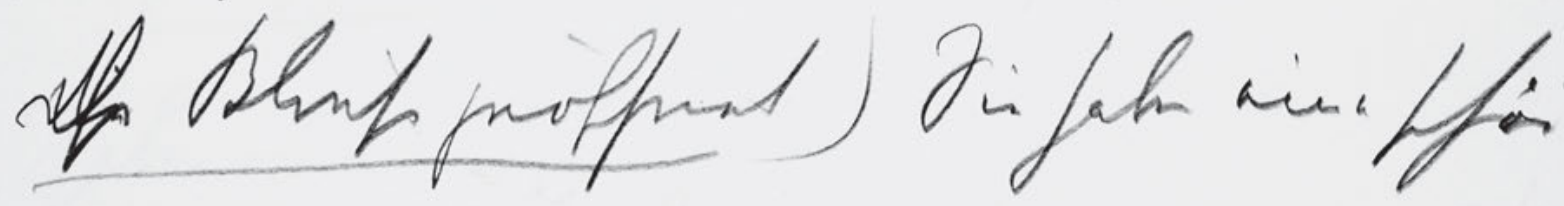
mentefort, bem.

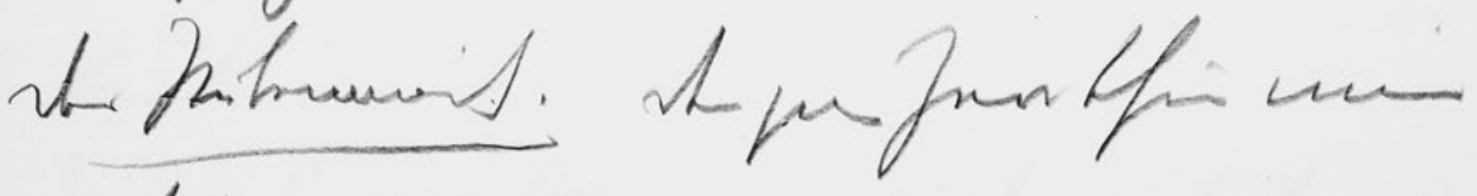
Anomifs.

128 
47

Blusen? Gfallt Sie dem junge Herrn nicht.

Der junge Herr (fasst die Bluse an, wobei

er das Stubenmädh zu sich herabzieht.)

$5 \quad$ Blau? . Das ist ganz ein schönes Blau.

Sie sind sehr nett angezoge, Marie ....

Das Stuben .Aber junger Herr . .

Der jung Herr. Na, was ist den̄? . Oh! . (er hat

dieihr Bluse geöffnet) Sie haben eine schön

weiße Haut, Marie.

Das Stubenmädh. Der jung Herr thun mir schmeicheln. 
HSz3 48

Handschriften und Typoskript

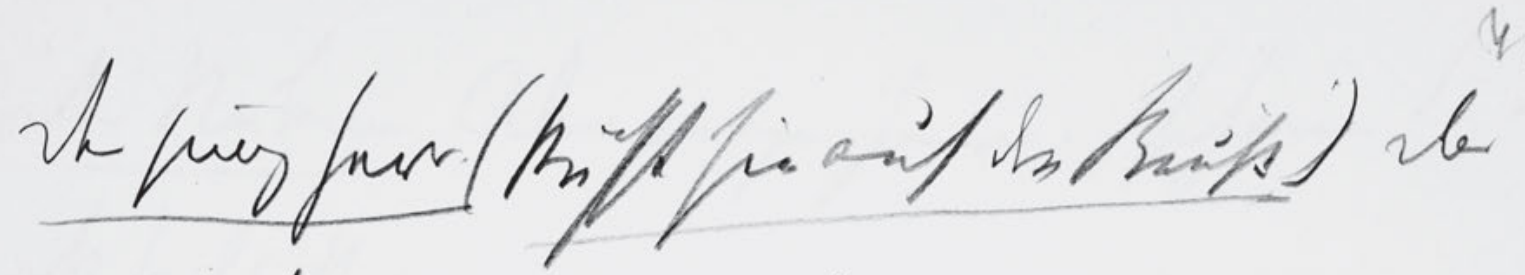
ker it miff ma/pin. de hintrum.

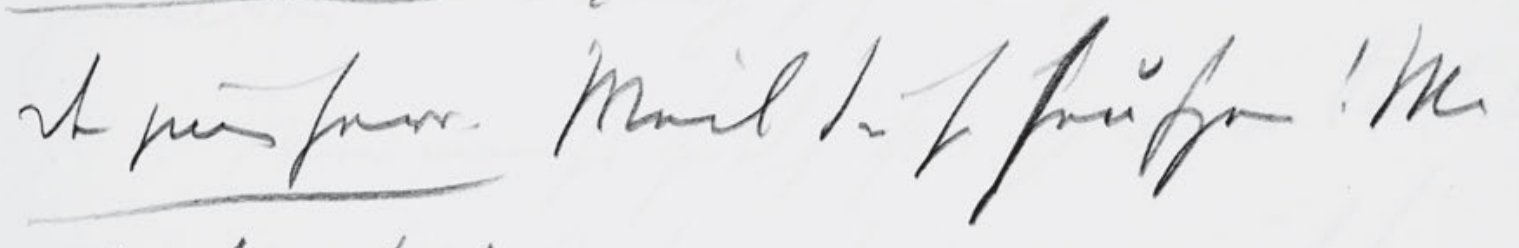

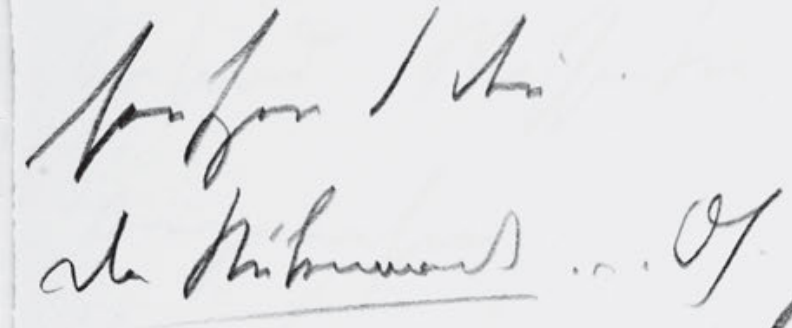
Atring $\frac{\text { b Ritrom }}{\text { lant'. }}$

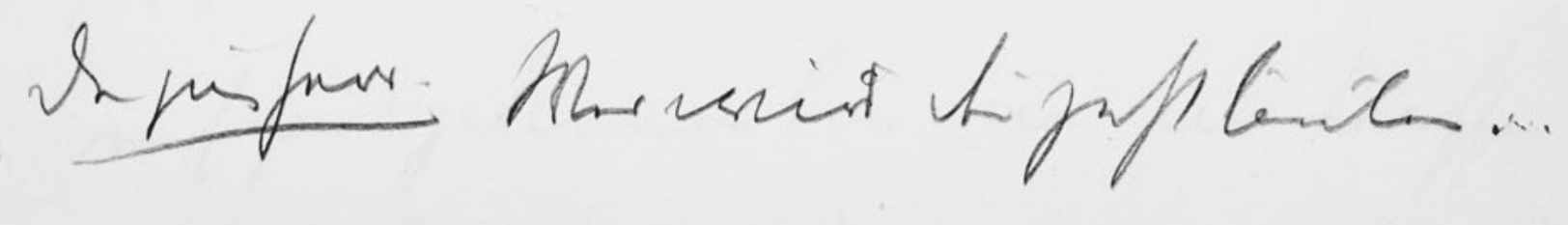

130 
48

Der jung Herr. (küsst sie auf die Brust) Das

kan̄ doch nicht weh thun.

Das Stubenm. . Oh nein.

${ }_{5} \quad$ Der jung Herr. Weil sie so seufzen! Wa

seufzen $S$ deñ.

Das Stubenmad .... Oh. Herr Alfred ...

Der jung Herr. Und was Sie für nette Pantoffe

haben .........

10 Das Stubenm. .. Aber . . jung Herr . . wen̄s draußen

läut? -

Der jung Herr. Wer wird den̄ jetzt läuten ..... 
HSz3 49

Handschriften und Typoskript

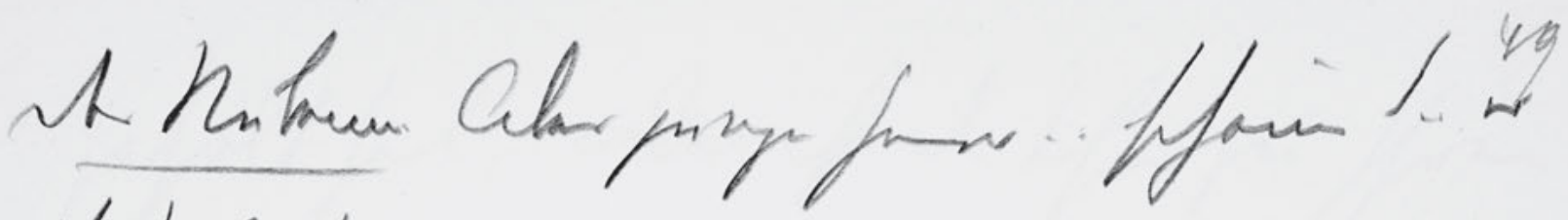
ipfolift...

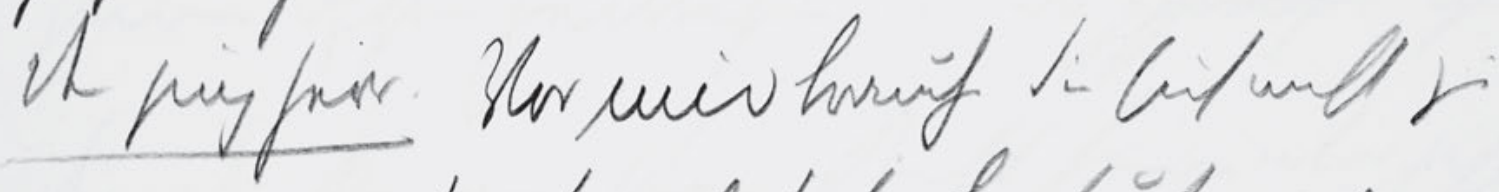

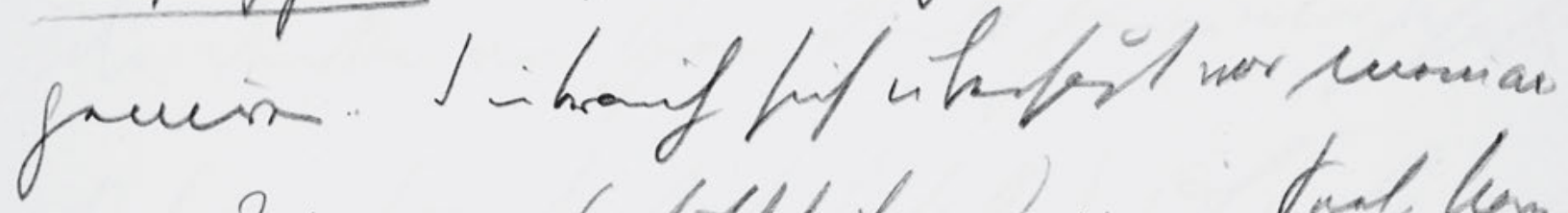

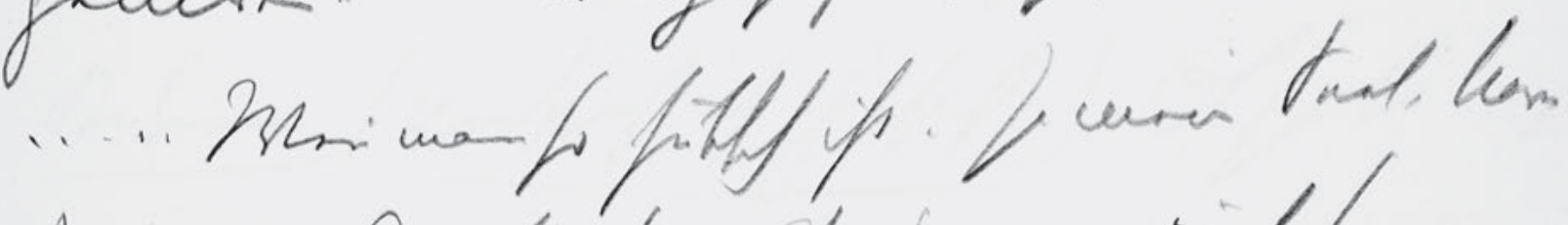

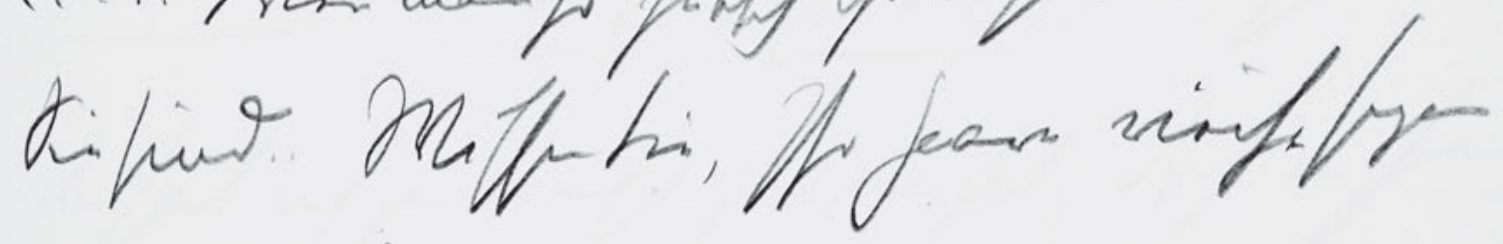
argranfon..

ot Antrumaign for Cieforo....

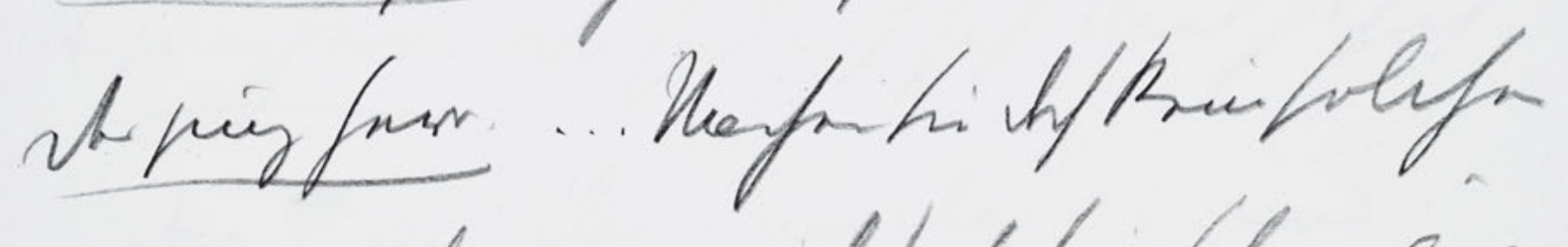

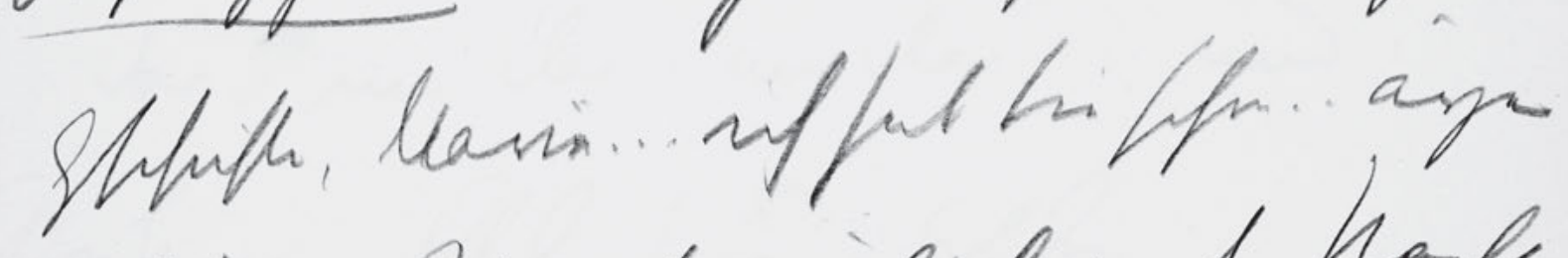
gutup... Thi if urialifis the the

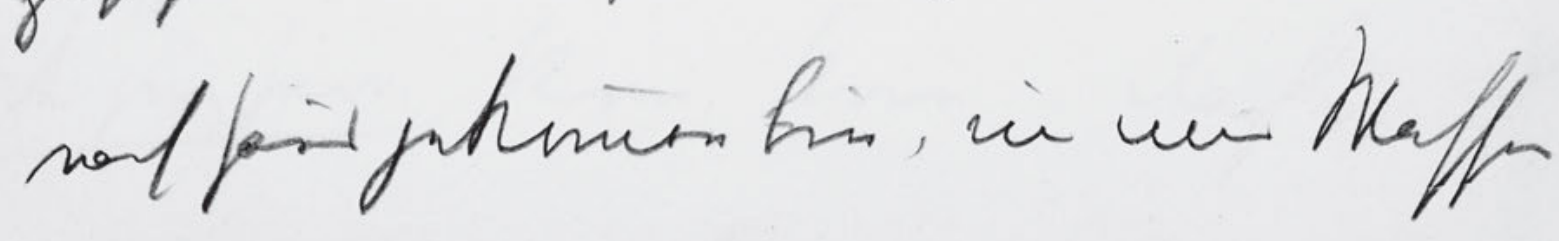

132 
Das Stubenm. Aber junger Herr .. Schauen S - es ist so licht .....

Der jung Herr. Vor mir brauchen Sie sich nicht zu

5 geniren .. Sie brauchen sich überhaupt vor nieman

.... Weñ man so hübsch ist. Ja mein Seel, Marie

Sie sind . Wissen Sie, Ihr Haare riechen sogar angenehm . .

Das Stubenmädhen. . Herr Alfred ....

$10 \quad$ Der junge Herr. ... Machen Sie doch keine solchen

Gschichten, Marie ... ich hab sie schon . . ärger

gesehn ... Wie ich neulich in der Nacht

nach Haus gekomen bin, und mir Wasser 
HSz3 50

Handschriften und Typoskript

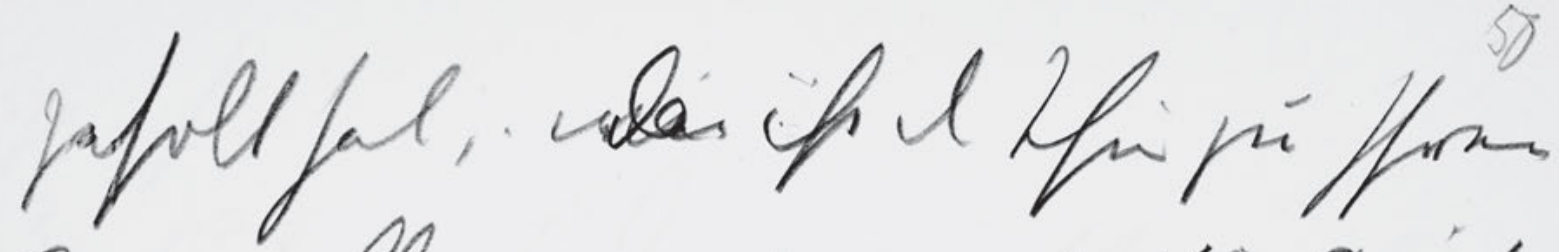

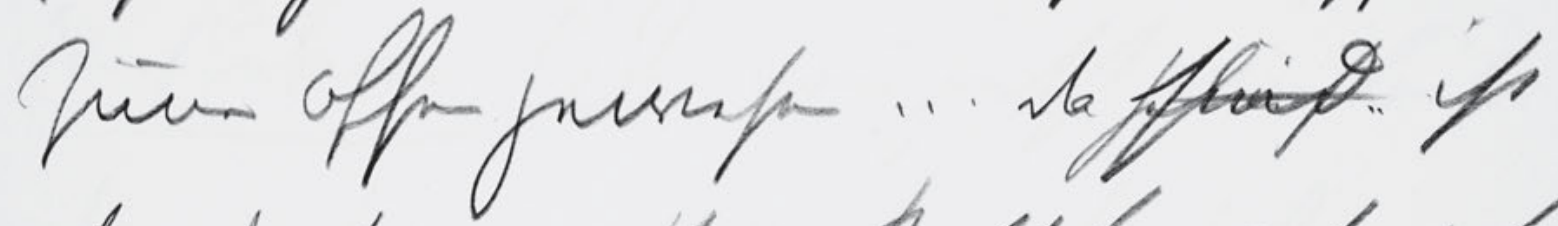

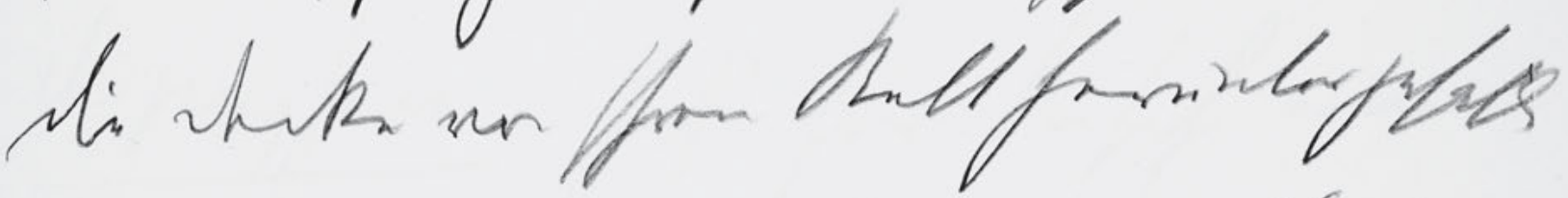

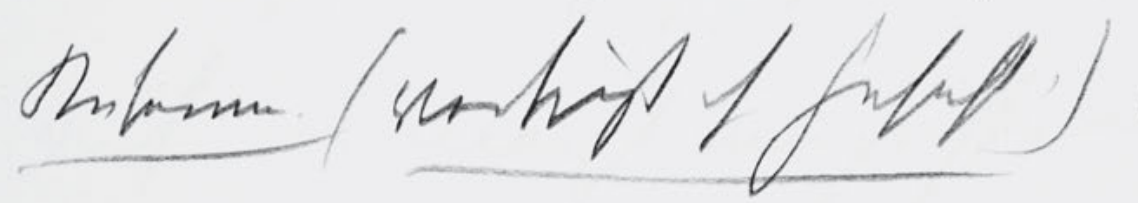
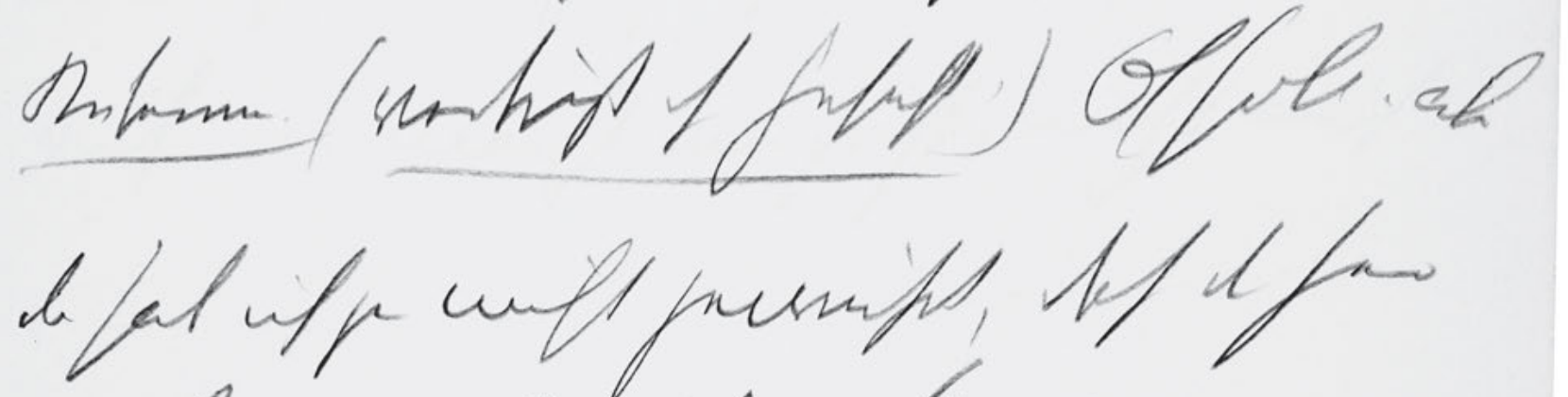

Alfind thengfir

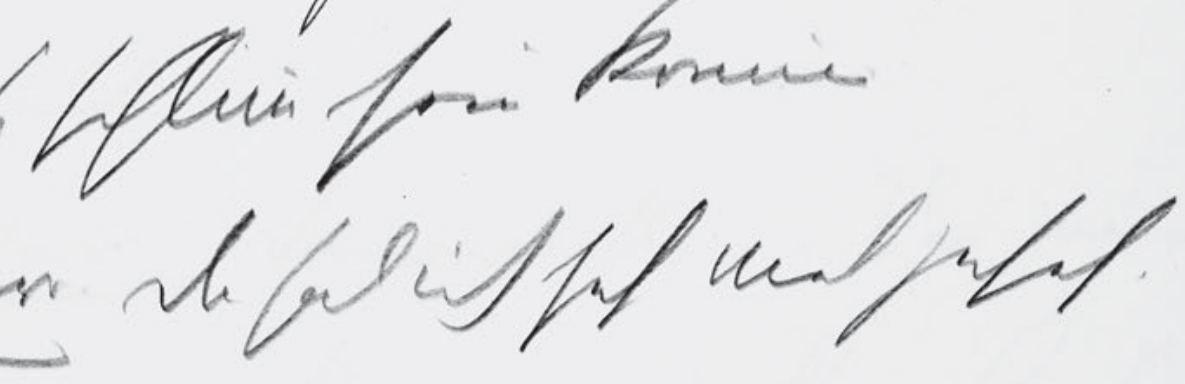

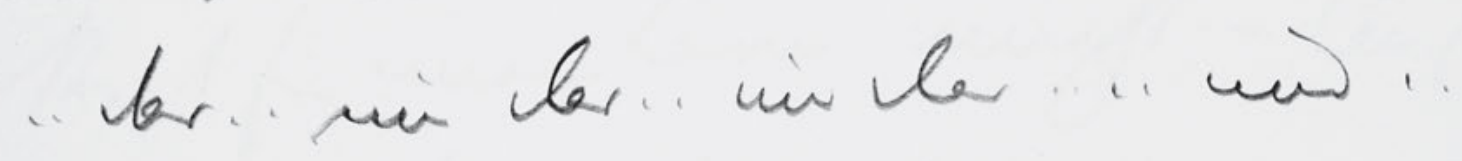

Minmen. Alb jom alfa strisgur km, hori

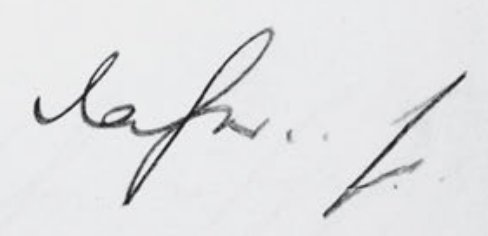

134 
50

geholt hab, . ${ }^{\text {wie }}$ da ist die Thür zu Ihrem

Zimer offen gewesen ... da ${ }^{\text {habich }}$ sind . . ist

die Decke von Ihrem Bett herunter gefallen

5 Stubenma. (verbirgt ihr Gesicht.) Oh Gott . aber

da hab ich gar nicht gewußt, dass der Herr

Alfred so schlim sein können.

Der jung Herr. Da hab ich sehr viel geseh.

.. das . . und das . . und das .... und . .

10 Stubenm. Aber Herr... Alfre.

Der jung Herr. Kom, kō̄ . . . daher . . so 
HSz3 51

Handschriften und Typoskript

j.,

s)

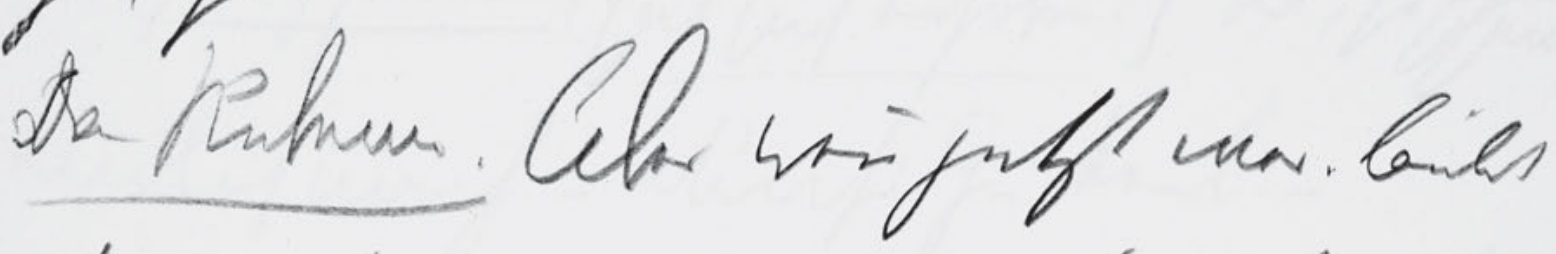

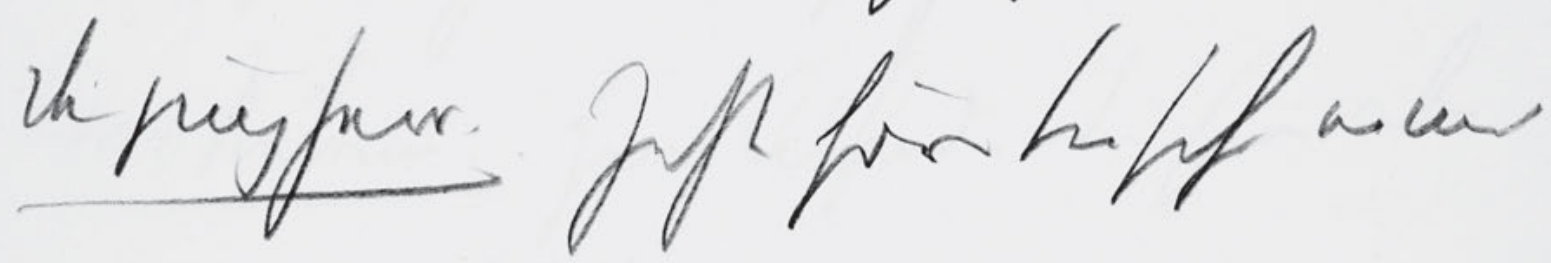

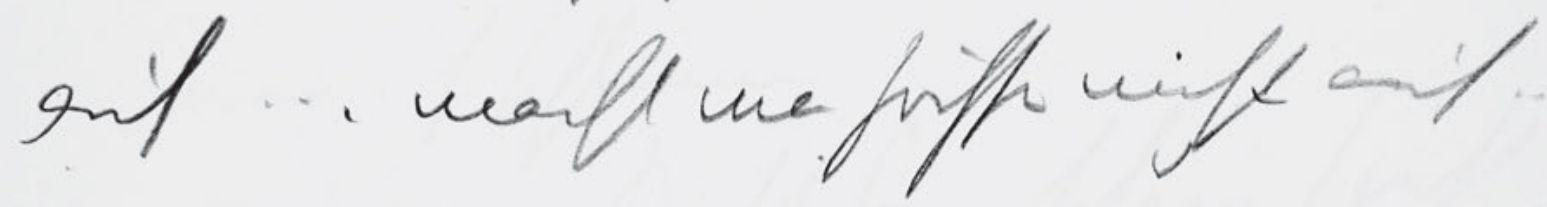

Qt hlingnet

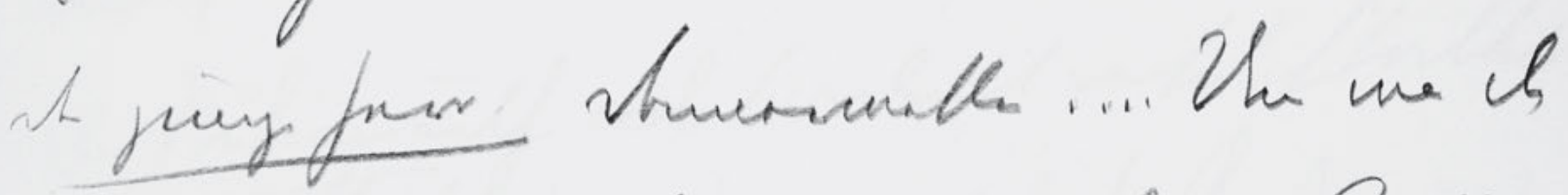

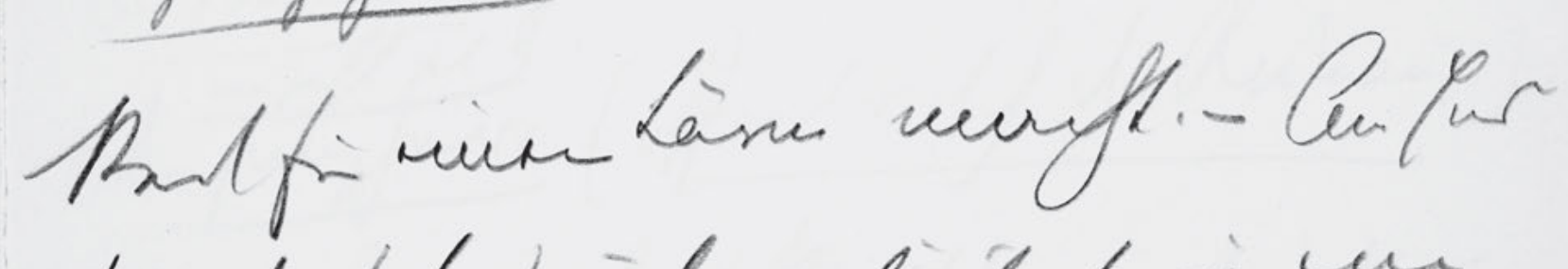

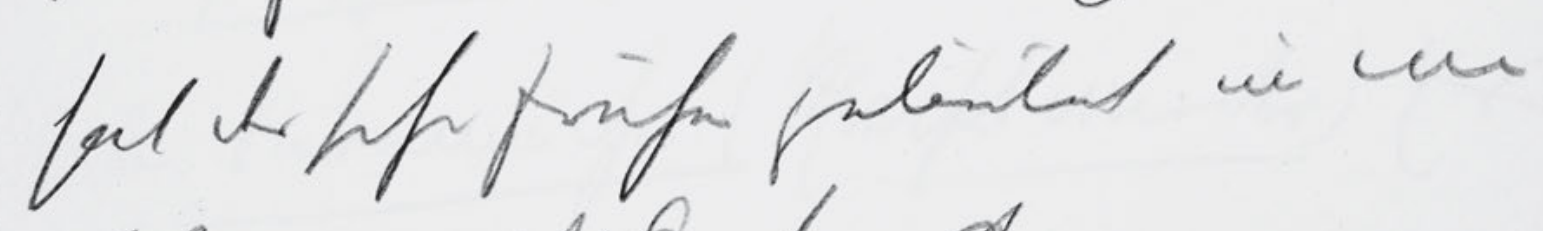

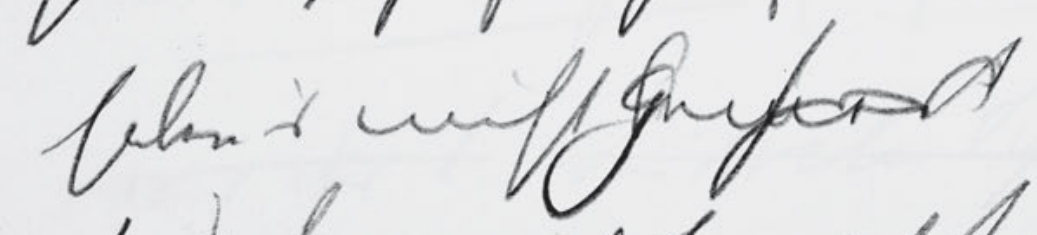
sh thmen. of we wat life antyater.

136 
51

ja, so .....

Das Stubenm. Aber wen̄ jetzt wer . läutet

Der jung Herr. Jetzt hören Sie schon einmal

5 auf ... macht man höchste nicht auf..

Es klingelt . .

Der junge Herr. Donnerwetter .... Und was der

Kerl für einen Lärm macht. - Am End

hat der schon früher geläutet un wir

haben's nicht ${ }^{b} \mathrm{ge}^{\text {merk }}$ hort

Das Stubenm. Oh . . ich hab scho aufpaßt. 
HSz3 52

Handschriften und Typoskript

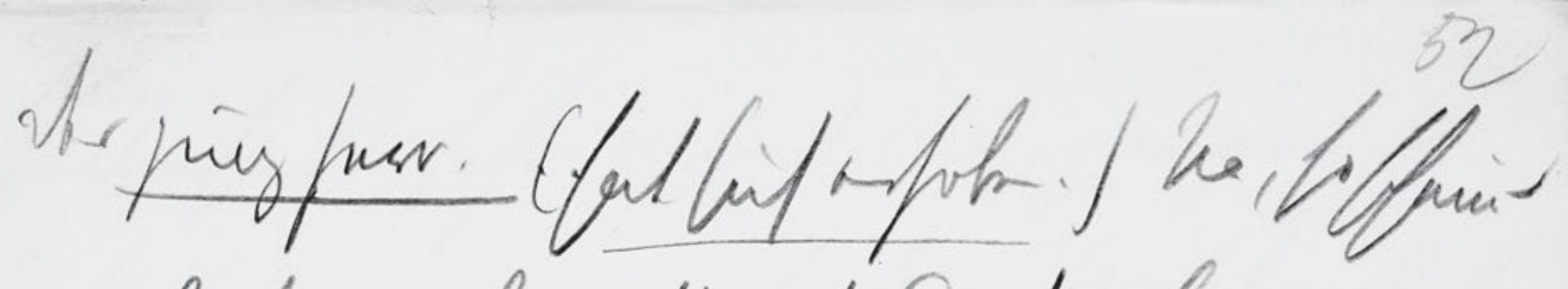

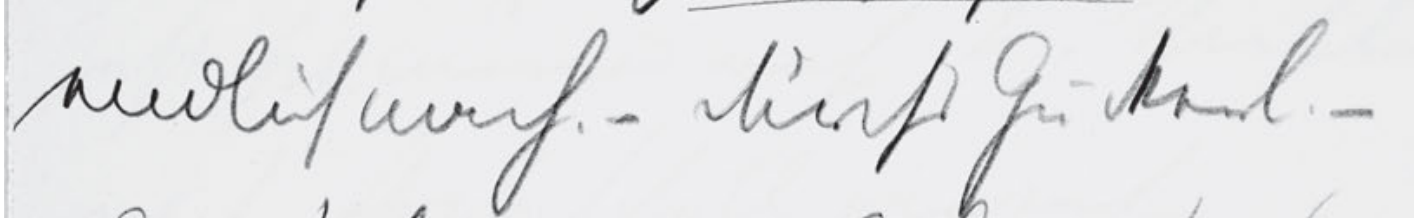

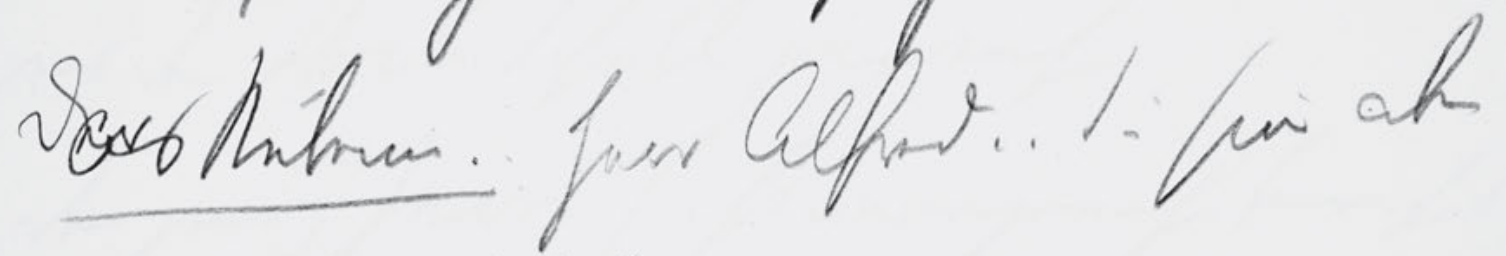
… unis thflimen.

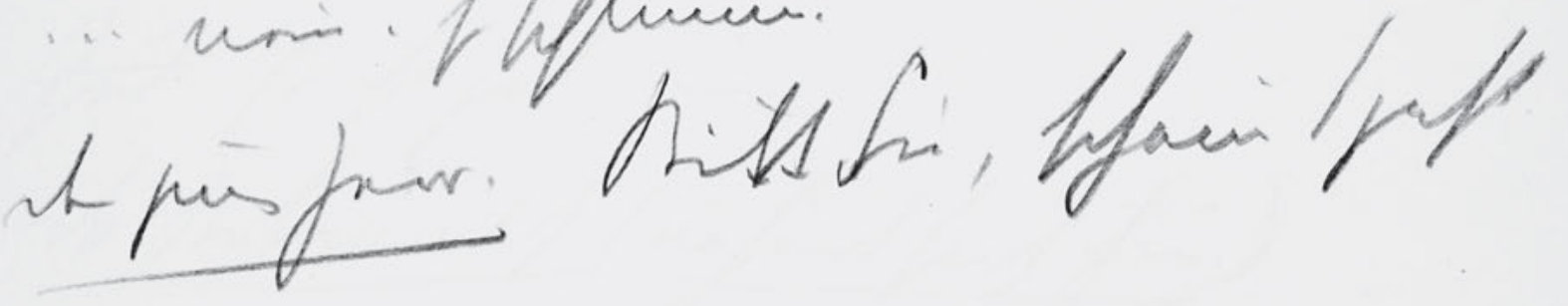
nenf....

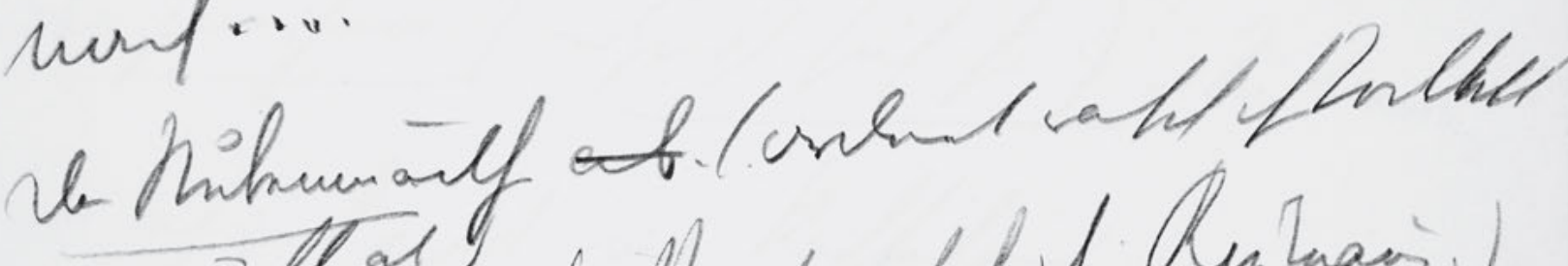

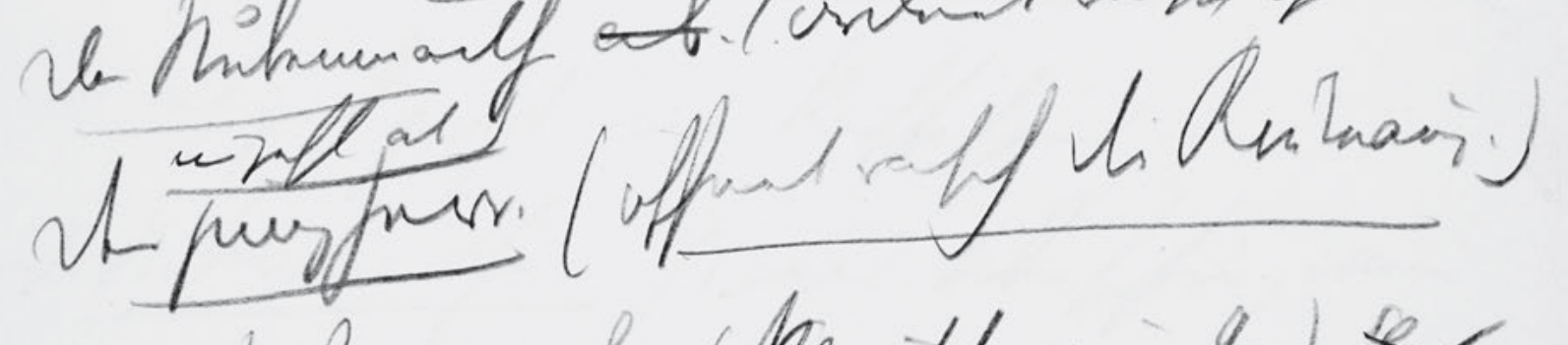

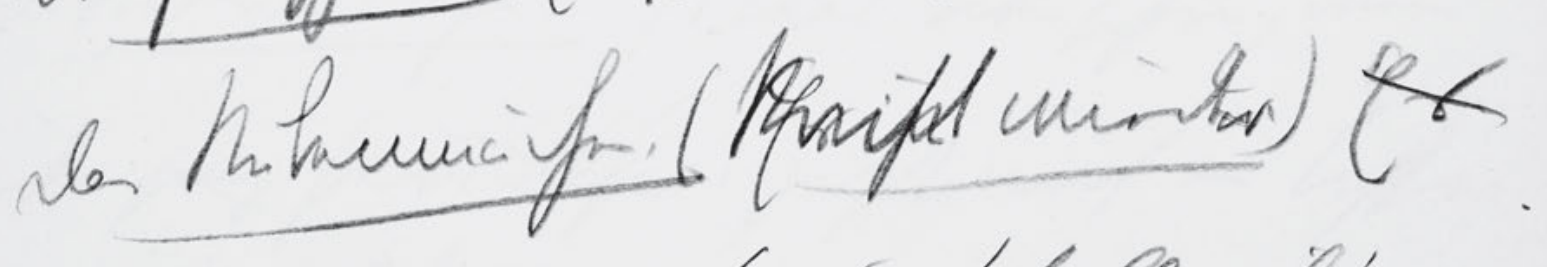


52

Der junge Herr. ${ }^{*}$ (hat sich erhoben.) Na, so schaun S endlich nach. - Durchs Guckerl. $\mathrm{D}^{\mathrm{er}}$ as Stubenm. . Herr Alfred .. Sie sind aber

5 ... nein . so schlimm.

Der jung Herr. Bitt Sie, schaun S jetzt nach .....

Das Stubenmädchen ab. *ordnet rasch ihre Toil ${ }^{\mathrm{l} e t t}$ un geht $\mathrm{ab}$ )

Der jung Herr. (öffnet rasch die Rouleaux.)

10 Das Stubenmä hen. ( ${ }^{\text {Esist }}{ }^{\mathrm{kom}} \overline{\mathrm{m}}$ wieder) Es

war der $D$ der Doctor Schüller ist's gewesen.

- Aber grad ist er Niemand Es ist Der ist 
gutnfals lifu mind ungengen..

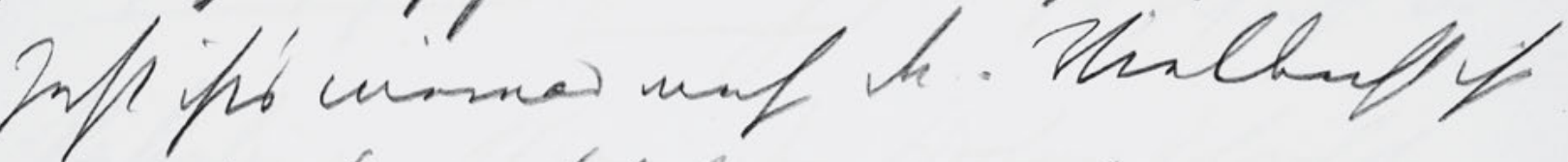
mosh boch Inte jumat st mis furs fineryouftrofs, fint. Ir if pit. -

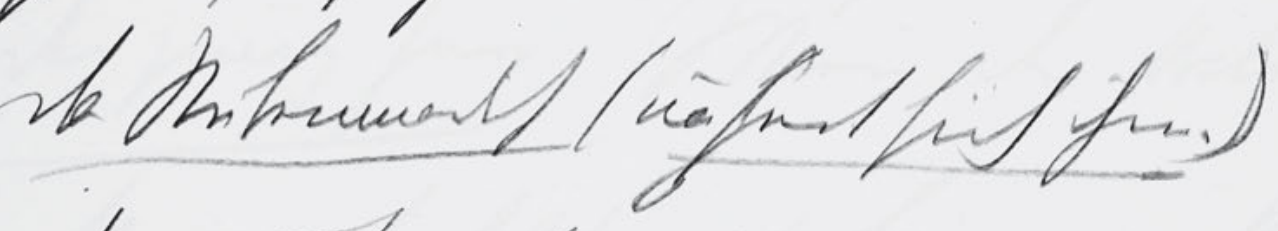

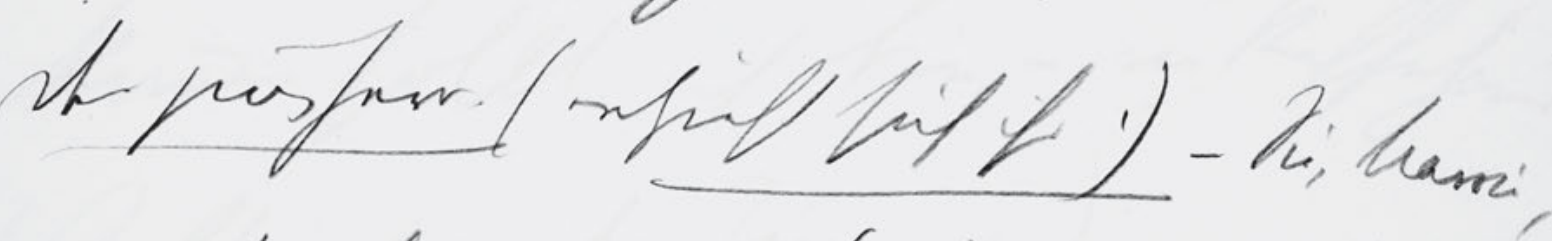
- ifgefert mir kefferis...

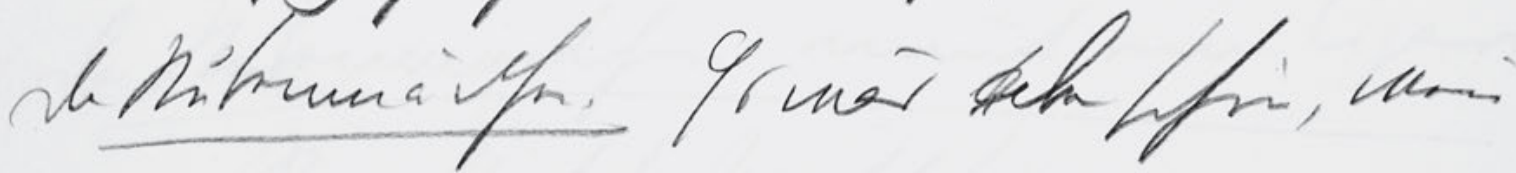

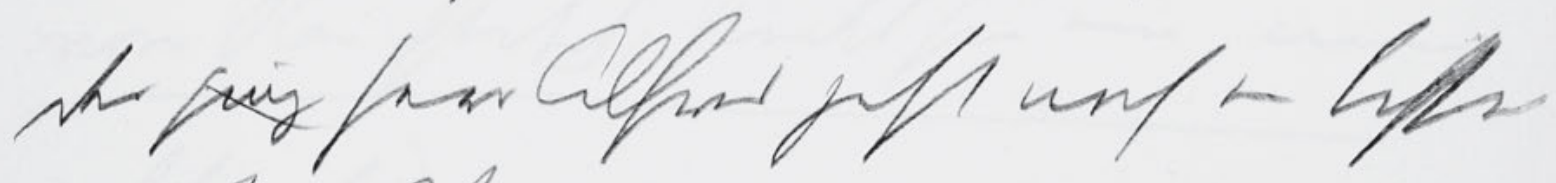
raf alsuch. 
53

jedenfalls schon wiede weggangen. -

Jetzt ist's niemand mehr da. - Vielleicht ist

es der Docto Schüller gewesen

$5 \quad$ Der jung Herr. (ist unangeneh $m$ berührt)

Gut. Es ist gut. -

Das Stubenmadch (nähert sich ihm.)

Der jung Herr. (entzieht sich ihr.) - Sie, Marie,

- ich geh jetzt ins Kaffehaus ... .

10 Das Stubenmädchen. Es wär ${ }^{[?]}$ aber schön, wen̄

der junge Herr Alfred jetzt noch ein bissel

zu Haus bleiben. 
HSz3 54

Handschriften und Typoskript

thr

nuy/urs

$5 y$

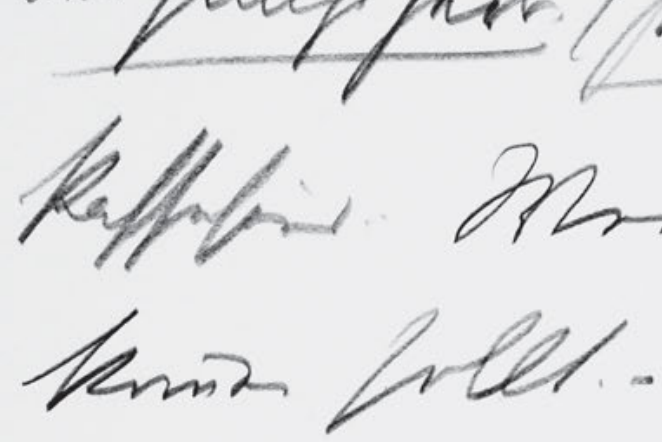

mong. Afreffe a sthmakf.

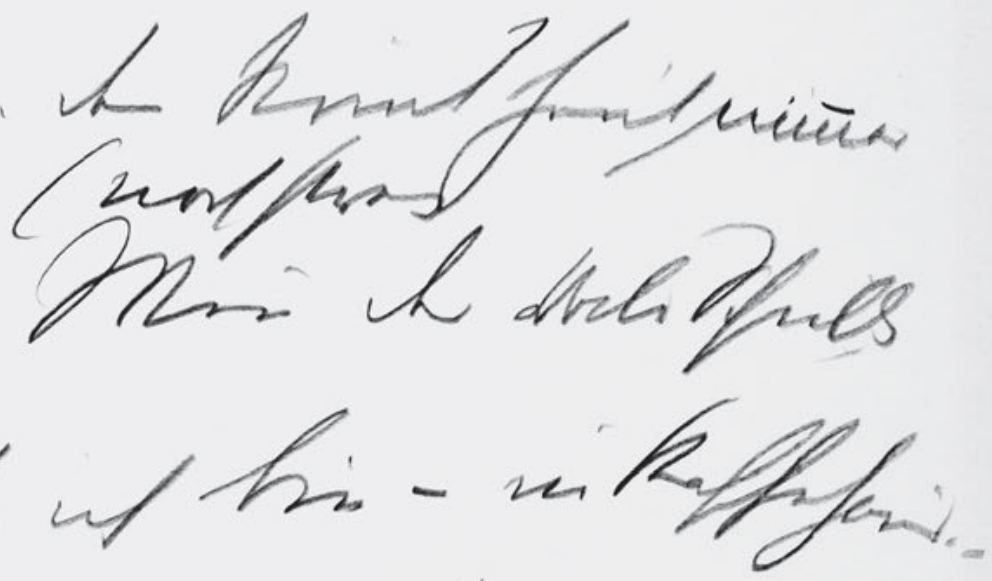

fimir folet.

A hoter thill.

1 - 1

(Afll in renth gimunt)

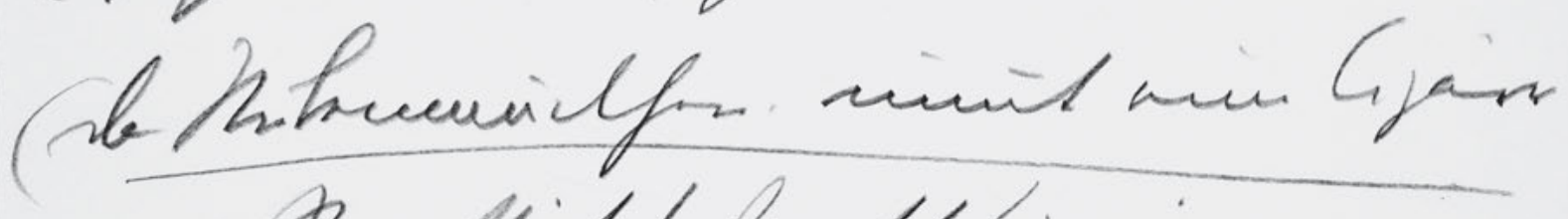

som karifitst funtifin wi un

safl at:

142 
Der junge Herr. (streng) .. Ich geh jetzt in

Kaffehaus . W Weñ der Doctor Schüller

komen sollt. -

Da Stubenmädchen . Der kō̄t heut nimer

(noch streng

Der jung Herr. Weñ der Docto Schüller

komen sollt, ich bin - im Kaffehaus. -

(Geht in s andre Zimmer.)

(Das Stubenmädchen. nī̄t eine Cigarr

vom Rauchtisch, steckt sie ein und

geht $\mathrm{ab}$.) 
HSz4 55

Handschriften und Typoskript

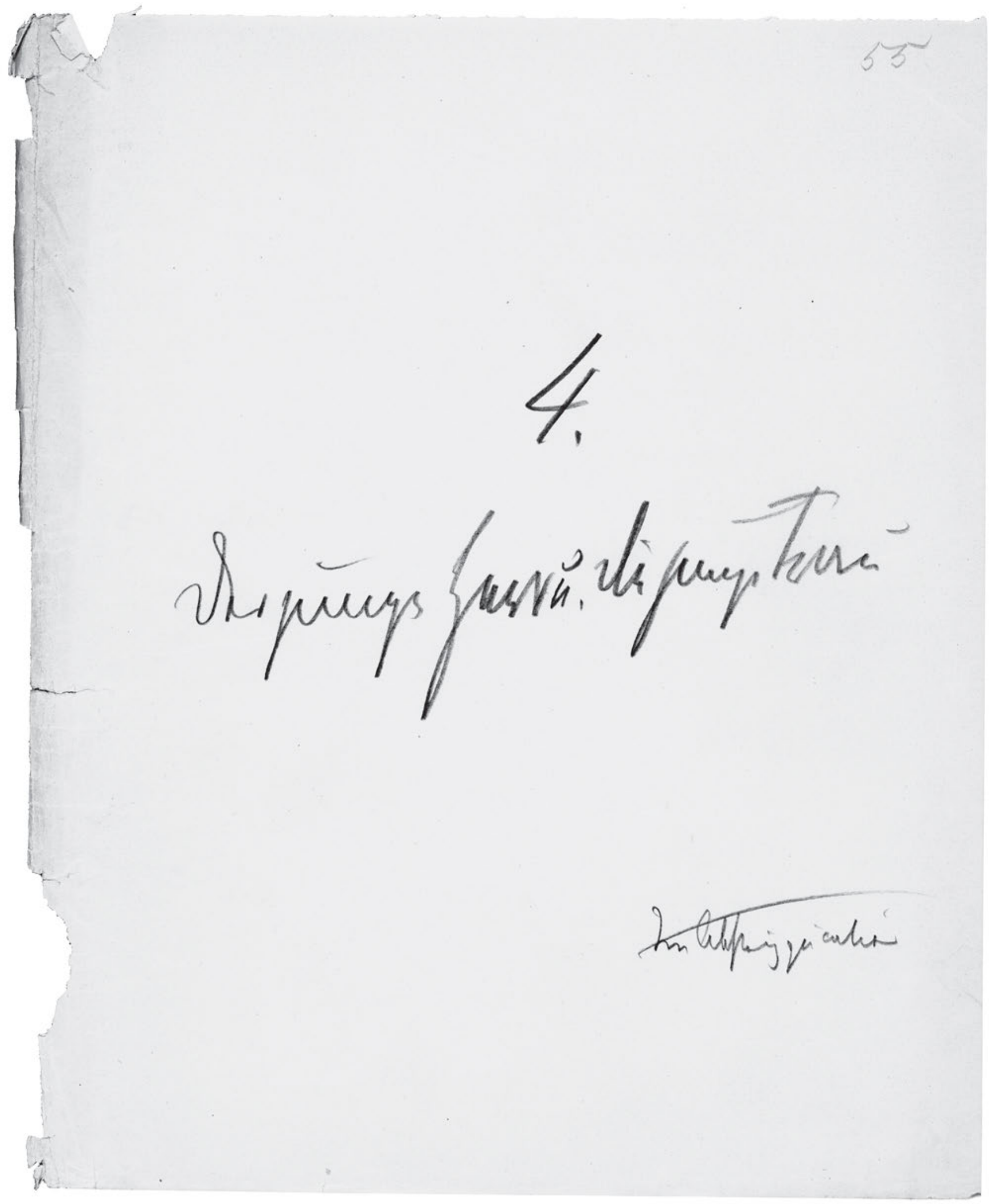

144 
4.

Der junge Herr u. die junge Frau

Im Absteigquartier 
HSz4 56

Handschriften und Typoskript

$2 t / 11-$

,$-2 \times / 4$

Qlouritg

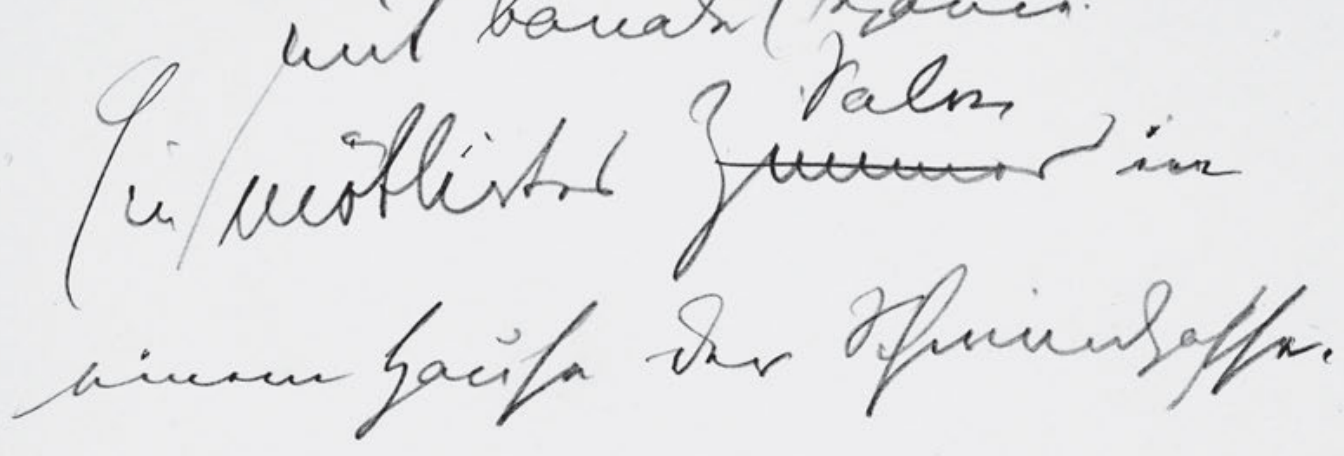

wit banas (Sawn.

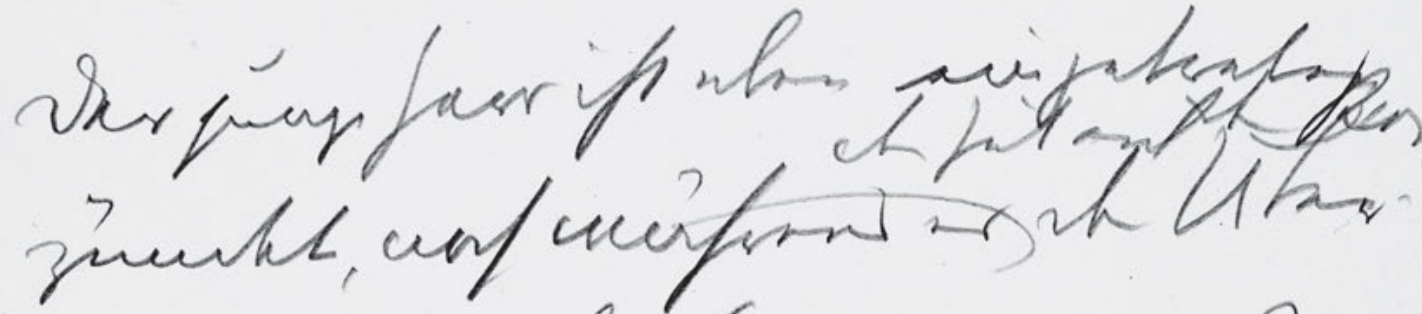

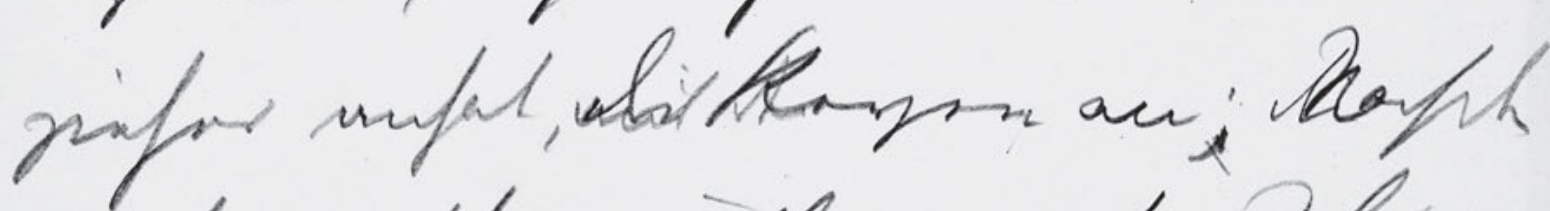

ar bergutas,

offerint or $h$

mins Shbis

yous Nobry

paror itr

julow ya

intor le Raryint

bir mi mis

56 
56

27/11 u $28 / 11$

Abend.-

mit banaler Elegance.

Ein/möblirtes Zimmer in

einem Hause der Schwindgasse.

Der junge Herr ist eben eingetreten,

den Hut auf dem Kopf

zündet, noch während er)den Über-

zieher anhat, ${ }^{\text {mit }}$ die ${ }^{\text {den }}$ Kerzen an;. ${ }^{\text {die Nachdem }}$

er das gethan, öffnet er die Thür

zum Nebenzimmer und wirft

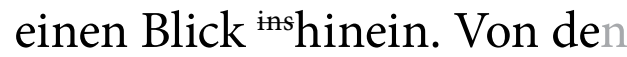

Kerzen des Salons geht der Lichtschein

inüber das Parquet bis zu einem 
HSz4 57

Handschriften und Typoskript

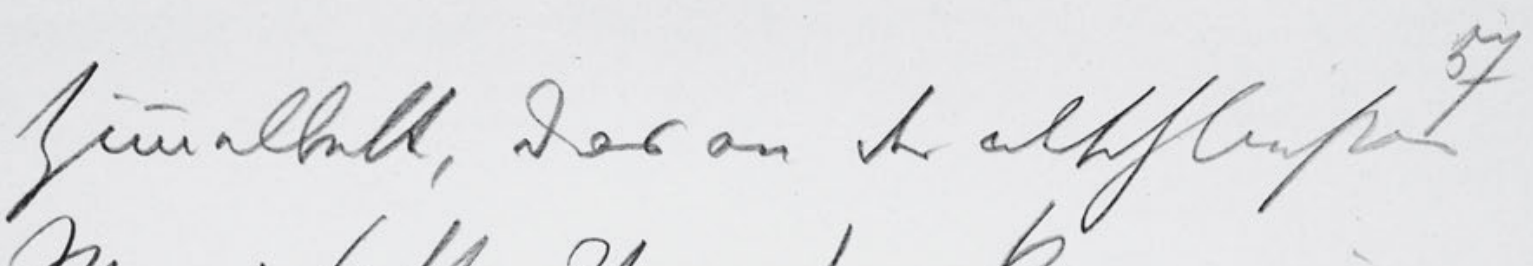
Hent fuft. Hos shem Kawnin,

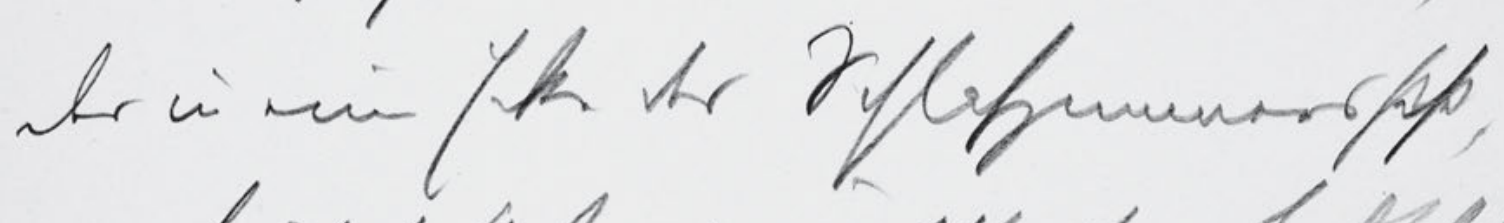

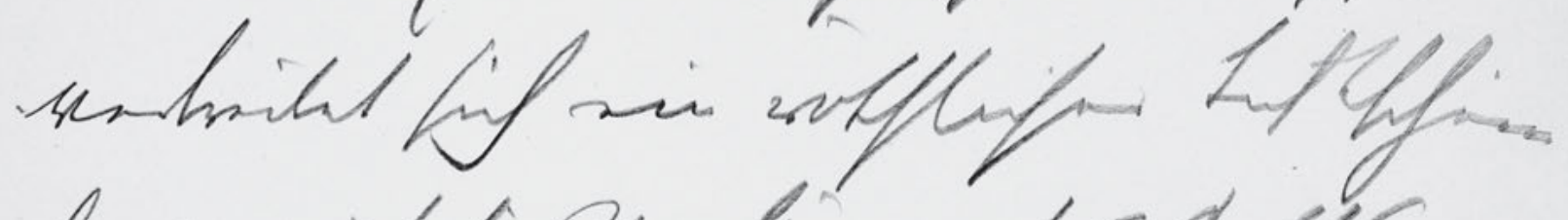
bor with Horfings to chlthi-

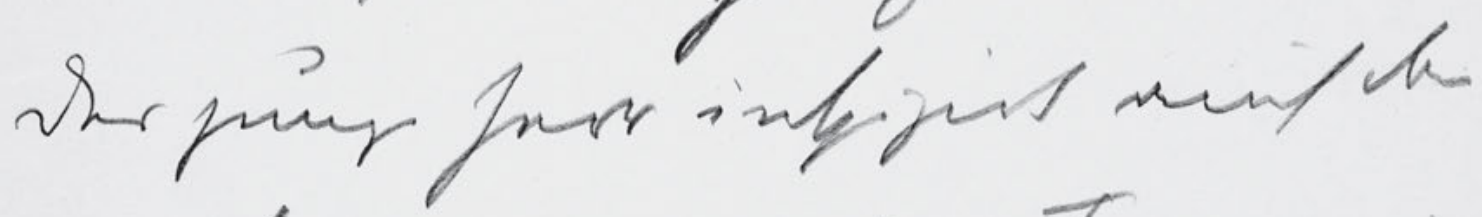

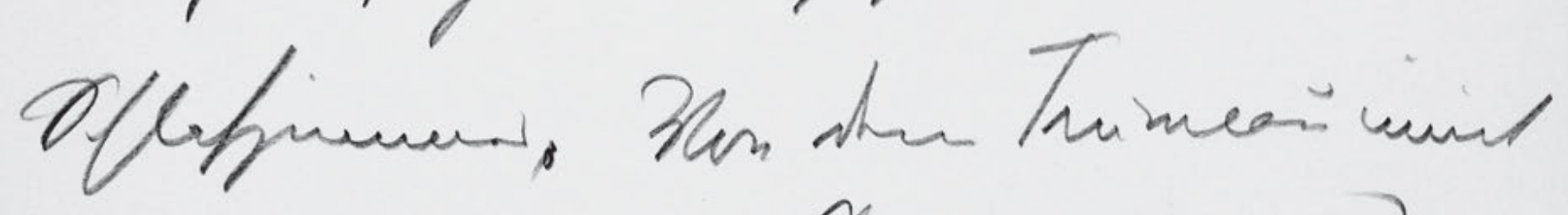

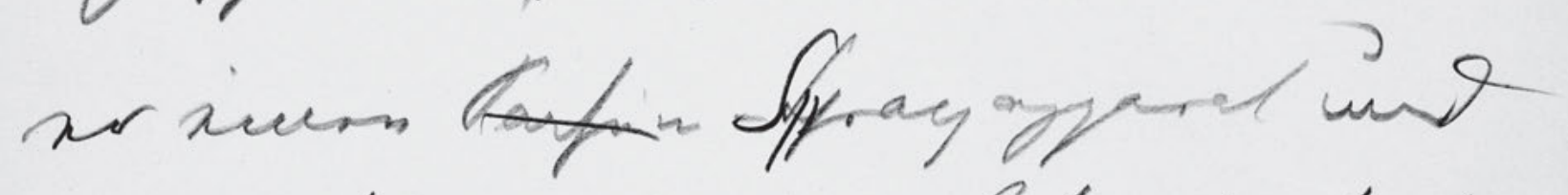

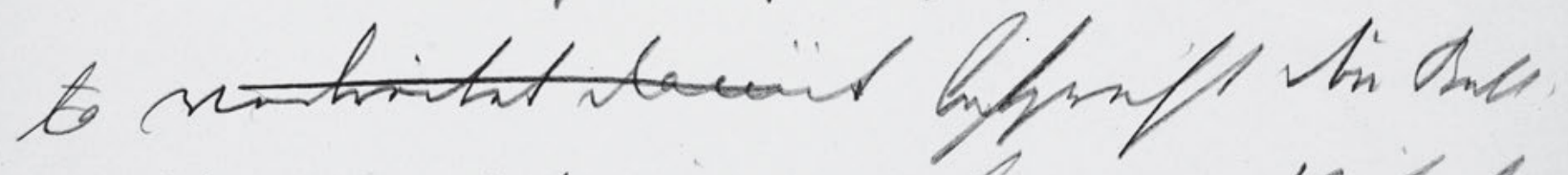

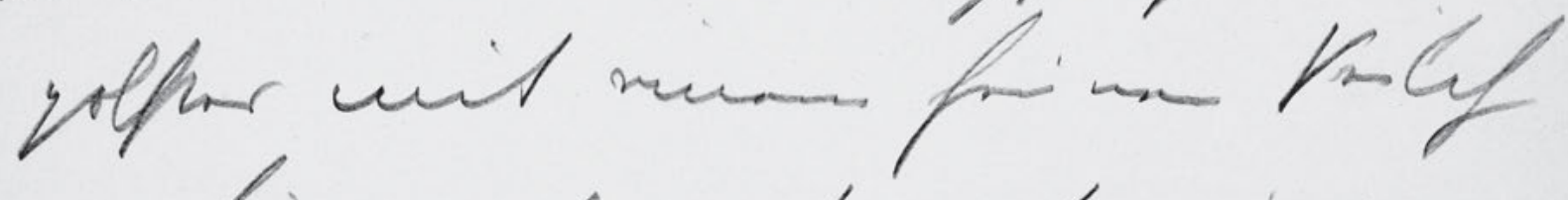
vafine, vañ

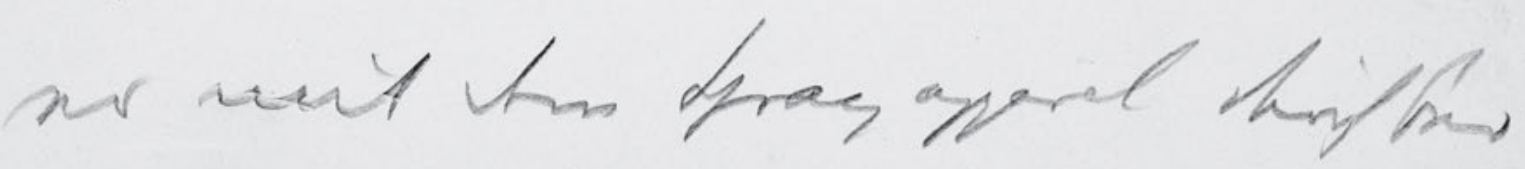

148 
Himelbett, das an der abschließen

Wand steht. Von dem Kamin, der in einer Ecke des Schlafzimmers ${ }^{\text {stel }}$ ist,

5 verbreitet sich ein röthlicher Lichtschein

bis auf die Vorhänge des Betts. -

Der junge Herr inspizirt auch das

Schlafzimmer'. Von dem Trumeau nim̄t

er einen Parfum ${ }^{-\varsigma}$ Sprayapparat und

10 'la? verbreitet damit besprüht die Bett-

polster mit einem feinen Veilchen

parfum. Dañ ?f? parfumirt geh

er mit dem Sprayapparat durch beid 
HSz4 58

Handschriften und Typoskript

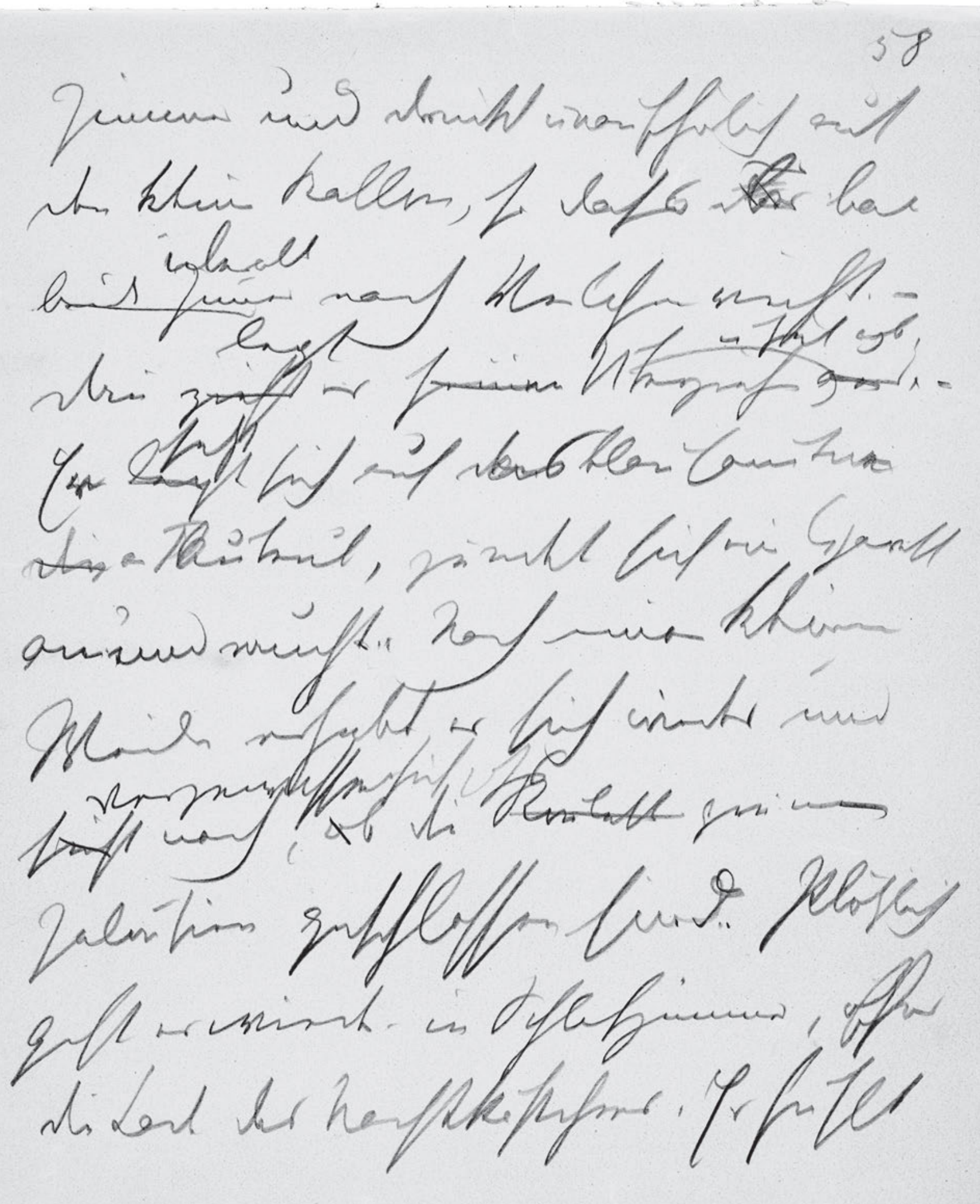

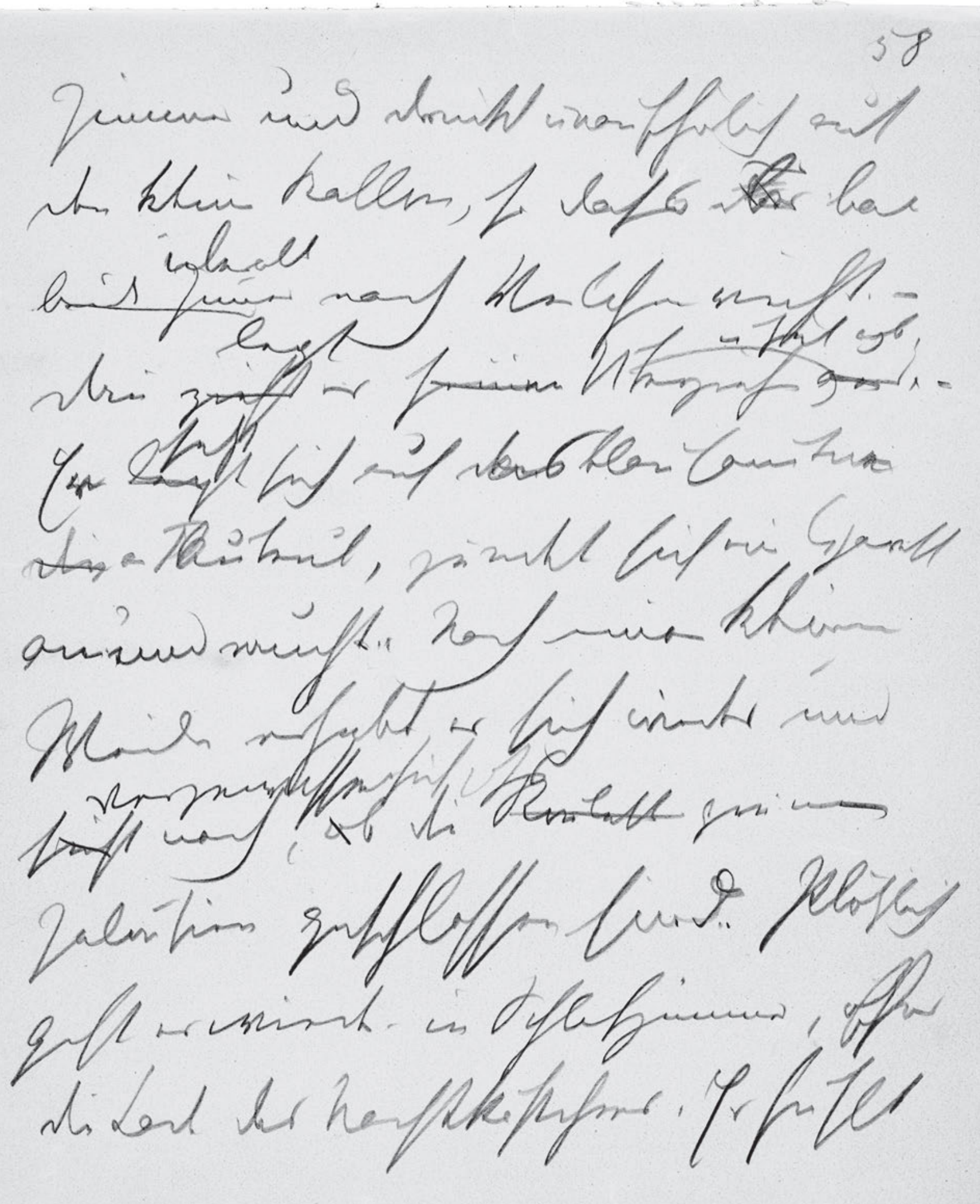

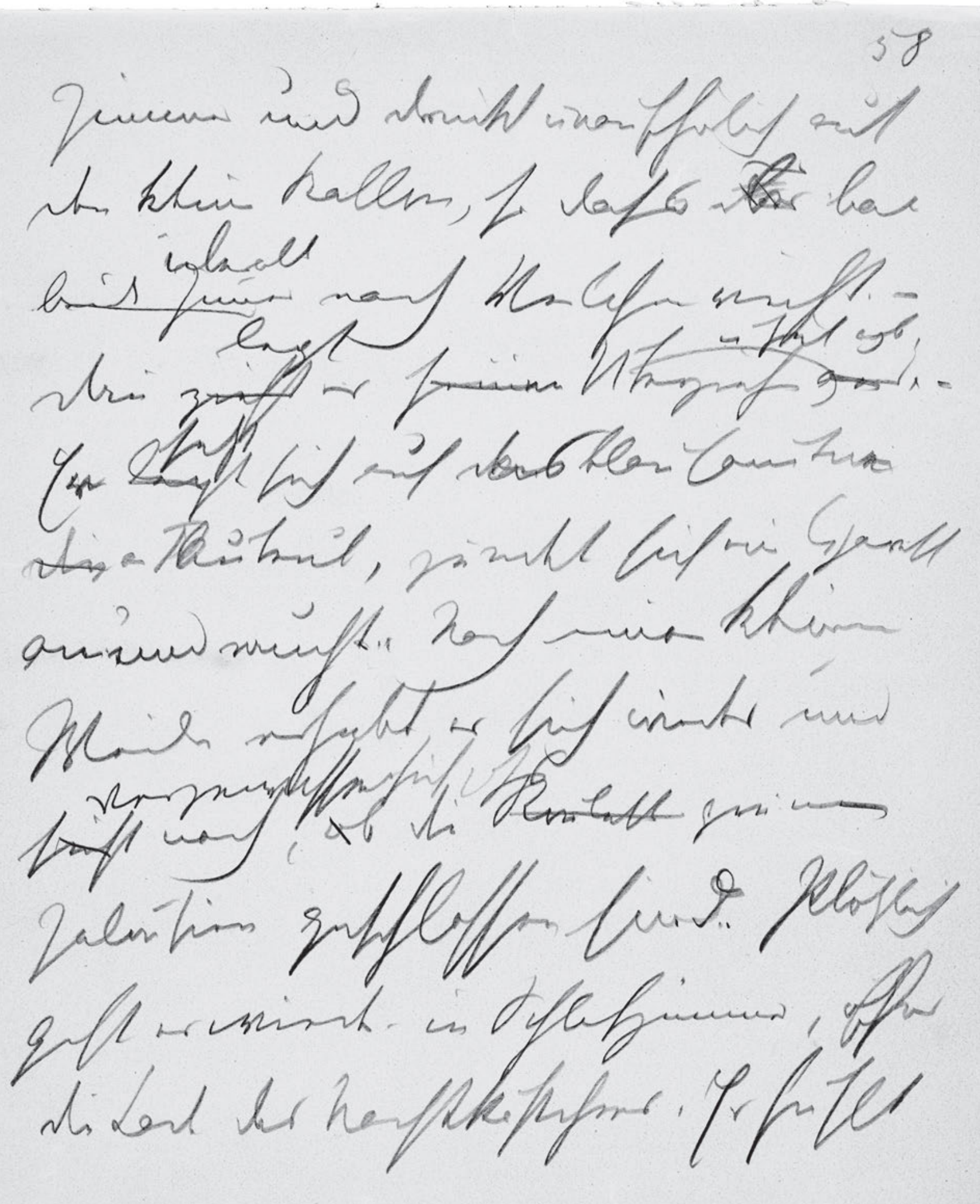

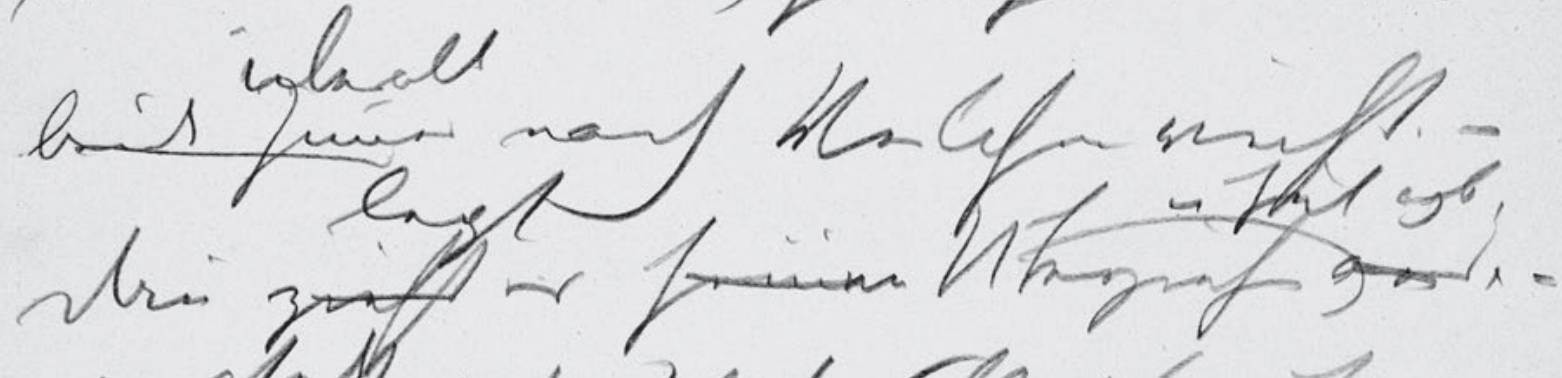

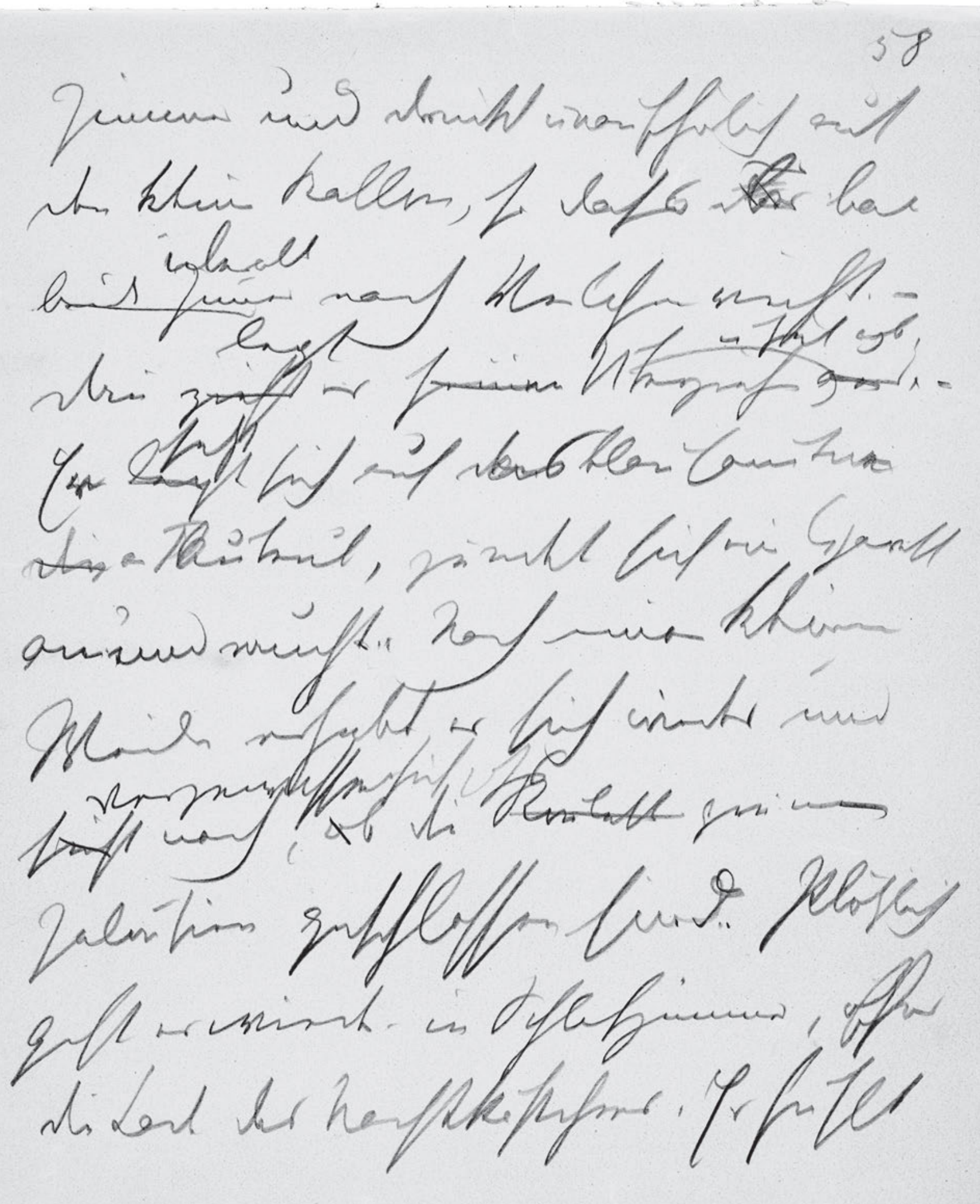

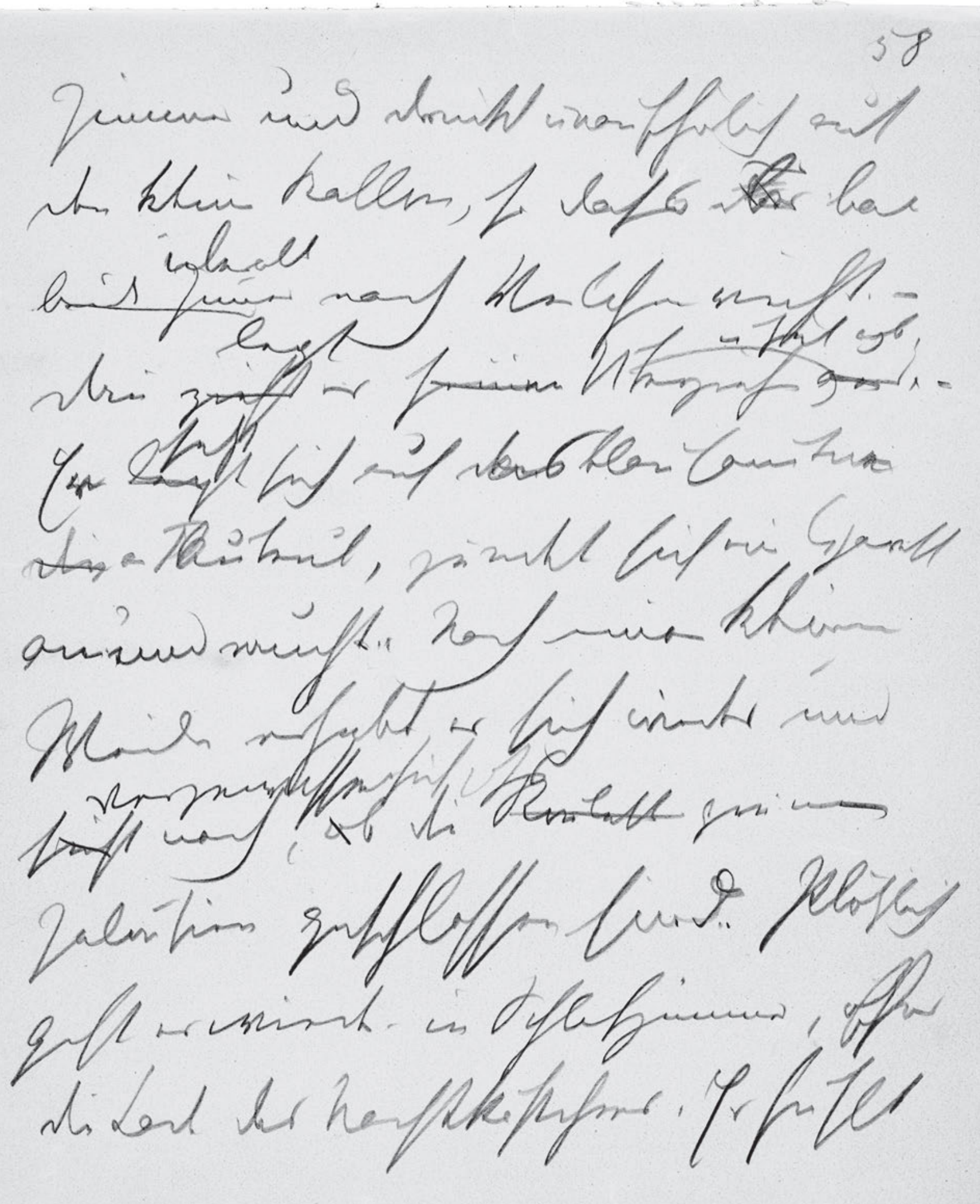

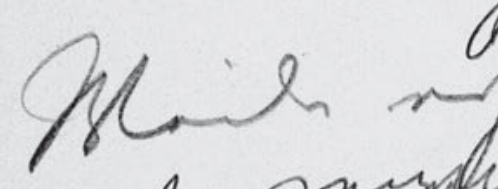


58

Zimmer und drückt unaufhörlich auf

den kleinen Ballon, so dass ${ }^{\text {dat }}$ bis bal

überall

beid Zim̄er nach Veilchen riecht. -

legt

u Hut ab,

Dā̄ zieht er seinen Überzieher aus. setzt

Er legt sich auf $d^{\text {en }}$ as blausamten ${ }^{\text {en }} e$

Divan F!? auteul, zündet sich eine Cigarett

an. und raucht .. Nach einer kleinen

Weile erhebt er sich wieder und vergewissert sich dss

Jalousien geschlossen sind. . Plötzlich

geht er wieder - in Schlafzimmer, offnet

die Lade des Nachtkästchens. Er fühlt 
HSz4 59

Handschriften und Typoskript

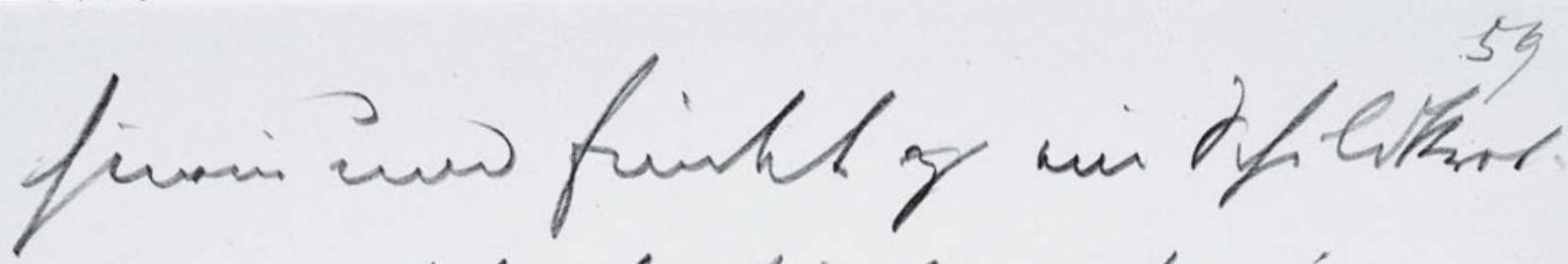
farmushl. Er finft nay min

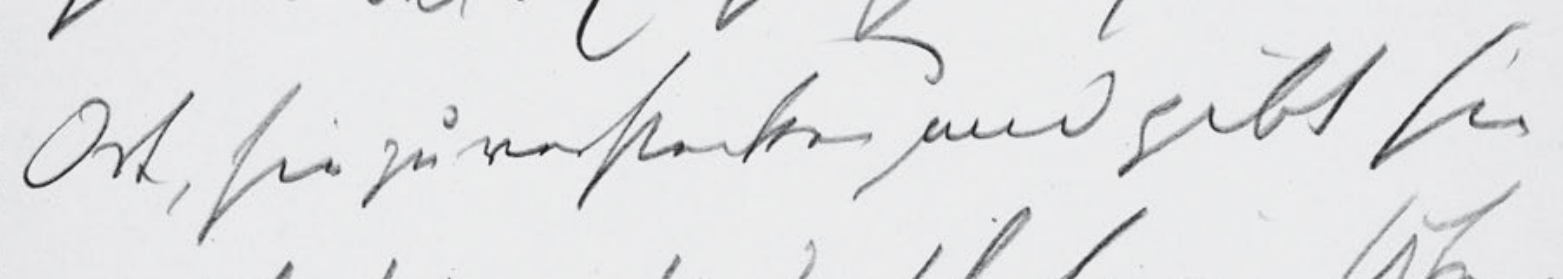
suilief is di beff frum the

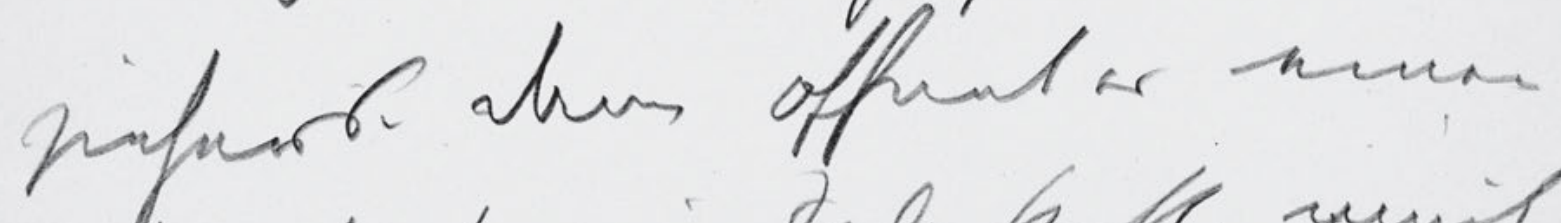

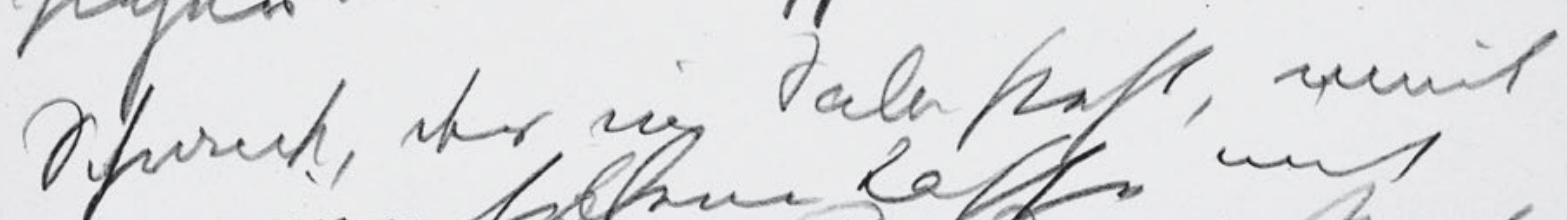

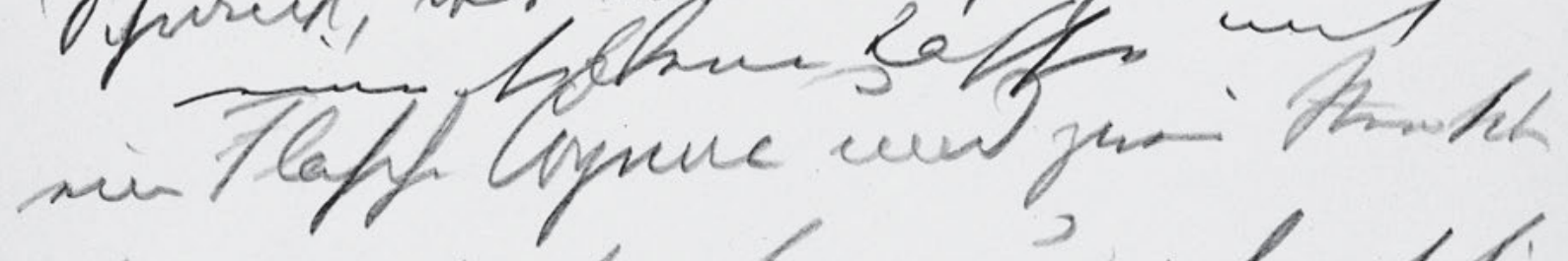

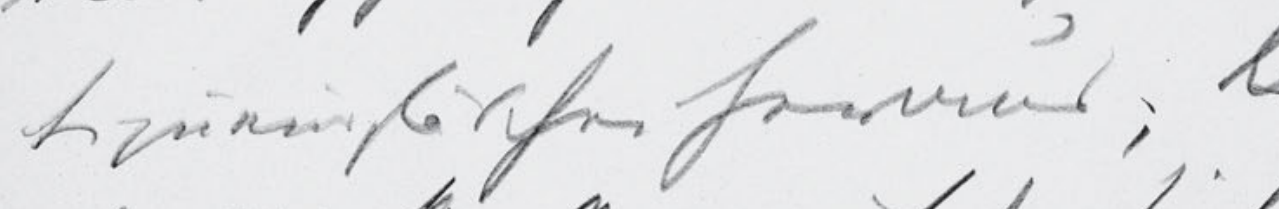
palel the aler with

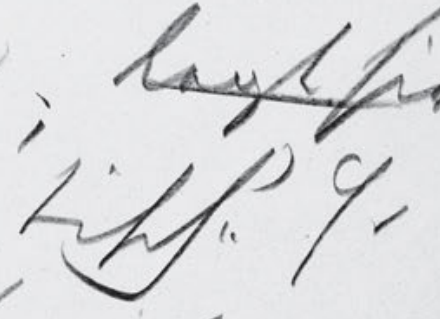

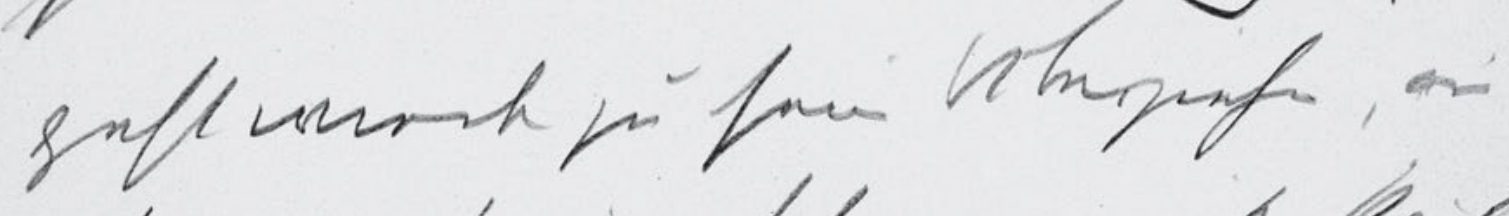

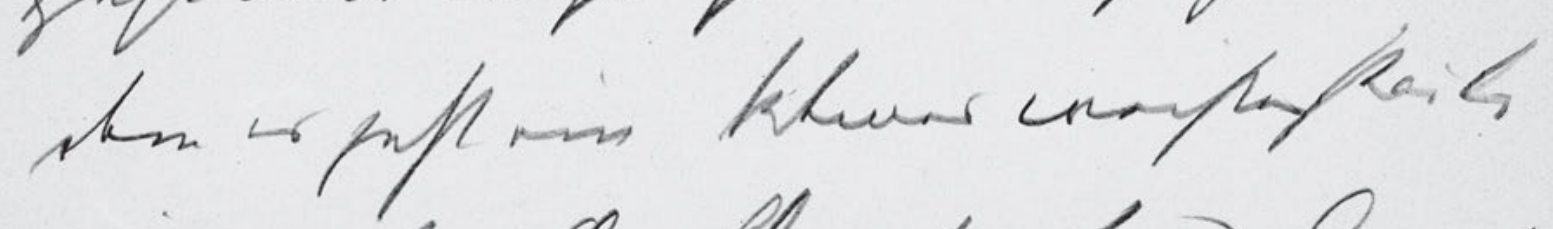

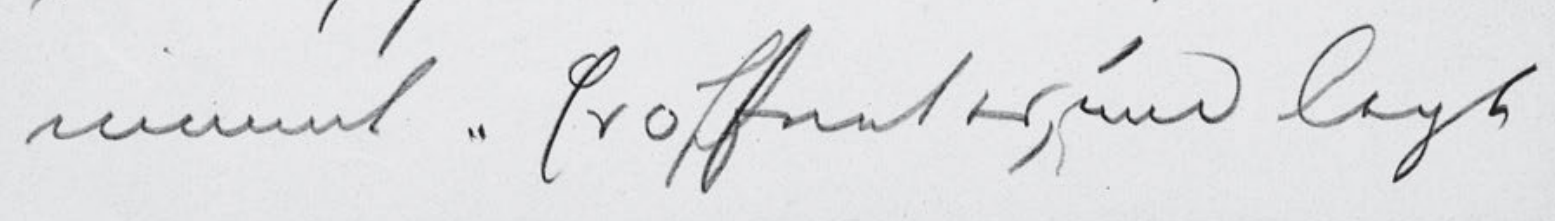

152 
hinein und findet ' $z$ ? eine Schildkrothaarnadel. . Er sucht nach einem Ort, sie zu verstecken und gibt sie endlich in die Tasche seines Überziehers, dann offnet er einen

Schrank, der im Salon steht, nī̄t eine silberne Tasse mit eine Flasche Cognac und zwei 'Sten? klein

Liqueurgläschen heraus; legt sie

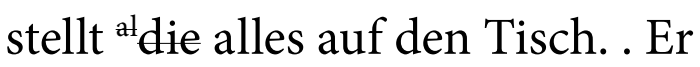
geht wieder zu sein Uberzieher, aus dem er jetzt ein kleines weißes Päck nimmt . . Er öffnet es, und legt 
HSz4 60

Handschriften und Typoskript

abjuin Gover igfll wert gi

60

Pfrant, wint 2 khen tull w

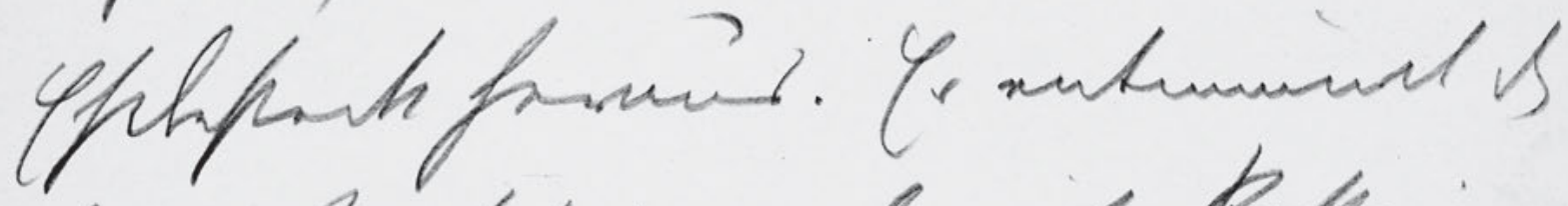

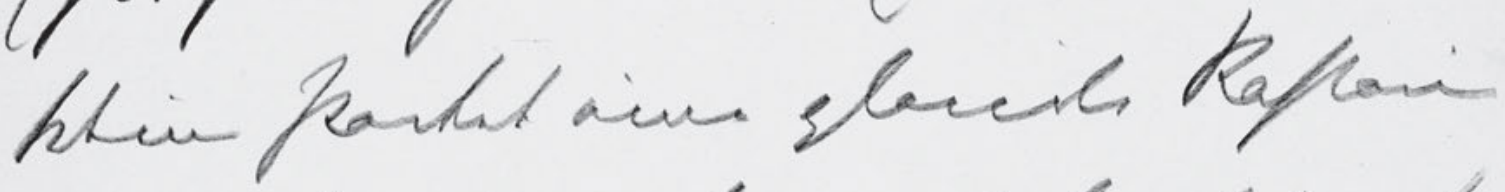
min ipt in dan mi lar Cosnar min ung trunts. sub and, sheen frift on/fain

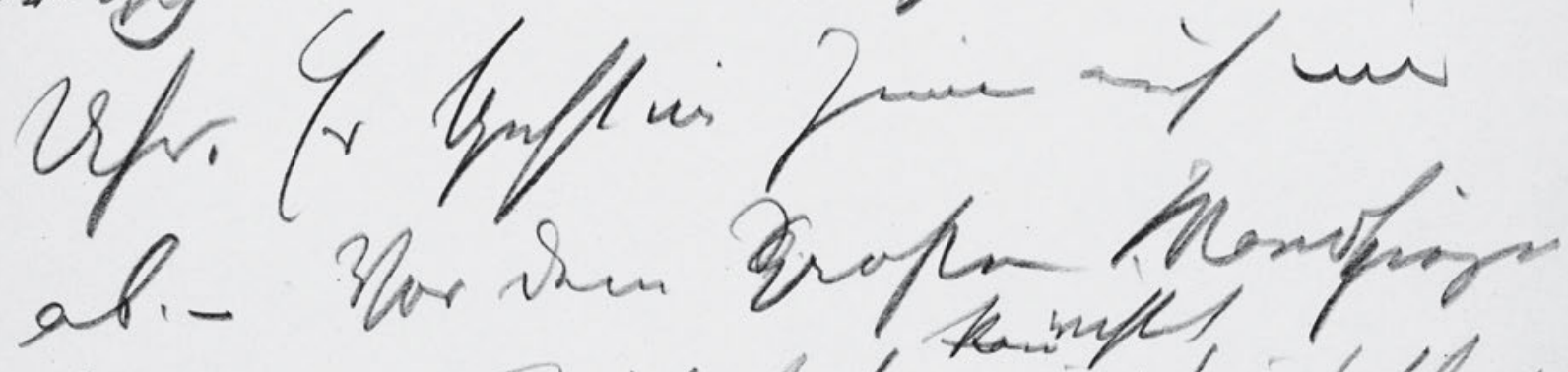

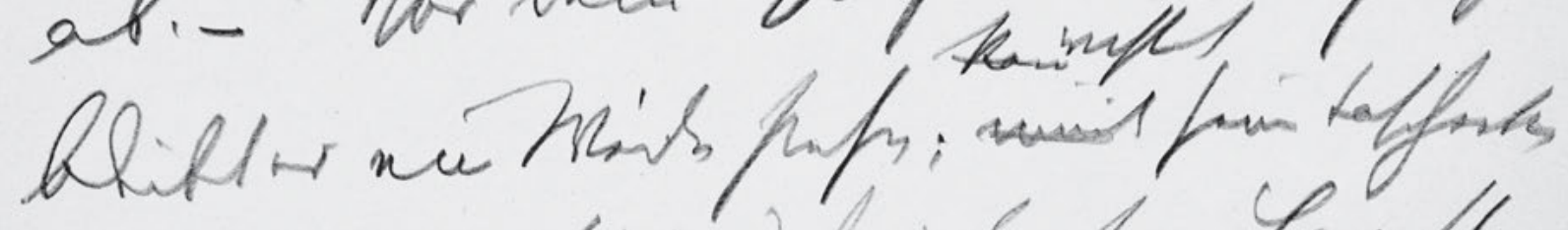

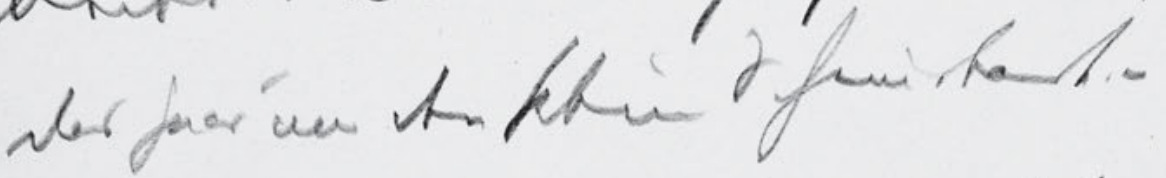

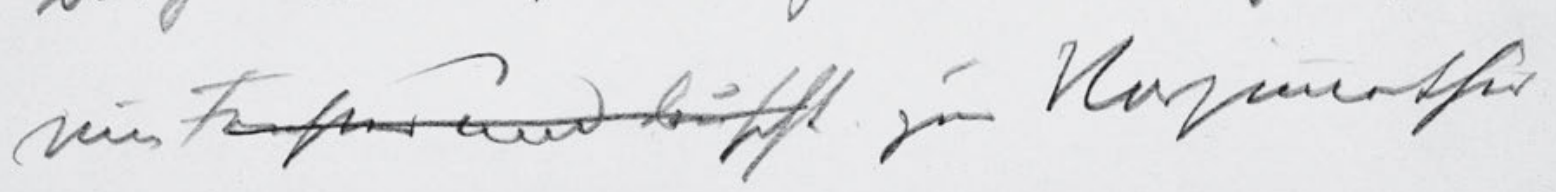

154 
60

es zum Cognac; geht wieder zum

Schrank, nī̄t 2 kleine Teller und

Eßbesteck heraus. Er entnimmt dem

$5 \quad$ kleinen Packet eine glacirte Kastanie

und ißt sie. Dann schenkt er sich

ein Glas Cognac ein und trinkt es

rasch aus. Dann sieht er auf seine

Uhr. Er [?]geht im Zimer auf und

ab. - Vor dem sgroßen Wandspiegel

'kam? richtet

bleibt er eine Weile stehn; nimt seinen Taschen?kamm?

das Haar und den kleinen Schnurrbart. - Er geht

zum Fenster und lauscht. zur Vorzimerthür 
HSz4 61

Handschriften und Typoskript

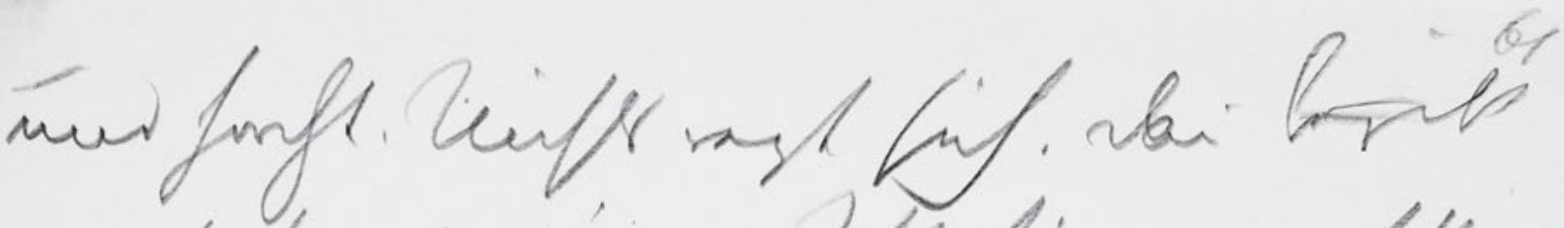

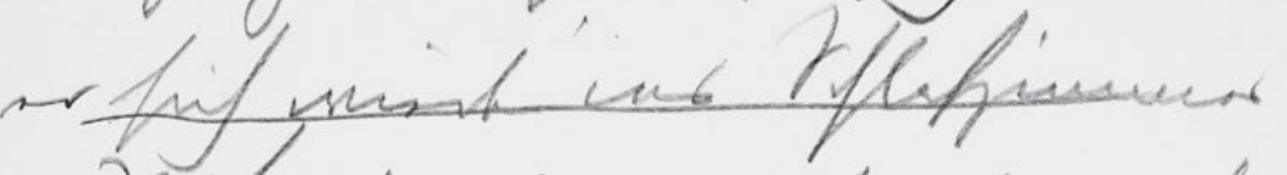

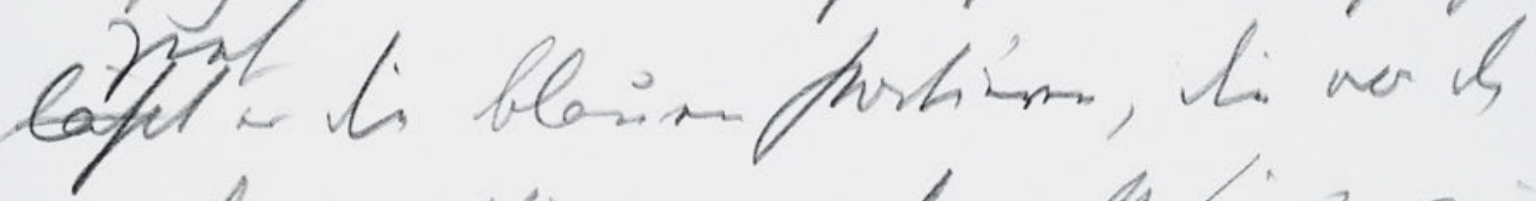

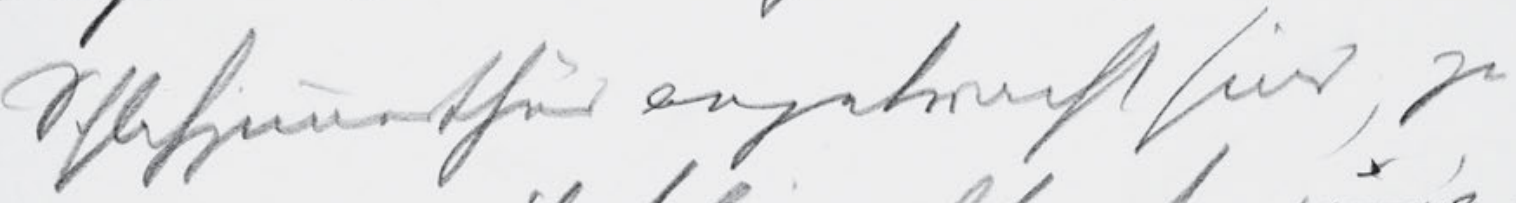
Lamum Yokhiyall. sh juigen

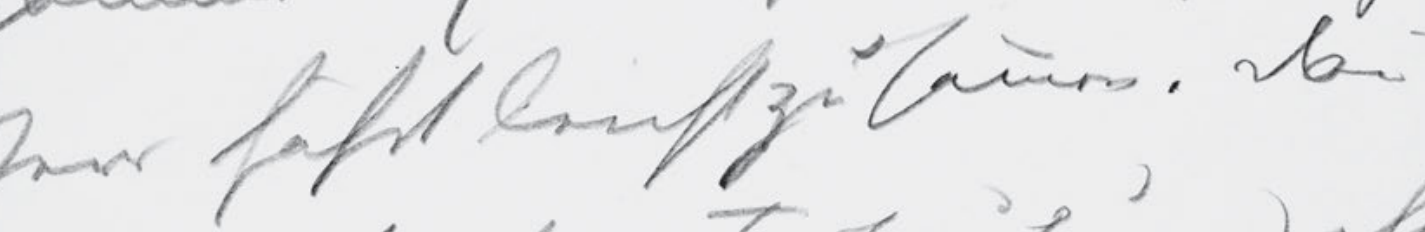

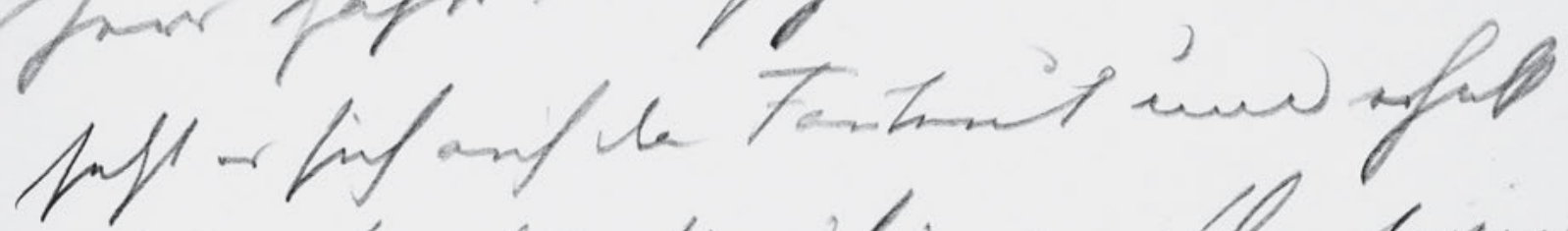

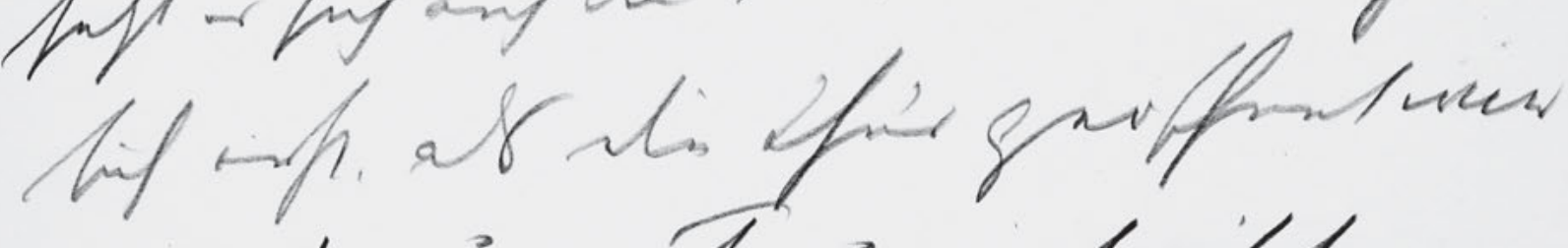

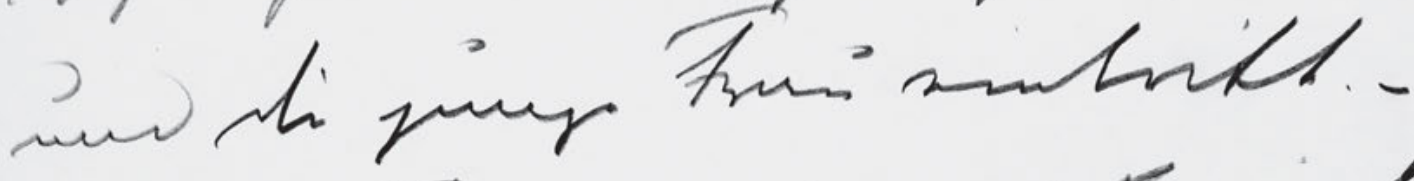

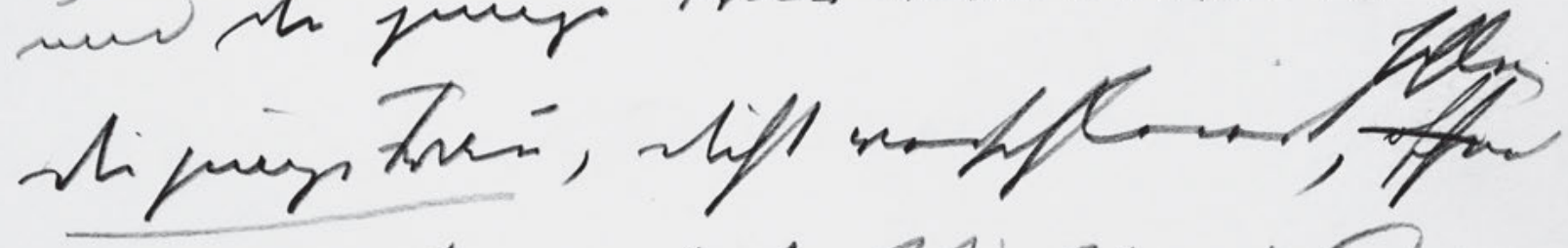

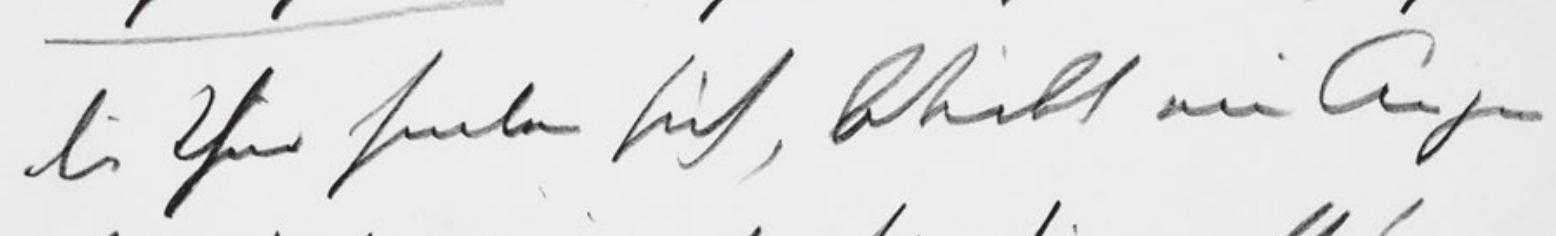

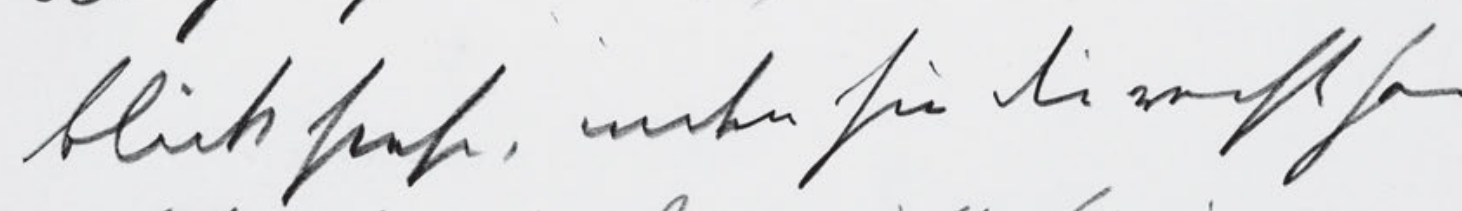

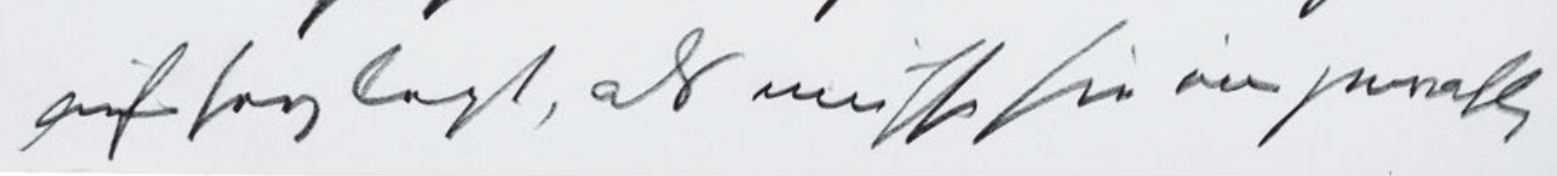

156 
61

und horcht. Nichts regt sich. Dan̄ begibt er sich wieder ins Schlafzimmer schließt zieht

läßt er die blauen Portiéren, die vor der

5 Schlafzī̄erthür angebracht sind, zu-

sammen. Es klingelt. Der junge

Herr fährt leicht zusā̄en. Dā̄

setzt er sich auf das Fauteul und erhebt

sich erst, als die Thür geoffnet wird

10

und die junge Frau eintritt. -

schlie

Die junge Frau, dicht verschleiert, offnet

die Thür hinter sich, bleibt einen Augen

blick stehen, indem sie die rechte Hand

aufs Herz legt, als müsste sie eine gewaltig 
HSz4 62

Handschriften und Typoskript

Lrsys hurifums,

62

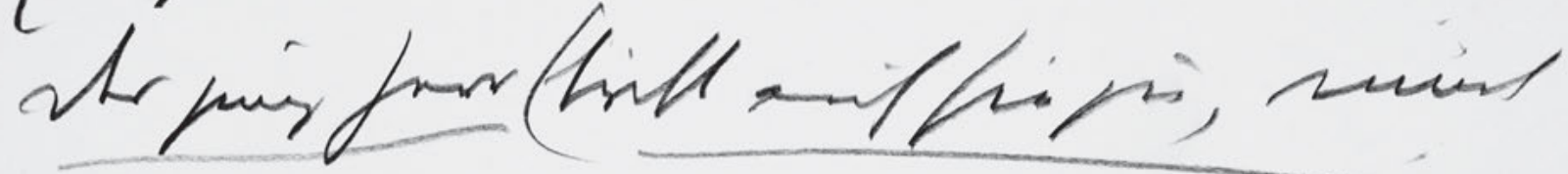

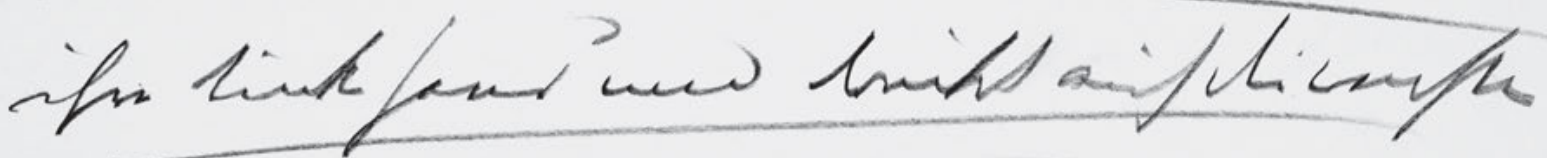

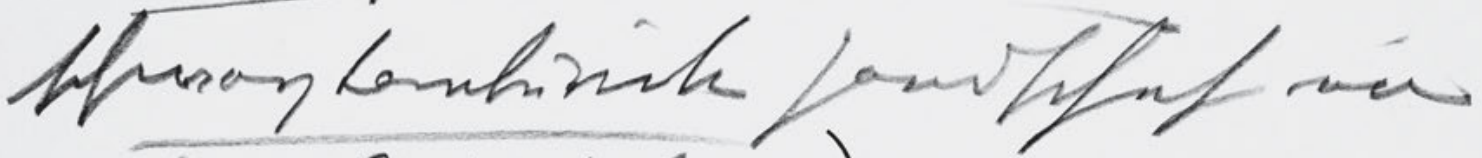

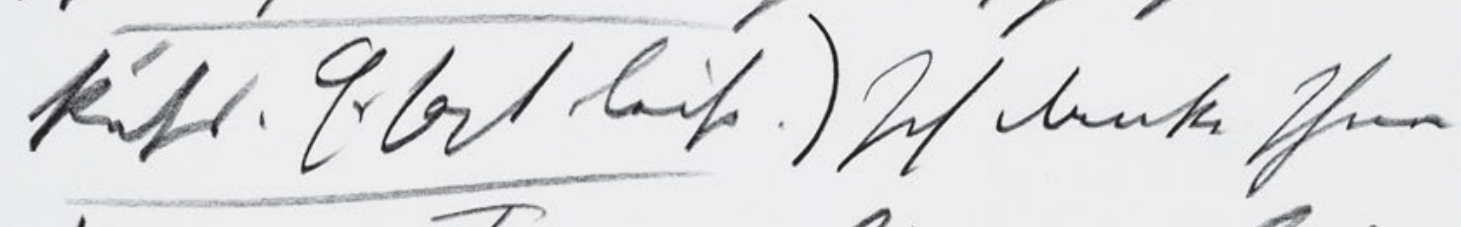

diping Ami:

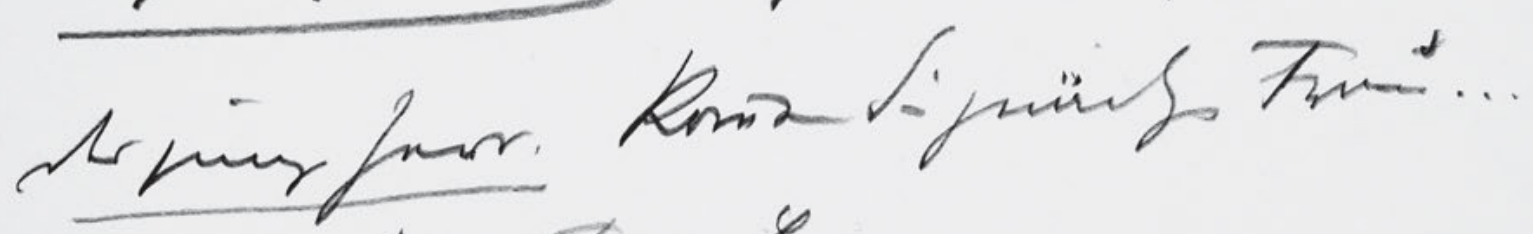

knat Jos, Froñ Yumun..

Ligin ford. Laffer hi mil wry min

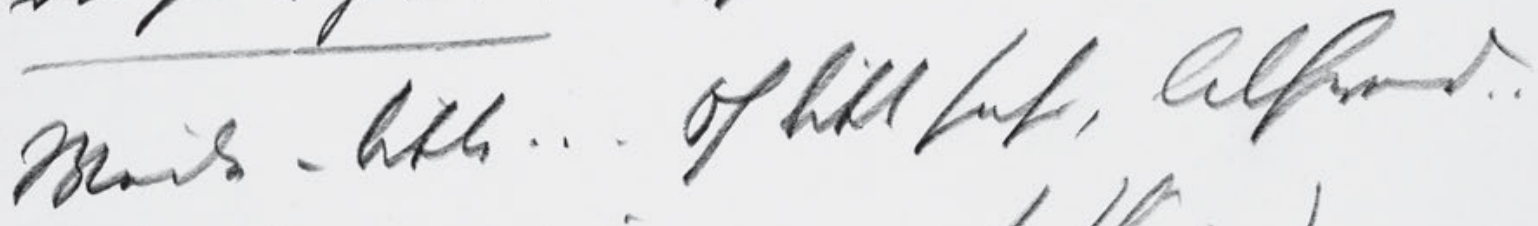

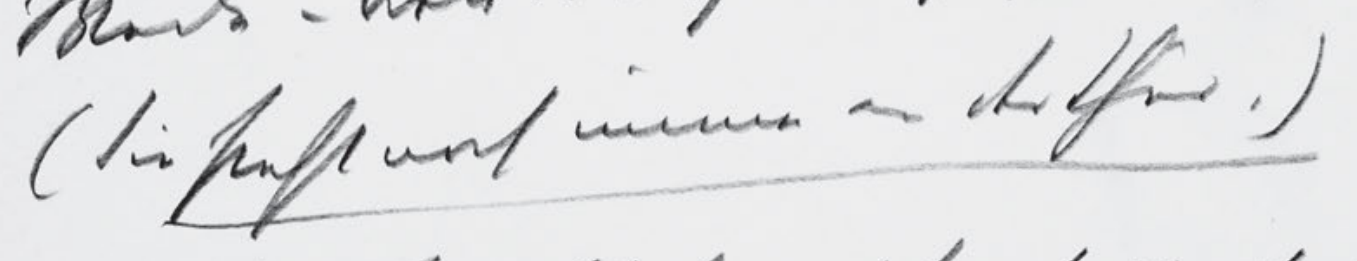

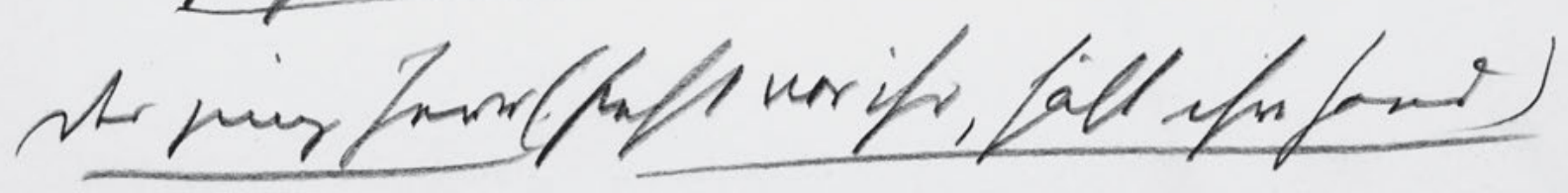

158 
62

Erregung bemeistern.

Der junge Herr (tritt auf sie zu, nī̄t ihre linke Hand und drückt auf die weißen

5 schwarz tamburirten Handschuhe einen

Kuss. Er sagt leise.) Ich danke Ihnen.

Die junge Frau. Alfred - Alfred.

Der junge Herr. Kō̄en Sie gnädige Frau ...

komen Sie, Frau Emma[?] . .

${ }_{10}$ Die jung ${ }^{\text {Herr } F r a u . ~ L a s s e n ~ S i e ~ m i c h ~ n o c h ~ e i n e ~}$

Weile - bitte ... Oh bitt sehr, Alfred . .

(Sie steht noch immer an der Thür.)

Der junge Herr'(steht vor ihr, hält ihre Hand) 
HSz4 63

Handschriften und Typoskript

liping Trum... Ore his if thi ryoutes

Ar pingur. thin miv.

hepus

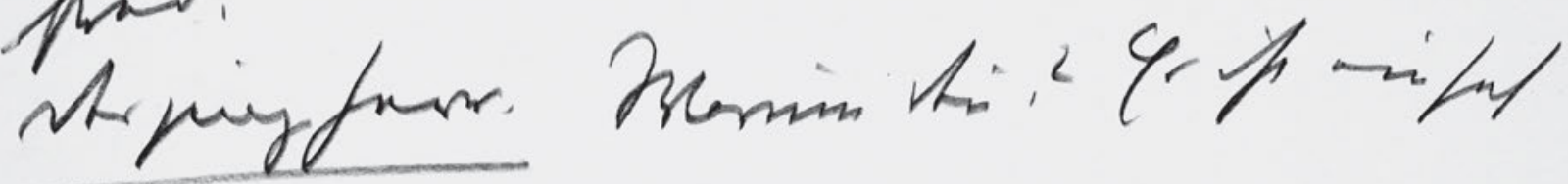
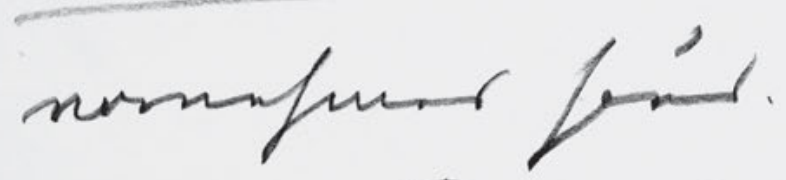

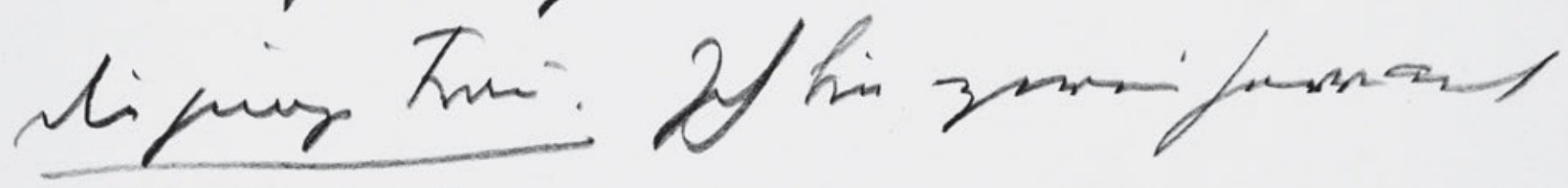

L hip hyogret

tiping fors.

Sntamen.

Arpus trumi
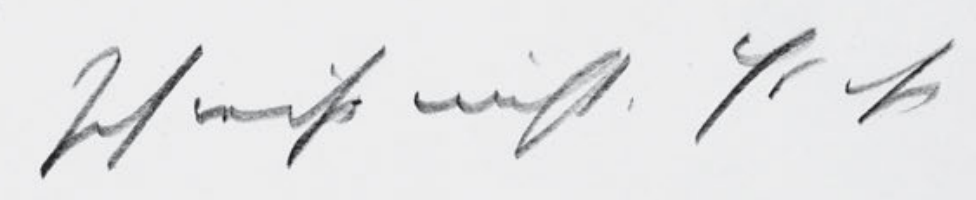

nirluy.

singisfrers

Rarth, puif tra-ah

160 
Die junge Frau ... Wo bin ich deñ eigentlich

Der junge Herr. Bei mir .

Der jung ${ }^{\text {Hef Frau. }}$. Dieses Haus ist schrecklich, Al-

5 fred.

Der junge Herr. Warum deñ? Es ist ein seh vornehmes Haus.

Die junge Frau. Ich bin zwei Herrn auf

der Stiege begegnet.

10 Die jung Herr. .. Bekannte.

Der jung Frau. Ich weiß nicht. Es ist

möglich.

Die jung Herr. Pardon, gnädig Frau - aber 
HSz4 64

Handschriften und Typoskript

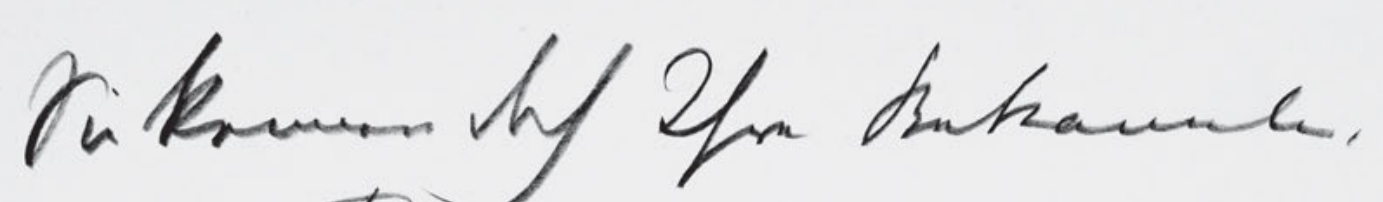
dignig trons.

Hoher pe mes mofu.
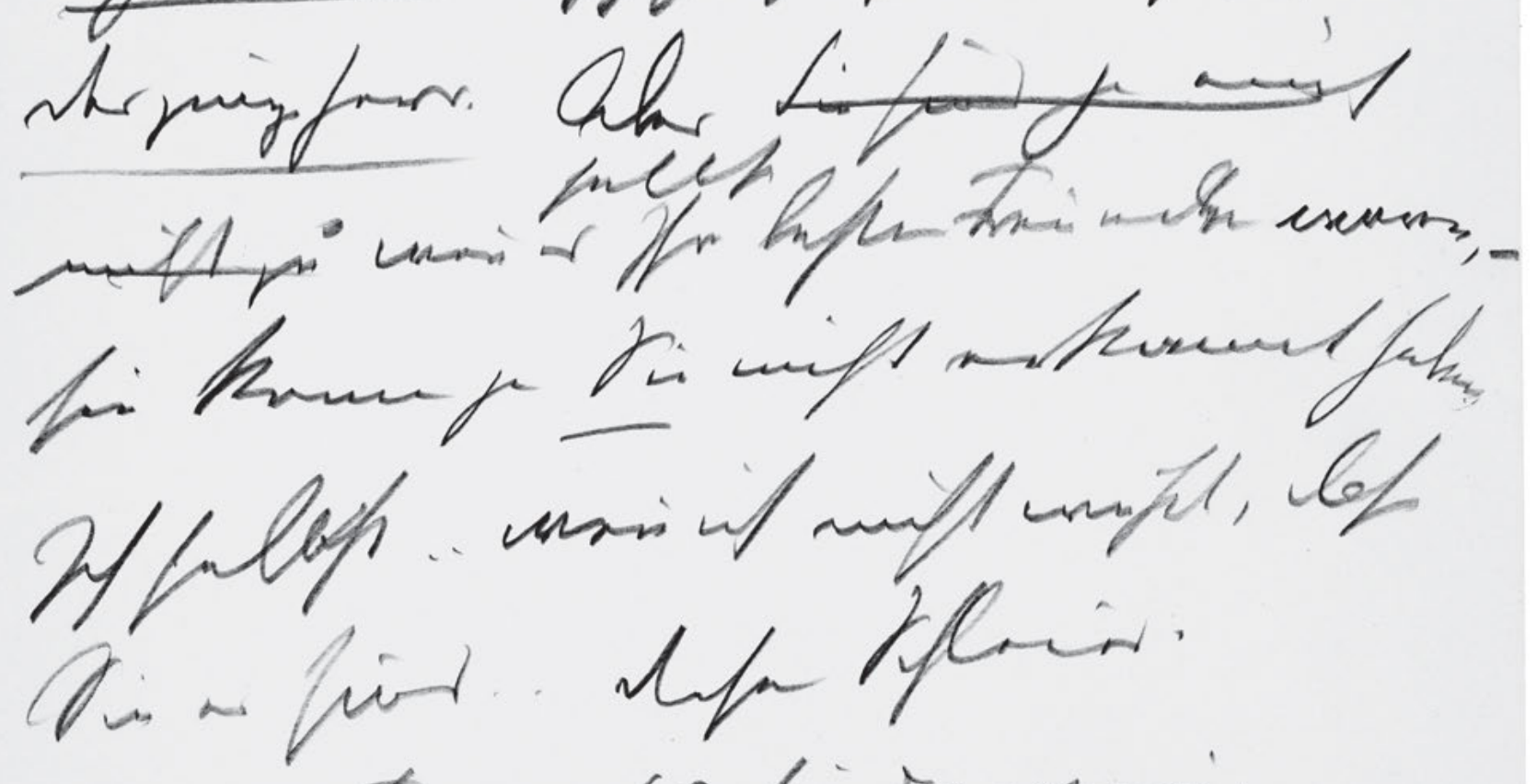

digir trui.
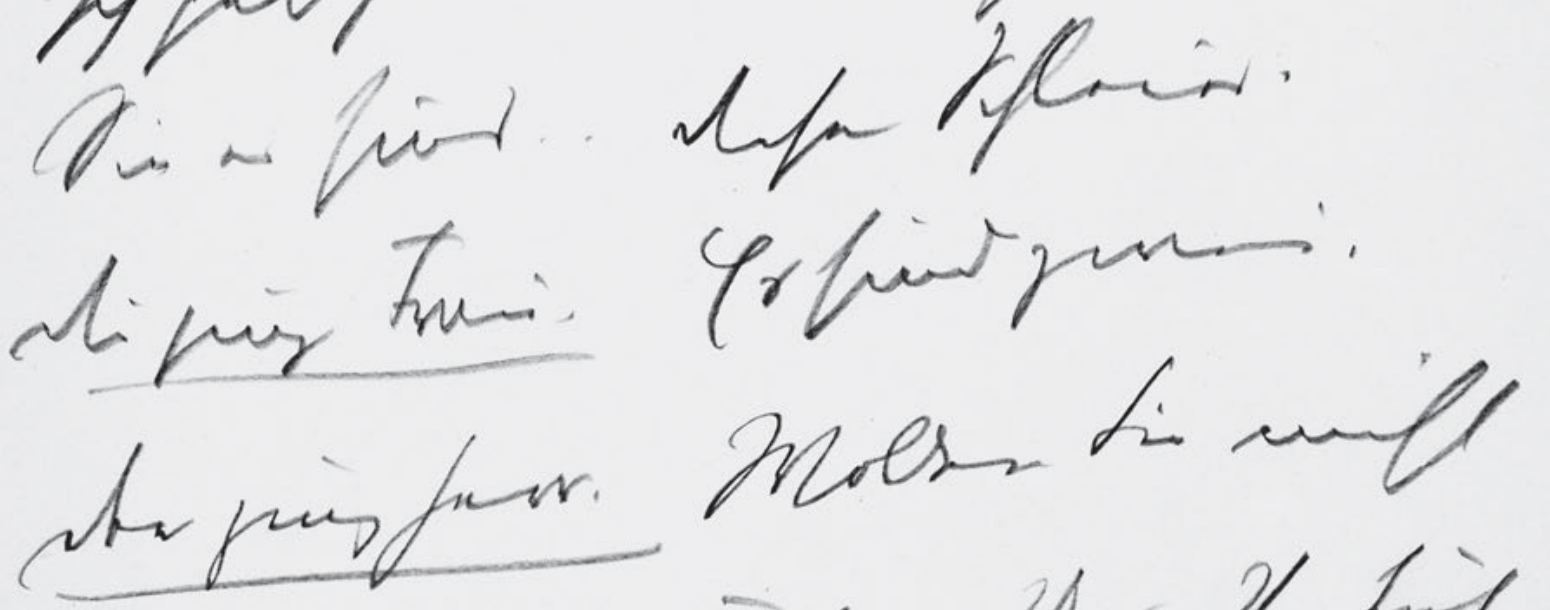

a)

Qh.

$6 n$ 
Sie kennen doch Ihre Bekannten.

Die junge Frau. Ich habe ja gar nichts gesehn ..

Der junge Herr. Aber Sie sind ja auch

selbst

5 nicht $\mathrm{zu}$ weñ es Ihre besten Freunde waren, -

sie konnen ja Sie nicht erkannt haben.

Ich selbst . . weñ ich nicht wüßt, dass

Sie es sind . . dieser Schleier.

Die junge Frau. Es sind zwei.

10 Der jung Herr. Wollen Sie nicht

'ah? ein bischen näher . . Und Ihren Hut

legen Sie doch wenigstens ab. 
HSz4 65

Handschriften und Typoskript

Ltping tro.

Akr falet

Cos

par.

2

deimits

the

atenug forr.

alf th topain.

Siguig tro

Graiprom

Atruizfurs.

Ringr,

hut Tymar

- Wuras

Li.

uncupfener/ofs

sispor.

hivin Tron

Jak kimifter

hib.

alpor?

164 
65

Der junge Frau. Was fällt Ihnen ein, Al

fred? Ich habe Ihnen gesagt: Fünf

Minuten .. Nein, länger nicht . . ich

5 schwöre Ihnen . .

Der junge Herr. . Also den Schleier . .

Die jung Frau. Es sind zwei.

Der junge Herr. Nun ja, beid Schleier

- Ich werde Sie doch wenigstens sehn

dürfen.

Die jung Frau. Haben Sie mich denn

lieb, Alfred? . 
HSz4 66

Handschriften und Typoskript

grifung wors

dinging Trmis

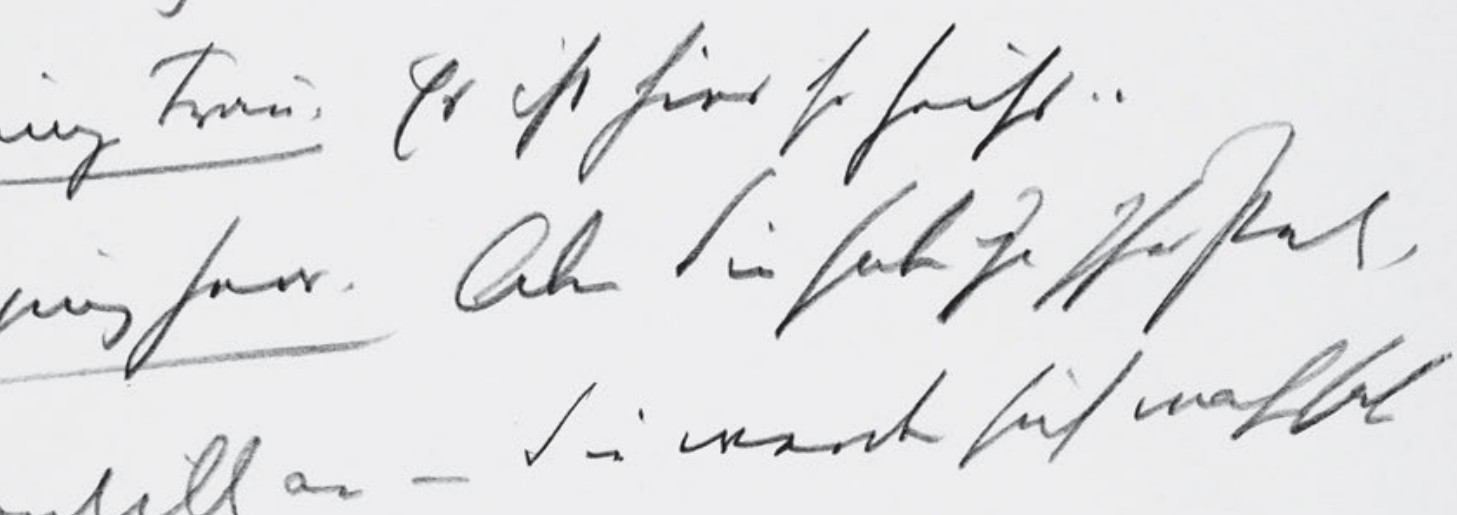

mantill ar

dingig

neterfen

topte mifthifar

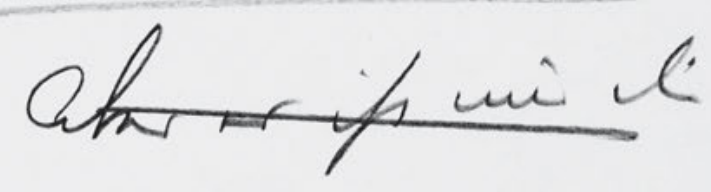

Con

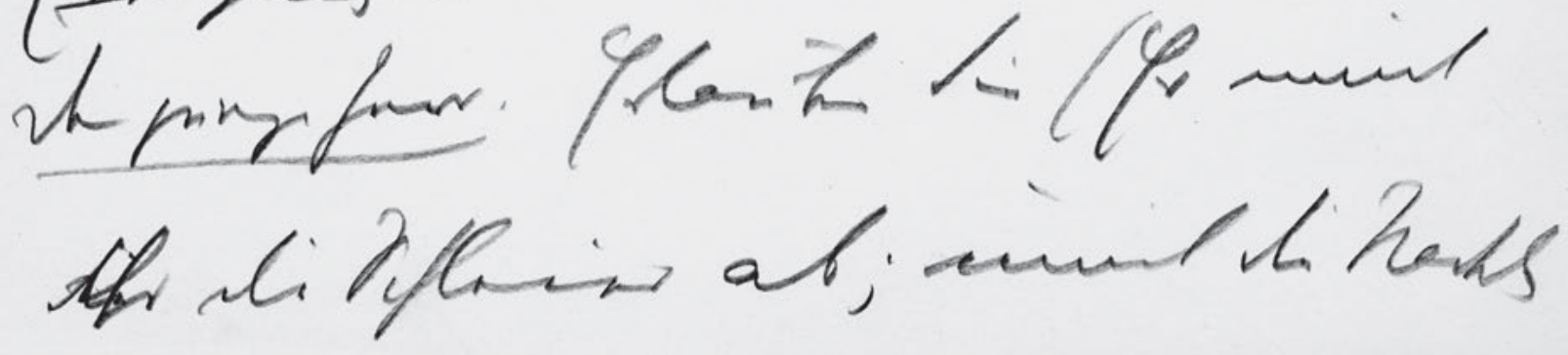

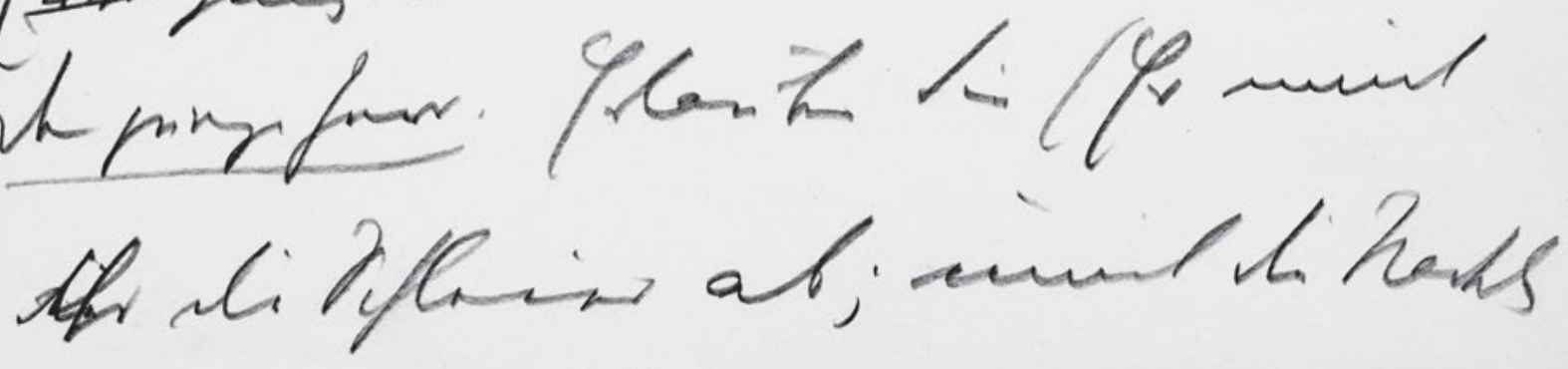

166 
66

$\underline{D^{i e}}$ er jung Herr (tief verletzt) Emma - Sie fragen mich . .

Die junge Frau. Es ist hier so heiß . .

5 Die jung Herr. Aber Sie haben Ija Ihre Pelz-

mantill an - Sie werden sich wahrhaft

Die jung Frau. verkühlen.

Die junge Frau (tritt endlich ins Zimmer,

setzt wirft sich auf den Fauteul)

10 Ich bin todtmüd. Aber es ist nur die

Erregung.

Der junge Herr. Erlauben Sie (Er nimt

dieihr die Schleier ab; nimt die Nadel 
HSz4 67

Handschriften und Typoskript

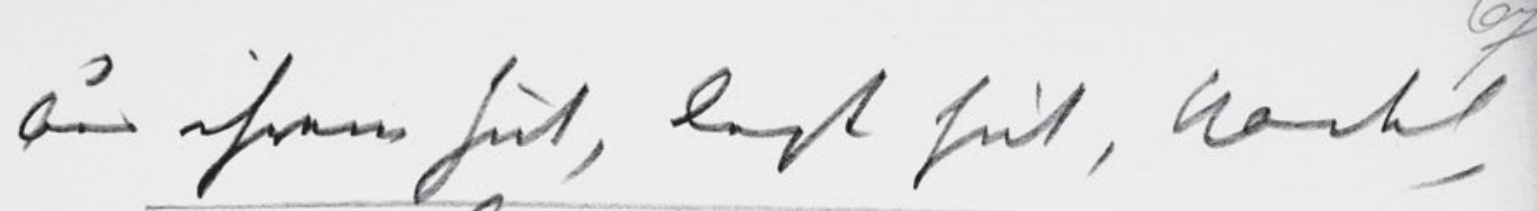

opar hifo

hiping tran

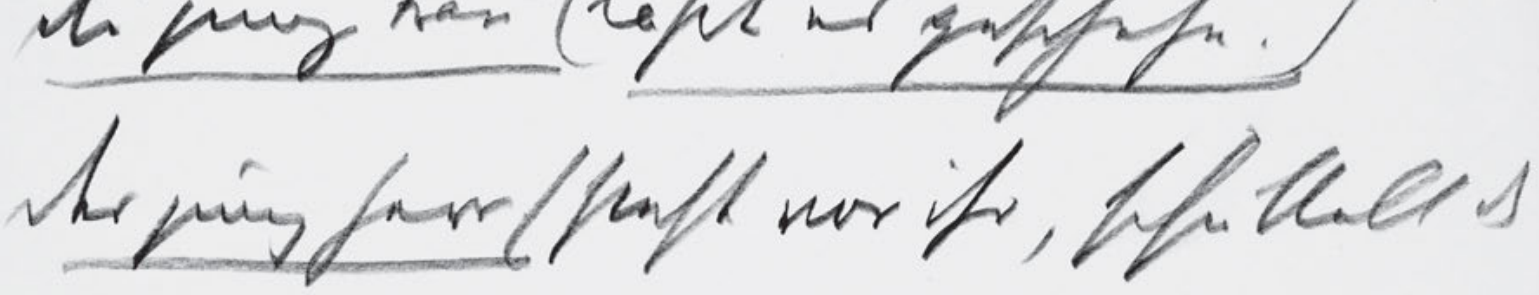

(lof)

(lething

6 ?

raiping tras.

Mr fult zi?

Lis.

diping tori. Minfor.

shmignor. . Alkin.. als un

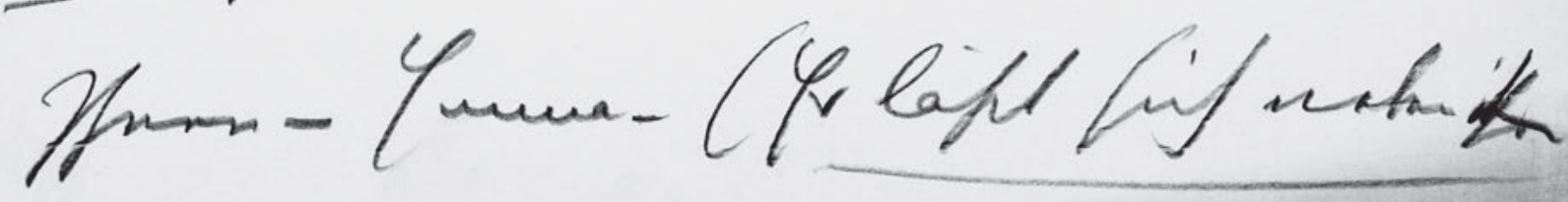

168 
67

aus ihrem Hut, legt Hut, Nadel,

Schleier beiseit)

Die junge Frau (läßt es geschehn.)

5 Der jung Herr (steht vor ihr, schüttelt den

Kopf)

Die jung Frau. Was haben Sie?

Der jung Herr. So schön waren Sie noch

nie.

10 Die jung Frau. Wieso? .

Der jung Herr. .. Allein . . allein mit

Ihnen - Emma - (Er läßt sich neben ${ }^{\mathrm{ihr}} \mathrm{dem}$ 
HSz4 68

Handschriften und Typoskript

Fanlent wist, any asi kuin, unis

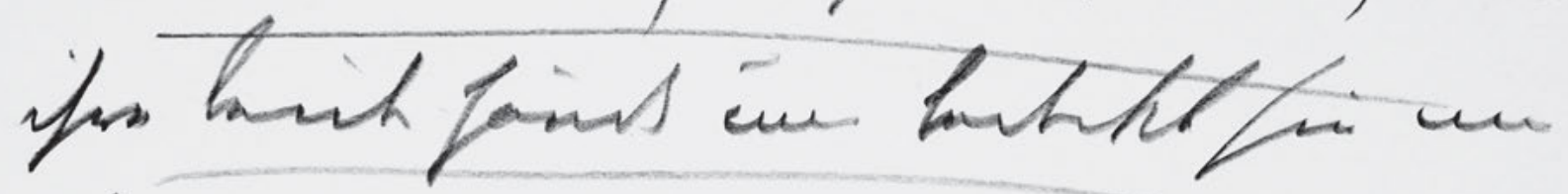
fand (ton.)

Chipuyz tras: Werpfe.. befh myt mert sofm ... Mer lis un struigfors

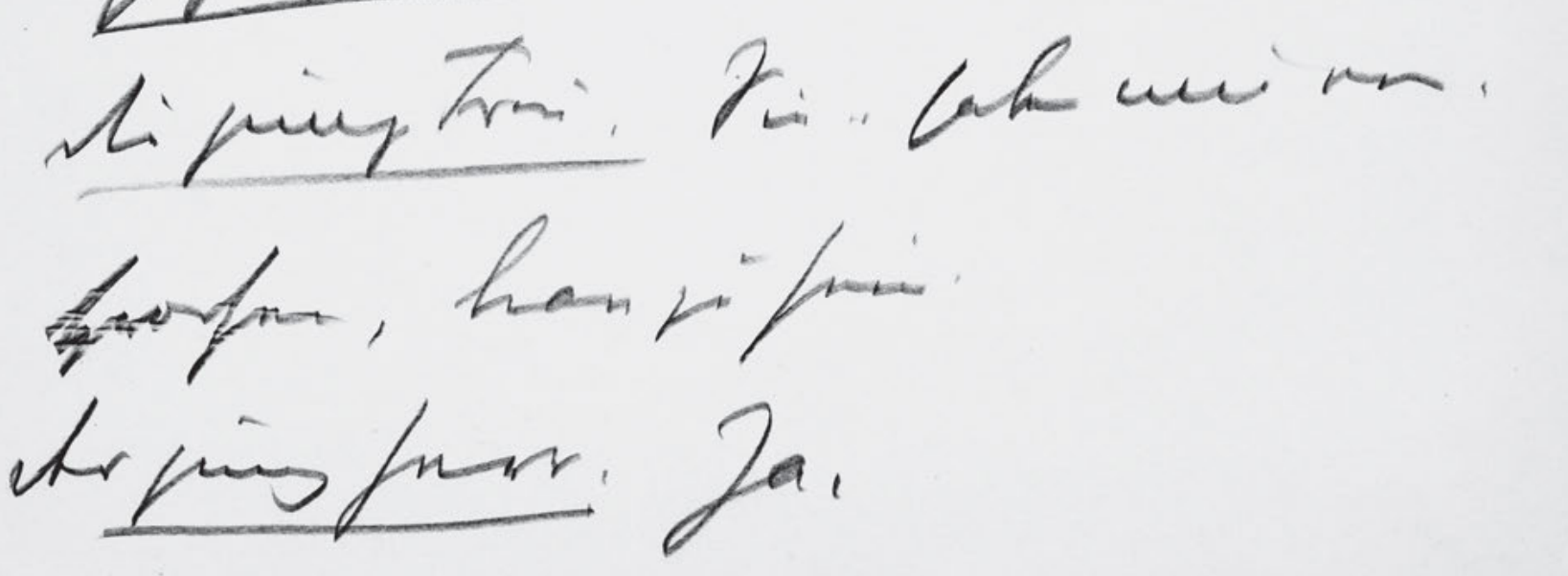

170 
68

Fauteul nieder, auf ein Kniee, nimt

ihre beiden Hände und bedeckt sie mi

Küssen.)

${ }_{5}$ Die junge Frau. Und jetzt ... lassen Sie

mich wieder gehn ... Was Sie von

mir verlangt haben, hab ich gethan -

Der junge Herr (läßt seinen Kopf auf ${ }^{\mathrm{I}}$ ihren

Schoß sinken)

10 Die junge Frau. Sie . . haben mir ver-

sprochen, brav zu sein.

Der jung Herr. Ja. 
HSz4 69

Handschriften und Typoskript

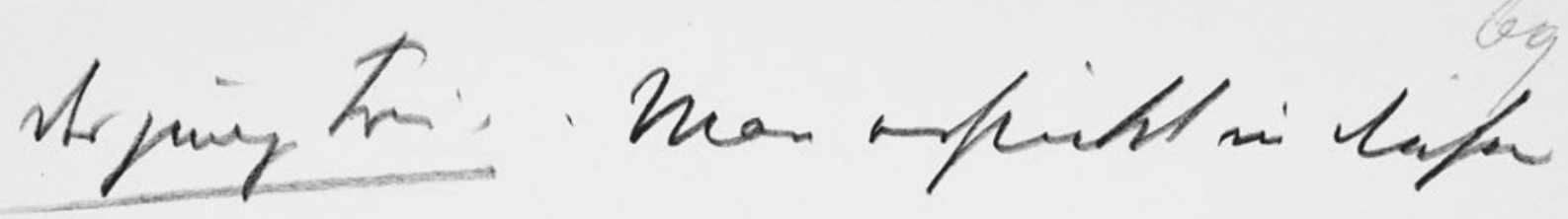

pomins
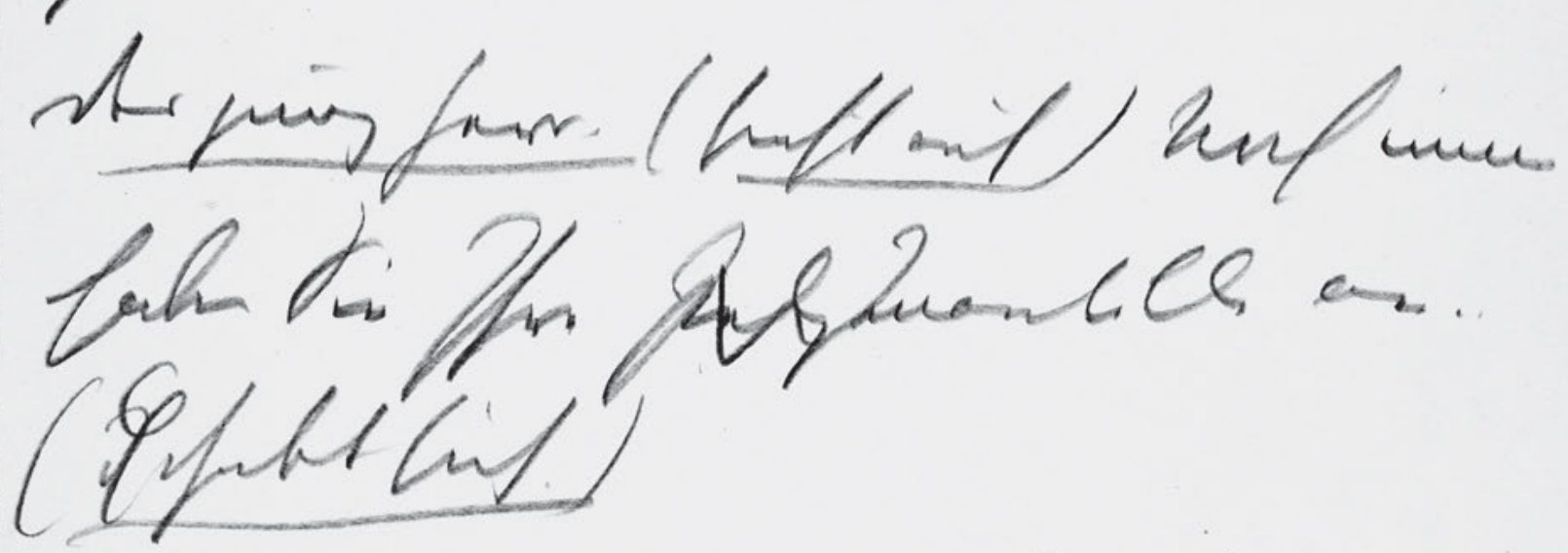

Ar ping Trans.

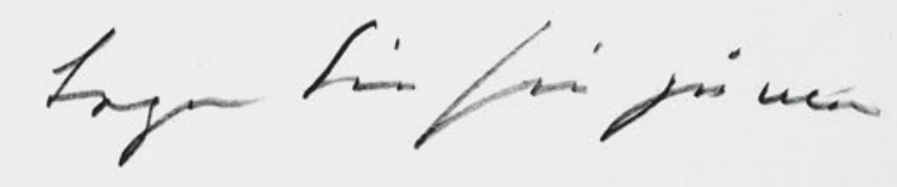

jin.

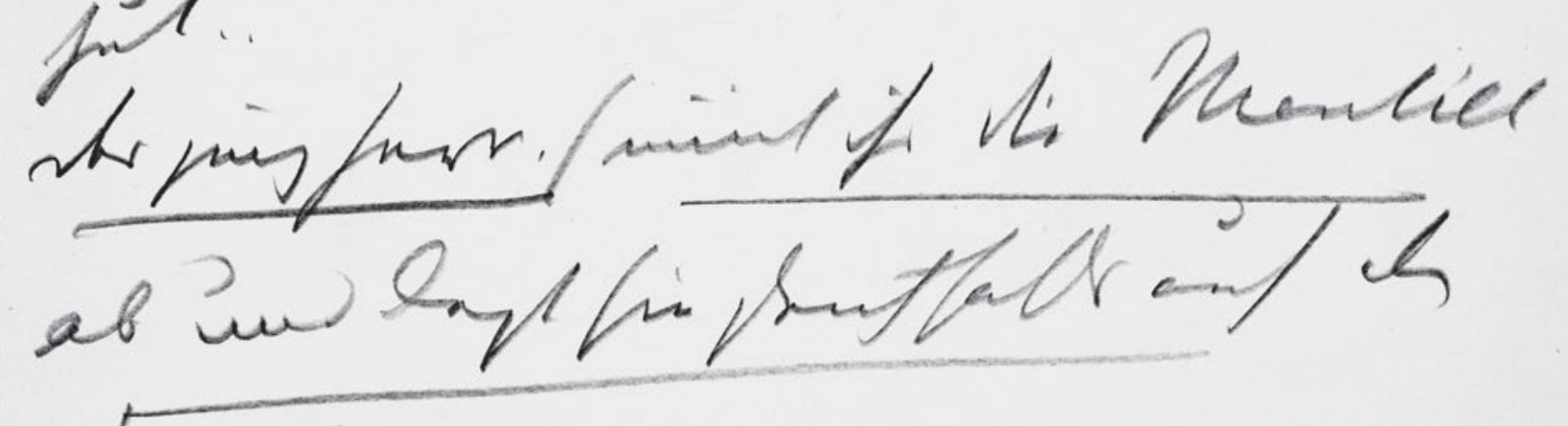

min)

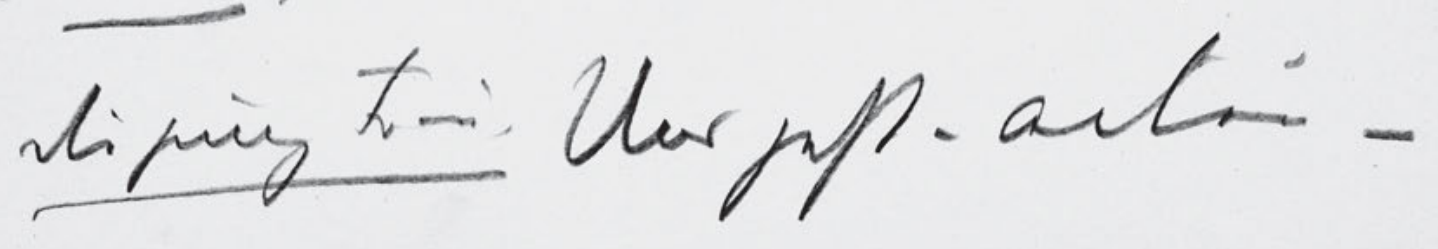

172 
69

Der junge Frau. . Man erstickt in diesem

Zimmer.

Der jung Herr. (sieht auf) Noch immer

5 haben Sie Ihre Pelz ${ }^{\mathrm{m}}$ Mantille an ..

(?d? Erhebt sich.)

Der junge Frau. .. Legen Sie sie zu mein

Hut . .

Der jung Herr. (nī̄t ihr die Mantill

10 ab und legt sie gleichfalls auf den

Divan)

Die jung Frau. Und jetzt - adieu - 
HSz4 70

Handschriften und Typoskript

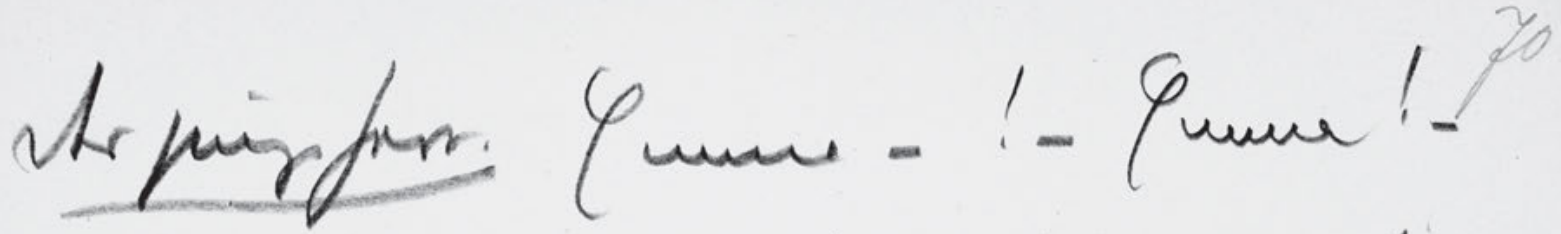

Drij jivg tomi

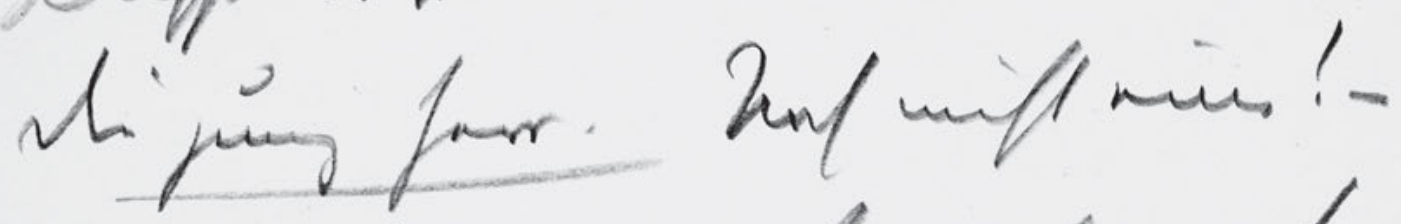

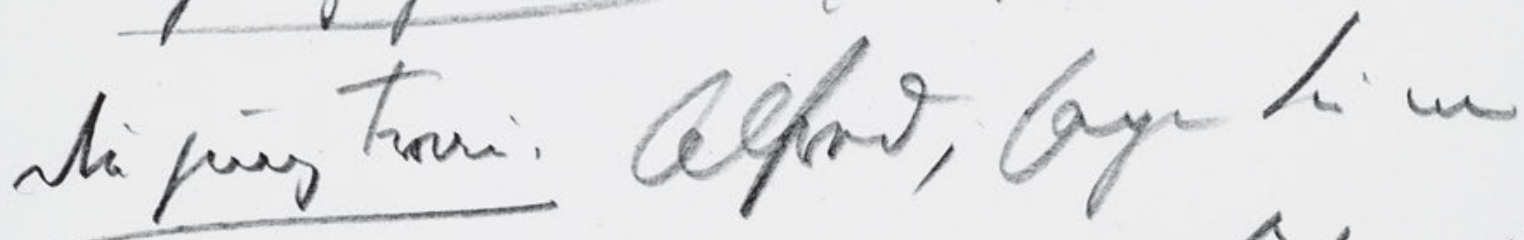

- weral jors jonen', mis fat or f:

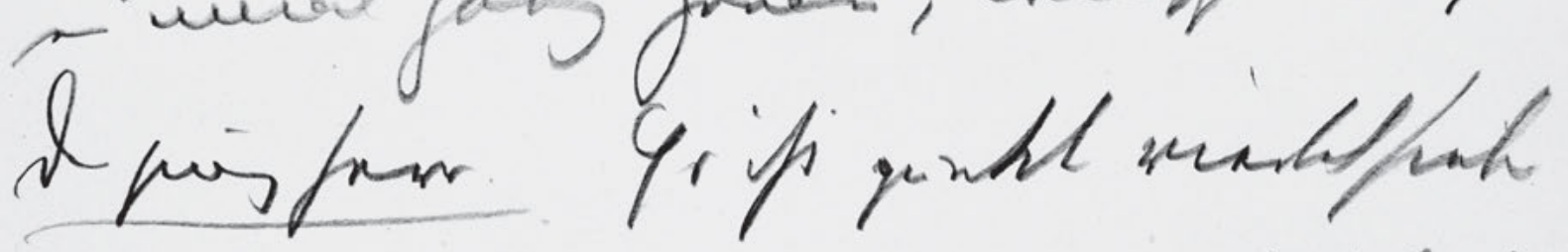

dipus Tor

Inf foelt if binft

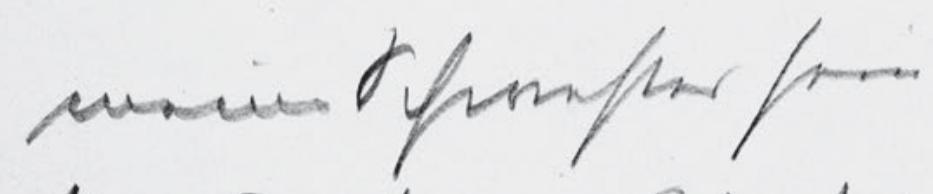

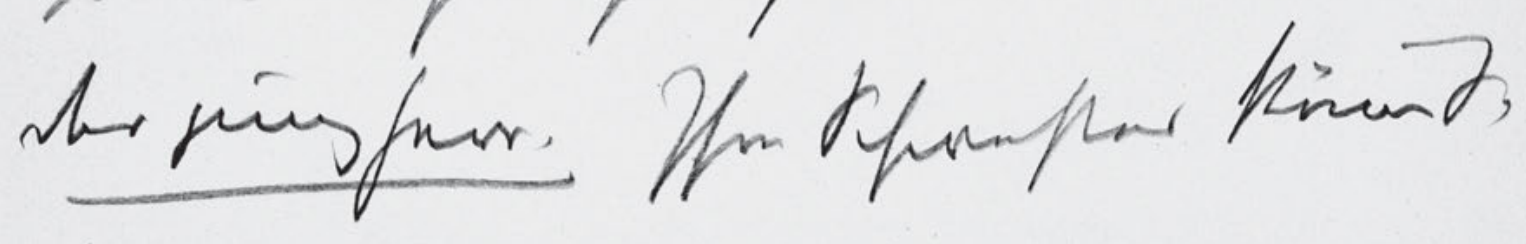

to ofterpo.

174 
Der junge Herr. Emma - ! - Emma! -

Die junge Frau. Die fünf Minuten sind längst vorbei.

$5 \quad$ Die jung Herr. Noch nicht eine! -

Die jung Frau. Alfred, sagen Sie mir

einmal ganz genau, wie spät es ist.

Der jung Herr. Es ist punkt viertel sieben

Die jung Frau. Jetzt sollte ich längst bei

10 meiner Schwester sein.

Der jung Herr. Ihre Schwester kön̄en Sie

so oft sehen . . 
HSz4 71

Handschriften und Typoskript

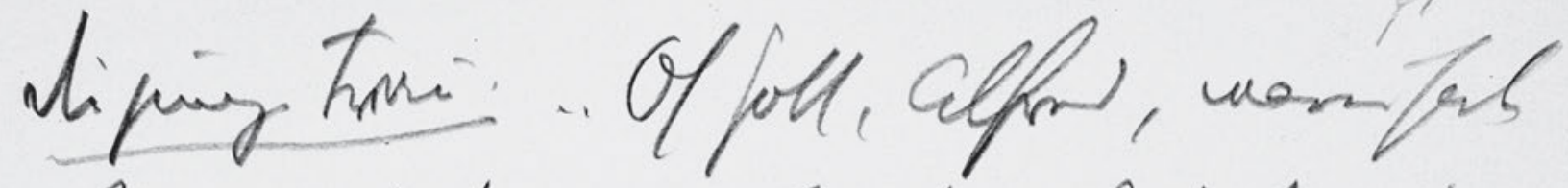
Pis mif dye' in lastret. Afthic if

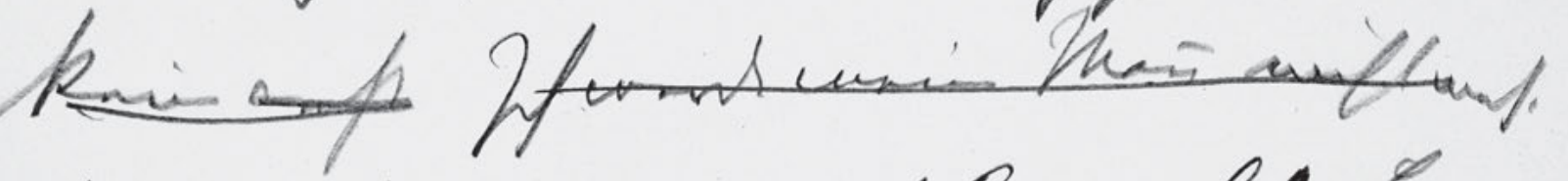

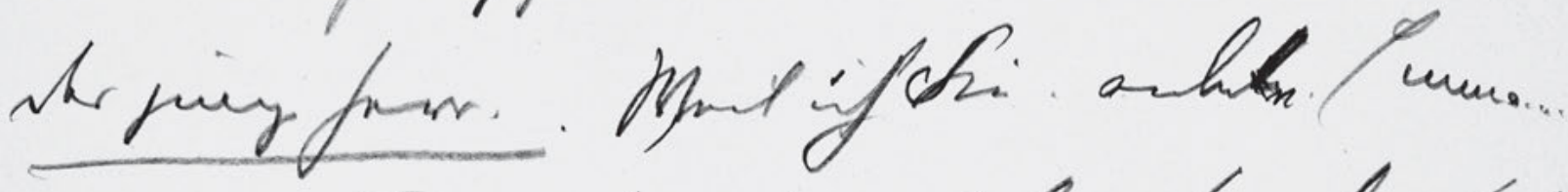

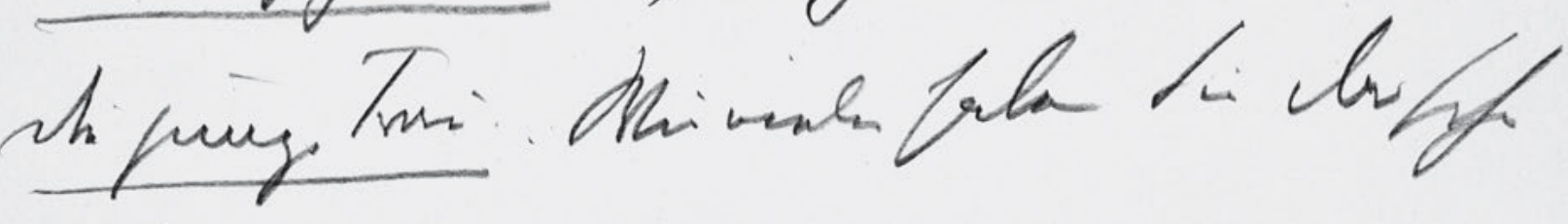
sifart.

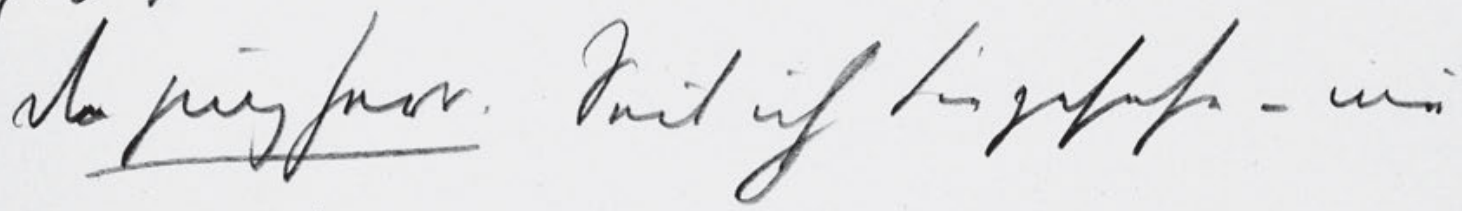
muntm -

liping Trmis =

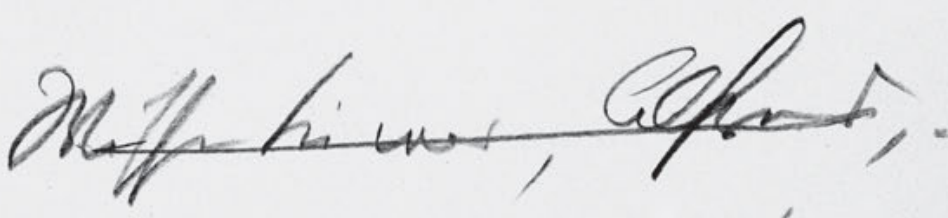

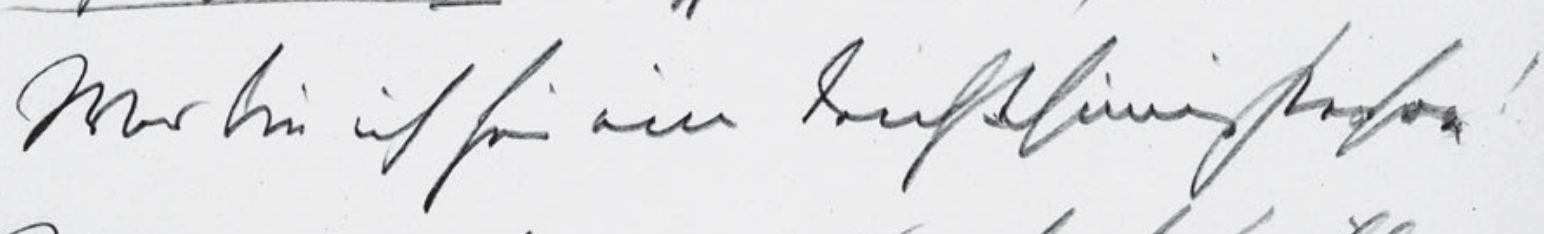

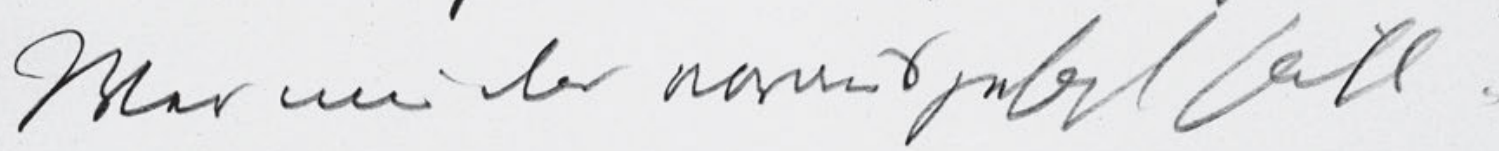

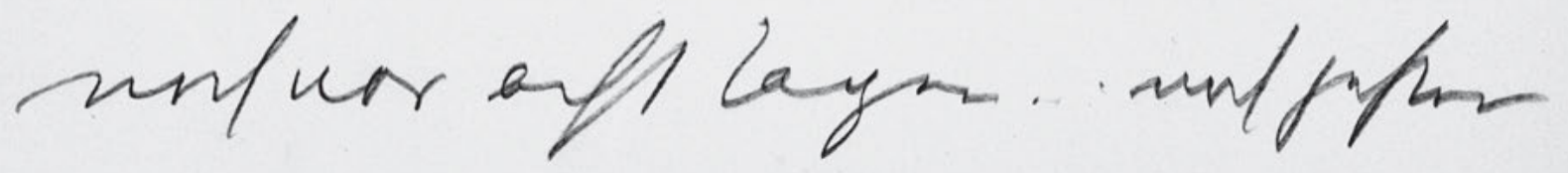

176 
71

Die junge Frau. .. Oh Gott, Alfred, warum haben

Sie mich dazu verleitet. Jetzt bin ich

keine anst Ich werde meinen Mañ nicht meh -

${ }_{5} \quad$ Der junge Herr. . Weil ich Sie . anbe ${ }^{[?]}$ te. Emma ....

Die junge Frau. . Wie vielen haben Sie das schon

gesagt -

$\underline{D^{i e} e r}$ jung Herr. Seit ich Sie gesehn - nie-

mandem -

10 Die jung Frau. - Wissen Sie was, Alfred, -

Was bin ich für eine leichtsinnig Person!

Wer mir das voraus gesagt hätt -

noch vor acht Tagen .. noch gestern. 
HSz4 72

Handschriften und Typoskript

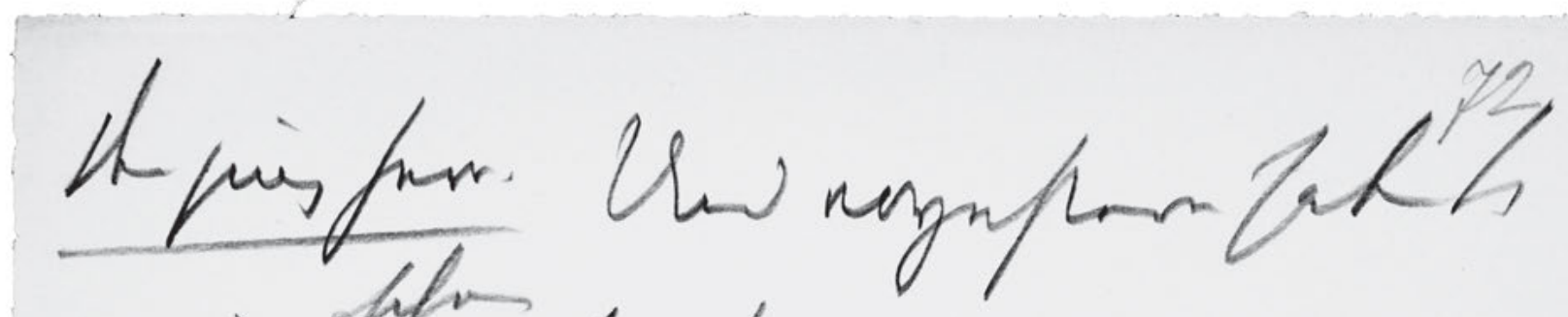

mei gy vertyory.

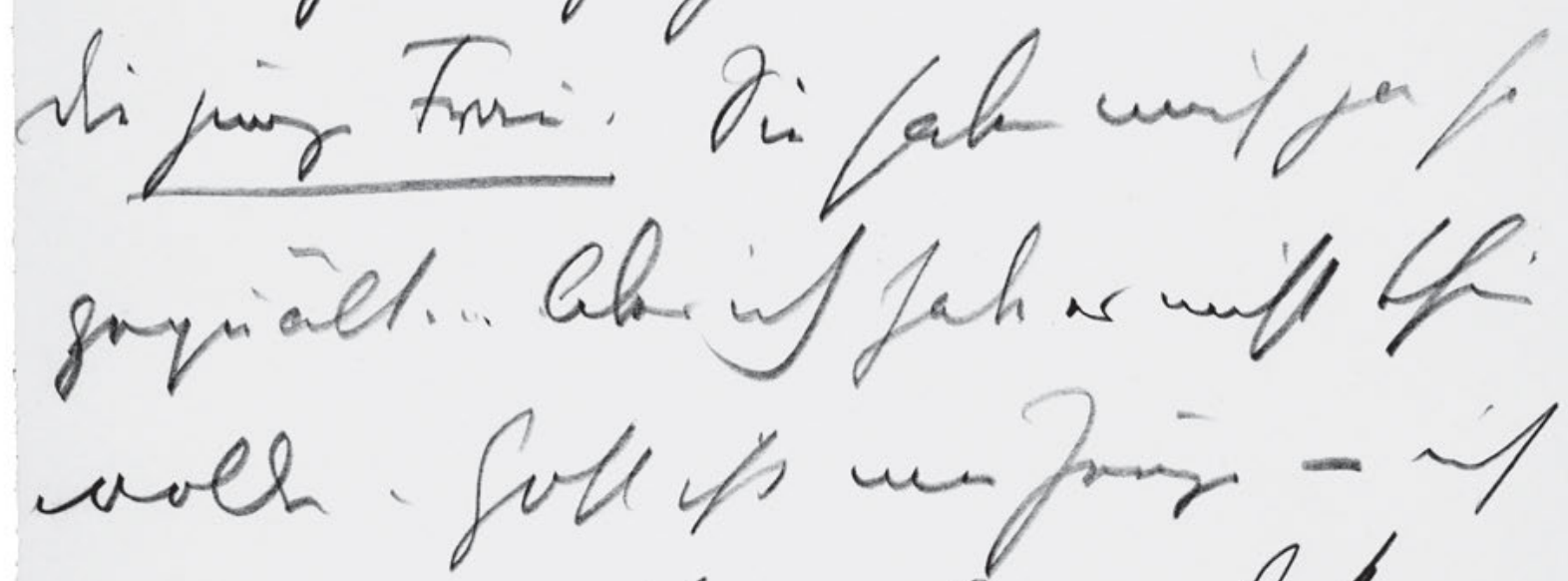

wolk foll ifs

taler mift thin

st Jun rapar cibror for

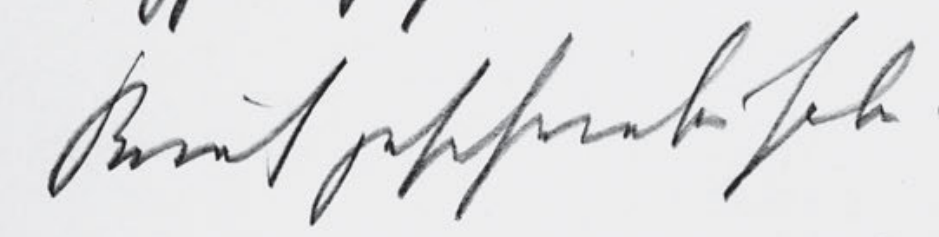

shepigfiors.
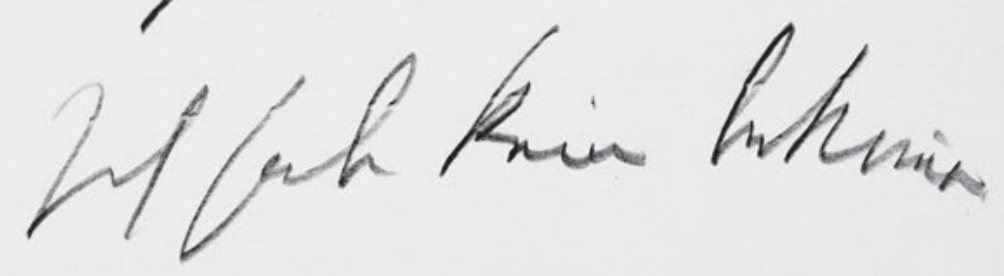

178 
72

Der jung Herr. Und vorgestern haben Sie schon mir ja/versprochen . .

Die junge Frau. Sie haben mich gar so

5 gequält.... Aber ich habe es nicht thun

wollen - Gott ist mei Zeuge - ich

hab es nicht thun wollen .... Gestern war

ich faest entschlossen .. Wissen Sie, dass

ich Ihnen gestern Abend sogar einen langen

10 Brief geschrieben habe.

Der jung Herr. Ich habe keinen bekomen 
HSz4 73

Handschriften und Typoskript

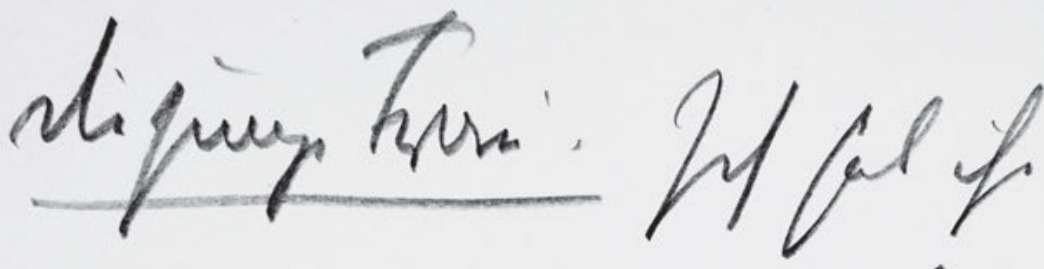

of if

fits th

un lik

lifa

is

streing fors.

Yrits hy

dipuis Trani.

of

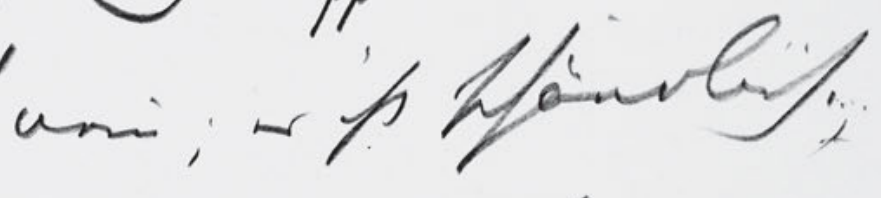

ser peir

2

aulin

ctping forst

f

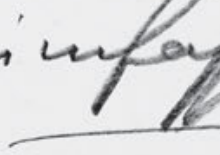

b

lipus tran.

ro.jalle

Lffrers.

180 
73

Die junge Frau. Ich hab ihn wieder zerrissen.

Oh ich hätte Ihnen lieber diesen Brief schicken

sollen. Dē̄

5 Der jung Herr. . Es ist doch besser so . .

Die jung Frau. Oh nein; es ist schändlich'....

von mir ... Ich begreife mich selber nicht .....

.. Adieu, Alfred ... lassen Sie mich.

Der jung Herr (umfasst sie und bedeck

10 ihr Gesicht mit heißen Küssen ..)

Die jung Frau .. So . . halten Sie Ihr Wort . . 
HSz4 74

Handschriften und Typoskript

drungenor...

$$
\text { Rr/ min . Rift. un }
$$

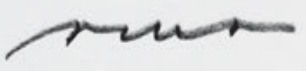

Aryis tron.

th sem

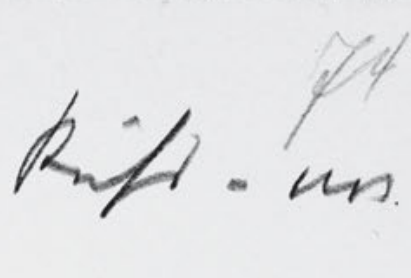

finifin an

Lip

Arjungforr

zoes w

hifi

6 hiff

vorn.

Yume...

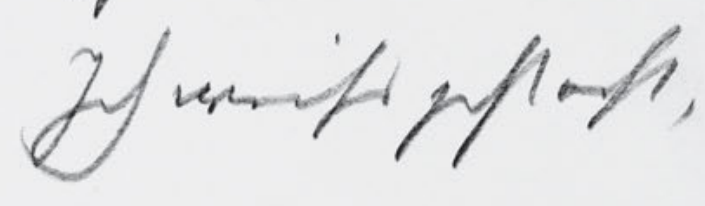

mur lint ifs.

or whenaryflytos.)

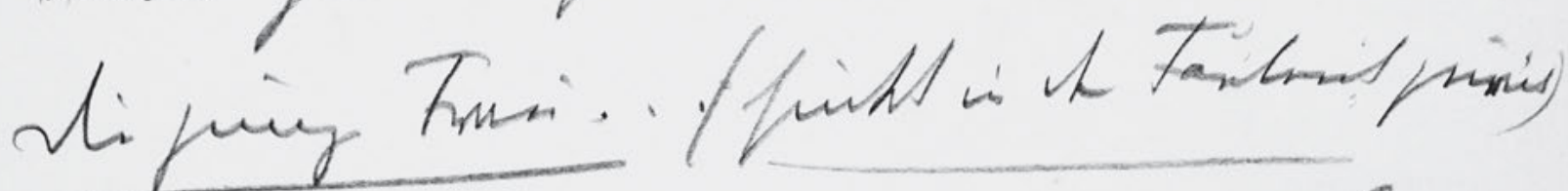

shis fors

(

Sthi

ui.

yes

182 
74

Der junge Herr. .. Noch einen . . Kuss - noc einen.

Der jung Frau. Den letzten. (Er küsst

5 sie; sie erwidert den Kuss; ihre

Lippen bleiben lange an einand geschlossen.)

Der junge Herr. . Soll ich Ihnen etwas

sagen, Emma ... . Ich weiss jetzt erst, was Glück ist . .

10 Die junge Frau ... (sinkt in den Fauteul zurück)

Der jung Herr (setzt sich auf die Lehne,

schlingt einen Arm leicht um ihren 
HSz4 75

Handschriften und Typoskript

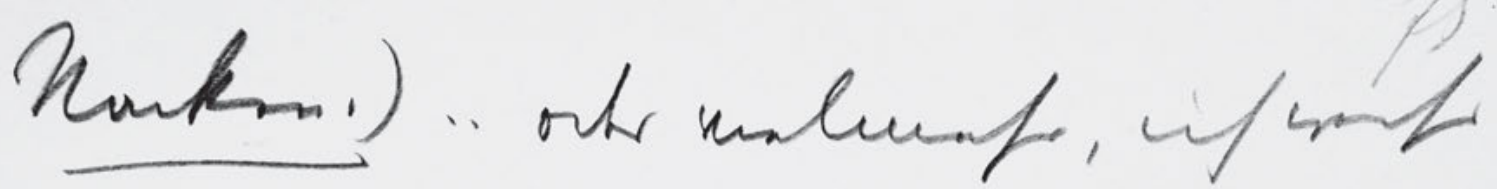

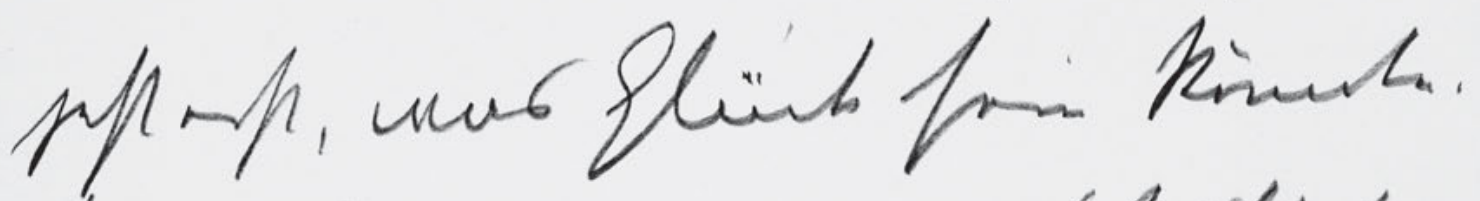

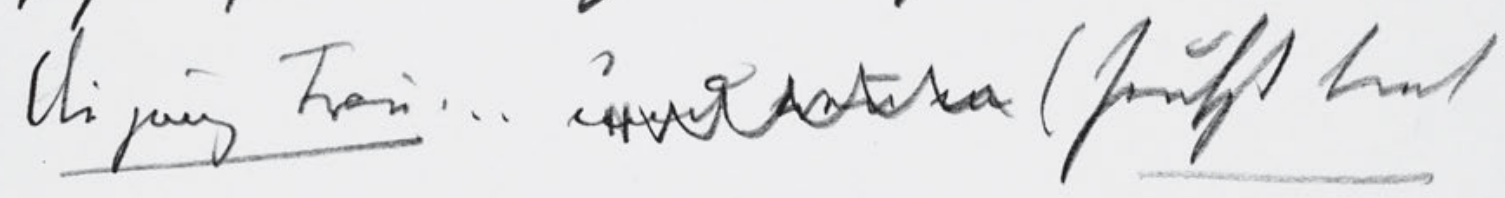
gifl)

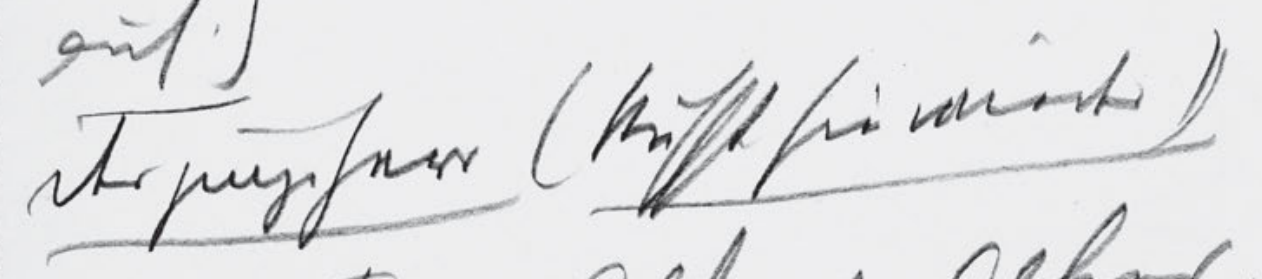

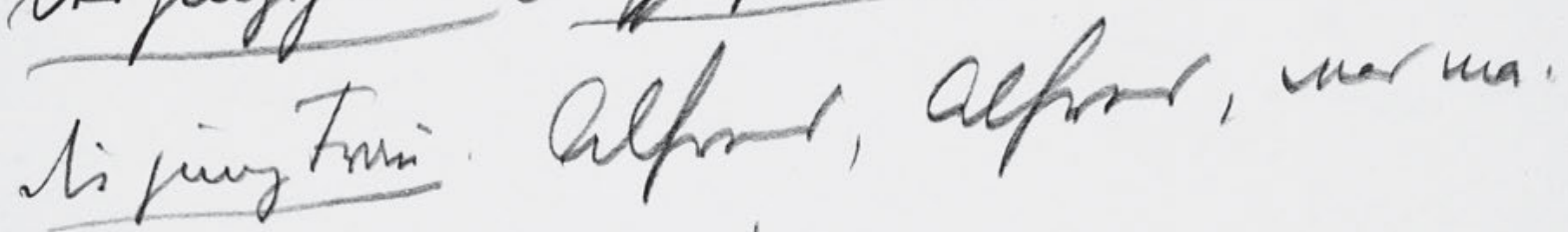
of tis añ uni?

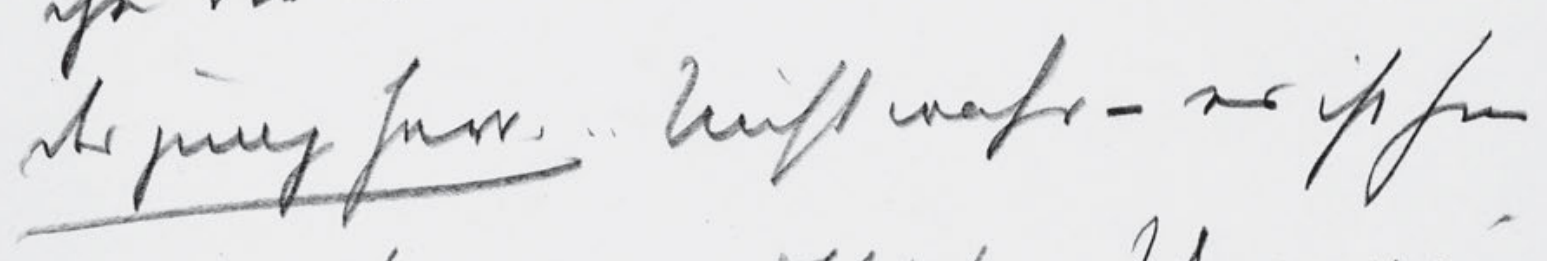
or miff fringrumitling... Uner we bis for frefifor. Yript ony

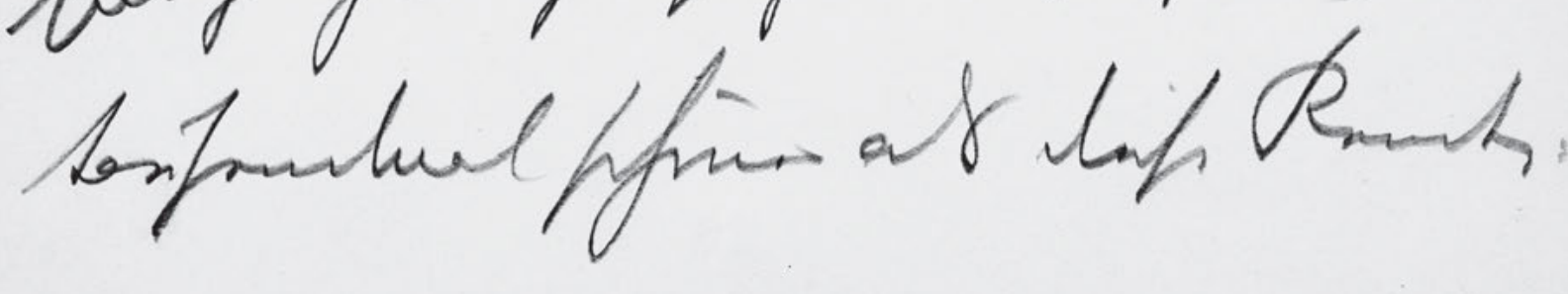

184 
75

Nacken.) .. oder vielmehr, ich weiss

jetzt erst, was Glück sein könnte.

Die jung Frau. .. und weñ ${ }^{2} \mathrm{~m}^{?}$ (seufzt tief

5 auf.)

Der junge Herr (küsst sie wieder)

Die junge Frau. Alfred, Alfred, was ma= chen Sie aus mir!

Der junge Herr. .. Nicht wahr - es ist hier

10 gar nicht so ungemütlich .... Und wir

sind ja hier so sicher! . . Es ist ${ }^{[?]}$ doch

tausendmal schöner als diese Rendez= 
HSz4 76

Handschriften und Typoskript

$\sin ^{2} 6$ un thinn...

thipus Tren'. Opmithimy un mife dirrem.

Ispuig torer. Offermal aniteres

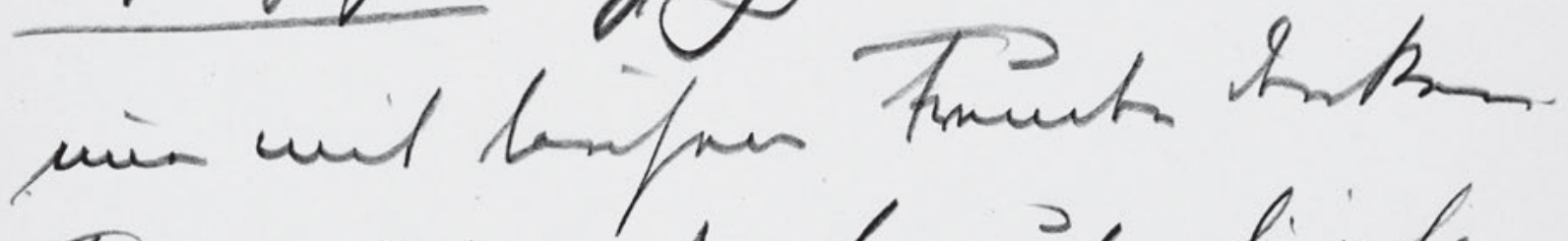

Tri mif ft prov.

In tis ans

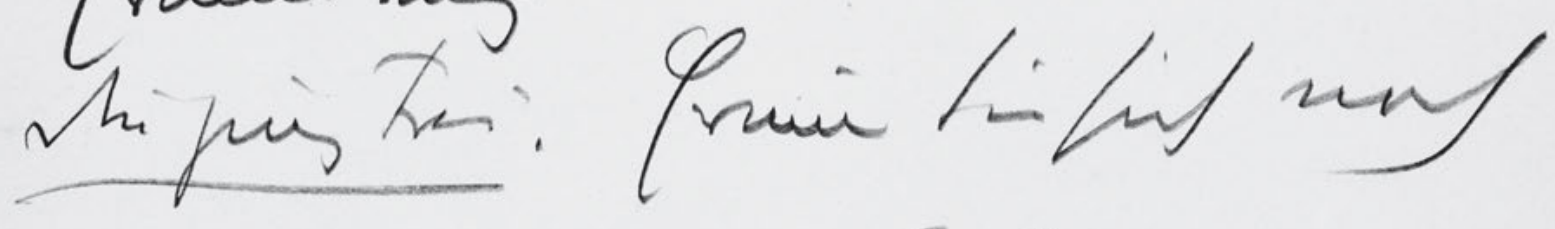

an in juthtunes. bol.

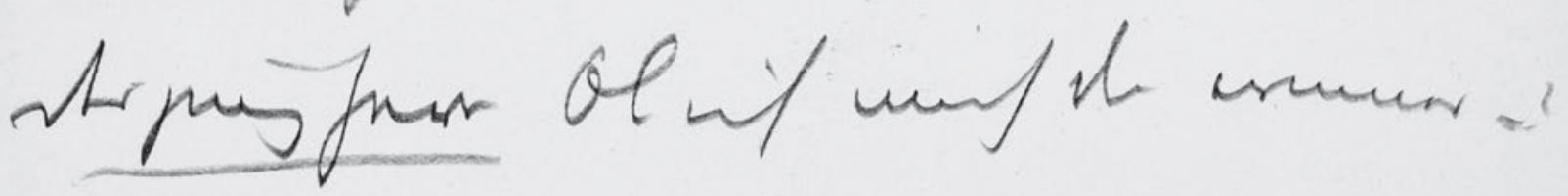

186 
76

vous im Freien .....

Die jung Frau. Oh erinne Sie mich nur nicht daran . .

${ }_{5} \quad$ Der junge ${ }^{\mathrm{F}} \mathrm{Her}$. ${ }^{\text {Oh, }}$, ${ }^{\text {ich }} \mathrm{Ich}$ werd auch daran

imer mit tausend Freuden denken.

Für mich ist jede Minute, die ich an

Ihrer Seite verbringen durfte eine sü seße

Erinnerung.

10 Die jung Frau. Erinner Sie sich noch

an den Industriellenball.

Der jung Herr Ob ich mich da erinner - ? 
HSz4 77

Handschriften und Typoskript

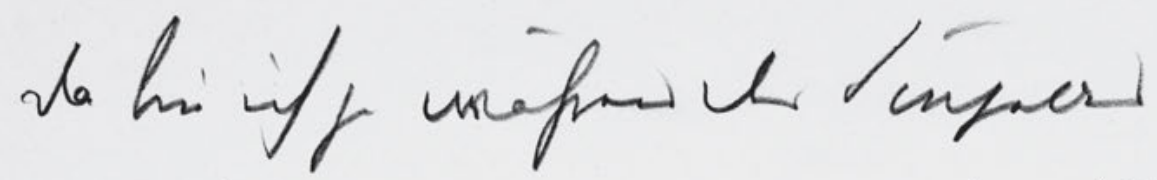
ath gafaffor, ven waf wh
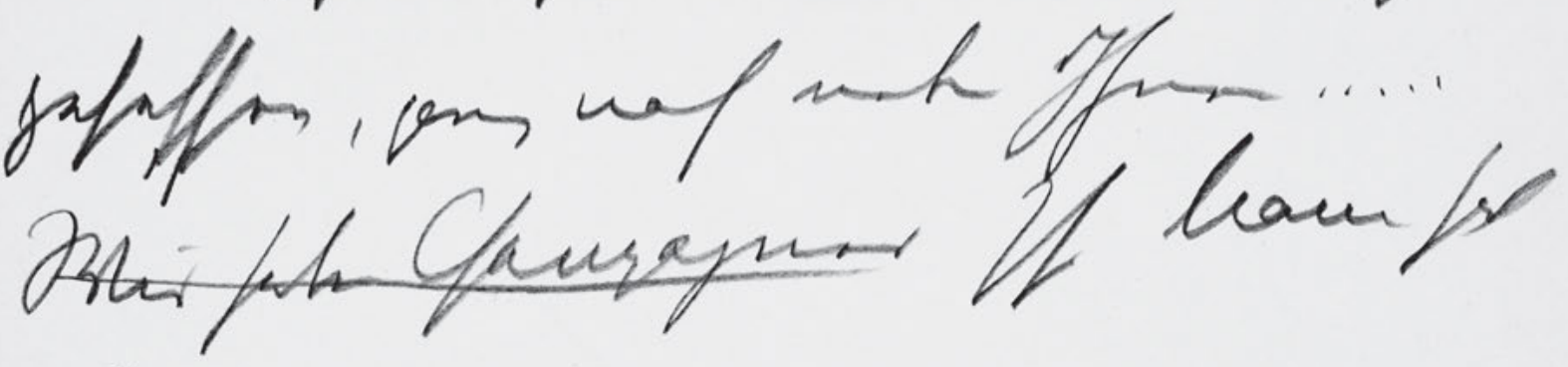

Qanzaymon.

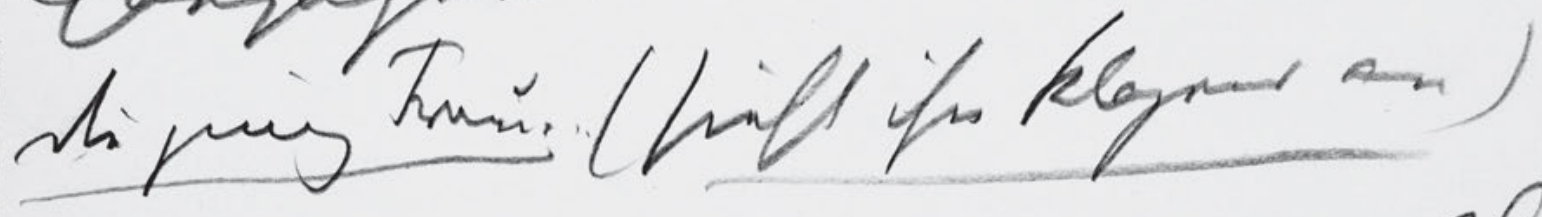
berifinor 
77

Da bin ich ja während des Soupers neben Ihnen gesessen, ganz nah neben Ihnen .... Wir haben Chanpagner Ihr Mann hat 5 Chanpagner.

Die jung Frau. .. (sieht ihn klagend an)

Der jung Herr Ich wollte nur vom Chanpagne reden .... Sagen Sie Emma, wollen Sie nicht ein Glas Cognac trinken?

${ }_{10} \quad$ Die junge Frau. ... Einen Tropfen ... Aber geben Sie mir vorher ein Glas Wasser. Der jung Herr. Ja . . . Wo ist den̄ nur - 
HSz4 78

Handschriften und Typoskript

ange.

C

Cr

ui paft in

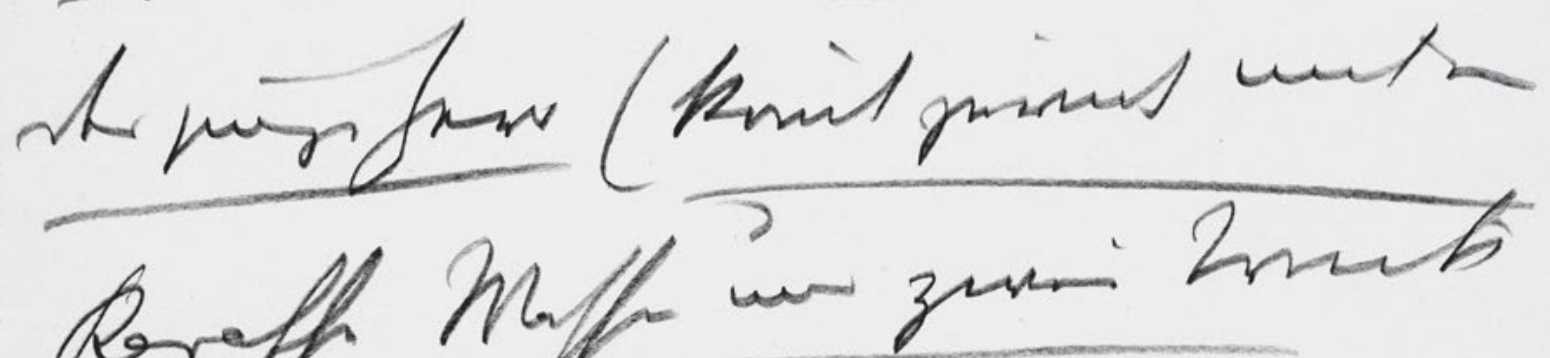

Braff

striging tran.

Mo nern tai she

sh puing fors.

Jen Habryumun...

Simiz Fusi (of

diguz Trun.

zapturns iffinters

190 
78

Ach ja .. ( $\underline{E r}^{z}$ Schlägt die Portière zuruc

und geht ins Schlafzimmer.)

Die junge Frau (sieht ihm nach.)

$5 \quad$ Der junge Herr (kō̄t zurück mit ein

Karaffe Wasser und zwei Trink

gläsern)

Die jung Frau. Wo waren Sie denn. ?

Der jung Herr. Im Nebenzimmer . . . .

$10 \quad$ Die junge Frau. '(Schenkt ein Glas Wasser ein)

Die junge Frau. Jetzt werde ich Sie etwas 
HSz4 7

Handschriften und Typoskrip

from, Cefar - in Ifroum Di nui,

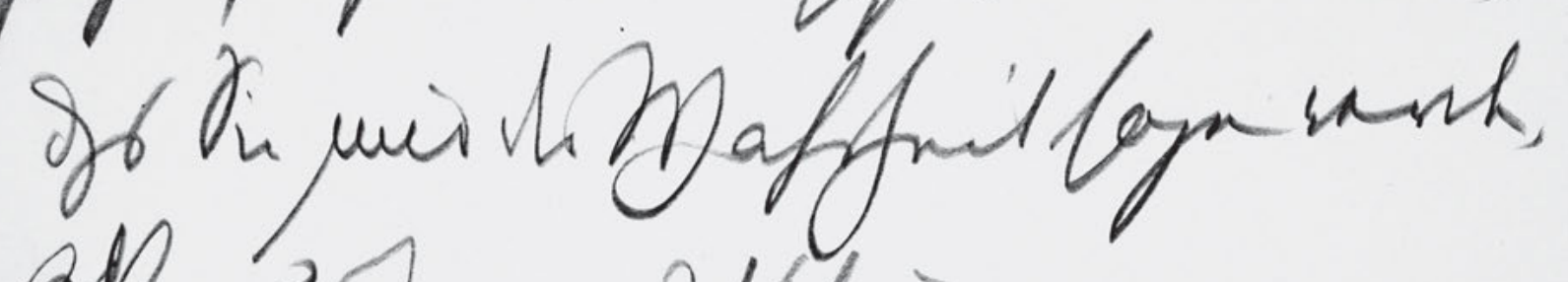
apter jus Juser. Hepurion. dizü, tri Moris difon Rimin Iforpmetrin aust Tr-..?

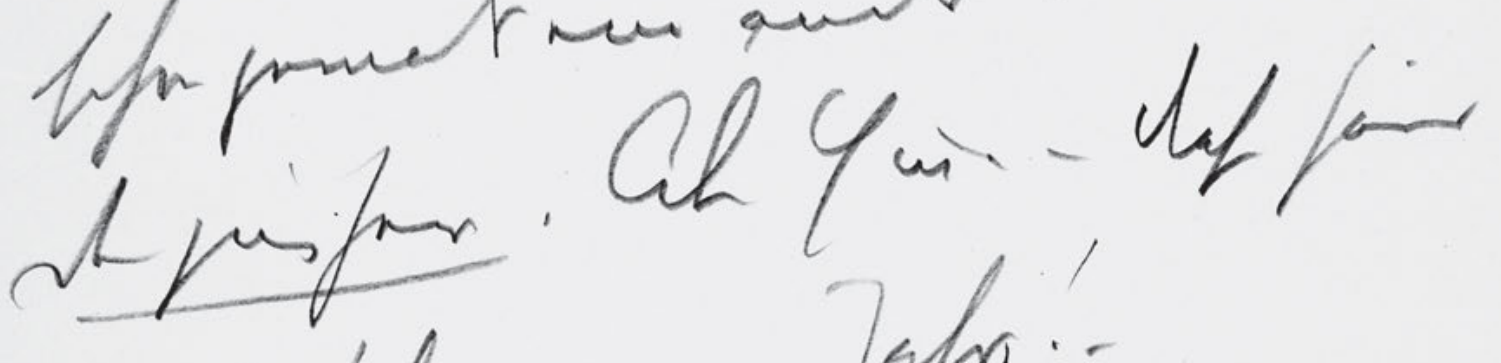
puff for poner Jafor..

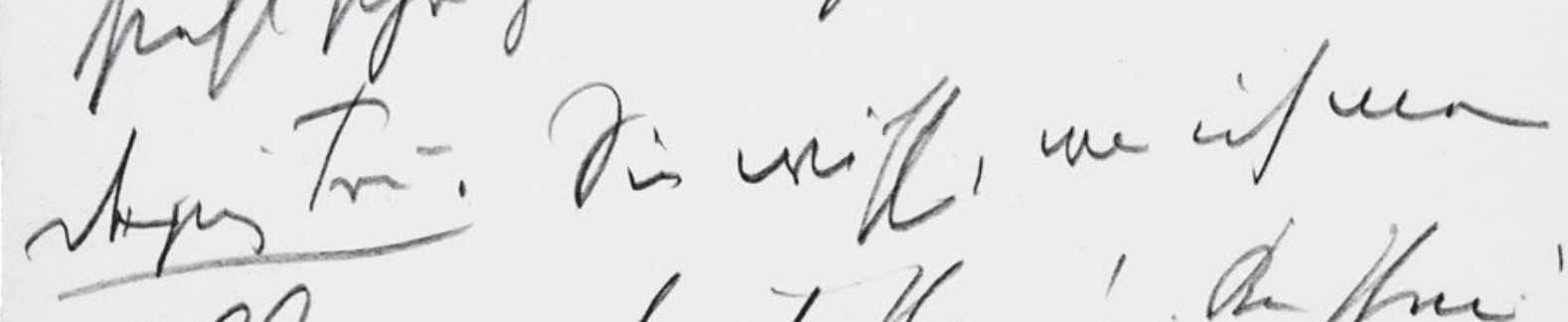

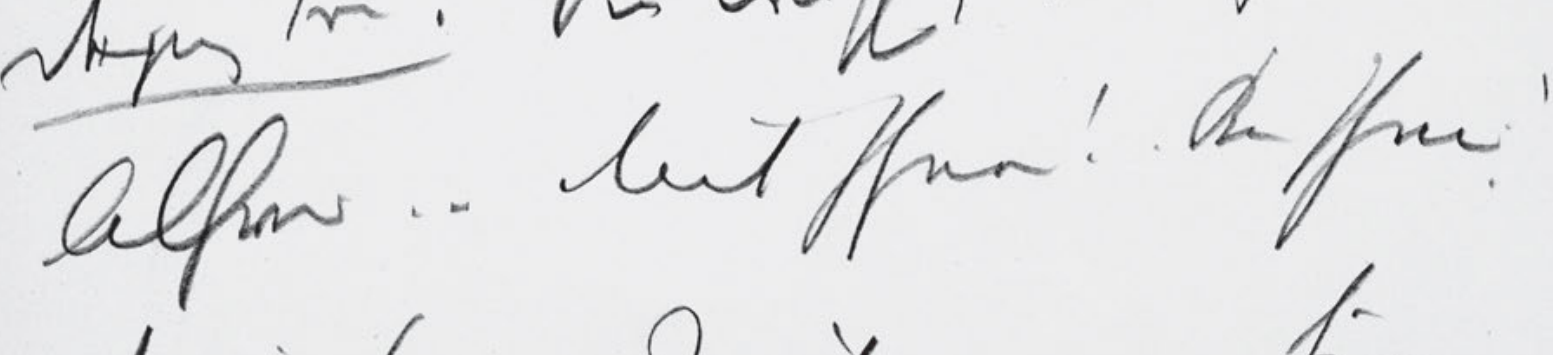
stpisforr. Kut m-fir.

192 
79

fragen, Alfred - und schwören Sie mir, dss Sie mir die Wahrheit sagen werden, AlfrDer jung Herr. Ich schwöre. -

5 Die junge Frau. War in diesen Räumen

schon jemals eine andre Frau .. ? .

Der jung Herr . Aber Ē̄a - dieses Haus

steht schon zwanzig Jahre! -

$\mathrm{D}^{\mathrm{e} i r}$ jung Frau. Sie wissen, was ich meine

10 Alfred . - Mit Ihnen! . Bei Ihnen!

Der jung Herr. Mit mir - hier - 
HSz4 80

Handschriften und Typoskript

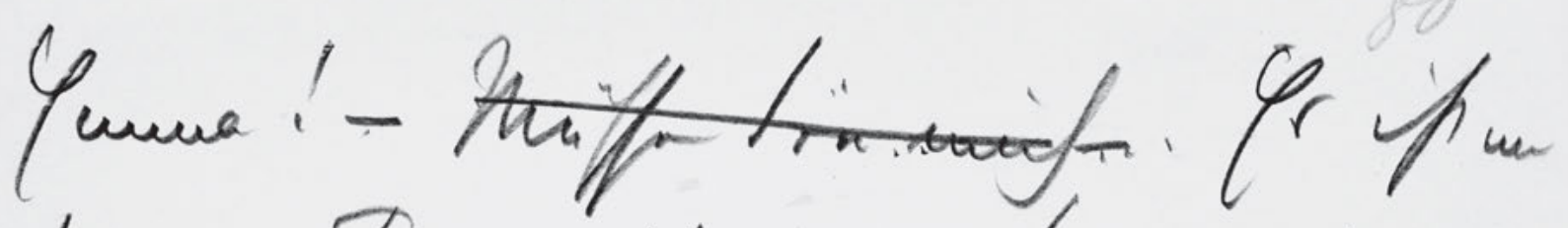

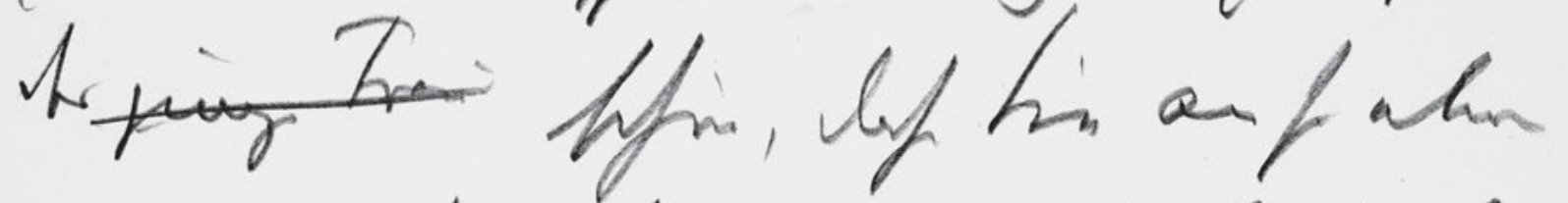

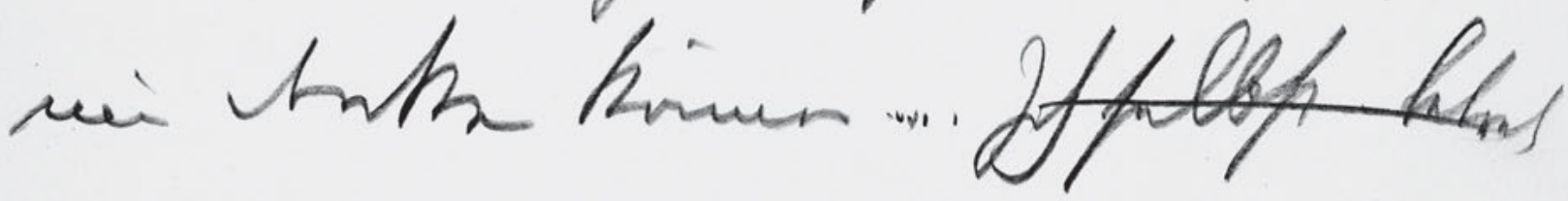

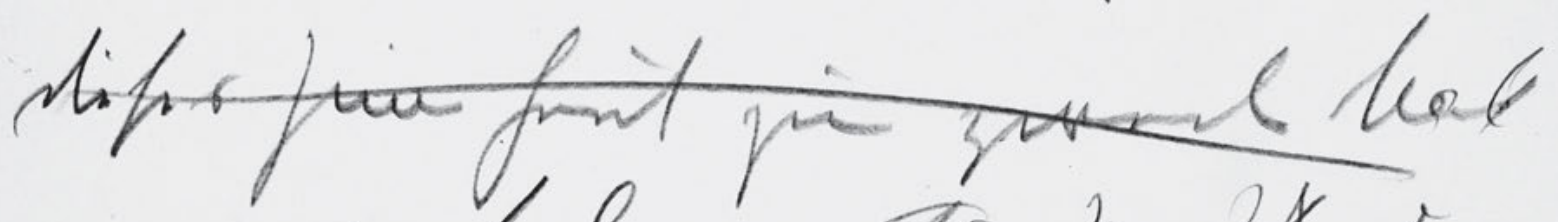

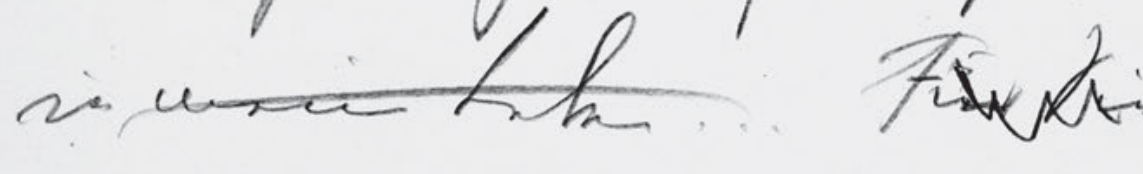

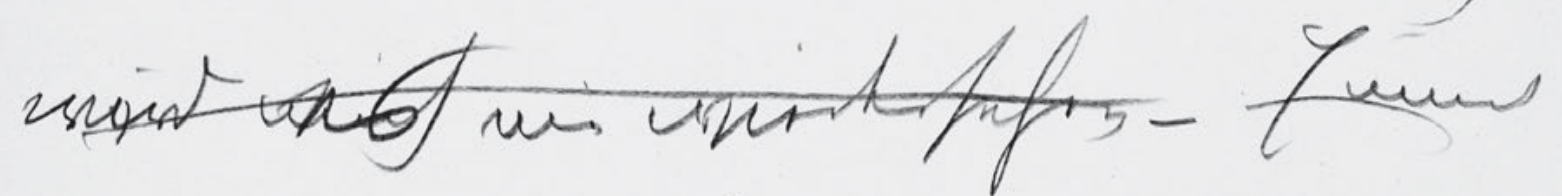
whe of attwin h.

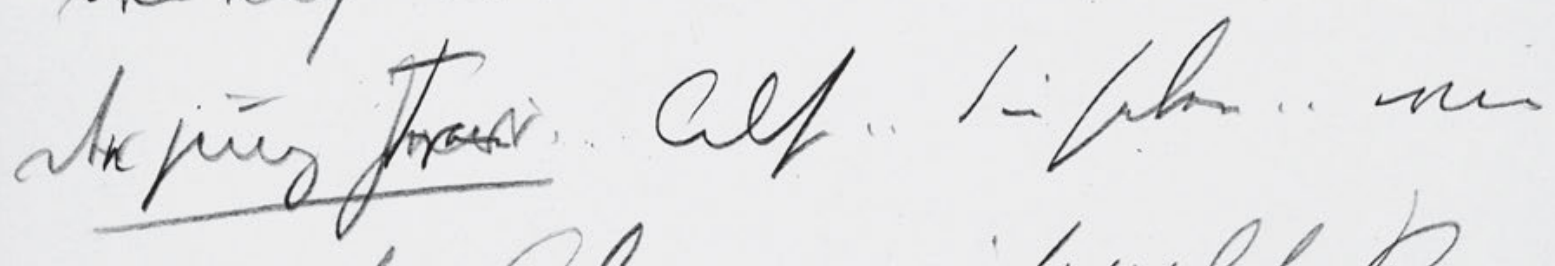
tollif. Ah uni, if well $k$ link wift proy.

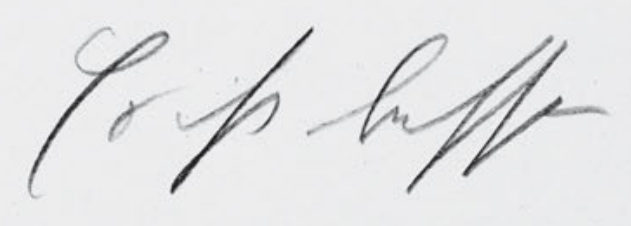

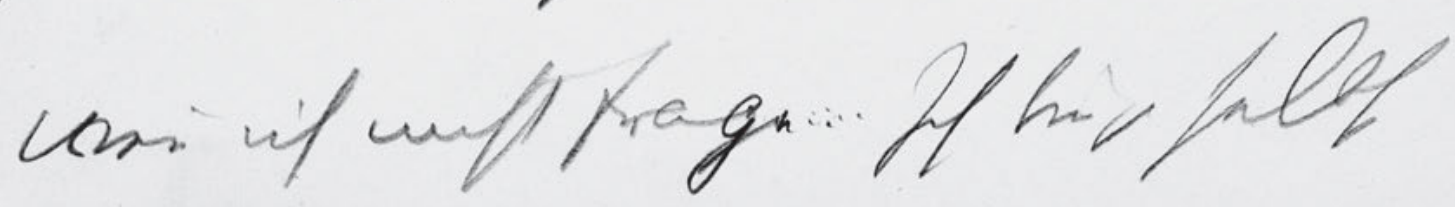

194 
80

Emma! - Müssen Sie “mich ... Es ist nic

Der junge Frau schön, dass Sie an so etwas

nur denken können ..... I Ich selbst . betrete

5 dieses Zimer heut zum zweiten Mal

in meinem Leben .. . Für Sie Und ${ }^{\text {esich }}$

$w^{\text {i }}$ erd ${ }^{\text {mich }}$ es nie wiedersehen - Einmal

war ich allein da..

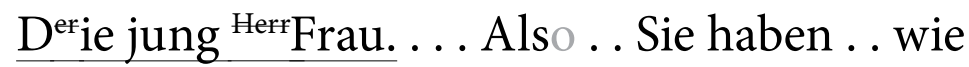

10 soll ich .. Aber nein, ich will Sie

lieber nicht fragen. Es ist besser

weñ ich nicht frage ..... Ich bin ja selbst 
HSz4 81

Handschriften und Typoskript

zpies. Aet wiff inf.

serpingor

s une ak th the '

Mer

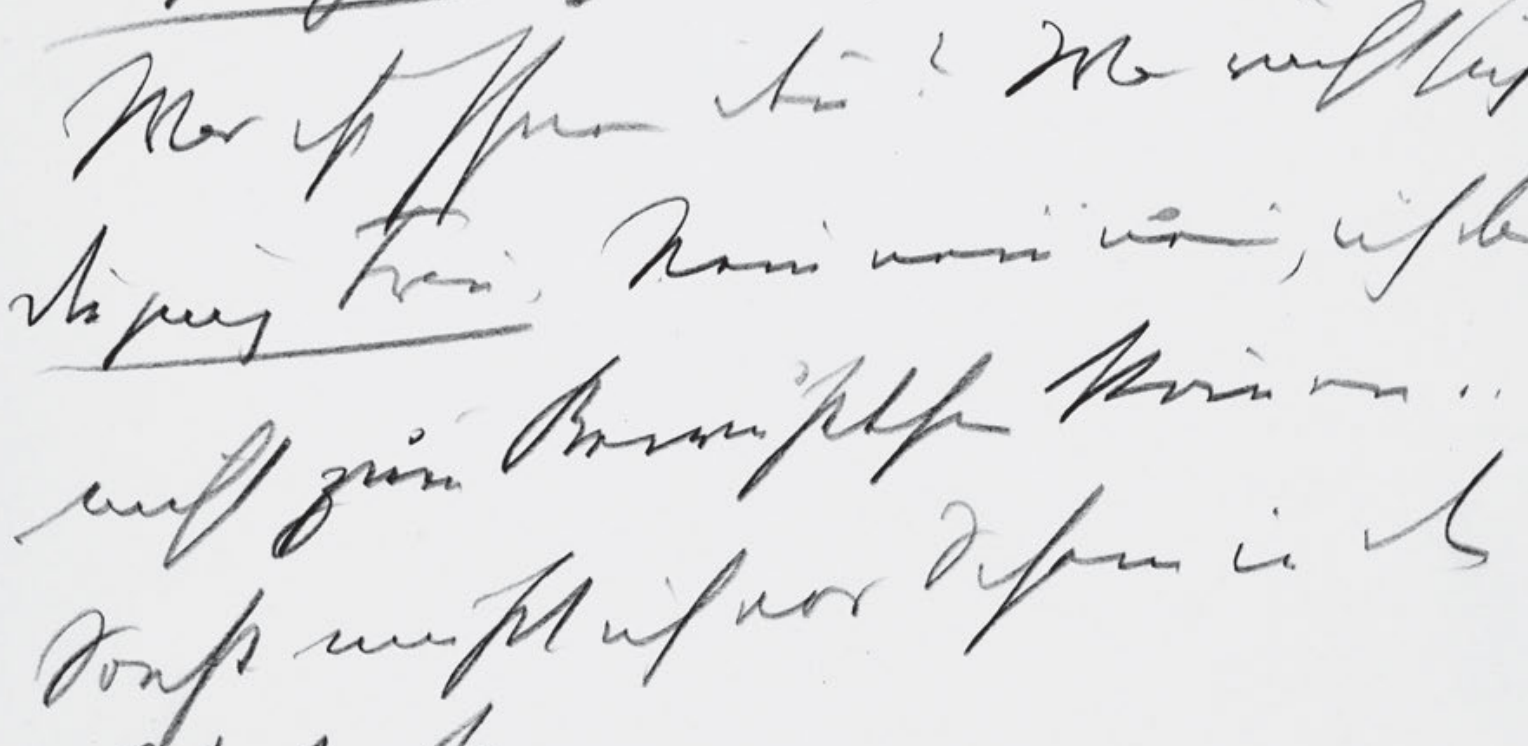

tis 'me mifleif!

hipuy

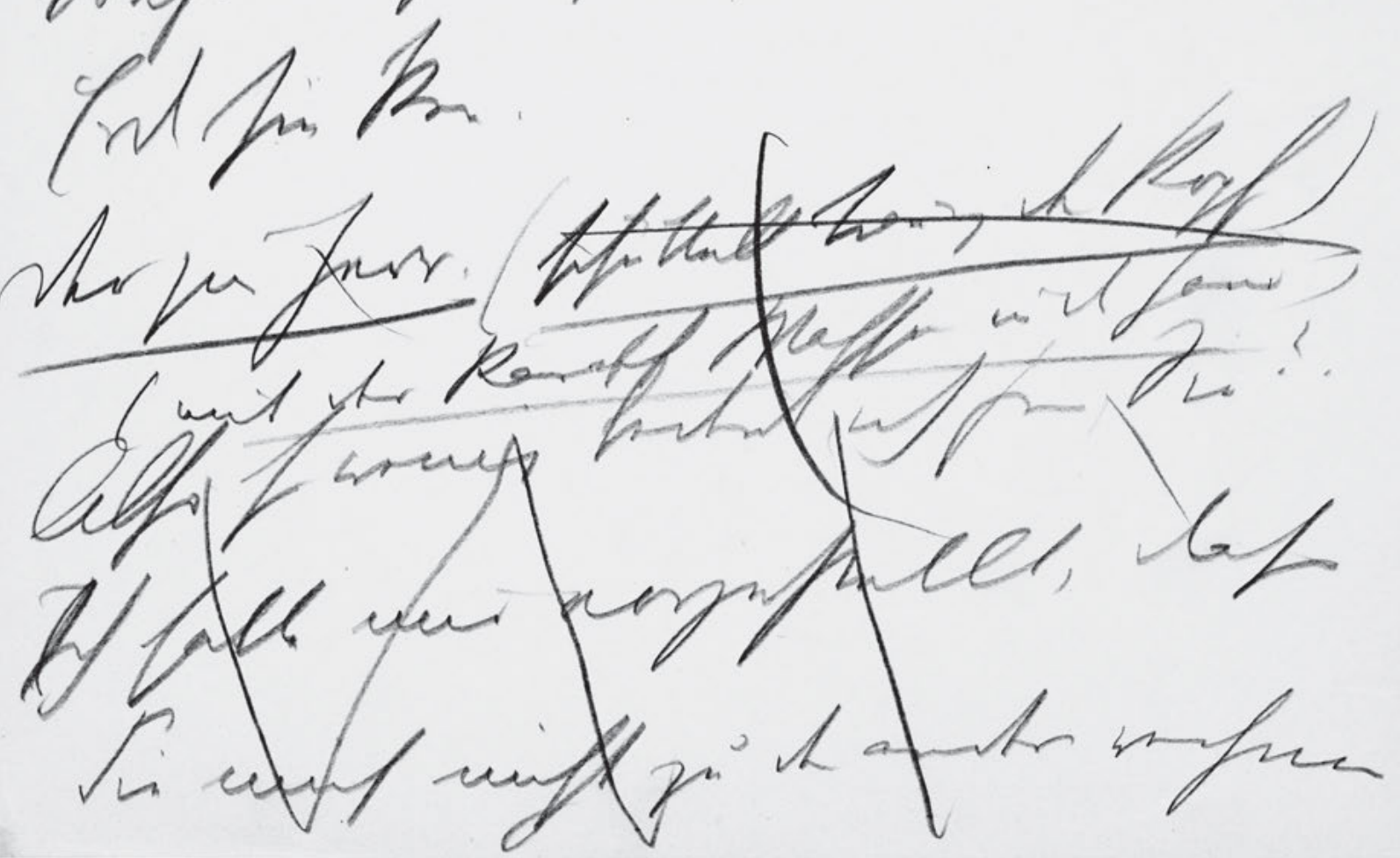

196 
Schuld. Alles rächt sich.

Der jung Herr Ja was haben Sie denn?

Was ist Ihnen deñ? Was rächt sich?

Die jung Frau. Nein nein nein, ich darf

$5 \quad$ nicht zum Bewußtsein komen ..

Sonst müßt ich vor Scham in die

Erde sinken.

Der jun Herr. (schüttelt traurig den Kopf)

(mit der Karaff Wasser in d Hand)

Also so wenig bedeut ich fur Sie? .

10

'Ich hatte mir vorgestellt, dass

Sie mich nicht zu den andern rechnen 
HSz4 82

Handschriften und Typoskript

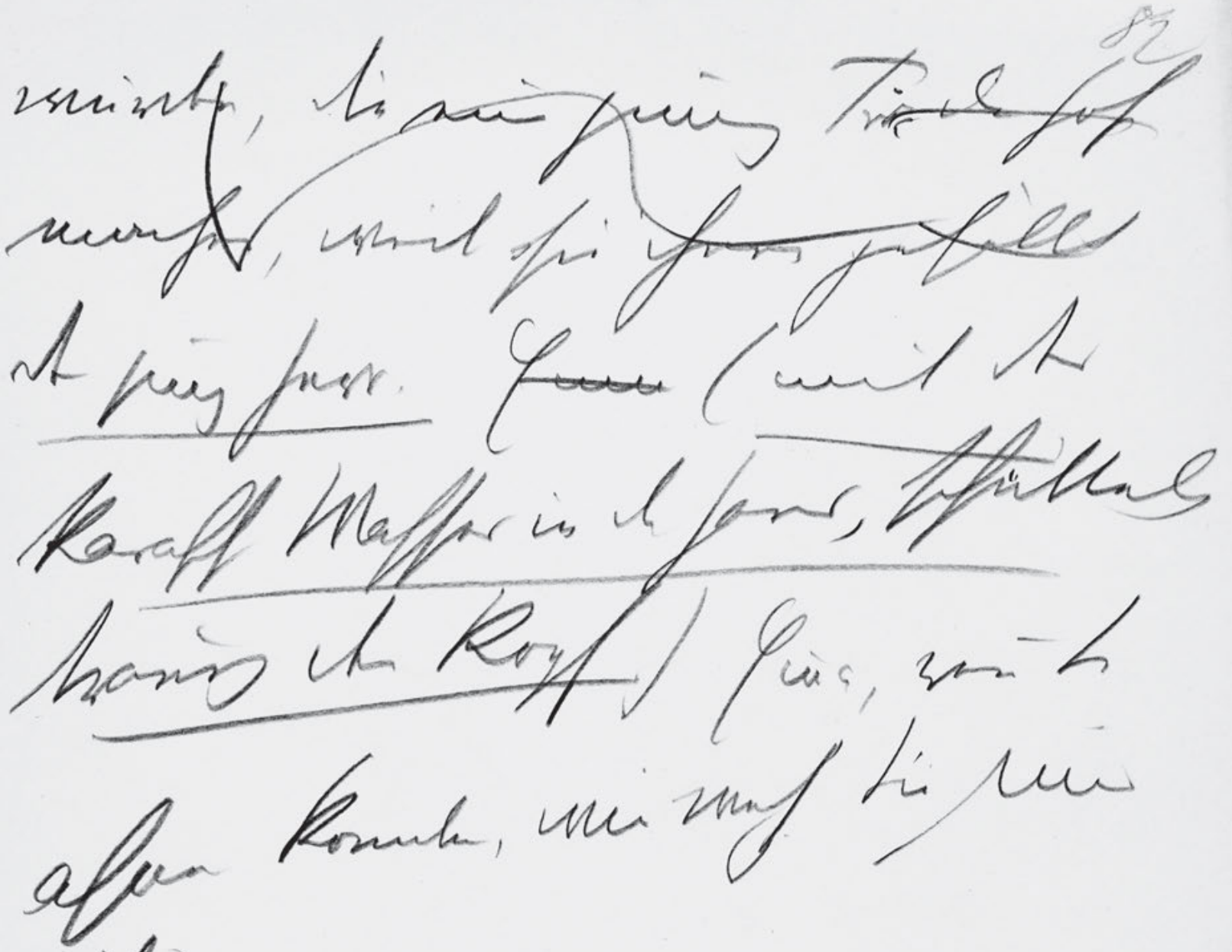

Shim .....

difuis Frum

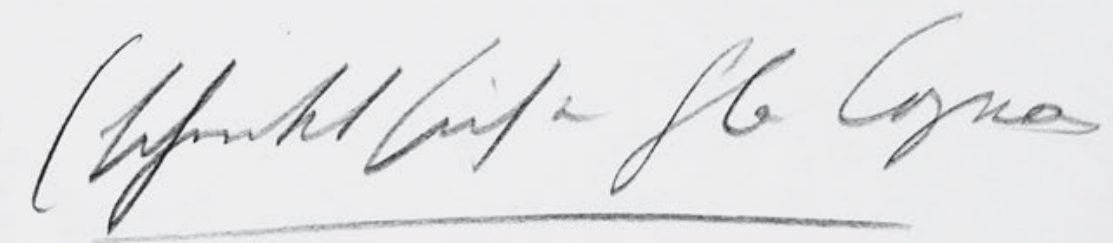

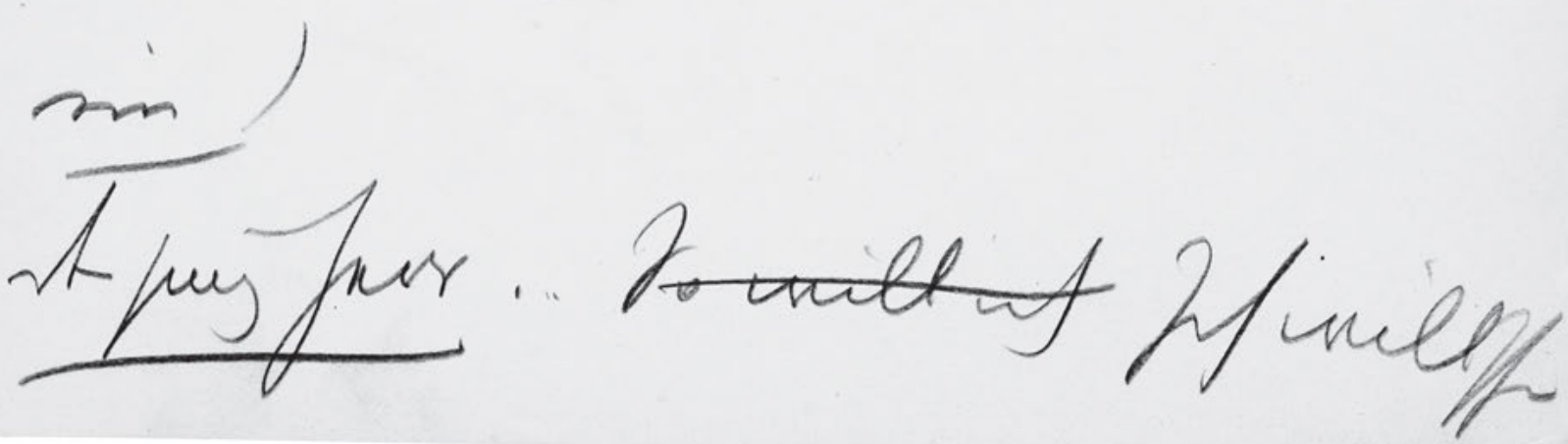

198 
82

würden, die eine jung Frau den Hof

machen, weil ${ }^{[?]}$ sie ihnen gefällt

Der jung Herr. Emma (mit der

$5 \quad$ Karaffe Wasser in der Hand, schüttelt

traurig den Kopf) Ē̄a, wē̄ Sie

ahnen konnten, wie weh Sie mir

thun .......

$\underline{\text { Die jung Frau (schenkt sich ein Glas Cognac }}$

10 ein)

Der jung Herr ... So will ich Ich will Ihn 
HSz4 83

Handschriften und Typoskript

alentor, Yuic Mmi hi wey

th

$$
\text { m }
$$

$$
\text { use / }
$$

$$
\text { men }
$$




\section{3}

etwa sagen, Ē̄a. Wē̄ Sie mich zu

den sich schämen, hier zu sein -

weñ ${ }^{{ }^{i e}}$ Ich ${ }^{\text {mich }}$ Ihnen also gleichgiltg bin -

5 wen Sie nicht fühlen, dass Sie fu

mich die Erlösung und das d all

Seligkeit der Welt bedeuten -

- so gehn Sie lieber -

Die jung Frau. Ja - das werd ich

$10 \quad$ auch thun .. [?]

Der jung Herr. (sie bei der Hand fassend) 
HSz4 84

Handschriften und Typoskript

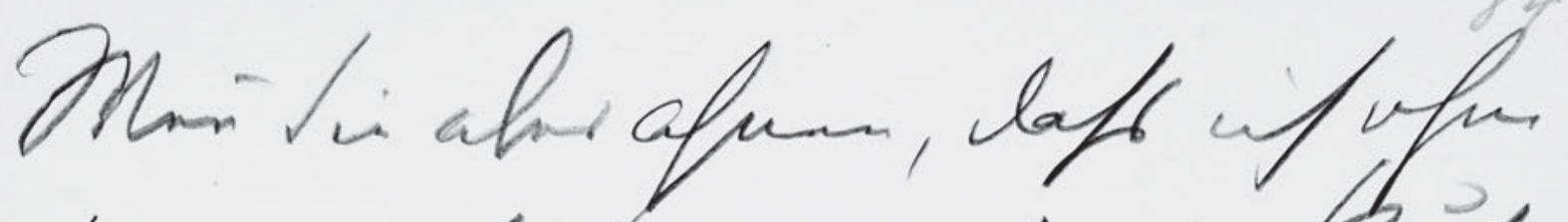

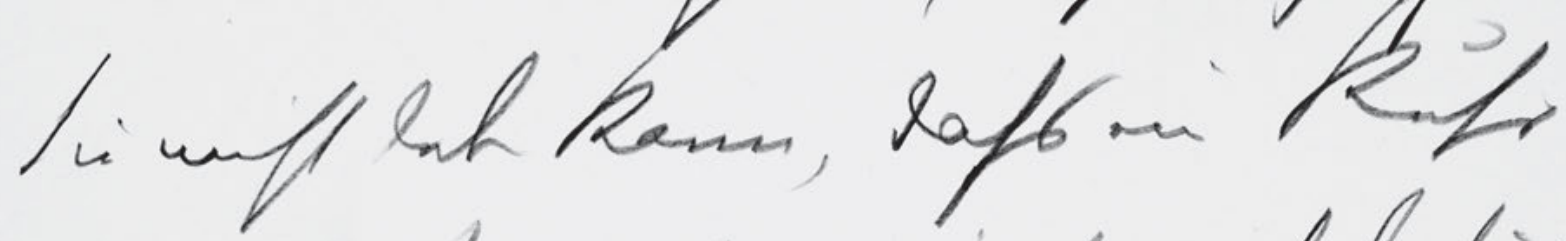

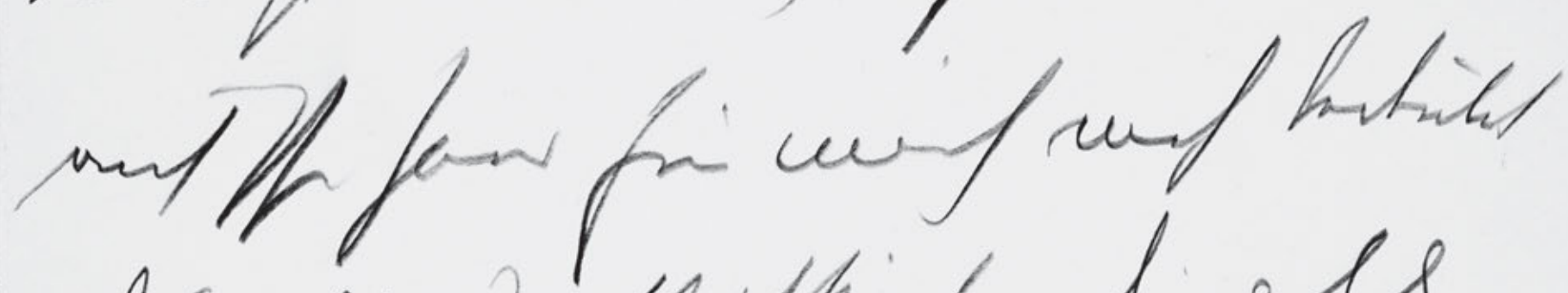

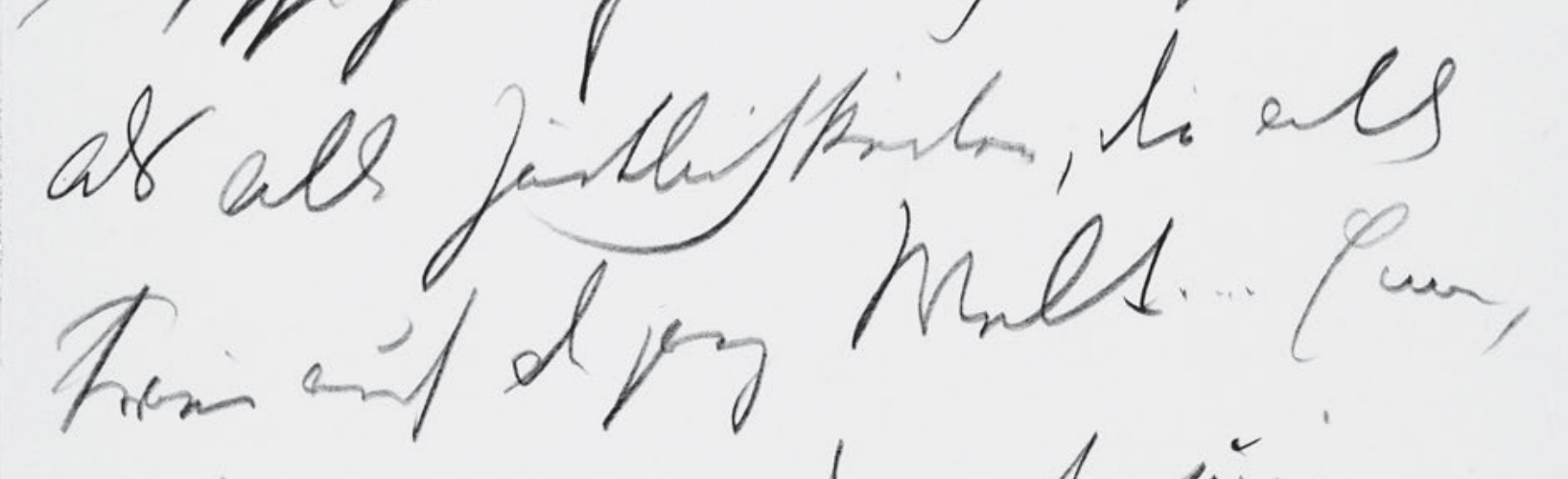
if hi weft mi $\lambda$ and ginis,

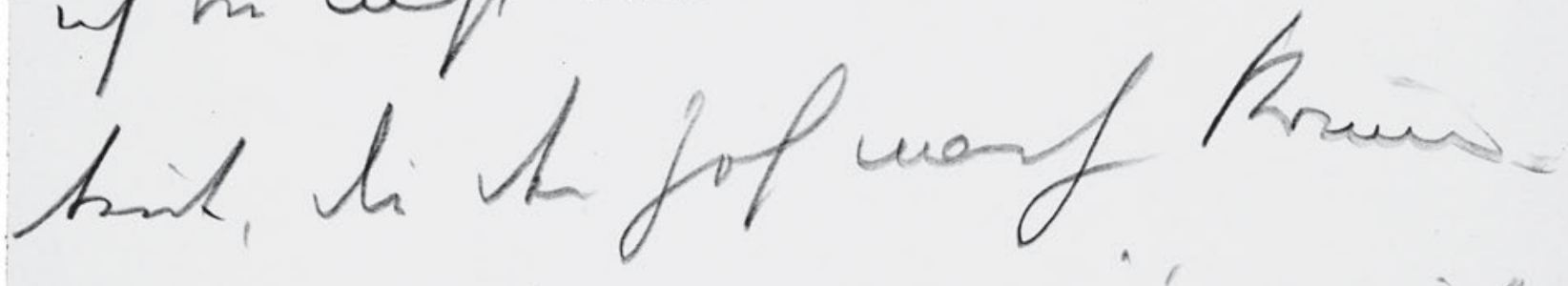
sif himblenf pivars... if

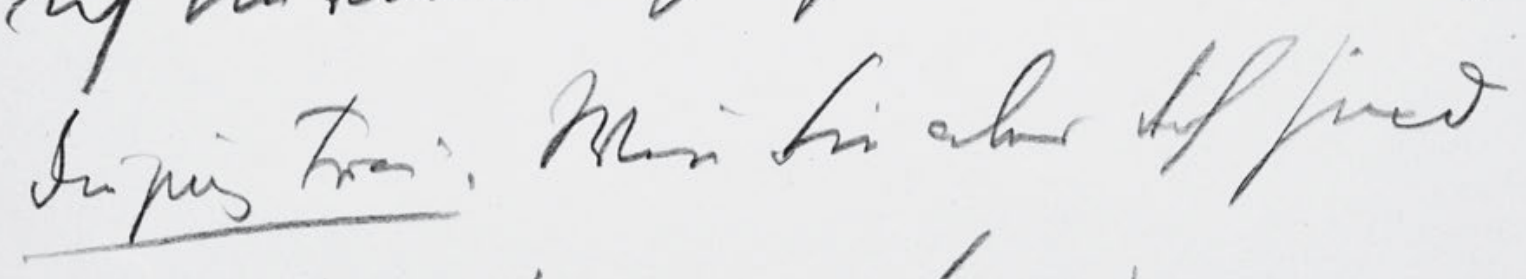
wer I anato pos

202 
84

Wē̄ Sie aber ahnen, dass ich ohne

Sie nicht leben kann, dass ein Kuss

auf Ihre Hand für mich meh bedeutet

5 als alle Zärtlichkeiten, die alle

Frauen auf der ganz Welt .... Emma,

ich bin nicht wie die andern jung

Leute, die den Hof machen können -

ich bin vielleicht zu naiv . . ich . .

10 Die jung Frau. Weñ Sie aber doch sind

wie d andern jung Leute? . . 
HSz4 85

Handschriften und Typoskript

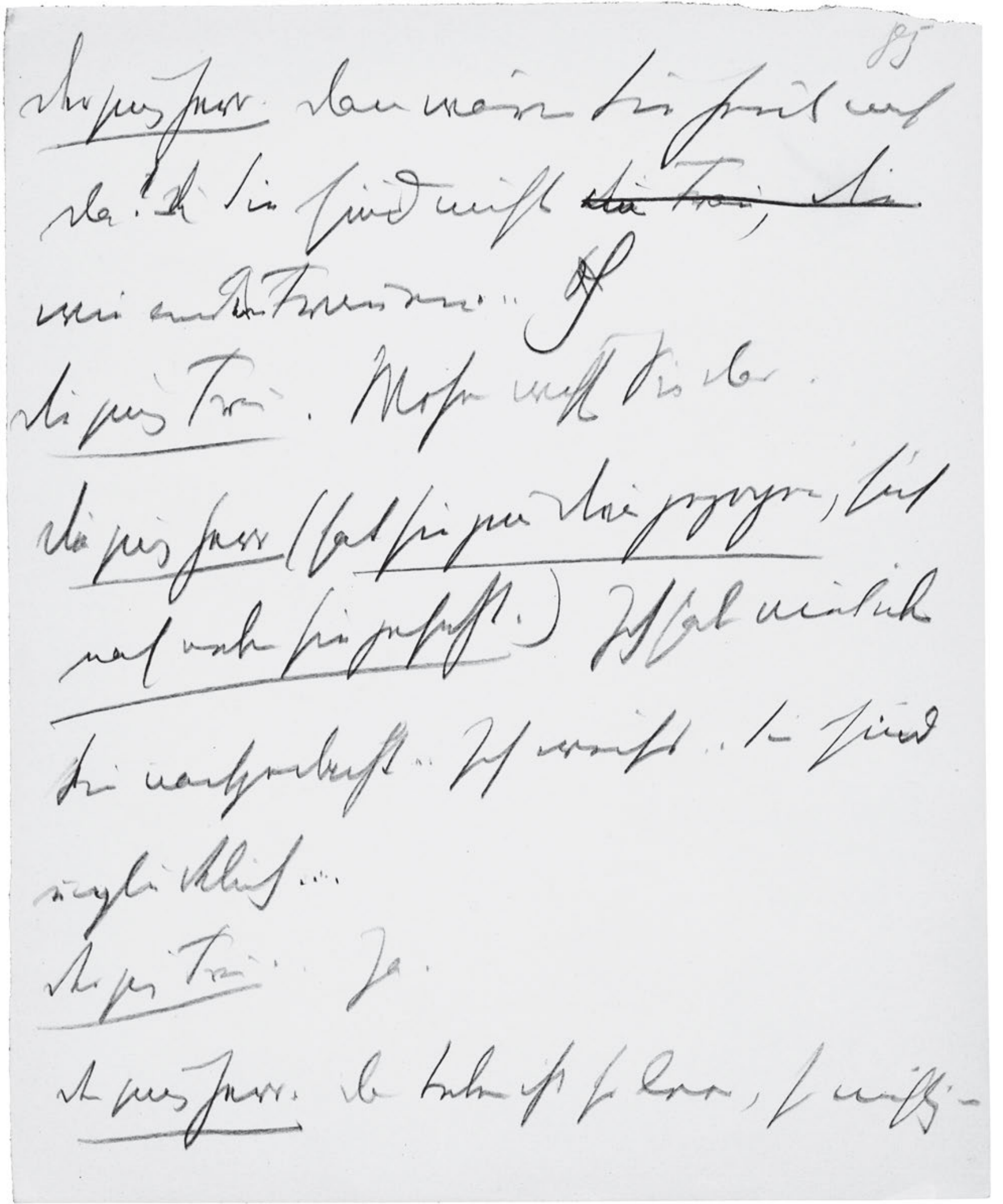


85

Der jung Herr. Dann wären Sie heute nich

da? ! ${ }^{+}$Den̄ Sie sind nicht ${ }^{\text {die }}$ eine Frau, die

wie andere Frauen ... Oh

5 Die jung Frau. Woher wissen Sie das.

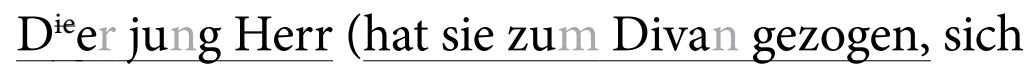

nah neben sie gesetzt.) Ich habe viel über

Sie nachgedacht .... Ich weiss .. Sie sind

unglücklich ......

10 Der jung Frau .. Ja.

Der jung Herr. Das Leben ist so leer, so nichtig - 
HSz4 86

Handschriften und Typoskript

siè lum, - f / Pan -

fang! Io pitt wir

Imethess

7

mint

dipunter

Gat mi cantis tim

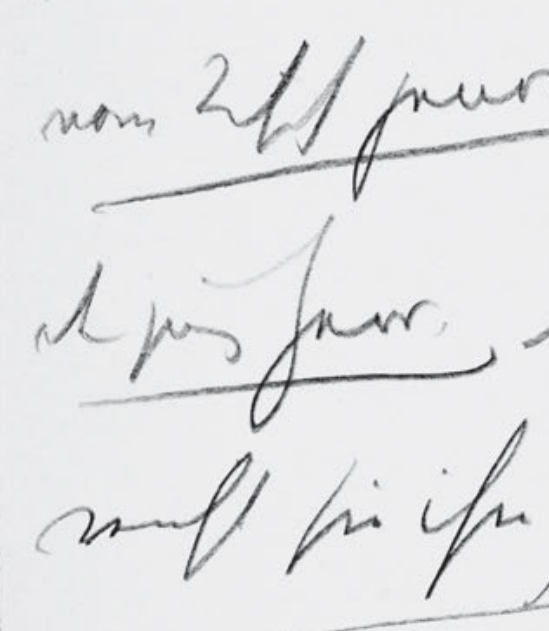

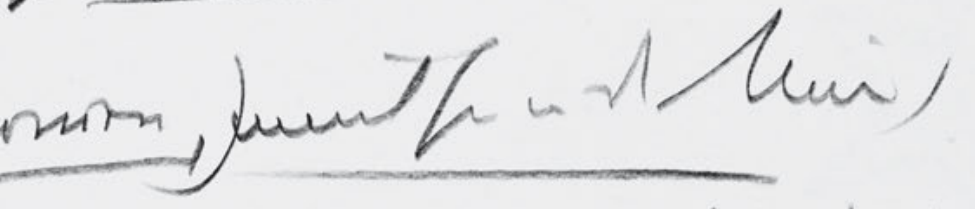

Itex fing to

prapre, hi

lin h

alpt 12 


\section{$8^{7} 6$}

und dann, - so kurz - so entsetzlic

kurz ${ }^{*}$ ! Es gibt nur ein Glück ... .

einen Menschen finden, von dem man geliebt

5 wird -

Die jung Frau (hat eine candirte Birne

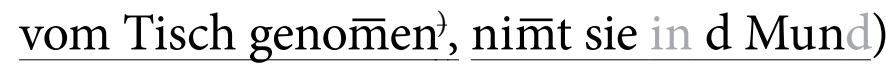

Der jung Herr. Mir die Hälfte! (Sie

reicht sie ihm mit den Lippen:)

${ }_{10} \quad \mathrm{D}^{\mathrm{e}}$ ie junge Frau ${ }^{*}{ }^{\mathrm{nim}}{ }^{\mathrm{m}}$ fasst die Hand des jung

Herrn, die sich zu verirren drohen)

Was thun Sie den̄ Alfred . Ist das 
HSz4 87

Handschriften und Typoskript

Dhrapos.

ch purgars

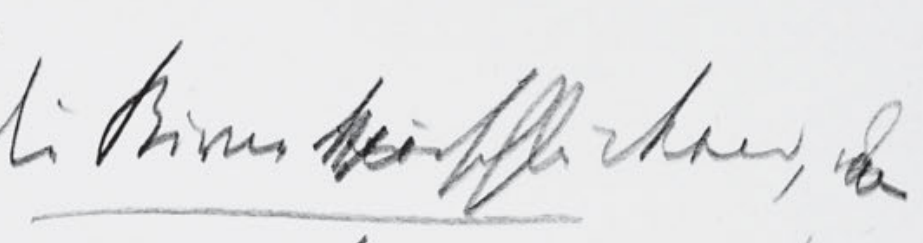

gends kifurs

lar Anbu ip

\%

prig...

Itruers ah

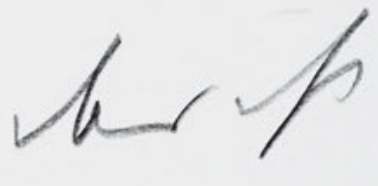

of hom Gou

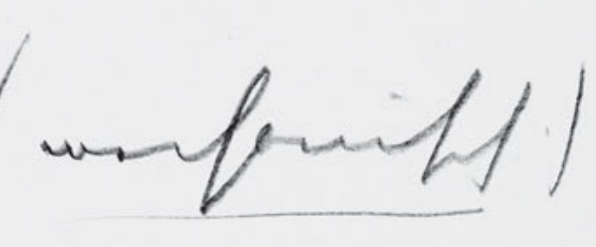

Glja

diguiz Trai.

(ipurif)

Jan

Pi, Cefor, min di
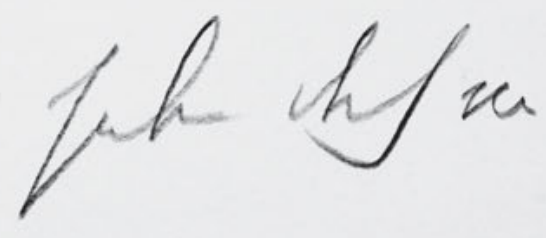

208 


\section{${ }^{6} 87$}

Ihr Versprechen.

Der jung Herr (die Birne kau? ${ }^{\text {ker? }}$ schluckend, ?die?? $\mathrm{wi}^{\text {? }}$

Hände kühner) Das Leben ist so

$5 \quad$ kurz ...

Der jung Frau (schwach) Aber das ist

ja kein Grund -

Der jung Herr (mechanisch.) Ohja . .

Die junge Frau. (schwächer.) Schauen

10 Sie, Alfred, und Sie haben doch ve 
HSz4 89

Handschriften und Typoskript

Usinfon, horn Vun w ipto

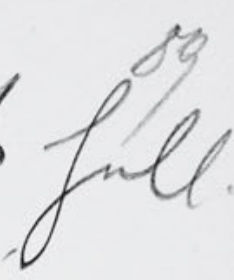

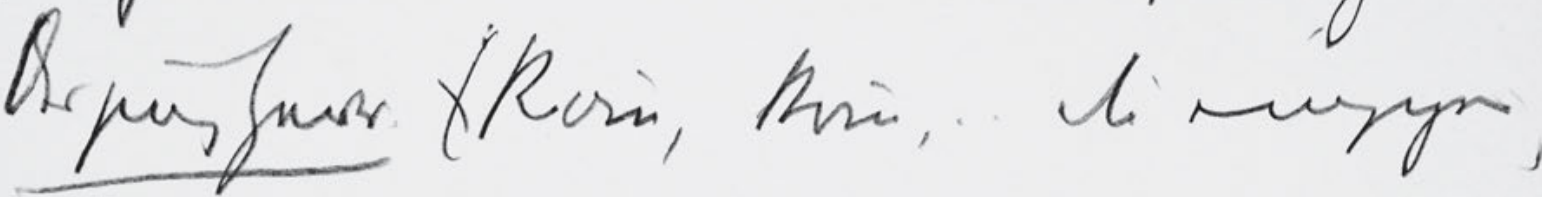

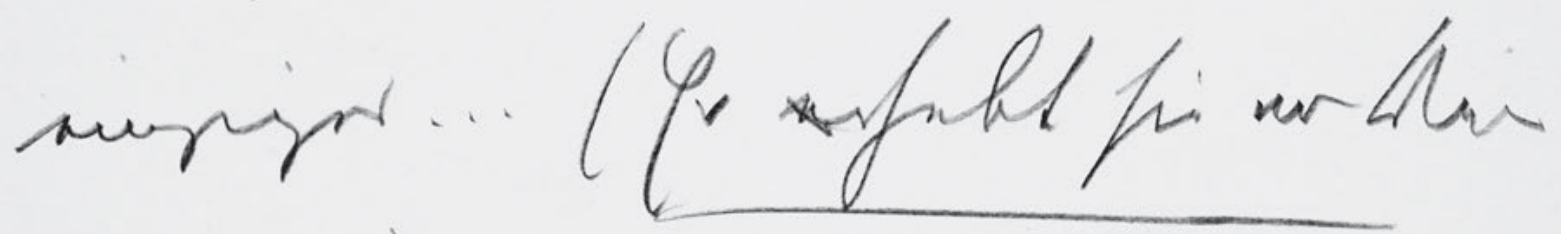
ruger)

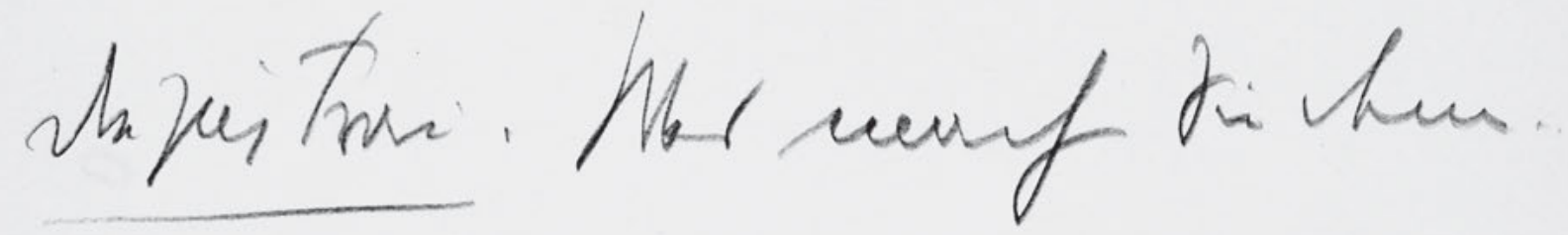

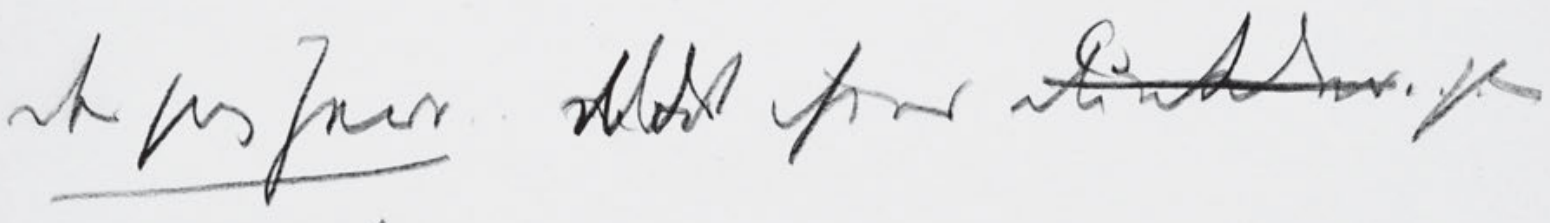
miff frel. th

$$
\text { thing/n }
$$
prim

210 
89

sprochen, brav .... Und es ist so hell . .

Der jung Herr. (Kō̄, kō̄, . d du einziges, einziges ... (Er erhebt sie vom Divan

5 empor)

Die jung Frau. Was machen Sie denn . .

Der jung Herr. . DortDa d ist es dunkler. “ gar

nicht hell.

Die jung Frau. Ist deñ d noch ein

10 Zimer... 
HSz4 90

Handschriften und Typoskript

sougfor

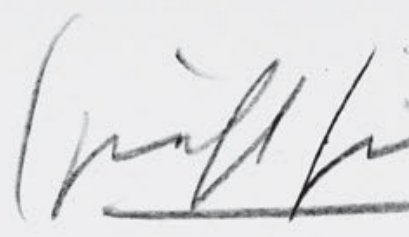

il

virima

himtas

hajers trom.

Bhal mish

$\varphi$

pro

sher piry juor.

L

2

repretis

dipuig Fon.

Ps ping fo...

of ore

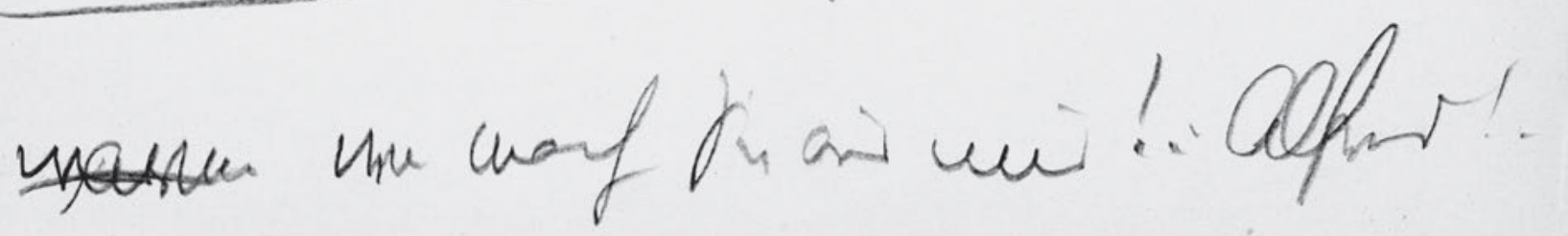

212 


\section{0}

Der jung Herr (zieht sie mit.) Ein

schönes .. und ganz dunkel.

Die jung Frau. Bleiben wir doch lieb

5 hier.

Der junge Herr. (bereits mit ihr hinter

den Portiéren, im Schlafzī̄er,

nestelt ihr die Taille auf)

Die jung Frau. Sie sind so ... Oh Gott

$10 \quad$ warum was machen Sie aus mir! . Alfred! . 
HSz4 91

Handschriften und Typoskript

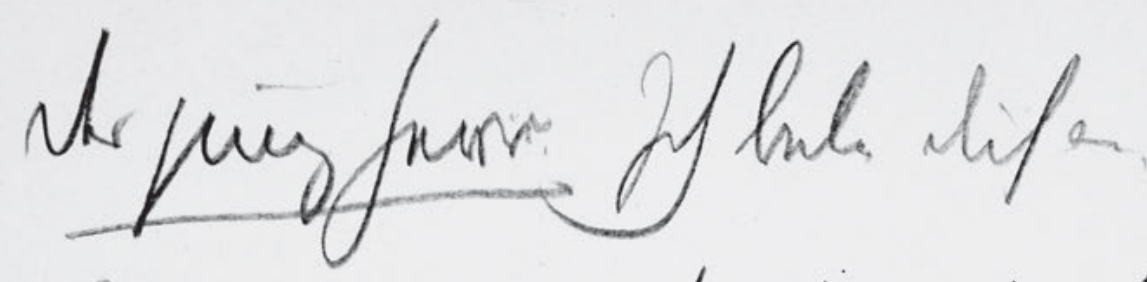

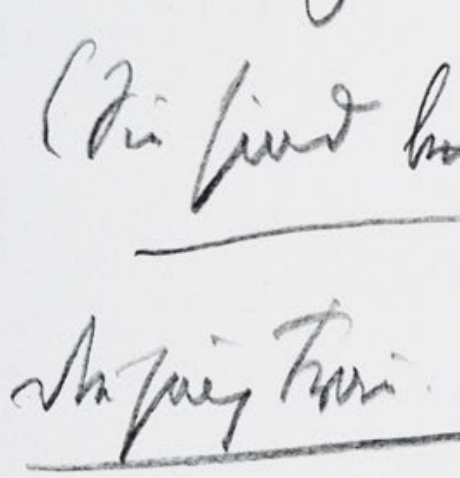

Yune

shem..

$\frac{\text { sh mour }}{\text { dignitor }}$

lijuginer

$$
\text { vifep.thr }
$$

ther 1

liguiz trui

If hay

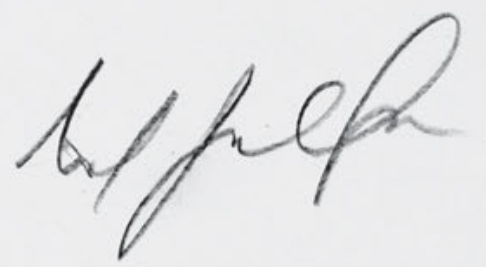

havrnglt we ja ald 
91

Der jung Herr. Ich bete dich an, Emma! .

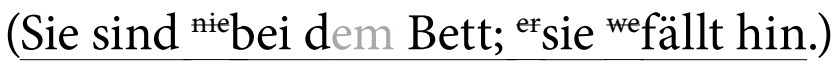

Die jung Frau. .. So wart doch .. wart doch

(Schwach)

5 wenigstens .. Geh ... ich ruf dich ...

dann . .

Der jung Herr Laß mich doch helfen.

Die jung Frau . Du zerreißt mir ja alles

Die jung Herr. Du hast . . kein Mied an

10 Die jung Frau. Ich trag nie ein Miede. 
HSz4 92[a]

Handschriften und Typoskript

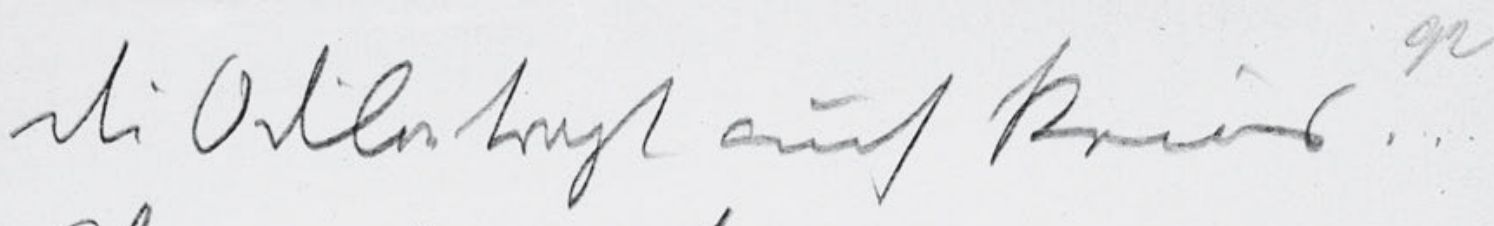

Alor da jistkaung hi un

onfthurphls..

L pusfors (the

thefie pro Tup

uighold afigh a.d

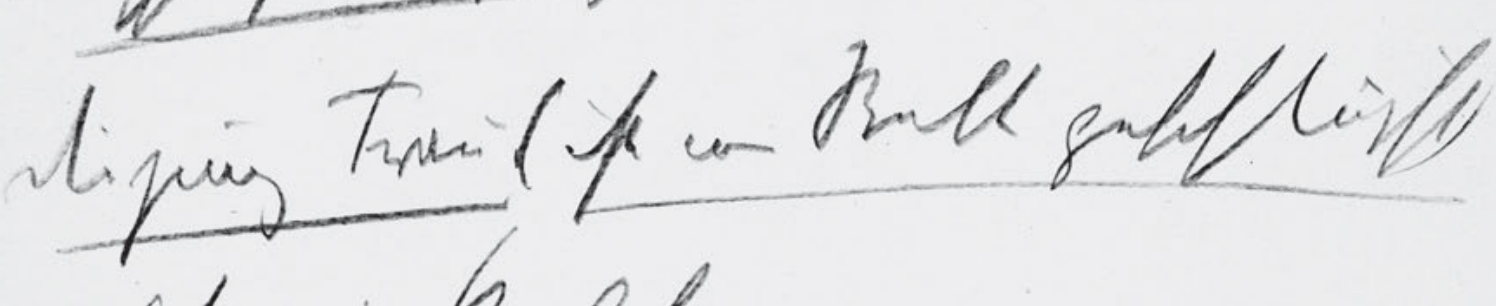

Gum Rall.

Lejper theifinad mas

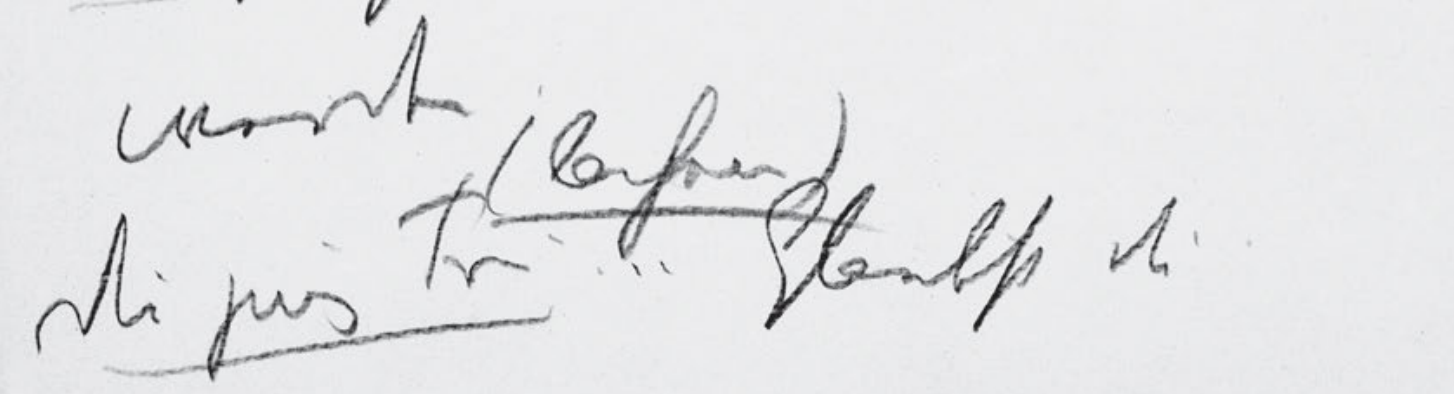

216 
Die Odilon tragt auch keins ...

Aber die Schuh kannst du mi

aufknöpfeln. -

5 Der jung Herr (knöpfelt die Schuhe auf,

küsst ihre Füße)

Die jung Frau (ist ins Bett geschlüpft)

Oh wie kalt.

Der jung Herr. Gleich wirds war

10 werden.

(lachend)

Die jung Frau ... Glaubst du. 
HSz4 92[b]

Handschriften und Typoskript

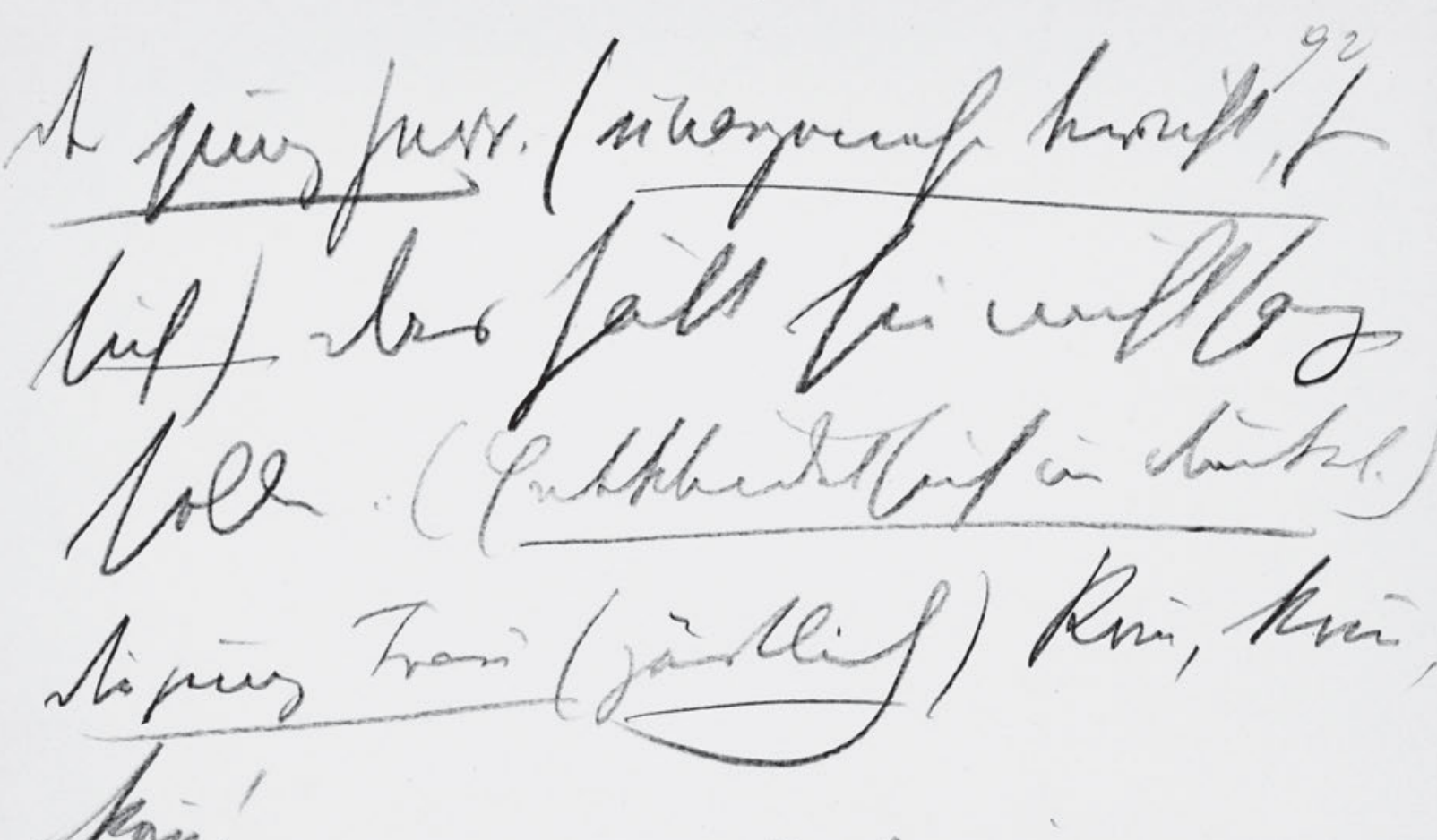

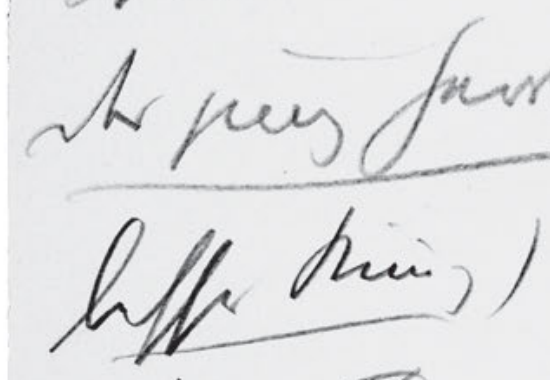
Shifies Tro.
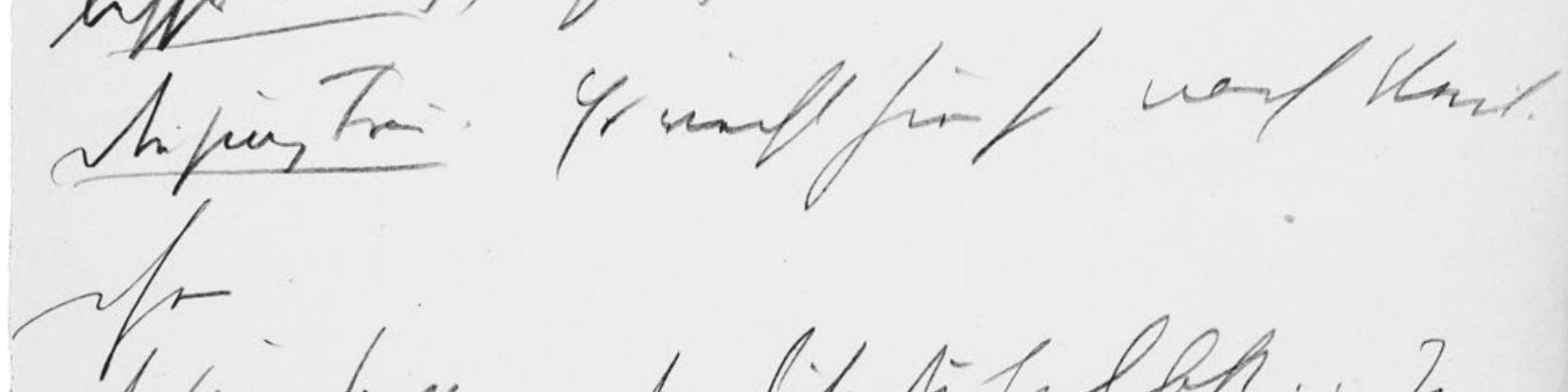

theng far...

( 2 ifi.)

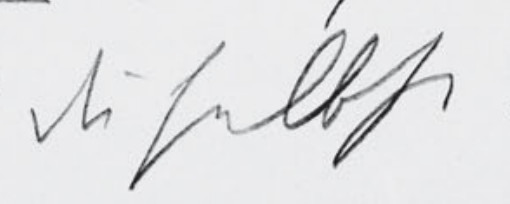

. 2 
Der jung Herr. (unangenehm berüht, für

sich) Das hätt sie nicht sagen

sollen .. (Entkleidet sich im Dunkl.)

${ }_{5}$ Die jung Frau (zärtlich) Kō̄, kō̄, kom!

Der jung Herr (dadurch wieder in heitre bessr Stī̄g) Gleich - - [?]

Die jung Frau. Es riecht hier so nach Veil-

10 chen

Der jung Herr. .. Das bist du selbst . . Ja

.. . (Zu ihr.) du selbst . . 
HSz4 93

Handschriften und Typoskript

lipure tre
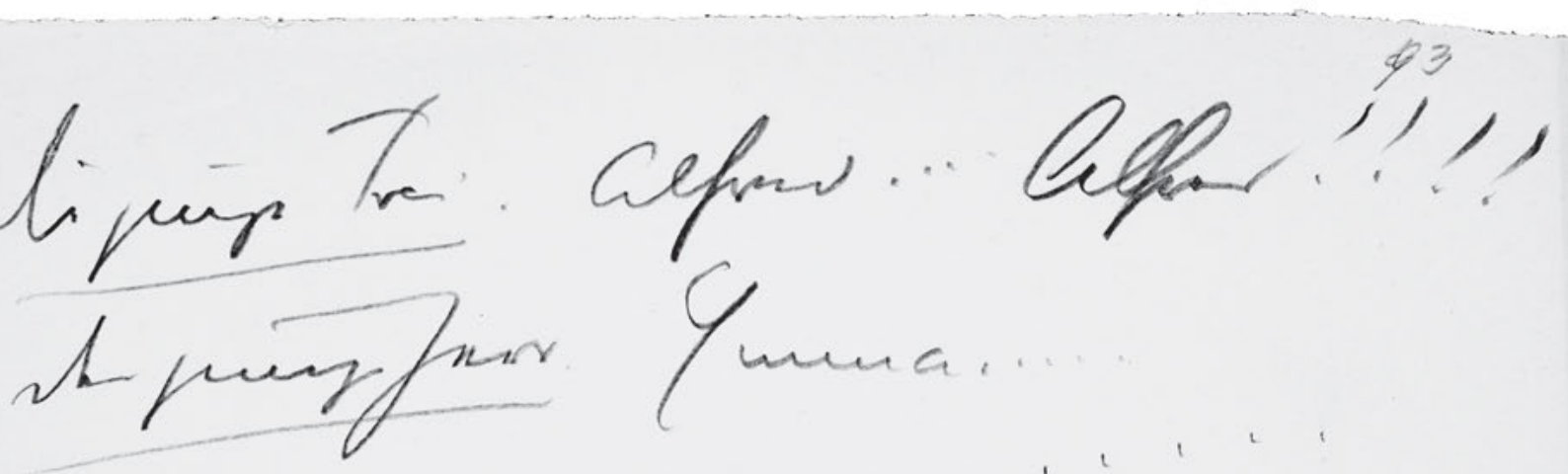

Gmua....

st pung jors. Ifath he

hit ge... if
Miging Trum

w.... di gerym

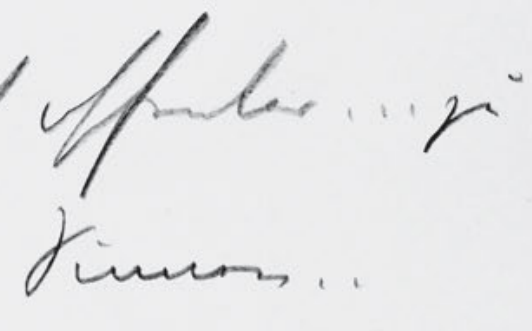

renger

slfom min

st ping forr.

Opunf

weft. Yr ifter pons

sulepmasfoniby

uxern tuen

220 
93

Die junge Frau. Alfred .... Alfred!!!!

Der junge Herr. Emma .....

${ }_{5} \quad$ Der junge Herr. .. Ich habe dich offenbar ... zu

lieb . . ja . . ich bin wie von Sinnen . .

Die junge Frau.........

Der junge Herr. ... Die ganzen Tage über bin

ich schon wie verrückt ... Ich habe geahnt...

10 Die junge Frau. Mach dir nichts draus..

Der jung Herr. Oh gewiss nicht. Es ist ja gerade

selbstverständlich .. wenn man . . 
HSz4 94

Handschriften und Typoskript

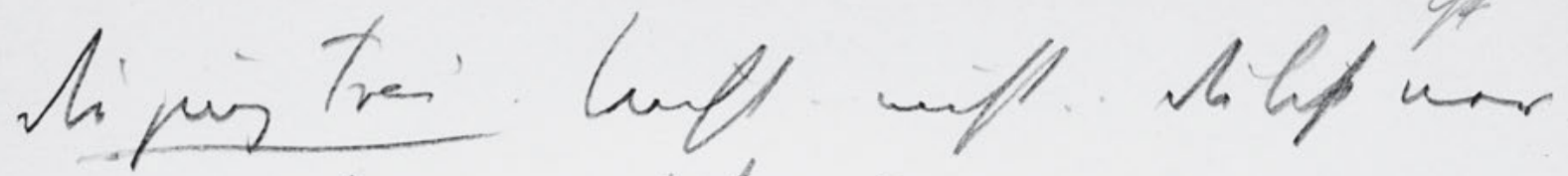

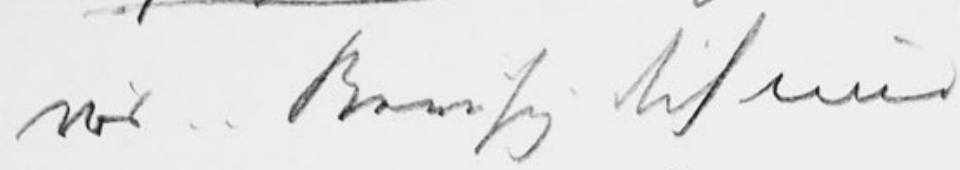

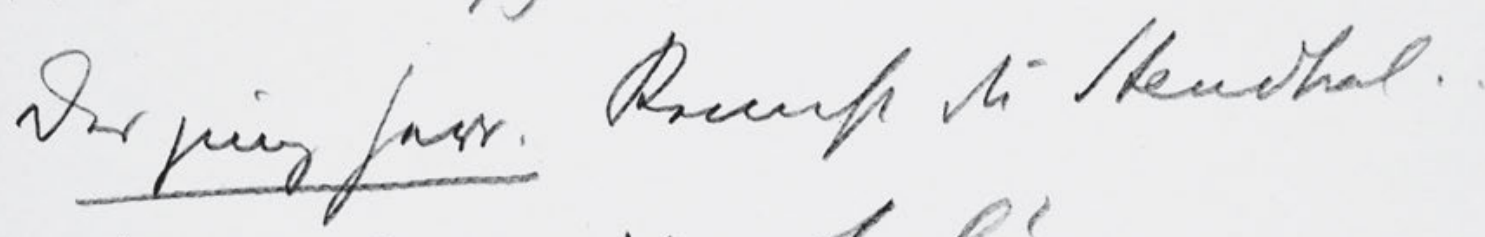
Stigis to

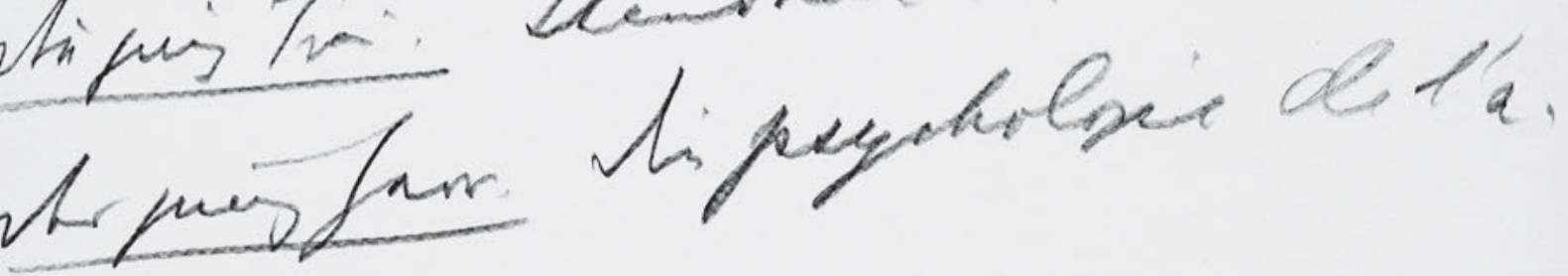
monar

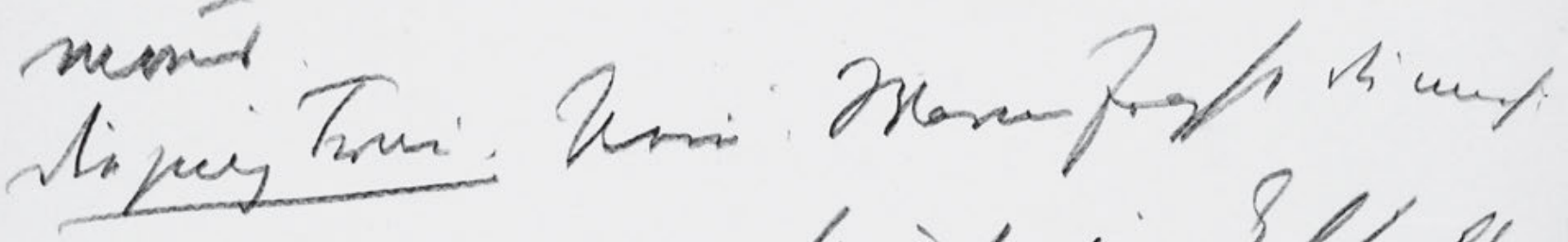
ste nuigener do henit nim fo

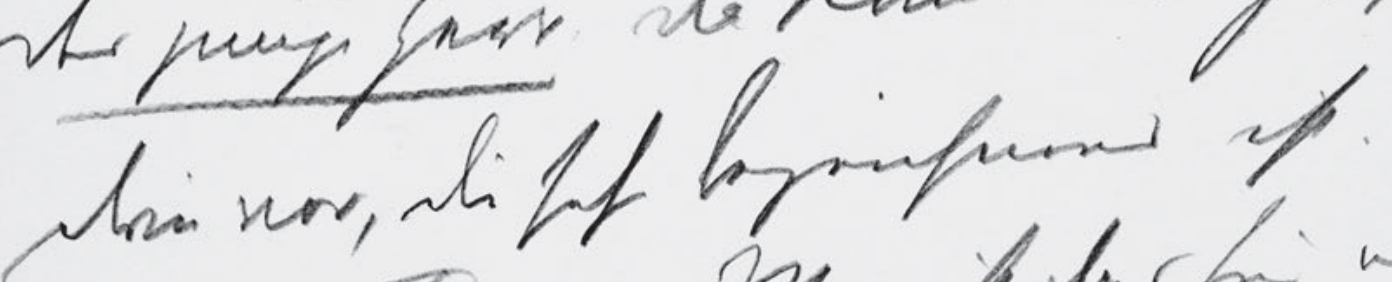

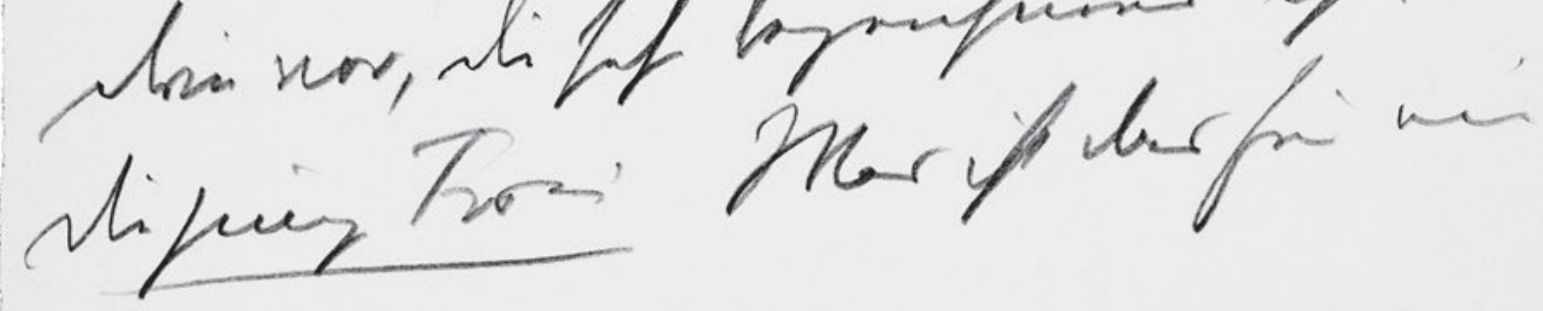
fophifs

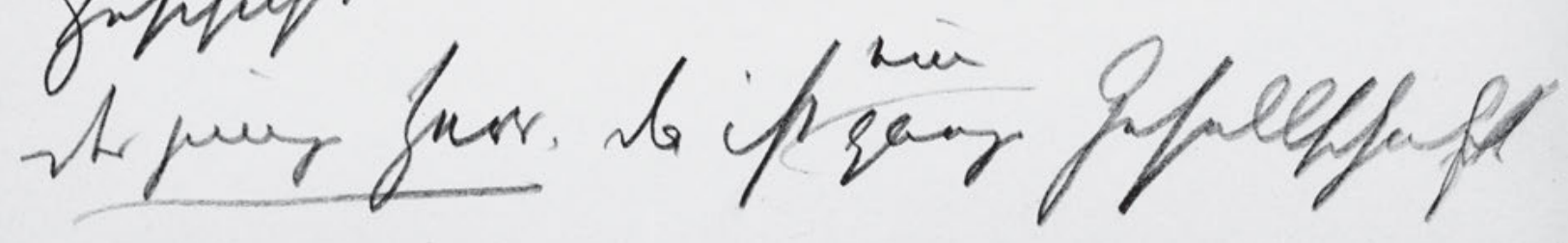

222 
94

Die jung Frau . Nicht . . nicht . . du bist ner-

vös .. Beruhig dich nur . .

Der junge Herr. Kennst du Stendhal . .

$5 \quad$ Die jung Frau. Stendhal? .

Der jung Herr. Die psychologie de l'a-

mour.

Die jung Frau. Nein. Warum fragst du mich.

Der junge Herr. Da kō̄t eine Geschicht

drin vor, die sehr bezeichnend ist.

Die junge Frau Was ist das für ein

Geschichte?

eine

Der junge Herr. Da istganze Gesellschaft 
HSz4 95

Handschriften und Typoskript

xm Canalhn offinongrain thiging Tusin. Do

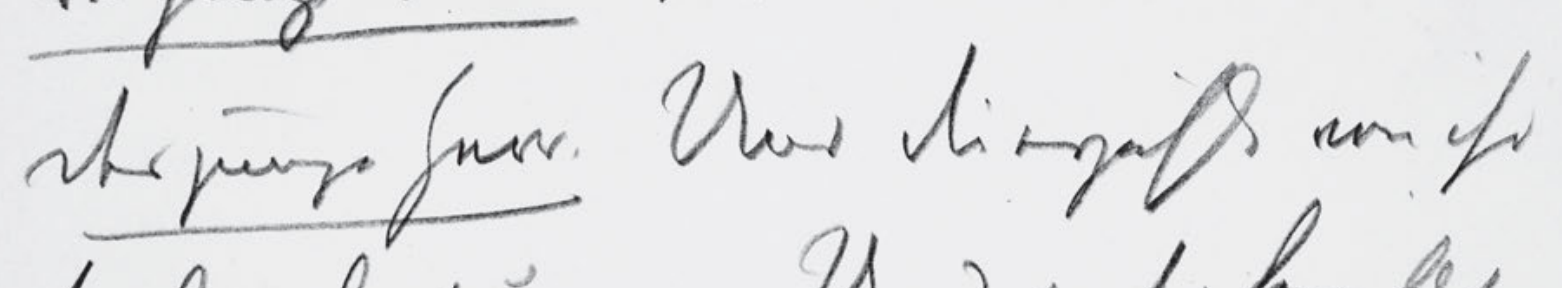

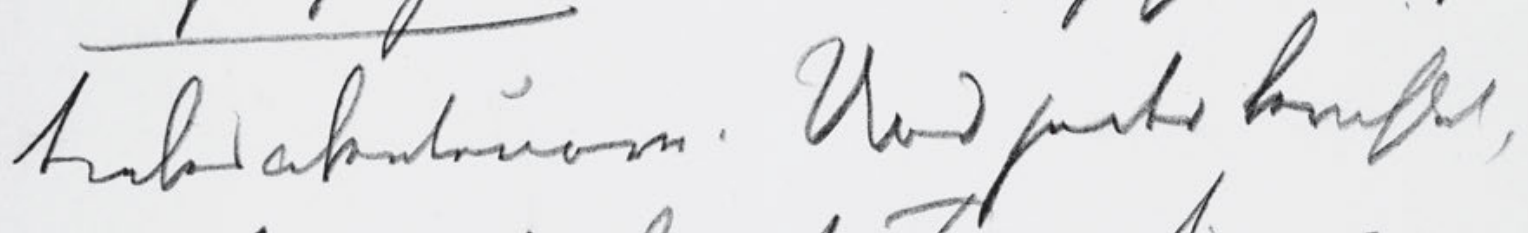

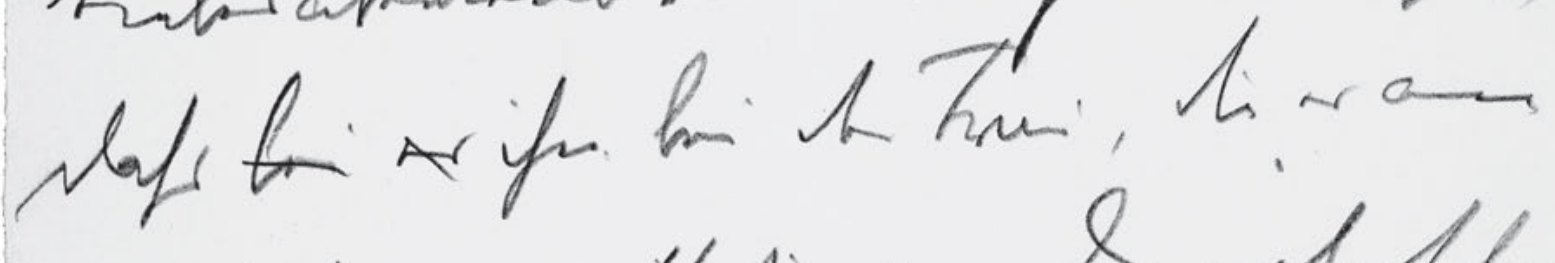
uriph, weft is,

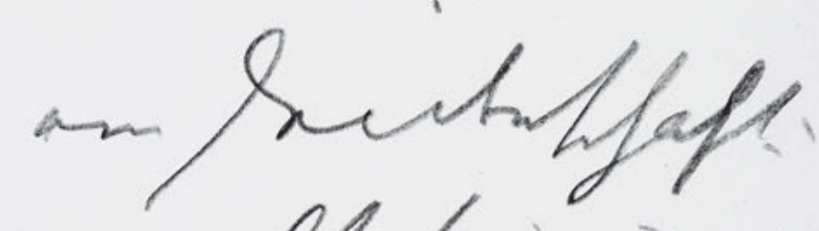

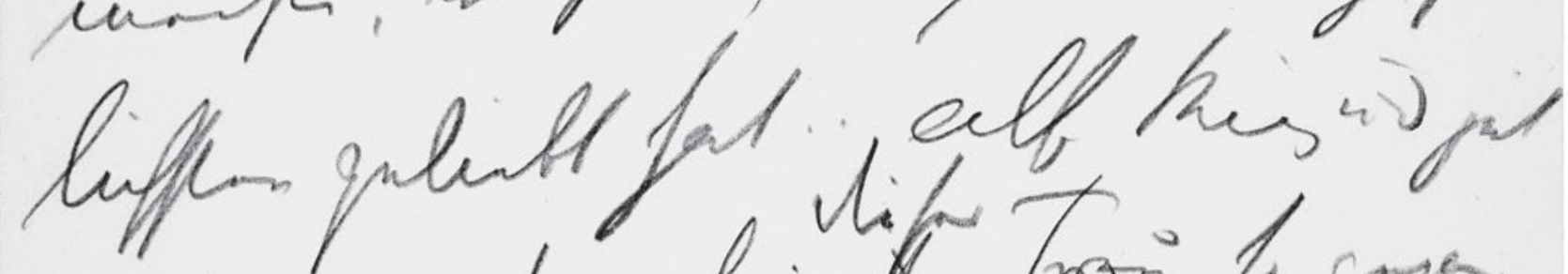

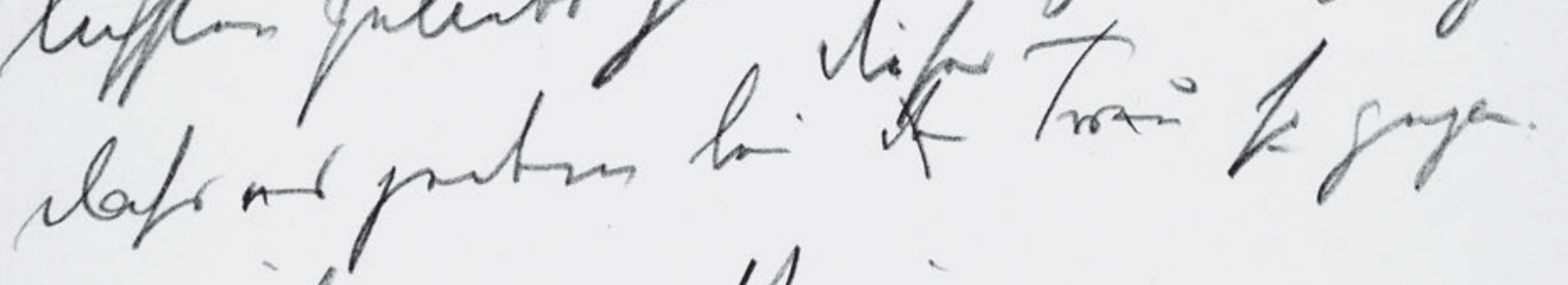
grop wi py mir. Mipuis tra Ja.

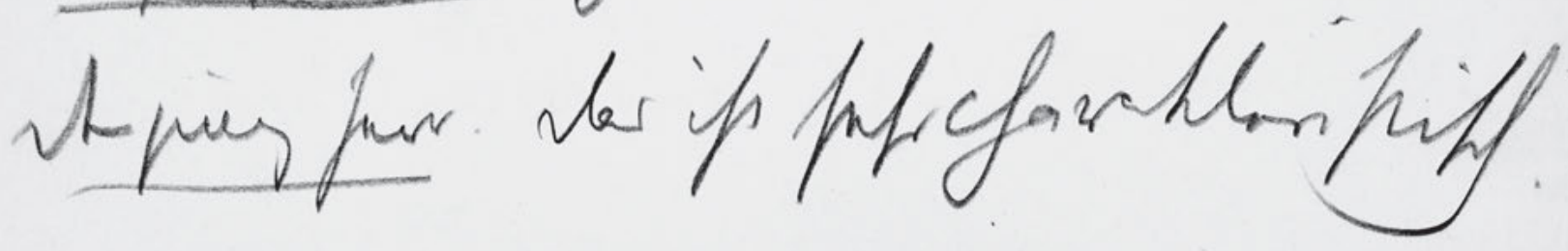

224 


\section{5}

von Cavallerieoffizieren zusā̄en.

Die junge Frau. So.

Der junge Herr. Und die erzähl von ihr

5 Liebesabenteuern. Und jeder berichtet, dass bei er ihn. bei der Frau, die er am meisten, weißt du, am leidenschaft $=$ lichsten geliebt hat .. also kurz und gut dieser dass es jedem bei der Frau so gegan10 gen ist wie . jetzt mir . .

Die junge Frau. Ja.

Der jung Herr. Das ist sehr charakteristisch. 
HSz4 96

Handschriften und Typoskript

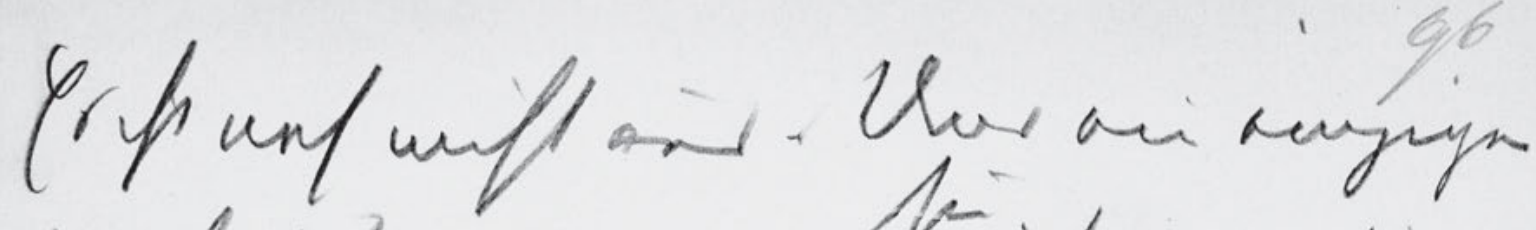
Atheright. or wer fin in for ven tak ung wifl aflist, ab, whollenithal fingn, - ba un lmarifuph trambarb. hipier tre $\partial_{0}$.

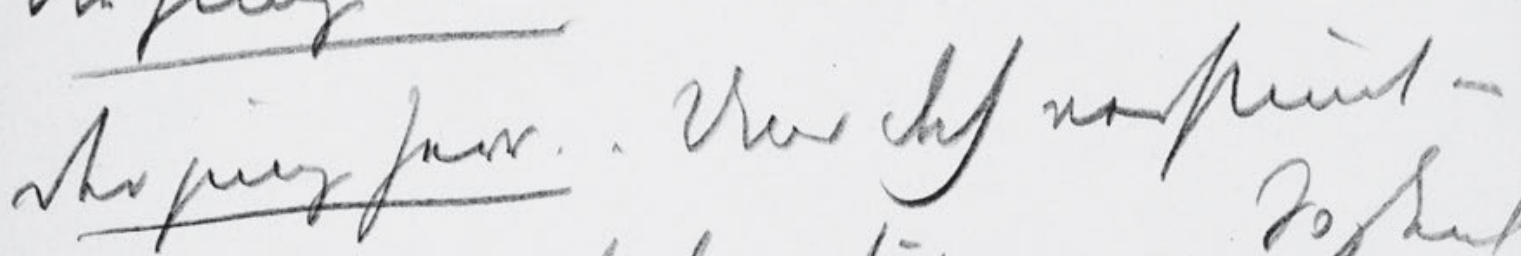
sime, br fither timum. Po hal pls wrymalift.

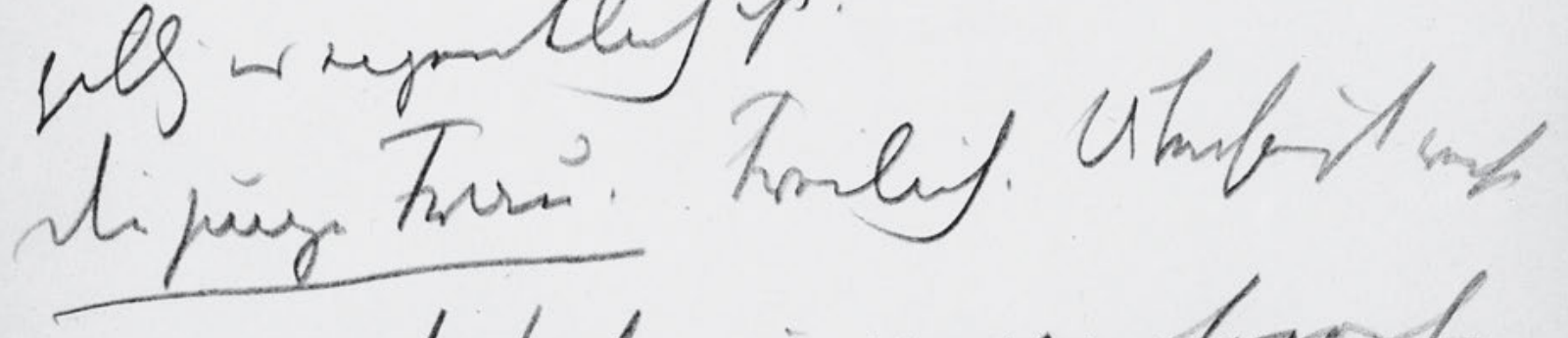
sip..tifapmirg antrofo

226 
96

Es ist noch nicht aus - Und ein einziger

sei

hat behauptet . . es wäre $\mathrm{ihm}$ in sein

ganzen Leben noch nicht passirt, aber,

5 setzt Stendhal hinzu, - das war ein

berüchtigter Brambarbas,

Die junge Frau . So. -

Der junge Herr. . Und doch verstim̄t es

einen, das ist das dumme .. So gleich-

10 giltig es eigentlich ist.

Die junge Frau. Freilich. Überhaupt weiß

du ja . . du hast mir ja versprochen

11 punktförmige Verschmutzung nach Frau.. 
HSz4 97

Handschriften und Typoskript

hern pifini.

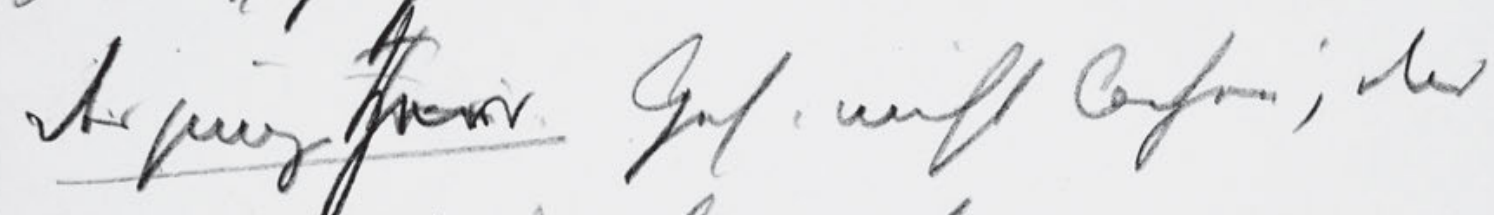

biffrit taf unfe.

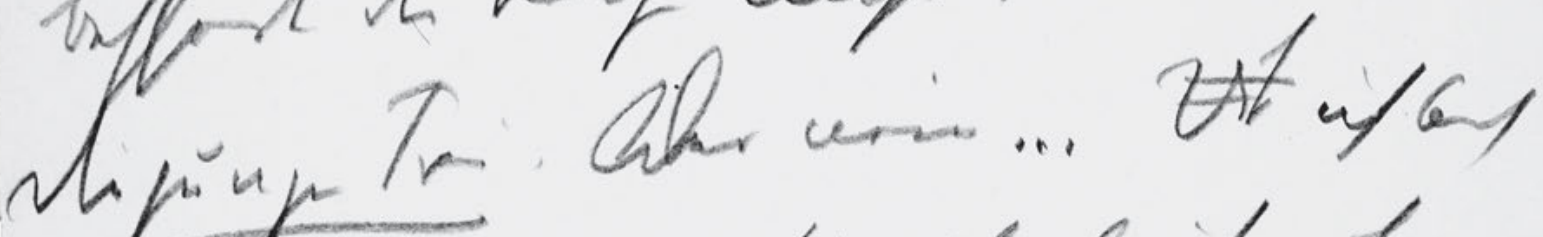

ry

$\checkmark$ mift. var un thewital if th nus

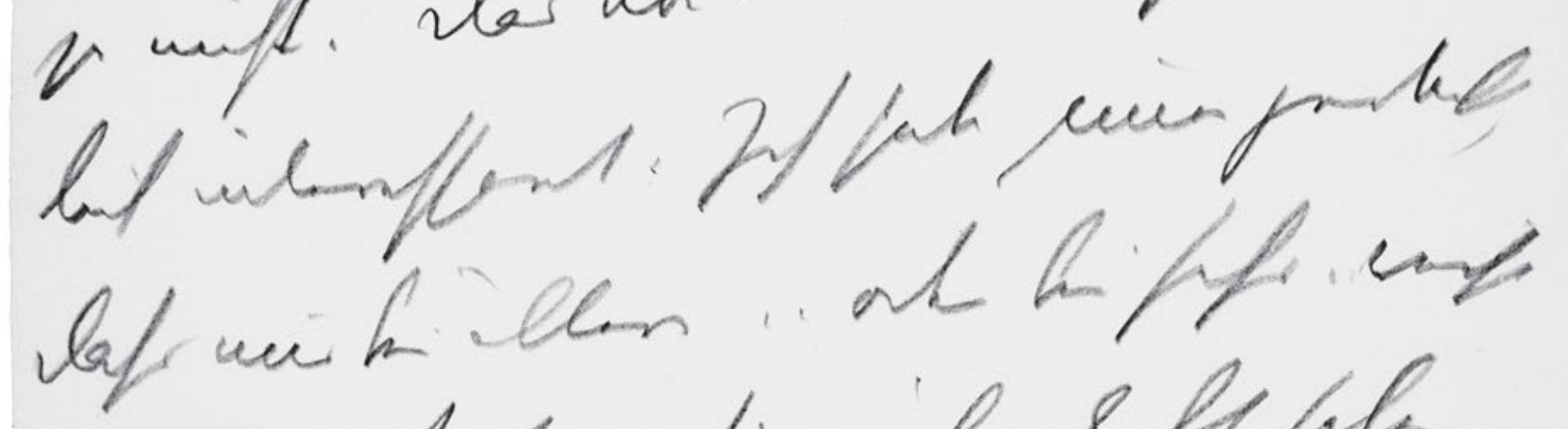
silfor Arovion, li wit pustefila. 
brav zu sein . .

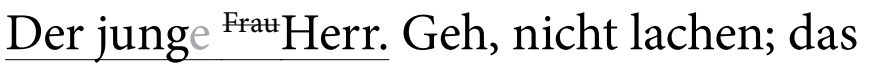
bessert die Sache nicht.

${ }_{5} \quad$ Die junge Frau . Aber nein ... U ${ }^{\text {? }}$ ? ich lach ja nicht. Das von Stendhal ist üb wirklich interessant. Ich habe ī̄er gedacht, dass nur bei ältern . . oder bei sehr . . weist du, bei Leuten, die viel gelebt haben.

${ }_{10} \quad$ Der junge Herr. Was fallt dir ein? !

Das hat damit gar nichts zu thun.

Ich habe übrigens die hübschest Geschich 
HSz4 98

Handschriften und Typoskript

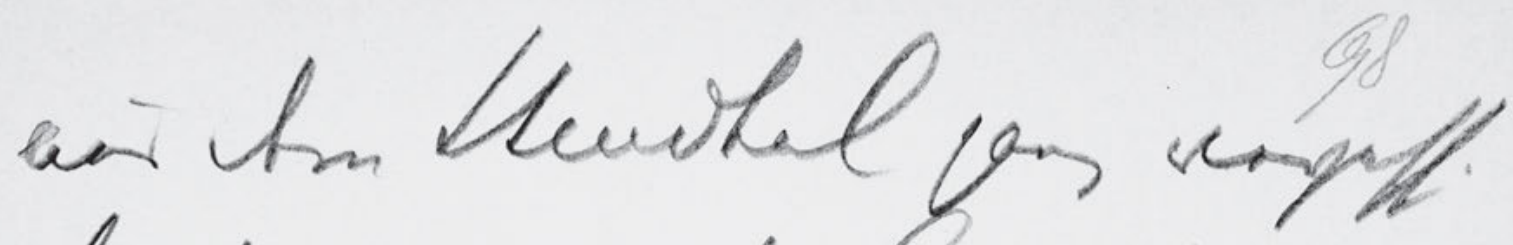

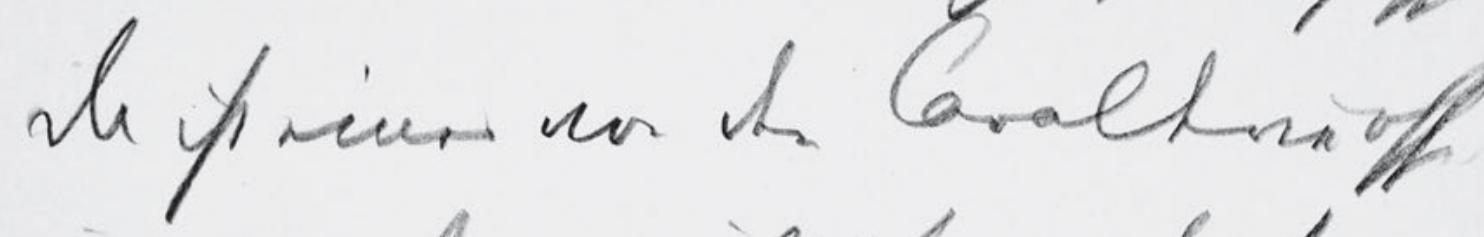
pirm, he saleters, bof -

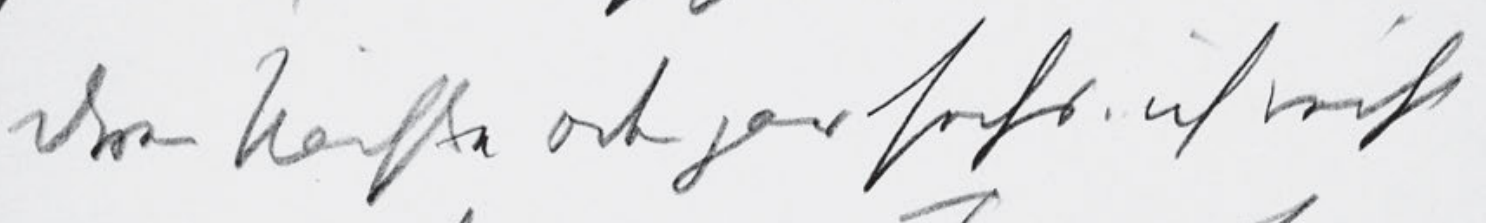

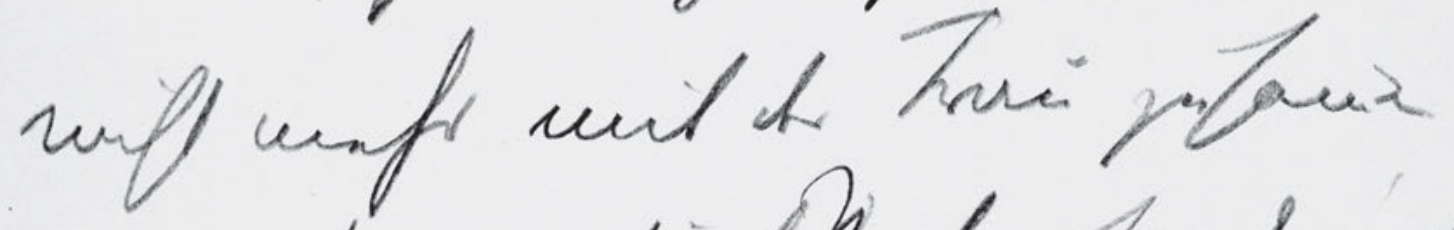

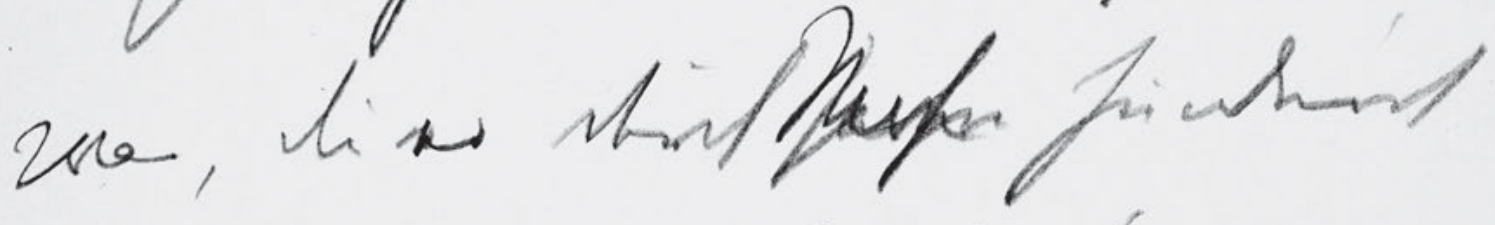

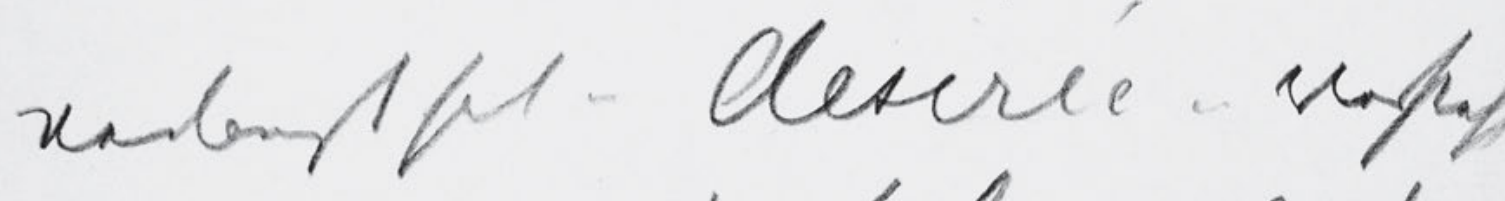
di - wew stivglom wek tif

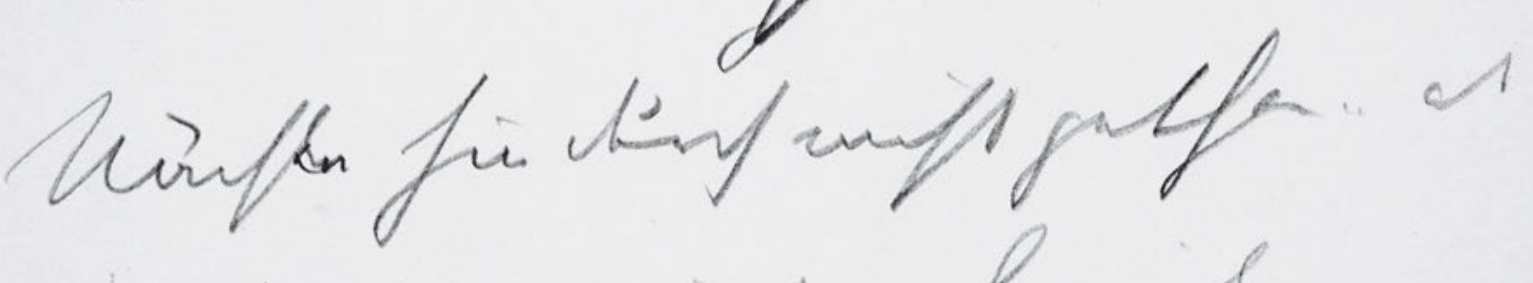
serfleit garmet h.s. 1

230 
98

aus dem Stendhal ganz vergessen.

Da ist einer von den Cavallerieoffi-

zieren, der erzählt sogar, dass er

5 drei Nächte oder gar sechs .. ich weiß

nicht mehr mit der Frau zusā̄en

war, die er durch ${ }^{\text {fahre }}$ Mona hindurch

verlangt hat - desirée . . verstehs

du . - und die haben alle diese

Nächte hin durch nichts gethan .. als

vor Glück geweint . . beide. 
HSz4 99

Handschriften und Typoskript

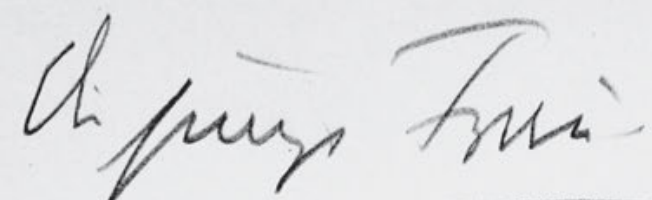

$$
\text { Brit - ? }
$$
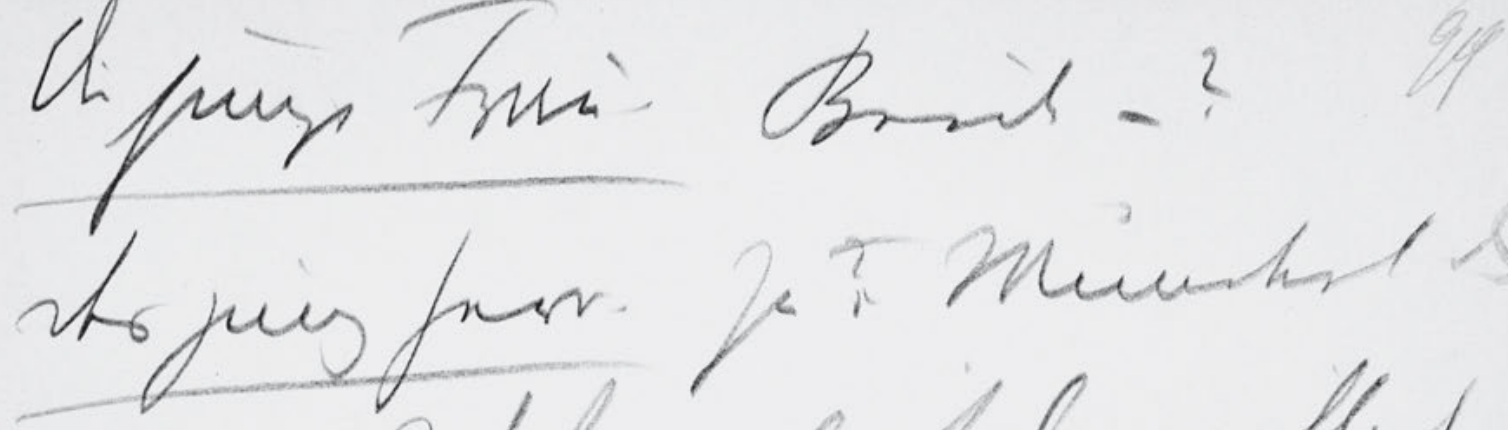

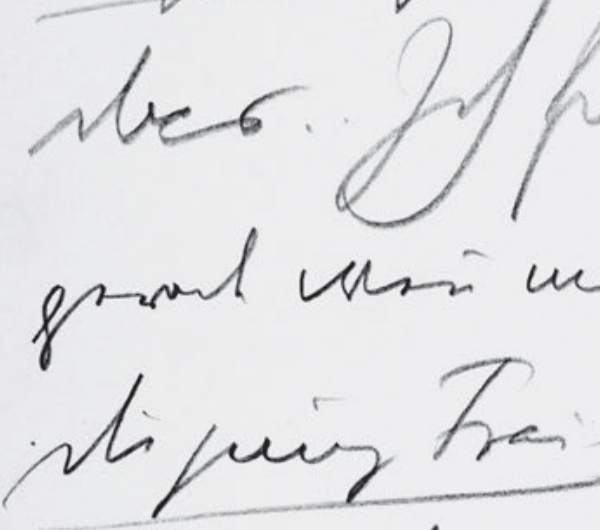

2 i Mun torts Abr nubl gunes mis, li unft

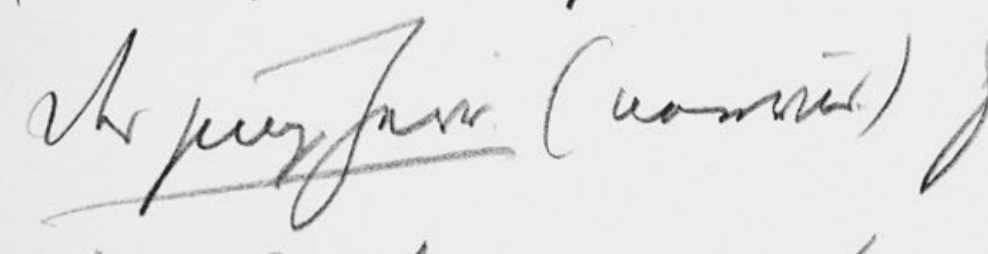
if lip tewith

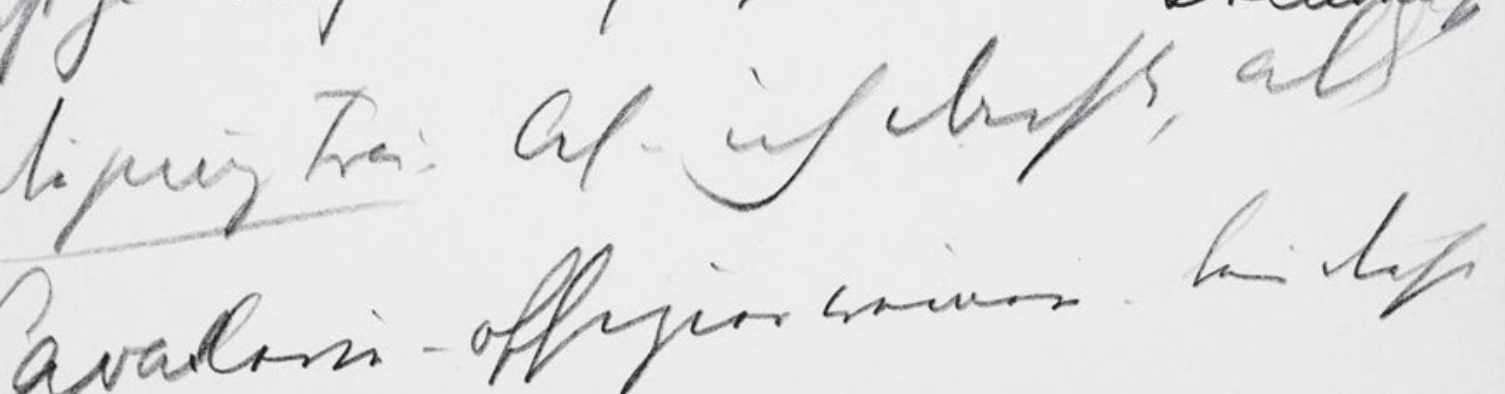
falrengi

232 
Die junge Frau. Beide - ? 99

Der jung Herr. Ja? . Wundert d

das .. Ich find das so begreiflich -

gerade wē̄ man sich liebt . .

$5 \quad$ Die junge Frau. Aber es gibt gewiss

viele, die nicht weinen.

Der junge Herr. (nervös.) Gewiss . . das

ist ja auch ein exceptionell Fall.

Stendhal ? $\mathrm{s}$ ?

Die junge Frau. Ah - ich dachte, alle

10 Cavallerie-offizier weinen . bei diese

Gelegenheit 
HSz4 100

Handschriften und Typoskript

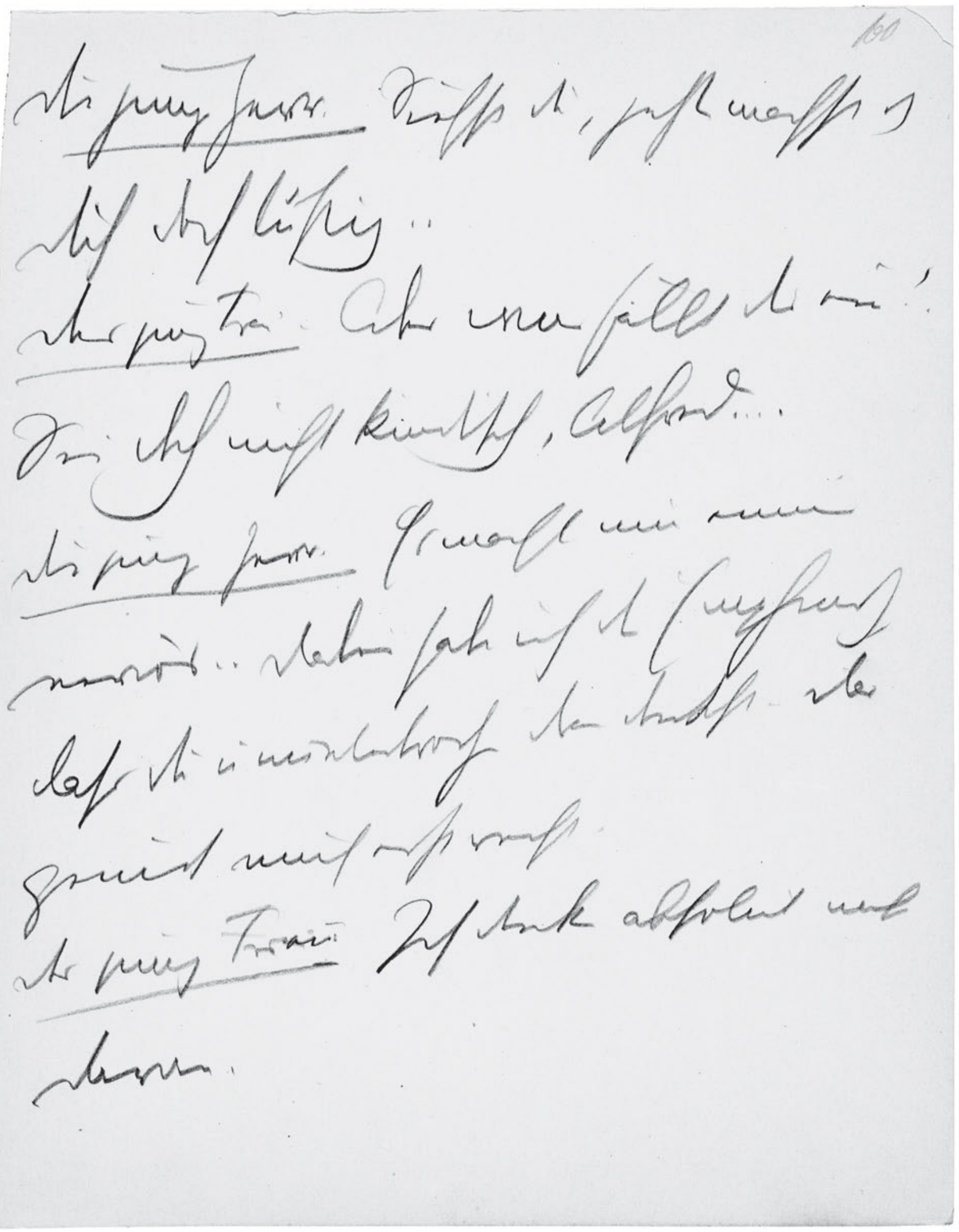

234 
100

Die junge Herr. Siehst du, jetzt machst du dich doch lustig . .

Der jung Frau. Aber was fällt dir ein! .

${ }_{5} \quad$ Sei doch nicht kindisch, Alfred ....

Die junge Herr. Es macht nun einma

nervös .. Dabei habe ich die Empfindg,

dass du ununterbrochen dran denkst - das

genirt mich erst recht.

10 Der jung Frau. Ich denke absolut nicht daran. 
HSz4 101

Handschriften und Typoskript
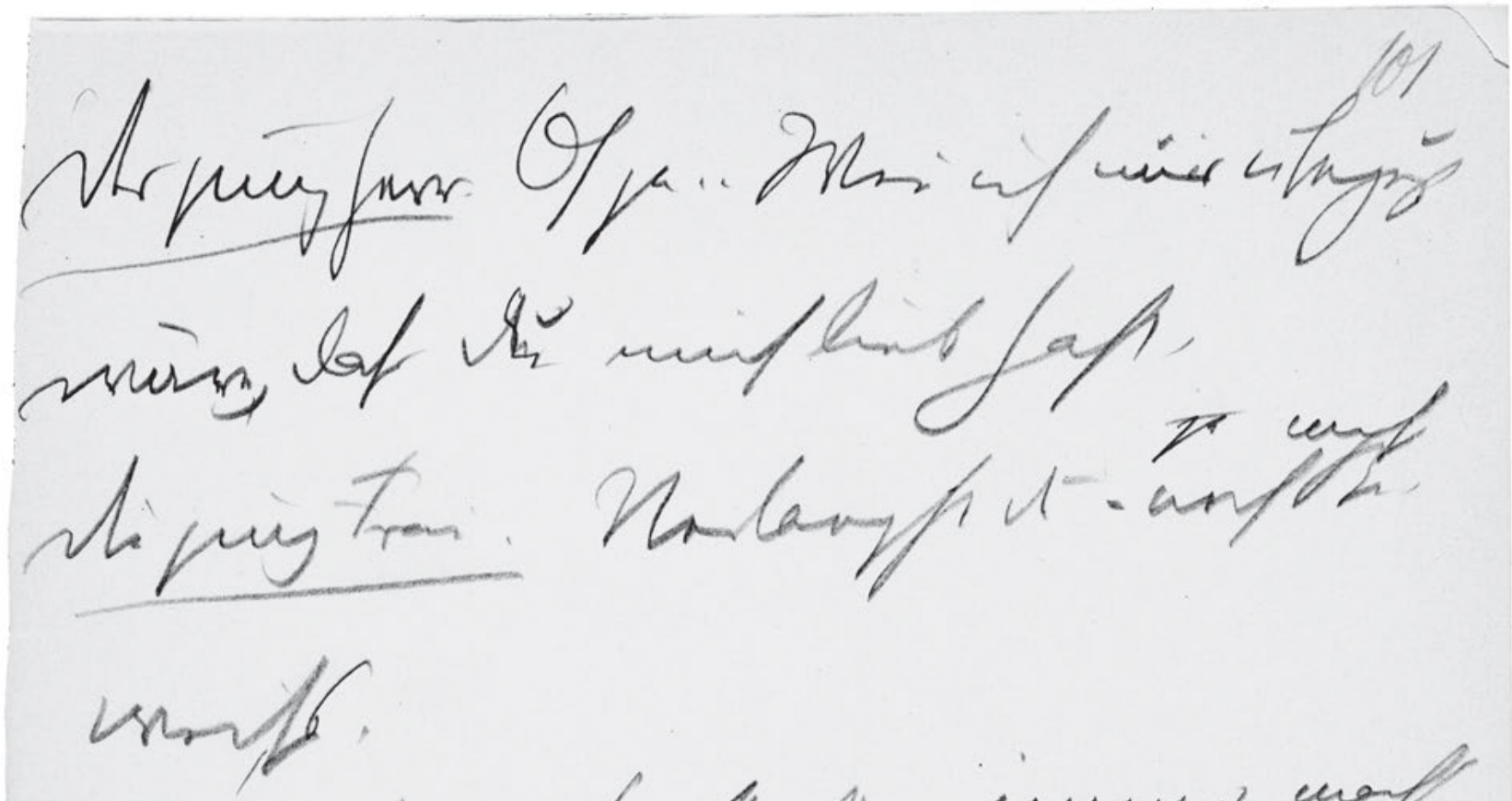

Arpunguor

linffs si inum maft

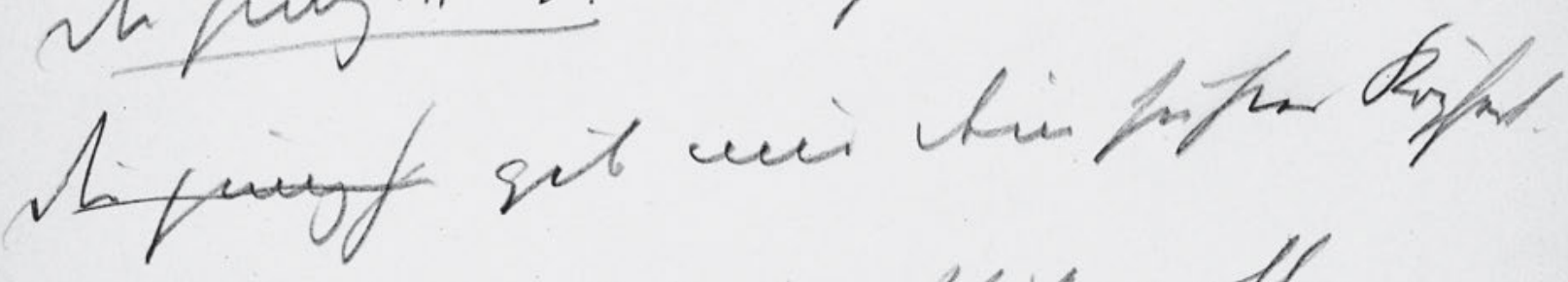
difusjors As lipung Trmi. Ifit inofl. Jufisinenthal.

236 
101

Der jung Herr. Oh ja .. Weñ ich ?mir? nur überzeugt

wäre, dass du mich lieb hast.

Die jung Frau. Verlangst du $-\begin{gathered}\text { ga mehr } \\ \text { noch Be- }\end{gathered}$

5 weiss.

Der jung Herr. Siehst du - . immer machs

du dich lustig

Die jung Frau. Wieso den̄? . . Kō̄ . .

Die jung He gib mir dein süßes Köpferl.

$10 \quad$ Die jung Herr. Ah, das thut wohl . .

Die junge Frau. Hast du mich lieb. 
HSz4 102

Handschriften und Typoskript

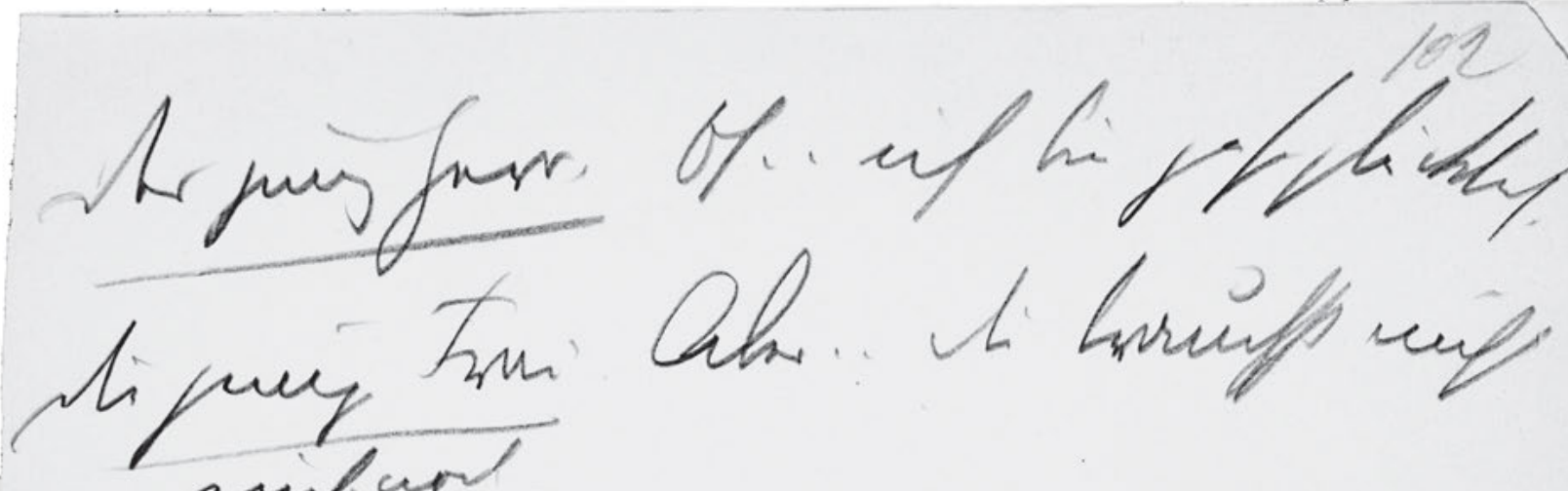
grimen

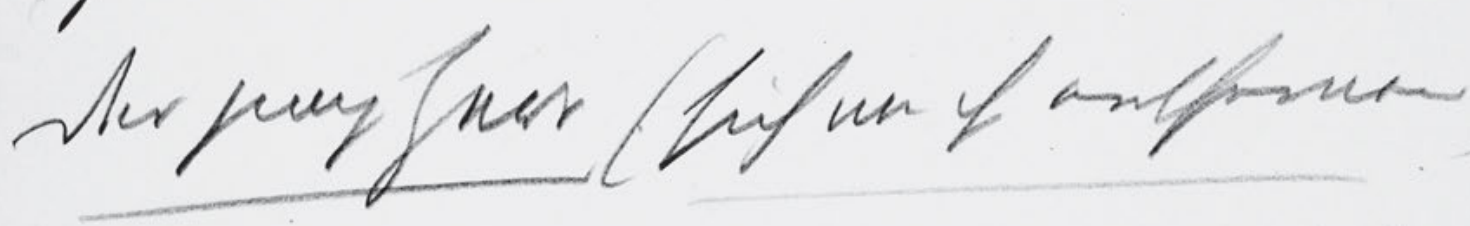

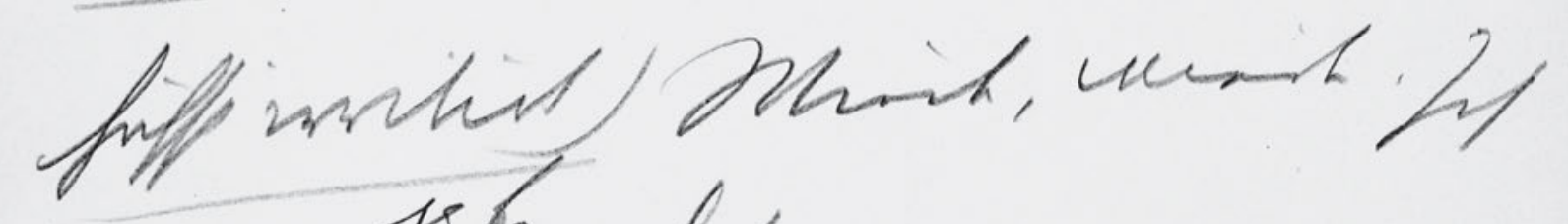

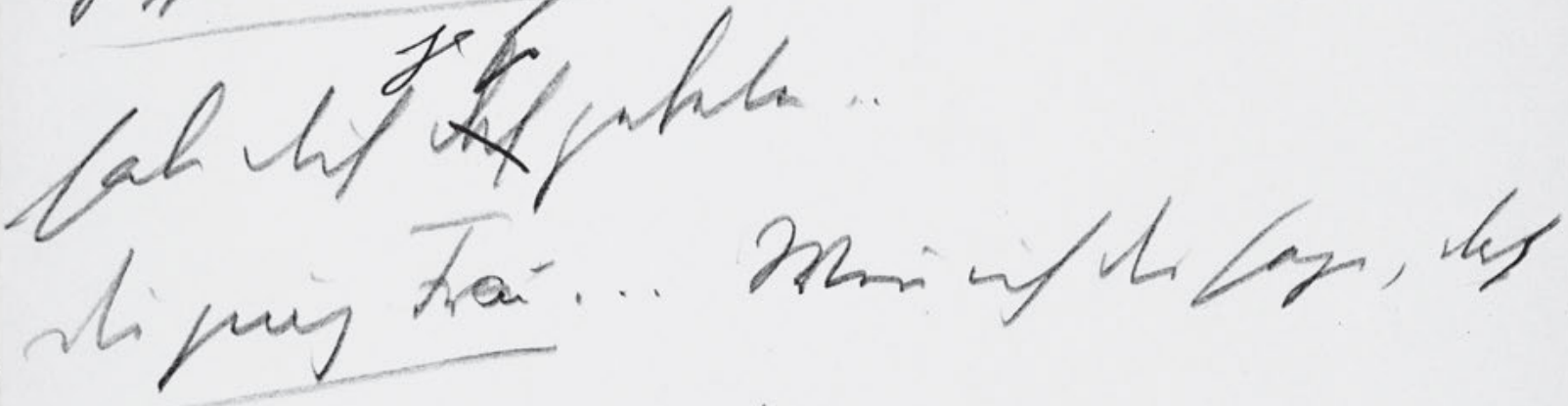

Li cuffumm freef

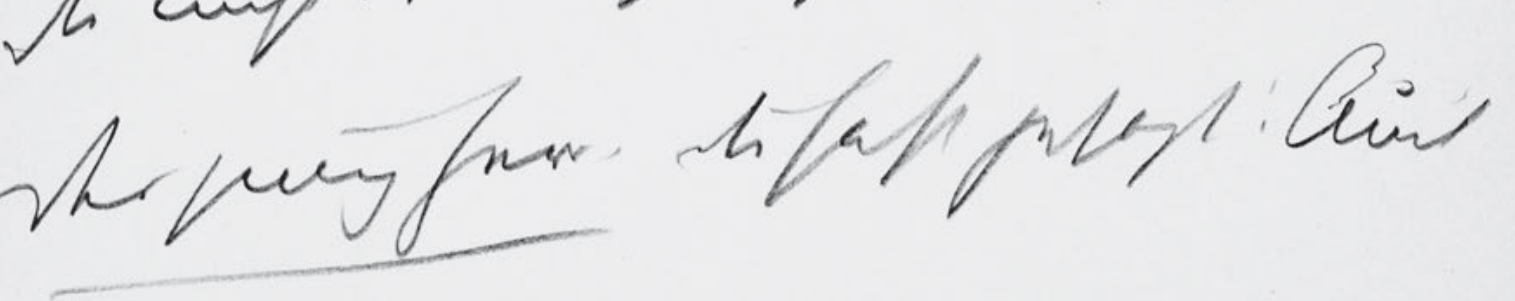

nntpirmina...

238 


\section{2}

Der jung Herr. Oh .. ich bin ja so glücklich.

Die junge Frau . Aber .. du brauchst nicht auch noch

zu weinen.

${ }_{5}$ Der junge Herr (sich von ihr entfernend,

höchst irritirt) Wieder, wieder. Ich ja so

habe dich doch gebeten ...

Die jung Frau ... Weñ ich dir sage, dass

du nicht weinen sollst.

10 Der jung Herr. Du hast gesagt: Auch

noch zu weinen .... 
HSz4 103

Handschriften und Typoskript

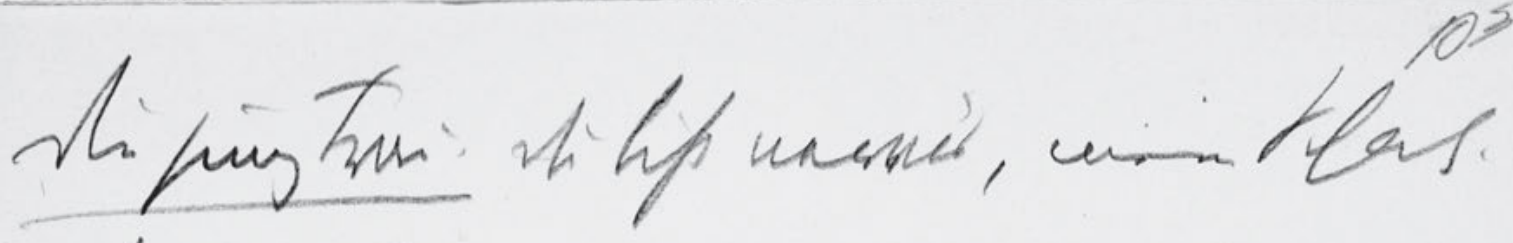
Atreusgurr lermift

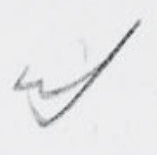

Mifuig tim

Charch fullefir unt

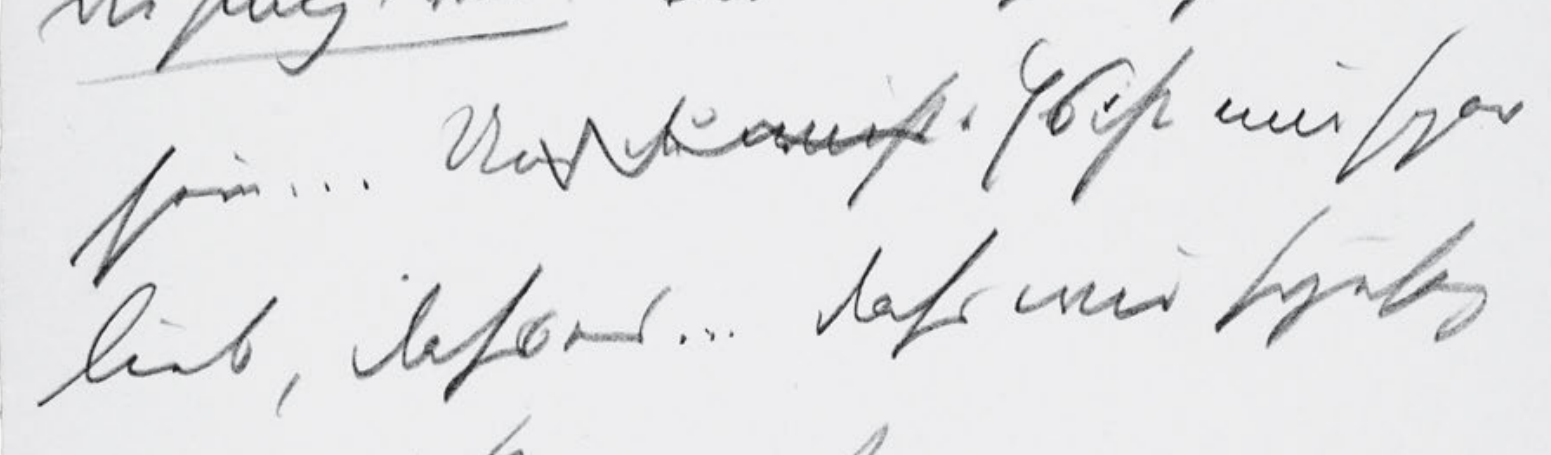
nonifat Reurnes ar vius stipun turi.

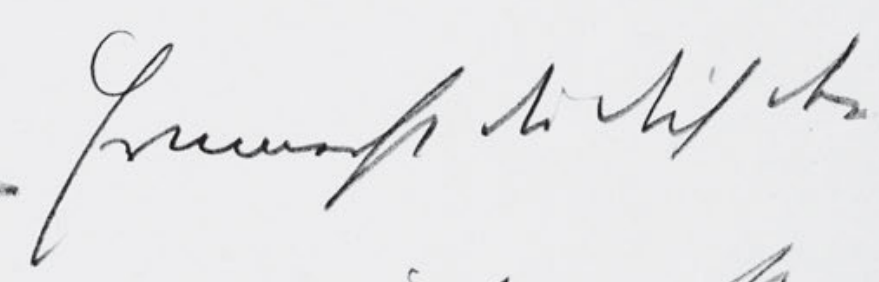
cuifl bles nar nin wifer $x / 3$

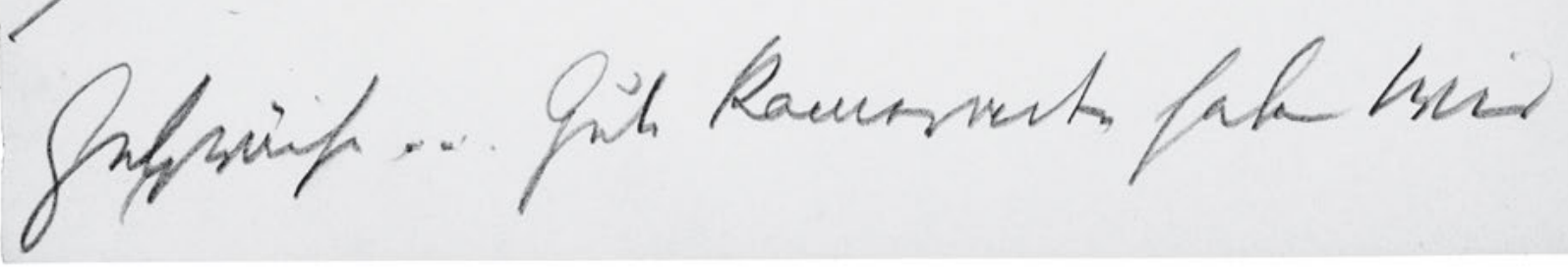

240 
103

Die jung Frau. Du bist nervös, mein Schatz.

Der jung Herr. Das weiss ich.

Die jung Frau. Aber du sollst es nich

5 sein ... Und du weiß. Es ist mir sogar

lieb, dass es .... dass wir sozusag

wie gute Kameraden .

Der jung Herr. Schon wieder fangst du an ...

10 Die jung Frau. Erinnerst du dich den nicht? Das war eins unsrer ersten Gespräche ..... Gute Kameraden haben wir 
HSz4 104

Handschriften und Typoskript

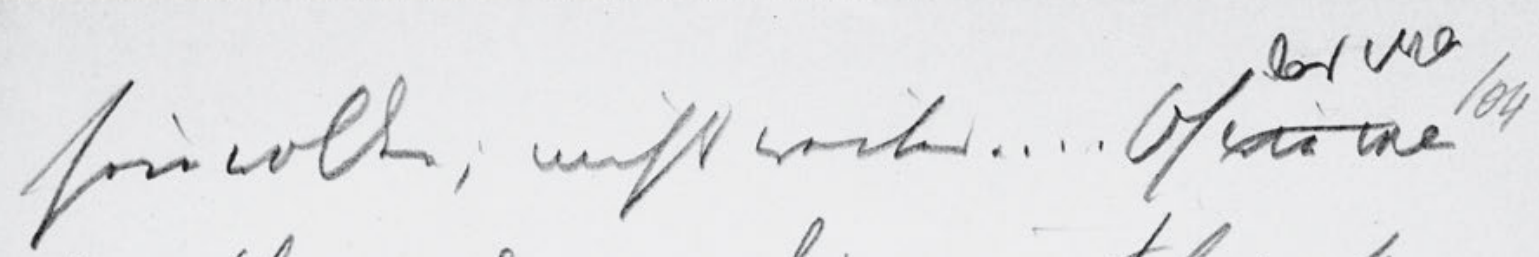

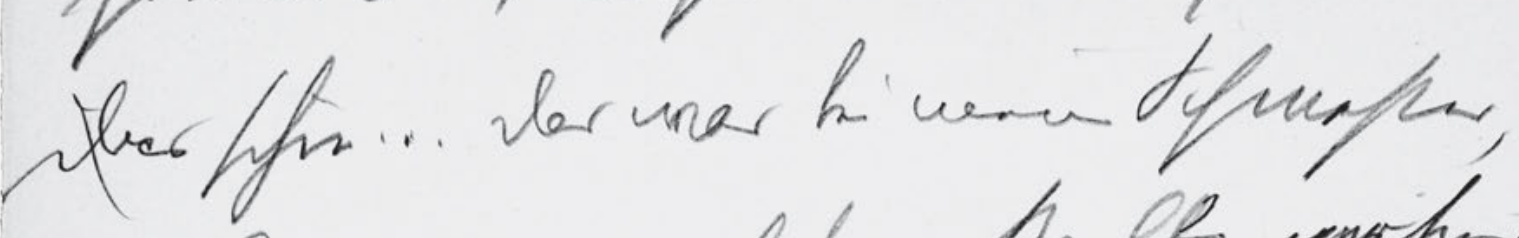

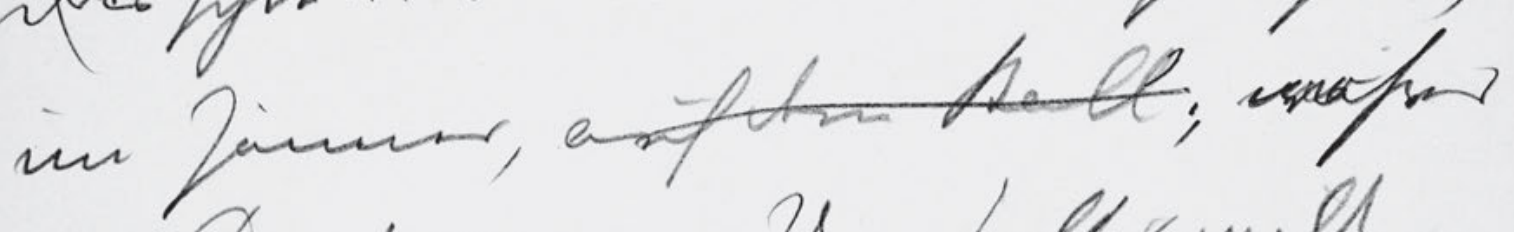

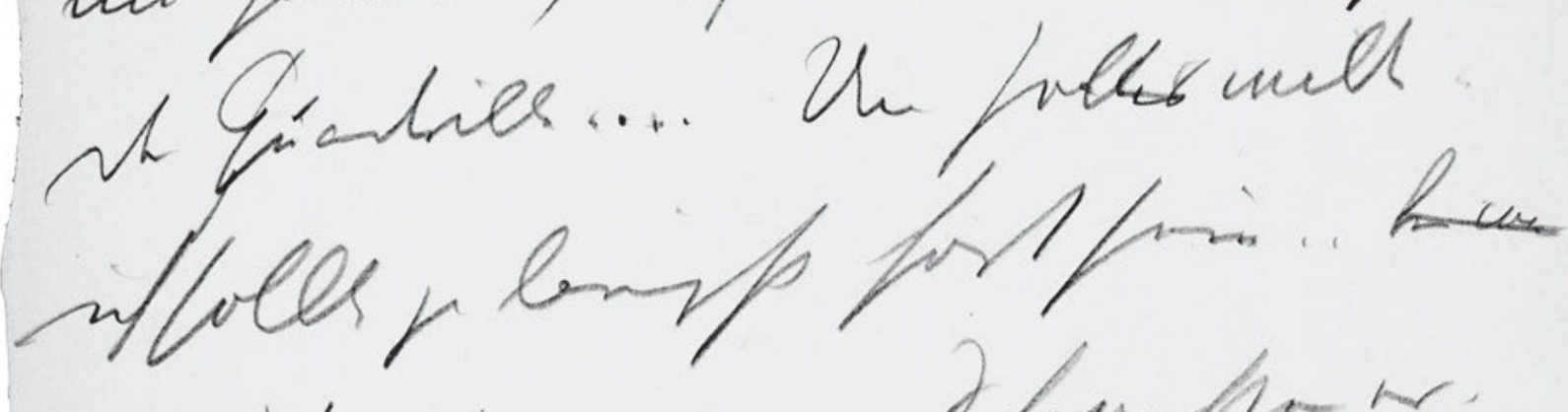

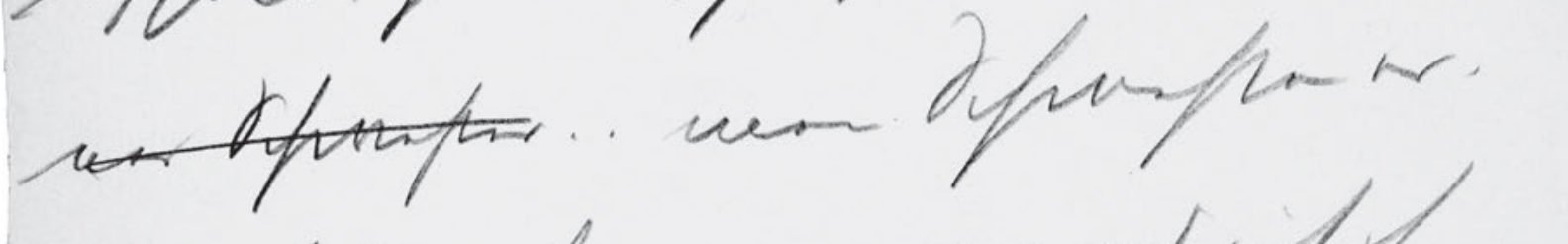

mathl cuif

Lengr

Achis Glepr

Le pusfors

Pun -'t milge

qu nuif unbaff

shrustrañ. Za - fo! -

242 
sein wollen; nichts weiter .... Oh wie war 104

das schön .... das war bei meiner Schwester, im Jänner, auf dem Ball;, ${ }^{\text {vo }}$ während der Quadrille .... Um Gottes willen -

5 ich sollte ja längst fort sein . . bei mei

ner Schwester .. meine Schwester er-

wartet mich ja - was werd ich ih

den sagen ... Adieu, Alfred -

Der jung Herr. . Emma - ! so willst

10 du mich verlassen.

Der jung Frau. . Ja - so! - 
HSz4 105

Handschriften und Typoskript

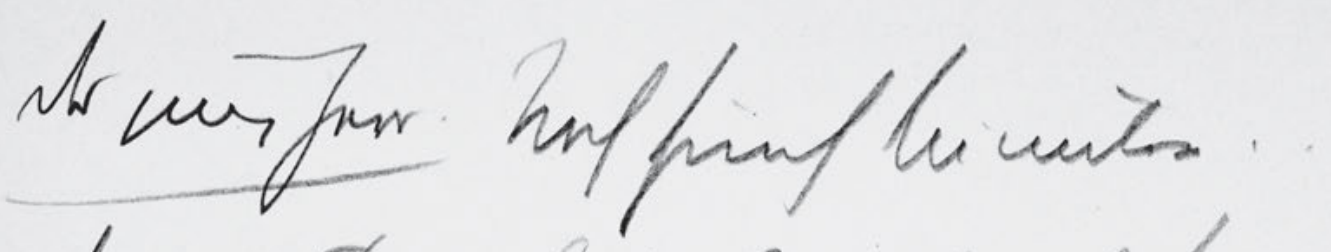

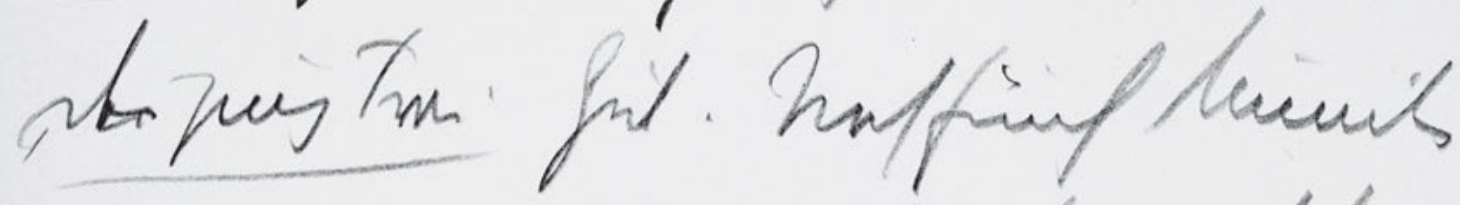

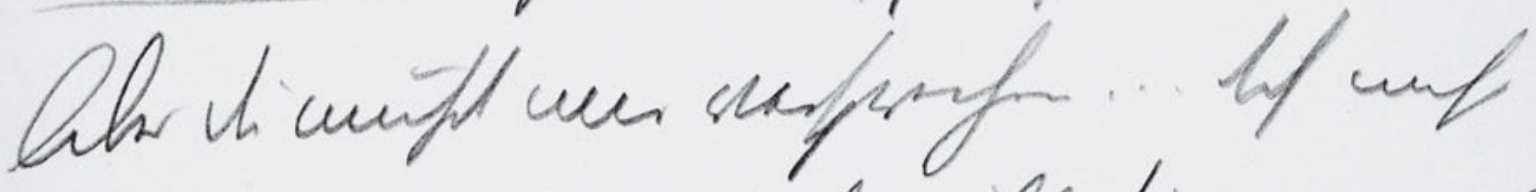

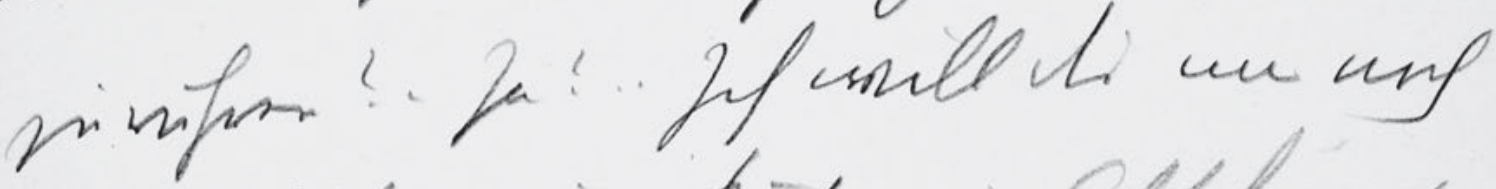

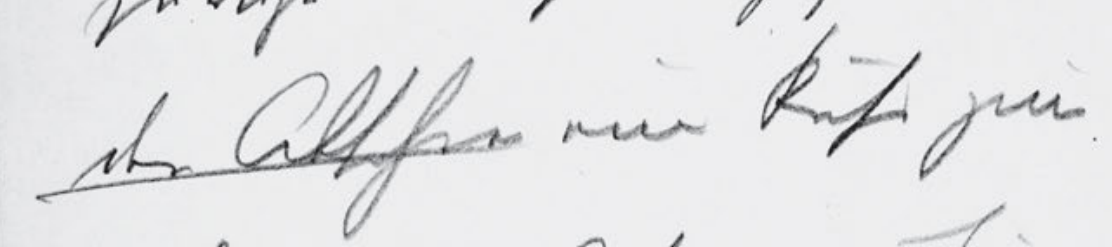

gahm

fol is

fonfeferfit tow

enil … stivenis fifer

jeffor.

tr puesforr f wene... uns ang

h.

244 
105

Der jung Herr. Noch fünf Minuten . .

$\underline{D^{i e} e r ~ j u n g ~ F r a u . ~ G u t . ~ N o c h ~ f u ̈ n f ~ M i n u t e n ~}$

Aber du mußt mir versprechen ... dich nicht

$5 \quad$ zu rühren? - Ja? . . Ich will dir nur noch

den Abschie einen Kuss zum Abschied

geben ... - . Pst . . ruhig . . nicht ruhren

hab ich gesagt, sonst steh ich gleich

auf . . . du mein süßer . . süßer . . .

10 Der jung Herr. Emma .... meine ange

be. . . . . . . . . - . 
HSz4 106

Handschriften und Typoskript

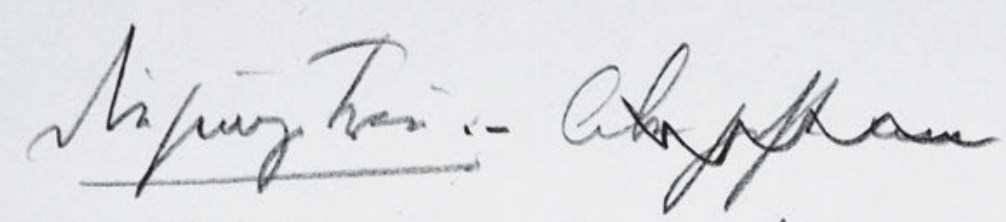

106. sinfe... me

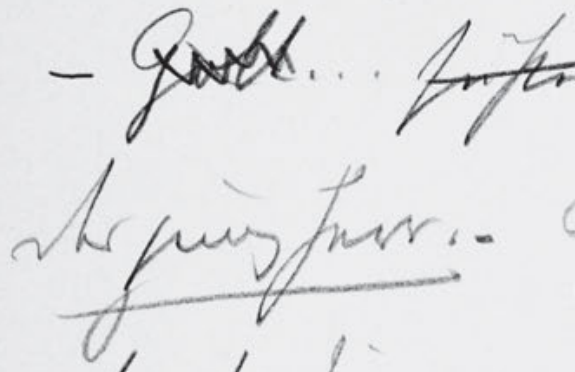

lemingerme

ip te finemal.

an pur

soring gor

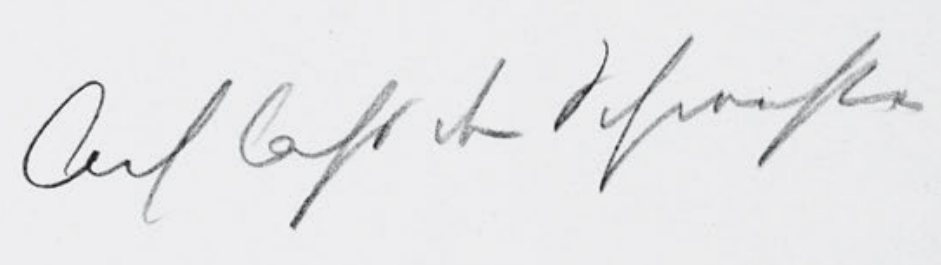

nention

dapes Tren

net

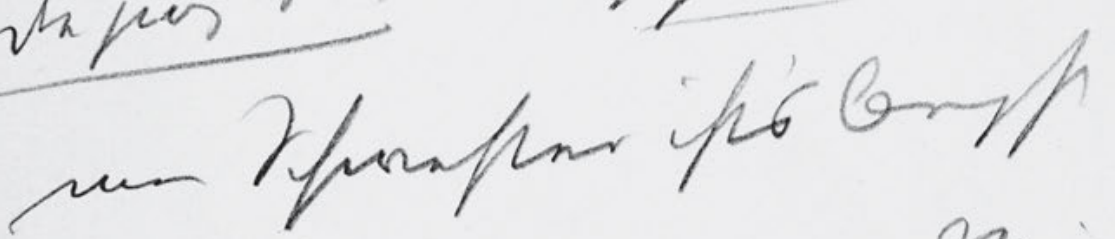

rigat

Quen

W

ip. Lim mantley

246 
106

Die junge Frau. - Aber jetzt ${ }^{\text {}} \mathrm{m} e^{?}$ Du bist . . ein

- Gott .. . süßer . Kleiner Mein Alfred -

Der jung Herr. - Ah; . . . es gibt keine bei dir

5 ist der Himmel...

Die junge Frau. Aber jetzt muss ich wirkli fort . .

Der jung Herr. Ach lass dein Schwester

warten

10 Die jung Frau. Nach Haus muss ich. Fur

mein Schwester ist's langst zu spät . .

Aber ... mein Mann ... . Wie spät vie

Uhr ist es deñ eigentlich? 
HSz4 107

Handschriften und Typoskript

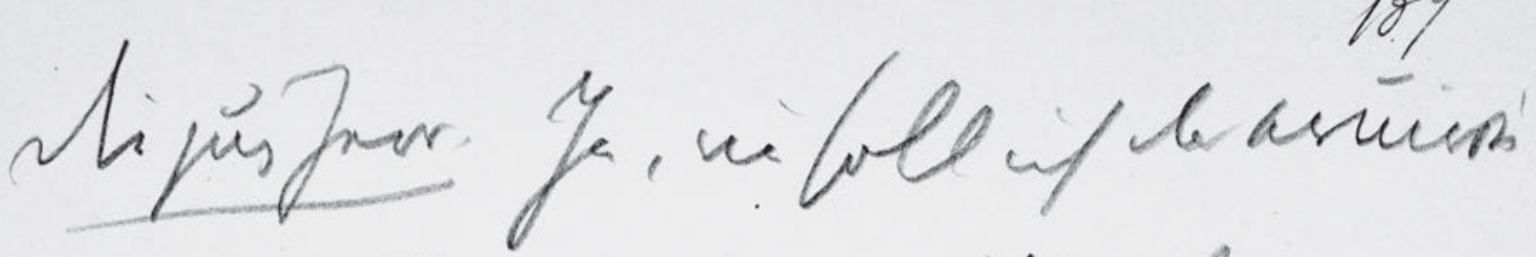

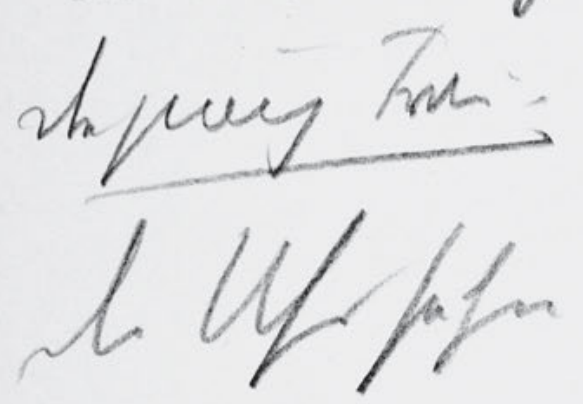
licuft ah ant

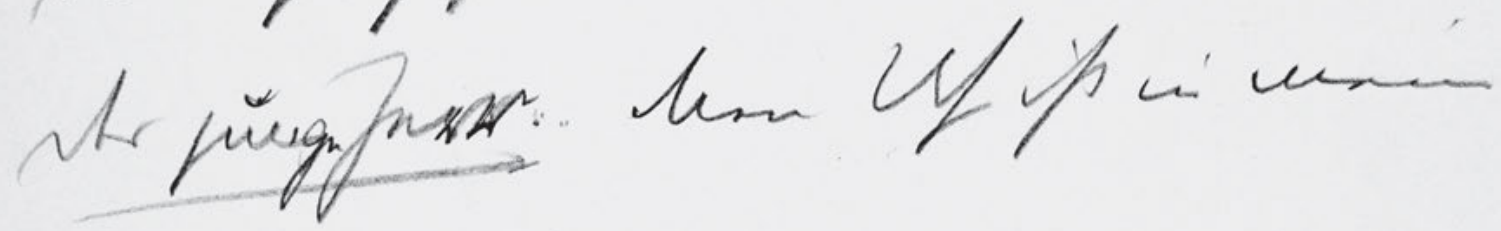
filet

Lipuistron go folifer

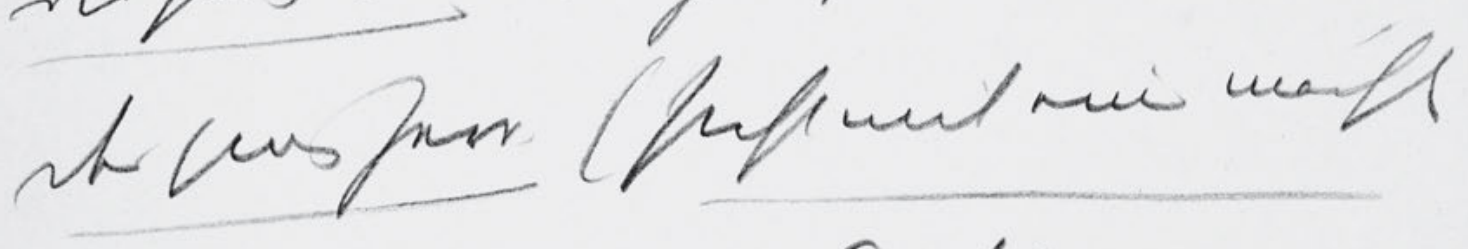
Rint af.)

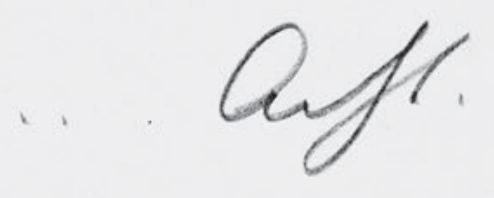
sipus tru (afolt ing rafti) Is folmonel Ruth lefwr.

248 
107

Die jung Herr. Ja, wie soll ich das eruiren?

Die jung Frau. Du mußt eben auf

die Uhr sehn ..

${ }_{5}$ Der junge Herr. . . Meine Uhr ist in meinem

Gilèt.

Die jung Frau. So hol'[?] sie

Der jung Herr. (steht mit einem mächt

Ruck auf.) .. Acht.

10 Die jung Frau . (erhebt sich rasch.) Um

Gotteswillen ... . Rasch - Alfred - 
HSz4 108

Handschriften und Typoskript

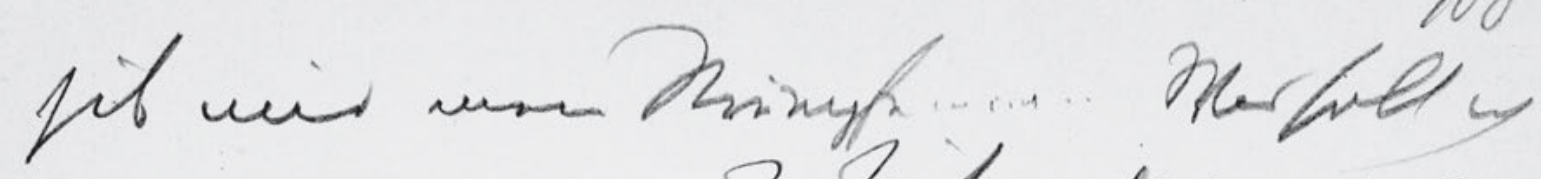

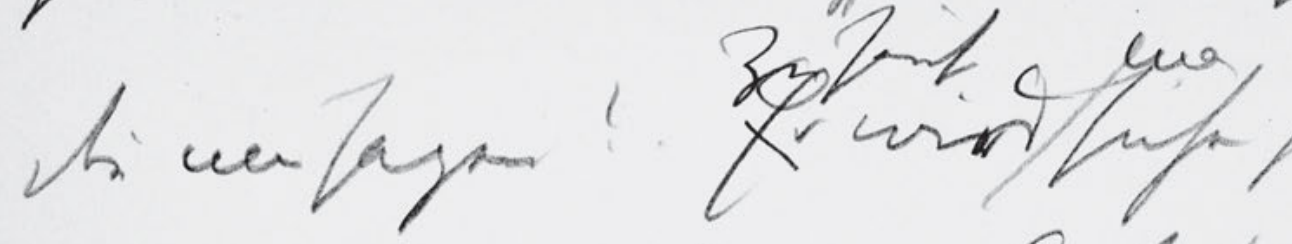

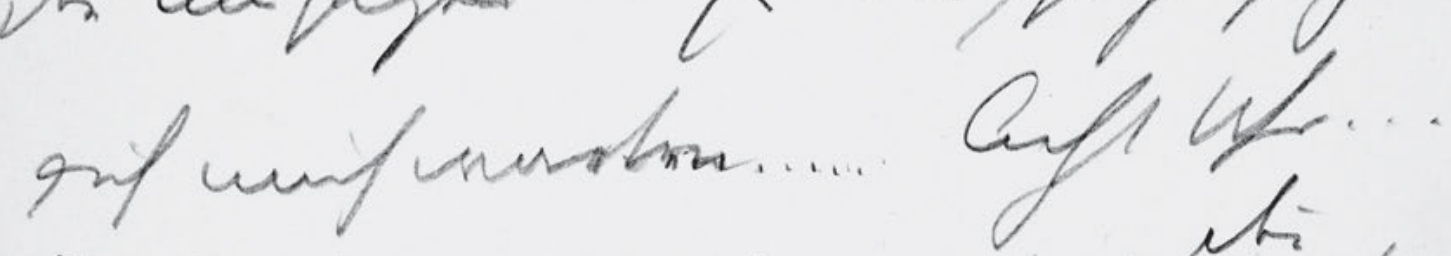

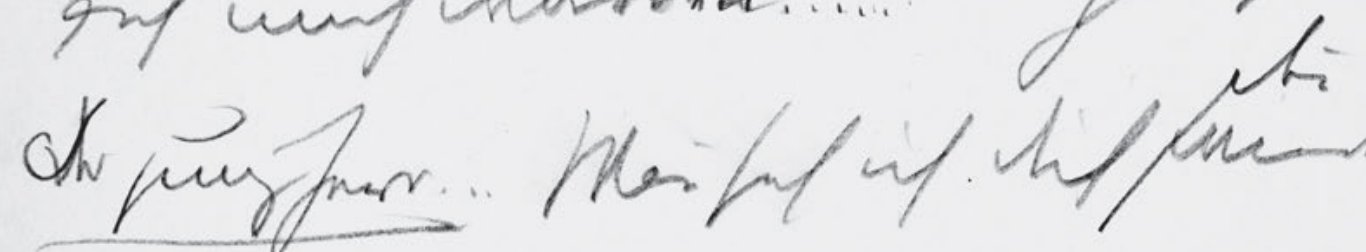
sh pus Tum hin....

Mtging form

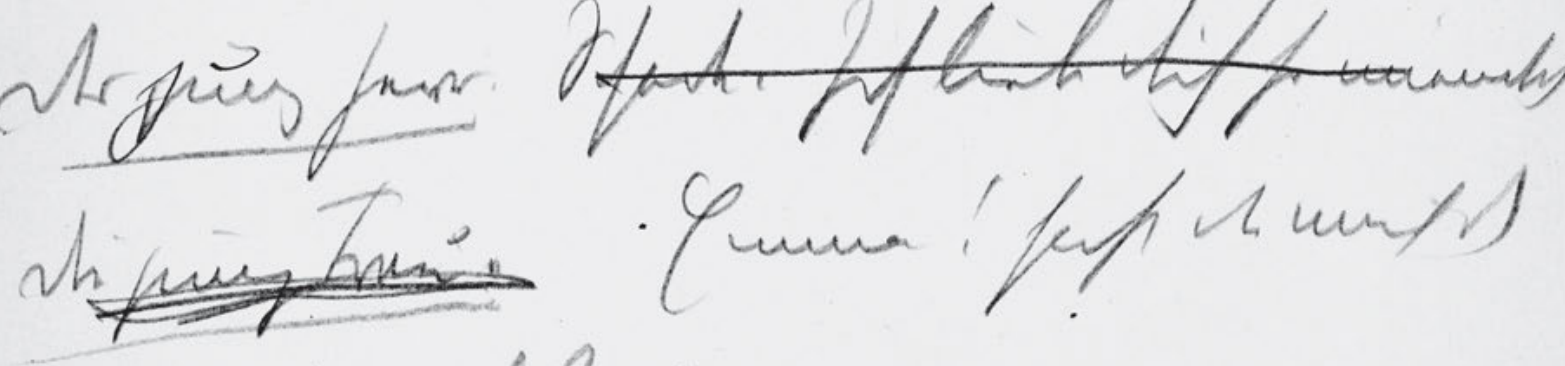
mef weflons.

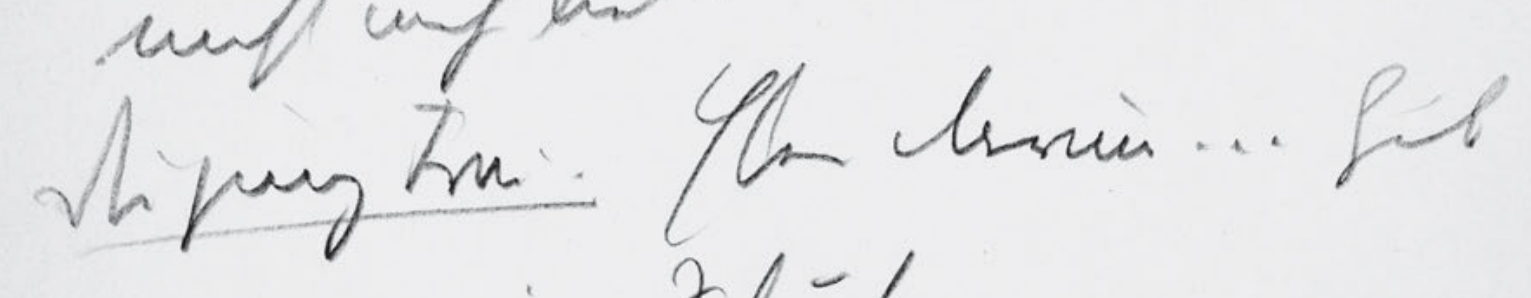
nui minim Opinfa.

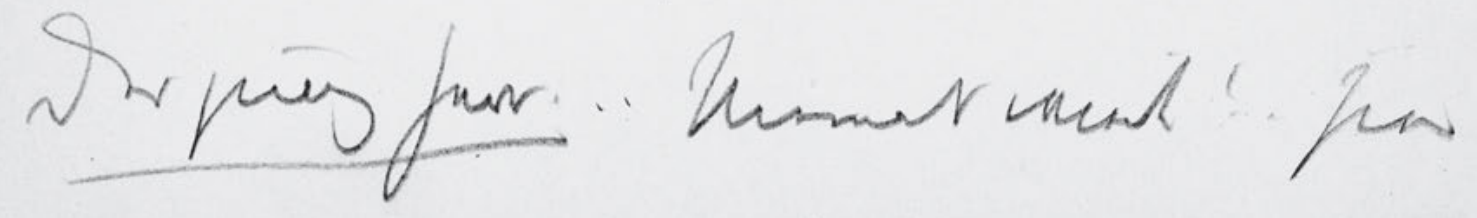

250 


\section{8}

gib mir mein Strümpfe ......... Was soll ich

$$
\text { Zu Hause man }
$$

den̄ nur sagen? . Er wird/sicher schon

auf mich warten ...... Acht Uhr ...

$$
\text { dē }
$$

5 Der junge Herr. .. Wañ seh ich dich wieder ..

Die jung Frau. Nie ......

Der jung Herr. Schade. Ich liebe dich so unendlh

Die junge Frau. Emma! Hast du mich den

nicht auch lieb.

${ }_{10} \quad$ Die junge Frau. Eben darum ... Gib

mir meine Schuhe..

Der jung Herr. . . Niemals wieder? . Hier 
HSz4 109

Handschriften und Typoskript

tur itrpf

dipus tor

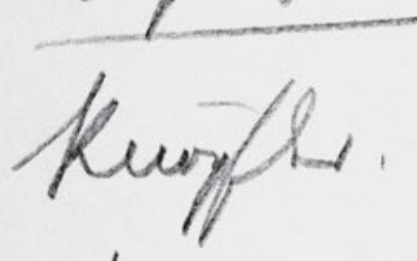

ch puisgrar.

Mipus Tuin

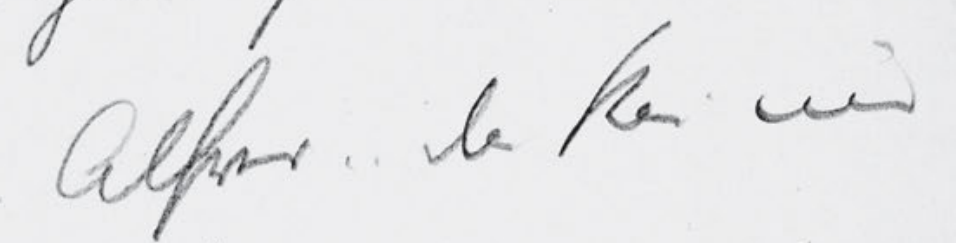

binas ut
stives frior

thopora.. trants

Mure

dispus tre

marfol

y hes

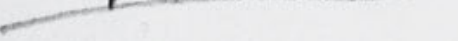

fwyr

2

252 
109

sind die Schuhe.

Die jung Frau. In meinem Sack ist ein Schuh

knöpfler. Ich bitte dich, rasch . .

$5 \quad$ Der jung Herr. Hier ist der Knöpfler...

Die jung Frau. Alfred . . das kan̄ uns

beide den Hals kosten . .

Der jung Herr (höchst unangenehm beruhrt)

Wies $?$

10 Die jung Frau Ja was soll ich den $n$

sagen? Wen er mich fragt: Woher 
HSz4 110

Handschriften und Typoskript

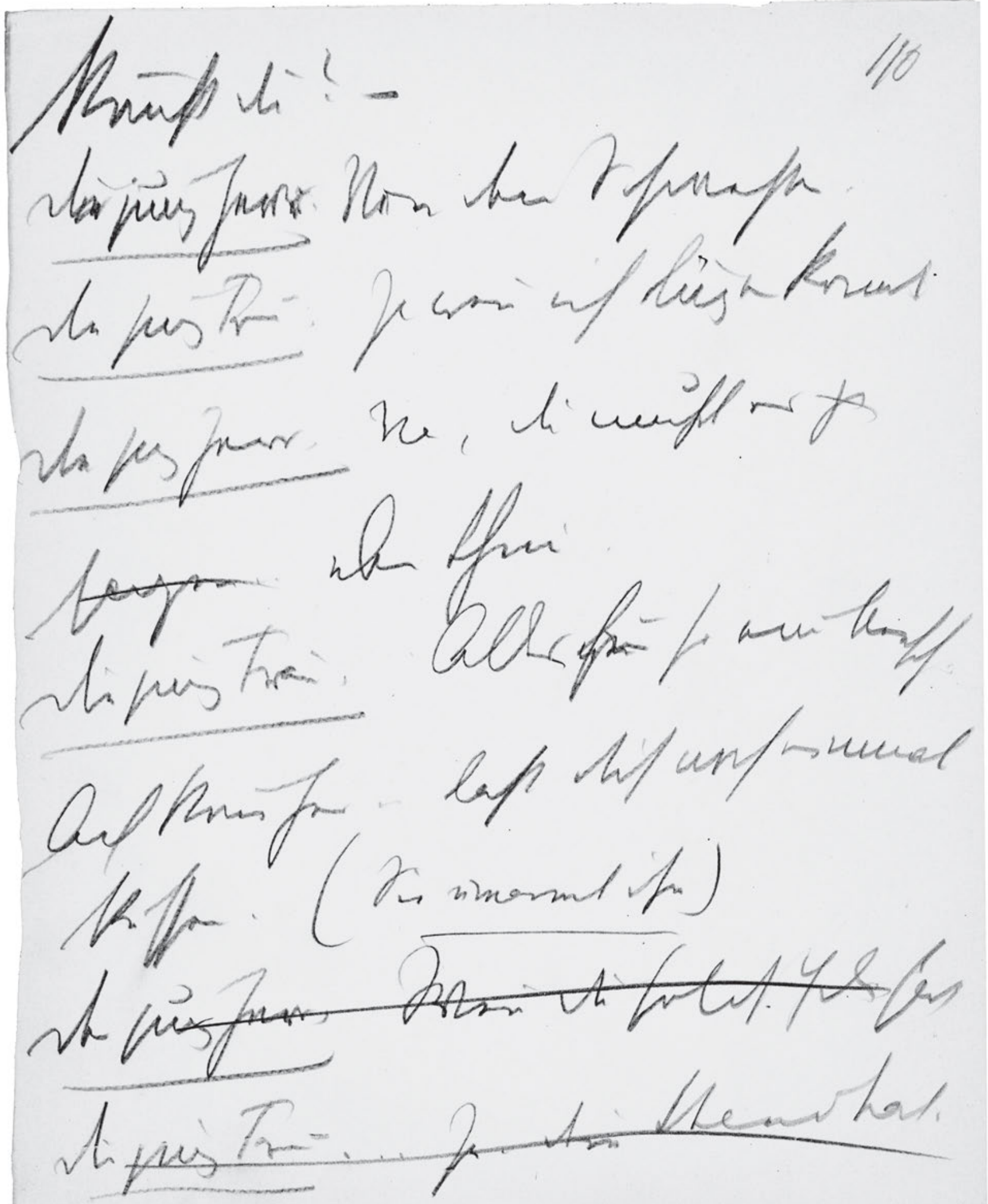

254 
komst du? -

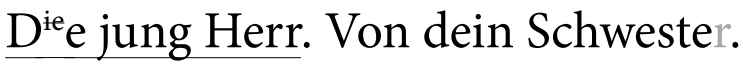

Die jung Frau. Ja weñ ich lügen konnt

$5 \quad$ Die jung Herr. Na, du mußt es ?’ja?

sagen .. eben thun.

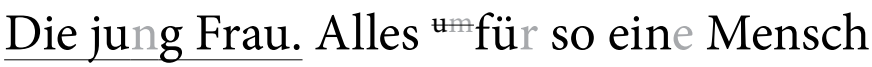

Ach kō̄ her - laß dich noch einmal

küssen. (Sie umarmt ihn)

Der jung Herr, Weñ du solch Eile has

Die jung Frau ... Ja . dein Stendhal. 
HSz4 111

Handschriften und Typoskript

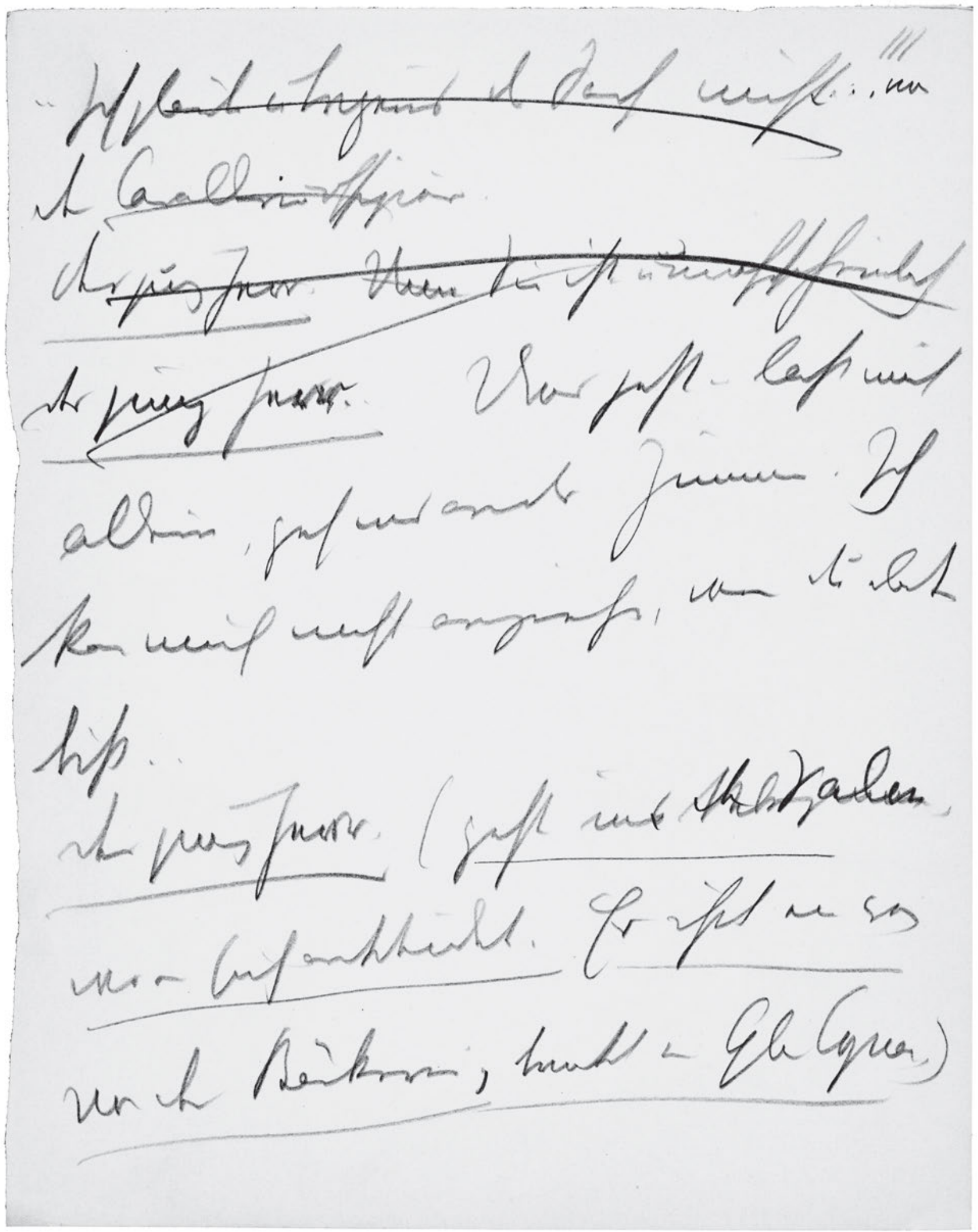

256 
111

. Ich glaube übrigens die Sache nicht . . von

dem Cavallerieoffizier.

Der jung Herr. Un? $w^{?}$ Sie ist unwahrscheinlich

${ }_{5}$ Der jung Herr. . Und jetzt - laß mich

allein, geh ins andr Zimmer. Ich

kan mich nicht anziehn, wen du dabe

bist . .

Der jung Herr. (geht ins ${ }^{\text {Nebenzim̄er }}$ den Salon,

wo er sich ankleidet. Er ißt ein wenig

von der Bäckerei, trinkt ein Glas Cognac.) 
HSz4 112

Handschriften und Typoskript

had unum
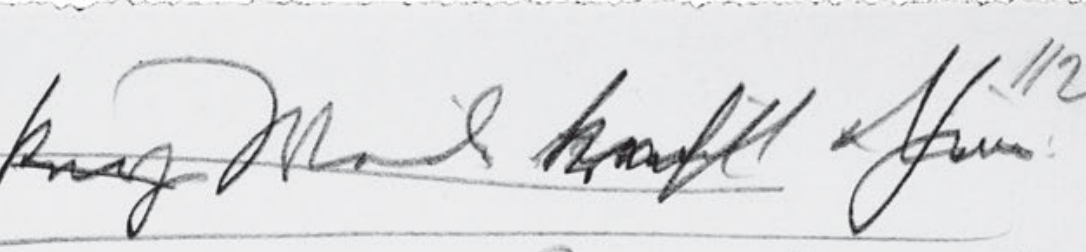

If hin laup

herfon Mral unf

ligujtor
demprom

CAlfori:"

unithel?

Migus trom

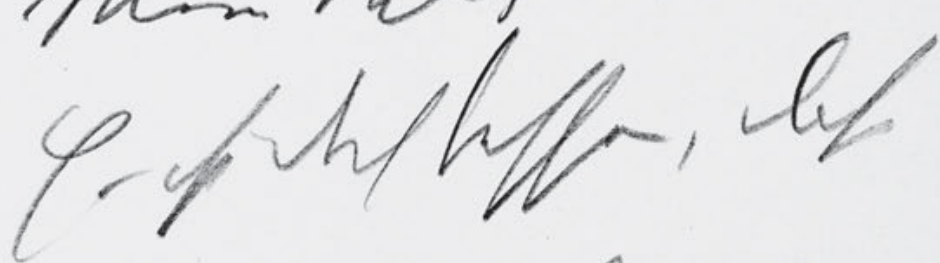

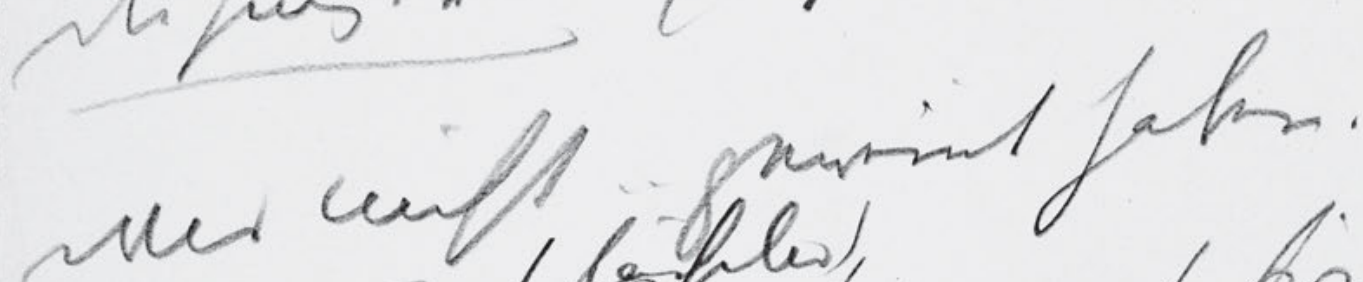

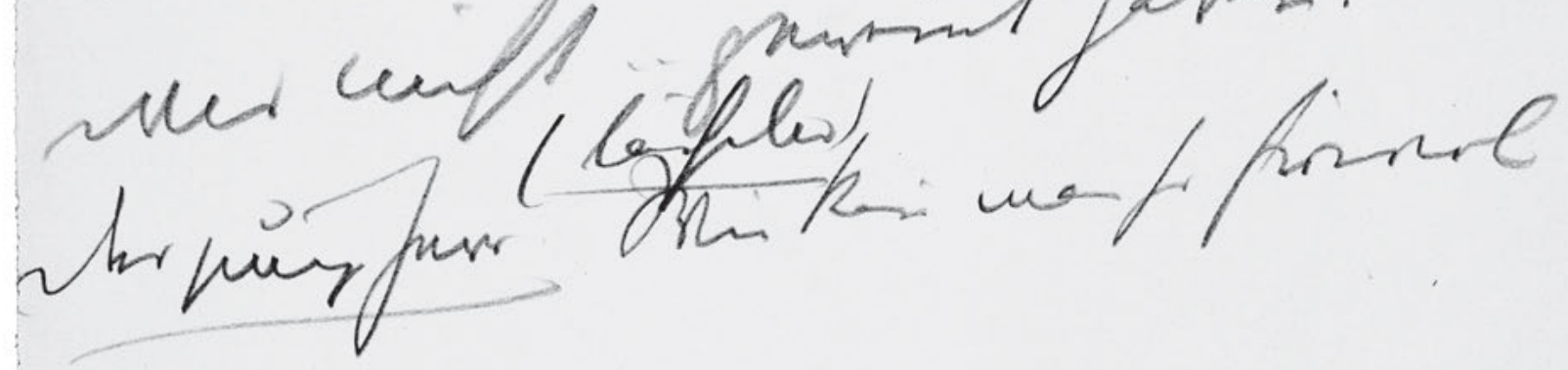

mote? -

dipung trañ. Me nosibergfen

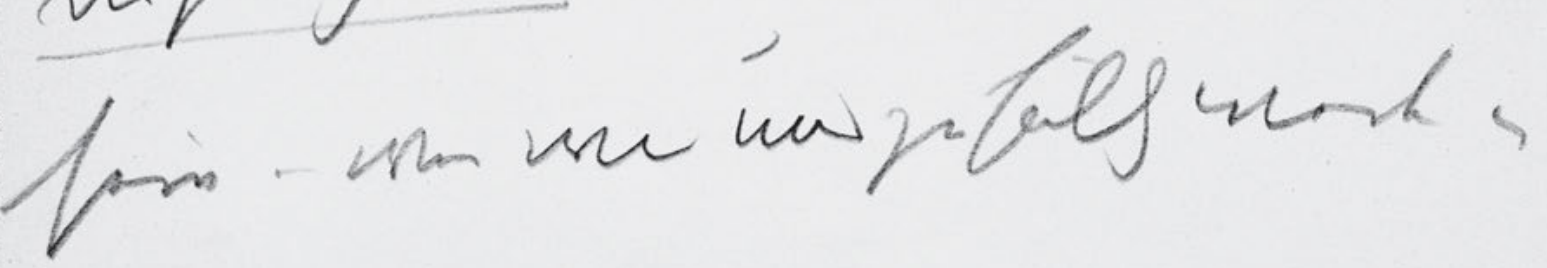

258 
Nach einer kurzen Weile ${ }^{[?]_{\mathrm{komt}}}$ ruft ${ }^{{ }^{e} \text { die }}$ Jung:

Ich bin längst Nach eine Weile ruft

die junge Frau - (Alfred! . -

5

${ }^{A}$ Der jung Herr. Mein Schatz? -

Die jung Frau. Es ist doch besser, dass

wir nicht . geweint haben.

(lächelnd)

Der junge Herr. Wie kan̄ man so frivol

reden? -

${ }_{10} \quad$ Die jung Frau . . . Wie wird das jetzt n[?]

sein - wen wir uns zufällg wieder in 
HSz4 113

Handschriften und Typoskript

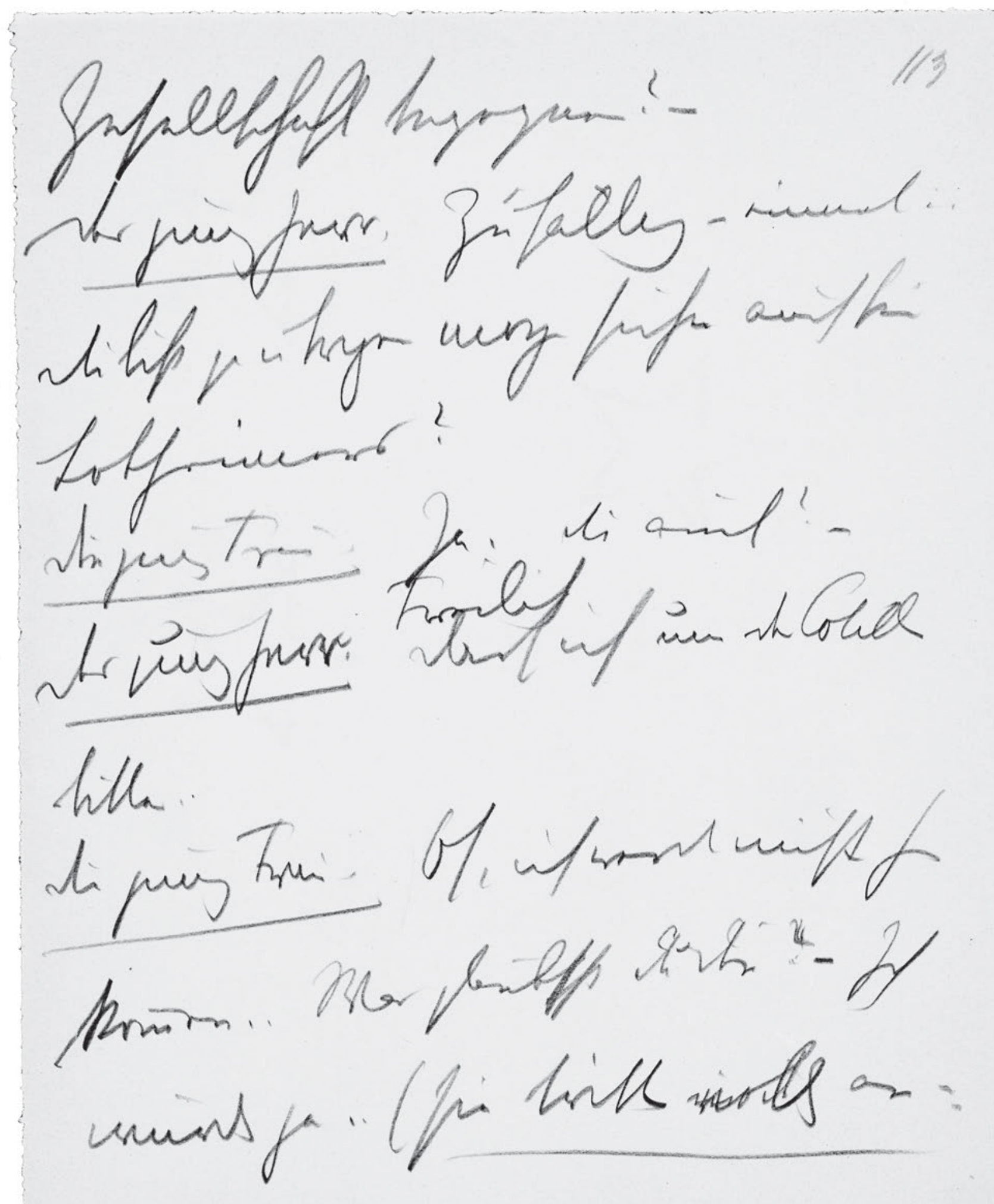


Gesellschaft begegnen? -

Der jung Herr. Zufällig - einmal . .

Du bist ja übrigens morgen sicher auch bei

5 Lobheimers?

Die jung Frau. Ja. Du auch? Freilich

Der jung Herr. Darf ich um den Cotillon bitten . .

Die jung Frau. Oh, ich werde nicht hin

10 komen .. Was glaubtst du den $\bar{n}^{! !}$? - Ich

würde ja .. (sie tritt ${ }^{\text {in }}$ vollg an= 
HSz4 114

Handschriften und Typoskript

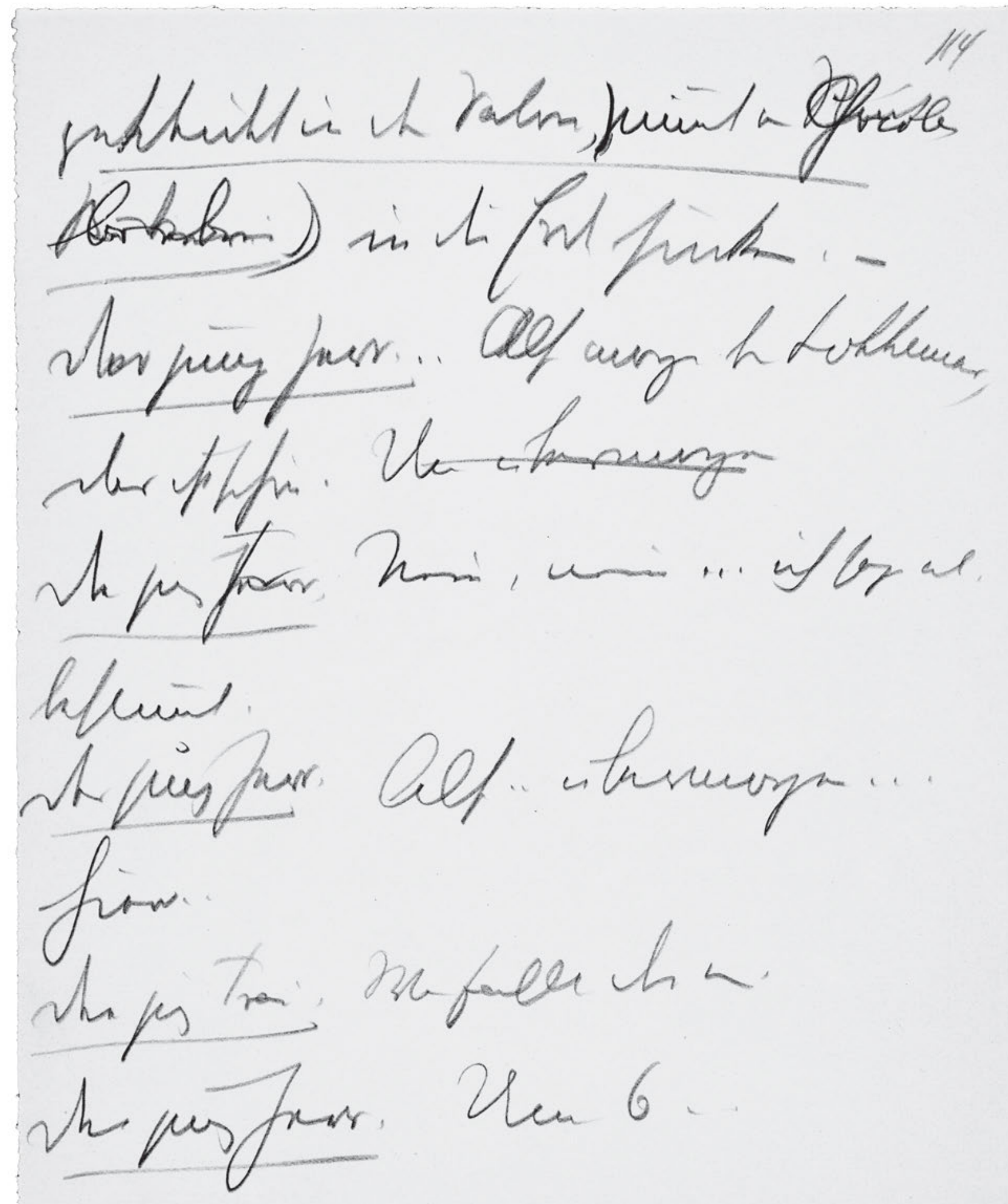


114

gekleidet in den Salon, ${ }^{\dagger}$, nim̄t ein ${ }^{\text {Stück }}{ }^{2}$ hocolad

Bäckereibonbon) in die Erde sinken. -

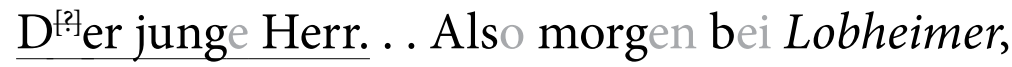

5 das ist schön. Und übermorgen

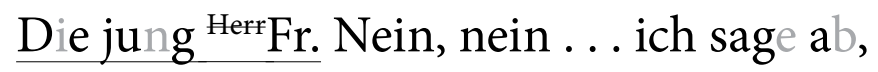

bestim̄t.

Der jung Herr. Also . übermorgen ...

hier. .

10 Die jung Frau. Was fallt dir ein.

Der jung Herr. Um 6 . . 
HSz4 115

Handschriften und Typoskript

vipug tra

Megn,

chyow

jar an lak

115

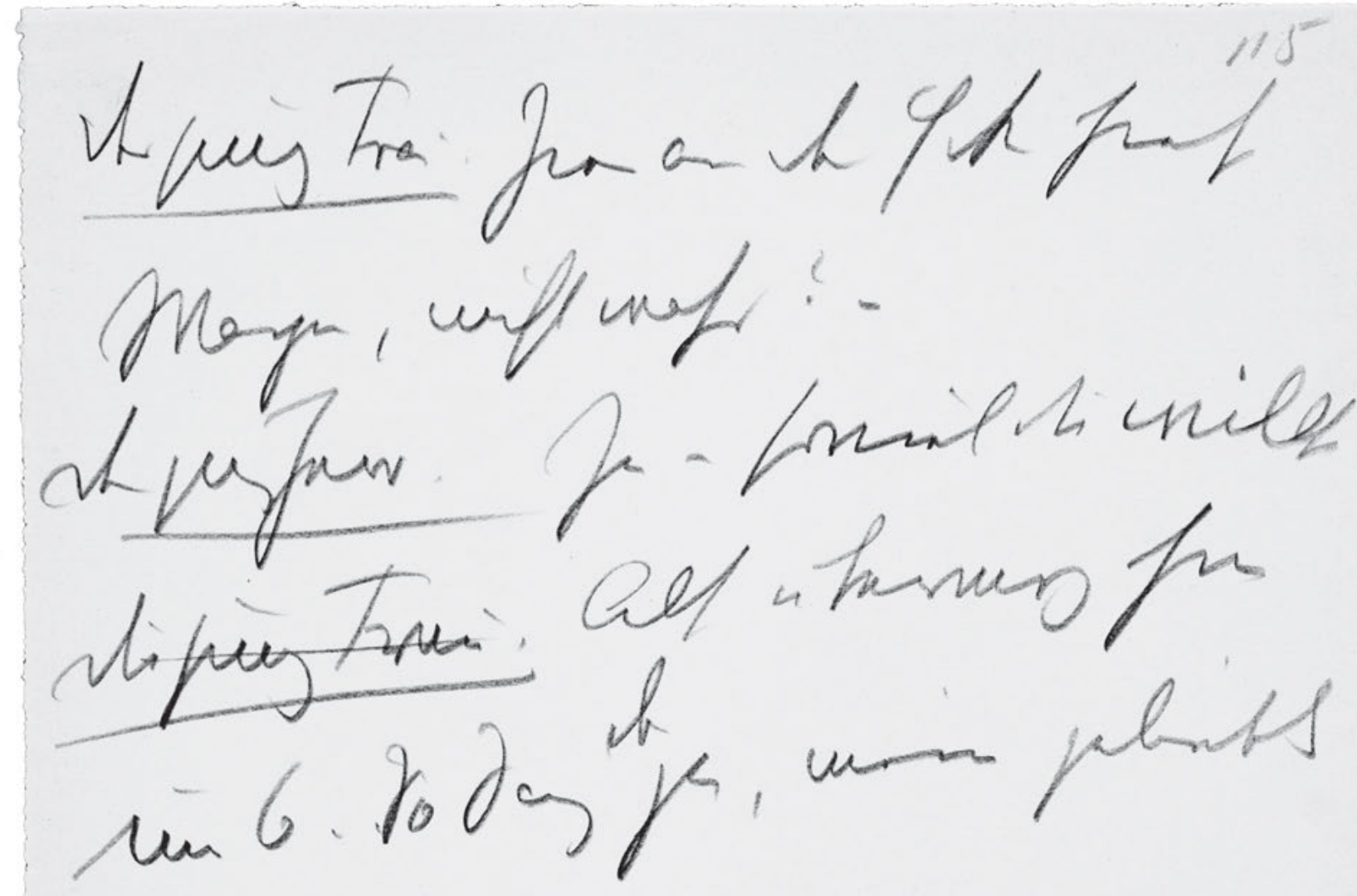

glaj!

his tro

b. hlporf us

bin Cothlos

sumprn

the

(nivernt fir.)

hriqupe.

264 
Der jung Frau. Hier an der Ecke stehen

Wagen, nicht wahr? -

Der jung Herr. Ja - soviel du willst

5 Die jung Frau. Also übermog hier

do

um 6 . 'So Sag ja, mein geliebter

Schatz!

Die jg Frau. .. Das . . besprechen wir

morgen beim Cotillon . .

10 Der jung Herr. (umarmt sie.) Mein Engel. 
HSz4 115 a

Handschriften und Typoskript

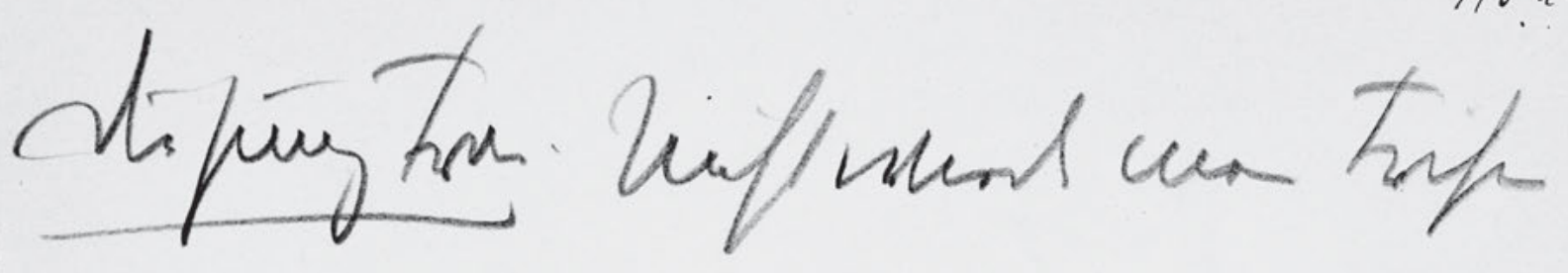

micuss

shejgus alf urym hotola

therguse Alf urym hotota

$1 / 5 a-$

Lipueg Train...

Ll mofl....

highers.

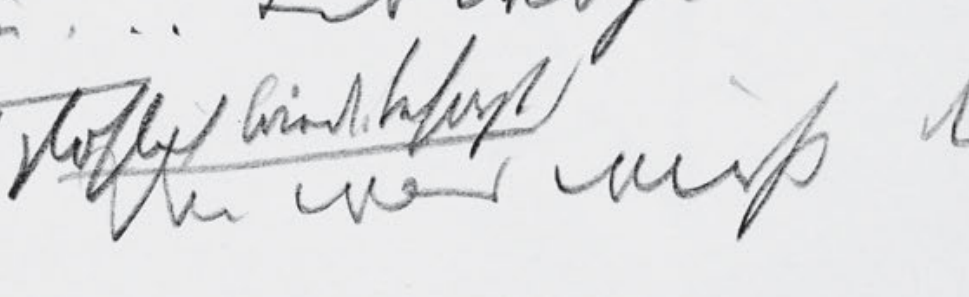

L

dipung

mif

266 


\section{$115 \mathrm{a}-$}

Die jung Frau. Nicht wied mein Frisur

ruiniren.

Der jung Herr. Also morgen bei Lobheim

5 und übermorgen .. in meinen Armen.

Die jung Frau. .. Leb wohl! . . . . .

(plotzlich 'w'iede besorgt)

Der jung Herr. Und was wirst du

ihm heut sagen - ? .

Die jung Frau. . - Frag nicht . . frag

${ }_{10}$ nicht - . es ist zu schrecklich. - 
HSz4 116

Handschriften und Typoskript

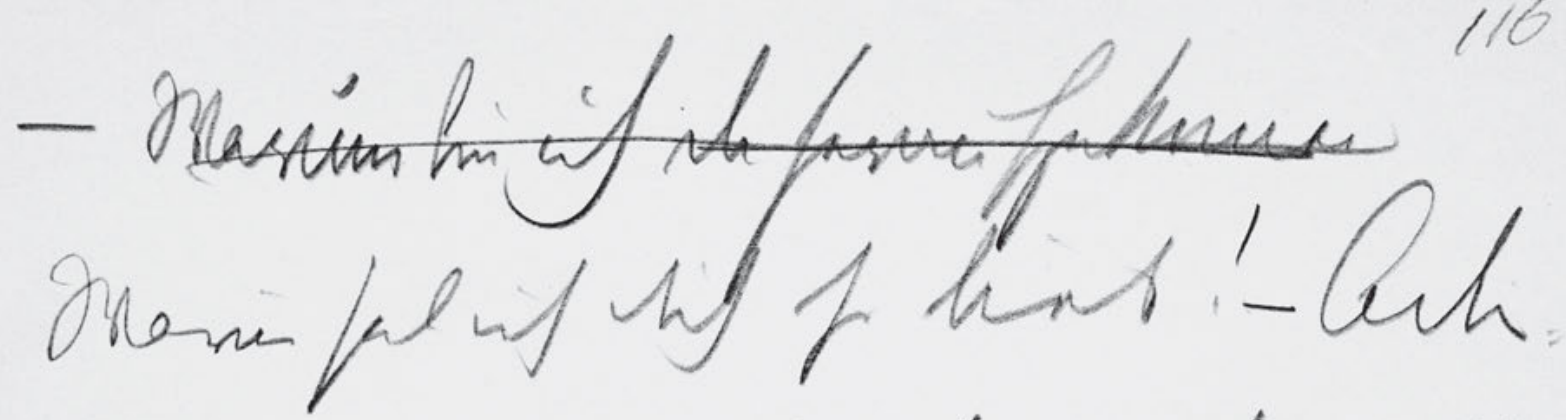

- Mring mints lumiff andy Dinge borpon
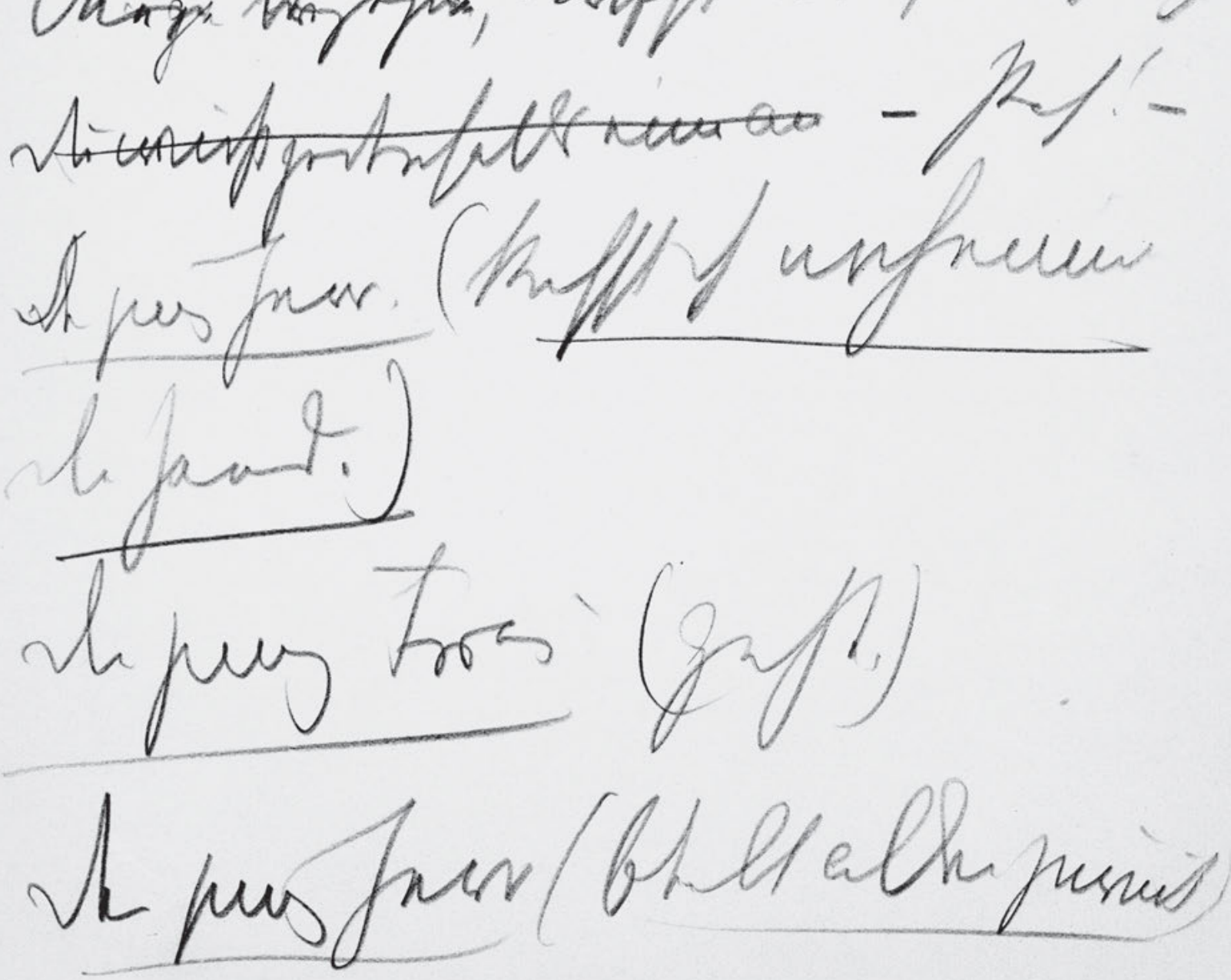

268 


\section{6}

- Warum bin ich da heraufgekomen

Warum hab ich dich so lieb! - Adieu:

- Weñ ich wieder Menschen auf der

$5 \quad$ Stiege trbegegne, trifft mich der Schlag.

Du wirst jedenfalls eine an - Pah! -

${ }^{[?]}$ Der jung Herr. (kusst ih nocheinmal

die Hand.)

Die jung Frau (geht.)

10 Der jung Herr (bleibt allein zurück) 
HSz4 117

Handschriften und Typoskript

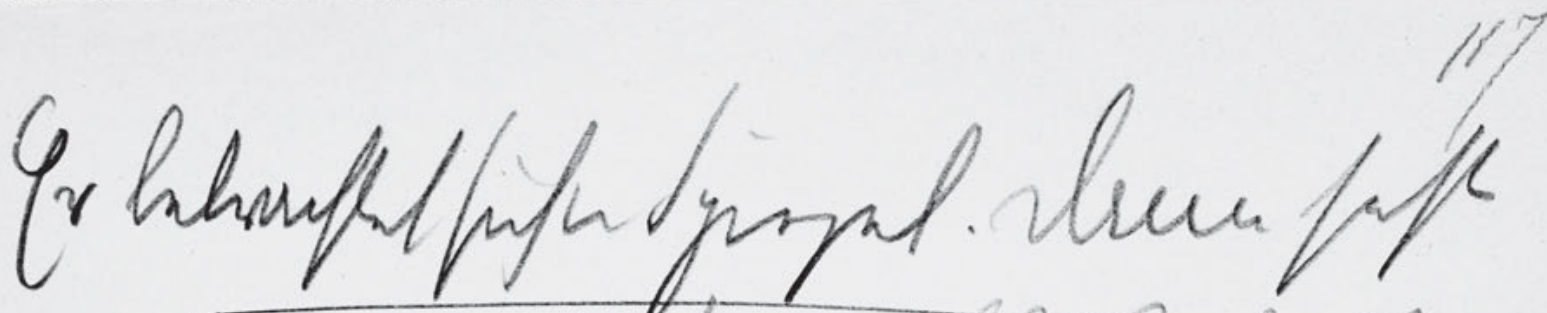

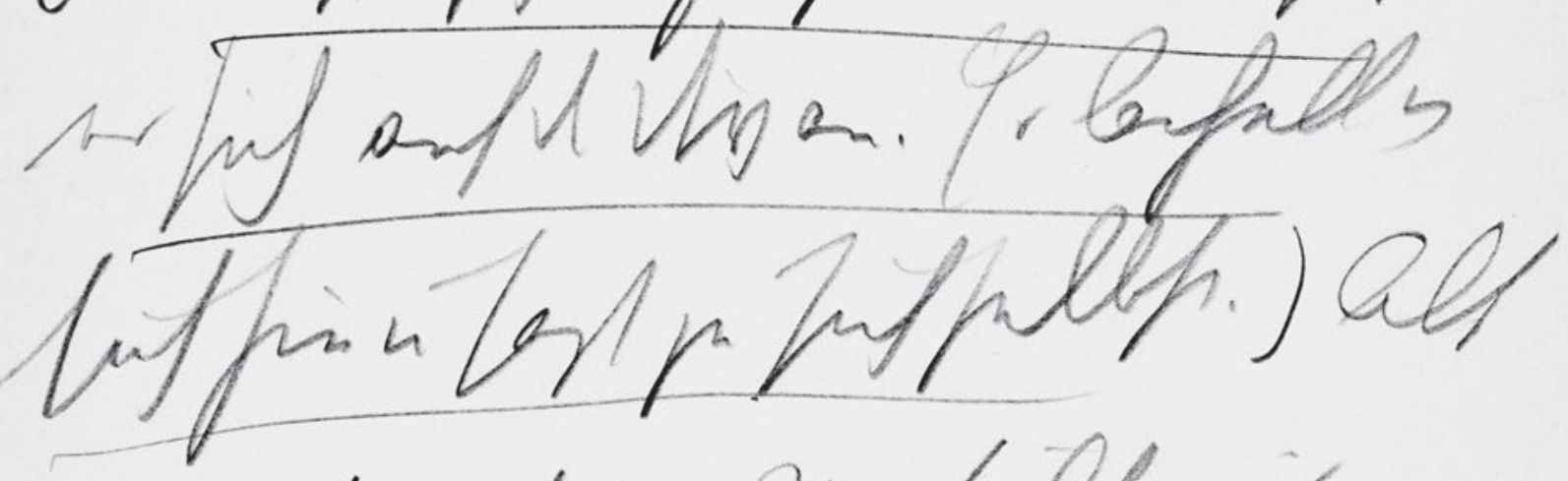

wife fal w

ifin Nofaltur u

nue aspentis Tru

270 
Er betrachtet sich im Spiegel. Dann setzt

er sich auf den Divan. Er lachelt vo

sich hin u sagt zu sich selbst.) Als

$5 \quad$ jetzt hab ich ein Verhältnis mi

einer anständigen Frau . . 
1.

$\mathrm{Zu}$ Seite 66

Es klopft.

Die junge Frau. Um Gotteswillen.

Der junge Herr. So erschrick doch nicht.

Es klopft nochmals.

Die j. F. läuft ins Nebenzimmer.

Der j. H. bei der Türe- Was wollen Sie denn zum

Teufel hinein, hab ich Ihnen nicht gesagt, dass ich nicht zu Hause bin?

Diener | von draussen | Ich bitte, gnädiger Herr, es sind zwei Herren da.

Der j. H. Wie, was? zwei Herren?

Er öffnet die Türe, der Diener tritt ein.

Der j. H. Warum haben Sie nicht gesagt, dass ich nicht zu Hause bin?

Diener. Ich hab es ja gesagt, aber die Herren sagen, es ist von grösster Wichtigkeit, sie wollten bis der gnädige Herr nach Hause kommt- da sind sie schon. 
Max und Eduard.

Eduard | Totenblass |

$\operatorname{Max} \mid$ schlank, schwarz, düster. |

Max. Ich habs ja gewusst, dass Du zu Hause bist.

Der j. H. Allerdings, aber Ihr entschuldigt, ich bin wirklich- eben war ich daran ein Bad zu nehmen-

Max. Es ist nicht Zeit ein Bad zu nehmen, es handelt sich um Wichtigeres. Du musst unserm armen Freunde Eduard einen grossen Dienst erweisen.

Der j. H. Ein Duell?

Eduard | nickt ü |

Der j. H. Was ist denn geschehen?

Max. Vor einer Stunde ist er erwischt worden.

Der j. Herr. Erwischt.

Max. Ja.- Nun wirst Du ihn wohl nicht mehr beneiden, um sein Glück bei verheirateten Frauen. Es kann auch einmal schlimm ausgehen, wie sich zeigt.

Der j. H. Warum denn schlimm? es ist ja noch nicht entschieden. | legt Eduard wie ermutigend die

$39 \mathbf{J a}] \mathbf{J}$ überschreibt $\mathbf{H}$.

40f. Zeile 41 überschreibt Zeile 40.

44 legt] handschriftliche Korrektur mit blauem Stift bei $\mathbf{t}$. 
Hand auf die Schulter |

Max. Diese Sache ist entschieden. Er bittet Dich sein zweiter Sekundant zu sein. Wir müssen das Nähere mit Dir besprechen. Morgen Früh um 8 werden die Zeugen bei Ihm sein.

Der j. H. Nun ja, in zwei Stunden steh ich Euch zur Verfügung- mein Bad- Ich habe so gut wie nichts an- Ich kann mir den Tod holen.

Max. Nimm Dein Bad. Wir werden warten. Wir wollen unterdessen den Duellkodex durchsehen. Du hast doch in Deiner Bibliothek einen Duellkodex?

Der j. H. Zum Kuckuck Ihr könnt hier nicht wartenErwartet mich im Kaffeehaus. Hier ist der Kodex. Nehmt ihn mit.

Max. Soll ich Dirs auf den Kopf zusagen- Du hast ein Weib bei Dir-

Der j. H. Nein. Ja- kein Weib- ein junges Mädchen. Sie vergeht indess vor Angst. Geht ins Kaffeehaus. In einer Stunde bin ich bei Euch.

Max. Ein junges Mädchen? Was für ein LeichtsinnBrüder sind noch gefährlicher als Gatten. 
Der j. H. Ich weiss. Hier ist der Kodex. Geht.

Max. Du bist ein Egoist.

Der j. H. Ich weiss. In zwei Stunden- In einer-

Max. Wir werden warten. | Sie wenden sich zu gehen | wie sie bei der Türe sind, verschwindet der junge Herr ins andre Zimmer, in der Meinung dass die beiden andern fortgegangen sind. | | Bei der Türe sinkt Eduard in die Knie |

Max. Na, da haben wirs.

Eduard. Ich kann nicht weiter-

Max. Mein Lieber, so geht das nicht. Wenn man ein Don Juan ist, muss man die Folgen auf sich nehmen. Nebstbei könnte es als indiskret gelten, wenn wir in diesem Zimmer bleiben.

Eduard | ist auf das Sofa gesunken. |

Max. So wollen wir wenigstens keine Zeit versäumen. Ich will Dir zu Deiner Beruhigung aus dem Kodex vorlesen, damit Du weisst wie Du Dich morgen zu benehmen hast. Warte- Wo ist denn unser Fall. | Er blättert | So- Hier| Er liest | Man übergibt dem Gegner ein

82 Zimmer] i überschreibt ö. 
Taschentuch, welche dieses an zwei diagonal gegenüberliegenden Enden erfassen, wenn einer der Kämpfer vor dem Signale feuert, ist sein Gegner berechtigt ihn, wie er will, über den Haufen zu schiessen. War dem so Handelnden die geladene Waffe zugefallen und hat er den Gegner getötet, so sind die Sekundanten bei ihrer Ehre verpflichtet, den Fall sogleich zu Protokoll zu nehmen und gegen den Meuchelmörder ohne Verzug die gerichtliche Verfolgung einzuleiten.

Eduard | erhebt sich vom Sofa, sieht Max wie verzweifelt an und stürzt mit einem Hysterischen Lachen davon. | Max ihm nach. 


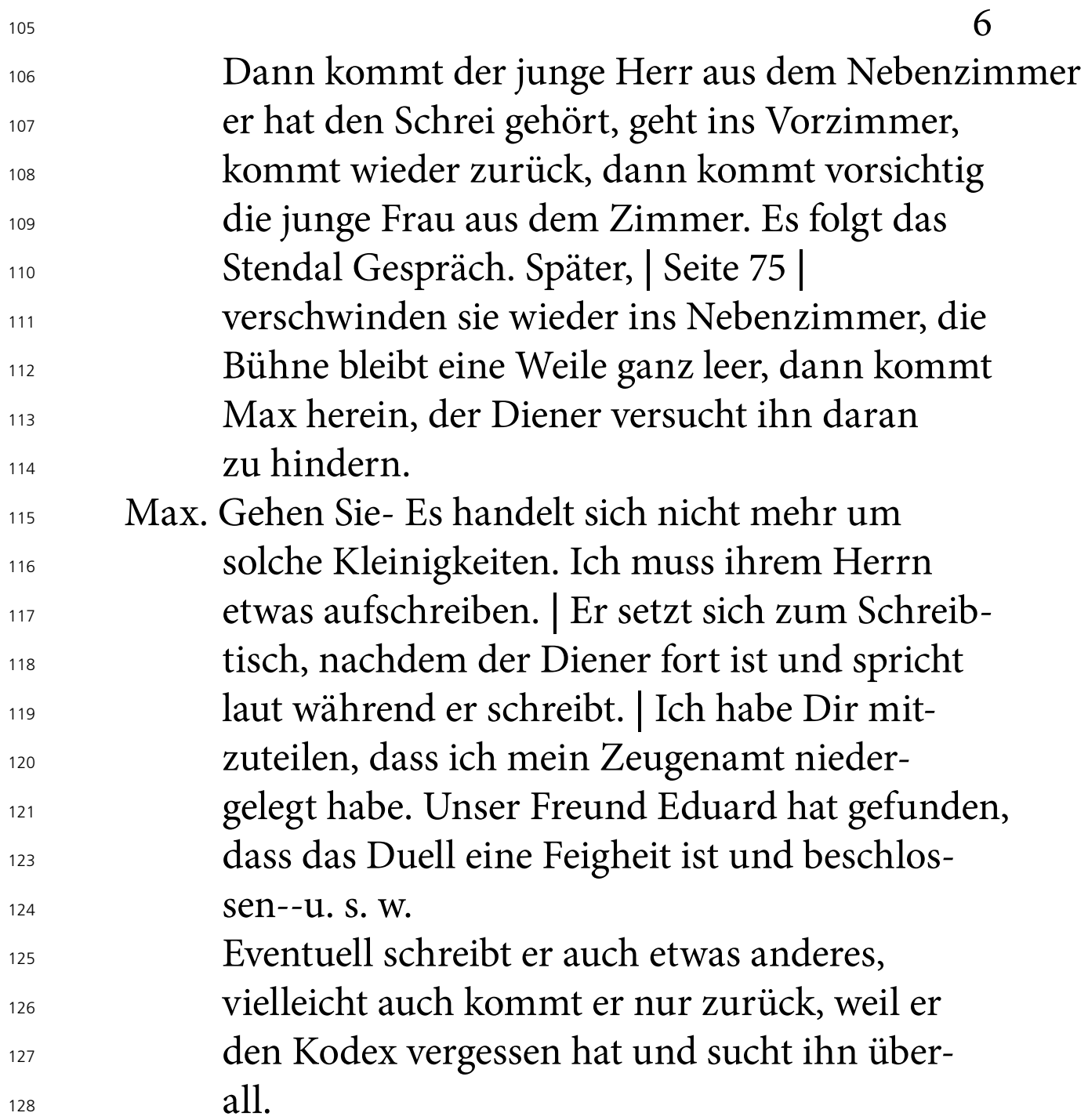

$105 \quad$ Handschriftliche Paginierung mit Bleistift korrigiert falsche maschinschriftliche Paginierung (7).

115 händisch mit blauem Stift nach nicht gestrichen: ke.

$119 \mathbf{e r}] \mathbf{r}$ undeutlich lesbar, überschreibt möglicherweise ein anderes Graph, das

- wie ein noch leicht sichtbarer Punkt - zuvor ausradiert wurde.

123 Feigheit] handschriftliche Korrektur mit blauem Stift: i überschreibt $\mathbf{u}$.

125 schreibt] handschriftlich mit blauem Stift i ergänzt. 


$\begin{array}{ll}{ }_{129}^{129} & 7 \\ { }_{131} & \text { Nach einigen Minuten entfernt er sich wieder } \\ { }_{132} & \text { und der junge Herr und die junge Frau treten auf. } \\ { }_{134} & \text { Dann geht die Scene weiter zum Schluss, wie } \\ \text { im Original. }\end{array}$

$129 \quad$ Handschriftliche Paginierung mit Bleistift korrigiert falsche maschinschriftliche Paginierung (8). 
Herausgebereingriffe

Das unruhige Satzbild wurde normalisiert (v. a. Vereinheitlichung der Einzüge); fehlende und überschüssige Leerzeichen/Wortabstände wurden korrigiert; fehlende Punkte am Satzende wurden ergänzt; vereinheitlicht wurde die Zeichensetzung bei den Sprecherangaben (Tilgung überschüssiger Kommata und Punkte, einheitlicher Abschluss mit Punkt). Die spezifische Realisierung von Gedankenstrichen als Divise (ohne vorhergehenden Abstand) wurde beibehalten. Beifolgenden offenkundigen Druck-und Satzfehlernwurde eingegriffen:

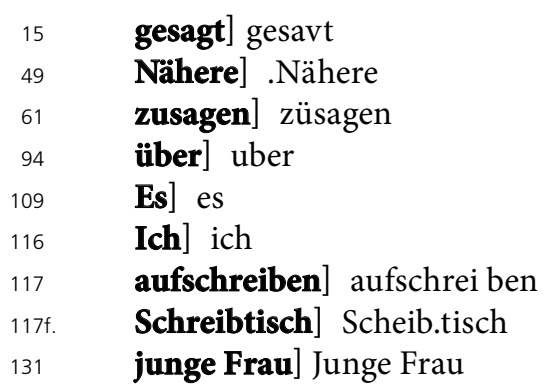


HSz5 118

Handschriften und Typoskript

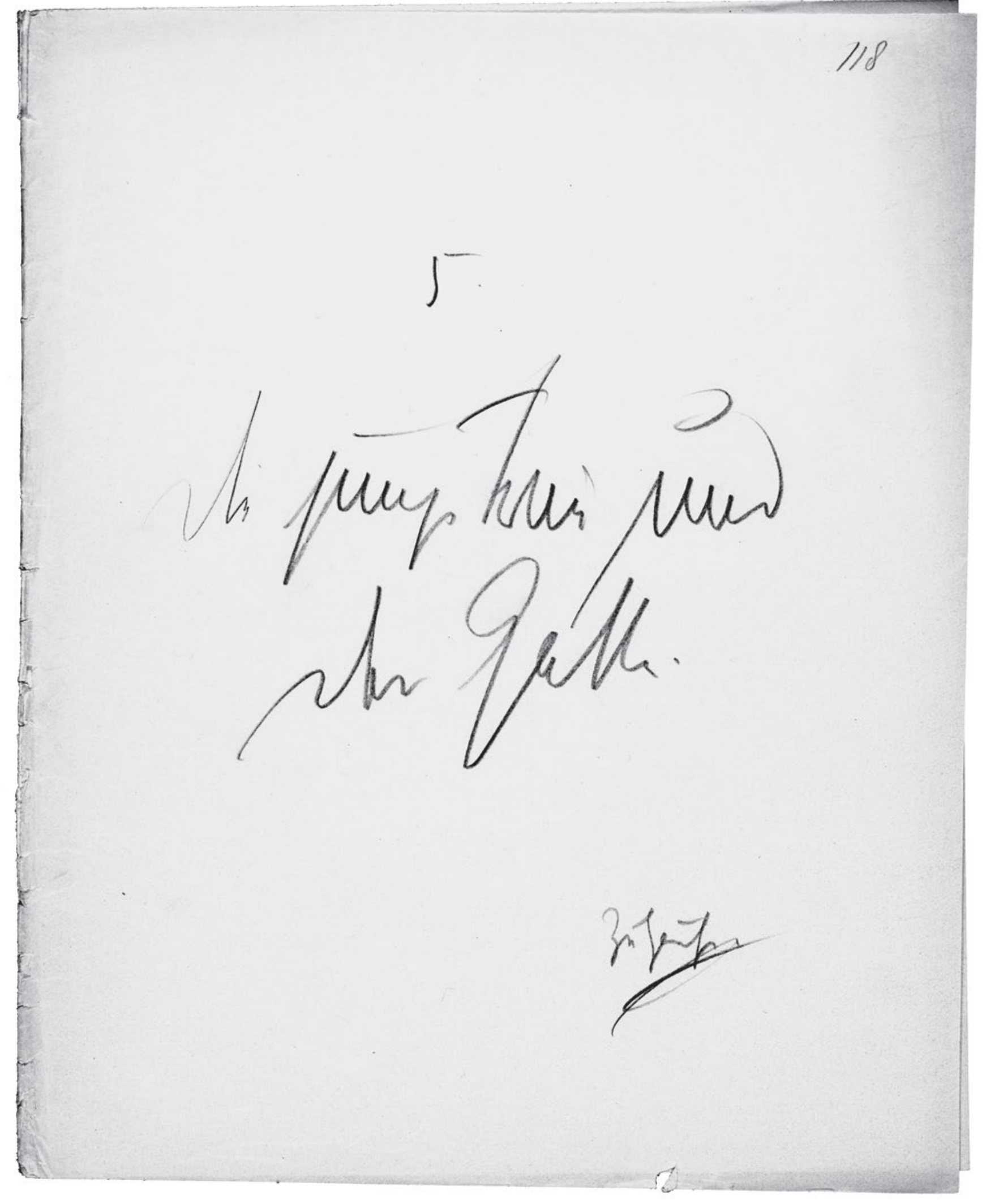

280 
5.

Die junge Frau und

der Gatte. 
HSz5 119

Handschriften und Typoskript

2ate

119
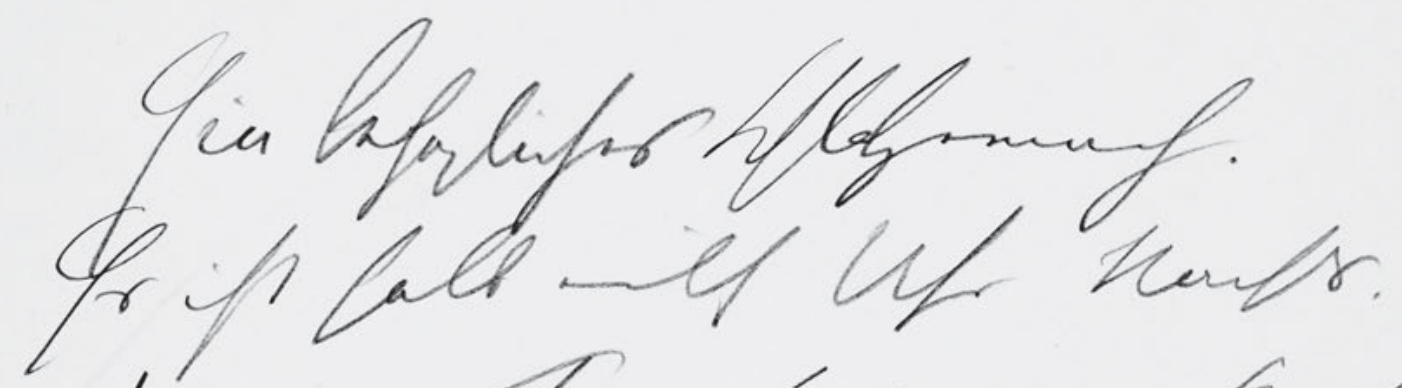

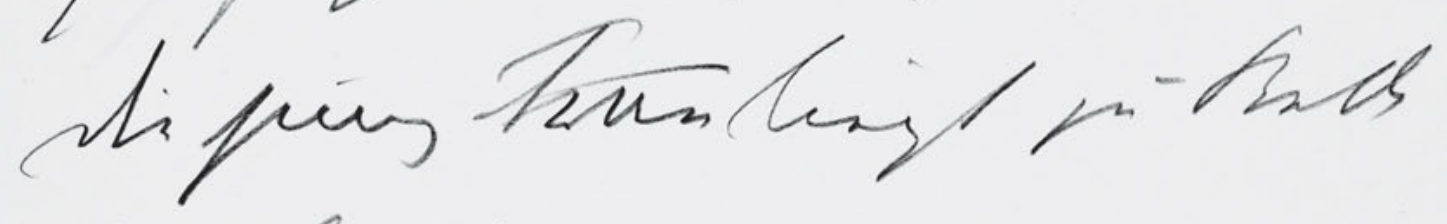
und hinfte
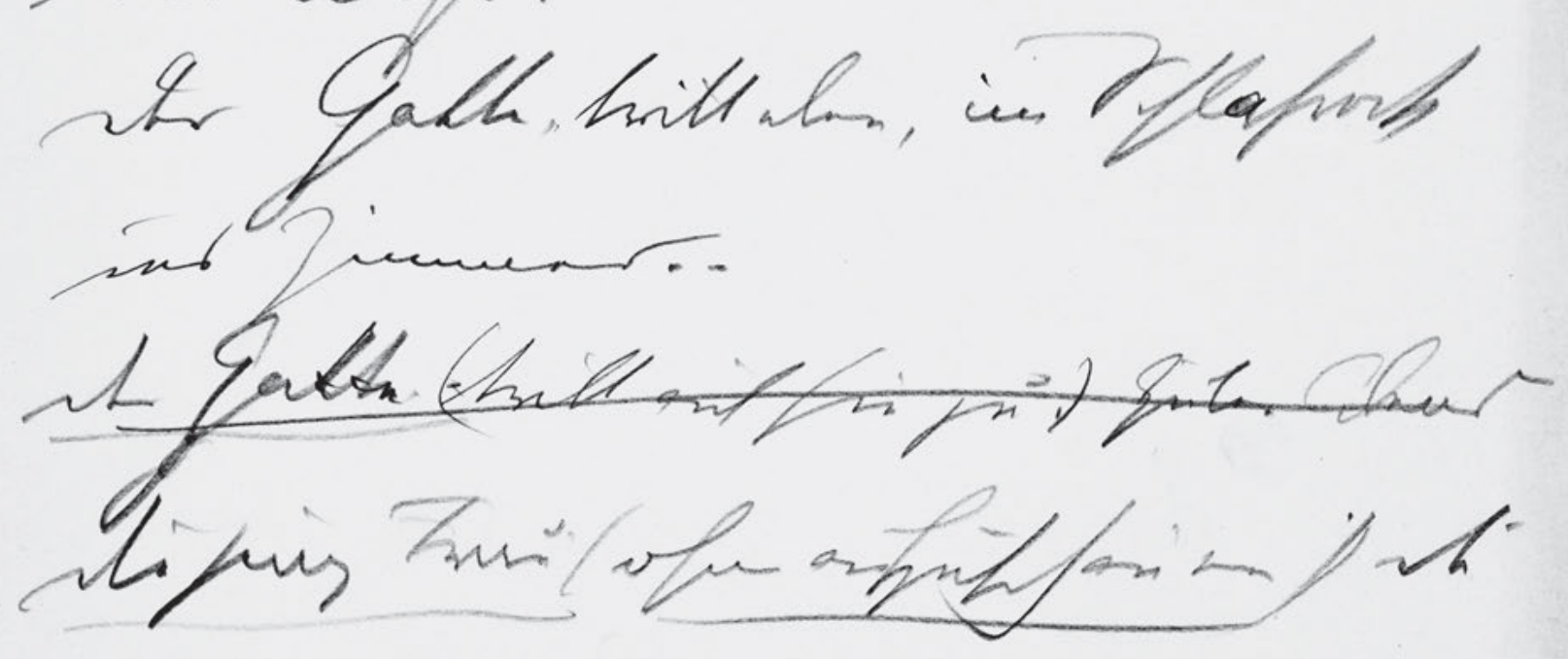

achisaff wift unfer

st Gath. Rom. If his pisuis. Our aspuntu..

282 
?29/11?

119

Ein behagliches Schlafgemach.

Es ist halb eilf Uhr Nachts.

Die jung Frau liegt zu Bette

$5 \quad$ und liest.

Der Gatte, tritt eben, im Schlafrock

ins Zimmer . .

Der Gatte. (tritt auf sie zu.) Guten Abend

Die jung Frau (ohne aufzuschauen) Du

10 arbeitest nicht mehr.

Der Gatte. Nein. Ich bin zu müde.

Und außerdem . . 
HSz5 120

Handschriften und Typoskript

Mifuig Trun: - Lim? -

120

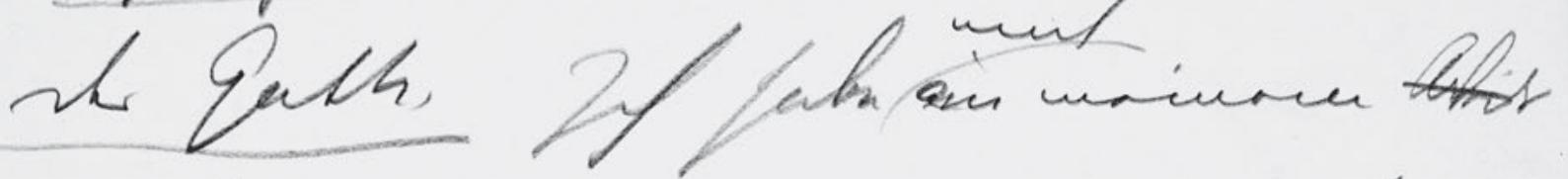

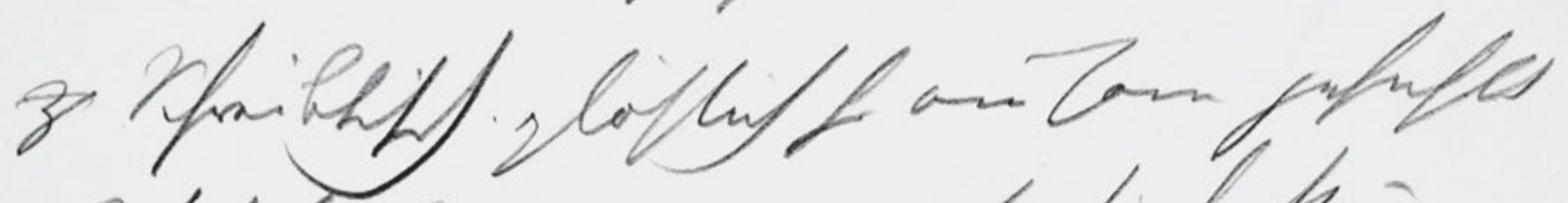

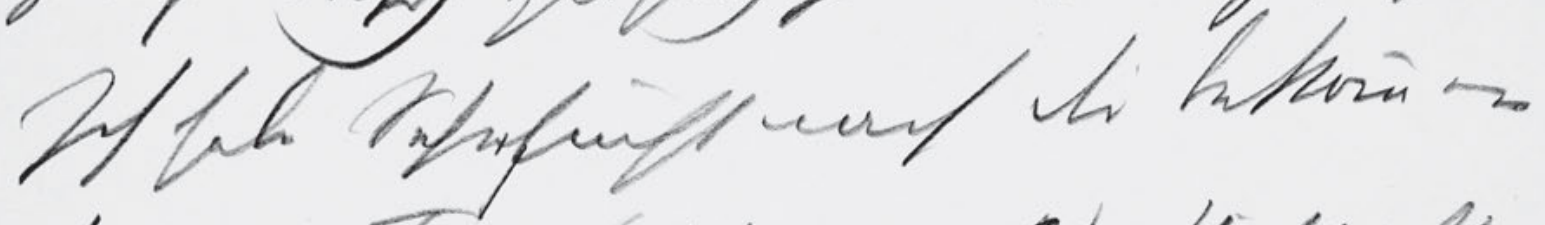
difing Train (Ifontarif)-thibluy:

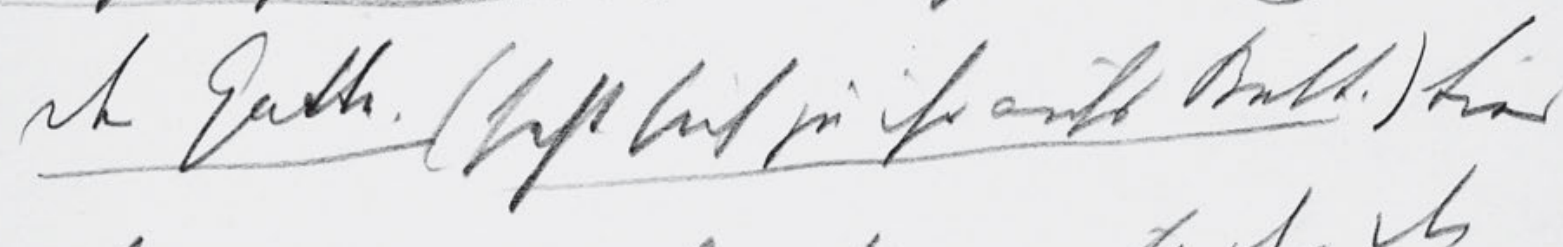

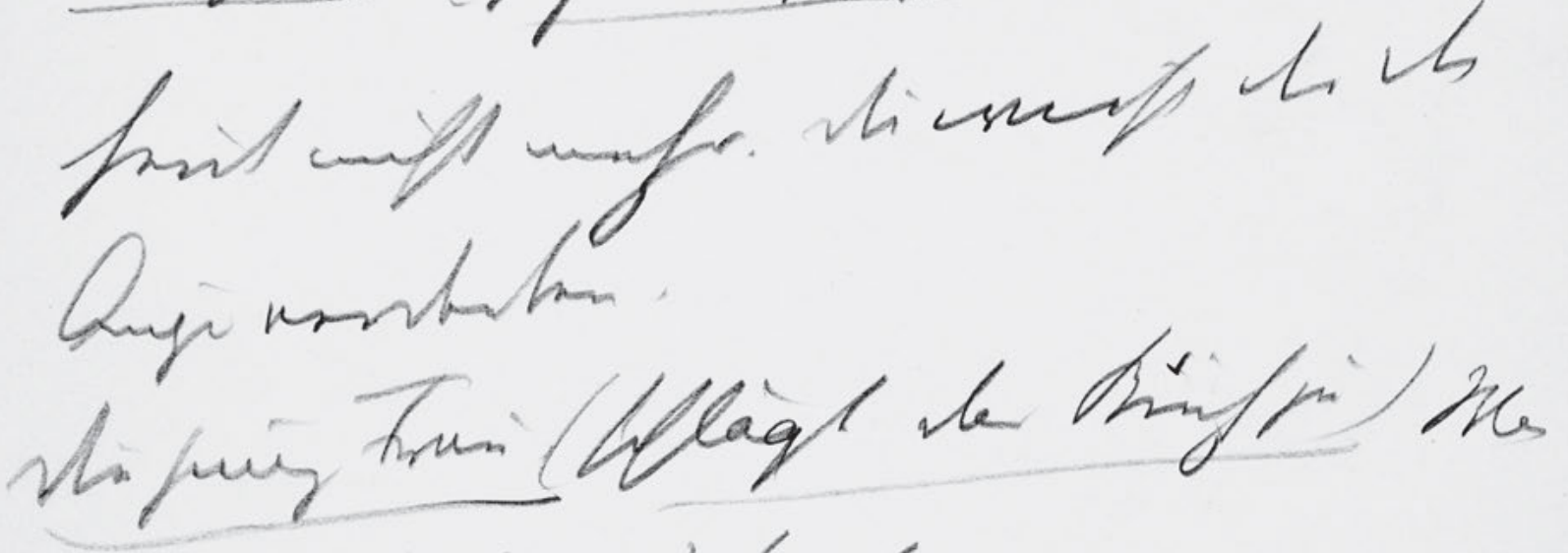

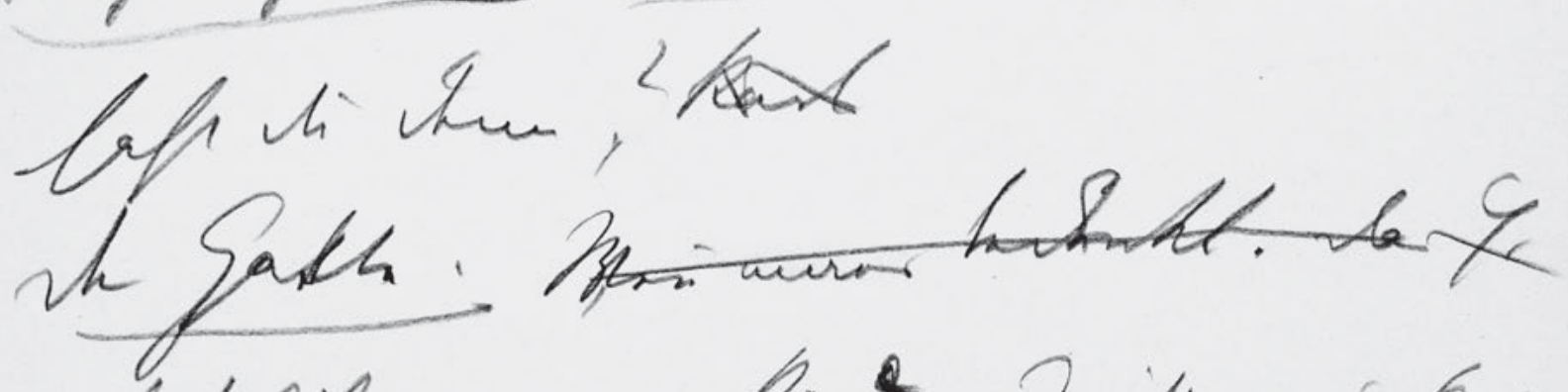

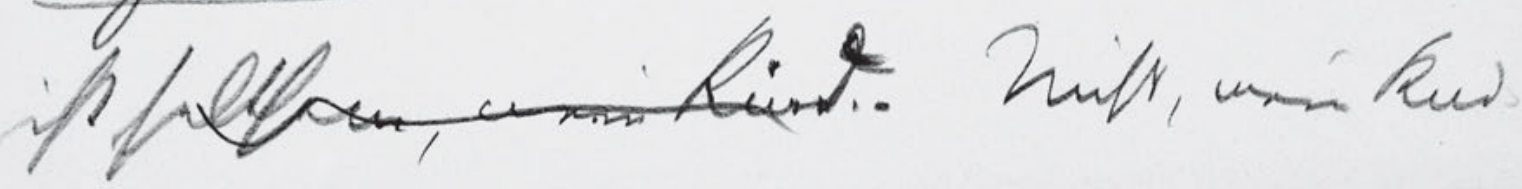

284 
Die junge Frau. - Nun? - $\quad 120$

mich

Der Gatte. Ich habe an meinem Arbeits

zi Schreibtisch . plötzlich so einsam gefuhlt

Ich habe Sehnsucht nach dir bekomen

$5 \quad$ Die junge Frau. (schaut auf) - Wirklich?

Der Gatte. (setzt sich zu ihr aufs Bett.) Lies

heut nicht mehr. Du wirst dir die

Augen verderben.

Die junge Frau (schlägt das Buch zu) Was

10 hast du denn'? Karl

Der Gatte. Wen̄ mans bedenkt. Das Es

ist seltsam, mein Kind. - Nichts, mein Kind. 
HSz5 121

Handschriften und Typoskript

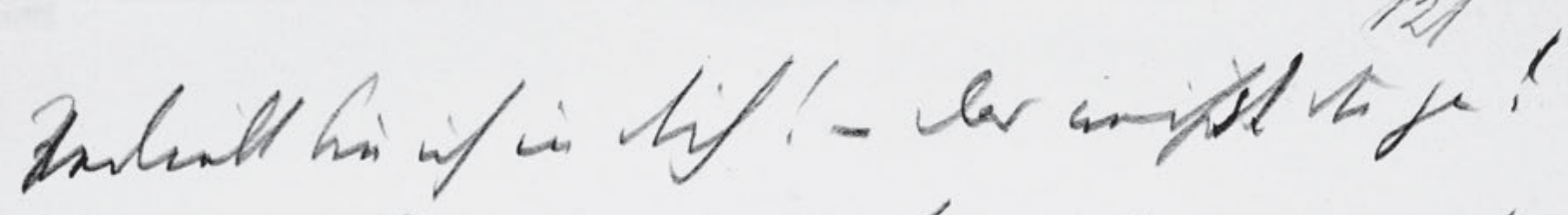

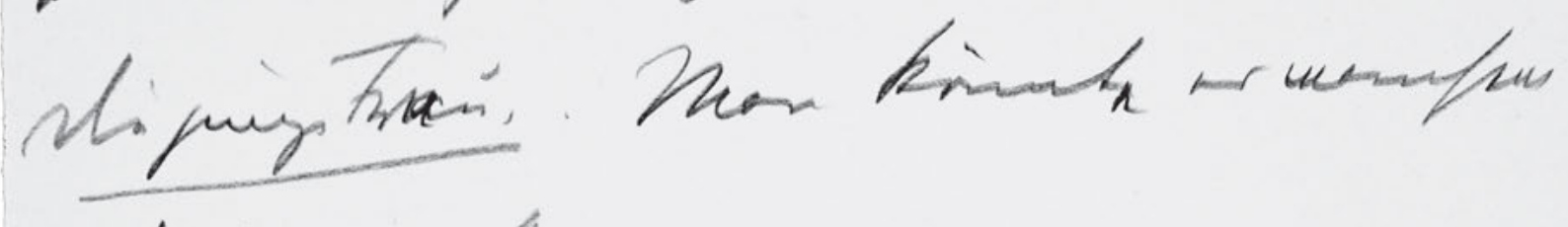
fapinarysa.

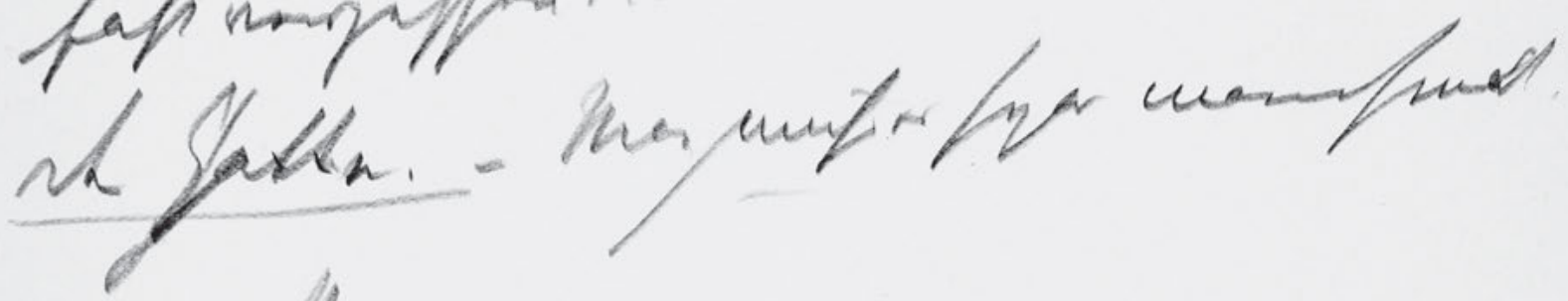
masifon....

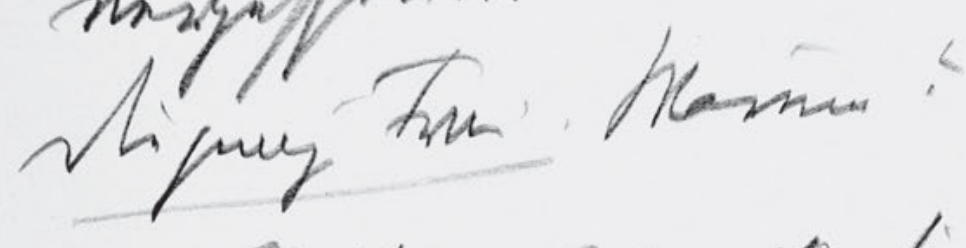

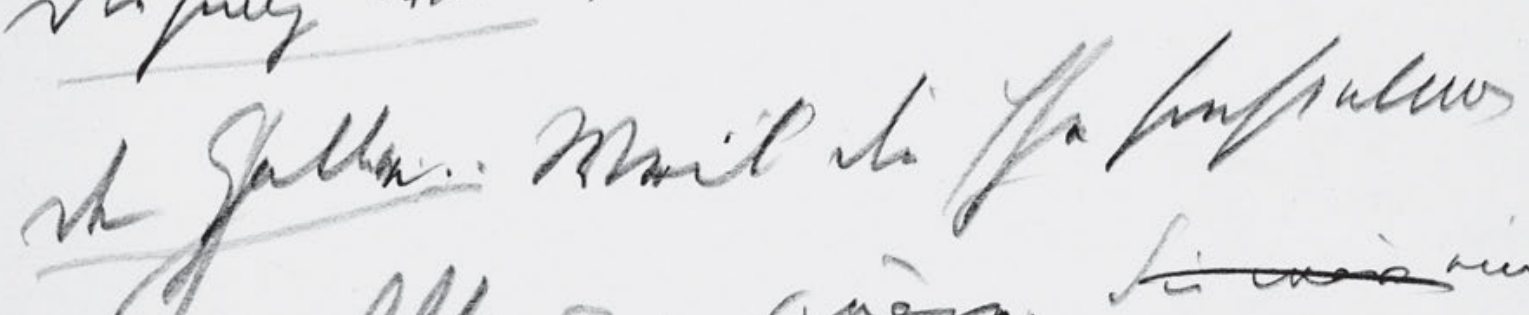
nnolthwinurvèr.

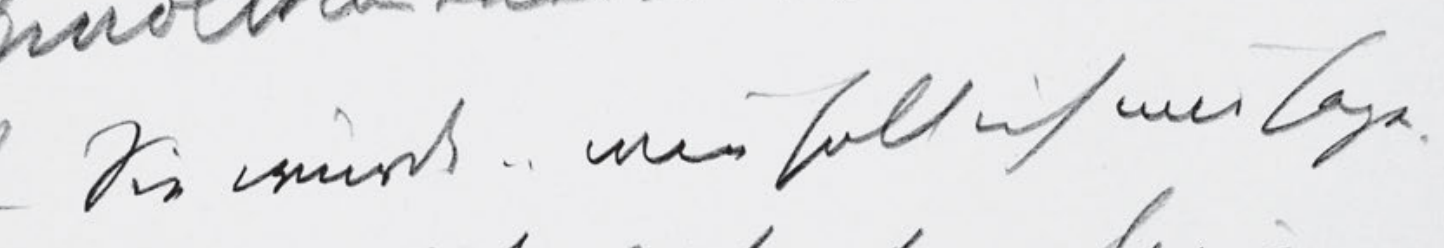

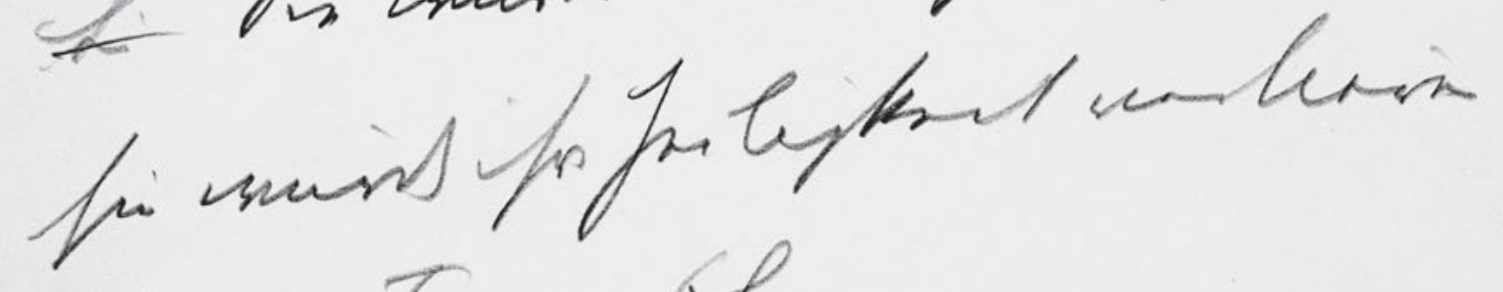
stopus Fren of

286 
?Z?Verliebt bin ich in dich! - Das weißt du ja?!

Die junge Frau. . Man könnte es manchma fast vergessen ...

5 Der Gatte. - Man muss es sogar manchmal . vergessen ....

Die junge Frau . Warum?

Der Gatte... Weil die Ehe sonst etwas

unvollkō̄enes wäre. Sie wäre eine

$10 \quad$ Li Sie würde .. wie soll ich nur sagen.

sie würde ihre Heiligkeit verlieren

Die jung Frau. Oh . . 
HSz5 122

Handschriften und Typoskript

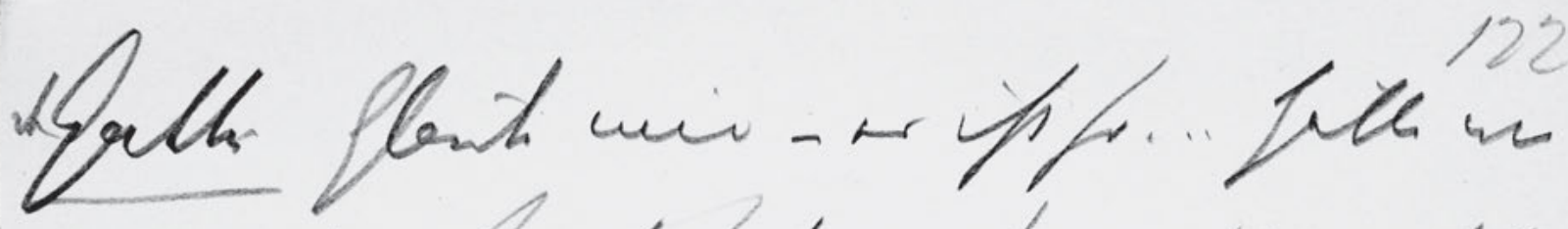
is the funf fufom, hi uni pefe cutroment ne furish f fwi, unf

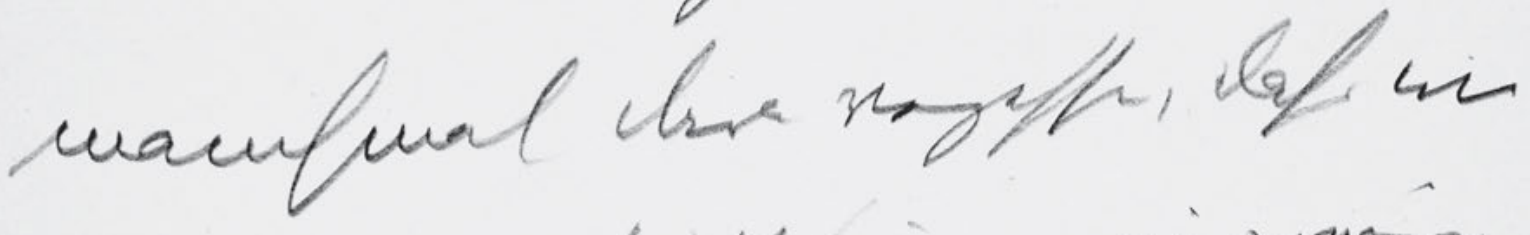
monank on holl wi - eirmar ar inol gar mift ungfor

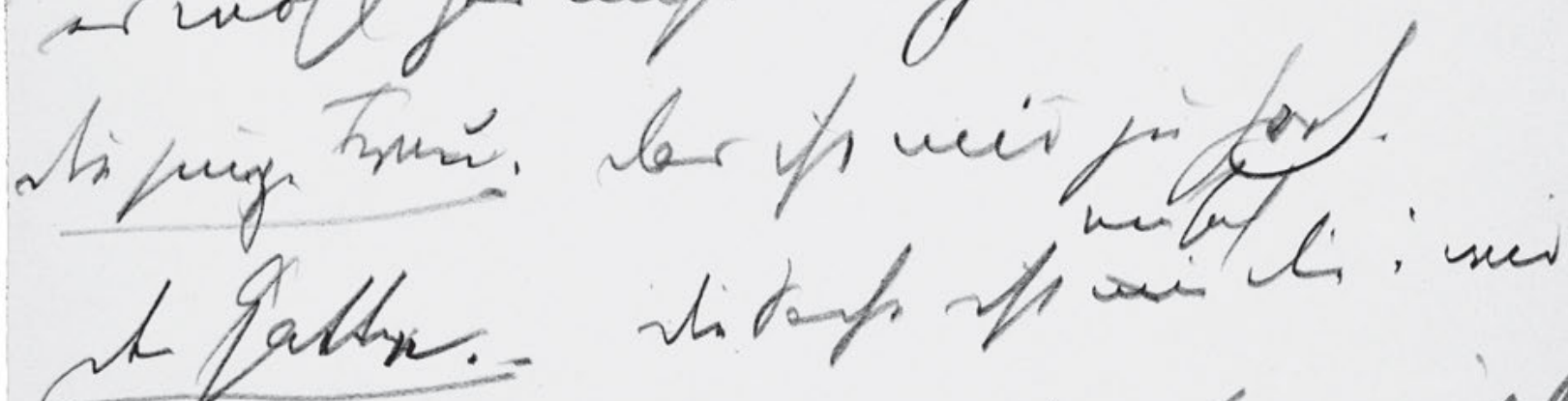

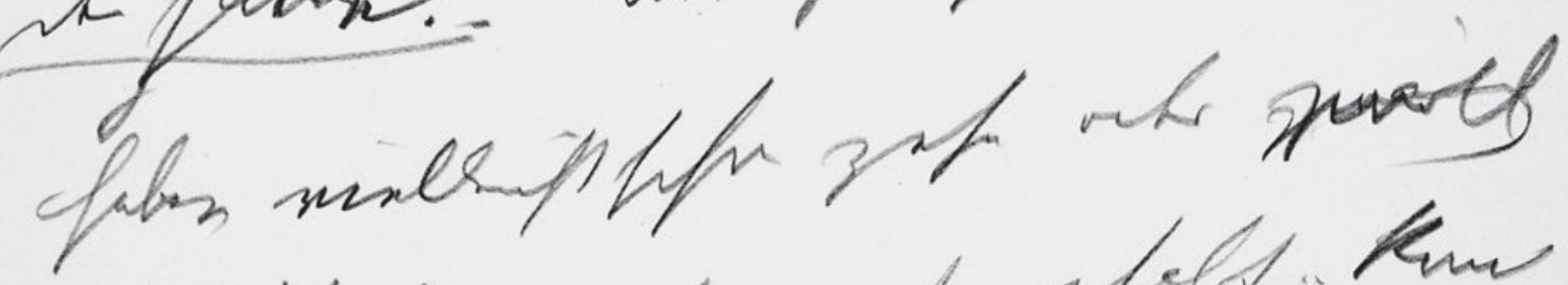

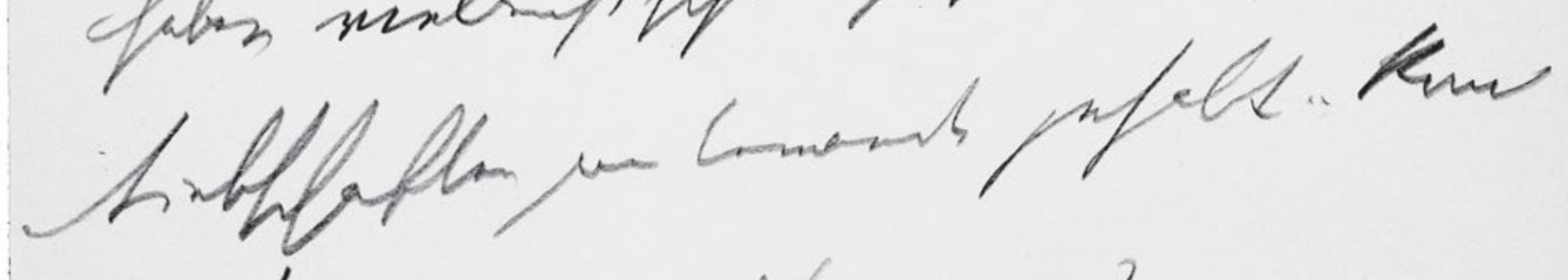
soli wift anffiner-?

288 


\section{2}

Der Gatte. Glaube mir - es ist so ... hätte wir

in den fünf Jahren, die wir jetzt

miteinander verheiratet sind, nicht

5 manchmal daran vergessen, dass wir

ineinander verliebt sind - wir wären

es wohl gar nicht mehr.

Die junge Frau. Das ist mir zu hoch.

einfach

Der Gatte. - Die Sache ist nur die: wir

haben vielleicht schon zehn oder ${ }^{z w a n z}$ zwölf

Liebschaften miteinande gehabt .. Komt

es dir nicht auch so vor - ? - 
HSz5 123

Handschriften und Typoskript

lipung trais lementsi. ?

123

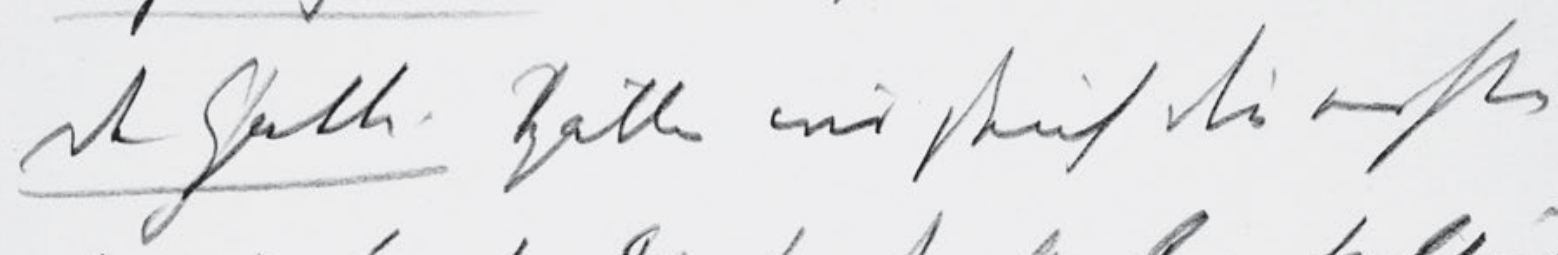

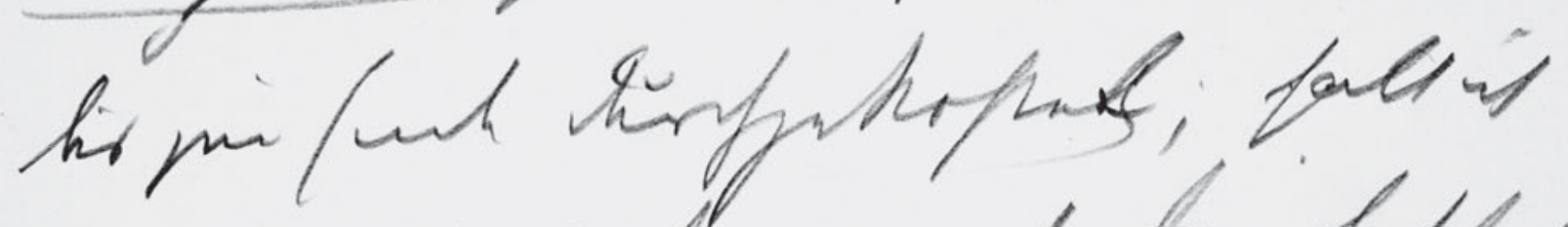

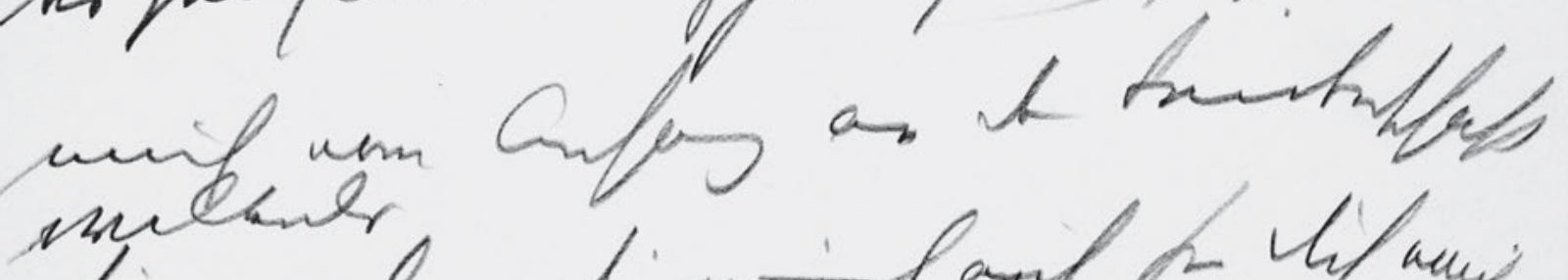

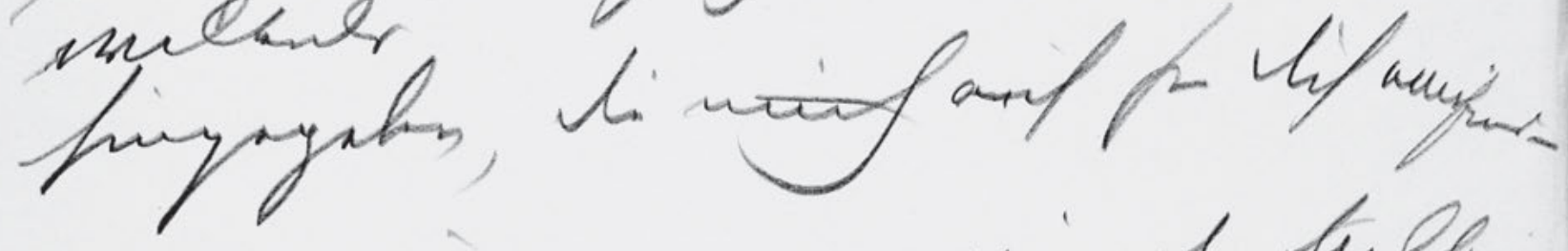

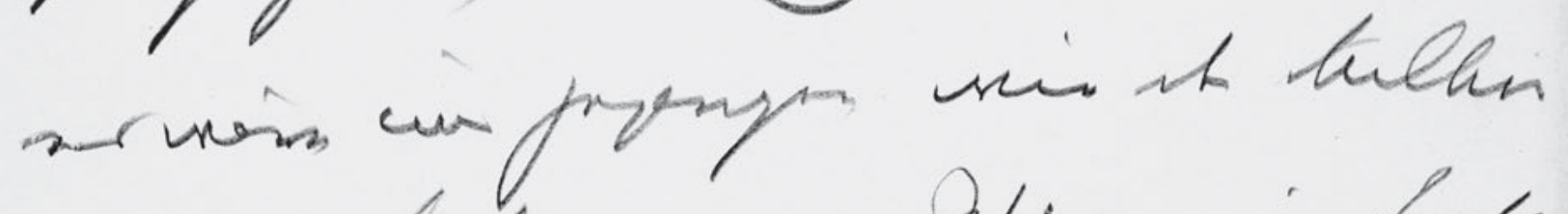
entorn habr paem. Aliv unainfors witerwantr.

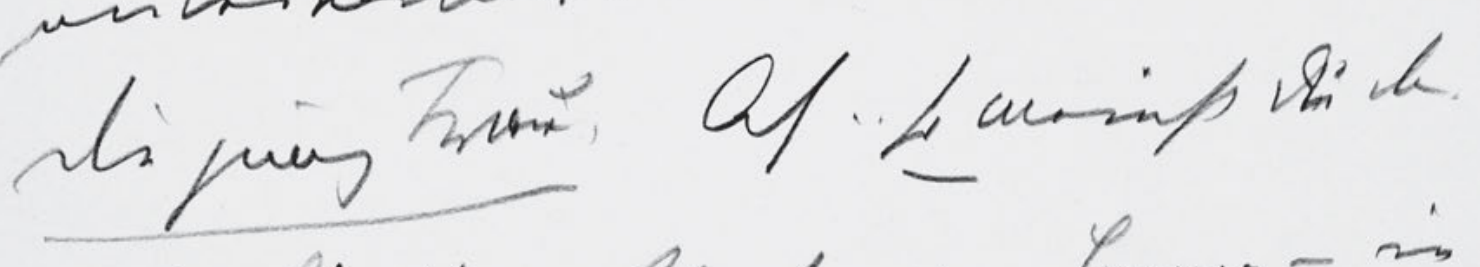

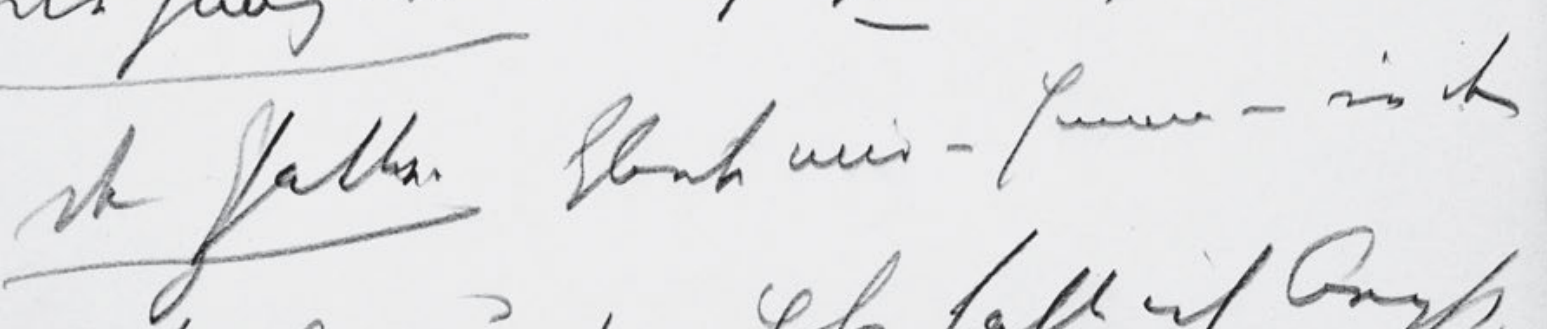

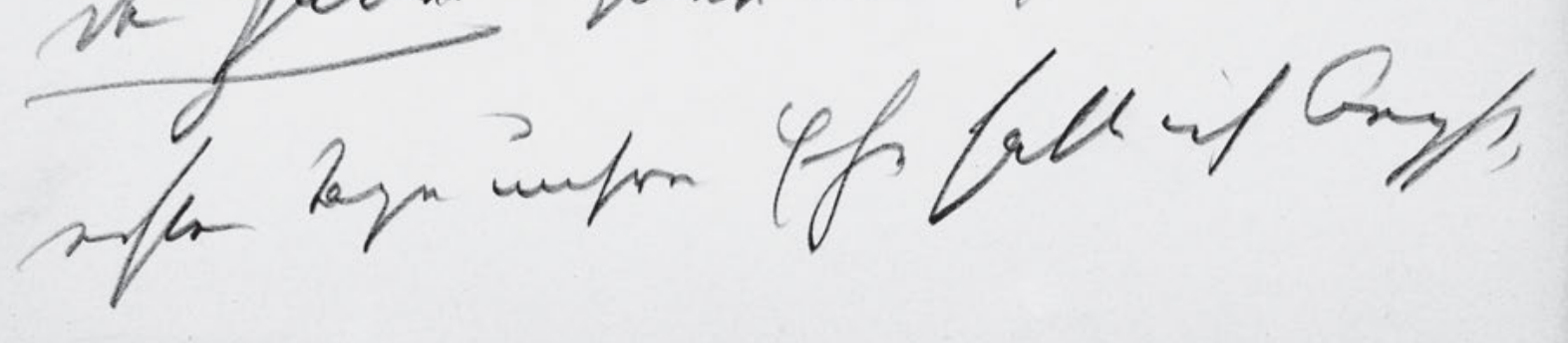

290 
Die jung Frau. Meinst du - ?

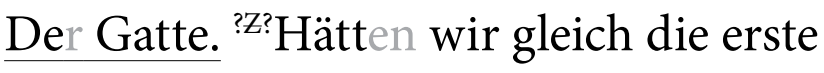
bis zum Ende durchgekoste ${ }^{[?]}$; hatt ich 5 mich vom Anfang an der Leidenschaft willenlos hingegeben, die mich ${ }^{\text {an }}$ ich fu dich empfind es wäre uns gegangen wie den Million andern Liebespaaren. Wir wären fertig miteinander.

10 Die jung Frau. Ah .. so meinst du das.

Der Gatte. Glaub mir - Emma - in den ersten Tagen unsrer Ehe hatte ich Angst, 
HSz5 124

Handschriften und Typoskript

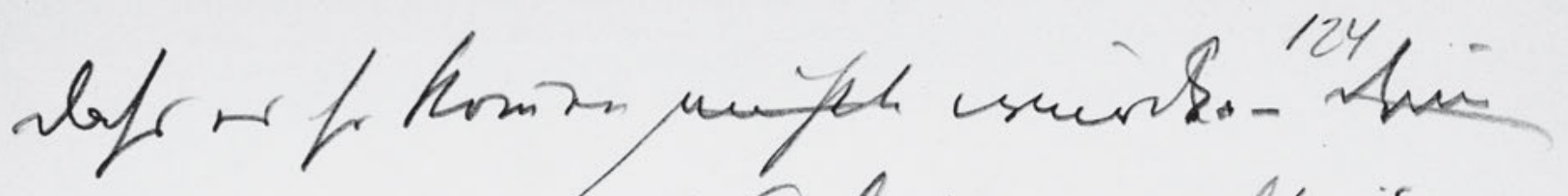
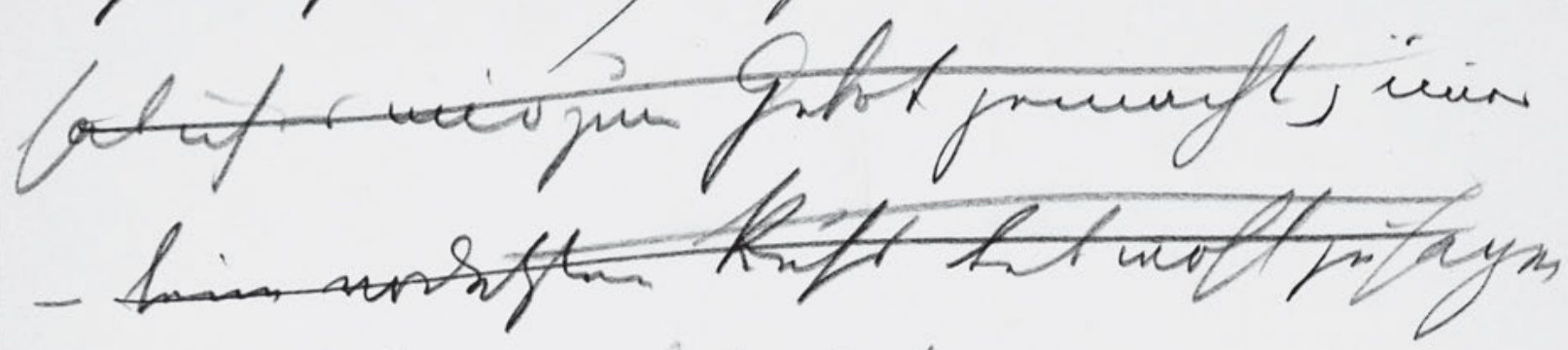

vapin Frun. Maur.

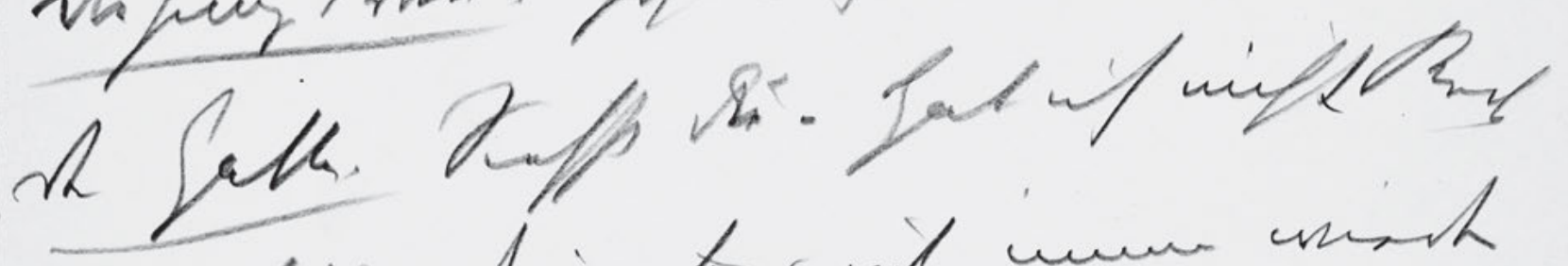

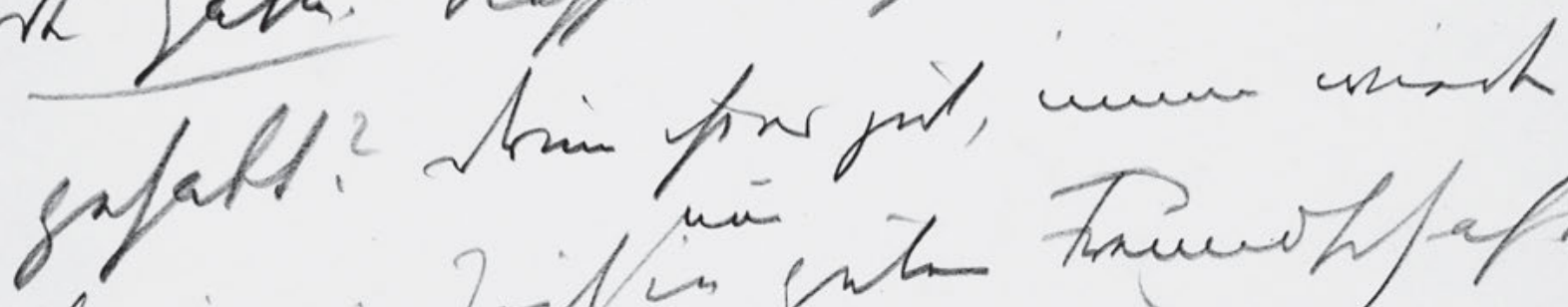
fining

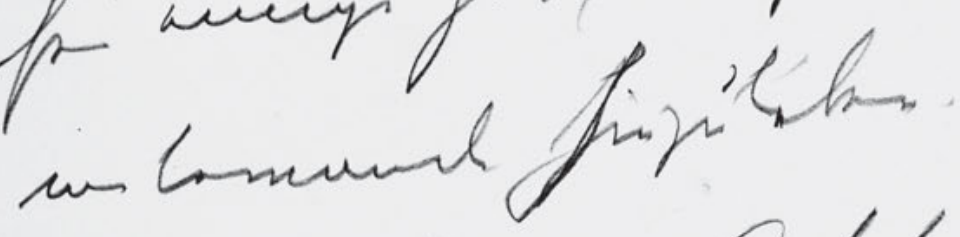
siguig Truna. Offor.

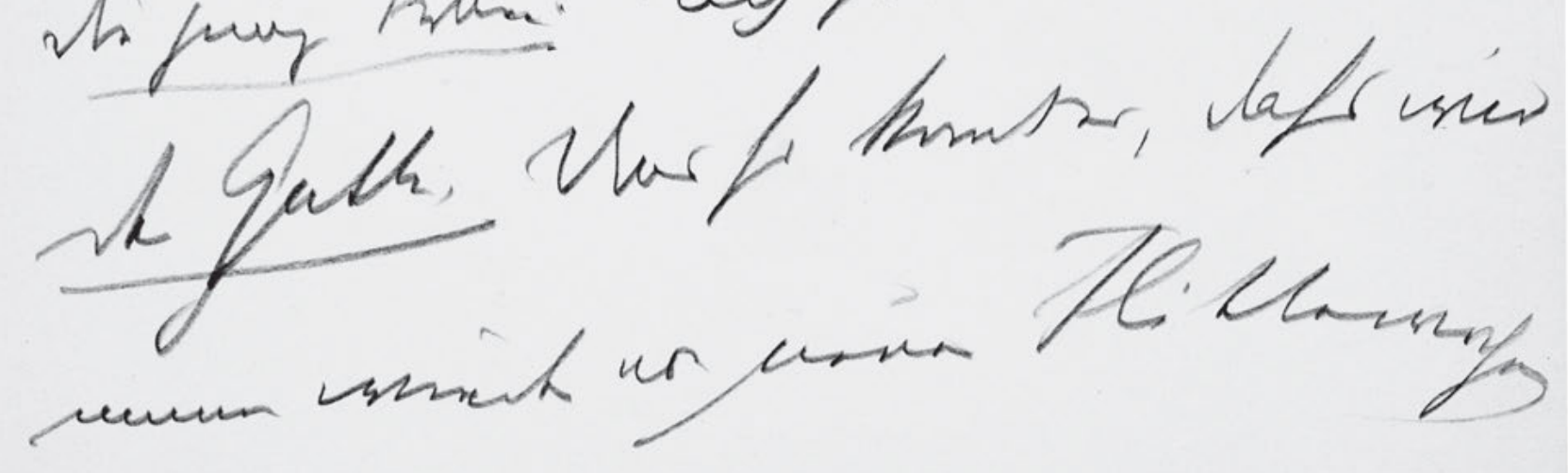

292 
124

dass es so kōmen müßte würde. - Drum

hab ich es mir zum Gebot gemacht, ī̄er

- beim vorletzten Kuss Leb wohl zu sagen

${ }_{5} \quad$ Die junge Frau. Ich auch..

Der Gatte. Siehst du - Hab ich nicht Recht

gehabt? Drum ist es gut, immer wieder

für einige Zeit in guter Freundschaft

miteinander hinzuleben.

10 Die junge Frau. . Ach so.

Der Gatte. Und so komt es, dass wir

immer wieder von neuem Flitterwochen 
HSz5 125

Handschriften und Typoskript

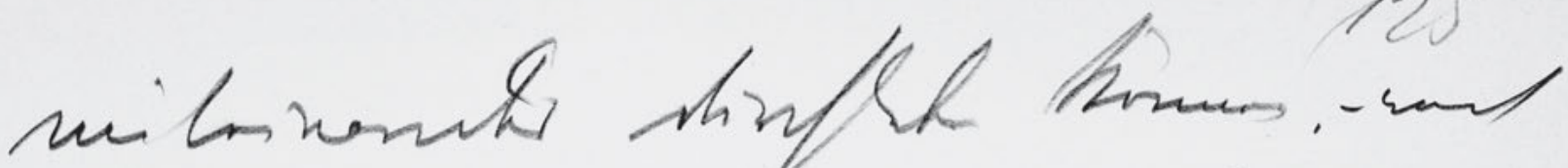

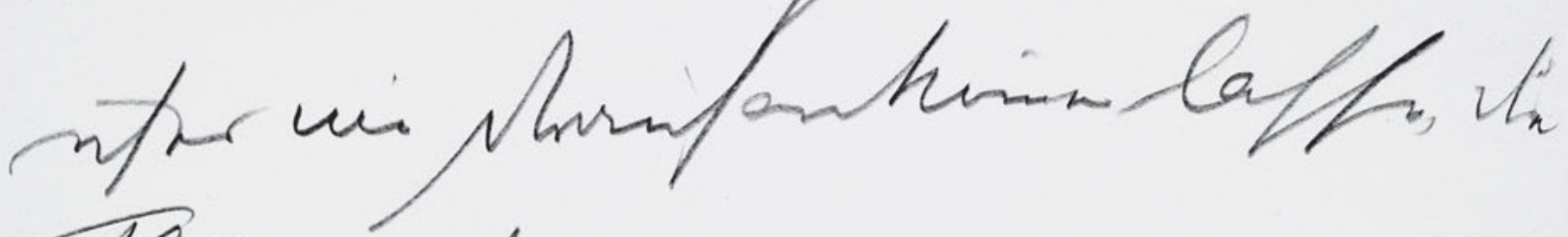

Bhithming

dipin

Satto Riflis

mister niun Inmoterfornost

alynhinf in forin -?

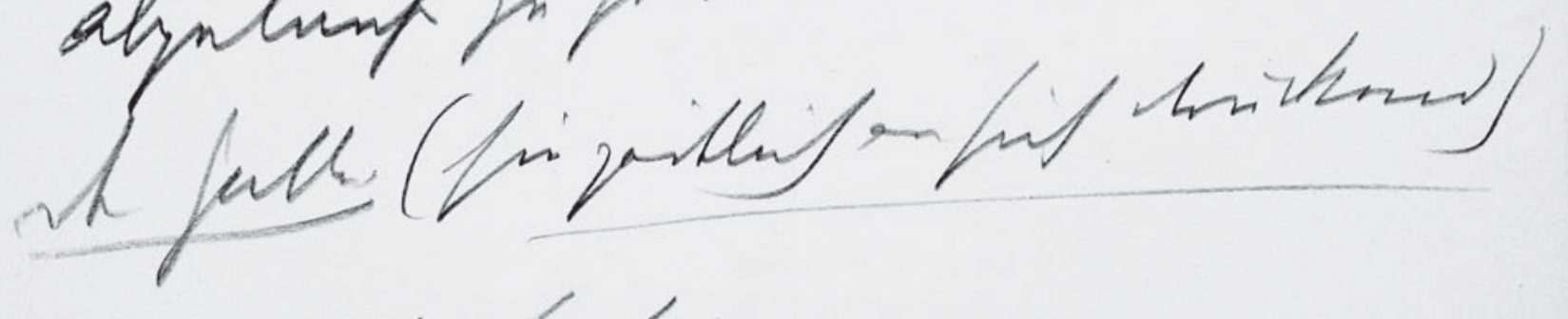

q6 haps fofm.

294 


\section{5}

miteinander durchleben können, - weil

ich es nie drauf ankomen lasse, die

Flitterwochen . . .

5 Die jung Frau .. Zu Monaten auszu-

dehnen.

Der Gatte. Richtig.

Die junge Frau .. Und jetzt . . scheint also

wieder eine Per Freundschaftsperiode

$10 \quad$ abgelaufen zu sein - ?

Der Gatte. (sie zärtlich an sich drückend)

Es durfte so sein. 
HSz5 126

Handschriften und Typoskript

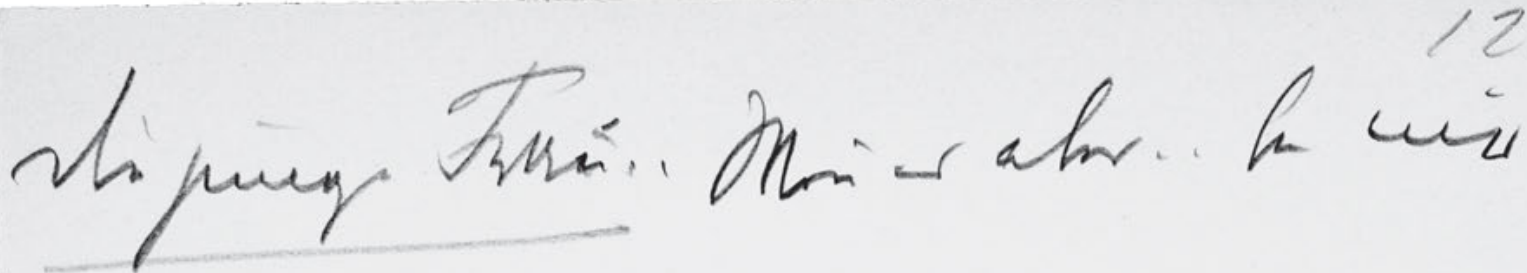
auturnais

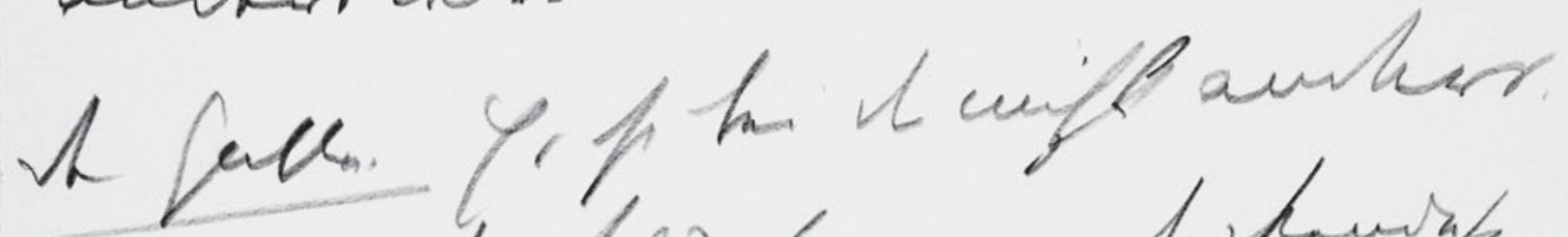

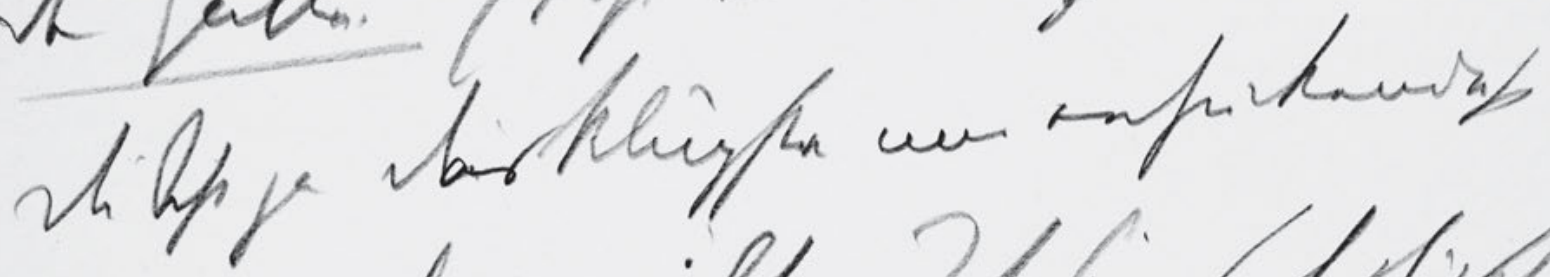

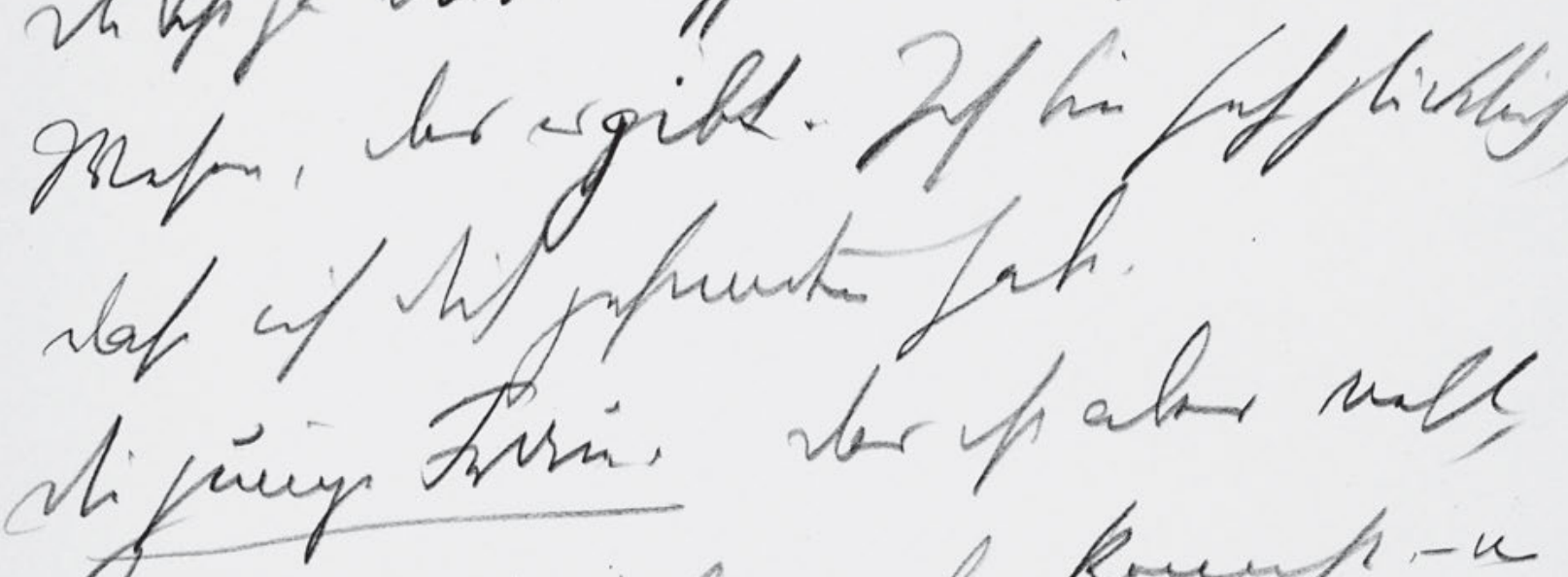

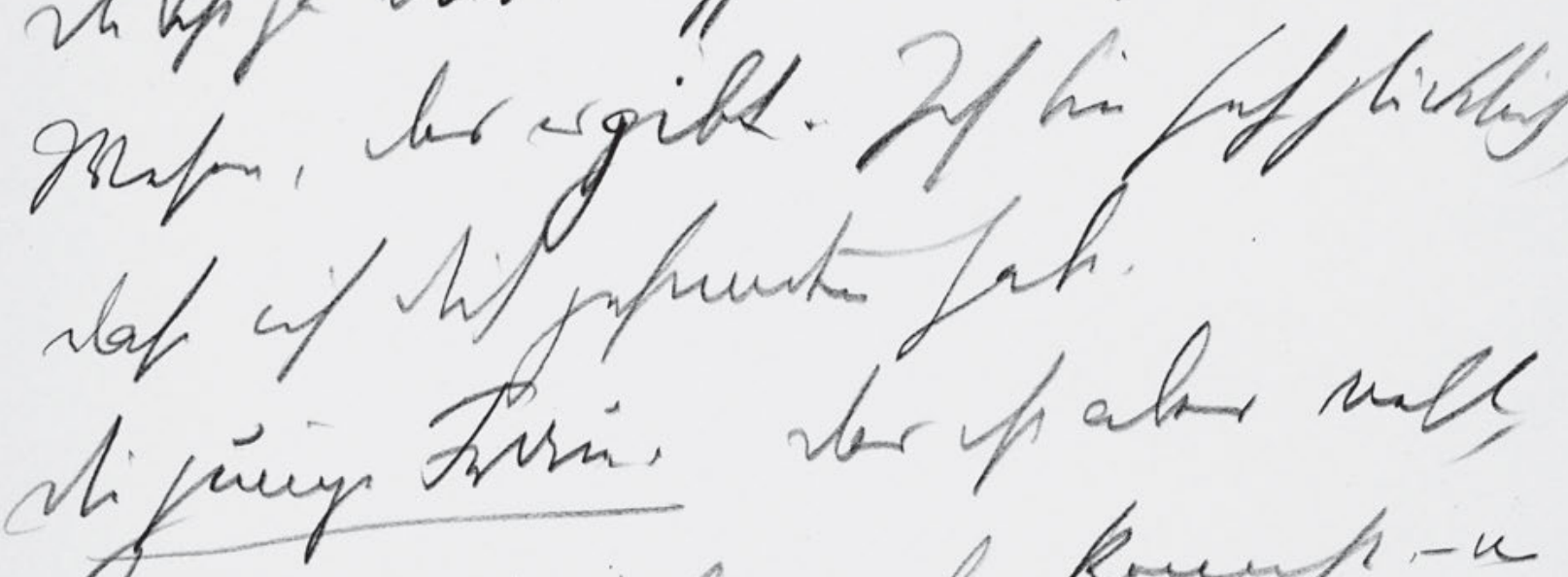

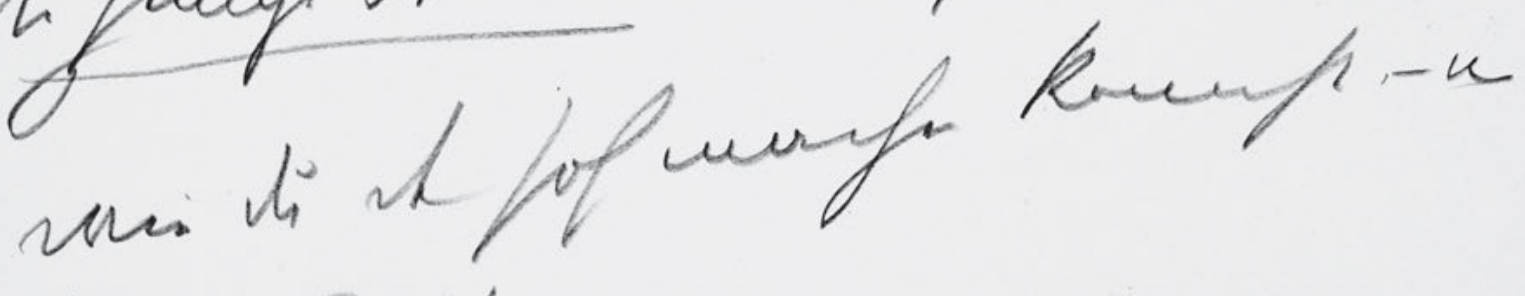

pat in frit.

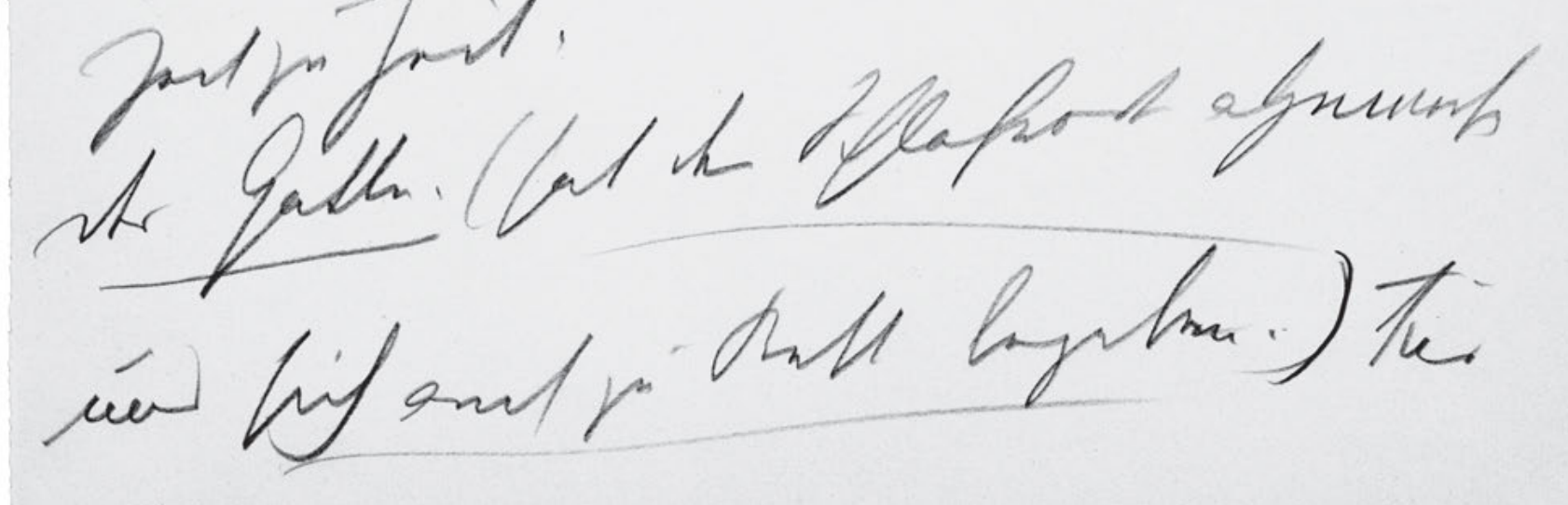

296 


\section{6}

Die junge Frau. . Weñ es aber . . bei mir anders wäre.

Der Gatte. Es ist bei dir nicht anders.

${ }_{5} \quad$ Du bist ja das klügste und entzückendest

Wesen, das es gibt. Ich bin sehr glücklich, dass ich dich gefunden habe.

Die junge Frau. Das ist aber nett, wie du den Hof machen kannst, - vo

Zeit zu Zeit.

Der Gatte. (hat den Schlafrock abgeworfen

und sich auch zu Bett begeben.) Für 
HSz5 127

Handschriften und Typoskript

suin hame, At fif mis hrifres

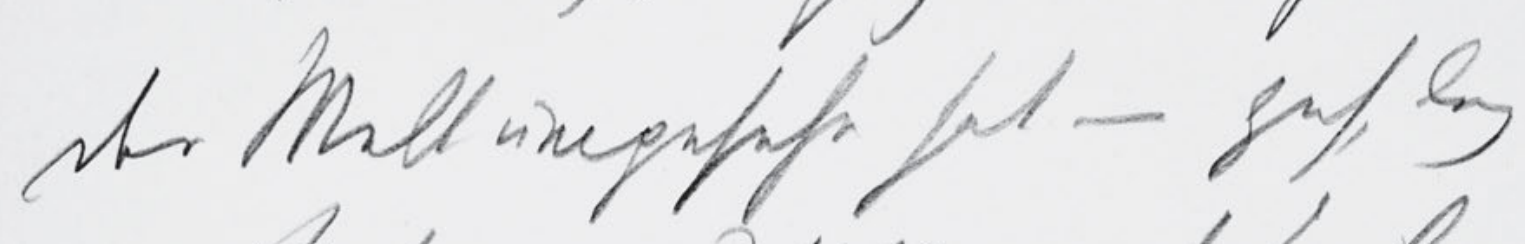

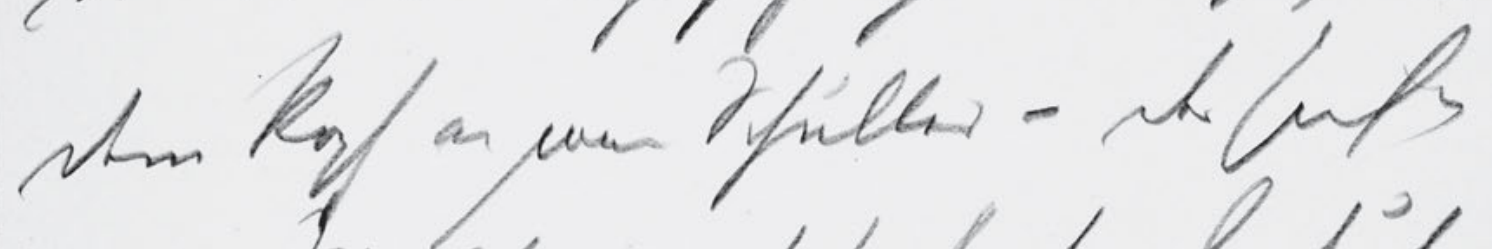

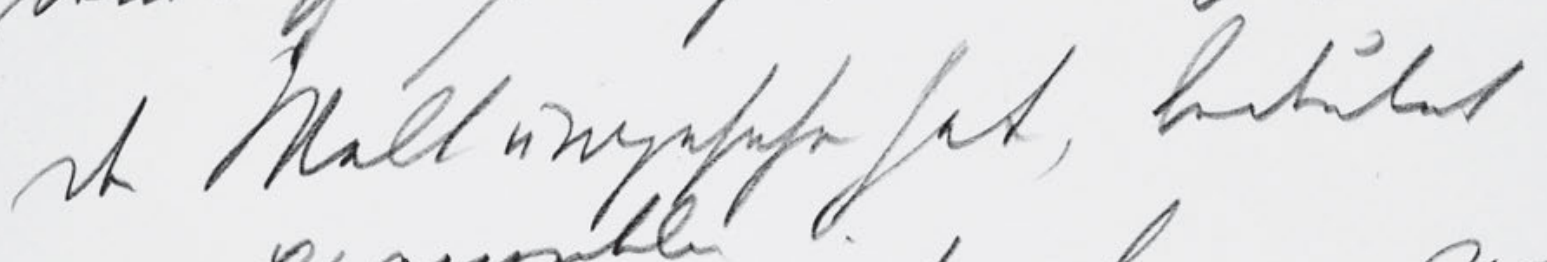

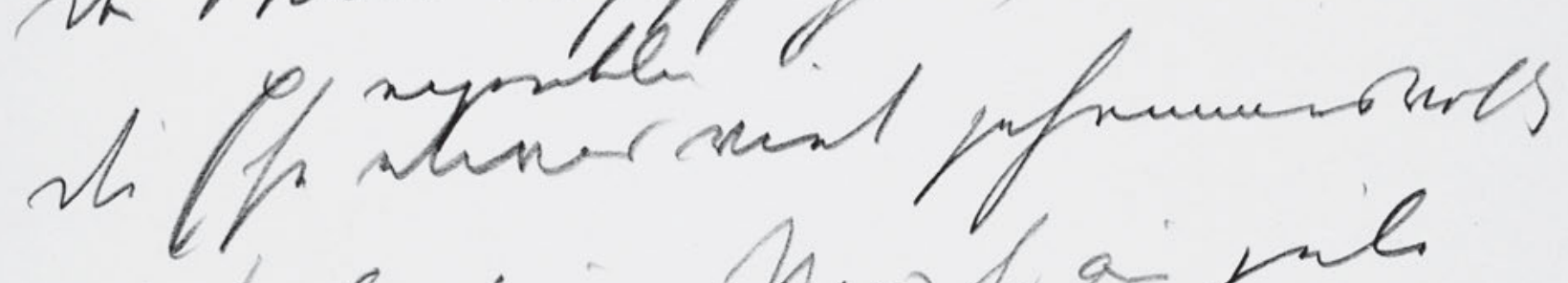
atp low juis nuiga pil. Tamilin. For fand hont wir

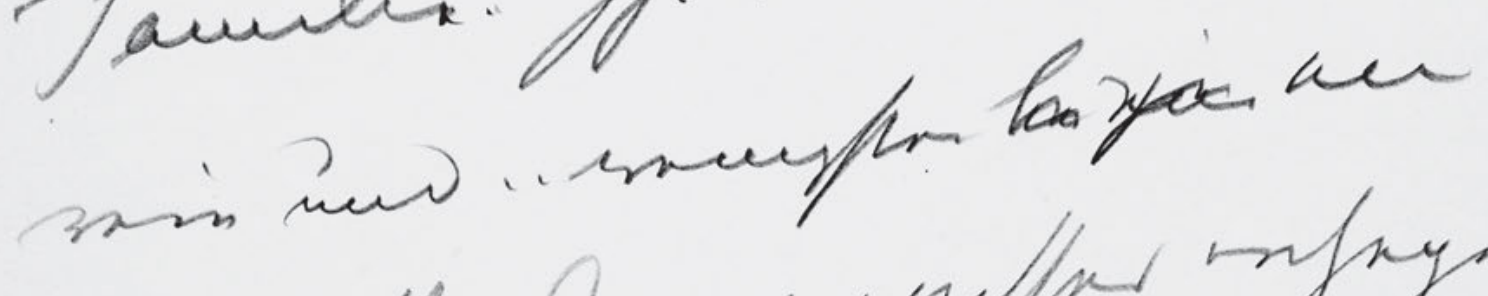

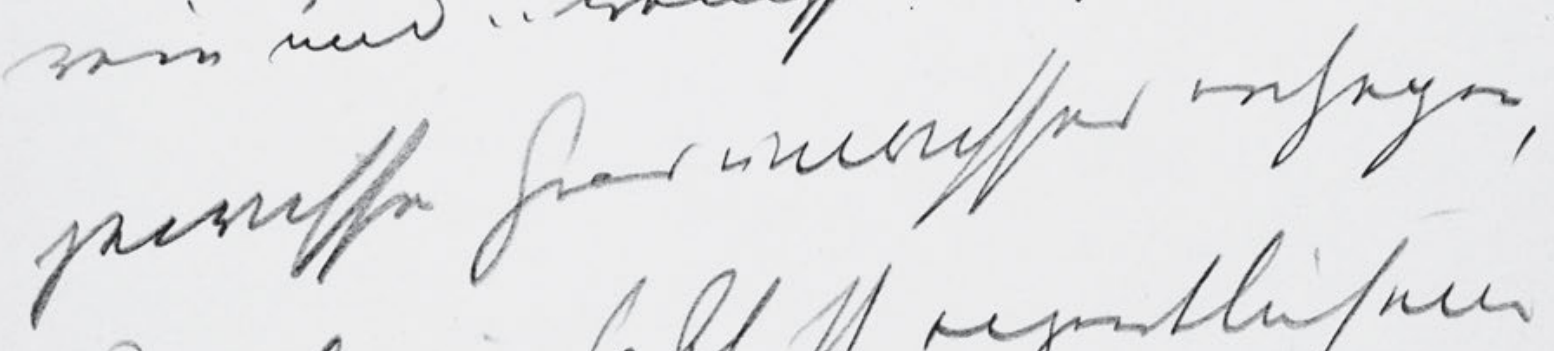
sur verni gat ff ryonthifun nintelermm shat fo le Mrar

298 
einen Mann, der sich ein bischen in

der Welt umgesehn hat - geh, leg

dein Kopf an mein Schulter - der sich in

5 der Welt umgesehen hat, bedeutet

eigentlic

die Ehe etwas viel geheimnisvolle

als für Euch jung Mädhe aus gute

Familie. Ihr komt tretet uns

rein und . . wenigstens ${ }^{\text {bei }}$ in ${ }^{\text {eine }} \mathrm{zu}$ eine

gewissen Grad unwissend entgegen,

und darum habt Ihr eigentlich eine

viel klarern Blick fur das Wesen 
HSz5 128

Handschriften und Typoskript

1 Lint a tmi

chipung tren (b four)

sh Gath prift sin unir fiin

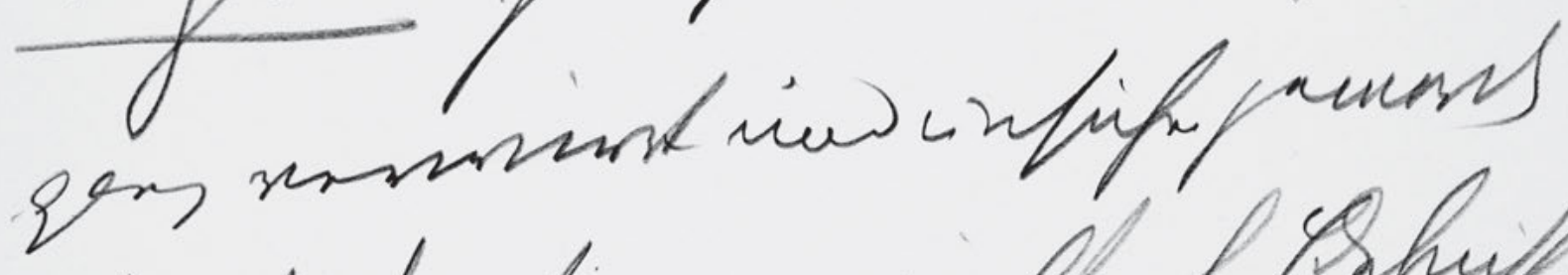

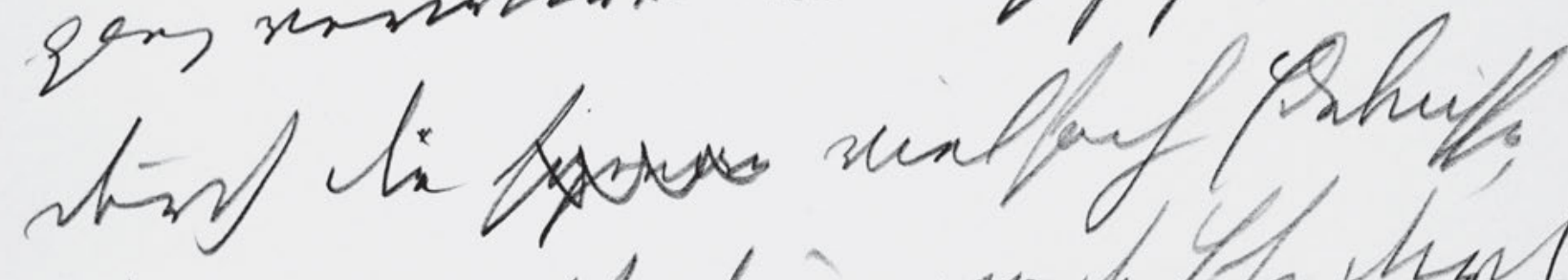
di mi nolforming wo the has

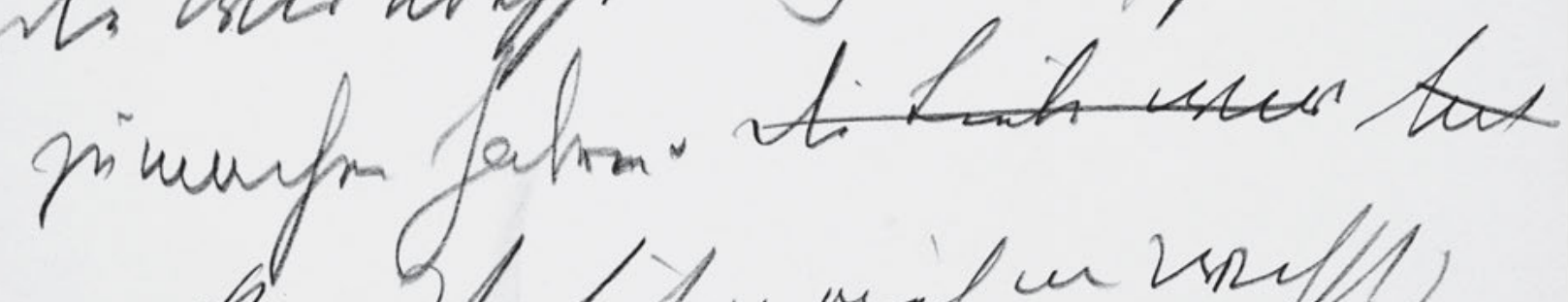

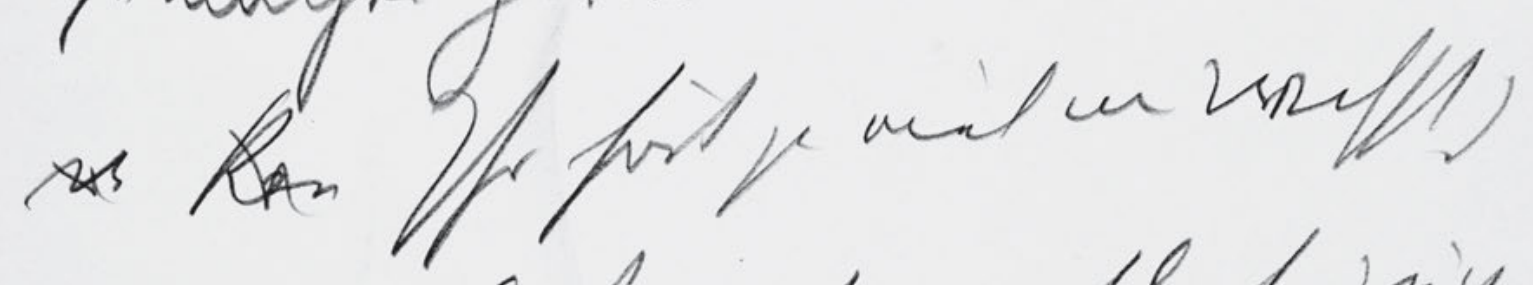

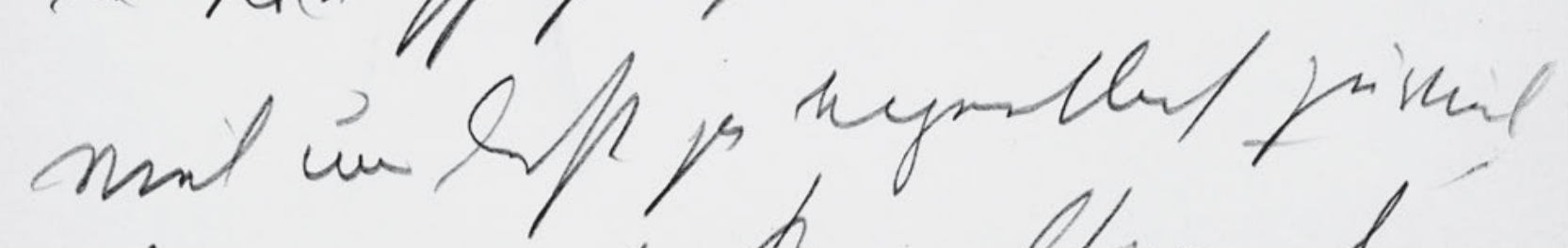

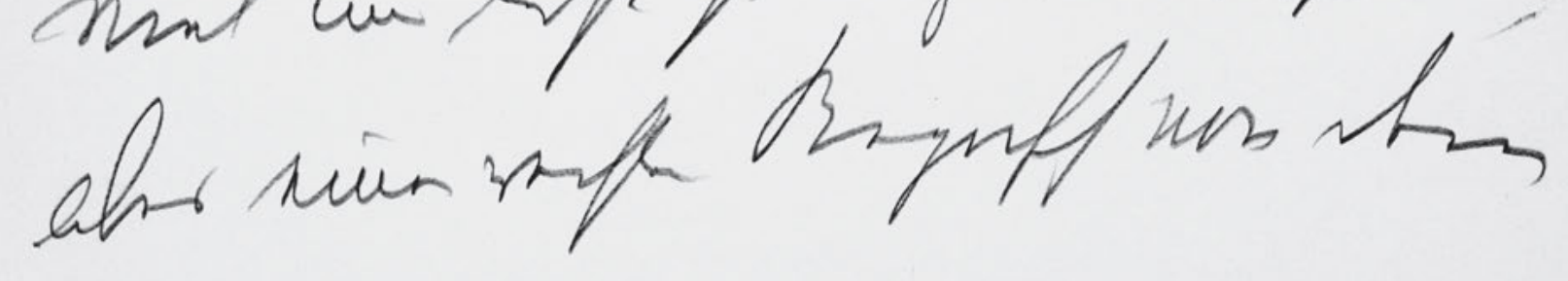

300 


\section{8}

der Liebe als wir.

Die jung Frau (lachend) Oh!

Der Gatte. . Gewiss. Deñ wir sind

5 ganz verwirrt und unsicher geworden

durch die sogenan vielfachen Erlebnisse,

die wir nothgedrung vor der Ehe durch-

zumachen haben. Die Liebe wir tut

? $\#$ ? kan Ihr hört ja viel un wisst ${ }^{?} \mathrm{z}$ ?

viel und lest ja eigentlich zu viel,

aber einen rechten Begriff von dem 
HSz5 129

Handschriften und Typoskript

mar viver lamion m the fat wh th tabt/ g in/

nofr nufer. Harssun bes, the monfo gunomfin th tish urum
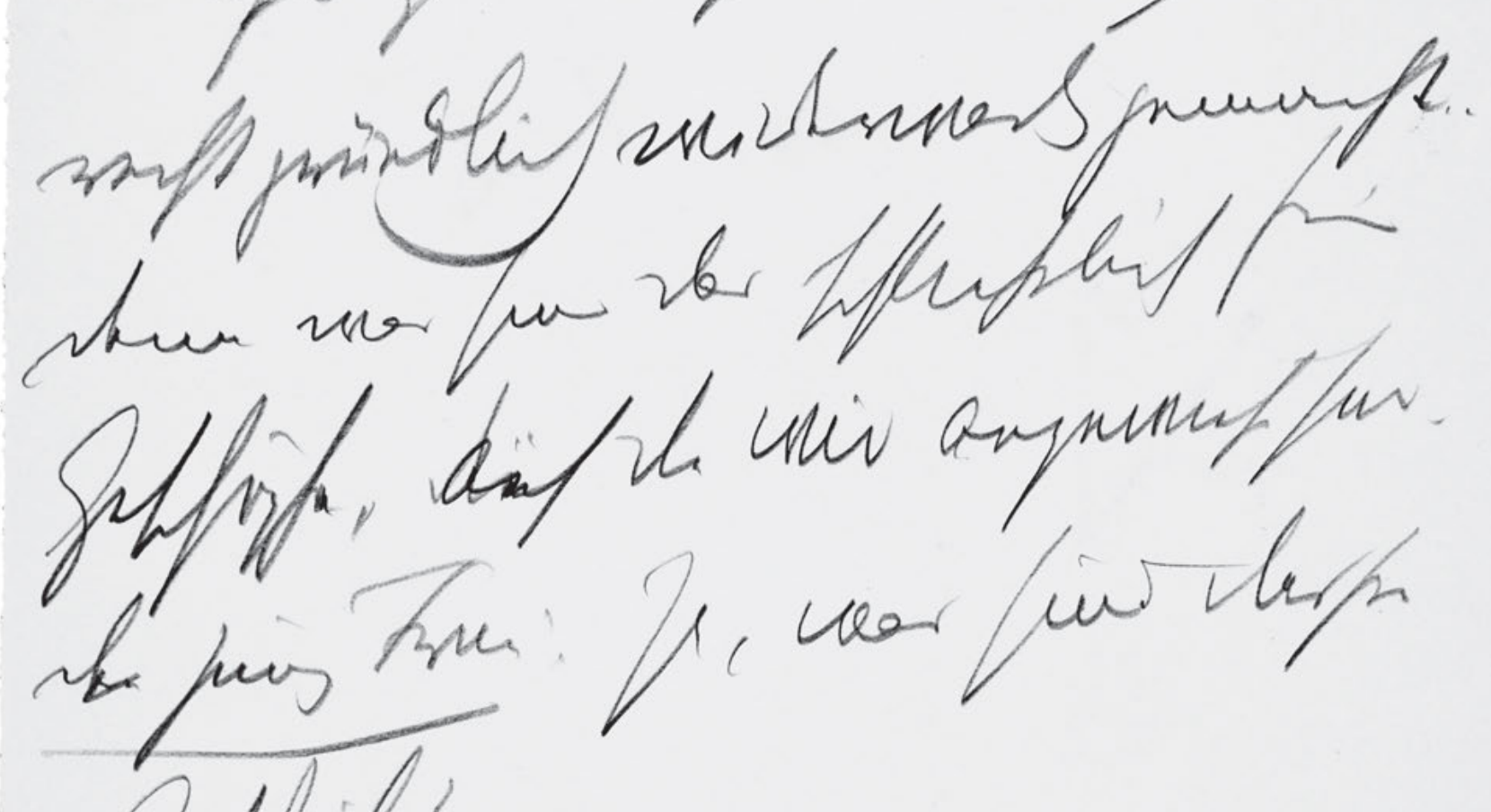

$$
\text { in thir arjumiffur. }
$$

$$
\text { H, ver uir vara }
$$
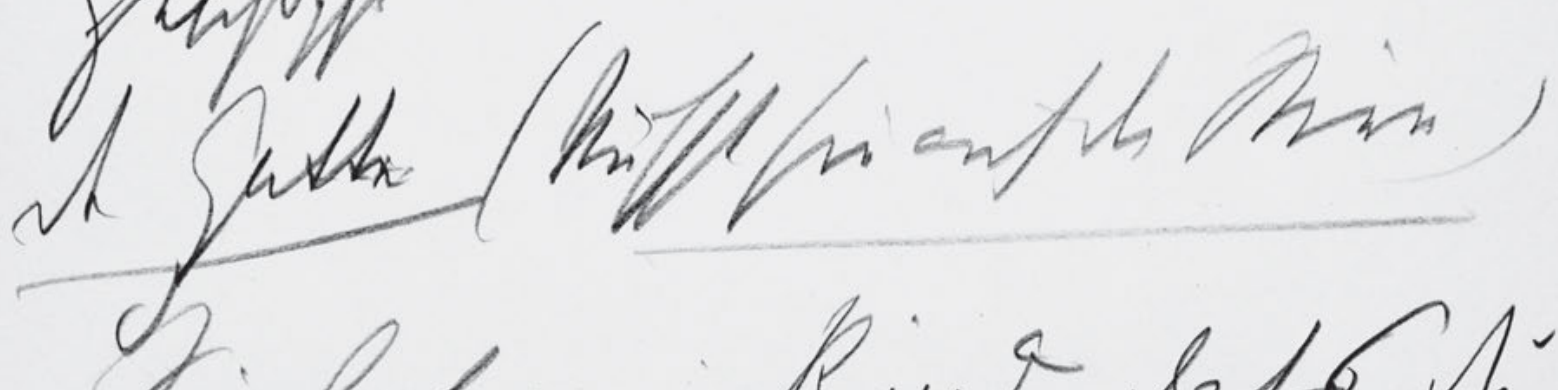

si fnt, wrin hivar, lafo

302 


\section{9}

was wir Männer in der That erleben, habt ja doch

wisst Ihr nichts. Uns wird das, was

man so gemeinhin die Liebe nennt,

5 recht gründlich widerwartg gemacht . .

denn was sind das schließlich für

Geschöpfe, dieauf die wir angewiesen sind.

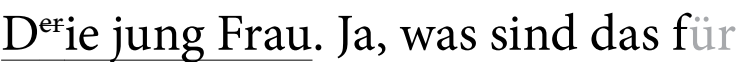

Geschöpfe? -

10 Der Gatte (küsst sie auf die Stirn)

Sei froh, mein Kind, dass du 
HSz5 130

Handschriften und Typoskript

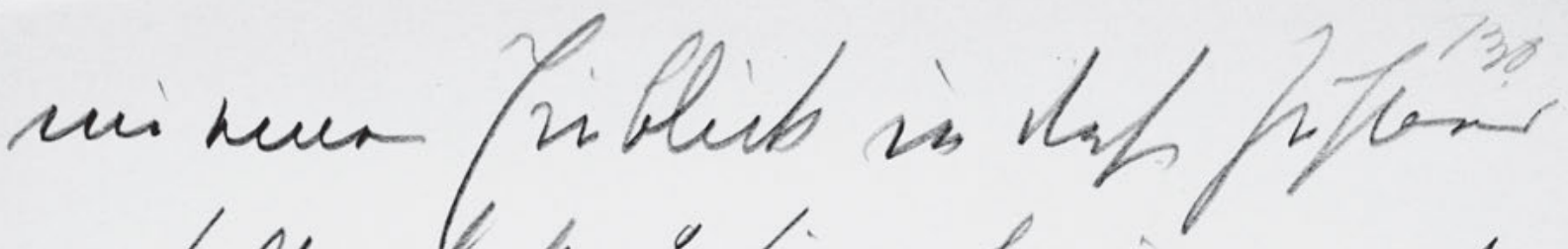

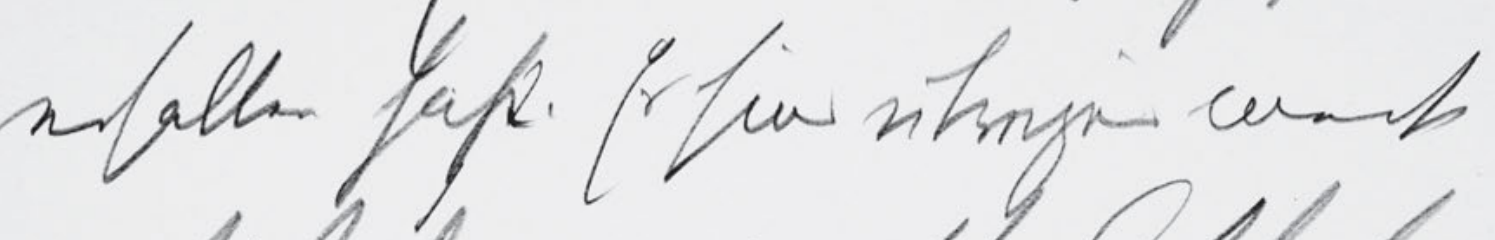
soff bibinusmorta

Prafa - unera wistenuch Dar bif in -

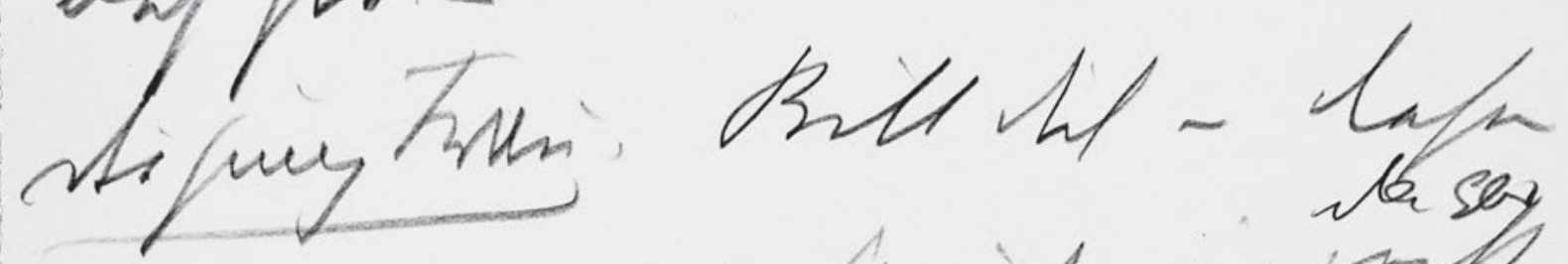

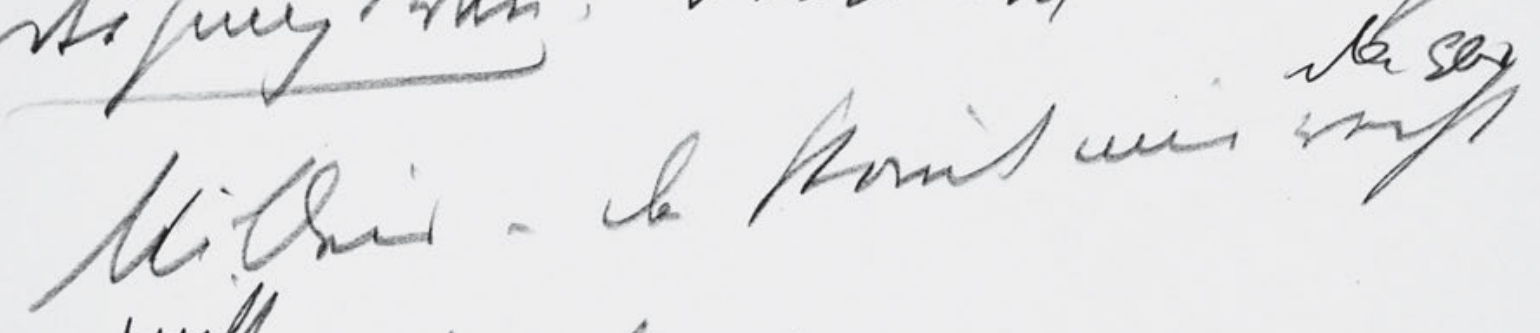
unif

shenguherf ur

st Gath (milo) Pinntiux

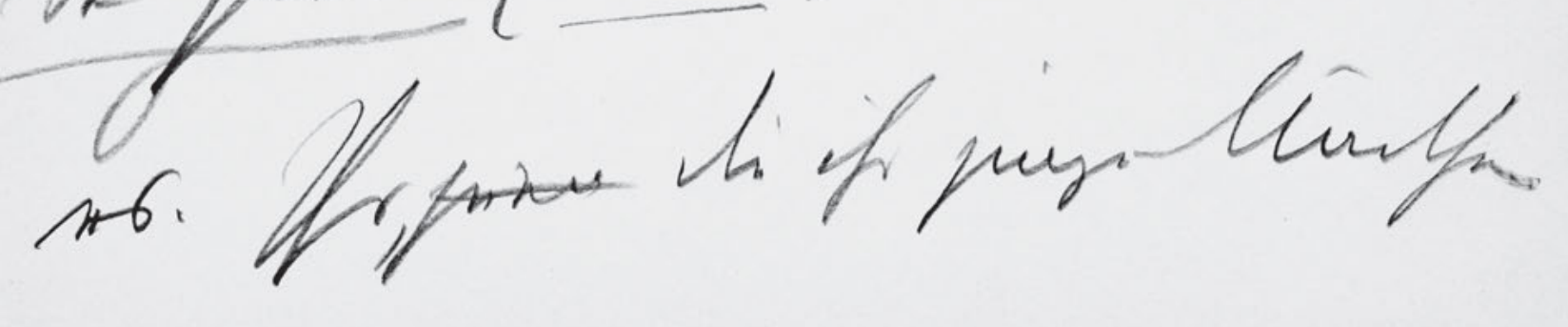

304 


\section{0}

nie einen Einblick in diese Zuständ erhalten hast. Es sind übrigens meist recht bedauernswerthe Geschopf

${ }_{5}$ Wesen - werfen wir keinen Stein auf sie. -

Die jung Frau. Bitt dich - dieses da gar

Mitleid - das kō̄t mir recht nicht unangebracht vor

10 Der Gatte . (mild) Sie verdienen es. Ihr, ?jung? die ihr junge Mädchen 
HSz5 131

Handschriften und Typoskript

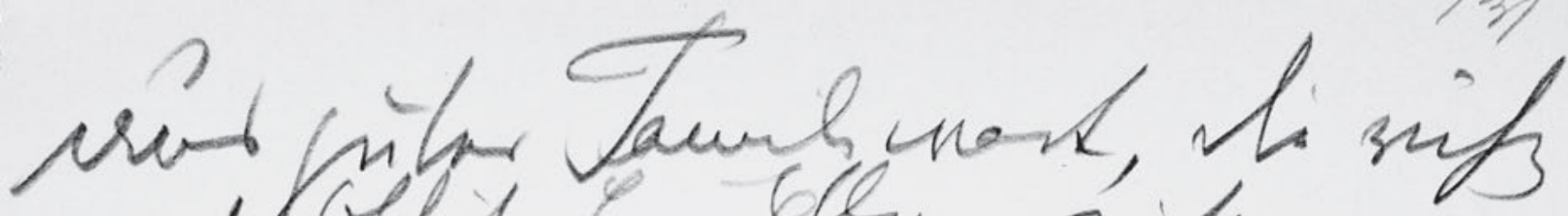

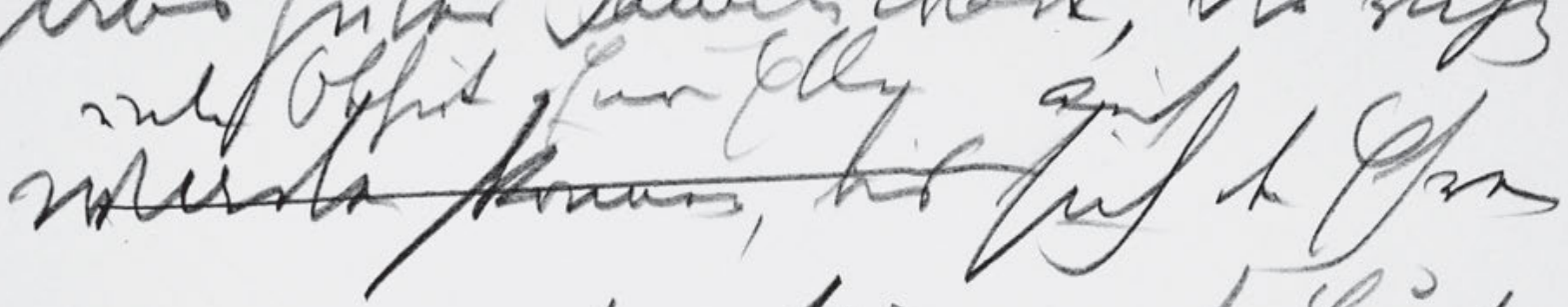

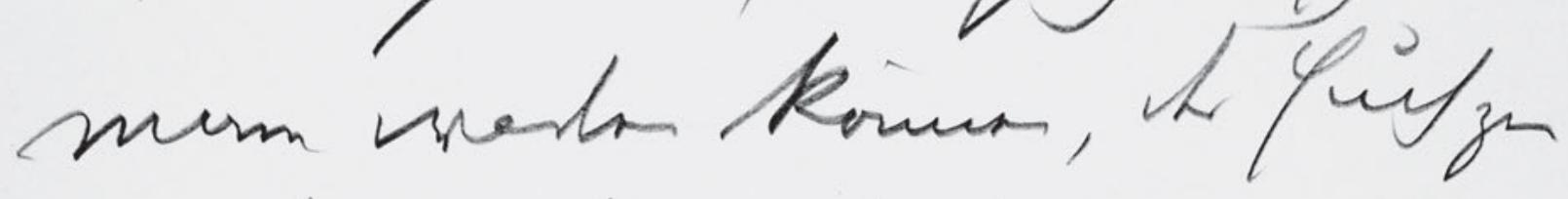
Of hyfoti- ifs knutger der lsuit mift, la h urife ne

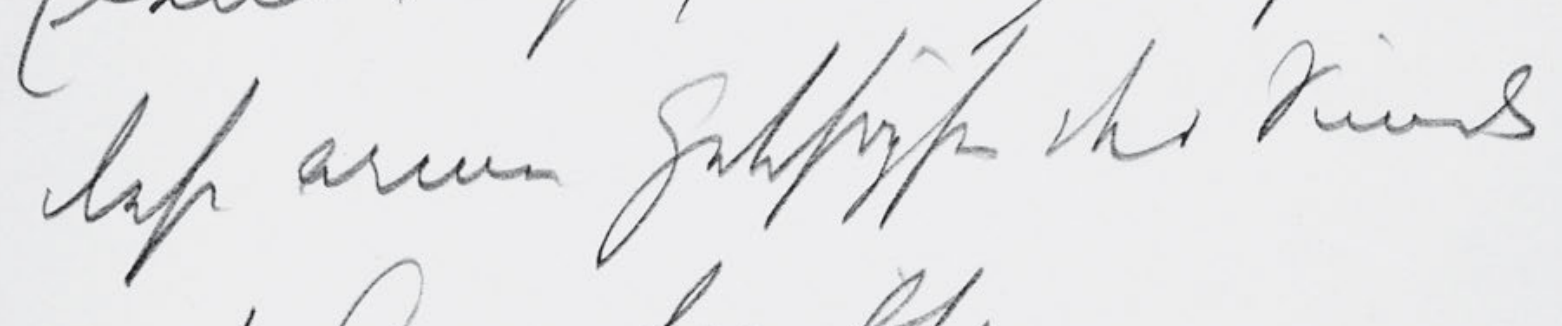
sit hum hroitt. wipuito Dourtant ingen ale

th path rar unftis nifilays M mani ga and mpte wi br

306 
131

aus guter Familie wart, die ruhig

unter Obhut Eurer Eltern auf

warten können, bis sich den Ehren

mann warten können, der Euch zur

5 Ehe begehrt; - ihr kennt ja das

Elend nicht, das die meisten von

diesen armen Geschöpfen der Sünde

in die Arme treibt.

Die jung Frau. So - verkauf sich dē̄

$10 \quad$ alle?

Der Gatte. Das möcht ich nicht sagen.

Ich meine ja auch nicht nur das 
HSz5 132

Handschriften und Typoskript

uatrones trut

if wifl

nim ant cuaralfalf

Che
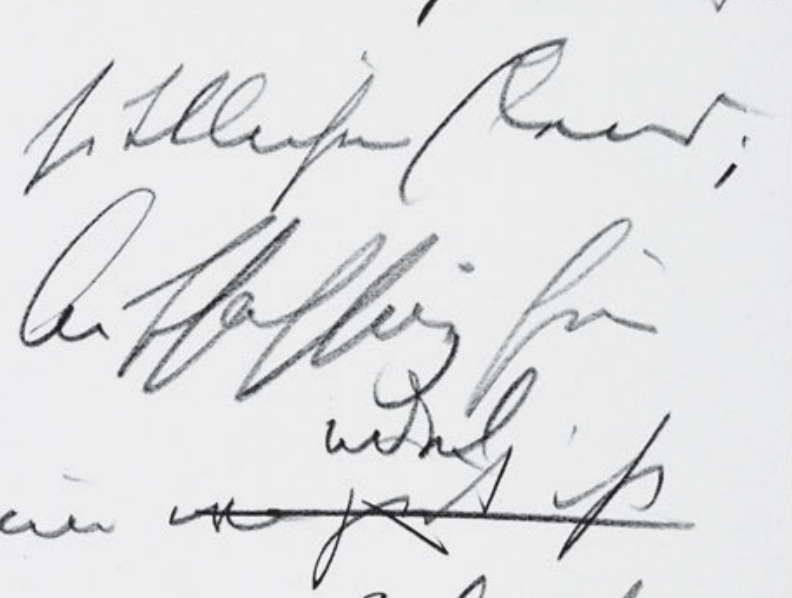

sar, wat alenth

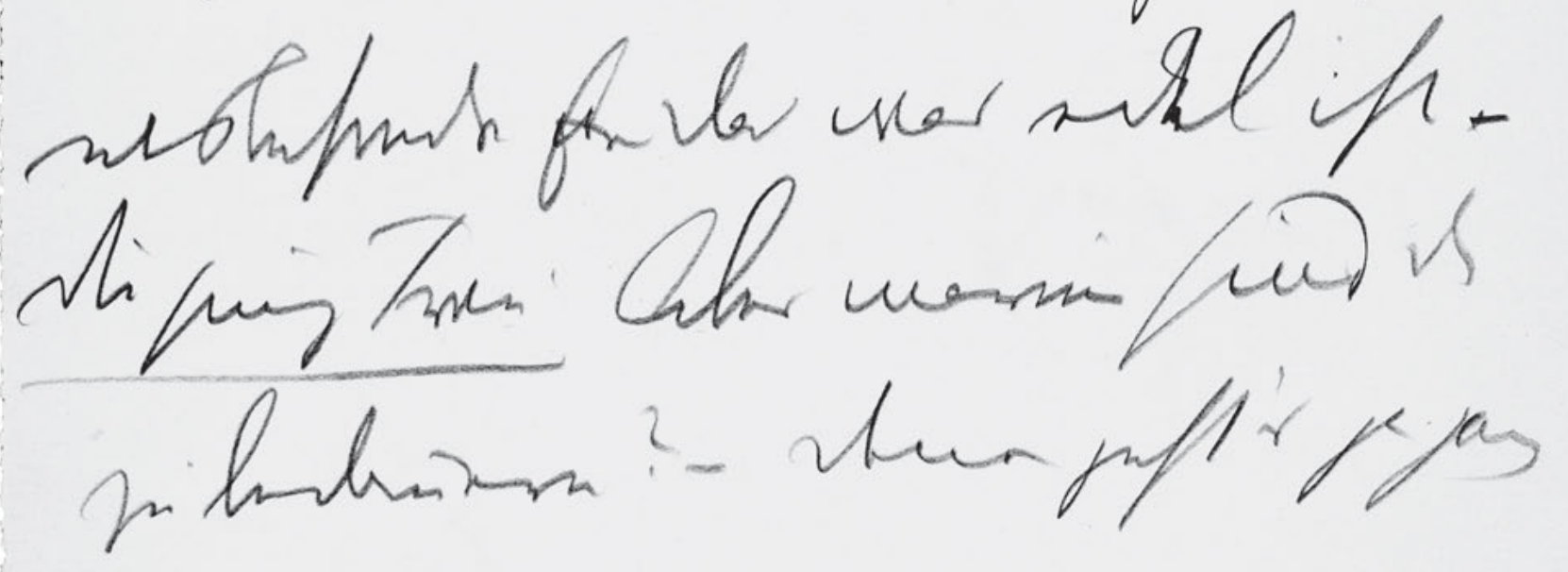$$
\text { git? }
$$$$
\text { . }
$$

h piftorn.

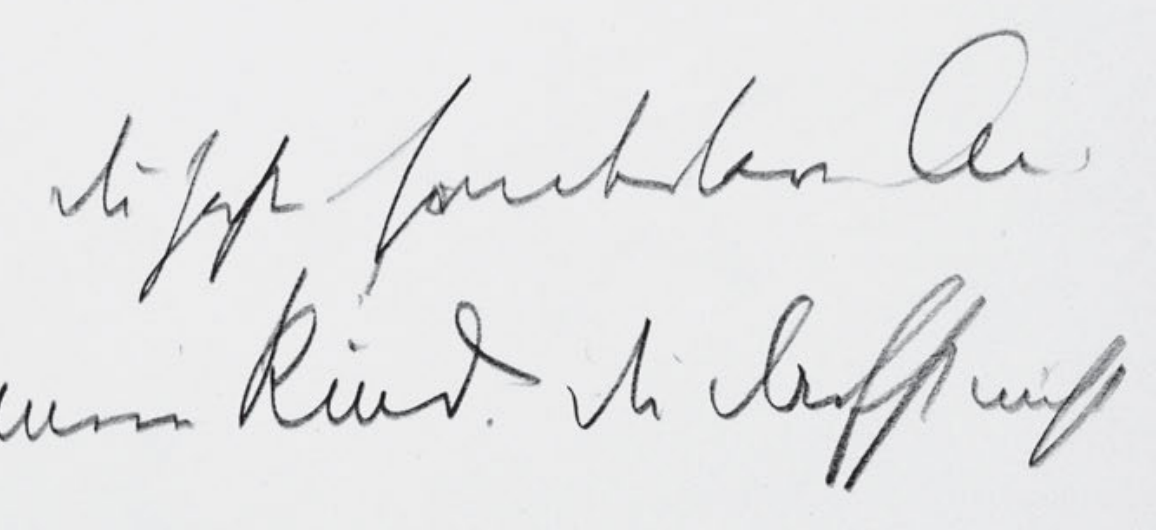

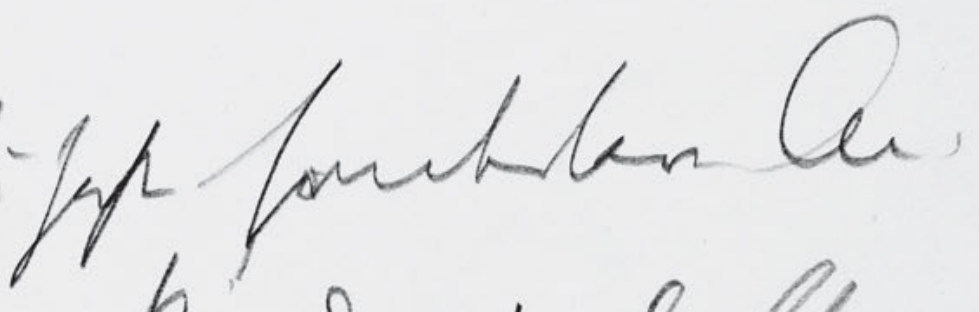




\section{$1^{1} 32$}

materielle Elend. Aber es gibt auch -

ich möcht sagen - ein sittliches Elend;

angeb

eine mangelhafte Auffassung für

edel

5 das, was erlaubt und was gut ist

insbesondre ${ }^{[?]}$ fur das was edel ist ${ }^{*}$

Die jung Frau Aber warum sind d

zu bedauern? - Denen geht's ja ganz

gut?

10 Der Gatte. Du hast sonderbare An-

sichten, mein Kind. Du darfst nicht 
HSz5 133

Handschriften und Typoskript

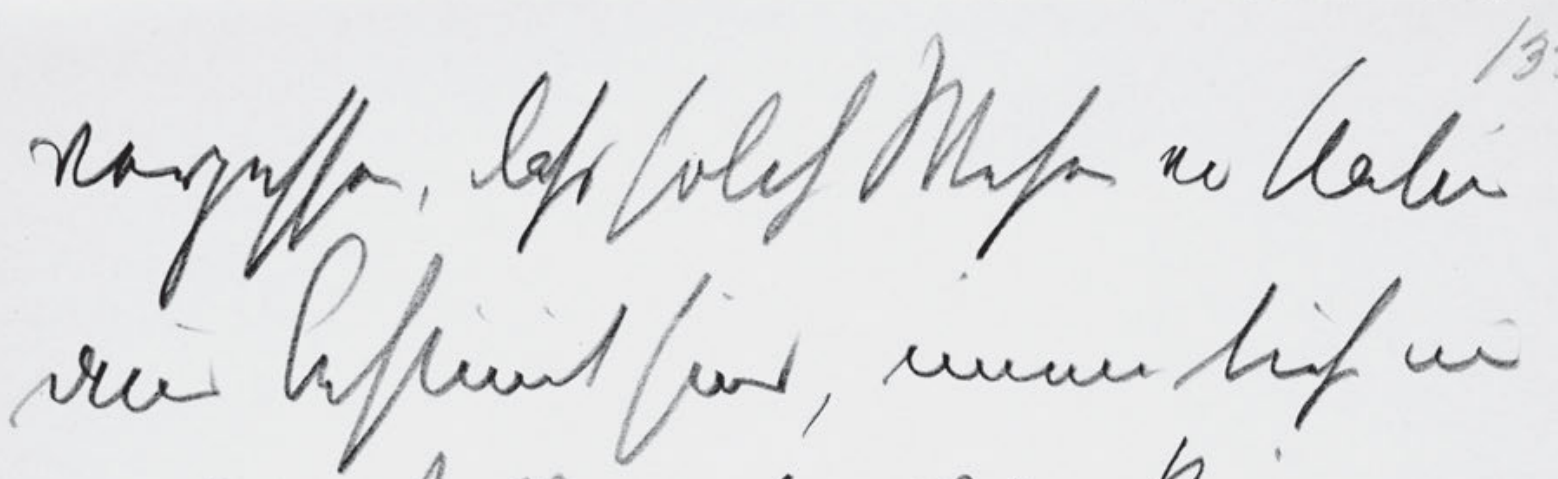
hap rifallon da plt-Riux diffaldon

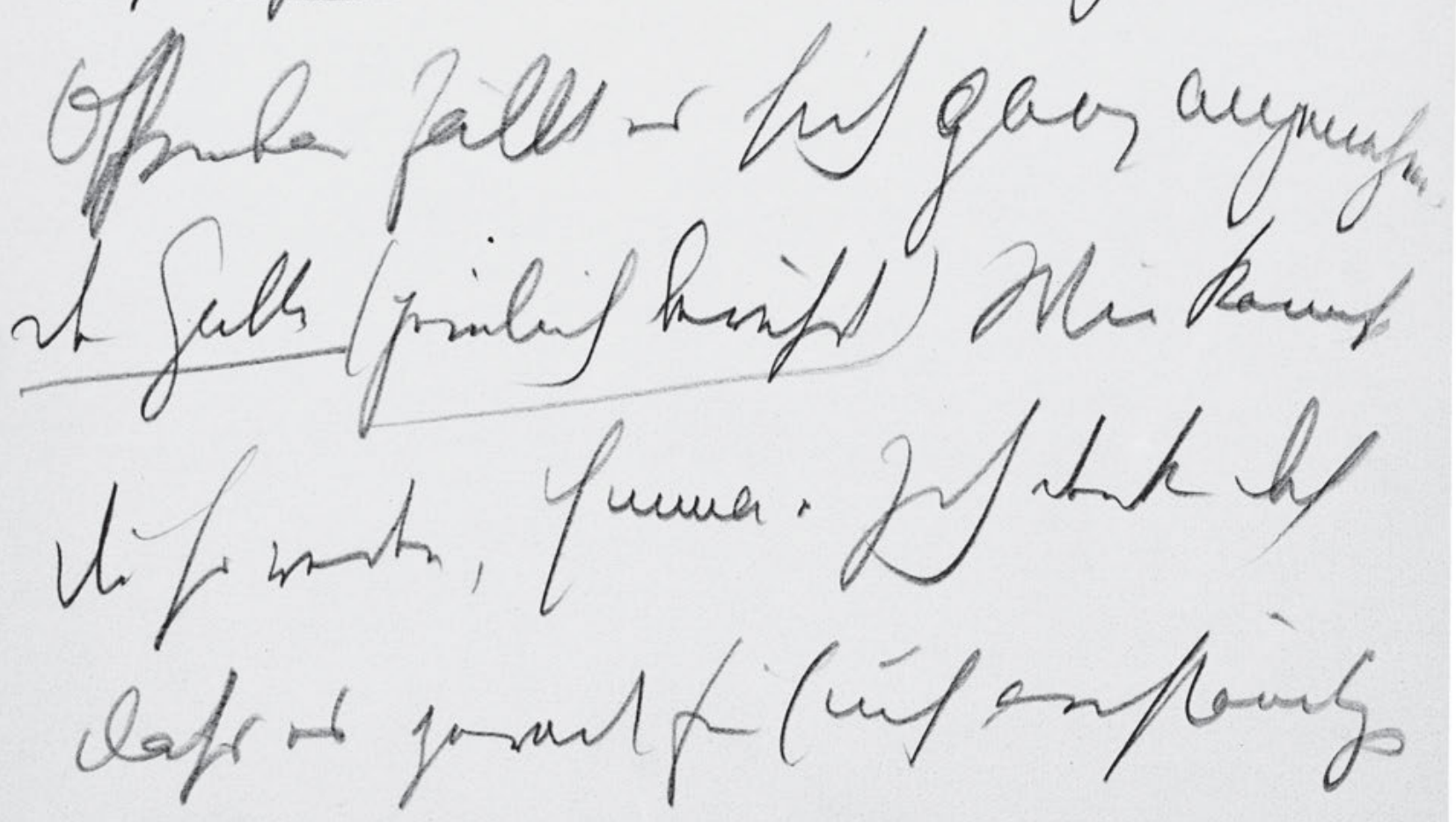

310 
vergessen, dass solche Wesen von Natur

aus bestim $\mathrm{m}$ sind, immer tiefer und

tiefer zu fallen. Da gibt es keines

5 Aufhalten.

Die junge Frau (sich an ihn schmiegend)

Offenbar fällt es sich ganz angenehm.

Der Gatte (peinlich berührt) Wie kannst

du so reden, Emma. Ich denke doch

10 dass es gerade für Euch anständige 
HSz5 134

Handschriften und Typoskript

$T$

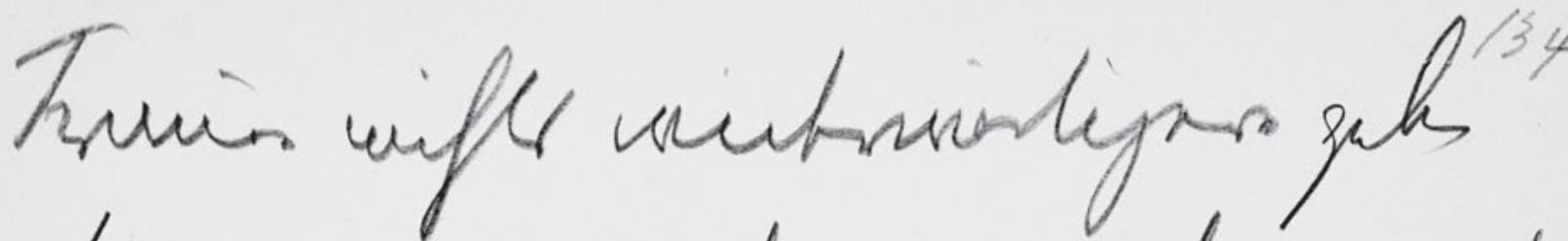

karm

shpug twi

Trsiby

dod frably

fut of ang

iriabl

inf no

Pry

hipo smit.

ch ath.

th

th

Mu fales his.

312 


\section{4}

Frauen nichts widerwärtigers geben

kann als alle diejenigen, die es nicht

sind.

$5 \quad$ Die jung Frau. Freilich, Karl, freilich: Ich

hab ${ }^{\text {aja }}$ auch nur so gesagt.. Geh, red

weider ter. Es ist so nett, wē̄

du so redst. Erzähl mir was.

Der Gatte. Was denn? -

10 Die jung Frau . Nun, - von diesen Geschöpfen

Der Gatte. Was fallt dir dē̄ ein? 
HSz5 135

Handschriften und Typoskript

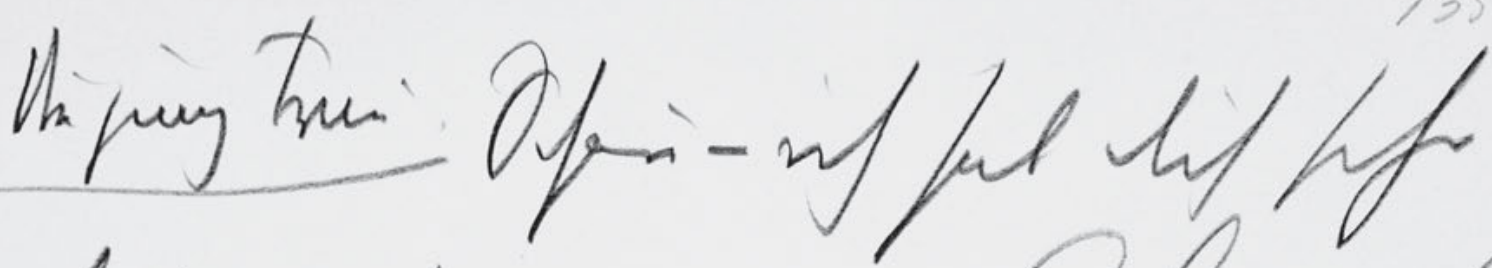

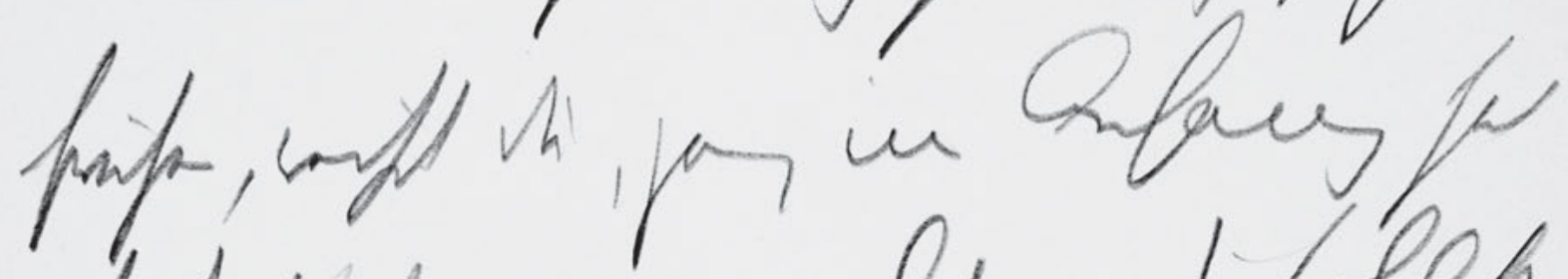

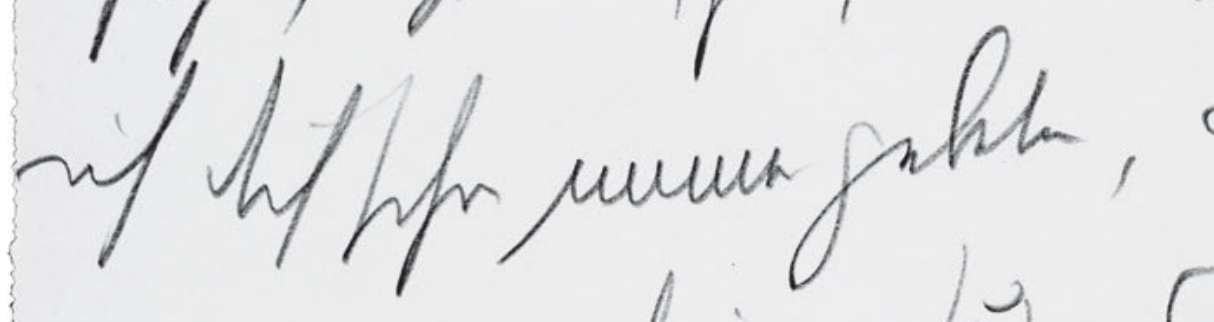

135

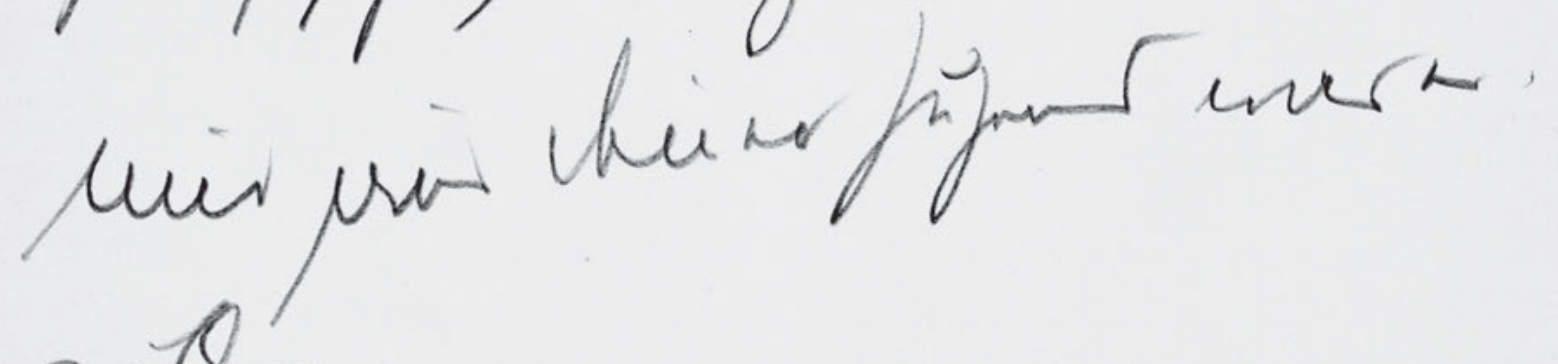

$2 a$

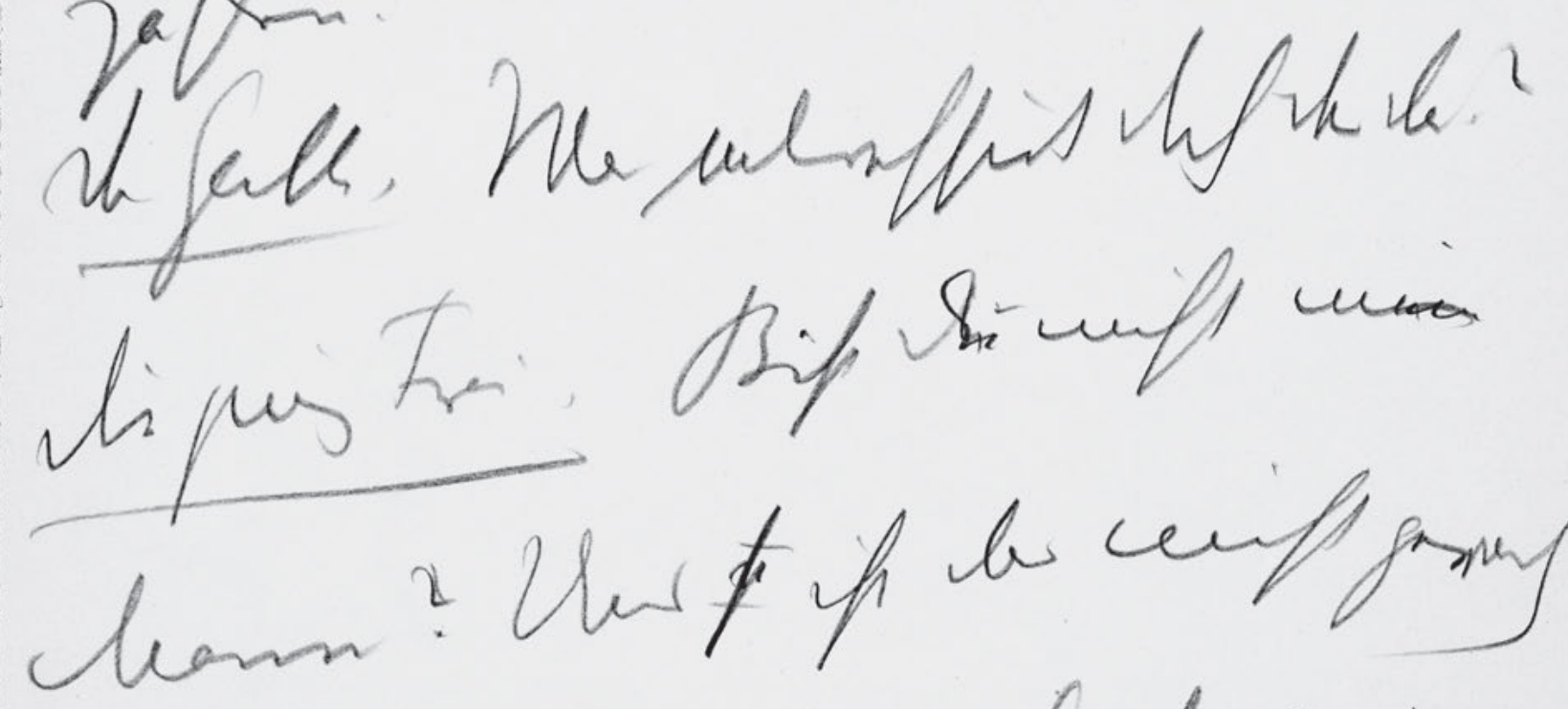
sum Vugrafypit.

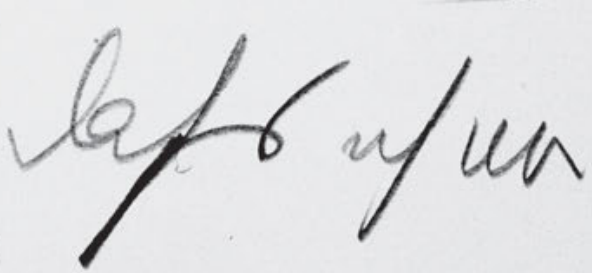

314 
Die jung Frau . Schau - ich hab dich scho

früher, weißt du, ganz im Anfang hab

ich dich schon immer gebeten, du sollst

5 mir aus deiner Jugend was er-

zählen.

Der Gatte. Was intressirt dich den das?

Die jung Frau. Bist du nicht mein

Mann? Und ${ }^{u}$ ? $s$ ist das nicht gerade

10 eine Ungerechtigkeit, dass ich von 
HSz5 136

Handschriften und Typoskript

heur kngaysafint
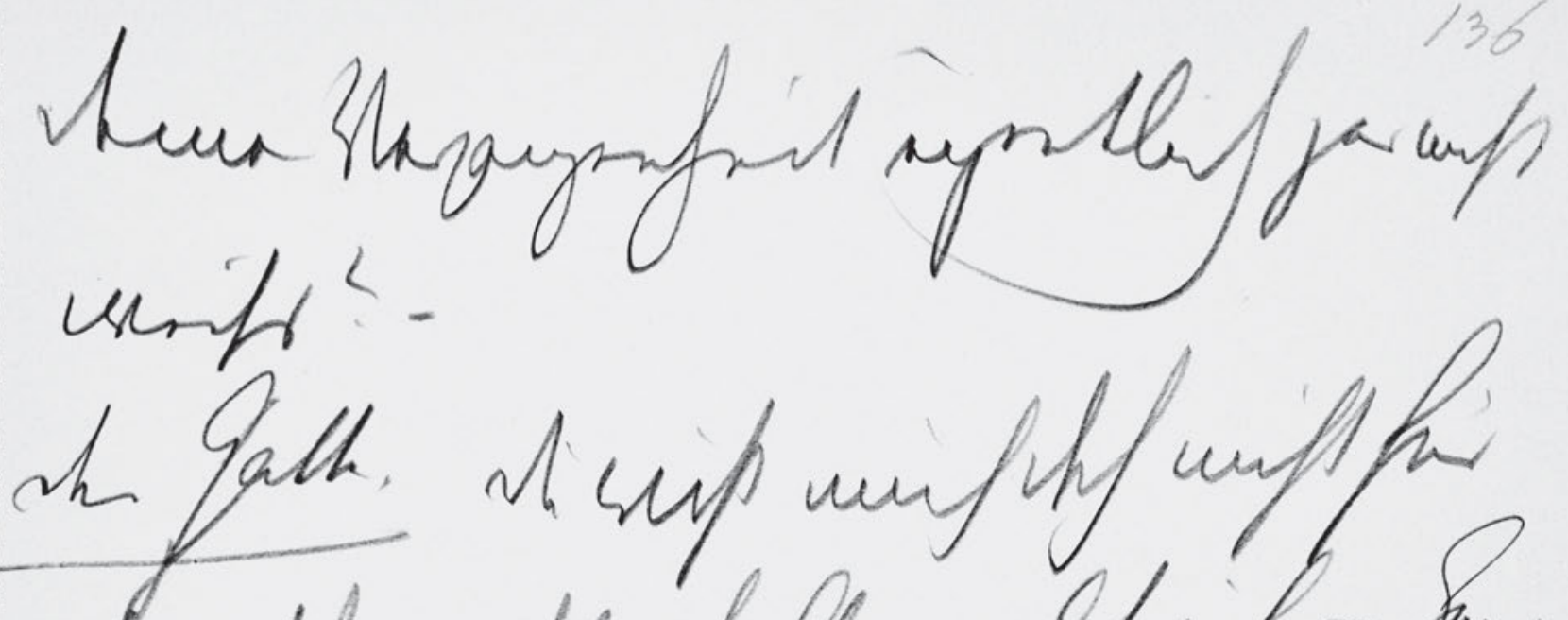

sim min

1

P

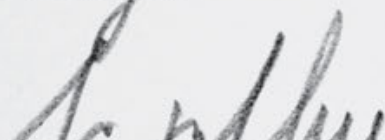

Cuma... la y y

milifaris

ahipun true

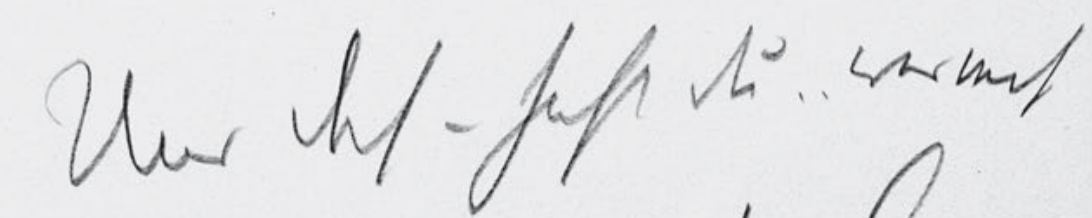

1 hous

sefallen whigm

wis.

316 


\section{6}

deiner Vergangenheit eigentlich gar nichts

weiss? -

Der Gatte. Du wirst mich doch nicht für

so geschmacklos halten, dass ich - Genug,

Emma ... das ist ja wie eine Entweihung.

[???]

Du bist mein mir. . vor Gott angetrautes

Weib ...

Die jung Frau . Und doch - hast du .. wer weiss

10 wie viel andre Frauen so in den Armen

gehalten wie jetzt mich. 
HSz5 137

Handschriften und Typoskript

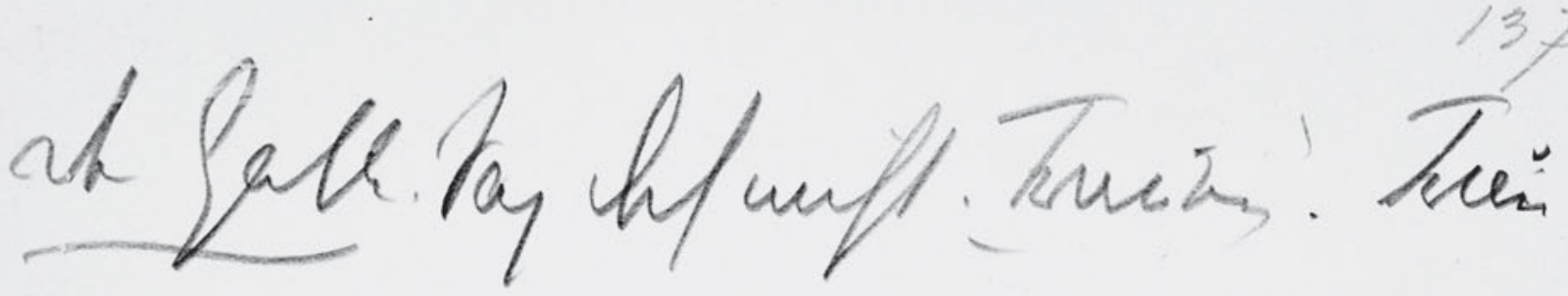
lifisi.

ta pur tur. Olog

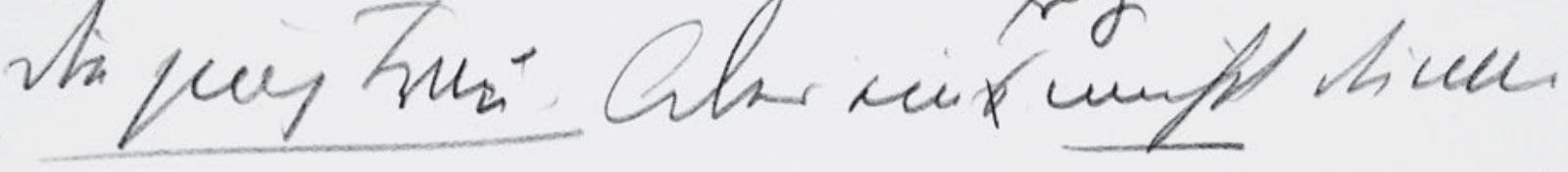

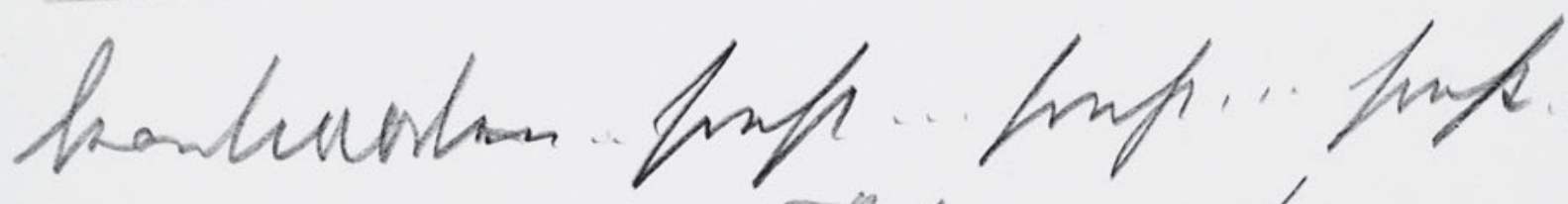

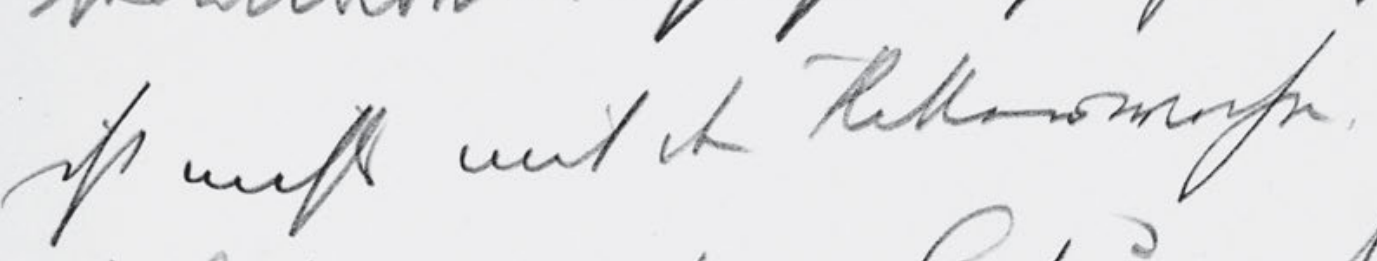

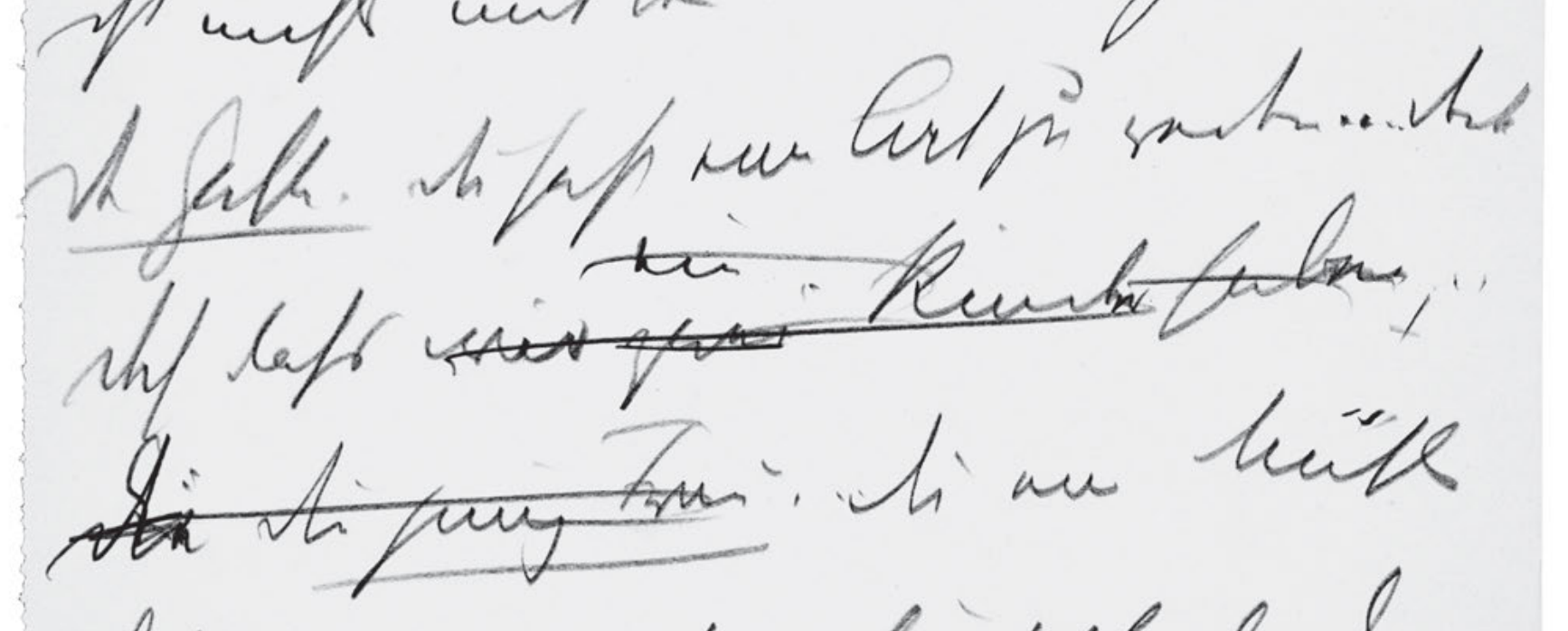
lif lafr infpr biostl al h. hight.

318 
Der Gatte. Sag doch nicht . ,Frauen. Frau

bist du . .

Frage

Die jung Frau. Aber eins mußt du mir

${ }_{5}$ beantworten . . sonst ... sonst ... sonst . .

ist nichts mit den Flitterwochen.

Der Gatte. Du hast eine Art zu reden .... denk ein

doch dass wir zwei Kinder haben, . .

${ }^{D i e}$ Die Die jung Frau . “du ein Mutter

bist . . dass . unser Mäde ${ }^{t} r l$ da drin

liegt. . 
HSz5 138

Handschriften und Typoskript

var puin twi

cang

sue Artom.

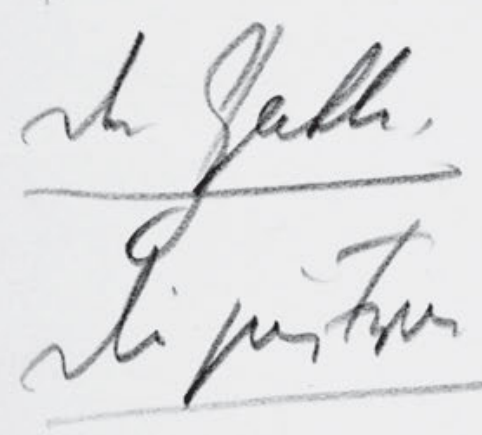

Ymu

sis if hi hitid.

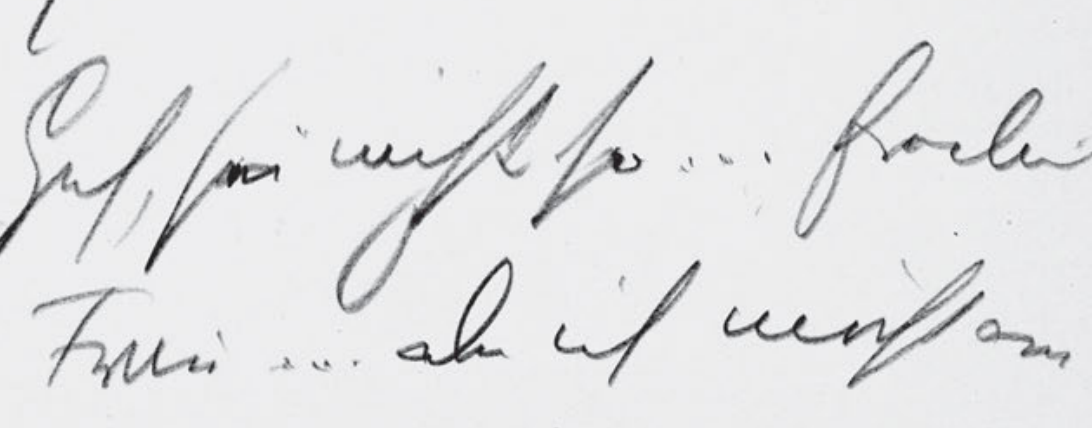

sh felt

nimplefs in

suluble pri

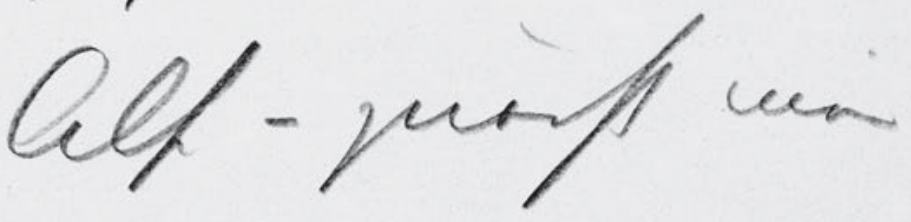

Aruy.

at galls (qufins)

Min -?

320 
(an ihn)

$\underline{\mathrm{D}^{\mathrm{er}} \text { ie junge Frau }}$. Aber ${ }^{\mathrm{ein}}$ ich möcht auch

einen Buben.

Der Gatte. Emma.

5 Die jung Frau. Geh, sei nicht so ... freilich

bin ich deine Frau .... aber ich möcht auc

ein bissel . . Geliebte sein . .

Der Gatte. Möchtest du . . ein bissel .

Die jung Frau. Also - zuerst mein

$10 \quad$ Frage -

Der Gatte (gefügig) Nun - ? 
HSz5 139

Handschriften und Typoskript

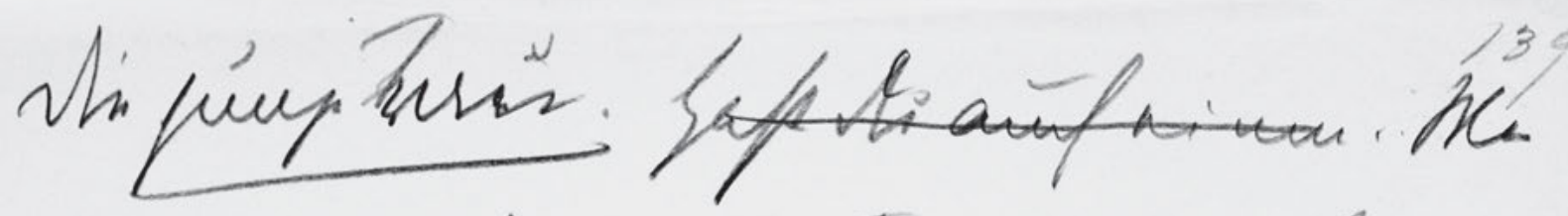

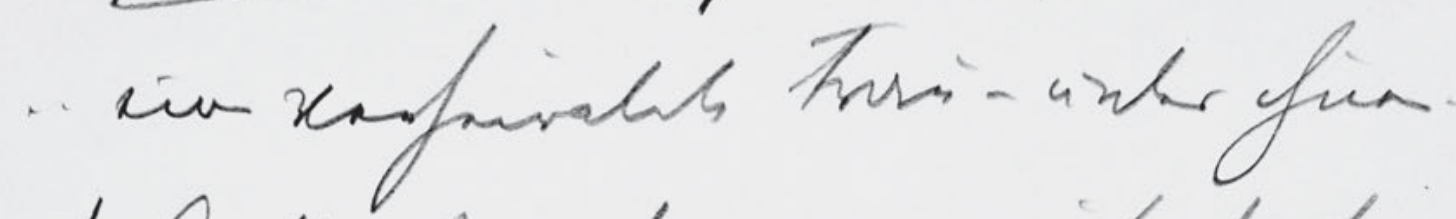
st bath. Meist-miuninf di ber-?

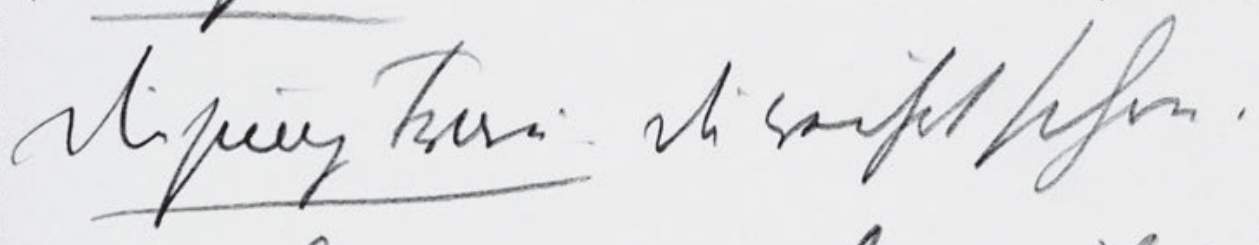

sh Sats. laiffloinsify) Mi poinp di enf daptorye!

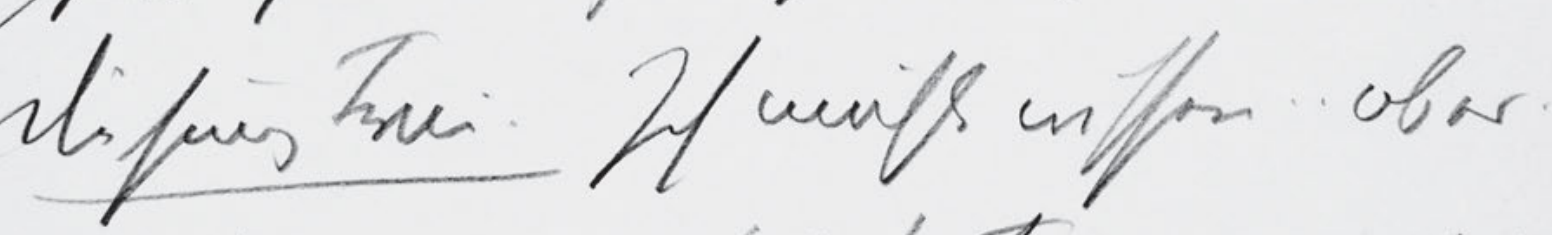

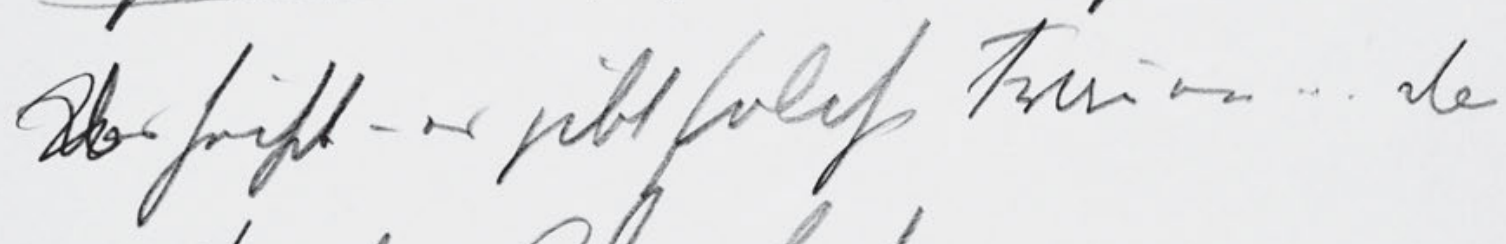
menting. Alor of ch

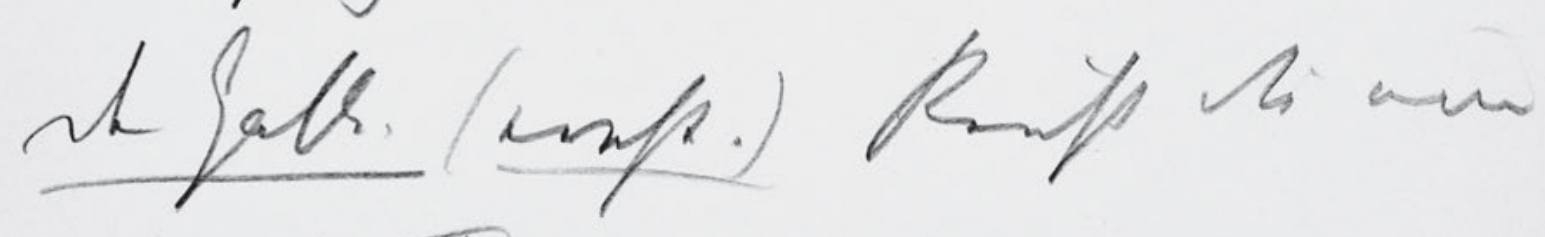
tole Tuni?

322 
Die junge Frau. Hast du auch einm . . War

.. eine verheiratete Frau - unter ihnen.

Der Gatte. Wieso - wie meinst du das - ?

${ }_{5}$ Die junge Frau. Du weißt schon.

Der Gatte. (leicht beunruhigt) Wie

kō̄st du auf diese Frage?

Die jung Frau. Ich möchte wissen .. ob es .

?N? das heißt - es gibt solche Frauen ... das

weiss ich .. Aber ob du .

Der Gatte. (ernst.) Ken̄st du eine

solche Frau? . . 
HSz5 140

Handschriften und Typoskript

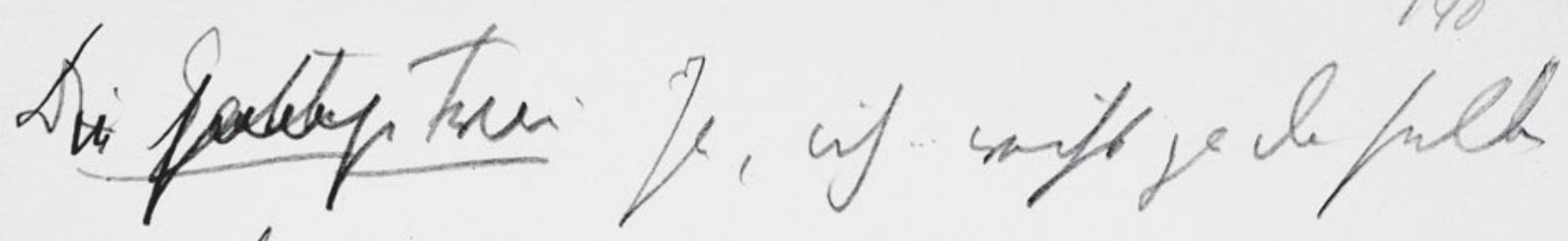
unifi.

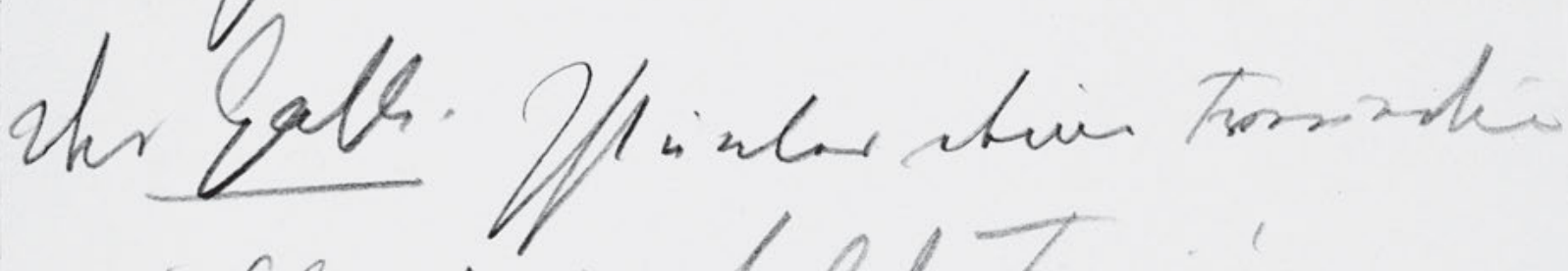
sialsuff icu bolf tom

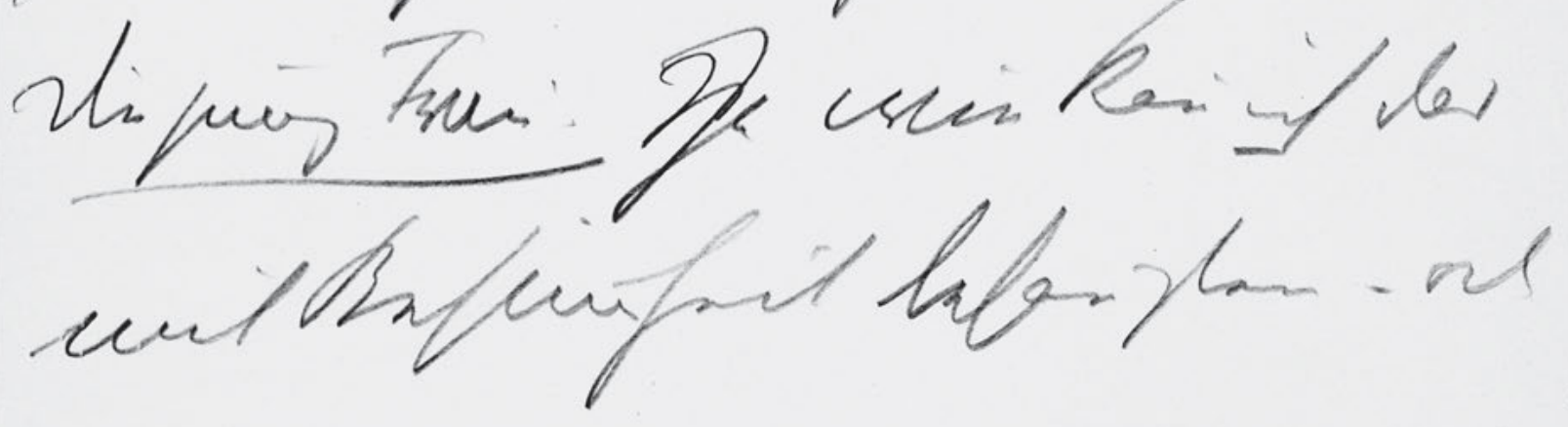
charnasion

sh fats. fot Sisuatheff- wut

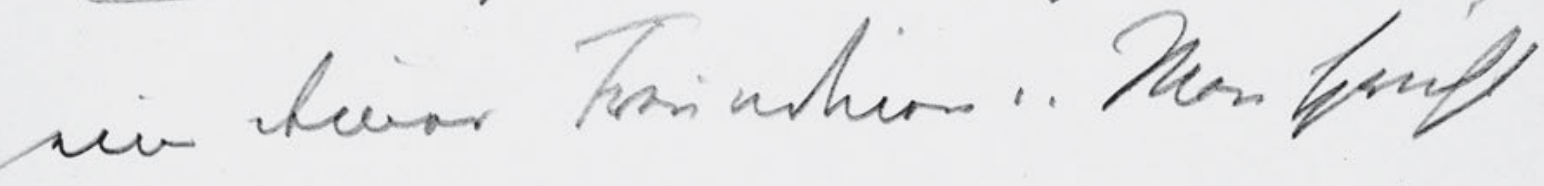
sta ya wanfor, ust ina to vos. fat di min geflenste. ?

324 
140

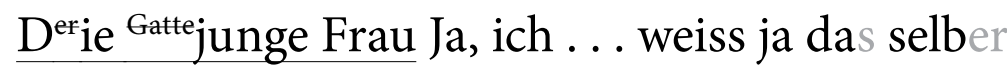

nicht.

Der Gatte. Ist unter deinen Freundin

$5 \quad$ vielleicht eine solche Frau?

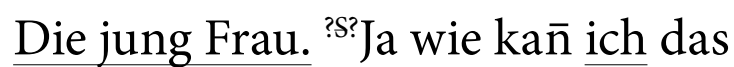

mit Bestimheit behaupten - od

verneinen.

Der Gatte. Hat dir vielleicht einmal

10 eine deiner Freundinen .. Man spricht

über gar manches, wen̄ man so ?ganz? -

hat dir eine gestanden - ? 
HSz5 141

Handschriften und Typoskript

difung Tun:(nintife) hron

14)

thath Gaf tik ugar min

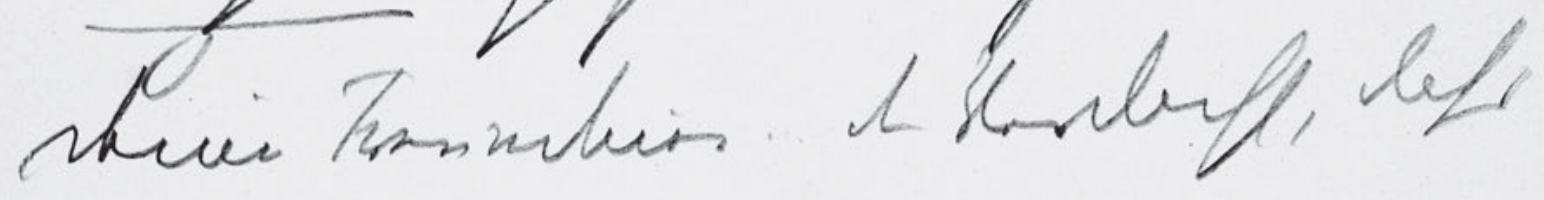
fir

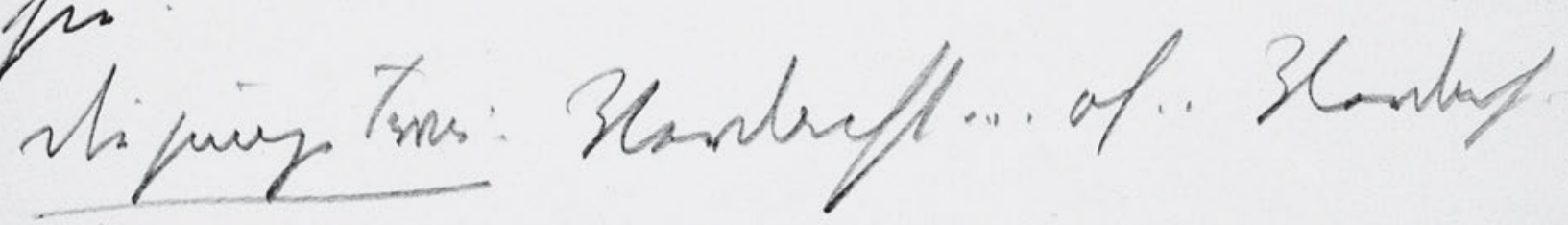
L Sath, Yreforit.

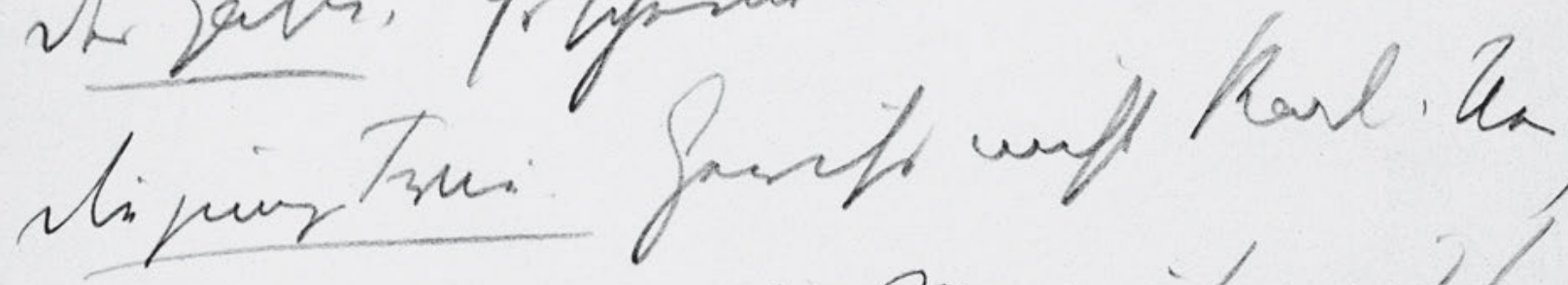
harl, fope wift. Mrri if weert

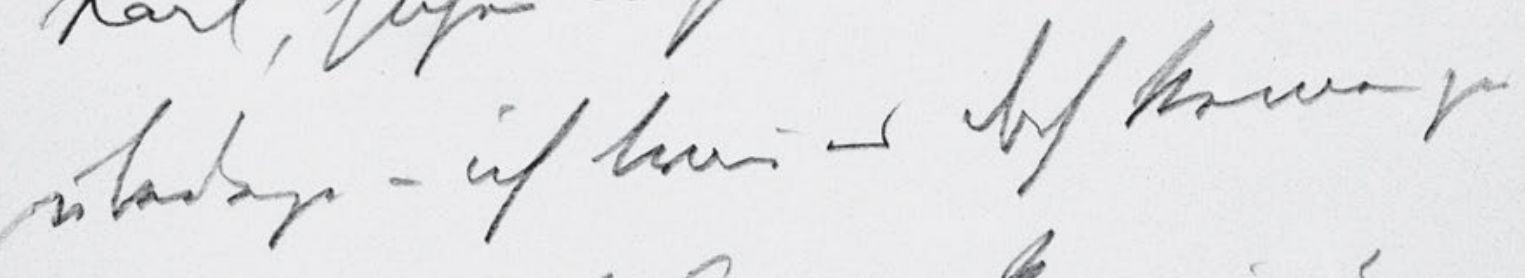

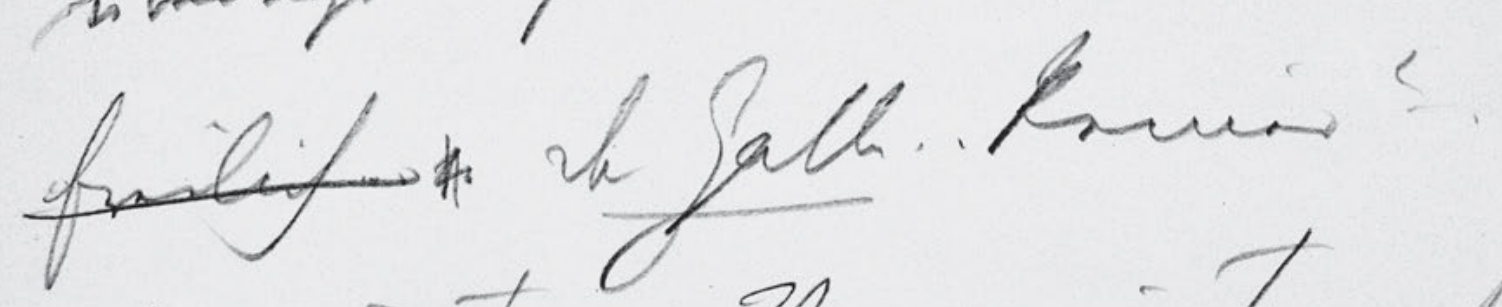

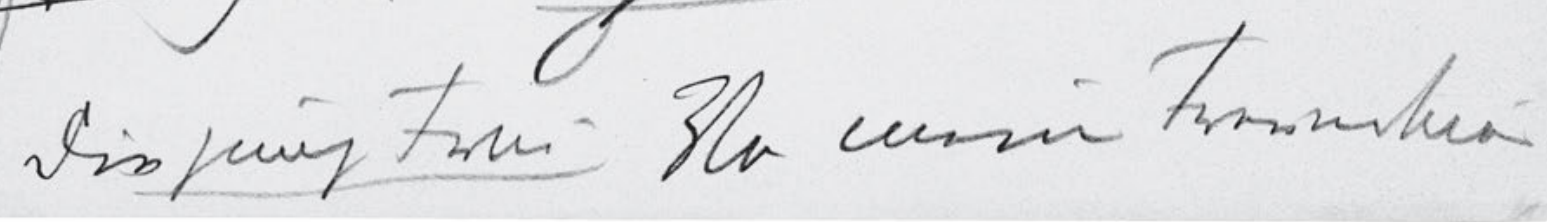

326 
Die junge Frau. (unsicher) Nein.

Der Gatte. Hast du bei irgend einer deiner Freundinen . . den Verdacht, dass

5 sie.

Die junge Frau. Verdacht .... oh . . Verdacht Der Gatte. Es scheint . .

Die junge Frau. Gewiss nicht Karl. Nein, Karl, sicher nicht. Weñ ich mirs so

10 überlege - ich trau es doch keiner zu. freilich ... [?] Der Gatte . Keiner? . Die jung Frau Von meinen Freundinen - 
HSz5 142

Handschriften und Typoskript

Krim.

142

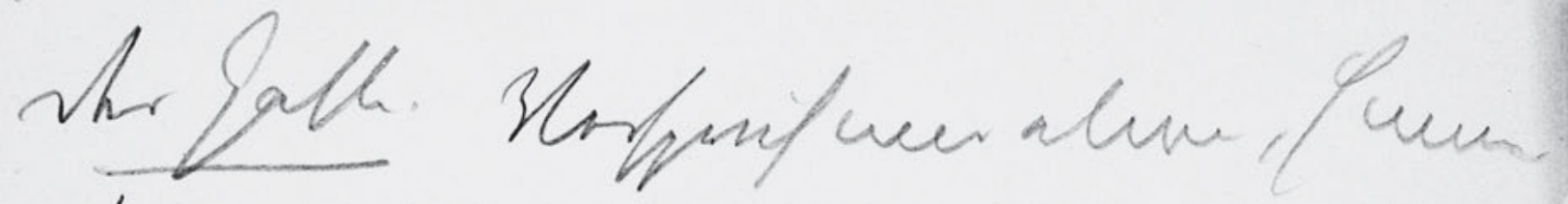
stafuertan: Uim?

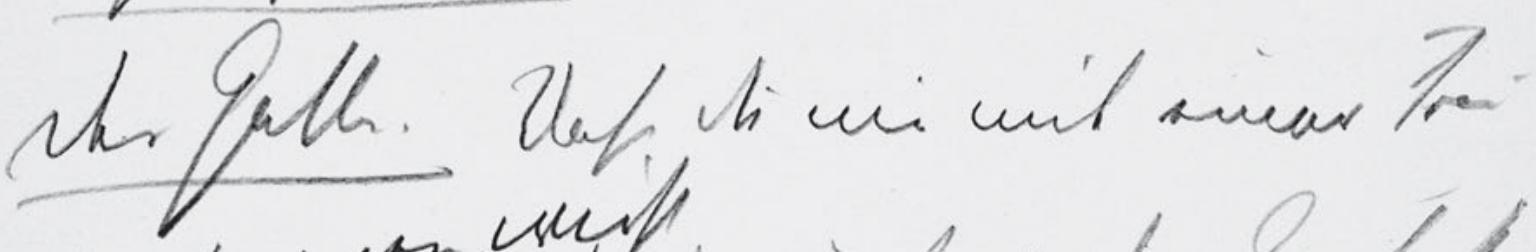

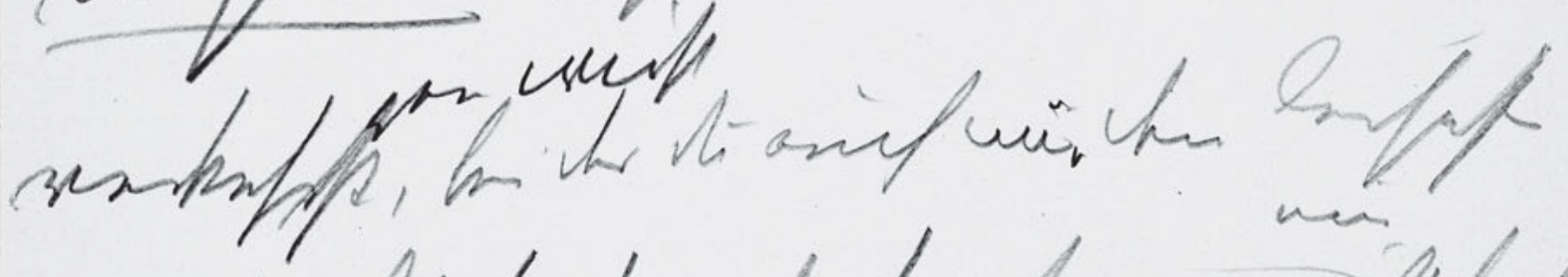

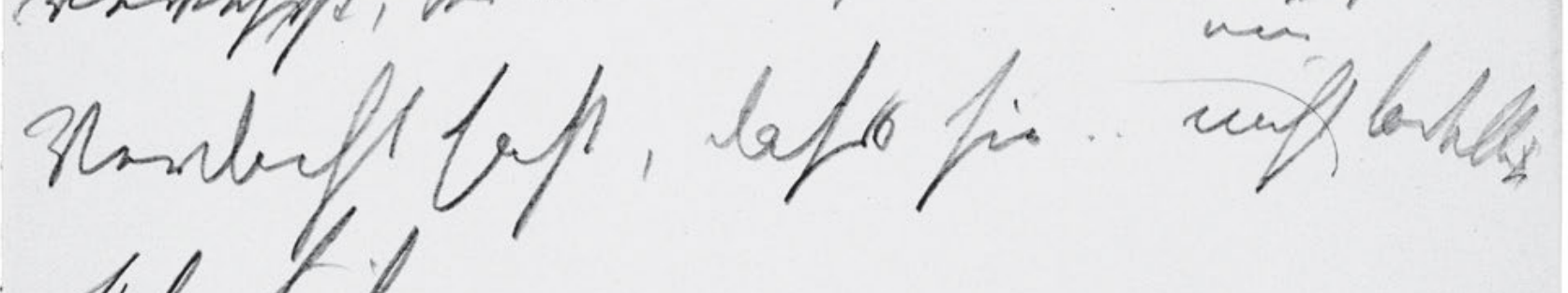
Ath iprofor.

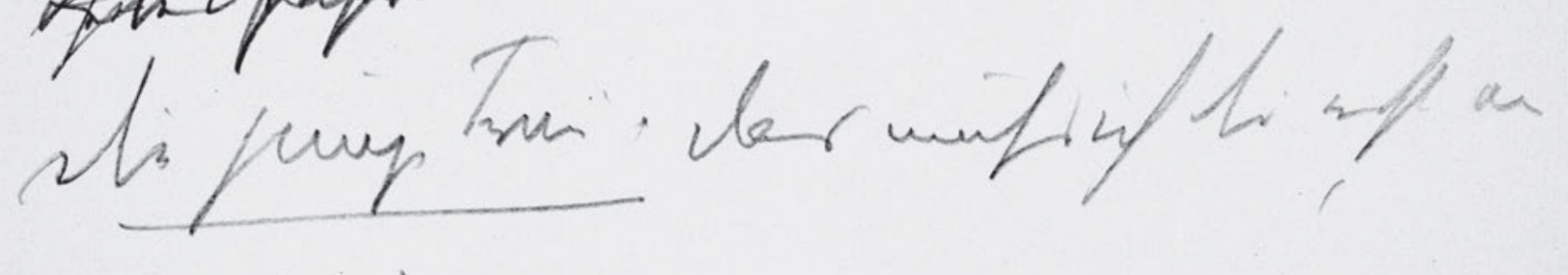
lyaspan:

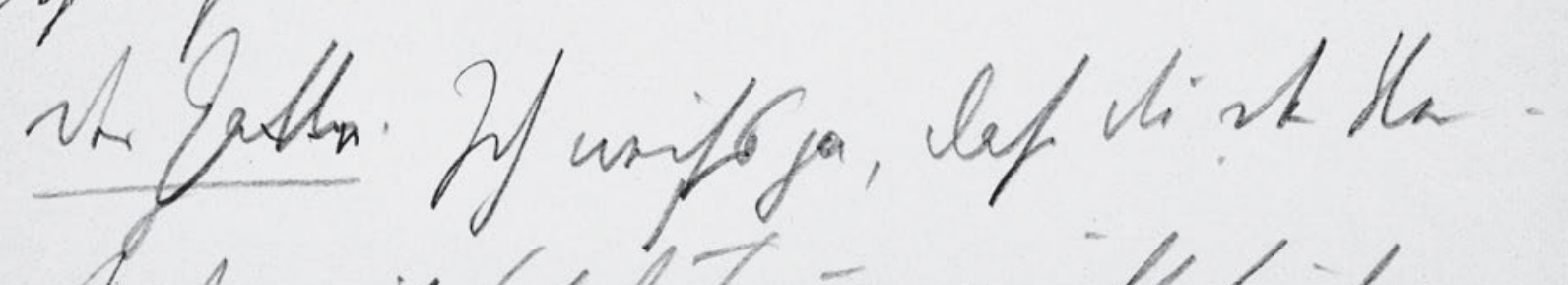

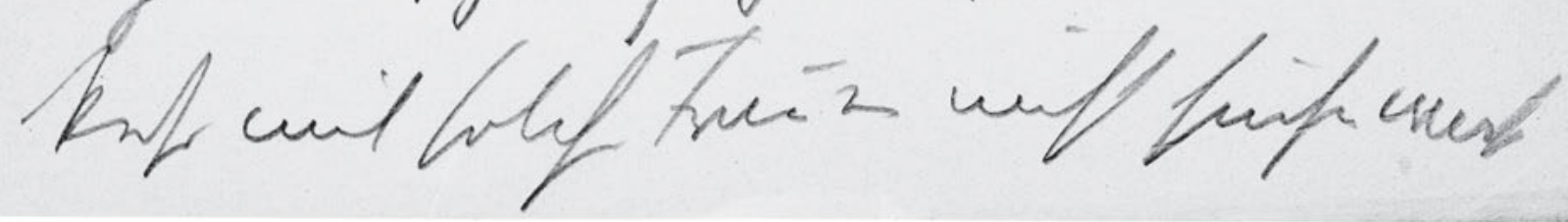

328 
142

keiner . .

Der Gatte. Versprich mir etwas, Emma

Die junge Frau. Nun? .

$5 \quad$ Der Gatte. Dass du nie mit einer Frau ren wirst

verkehrst, bei der du auch nur den leisesten

Verdacht hast, dass sie.. nicht tadellos ${ }^{s}$ se

${ }^{\text {sei ware }}$ Leben führe.

Die junge Frau . Das muss ich dir erst ver

$10 \quad$ sprechen?

Der Gatte. Ich weiss ja, dass du den Ver-

kehr mit solchen Frauen nicht suchen wirst 
HSz5 143

Handschriften und Typoskript

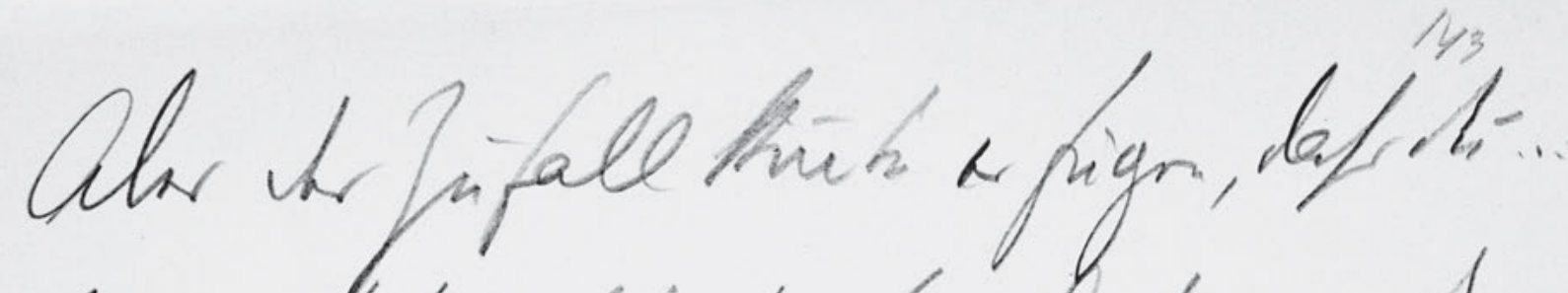

Ja ob iptor fofi ainb laf

pris

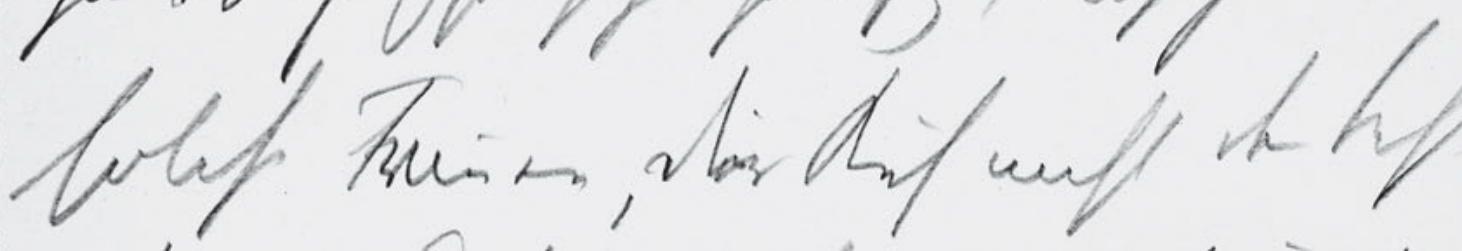

ip, sh fapallebeft un a funityo

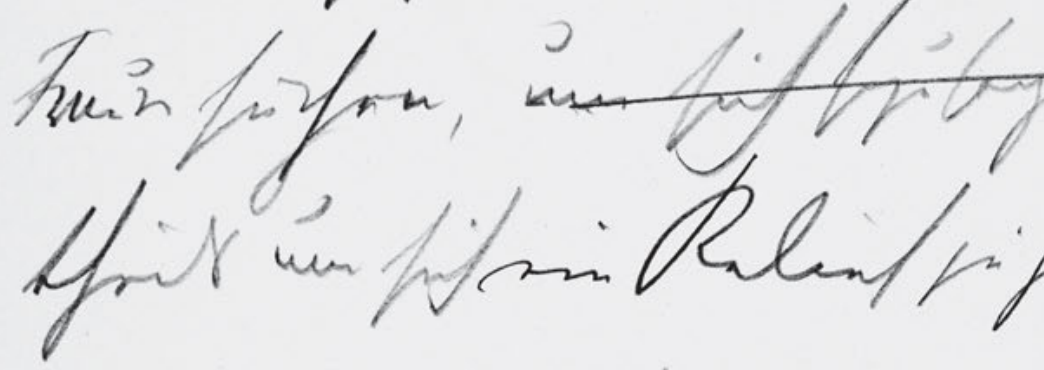

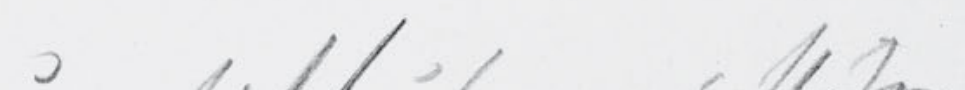

ari ni prosiffe. mi bel aflay.

an

finures/nar/s

theng tam fo.

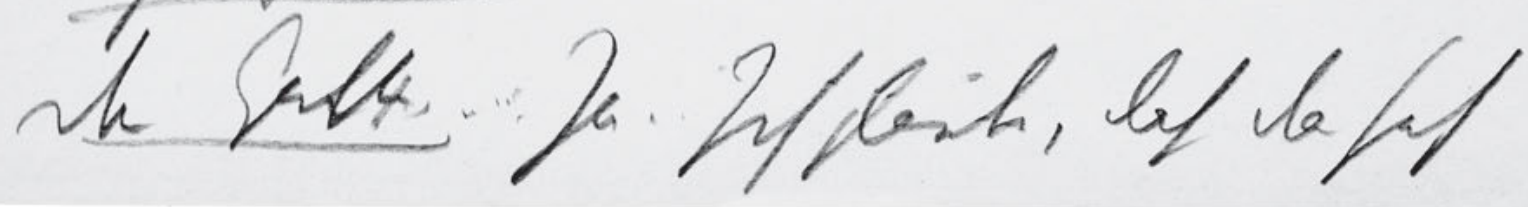

330 
143

Aber der Zufall kön̄te es fügen, dass du ...

Ja es ist sogar sehr häufig, dass gerad

solche Frauen, $\mathrm{d}^{\mathrm{ie} e}$ ere Ruf nicht der beste

5 ist, die Gesellschaft von anständigen

Frauen suchen, um sich sozusagen zu stützen

theils um sich ein Relief zu geben, theils . .

aus eine gewissen - wie soll ich sagen .

aus eine gewissen Heimweh nach der

10 Tugend.

Die jung Frau. So.

Der Gatte. ..... Ja . . Ich glaube, dass das seh 
HSz5 144

Handschriften und Typoskript

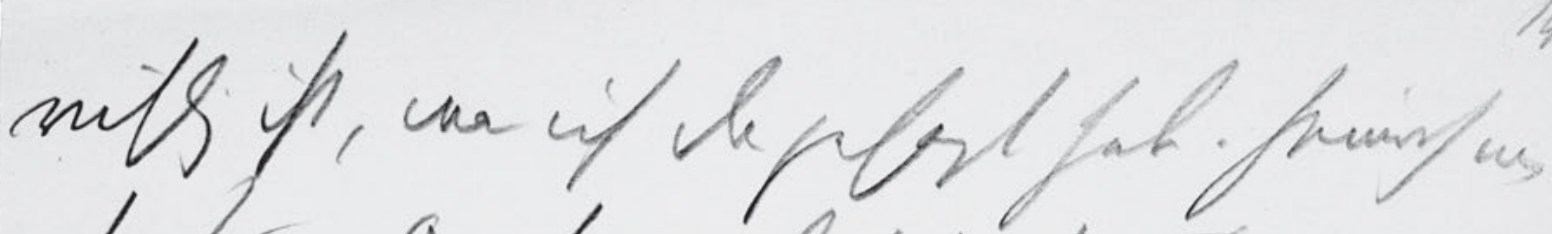

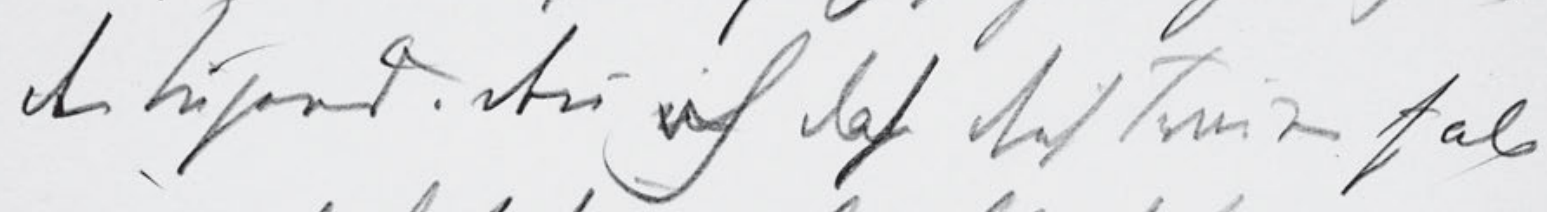

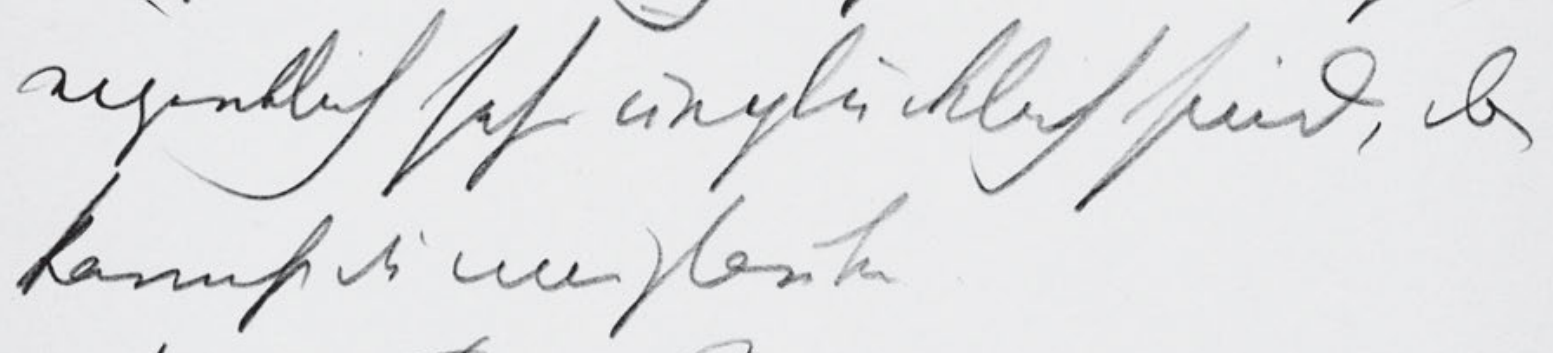
vipus Tus: Remin :-

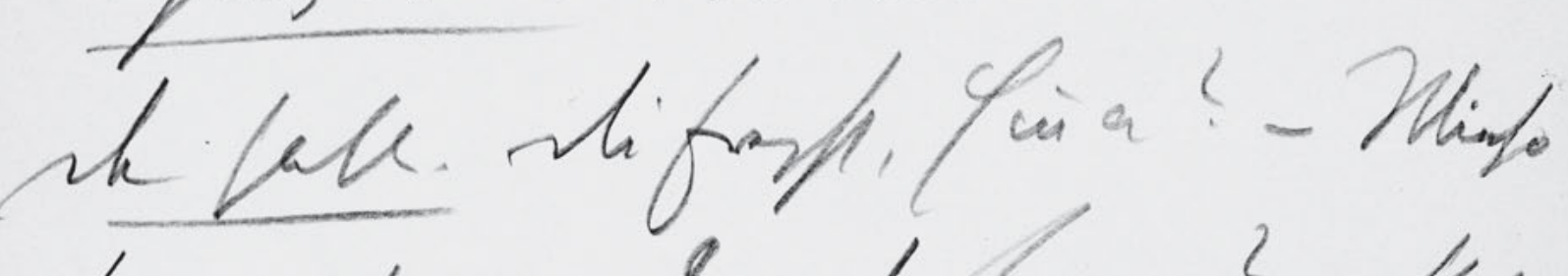

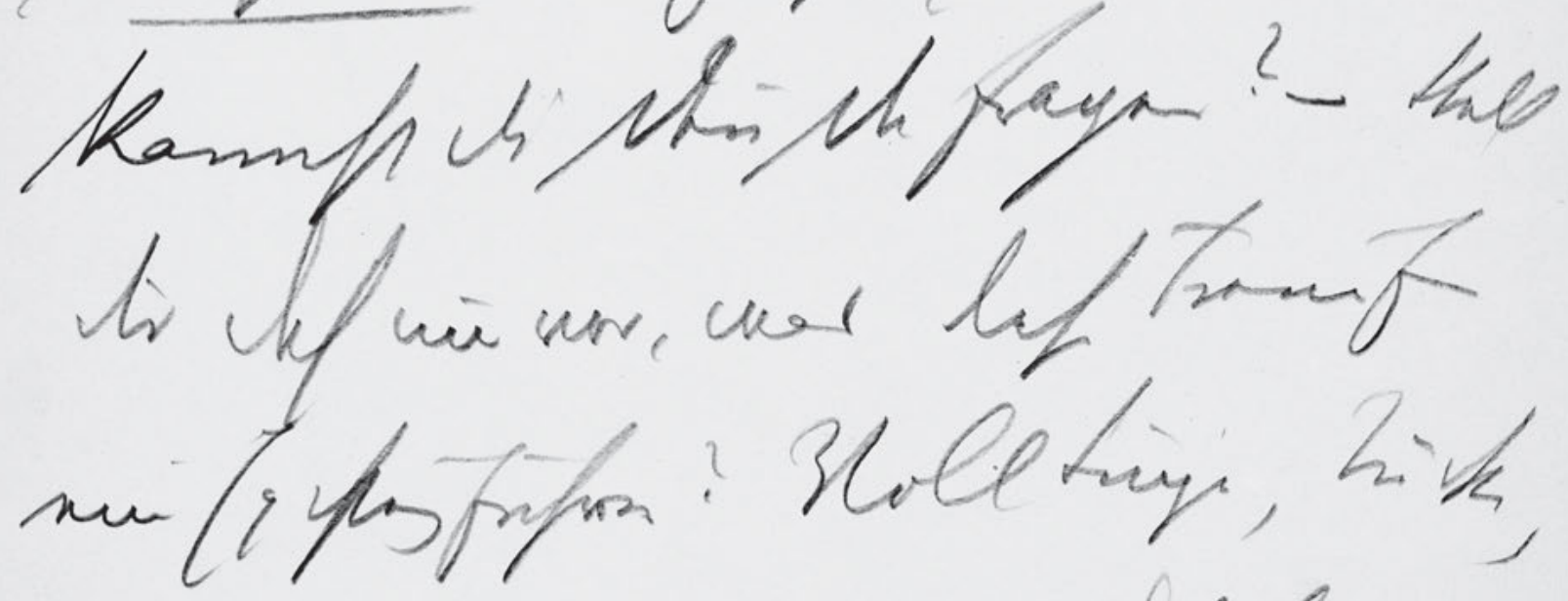
Qpuringit.

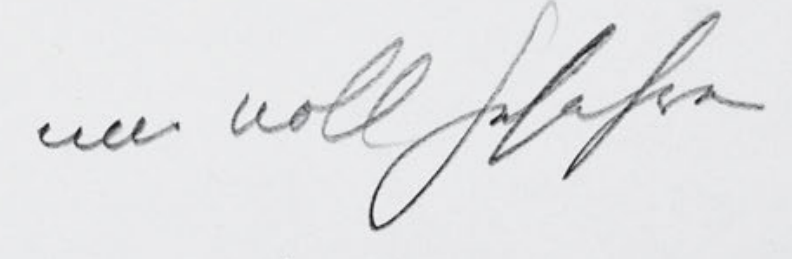

332 
richtig ist, was ich da gesagt hab. Heimweh nac

der Tugend. Deñ ich dass diese Frauen 's? all

eigentlich sehr unglücklich sind, das

$5 \quad$ kannst du mir glauben.

Die jung Frau. Warum? -

Der Gatte. Du fragst, Ē̄a? - Wieso

kannst du dē̄ das fragen? - Stell

dir doch nur vor, was diese Fraue für

10 eine Existenz führen? Voll Lüge, Tücke,

Gemeinheit .. und voll Gefahren. 
HSz5 145

Handschriften und Typoskript

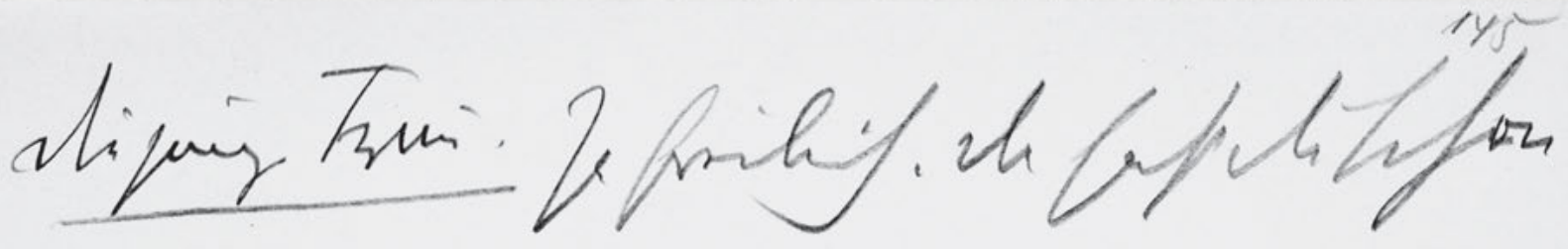

Rufl.

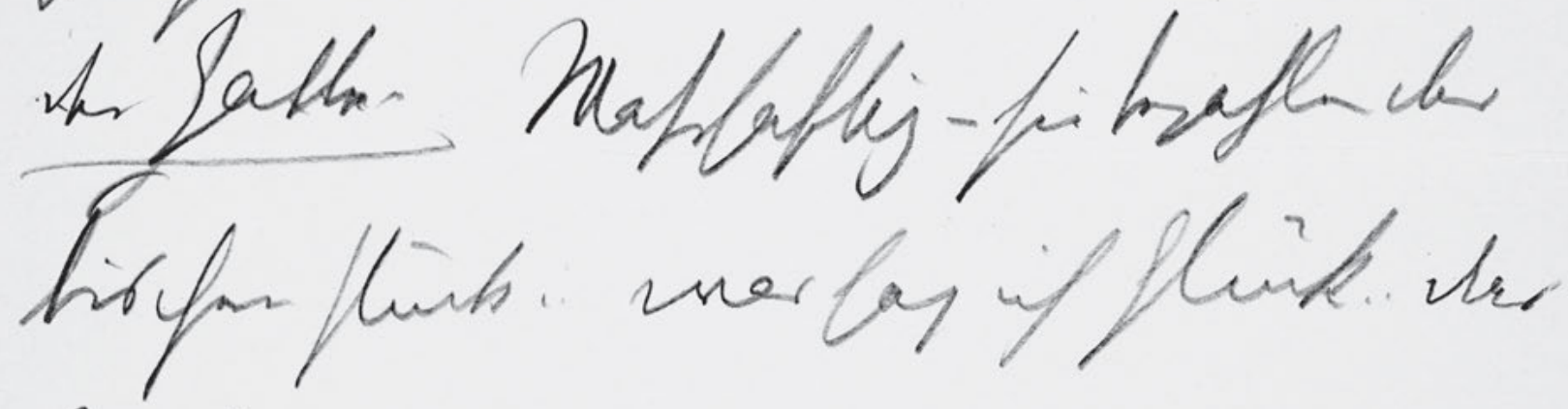

hiryon

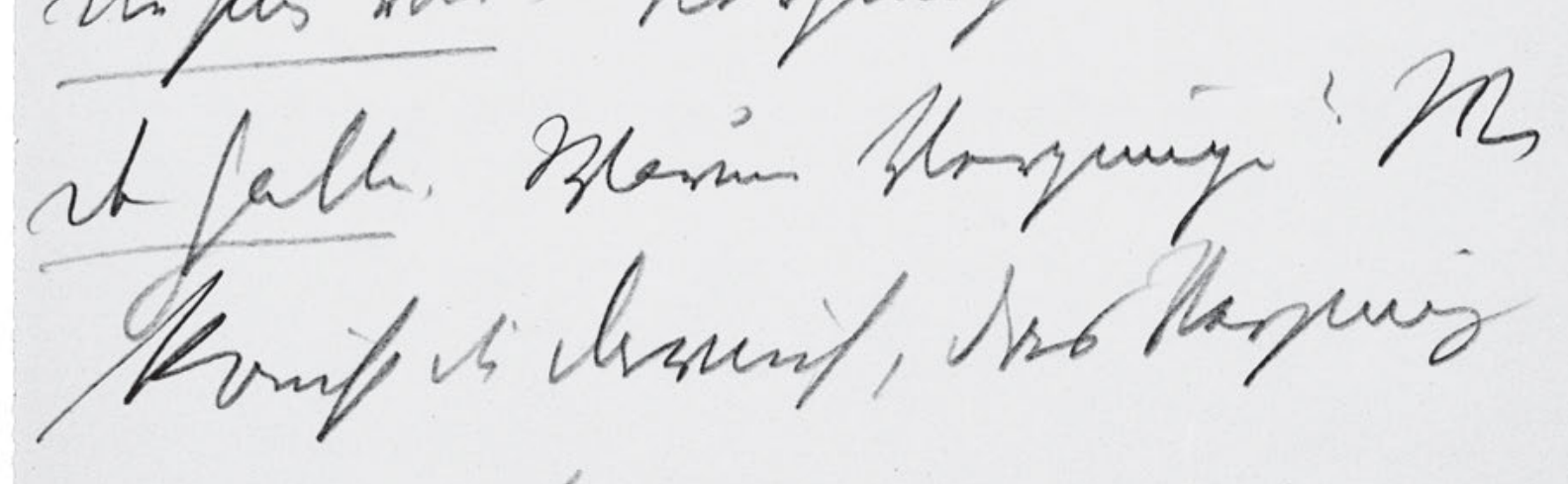

Bingent

qigin Trui

Ani-nher ment

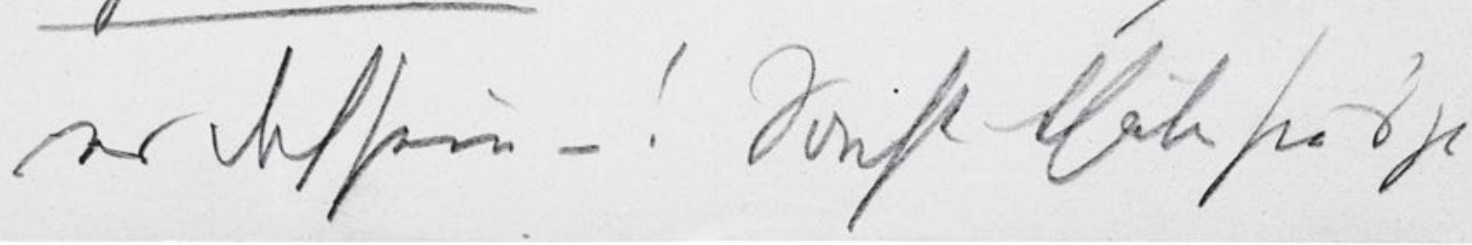

334 
145

Die junge Frau. Ja freilich, da hast du schon

Recht.

Der Gatte. Wahrhaftig - sie bezahlen das

5 bischen Glück .. was sag ich Glück . . das

bischen

Die jung Frau. Vergnügen.

Der Gatte. Warum Vergnügen? Wie

kō̄st du darauf, das Vergnügen

$10 \quad$ zu neñen ? $s$ ?

Die jung Frau. Nun - etwas muss

es doch sein - ! Sonst thäten sie's ja 
HSz5 146

Handschriften und Typoskript

vaift

146

sh Salk. Unft yor... millo its.

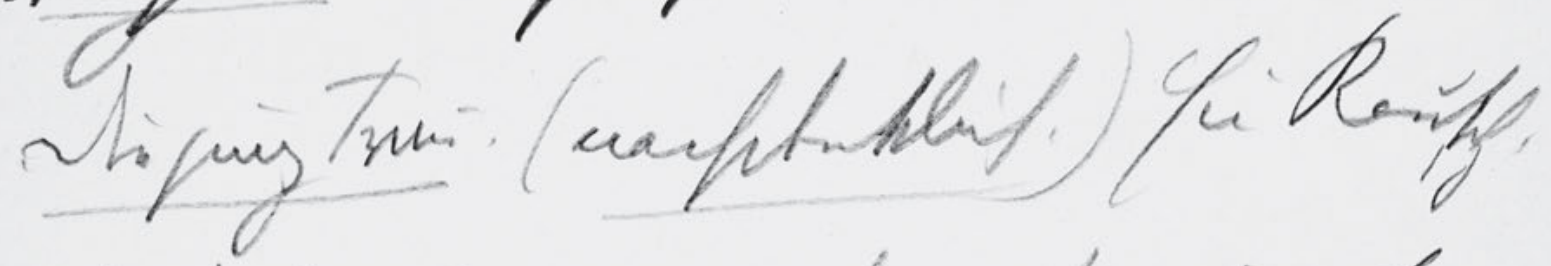

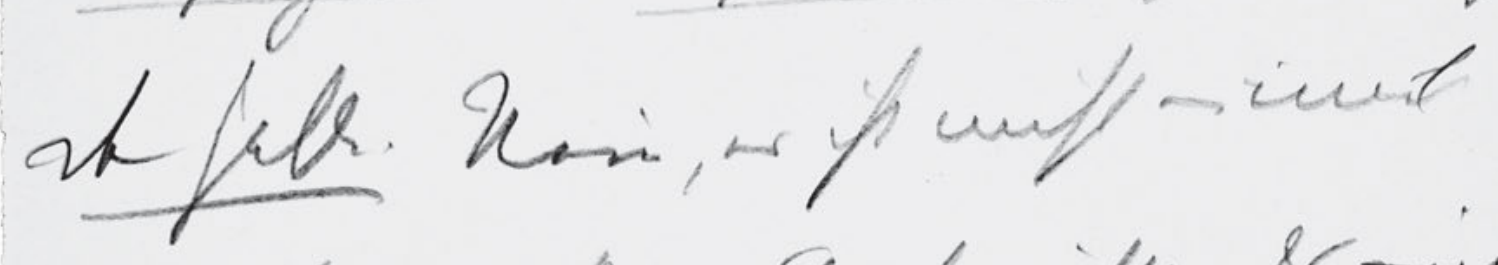

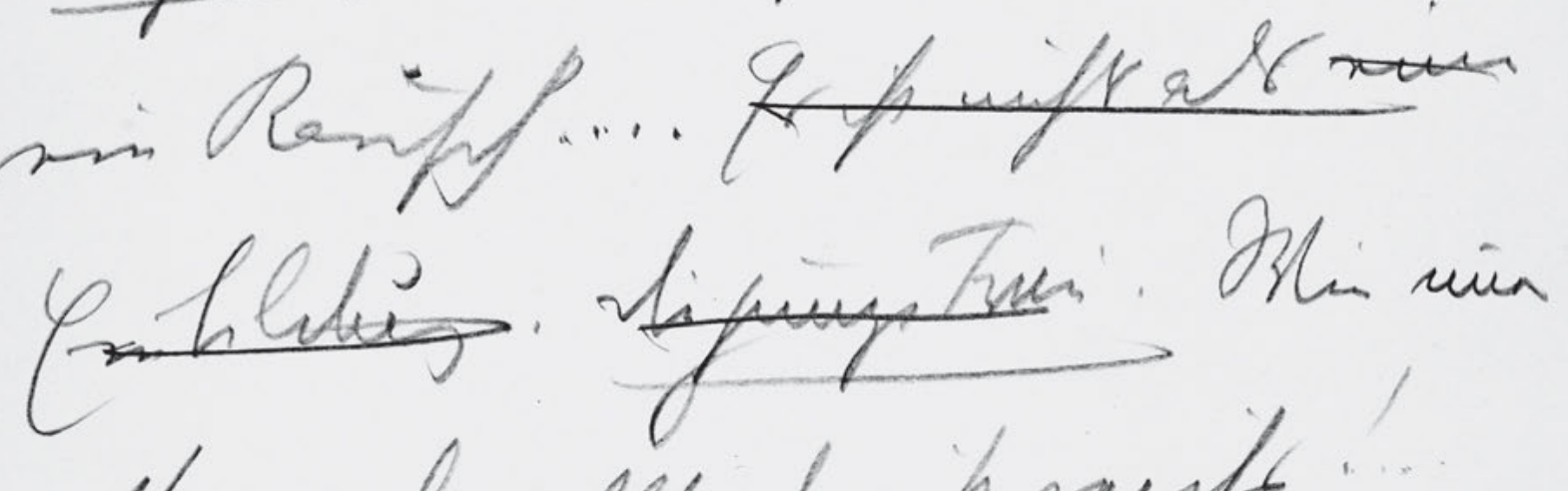

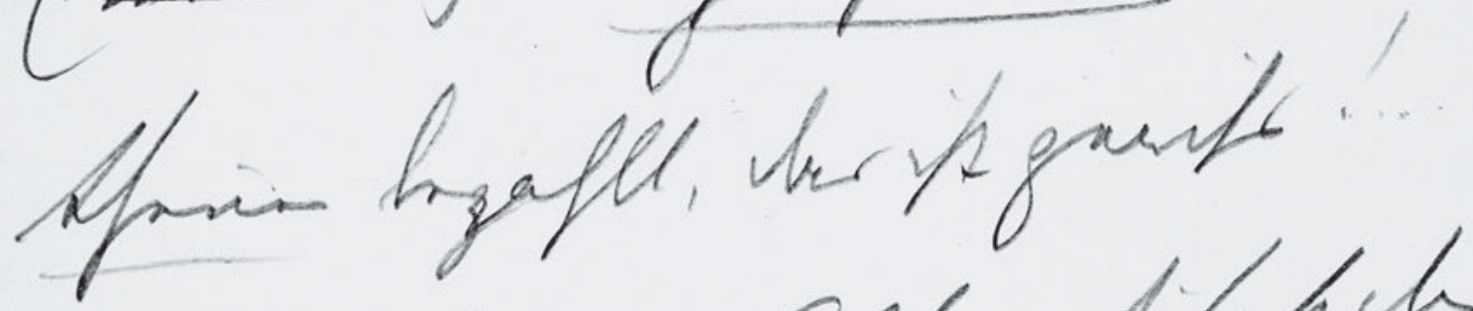

stipiesm Alf... Siffich

si muat un prumeft. - unft maft.

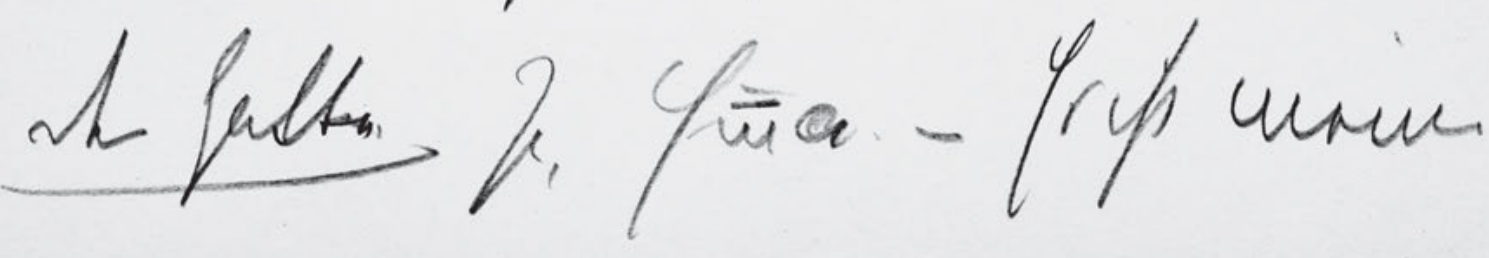

336 


\section{6}

ja nicht.

Der Gatte. Nichts ist es ..... . ein Rausch . .

Die junge Frau . (nachdenklich.) Ein Rausch.

5 Der Gatte. Nein, es ist nicht einmal

ein Rausch ...... Es ist nichts als eine

Einbildung. Die junge Frau. Wie imer

theuer bezahlt, das ist gewiss! . .

Die jung Frau. Also .. du hast das

10 einmal mitgemacht, - nicht wahr ..

Der Gatte. Ja, Ē̄a. - Es ist meine 
HSz5 147

Handschriften und Typoskript

Suniry

lis ping has:

)

14y

if $\mathrm{in}$

ahr fall the foild

Mjuis Tum. Jilony.

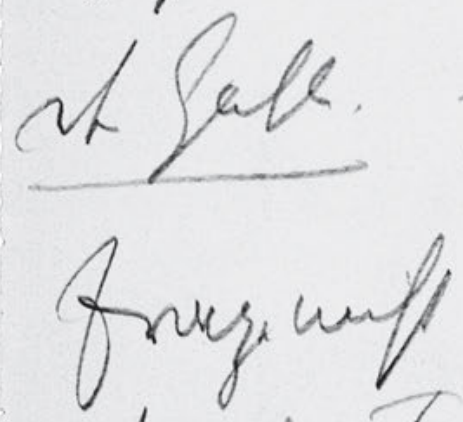

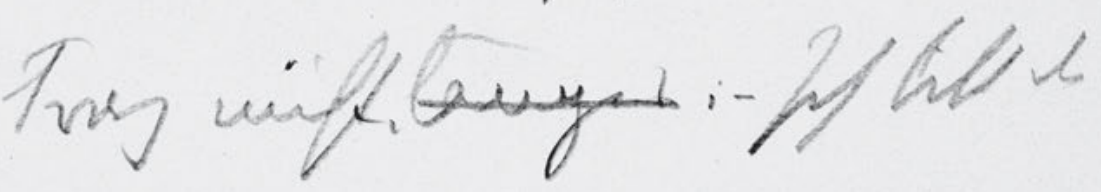

sifuing. Trin. Ah Ravl'...

A fath,

risitors

liming tmimp-?

338 
traurigst Erinnerung . .

Die jung Frau. Wer ists? . Sag! . Ken

ich sie.

$5 \quad$ Der Gatte. Was fällt dir ein?

Die jung Frau. Ist's lange her? . War es

sehr lang bevor du mich geheiratet hast.

Der Gatte. Frag nicht, länger;- Ich bitt di

frage nicht.

${ }_{10} \quad$ Die junge Frau. Aber Karl! ...

Der Gatte, ... Sie ist todt.

Die jung Frau. Im Ernst - ? 
HSz5 148

Handschriften und Typoskript

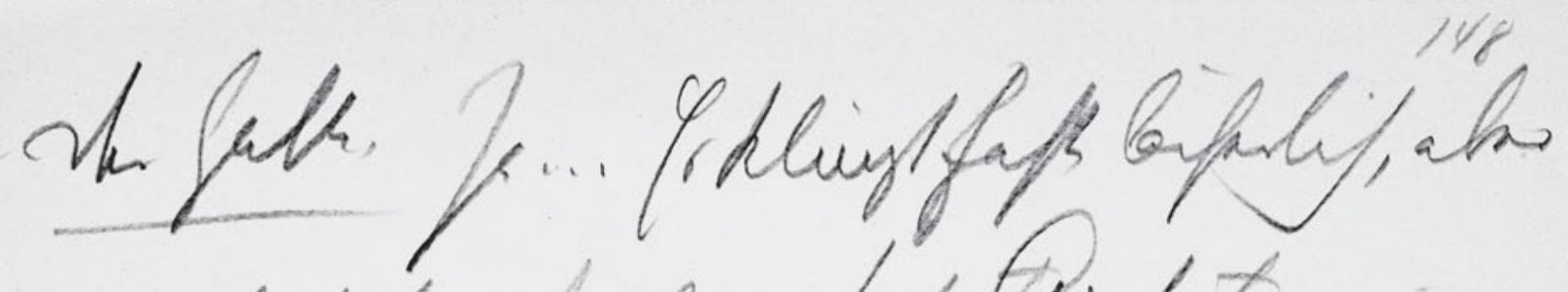

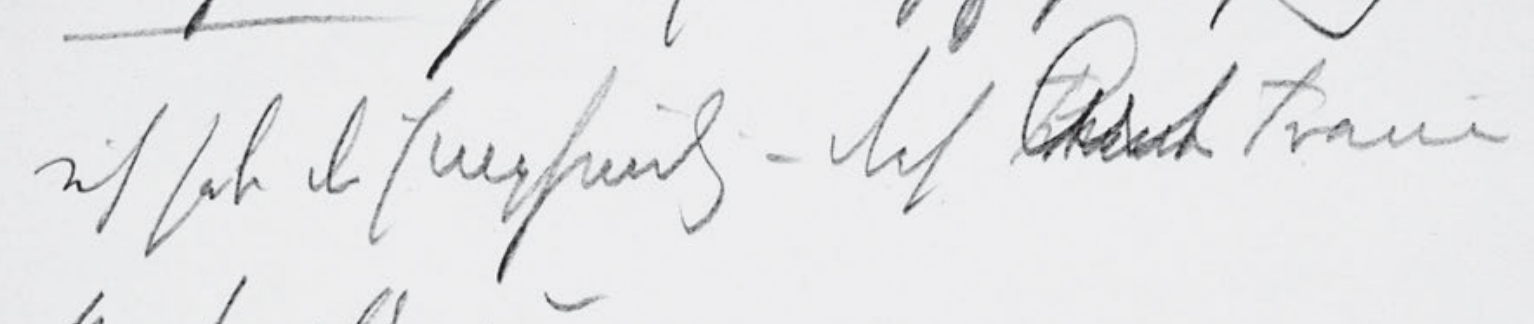

pratr alt jǘs.

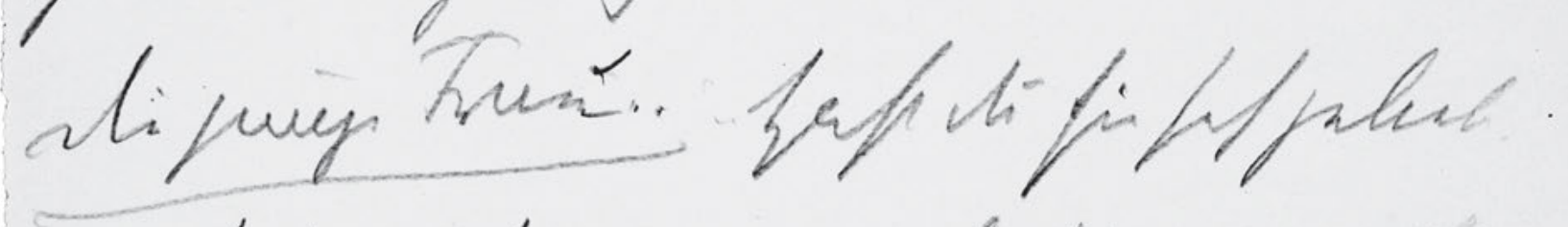

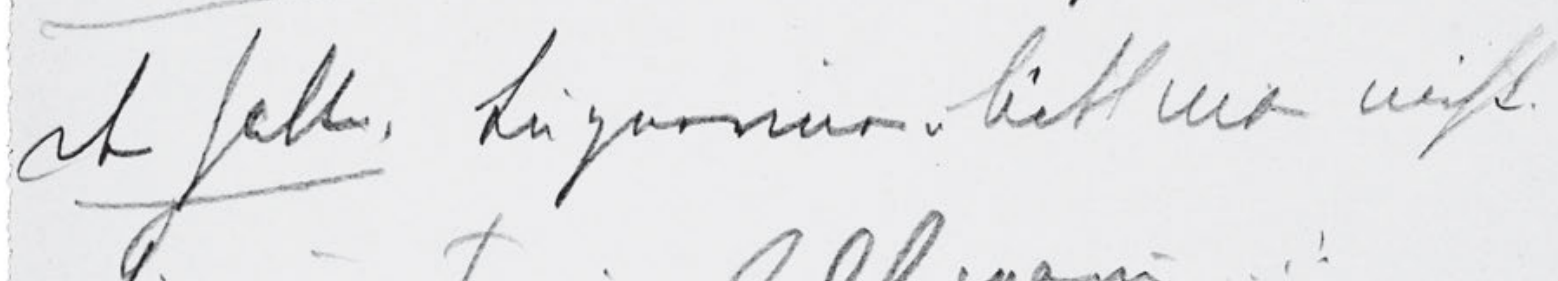
Lipuny trmi Alfornami...

at wer. Yinkonts.

disung tami. Qlf m.

sh fabl. Junif unf anj dine. is

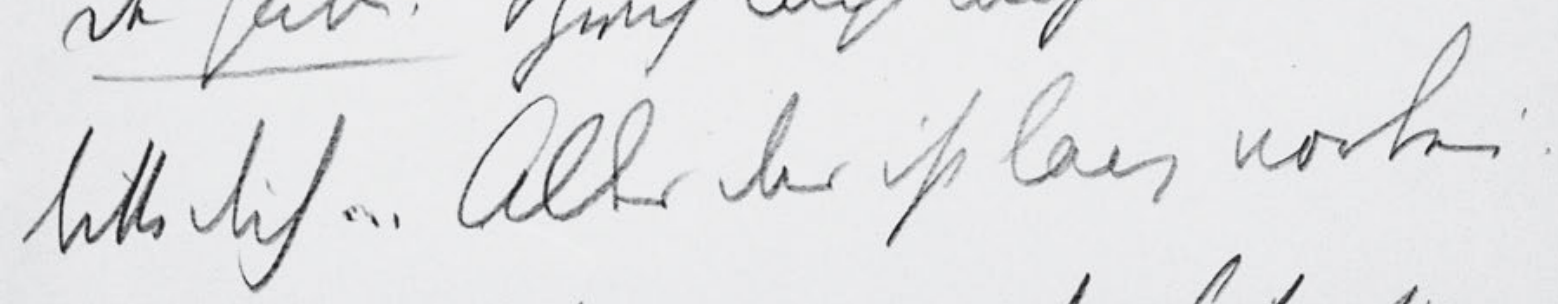

subints bif unziu. Mer hft di

340 


\section{8}

Der Gatte. Ja ... Es klingt fast lächerlich, aber

ich habe die Empfindung - diese ${ }^{\text {Fraute }}$ Art Frauen

sterben alle jung.

$5 \quad$ Die junge Frau..... Hast du sie seh geliebt.

Der Gatte. Lügnerinen liebt man nicht. -

Die junge Frau. Also warum .... !

Der Gatte. Ein Rausch . .

Die jung Frau. Also doch? . .

10 Der Gatte. Sprich nicht meh davo . ich

bitte dich... Alles das ist lang vorbei.

Geliebt hab ich nur eine - das bist du. 
HSz5 149

Handschriften und Typoskript

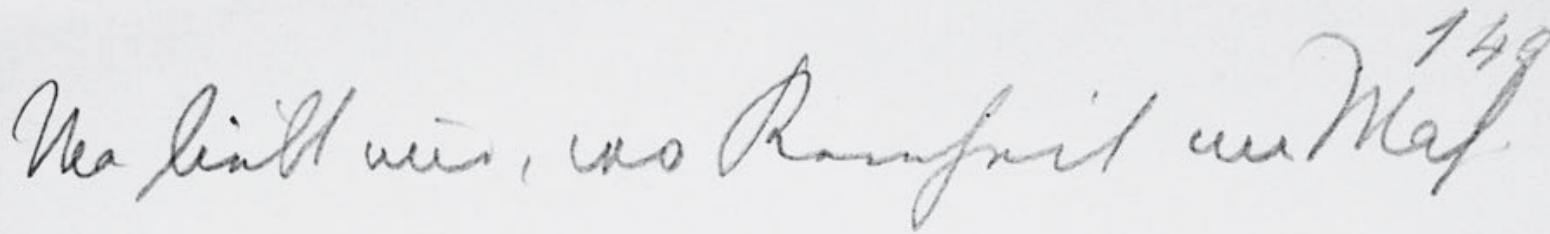
jait ip.

Difung tami Raal.

the Gath, of min fifm, mi mefl

ntel for ma firs in blefo Anum.

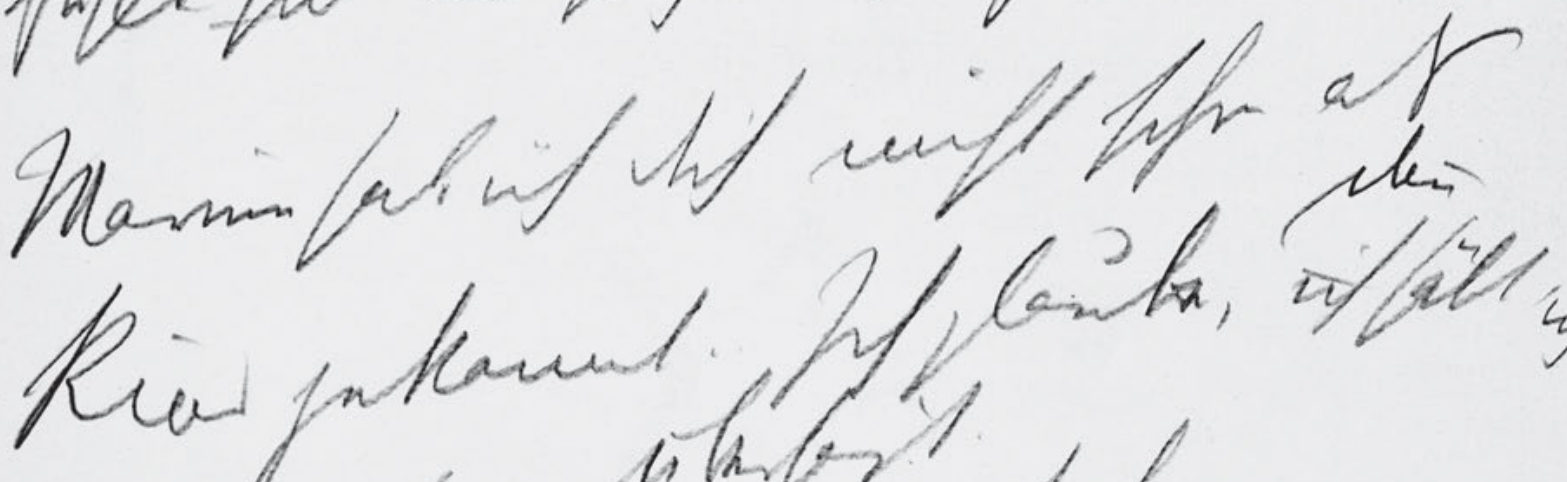

4)

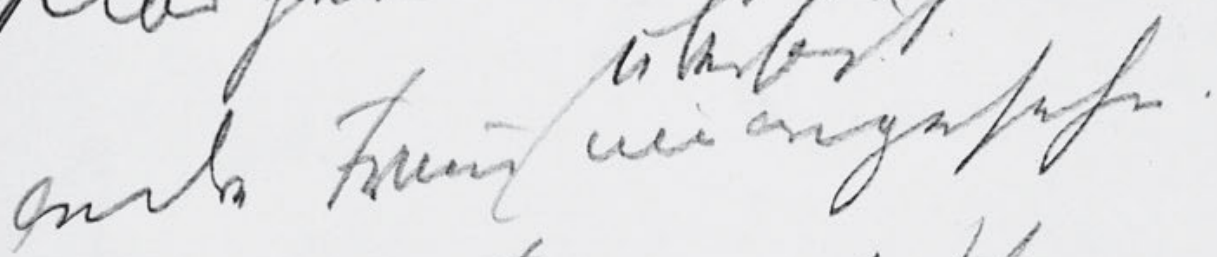

vipuesp trin'...

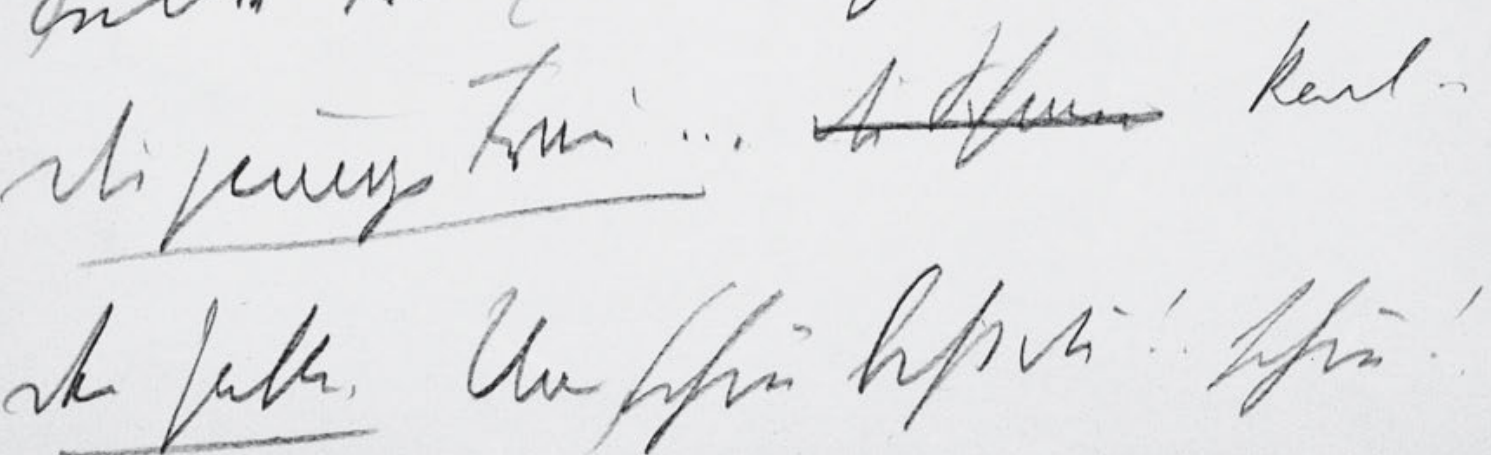

342 
Man liebt nur, wo Reinheit un Wahr-

heit ist . .

Die junge Frau. . Karl . .

5 Der Gatte. Oh wie sicher, - wie wohl

fühlt sich man sich in solchen Armen ..

Warum hab ich dich nicht schon als

dan̄

Kind gekannt. Ich glaube, ich hätt ich

andre Frauen überhaupt

${ }_{10}$ Die junge Frau ... Du Schmei Karl . .

Der Gatte. Und schön bist du! . Schön! 
HSz5 150

Handschriften und Typoskript

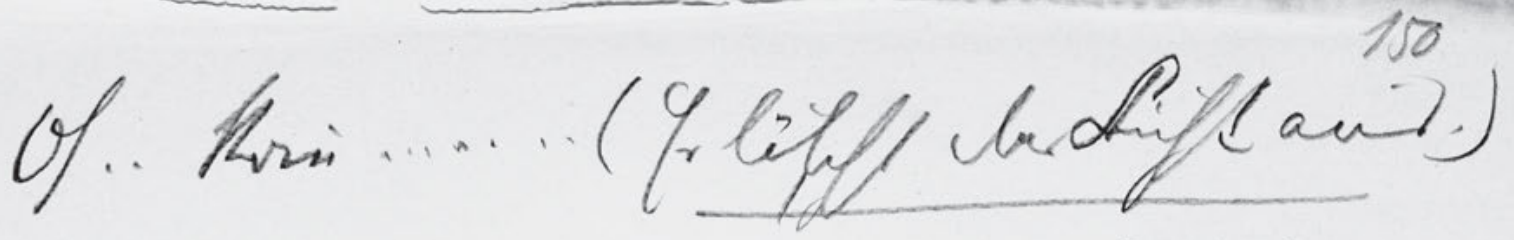

itifun thum

pats. Mattli numun if ford

ver fafta...

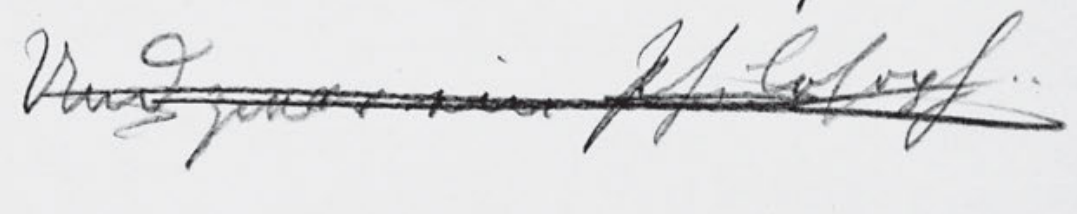

chater cunft.

sine Gate. Mne un tifat.

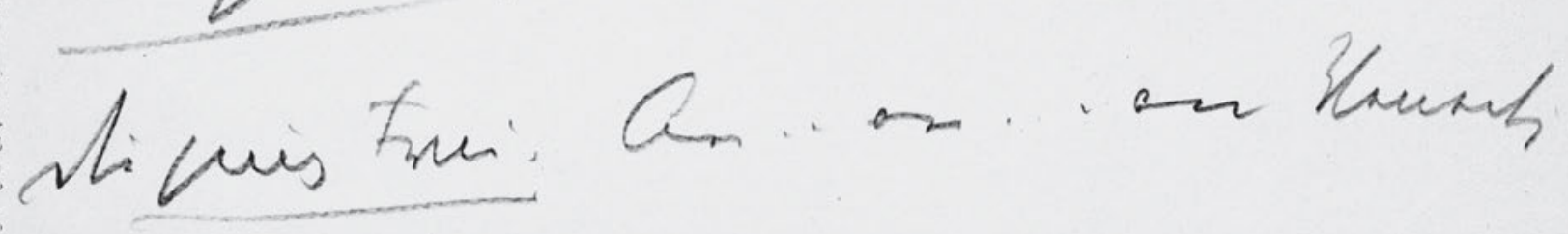

at fath. "sisth houft...

vipuig trm ga......

st fuk the.

344 
Oh . Ko $\overline{\mathrm{m}} . . . . .$. (Er löscht das Licht aus.)

Die junge Frau. Diesmal ist's sicher .. ein

$5 \quad$ Bub. Weißt du .. woran ich heut

Der Gatte. ... Und zwar ein Philosoph ..

denken muss.

Der Gatte. Woran, . . mein Schatz . .

Die jung Frau. An .. an ... an Venedig.

${ }_{10}$ Der Gatte. .. Die erste .. Nacht ....

Die jung Frau. Ja .. so ...

Der Gatte. Was .. so! 
HSz5 151

Handschriften und Typoskript

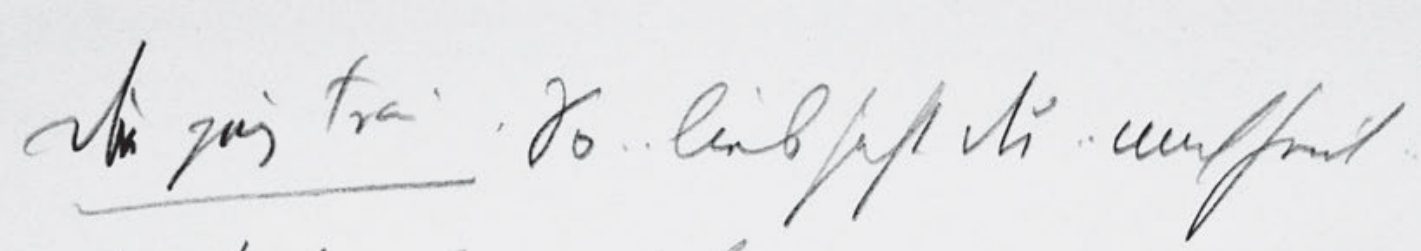

th fult. g...then

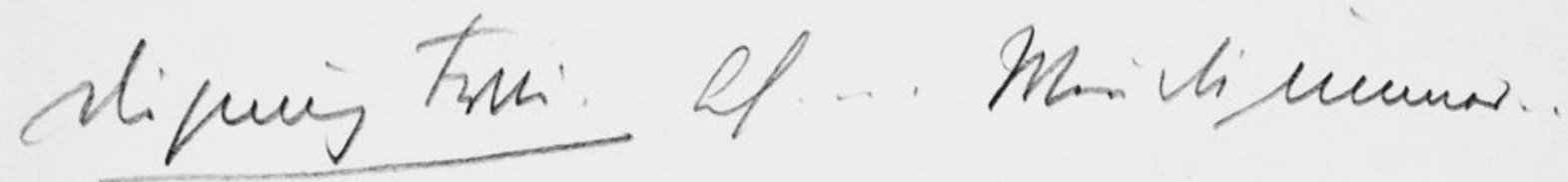

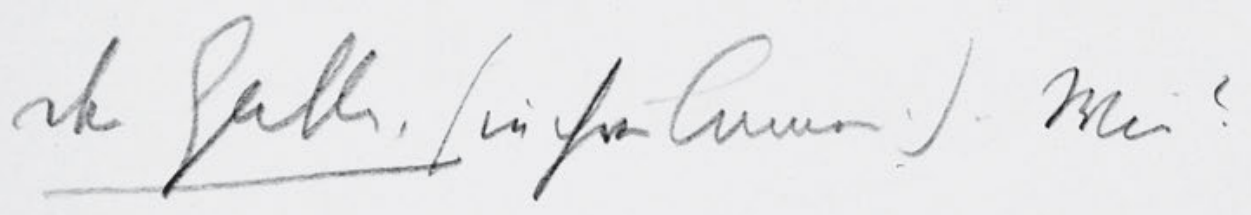

diverijtruni' "Mrin Rav!

th Fall, Ne curmbifs si: Ma.

uime..

di puestrai. Ling.

sh fath, hi, wer met ha, ine sif niment...?

346 
Die jung Frau . So . . lieb hast du .. mich heut . .

Der Gatte. Ja . . so lieb.

Die jung Frau. Ah .... Weñ du immer . .

$5 \quad$ Der Gatte. (in ihren Armen.). Wie? .

Die jung Frau. .. Mein Karl!

Der Gatte. Was meintest du: Wen̄

immer. .

Die jung Frau. Nun ja -

10 Der Gatte. Nun, was wär den, wen

ich immer... ? . 
HSz5 152

Handschriften und Typoskript

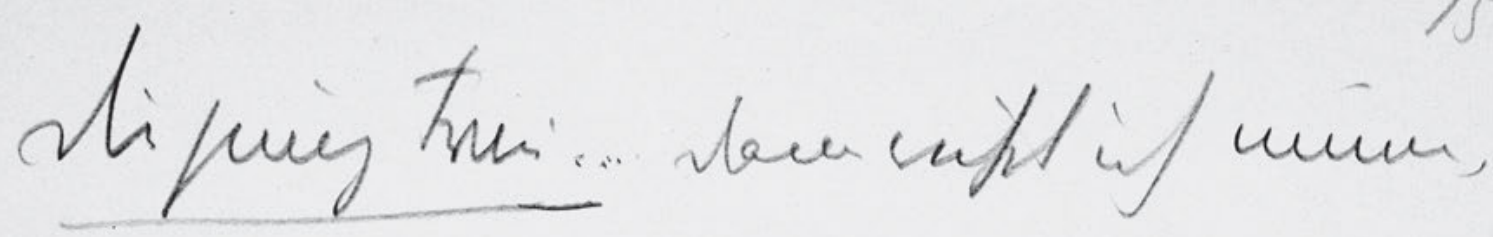
laf vi mifhis inf...

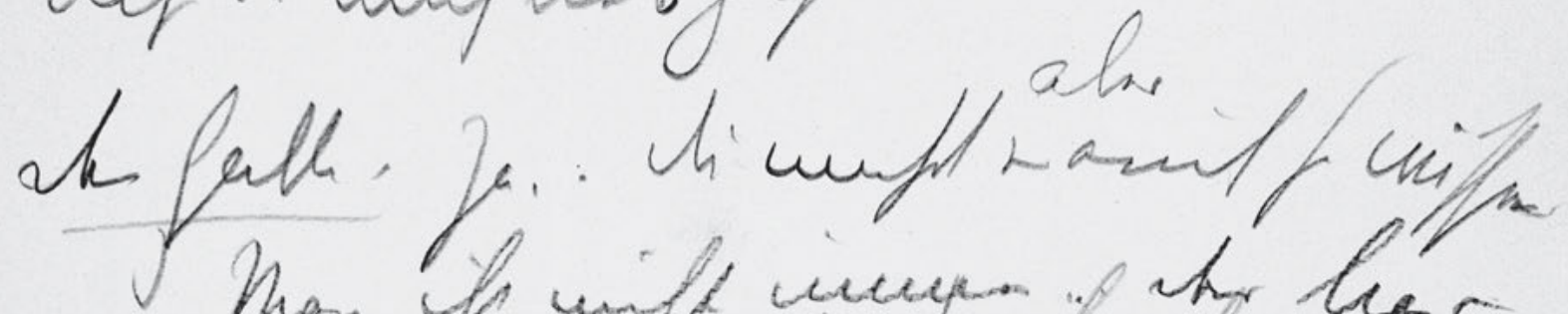

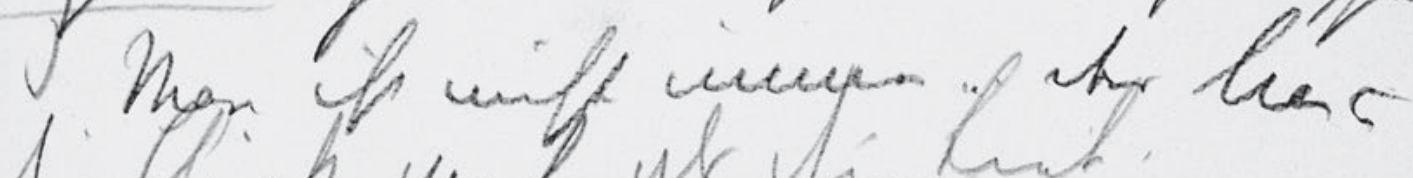
vigip mafe ot li ent

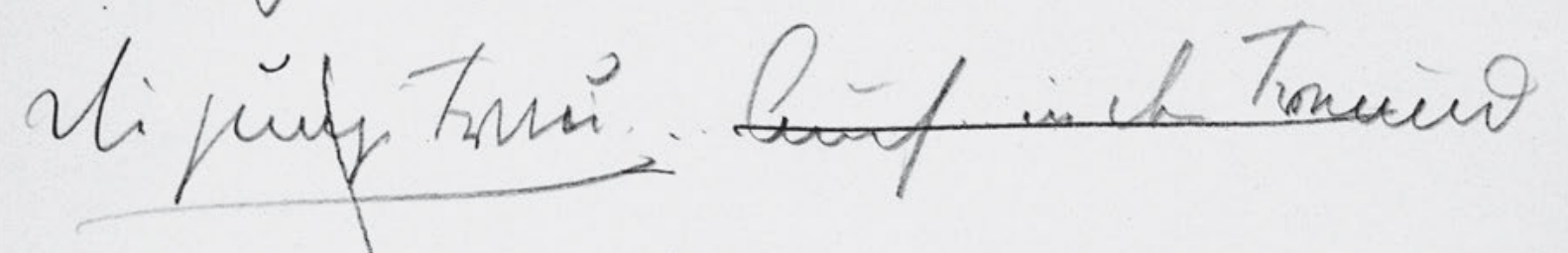

Ats. Fabs

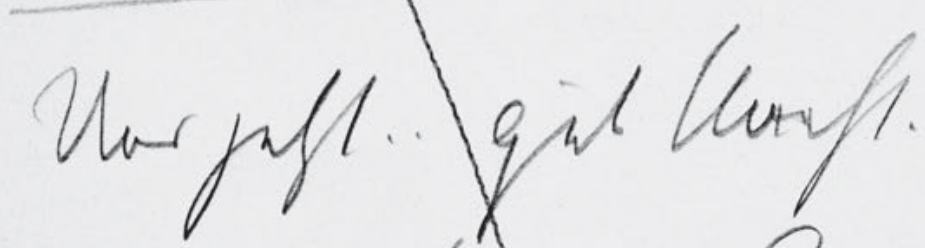

liping ton

Githlueft'

348 


\section{2}

Die jung Frau...... Dann wüßt ich immer,

dass du mich lieb hast...

aber

Der Gatte. Ja .. du mußt es auch so wissen

Man ist nicht immer ... der ?lieb?

$5 \quad$... Die Ehe ist mehr als die Liebe.

Die junge Frau. .. Auch .. in der Freund-

schaft. Freilich freilich.

Der Gatte. Die Ehe ist nicht nur Rausch ...

Und jetzt .. gute Nacht.

10 Die junge Frau. Gute Nacht! 
HSz5 153

Handschriften und Typoskript

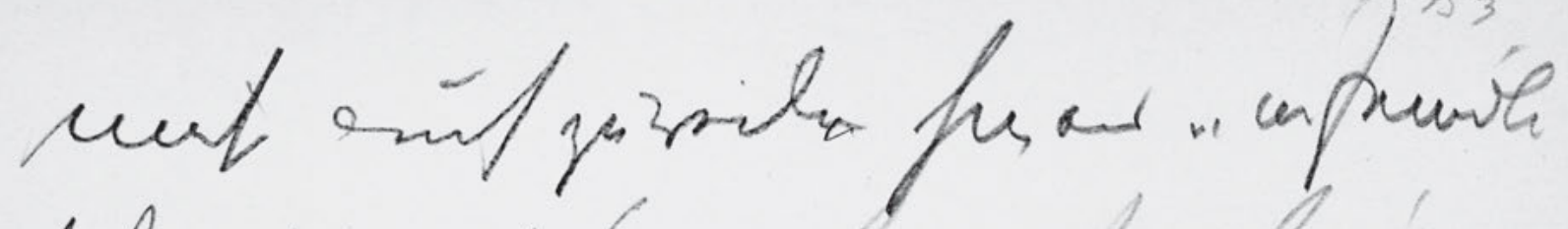

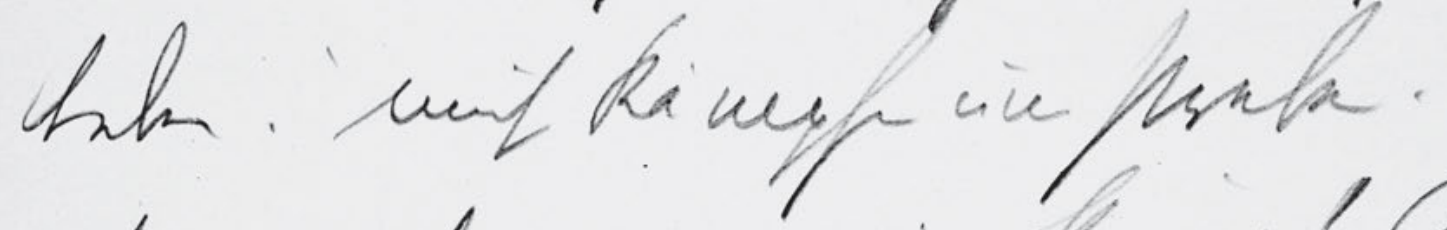
cher nyft wi, urin Heni! Alh batpouignit with ffer ber shats

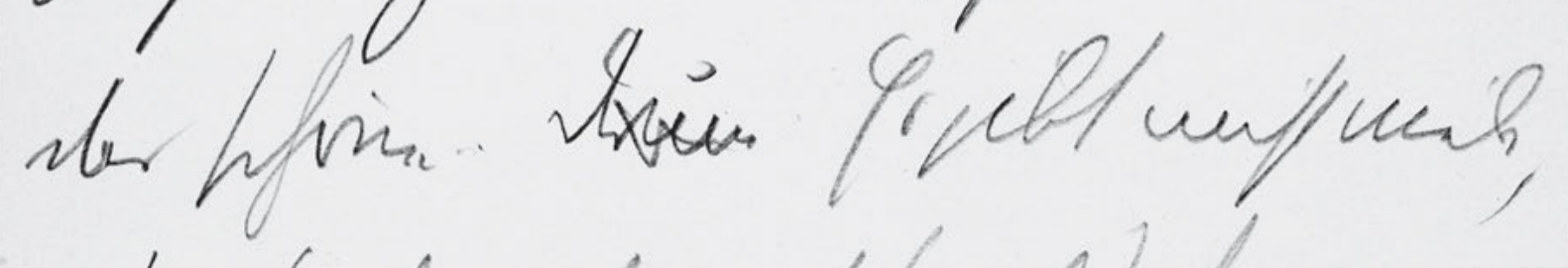

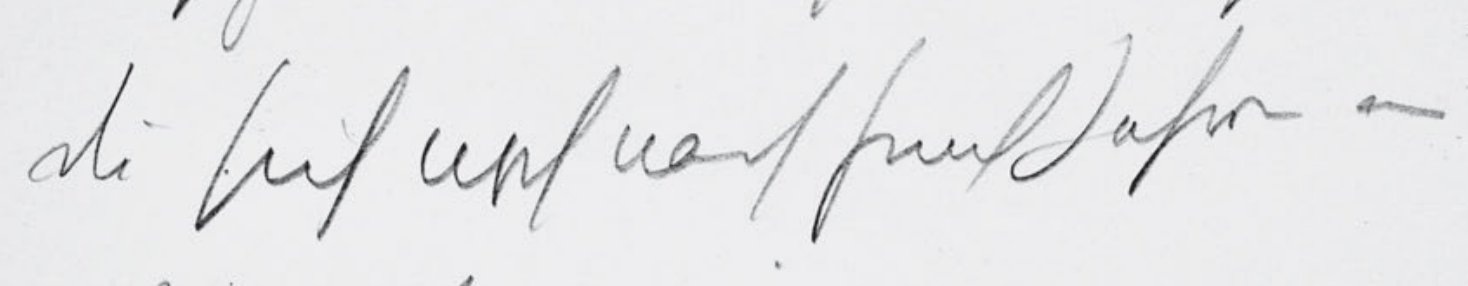
- Mrumbi asuiurm.... the pus tapin.

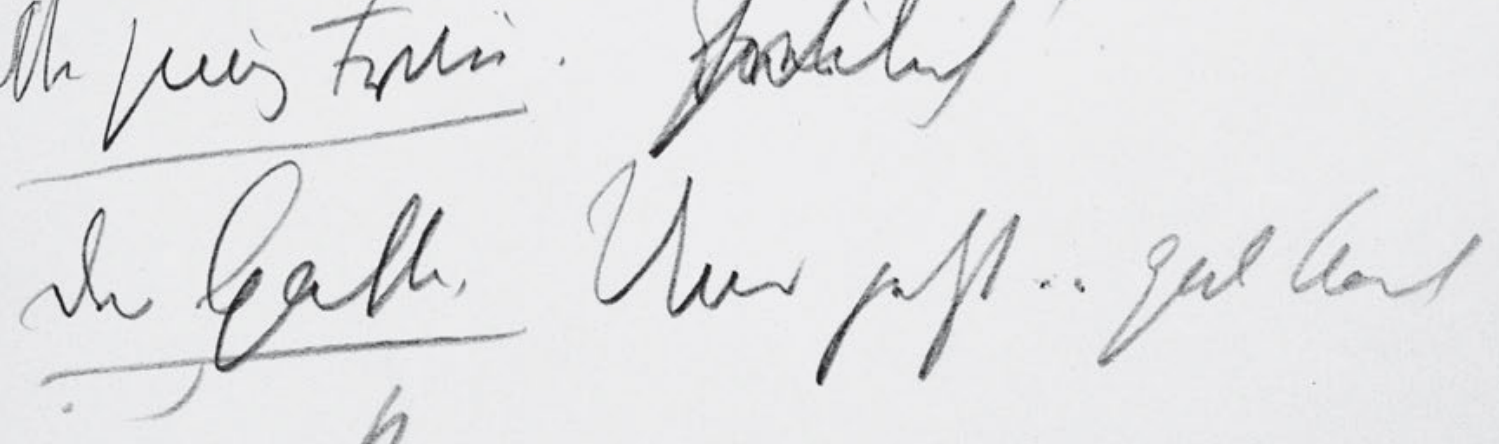
un Rut.

350 
muss auch zuweilen hinaus ... ins feindlic

Leben: muss kämpfen und streben! .

Das vergiss nie, mein Kind! Alles

5 hat seine Zeit . in der Ehe - das ist eben

das schöne .. drum Es gibt nicht viele,

die sich noch nach funf Jahren an

- Venedig erinnern ....

Die jung Frau. ${ }^{\text {Gute }}$ Freilich!

10 Der Gatte. Und jetzt . . gut Nach

mein Kind . . 
HSz5 154

Handschriften und Typoskript

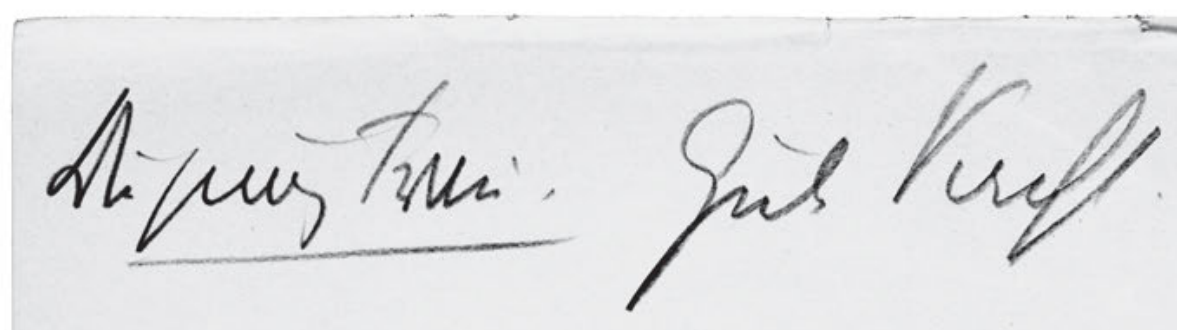

$$
\sqrt{ }
$$

352 
Die jung Frau. Gute Nacht. 
HSz6 155

Handschriften und Typoskript

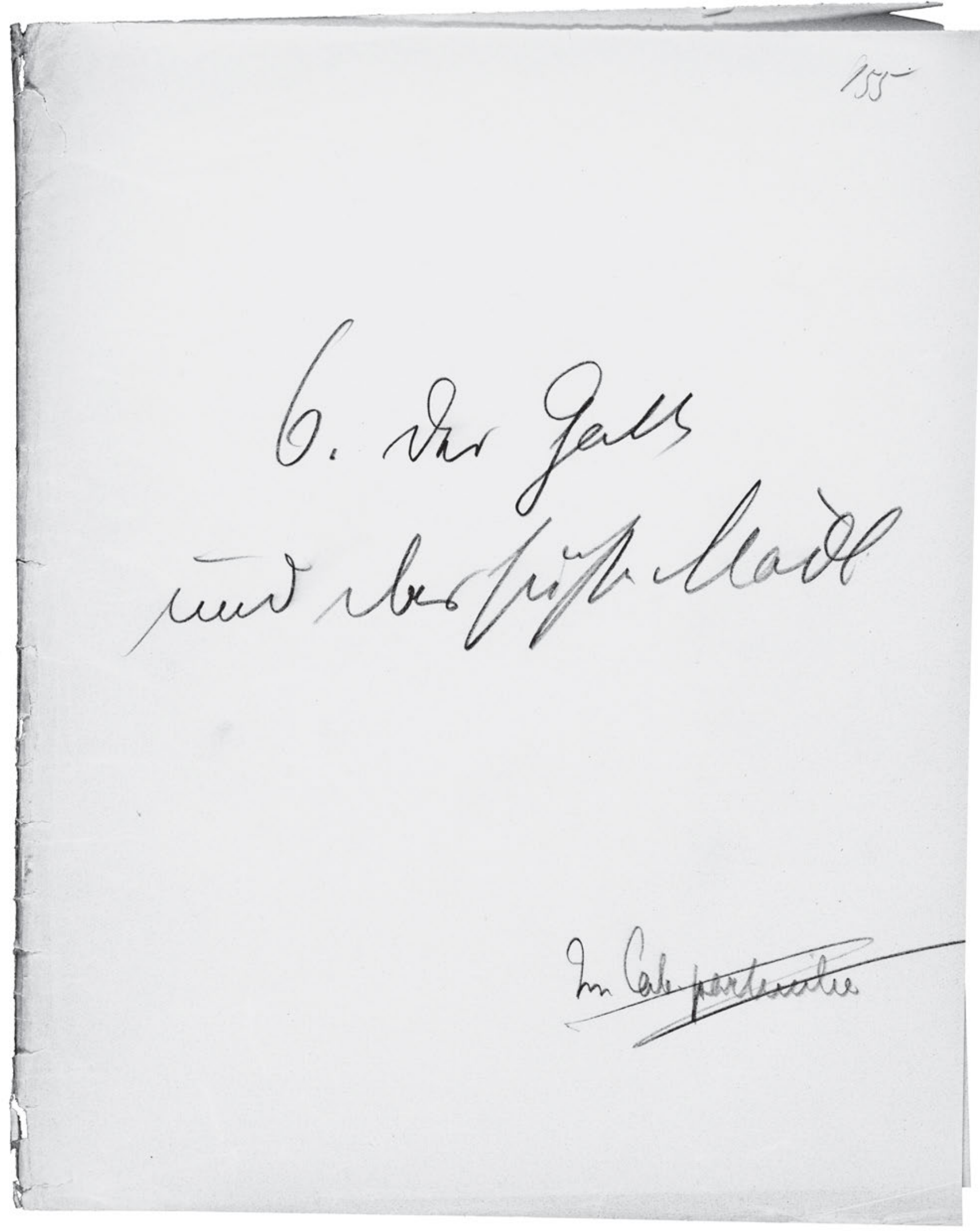

354 
155

\section{Der Gatte}

und das süße Mädl

Im Cab. particutie 
HSz6 156

Handschriften und Typoskript

$10 / 12 \%$

156

Yerpanes. the Gotofas.
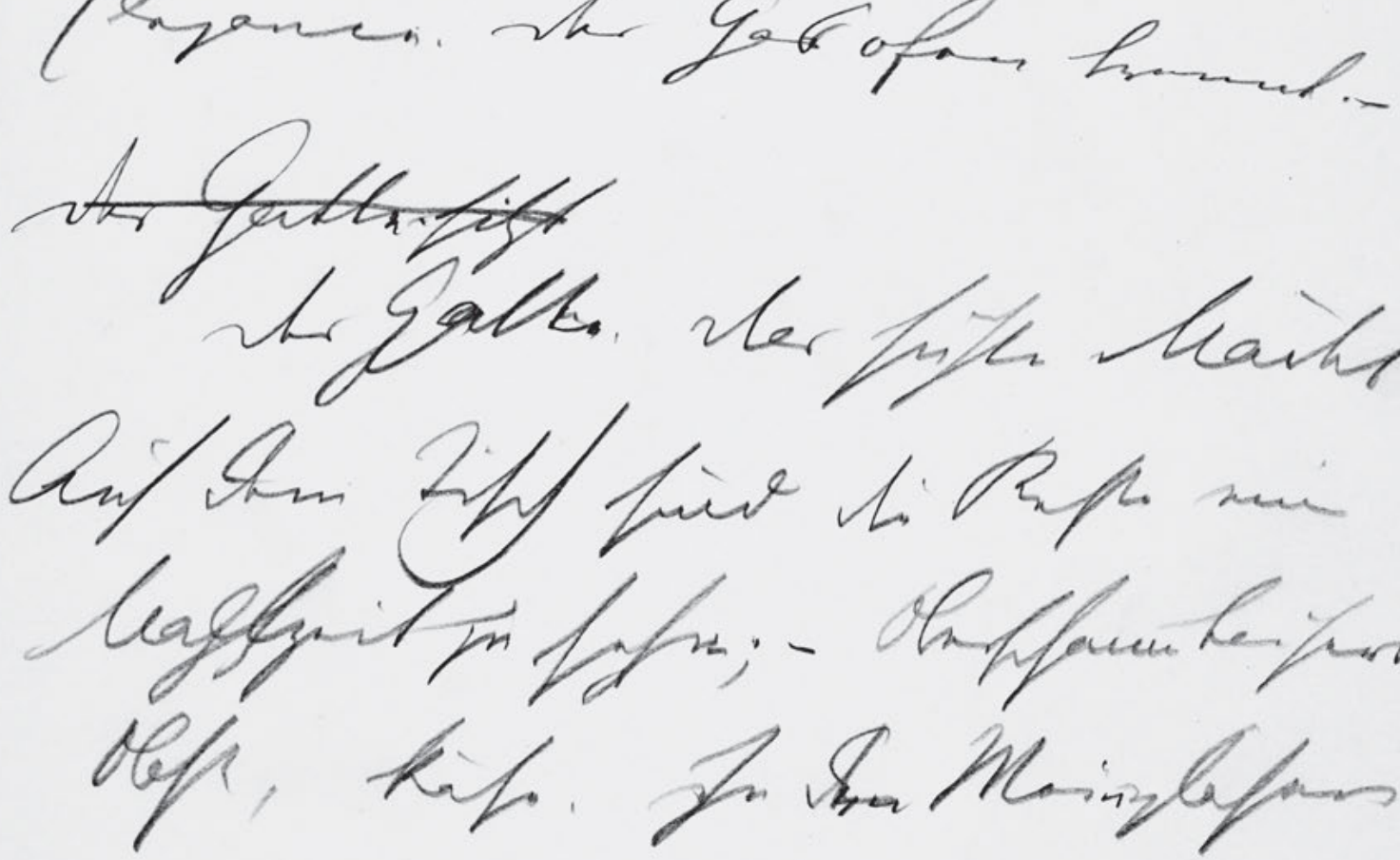

firio Li hape mi

vin nimariffer suniflan Dtove.

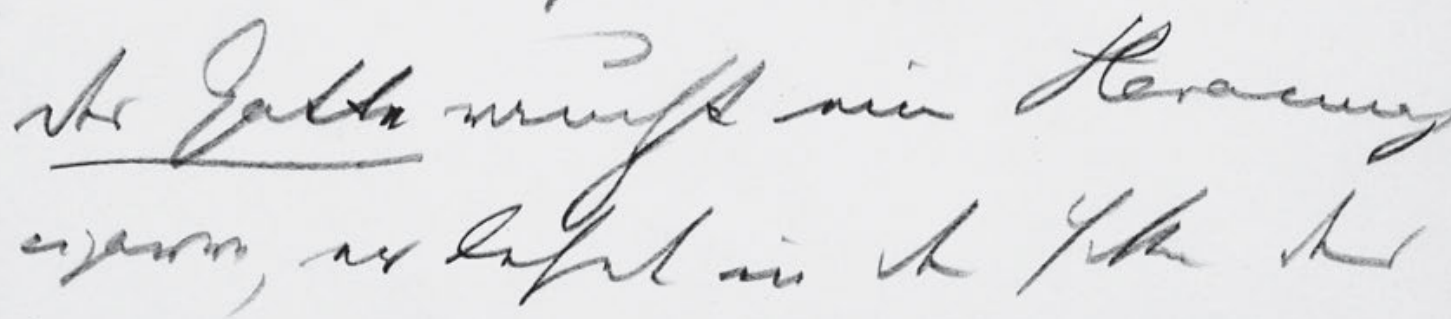
Anurt. En/L

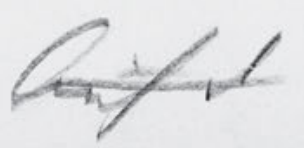

356 
10/1296.

156

Ein Cabinet particulier

im Riedhof. Behaglich, mäßige

Elegance. Der Gasofen brennt. -

${ }_{5}$ Der Gatte sitzt

Der Gatte. Das süße Mädel.

Auf dem Tisch sind die Reste einer

$\mathrm{Ma}^{\text {th }}$ hlzeit zu sehen; - Oberschaumbaisers,

Obst, Käse. ${ }^{i}$ In den Weingläsern

ein ungarischer weißer Wein. -

Der Gatte raucht eine Havannah=

cigarre, er lehnt in der Ecke des

Divans. Auf de Aufd 


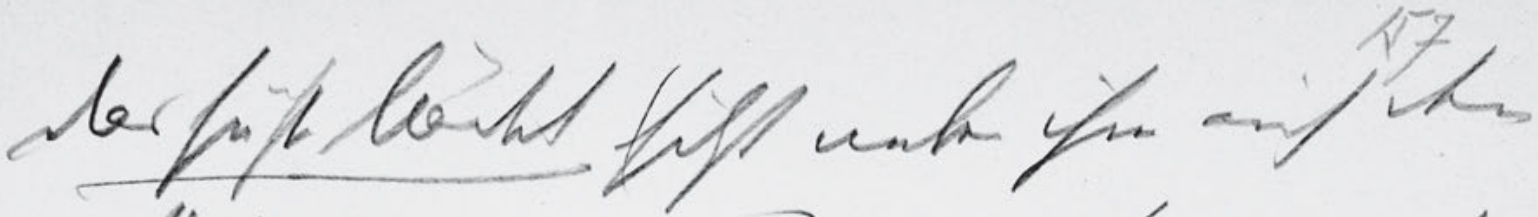

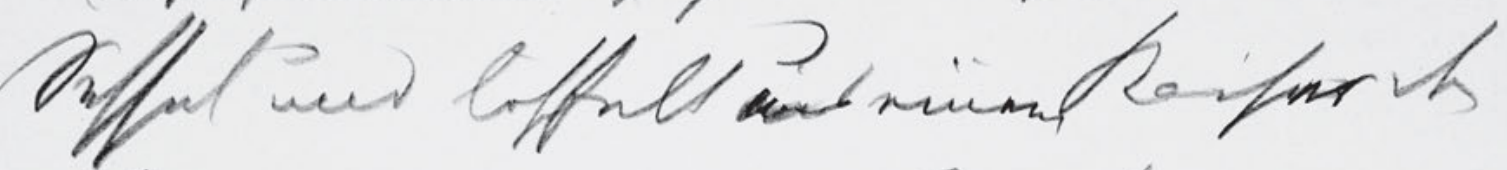
bhalform fromin, in fin thti un

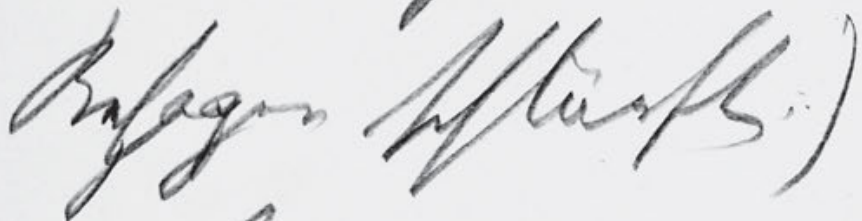

se Gall Prumbir:-

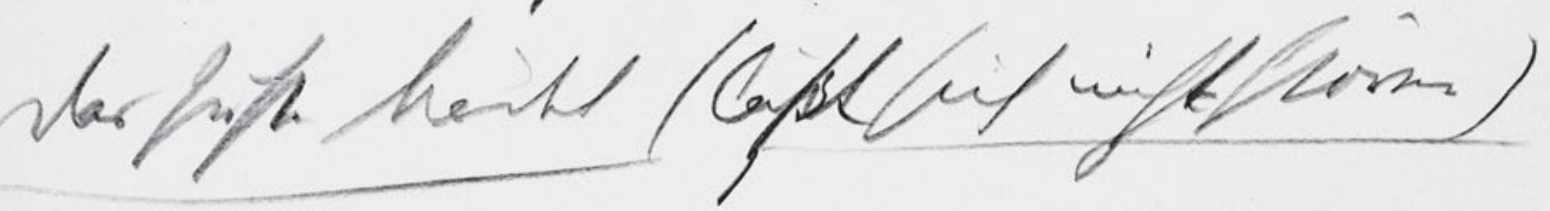
y: -

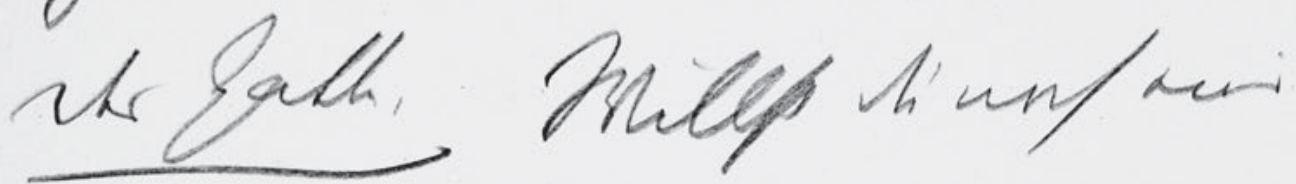

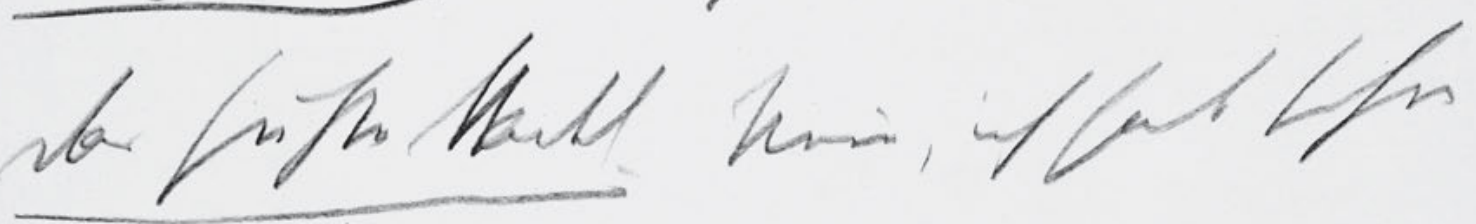

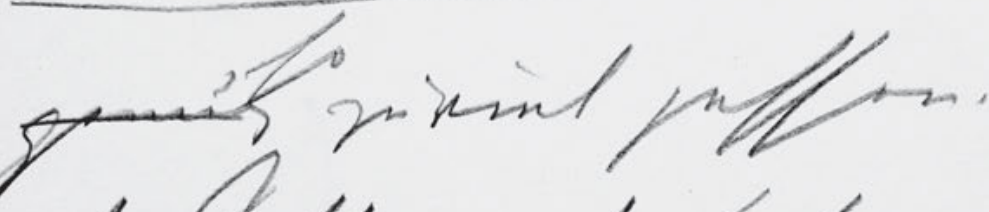

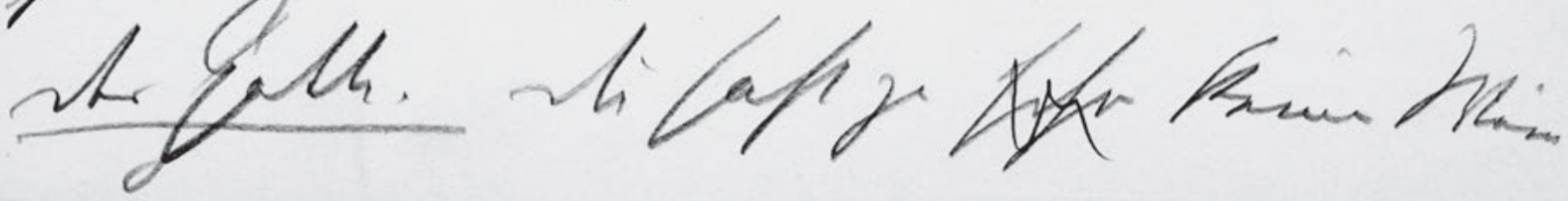




\section{7}

Das süße Mädel (sitzt neben ihm auf dem

Sessel und löffelt aus einem Baiser den

Oberschaum heraus, den sie schlü mit

5 Behagen schlürft . .)

Der Gatte. Schmeckt's? -

Das süße Mädel (läßt sich nicht stören)

$\mathrm{Oh} !-$

Der Gatte. Willst du noch eins.

10 Das süße Madel. Nein, ich hab schon

so

genug $\mathrm{zu}$ viel gessen.

Der Gatte. Du hast ja schon keinen Wein 
HSz6 158

Handschriften und Typoskript

menf.

shofth

(Y) fonth win)

158

mpar hash.

Kain...aher

Ifouin ?,

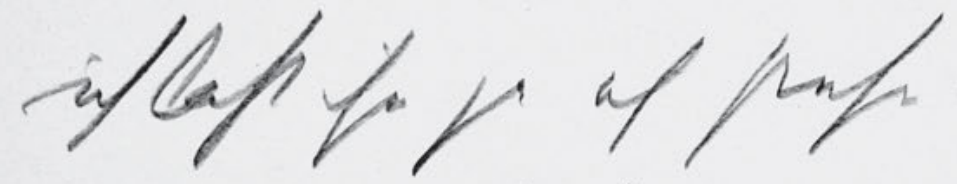

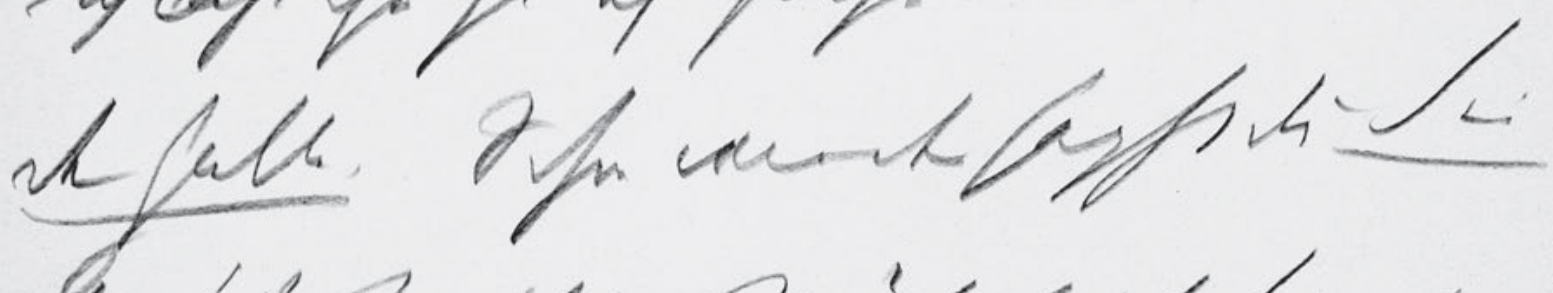

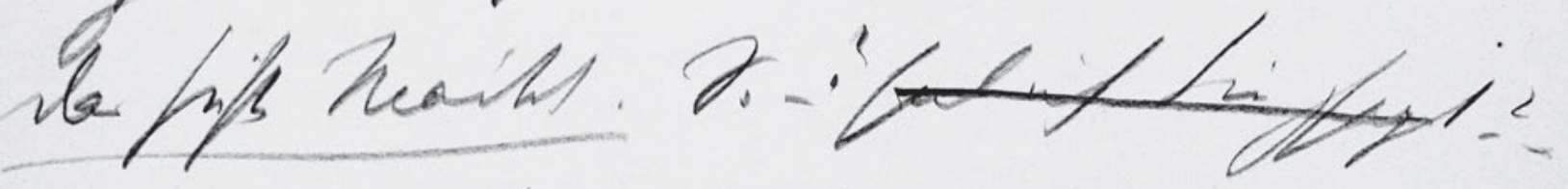

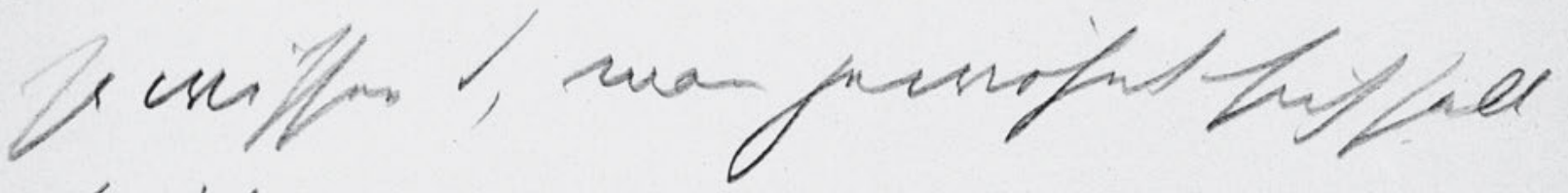

fifurar.

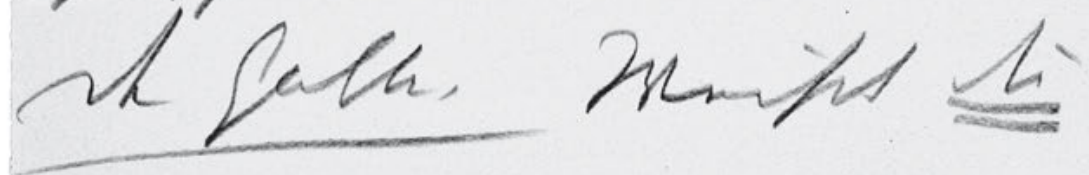

ster finf mente. Mer St:

cEen.
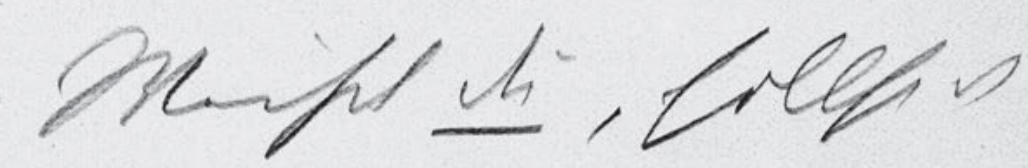

Laym; nift.

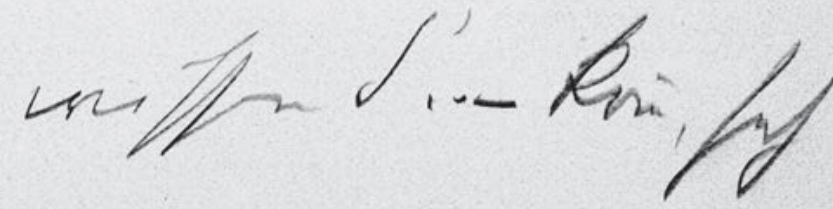

360 


\section{8}

mehr. (Er schenkt ein)

Das süße Mädel. . Nein . . aber schaun 'S, ich laß ihn ja eh stehn.

$5 \quad$ Der Gatte. Schon wieder sagst du Sie

Das süße Mädel. So - ? hab ich Sie gsagt? -

Ja wissen S, man gewöhnt sich halt

so schwer.

Der Gatte. Weißt du

10 Das süß Mädel. Was den̄?

Der Gatte. Weißt du, sollst du

sagen; nicht: wissen S’. . - Kō̄, set $z$ 
HSz6 159

Handschriften und Typoskript

Afpinir..

sis

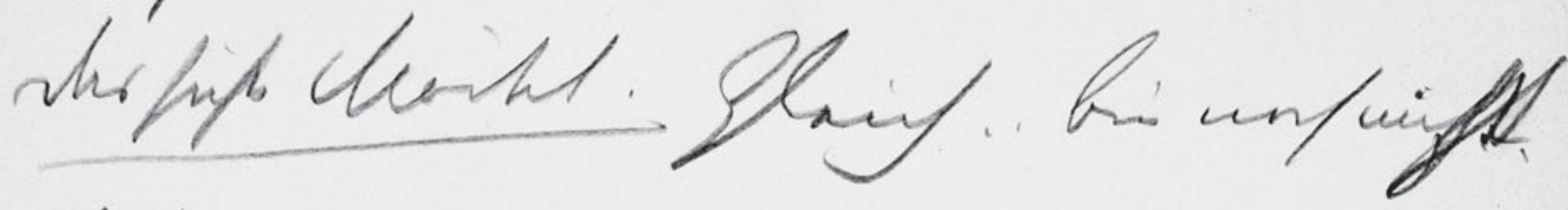

fitig

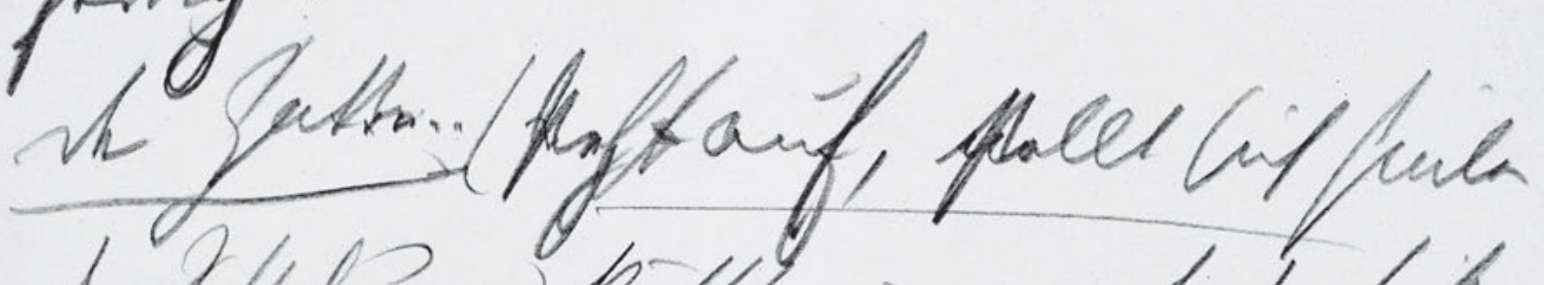

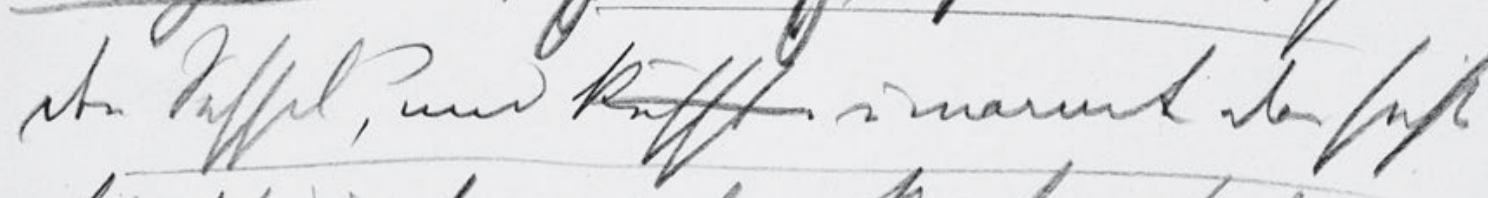

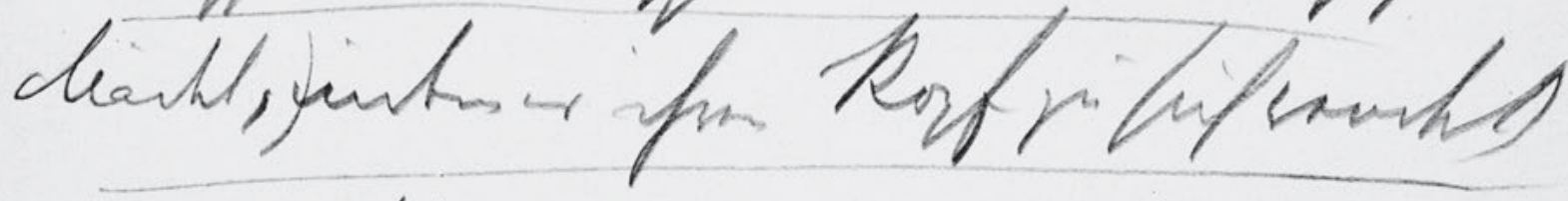

sarfightlaink ho, une iff thi

A fath.

if fah

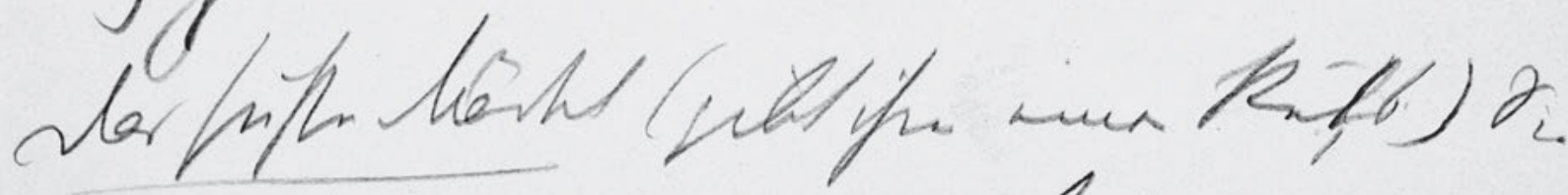

fiur. of peache, sh liff fon thath

362 
159

dich zu mir .. -

Das süße Mädel. Gleich . . bin noch nicht. fertig . .

$5 \quad$ Der Gatte. . (steht auf, ?na? stellt sich hinter

den Sessel, und küsst umarmt das süße

Mädel ${ }^{\ddagger}$, indem er ihren Kopf zu sich wendet)

Das süße Mädel. Na, was ist den̄.

Der Gatte. Gib mir einen Kuss Einen

10 Das süße Mädel Mein M Kuss mocht

ich haben.

Das süße Mädel (gibt ihm einen Kuss) Sie

sind .. oh pardon, du bist so ein kecker 
HSz6 160

Handschriften und Typoskript

cernt/.

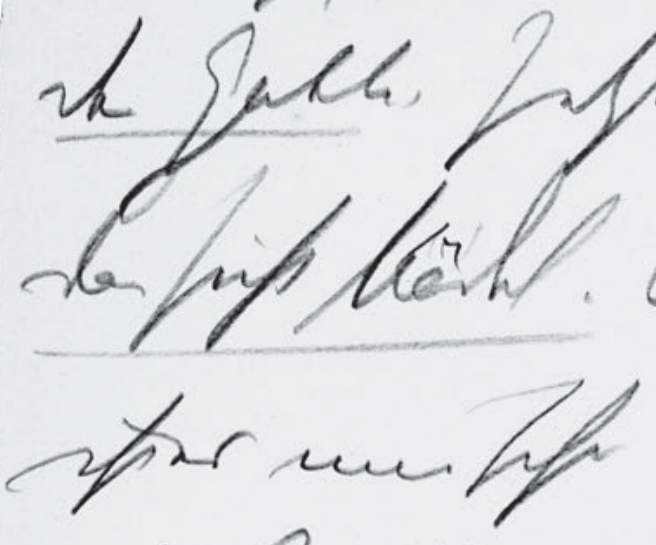

cheffin.
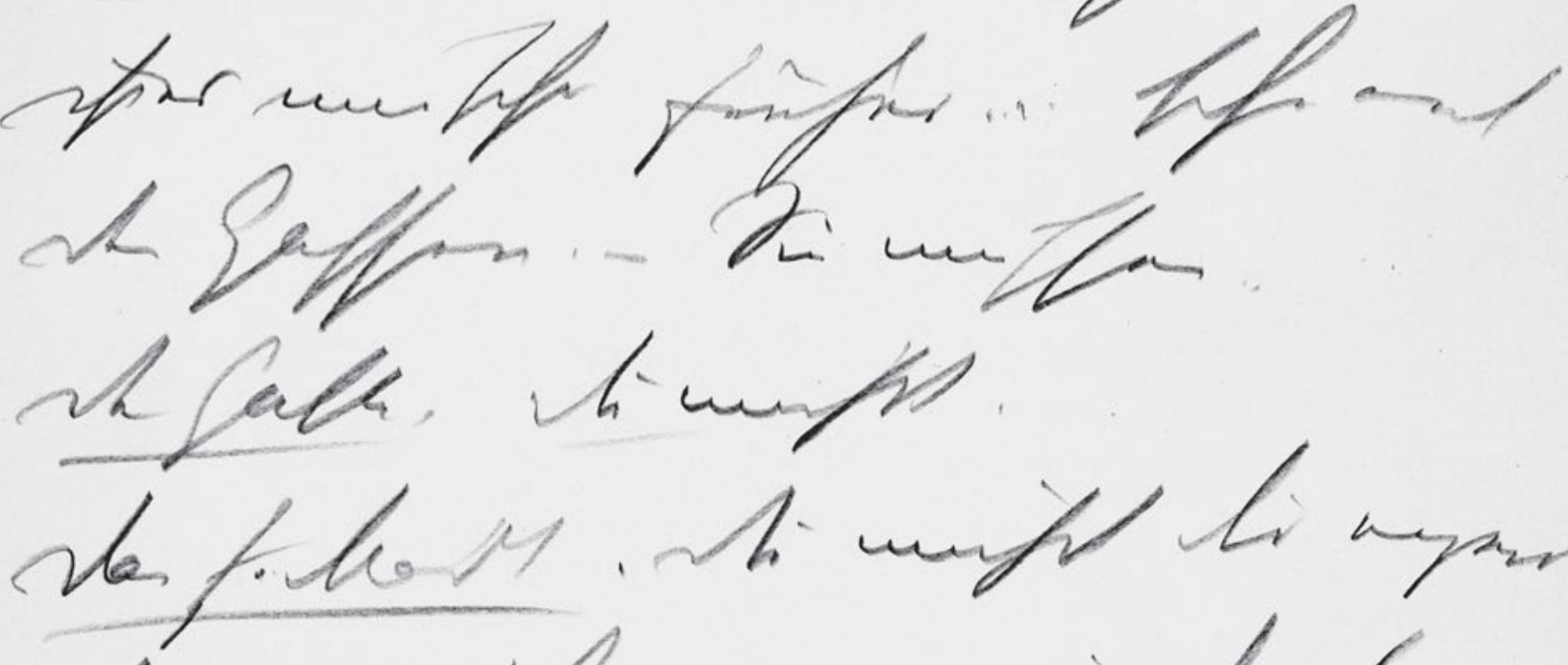

two th

A/unis, acieg/

160 
Mensch.

Der Gatte. Jetzt fällt dir das ein?

Das süß Mädel. Ah nein, eingefalln

5 ist es mir scho früher .... scho auf

der Gassen. - Sie müssen . .

Der Gatte. Du mußt.

Das s. Madl . Du mußt dir eigent

lich was schones von mir denken.

$10 \quad$ Der Gatte. Warum dē̄?

Das süße Mädl. Dass ich gleich von

der Gassen so mit Ihnen in chambre 
HSz6 161

Handschriften und Typoskript

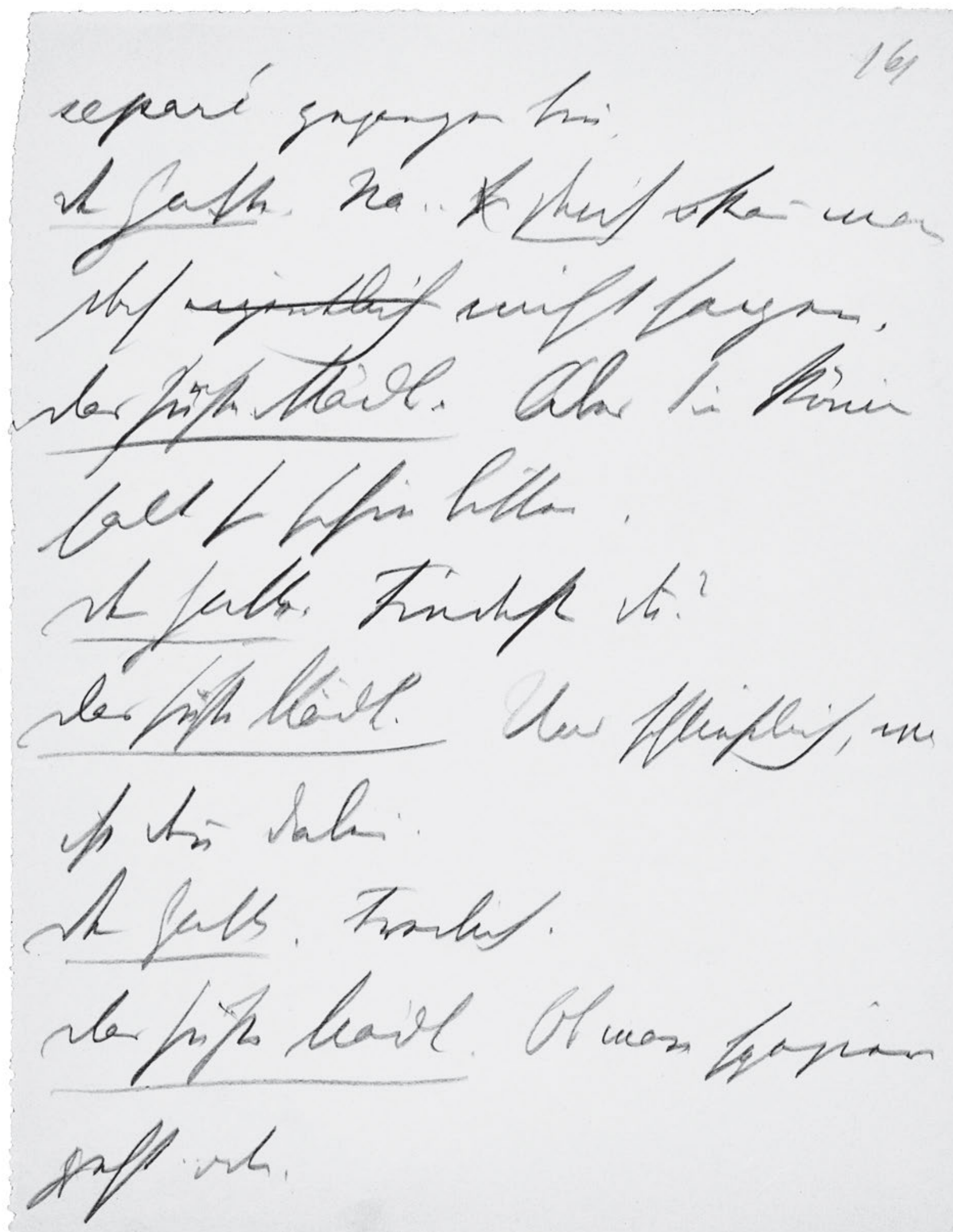

366 
separé gegangen bin.

Der Gatte. $\mathrm{Na} .$. ? $s{ }^{?}$ gleich ${ }^{\text {[?] }} \mathrm{kan̄}$ man

doch eigentlich nicht sagen.

5 Das süße Mädl. . Aber Sie könen

halt so schön bitten.

Der Gatte. Findest du?

Das süße Mädl. Und schließlich, was

ist deñ dabei.

10 Der Gatte. Freilich.

Das süße Mädl. Ob man spaziern

geht . oder, 


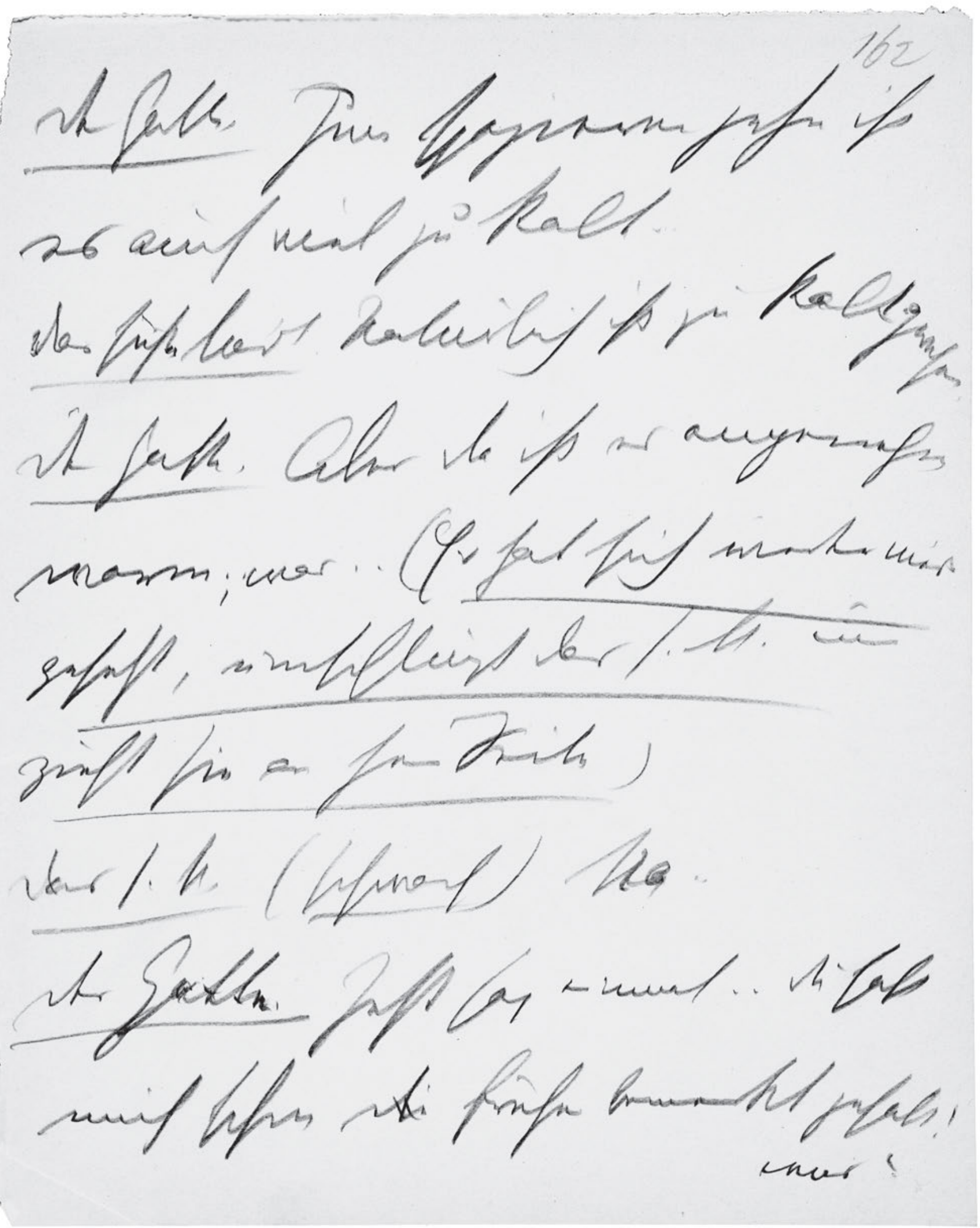


162

Der Gatte. Zum spazieren gehn ist es auch viel zu kalt...

Das süße Mädl. Natürlich ist zu kalt gwesen.

${ }_{5}$ Der Gatte. Aber da ist es angenehm

warm; "was . . (Er hat sich wieder ?nied?

gesetzt, umschlingt das s. M. und

zieht sie an seine Seite)

Das s. M. (schwach) Na ..

10 Der Gatte. Jetzt sag einmal . . du hast

mich schon die früher bemerkt gehabt!

was? 
HSz6 163

Handschriften und Typoskript

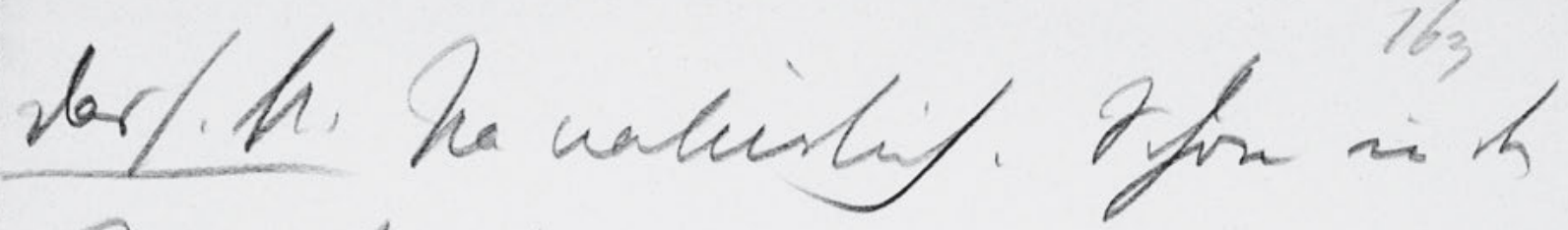

Dimengafuns

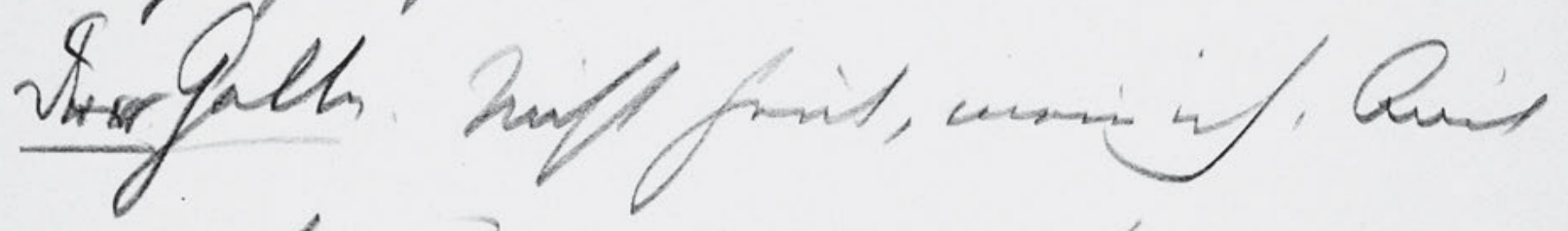

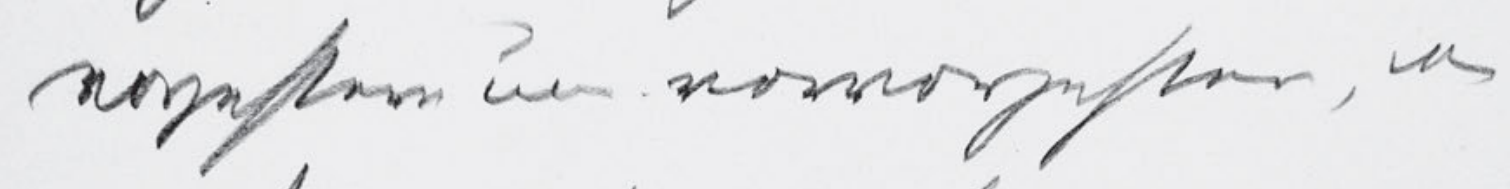

rif hr curfferenge $h$.

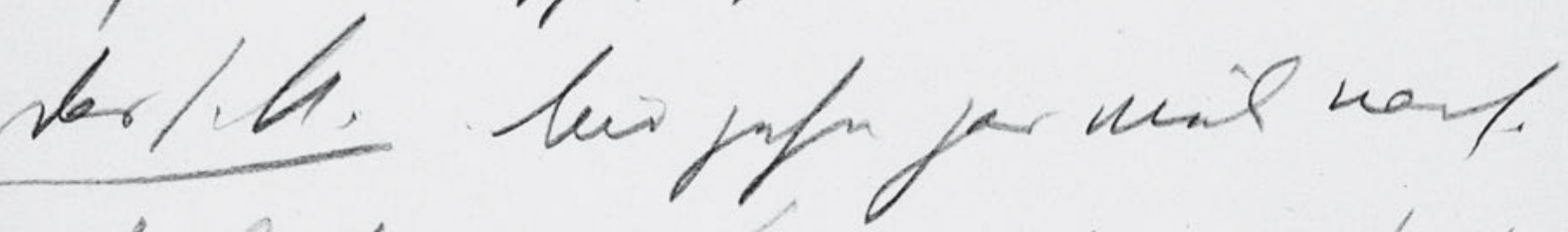

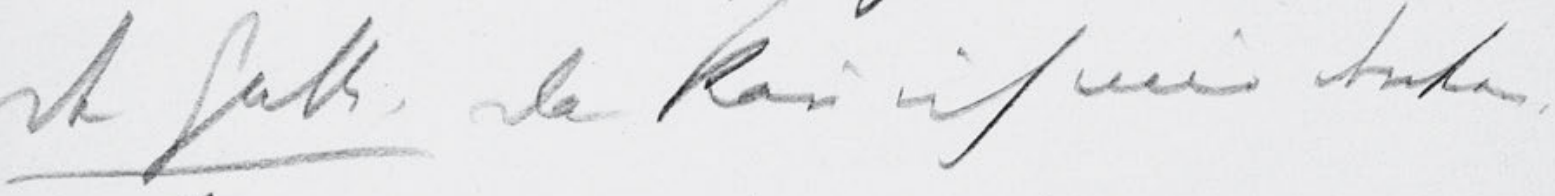

Qher ot siney.

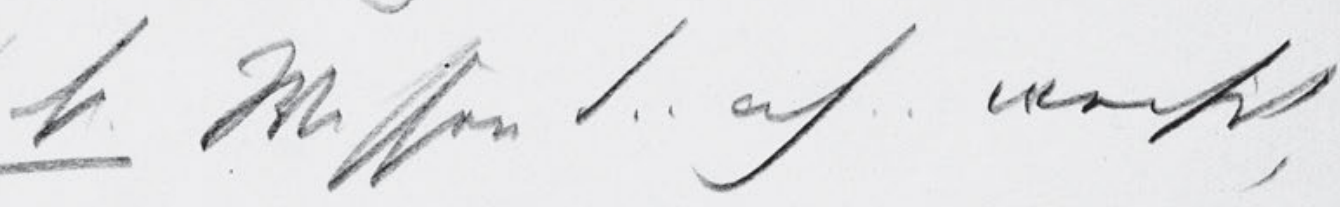

mar wir uribly yeffir ifs:

da if un then ur unimith

370 
163

Das s. M. Na natürlich. Schon in der

Singerstraßen.

Der Gatte. Nicht heut, mein ich. Auch

5

vorgestern und . vorvorgestern, 'wie?

ich dir nachgegangen bin ..

Das s. M. .Mir gehn gar viele nach.

Der Gatte. Das kan̄ ich mir denken.

Aber ob du mich.

10 Das s. M. Wissen S .. ah .. weißt,

was mir neulich passirt ist? .

Da ist mir der Man̄ von meiner Cousin 
HSz6 164

Handschriften und Typoskript

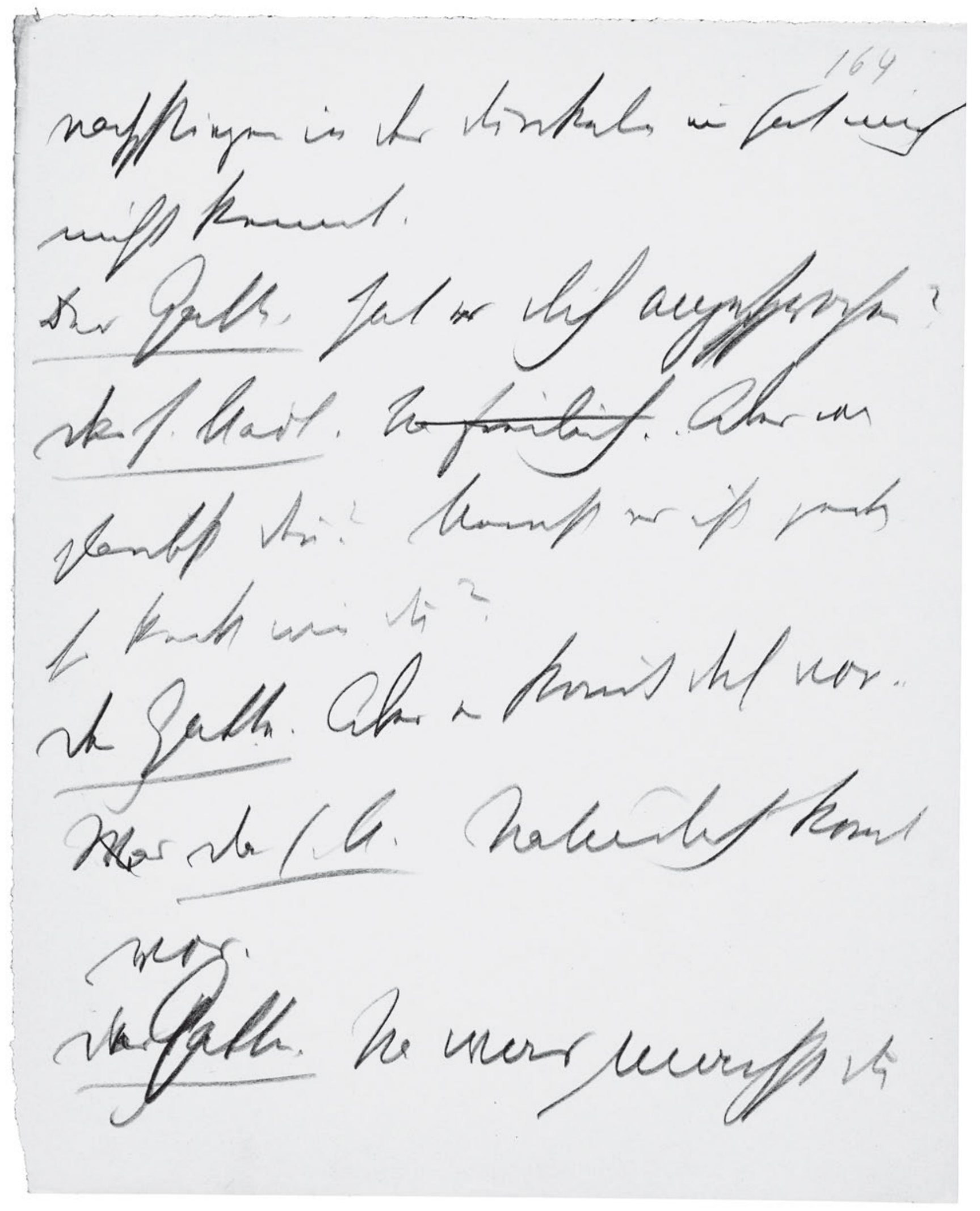

372 
164

nachgstiegen in der Dunkeln un hat mich

nicht kennt.

Der Gatte. Hat ${ }^{\text {[?] }}$ er dich angesprochen?

$5 \quad$ Das s. Mädl. Na freilich. “ Aber was

glaubst den̄? Meinst es ist jeder

so keck wie du?

Der Gatte. Aber es kō̄t doch vor . .

Was Das s M. Natürlich komt

vor.

D ${ }^{\text {as }}$ er Gatte. Na was machst du 
HSz6 165

Handschriften und Typoskript

ch?

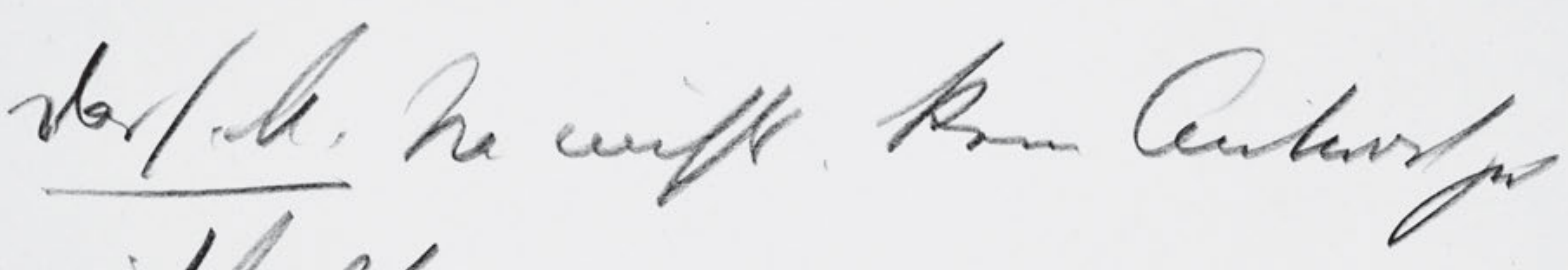
iffalt.

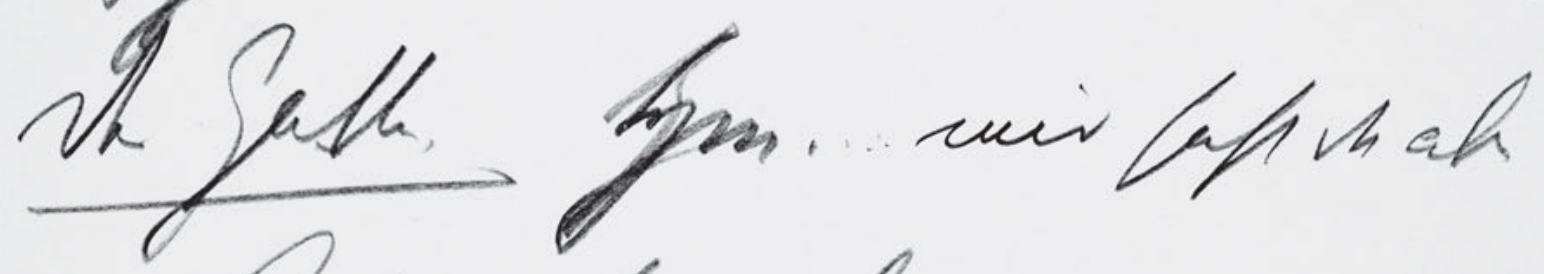

su Anlinat yput

ch/h ha

sefts

Mpunt

ba/ 6 .

of li in un latio

374 


\section{5}

da? -

Das s. M. Na nichts. Keine Antwort geb

ich halt.

${ }_{5}$ Der Gatte. Hm .... . mir hast du aber

eine Antwort gegeben ..

Das s. M. Na, sind S vielleicht bös?

Der Gatte (küsst sie heftig.) . . deine Lippen

schmecken noch nach dem Ober

10 Schaum

Das s M. Oh, die sind von Natur 
HSz6 166

Handschriften und Typoskript

vinirfith.

wargeuth she folm it if mat

subt?

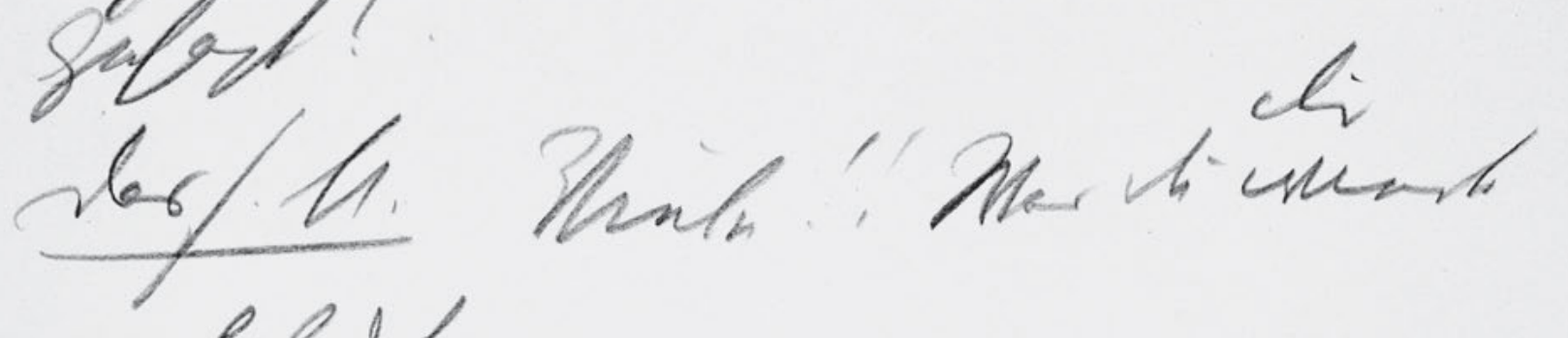
smiles

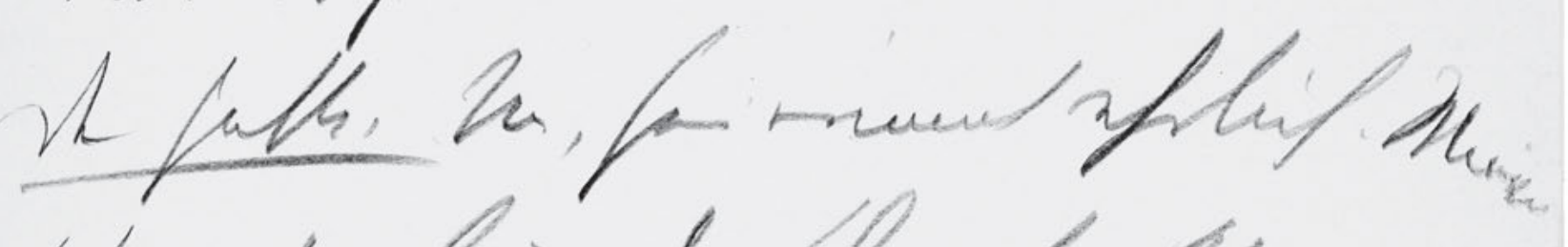

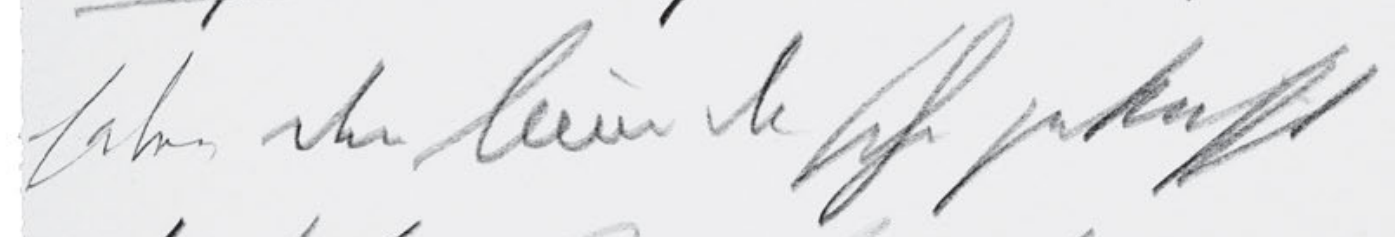
derth the foesfinuy trint neopf wirty ih/ wifflanth masi of tor fay.. sh fall. Dhermo stivift?

376 
166

aus süss.

$D^{\text {as }}$ er ${ }^{\text {s.M }}{ }^{\mathrm{M}}$ Gatte. Das haben dir schon viel gesagt? .

dir

5 Das s. M. Viele!! Was du wieder

einbildst.

Der Gatte. Na, sei einmal ehrlich. Wieviel

haben den Mund da scho geküsst

Das s. M. Was fragst mich den̄? Du

möchst mirs ja doch nicht glauben,

wen̄ ich dirs sag! . .

Der Gatte. Warum den̄ nicht? . . 
HSz6 167

Handschriften und Typoskript

ab/u

has

loy

stats, ho

- nur

a a leffle

nor/

4.

M

shen.

unfle lor form.

nar/. la

$($ rij

um if lonvery de.

mermi mifticif funt?

therbs,

if $\mathrm{fl}$

ha grath.

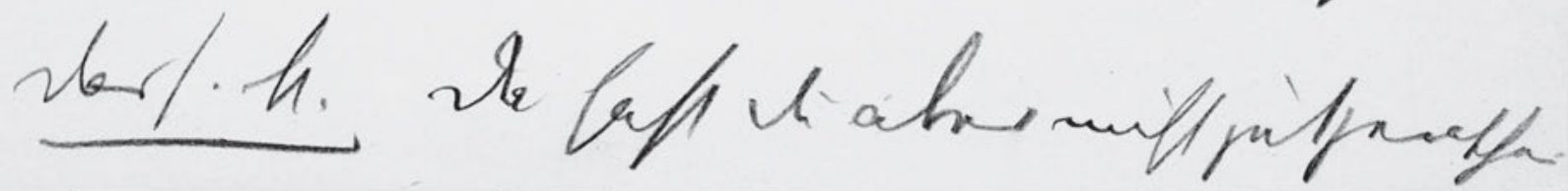

378 


\section{7}

Das s M. Na, rath einmal.

Der Gatte. Na . sagen wir ... aber du darfst nicht bös sein.

5 Das s. M. Warum soll ich den bös sein?

Der Gatte. .. Also, ich schätze . zwanzig

Das s. M. (sich von ihm losmachend) Ja warum nicht gleich hundert? .

10 Der Gatte. Ja, ich hab eben .. gerathen.

Das s. M. Da hast du aber nicht gut gerathen. 
HSz6 168

Handschriften und Typoskript

s all.

eef. 2aft

deftely

Pralie/.

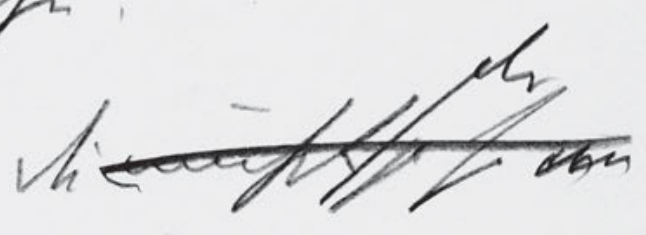

urfucionthon...

Iiv, lifrifar

ch faffon

asurints baft wir this

witgrifts wit the mht repare?
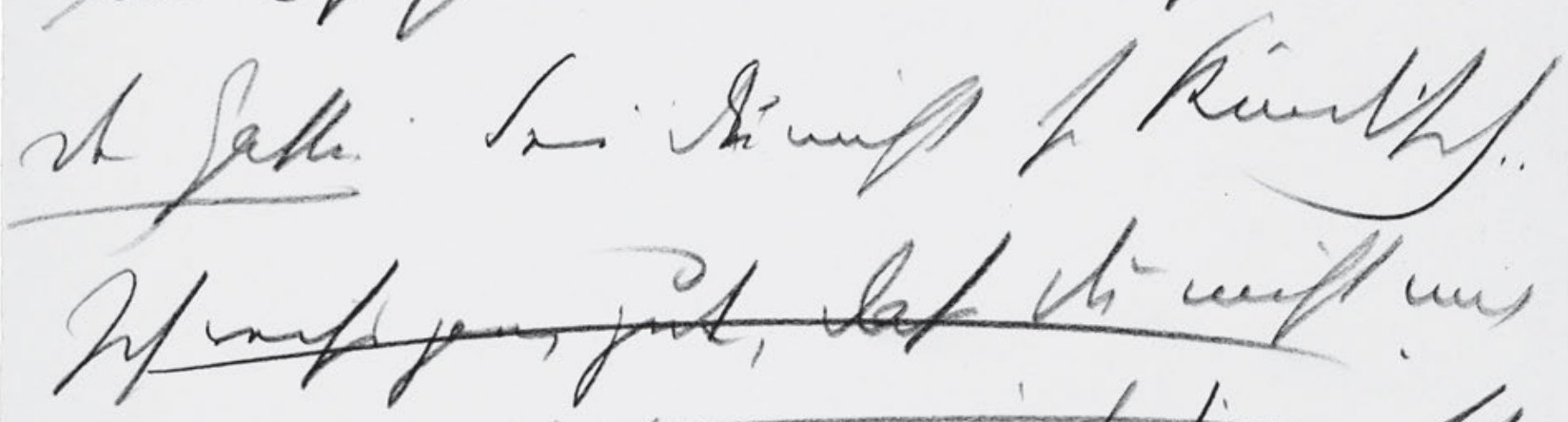

rogumap

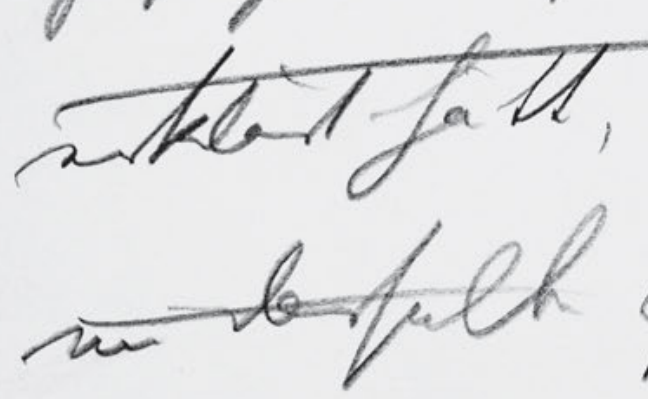

, lafbra

teifleids

un

if Ut me on/s

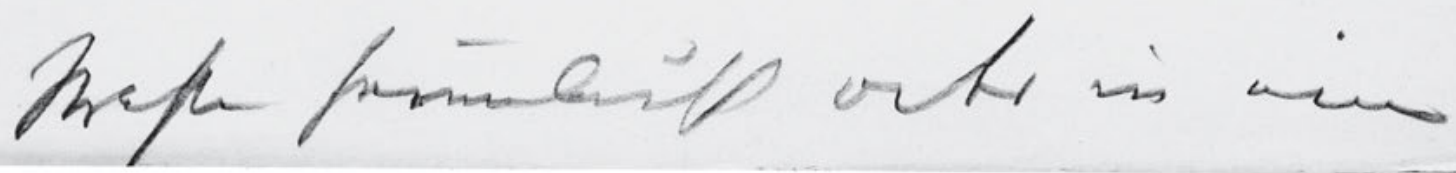

380 
168

Der Gatte. Also .. zehn.

Das s. M. Freilich . . du mußt fa sa ?ir was?

vo mir denken ... Eine, die sich auf

$5 \quad$ der Gassen ?ein?anreden laßt und gleich

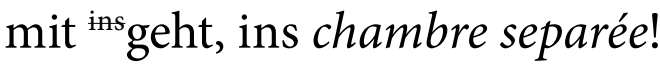

Der Gatte. Sei du nicht so kindisch . .

Ich weiss ganz gut, das du nicht mit

gegangen wärst, wen̄ ich dir nicht

10

erklärt hätt, dass es schließlich ein

un dasselbe ist, ${ }^{\ominus} \mathrm{Ob}$ man auf $\mathrm{d}$

Straßen herumlauft oder in einem 
HSz6 169

Handschriften und Typoskript
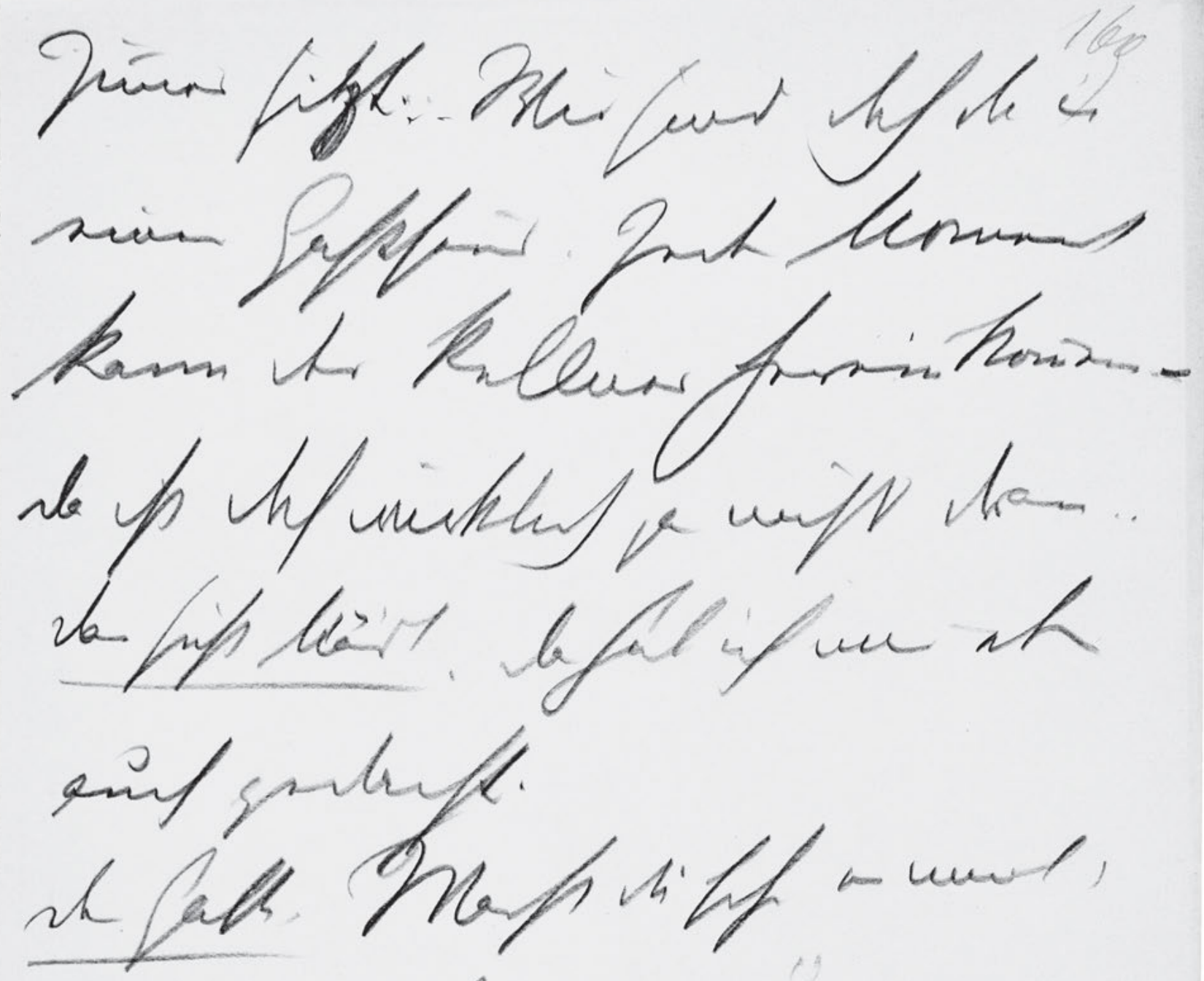

min chemble sefearce.

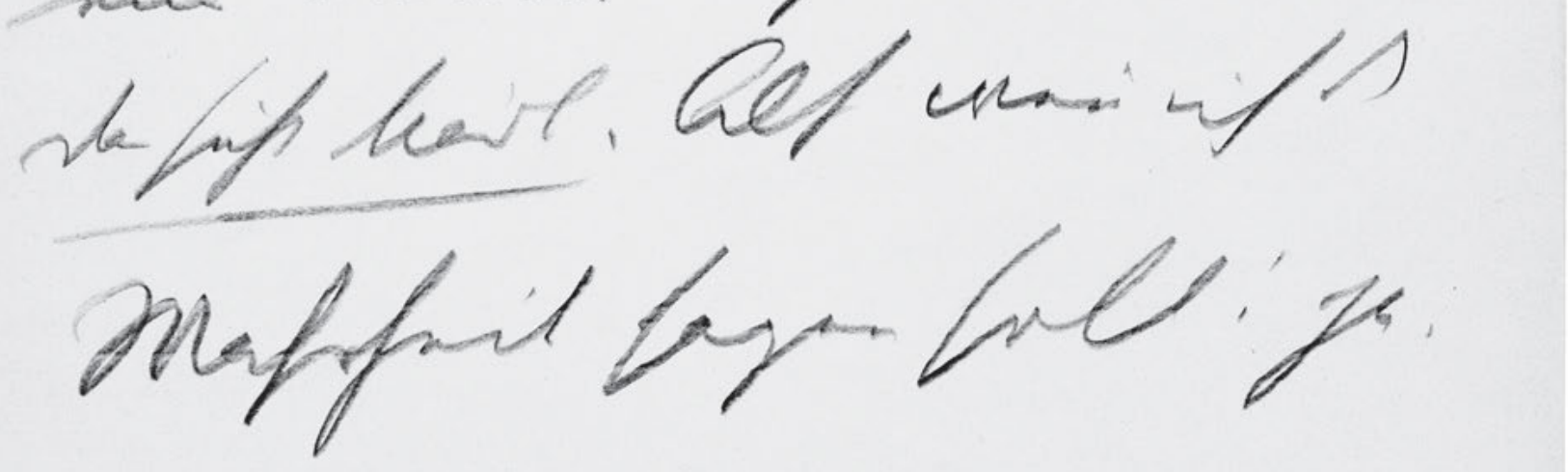

382 
Zimer sitzt .... Wir sind doch da in

einem Gasthaus. Jeden Moment

kann der Kellner herein komen " -

5 Da ist doch wirklich gar nichts dran ..

Das süß Mädl. Das hab ich mir eben

auch gedacht.

Der Gatte. Warst du scho einmal i

einem chambre separéè.

10 Das süß Mädl. Also weñ ich d

Wahrheit sagen soll: ja. 
HSz6 170

Handschriften und Typoskript

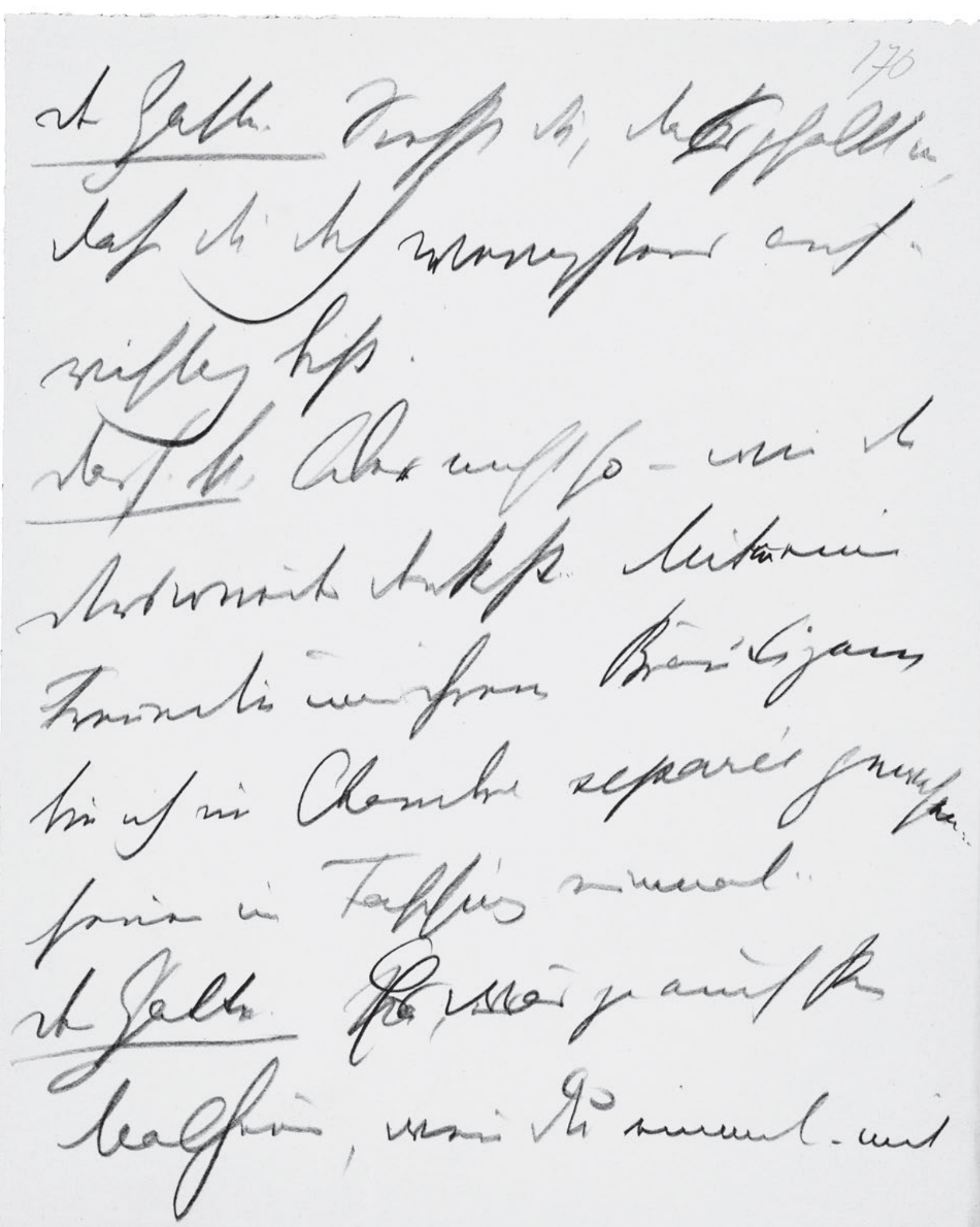

raf

384 
170

Der Gatte. Siehst du, da ${ }^{s s}$ s gfallt m, dass du doch wenigstens aufrichtig bist.

5 Das s. M. Aber nicht so - wie du

dirs wieder denkst . . . Mit ${ }^{[?]}$ meiner

Freundin und ihrem Bräutigam

bin ich im Chambre separée gewesen ...

heuer im Fasching einmal . .

10 Der Gatte. ${ }^{\mathrm{Na} \text {, es }}$ Es wär ja auch kein

Malheur, wen̄ du einmal - mit 
HSz6 171

Handschriften und Typoskript

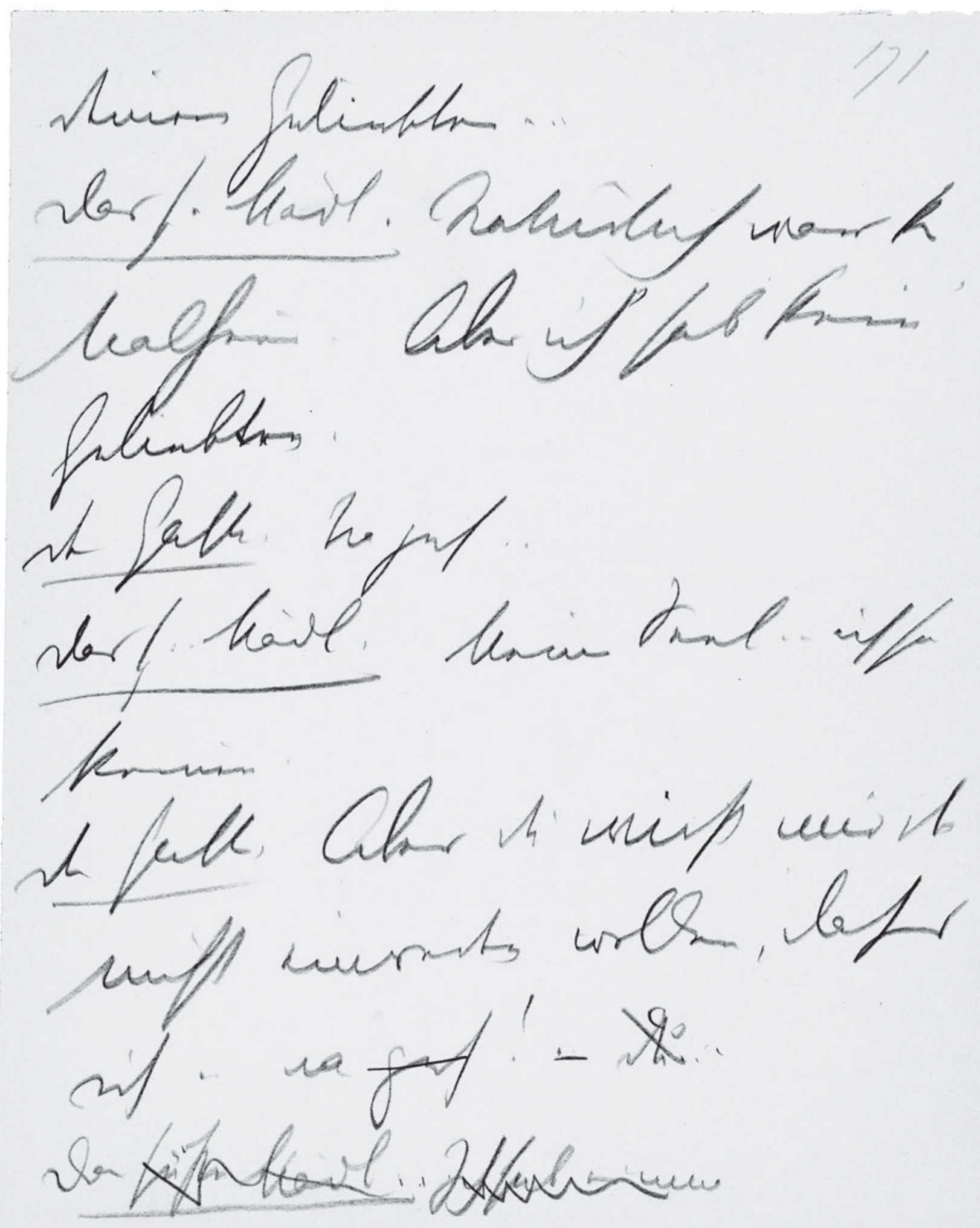

386 
171

deinem Geliebten ...

Das s. Mädl. Natürlich wars kei

Malheur. Aber ich hab kein'

5 Geliebten.

Der Gatte. Na geh . .

Das s. . Mädl. Meiner Seel . . ich ha

keinen.

Der Gatte. Aber du wirst mir do

10 nicht einreden wollen, dass

ich . . na geh! '- Du. . .

Das süße Mädl . . Ich hab ?einma? 
HSz6 172

Handschriften und Typoskript

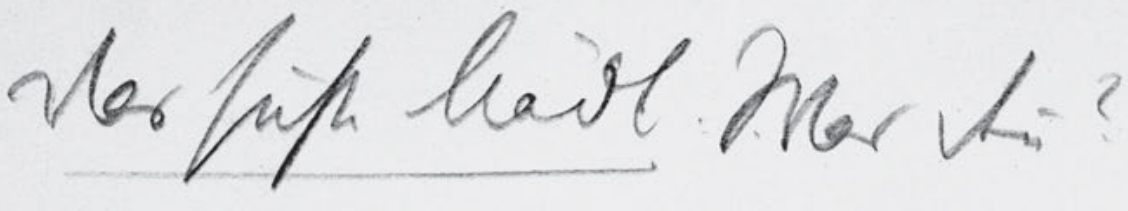

Rrimen

Ipra fwit anf at mi falks

Tefor.

I Gath

Uner whar wawn tam ti?

sar

af

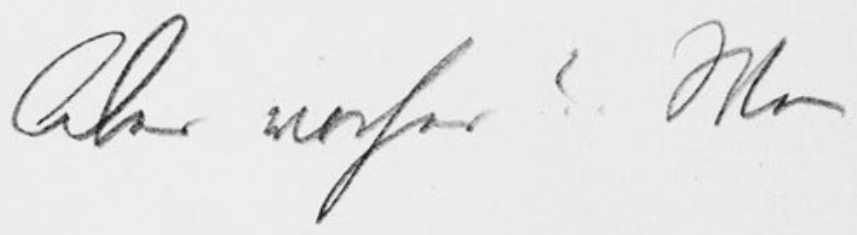

mourt tis?

sariph beint

Ma jur

uffos

2

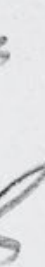


172

Das süße Mädl . 'Was deñ? . Ich hab halt

keinen .. schon seit mehr als eine halben Jahr ....

$5 \quad$ Der Gatte. . Und wer waren d?e?nn die? . .

Das' Ah so ... Aber vorher?. Wer

wars deñ? -

Das süß Mädel . Was sind S deñ gar

so neugierig.

10 Der Gatte. Ich bin neugierig, wei

ich dich lieb hab! 
HSz6 173

Handschriften und Typoskript

borfift bint.

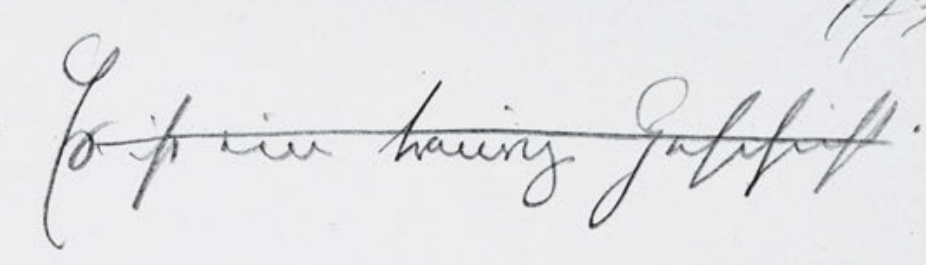

2\%'rnaf: -

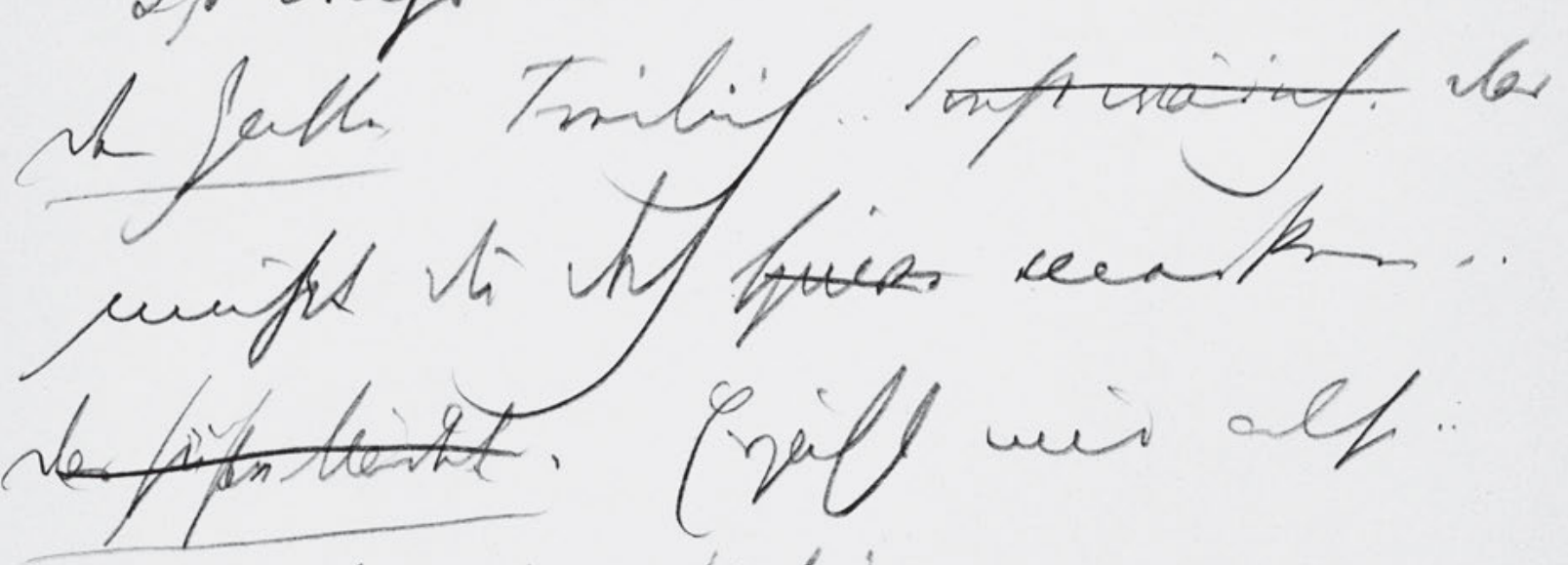

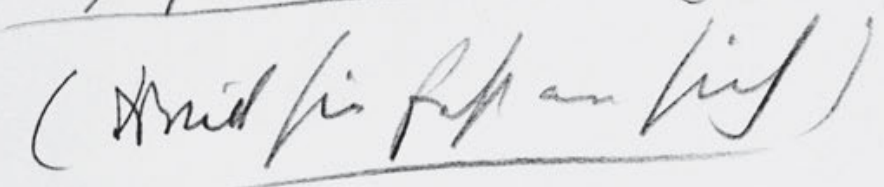

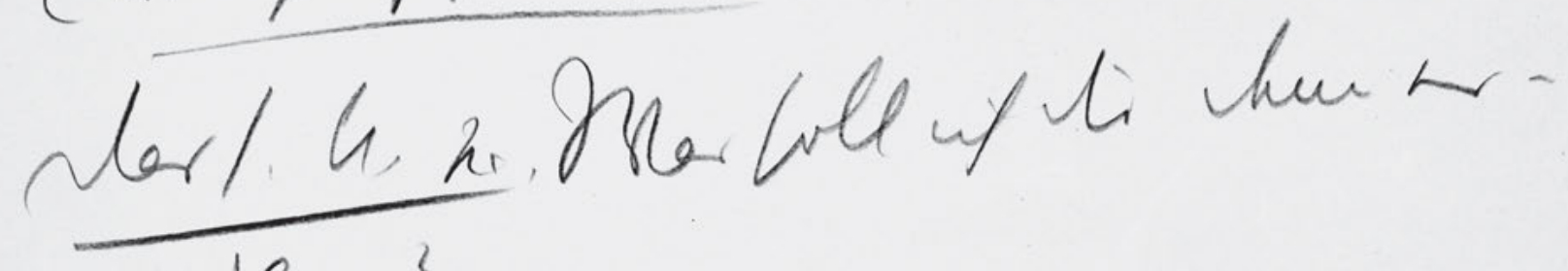

sfen?

s uth zo bop lif lany

niof of sulf

390 


\section{3}

Das süße Mädel . Es ist eine traurige Geschicht.

I'ss' wahr? -

Der Gatte. Freilich .. Sonst wär ich. Das

5 mußt du doch spüren merken - .

Das süße Mädel. Erzähl mir also . .

(Drück sie fest an sich)

Das s. M. ?Na?, Was soll ich dir denn er-

zählen?

10 Der Gatte. So laß dich $\mathrm{d}^{[?]}$ och nicht so

lang bitten .. Wer's gewesen .

möcht ich wissen. 
HSz6 174

Handschriften und Typoskript

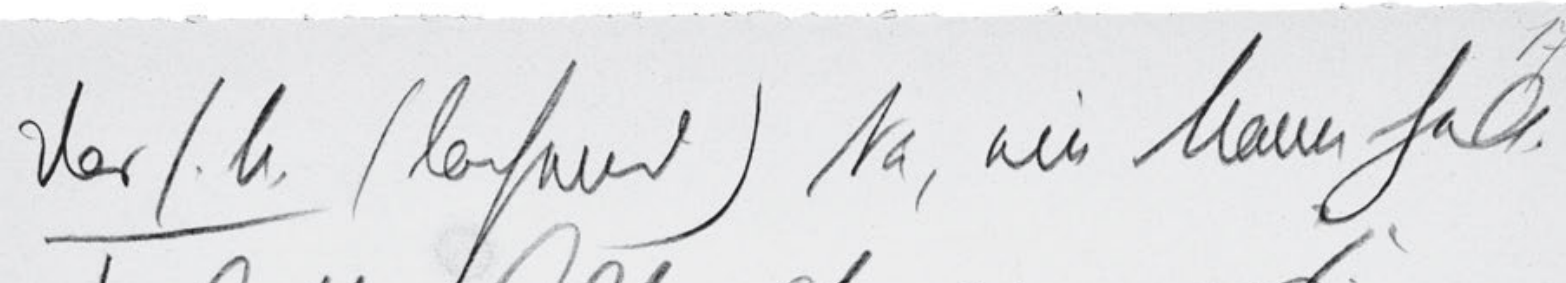
mor fall Wof alf - wa wres.'

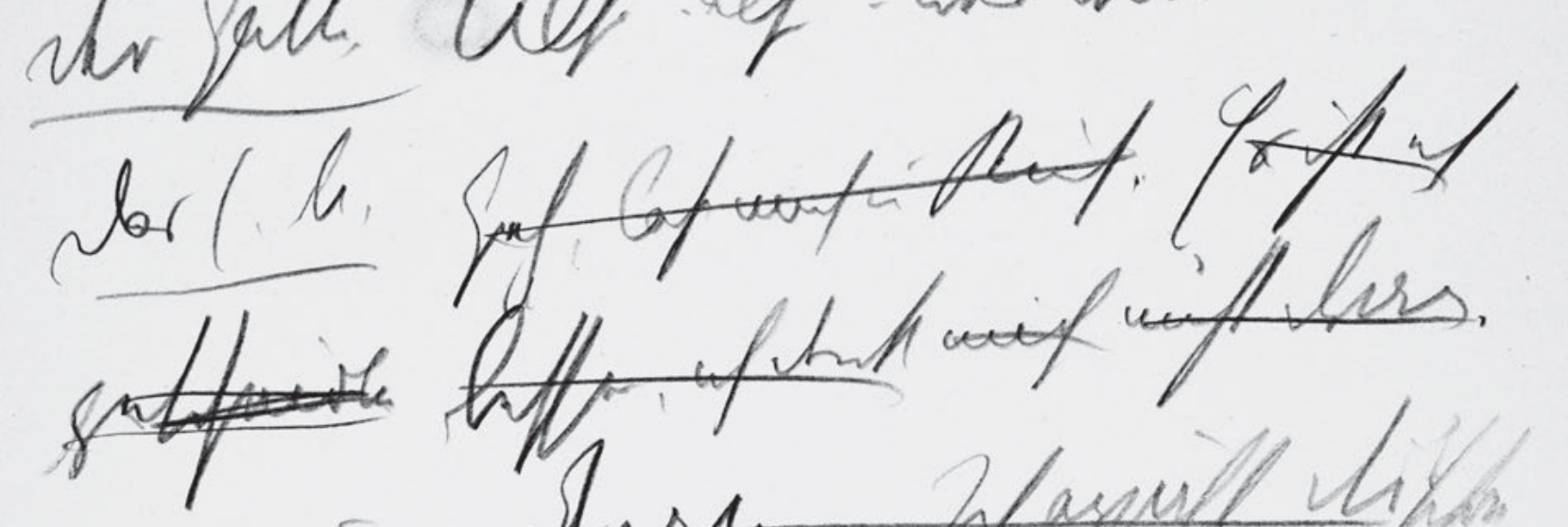

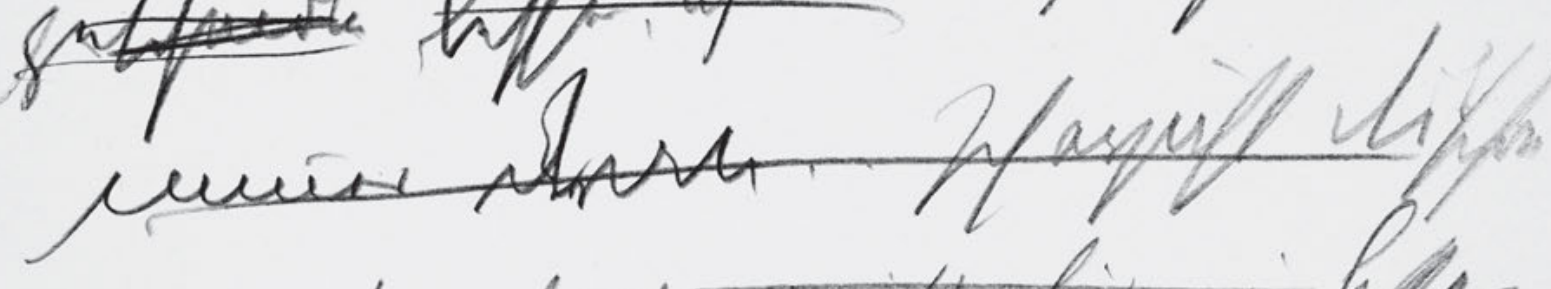

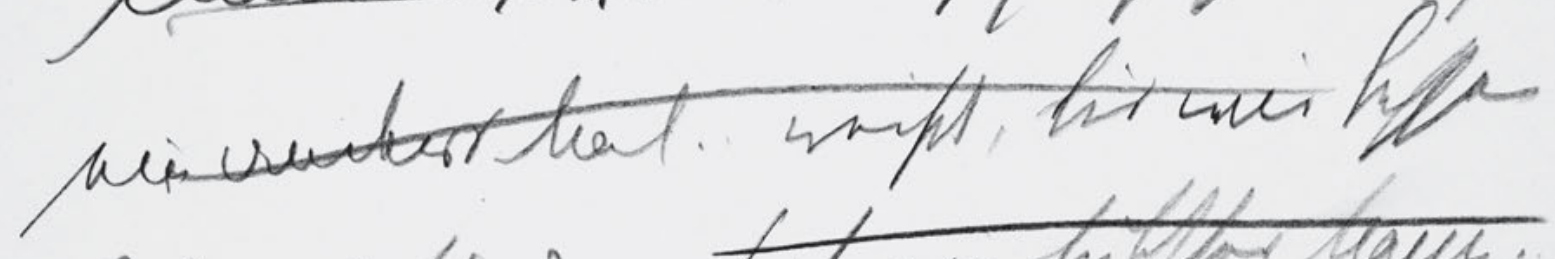

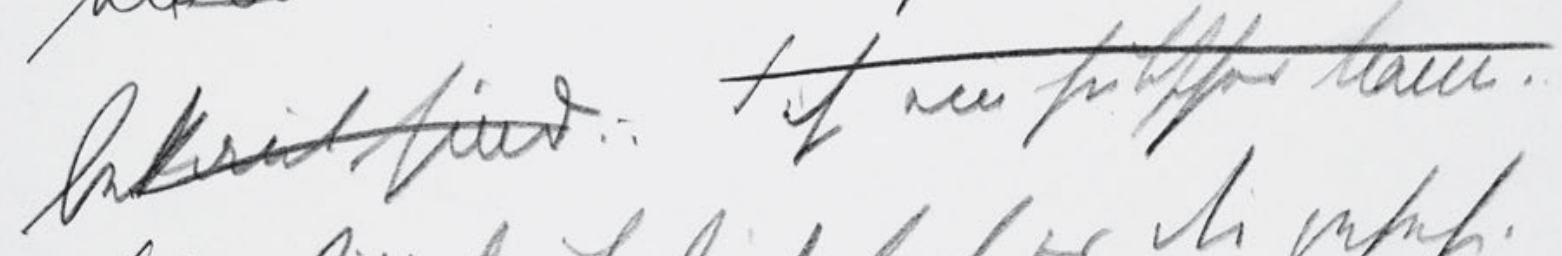

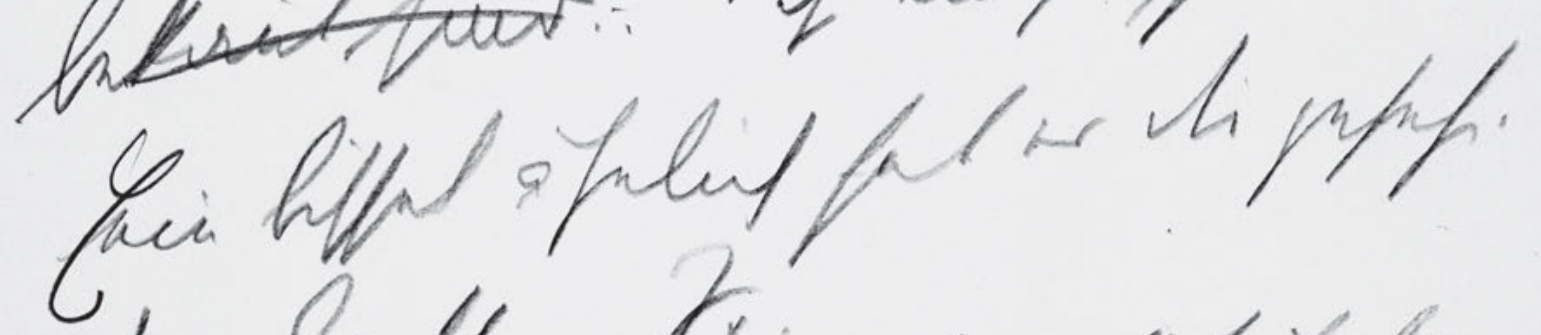
der fals po

vert. L.

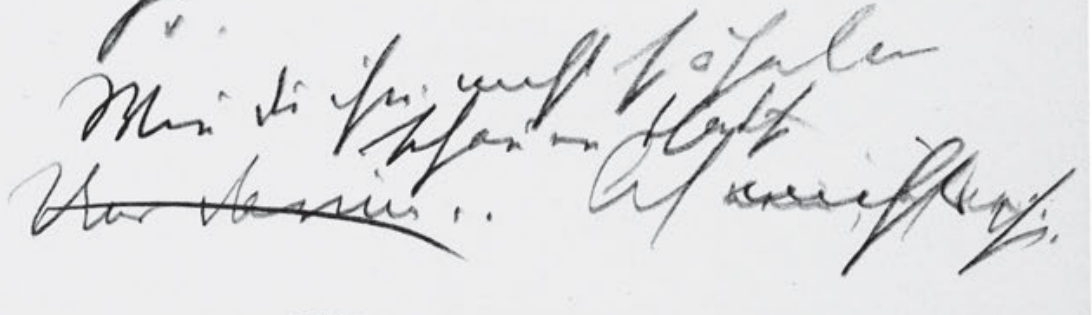

at fult. Merift Darme ? Ner naw Jan ?

392 


\section{4}

Das s. M. (lachend) Na, ein Mann halt.

Der Gatte. Also . also - wer war's?

Das s. M. Geh, laß mich in Ruh . . Es ist eh

5 gescheidte besser, ich denk mich nicht dran.

nim̄er dran . . Ich erzähl dir's schon

ein anders $\mathrm{Mal}$.. weißt, bis wir besser

bekan̄t sind ... S ist ein hübscher Mann ..

${ }^{e}$ Ein bissel ähnlich hat er dir gesehn.

$10 \quad$ Der Gatte. So.

Weñ du ihm nicht so ähnlich

schauen thätst

Das s. . M. Und darum. . Ah nein, ich? ?ve? nichts ist.

Der Gatte. Was ist darum? .

Was wär dañ - ? 
HSz6 175

Handschriften und Typoskript
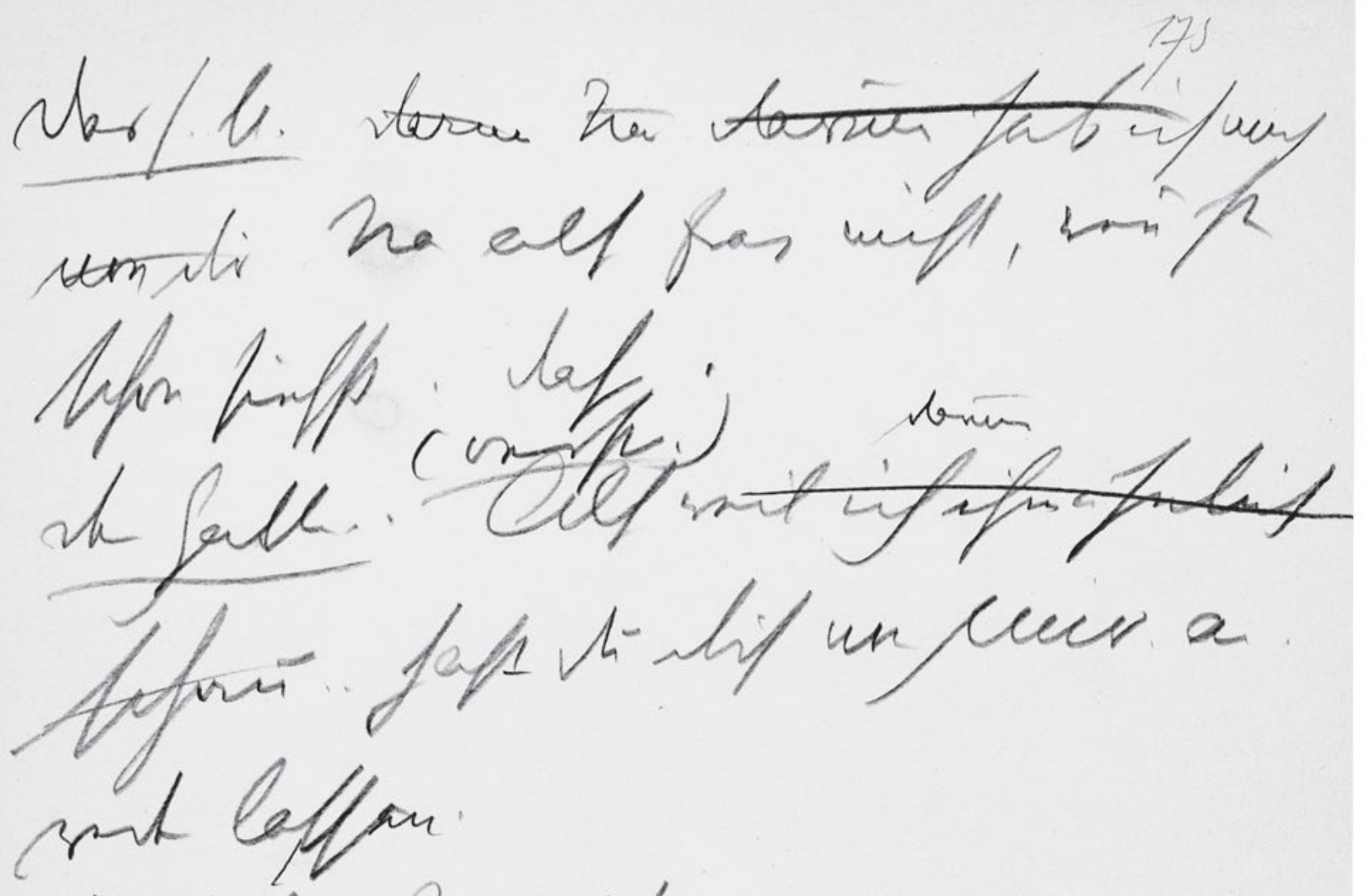

ver/b. ha alfja.

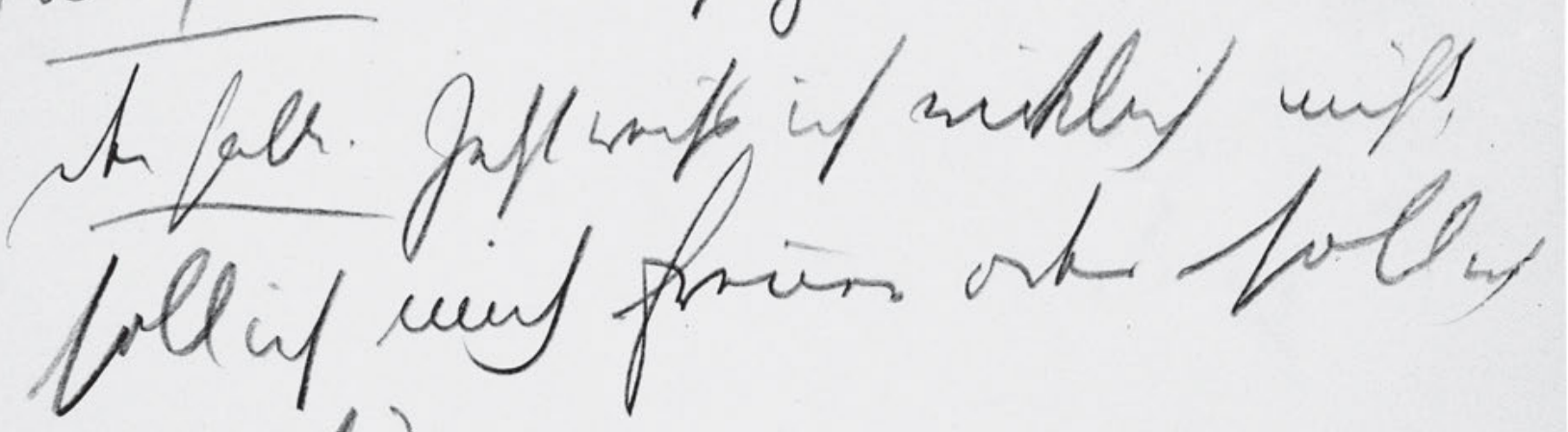
benif aryesm

lerl.h. he if on tiver

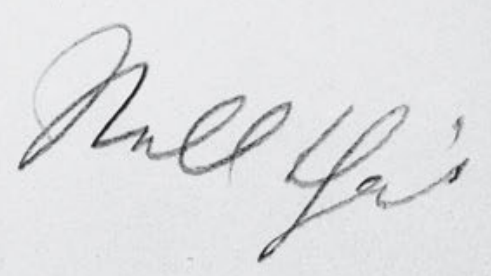

394 


\section{5}

Das s. M. Darum Na Darum hab ich mich

von dir $\mathrm{Na}$ also frag nicht, wen̄ st

schon siehst . dass .

(verste.) darum

5 Der Gatte. . Also weil ich ihm ähnlich

schau .. hast du dich von mir. an-

reden lassen.

Das s. M. Na also ja . .

Der Gatte. Jetzt weiss ich wirklich nicht,

soll ich mich freuen oder soll ich

mich ärgern

Das s. M. Na ich an deiner Stell thät 
HSz6 176

Handschriften und Typoskript

miftion.

d.gak hasa.

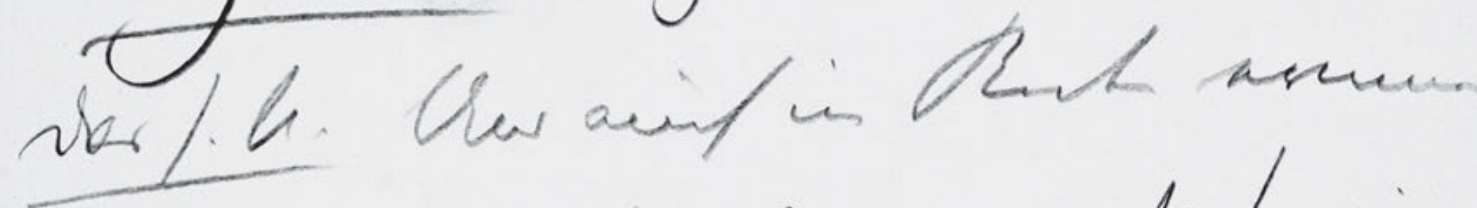

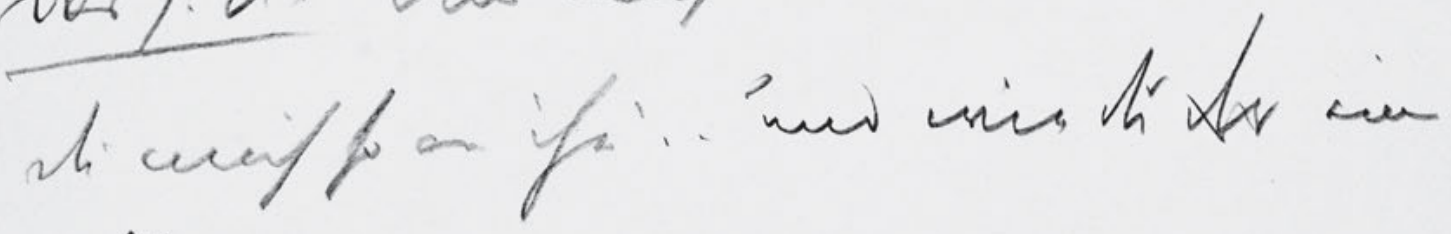
sufferpe....

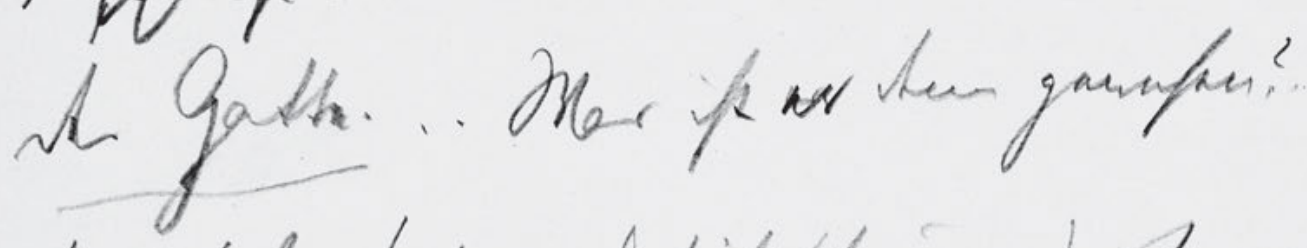

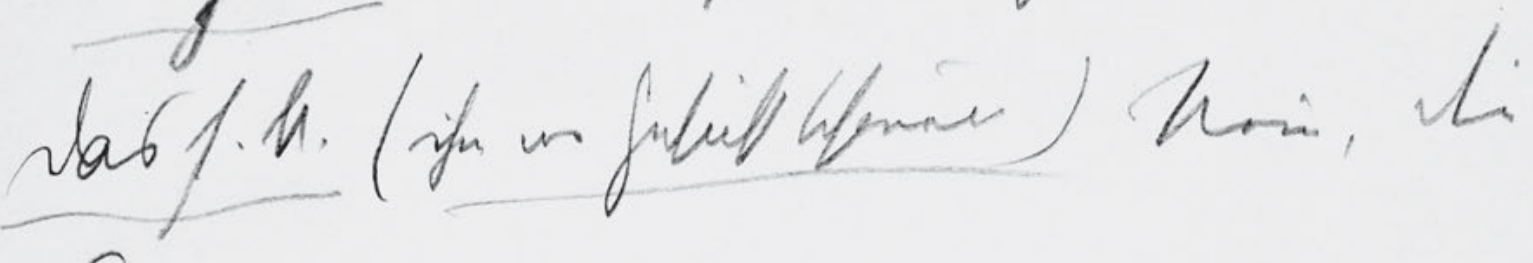

Ging -

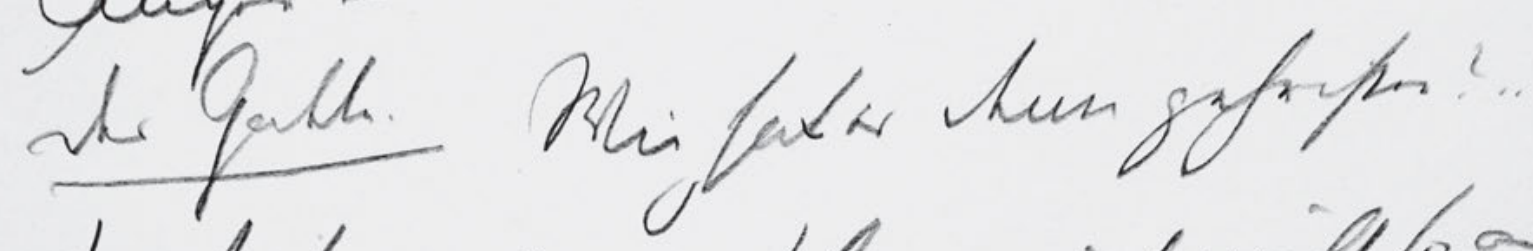

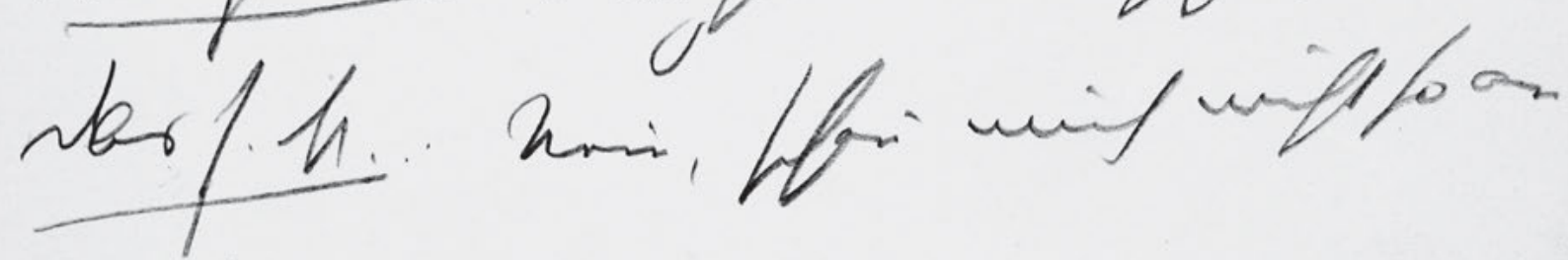

sif hill lif.

it gall ( imfoingt fin.tauge, frifer.

396 
176

mich freuen.

Der Gatte. Na ja . .

Das s. M. Und auch im Reden erinners

5 du mich so an ihn ... und wie du dir einen

anschaust.....

Der Gatte. . . Was ist ${ }^{\text {es }}$ er denn gewesen? . .

Das s. M. (ihm 'ins? Gesicht schauend) Nein, die

Augen -

10 Der Gatte. Wie hat er denn geheißen? . .

Das s. M. . . Nein, schau mich nicht so an

ich bitt dich ...

Der Gatte. (umfängt sie.'Langer, heißer 
HSz6 177

Handschriften und Typoskript

Rifi)

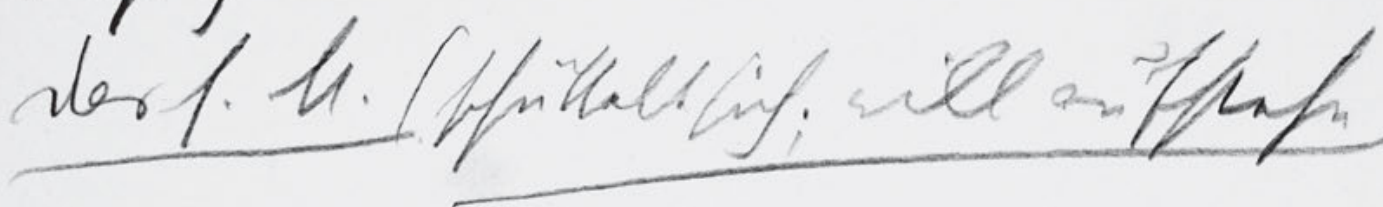

sh fath

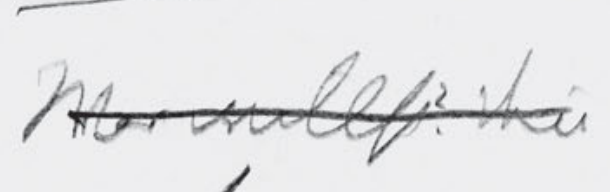

Manui

saff

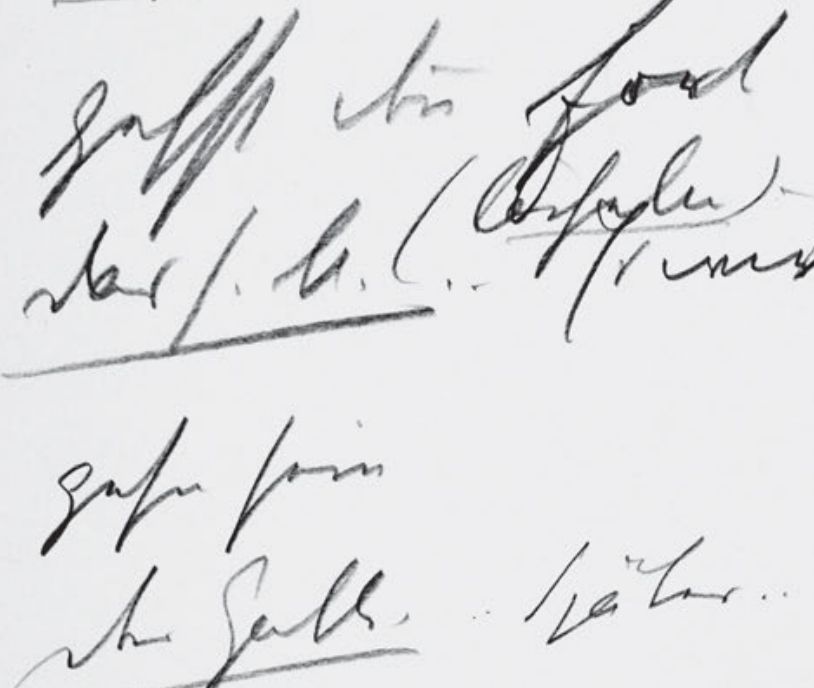

- foad no unis.?

ber/le.

hrim, of mint

suthifle

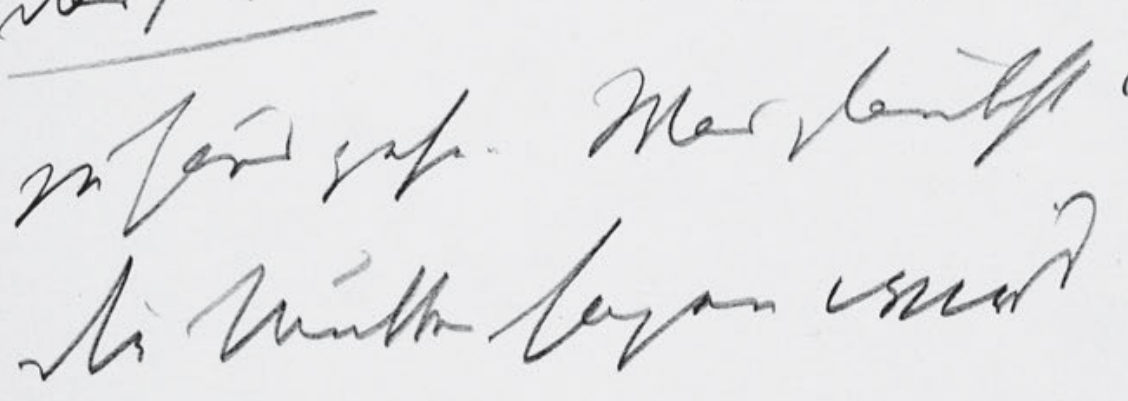

ha

cell,

shi nofupte tiur buta

398 
Kuss.)

177

Das s. M. (schüttelt sich; will aufstehn)

Der Gatte. Was willst? deñ Warum

gehst den fort von mir?

5 Das s. M. . . Es wird Zeit zum Zhaus

gehn sein

Der Gatte. . . später . .

Das s. M. Nein, ich muss wirklich ba

zuhaus gehn .. Was glaubst denn, was

10 die Mutter sagen wird

Der Gatte. Du wohnst bei deiner Mutter. 
HSz6 178

Handschriften und Typoskript

curve hioten He

tefle zo - he ha huth

alk curty?

salid.

mir: gyesen

Munth

for

star 


\section{8}

$\mathrm{D}^{\text {as }}$ er s. M. Natürlich wohn ich bei

meiner Mutte ${ }^{*}$ Was hast deñ geglaubt

Der Gatte. So - bei der Mutter ... Wohnst d

$5 \quad$ allein mit ihr!?

Das s. M. Ja freilich`Allein! - ${ }^{\text {Sieben }}$ vier sind

wir! ${ }^{\text {viex }}$ Zwei ${ }^{\text {Mäd }}$ Buben und noch zwe

Mädeln

Der Gatte. . . So setz dich doch nicht so weit

10 fort von mir .... Bist du die älteste.

Das s. M. Nein, ich bin die zweite,

Zuerst kō̄t die Kathi; aber die ist 
HSz6 179

Handschriften und Typoskript

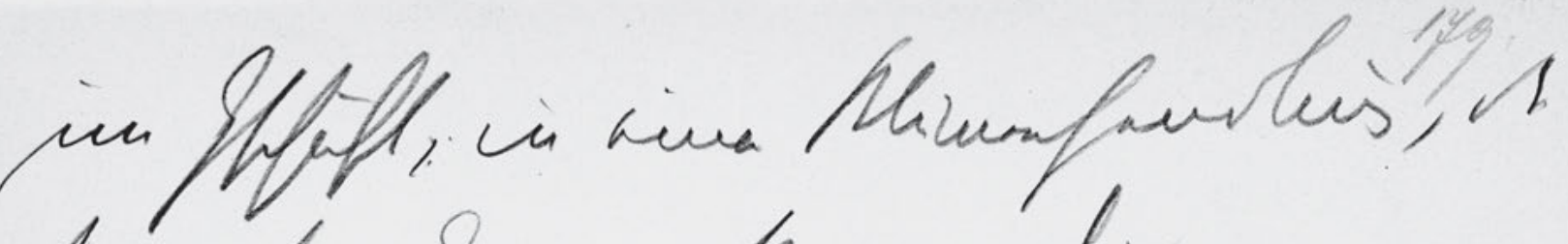

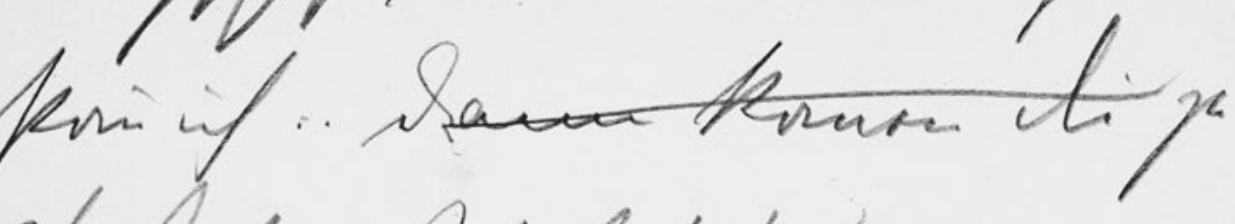

The Jalc. Mrifiti?

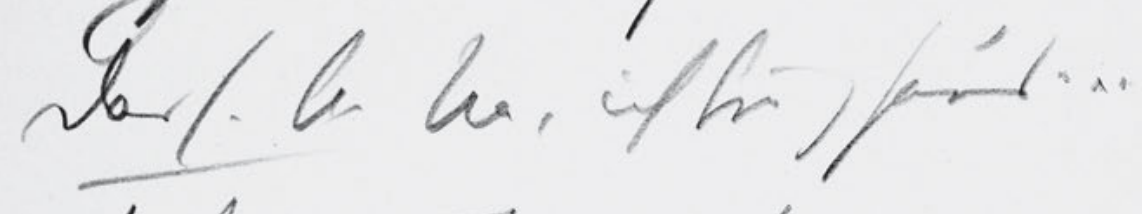

st fath. Jumen

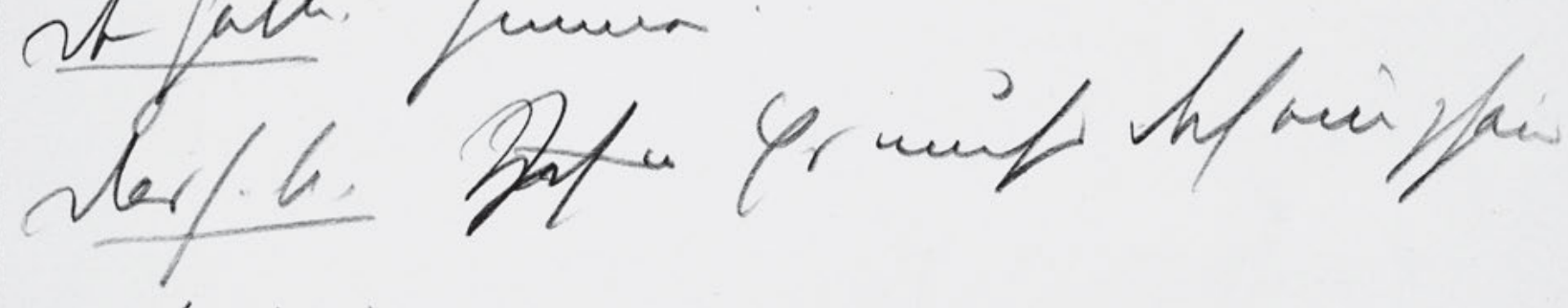
timi?

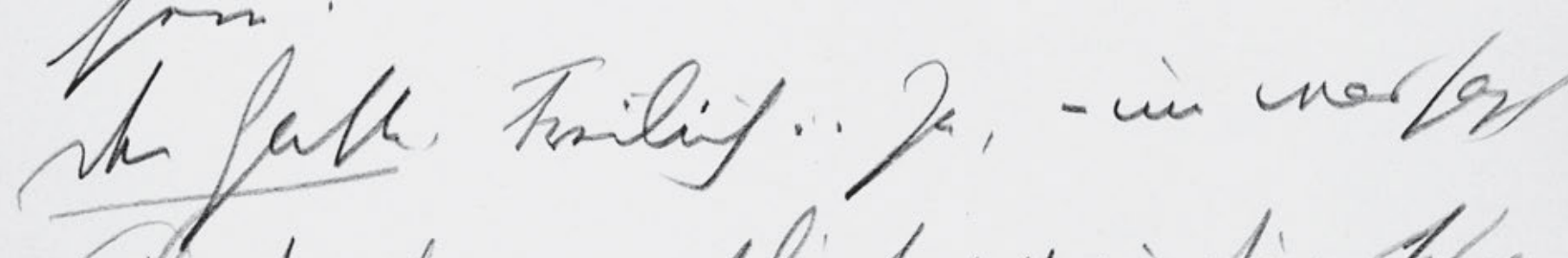
thi dis de syonthif, uni di tives nealforiflomift.

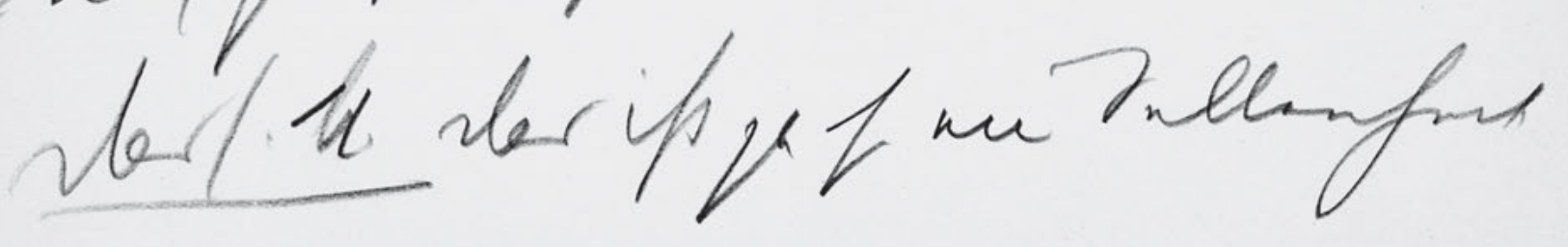

402 
179

im Gschäft ${ }^{\circ}$, in einer Blumenhandlung, $\mathrm{d}$

kō̄ ich . . dann komen die $\mathrm{z} w$

Der Gatte. Wo bist du? .

$5 \quad$ Das s. M. Na, ich bin $z$ haus ...

Der Gatte. Immer?

Das s. M. ${ }^{N a}$ Ich [?] Es muss doch eine zhaus

sein?

Der Gatte. Freilich ... Ja, - und was sags

10 deñ du da eigentlich, weñ du - so ?spat?

nach haus komst...

Das s. M. Das ist ja so eine Seltenheit 
HSz6 180

Handschriften und Typoskript

sh futh

$188 ;$

'ques/ hif hy

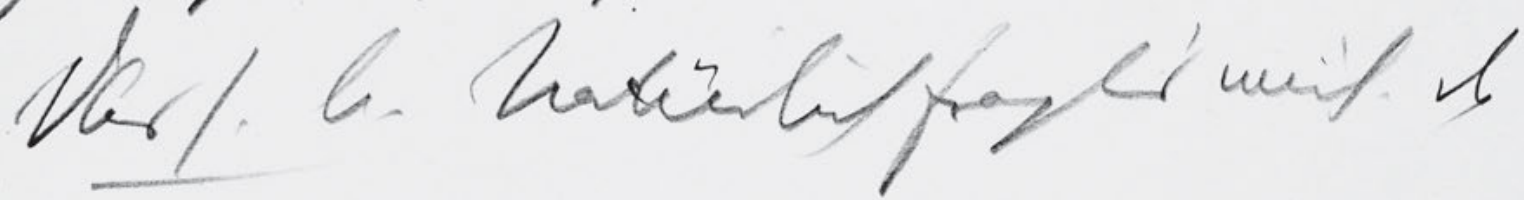

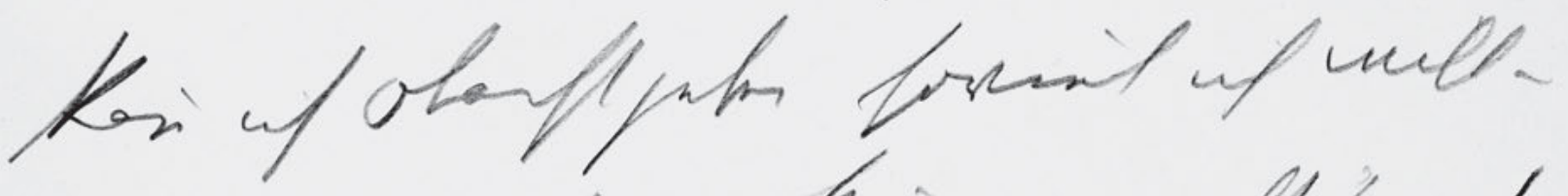
smic war for hom, surft/ ant

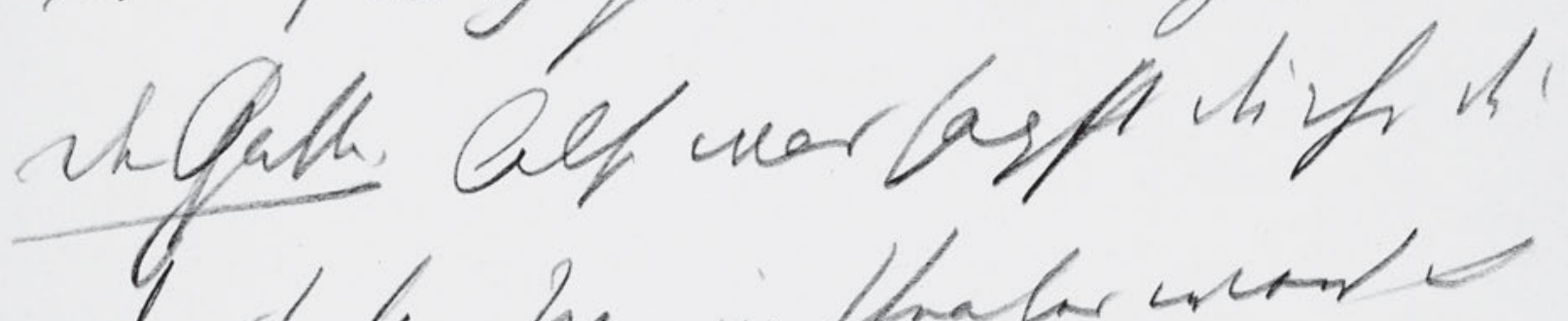

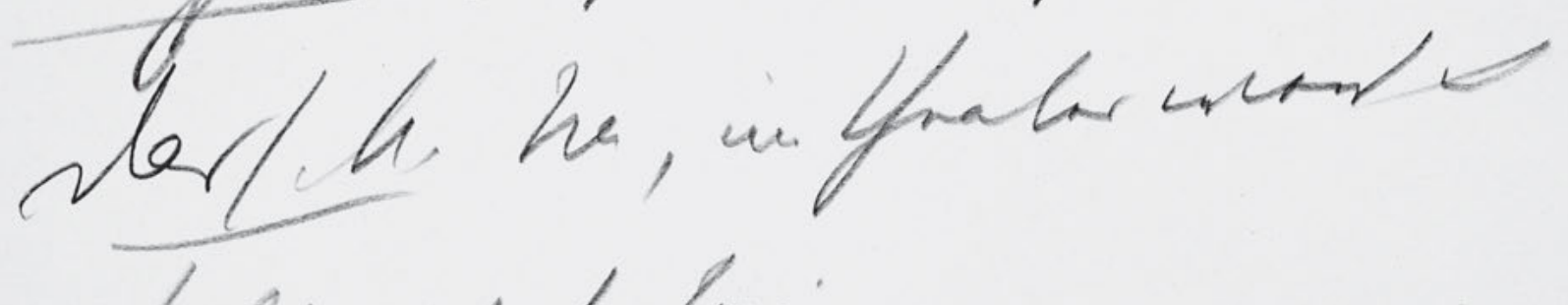

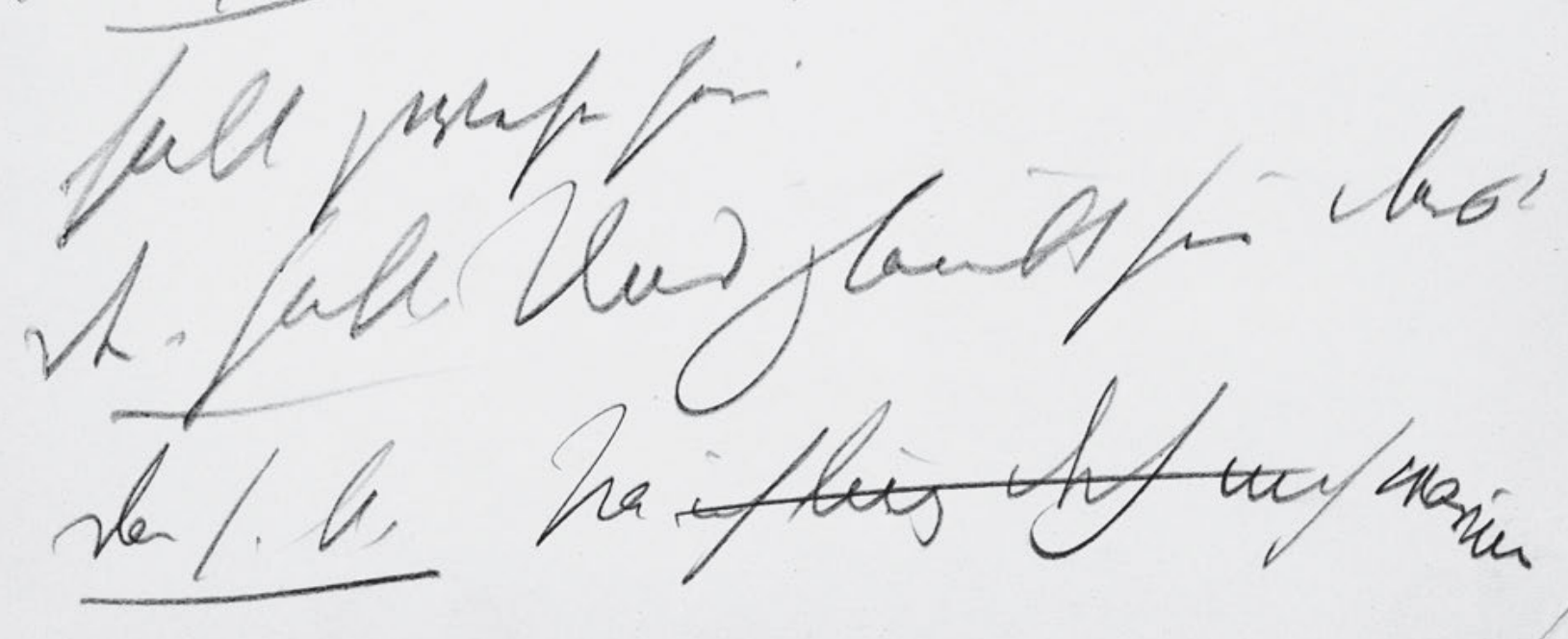

404 
180

Der Gatte. Also heute . . deine Mutter

fragt dich doch.

Das s. M. Natürlich fragt's mich. Da

$5 \quad k a \bar{n}$ ich obacht geben soviel ich will -

wē̄ ich nach Haus kō̄, wacht 's auf.

Der Gatte. Also was sagst du ihr da?

Das s M. Na, im Theater werd ich

halt gwesen sein

$10 \quad$ Der. Gatte. Und glaubt sie das?

Das s. M, Na ich lüg doch nich warum

1 Strich in Tinte. 
HSz6 181

Handschriften und Typoskript

oll mir sum mift tauta.s

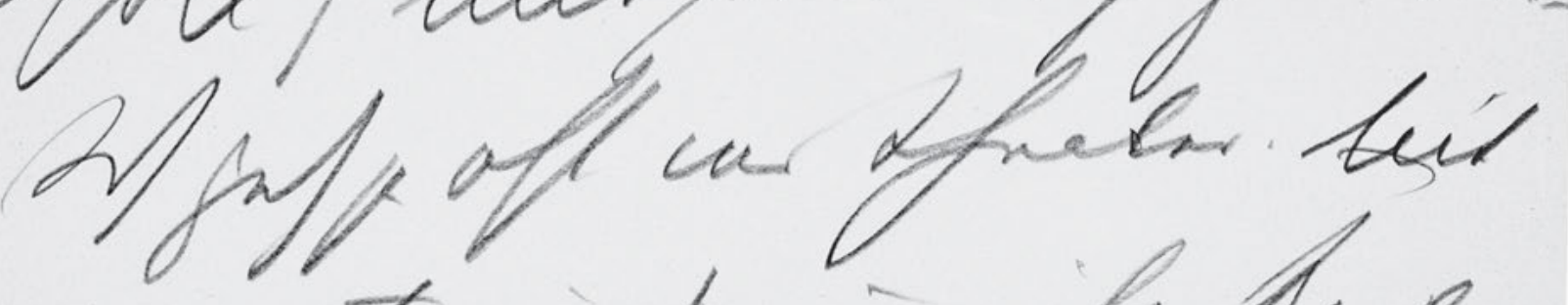

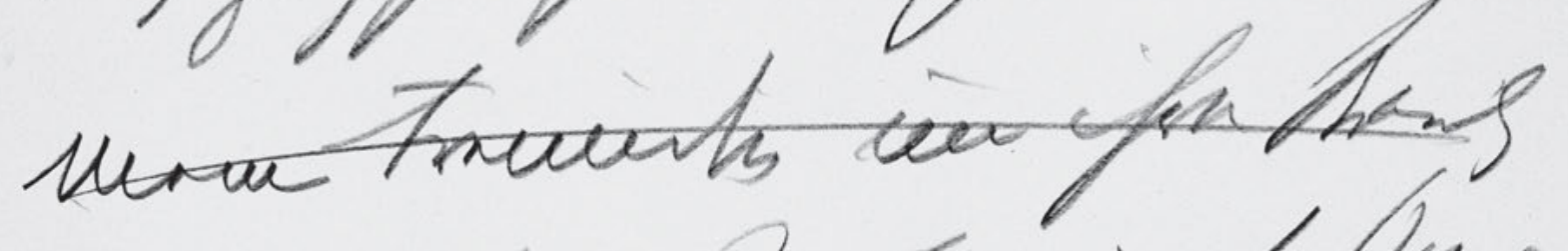
we of rfterintas in ther. unt hreurea inceis veryta hing un curio allers trinst

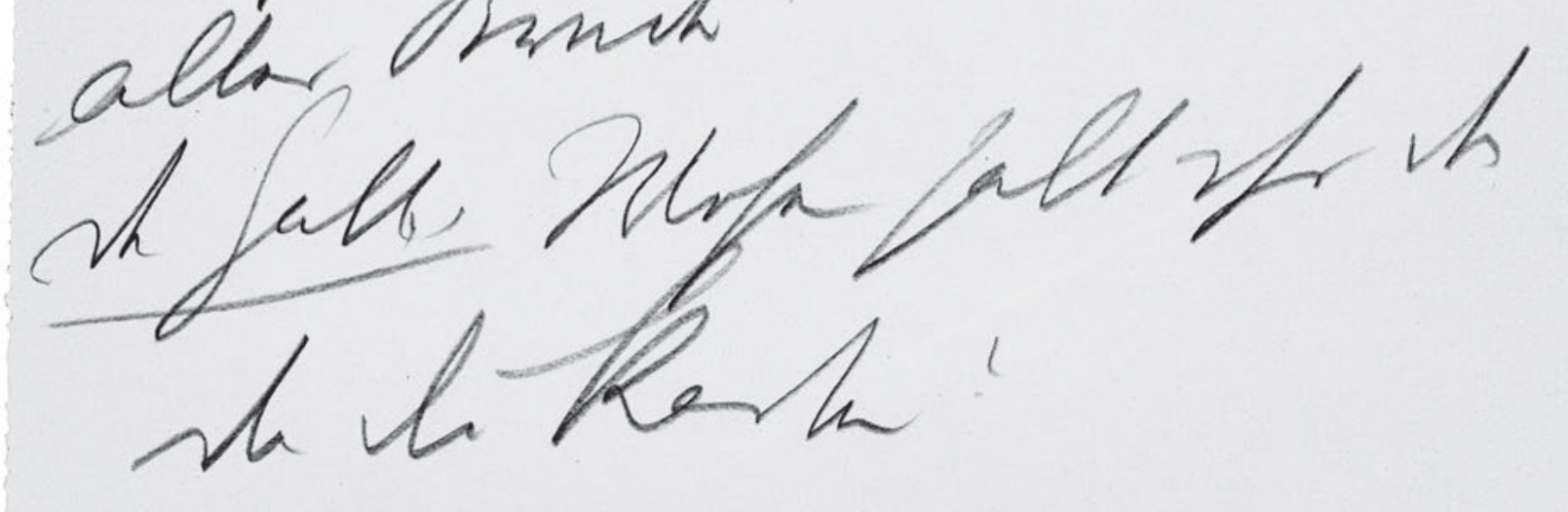

406 


\section{1}

soll s' mir denn nicht glauben. ? ? -

Ich geh ja oft ins Theater. Mit

meiner Freundin und ihrem Bräutg

5 war ich erst am Soñtag in der Oper.

Erst am Son̄tag war ich in der Oper

mit dem Br meiner Freund

und ihrem Bräutigam und meinem

alter Bruder.

10 Der Gatte. Woher habt ihr den

da die Karten? 
HSz6 182

Handschriften und Typoskript

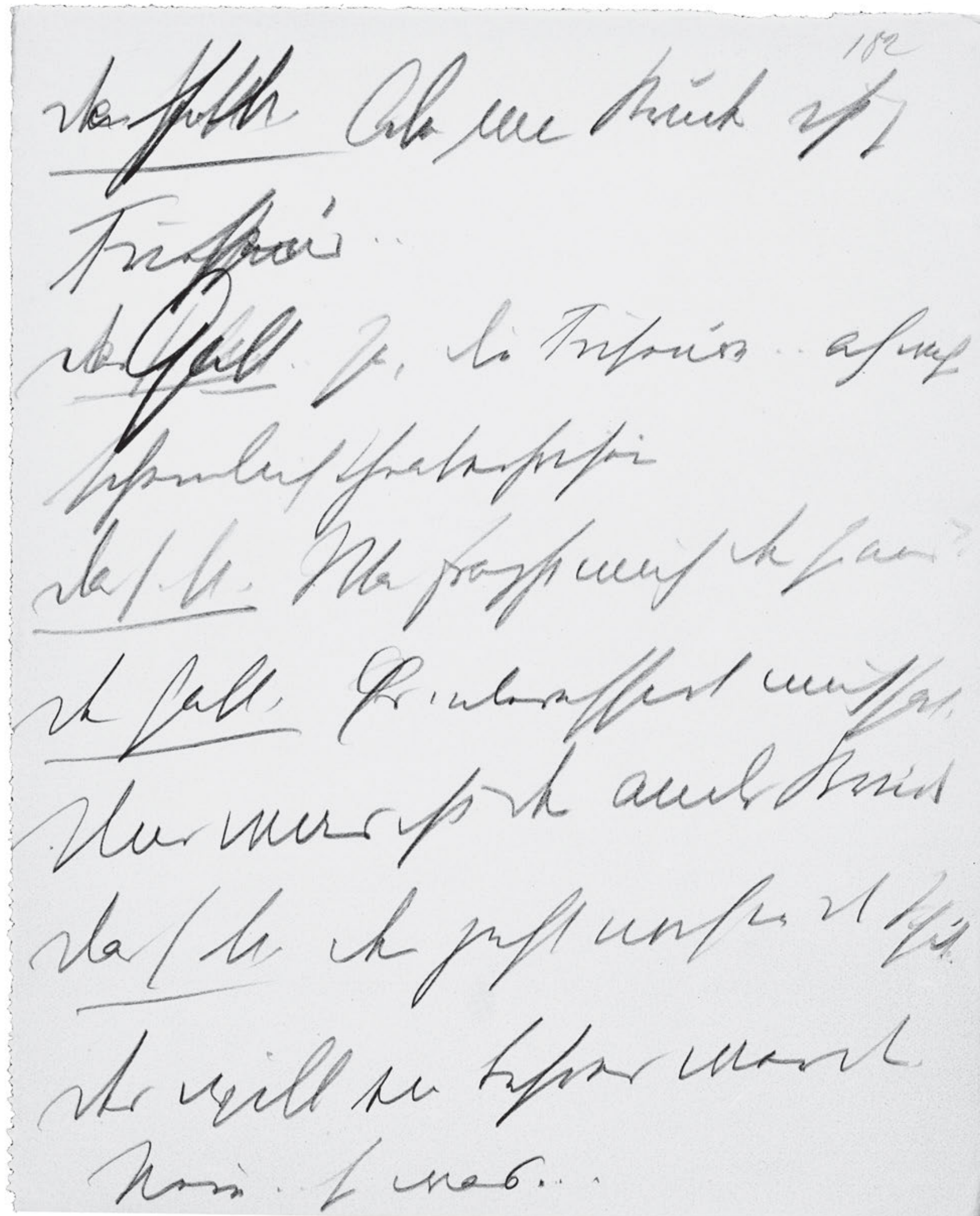

408 
$\underline{D^{\text {er }} \text { as }}{ }^{\text {Gatte }}$ s. M. Aber mei Bruder ist $j$

Frie ${ }^{\text {seut }}$ seur . .

Das ${ }^{\text {s. Ma }}$ Gatt . . Ja, die Friseure . . ah wahr

5 scheinlich Theaterfriseur

Das s. M. Was fragst mich den so aus?

Der Gatt. ${ }^{[?]}$ Es interessirt mich hal.

Und was ist der andre Brud

Das s M. Der geht noch in d Schule.

10 Der will ein Lehrer werden.

Nein . . so was... 
HSz6 183

Handschriften und Typoskript

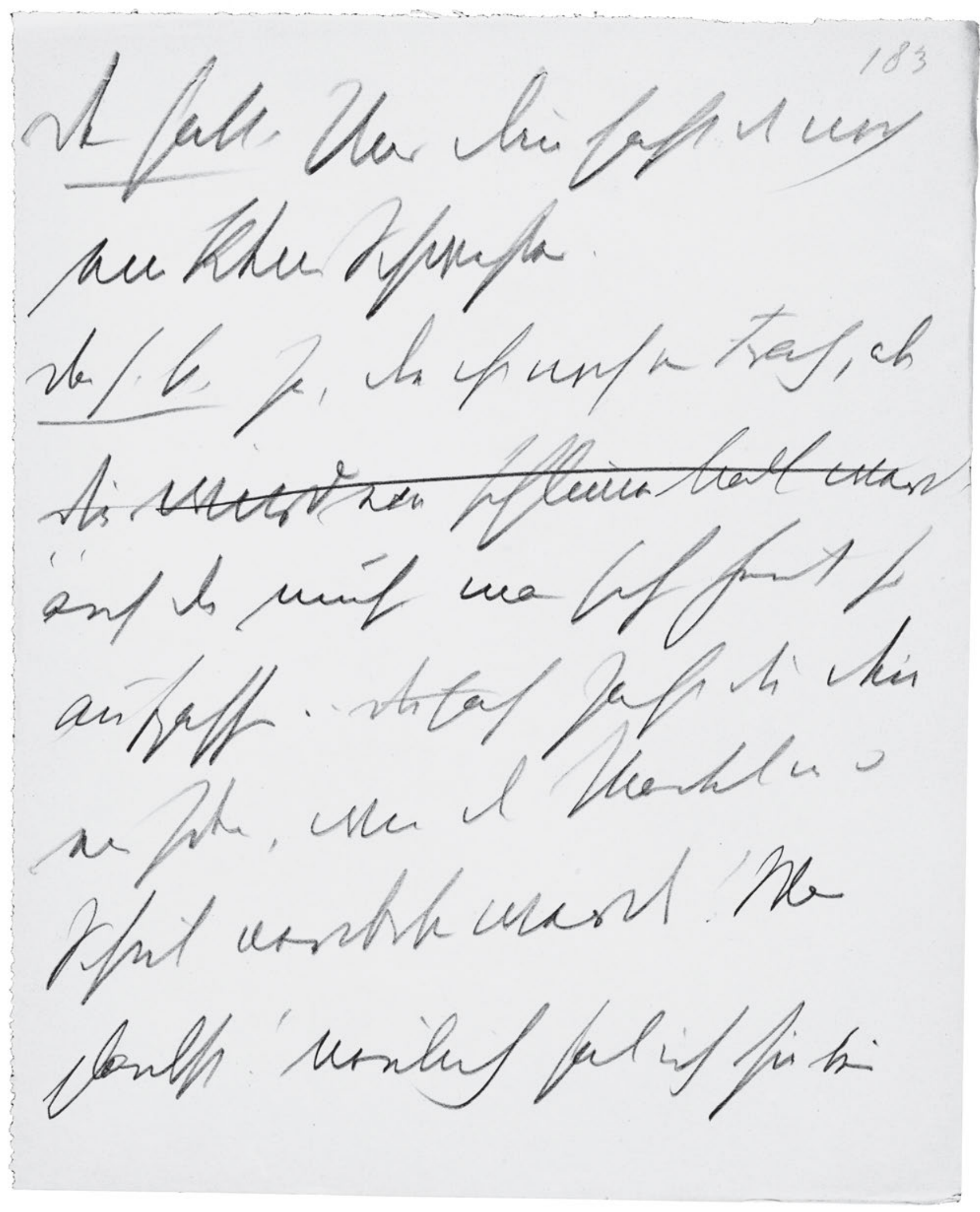

410 
183

Der Gatt. Und dan̄ hast d noch

eine kleine Schwester.

Das s. M. Ja, die ist noch ein Fratz, aber

5 die wird ein schlime Madl werd

auf die muss man schon heut so

aufpassen . . du has Hast du deñ

ein Idee, wie die Madel in d

Schul verdorben werd! Was

10 glaubst! neulich hab ich sie bei 
HSz6 184

Handschriften und Typoskript

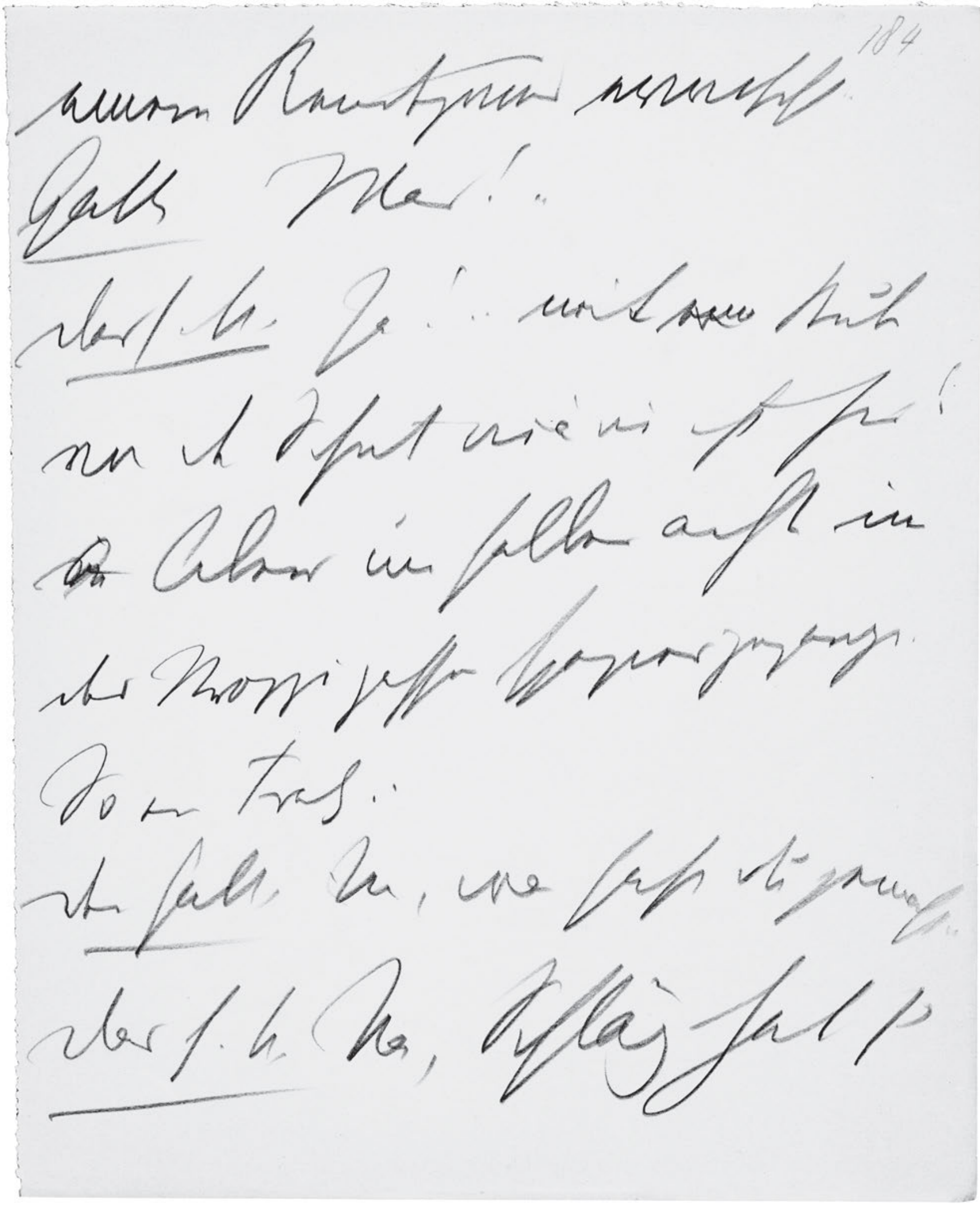

$$
\text { Plar. }
$$

412 


\section{4}

einem Rendezvous erwischt . .

Gatte Was! . .

Das s. M. Ja! . . mit eine Buben

$5 \quad$ von der Schul vis à vis ist sie [?]

?*?am Abend um halber acht in

der Strozzigassen spazier gegangen.

So ein Fratz . .

Der Gatt. Na, was hast du gemacht . .

$10 \quad$ Das s. M. Na, Schläg hat s' 
HSz6 185

Handschriften und Typoskript

Ruig!

chall. Po fury hipt?

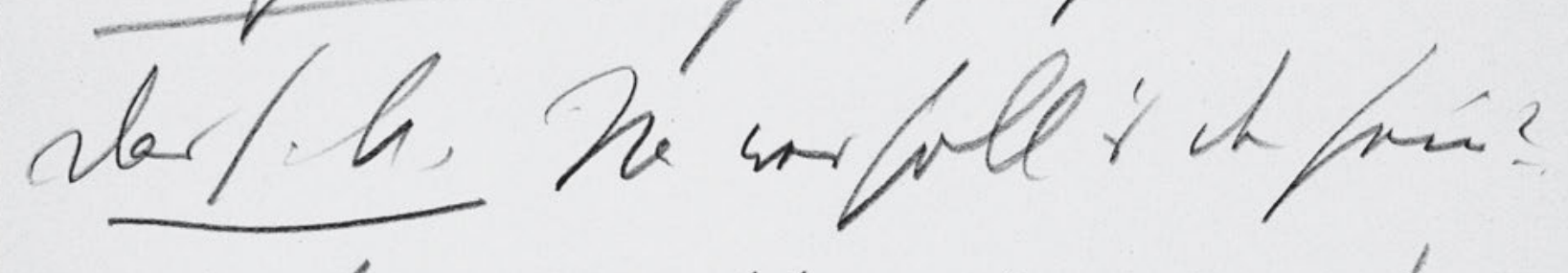

shetwith Affot af werts a trem.

par; sh Altm if a frsat,

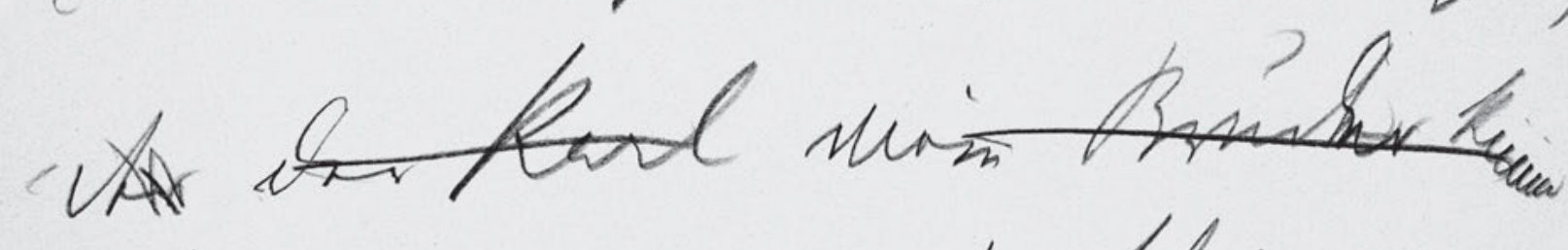

Iif wis wift, the thiur

hrint unir alls ant muf.

414 
kriegt! .

Der Gatte. So streng bist du. ?

Das s. M. Na wer soll's denn sein? .

${ }_{5}$ Die Mutter thut eh nichts als raun-

zen; die Altre ist im Gschäft,

die Mutter thut nichts als raunzen; -

der der Karl mein Bruder kümmert

sich um gar nichts, der kleine

10 kō̄t imer alles auf mich. 
HSz6 186

Handschriften und Typoskript
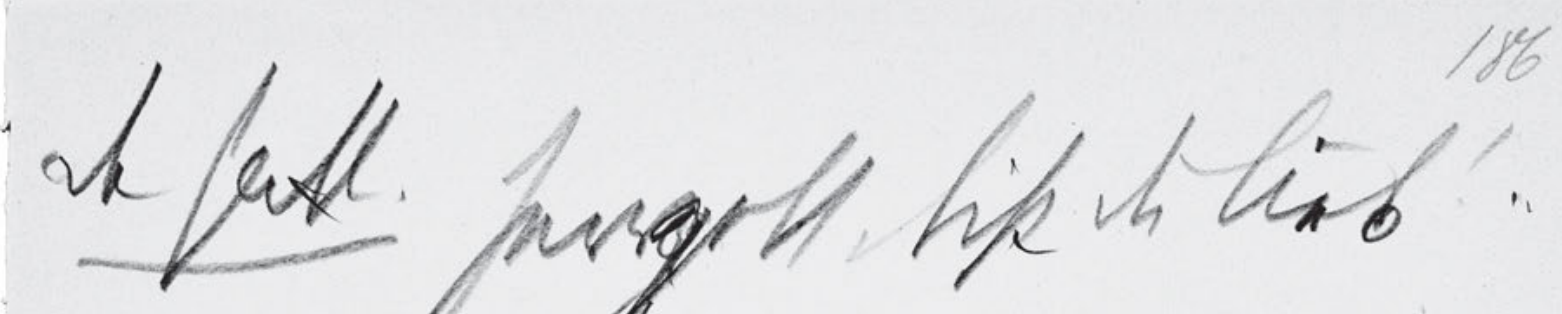

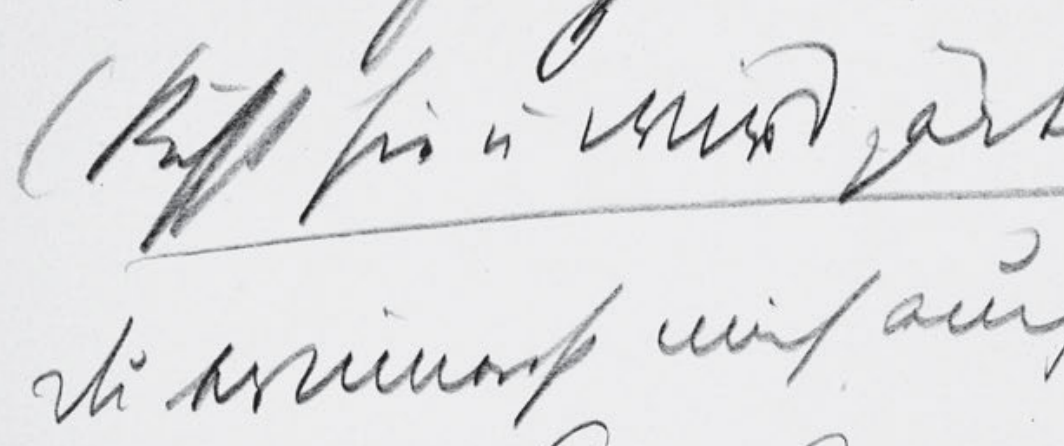

we/the

An.. Ju: a can hs

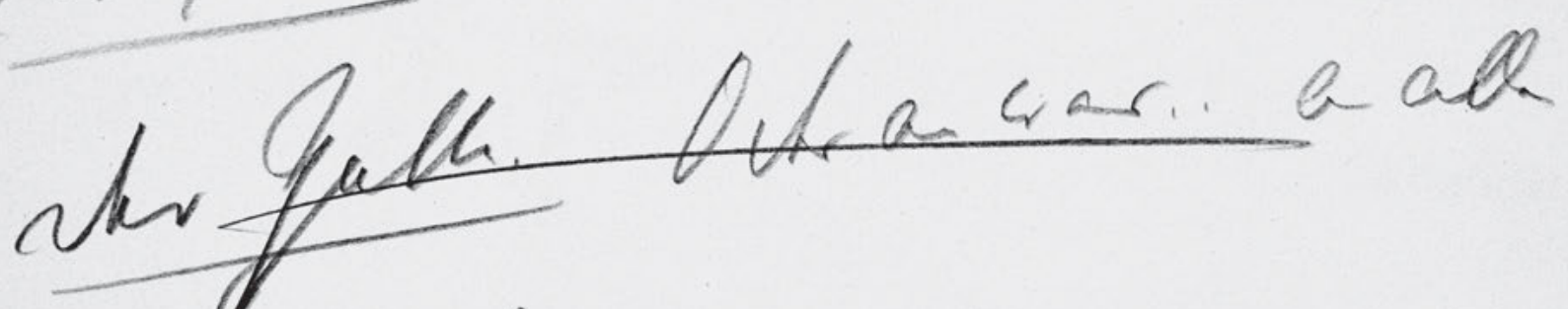
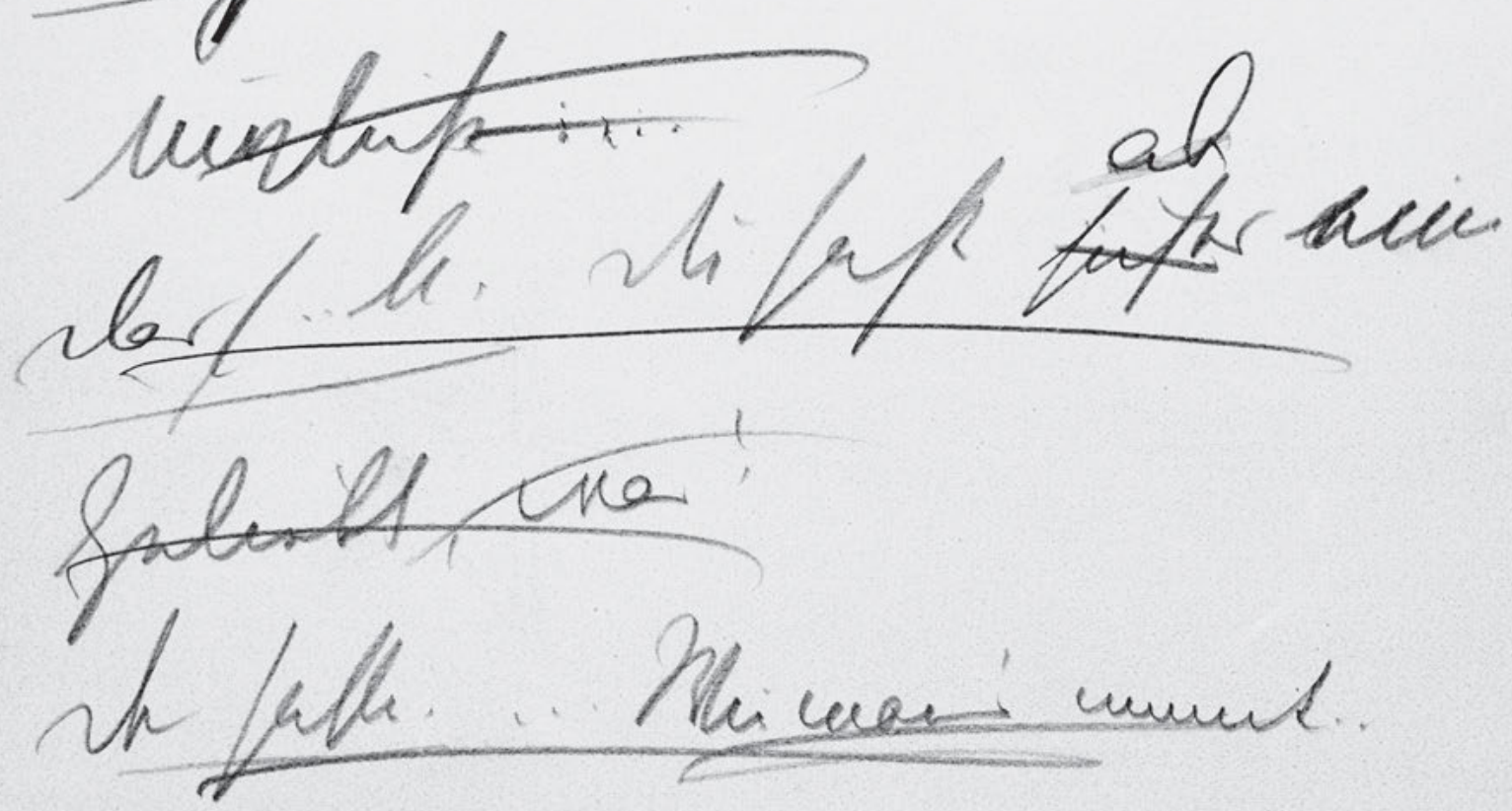

416 


\section{6}

Der Gatte. Herrgott, bist du lieb! . .

(küsst sie u wird zärtlicher ...)

Du erinnerst mich auch als wen ...

5 Das s. M. An .. So: an wen den

Der Gatte. Oder an was .. an alles

mögliche $\ldots$

$a b$

Das s. . M. Du hast sicher aeine

Geliebte, was?

10 Der Gatte. ... Wie man's nimmt . .

2 Strich durch Gatte: vermutlich nicht als Streichung zu verstehen. 
HSz6 187

Handschriften und Typoskript
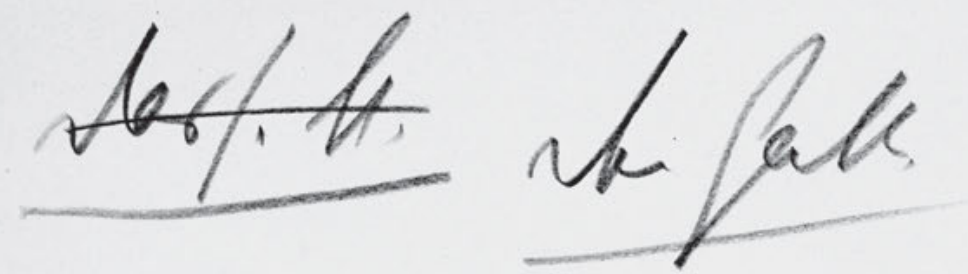

$718 y$

lapeinds

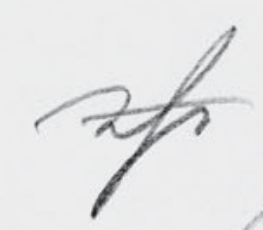

Q Mruna

wa. Felo

Asule,

$\Lambda$
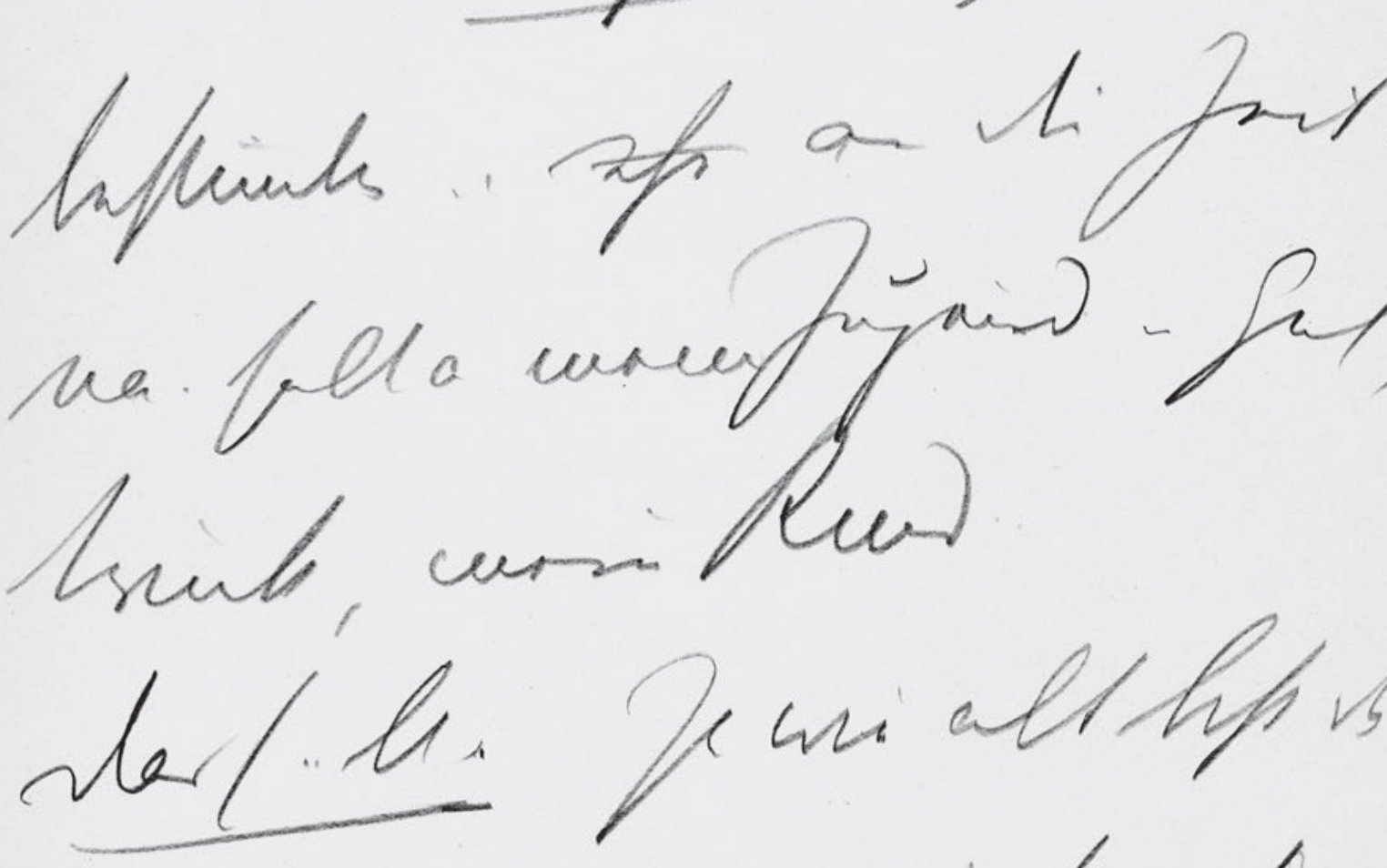

wi alt hifs

1

Nhen. si

n mual un

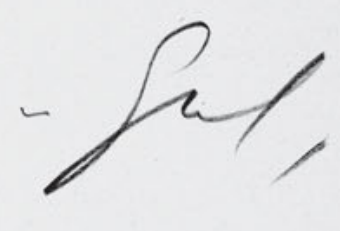




\section{7}

Das s. M. Der Gatte. An niemand

bestimtes . . ehe an die Zeit . .

na . halt a meine Jugend - Geh,

5 trink mein Kind. .

Das s. . M. Ja wie alt bist du

denn . du . ja . . ich weiss ? ja?

noch nicht einmal wie du heißt!

Der Gatte. Im Ernst? . Karl 
HSz6 188

Handschriften und Typoskript

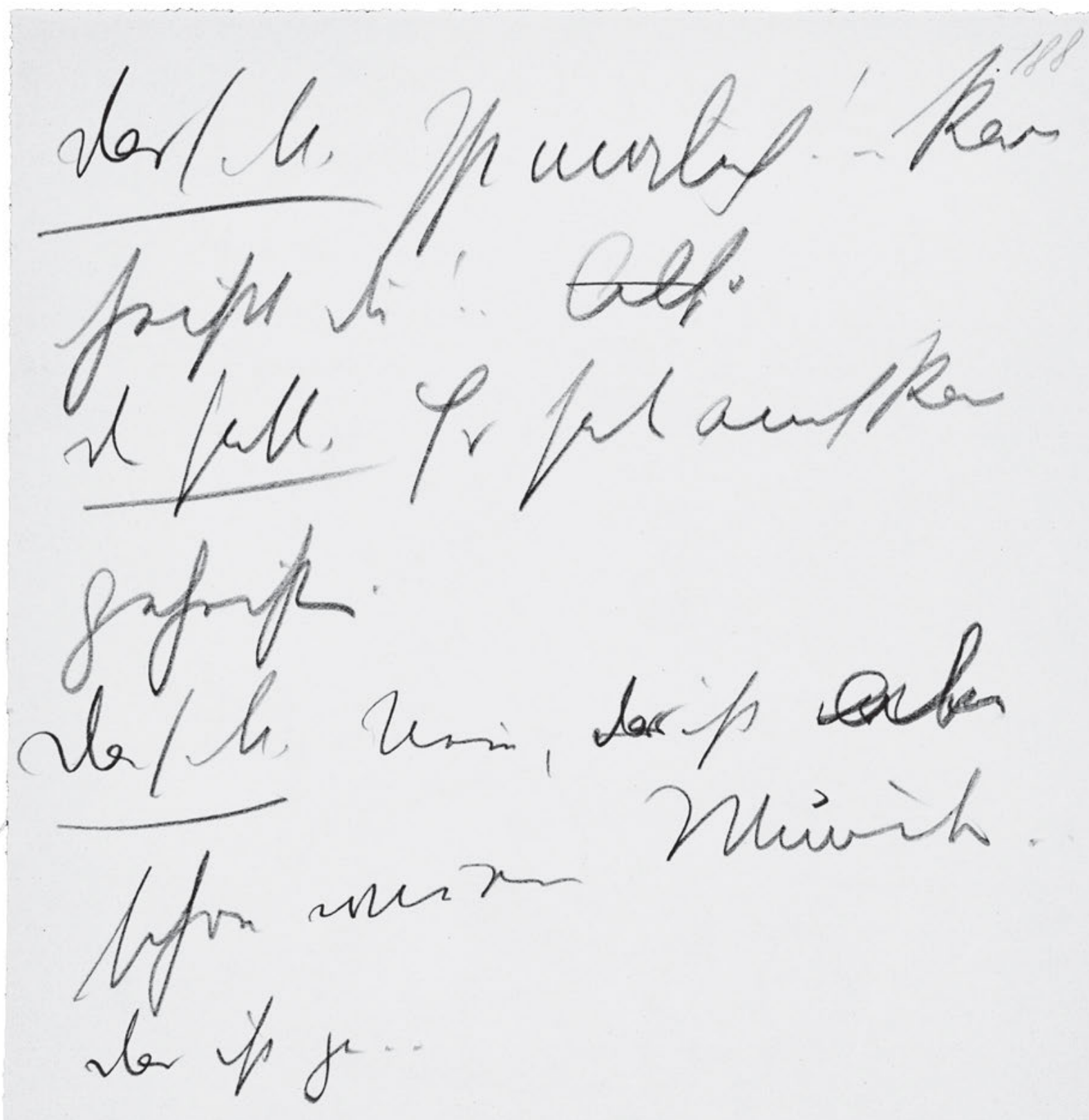

420 


\section{8}

Das s M. Ist möglich! - Karl

heißt du! . Also

Der Gatte. Er hat auch Karl

5 geheißen.

Das s M. Nein, ${ }^{\text {es }}$ das ist ${ }^{\text {wie }}$ abe

schon wie ein Wunder..

das ist ja . . 
HSz6 [188a]

Handschriften und Typoskript

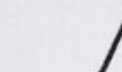

vers: II

th alle

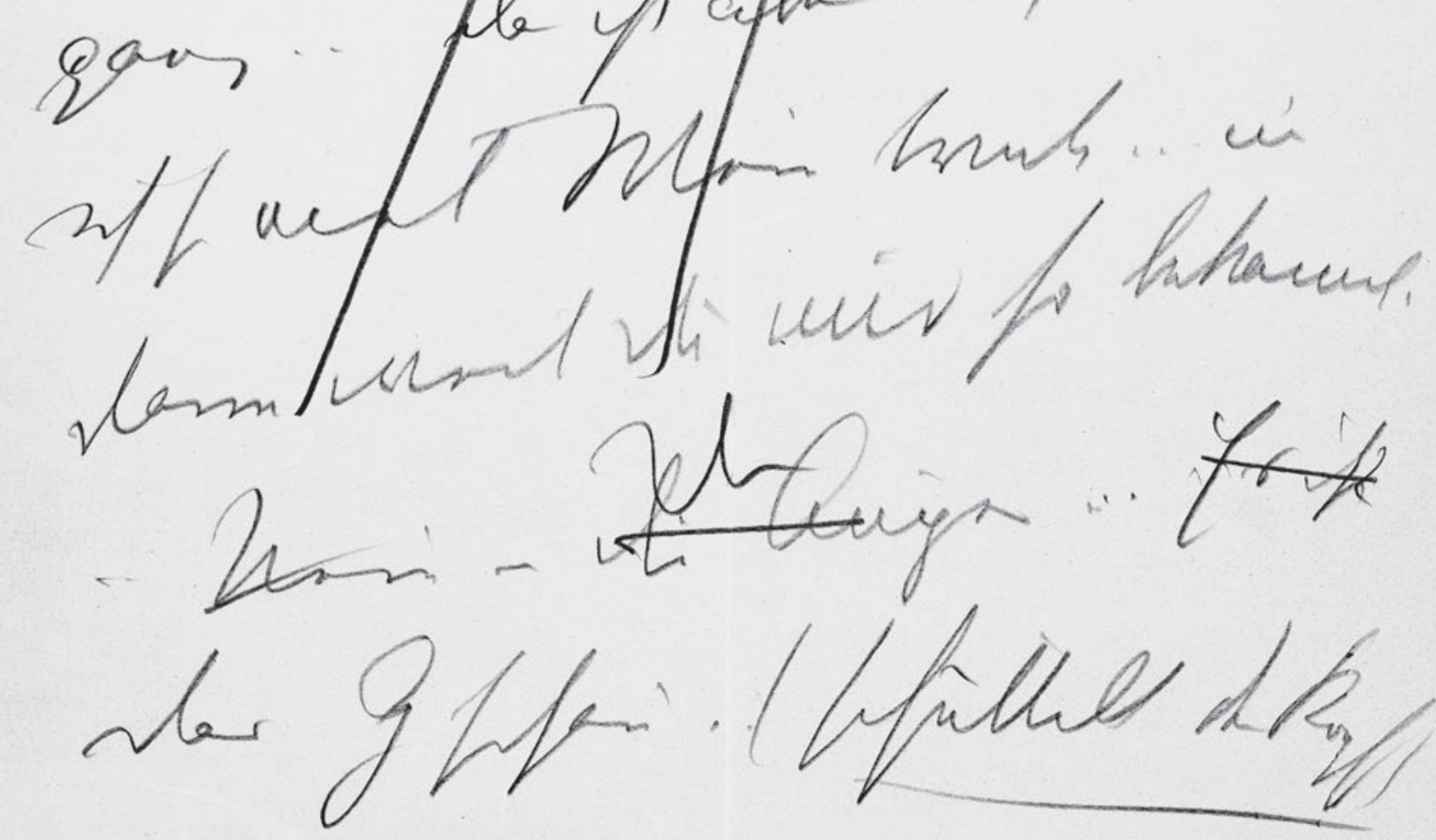

422 
Deras s. M. Und wer $w^{\mathrm{er}}$ s du bist ..

Der Gatte. Ist dir das nicht sehr

egal?

Das s. M. Nein, wie man oft

5 ganz . das ist aber nur, weil du

ich so viel Wein trink ... un

dann weil du mir so bekannt.

$\mathrm{d}[?]$

- - Nein - die Augen ... “Es ist

das Gschau . . (schüttelt den Kopf) 
HSz6 189

Handschriften und Typoskript

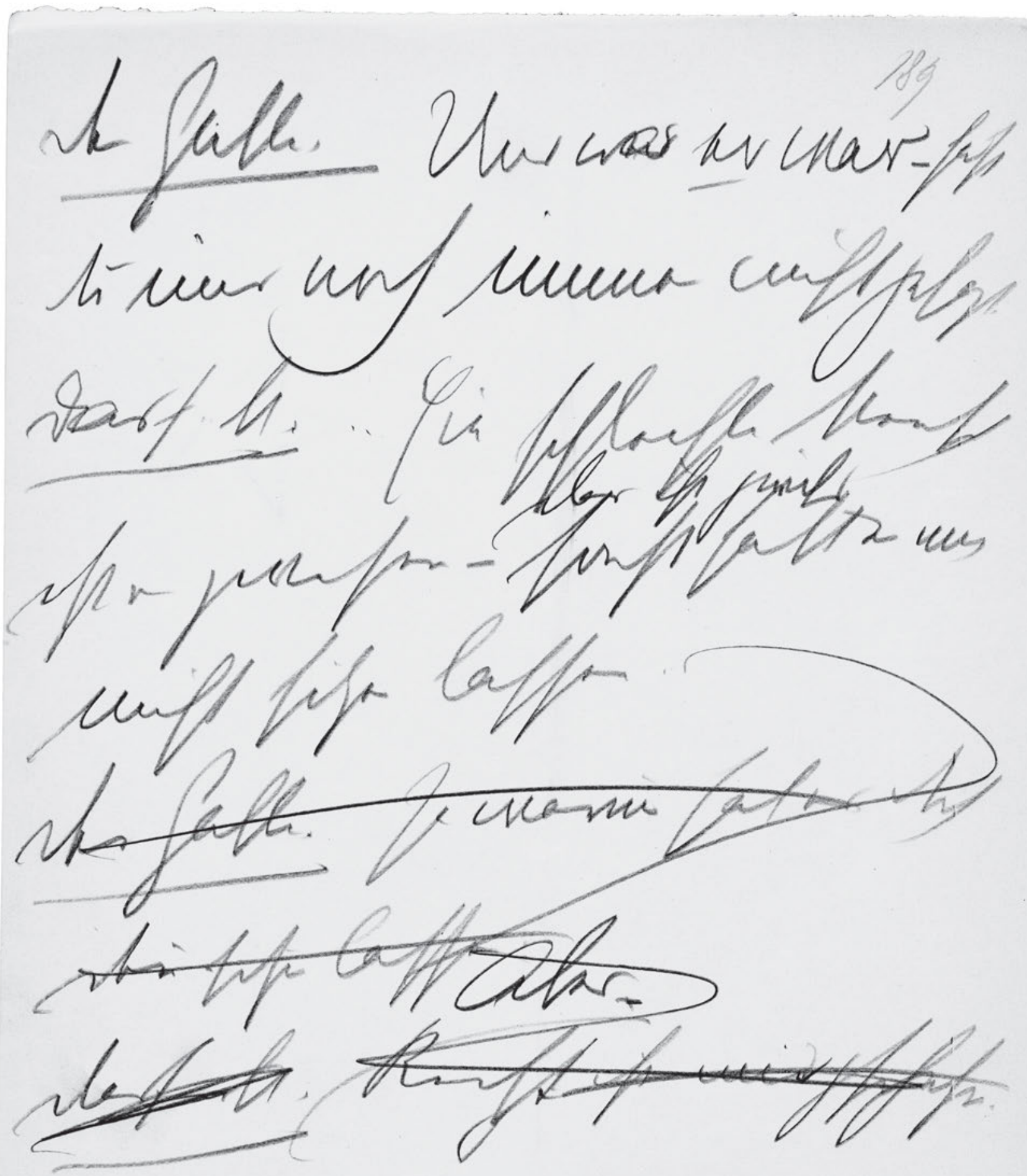

424 


\section{9}

Der Gatte. Und weras er war - hast

du mir noch immer nicht gesagt.

Das s. M. . . Ein schlechter Mensch

das ist gwiss

ist er gwesen - sonst hätt er mich

nicht sitzen lassen.

Der Gatte. Ja warum hat er dich

deñ sitzen lassen

Aber -

Das s. M. Recht ist mis'r gschehn. 
HSz6 190

Handschriften und Typoskript

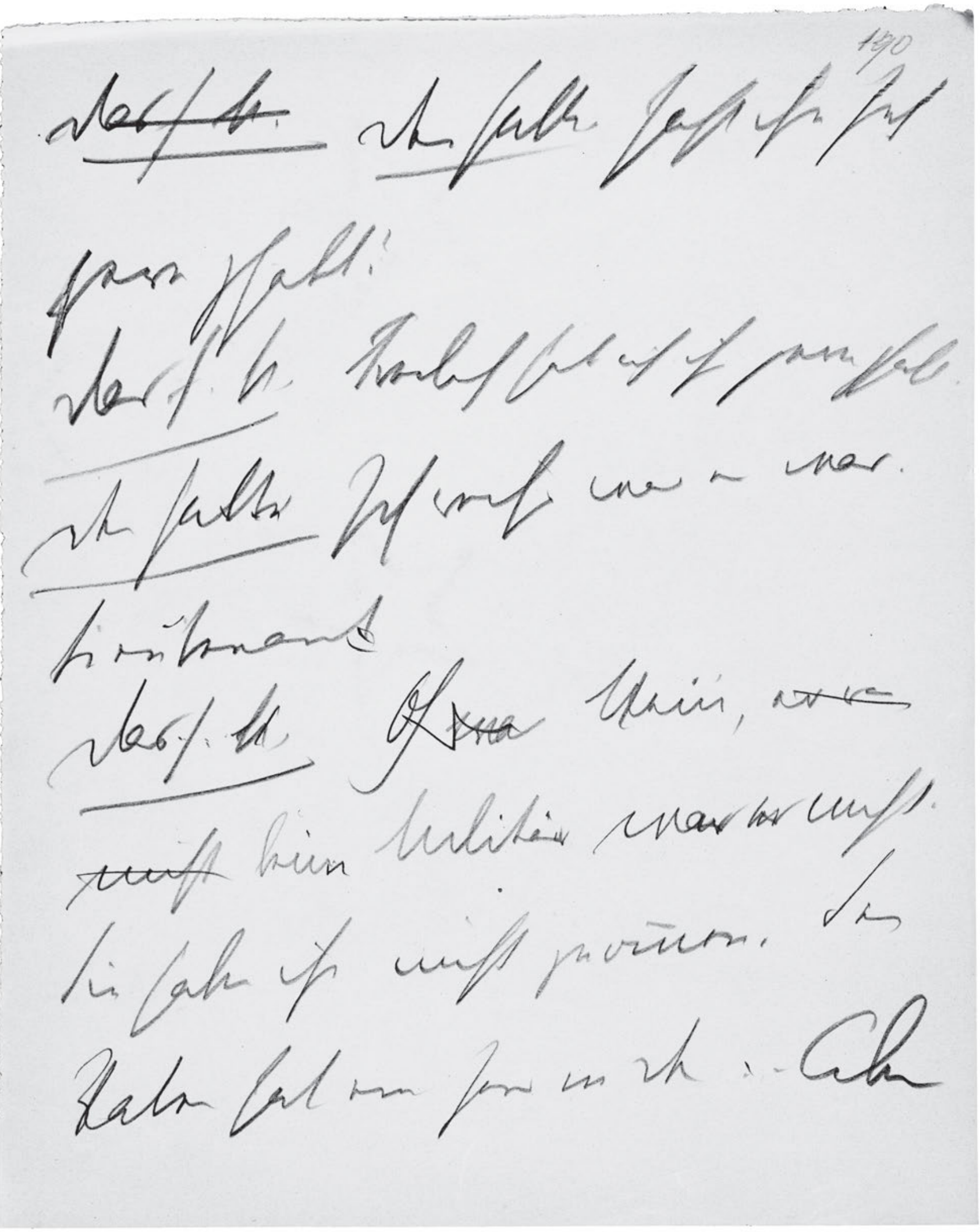




\section{0}

Das s M. Der Gatte. Hast ihn seh

gern ghabt?

Das s. M. Freilich hab ich ihn gern ghabt.

5 Der Gatte. Ich weiss was er war.

Lieutenant

Das ..s. ...M. Oh wa[?] ${ }^{M}$ Nein, er war

nicht beim Militär war ${ }^{\mathrm{n}}$ er nicht.

Sie haben ihn nicht gnō̄en. Sein

10 Vater hat ein Haus in der .. - Aber 
HSz6 191

Handschriften und Typoskript

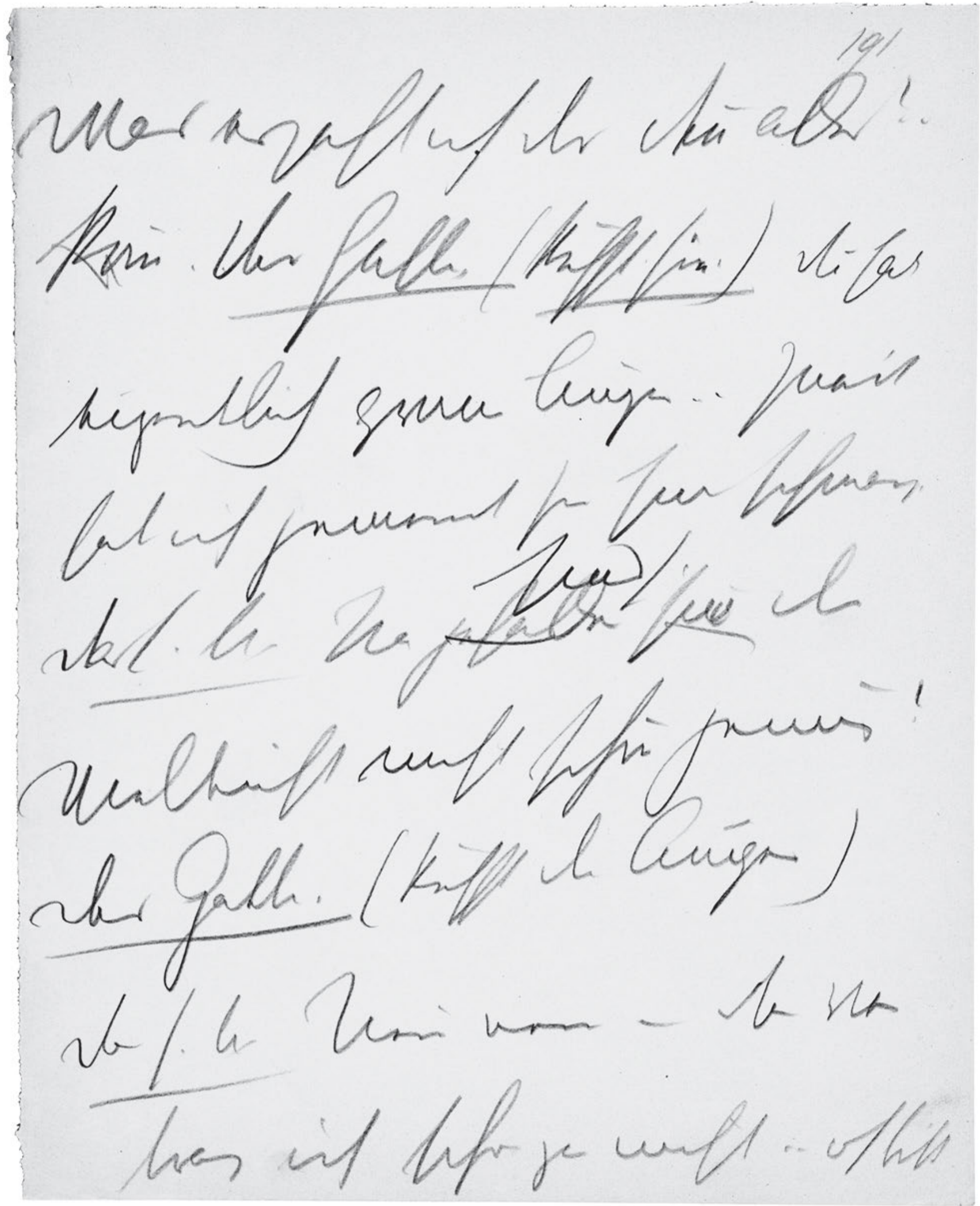

428 
191

was erzahl ich dir dē̄ alles? .

kom . 'Der Gatte. (küsst sie.) Du has

eigentlich graue Augen ... ? Zuers?

5 hab ich gemeint sie sind schwarz.

sind $\mathrm{s}$

Das s. M. Na gefallen sie dir

vielleicht nicht schön genug?

Der Gatte. (küsst die Augen)

Das s. M. Nein nein - das ver

10 trag ich schon gar nicht .. oh bitt 
HSz6 192

Handschriften und Typoskript

lit - of fult

of whe wat

lapuni

butflif men

sin homent - hle th

st fork. (uiving arthifg)

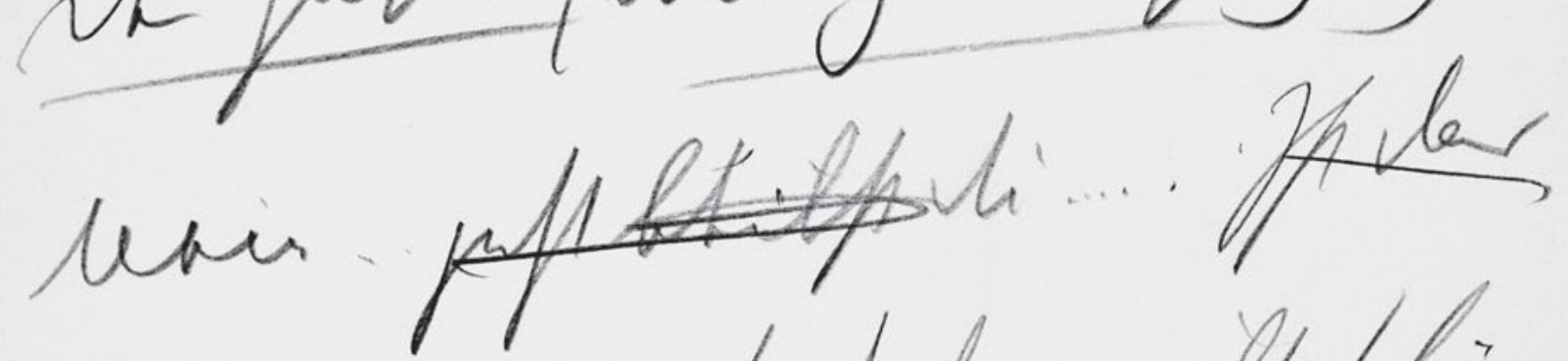

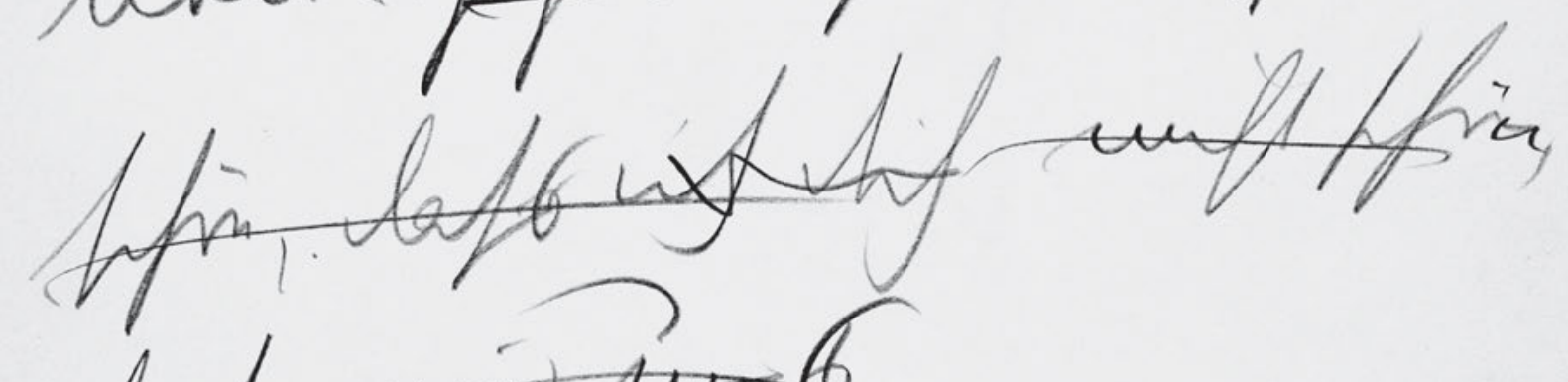

bat

var/. he Ahrigh has ist, Rew

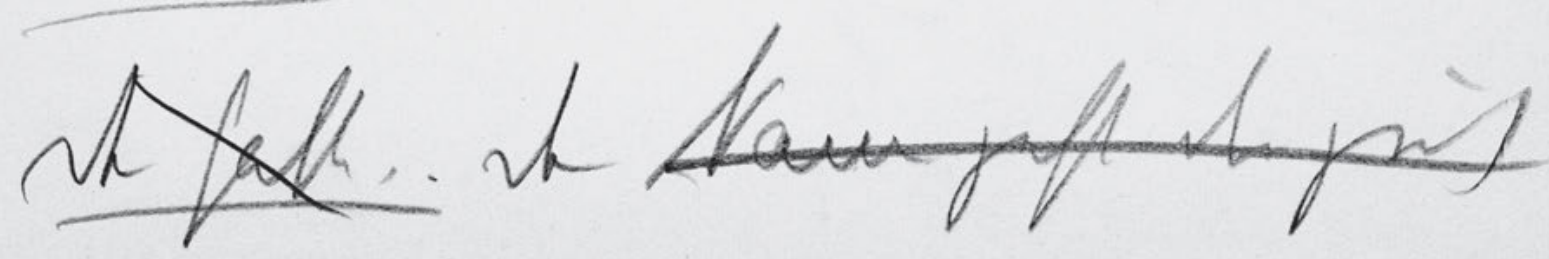

430 
dich - oh Gott . . oh Gott . . nein

laß mich aufstehn . . nur für

ein Moment - bitt dich

5 Der Gatte. (wird zärtlicher) Oh

nein . . jetzt bleibst du . . . . . Ist das

schön, . dass ich dich nicht schön, dass wir uns . .

Das s. M. Aber ich bitt dich, Karl-

10 Der Gatte. . Der Name geht dir gut 
HSz6 193

Handschriften und Typoskript

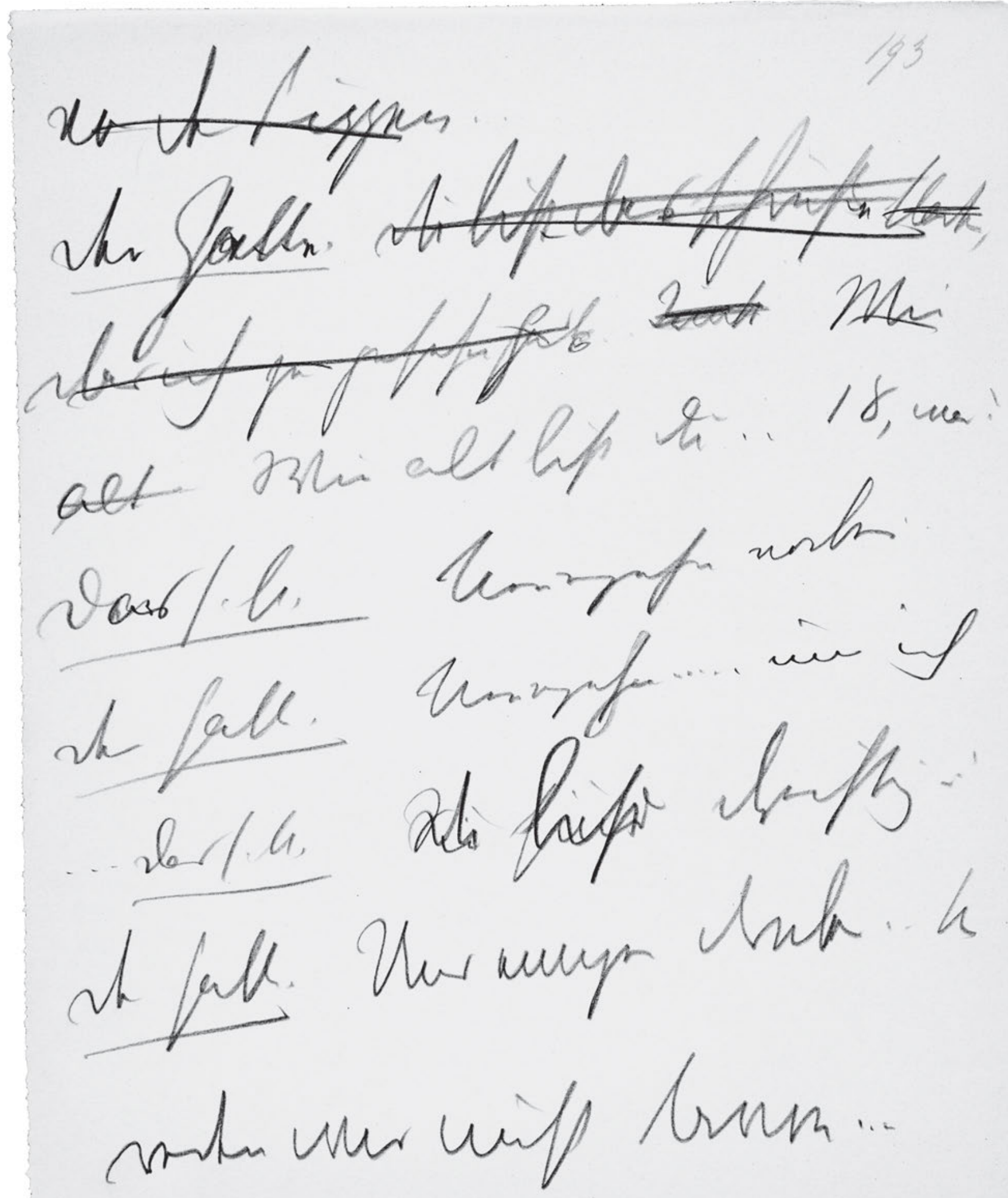

432 
193

von den Lippen . .

Der ?s? Gatte. Du bist das schënste Madel,

das ich je gesehn hab. . Trink Wie

$5 \quad$ alt Wie alt bist du . . 18, was?

$\underline{D^{\text {er }} \text { as s. } M . ~ N e u n z e h n ~ v o r b e i . ~}$

Der Gatte. Neunzehn ..... und ich

... Das s. M. ${ }^{\text {Sie }}{ }^{\mathrm{Du}}{ }^{\text {sind }}$ bist dreißig - !

Der Gatte. Und einiges druber . . Na

10 reden wir nicht davon ...- 
HSz6 194

Handschriften und Typoskript

br/An...

lophis, wi pat.

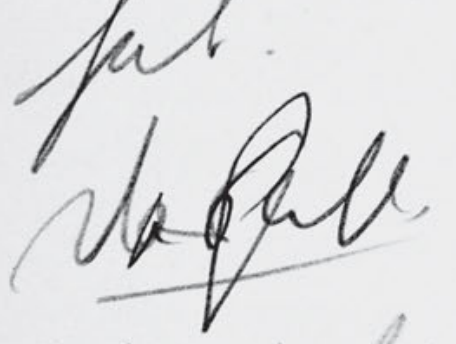

verpating Mis lars
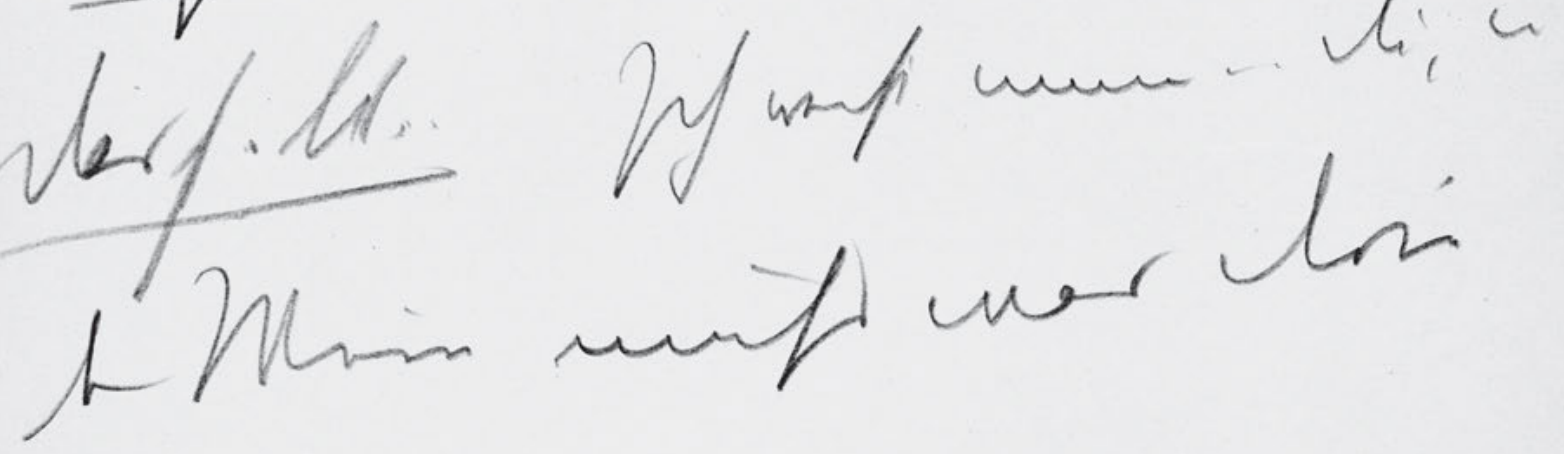

gumprom

on wall

j

$\operatorname{la} / 1 /$

Mt hisgr

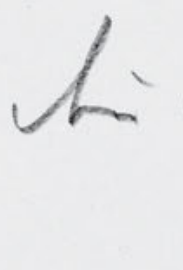

loy

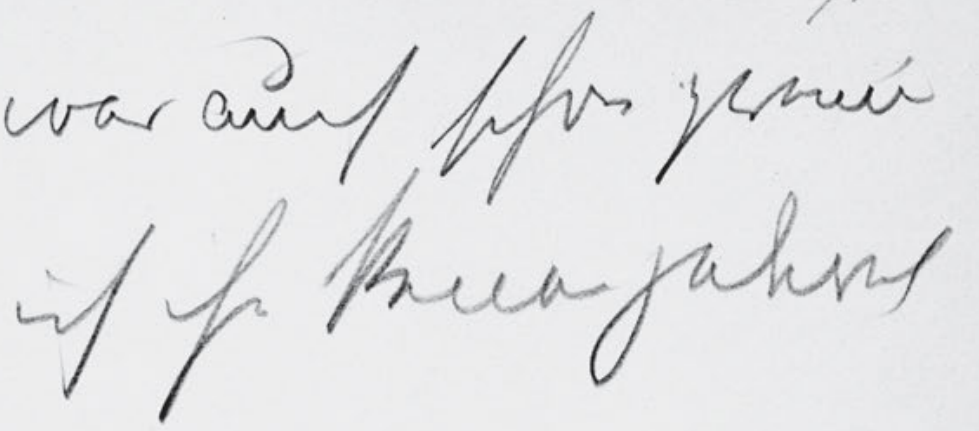




\section{4}

Das s. M. . . Er war auch schon zweiund

dreißig, wie ich ihn kenen gelernt

hab.

$5 \quad$ D ${ }^{\text {as }}$ er Gatte. Wie lang ist das her?

Das s. M. . Ich weiß nimm .. du, in

dem Wein muss was drin

gewesen sein.

Der Gatte. Ja warum den̄.

10 Das s M. Ich bin ganz . . weißt - mir 
HSz6 195

Handschriften und Typoskript

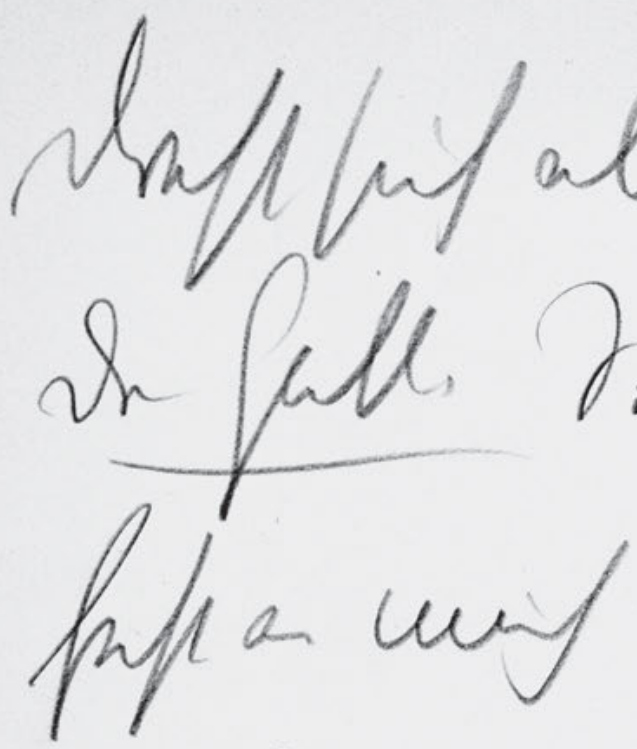

$\log 5$

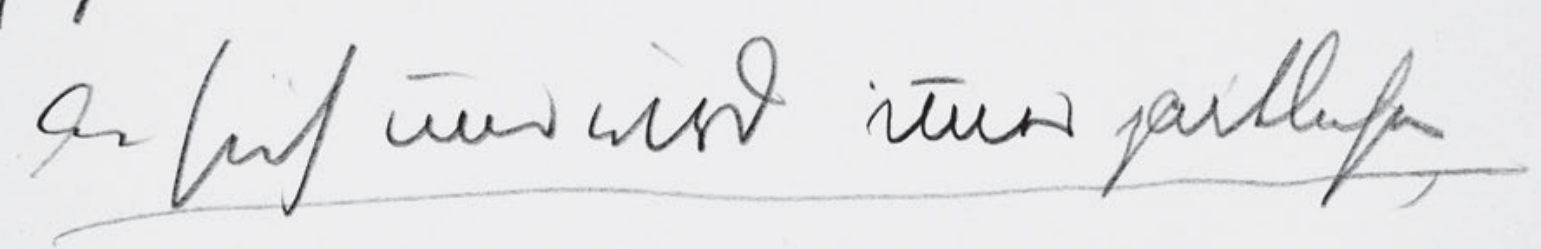

juimpt Raw al.
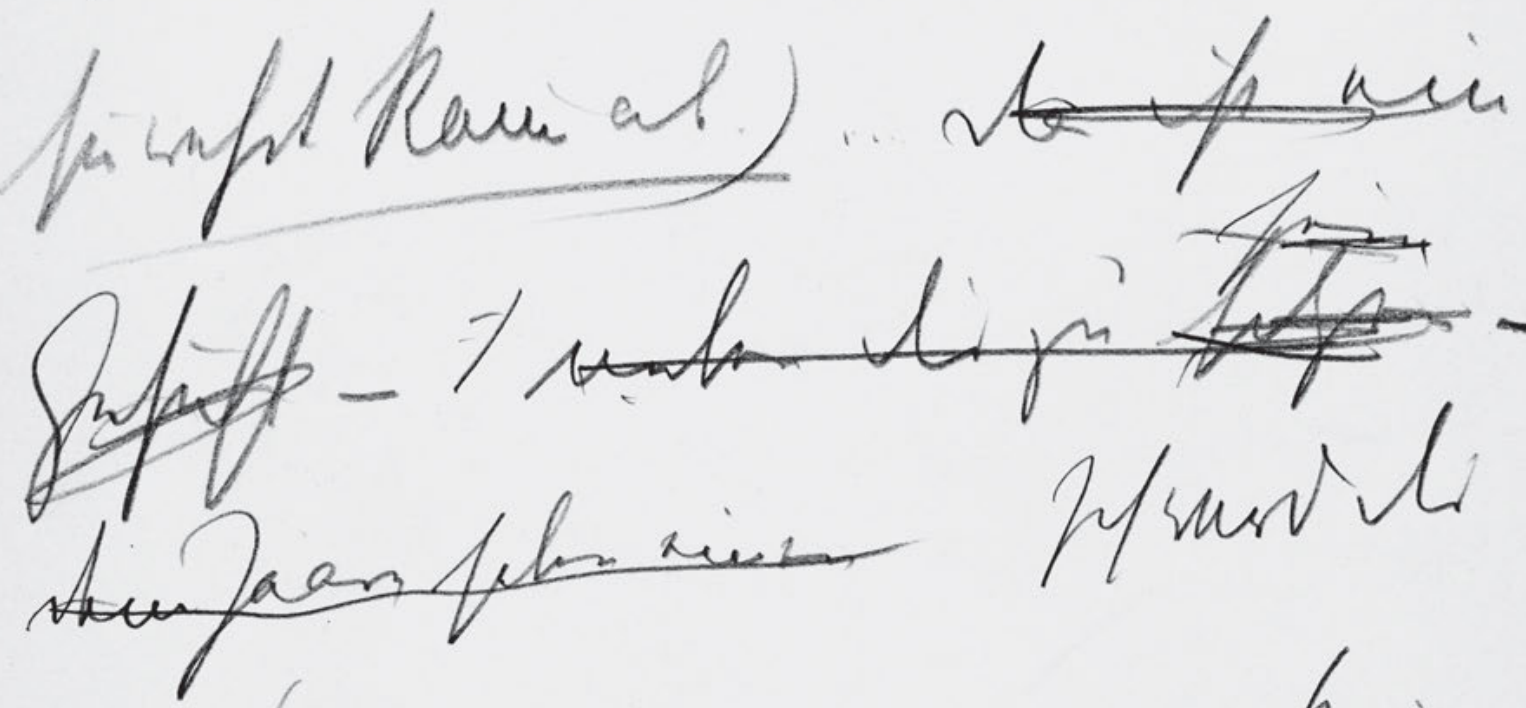

we Gysa. moin refut.

$$
\text { minort }
$$

436 


\section{5}

dreht sich alles .

Der Gatte. So halt halt dich

fest an mich. So . . (Er drückt ? sie $^{?}$

an sich und wird imer zärtlicher,

sie wehrt kaum ab.) .... Das ist ein

sein

Gefühl - [?] neben dir zu sitzen -

deine Haare haben einen Ich werd dir

was sagen . . mein Schatz . . wir könnten 
HSz6 196

Handschriften und Typoskript

ph wishlig gafm.

106

s.t.

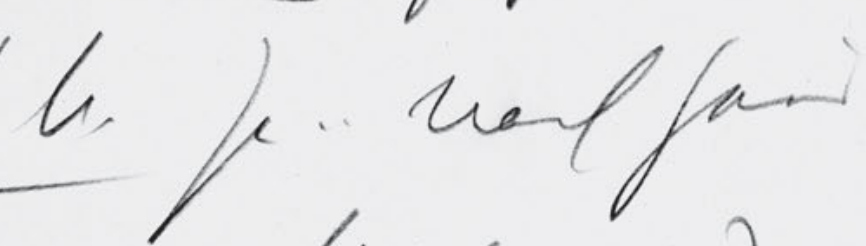

at heft. Wif

thel Wiff

ter/lis

Ner unife

n. of um ... of grt

ur

va fall hi hi rin.

t fath.

alf pi

Riv- har vianffe ha

Ln... wron

shiusiu un tors

inftsis

sulh 
196

jetzt wirklich gehn . .

Das s. M. Ja .. nach Haus.

Der Gatte. Nicht grad nach Haus.

${ }_{5} \quad$ Das s M. Was meinst deñ $-\ldots \mathrm{Oh}$

nein, oh nein ... ich geh nirgends hin.

was fallt dir deñ ein -

Der Gatte. Also . . hör mich einm

an .. mein Kind - das nächst Mal

weñ wir uns treffen . 'weißt du da

richten wir das so ein .. dass ..... 
HSz6 197

Handschriften und Typoskript

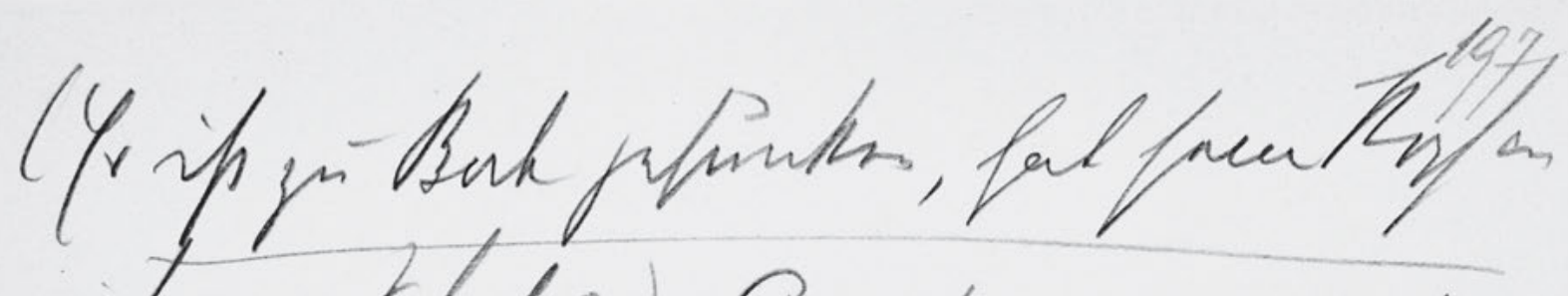

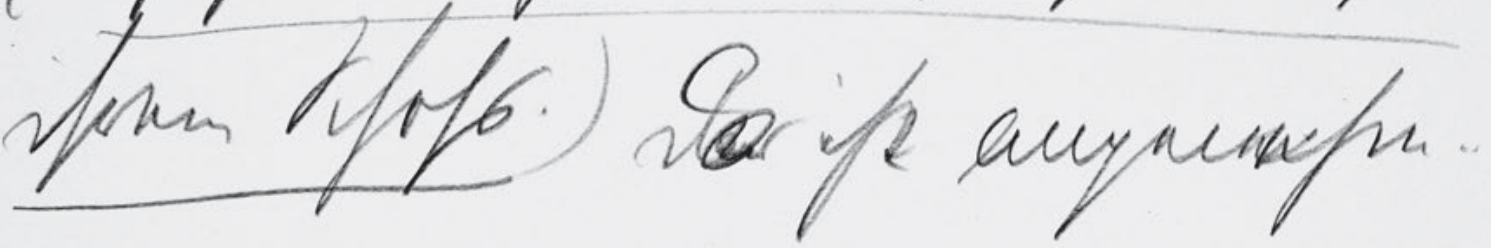
of he paujnurfin.

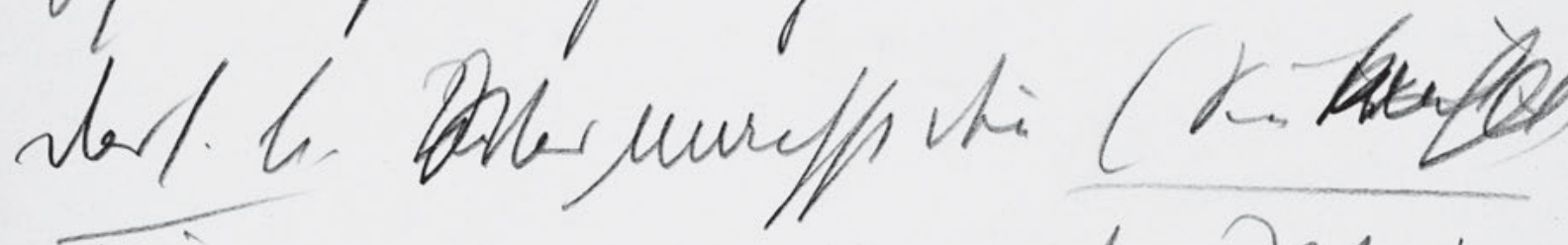

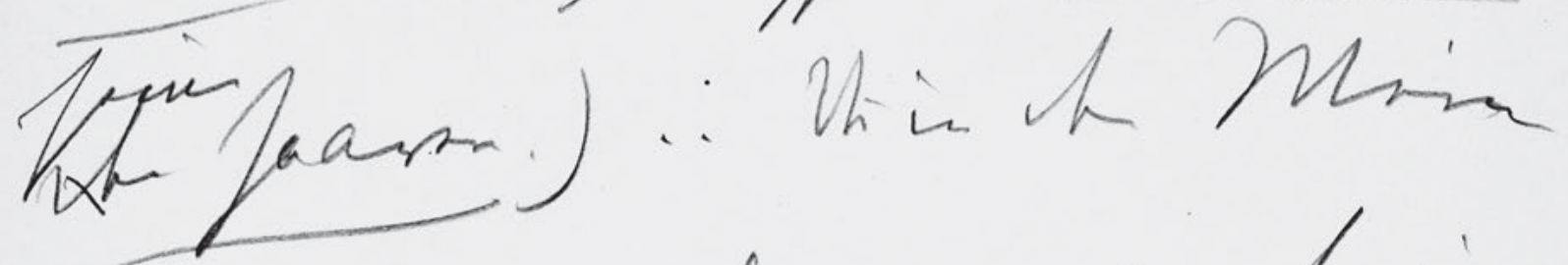

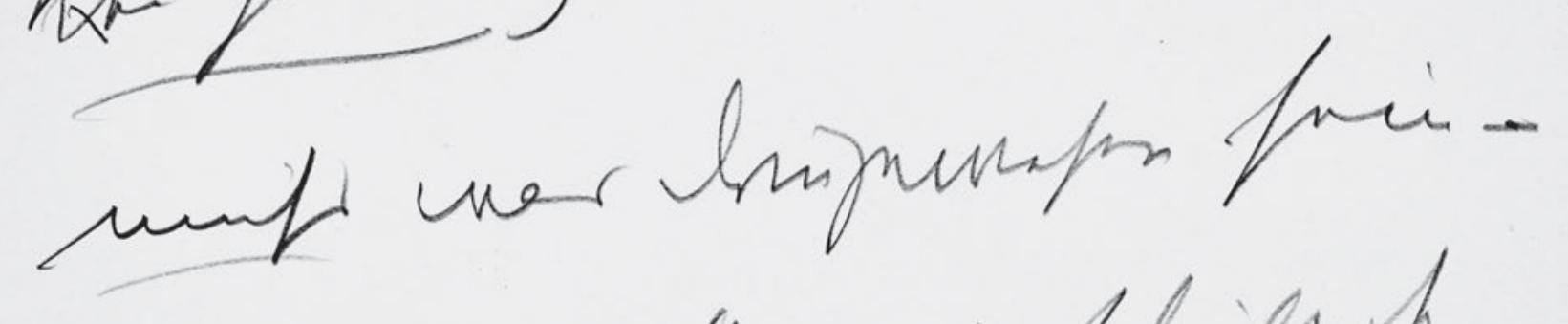

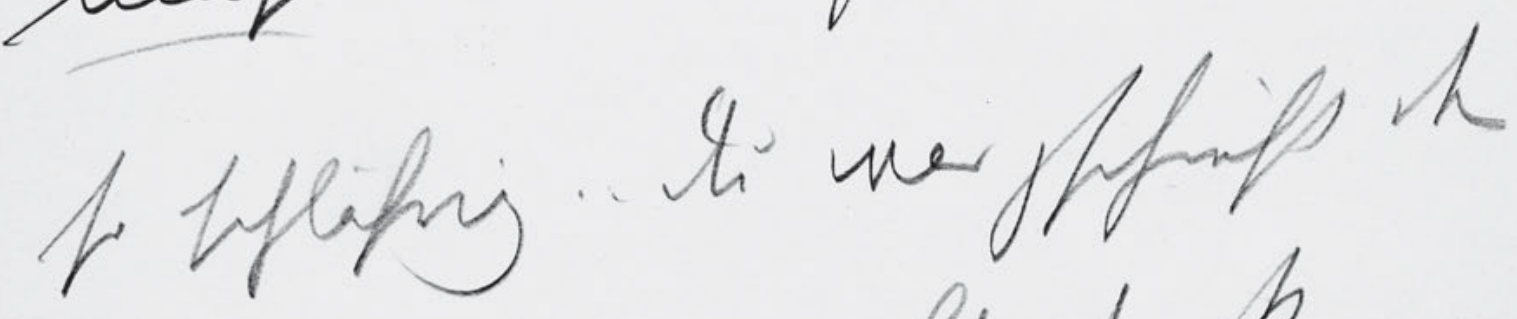
virin if mum entpry kam. sergath ha... ahr. Lfori ela

440 
(Er ist zu Boden gesunken, hat seinen Kopf 'an?

ihrem Schoss.) Dsa ist angenehm ..

oh da ist angenehm . .

$5 \quad$ Das s. M. ${ }^{N}{ }^{N}$ Was machst den (Sie ${ }^{\text {k[??] }}$ wühlt)

seine

den Haaren.). . ${ }^{\mathrm{D} u}{ }^{?}$ in dem Wein

muss was dringewesen sein -

so schläfrig . . Du was gschieht denn

wen̄ ich nī̄mer aufstehen kann.

10 Der Gatte. Aber . . aber . . schau . . aber 
HSz6 198

Handschriften und Typoskript

Renl... und miner

if lik the

N

pallur.

th

foris

fustin

Prelner...

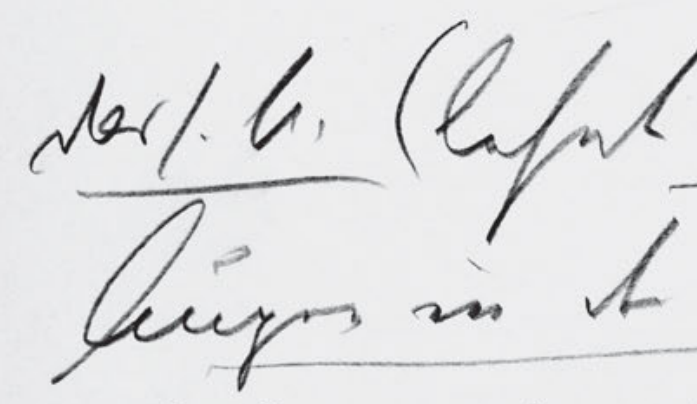

$$
9
$$




\section{8}

Karl ... und wen̄ wer hereinkō̄t.

. . ich bitt dich .. der Kellner ...

Der Gatte. Da ... kō̄t ... . kein

${ }_{5} \quad$ Kellner....... herein ........

Das s. M. (lehnt mit geschlossnen

Augen in der Divan Ecke.)

Der Gatte. (geht in dem kleinen Raum

10 auf u . ab, nachdem er sich eine

Cigarette angezündet.)

Längres Schweigen 
HSz6 199

Handschriften und Typoskript

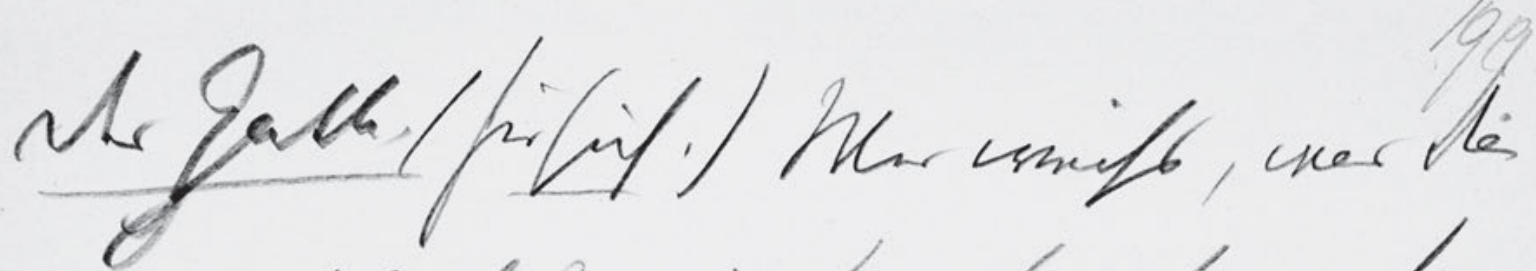

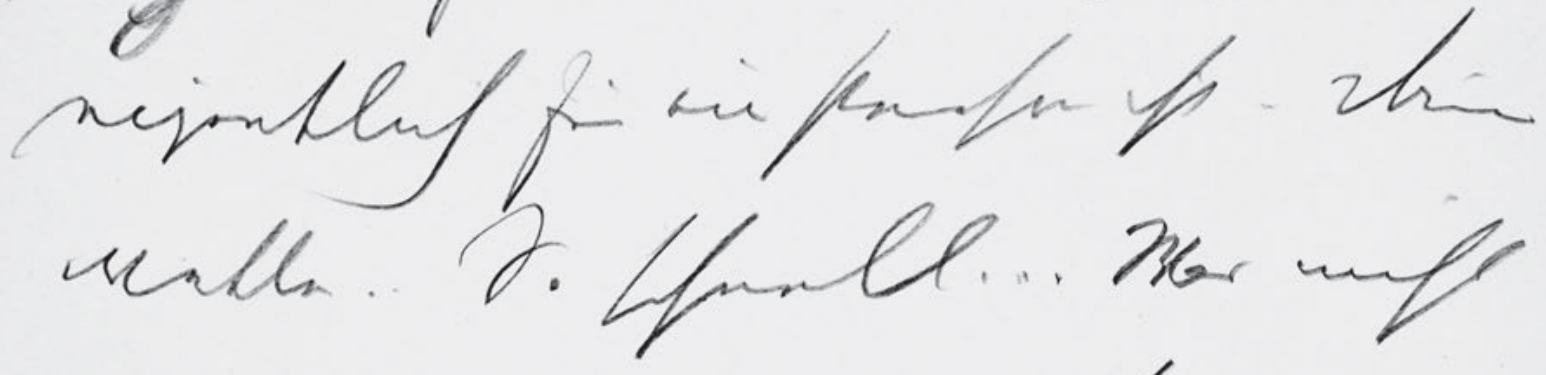

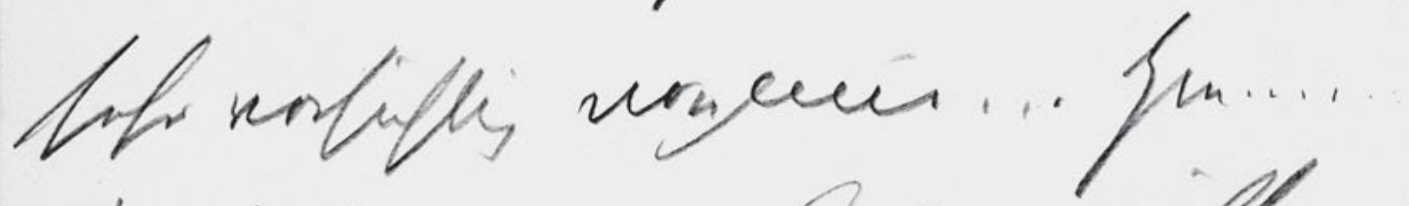

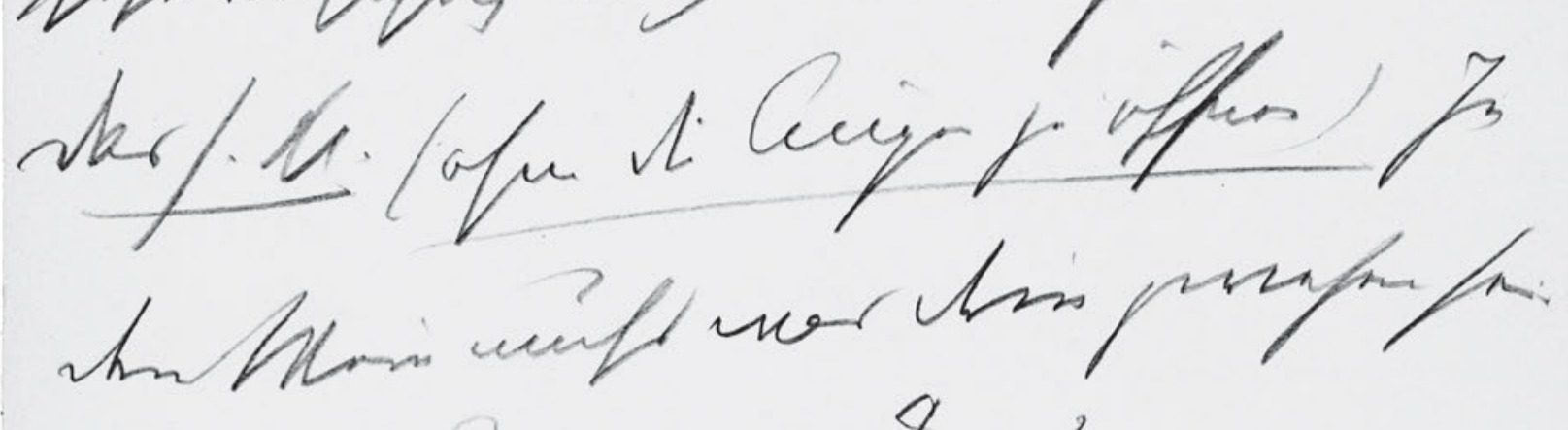
Arfath fuversion thu? berlas Iomp.

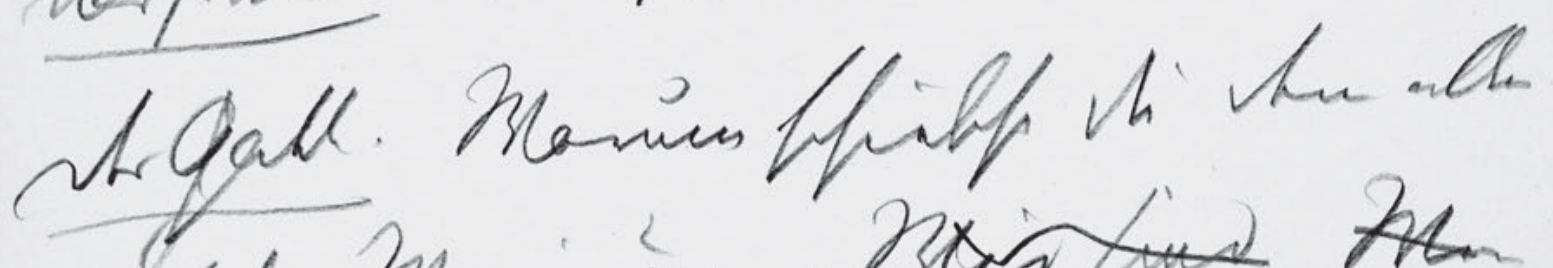

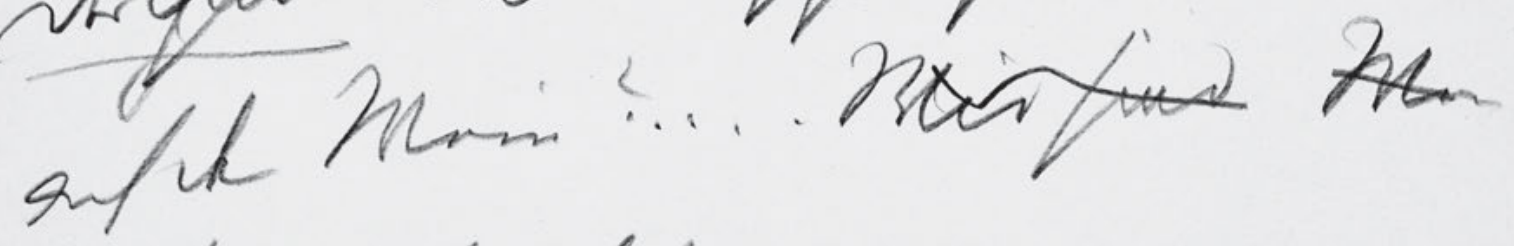

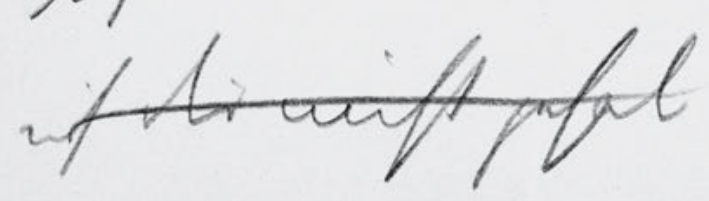

444 


\section{9}

Der Gatte. (für sich.) Wer weiss, was das eigentlich für eine Person ist - Dō̄er wetter . . So schnell .... War nicht

5 sehr vorsichtig von $\operatorname{mir} \ldots \mathrm{Hm} \ldots .$.

Das s. M. (ohne die Augen zu öffnen) In dem Wein muss was drin gewesen sein. Der Gatte. Ja warum denn?

Das s. M. Sonst...

10 Der Gatte. Warum schiebst du denn alles auf den Wein? .... Wir sind Wenn ich dir nicht gefal 
HSz6 200

Handschriften und Typoskript

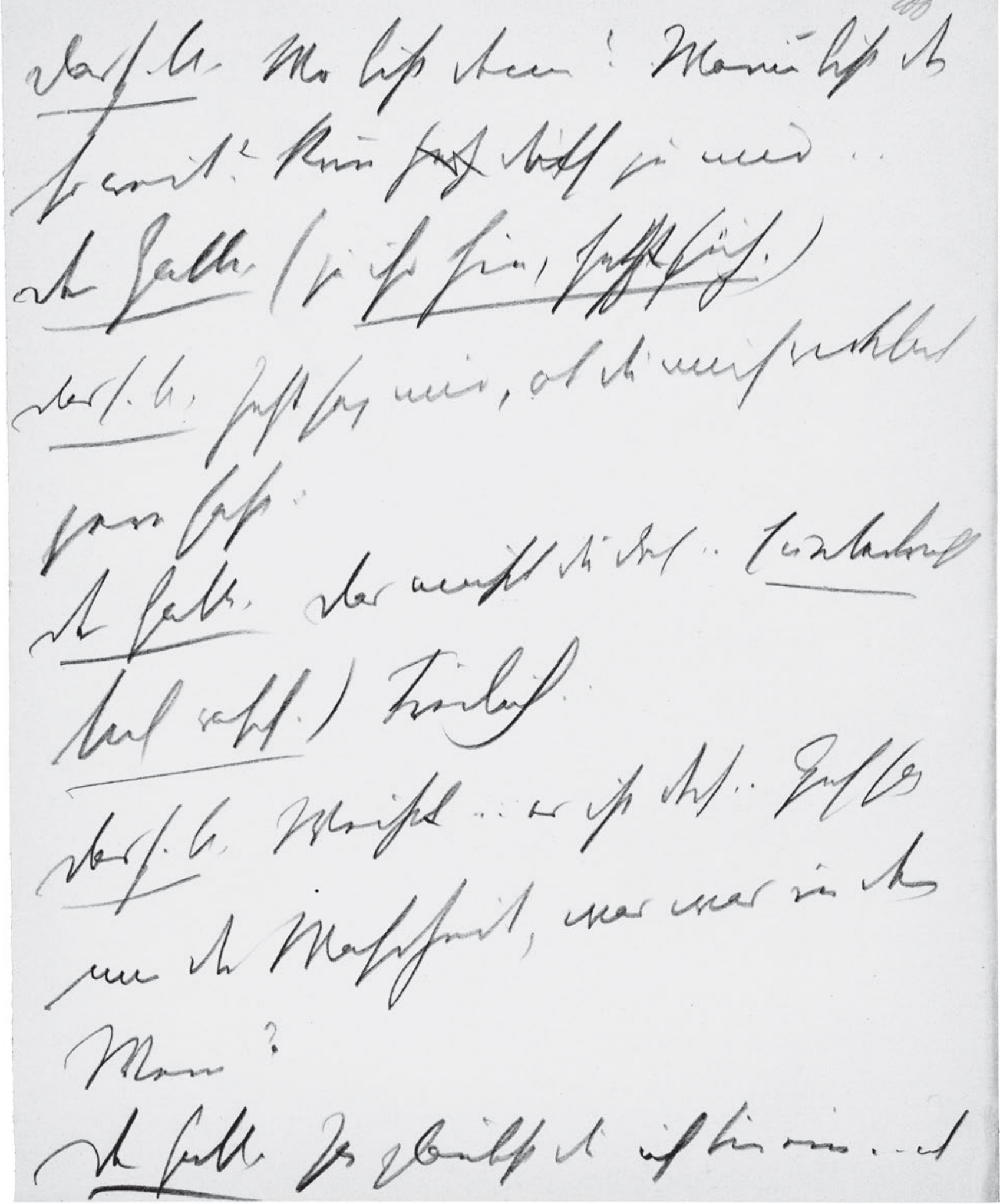

446 
200

Das s. M. Wo bist denn? .Warum bist denn

so weit? Kōm setz $\mathrm{d}^{\mathrm{ich}}$ och zu mir . .

Der Gatte. (zu ihr hin, setzt sich.)

${ }_{5} \quad$ Das s. M. Jetzt sag mir, ob du mich wirklich

gern hast . .

Der Gatte. Das weißt du doch . . (unterbricht

sich rasch.) Freilich . .

Das s. M. Weißt ... es ist doch . . Geh sag

10 mir die Wahrheit, war was in dem

Wein?

Der Gatte. Ja glaubst du ich bin ein .. ich 
his ffluntf-

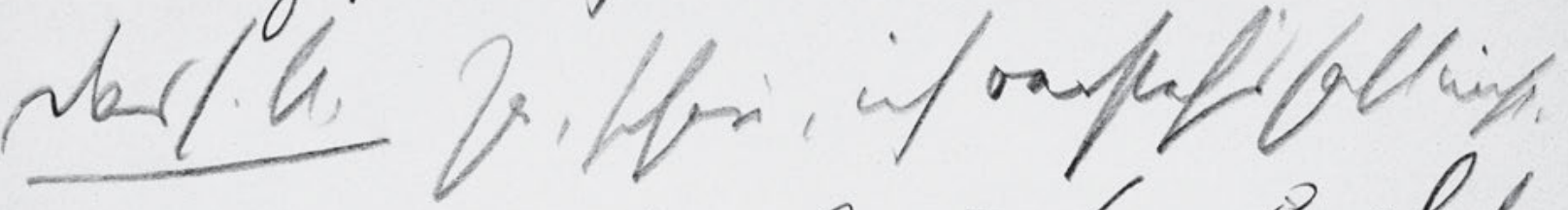

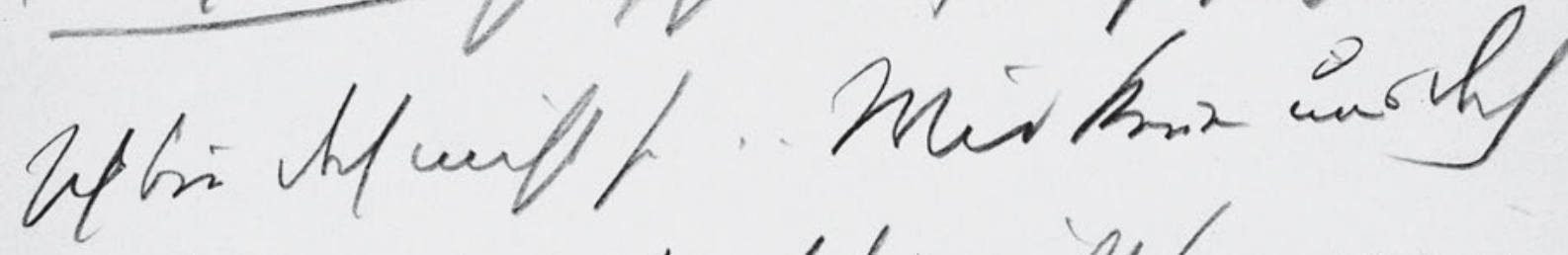

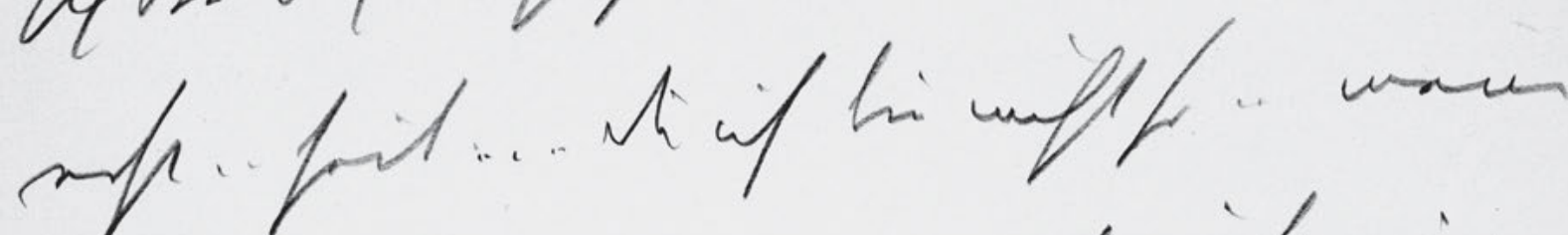
traliur fold, =

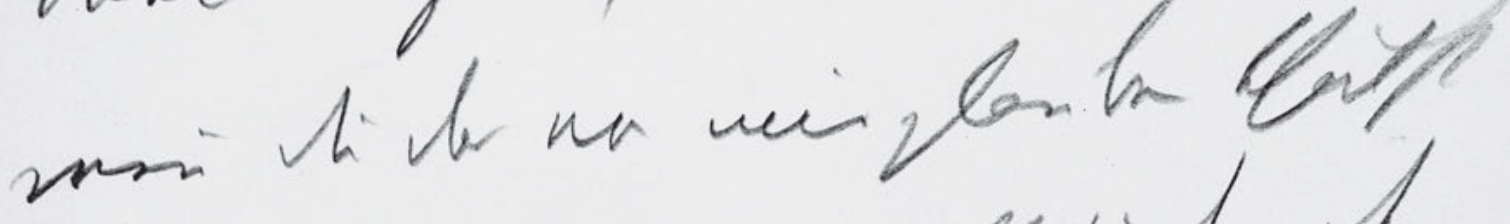
chrfall. p-urmalfisich a Posym. Af bents wift the un Mi. Mf fent foll, bef 1 mul lind fof bith Jan.. 


\section{1}

bin ein Giftmischer.

Das s. M. Ja, schau, ich versteh's halt nicht. Ich bin doch nicht so .. Wir ken̄en uns doch

${ }_{5}$ erst . . seit ..... du ich bin nicht so . . meiner

Seel und Gott, - mein das ist mir

weñ du das von mir glauben thätst.

Der Gatte. Ja - was machst du dir denn

fur Sorgen. Ich glaub gar nichts schlechtes

von dir. Ich glaub halt, dass du

mich lieb hast.

Das s. M. Ja .....? - 
HSz6 202

Handschriften und Typoskript

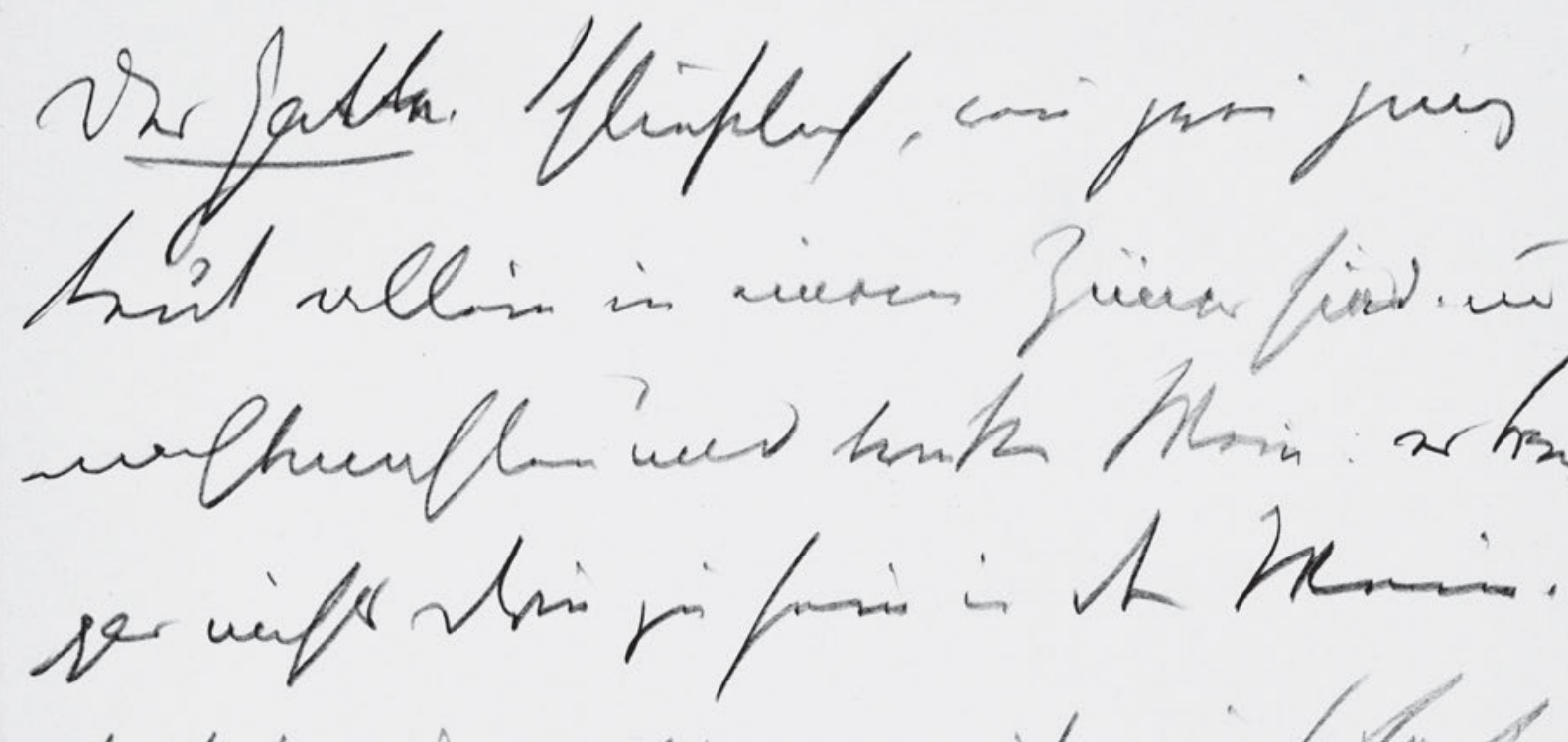

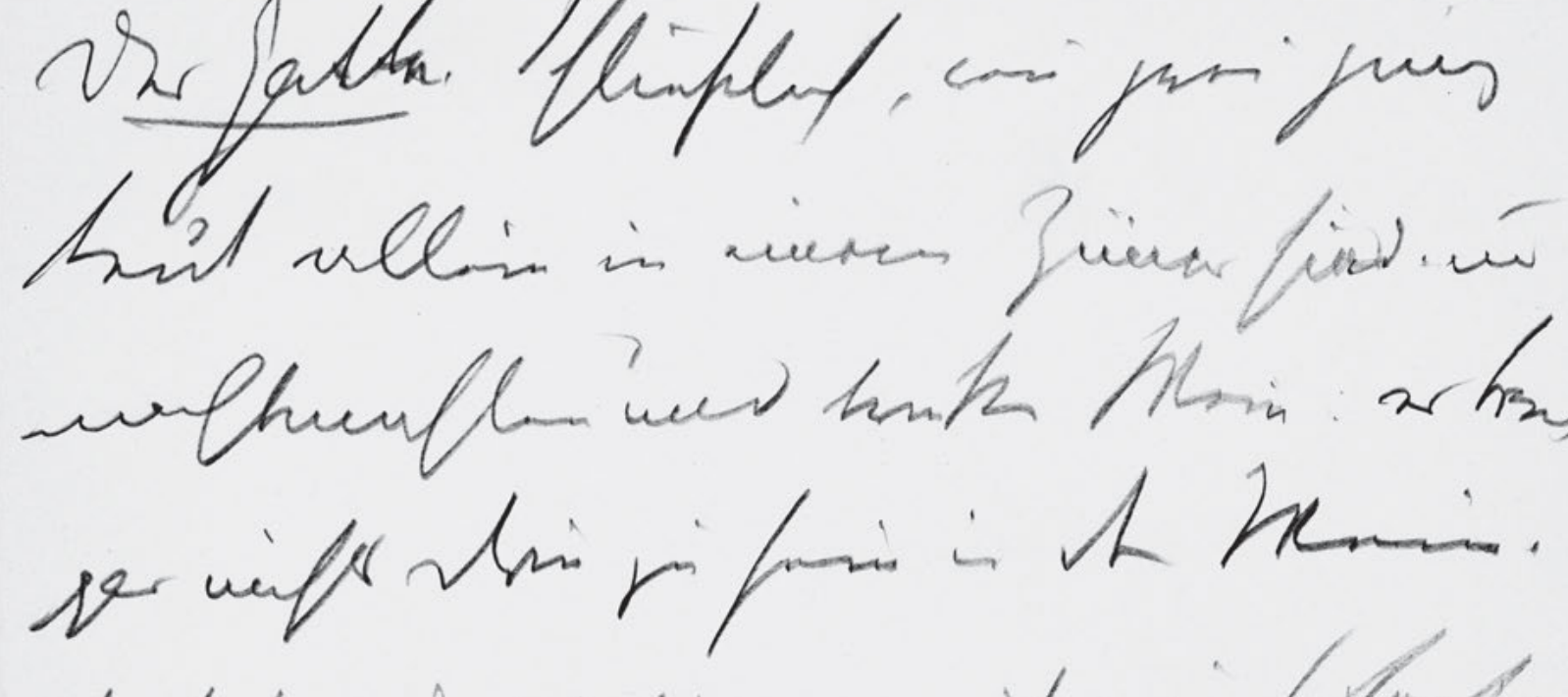

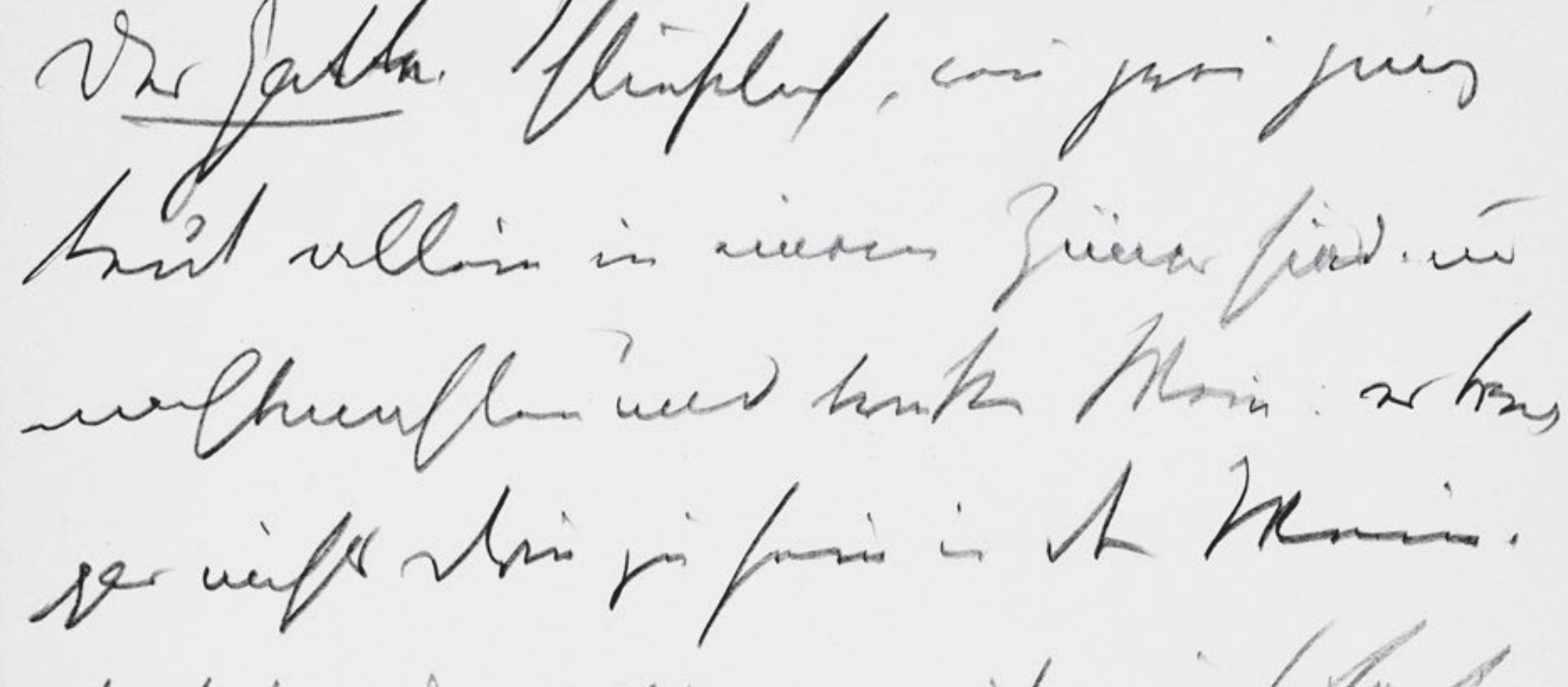

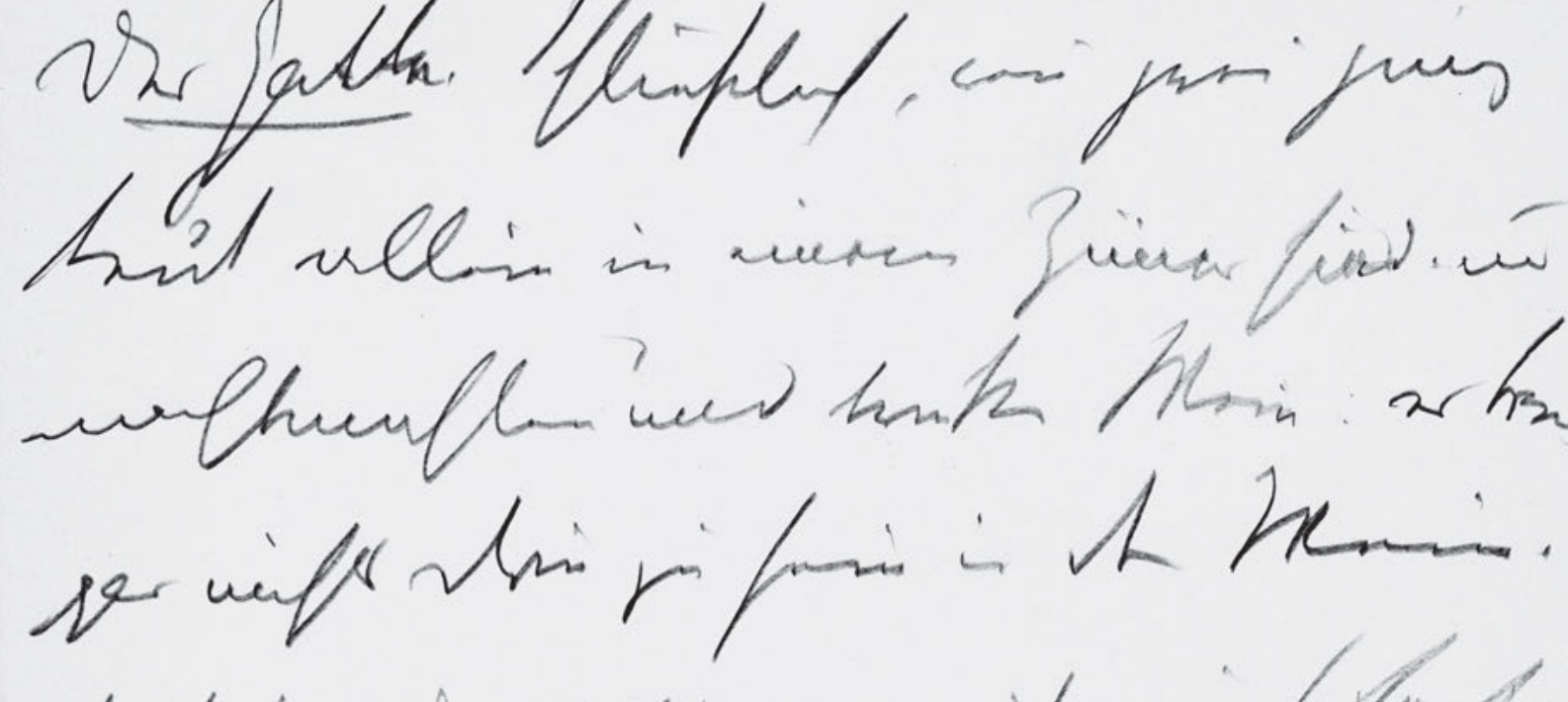

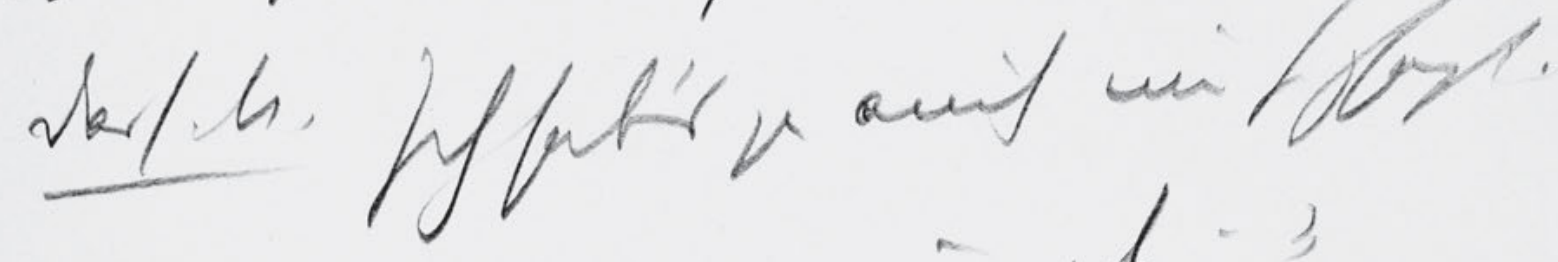

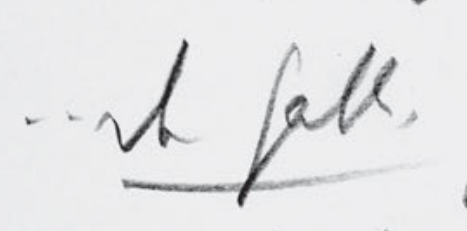

$282^{\cdots}$ ball.h. a wermin th.

450 


\section{2}

Der Gatte. Schließlich, wen̄ zwei jung

Leut allein in einem Zimer sind . . und

nachtmahlen und trinken Wein . es ?brauch?

$5 \quad$ gar nichts drin zu sein in dem Wein.

Das s. M. Ich hab's ja auch nur so gsagt.

. . Der Gatte. Ja warum den̄?

Das s. M. (eher trotzig) Ich hab mich

halt gschämt.

10 Der Gatte. Das ist lächerlich .. daz

liegt gar kei Grund vor. Umsomehr als

4 punktförmige Verschmutzung bei Wein .; kein Doppelpunkt. 
HSz6 203

Handschriften und Typoskript

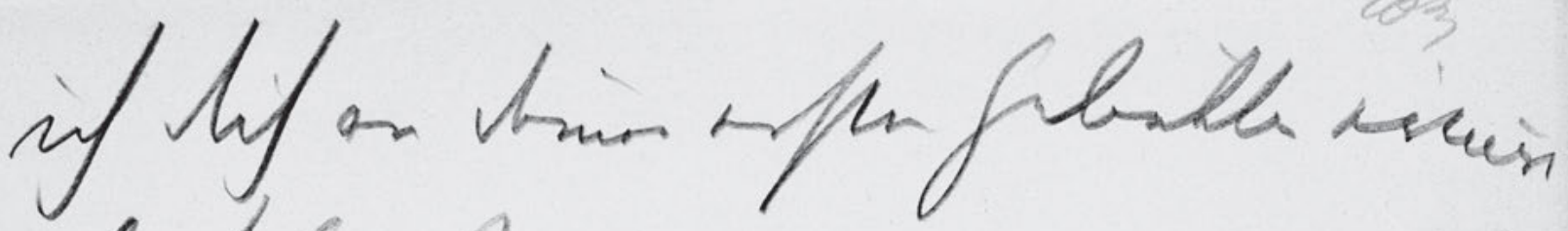

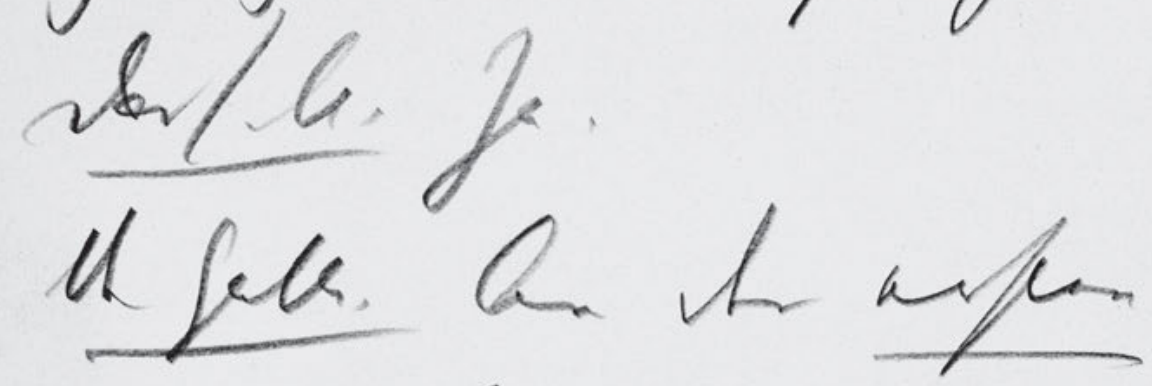

da/le bage..

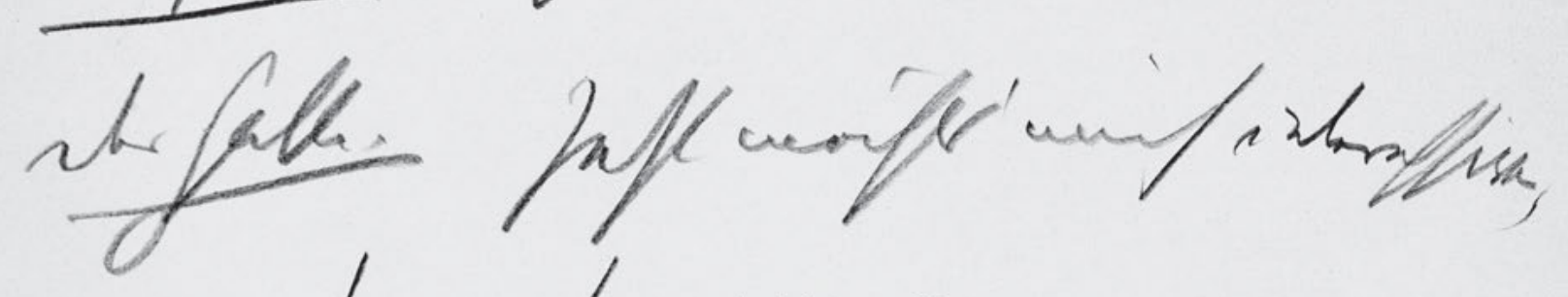

thir wiff mit /

bet. Intate wis

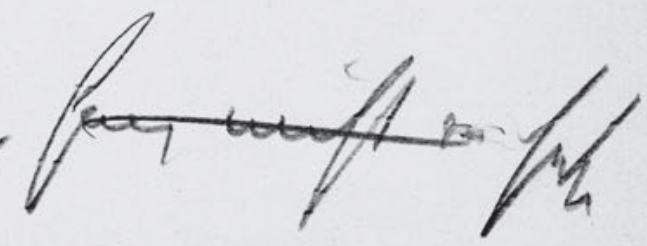

452 
203

ich dich an deinen ersten Geliebten erin̄re

Das s. M. Ja.

Der Gatte. An den ersten.

${ }_{5} \quad$ Das s M. Na ja. .

Der Gatte. Jetzt möcht's mich interessiren, wer die andern waren.

Das s. M. Niemand.

Der Gatte. Das ist ja nicht wahr . . das

10 kan̄ ja nicht wahr sein

Das s. M. Geh bitt dich, frag nicht [???] seki 
HSz6 204

Handschriften und Typoskript

neis/mift..

20y
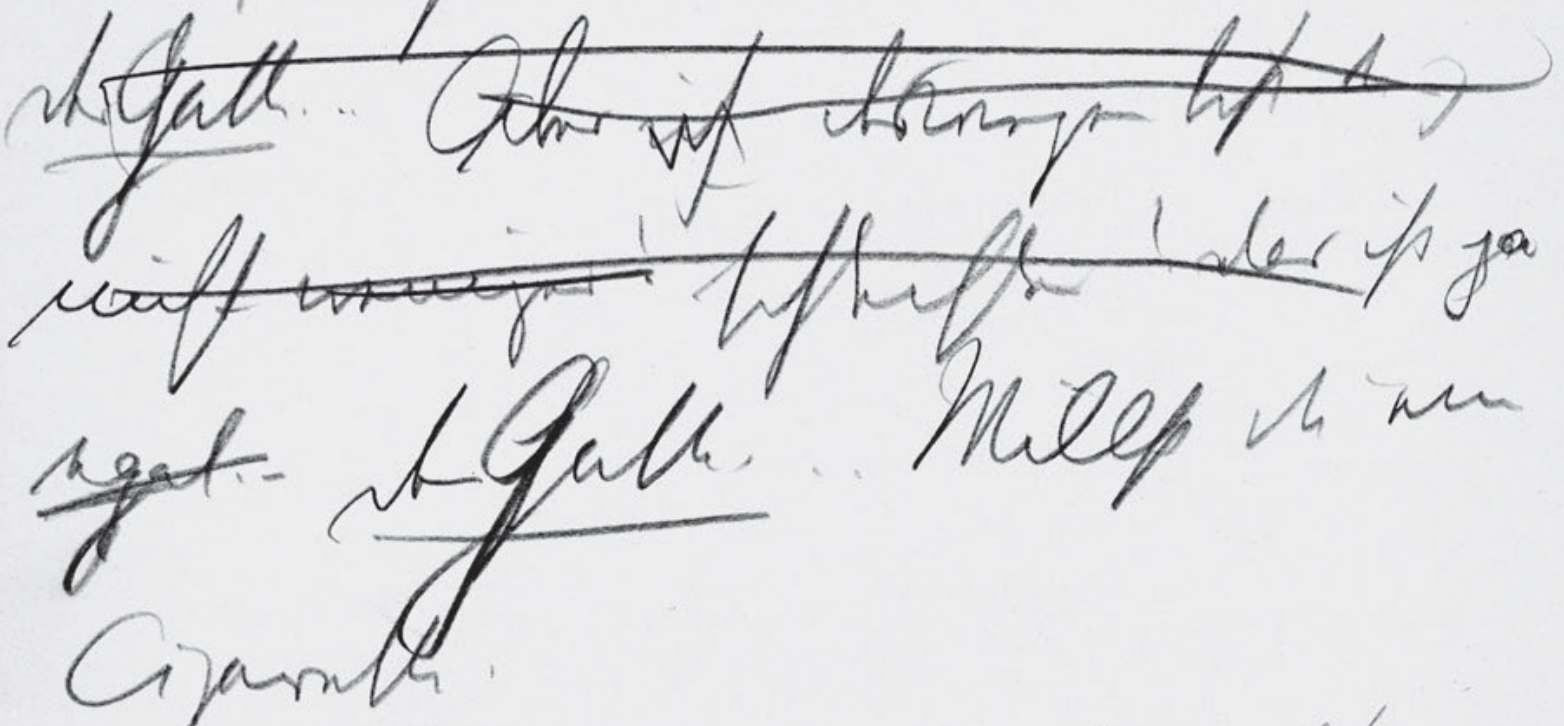

mele

debl.ll Mnim, of burh ffrin..

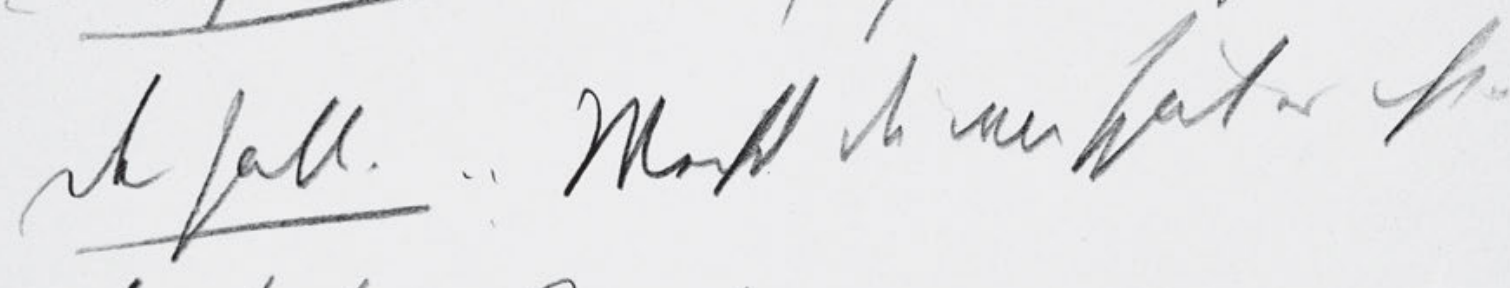

ba/.h

ha.'

ch futhe

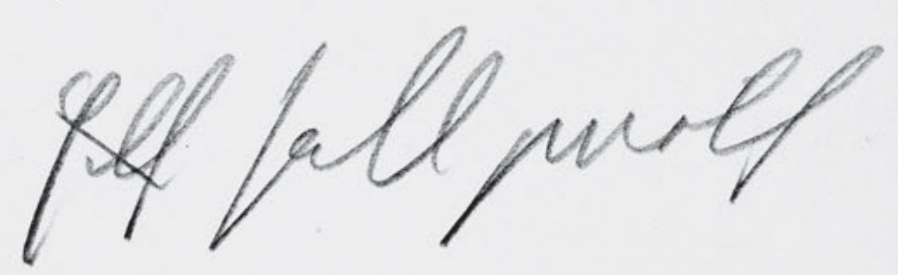

lar/la. zo!

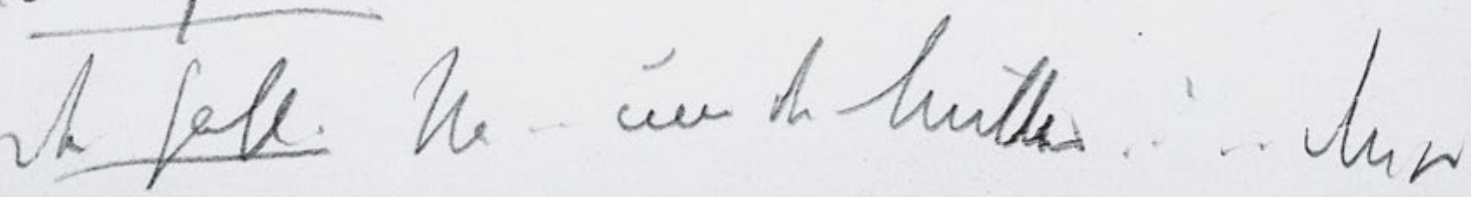

454 
mich nicht. ${ }^{*}$

Der Gatte. . . Aber ich deswegen bist duj

nicht weniger! schlechter! Das ist ja

5 egal.- Der Gatte. .. Willst du eine

Cigarette.

Das s. M. Nein, ich dank schön . .

Der Gatte. . . Weißt du wie spät es ist . .

Das s. M. $\mathrm{Na}-$ ?

10 $\quad$ Der Gatte Eilf Halb zwölf!

Das s. M. . So!

Der Gatte. Na . . und die Mutter . ? . . die [???] 
HSz6 205

Handschriften und Typoskript

or gevopht, war!

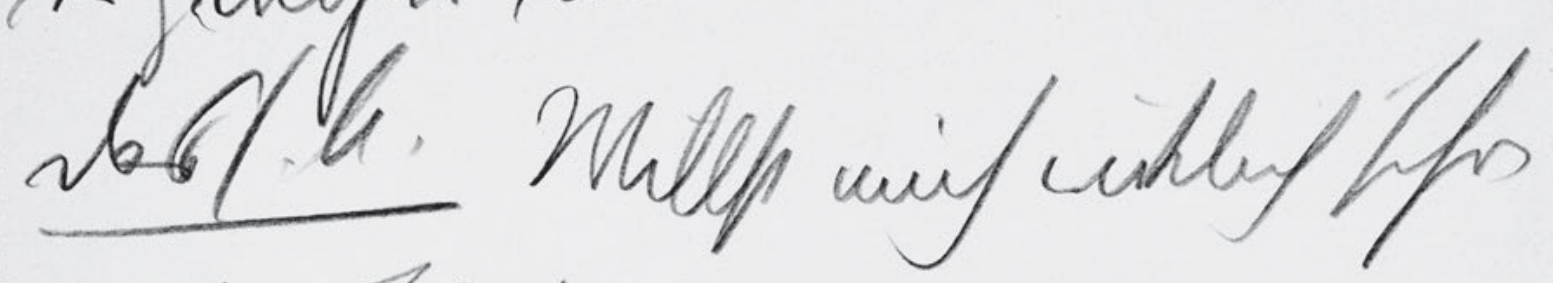

sear Pficton? -

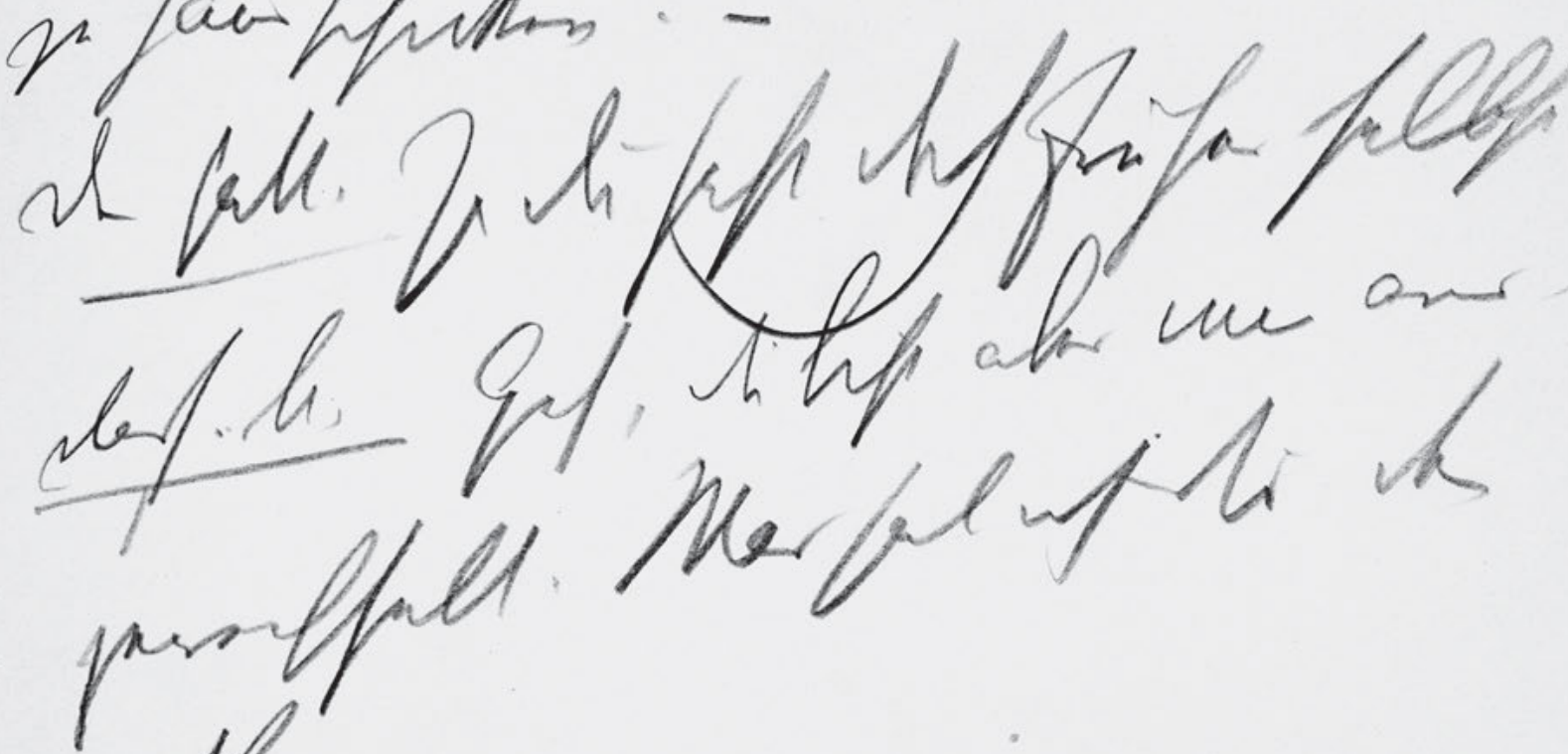

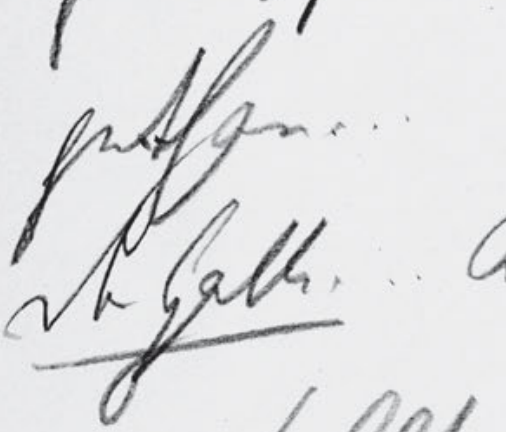

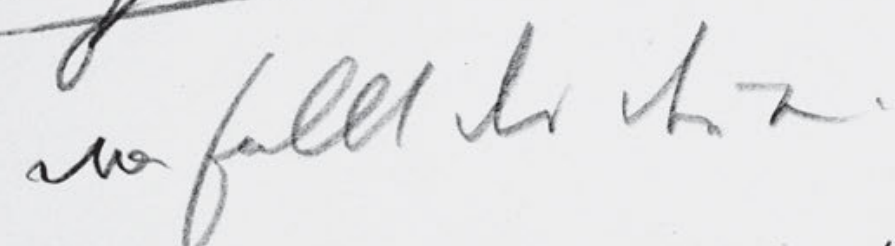

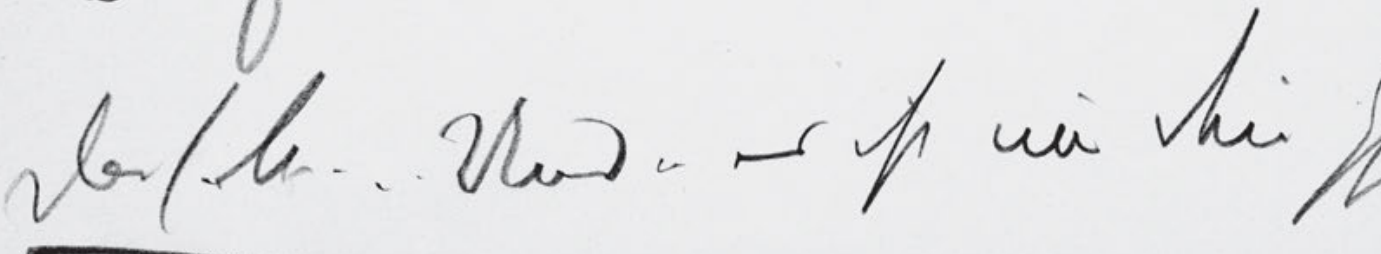


205

es gewöhnt ${ }^{*}$, was?

Das s. M. Willst mich wirklich schon

zu Haus schicken? -

5 Der Gatte. Ja du hast doch früher selbst -

Das s. M. Geh, du bist aber wie aus-

gewechselt. Was hab ich dir denn

gethan ....

Der Gatte. .. Aber . Kind . was hast du den̄

$10 \quad$ was fallt dir dē̄ ein.

Das s. M. . . Und . . es ist nur dein Gschau 
HSz6 206

Handschriften und Typoskript

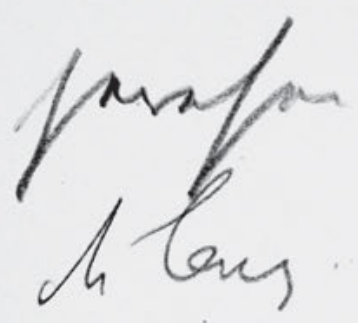

ulpall

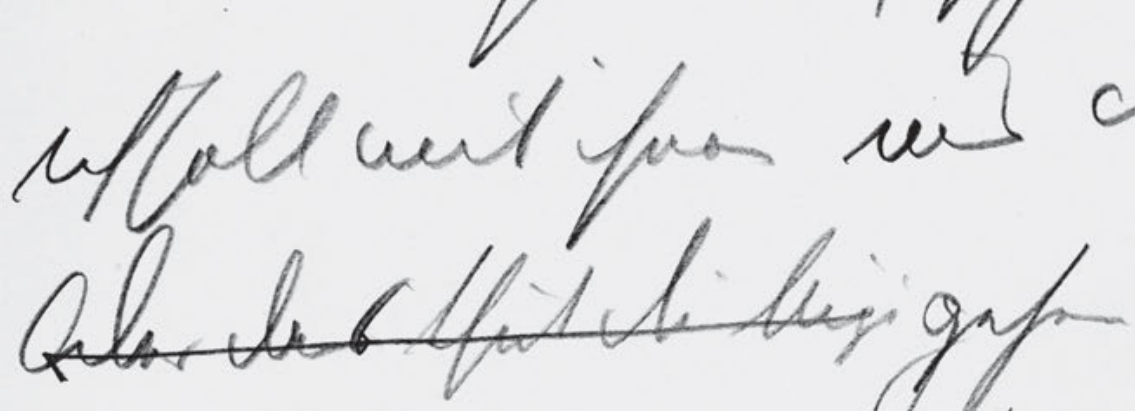

cemant.

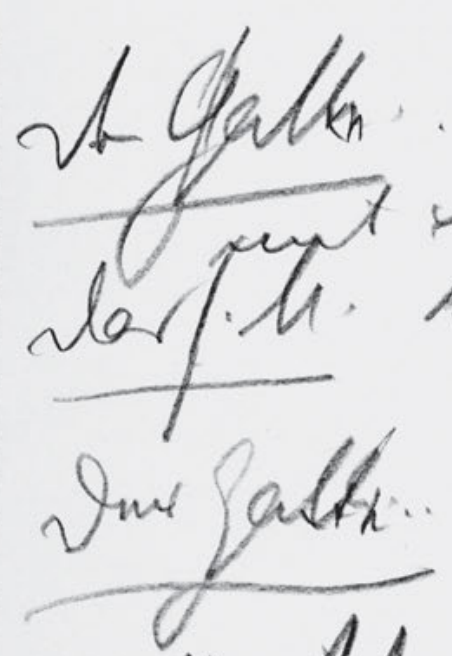

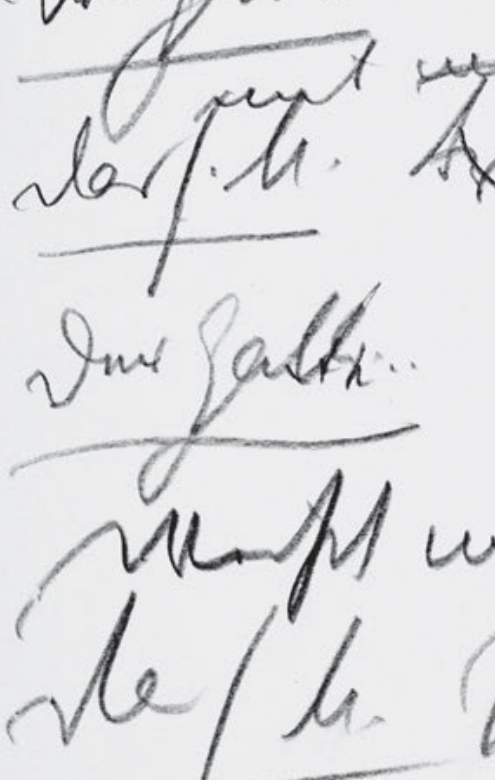

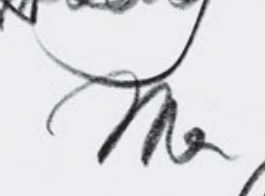


206

gewesen . . meiner Seel . . sonst hättst

du lang .... haben mich scho viele gebete, ich soll mit ihnen ins chambr separé.

$5 \quad$ Aber das thut die Mizi gehen ....

Der Gatte. . . Na . willst du . . bald wieder. mit mir hieher . . oder auch wo anders

Das s. M. Freilich Weiß nicht. -

Der Gatte. . Was heißt das wieder: Du

weißt nicht.

10 Das s M. Na wen̄ du mich erst fragst?

dich

Der Gatte. .. Also .. wann .. Ich muss nur 
HSz6 207

Handschriften und Typoskript

nor alo cnflelara, la montrent dar/sla  befle. abe if h ofl 
207

vor allem aufklären, dass ich nich

in Wien lebe. Ich kōm nur von

Zeit zu Zeit auf ein paar Tage her.

${ }_{5} \quad$ Das s. M. Ah geh . . du bist kei Wiener?

Der Gatte. Wiener bin ich schon

Aber ich lebe jetzt in der Nähe . .

Das s. M. Wo deñ?

Der Gatte. Ach Gott, das ist j??

10 egal.

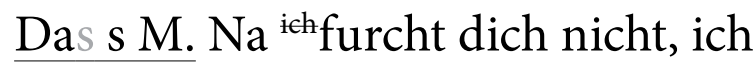


HSz6 208

Handschriften und Typoskript

timi nift fin

ch fable

umifl

tarmon. Heak in Grag.

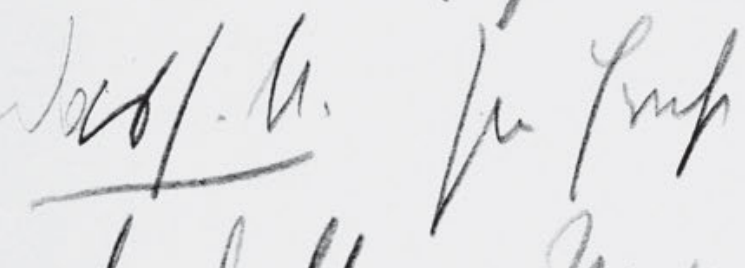

208

of wh uni - Mr bof

kempli andf

at falle

her

ner munt

h livar.

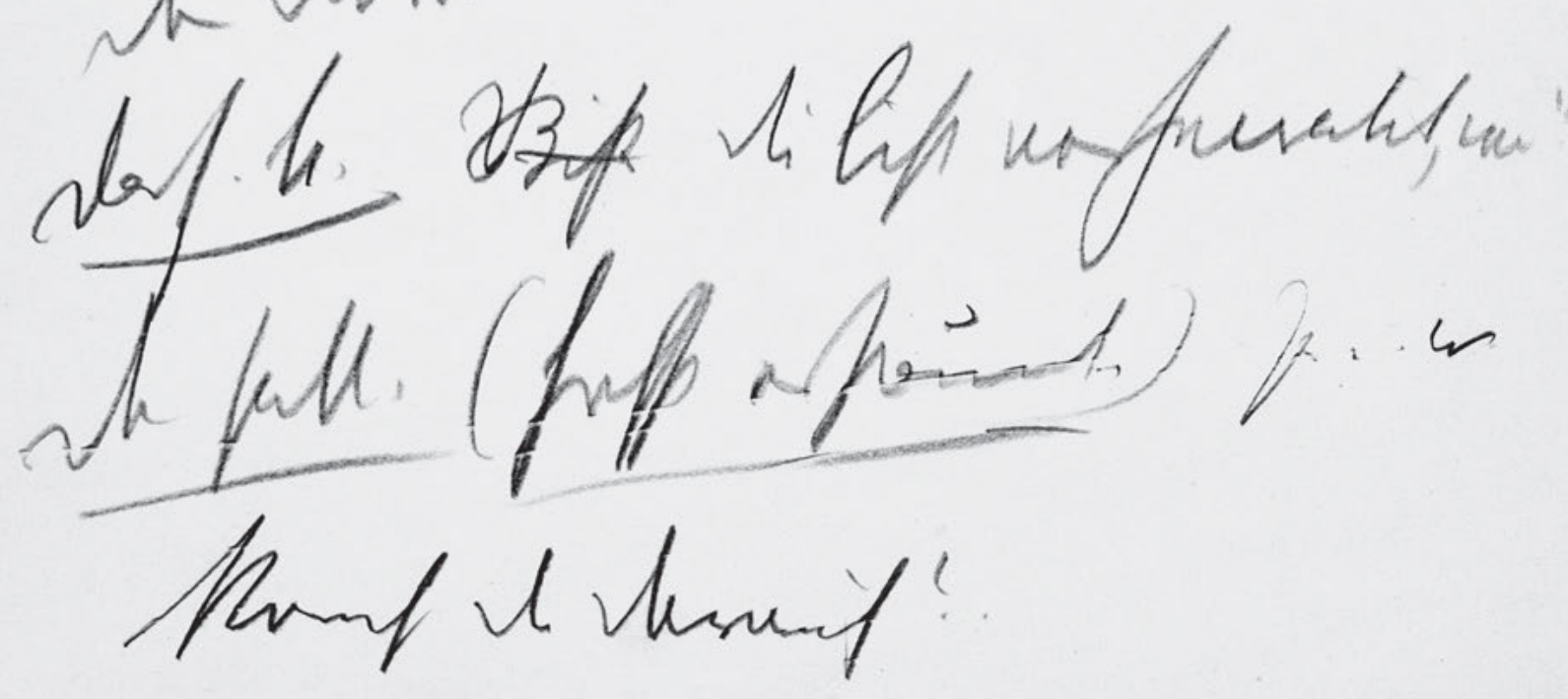

462 


\section{8}

kō̄ nicht hin.

Der Gatte. Oh Gott - wen̄ es dir Spass

mach ${ }^{\text {st }}{ }^{*}$, kannst du auch $h$

$5 \quad$ komen. Ich lebe in Graz.

(Das s. M. Im Ernst.

Der Gatte. Na ja, was wundert dh

den daran.

Das s. M. ${ }^{[?]}$ Bist Du bist verheiratet, was! ?

10 Der Gatte. (hochst erstaunt.) Ja .. w

komst du darauf? . 
HSz6 209

Handschriften und Typoskript

las/lu.

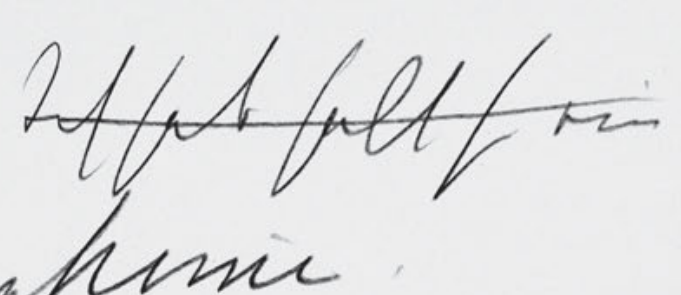

Uniryes sabfall va var/D. h

$$
1 \text { jar un }
$$
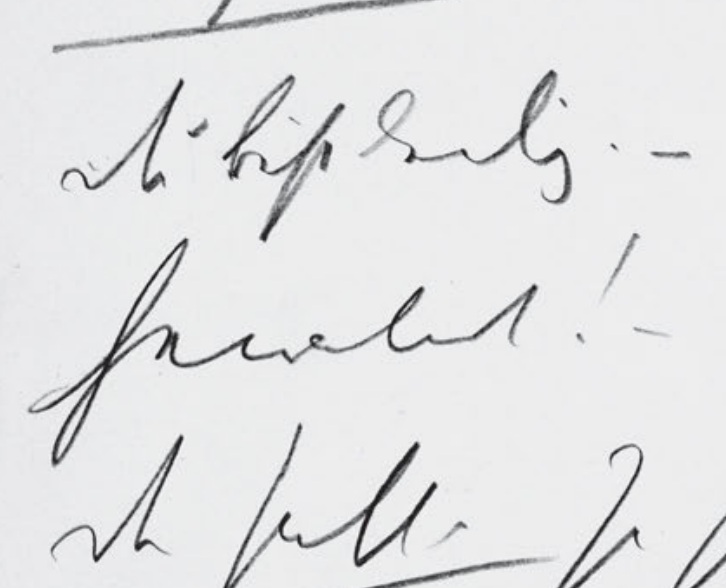
weln 1'

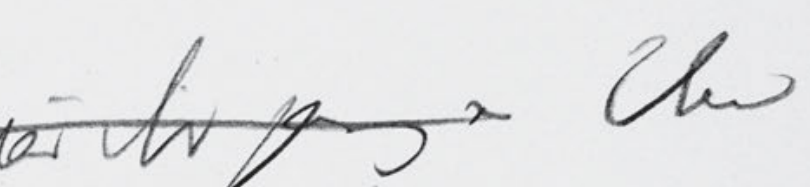


Das s. M. Ich hab halt so ein Mir ist halt

so vorgekomen.

$\mathrm{D}^{\mathrm{a} e s}$ Gatt. Das wär dir ganz e Und

$5 \quad$ das würde dich gar nicht geniren?

Das s. M. Na lieber ist mir scho, ja doch

du bist ledig. - Aber du bist verheiratet! -

Der Gatt. Ja sag mir nur, wie

kō̄st du den . da[?] dr?auf?

Das s. M. Weñ einer sagt - er lebt 
HSz6 210

Handschriften und Typoskript

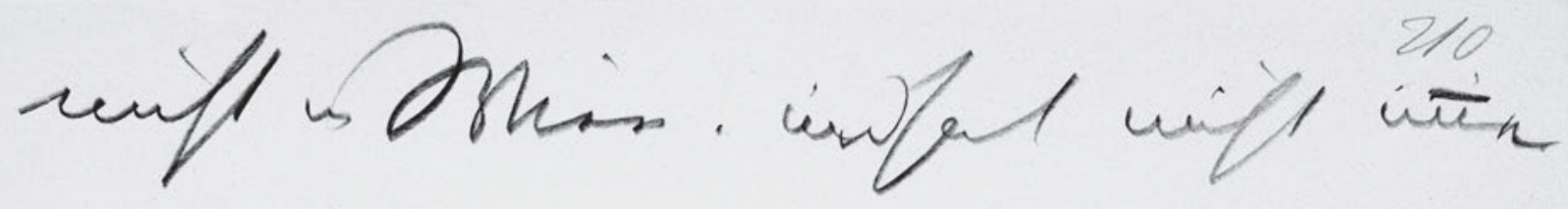

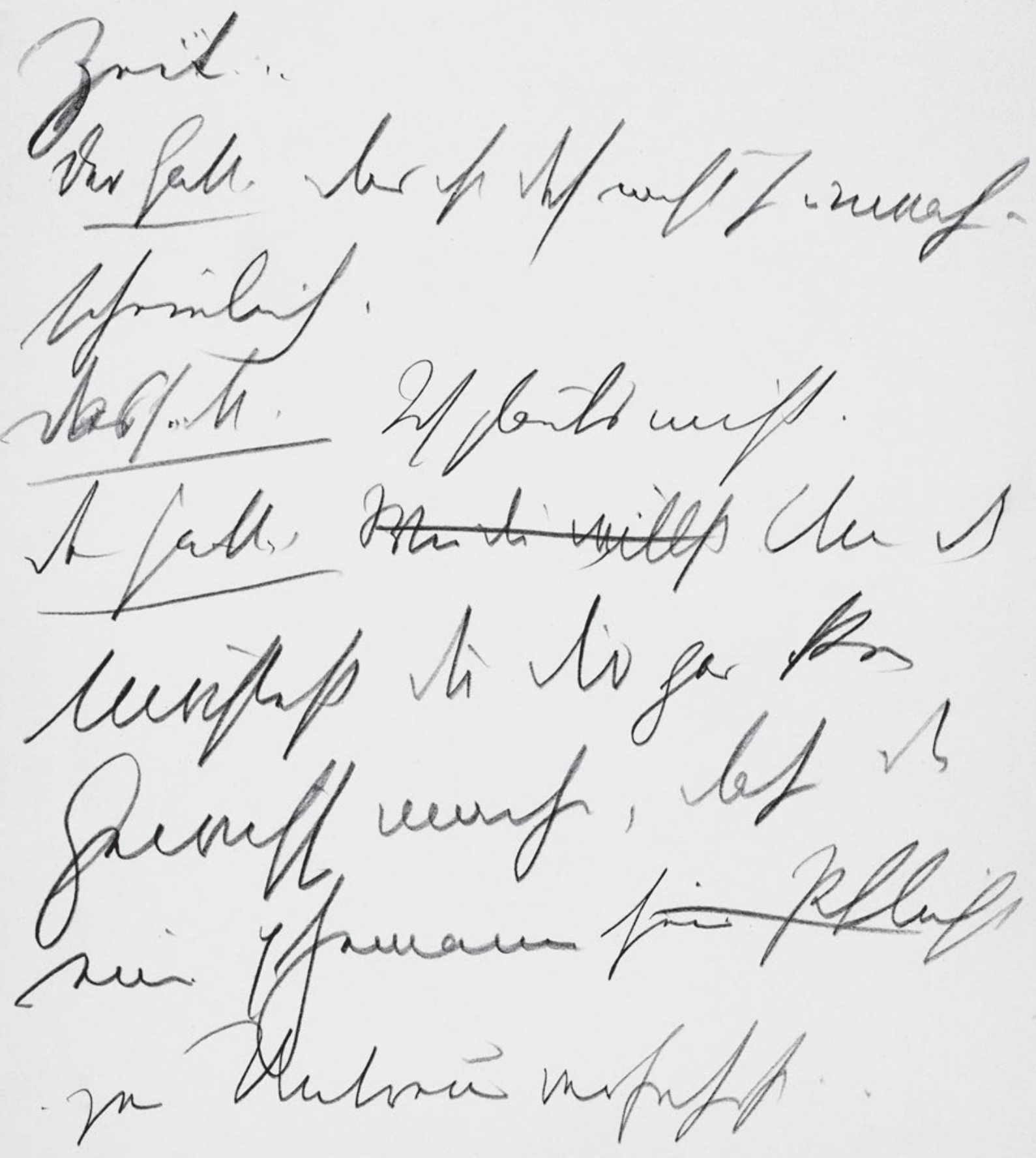




\section{0}

nicht in Wien . und hat nicht imer

Zeit ....

Der Gatte. Das ist doch nicht so unwahr-

5 scheinlich.

Das s. ... I. Ich glaubs nicht.

Der Gatte. Wie du willst Und d

möchtest du dir gar kein

Gewissen machen, dass du

10 einen Ehemann sein Pflicht

zur Untreue verfuhrst . . 
HSz6 211

Handschriften und Typoskript

lar/la

ver sheen tra newes
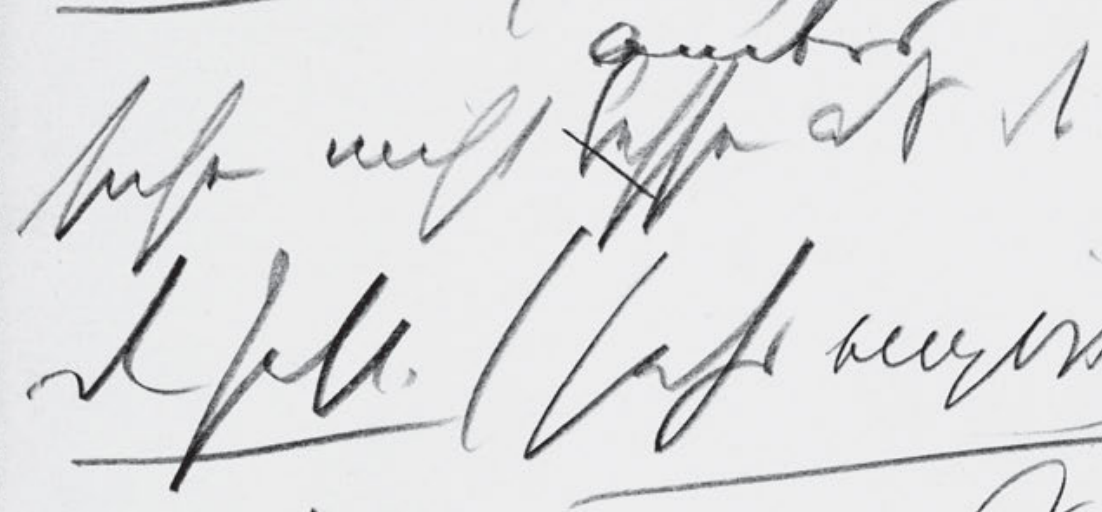

$$
\text { werots dis b }
$$

cestini inf uir

sifaly th to

verl.

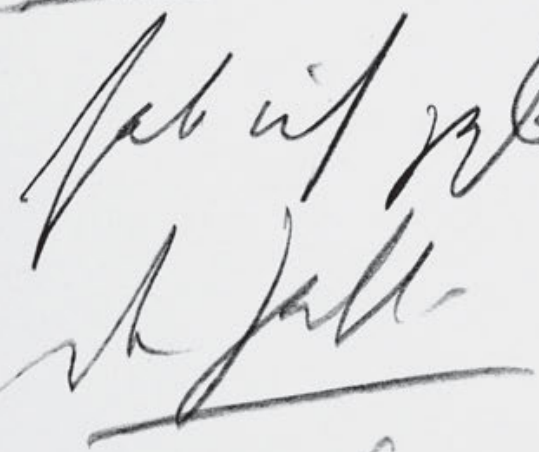

nuf

ory

me fatr

468 
Das s M. Ah was, deine Frau macht anders

sicher nicht besser als du.

$\underline{\text { Der Gatte. (sehr empört) Du, das }}$

${ }_{5}$ verbiet ich mir. Solche Bemer

kungen

Das s. M. Du hast ja kein Frau

hab ich geglaubt.

Der Gatte - Ob ich ein hab o

10 nicht - man macht keine 
HSz6 212

Handschriften und Typoskript

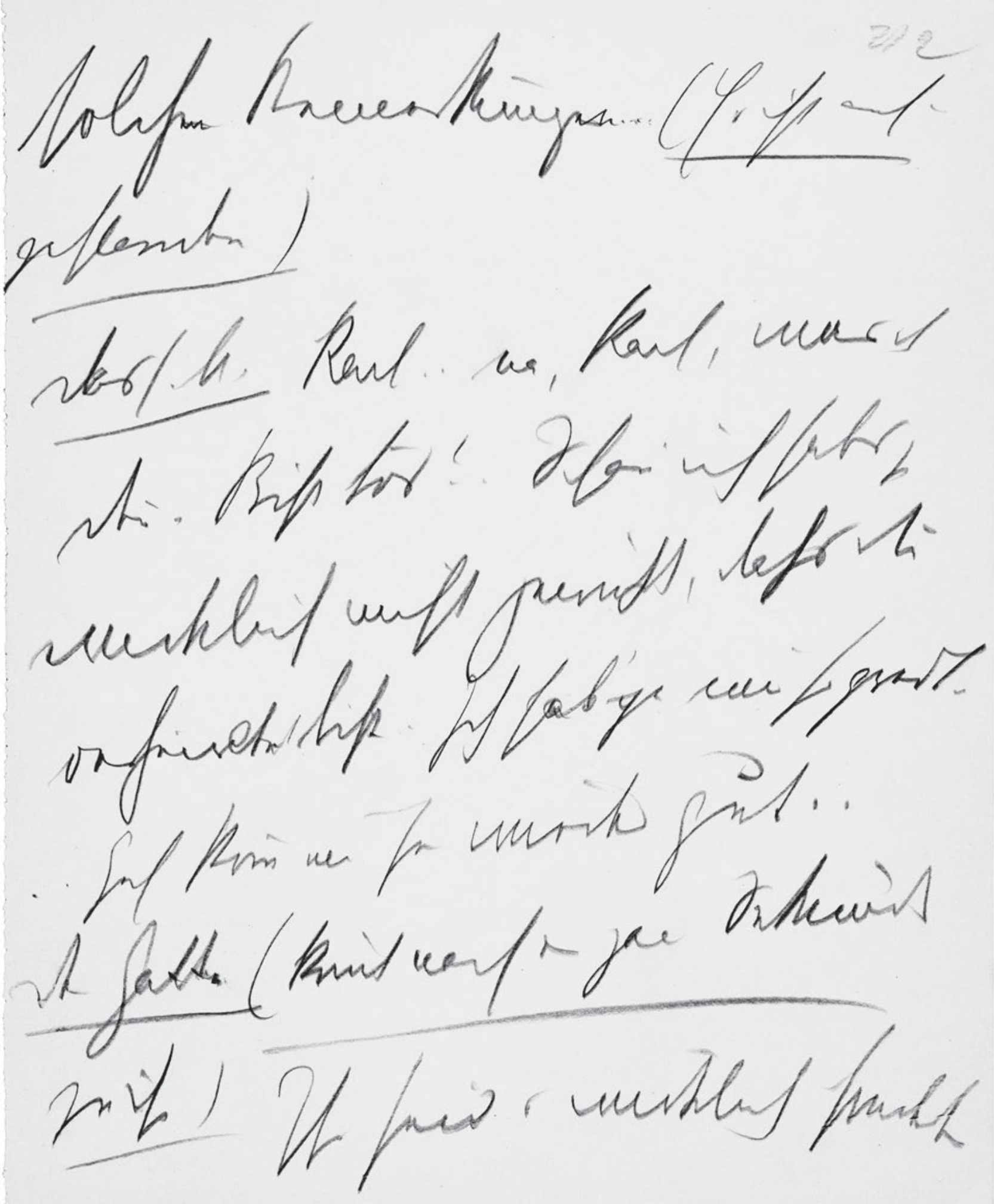

470 
212

solchen Bemerkungen ..... (Er ist auf-

gestanden)

Das s. M. Karl .. na, Karl, was is

5 den̄. Bist bös? . Schau ich habs ja

wirklich nicht gewußt, dass du

verheiratet bist .. Ich $\mathrm{h}^{[?]} \mathrm{ab}{ }^{\prime}{ }^{[?]}$ ja nur so gredt -

. Geh kō̄ und sei wieder gut . .

Der Gatte. (kō̄t nach ein paar Sekunden

10 zu ihr) Ihr seid s wirklich sonderbare 
HSz6 213

Handschriften und Typoskript

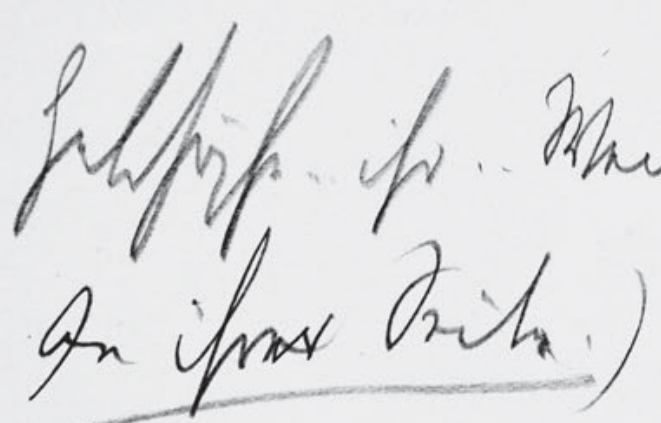

$$
\text { To }
$$

$\frac{\text { harla. }}{\text { that. }}$

tw

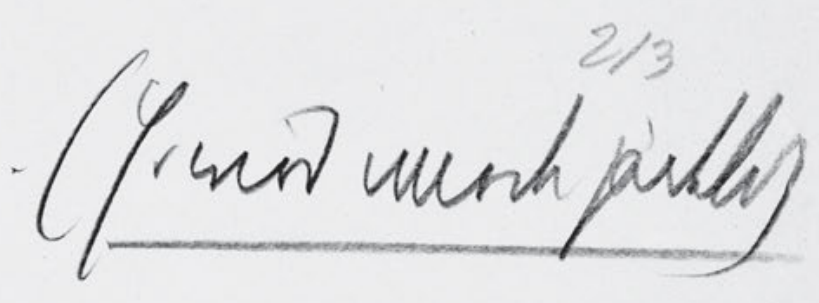

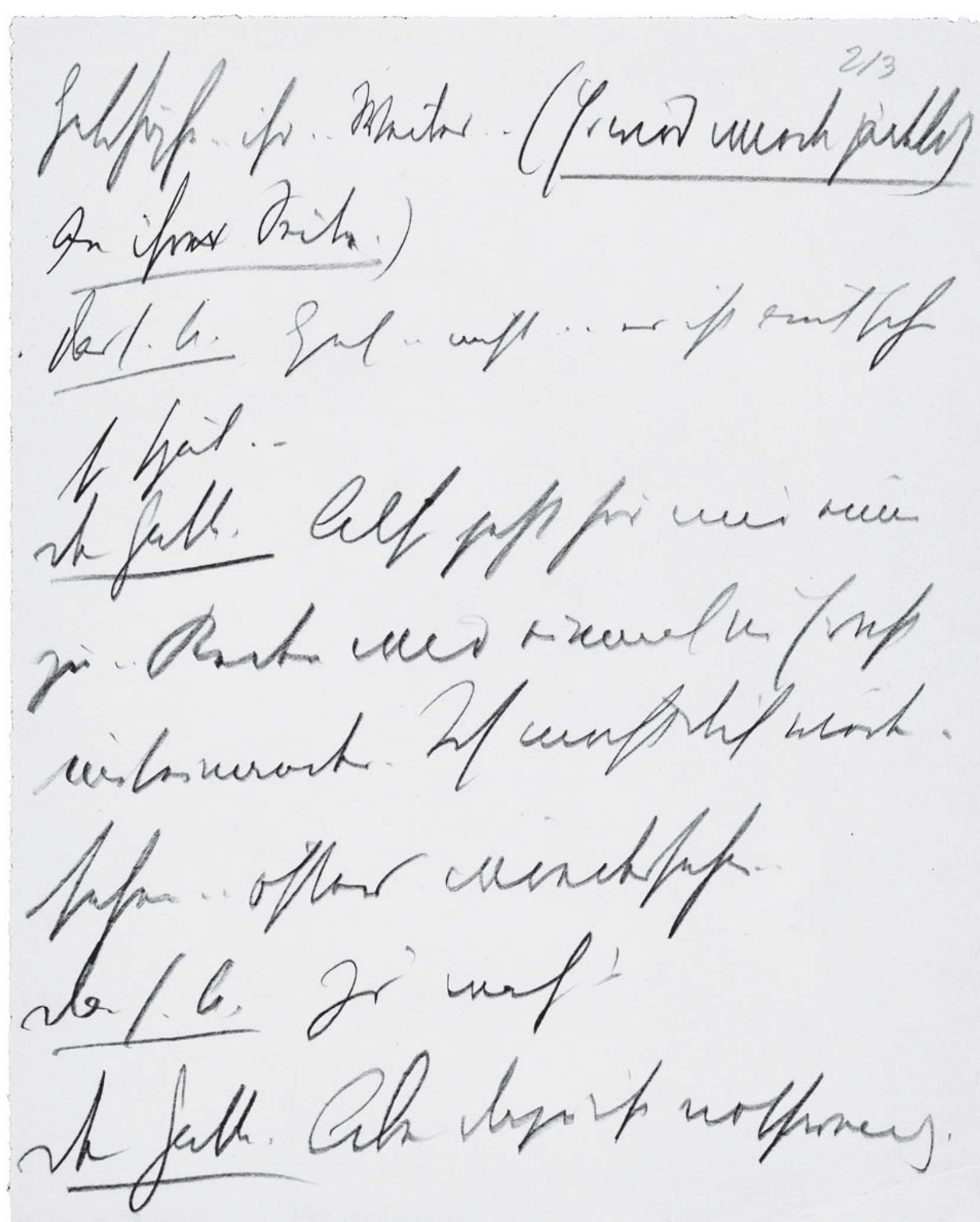




\section{3}

Geschöpfe ... ihr .. Weiber. - (Er wird wieder zärtlich an ihrer Seite.)

Das s. M. Geh . . nicht... es ist auch schon

5 So spät. -

Der Gatte. Also jetzt hör mir einm

zu . . Reden wir einmal im Ernst

miteinander. Ich muß dich wieder-

sehen . . öfter wiedersehen . .

10 Das s. M. Is' wahr?

Der Gatte. Aber dazu ist nothwendg, 
HSz6 214

Handschriften und Typoskript

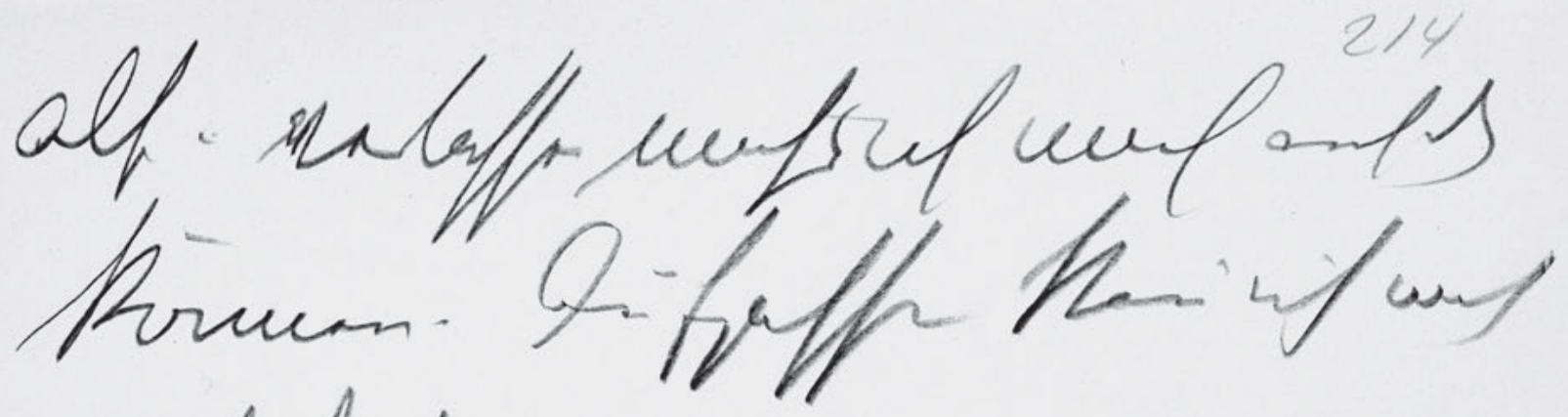

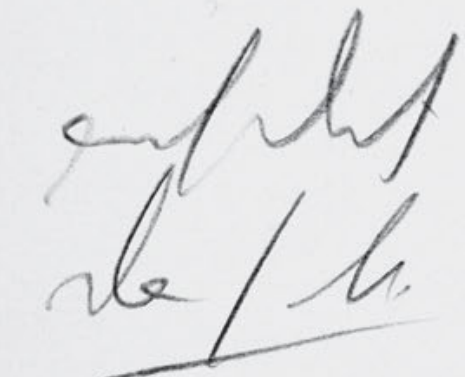

$$
\text { fur. }
$$

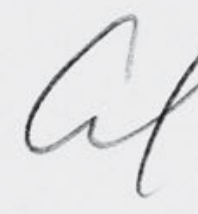


214

also .. verlassen muss ich mich auf dich

können. Aufpassen kan̄ ich nich

auf dich

$5 \quad$ Das s M. Ah ich pass schon selber

auf mich auf.

${ }^{a}$ Der Gatte. Du bist . . na also, uner

fahren kan̄ man ja nicht sagen -

aber .... . jung bist du - und - die Männer

sind im allgemeinen ein niederträch .

gewissenloses Volk ..... Wenn 
HSz6 215

Handschriften und Typoskript

stertich Offef'

the Gath.

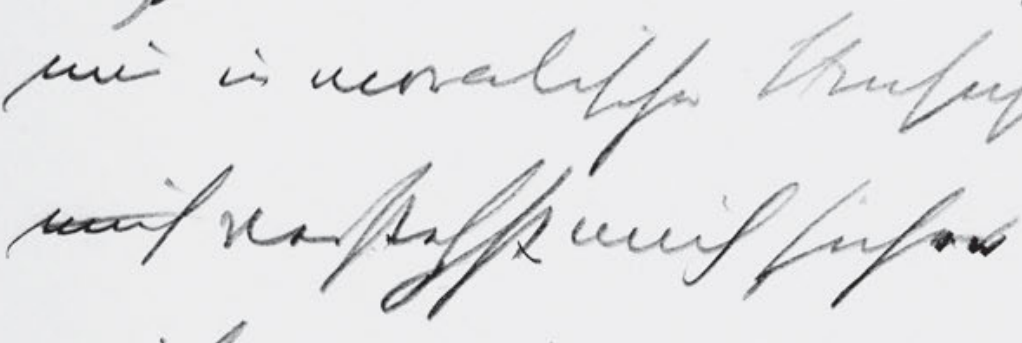

ha ats

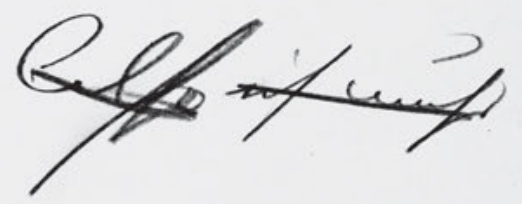

dert le ta ose \& Go, un mo

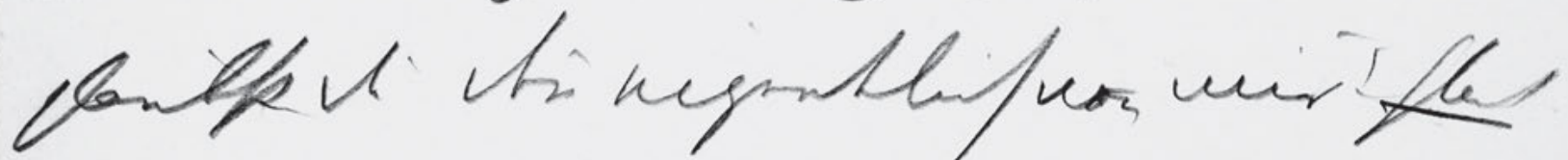

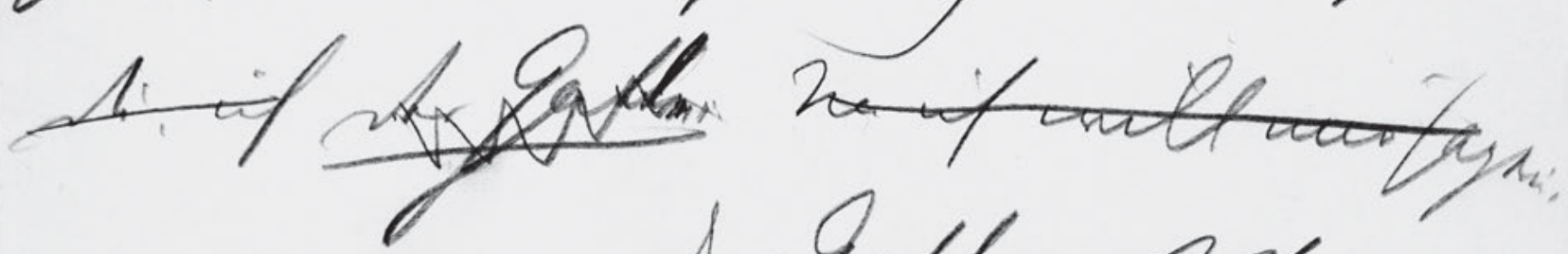

in $\mathrm{sh}$ Galk,

Aefo-ca,

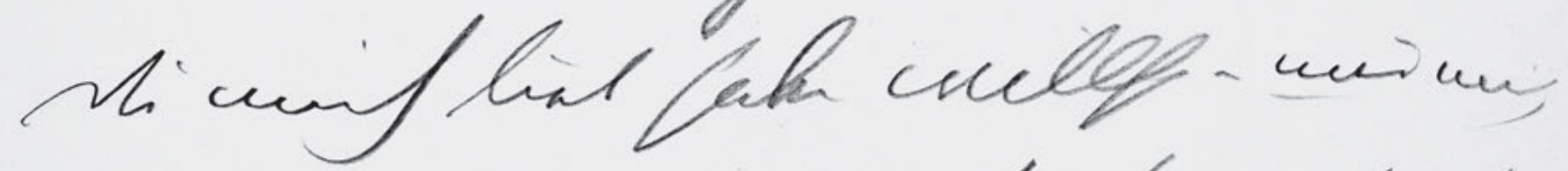
for temiens miven ba fler fof Afir riesmfla - ma

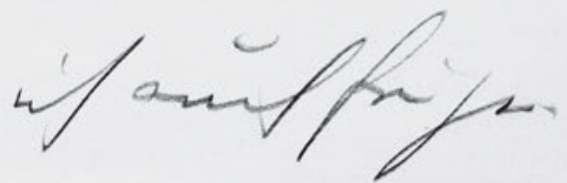

476 


\section{5}

Das s. M. Oh jeh!

Der Gatte. Weißt du Ich mein das nicht

nur in moralischer Hinsicht $-\mathrm{Na}{ }^{w e \bar{e}} \mathrm{~d}^{?} \mathrm{u}^{?} \mathrm{~d}$

5 mich verstehst mich sicher ... Also ich muss

mich weñ $\mathrm{du}$. .

Das s. M. Ja was Ja sag mir was

glaubst du deñ eigentlich von mir? Glaub

du, ich Der Gatte. Na ich will nur sagen:

10

wenn wir Der Gatte. Also - wen

du mich lieb haben willst - nur mich,

so können wir uns das schon sehr

schön einrichten - wē̄ ich auch für ge- 
HSz6 216

Handschriften und Typoskript

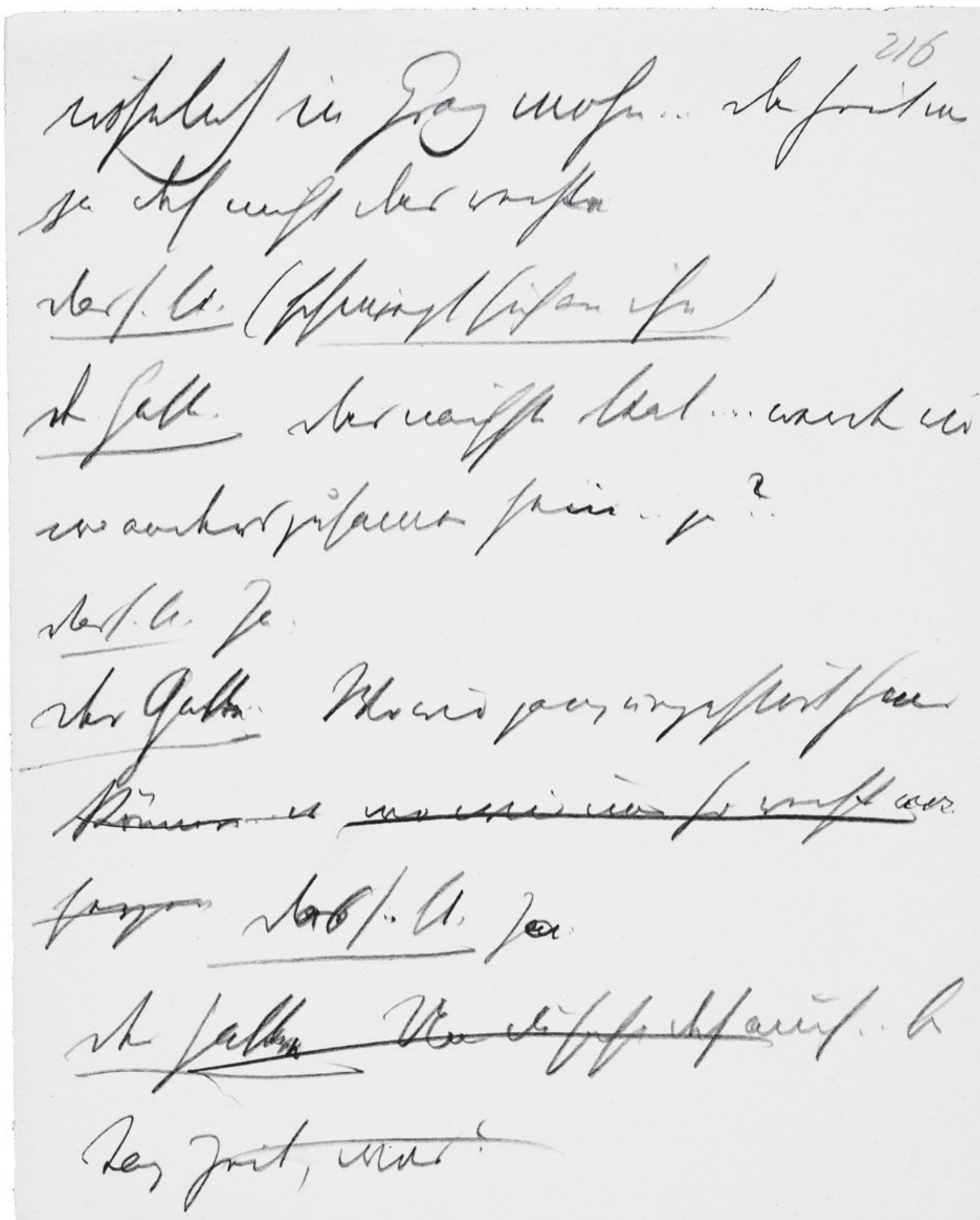


216

wöhnlich in Graz wohn ... das heut wa

ja doch nicht das rechte.

Das s. M. (schmiegt sich an ihn)

$5 \quad$ Der Gatte. Das nächste Mal .... werden wir

wo anders zusamen sein . . ja!? .

Das s. M. Ja.

Der Gatte. . Wo wir ganz ungestört $s^{\text {ein }}$ ind

können ... [?] wo wir uns so recht ${ }^{\text {. . . . }}$

Herzen Das s. . M. J J $^{[?]}$. .

Der Gatte Und du hast doch auch . . bei

Tag Zeit, was? 
HSz6 217

Handschriften und Typoskript

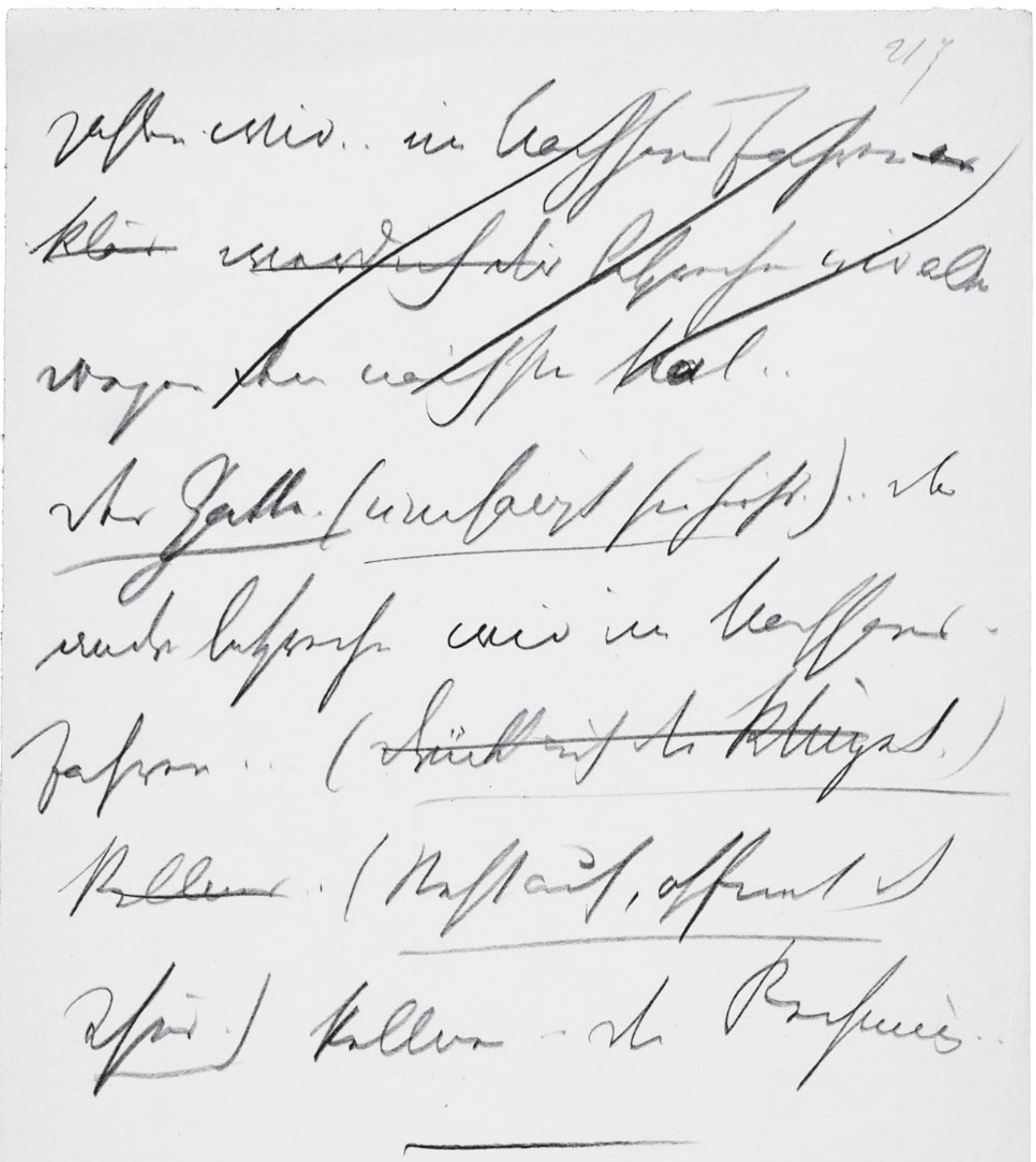

480 


\section{7}

zahlen .wir . . im Nachhausfahren er

klär werd ich dir besprechen wir alles

wegen dem nächsten Mal .

$5 \quad$ Der Gatte. (umfängt sie heiß.) . . Das

andre bespreche wir im Nachhaus-

fahren . . (drückt auf die Klingel.)

Kellner . . (steht auf, offnet die

Thür.) Kellner - die Rechnung . . 


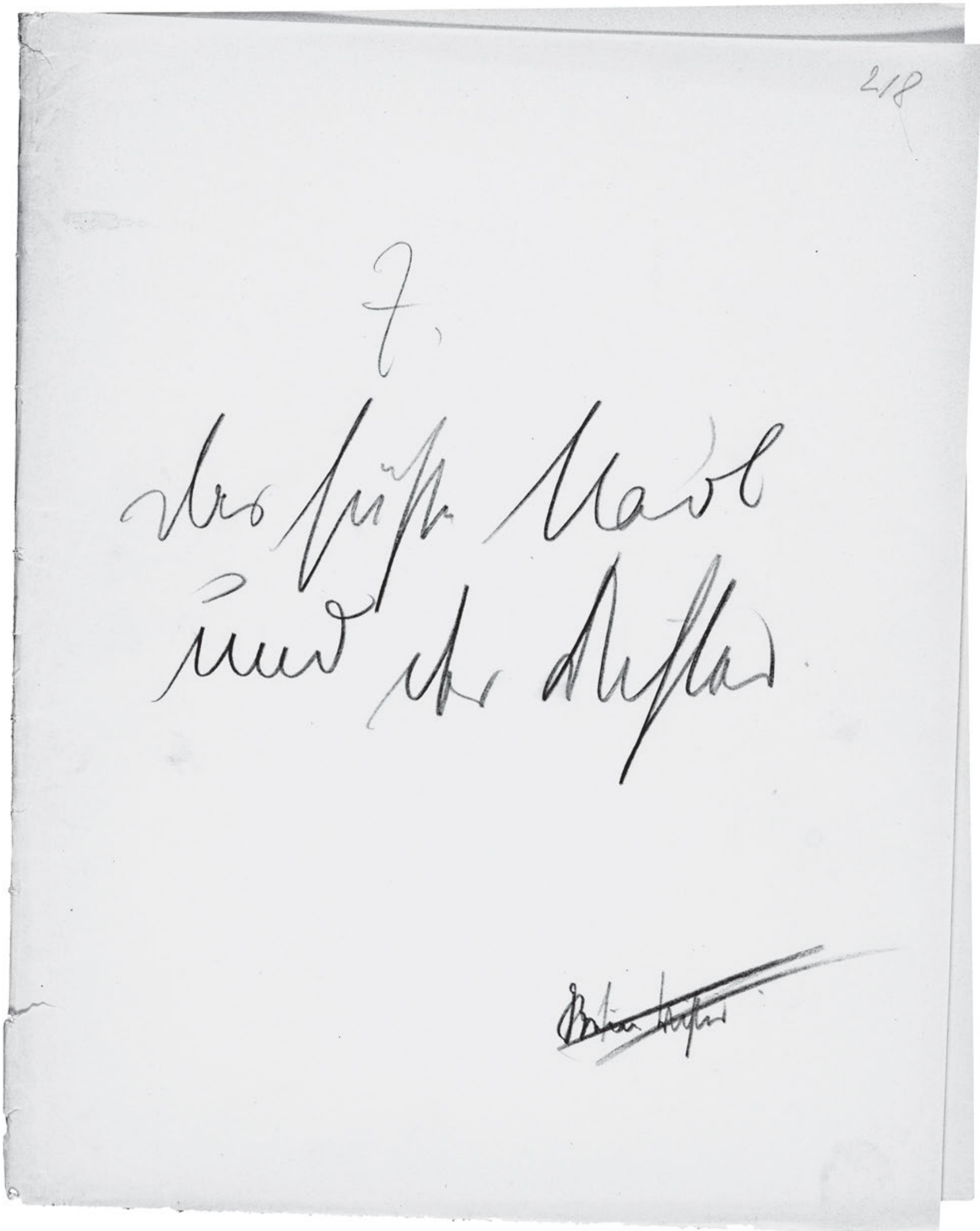




\section{8}

7.

Das süße Mädl

und der Dichter. 
HSz7 219

Handschriften und Typoskript

210

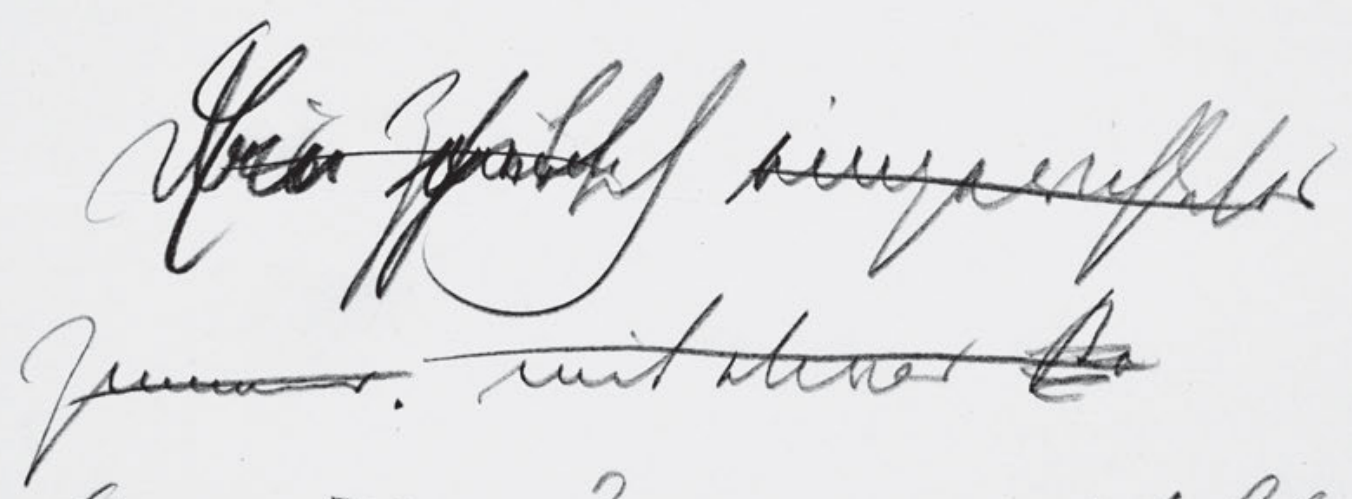

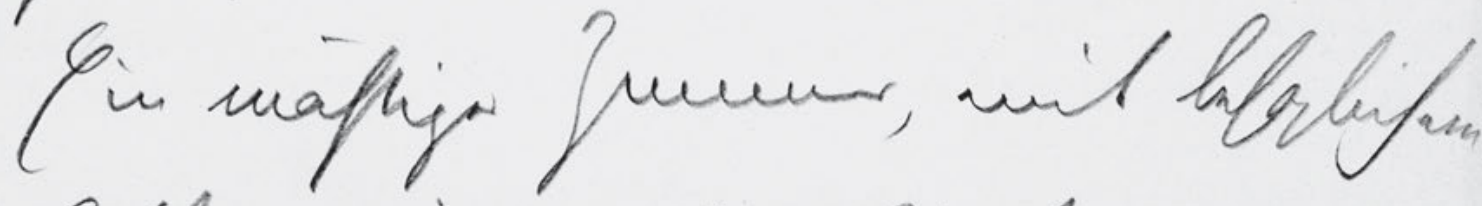

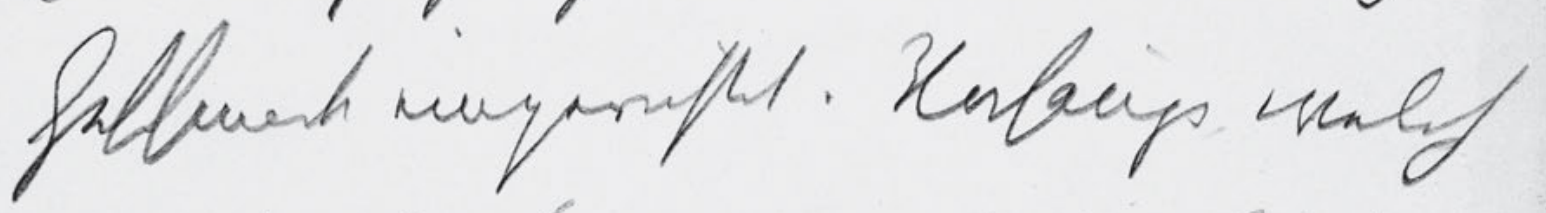
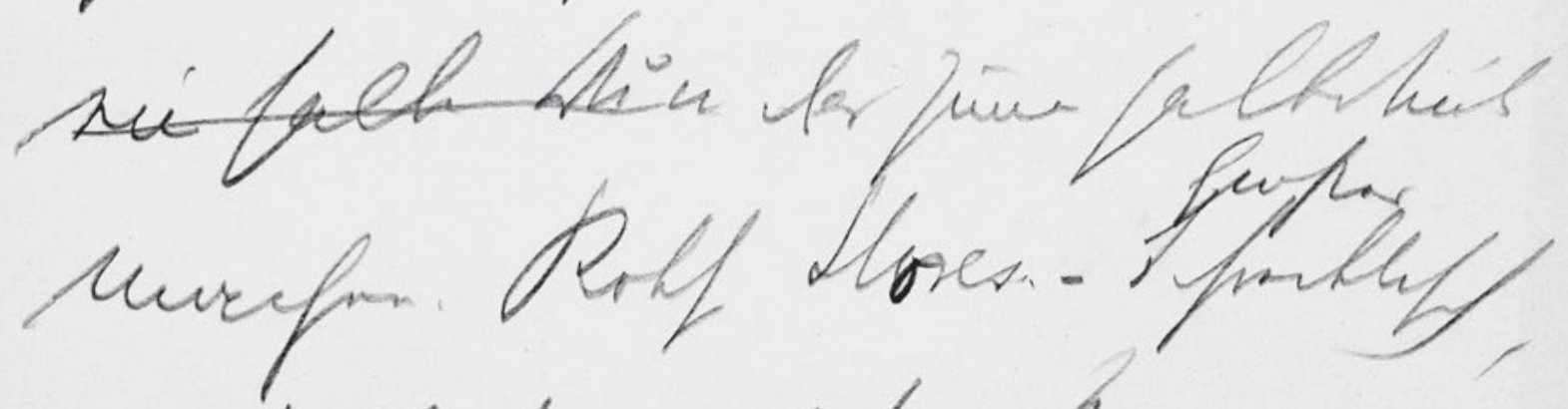

timifir fromenteryos.

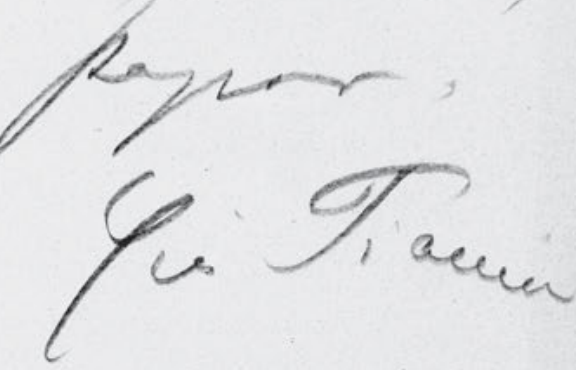
un $h$ Mornt.

484 
${ }^{\text {Das }}{ }_{\text {Ein }}{ }^{[? ?]} Z_{\text {Zimm }}$ hübsch eingerichtetes

Zimmer. mit etwas ${ }^{?} \mathrm{~B} \Theta$ ?

Ein mäßiges Zimmer, mit behaglichem

5 Geschmack eingerichtet. Vorhänge, welch

ein halbe Dun das Zim̄er halbdunk

$$
\text { Großer }
$$

machen. Rothe Stores .. - Schreibtisch,

unordentlich auf dem Papiere,

Bücher herumliegen. Ein Pianino

$10 \quad$ an der Wand. - 
HSz7 220

Handschriften und Typoskript

sab Ampt havt. ch thifar.

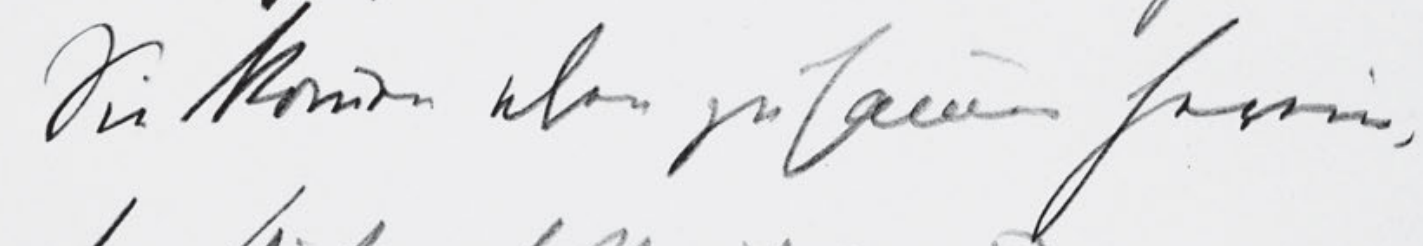
ste Siffer theiget

the thifh.

j,

220

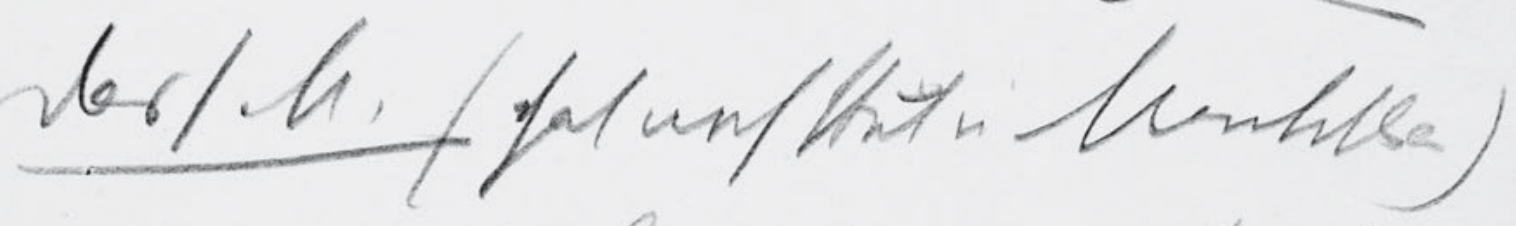

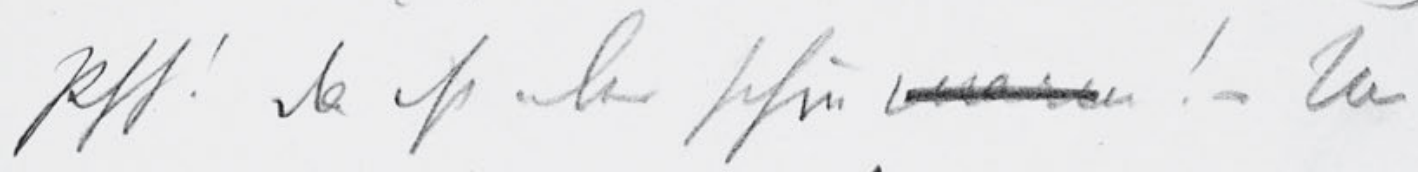

Iof Unit wan nef'

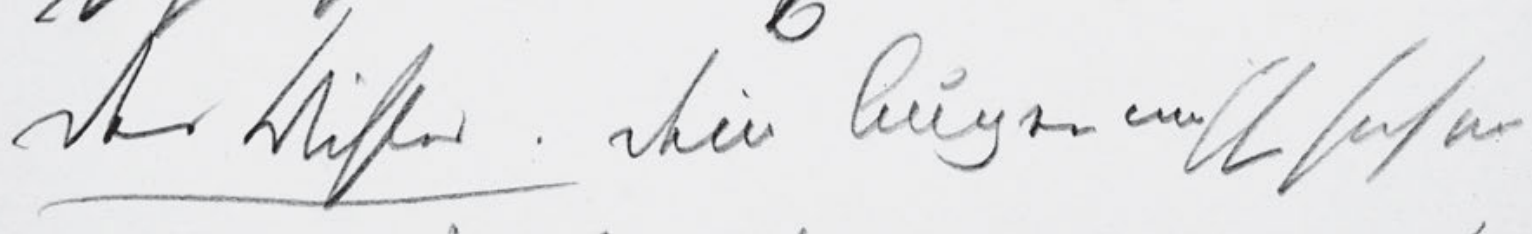

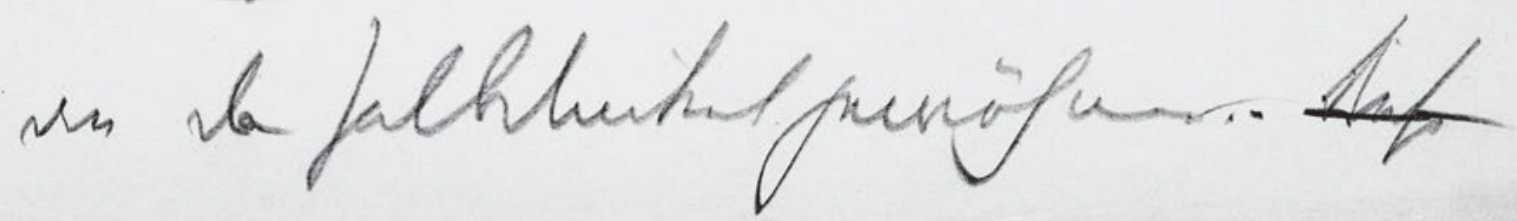

486 
$D^{\mathrm{er}}$ as ${ }^{\mathrm{Di}}$ süße Madl. Der Dichter. -

Sie kō̄en eben zusā̄en herein, der Dichter schließt zu. -

$5 \quad$ Der Dichter. So, mein Schatz . . (küsst sie)

Das s M. (hat noch Hut u Mantille an)

Pff! Da ist aber schön warm! - Und -

sehn thut man nichts!

Der Dichter . Dein Augen müssen sich noc

10 an das Halbdunkel gewöhnen. - Diese 
HSz7 221

Handschriften und Typoskript

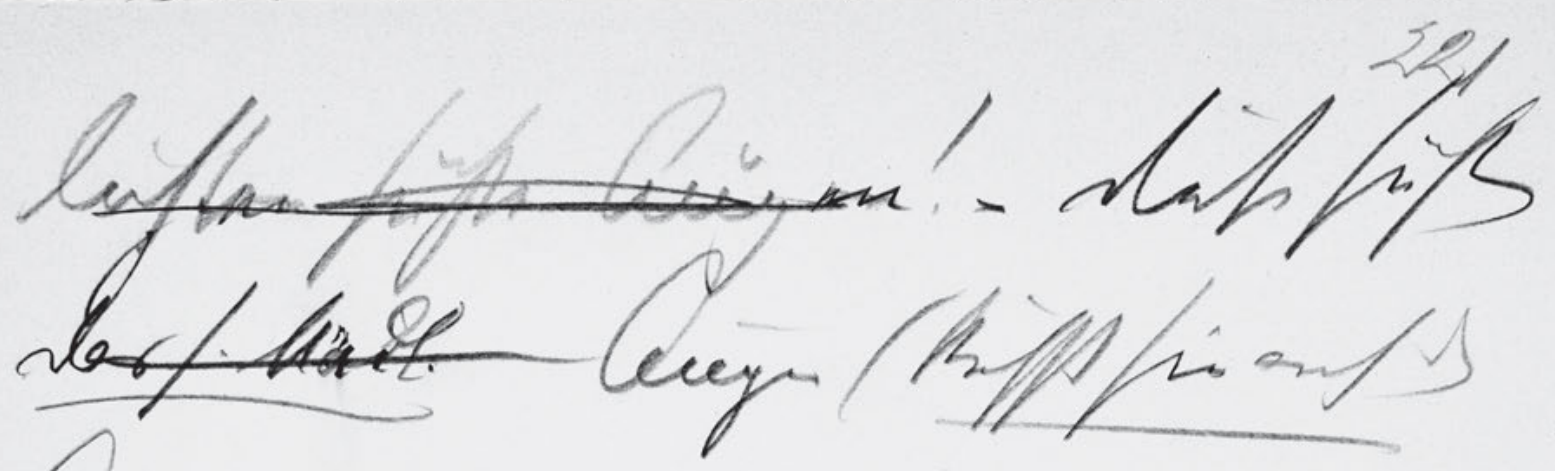

Quin)

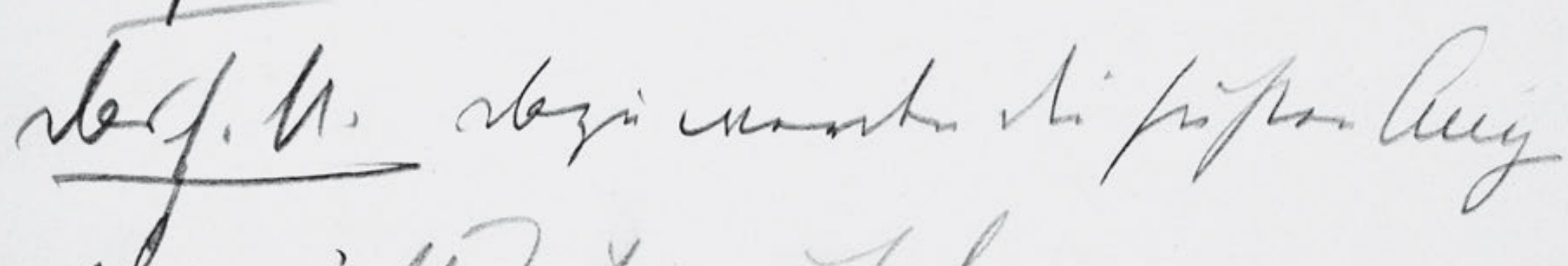

ator wift frot jues par

ser theft. Nessin hi

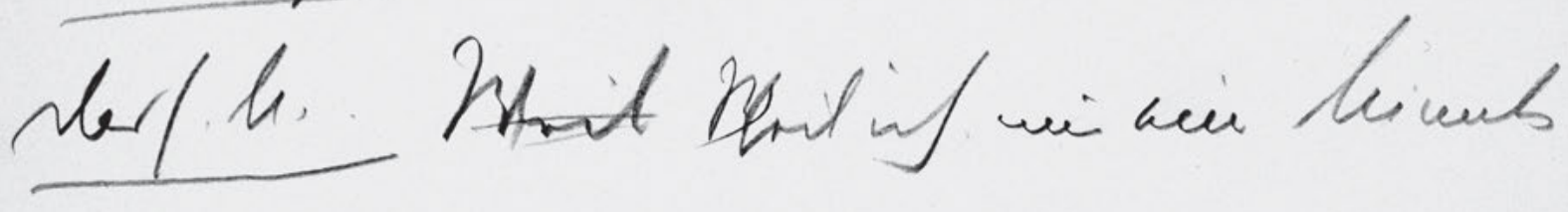

abhib'

she Alforr. L path ab. p!

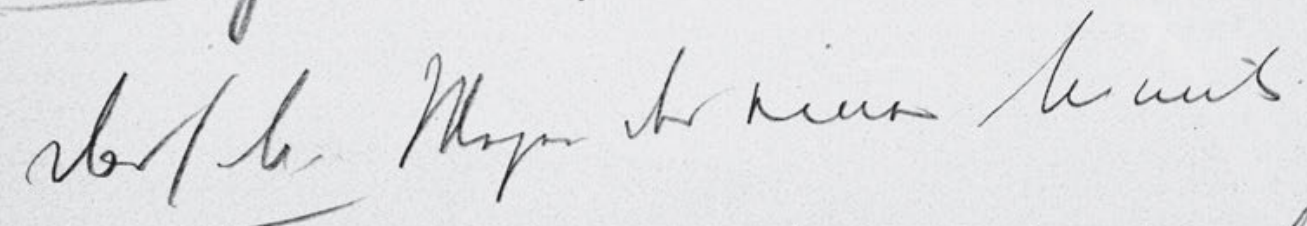

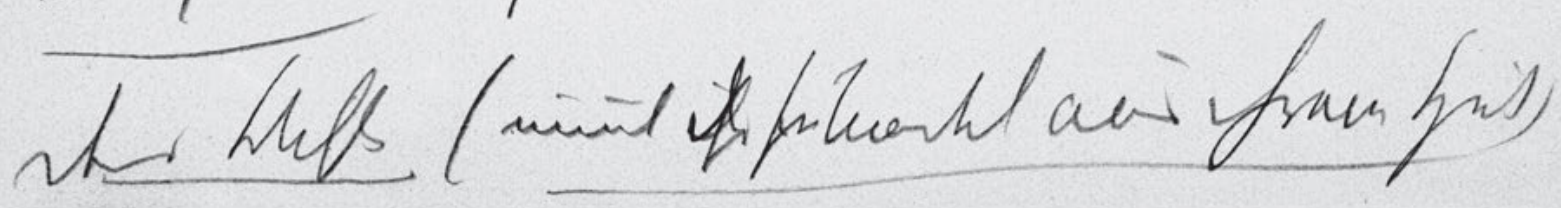

488 


\section{1}

lichten süße Augen! - Diese süßen

Das s. Mädl. Augen (küsst sie auf die

Augen)

$5 \quad$ Das s. M. Dazu werden die süßen Augen

aber nicht Zeit gnug haben.

Der Dichter. Warum den̄?

Das s. M. . Weil Weil ich nur eine Minute

dableib!

$10 \quad$ Der Dichter. Den Hut leg ab . ja? .

Das s M. Wegen der einen Minute.

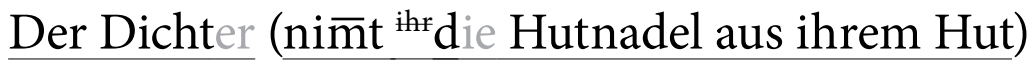


HSz7 222

Handschriften und Typoskript

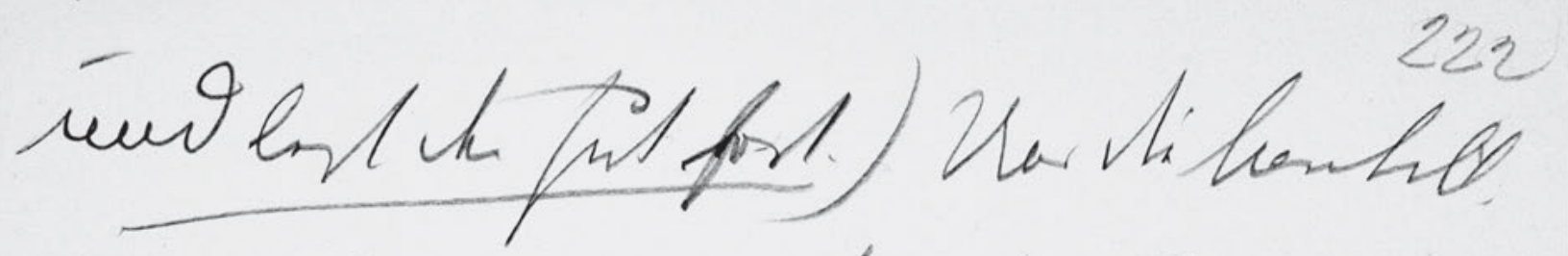
virfle Ba berculps

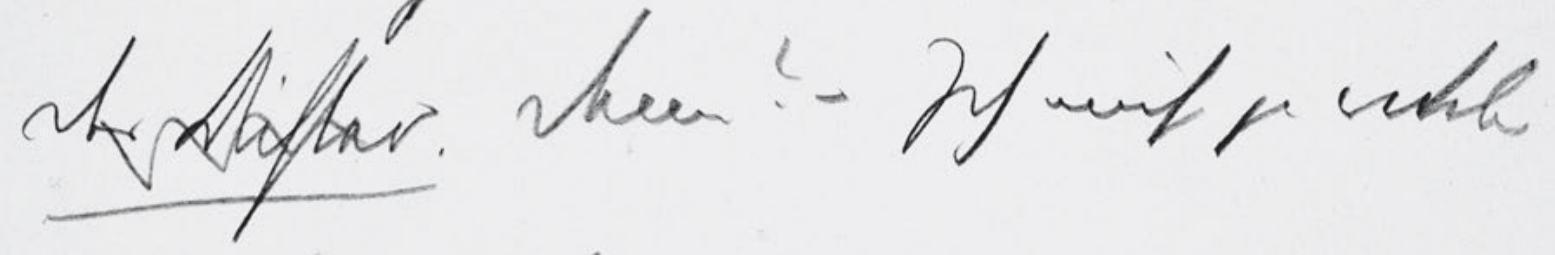
smit portype

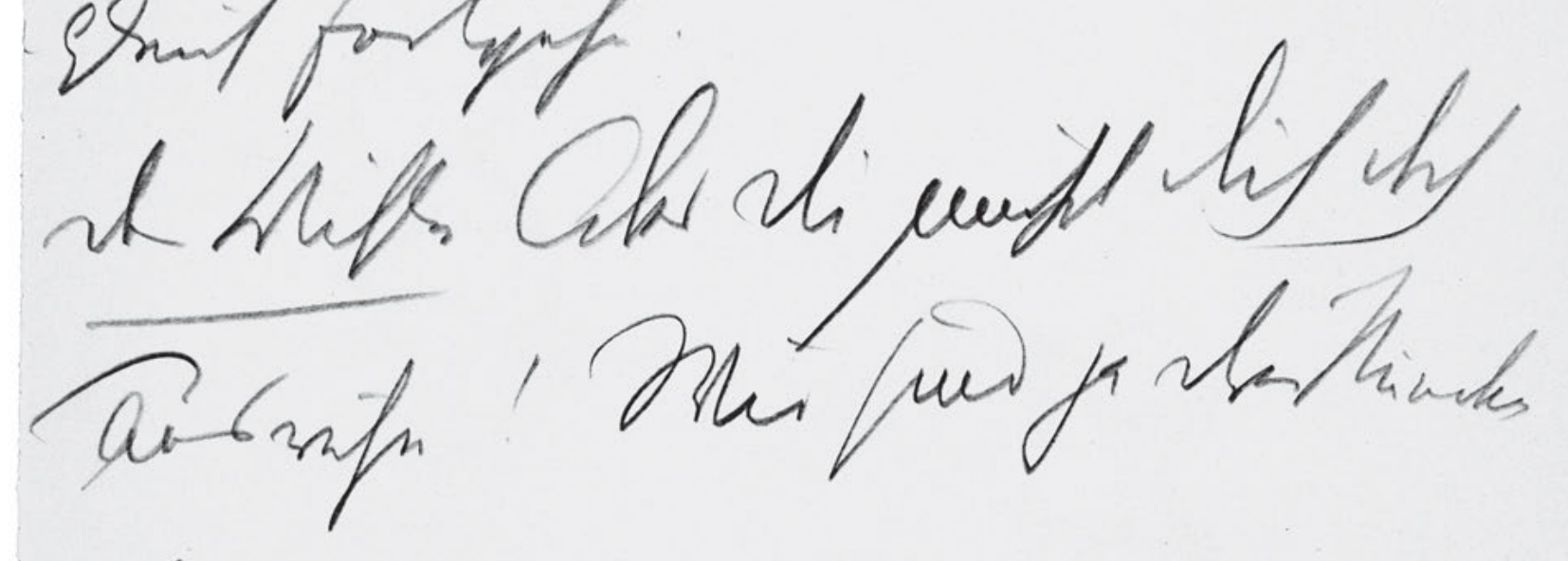

L Pranym.

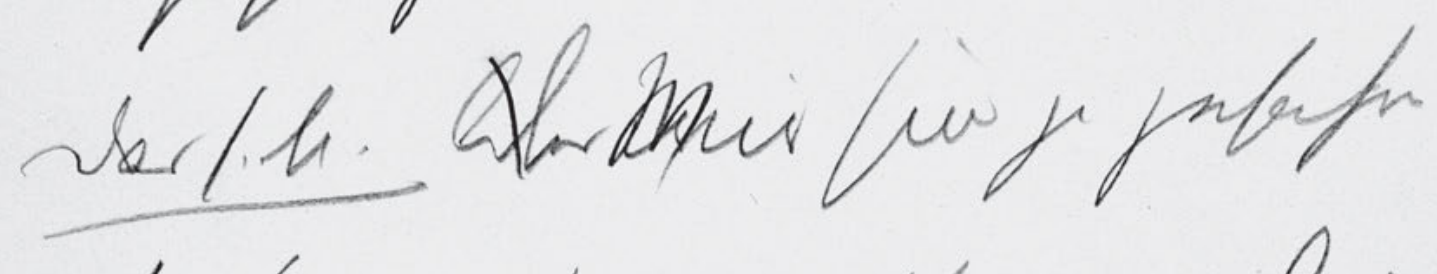

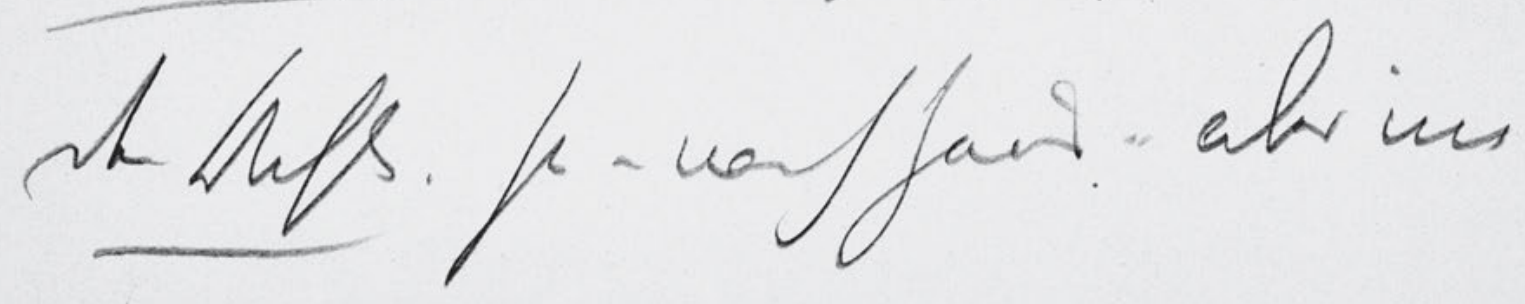

490 
und legt den Hut fort.) Und die Mantill.

Das s. M. Ja wozu denn? - Was willst

Der Dichter. denn? - Ich muss ja wklic

5 gleich fortgehn.

Der Dichter Aber du mußt dich doch

ausruhn! Wir sind ja drei Stunden

?d? gegangen.

Das s. M. Aber "Wir sind ja gefahre

10 Der Dichter. Ja - nach Haus . . aber im 
HSz7 223

Handschriften und Typoskript

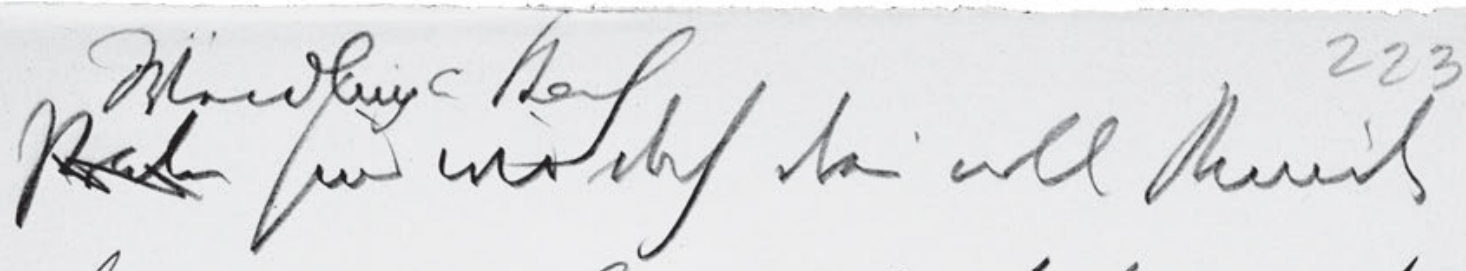
from ing berfon.... Alf fing the dectele mie ffris mort mi - Ming Mrfin sille tha finer muf ton ifortiff toffe ahurin to p fost. uns byim... In lig onit th tho.

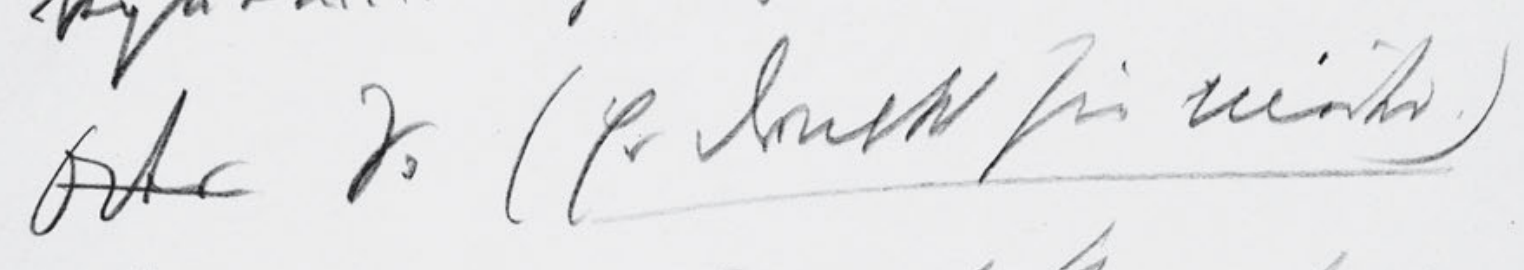
Anj lifof mier, flawefin

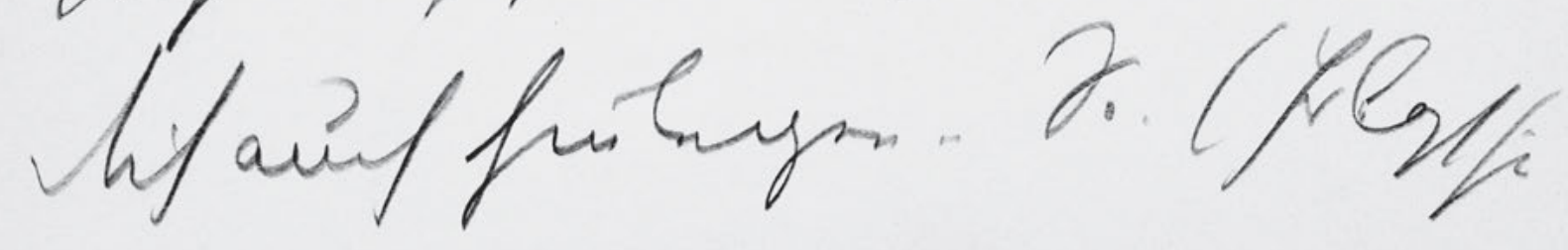

492 
Weidling a Bach

Prater sind wir doch drei volle Stunden

herumgelaufen ..... Also setz' dich

Das s. . M. . nur schön nieder mein

${ }_{5} \quad$ [?] Kind .... Wohin du willst . . Bitt.

hier auf den Schreibtischsessel

aber nein . . das ist zu hart. nich

bequem ... Setz dich auf den Divan ..

Oder So (Er druckt sie nieder.)

10 Bist du sehr müd, so kannst du

dich auch hinlegen.. So. (Er legt sie 
HSz7 224

Handschriften und Typoskript

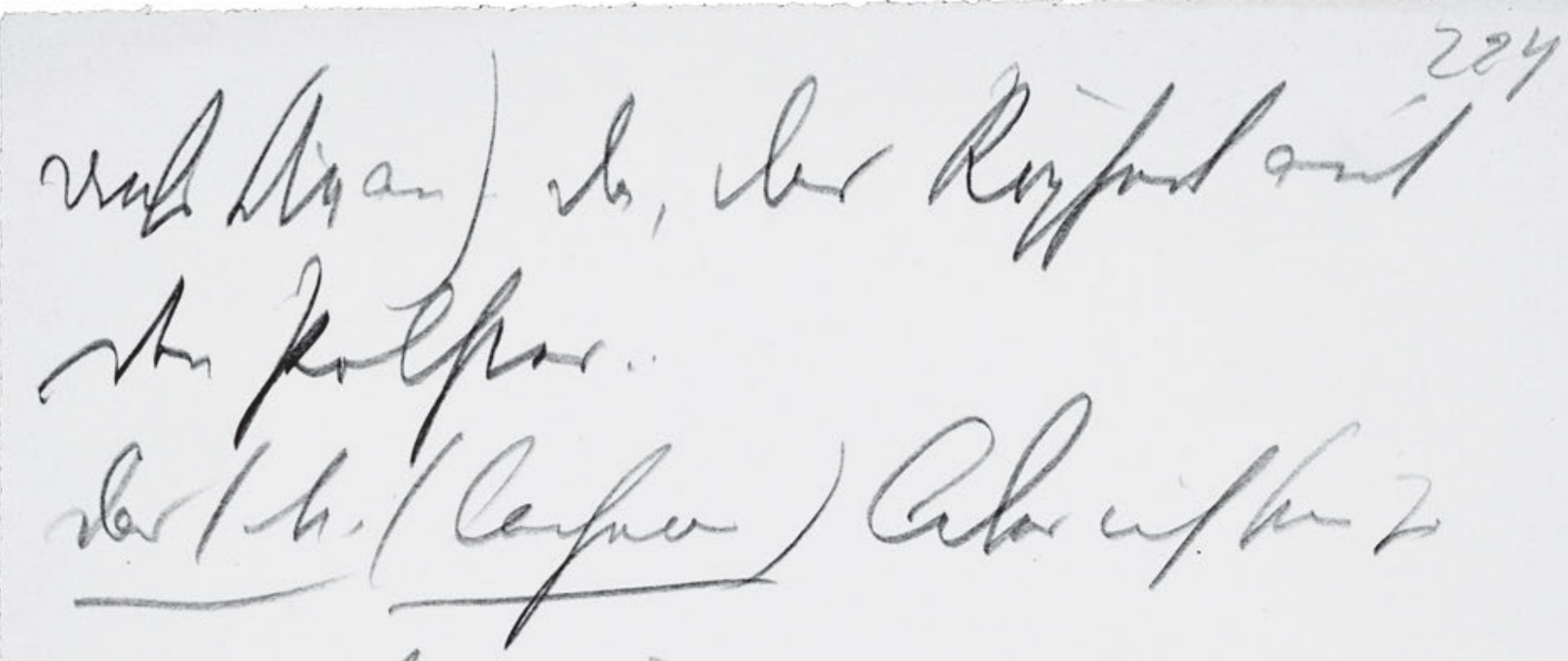

Uur uni siffaph if

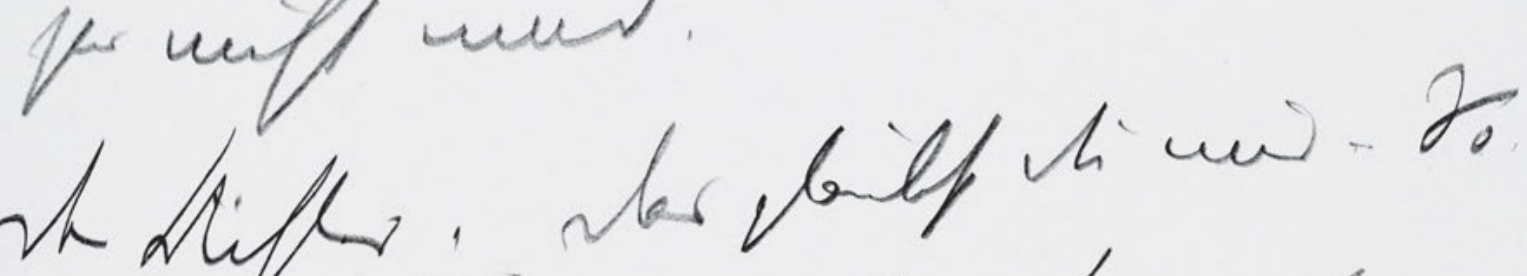

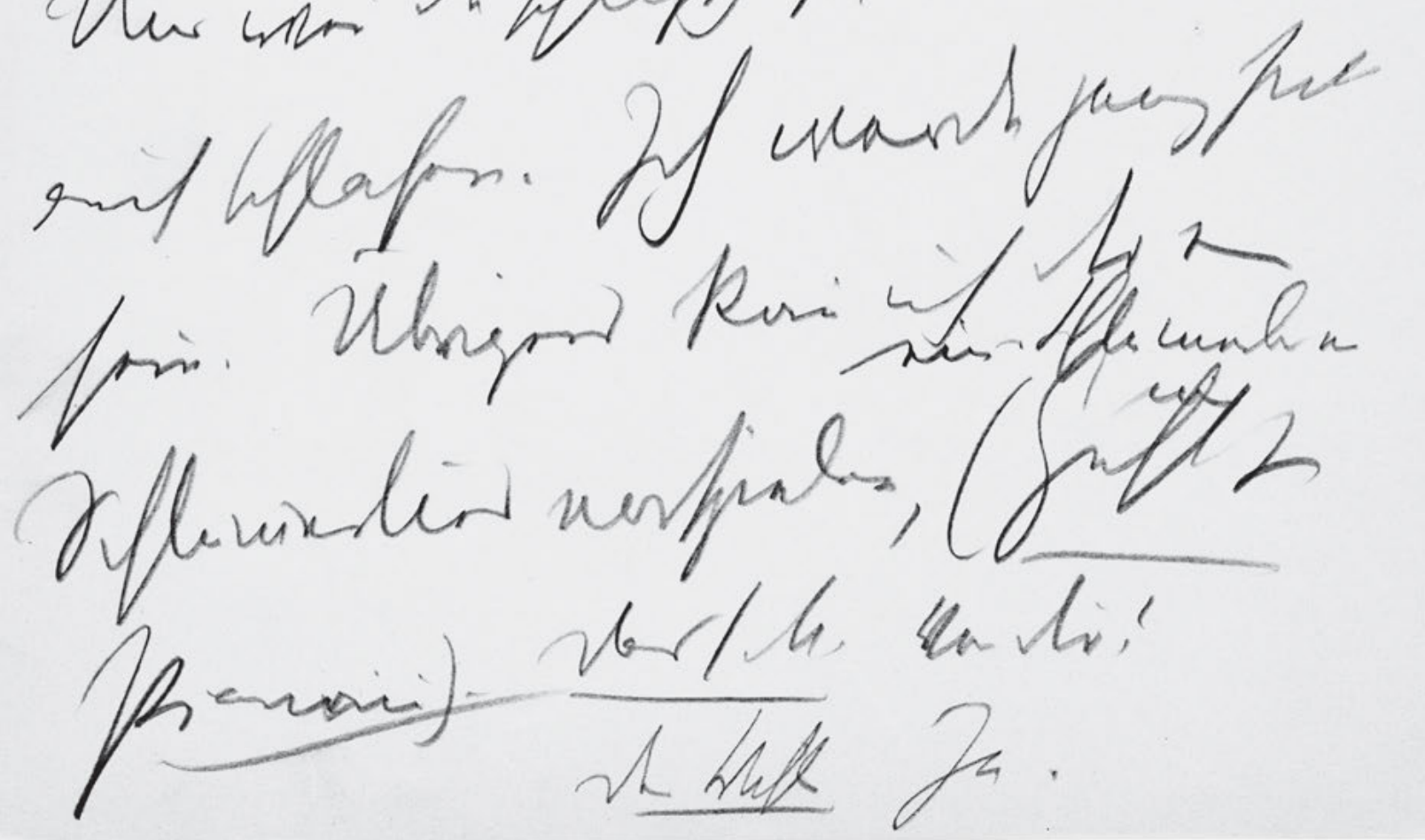

Rawn

494 
224

aufs Divan). Da, das Köpferl auf

den Polster . .

Das s M. (lachend) Aber ich bin ja

5 gar nicht müd.

Der Dichter. Das glaubst du nur - So.

Und wen̄ du schläfrg bist, kannst d

auch schlafen. Ich werde ganz still

sein. Übrigens kan̄ ich dir ein

ein [?] Schlumerlie ? $\mathrm{v} 0$ ?

mir

Schlū̄erlied vorspielen, (Geht zu

Pian ${ }^{\ominus}$ ini). Das s M. Von dir?

Der Dichter Ja. 
HSz7 225

Handschriften und Typoskript

bes/le.

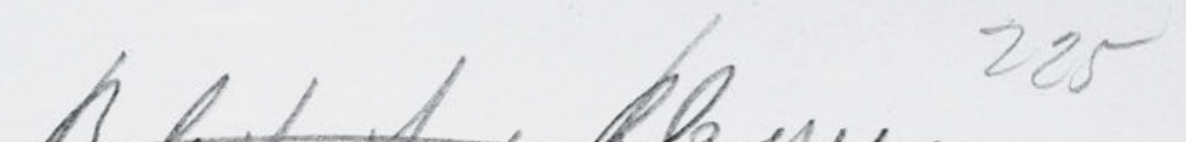

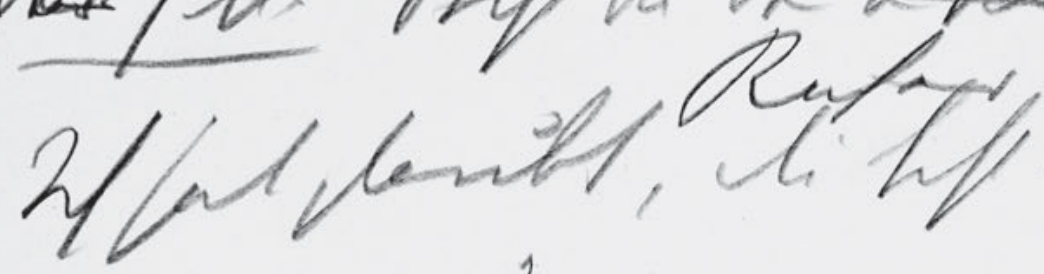

shorthe

hust? 2

def
his.

ver/.t.

sh ofsfy

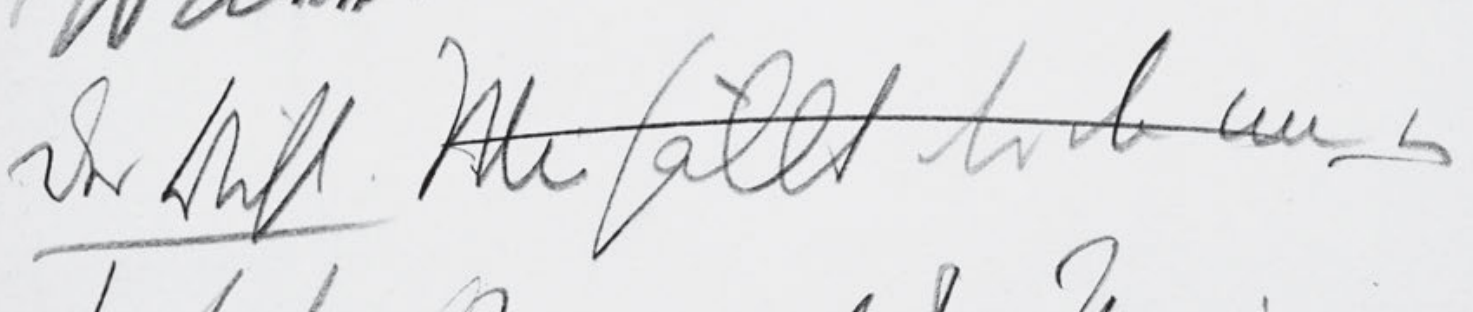

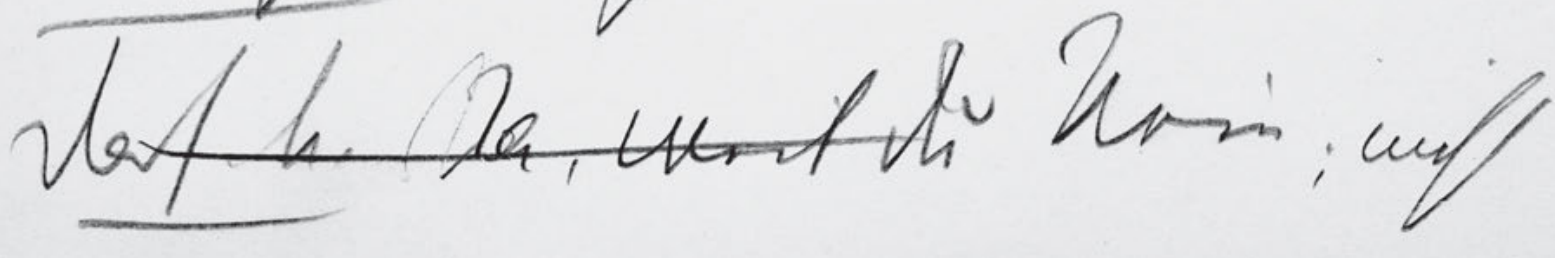

496 
$\mathrm{D}^{\mathrm{er}}$ as s M. Bist du den ein Klavier

Richard

Ich hab glaubt, du bist ein Dokter?

Der Dichter. Wieso? . Ich hab dir

5 doch gesagt, dass ich .. Schriftstell

bin.

Das s. M. Ist das nicht alles eins?

Die Schriftsteller sind doch alle

Doct $^{\theta}$ ers?

10 Der Dicht. Wie fällt dir das nur ?ein?

Das s. M. Na, weil du Nein; nicht 
HSz7 226

Handschriften und Typoskript
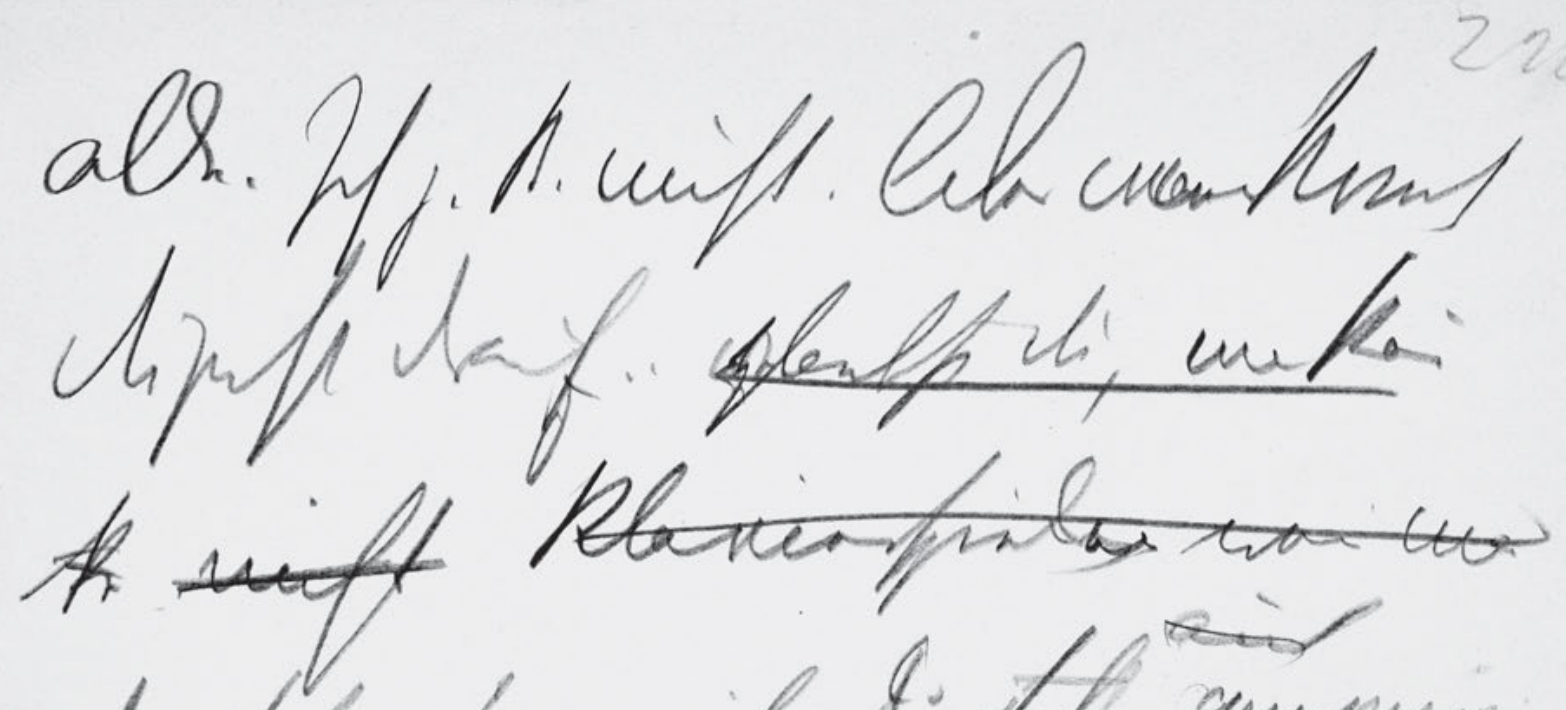

Merla, ha, wil ti hof

berla, ha, init ti hef

tage

1

nat her hi.

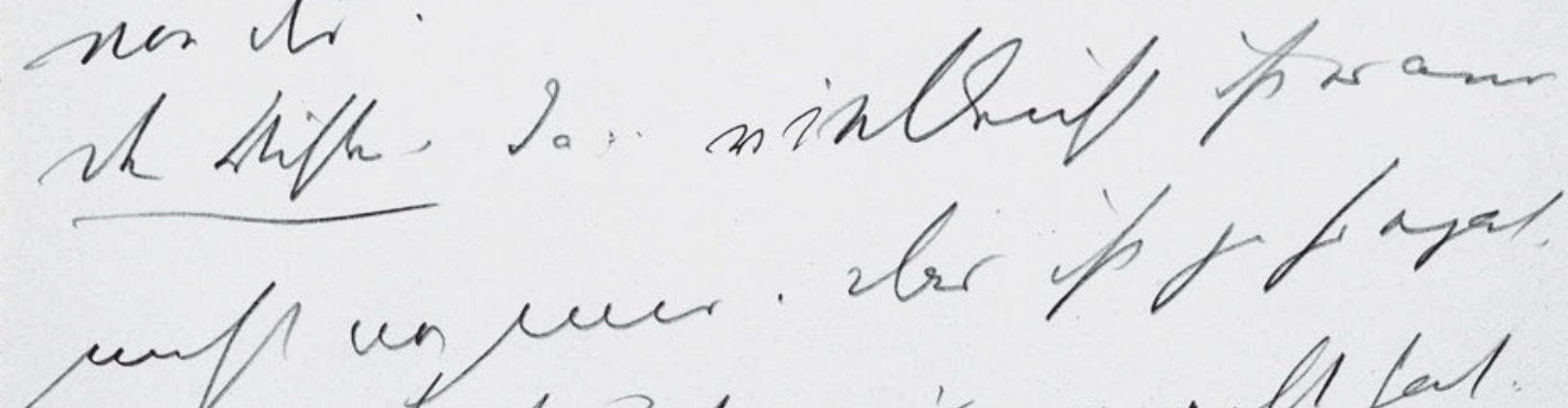

fint h

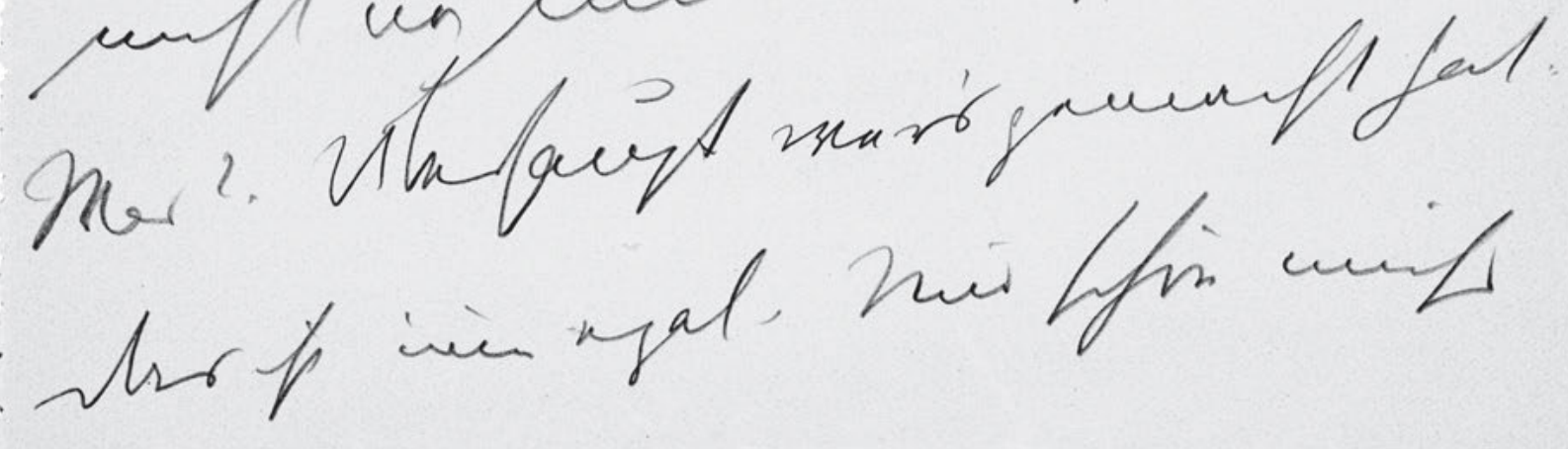

498 
alle. Ich z. B. nicht. Aber warie koms

du jetzt drauf . . ${ }^{\text {w[?] }}$ glaubst du, man kañ

$\mathrm{k}$ nicht Klavierspielen wenn ma auch

Das s. M. Na, weil du dicht componiren

thust Clavier spielen thust . . sagst,

das Stück was du da ${ }^{\mathrm{g}}$ spiel ${ }^{\text {st }}$ en thust, ist

von dir.

Der Dichter. Ja . . vielleicht ist es auc

10 nicht von mir. Das ist ja so egal.

Was? Überhaupt wer's gemacht hat:

das ist imer egal. Nur schön muss 
HSz7 227

Handschriften und Typoskript

ortim- miftinafor.

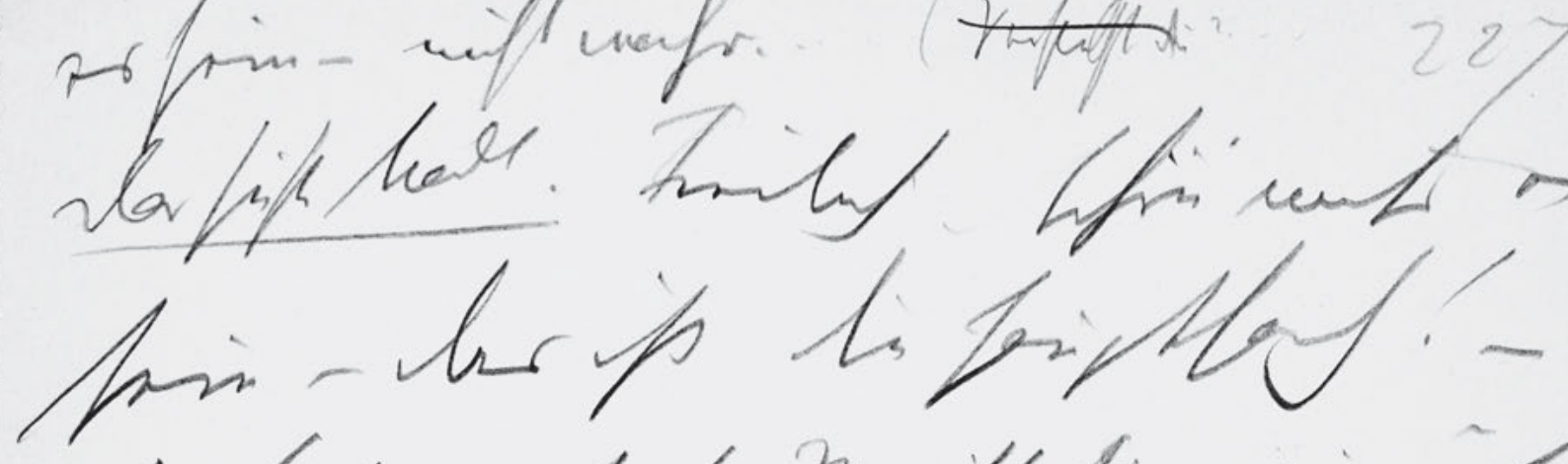

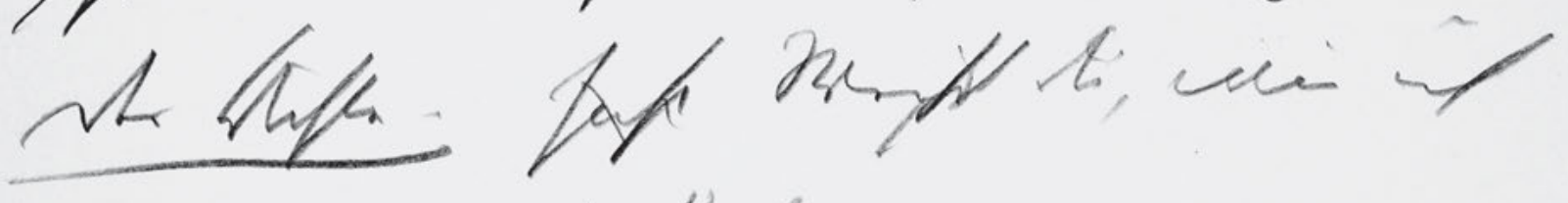
sarpamit jab..

affhthest. Merthur

wh tiffar. ha, is

now if abr net fat.

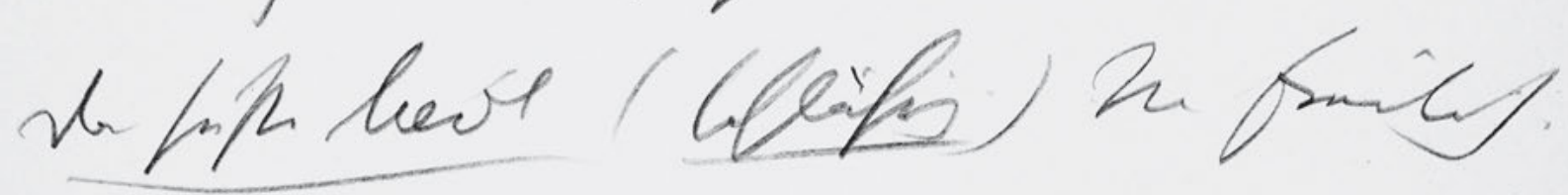

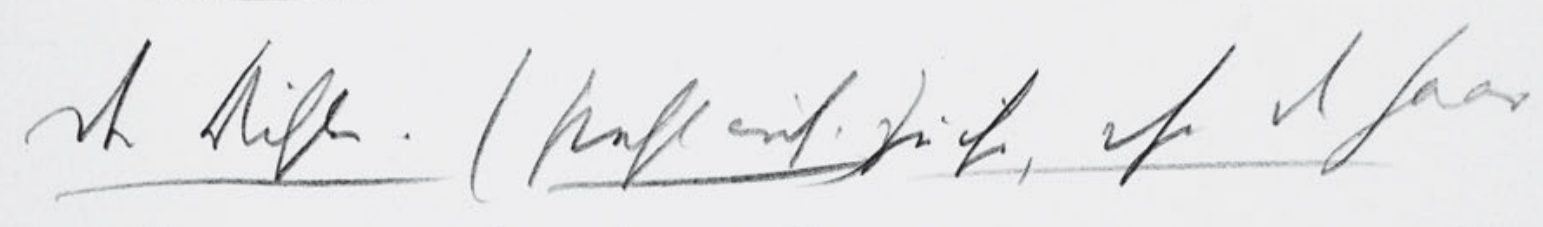

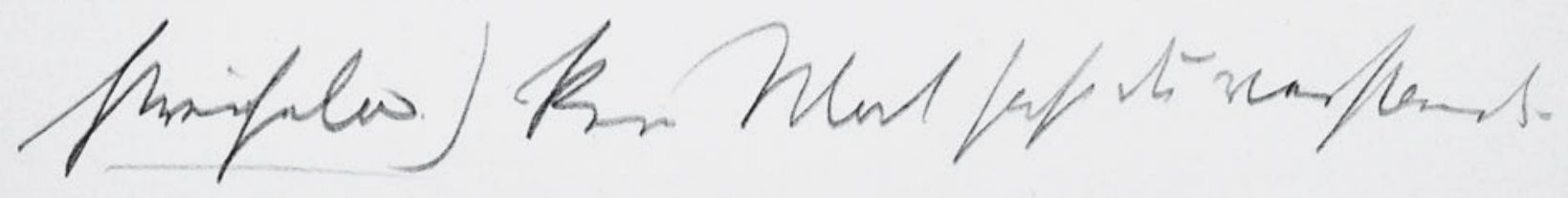

500 
es sein - nicht wahr ... (Verstehst du? . . 227

Das süße Madl. Freilich - schön muss es

sein - das ist die Hauptsach! -

Der Dichter. Hast Weißt du, wie ich

5 das gemeint hab...

Das suße Mädl . Was denn?

Der Dichter. Na, . dass es egal ist, wer

was ich eben gesagt hab.

Das süße Mädl (schläfrig.) Na freilich.

10 Der Dichter. (steht auf. ${ }^{\dagger}$ zu ihr, ihr d Haar

streichelnd.) Kein Wort hast du verstanden - 
HSz7 228

Handschriften und Typoskript

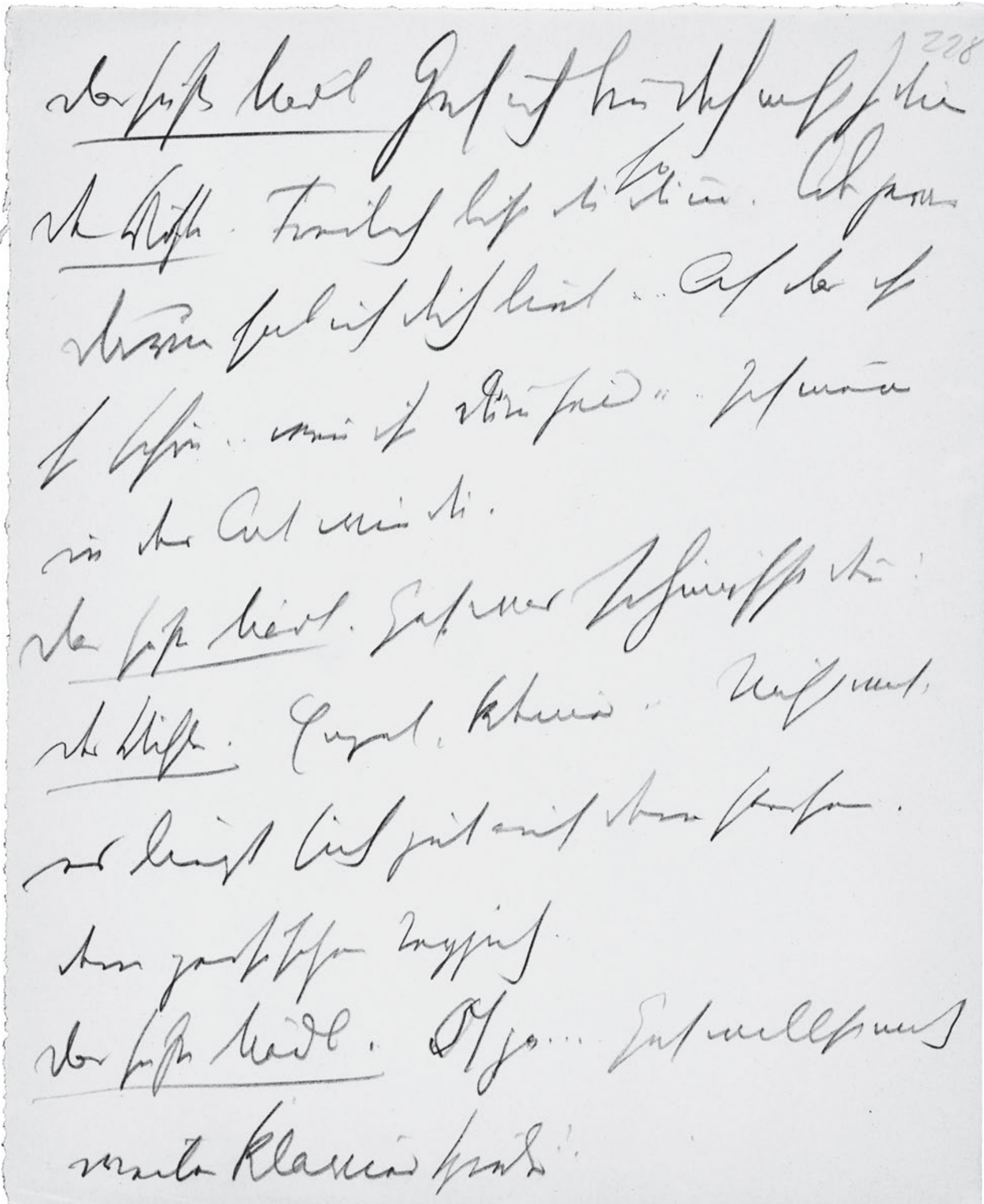

502 


\section{8}

Das süße Mädl Geh ich bin doch nicht so dum

Der Dichte . Freilich bist du dūm. Aber gerad

darum hab ich dich lieb ..... Ah das ist

5 so schön .. we $\bar{n}$ ihr dum seid .... Ich mein

in der Art wie du.

Das süße Mädl. Geh was schimpfst den̄?

Der Dichter. Engel, kleiner .. Nicht ? $w a h$, es liegt sich gut auf dem Perser .

10 dem persischen Teppich.

Das süße Mädl. Oh ja ... Geh willst nich

weiter Klavier spielen? . 
HSz7 229

Handschriften und Typoskript

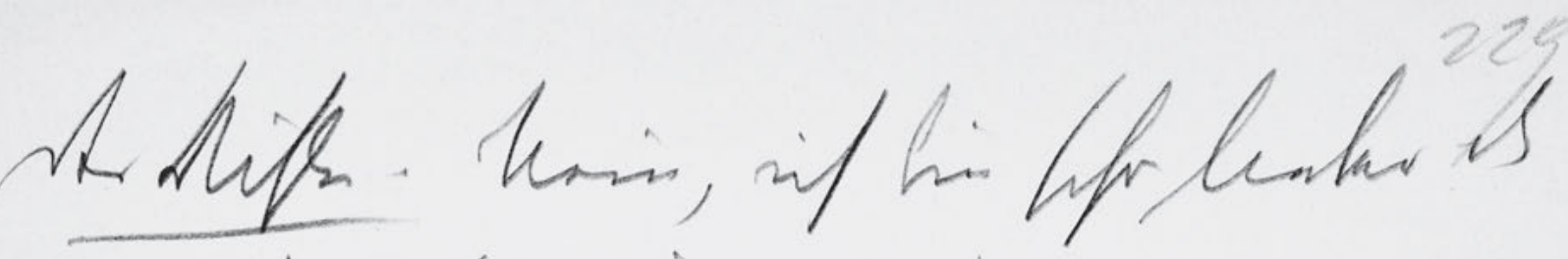

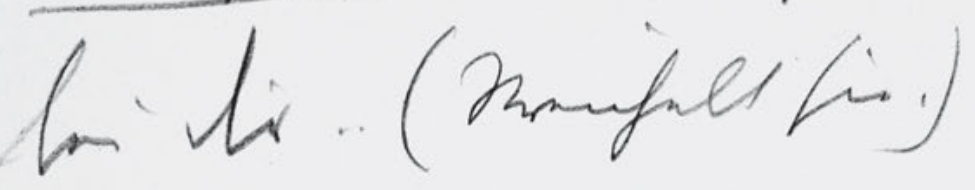
ath. In millp mift lab tuf

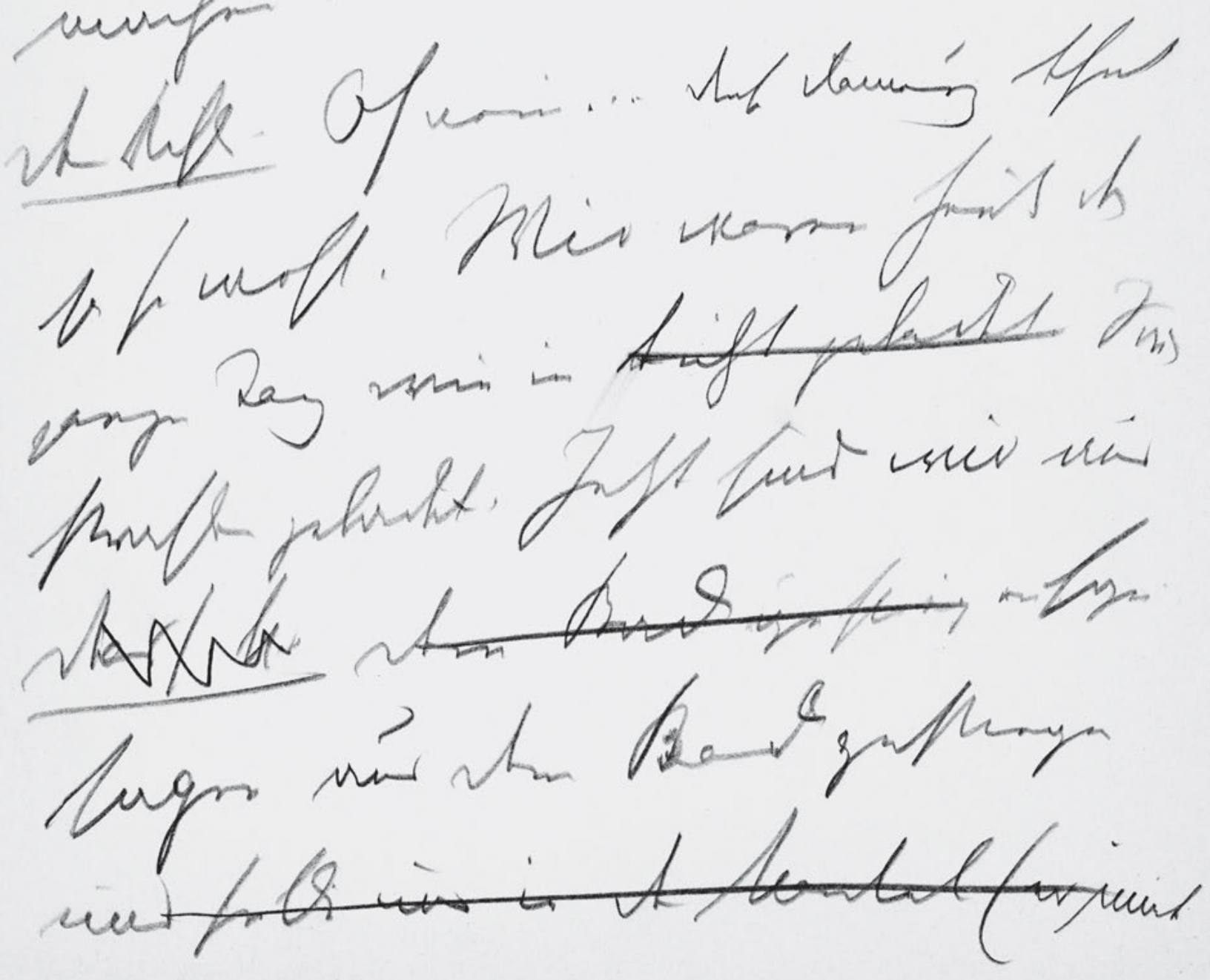

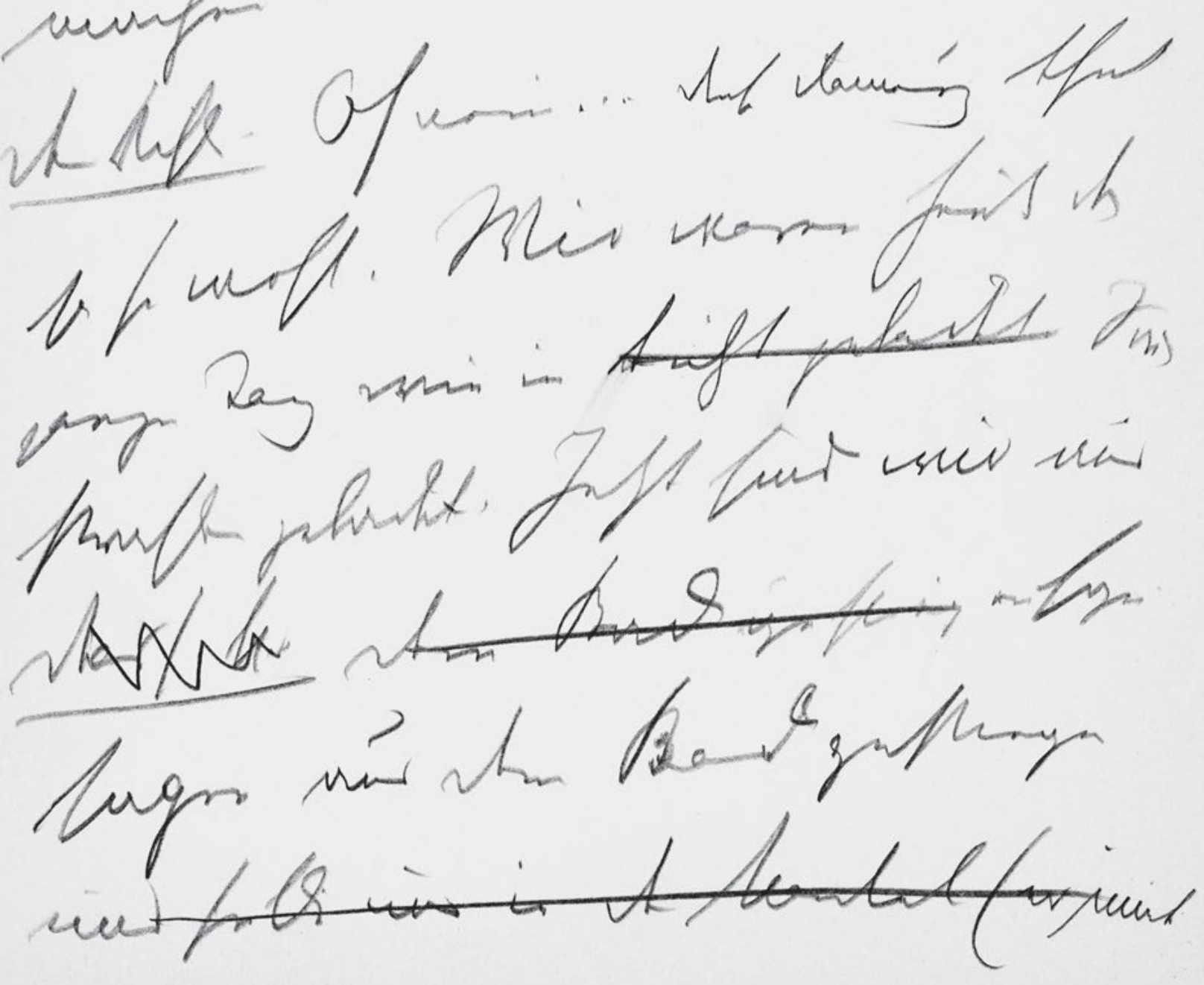

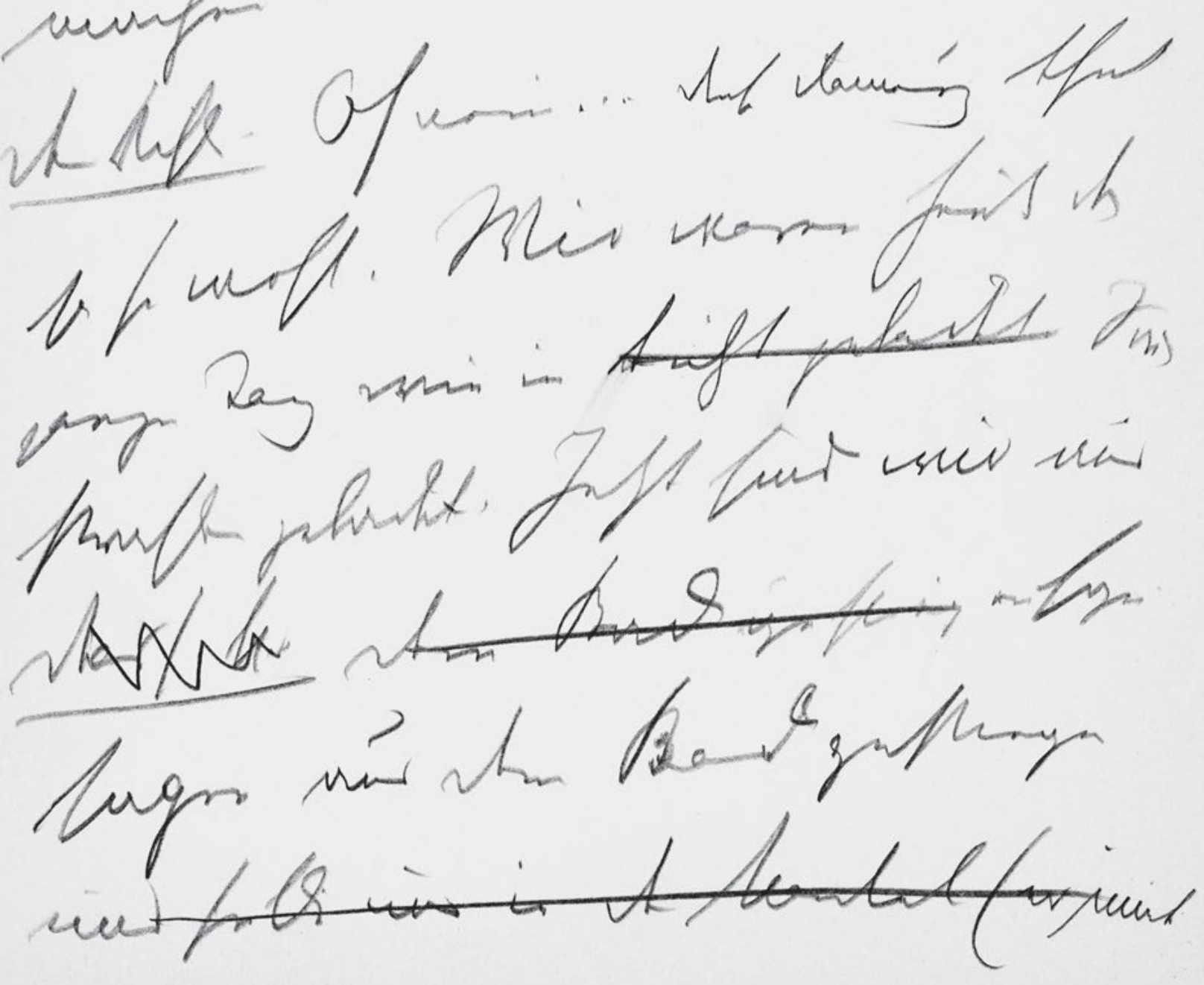

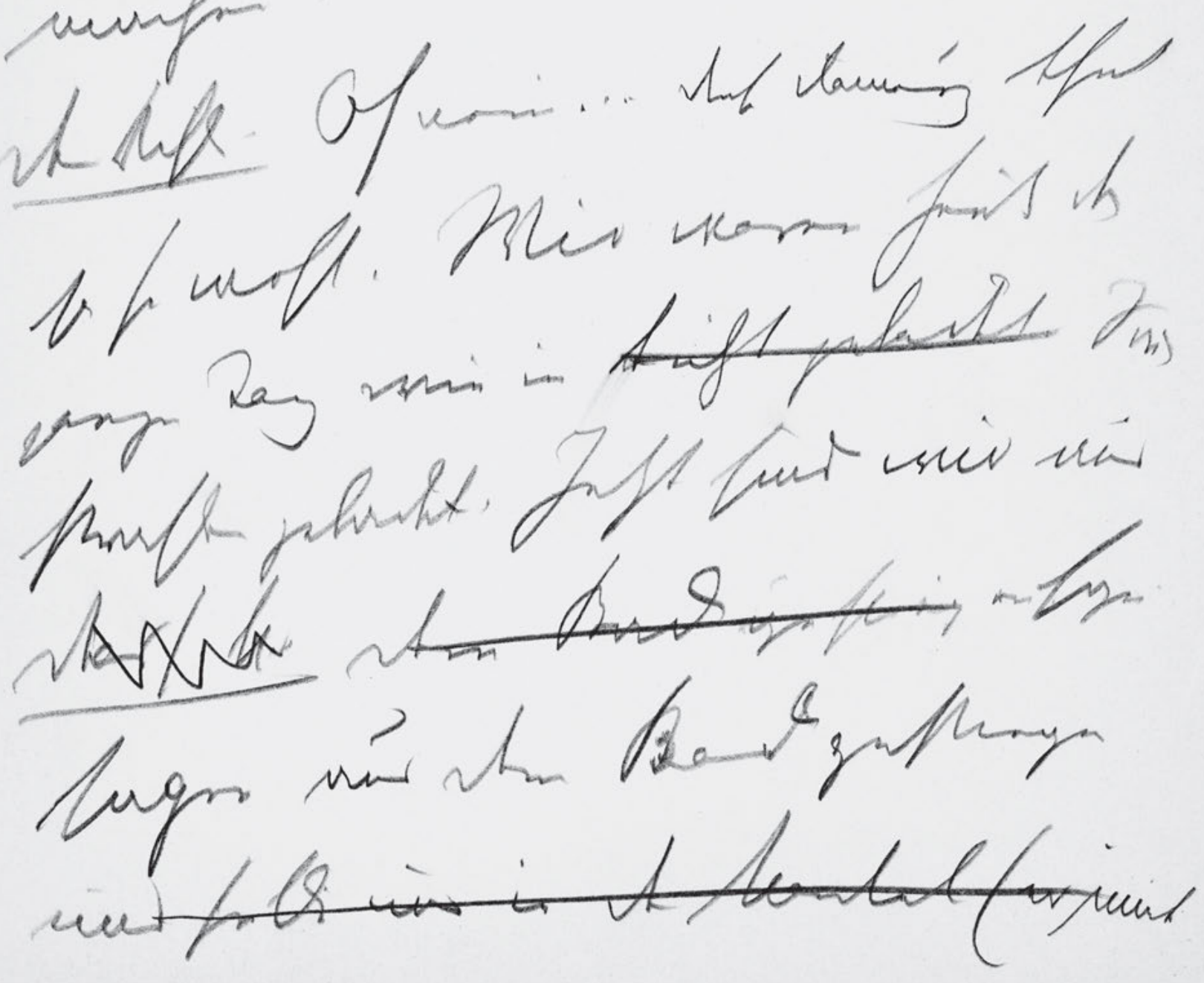

504 
Der Dichter. Nein, ich bin schon lieber da

bei dir . . (Streichelt sie.)

Das s. M. Geh .. willst nicht lieber Licht

5 machen?

Der Dichter. Oh nein ... diese Dǟ̄erung thut

ja so wohl. Wir waren heut den

ganzen Tag wie in Licht gebadet. Sō̄en

strahlen gebadet. Jetzt sind wir aus

$10 \quad$ Das s M. dem Bad gestieg ?wie? sozu

sagen aus dem Bad gestiegen

und hülle uns in den Mantel (er ?nim $t^{\text {? }}$ 
HSz7 230

Handschriften und Typoskript

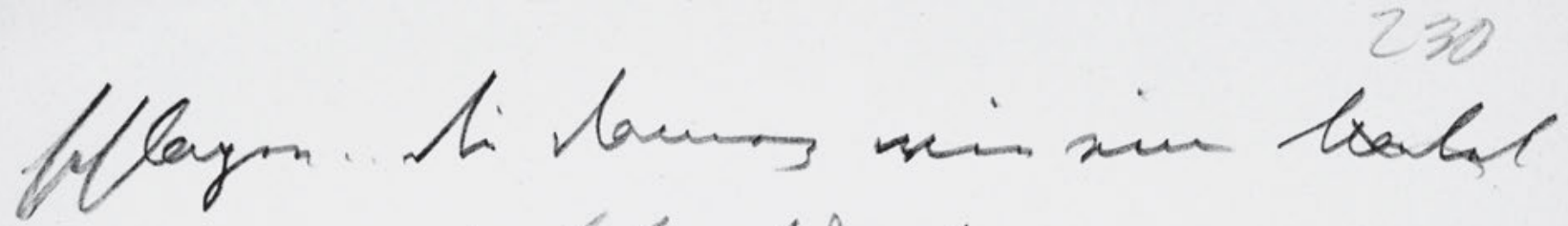

Detuonbl

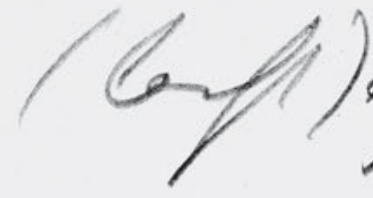

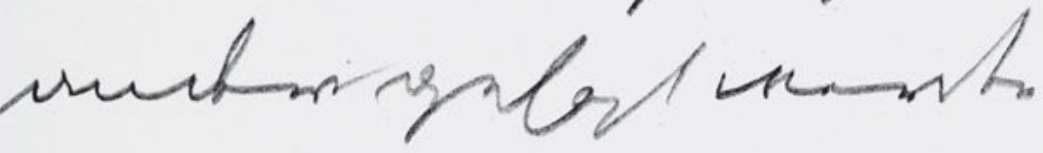

h

mift

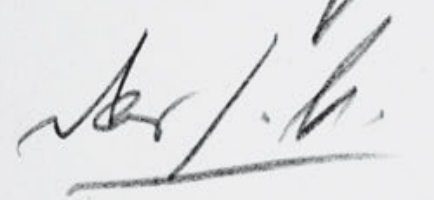

nipuifl

sthifh

(

hif haft in of

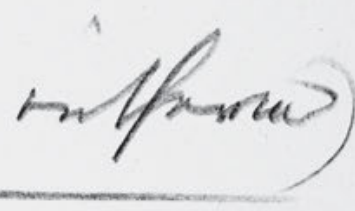

Oplobing,

,

lifurd in firt

(Nuits

holigh

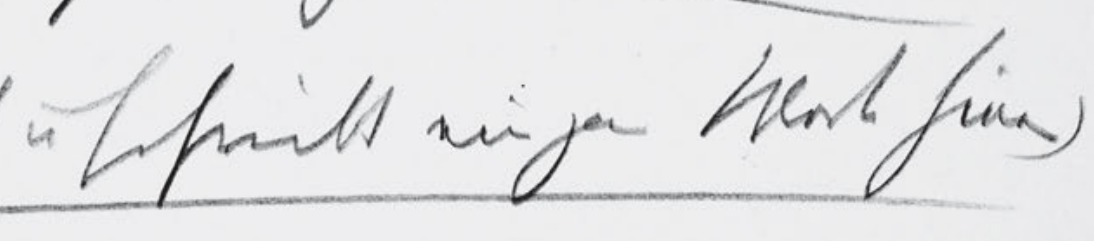

Hew muffert? (Hifw

(

Ma ifraits L

506 
230

schlagen .. die Damerg wie einen Mantel

Badmantel (lacht) ah nein .. da muss

anders gesagt werden .. Findest

5 du nicht?

Das s. M. Weiß nicht . .

$\underline{\text { Der Dichter (sich leicht von ihr entfernend) }}$

Göttlich, dieses ${ }^{\circledR}$ Dumheit. (Nimt ein

Notizbuch u schreibt ein paar Worte hinein)

${ }_{10} \quad$ Das s. M. Was machst deñ? . . (Sich na

ihm umwend) Was schreibst dir 
HSz7 231

Handschriften und Typoskript

tim anf.

23

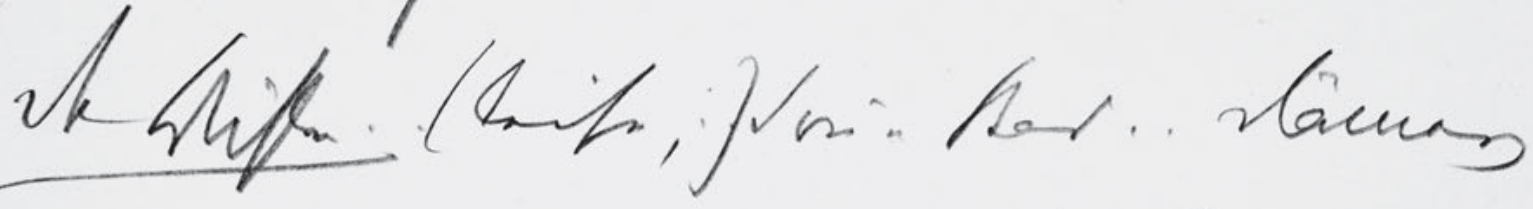

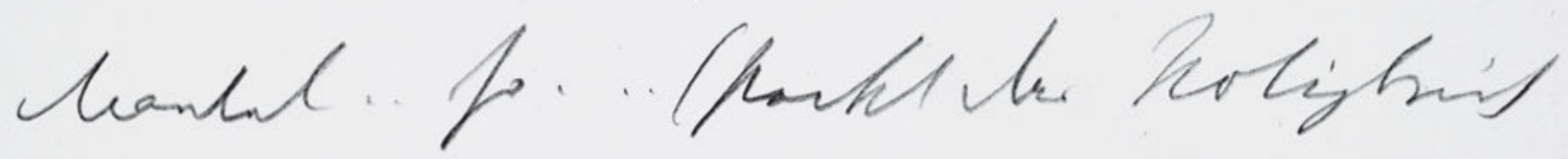

sin) (Rowit) hift... gasplos

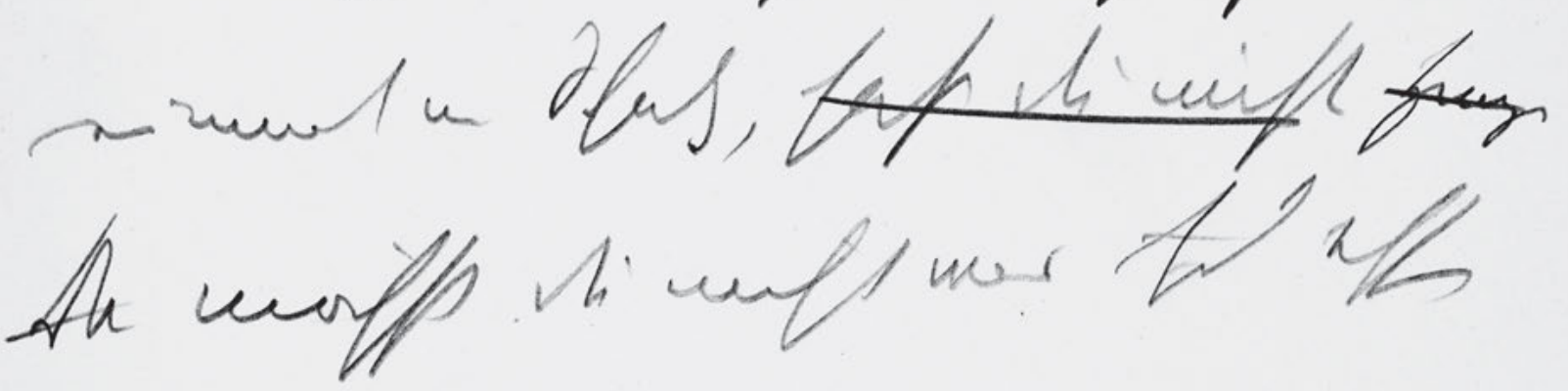

the miler.

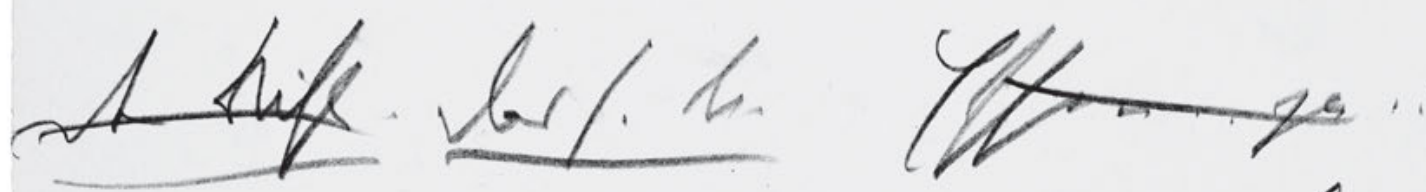

Whit

fot uf nymath

shife. Gu.. un mi hik hi

508 


\section{1}

denn auf.

Der Dichter. .(leise,: ) Son̄e Bad . . Dämerg

Mantel .. so . . . (steckt das Notizbuch

5 ein) $\left({ }^{\mathbb{N}}\right.$ Laut) Nichts . . . . Sag Jetzt sag

einmal $\mathrm{m}$ Schatz, hast du nicht Hunger

Du möchst . du nicht was ? sch? essen

oder trinken.

Der Dichter. Das s. M. Essen .. ja . . Durst

10 hab ich eigentlich keinen. Aber Appetit.

Der Dichter. Hm . . mir wär lieber du 
HSz7 232

Handschriften und Typoskript

lathe sifs

form

Oryar

da/ $/$

suthifs.
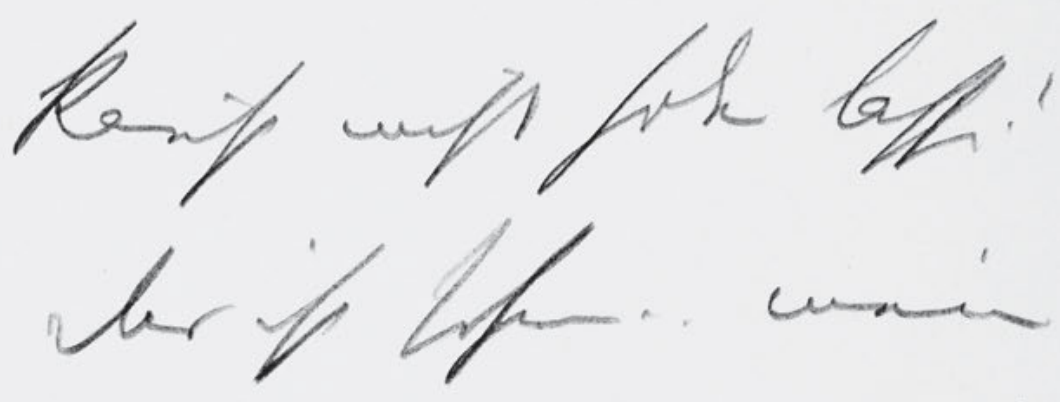

232

eel if

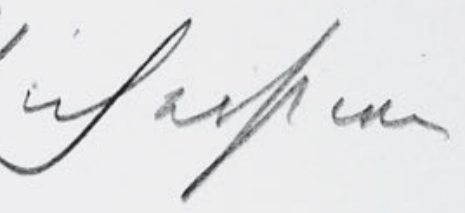

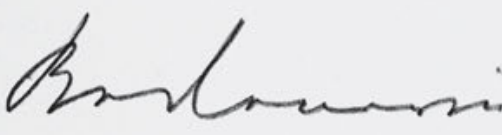

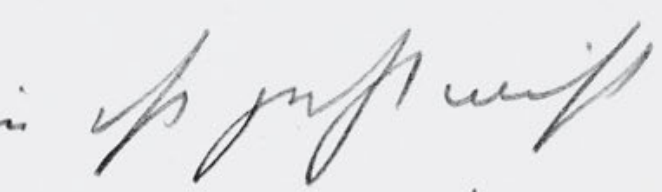

unearl

we nal

mufy $\alpha$.

br/a eh

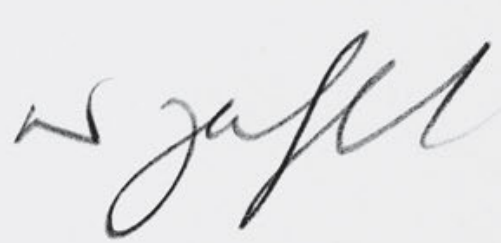

in

is unuthif mun an'

if uny

510 
232

hättest Durst ... Cognac hab ich ?nemli?

zu Haus . . aber essen müßte ich erst was

holen ...

$5 \quad$ Das s. M. Kan̄st nicht holen lassen?

Der Dichter. Das ist schwer . . meine

Bedienerin ist jetzt nicht mehr da.

na wart, ich geh schon selber. wa

mochtst dē

10 Das s M Aber es zahlt sich

ja ?wirk?lich nimer aus ich mus 


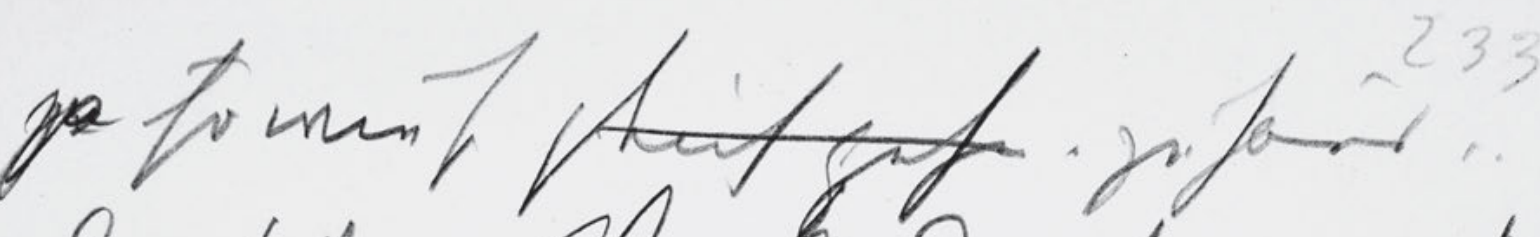

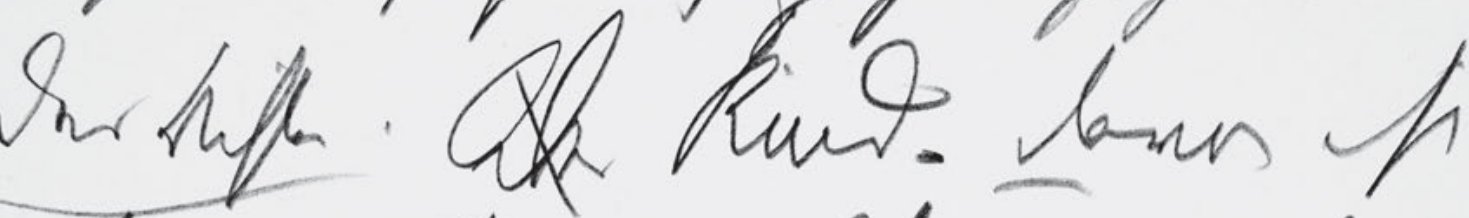

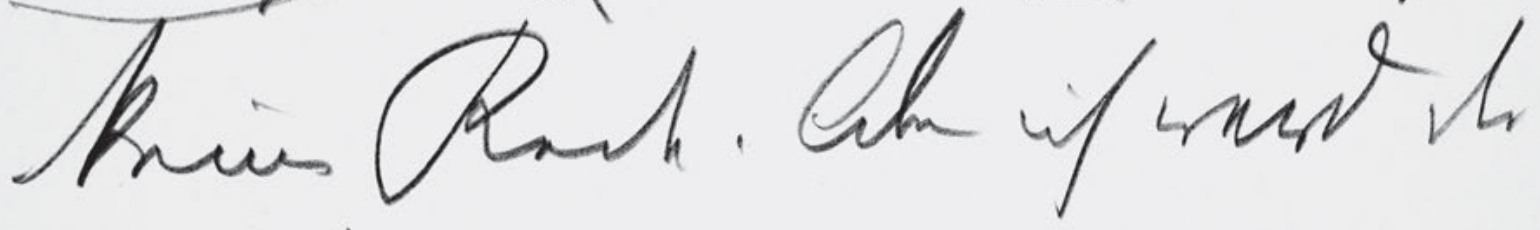

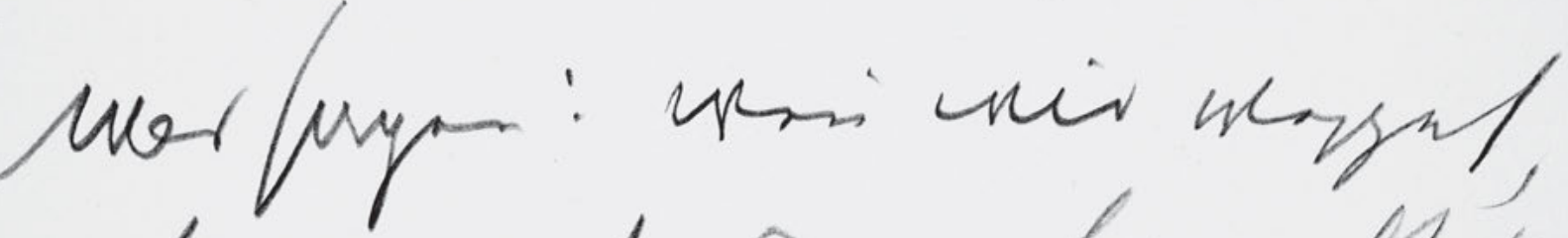

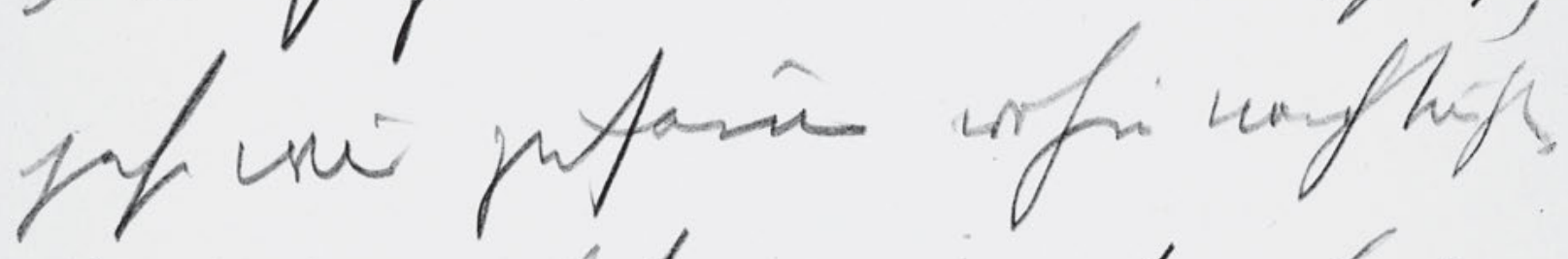
bor/h.

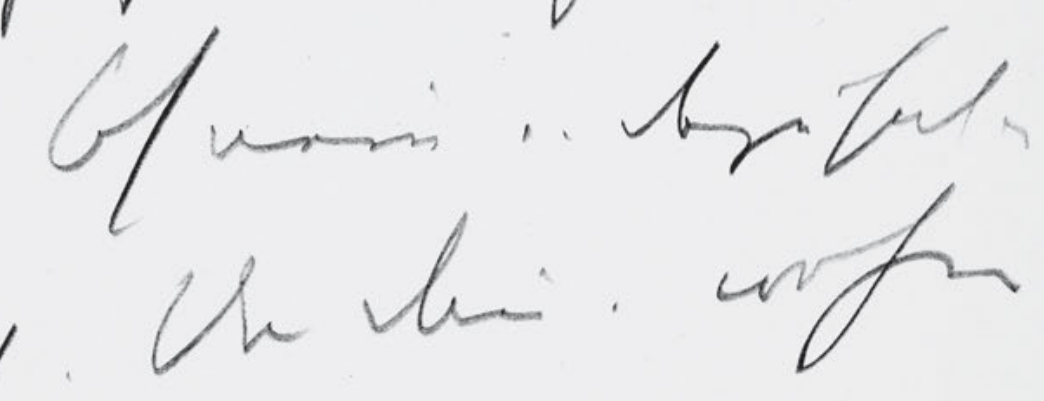

An inged

foln wis tur? Ger tarit gin

y um lathent.

chlife.

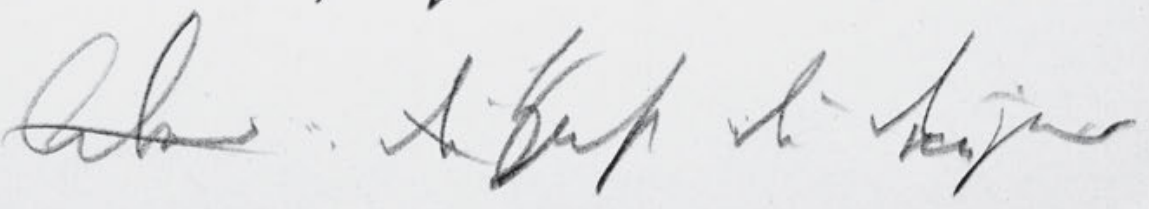


?ge? ja ${ }^{\text {[?] }}$ so wie so gleich gehn . zu Haus . .

Der Dichter . Aber Kind - davon ist

keine Rede. Aber ich werd dir

5 was sagen: we $\bar{n}$ wir weggeh,

gehn wir zusamen wohin nachtmahlen.

Das s M. Oh nein .. dazu hab ic

keine Zeit . Un dā̄ . wohin

wills

sollen wir denn? Es könt 'ja? ?ein?

10 ja wer bekan̄te sehn . .

Der Dicht. Aber ... du ${ }^{\mathrm{h}}$ Hast du dē̄ "gar 
HSz7 234

Handschriften und Typoskript
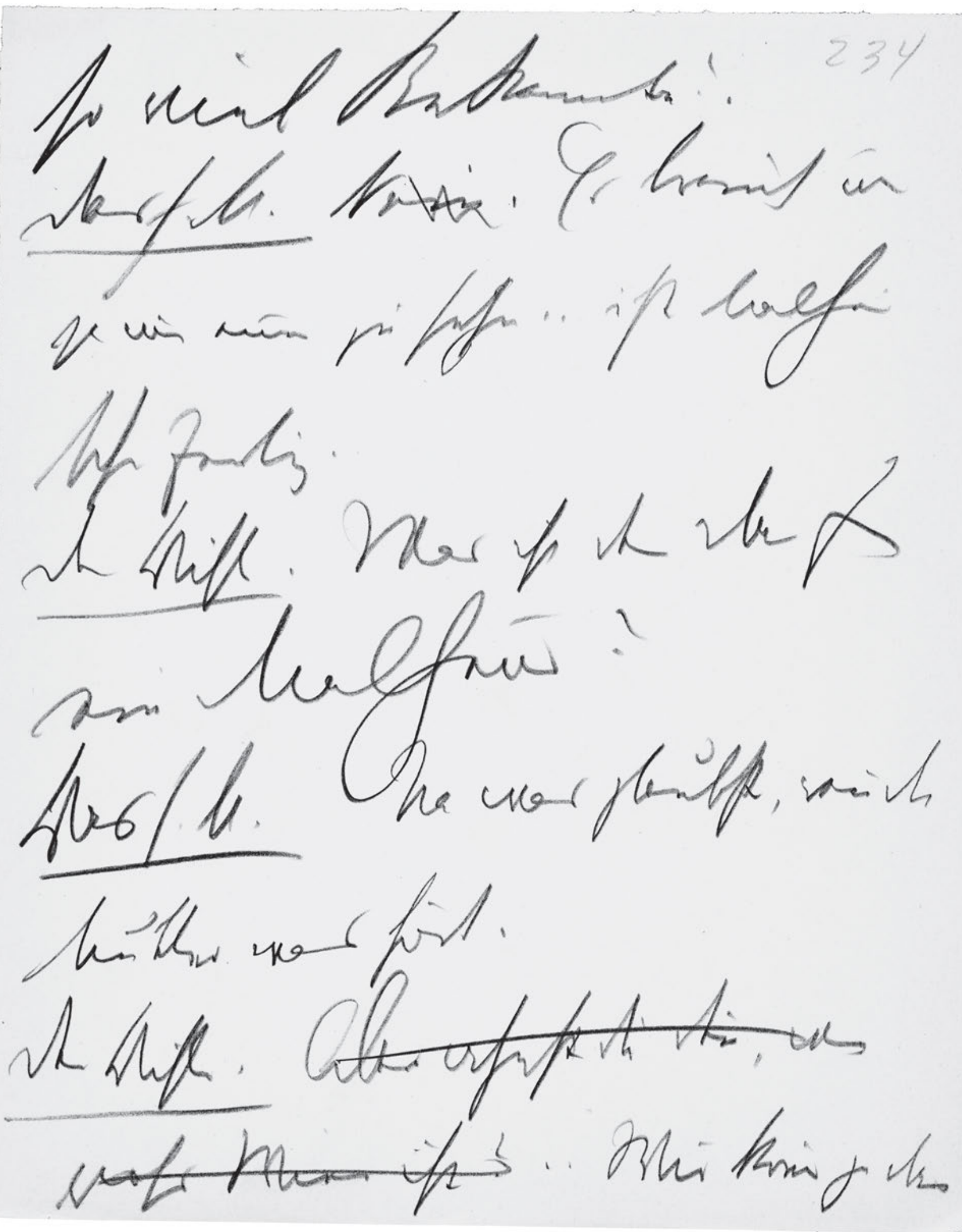

514 


\section{4}

so viel Bekannte? .

Das s. M. Nein. Es brauch uns

ja nur einer zu sehn .. ist Malheu

5 scho fertig.

Der Dicht. Was ist denn das für

ein Malheur?

Das s. M. Na was glaubst, wen̄ die

Mutter was hört.

10 Der Dichter. Aber ahnst du deñ, wie

gross Wien ist? .. Wir kön̄en ja dann 
HSz7 235

Handschriften und Typoskript

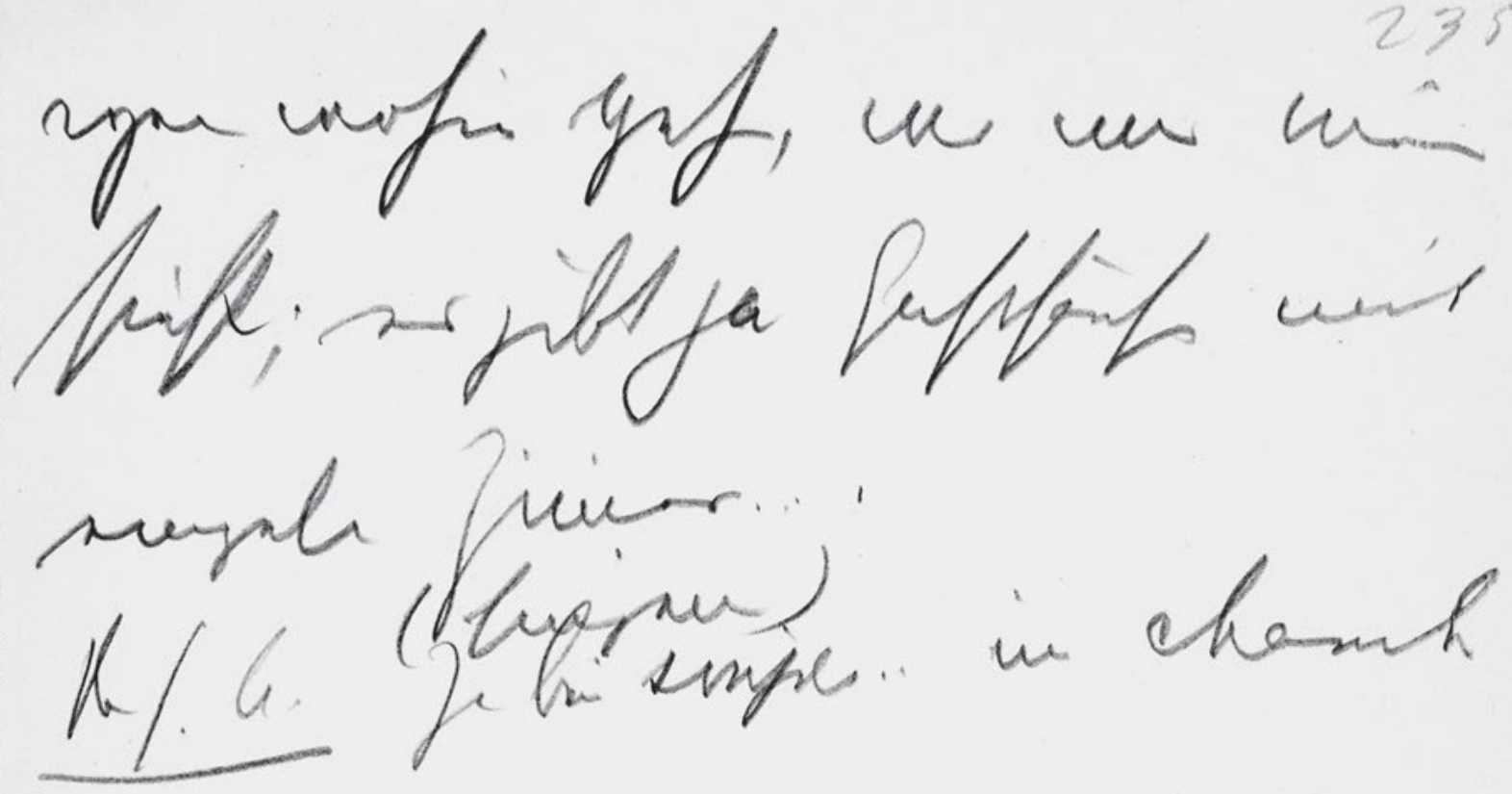

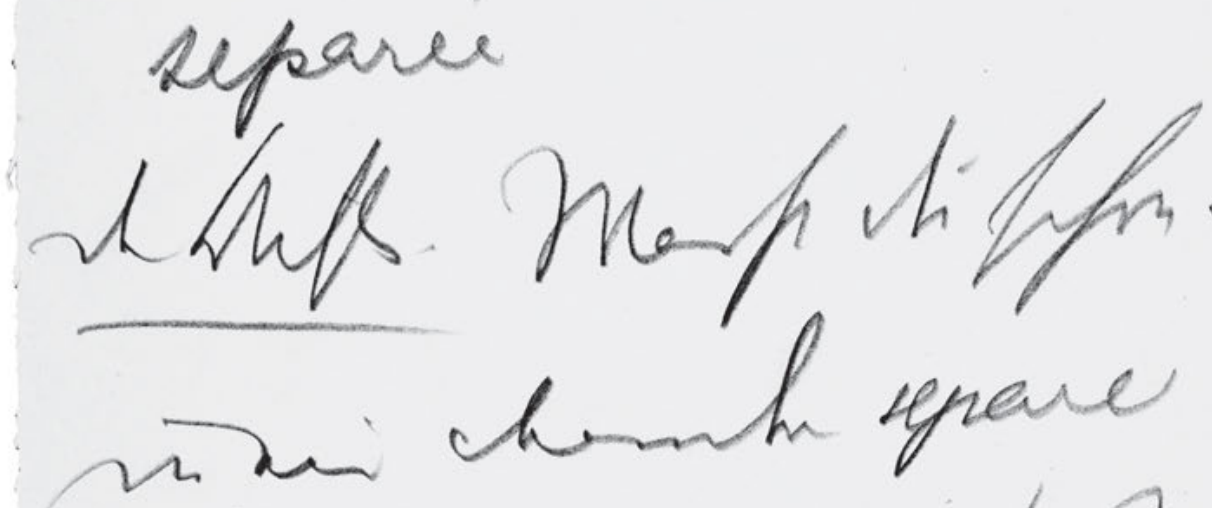
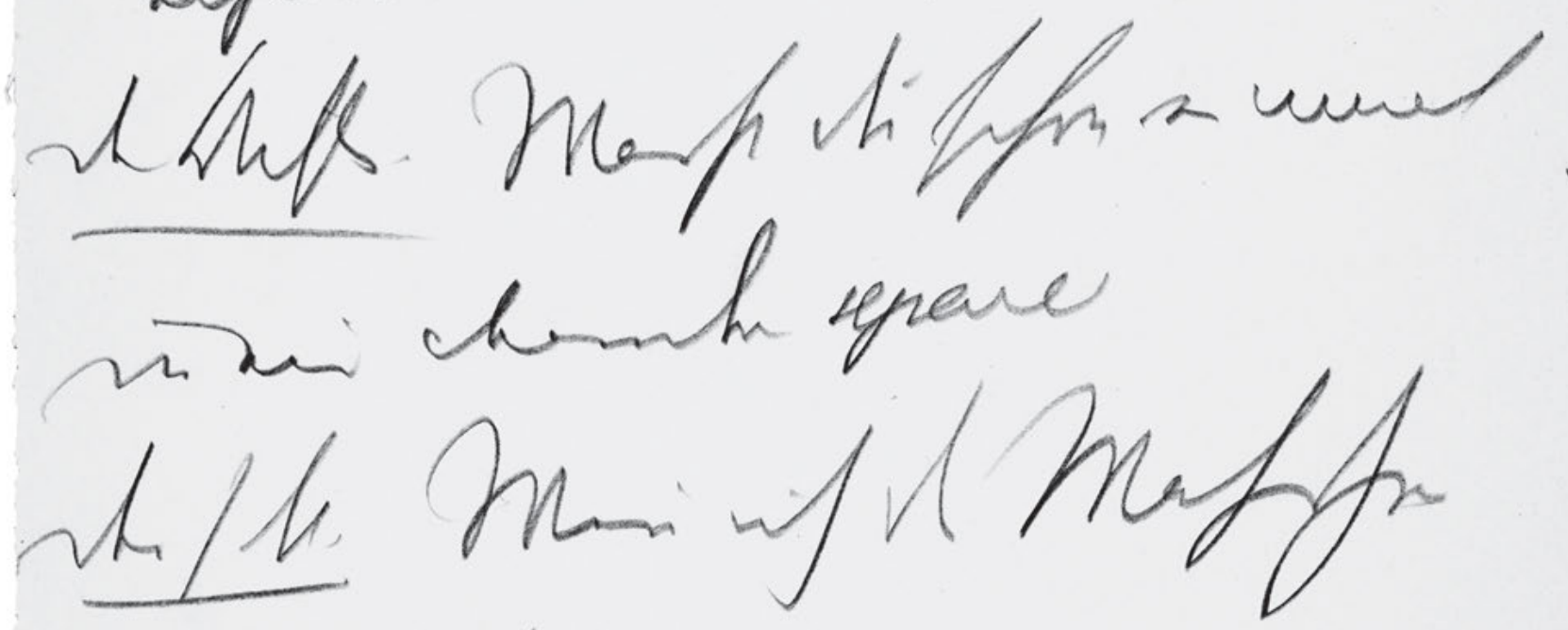
lapan wole - je.

516 


\section{5}

irgen wohin gehen, wo uns niem

sieht; es gibt ja Gasthäuser mit einzelne Zī̄er ....

$$
\text { (singend) }
$$

$5 \quad$ Das s. M. Ja beim soupèr . . im chambre separée

Der Dichter. Warst du schon einmal in ein chambre separee

Das s M. Weñ ich die Wahrhei

${ }_{10} \quad$ sagen $^{w}$ soll - ja. 
HSz7 236

Handschriften und Typoskript

rothe.

Maruar lo

tha

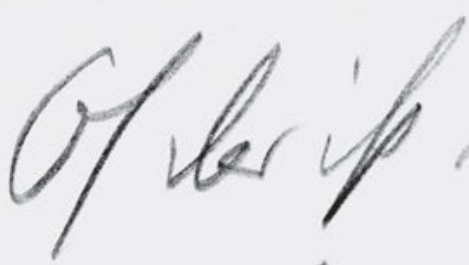

$r$

23

uef min

manf

..

O

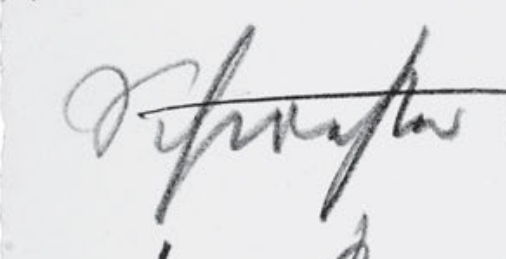

pror

Sin

ne mit unu

nif uifrominn...

$\frac{\operatorname{shl} \text { he }}{\sin \varphi_{u}}$

lent

Bample

un meft pilb.

518 
236

Der Dichter. Wer war der glückliche?

Das s M. Oh das ist nicht wie du

meinst . . ich war mit meine

$5 \quad$ Schwester und meine Freund un

ihrem Bräutigam ..... die haben

mich mitgenomen .....

Der Dichter. So . . Und das soll ich dir

am End glauben?

${ }_{10} \quad$ Das s. M. Brauchst mir ja nicht zu glauben! 
HSz7 237

Handschriften und Typoskript

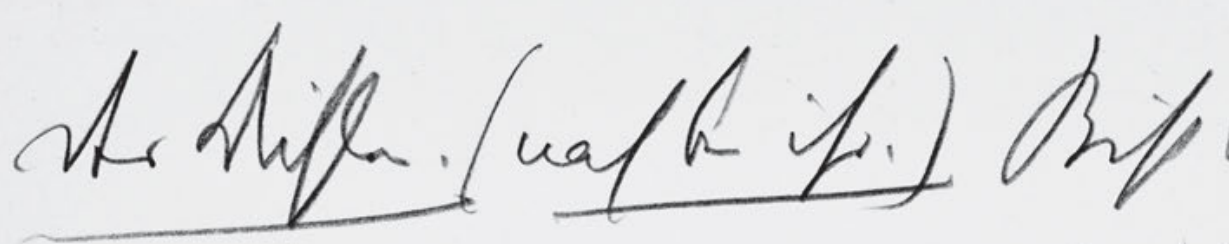

237

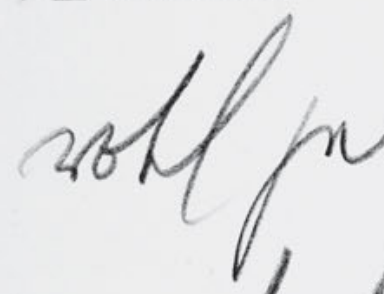

$$
\text { (a) }
$$

maft is

mat

Anit frin

and wajus

lea

riftiofer

an thi jigs unf

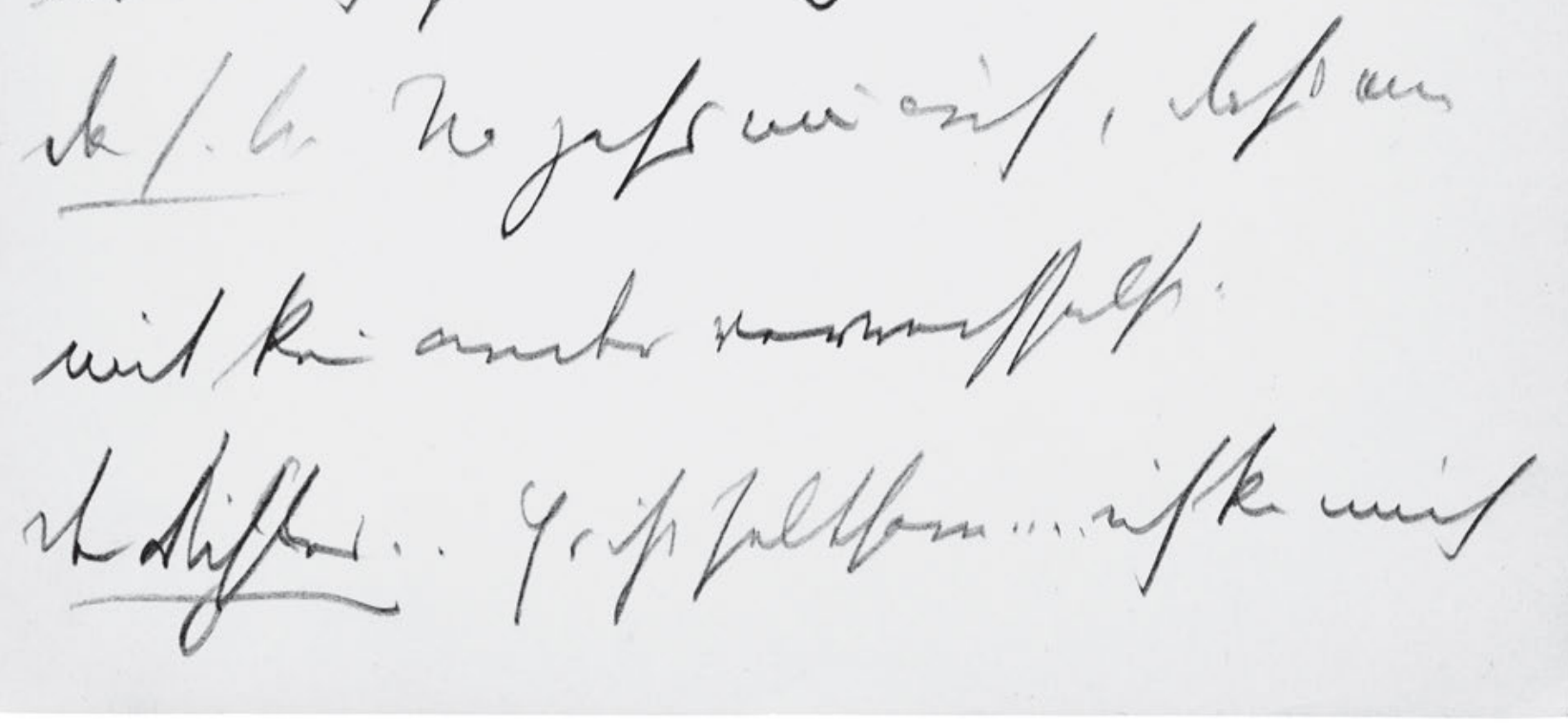

520 
Der Dichter. (nah bei ihr.) Bist du jetzt

roth geworden? Man sieht nichts

mehr?! ich kan̄ deine Züge nicht

5 mehr ausnehmen . . Lass mich fühlen

(Mit seiner Hand berührt er ihre Wangen)

Aber auch so erkeñ ich dich.

Das s. M. Na pass nur auf, dass mic

mit kein ander verwechselst.

${ }_{10}$ Der Dichter. . Es ist seltsam ... . ich ka mich 
HSz7 238

Handschriften und Typoskript

mift unf msnurr, wi tas
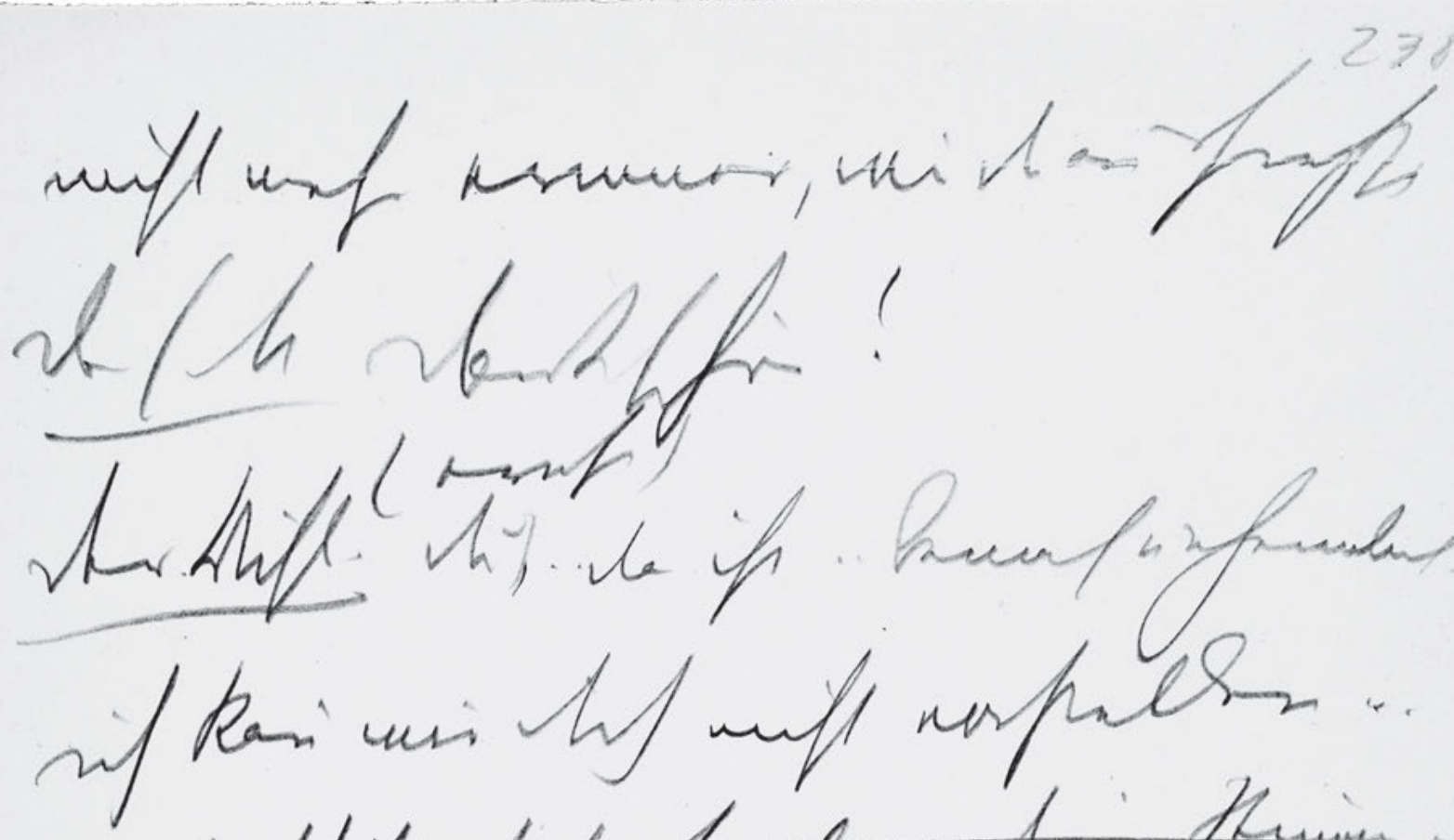

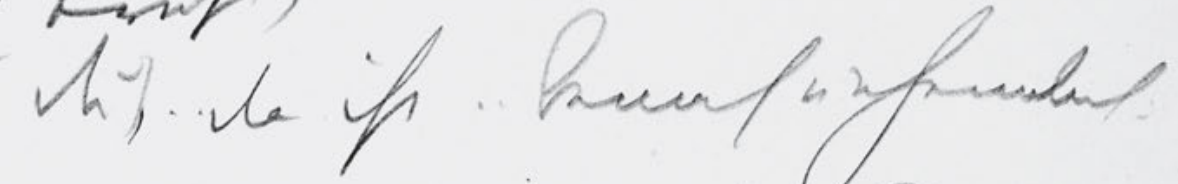
In in pursipt tiviful of h/alf

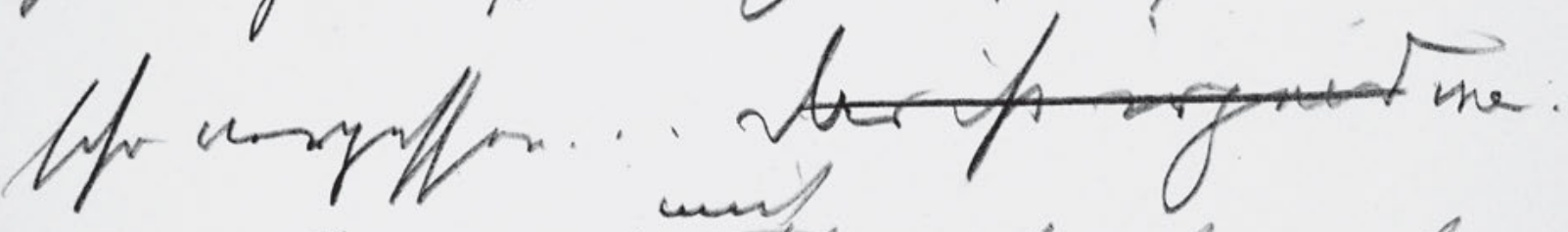

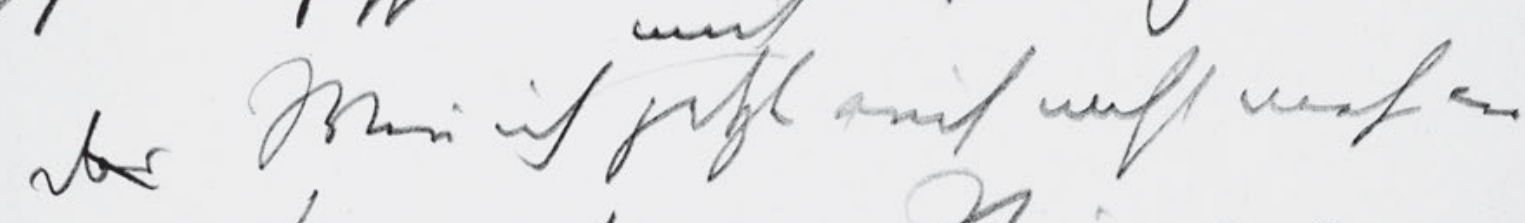
strbleng heve thi mone

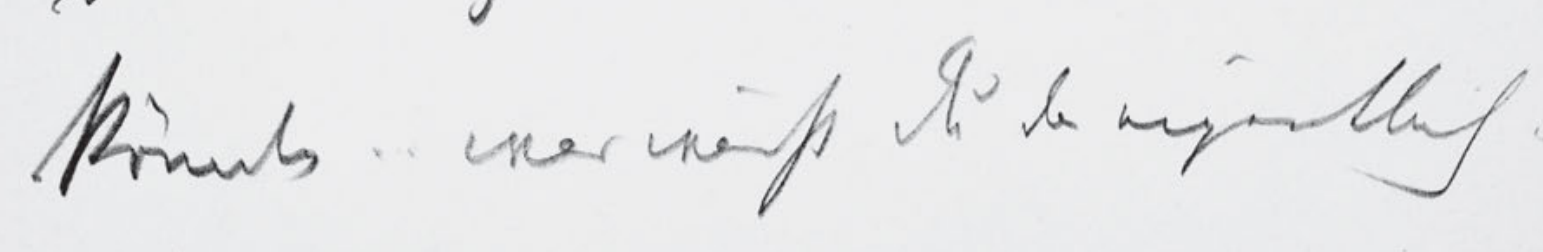

522 
nicht mehr erinner, wie du aussiehst

Das s M Dank schön!

(ernst)

Der .Dicht. Du$^{[2]}, \ldots$ das ist . . beinah unheimlich:

5 ich kan̄ mir dich nicht vorstellen ...

... Ich bitt dich .. sprich .... deine Stimme . .

In ein gewisse Sin̄e hab ich dich also

schon vergessen ... Das ist irgend was.

mich

das Weñ ich jetzt auch nicht mehr an

den Klang deiner Stim erinn

könnte . . was wärst du da eigentlich . . 
HSz7 239

Handschriften und Typoskript

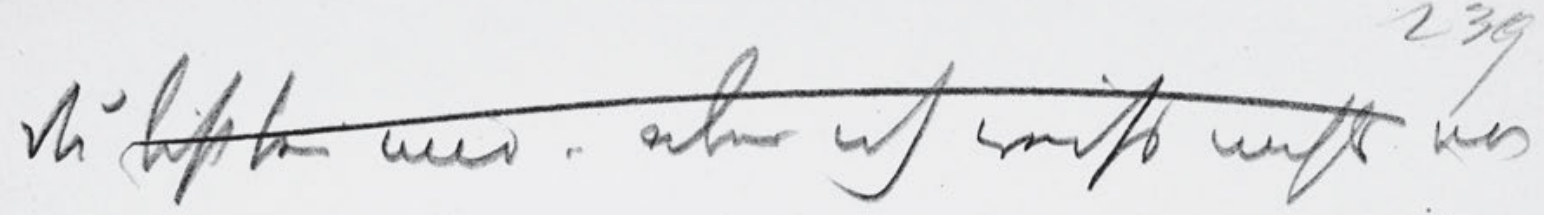

ti hat iftorn gifhif infrumber

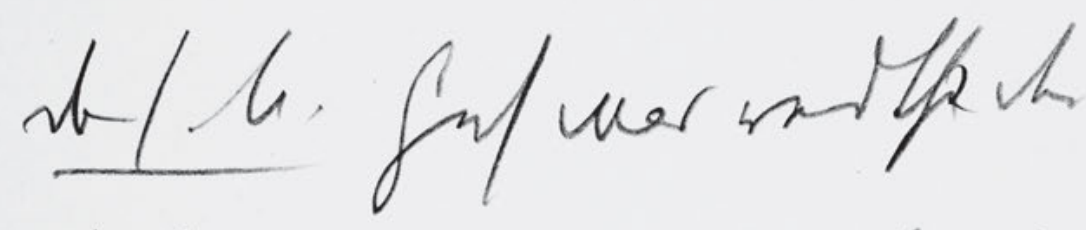
Shats. Rufs, un Yvarl wipt. In

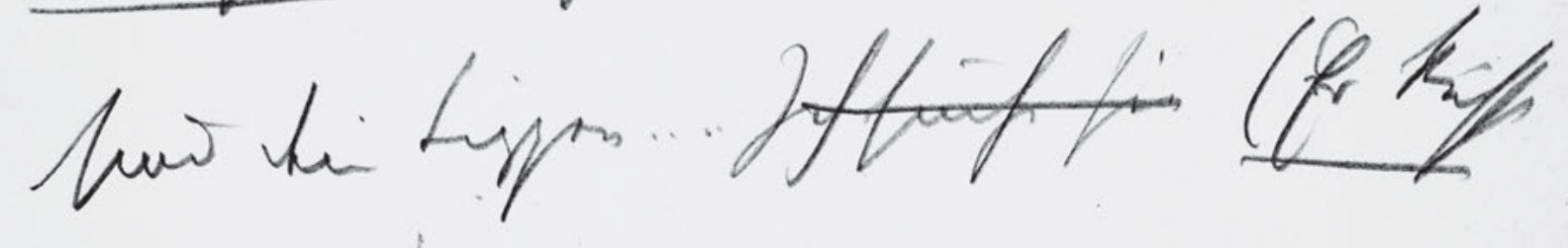
pinab.)

arth. A

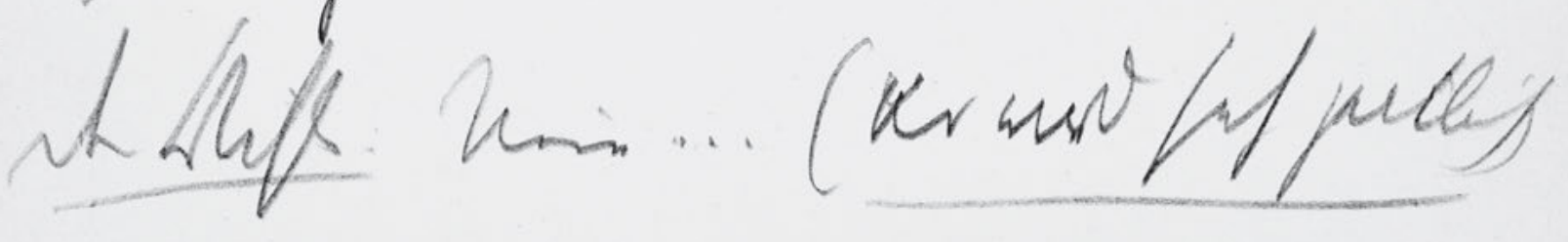
as, ot hi mithir gap.

524 


\section{9}

Du bist bei mir - aber ich weiss nichts von

dir .... . Nah u fern zugleich . . unheimlich

Das s M. Geh was redtst den -

5 Der Dichter. Nichts, mein Engel .. nichts .. W

sind deine Lippen ... . Ich suche sie ( ${ }^{\mathrm{e} E r}$ küsst

sie $a b$.

D’as s M. Willst nicht lieber Licht

machen?

${ }_{10} \quad$ Der Dichter. Nein .... ( ${ }^{[?]}$ er wird seh zartlich)

.. Sag, ob du mich lieb hast. 
HSz7 240

Handschriften und Typoskript

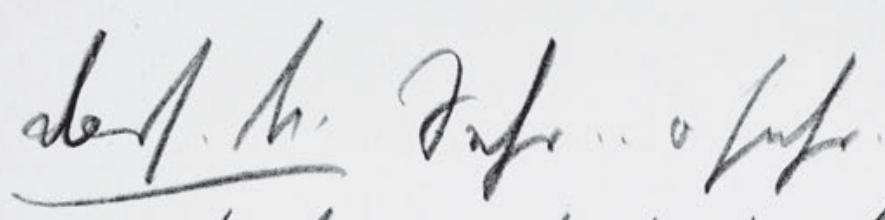

240

sh Llifs

uph to lop
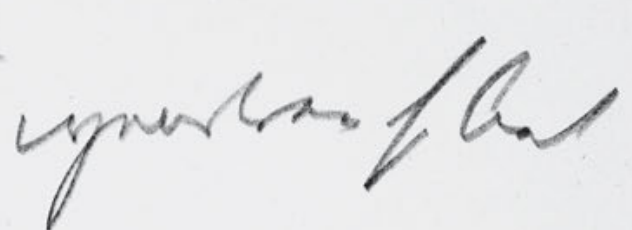

prfabt mis miy.

$\frac{\text { darte }}{\text { ch thefe }}$

Whetige
Oher..
staryg

ban.h.

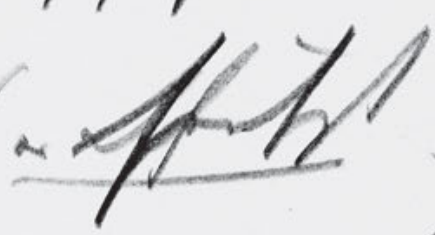

purenfon

Gruer mee lish, hi musth

pr

atela

Lrepani-

526 
Das s. M. Sehr . . o sehr . .

Der Dichter. . Hast du schon irgendwen so lieb gehabt wie mich.

$5 \quad$ Das s M. Ich hab dir ja [?] schon gesagt . . nein.

Der Dichter. Aber . . (er ?ath?seufzt.)

Das s. M. .... Das ist j mein Bräutg gewesen ...

Der Dichter. Es war mir lieber, du wurdes

$10 \quad$ jetzt nicht an ihn denken. -

Das s. M. Geh .. was machst deñ - schau . . 
HSz7 241

Handschriften und Typoskript

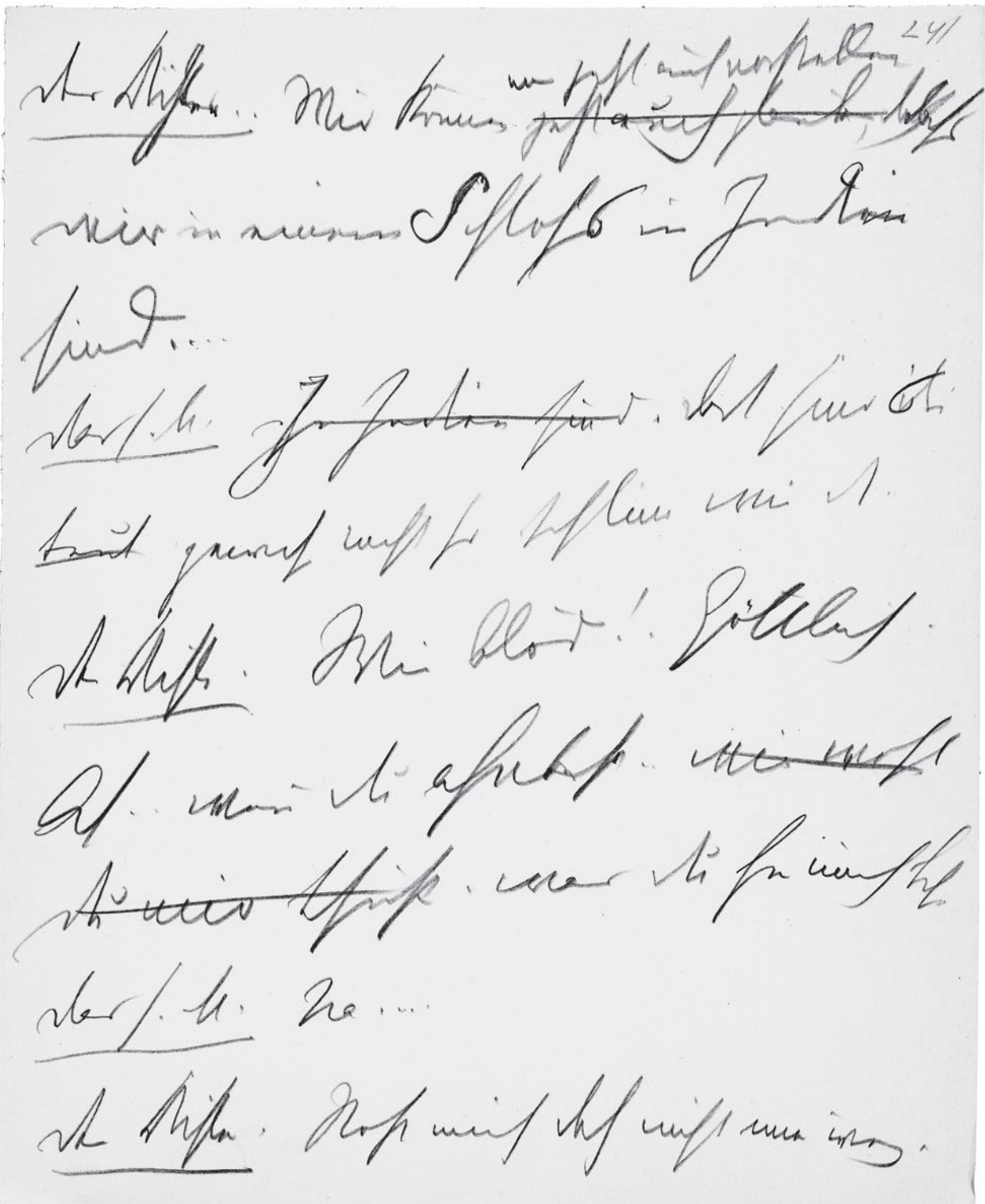

528 
uns jetzt auch vorstellen

Der Dichter. . Wir können jetzt auch glauben, ${ }^{\text {doch }}$ dass

wir in einem Schloss in Indien

sind ....

5 Das s. M. In Indien sind . Dort sind die's

Leut gewiss nicht so schlim wie d. .

Der Dichter. Wie blöd! . Göttlich.

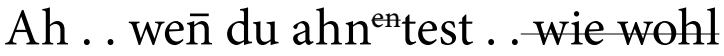

du mir thust . . was du fur mich bist

$10 \quad$ Das s. M. Na.....

Der Dichter. Stoß mich doch nicht ī̄er weg. 
HSz7 242

Handschriften und Typoskript

th hy un muling 242

mat:

st Sifta

(mitertis ping rai.

ber/.

la.

74

1. laffing

un

,

chefs.

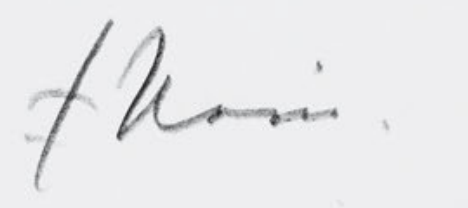

ver/a.

1

sin A hivil.

ho

nafmuith an the the

530 
ich thu dir ja nichts - vorläufig . . .

Das.s. M. .. Du .. das Mieder thut mir

weh . .

5 Der Dichter. (einfach.) Zieh's aus ..

Das s. M. Ja .. Aber du darfst desweg

nicht schlim werd.

Der Dichter. ( Nein.

Das s. M. (hat sich erhoben, und zieht

in der Dunkelheit ihr Mieder aus)

Der Dicht. (der wahrenddem auf dem Divan 
HSz7 243

Handschriften und Typoskript

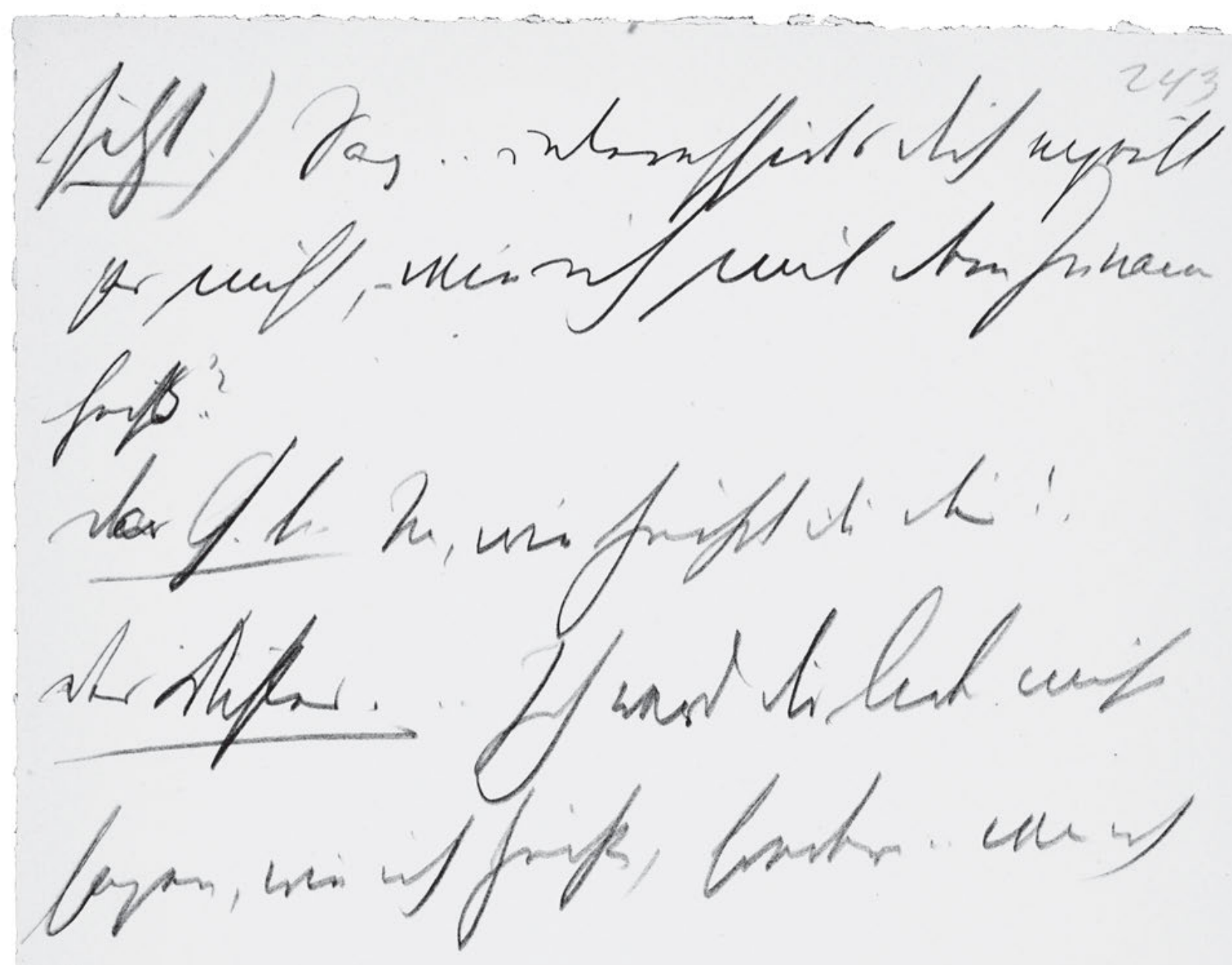

lom/ uran.

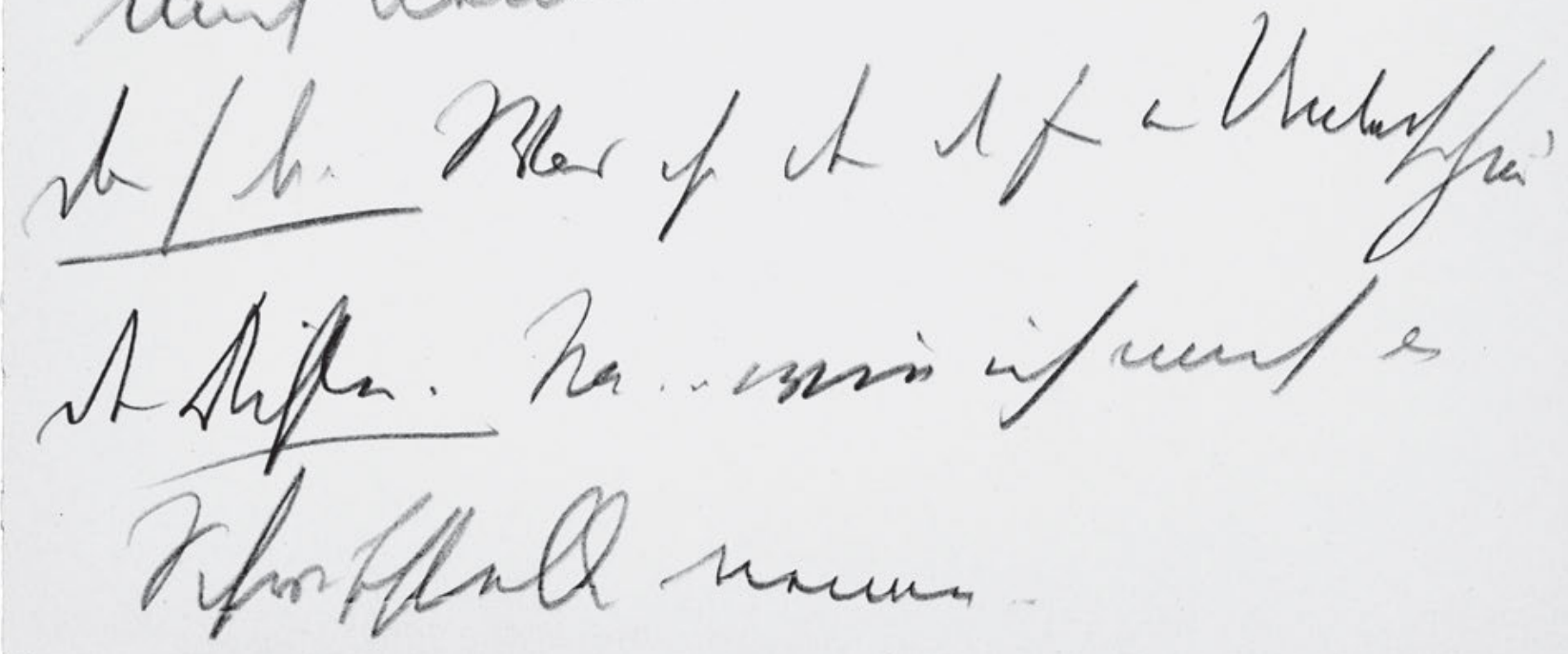

532 
243

sitzt.) Sag . . interessirts dich eigentl

gar nicht, - wie ich mit dem Zuname

hei ${ }^{\mathrm{ss}} \beta$ ??

${ }_{5} \quad \mathrm{D}^{\mathrm{er}}$ as ${ }^{G}$ S. M. Na, wie heißt du deñ? .

Der Dichter. .. Ich werd dir lieber nicht

sagen, wie ich heiße, sondern . . wie ich

mich nenne.

Das s M. Was ist denn da fur ein Unterschied?

${ }_{10}$ Der Dichter. Na ... wie ich mich al

Schriftsteller nenne. . 
HSz7 244

Handschriften und Typoskript

der/Vi.

ols
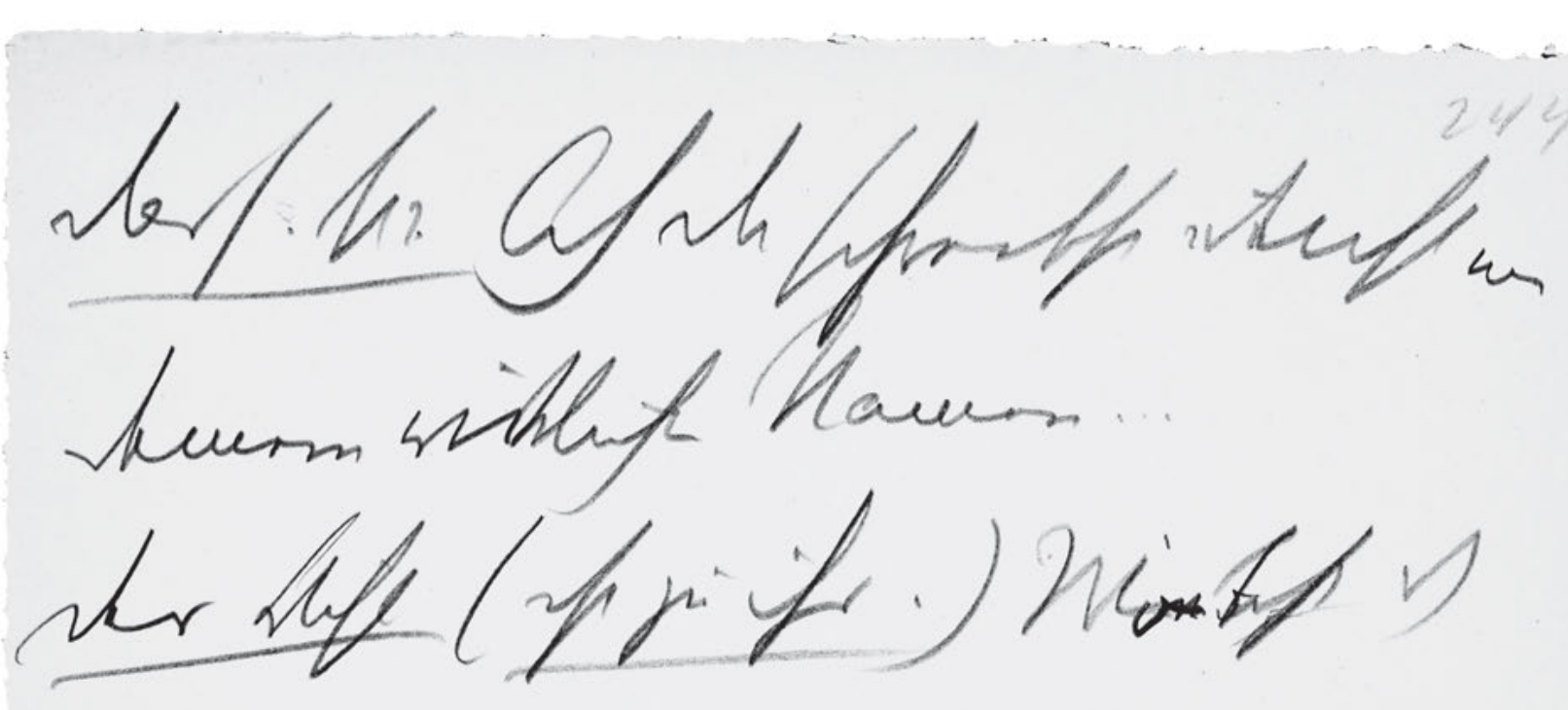

Nor

chafe.

Mar min

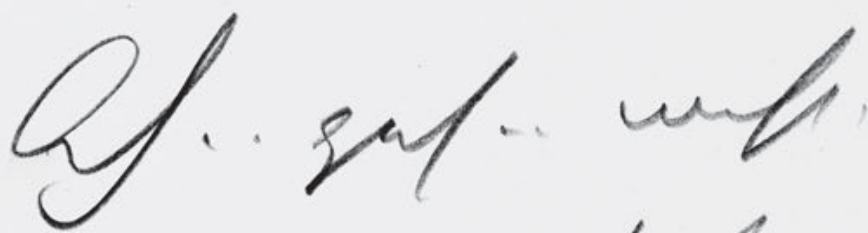

hy

Yran 
244

Das s. M[?]. Ah du schreibst [?] ${ }^{d}$ nicht 'un?

deinem wirklichen Namen ...

Der Dicht (ist zu ihr.) W $\mathrm{W}^{\mathrm{ie} ?} \mathrm{as}$ ? ?bist? $\mathrm{d}$

5 dē̄..

Das s. M. Ah .. geh .. nicht.

Der Dichter. Was einem da für ein

Duft entgegensteigt. Wie süss . .

(Er küsst ihren Busen.)

${ }_{10} \quad$ Das s. M Du zerreißt ja mei

Hemd. 
HSz7 245

Handschriften und Typoskript

sher the

Oy
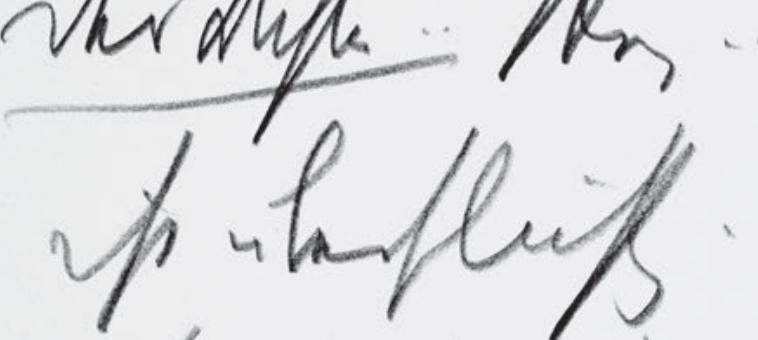

2
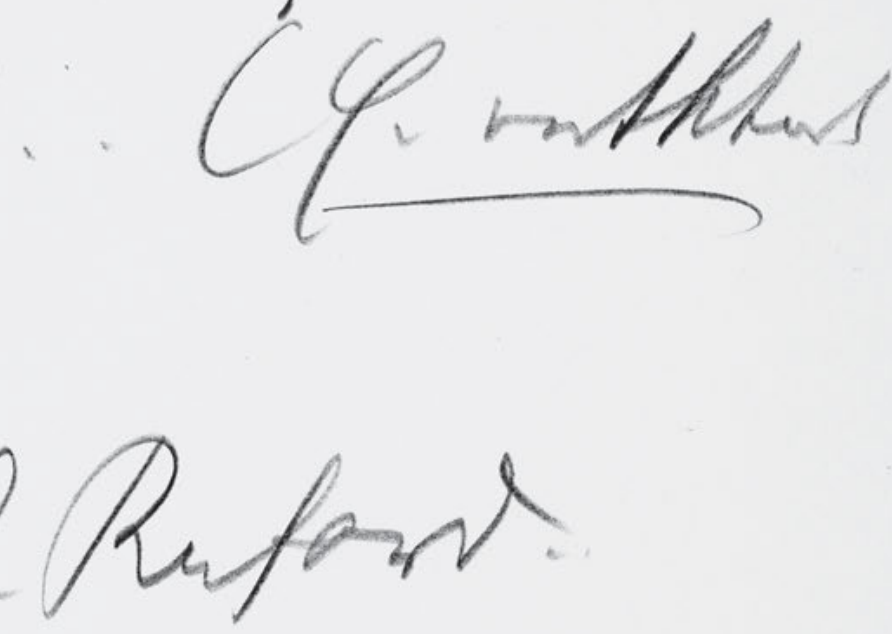

stift

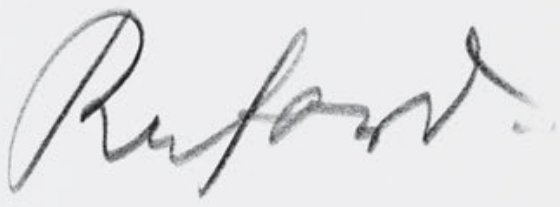

supir u

M

A thifs

of

pot

$$
1 \%
$$

b 


\section{5}

Der Dichter. . Weg . . weg . . alles das

ist überflüssig . . (Er entkleide

sie rasch.)

$5 \quad \mathrm{D}^{\mathrm{er}}$ as s M. Aber Richard..

Der Dichter. Und jetzt . . kō̄ . . in

unser indische Schloss .....

Das s M. Sag mir zuerst . . ob du

mich wirklich lieb has,

[?]? D? Dicht . Aber ich bete dich ja an . . 
HSz7 246

Handschriften und Typoskript

latiramp
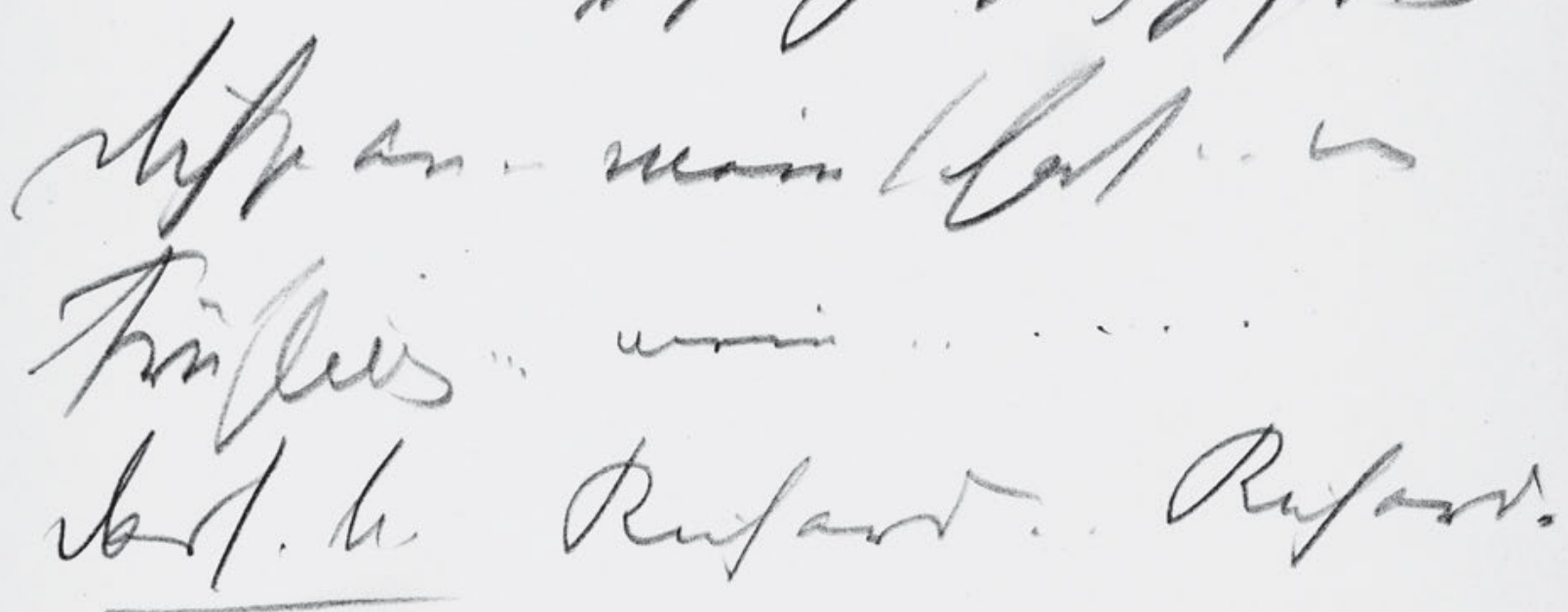

surglifs

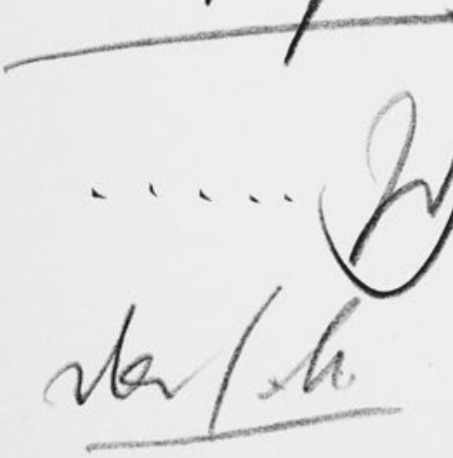

538 
246

(hat sie auf den Divan nieder ge

drückt - küsst sie heiss.) Ich bete

dich ja an - mein Schat $z$. ? m?

5 Frühling ... mein ......

Das s. M. Richard . . Richard.

Der Dichter. Das war überirdische Seligkeit

..... Ich nenne mich ...

${ }_{10}$ Das s. M. Richard . Oh mein Richard: 
HSz7 247

Handschriften und Typoskript

Mrlffla. II

Dor/lu. Mam

when wir Biehli..

uhifi. if

miff....

vinling nut

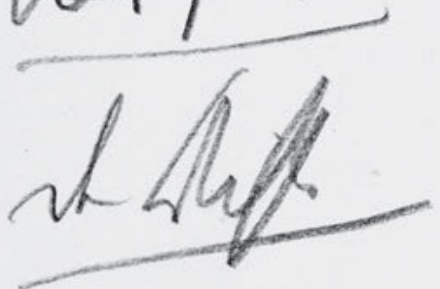

Onatis wif

540 
Der Dichter. Ich nen̄e mich . . Biebitz. -

Das s. M. . Warum nē̄st dich . Biebitz.

Der Dichter. Ich heiße nicht . Biebitz - ich neñe

5 mich so .... nun ... ken̄st du den Namen

vielleicht nicht?

Das s. M. Nein.

Der Dichter. Du ken̄st den Namen

Biebitz nicht ... Ah - göttlich! . Wirklich:

10 du sagst es nur, dass du ihn nich

ken̄st . . nicht wahr . . 
HSz7 248

Handschriften und Typoskript

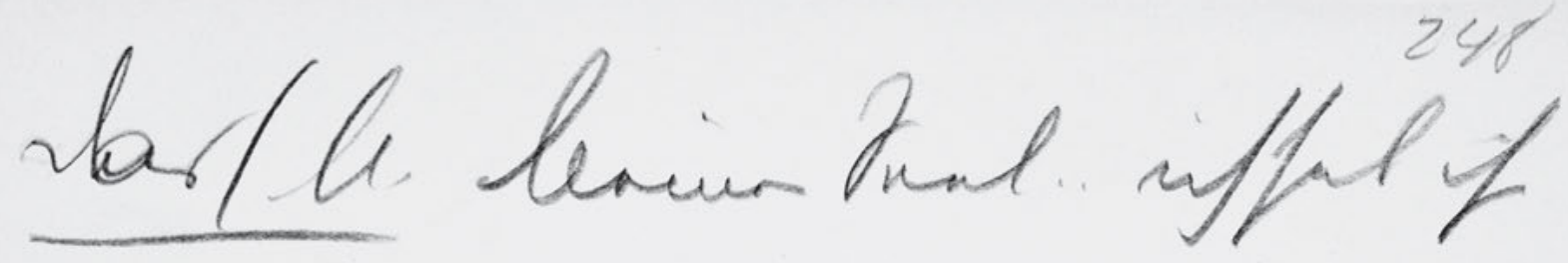
unigrfoid.

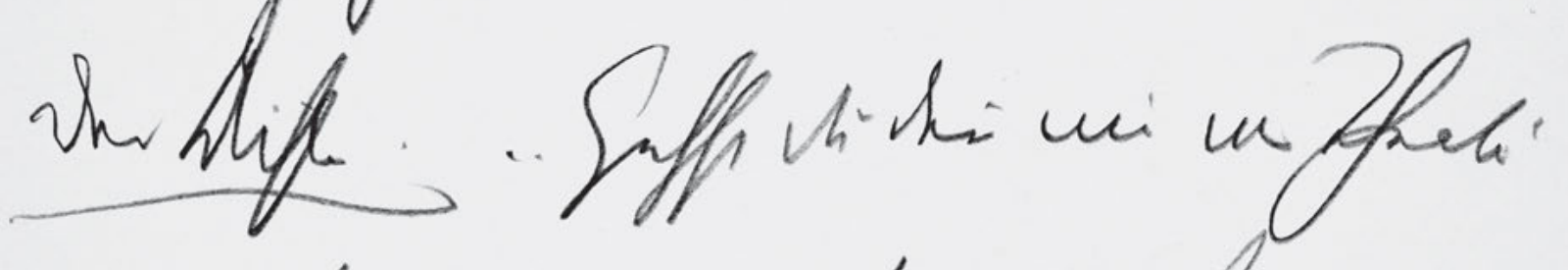

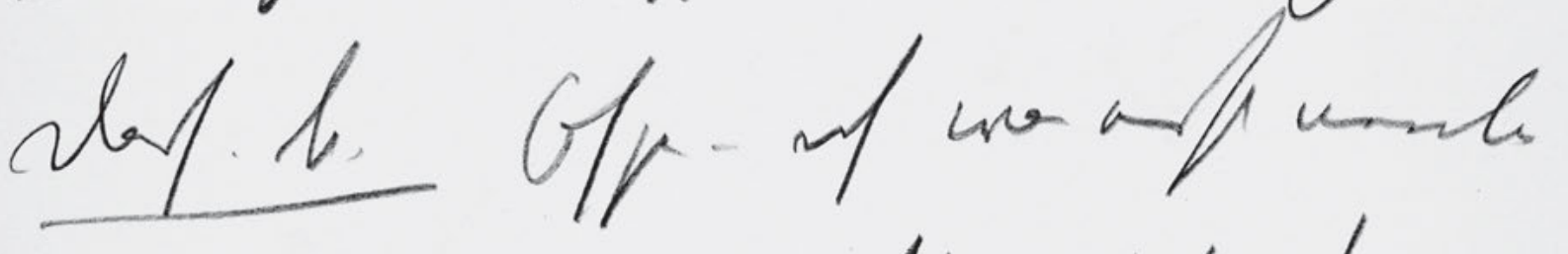
wit wurm. unft wit the rakel we cur triminim in

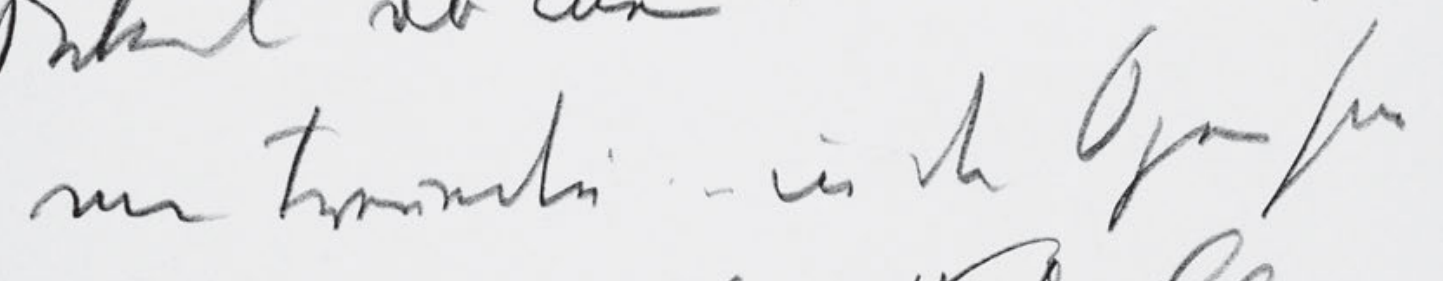
mu poump his Helecer.

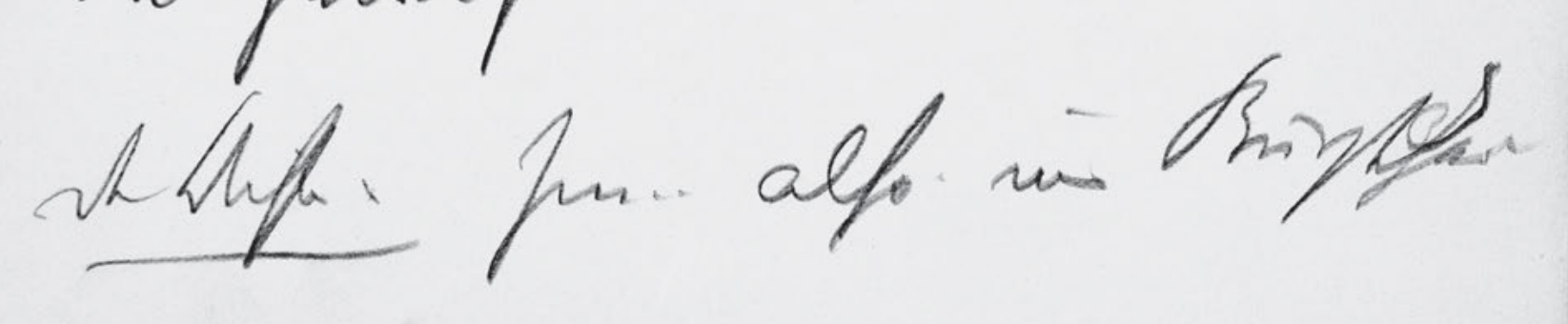

542 
248

Das s M. Meiner Seel . . ich hab ihn

nie gehört.

Der Dichter. .. Gehst du deñ nie ins Theater?

$5 \quad$ Das s. M. Oh ja - ich war erst 'neulic?

mit einem .. weißt mit dem

Onkel vo mein Freundin un ihr

mei Freundin . - in der Oper sin

wir gewesen . bei ${ }^{[?]}$ de? ?o? Cavalleria

10 Der Dichter. Hm .. also . ins Burgt ${ }^{t^{[?]}}$ heat 
HSz7 [248a]

Handschriften und Typoskript

4

luth hins.
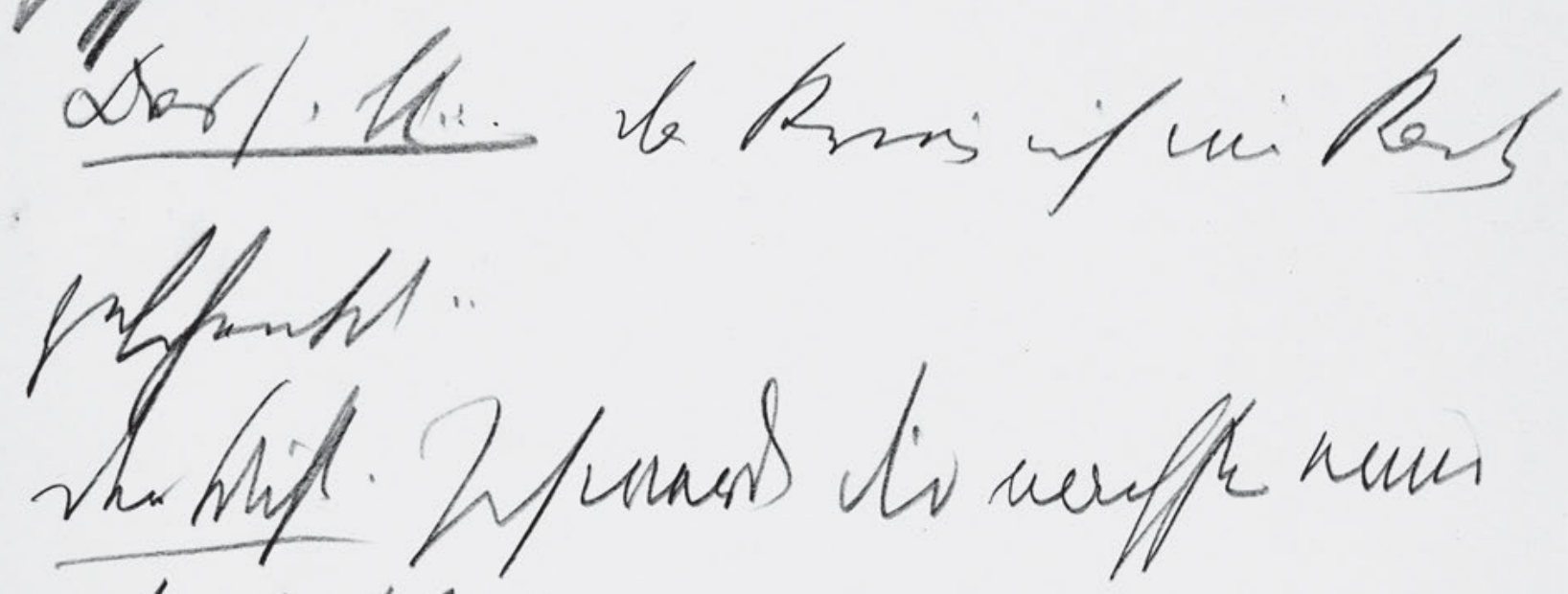

park fuik

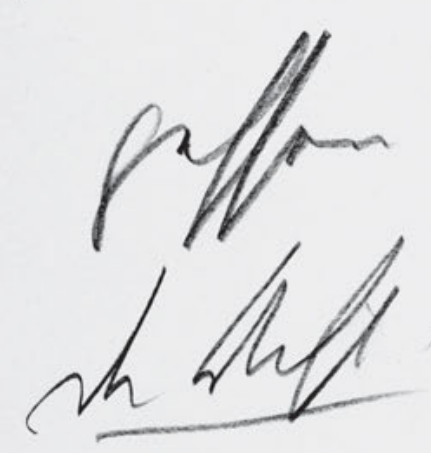

1

O

!

abrof co

wifl

sulep si uift pafo..

ver/h.

huff gion...

544 
gehst du nie.

Das s. M. ... Da krieg ich nie Karten

geschenkt . .

Der Dichte . Ich werde dir nachstens ein? $\mathrm{m}^{?}$

$5 \quad$ Karten schicken.

Das s. M. Oh ja! . aber dass nicht ver

gessen! . . Zu was lustig aber.

Der Dicht . Ja . . lustig . . zu was traurig

willst du nicht gehen . .

$10 \quad$ Das s. . M. Nicht gern . . 
HSz7 249

Handschriften und Typoskript

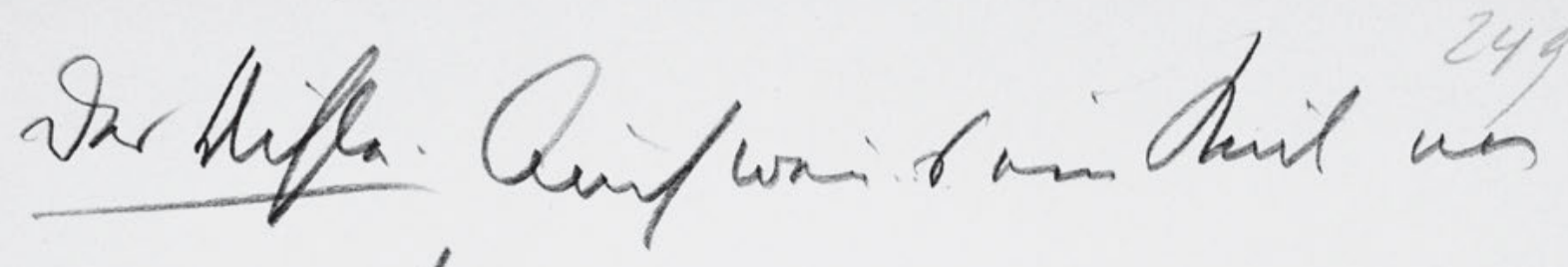
neir f?
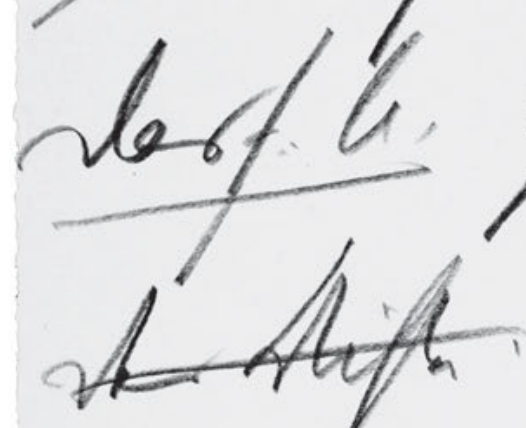

sthifh. teopl in Sintur li?

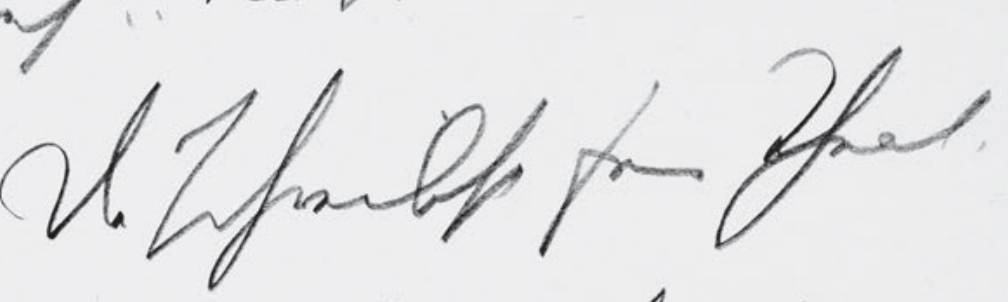
clenth if will in

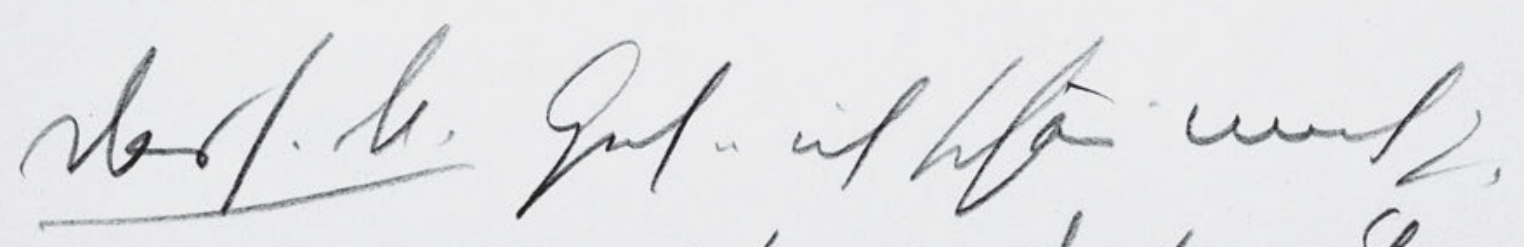

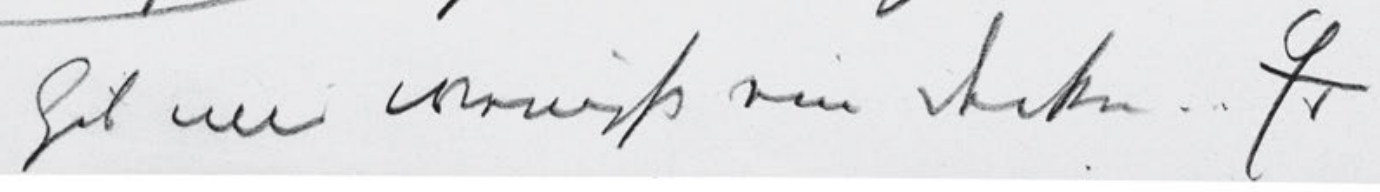

546 
Der Dichter. Auch wen̄ ${ }^{\cdots}$ s ein Stück von mir ist? . .

Das s. . M. Geh . . ein Stück von dir? .

${ }_{5}$ Der Dichter. Du schreibst furs Theat.

Der Dichter. .. Erlaube . ich will 'nur?

Licht machen .... [?] Ich habe dich noch

nicht gesehn .... seit du . . mei Gelieb

bist - (Engel! . . (Er zündet ei Kerze an)

10 Das s. M. Geh . . ich schäm mich ?ja?,

Gib mir wenigst eine Decken . . Er 
HSz7 [249a]

Handschriften und Typoskript

t difle Lifigifo, har laibl/ A difhe faiter

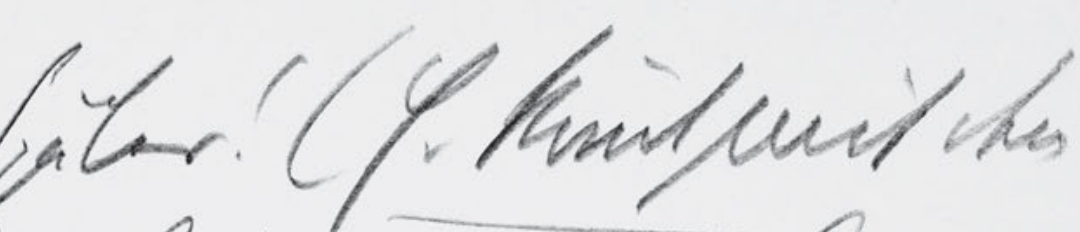
Shen Laint chiff areat is lang thit ingles chall. heid tibip O limofy 
Der Dichter. Später! (Er kō̄̄t mit dem

Licht zu ihr, betrachtet sie lang)

Das s. Mädel (bedeckt ihr Gesicht mit den Händen) Geh, Richard.

5 Der Dichter. Du bist schön . . : du bist die

Schönheit . . du bist vielleicht sogar

die Natur . . du bist die heilig Einfalt

Das s. Mädel. Oh weh .. du troopfst

mich ja an! Schau . was gibst

10

dēn nicht Acht: 
HSz7 250

Handschriften und Typoskript

Ninifar

250

(

/ener

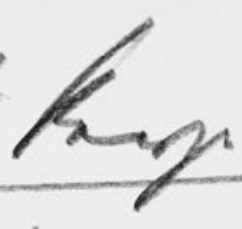


250

Der Dichter. (stellt die Kerze weg) Ge

nirts dich .. weñ ich laut zu denke?

Du kannst dir ja übrigens auch

${ }_{5}$ einbilden, dass ${ }^{\text {du }}$ ich $\mathrm{zu}^{\mathrm{mir}}{ }_{\text {dir }}$ spreche.

Du bist das . . was ich seit lang

gesucht habe .. du liebst mich ohne

mich zu kennen .. du liebst den

du liebst nicht .. Biebitz! Du liebst mich,

10 mich ... du würdest mich auch lieben,

wē̄ ich Schnittwaarencō̄is wär. 
HSz7 251

Handschriften und Typoskript

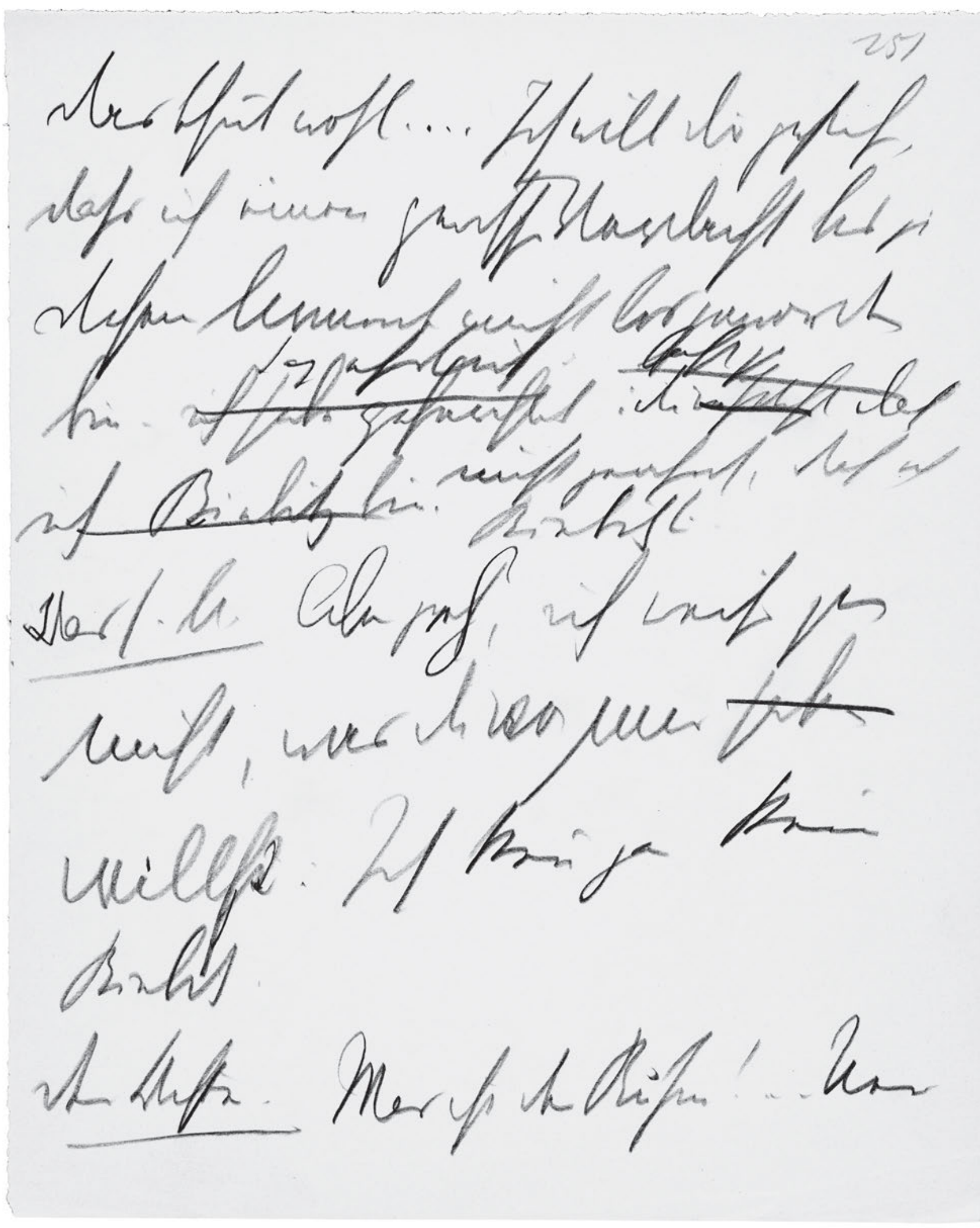

552 
251

Das thut wohl .... Ich will dir gestehen, dass ich einen gewissen Verdacht bis zu diesem Moment nicht los geworden

Sag ehrlich: hast ${ }^{?} \mathrm{j}$ ?

5 bin - ich habe gefurchtet :du ?wußtest? das nicht geahnt, das ich ich Biebitz bin. Biebitz bi.

Das s. M. Aber geh, ich weiss gar nicht, was du von mir haben willst: Ich ken̄ gar keinen

10 Biebitz.

Der Dichter. Was ist der Ruhm! . . Nein 
HSz7 252

Handschriften und Typoskript

mrypt war w

Rifar hin

1

anngly

batha.

2

phing

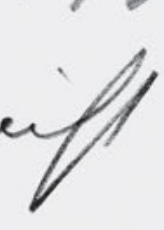

e

f

tat

if

] 


\section{2}

vergiss was ich gesagt habe .. Vergiss ?sog?

den Namen, den ich dir gesagt habe!

Richard bin ich und will ich für dich

5 bleiben. Ich hab auch nur gescherzt.

Ich bin ja nicht Schriftsteller . . ich bin .

Commis ... un am Abend spiel ich

bei Volkssanger Clavier.

Das s M. Ja . . jetzt ken̄ ich mich aber

10 nicht mehr aus .. nein, und $\mathrm{w}^{[?]}$ as

du ein ausschaust . . Ja was ist dē 
HSz7 253

Handschriften und Typoskript

2

wa frphith

253

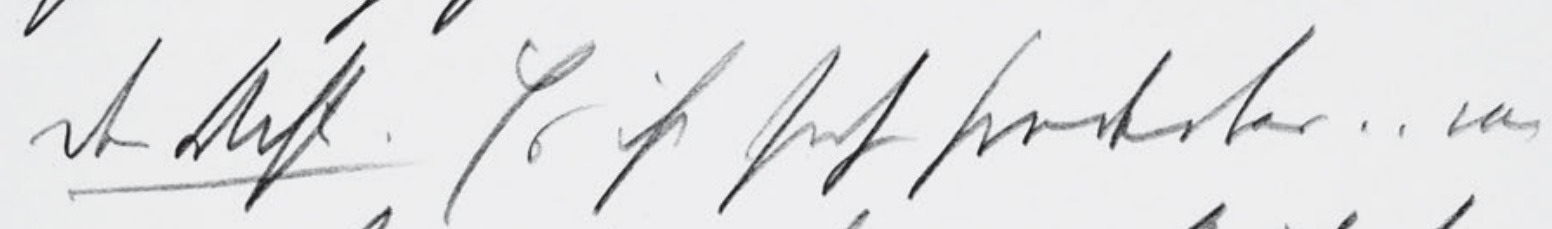

veir hinaf

neir hinef

ny.

w ti Arain.

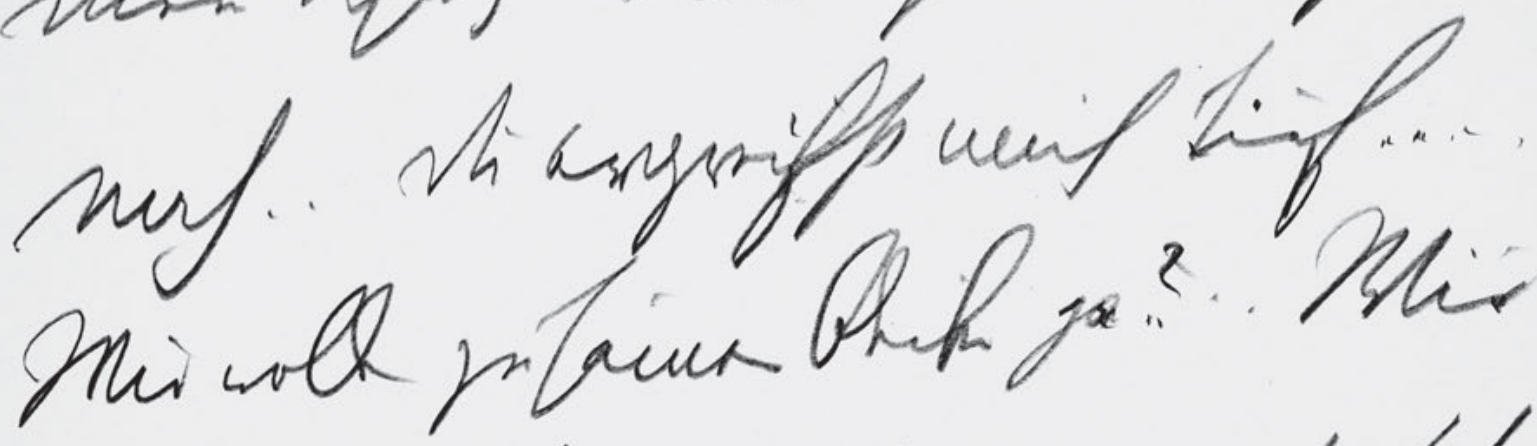

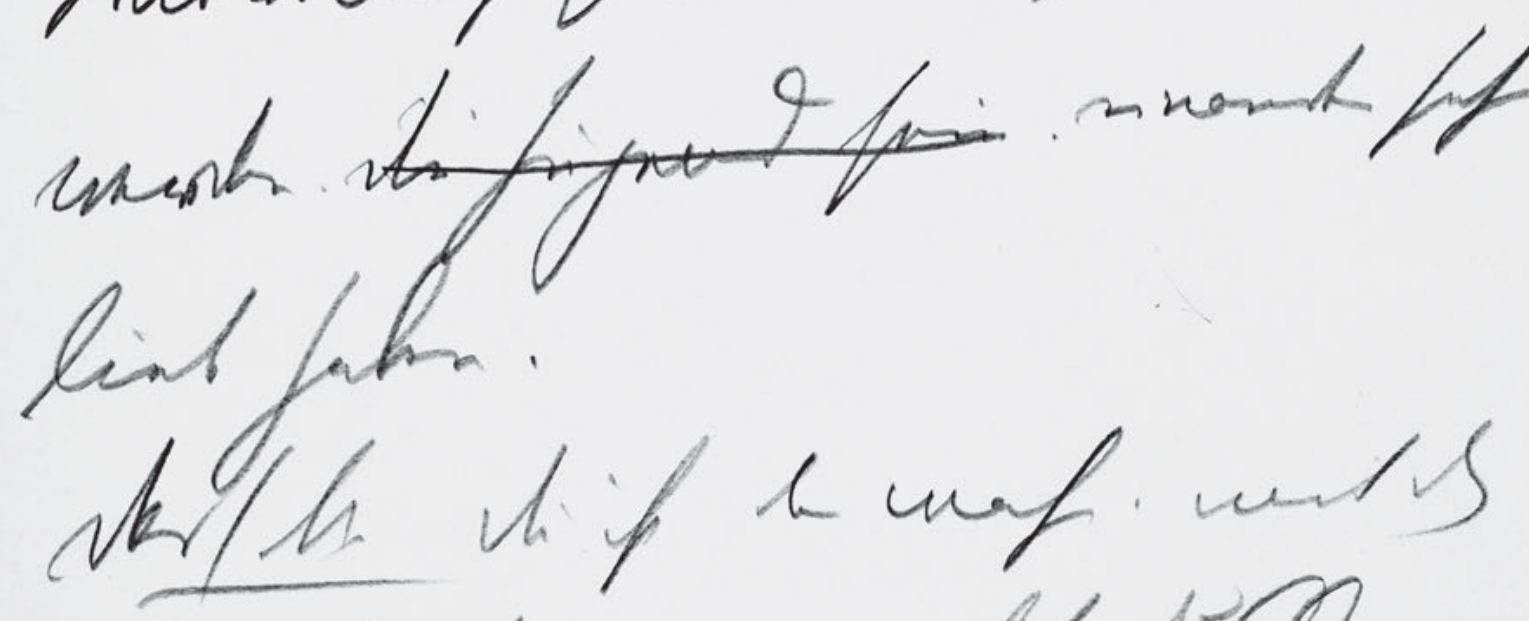

Nolptenyer
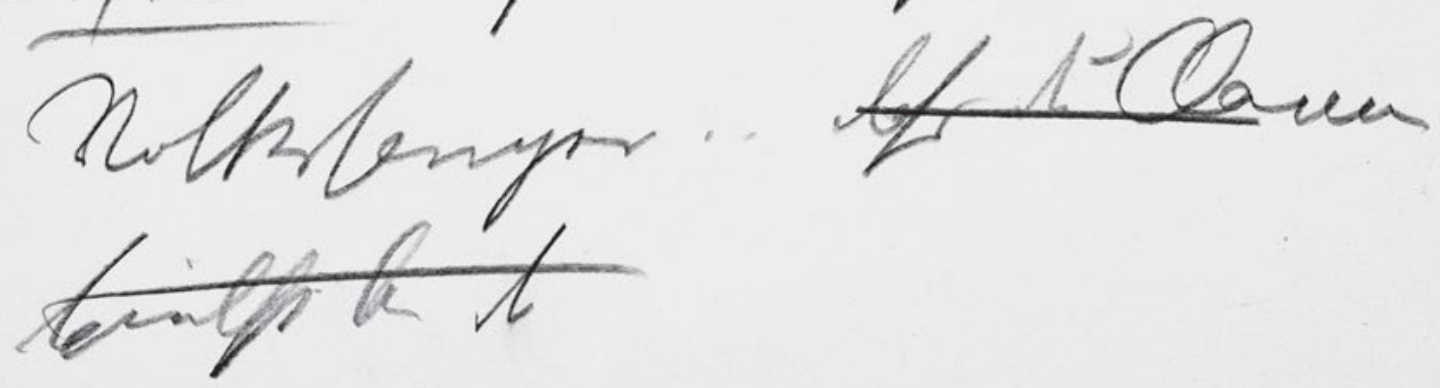

556 
Ja . was hast du denn ..

Der Dichter. Es ist sehr sonderbar .. was

mir beinahe noch nie passirt ist . .

5 mein Schatz .. mir sind die Thränen

nah .. du ergreifst mich tief .......

Wir wollen zusamen bleiben ja? . . Wir

werden . die Jugend sein . einander sehr

lieb haben.

10 Das s M. Du ist das wahr . mit den

Volkssanger .. dass du Clavier

spielst bei d[?] 
HSz7 254

Handschriften und Typoskript

virdifla

2

254

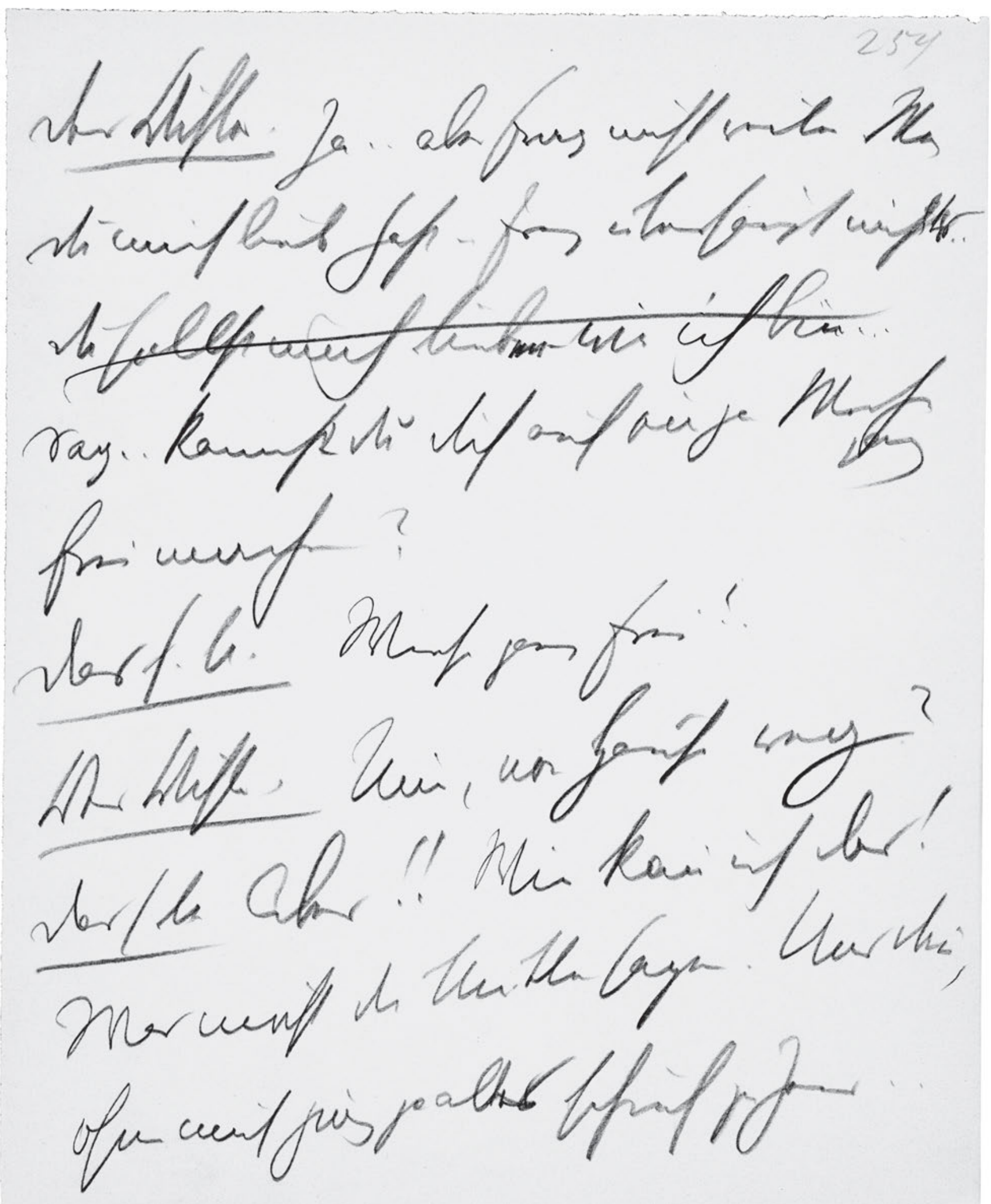

558 


\section{4}

Der Dichter. Ja . . aber frag nicht weiter. Wen

du mich lieb hast - frag überhaupt nichts . .

Du sollst mich lieben - wie ich bin ...

5 Sag . . kannst du dich auf ein pa Wochen

ganz

frei machen?

Das s. M. Wieso ganz frei? .

Der Dichter. Nun, vom Hause weg?

Das s M. Aber!! Wie kan̄ ich das!

10 Was möcht die Mutter sagen. Und dā̄, ohne mich ging ja allses schief zu Haus . . 
HSz7 255

Handschriften und Typoskript

silligh. Hfoth or mis tfin is

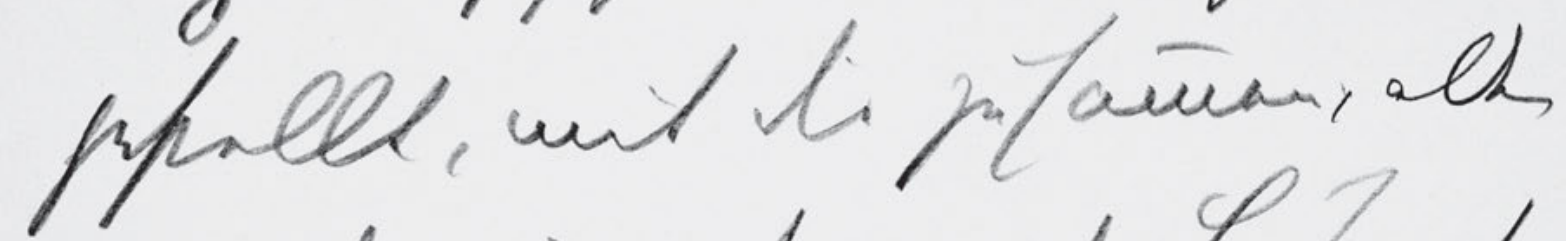

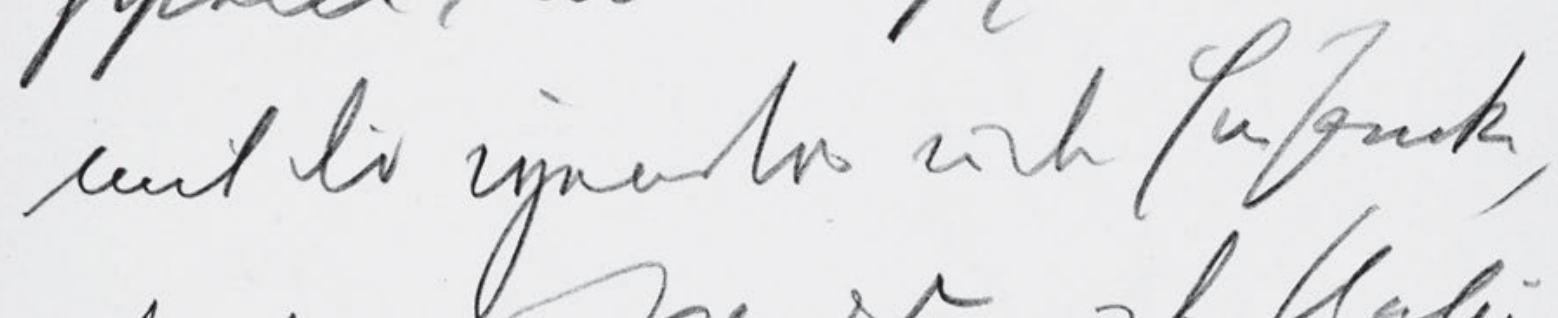

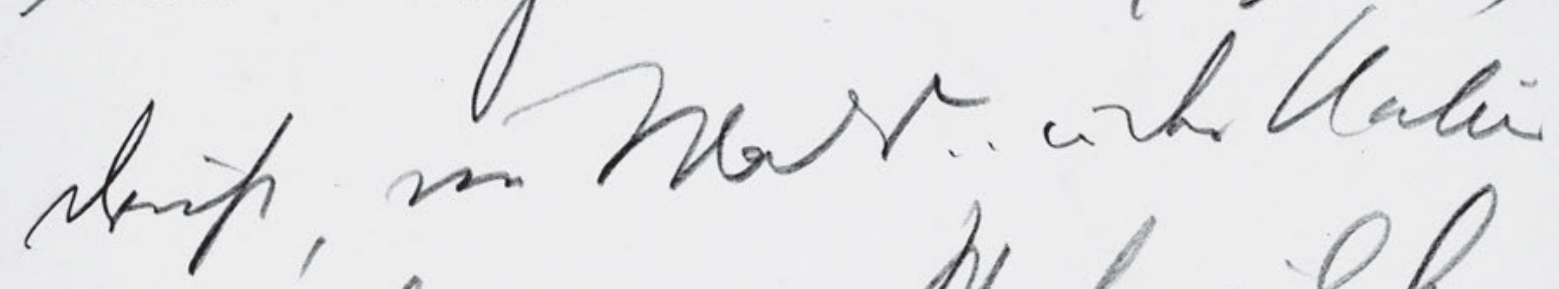
woth anijaa thrifo pilath.

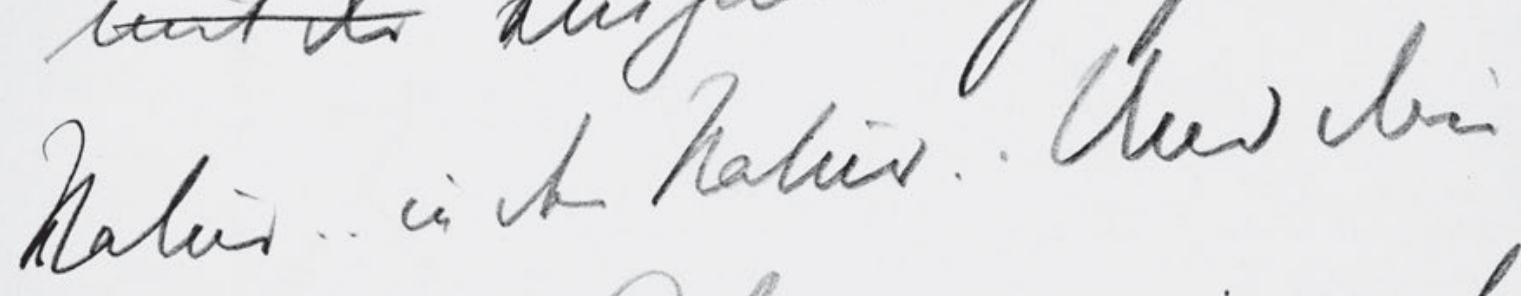

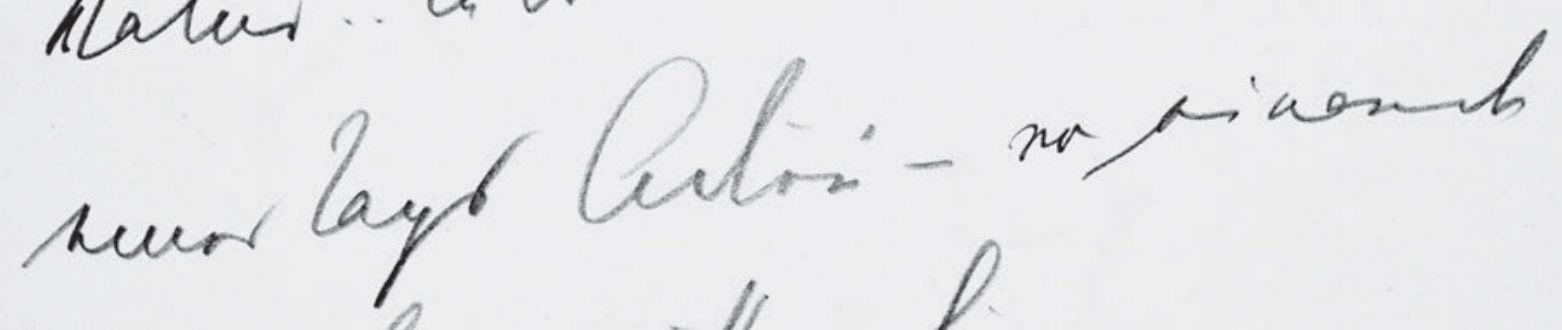

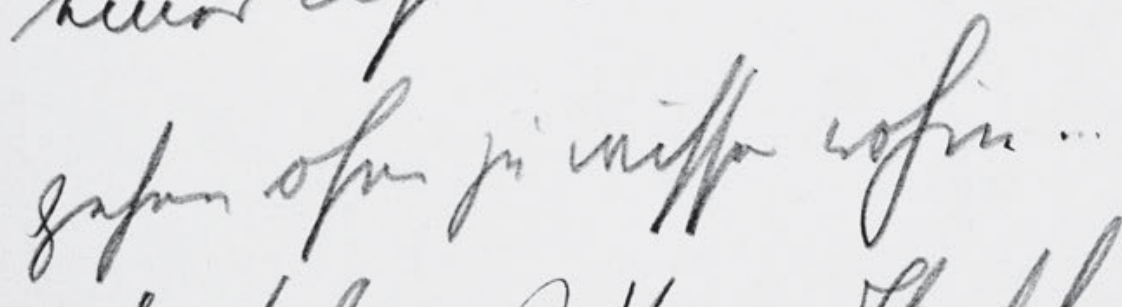

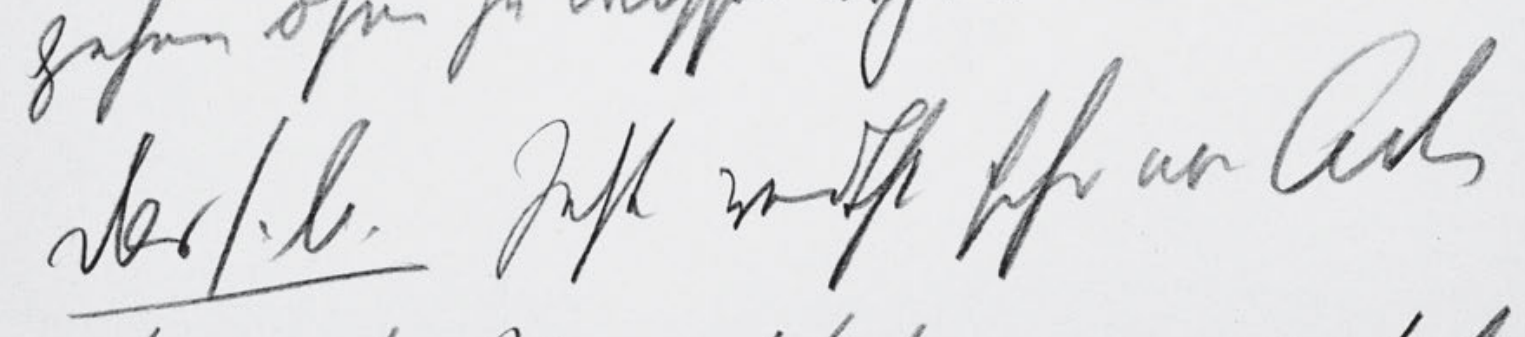

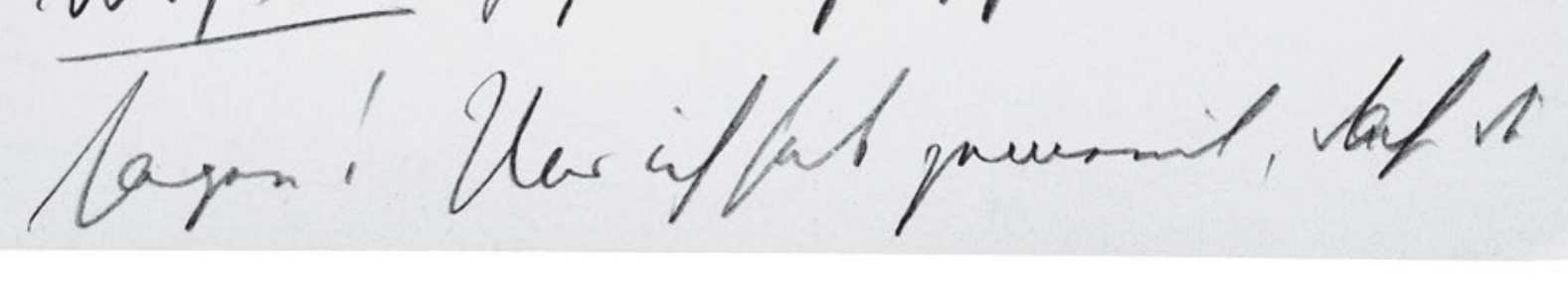

560 


\section{5}

Der Dichter. Ich hatte es mir schön vor gestellt, mit dir zusā̄en, allein mit dir irgend $w$ in der Einsamke,

5 drauß, im Wald . . in der Natur mit dir ${ }^{[?]}$ ein paa Wochen zu leben.

Natur . . in der Natur . . Und dan̄ eines Tags Adieu - von einande gehen ohne zu wissen wohin ... 10 Das s. M. Jetzt redtst scho vom Adieu sagen! Und ich hab gemeint, dass du 
HSz7 256

Handschriften und Typoskript

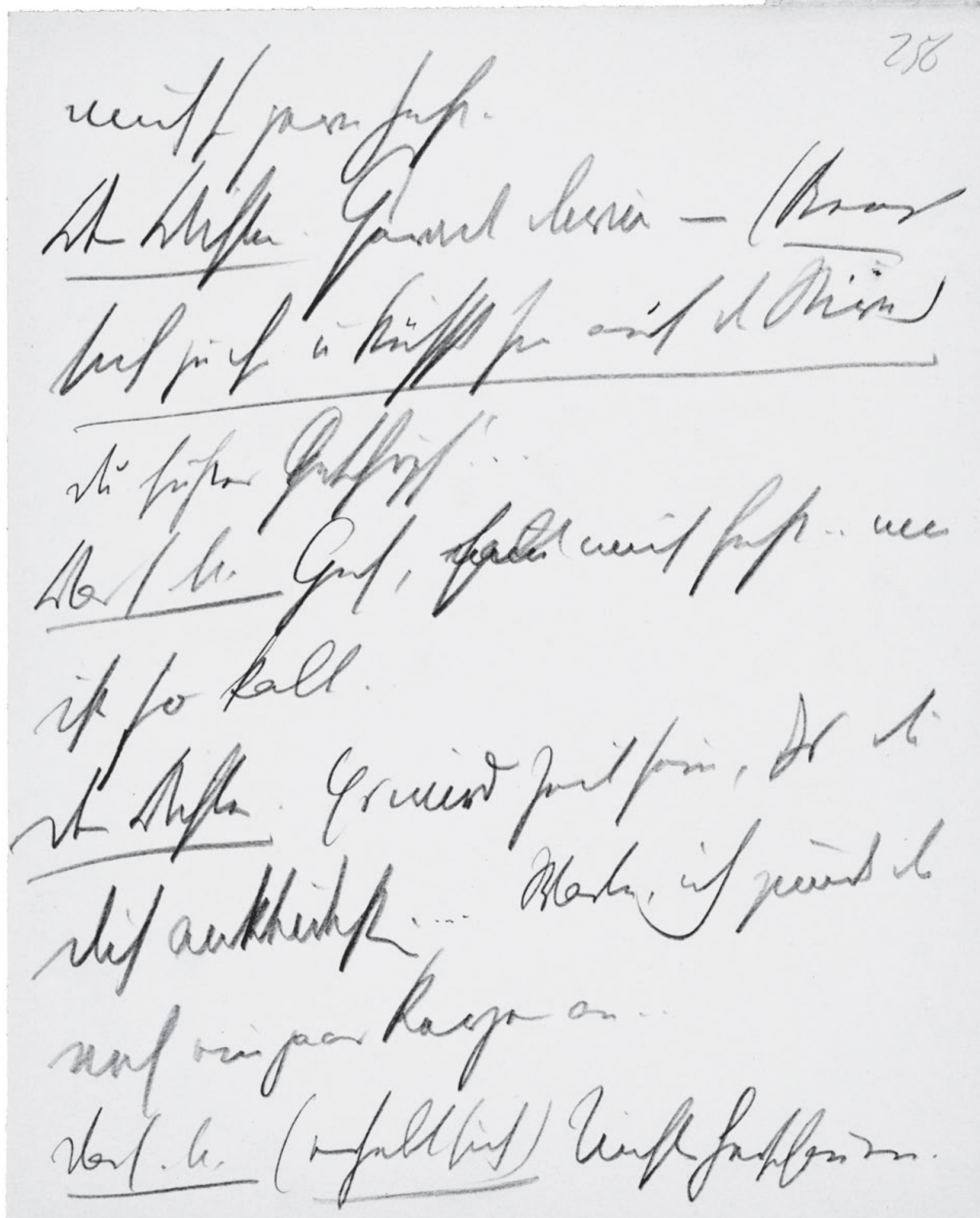

562 


\section{6}

mich so gern hast -

Der Dichter. Gerade darum - (Beugt

$\underline{\text { sich zu ihr u küsst sie auf die Stirn) }}$

5 du süßes Geschöpf! . .

Das s M. Geh, ${ }^{\text {nim }}$ halt mich fest .. mir

ist so kalt.

Der Dichter. Es wird Zeit sein, dss du

dich ankleidest ..... Warte, ich zünd dir

10 noch ein paar Kerzen an ..

Das s. M. (erhebt sich) Nicht herschauen. 
HSz7 257

Handschriften und Typoskript

Mrdifh thi

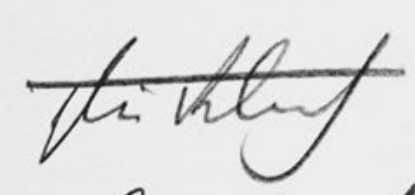

o

(th Frapers.).

25
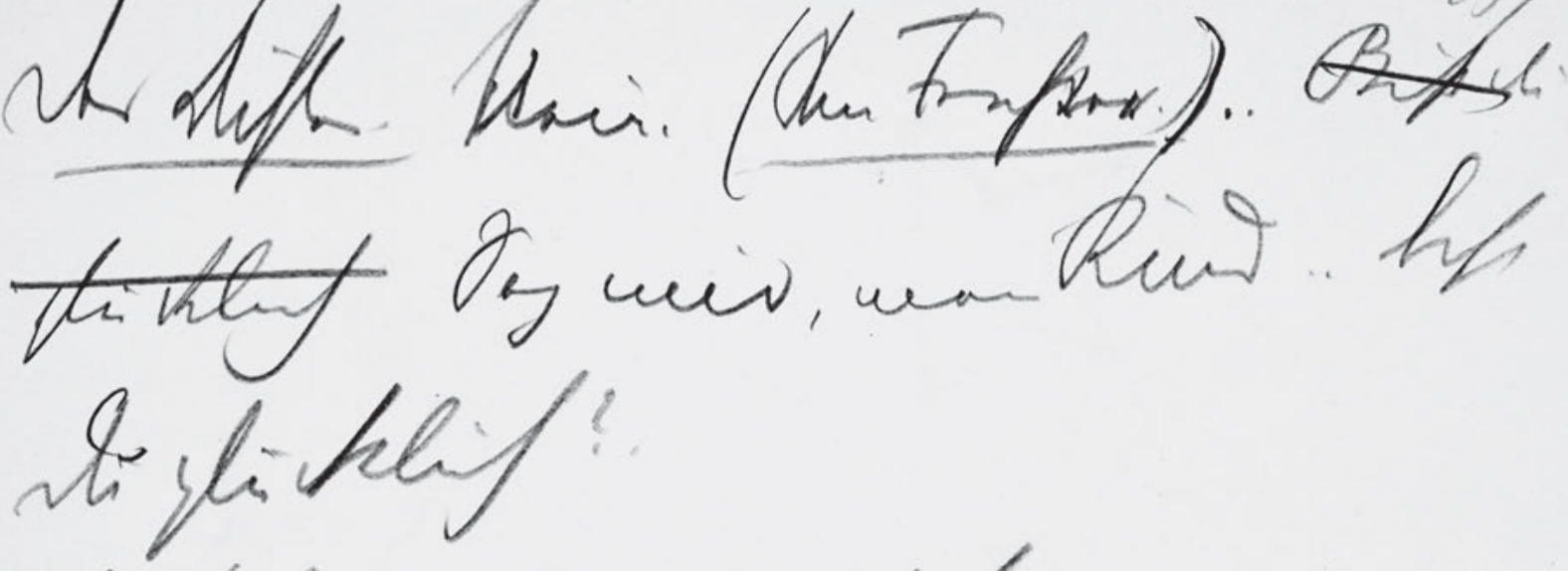

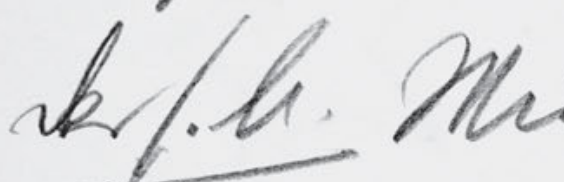

the thes

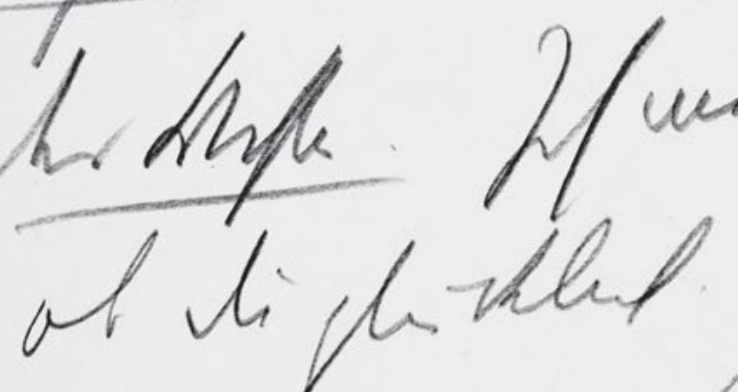

rerthe ka.'t

ch thes

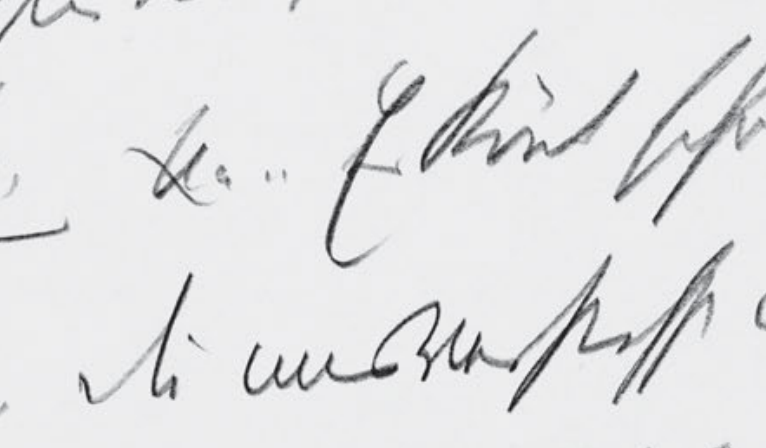

tum

him os

hanges

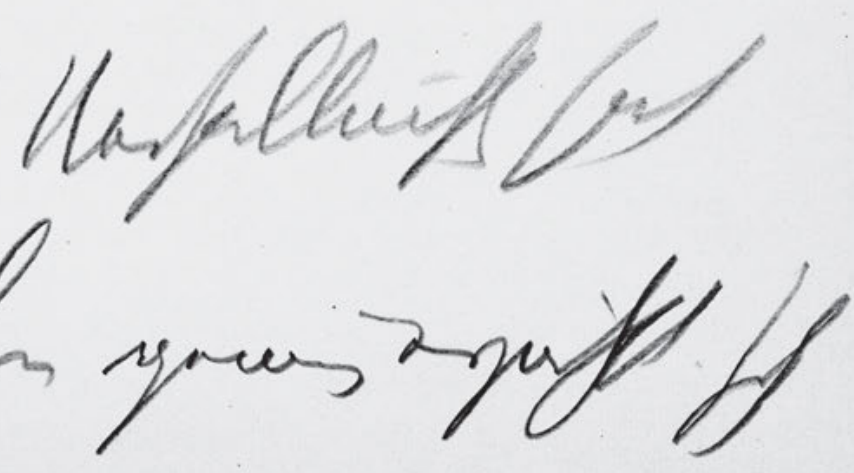

564 
Der Dichter. ${ }^{n}$ Nein. (Am Fenster.) . . Bist du

glücklich Sag mir, mein Kind . . bist

du glücklich? .

$5 \quad$ Das s. M. Wie meinst das ..

Der Dichter. Ich meine, im allgemein

ob du glücklich.

Das s. M. Na .. eEs kön̄t schon besser geh.

Der Dichter. Du misverstehst mich. Von

deinen häuslichen Verhaltnissen has

du mir ja schon genug erzählt. Ich 
HSz7 258

Handschriften und Typoskript
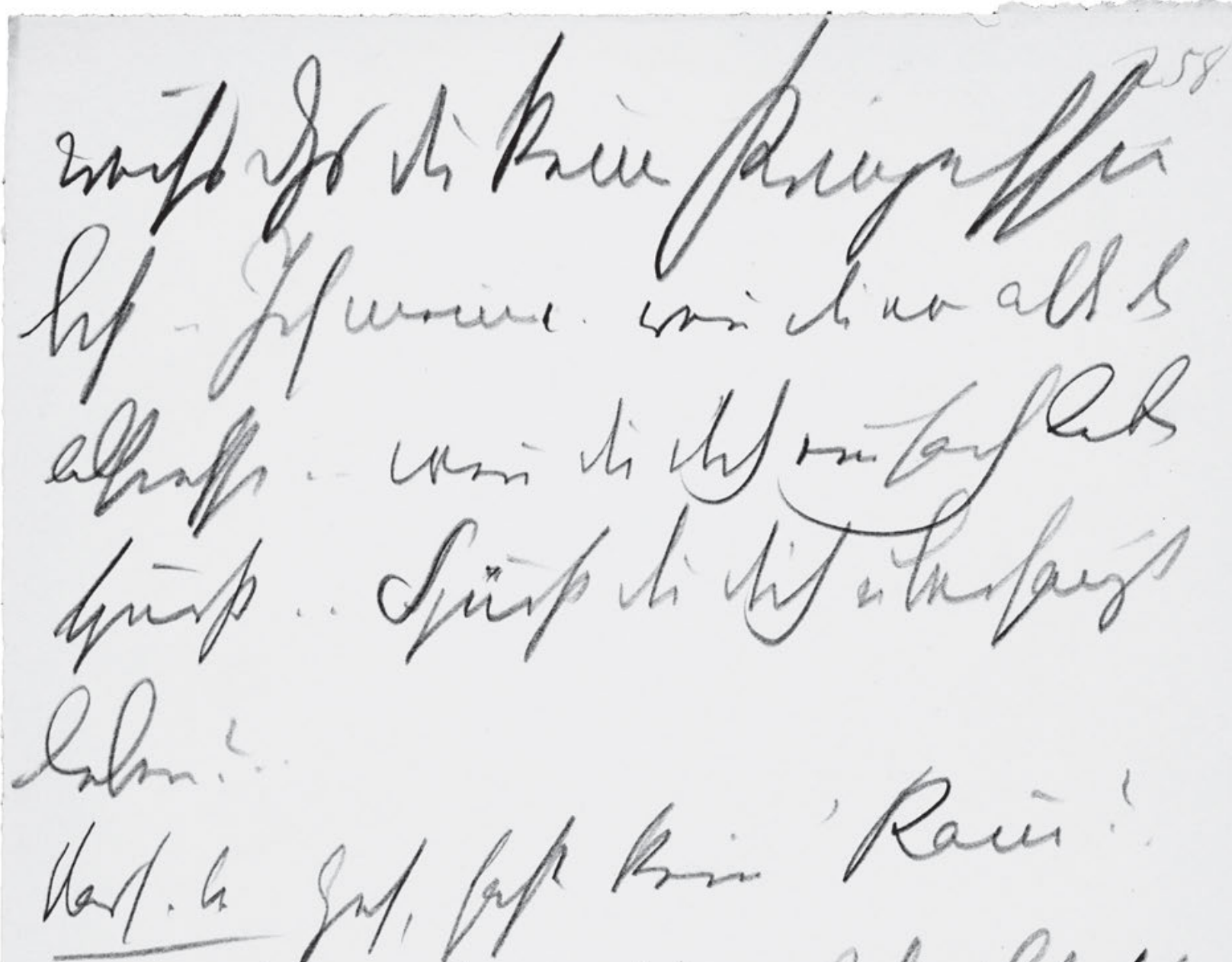

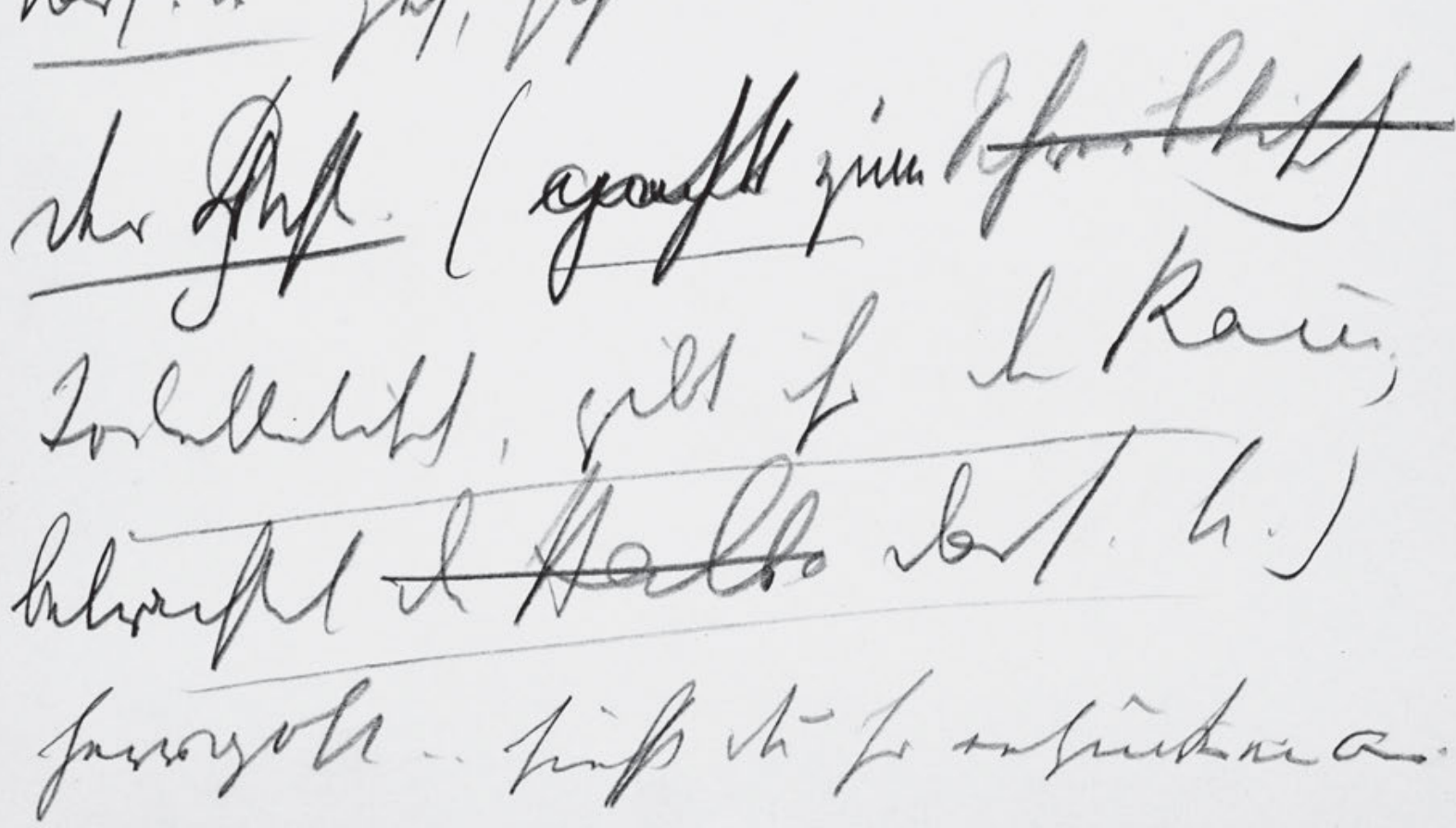

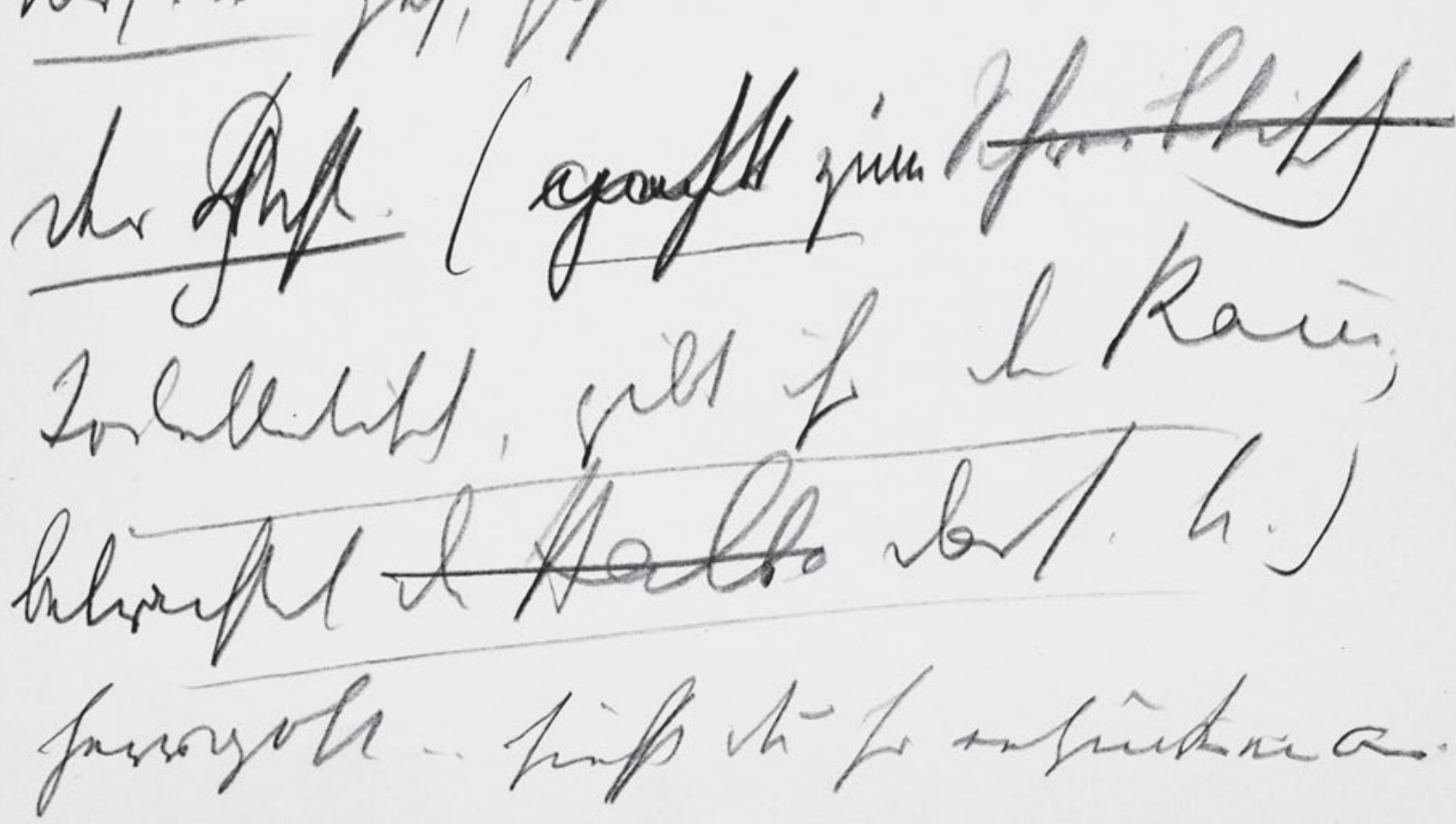

ap

hin

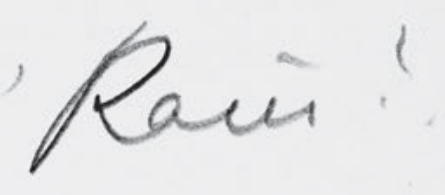

566 


\section{8}

weiss dss du keine Prinzessin

bist - Ich meine . wen̄ du von alle dem

absiehst . . wen̄ du dich einfach leben

5 spürst . . Spürst du dich überhaupt

leben? . .

Das s. M. Geh, hast kein' Kā̄? .

Der ${ }^{G}$ Dichter. $\left({ }^{\text {nimt }}\right.$ geht zum Schreibtisch

Toilettentisch, gibt ihr den Kā̄',

10 betrachtet die Halba das s. M.)

Herrgott . . siehst du so entzückend aus.

10 Halba: vermutlich: „Halbangekleidete" oder "Halbangezogene". 
HSz7 259

Handschriften und Typoskript
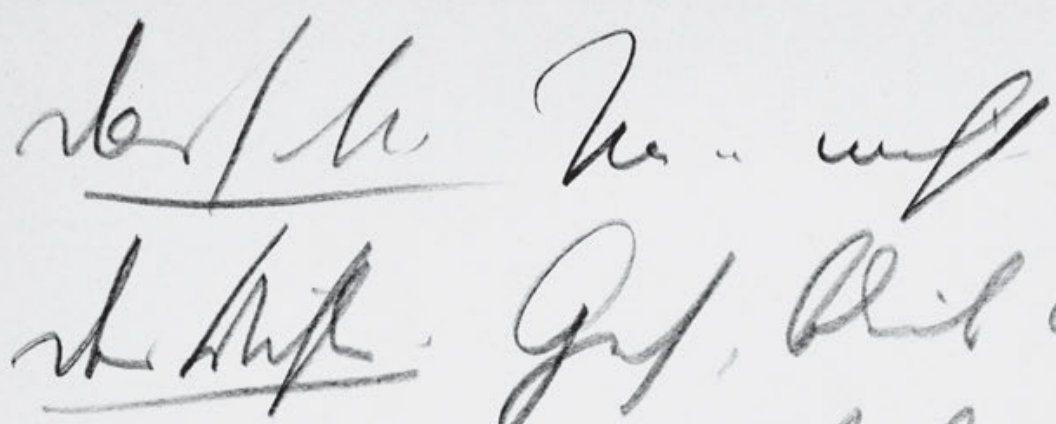

$2 \sqrt{9}$
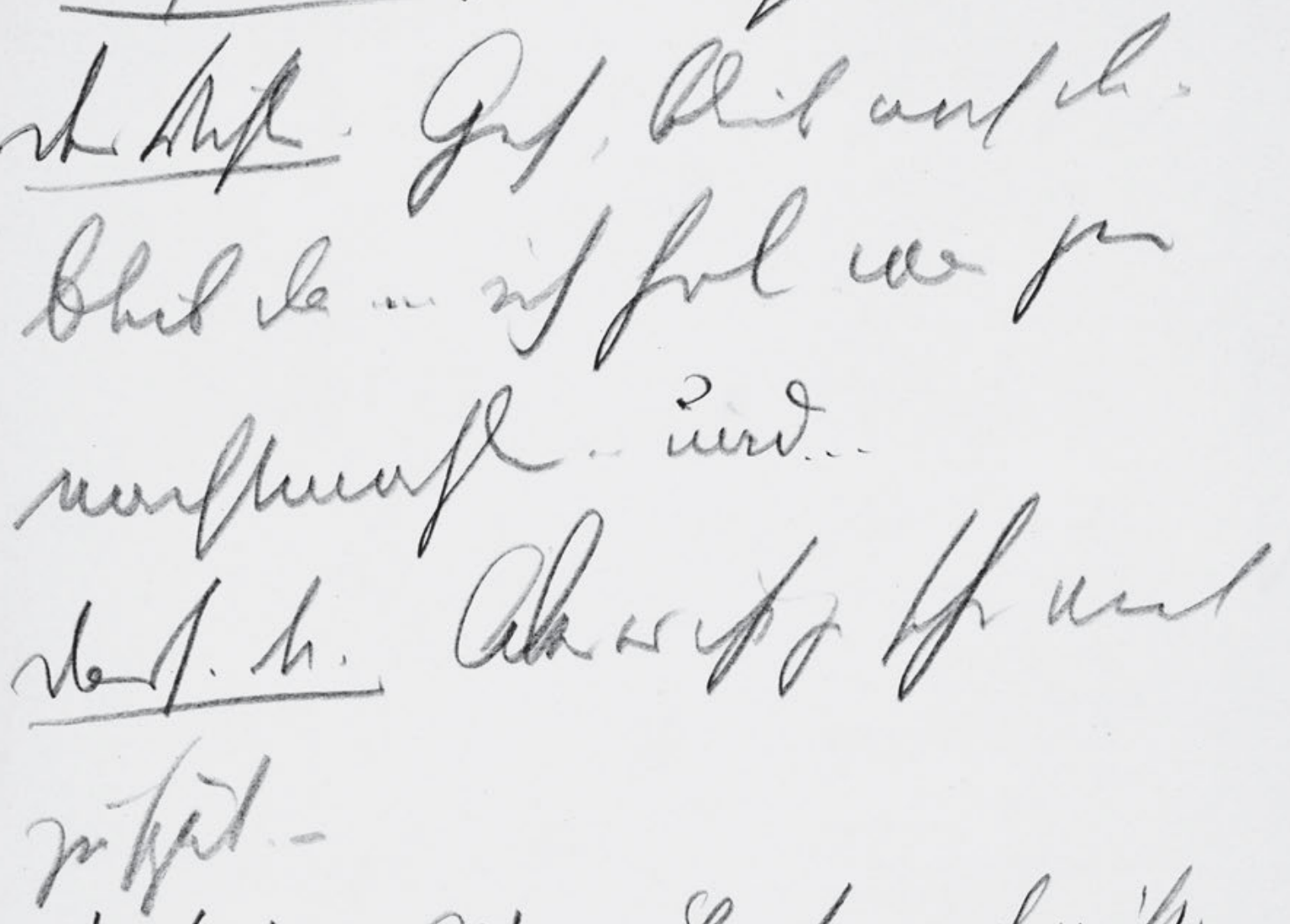

sthele.

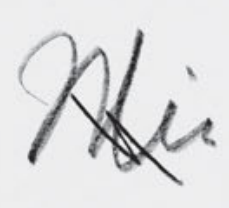

de/ $/ 4$

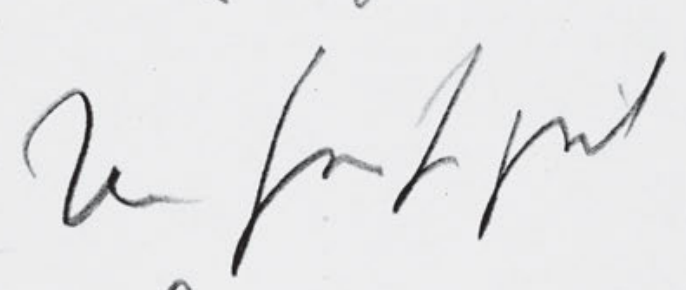

la kns

it mif abthines

568 
Das s M. Na . . nicht.

Der Dichter. Geh, bleib noch da -

bleib da ... . ich hol was zum

5 nachtmahlen .. und...

Das s. M. Aber es ist ja schon viel

zu spät. -

Der Dichter. Wie Es ist noch nicht neun

Das s M Na sei so gut . . da mus

10 ich mich aber tumeln ... 

Der Dichter. Wan̄ werden wir

uns denn wiedersehen?

Das s M. Na, wann willst mic

5 den $\bar{n}^{\text {- }}$ wiedersehn . .

Der Dichter. Morgen.

Das s. M. Was ist denn morgen fur ein Tag?

Der Dichter. Samstag.

Das s. M. Oh da kan̄ ich nicht . . da

10 muss ich mit meiner kleinen Schwester 
zum Vormund . .

Der Dichter. Also Son̄tag .... hm .. Son̄tag.

am Son̄tg . . jetzt werd ich dir was

${ }_{5}$ erklären: - ${ }^{[?]}$ Ich bin nicht Biebitz . . aber

Biebitz ist mein Freund . . ich werd

dir'n einmal vorstellen .. ?Dies? Am

Son̄tag ist das Stück von Biebitz;

ich werd dir eine Karte schicken

10 und werd dich dañ vom Theater

abholen ... du wirst mir sagen, 



\section{2}

wie dir das Stü ${ }^{\left[{ }^{2]}\right.} \mathrm{ck}$ gefallen hat; ja?

Das s M. Jetzt, die Gschicht mit ?d?

Biebitz - da bin ich schon ganz blöd.

5 Der Dichter. . . Ganz werd dich dich

doch erst ken̄en - weñ ich weiss,

was du bei diesem Stück empfun-

den hast...

Das s. M. So . . ich bin fertig. .

10 Der Dichter. Kō̄, mein Schatz . .

(Sie gehen. -) 
HSz8 263

Handschriften und Typoskript

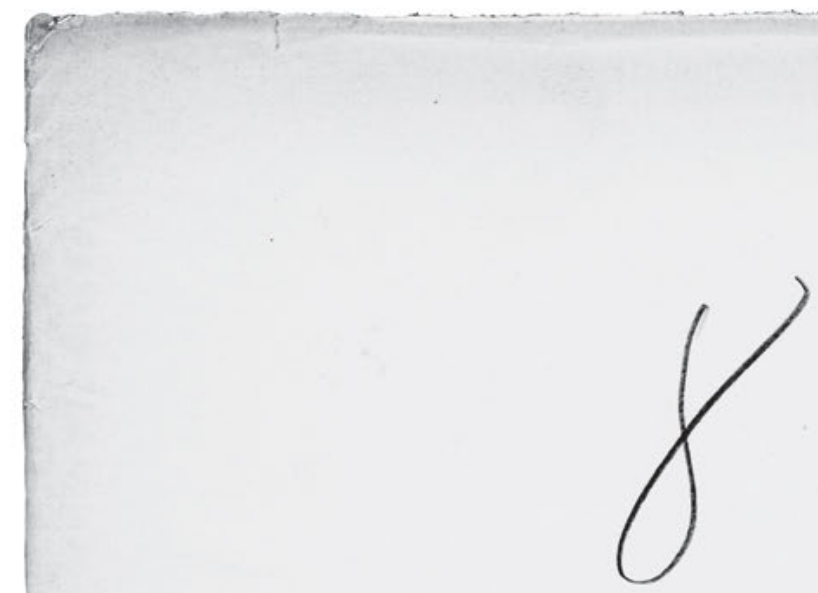

263
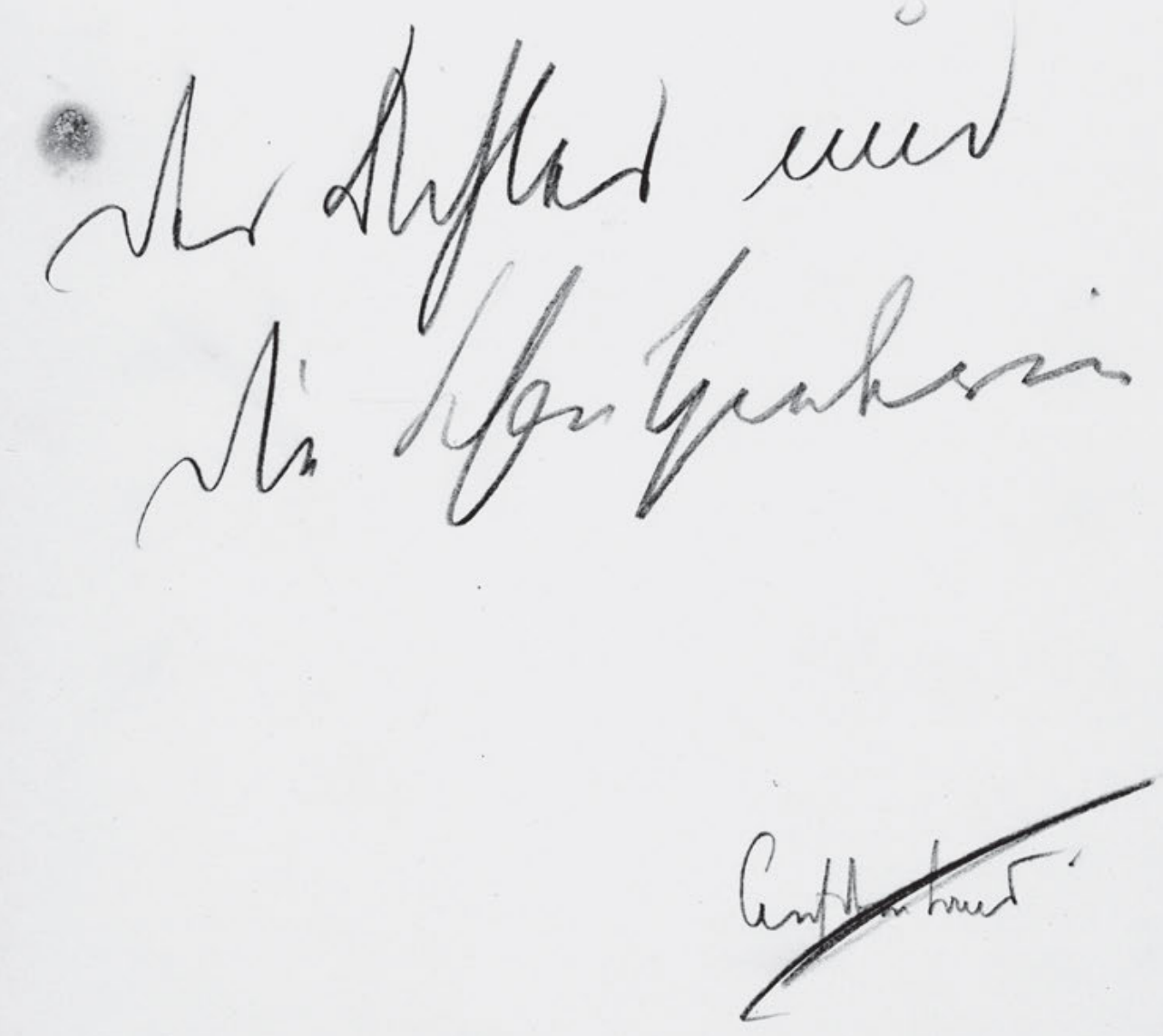

576 
263

8

Der Dichter und

die Schauspielerin 
HSz8 264

Handschriften und Typoskript

264

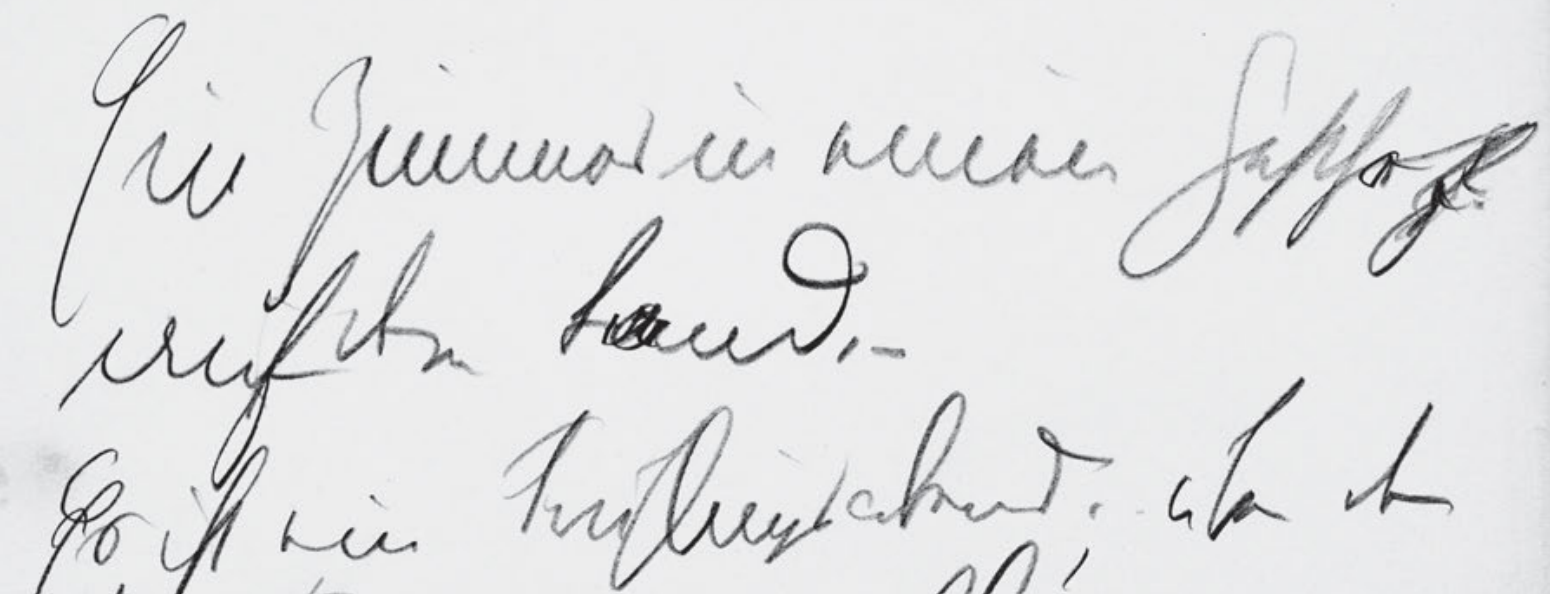


264

Ein Zimmer in einem Gasthof.

auf dem Land. -

Es ist ein Frühlingsabend; . über den

5 die Fenster stehen offen; im Zimer

ist es dunkel; aber der Mond liegt

Wiesen und Hügeln liegt

der Mond; deie Fenster stehen

offen.

10 Große Stille. 
HSz8 265

Handschriften und Typoskript

265

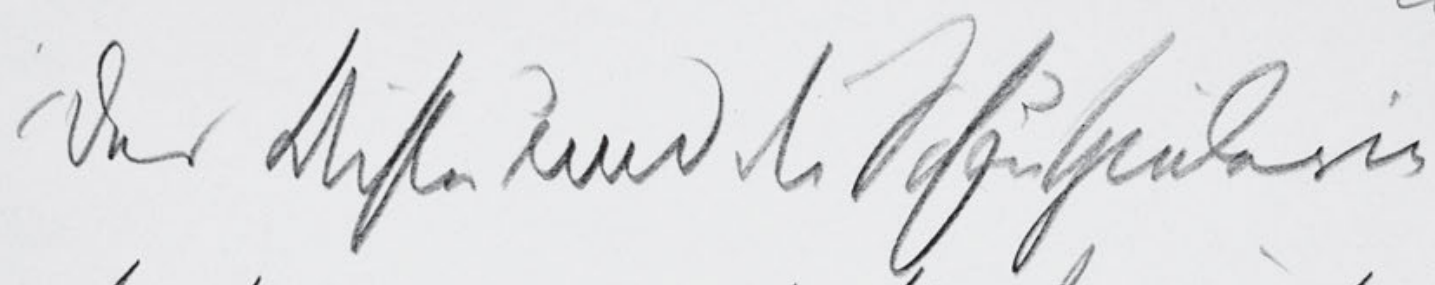
tarator sin; unifir fresoutas, subloff bur bifk, dur st hiff

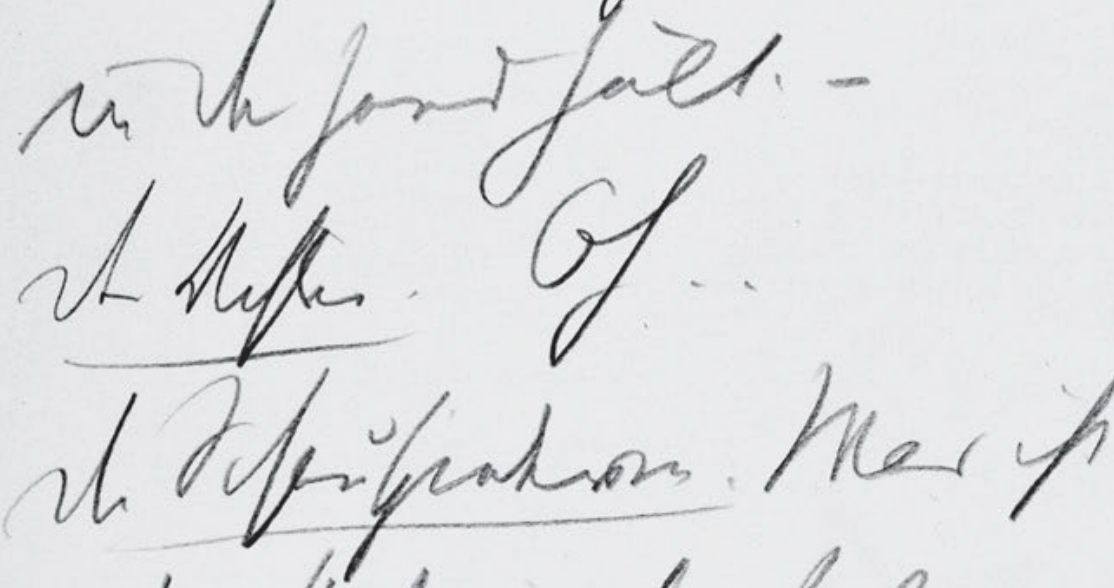

at dife

b Lafl

harentpien bै.

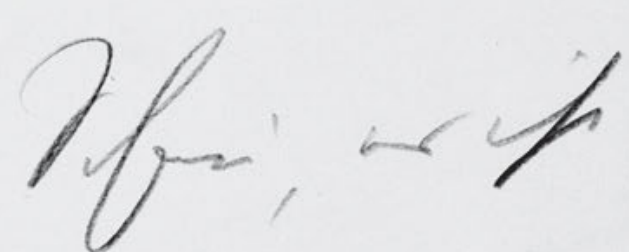

the gary

this

als us 
Der Dichter und die Schauspielerin

treten ein; wie sie hereintreten, verlöscht das Licht, das der Dicht

$5 \quad$ in der Hand hält. -

Der Dichter. Oh . .

Die Schauspielerin . Was ist den̄?

Der Dichter. Das Licht ... Aber wir

brauchen kein's. Schau, es ist

10 kei ganz hell. Wunderbar! 
HSz8 266

Handschriften und Typoskript

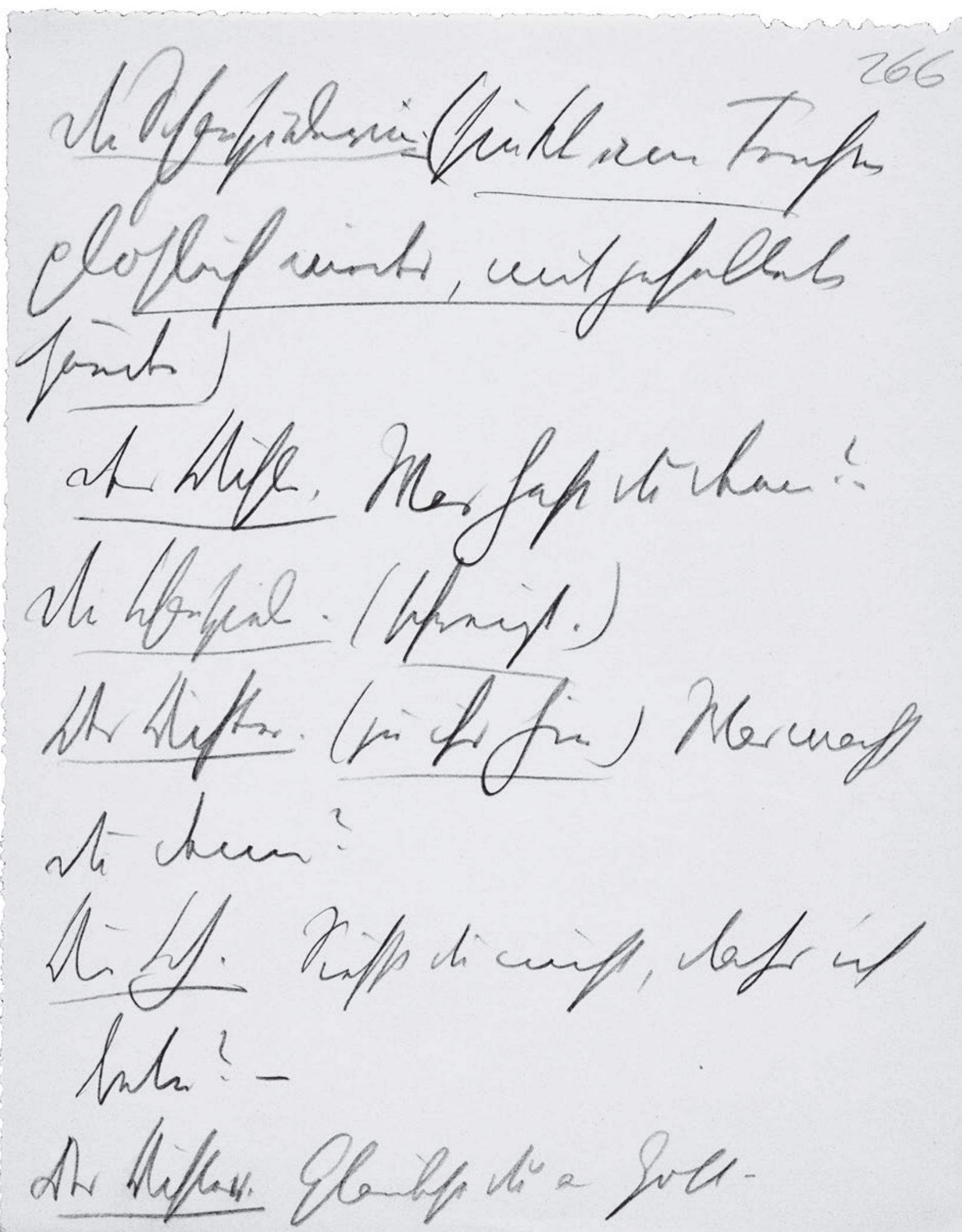

582 
Die Schauspielerin. (sinkt am Fenster

plotzlich nieder, mit gefalteten

Händen)

$5 \quad$ Der Dichter. Was hast du denn? -

Die Schauspiele. (schweigt.)

Der Dichter. (zu ihr hin) Was machs

du denn?

Die Sch. Siehst du nicht, dass ich

bete? -

Der Dichter. Glaubst du an Gott - 
HSz8 267

Handschriften und Typoskript

vilfingus. Q

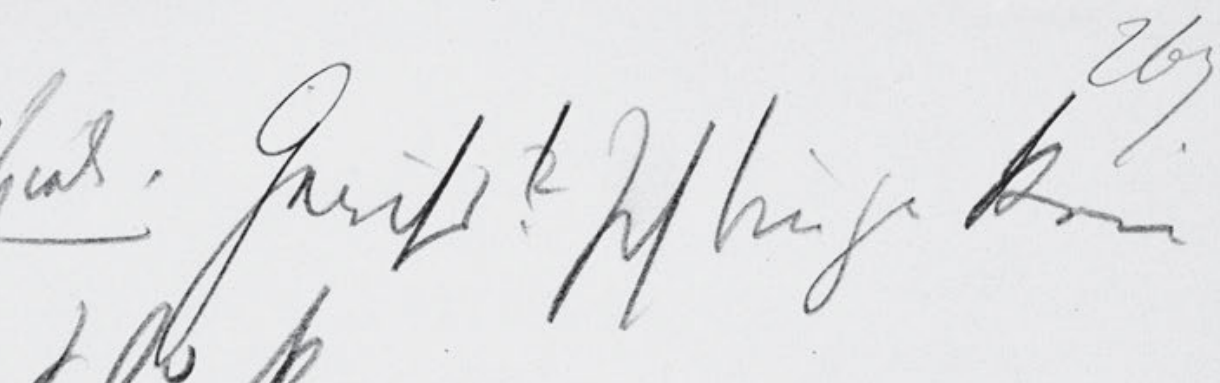
blepor fis k.
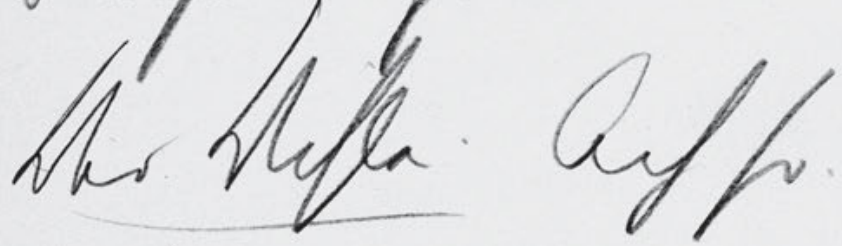

Milbitice

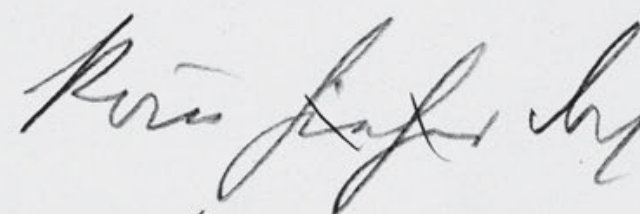

fir miv

miffir tarufe whli

miffir tamente nhlif

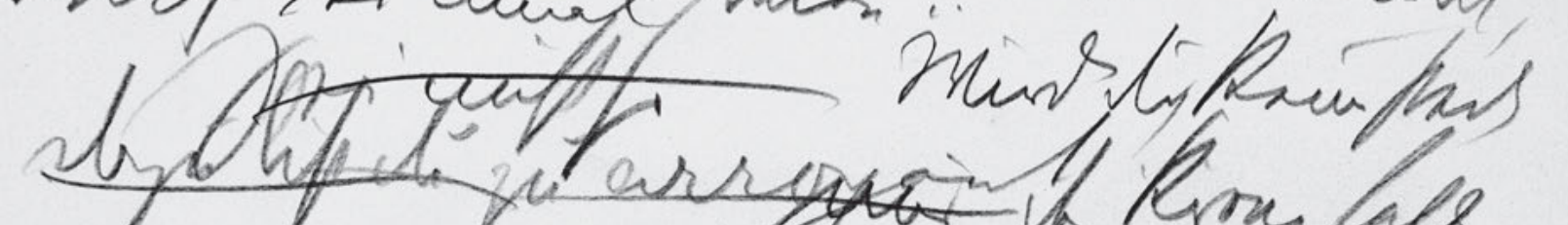
stration.

ing simfy

584 


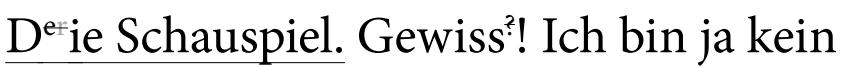

blaßer Schurke.

Der Dichter. Ach so.

${ }_{5}$ Die Schauspiele. Kō̄ hieher doch auch

hi zu mir . . Knie dich neben

mich hin . kannst wirklich

auch einmal beten . . Aber naturlich,

Sei nicht so

Wird dir keine Perle

dazu bist du zu arro ${ }^{\text {gant }}$ aus der Krone fallen.

10 Der Dichter. (kniet sich neben sie hin

und umfasst sie. und küsst sie) 
HSz8 268

Handschriften und Typoskript

the

g. Gulina.

tyabling

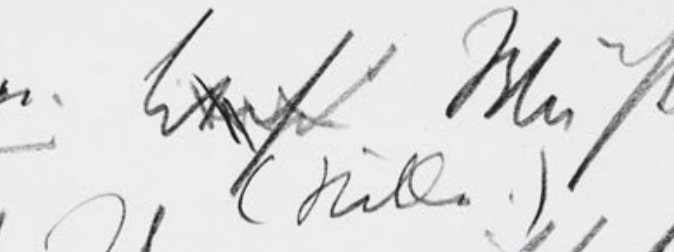

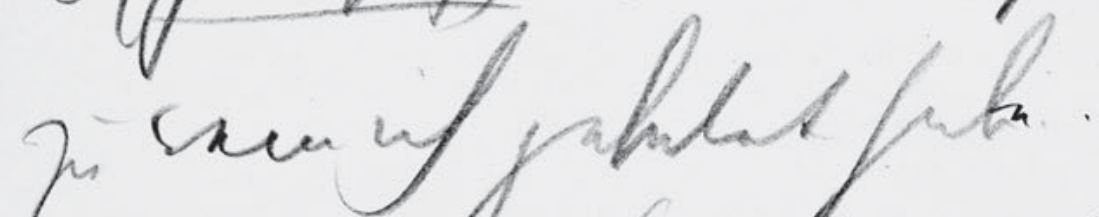

LL Elefar a

foll unga

if as

Mermifate he

th min

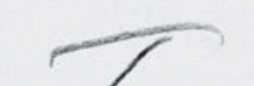

Dh Howicalasen.

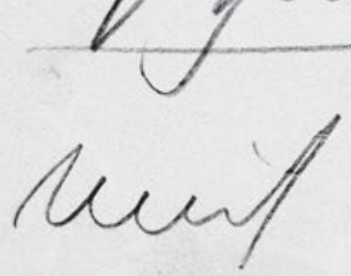

tha

y vita

586 
Die Schauspielerin. Weiß Wüstling! (Stille.)

(Erhebt sich) Und weißt du auch

zu wem ich gebetet habe.

5 Der Dichter Zu Gott, nehm ich an.

(großer Hohn)

Die Schauspieler . Jawohl! - . zu dir ha

ich gebetet . .

Der Dichter. Warum hast du denn

da zum Fenster hinausgeschaut? .

Sag mir lieber wo

10 Die Schauspielerin. ${ }^{[?]}$ Wo hast du

mich da eigentlich hingeschleppt, has 
HSz8 269

Handschriften und Typoskript

infuffar!

didifor

Ah liver, bur wos

ja hien Joh

stivllemp<smiles>[C]1C=CC=C1</smiles>

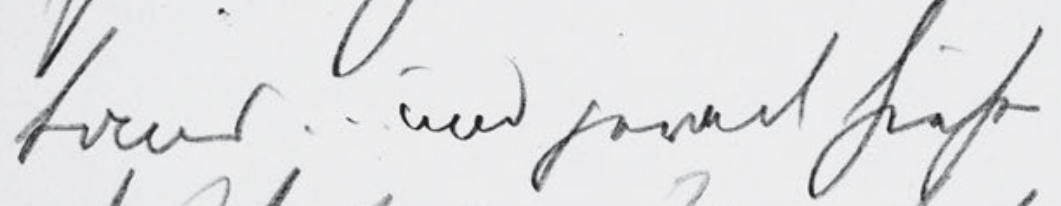
thiginin

2bog 
Verführer! .

Der Dichter: . Aber Kind, das war

ja deine Idee ... du wolltest ja aufs

5 Land ... und gerad hiehe

Die Schauspieler . Nun, hab ich nicht

Recht gehabt? .. .

Der Dichter. Gewiss . . . es ist ja entzücken

hier .. Wen man bedenkt, zwei Stund

vo Wien - und die voöll ${ }^{\mathrm{kemene}}$ ige

Einsamkeit . . Und was für eine 
HSz8 270

Handschriften und Typoskript

Gryen.

Arymen.

tolf

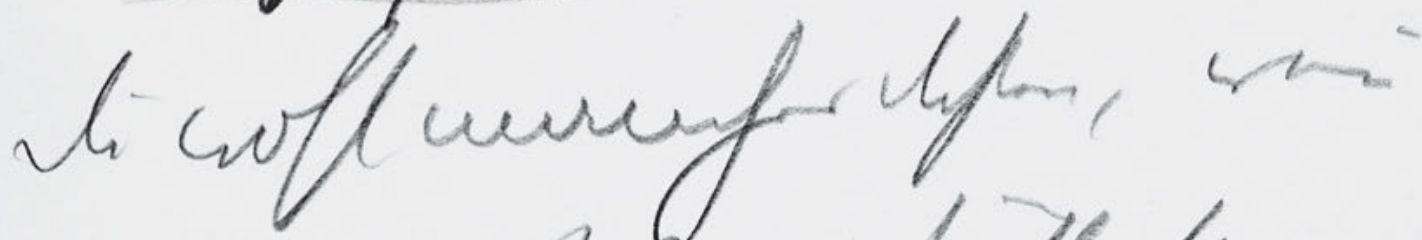

dínialy

sthiflar.

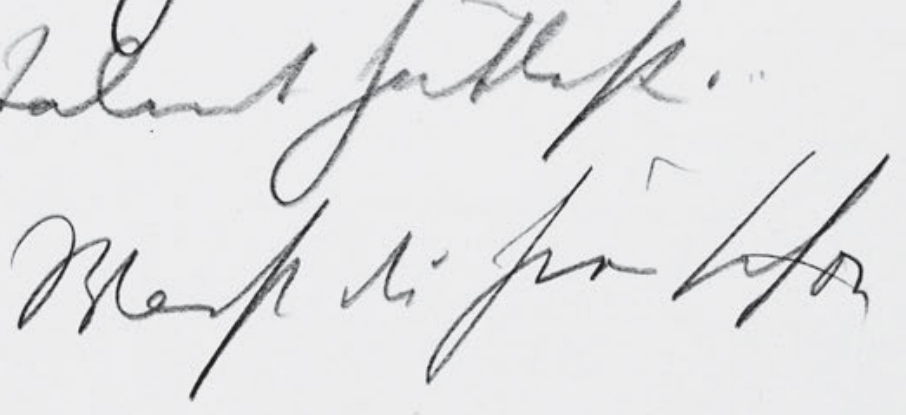

difinginh

une

$<$
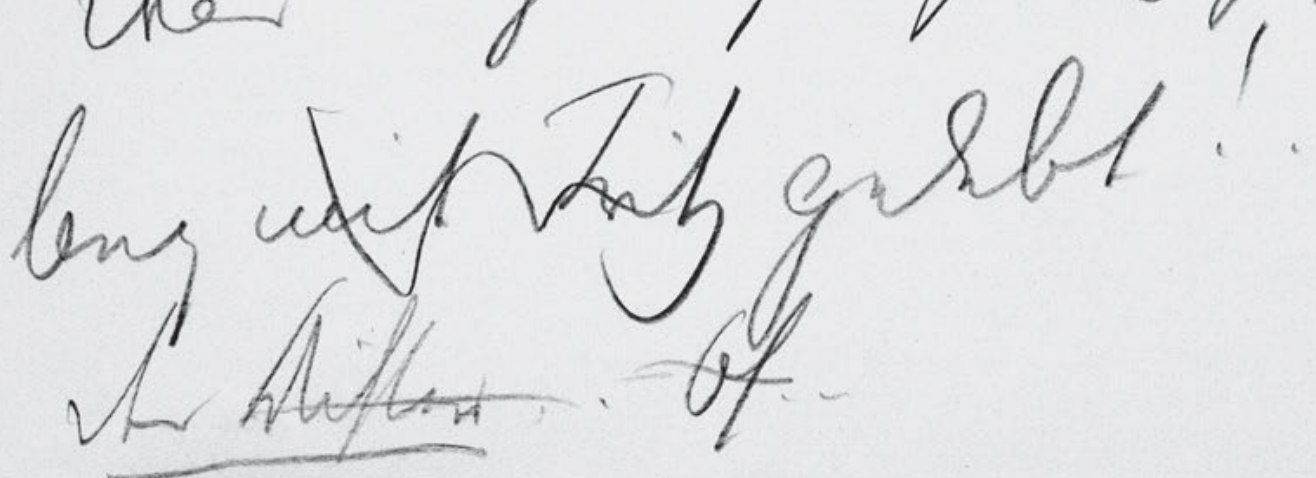

590 


\section{0}

Gegend.

Der ${ }^{\text {Dichter }}$ Schauspielerin. Was? 'Da könntes

du wohl manches dichten, weñ

5 du zufällig Talent hättest . . .

Der Dichter. Warst du hier schon

früher einmal

Die Schauspieler. Ob ich hie scho

war? . . Ja! . Hier hab ich Jahre

$10 \quad$ lang mit Fritz gelebt! .

Der Dichter . . -Oh. . 
HSz8 271

Handschriften und Typoskript

is ape

$2 \%$

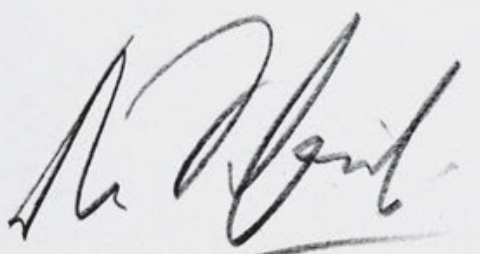

leifuiton
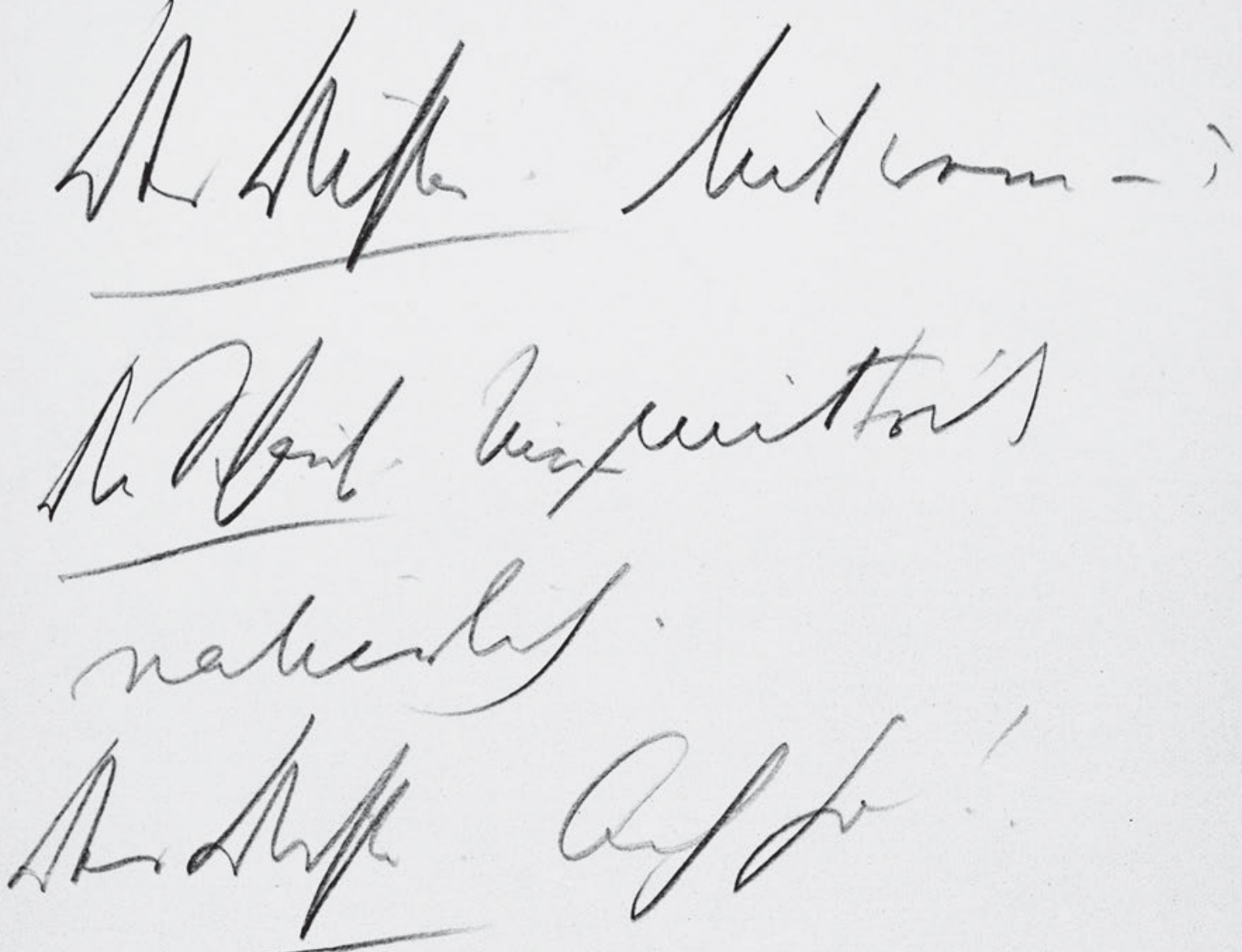

592 
271

Der Dichter. Mit wem - ?

Die Schausp. Nun ${ }^{+}$mit Fritz

natürlich.

$5 \quad$ Der Dichter. Ach so! . 
HSz8 272

Handschriften und Typoskript

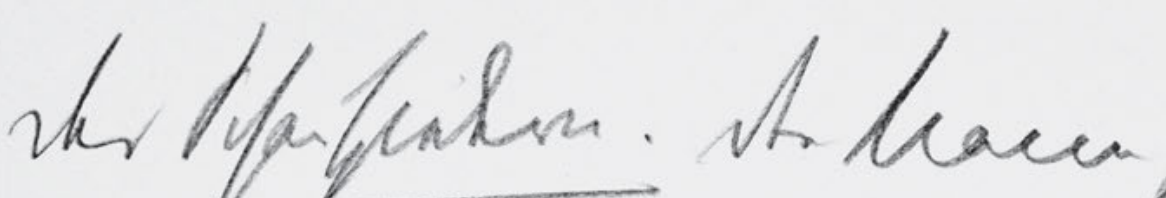

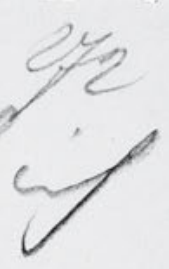

nofl anguhlat.

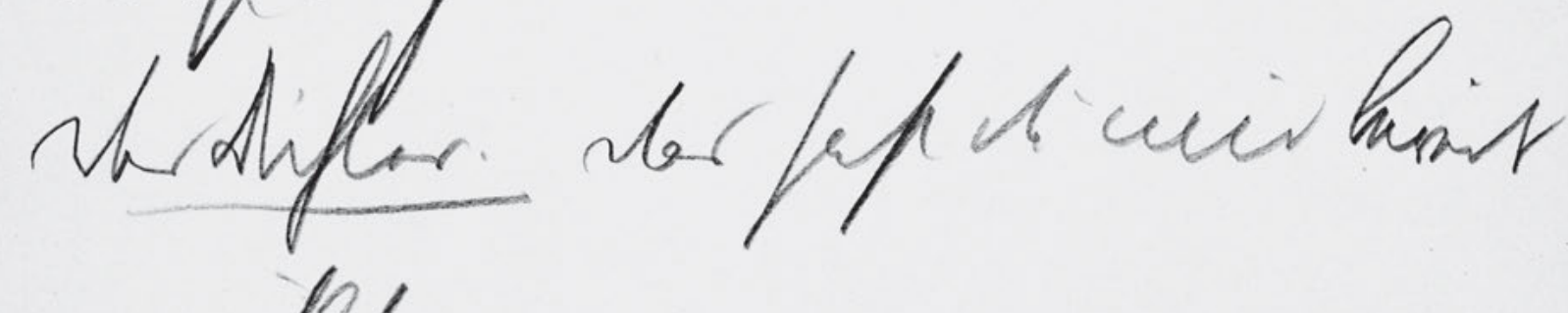
myeft
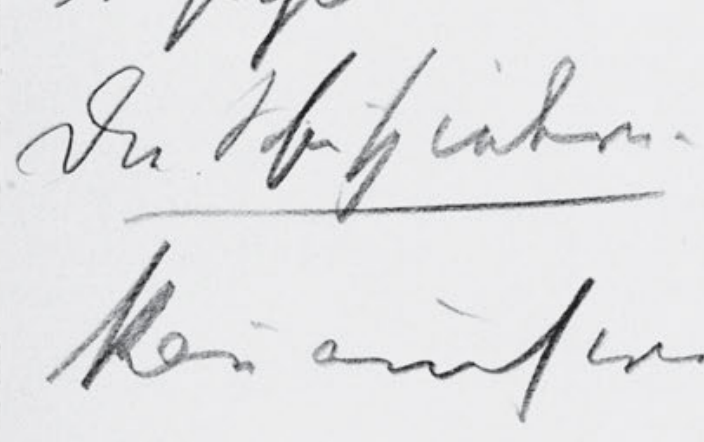
lenpers

chlape.

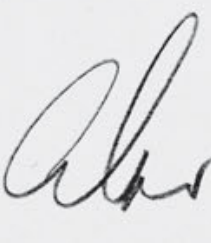

2

in 1
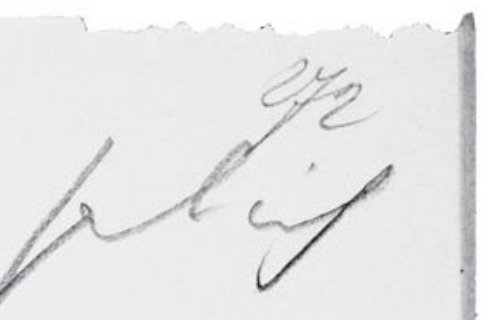
272

Der Schauspielerin . Den Mann hab ich

wohl angebetet! -

Der Dichter. Das hast du mir bereits

5 erzählt -

Die Schauspielerin. Ich bitt - du [?] ich

kañ auch wieder gehen, weñ ich $\mathrm{d} h$

langweile! .

Der Dichter. Aber du was fällt dir ein,

${ }_{10} \quad \mathrm{du}$ interessirst mich sogar! - 
HSz8 [272a]

Handschriften und Typoskript

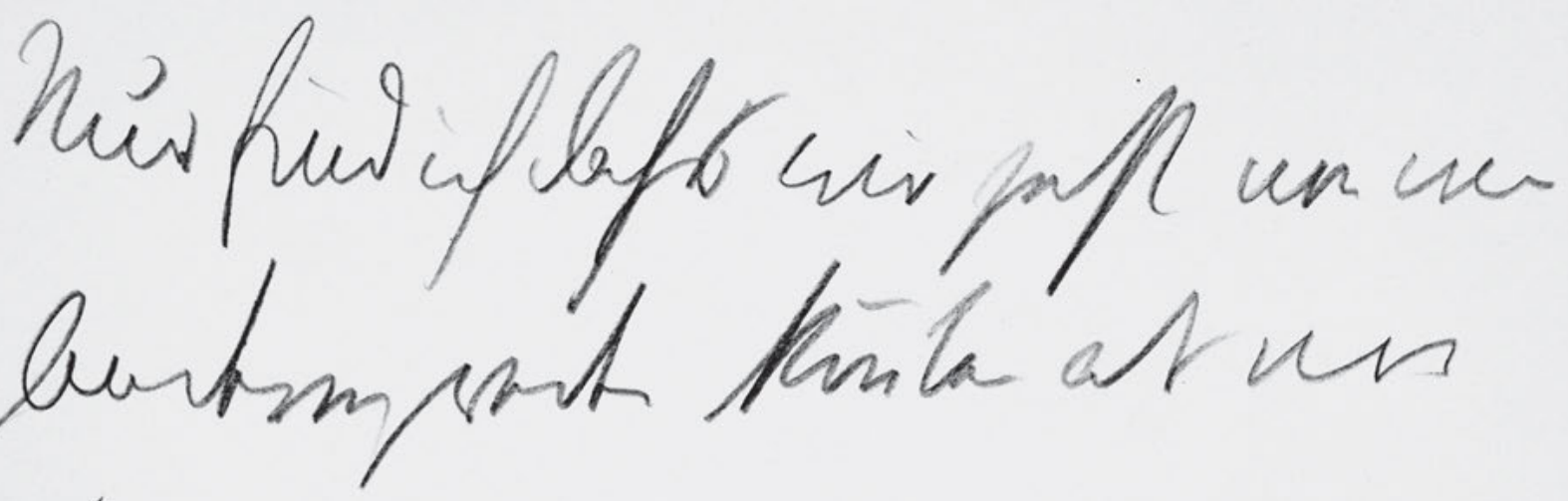

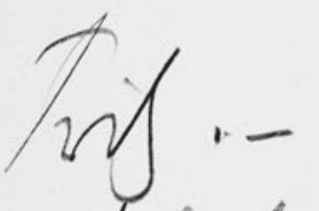

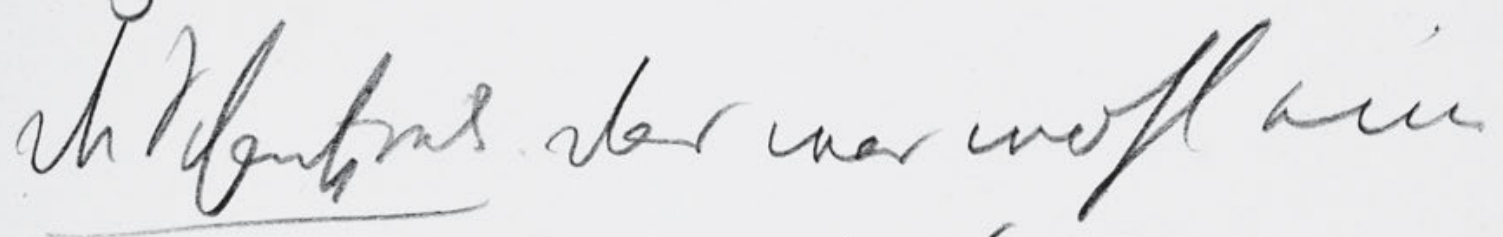

Mrrissǘs!. Ha!
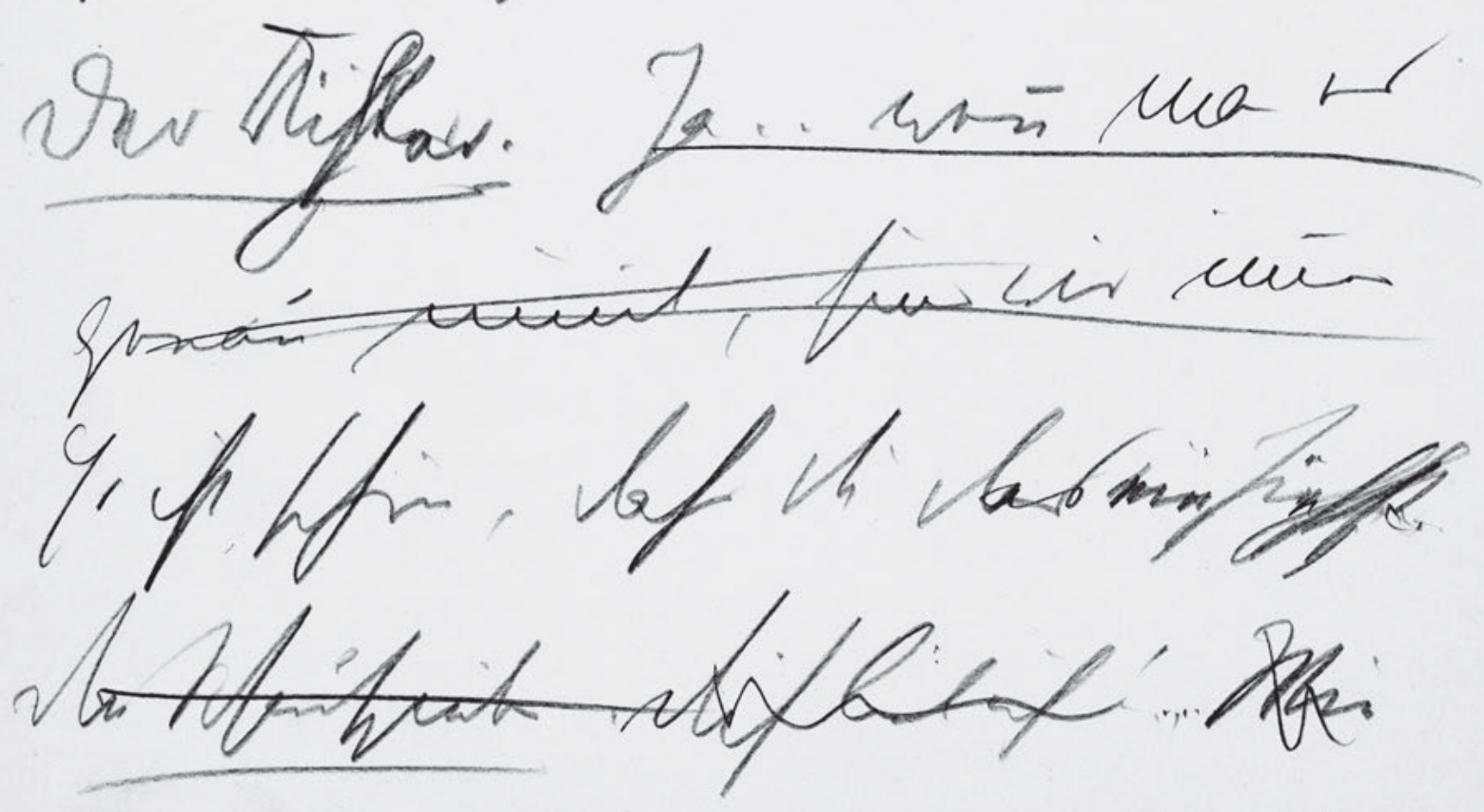

596 
Nur find ich dass wir jetzt von was

Anderm reden könten als von

Fritz. -

Die Schauspiel. Das war wohl eine

$5 \quad$ Verirrung! . . Na! -

Der Dichter. Ja .. weñ man es

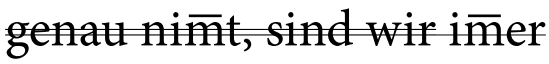

Es ist schön, dass du das einsiehst.

Die Schauspieler. Dich lieb ich! . . . . Wie 
HSz8 273

Handschriften und Typoskript

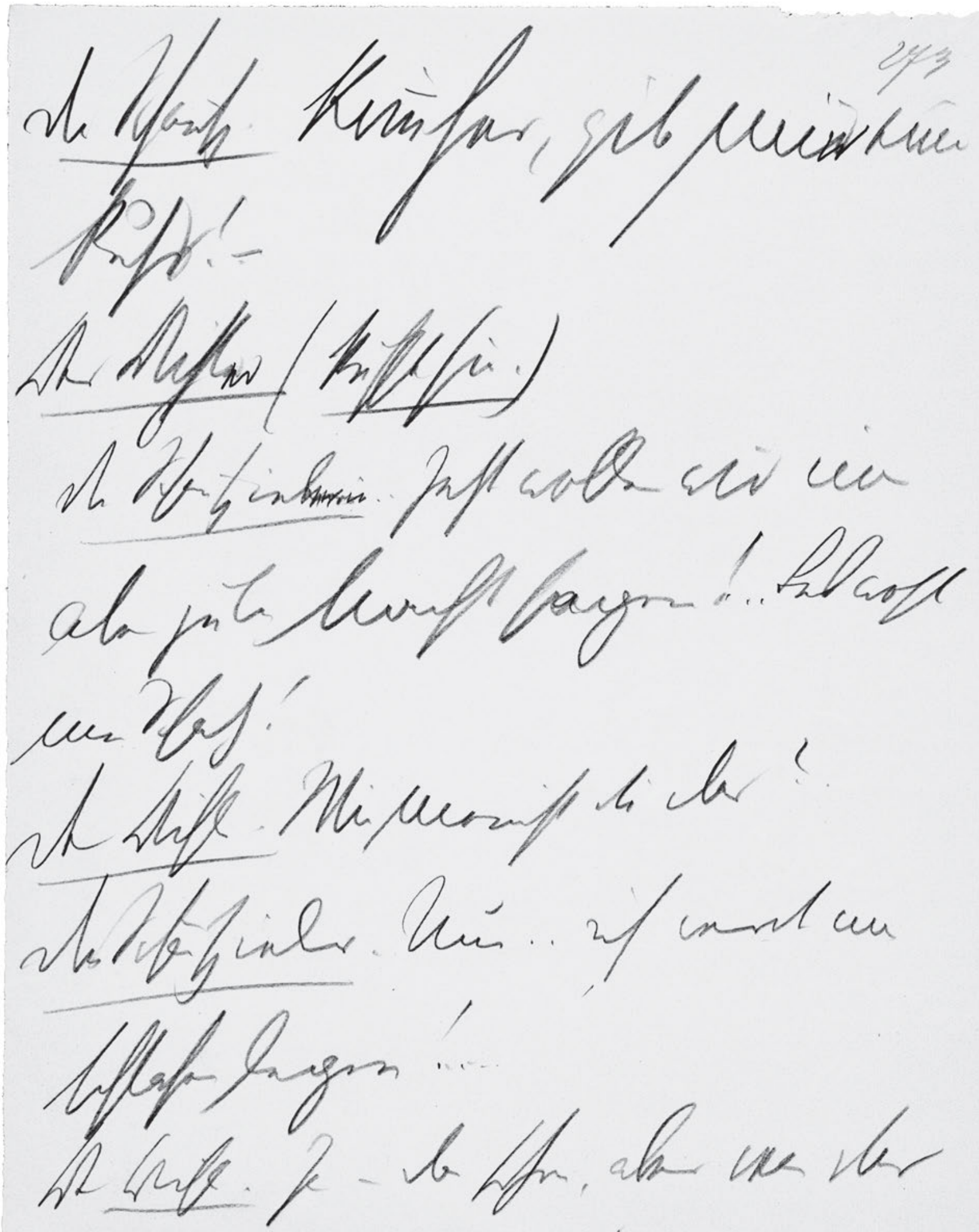

598 
273

Die Schausp. Kōm her, gib mir einen

Kuss! -

Der Dichter (küsst sie.)

${ }_{5} \quad$ Die Schauspielerin .. Jetzt wollen wir uns

aber gute Nacht sagen! . . Leb wohl

mei Schat $z$ !

Der Dicht. Wie meinst du das? .

Die Schauspieler. Nun . . ich werde mic

$10 \quad$ schlafen legen!....

Der Dicht. Ja - das schon, aber was das 
HSz8 274

Handschriften und Typoskript

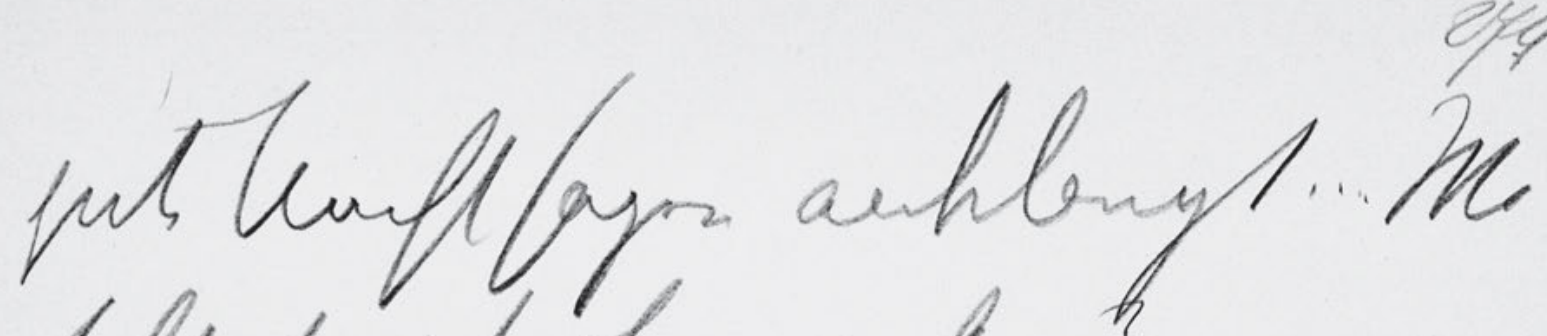
voll ticy absurenta

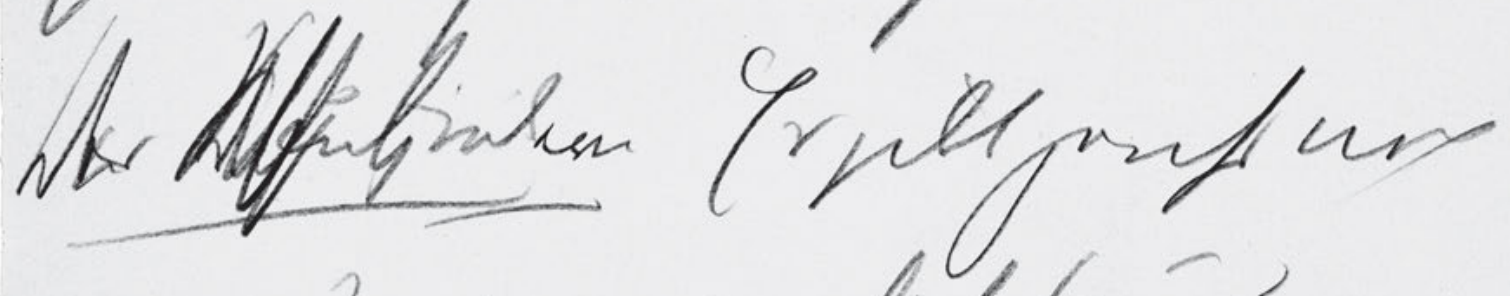

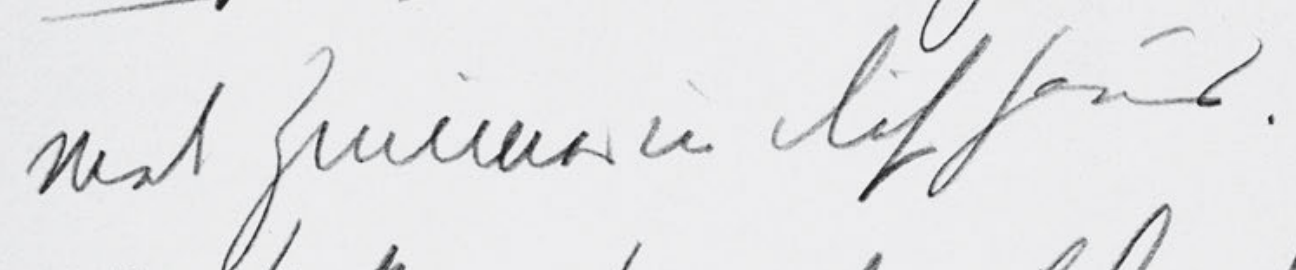

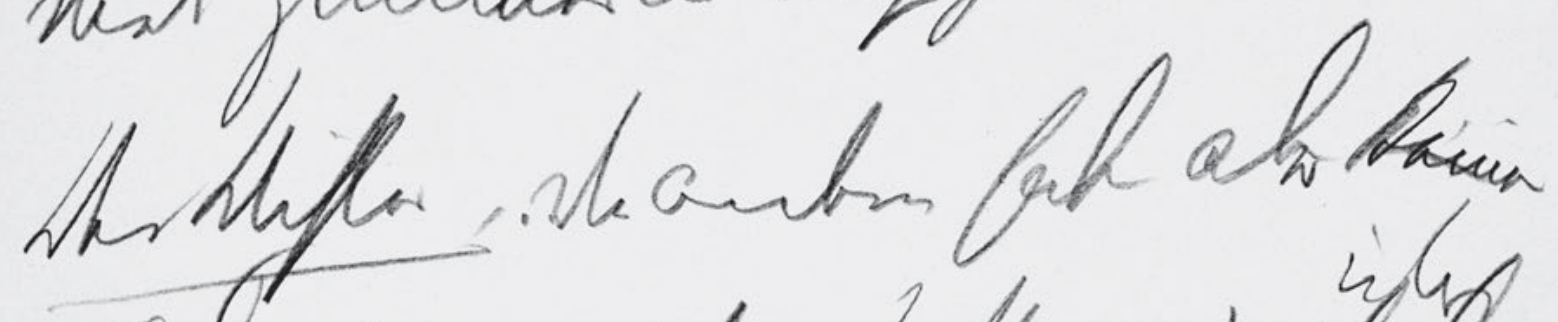

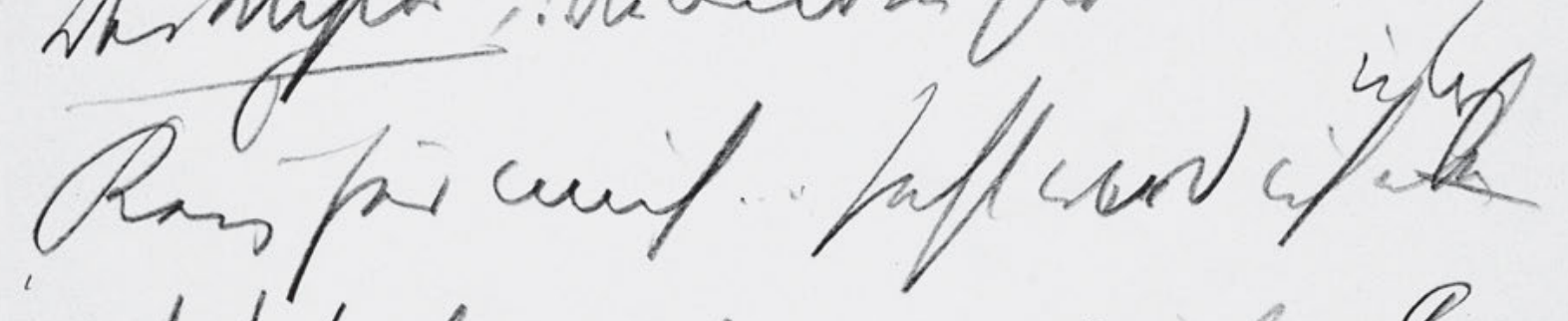
wif'tng hifgifinam. Ja. Hilst how wift

600 


\section{4}

gute Nacht sagen anbelangt .... Wo

soll deñ ich übernachten?

$\mathrm{D}^{\mathrm{er}} \mathrm{e}^{\text {Dieh }}$ Schauspielerin Es gibt gewiss noch

$5 \quad$ viele Zimmer in diesem Haus.

Der Dichter, , "Die andern haben aber keinen übrig

Reiz für mich .... Jetzt werd ich aber

doch Licht machen, meinst du

nicht? .

Die Schauspielerin. Ja. Willst du mir nicht 
HSz8 275

Handschriften und Typoskript

A Mle

pimal da hiffar, b an

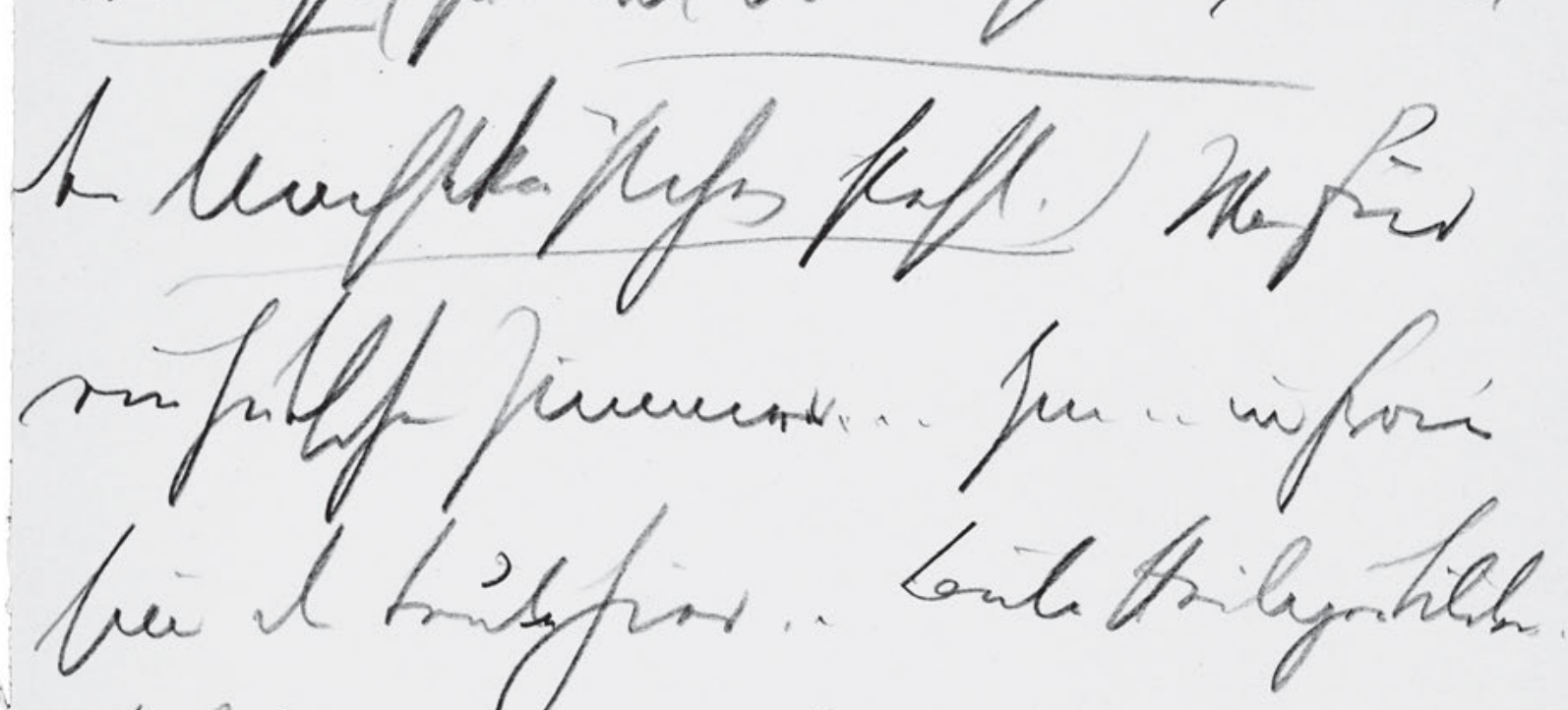

thetgingulori...

mifos,
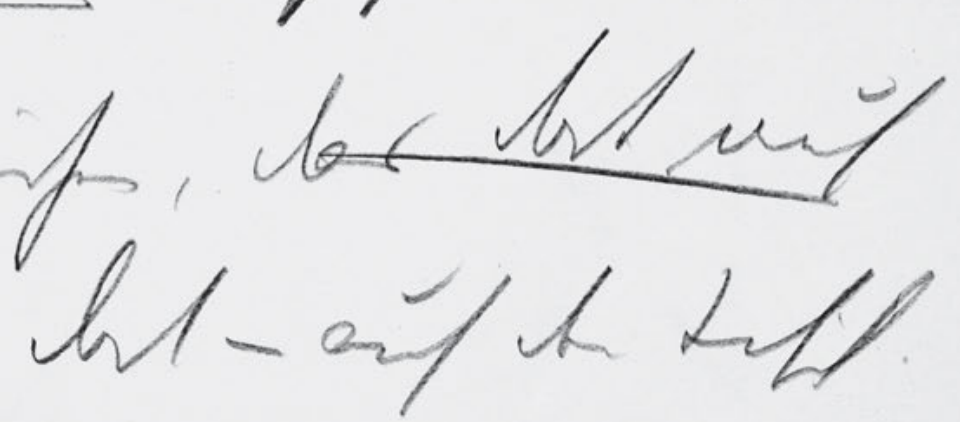

L

Alifer.

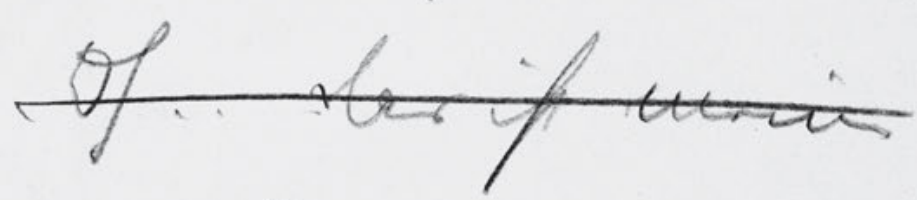

firr, naima mijig

602 
275

Der Dichter (zündet das Licht an, das auf dem Nachtkästchen steht.) Was für ein hübsches Zimmer .... . hm . . un frōm

5 sind die Leute hier . . Laute Heiligenbilder.

Die Schauspielerin .. Möchtest du mir d ${ }^{\text {a }}$ ie Tasche

Täschchen reichen, das dort auf

dem . . dort - auf dem Tisch.

Der Dichter. Oh..'das ist meine.

$10 \quad$ Hier, meine einzige! . . 
HSz8 276

Handschriften und Typoskript

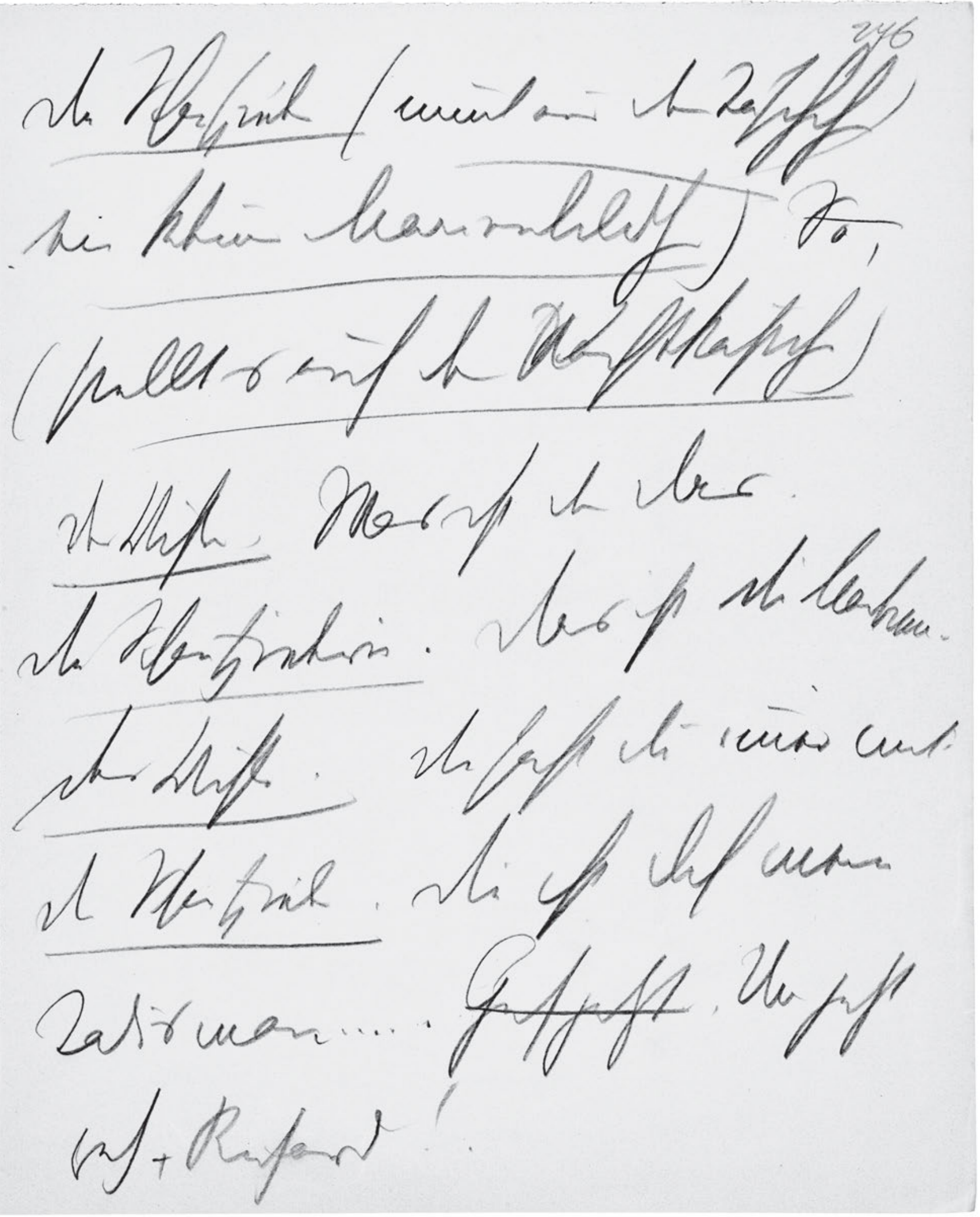

604 
276

Die Schauspieler (nī̄t aus dem Täschchen)

ein kleines Marienbildchen) So,

(stellt s auf den ${ }^{\text {S[?] Nachtkästchen) }}$

$5 \quad$ Der Dichter. Was ist den das.

Die Schauspielerin. Das ist die Madonna.

Der Dichte. Die hast du im̄er mit?

Die Schauspieler. Die ist doch mein

Talisman .... . Geh jetzt . Und jetzt

10 geh ${ }^{*}$, Richard! . 
HSz8 277

Handschriften und Typoskript

Dr whes

ad

Pll

11

Als mer fun bapt
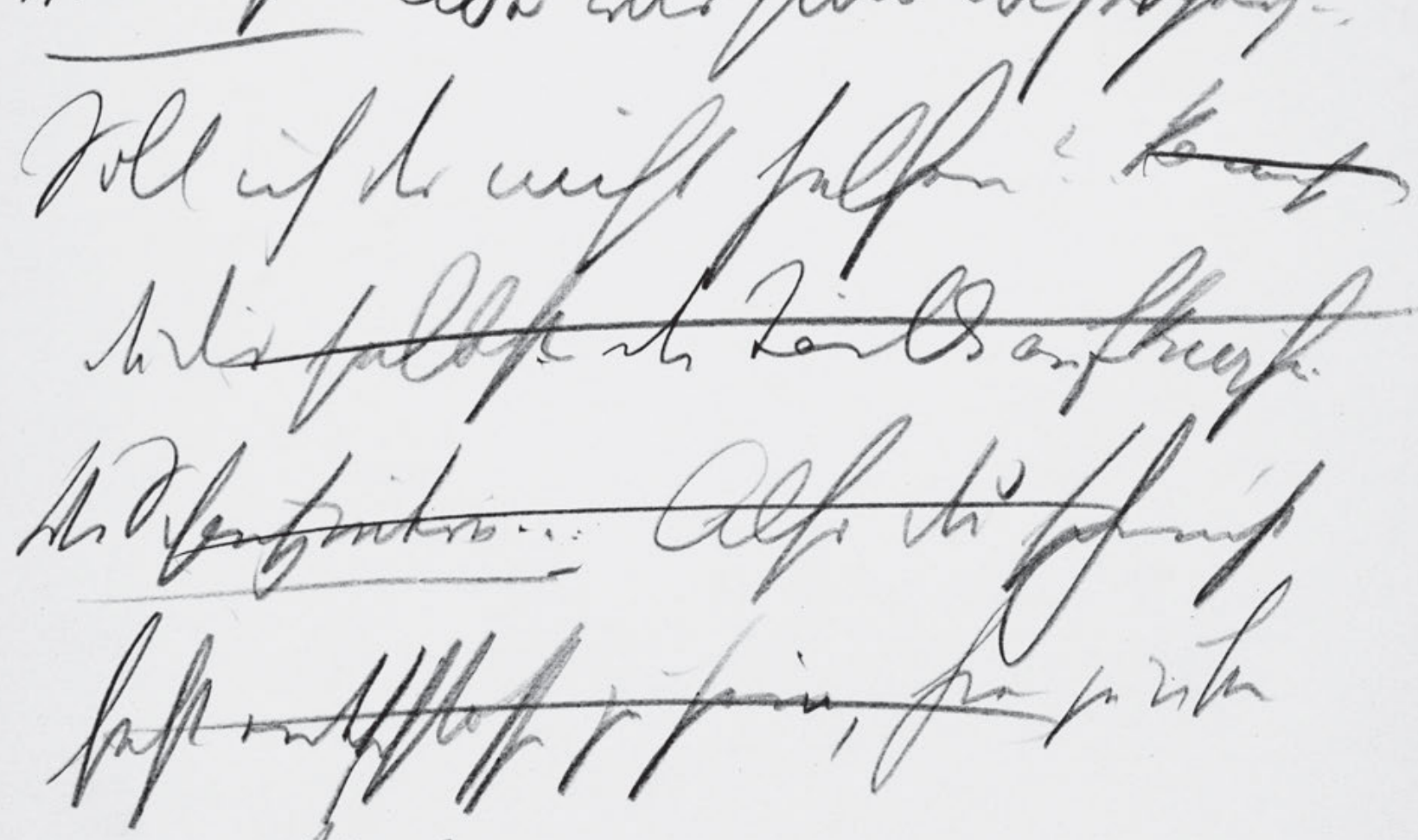

int

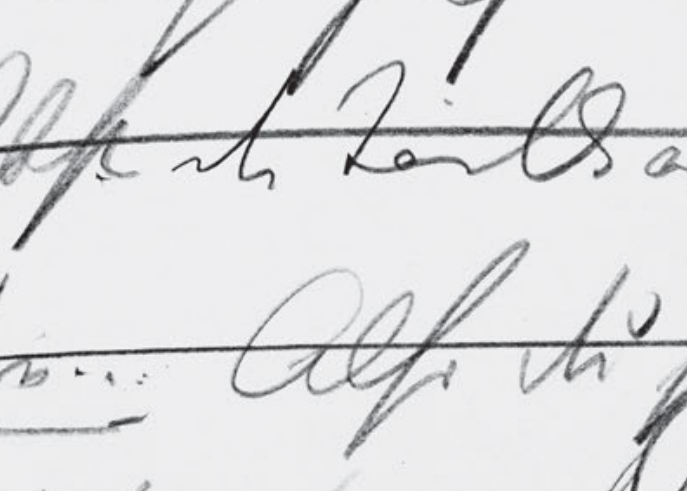

sapfrey

Us 
Der Dichter. Aber was sind das fur Scherz? .

Soll ich dir nicht helfen? 'Kannst

du dir selbst die Taille aufknöpfen.

$5 \quad$ Die Schauspielerin.... Also du scheinst

fest entschlossen zu sein, hier zu über

nachten?

Der Dicht. Ganz fest.

Die Schauspieler. Schön. Solass mich wenigsten ?

10

zehn Minuten allein das wurde dir 
HSz8 278

Handschriften und Typoskript

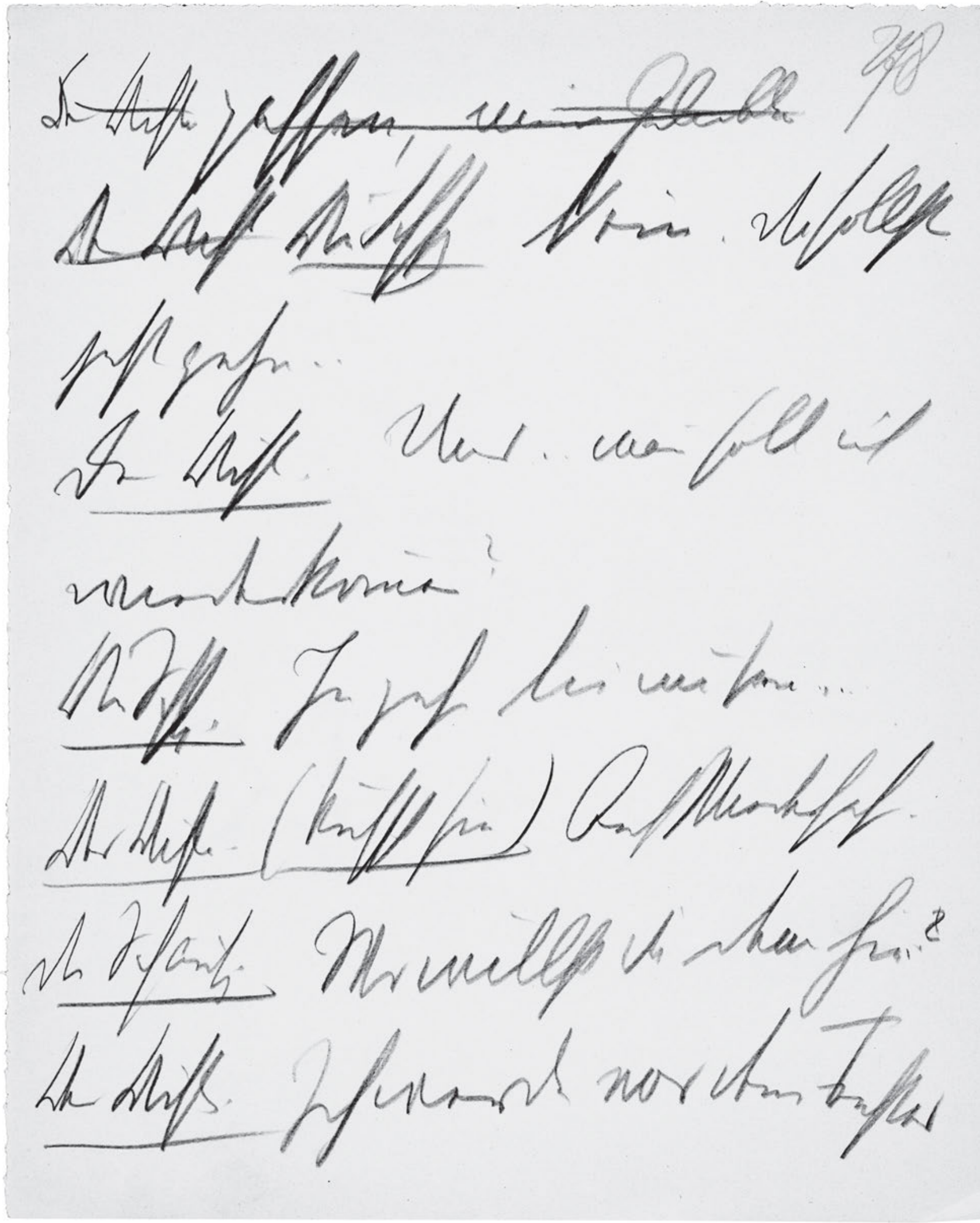

608 
278

Der Dichter passen, mein Geliebter

Der Dicht Die Schsp Nein. Du sollst

jetzt gehn . .

5 Der Dicht. Und .. wan̄ soll ich

wiederkomen?

Die Schsp. In zehn Minuten .....

Der Dichte. (küsst sie) Auf Wiedersehen.

Die Schausp. Wo willst du denn hin. ’?

10 Der Dichter. Ich werde vor dem Fenster 
HSz8 279

Handschriften und Typoskript vif uw ehy h. chlfent. ym. thing vilbic nut thelem
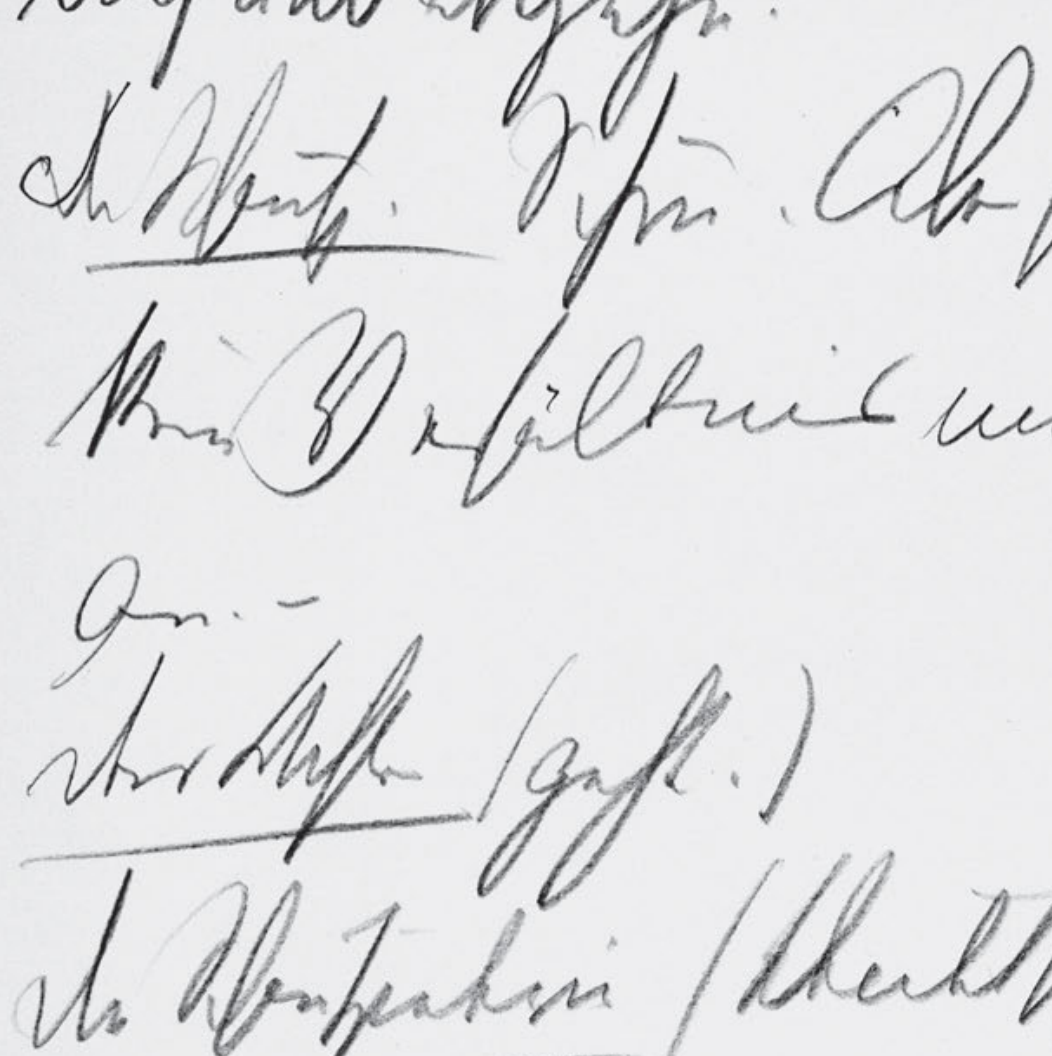


\section{9}

auf und abgehe.

Die Schausp. Schön. Aber fang mir

kein Verhältnis mit der Kellnerin

5 an. -

Derr Dichter (geht.)

Die Schauspielerin (kleidet sich aus; am

Fenster. Sie hört, wie ${ }^{\text {ef }}$ der Dichter über

die Holztreppe hinunter geht, u hört jetzt

seine Schritte unter dem Fenster Sie

geht, wie sie ausgekleidet ist, zum Fenster, 
HSz8 280

Handschriften und Typoskript

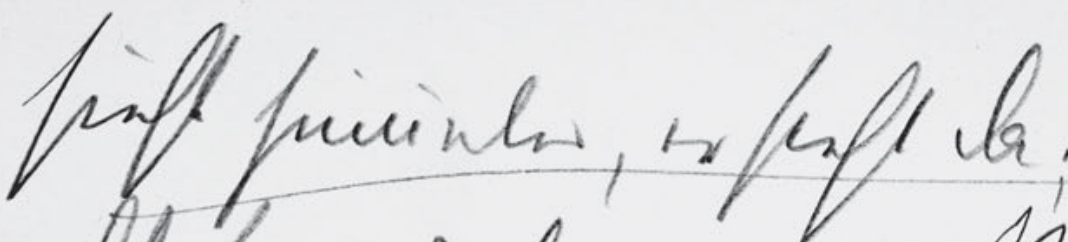

$28 y$

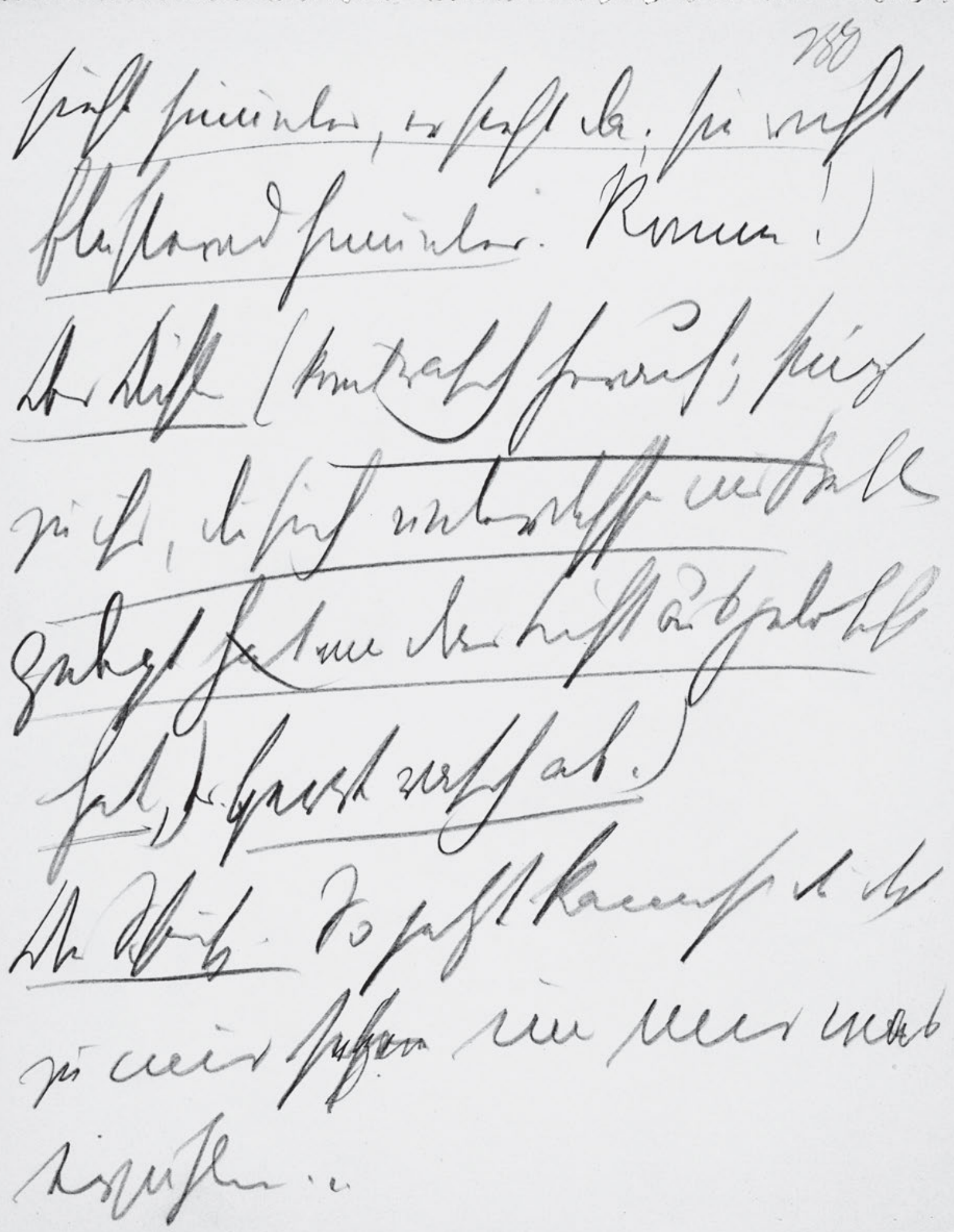

612 


\section{0}

sieht hinunter, er steht da; sie ruft

flüsternd hinunter. Komm!)

Der Dichter (kō̄t rasch herauf; stürz

$5 \quad$ zu ihr, die sich unterdessen ins Bett

gelegt hat und das Licht ausgeloscht

$\underline{\text { hat }}^{\dagger} \cdot$, er sperrt rasch ab.)

Die Schausp. So jetzt kannst du dich

zu mir setzen und mir was

10 erzählen ... 
HSz8 281

Handschriften und Typoskript

ch Hafla

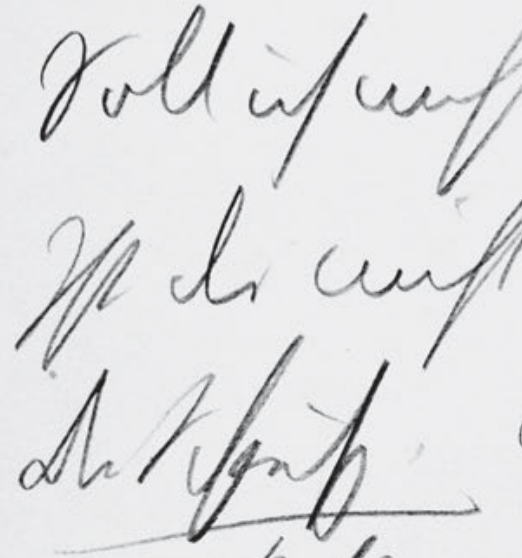

thr blife

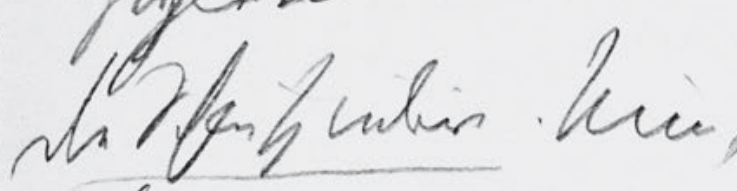
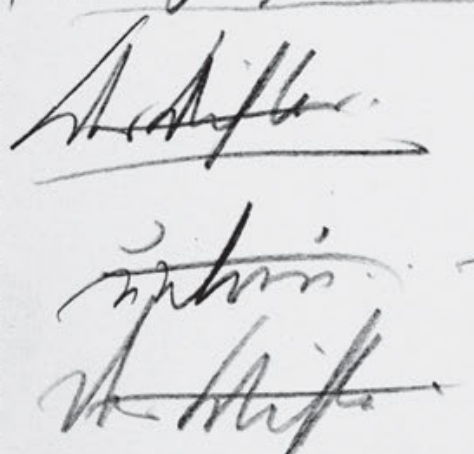

unm hy

th Miflar.

is
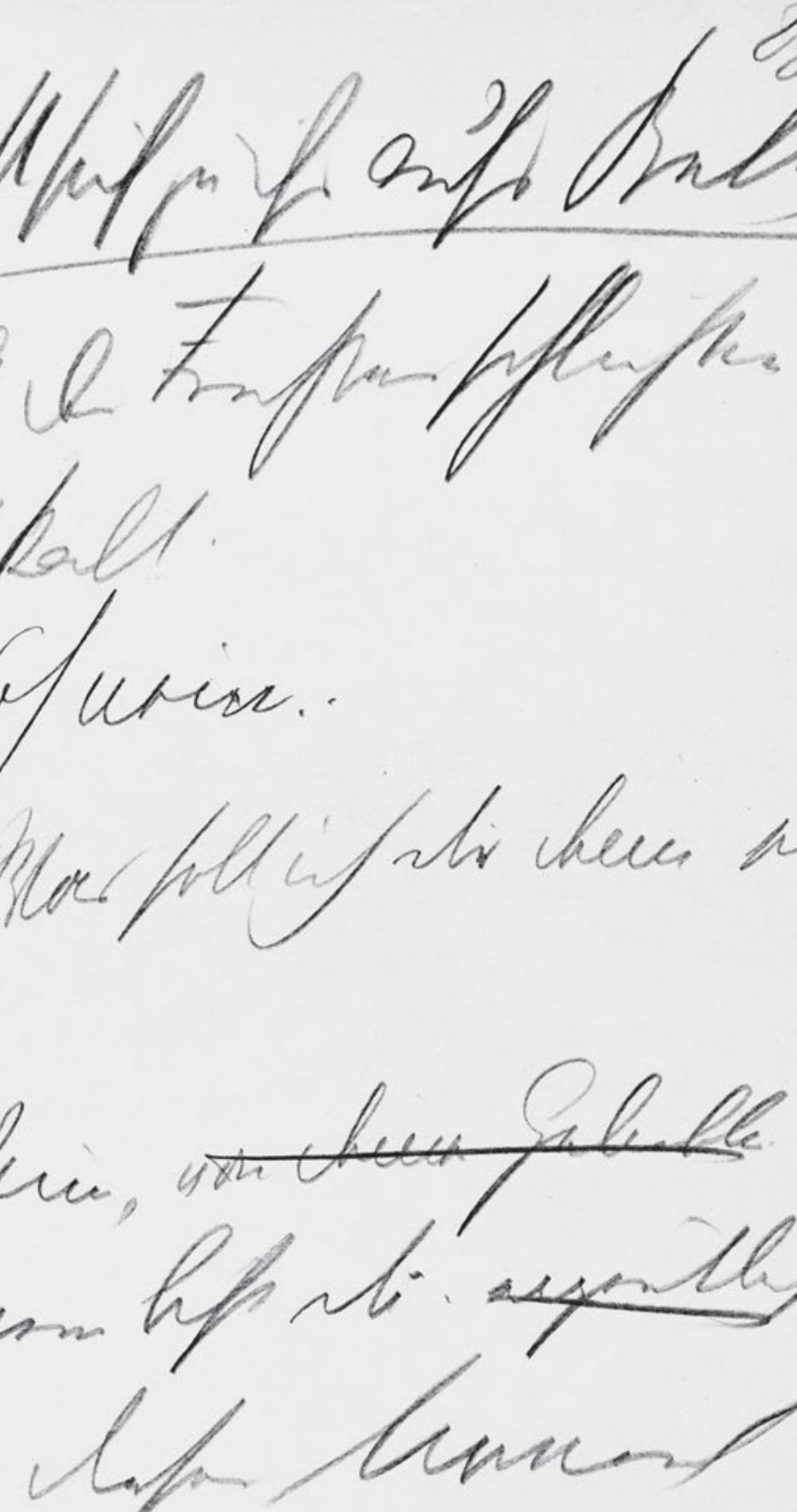

anf Anles 
Der Dichter (setzt sich zu ihr aufs Bett)

Soll ich nicht d'as? Fenster schließen?

Ist dir nicht kalt.

$5 \quad$ Die Schausp. Oh nein...

Der Dichter. Was soll ich dir denn erzählen.

Die Schauspielerin .Nun, von deine Geliebten.

Der Dichter. wem bist du . eigentlich

10 untreu .. in diesem Moment

Der Dichte. untreu?

Der Dichter .. Ich bin es ja leider noch nicht. 
HSz8 282

Handschriften und Typoskript

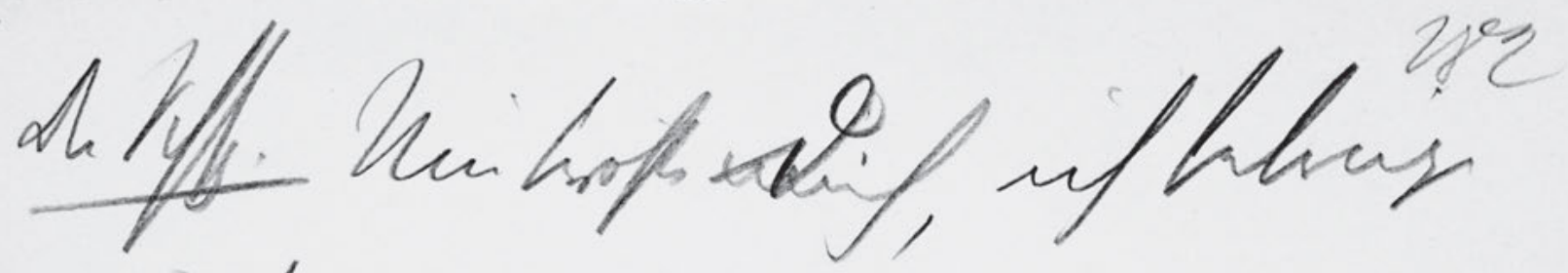

arifmewent

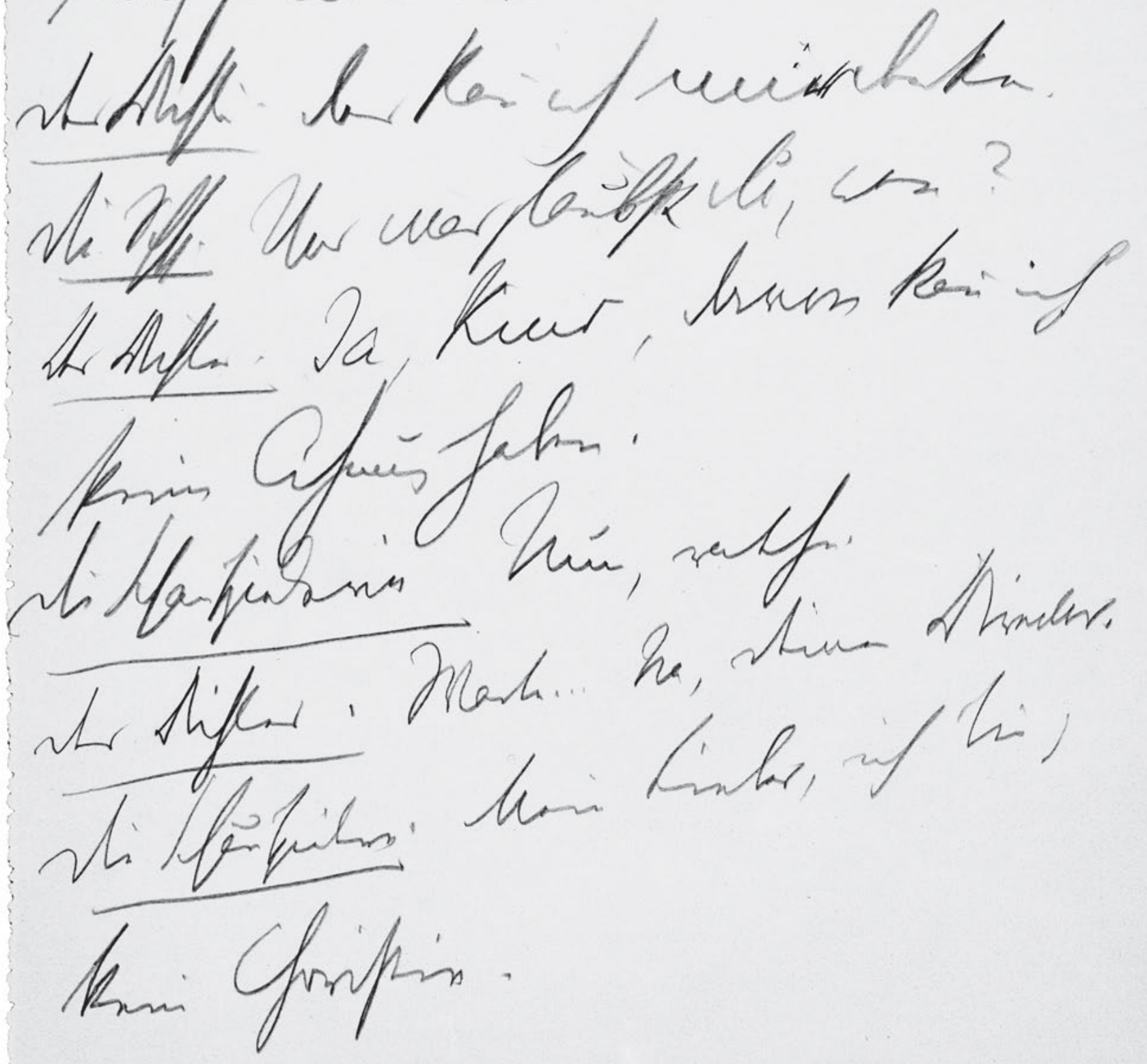

616 
282

Die Schsp. Nun tröste ${ }^{m}$ dich, ich betrüge auch jemanden.

Der Dichter. Das kan̄ ich mir denken.

$5 \quad$ Die Schsp. Und was glaubst du, wen?

Der Dichter. Ja, Kind, davon kan̄ ich

keine Ahnung haben.

Die Schauspielerin Nun, rathe.

Der Dichter. Warte ... Na, deinen Director.

10 Die Schauspielerin. Mein Lieber, ich bin $j$

keine Choristin. 
HSz8 283

Handschriften und Typoskript

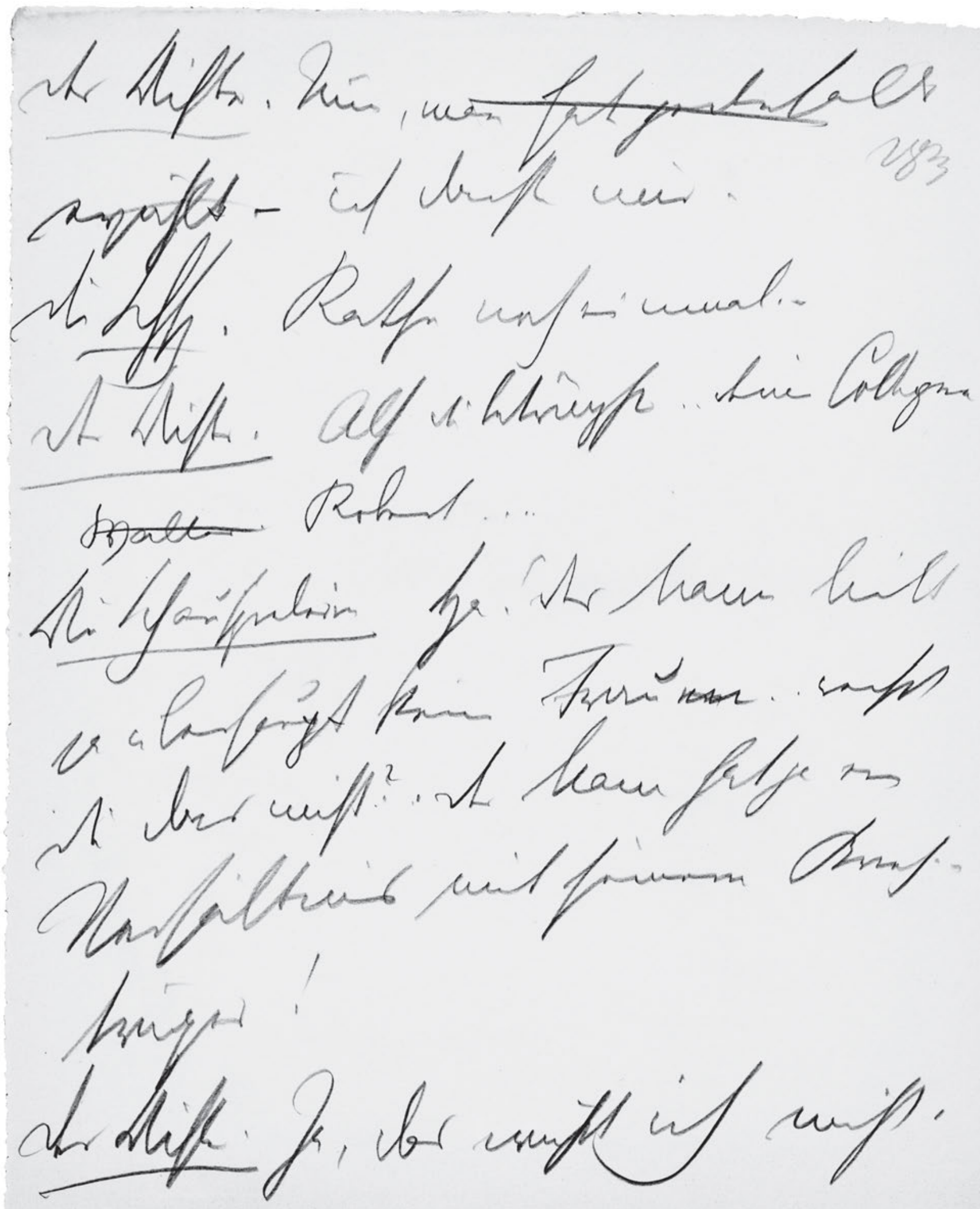

618 
Der Dichter . Nun, man hat jedenfalls

erzählt - ich dachte nur.

283

Die Schsp. Rathe noch einmal. -

Der Dichter. Also du betrügst . . deinen Collegen

$5 \quad$ Walter. Robert ....

Die Schauspielerin Ha! Der Mann liebt

ja überhaupt keine Frauen . . weißt

du das nicht. ?.. Der Mann hat ja ein

Verhältnis mit seinem Brief--

10 träger!

Der Dichter. Ja, das wußt ich nicht. 
HSz8 284

Handschriften und Typoskript

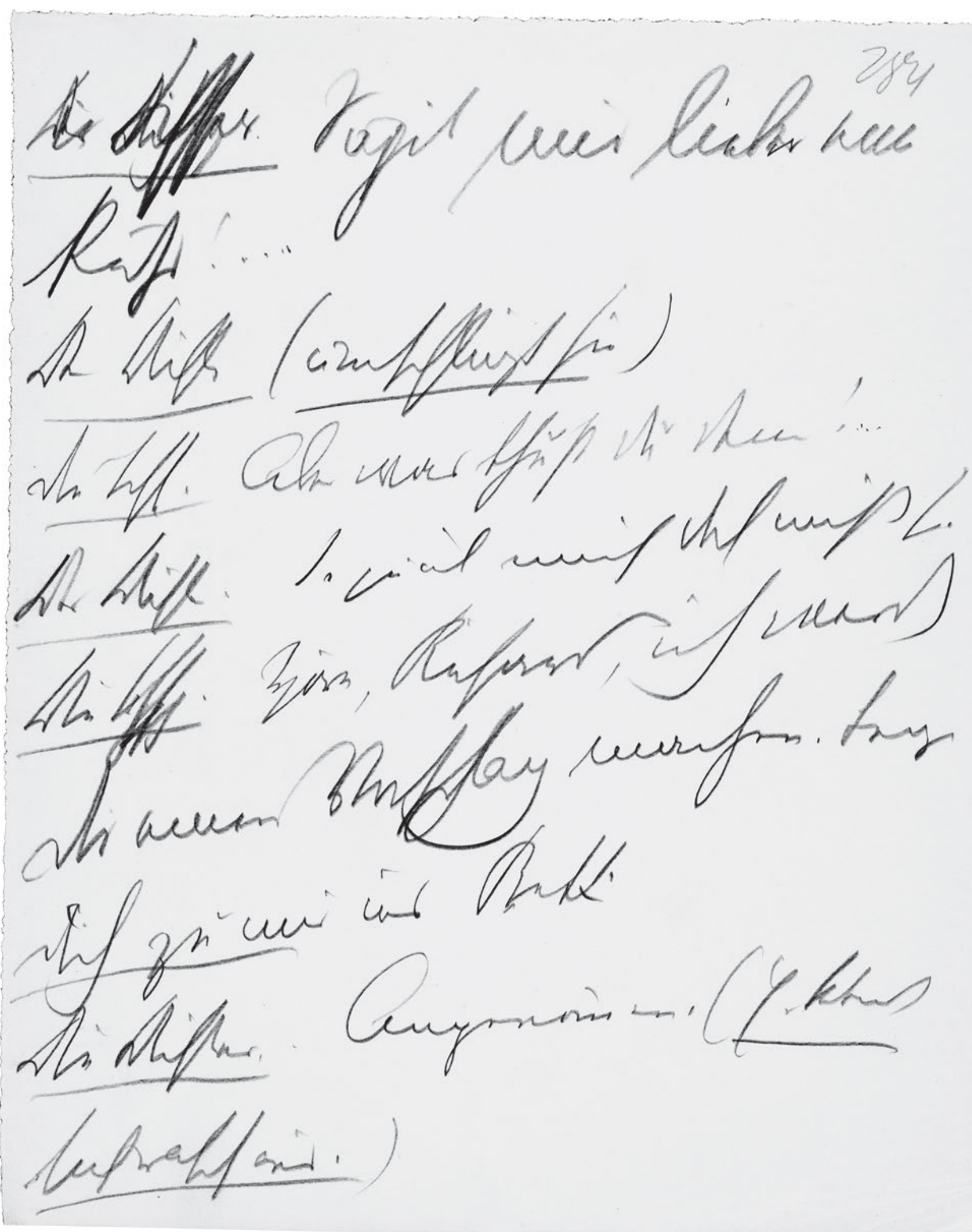

620 
284

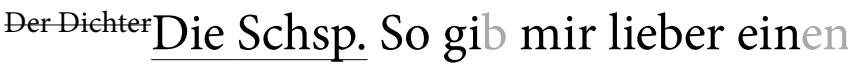

Kuss! . . . . .

Der Dichter (umschlingt sie)

$5 \quad$ Die Schsp. Aber was thust du denn! ...

Der Dichter. So quäl mich doch nicht so.

Die Schsp. Höre, Richard, ich werde

dir einen Vorschlag machen. Lege

dich zu mir ins Bett.

10 Die Dichter. . Angenō̄en. (Er kleid

sich rasch aus.) 
HSz8 285

Handschriften und Typoskript

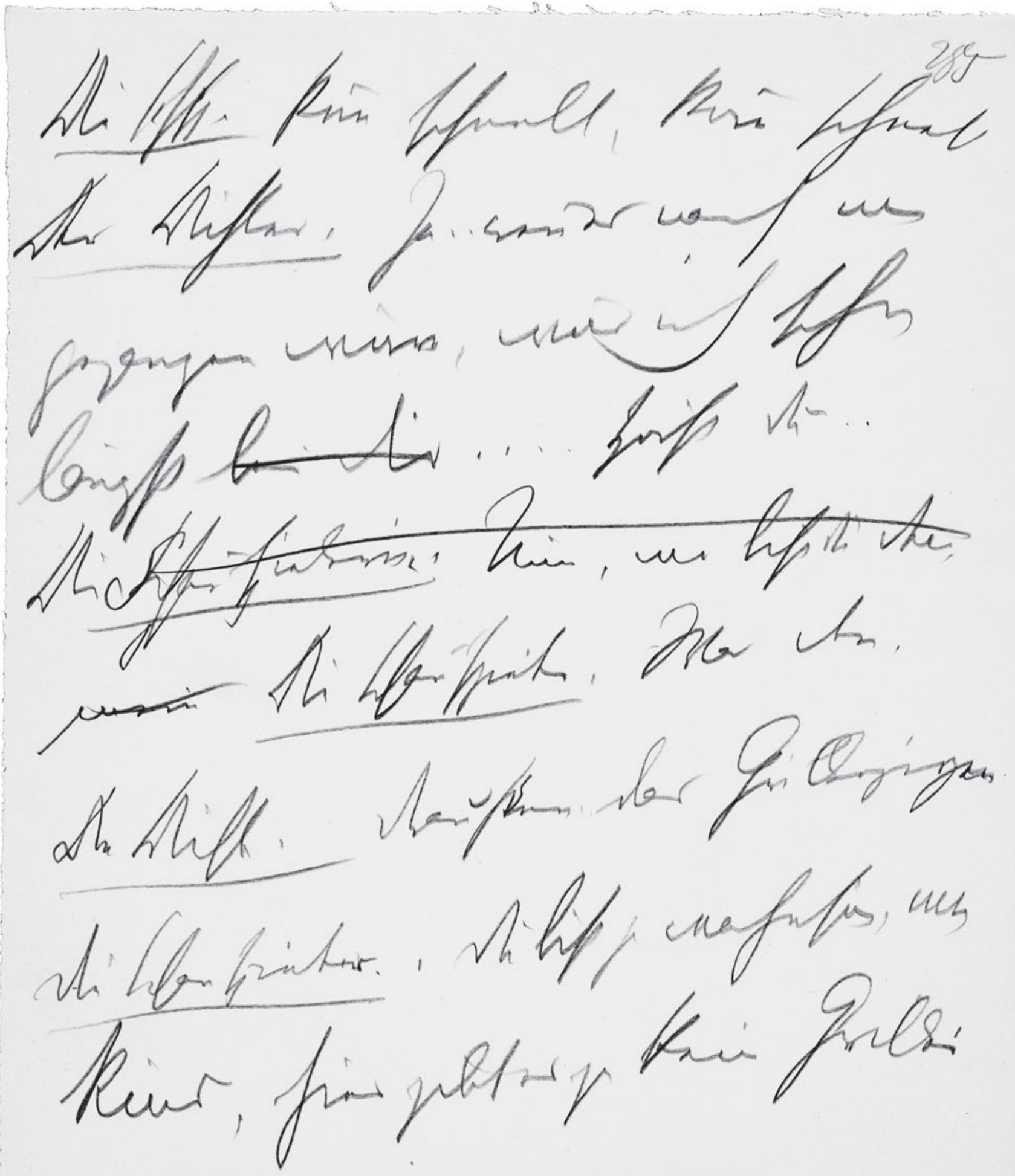

622 


\section{5}

Die Schsp. Kō̄ schnell, kō̄ schnel

Der Dichter. Ja . . wen̄ es nach mir

gegangen wäre, wär ich schon

5 längst bei dir .... Hörst du . .

Die Schauspielerin. . Nun, wo bist du denn,

mein Die Schauspieler. Was den.

Die Dichte. Draußen .. das Grillenzirpen.

Die Schauspieler. . Du bist ja wahnsing, mein

10 Kind, hier gibt es ja kein Grillen. 
HSz8 286

Handschriften und Typoskript

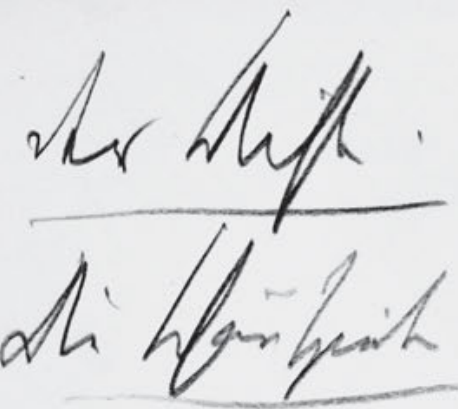

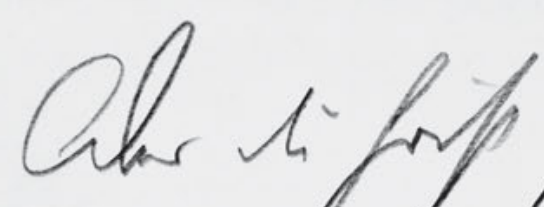

he

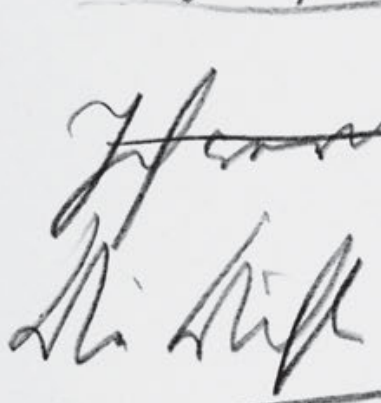

Oftici
,

fint. 286

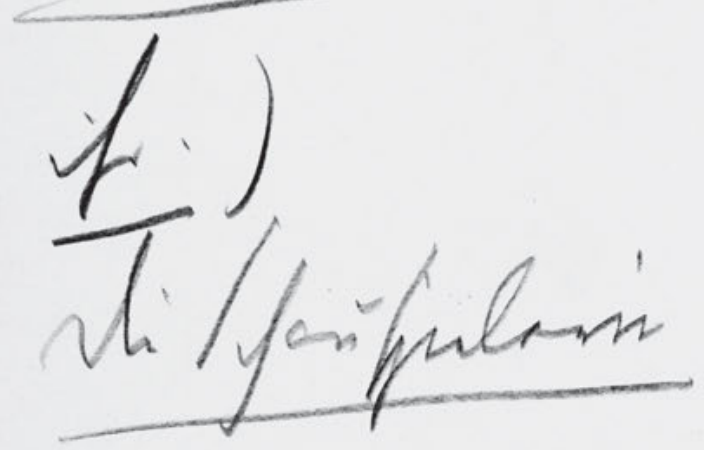

the hi
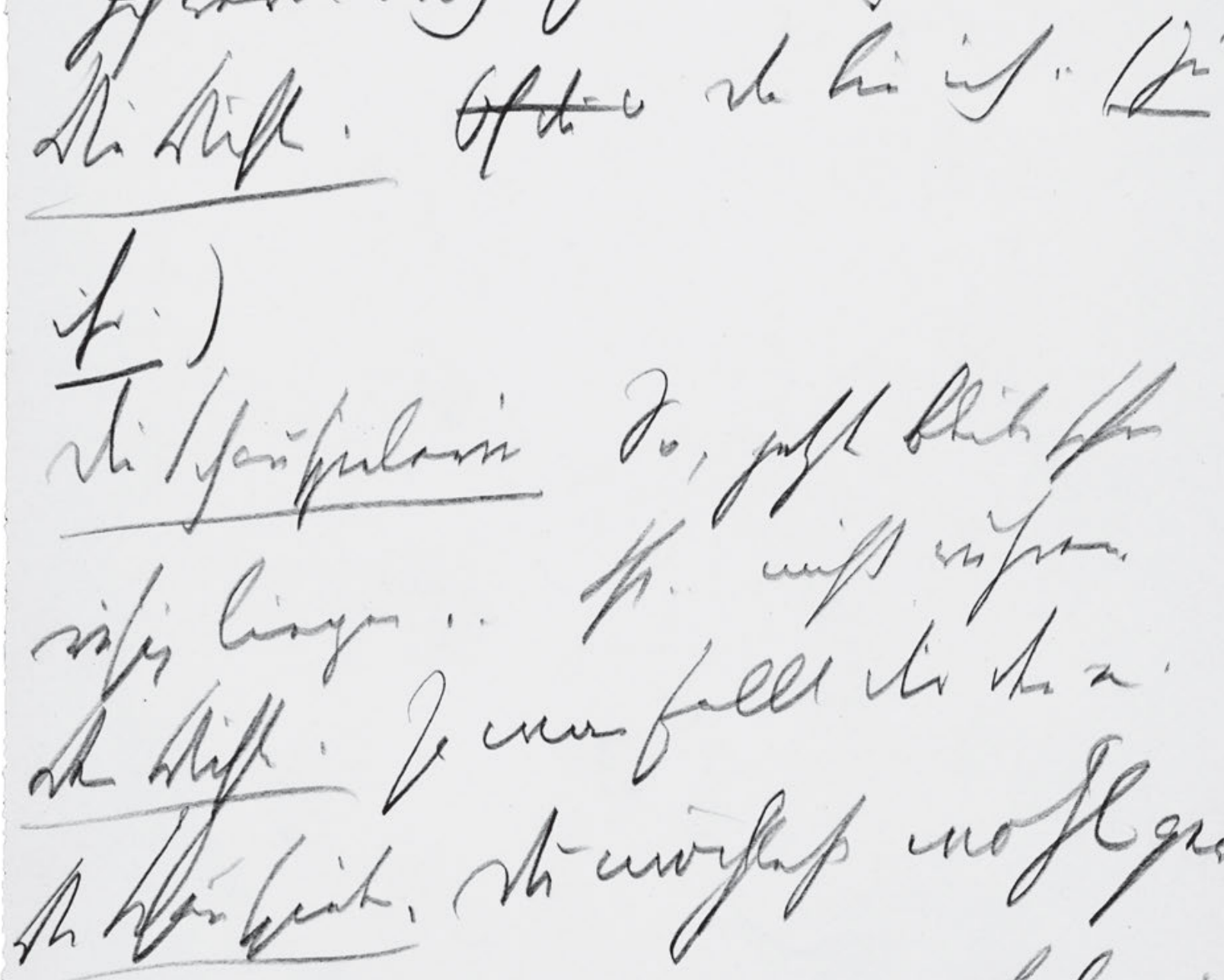

th uniflap

flich flo

2.

an

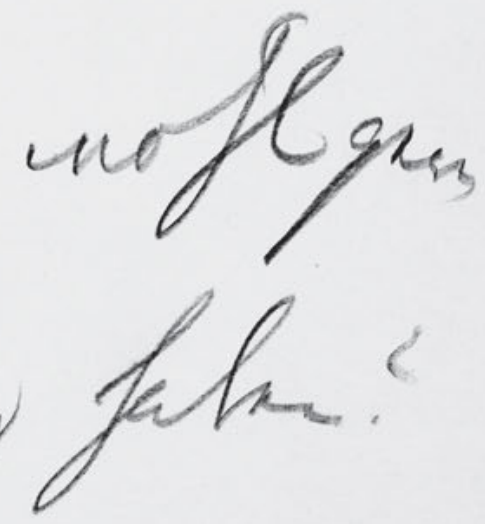

624 
286

Der Dichter. Aber du hörst sie doch . .

Die Schauspieler .Nun so kō̄, mein Grille -

Ich werde dich Gril endlich . .

$5 \quad$ Die Dichter. Oh du [?] Da bin ich .. ( $\underline{\mathrm{Zu}}$

ihr.)

Die Schauspielerin So, jetzt bleib schon

ruhig liegen .. Pst .. nicht rühren.

Der Dichter. Ja was fallt dir den ein.

10 Die Schauspieler. Du möchtest wohl gern

ein Verhältnis mit mir haben? 
HSz8 287

Handschriften und Typoskript
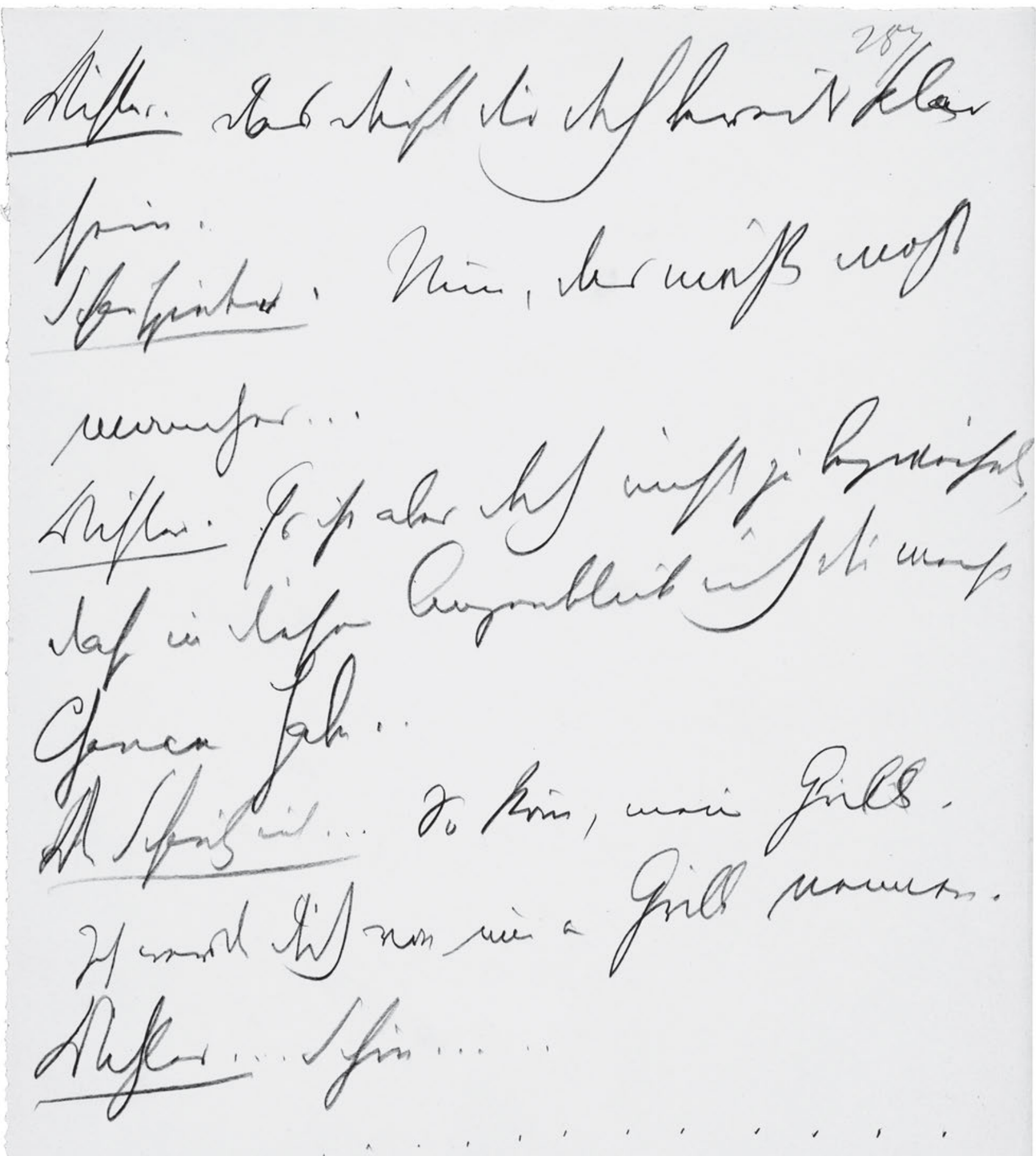

626 
Dichter. Das dürft dir doch bereits klar

sein.

Schauspieler. Nun, das möchte wohl

5 mancher...

Dichter. 'Es ist aber doch nicht zu bezweifeln, dass in diesem Augenblick ich die meist

Chance habe. .

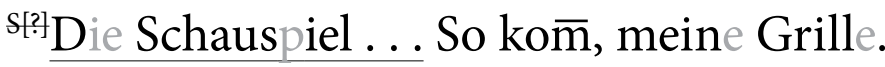

Ich werde dich von nun an Grille nennen.

Dichter.... Schön... . . 
HSz8 288

Handschriften und Typoskript

his

for fins, him, sas latring if?

288

Ah thfor.

de

if

mir suffoffigas

agal:

di. Forpution.

the gitify

Ifinar al6 in blingunij. 
Die Schauspiele . Nun, wen betrüg ich? . .

Der Dichter. Das ist mir wahrhaftig ganz egal . .

5 Die Schauspielerin

Das ist doch schöner als in blödsinnige

Stücken spielen .... was meinst du -

Der Dichter. Ja... es ist auch schöner als

für unverständige Komodiantinen

10 Stücke zu schreiben. Nun, ich meine

es ist gut, dass du doch zuweilen $a^{?} u$ uch? $^{\text {? }}$

in vernunftigen $\mathrm{zu}$ spielen hast . . 
HSz8 289

Handschriften und Typoskript

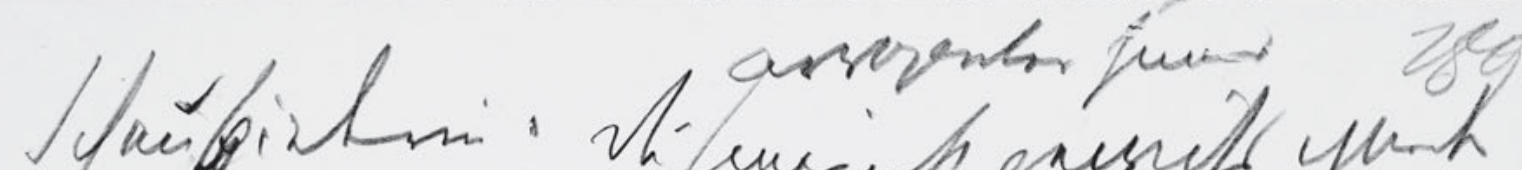
hive,

siffur. Ja wofl is)

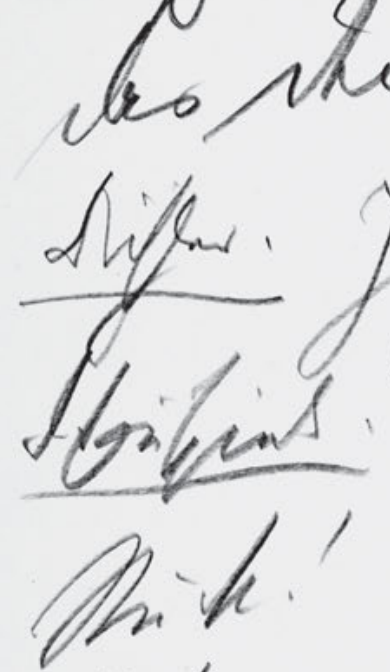

Gouk, aber jowo

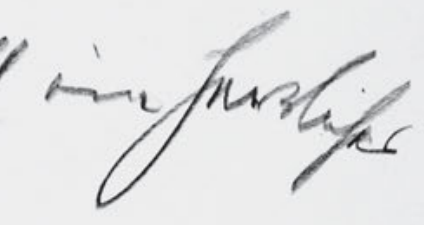

Alyer.

hinalfo.

Senfuiton

Oe, silift in suph Grus

Riforat.

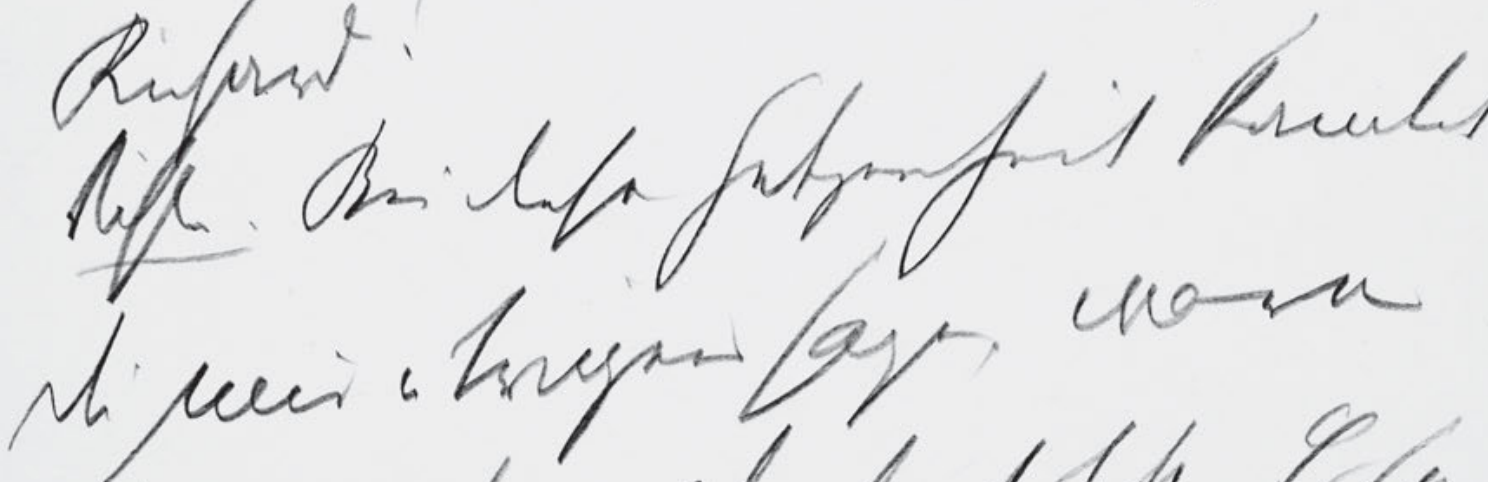

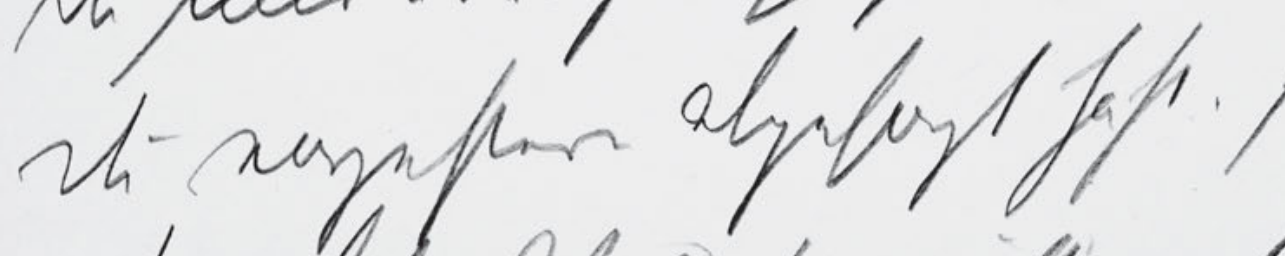
di chablobit mifg gafles.

630 
arroganter Hund

Schauspielerin . Du/meinst gewiss wieder

das deine.

Dichter. Ja wohl.

$$
\left(\left(\mathrm{ernst}^{\mathrm{t}+\mathrm{[3}}\right)\right.
$$

${ }_{5}$ Schauspiele. Nun, das ist wohl ein herrliches

Stück!

Dichter. Nun also . .

Schauspielerin, ${ }^{\mathrm{Ab}} \mathrm{Ja}$, du bist ein großes Genie,

Richard!

10 Dichter. Bei dieser Gelegenheit konntes

du mir übrigens sagen, warum

du vorgestern abgesagt hast. Es ha

dir doch absolut nichts gefehlt. 
HSz8 290

Handschriften und Typoskript

Ifosifuales. hin, if unoles

Mifenis

jin

Sis finta

norsus thar: Ane fatw

$$
\text { ( }
$$

Jis
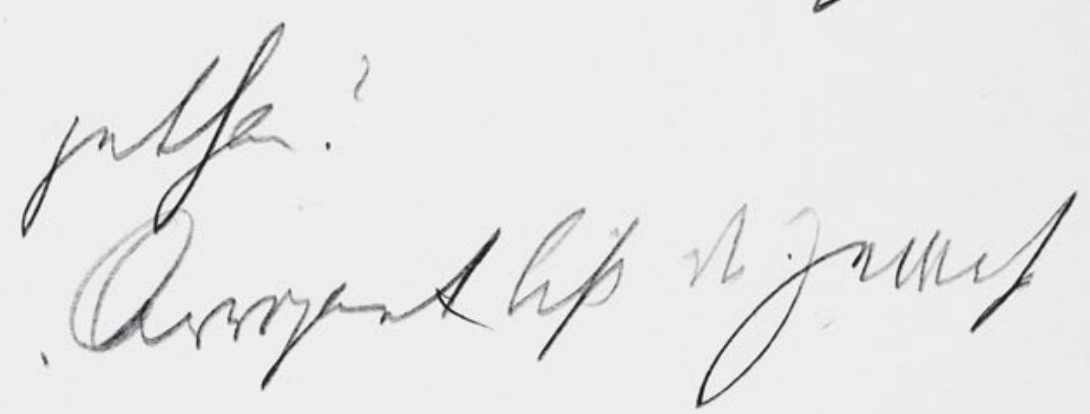

theler

Miginar

7

Dhifor

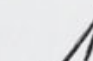


Schauspielerin. Nun, ich wollte dich ärger

Dichter. Ja warum denn? Was hab ich

dir denn gethan?

$5 \quad$ Schauspieler .Arrogant bist du gewese

Dichter. Wieso?

Schauspielerin. Alle im Theater finden es.

Dichter So.

Schausp. Aber ich habe ihnen gesagt: der

Man̄ hat wohl ein Recht, arrogant

zu sein: . Sie müßten mir 
HSz8 291

Handschriften und Typoskript

Alif.

xis

Has ue

Galin tis

onstrofs

Ater

thi

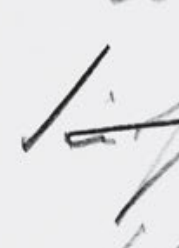

htrits andunte? fient

U

leer

thes.
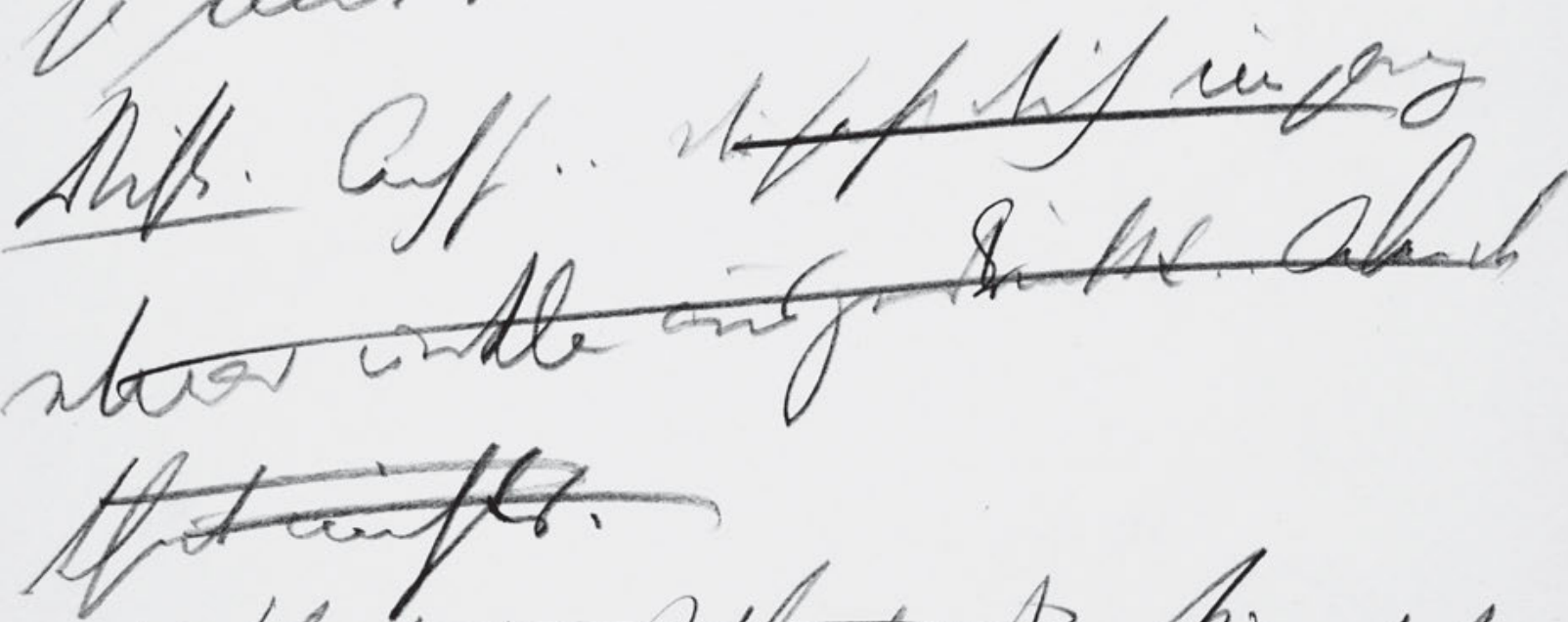

M

16 is

Lat.
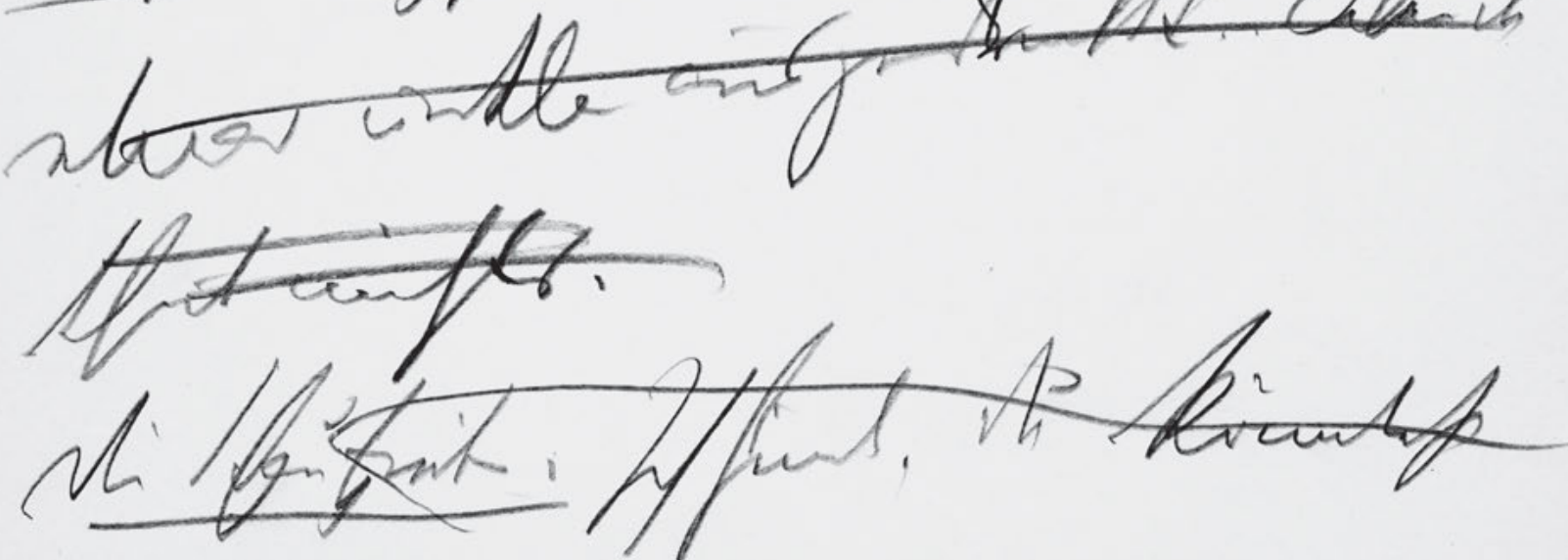

i

634 
291

Dichter. Nun, "Und was haben die ander geantwortet.

D Schauspiele. . Sie sind ja alle begeistert

${ }_{5}$ Dichter. Die Schauspiele. Was sollen mir

deñ dies Leute antworten? Ich rede

ja mit keinem.

Dichte. Ach so . . du hast dich im ganzen

etwas unklar ausgedrückt. . Aber da

thut nichts.

Die Schauspieler. Ich finde, du könntest 
HSz8 292

Handschriften und Typoskript

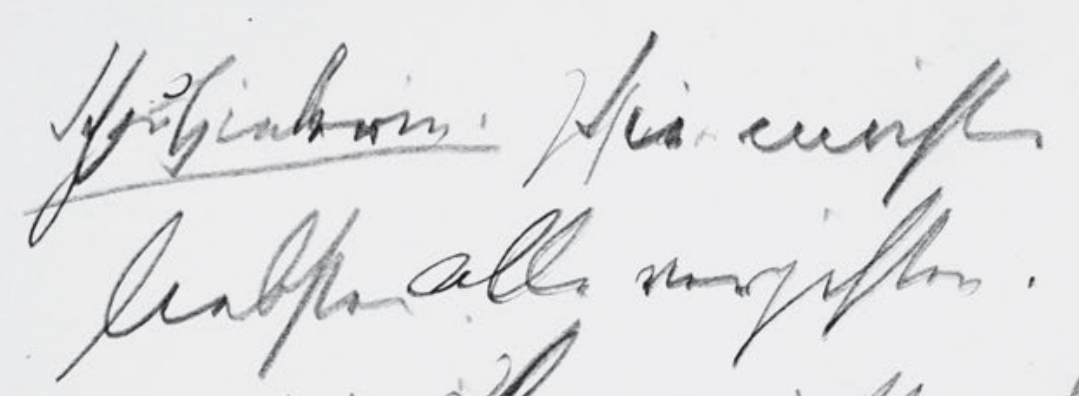

292

unfaes

Cilar lu

ners

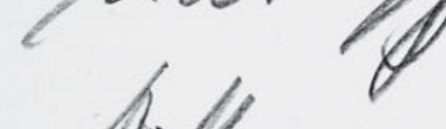

direfor.

rif inta

ay wir.

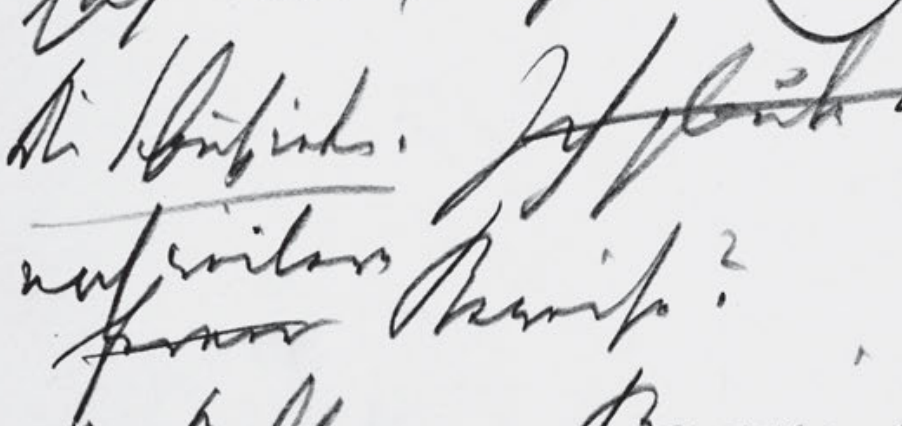

laf si wirfir

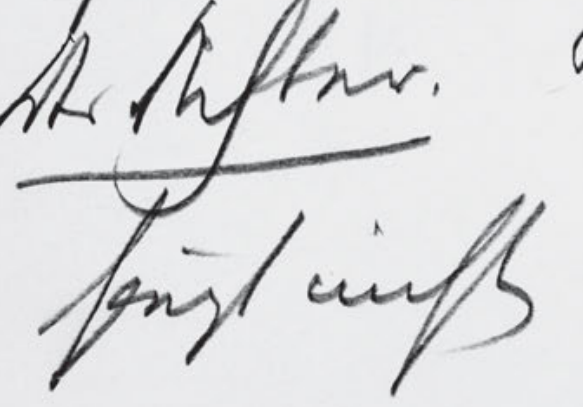

wonthen.

636

Handschiften und Typoskript 
Schauspielerin. ${ }^{\text {teh mo }}$ Sie möchten mich am

liebsten alle vergiften. Aber das

wird ${ }^{\mathrm{It}}$ ihnen nicht geling ${ }^{\mathrm{ent}} \mathrm{en} . .$.

$5 \quad$ Dichter. Denke jetzt nicht an die andren

Menschen .... Was wir erleben, Freue dich,

dich lieber, dass wir hier sind und

sag mir, dass du mich gernlieb hast.

Die Schauspieler. Ich glaube w Verlangst $\mathrm{d} u$

noch weitere

fernere Beweise?

Der Dichter. Bewiesen kan̄ das über

haupt nicht werden?. 


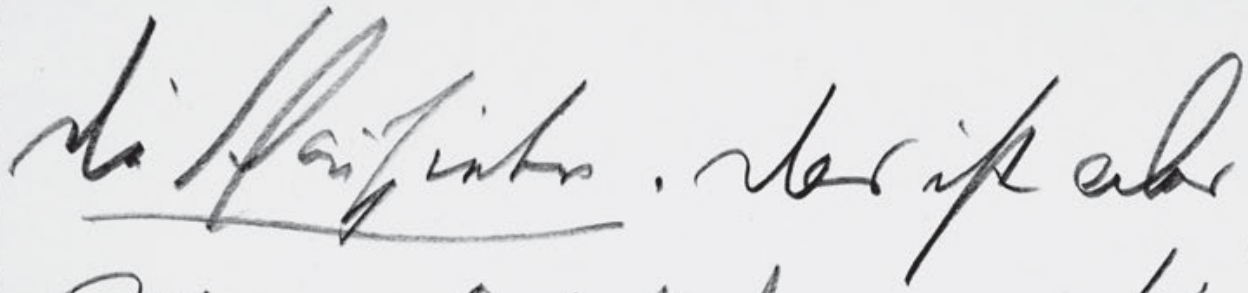

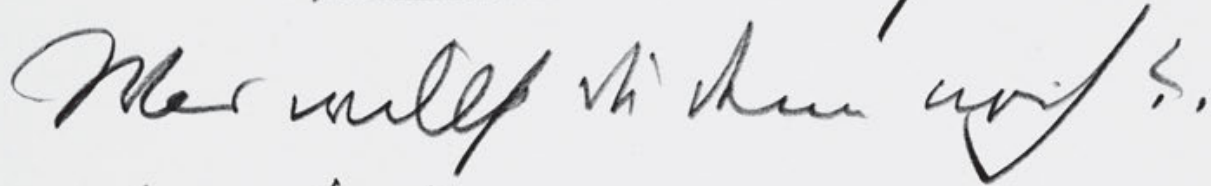

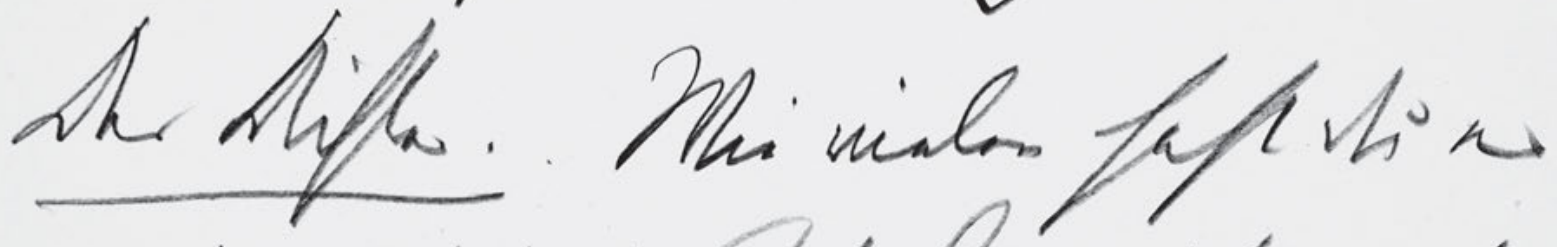
tofu aif shy hit himife mote taficialt ganet.

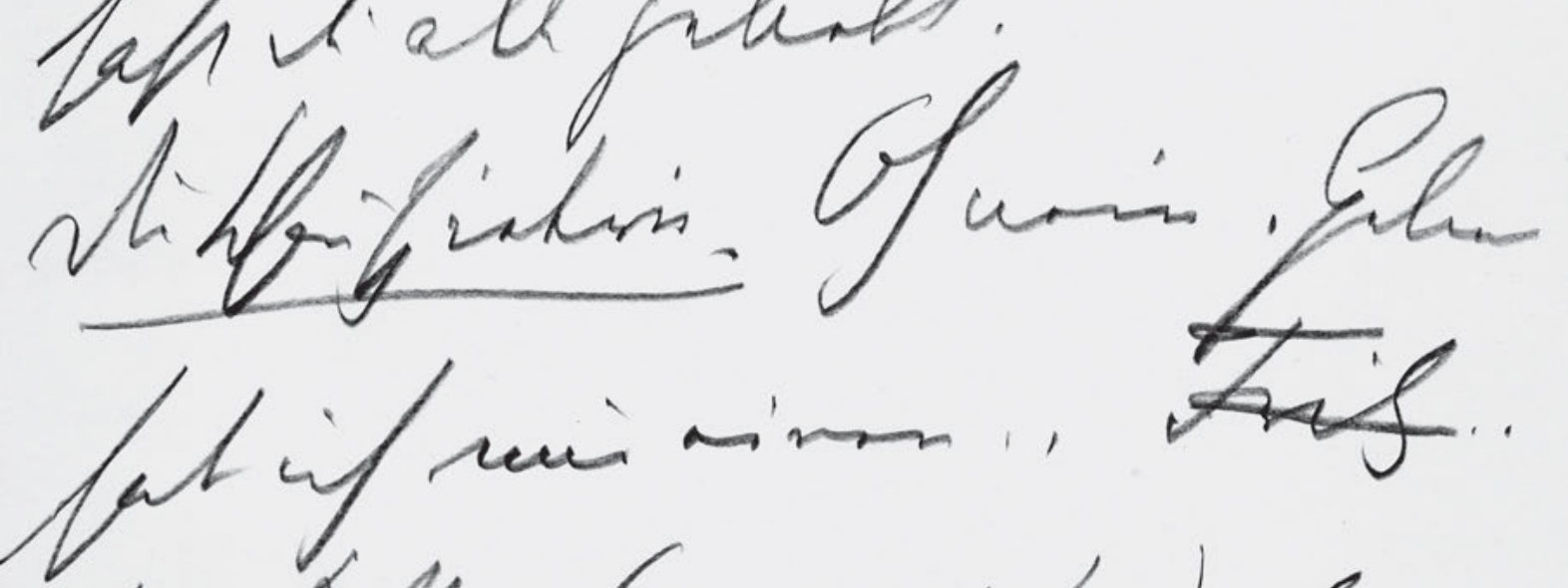
An thifh. (umonat in.) beri.. Silfeginl. Trib. 


\section{3}

Die Schauspieler . Das ist aber großartig!

Was willst du denn noch? .

Der Dichter .. Wie vielen hast du es

5 schon auf diese Art beweisen wolle....

hast du alle geliebt.

Die Schauspielerin. Oh nein . Gelieb

hab ich nur einen .. Fritz . .

Der Dichter . (umarmt sie.) Mein . .

${ }_{10} \quad$ Die Schauspiele. ... Fritz . . 
HSz8 294

Handschriften und Typoskript

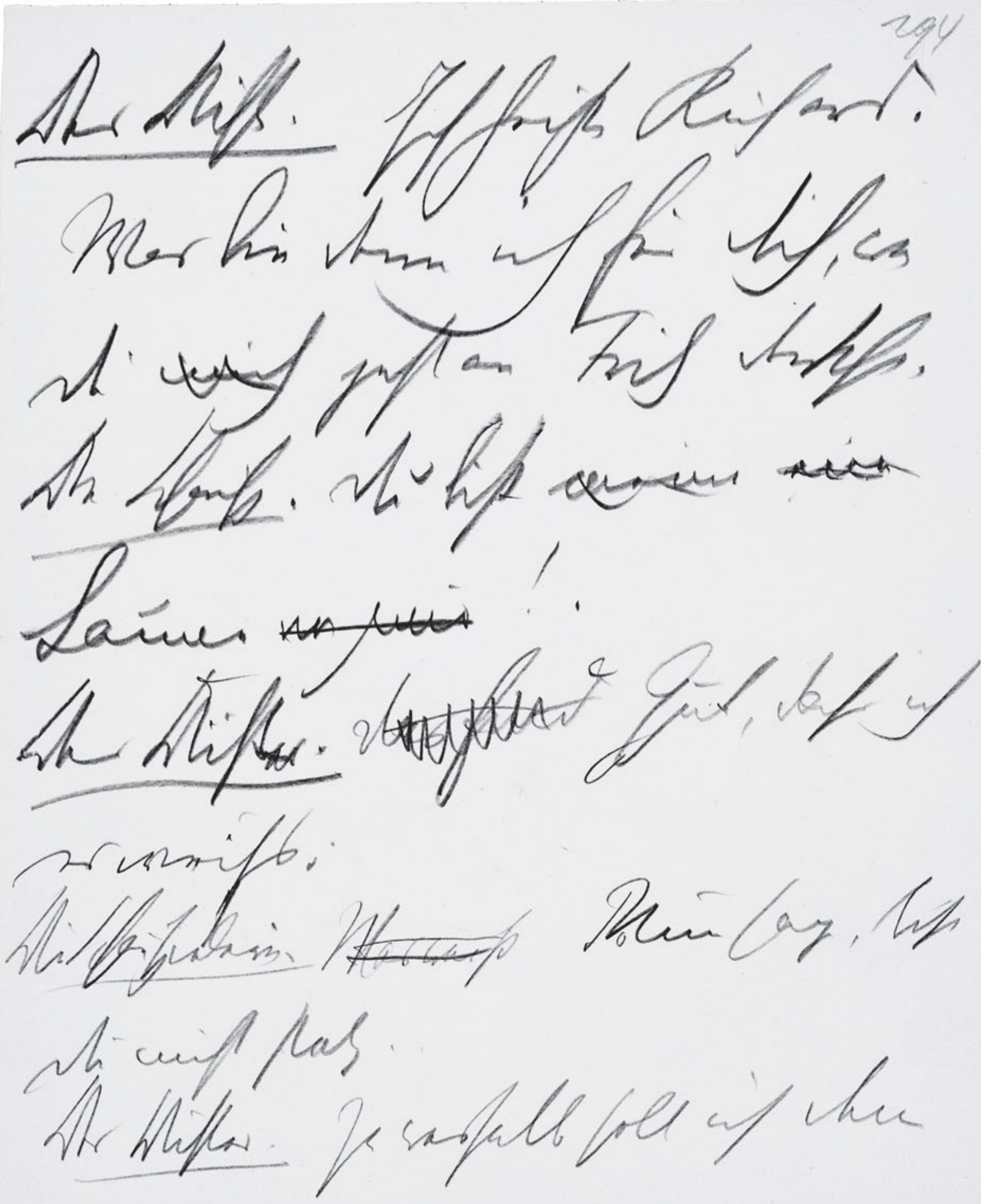


Der Dichte. Ich heiße Richard.

Was bin denn ich für dich, wen

du mich jetzt an Fritz denkst.

$5 \quad$ Die Schausp. Du bist meine eine

Laune von mir! .

Der Dichter. Das find Gut, dass ich

es weiss . .

Die Schauspielerin. Was weiß ${ }^{\text {se}} \mathrm{Nun}$ sag, bist

du nicht stolz . .

Der Dichter. Ja weshalb soll ich denn 
HSz8 295

Handschriften und Typoskript

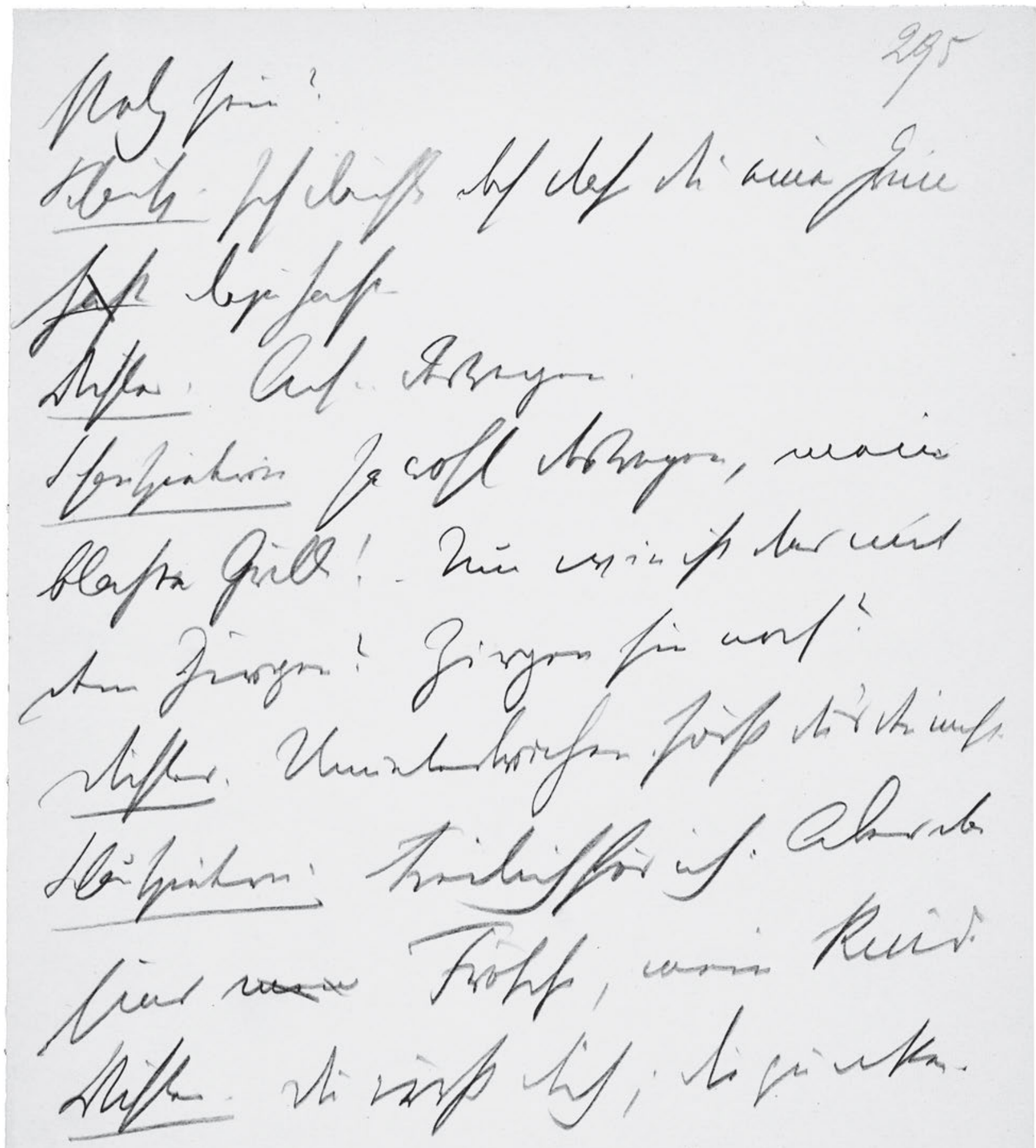

642 


\section{5}

stolz sein?

Schausp. Ich dächte doch dass du einen Grund

hast dazu hast -

5 Dichter. Ach .. deswegen.

Schauspielerin Ja wohl deswegen, meine

blaße Grille! . Nun wie ist das mit

dem Zirpen? Zirpen sie noch?

Dichter. Ununterbrochen. Hörst du's den nicht.

10 Schauspielerin. Freilich hör ich. Aber das

sind mein Frösche, mein Kind.

Dichter. Du irrst dich; die quacken. 
HSz8 296

Handschriften und Typoskript

Jorifuntor

stefor.

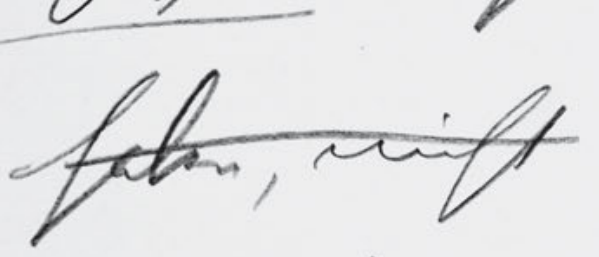

chifig w

wifl fir, wallew.

syofiunifh, wer migen we pakming. Sil mu min kyt
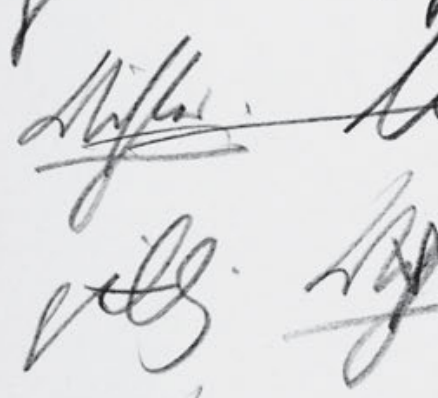

isph
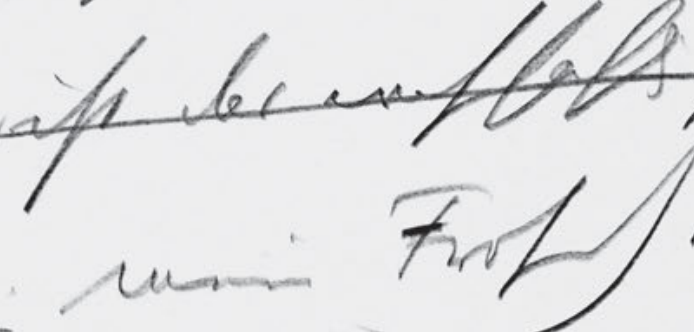

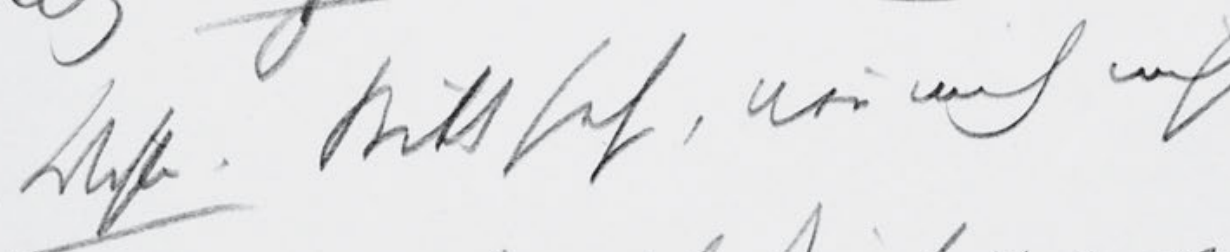

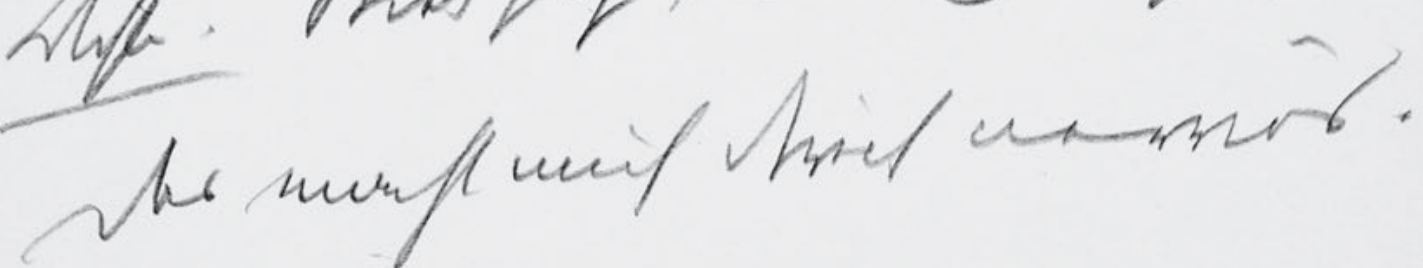

f

him, usin

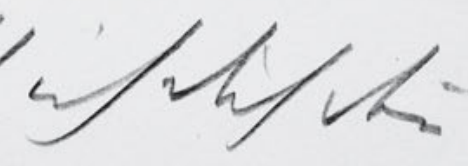

644 
Schauspielerin. Gewiss quacken sie. 296

Dichter. Aber nicht hier, mein Kind.

Hier wird gezirpt.

Schauspiele. . Also du möchst deine Willen

haben, nicht Du bist wohl das

${ }_{5} \quad$ eigensinnigste, was mir je un

gekomen ${ }^{\circledR}$ ist. Gib mir einen Kuss

Dichter. Mir ist das wah haftig ganz gleic

giltig. Dichter. mein Frosch.

Dichter. Bitte sehr, nē̄ mich nicht so.

10 Das macht mich direct nervös.

Schauspiele. Nun, wie soll ich dich den̄ 
HSz8 297

Handschriften und Typoskript

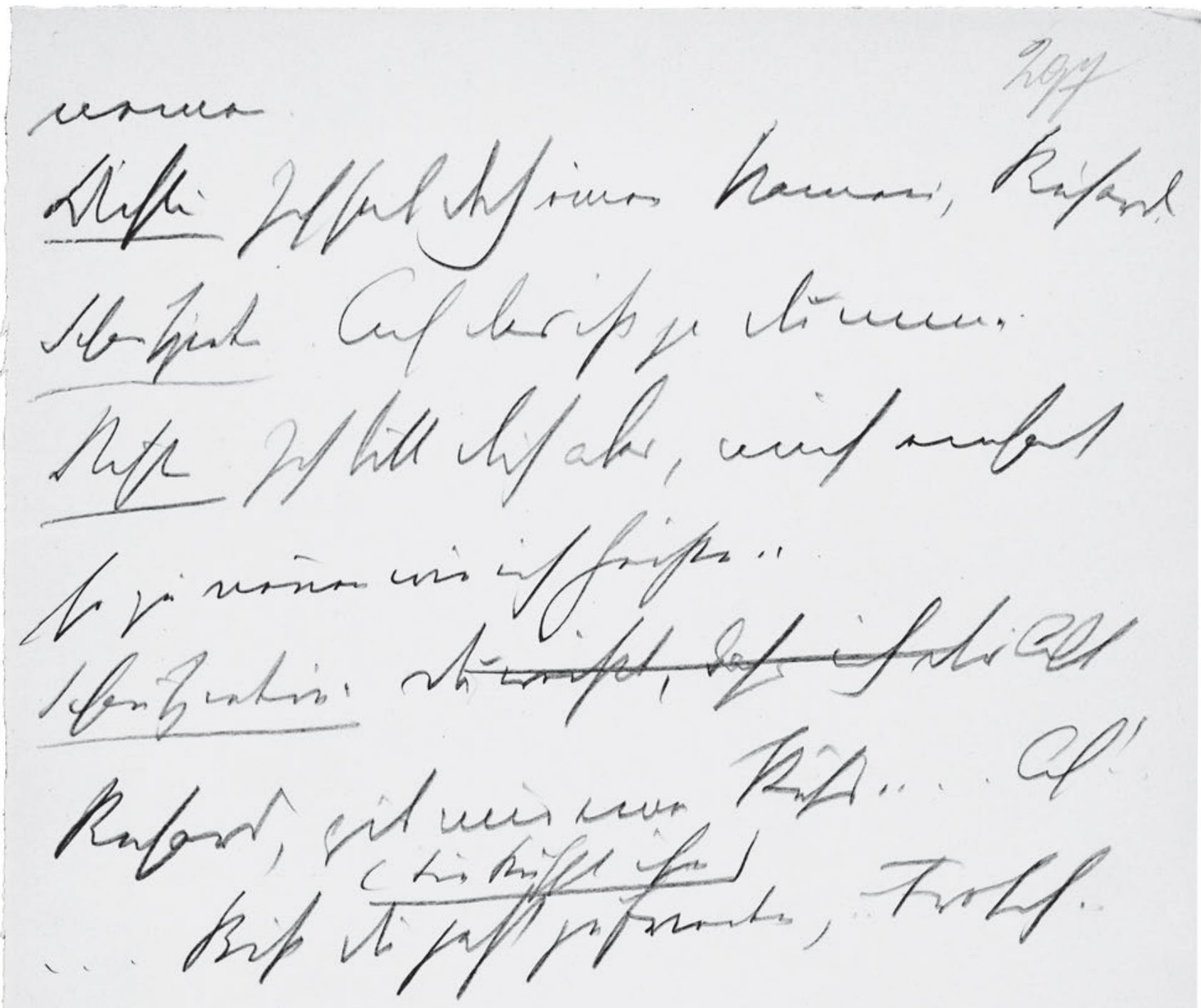

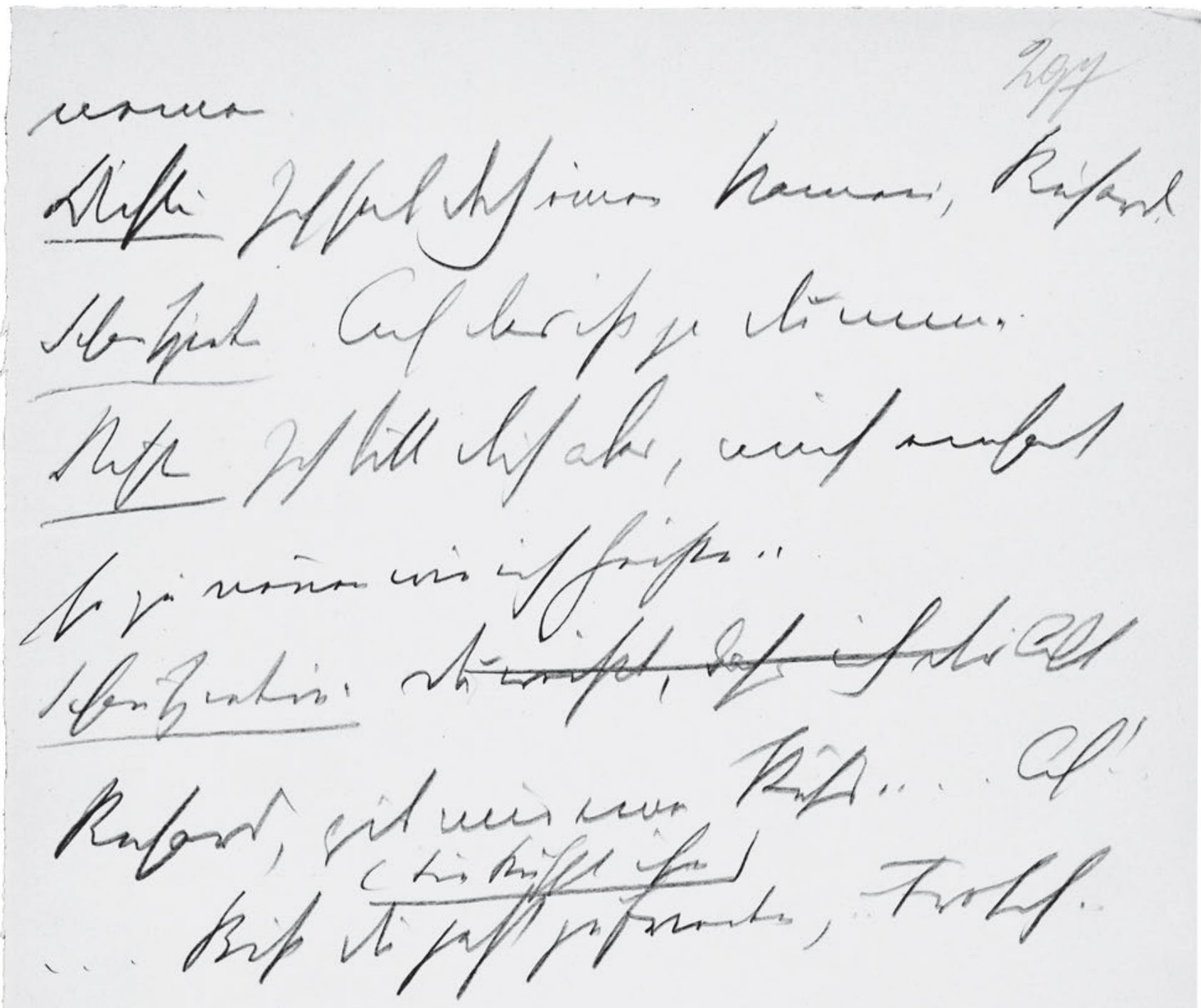

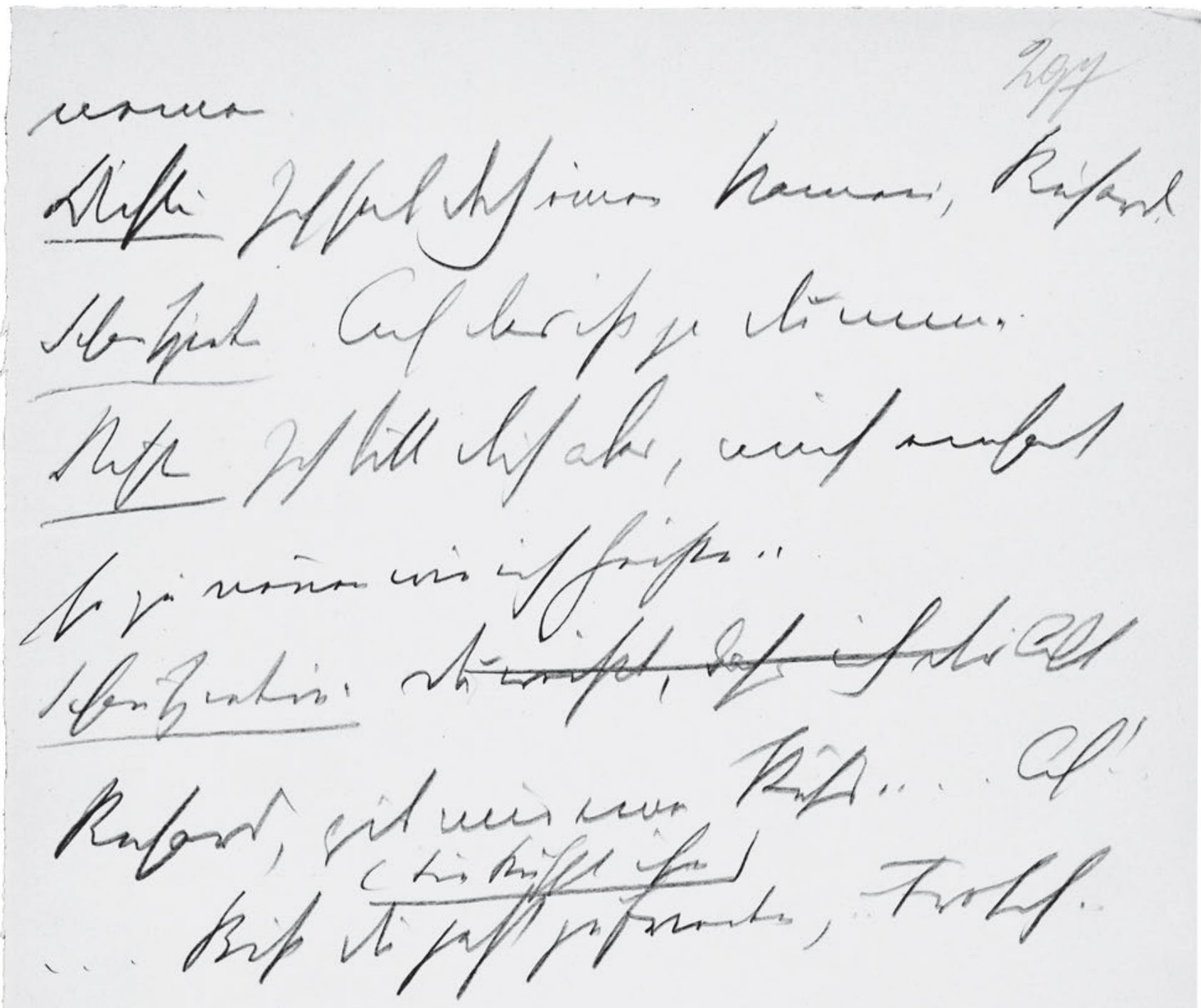

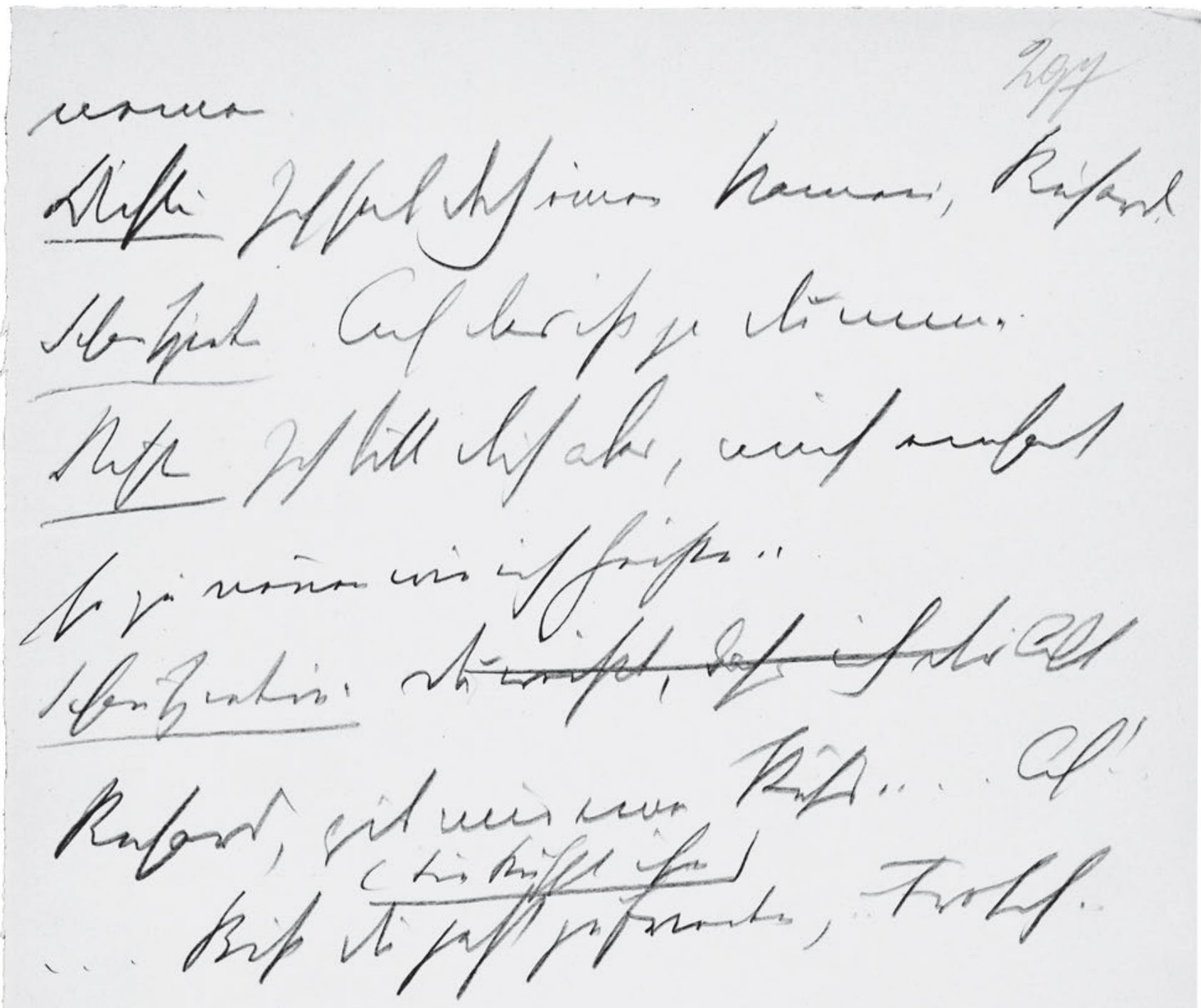

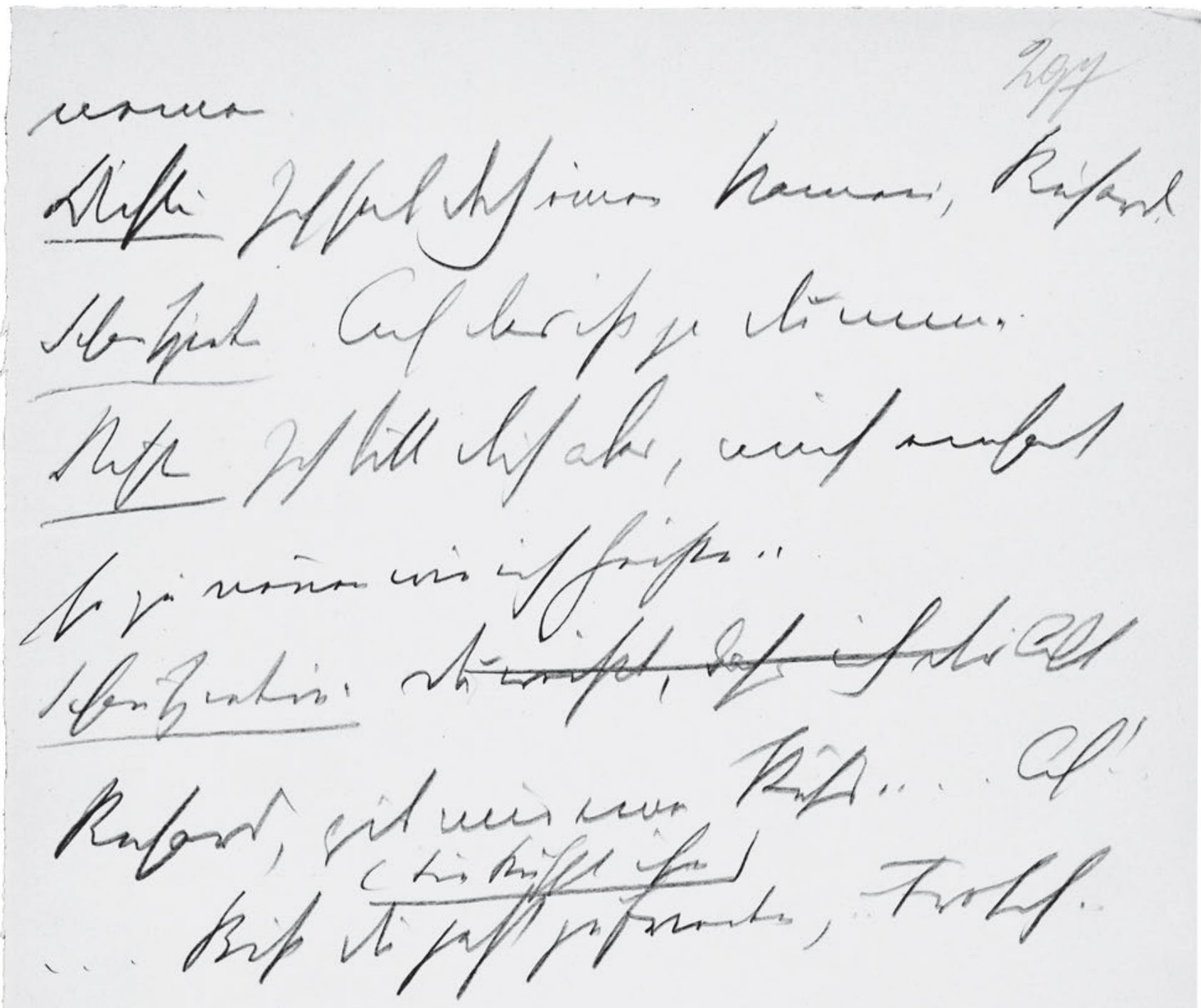

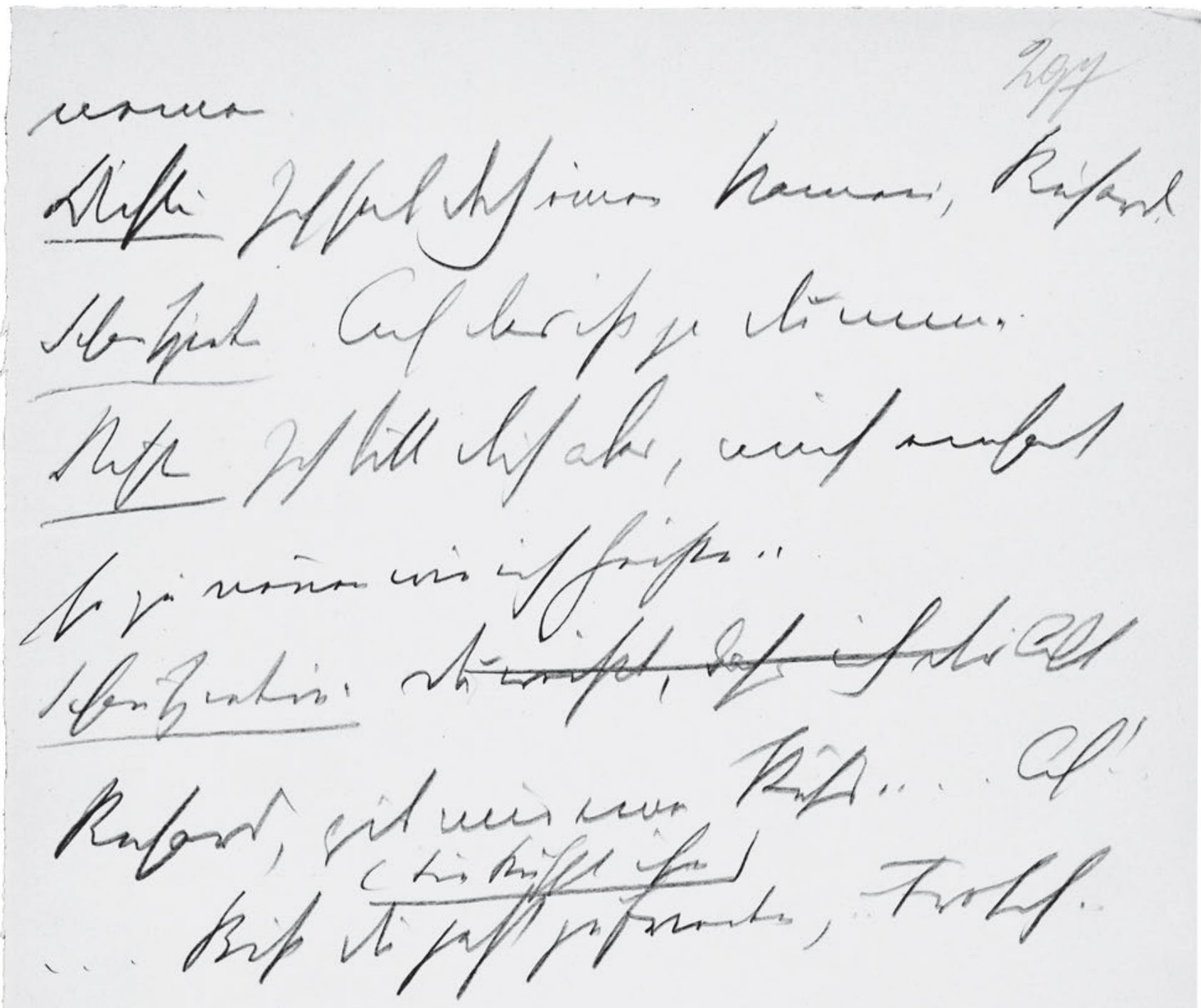

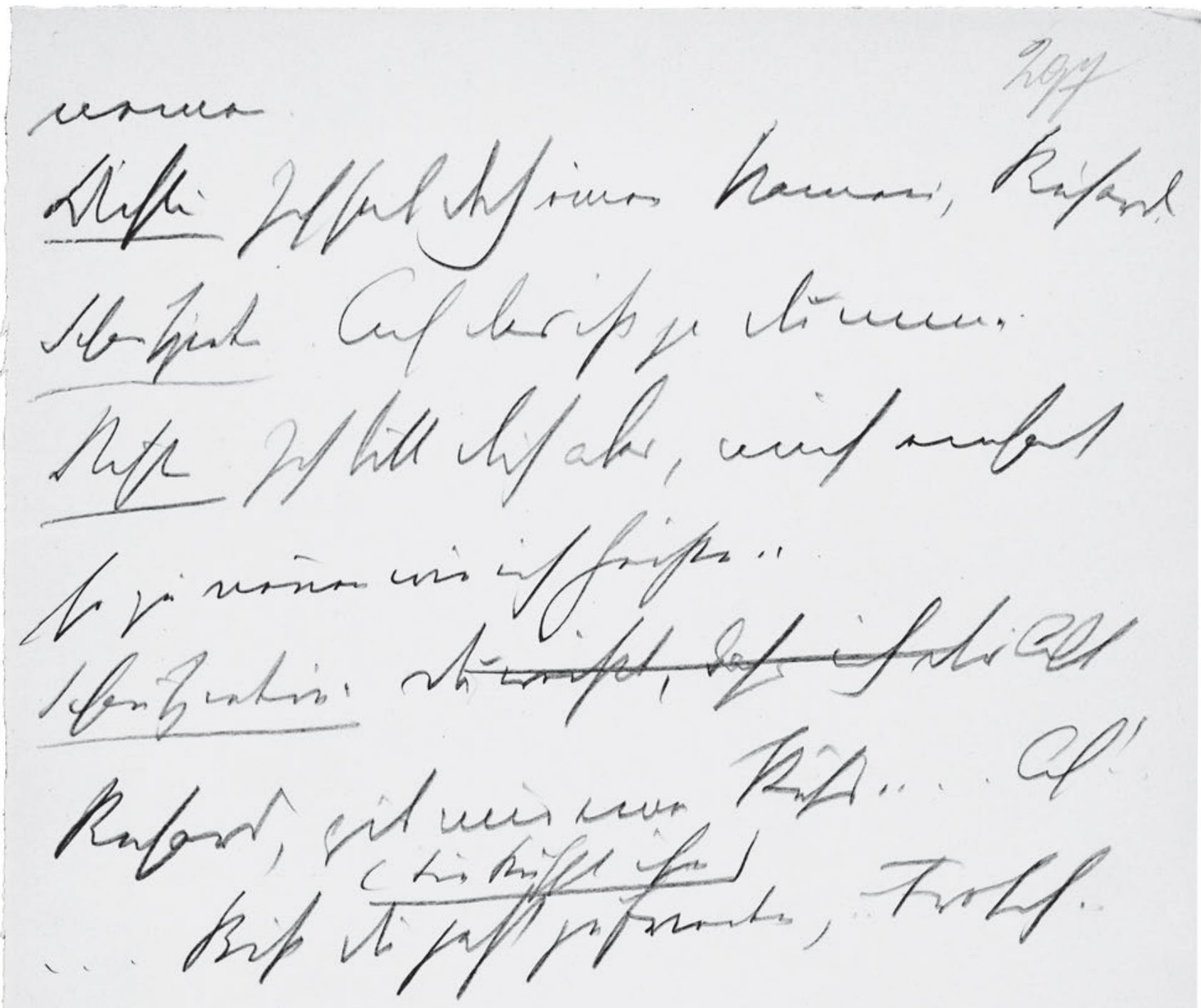

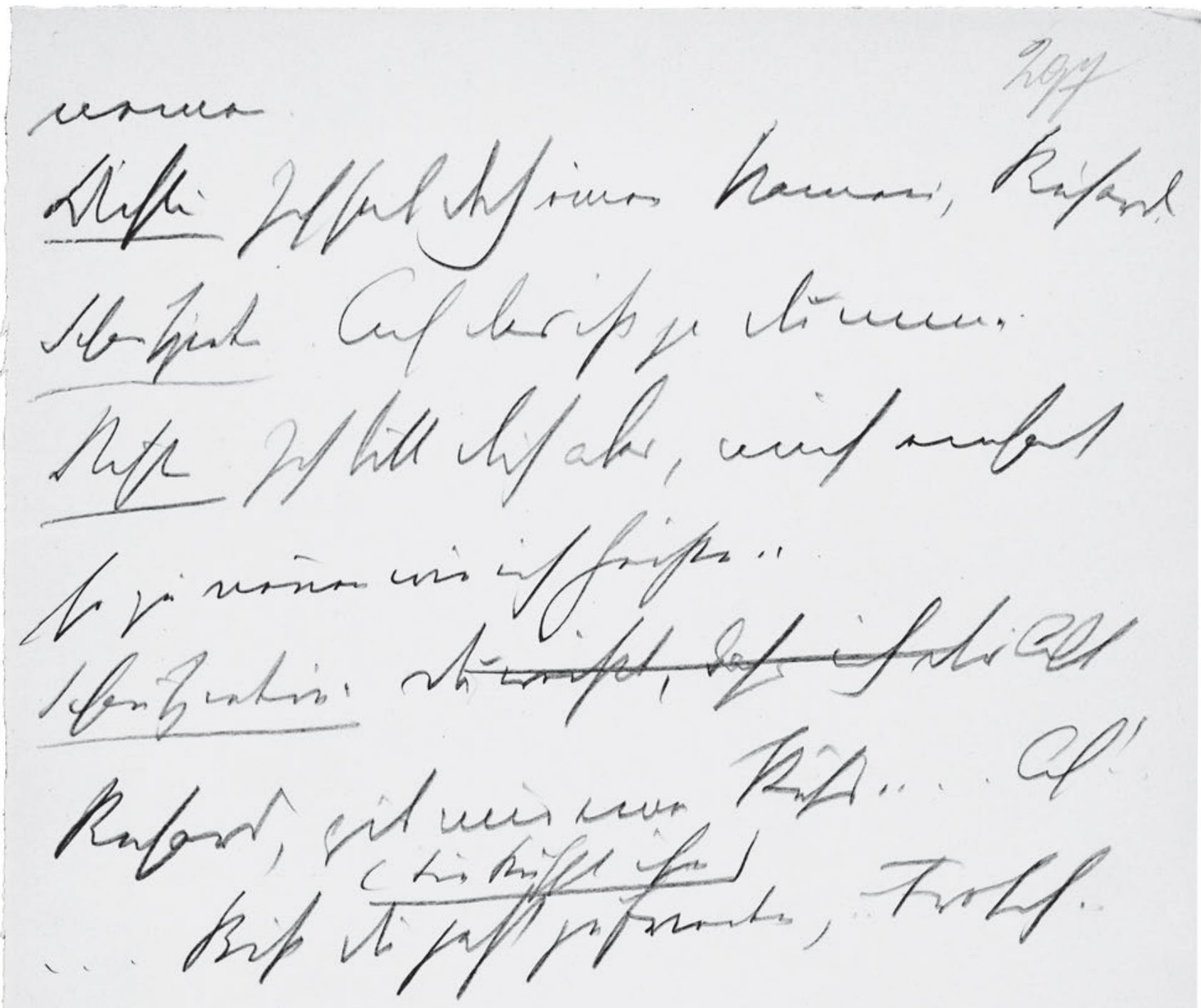

Sifte

sen

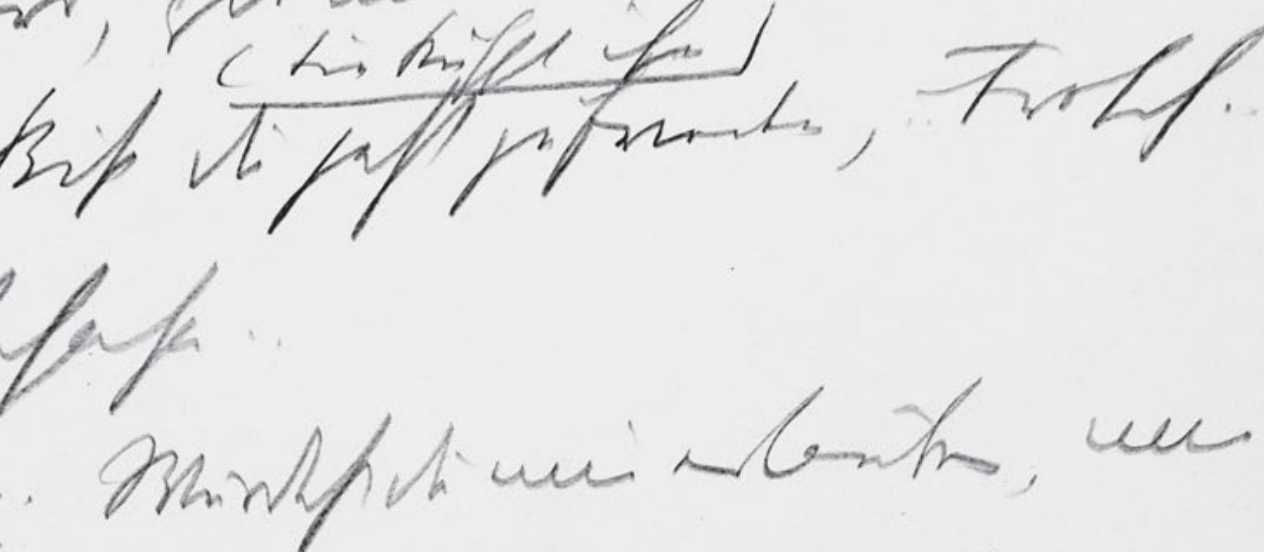

Giganth argipincter.

646 
297

nennen.

Dichter Ich hab doch einen Namen; Richard.

Schauspieler. Ach das ist ja dumm.

5 Dichter. Ich bitt dich aber, mich einfach

so zu nen̄en wie ich heiße . .

Schauspielerin. Du weißt, dass ich dir Als

Richard, gib mir einen Kuss .... Ah! .

(Sie küsst ihn)

... Bist du jetzt zufrieden, .. Frosch . .

Hahahaha . .

Dichter. Würdest du mir erlauben, mir

eine Cigarette anzuzünden? 
HSz8 298

Handschriften und Typoskript

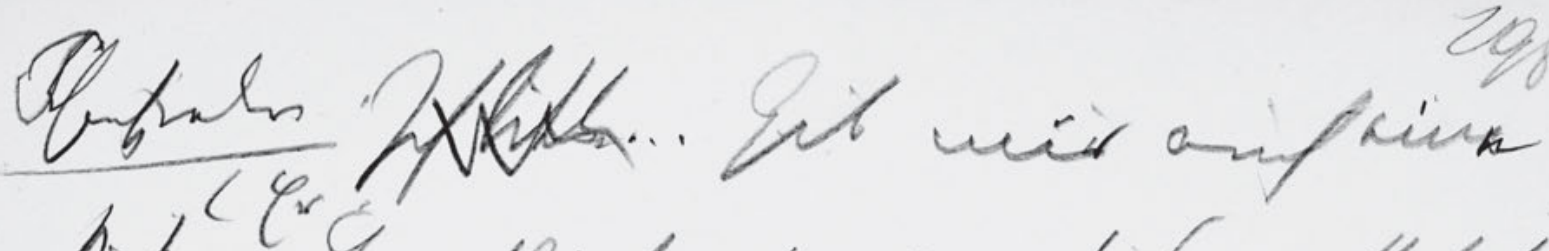

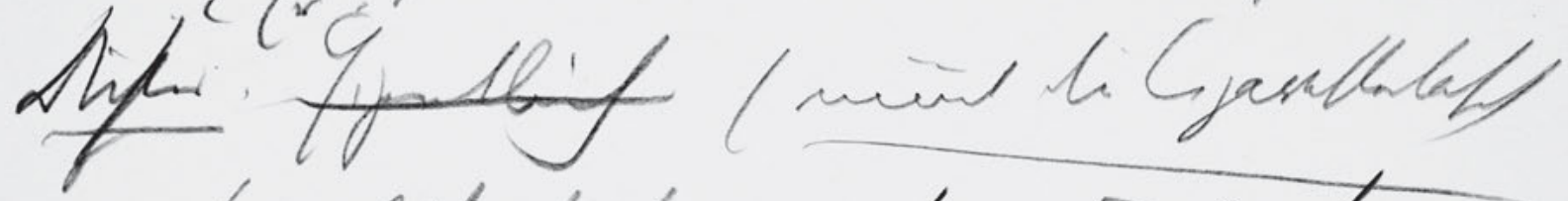

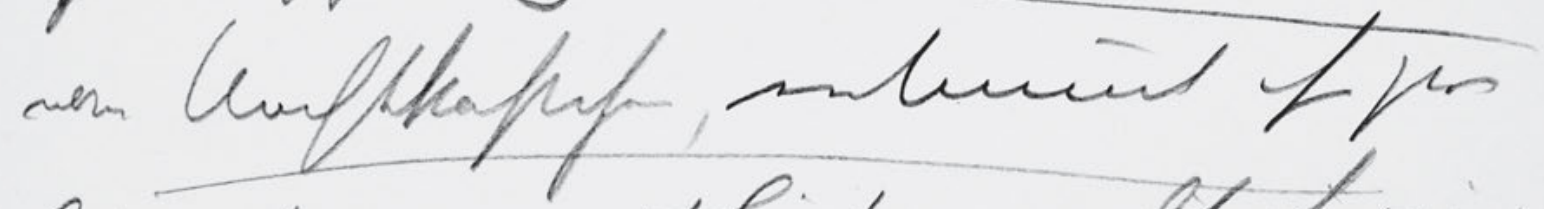

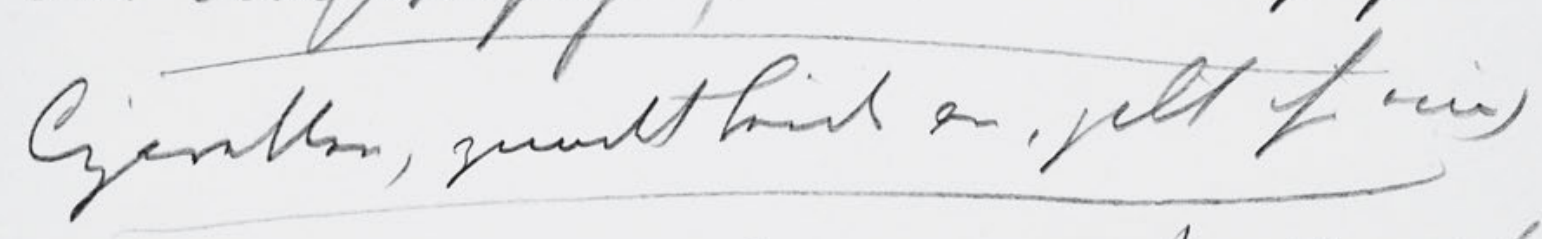
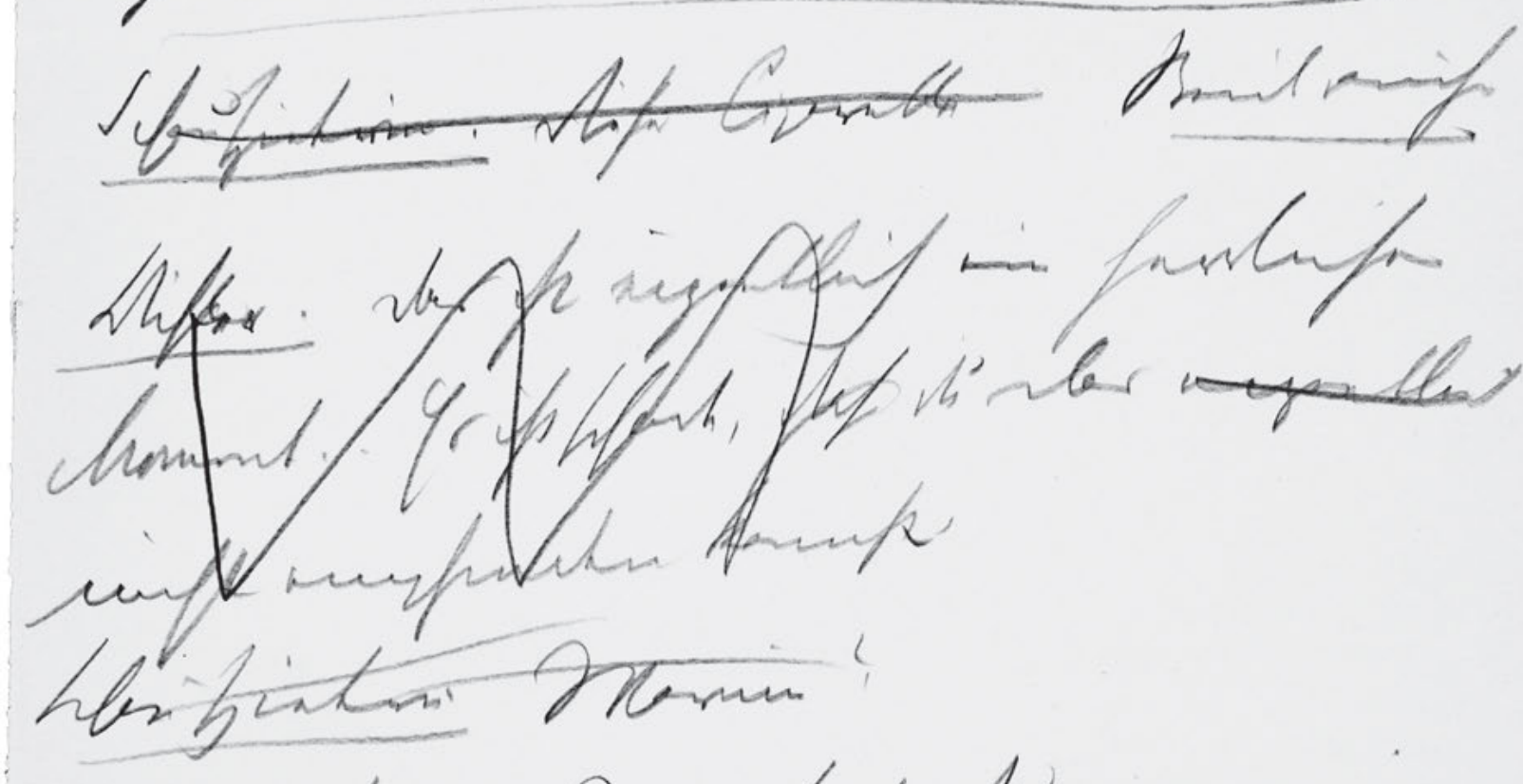

Affifintimi
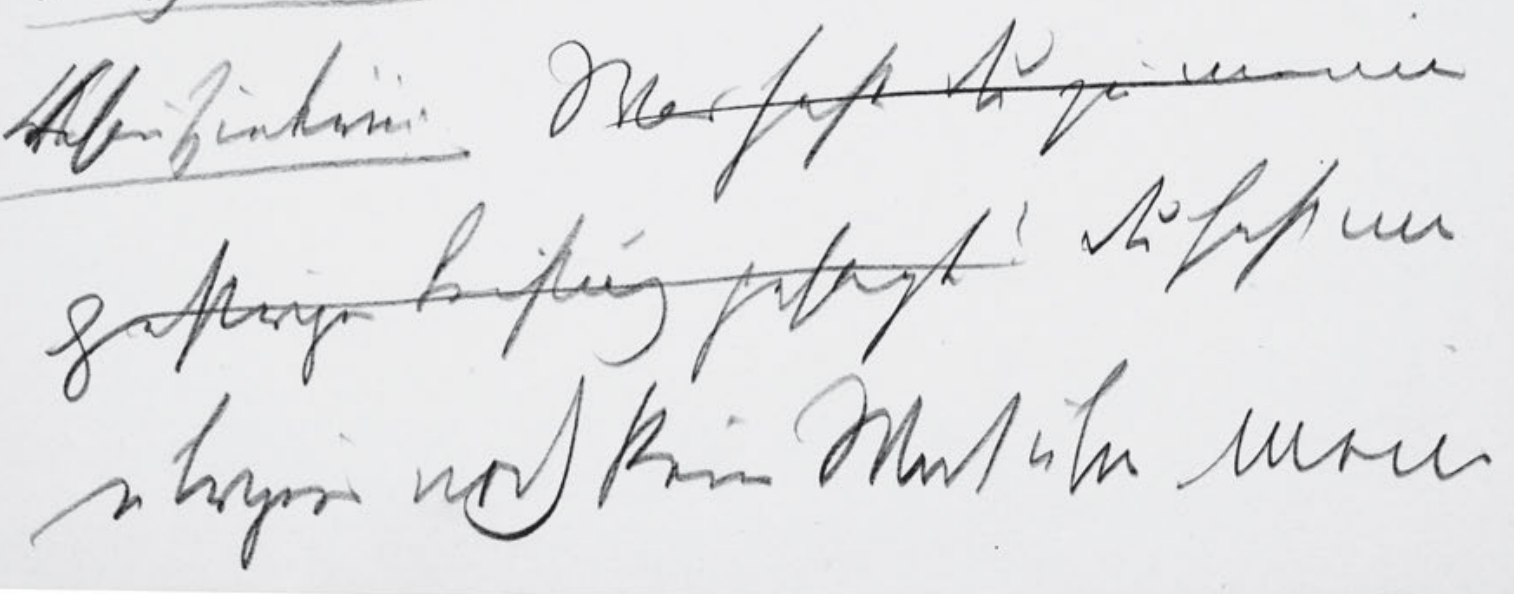

648 
298

${ }^{[?]}$ Schauspieleri .Ich bitte . . . Gib mir auch eine (Er

Dichter. Eigentlich (nī̄t die Cigarettentasch

vom Nachtkastchen, entnī̄t ihr zwe

5 Cigaretten, zundet beide an, gibt ihr eine)

Schauspielerin. Diese Cigarette Beid rauchen

Dichter. Das ist eigentlich ein herrlicher

Moment . . Es ist schade, dass du das eigentlich

nicht empfinden kannst.

$10 \quad$ Schauspielerin. Warum?

${ }^{D}$ Schauspielerin. Was hast du zu meiner

gestrigen Leistung gesagt? Du hast mir

übrigens noch kein Wort über meine 
HSz8 299

Handschriften und Typoskript

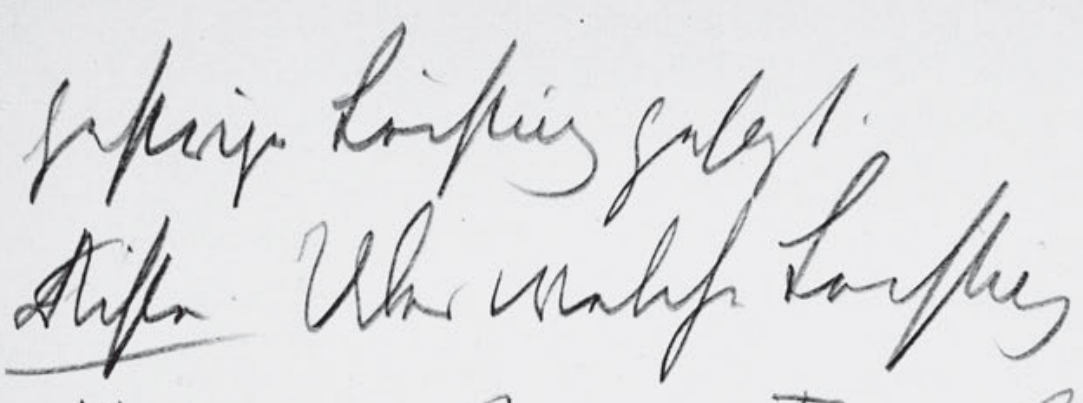

Upe

Ifoginar. hü.. Tramilen.

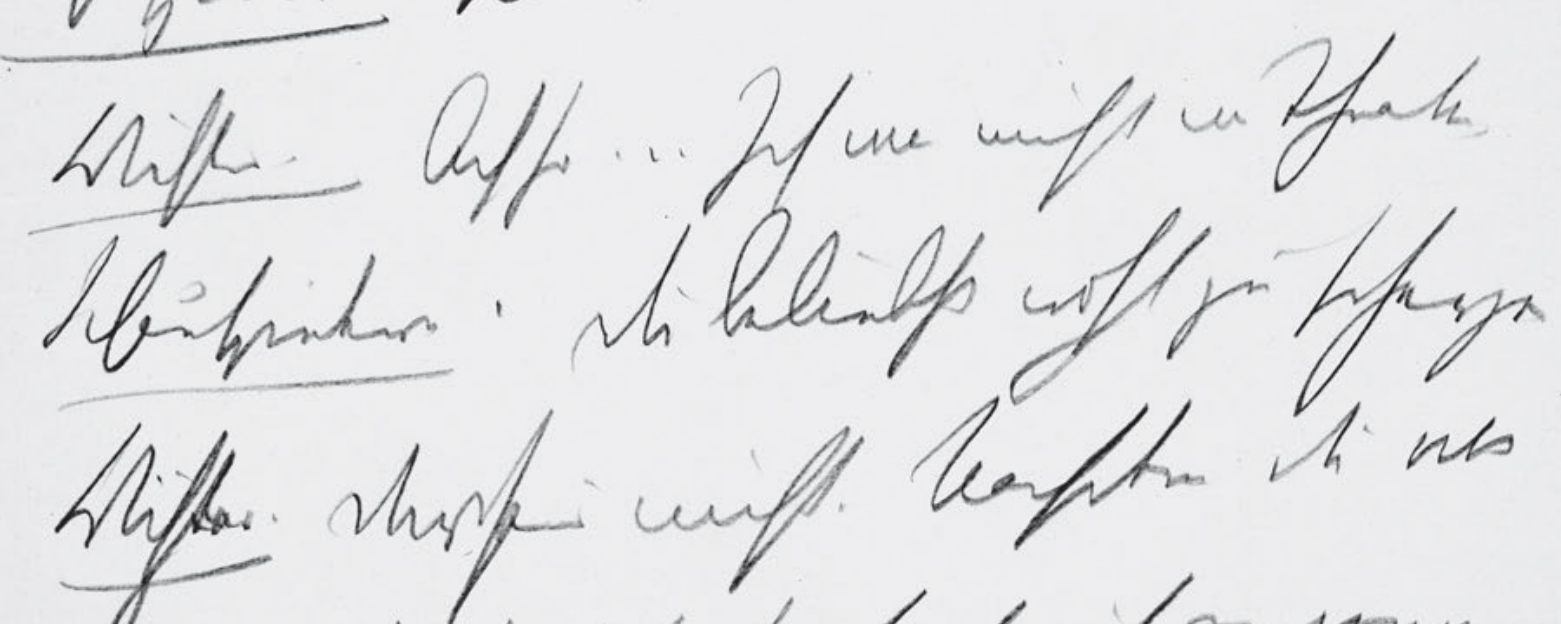

fry

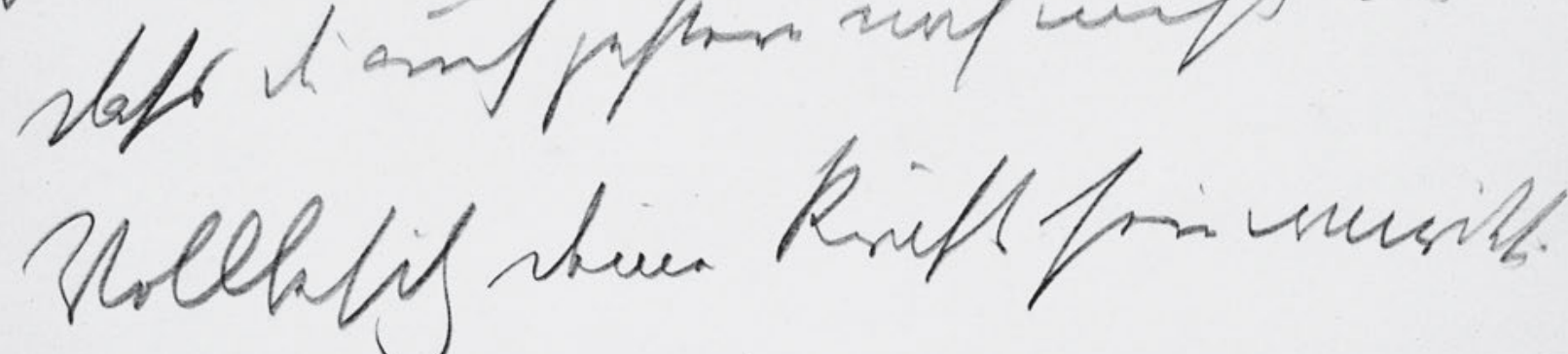

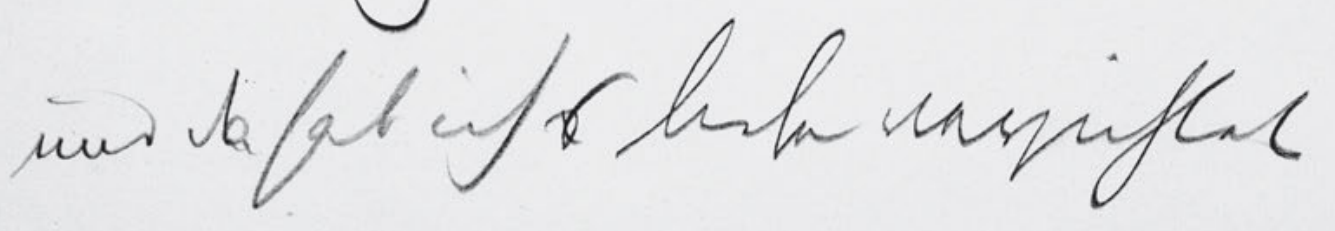

650 
gestrige Leistung gesagt.

${ }^{[?]}$ Dichter. Uber welche Leistung.

Schauspieler. Nun ... Francillon.

5 Dichter. Ach so ... Ich war nicht im Theater,

Schauspielerin . Du beliebst wohl zu scherzen

Dichter. Durchaus nicht. Nachdem du 'vor?

gestern abgesagt hast, hab ich angenomen

dass du auch gestern noch nicht im

10 Vollbesitz deine Kräfte sein würdest.

und da hab ich s lieber verzichtet. 
HSz8 300

Handschriften und Typoskript

loing 2 in.

Gase Wheth

fripint.

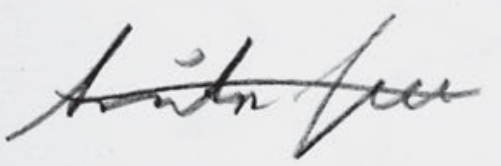

Go hiff inf

jo.

mitutame

It war fonfoxtional. L

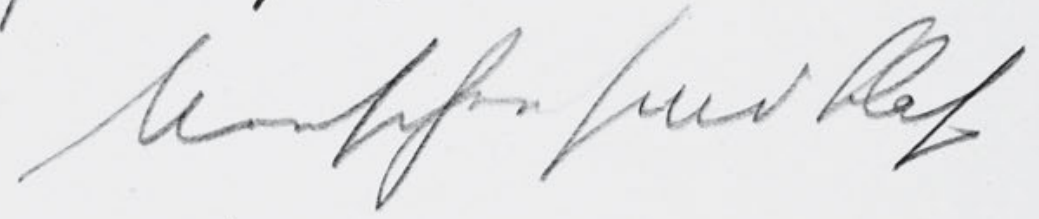

pacumst.

thifh.

leiph

sefipinterin.

Rohrt fagto, Poeter

bor hith / heme

ans in

thille.

(to

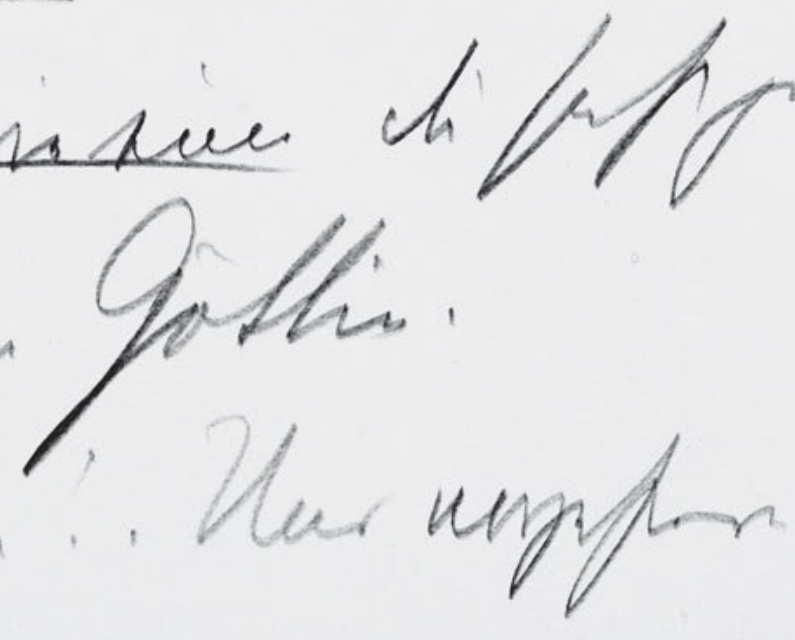




\section{0}

Schauspieler .. Du hast wohl viel versäumt

Es w Dichter. So.

Schauspieler. Es war sensantionell. Die

5 Leute sin Menschen sind blass

geworden.

Dichter. Hast du das deutlich bemerk

Schauspielerin. Robert sagte; ${ }^{\text {ich hat }}$ Kind

gespielt wie eine du hast gespielt

10 wie eine Göttin.

Dichter. Hm! . Und vorgestern noch so 
HSz8 301

Handschriften und Typoskript

hunh

30

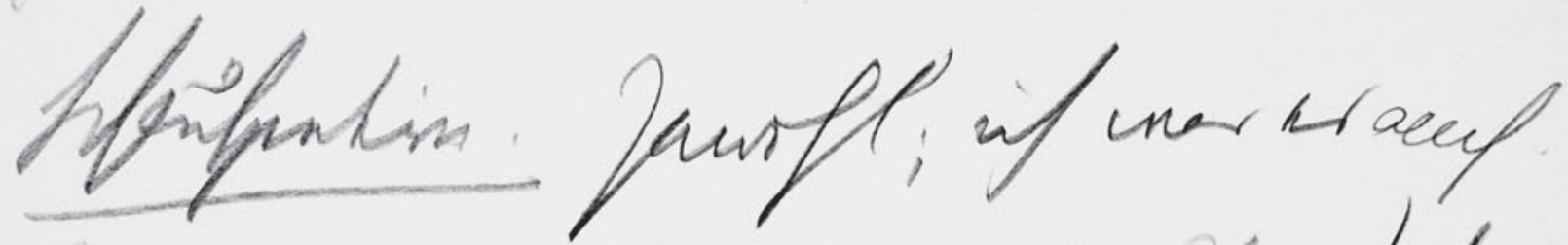

Mur infl tivanis? Morlif finfereat di

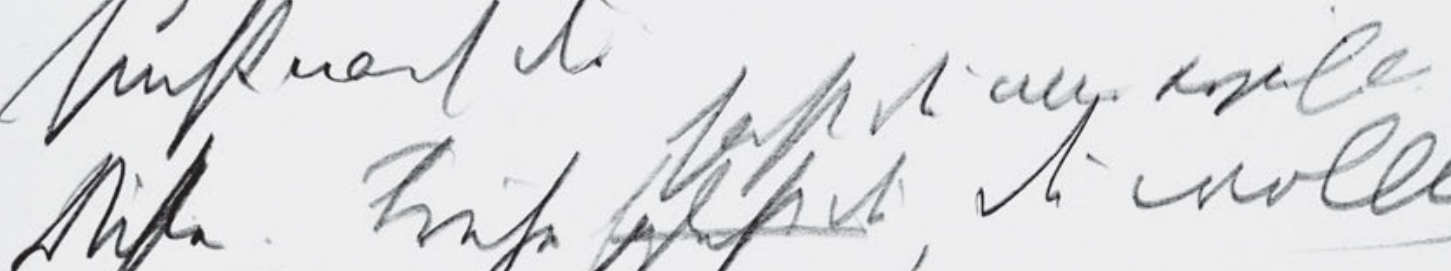

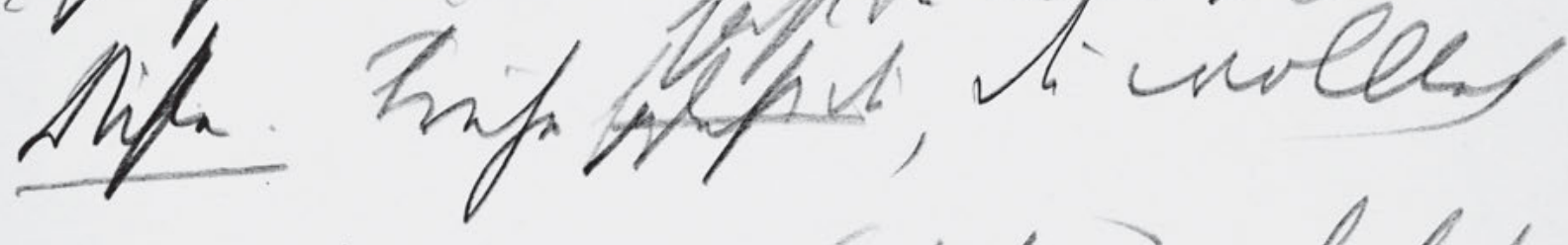

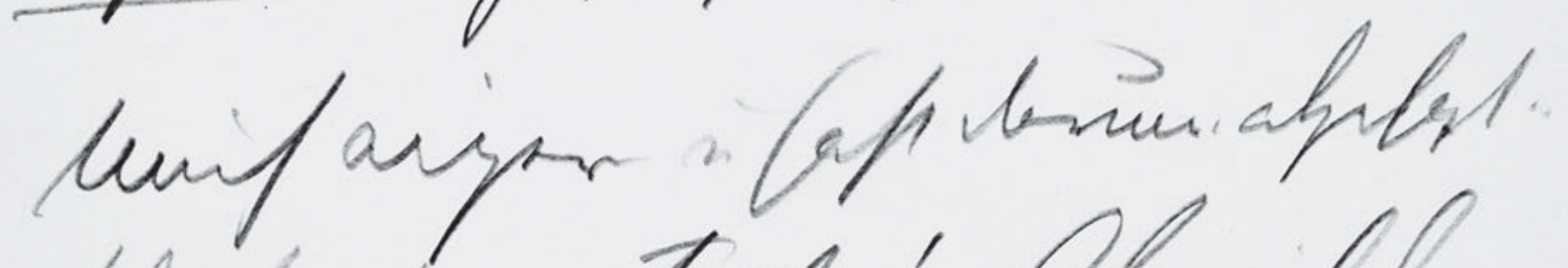
foigiatn.

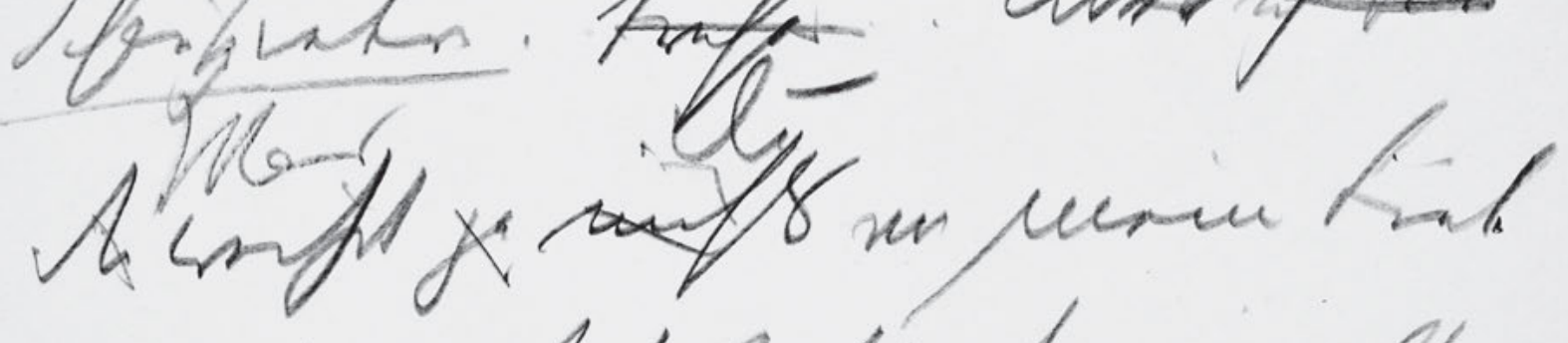

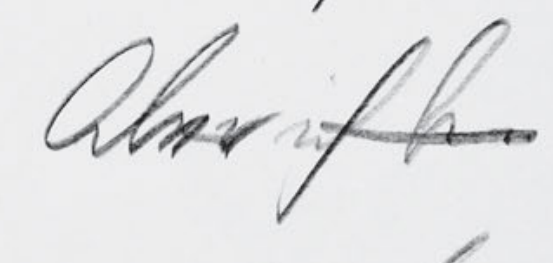

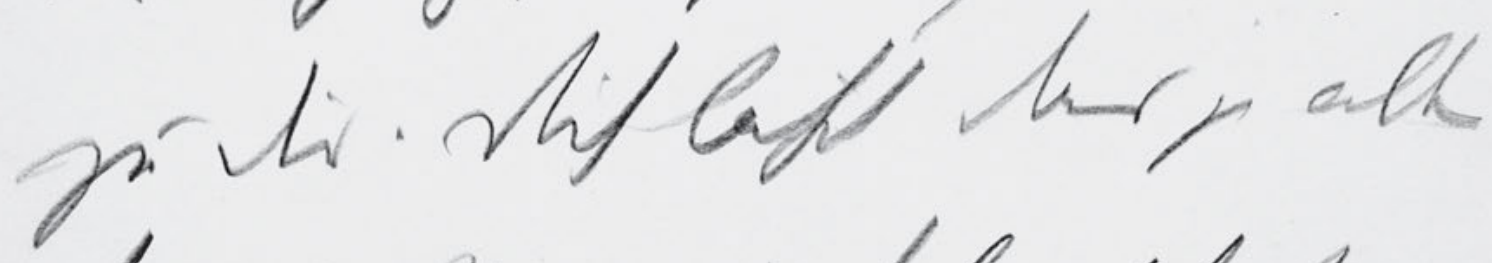
kall. Hour is his for he fuleg

654 


\section{1}

krank.

Schauspielerin. Jawohl; ich war es auch.

Und weißt du warum? . Vor Sehn-

5 sucht nach dir.

hast du mir erzähl

Dichter. Frühe sagtest du, du wolltes

mich ärgern u hast darum . abgesagt . .

Schauspieleri. 'Früher! . Aber ich bin

Was du

du weißt ja nichts von meine Liebe

zu dir. Dich läßt das ja alles

kalt. Und ich bin schon Nachtelang 
HSz8 302

Handschriften und Typoskript

$2 \mathrm{~s}$

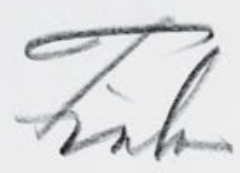

302

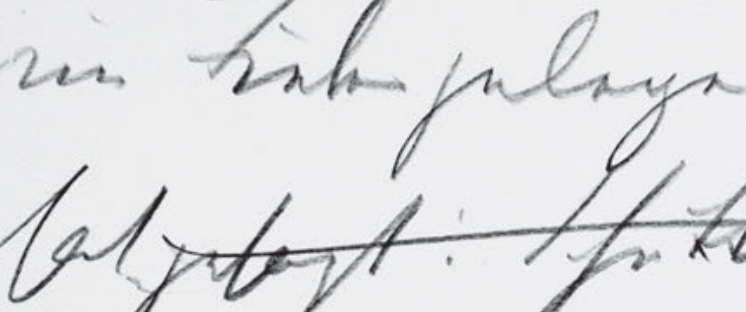

dy

he twi

Lon warnfli her.

nor link in li, we him me Lain -?!

Afs Naw tify...

Sabirisin.

Artmo

uift un hifon Sharsholls!

656 
302

im Fieber gelegen vor Liebe. Der Doctor

hat gesagt: Schüttelfrost . oder Lungen

entzündung. Jawohl... . 40 Grad!

5 Dichter. Für eine „Laune“ ist das ziemlich

hoch.

Schauspieler · Ja .. Laune! . . Ich vergotter

Laune nennst du das? . . Ich sterbe

vor Liebe zu dir, und du nennst es

$10 \quad$ Laune. - ? ! -

Dichter. Und Fritz ...

Schauspielerin. Frit $z$ ? . . Rede mir

nicht von diesem Galeerensträfling . . ! - 
H'Sz9 [1]

Handschriften und Typoskript

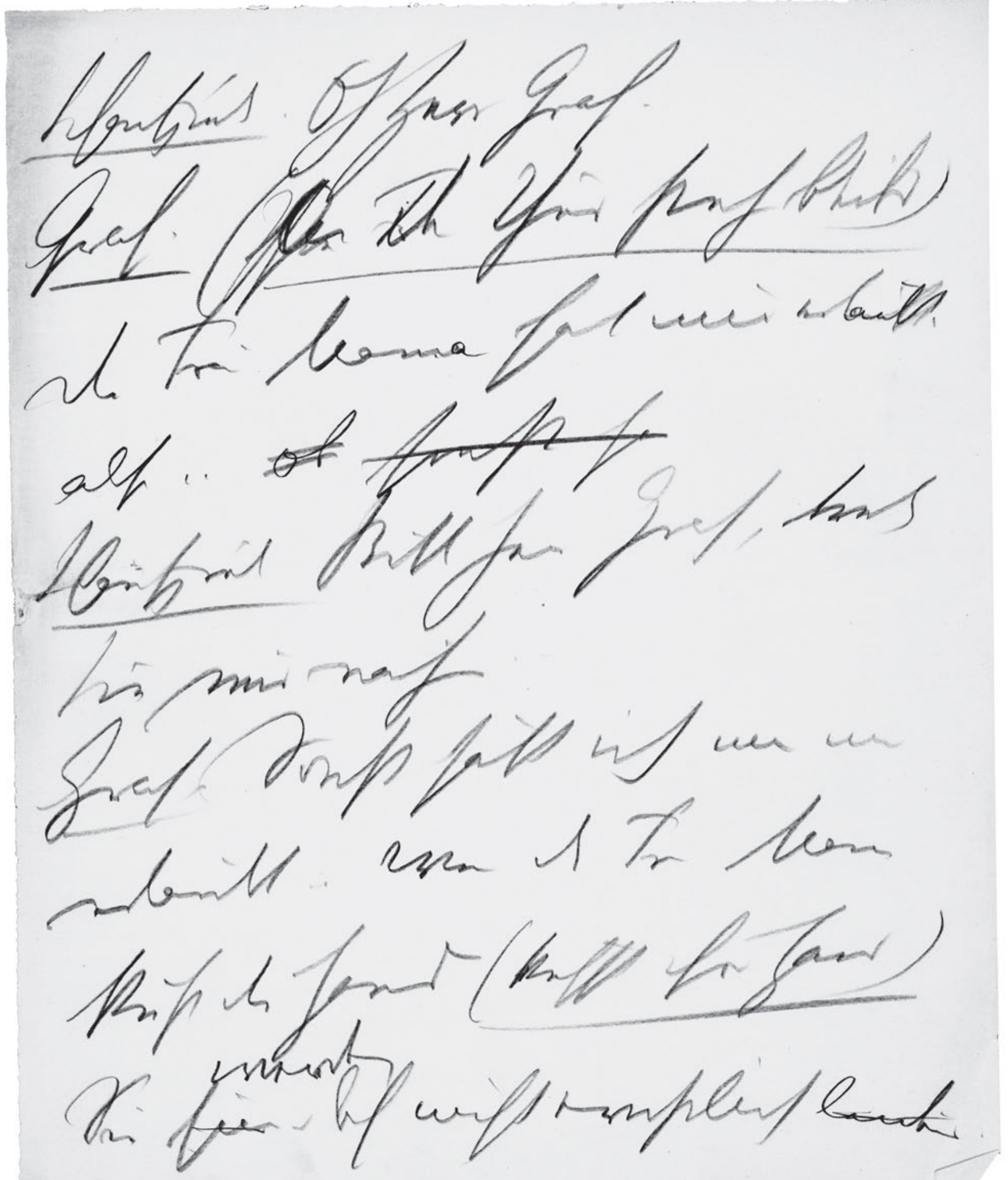

658 
Schauspiel . Oh Herr Graf.

Graf. ( ${ }^{\text {hre fr }}$ An der Thür stehen bleibend)

Die Frau Mama hat mir erlaubt, also .. ob sonst ha

$5 \quad$ Schauspiel Bitt Her Graf, treten

Sie nur näher.

Graf. Sonst hätt ich mir nie

erlaubt .. wen d Fr Mama

küß die Hand (küsst ihre Hand)

werden

10 Sie sind ?doch? nicht ernstlich leidend. 


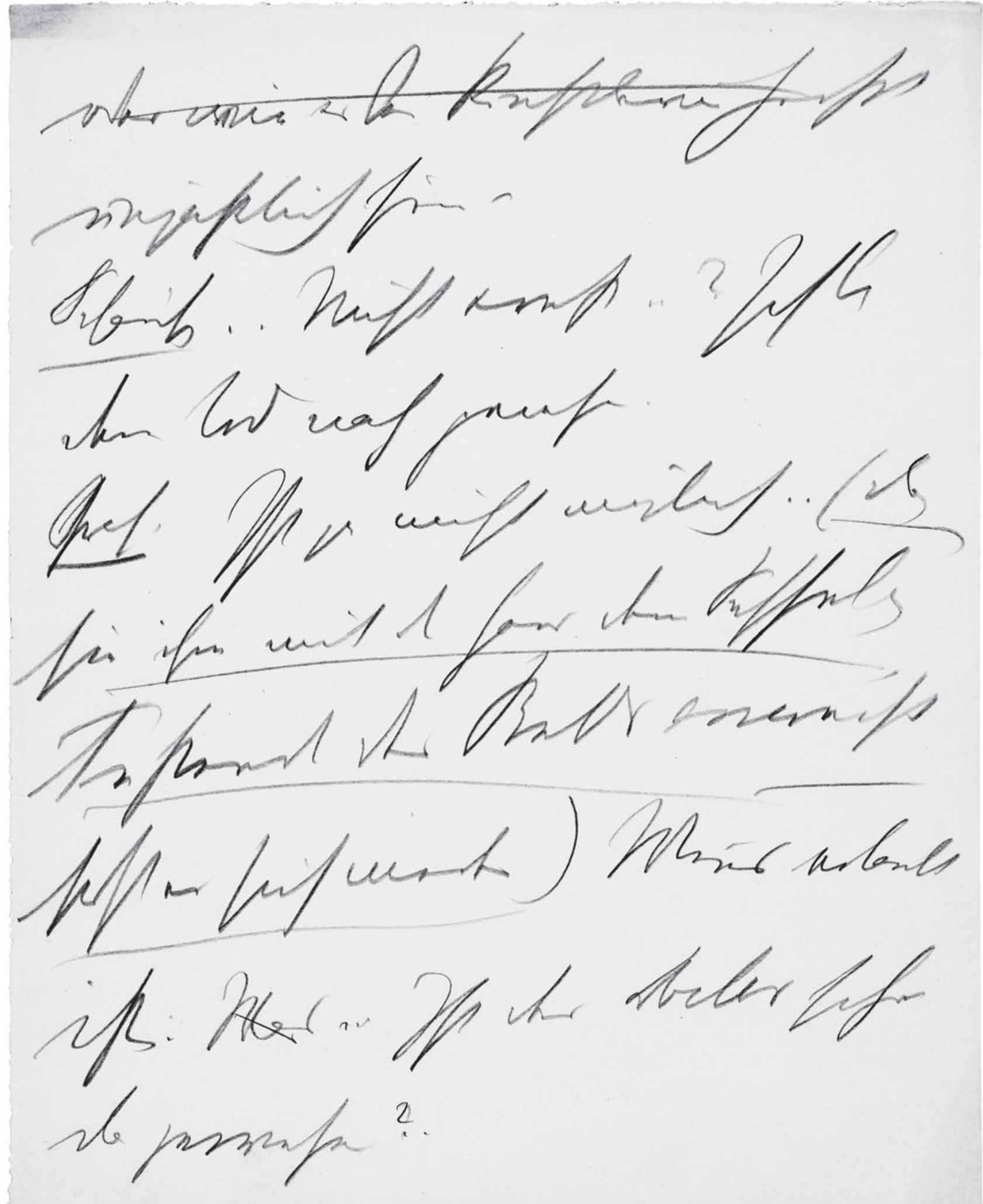


oder wie es bei Künstlerin heißt

unpäßlich sein -

Schausp .. Nicht ernst . . ? Ich bin

dem Tod nah gwesen.

$5 \quad$ Graf. Ist ja nicht möglich . . (da

sie ihm mit der Hand dem Sessel ?am?

Fußende des Betts anweist

setzt er sich nieder) Weñs erlaubt

ist: Was ... Ist der Doctor schon

$10 \quad$ da gewesen!? 
H'Sz9 [3]

Handschriften und Typoskript

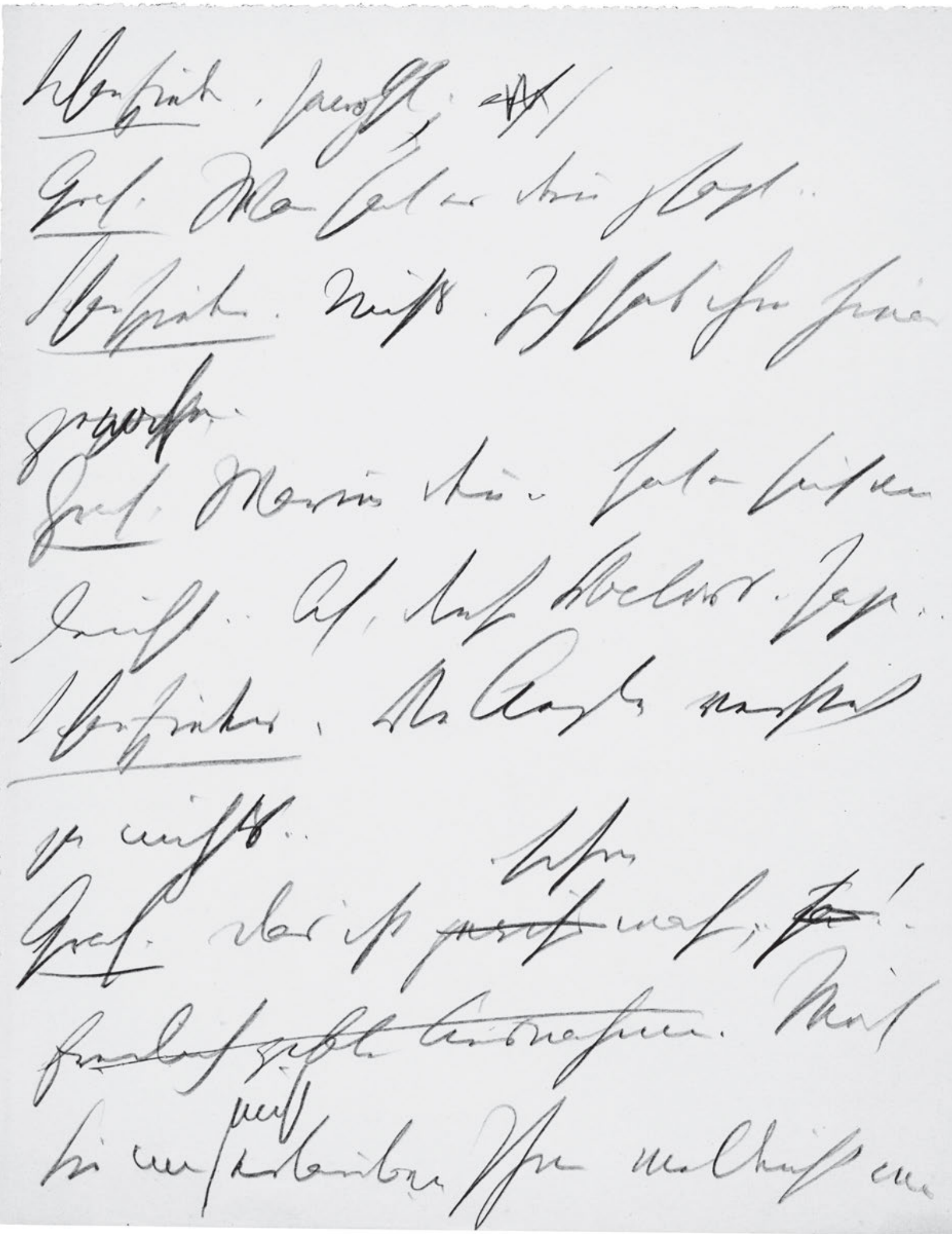

662 
Schauspieler. Jawohl', ?ich" ?h?

Graf. Was hat er deñ gsagt . .

Schauspieler. Nichts. Ich hab ihn hinaus

ge ${ }^{\text {jagt }}$ worfen.

${ }_{5} \quad$ Graf. Warum deñ . . hat er sich vie

leicht . . Ah, diese Doctors . Jaja ...

Schauspieler. Die Arzte versteh

ja nichts..

schon

Graf. Das ist gewiss wahr; . ?"ha! .

10 freilich gibts Ausnahmen. Möch

nicht

Sie mir erlauben Ihnen vielleicht 'ein? 
H'Sz9 [4]

Handschriften und Typoskript

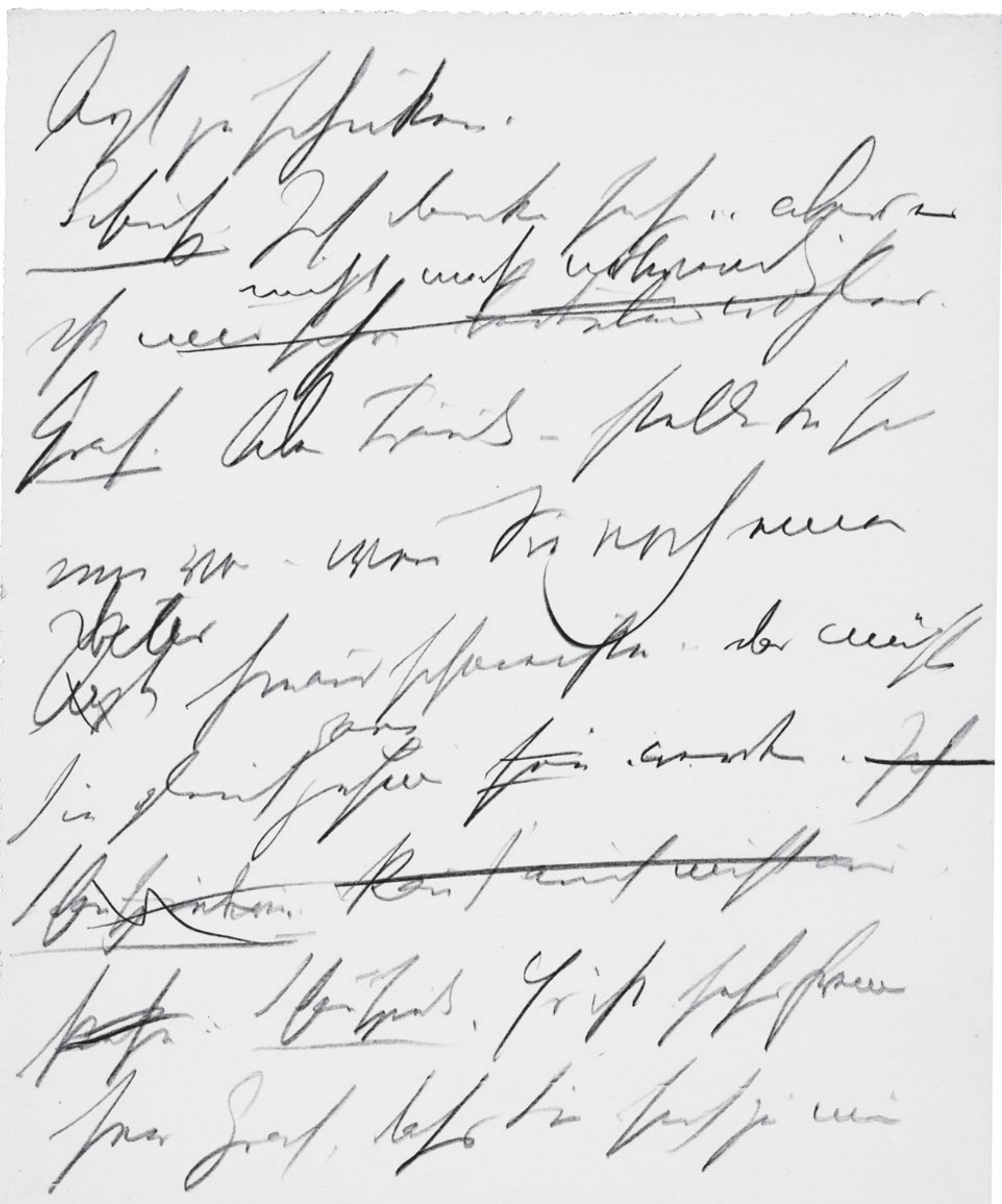

664 
Arzt zu schicken.

Schausp. Ich danke sehr ... aber es

nicht mehr notwendig

ist mir schon bedeutend wohler.

Graf. Aber Fräulein - stellen Sie sich

5 nur vor - wenn Sie noch einen

Doctor

Arzt hinaus schmeiße . . das müsst

ganz

Sie gleich gesund sein . 'werden . Ich

Schauspielerin. . kan̄ s' auch nicht aus-

stehn .... Schauspiel . Es ist sehr freun

10 Herr Graf, dass Sie sich zu mir 
Pacentes.

Prell s, ace pais; $14 \sin 2 y^{2}$ paver gertinab

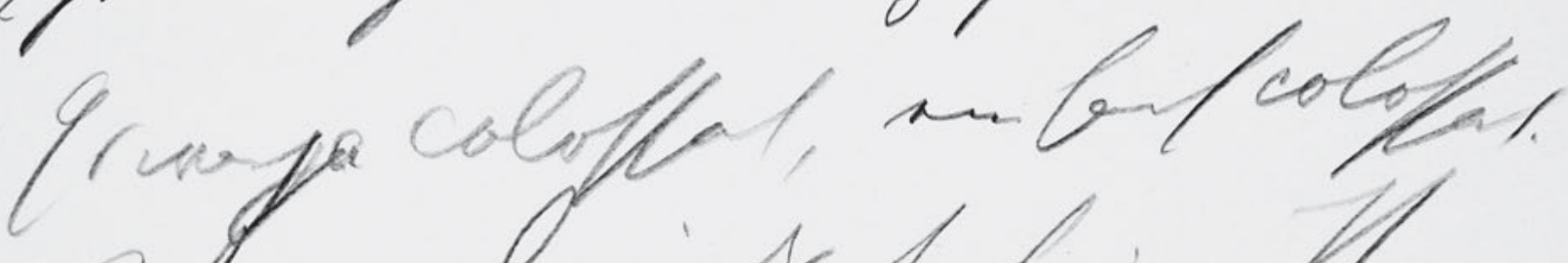

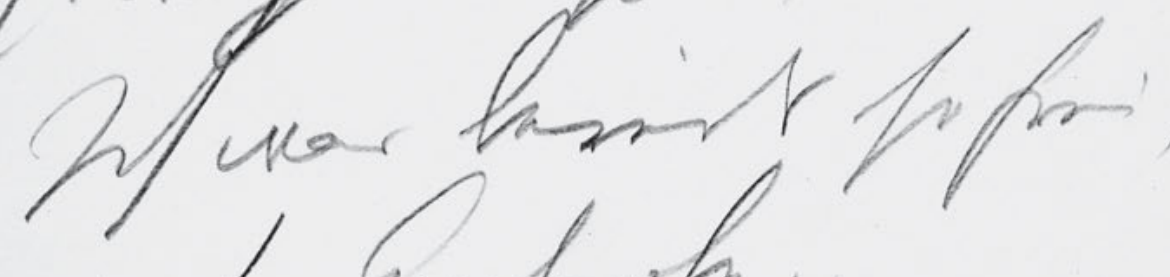

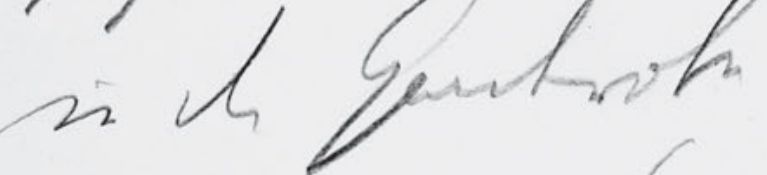

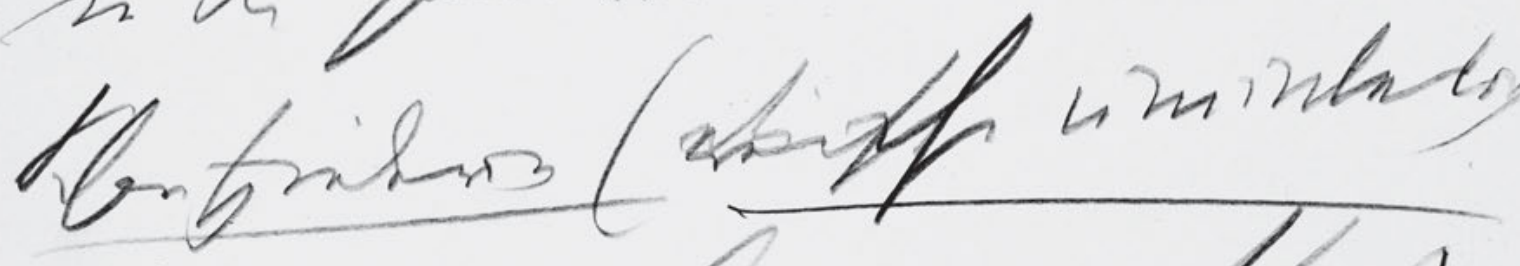

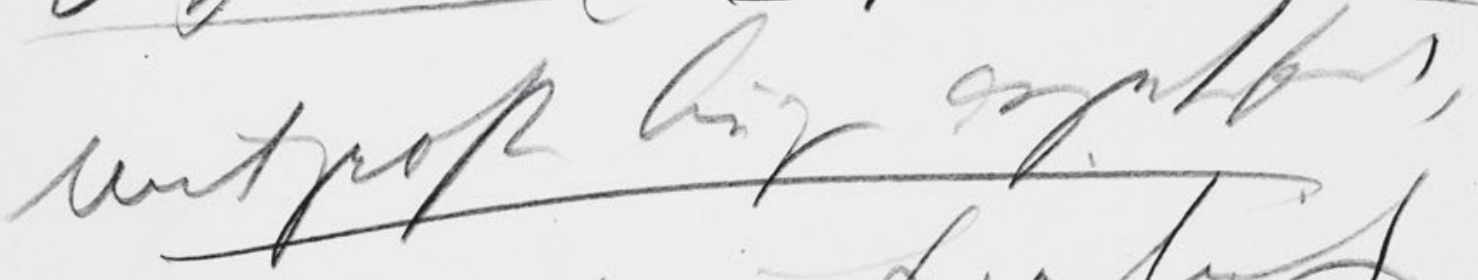

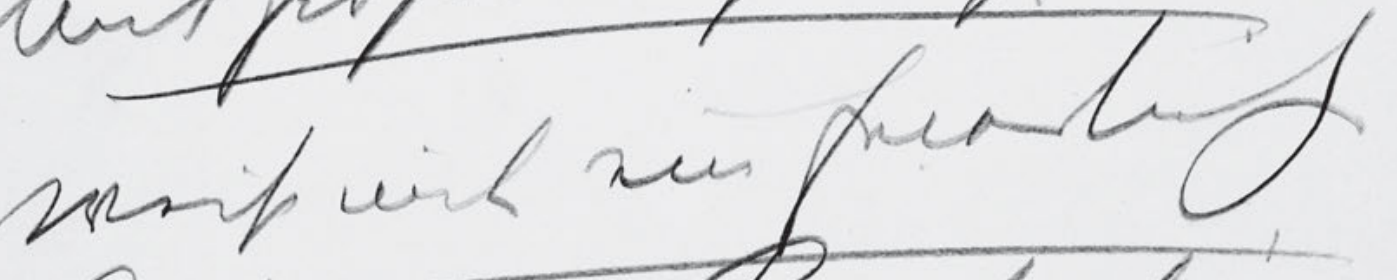

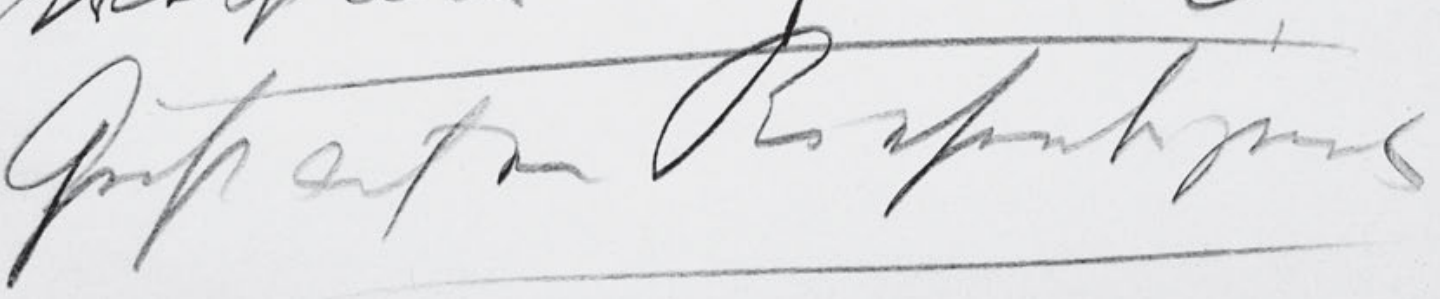


bemühen.

Graf. Ja, mei Fräulein;: ich hab 'Ih?

ja kōmen müssen, Ihnen zu ${ }^{\text {dem }}$ Ihrem Riesen

Triumph

succes gratuliren . gestern Abend.

5 Es war ja colossal, einfach colossal.

Ich war bereits so frei, Ihnen

in die Garderobe. .

$\underline{\text { Schauspielerin }}\left({ }^{\mathrm{die}_{\text {weist }}}\right.$ ihn ununterbroch

mit großen Augen angeschaut,

$10 \quad$ weist 'mit' ein feierlichen

?Gest? auf ein Riesen?bouquet? 


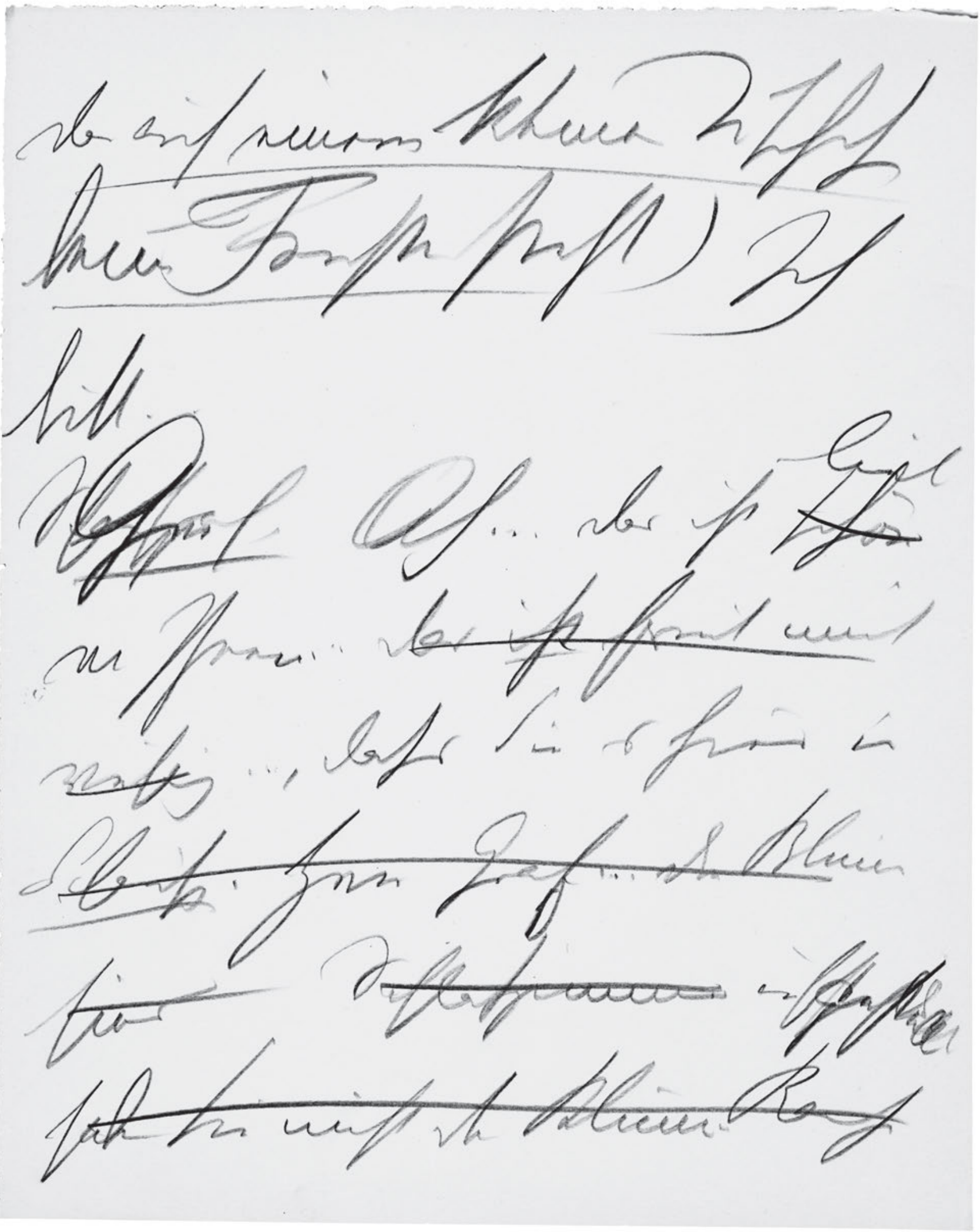


das auf einem kleinen Tischchen

beim Fenster steht) Ich

bitt .

lieb

Schauspie Gra. Ah ... da ist schön

vo Ihnen ... das ist freut mich

riesig ..., dass Sie s hier im

Schausp. Her Graf... die Blumen

sind Schlafzimmer auf stellt $^{\text {gestell }}$

haben Sie nicht der Blumen Rache

5 Bleistiftspuren am Zeilenanfang wohl nicht bedeutungstragend. 
H'Sz9 [7]

Handschriften und Typoskript

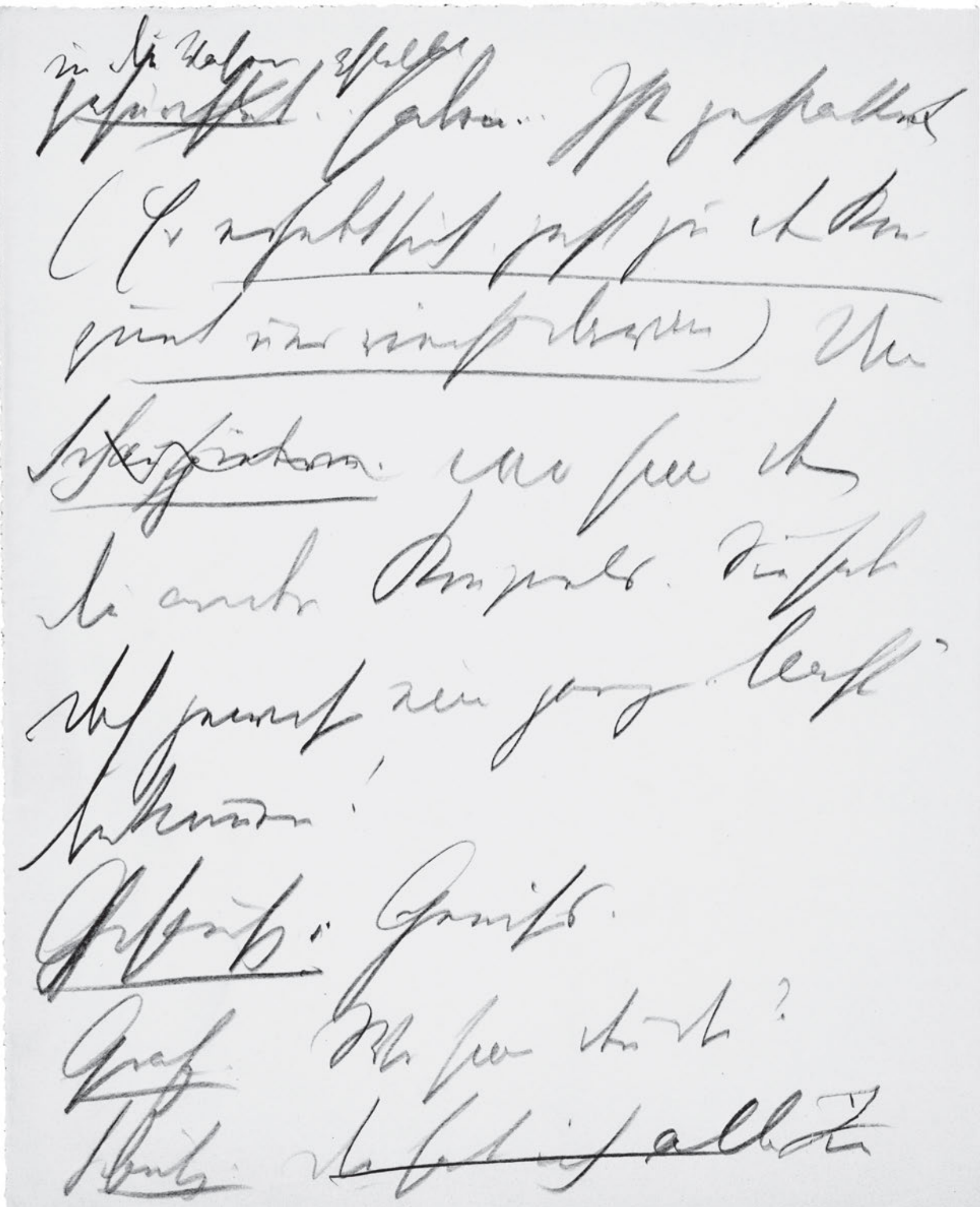

670 
in die Vasen gstellt gefürchtet . . haben ... Ist gestatte ${ }^{\sharp}$

(Er erhebt sich, geht zu dem Bouquet und riecht daran) Und

Schauspielerin. wo sind denn

5 die andern Bouquets. Sie haben doch gewiss eine ganze „Maht“ bekō̄en! GSchausp .. Gewiss. Graf. Wo sind deñ die?

${ }_{10} \quad$ Schausp. Die hab ich alle ${ }^{\mathrm{i}}$ In 
H'Sz9 [8]

Handschriften und Typoskript

Nench

we finom
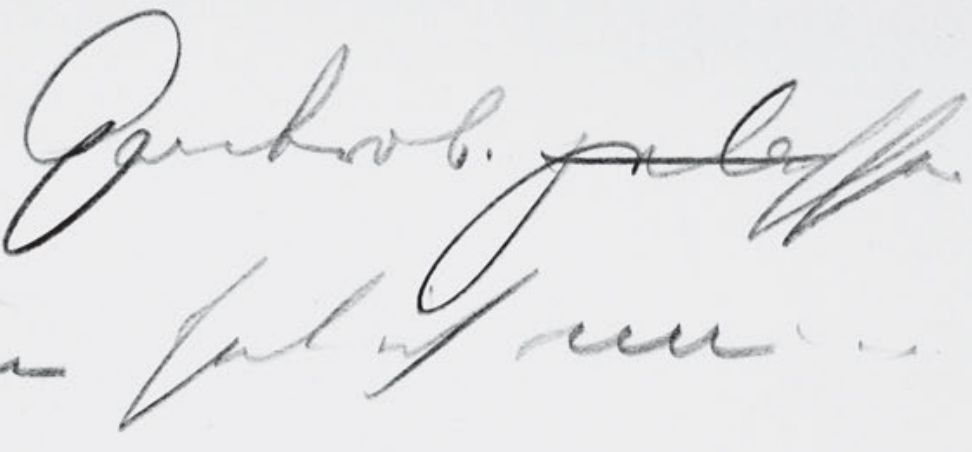

ila

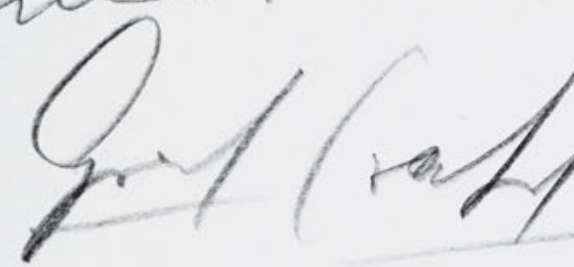

4

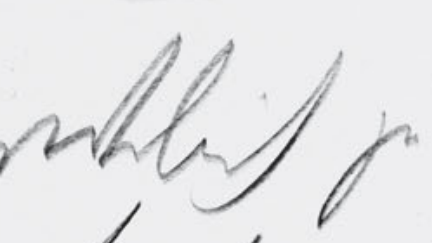

foitinis

2

a

Liml

nor ffar,

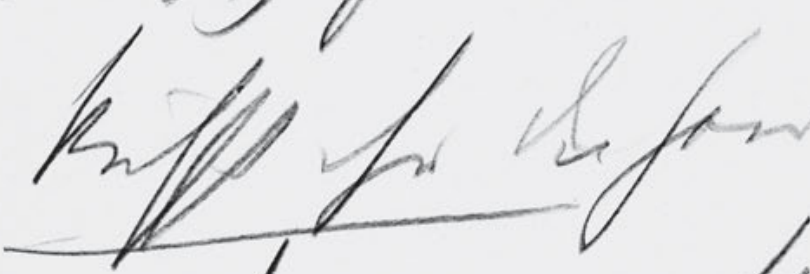

Ales

hir htem

norf

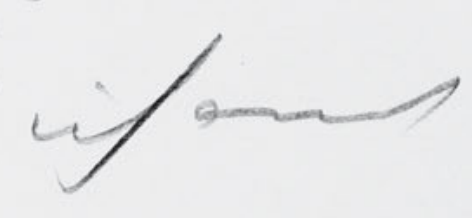


meiner Garderob. gelassen.

mitgenomen hab ich nur...

das.

Graf (rasch zu ihr zurück) Das

5 ist wirklich zu lieb von Ihnen,

. . (er küsst ihr die Hand.). Und

die andre ... mocht ich auch

schön bitten.

Schspler. (nī̄t die andre unt

10 der Bettdecke hervor u reicht sie 
H'Sz9 [9]

Handschriften und Typoskript
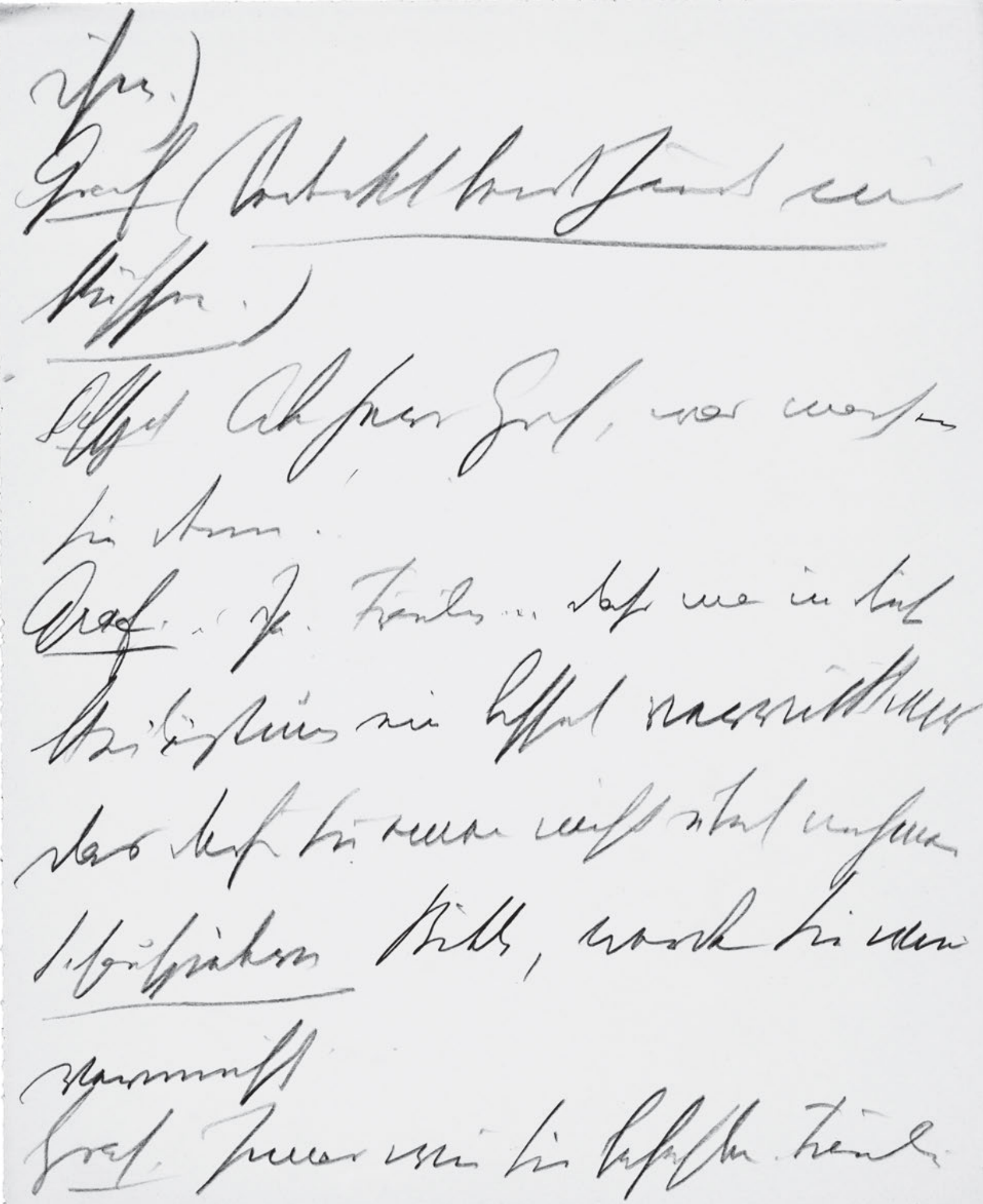

674 
ihm.)

Graf (bedeckt beid Hände mit

Küssen.)

Schspiel Aber Herr Graf, was machen

$5 \quad$ Sie denn!

Graf. [?] ?:?? Ja . Fräulein ... . dass man in diesem

Heiligtum ein bissel verrückt wird

das dürfen Sie einem nicht übel nehmen

Schauspielerin Bitte, werden sie wied

10 vernünftg.

Graf. Immer wie Sie befehlen . Fräulein. 
H'Sz9 [10]

Handschriften und Typoskript

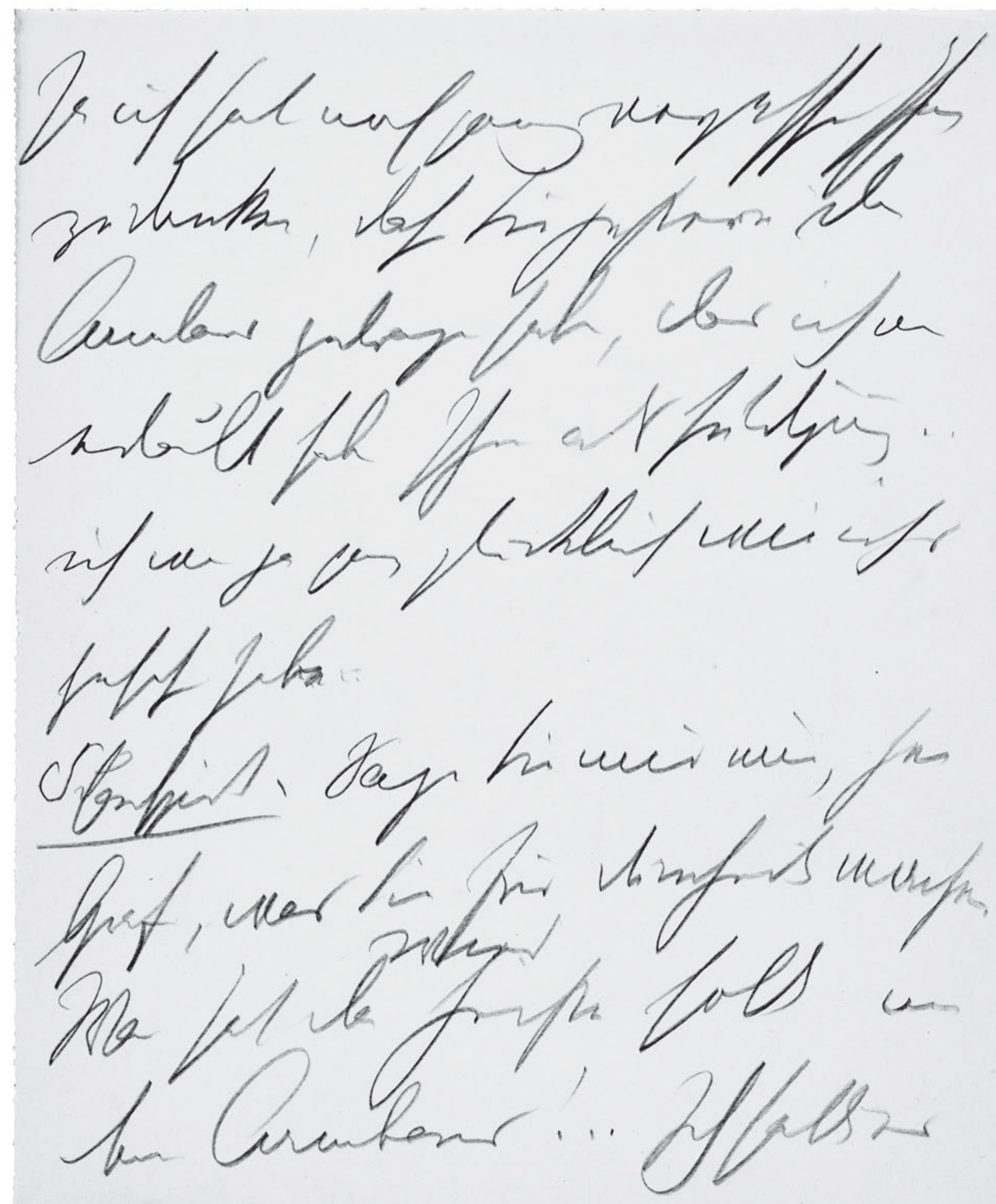

676 
Ja ich hab noch ganz vergessen Ihnen

zu danken, dass Sie gestern das

Armband getragen haben, das ich mir

erlaubt habe Ihnen als Huldigung . .

5 ich war ja ganz glücklich wie ichs

gesehen habe "-

Schauspiel. Sagen Sie mir nur, Her

Graf, was Sie für Dumheiten machen.

wied

Was hat das heißen soll mi

10 dem Armband!. . Ich hatte es 
H'Sz9 [11]

Handschriften und Typoskript

$1 / 1 / 1$
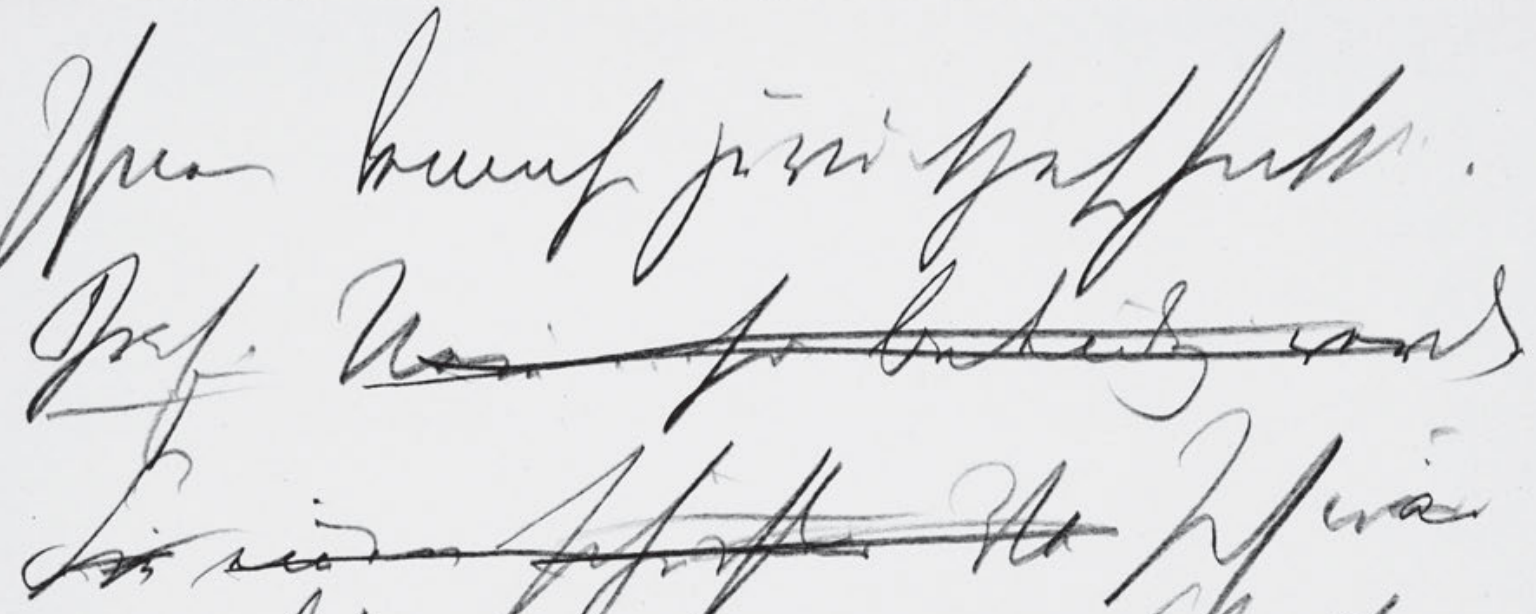

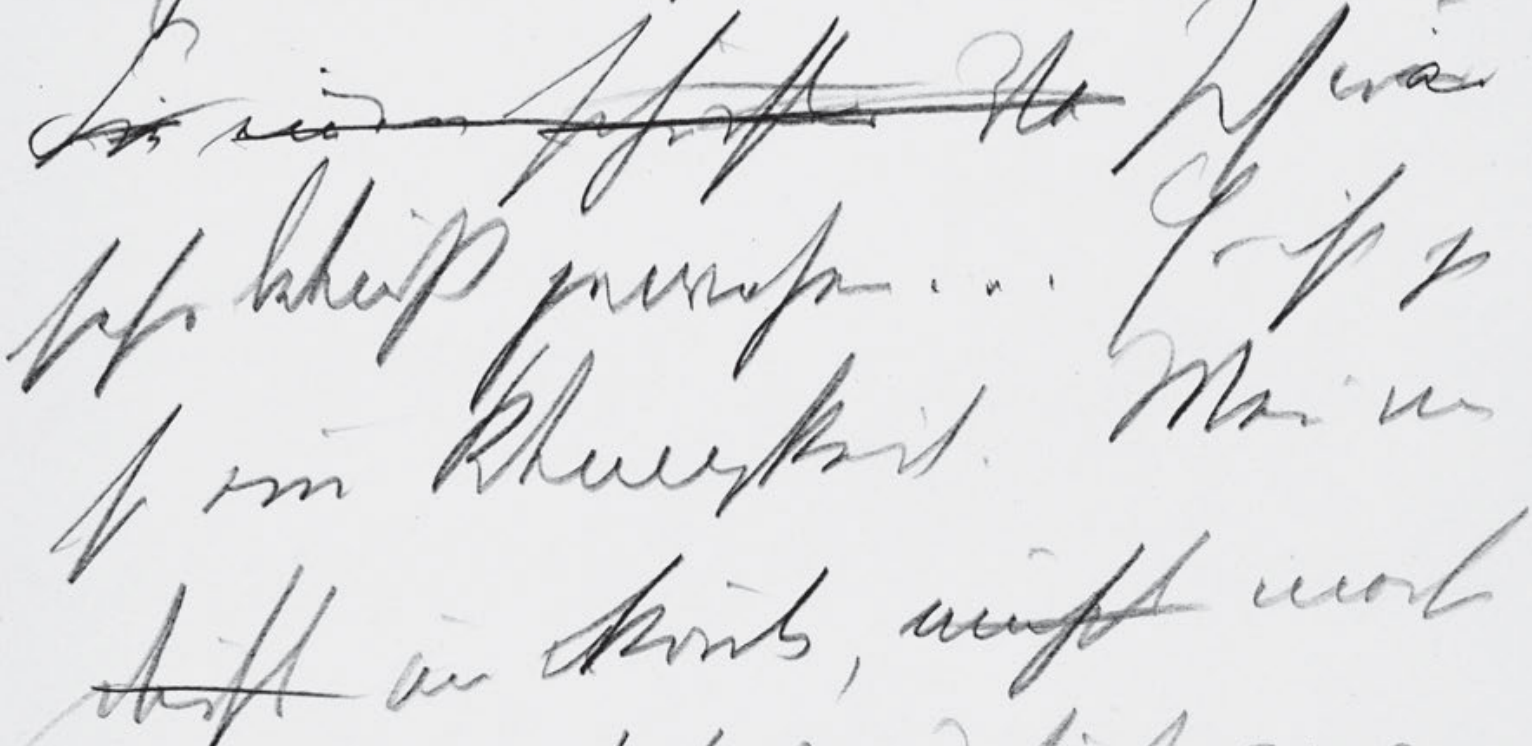

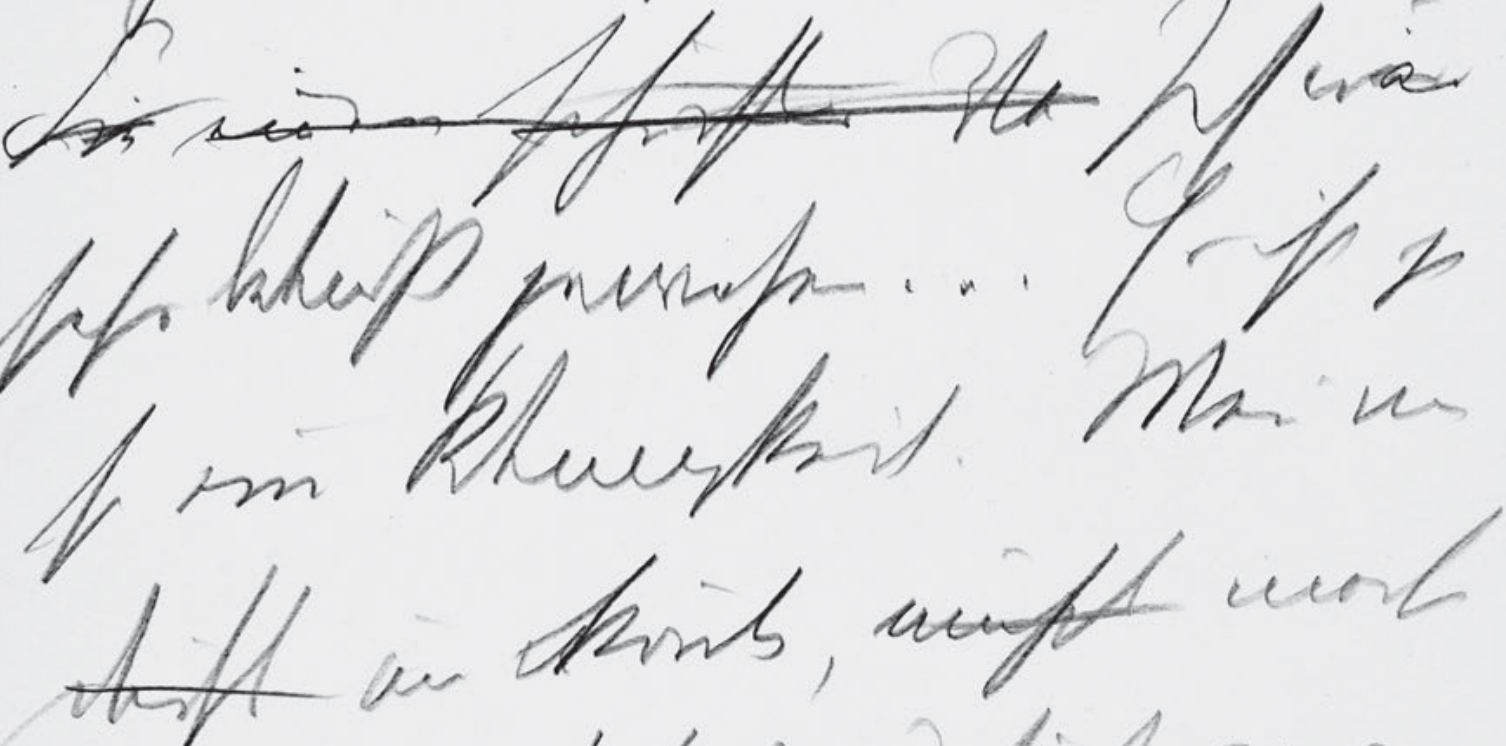
ni
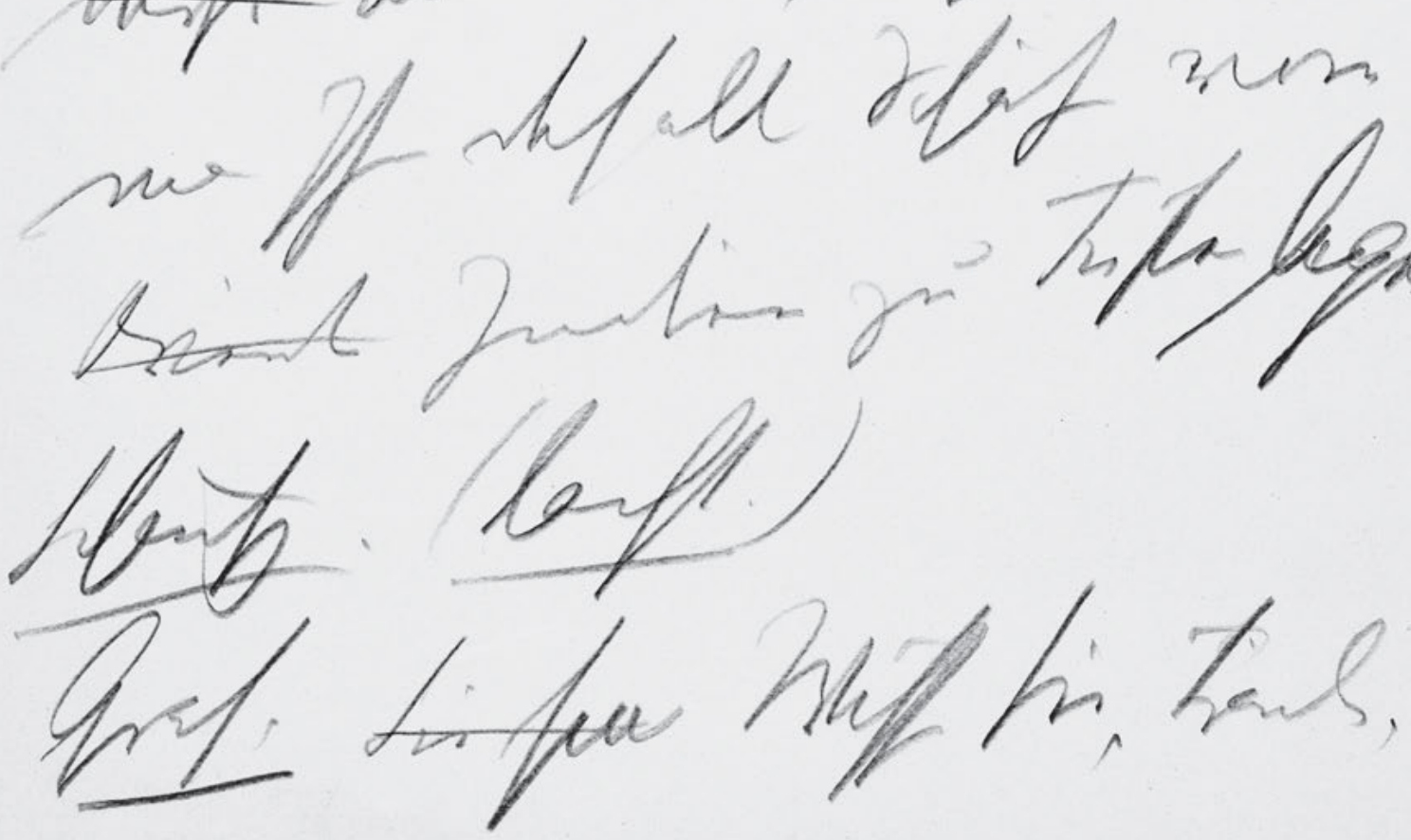

678 
Ihnen beinahe zurückgeschickt . .

Graf. Nein ... so beleidig werden

Sie einen schüchter Ve Ich wär

sehr beleidgt gewesen .... Es ist ja

5 so eine Kleinigkeit. Wen̄ man

dürft nur ${ }^{\mathrm{d}}$ könte, müßt mocht

man Ihnen doch alle Schätze vom

Orient Indien zu Füßen legen!

Schausp . (lacht.)

10 Graf. Sie sind Wissen Sie, Fräulein, 
H'Sz9 [12]

Handschriften und Typoskript

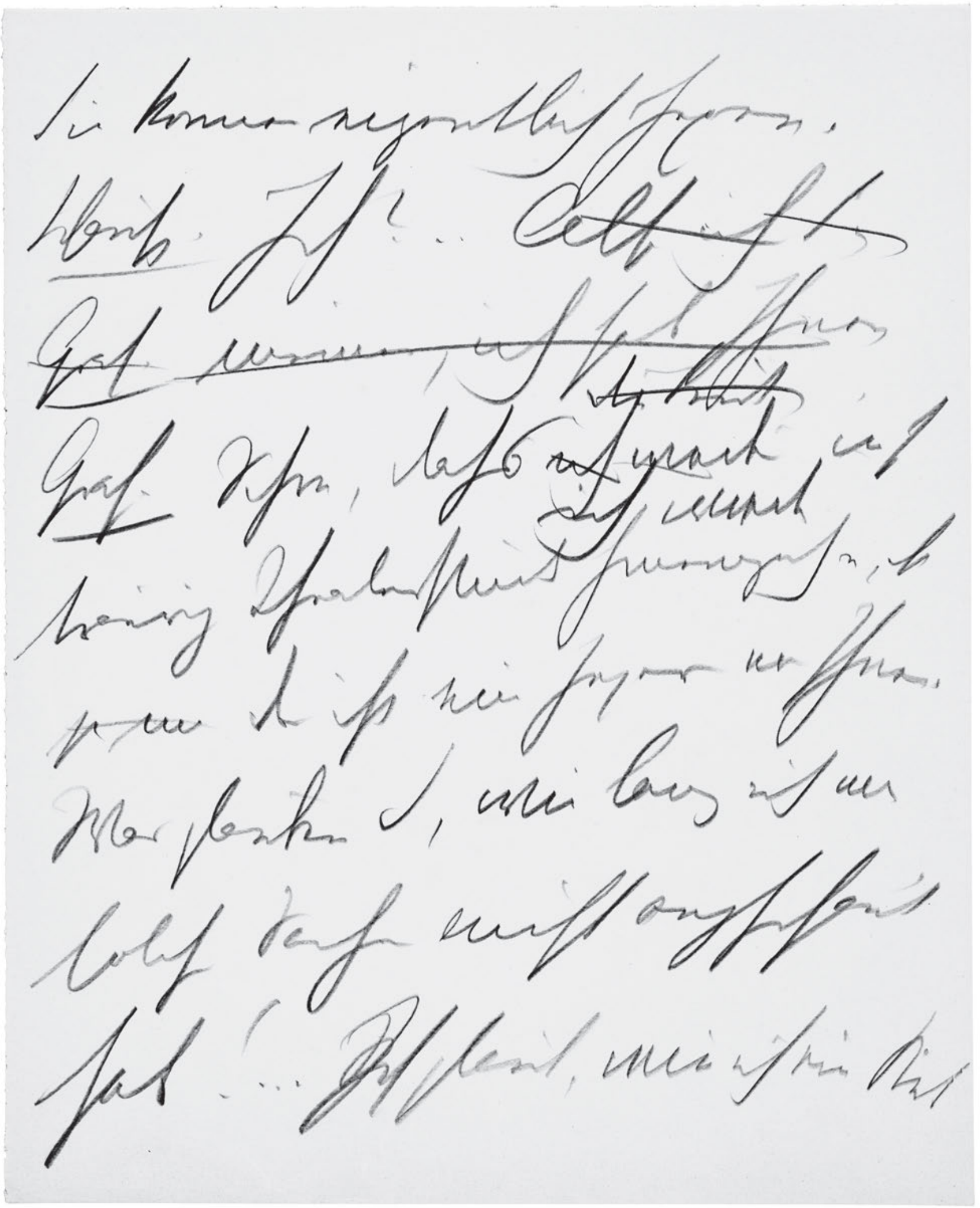

680 
Sie konnen eigentlich hexen.

Schausp. Ich? .. Als $\odot$ ich Sie

Graf. meinen, ich hab Ihnen

$$
\text { die Leut }
$$

Graf. Schon, dass ich wieder in so ich wieder

5 traurige Theaterstück hineingehe, ist

ja ? ${ }^{\text {w }}$ ? das ist ein Hexerei von Ihnen.

Was glauben $\mathrm{S}$, wie lang ich mir

solche Sachen nicht angschaut

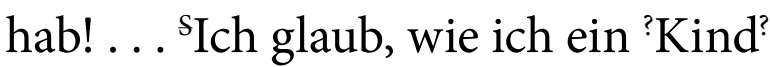


H'Sz9 [13]

Handschriften und Typoskript

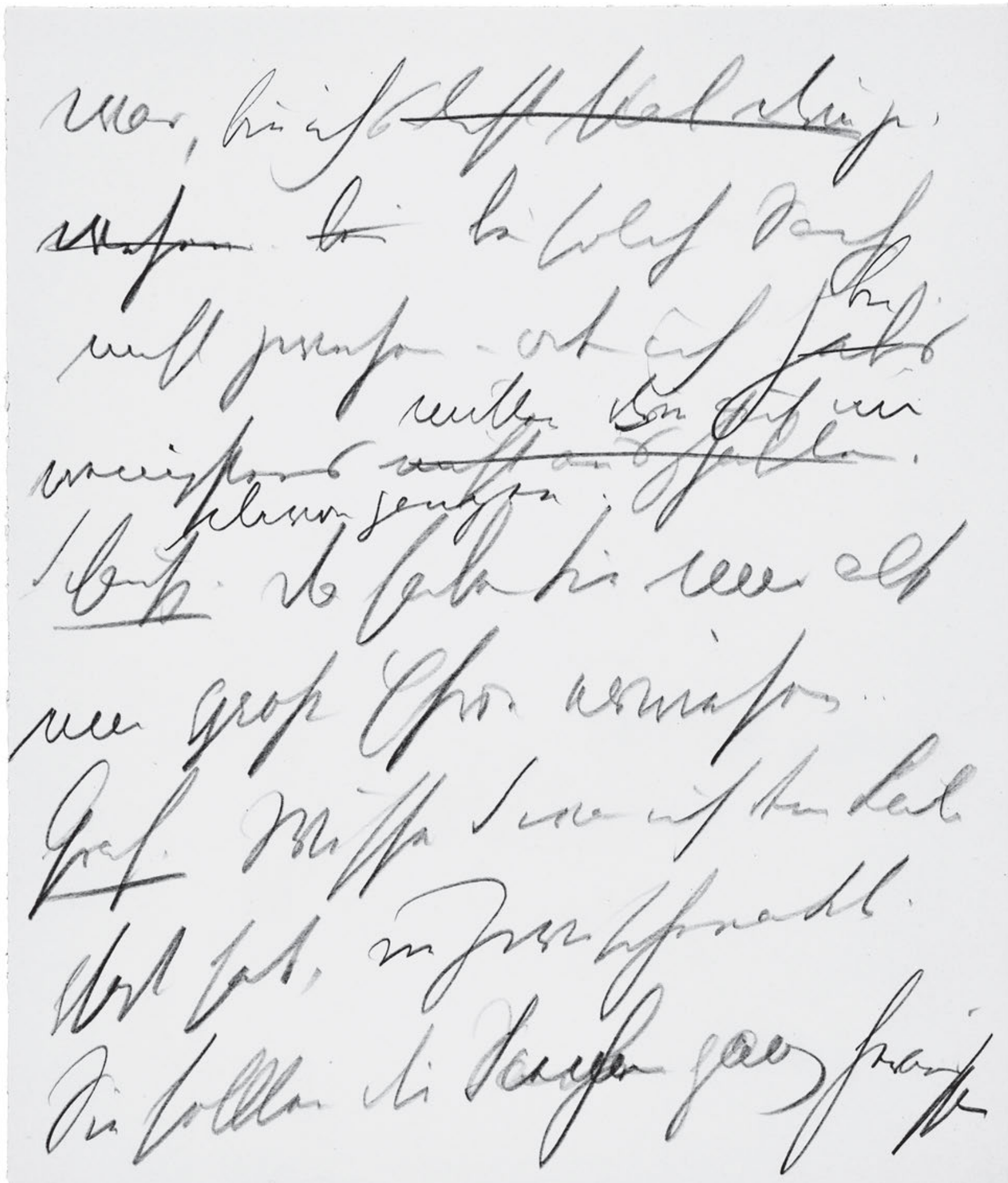

682 
war, bin ich s letzte Mal drin ge-

wesen . bei bei solche Sachen

bin

nicht gwesen - oder ich hab's

mitten drin auf und

wenigstens nicht ausghalten. davon gangen.

$5 \quad$ Schausp. Da haben Sie mir also

eine große Ehre erwiesen ..

Graf. Wissen S was ich dem Lulu

gsagt hab, im Zwischenakt.

Sie sollten die ${ }^{\text {Sachen }}$ Scenen ganz heraussen 
H'Sz9 [14]

Handschriften und Typoskript

Caffor,

Sis mifl milfas

str hith ive gon wo
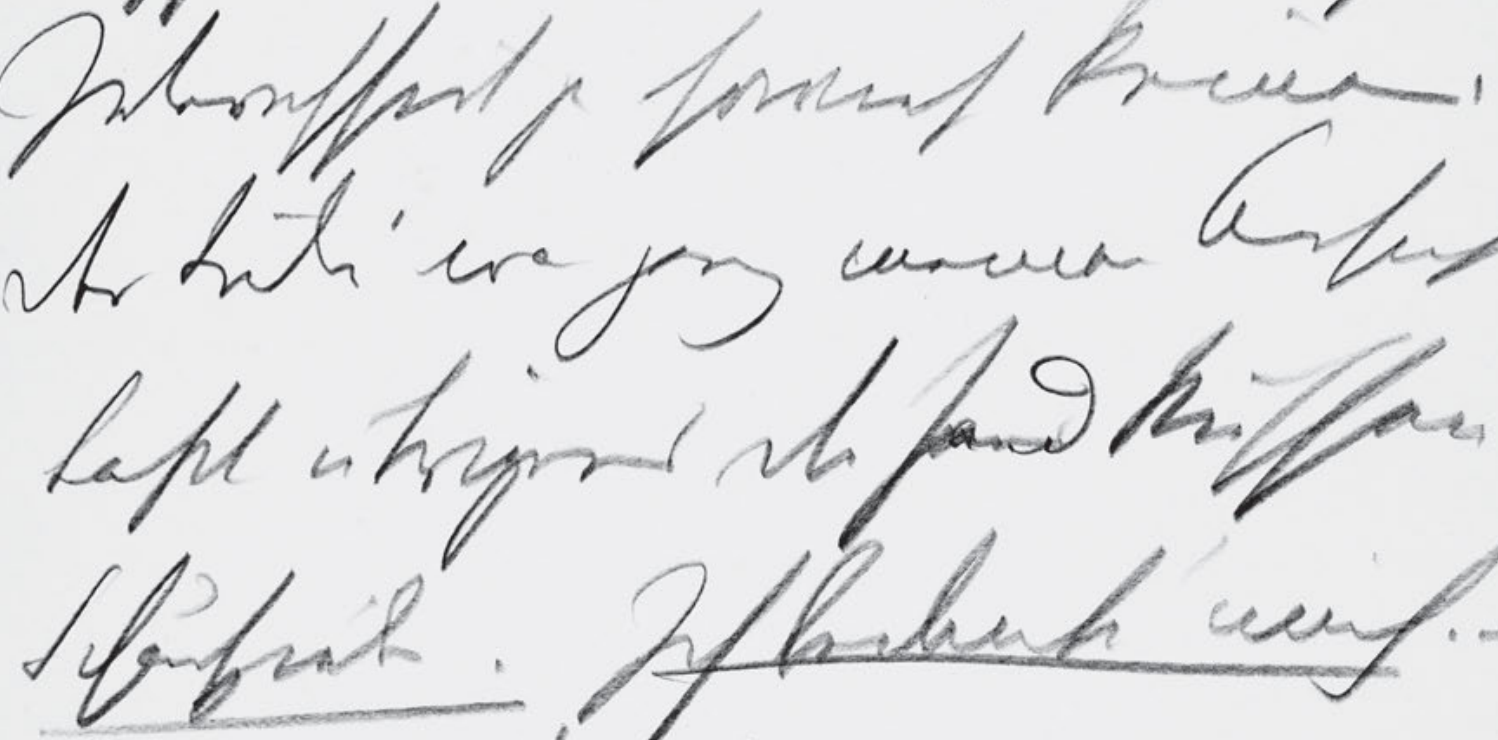

jisp.

hinh.
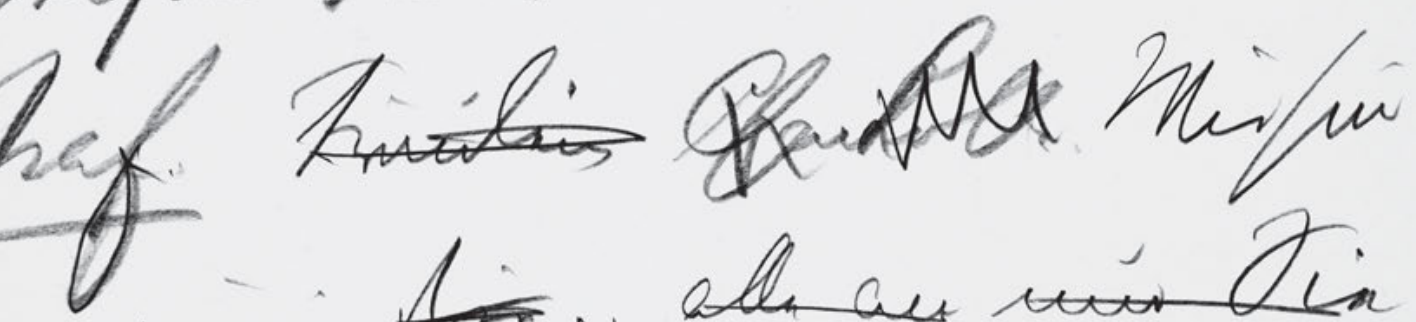

lev mosis

alk utrig Ifofinco fur jas

utollafs

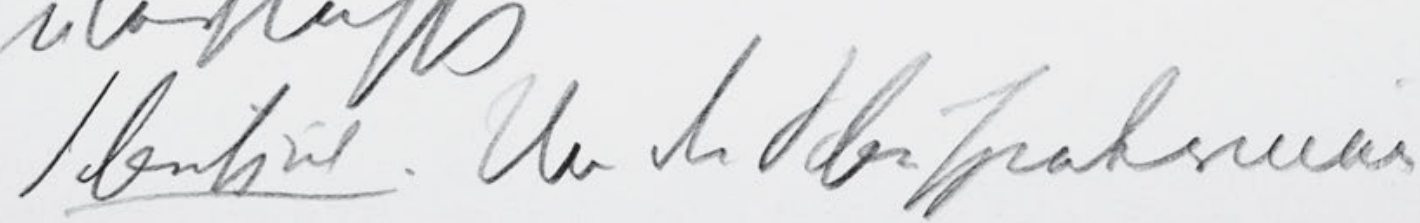

684 
lassen, wo Sie nicht mitspielen.

Interessirt ja sowieso keinen.

Der Lulu war ganz meiner Ansicht.

Laßt übrigens die Hand küssen.

5 Schauspieler. Ich bedanke mich. -

Heißen Dank.

Graf. Fräulein Char'Lotte. Wir sind

ganz einig drin . . alle an nur Sie

alle übrigen Schauspieler sind ganz

10 überflüssig.

Schauspiel. Und die Schauspielerinen [?] 
H'Sz9 [15]

Handschriften und Typoskript

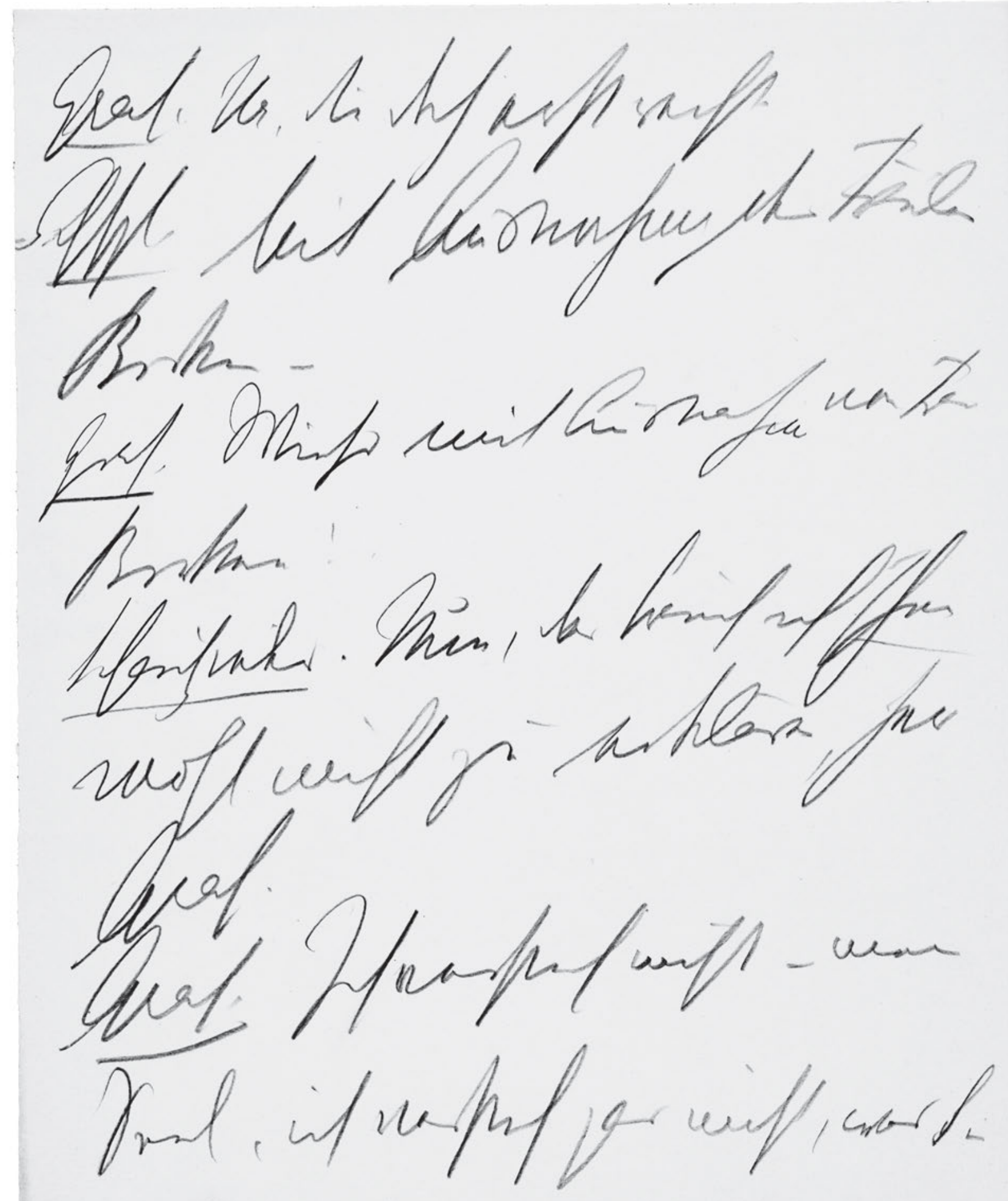

686 
Graf. Na, die doch erst recht.

Schspl. Mit Ausnahme des Fräulein

Birken -

Graf. Wieso mit Ausnahme von Frau

$5 \quad$ Birken! .

Schauspieler. Nun, das brauch ich Ihnen

wohl nicht zu erklären, Her

Graf.

Graf. Ich versteh nicht - mein

10 Seel, ich versteh gar nicht, was Sie 
H'Sz9 [16]

Handschriften und Typoskript

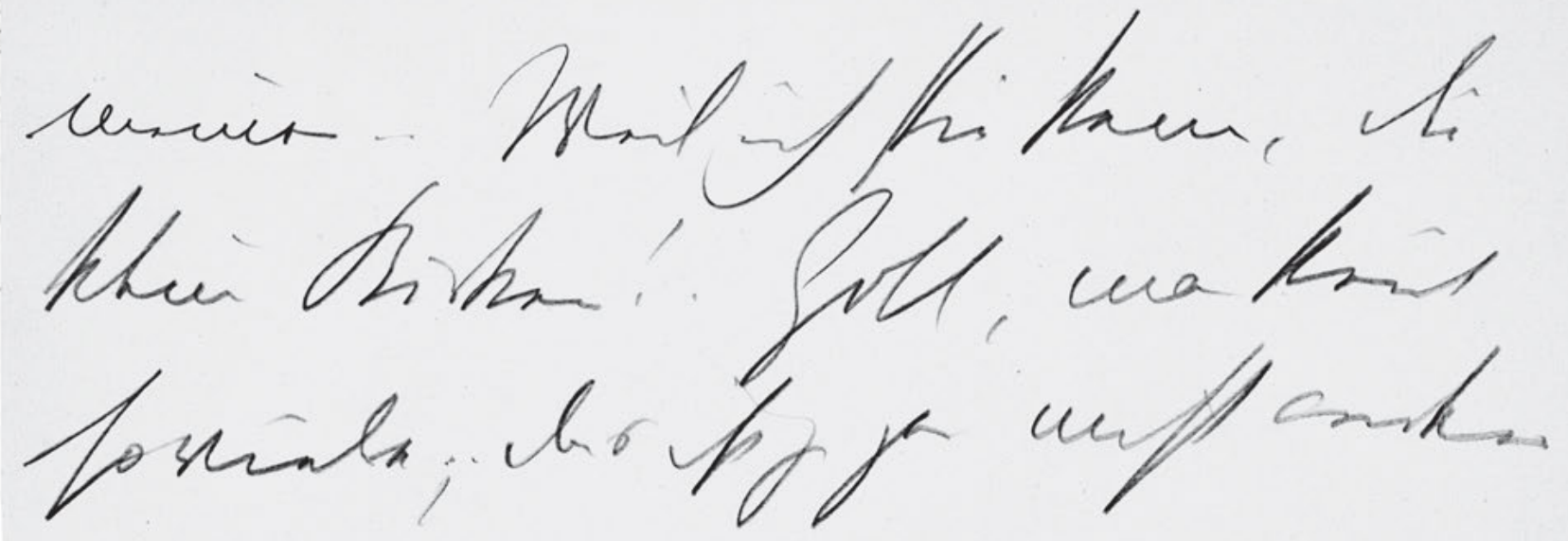

mule

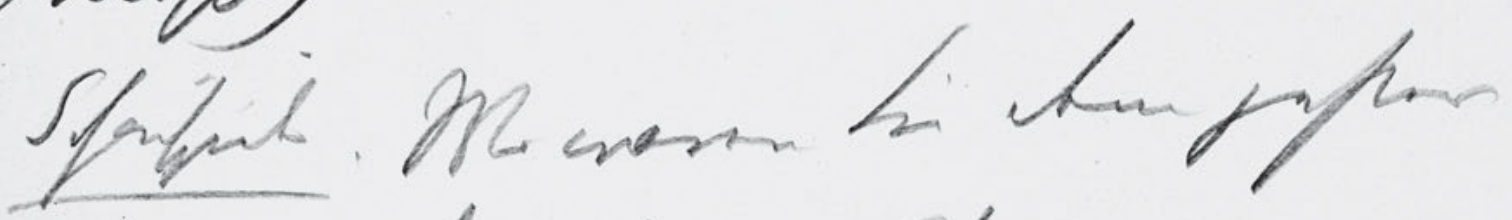
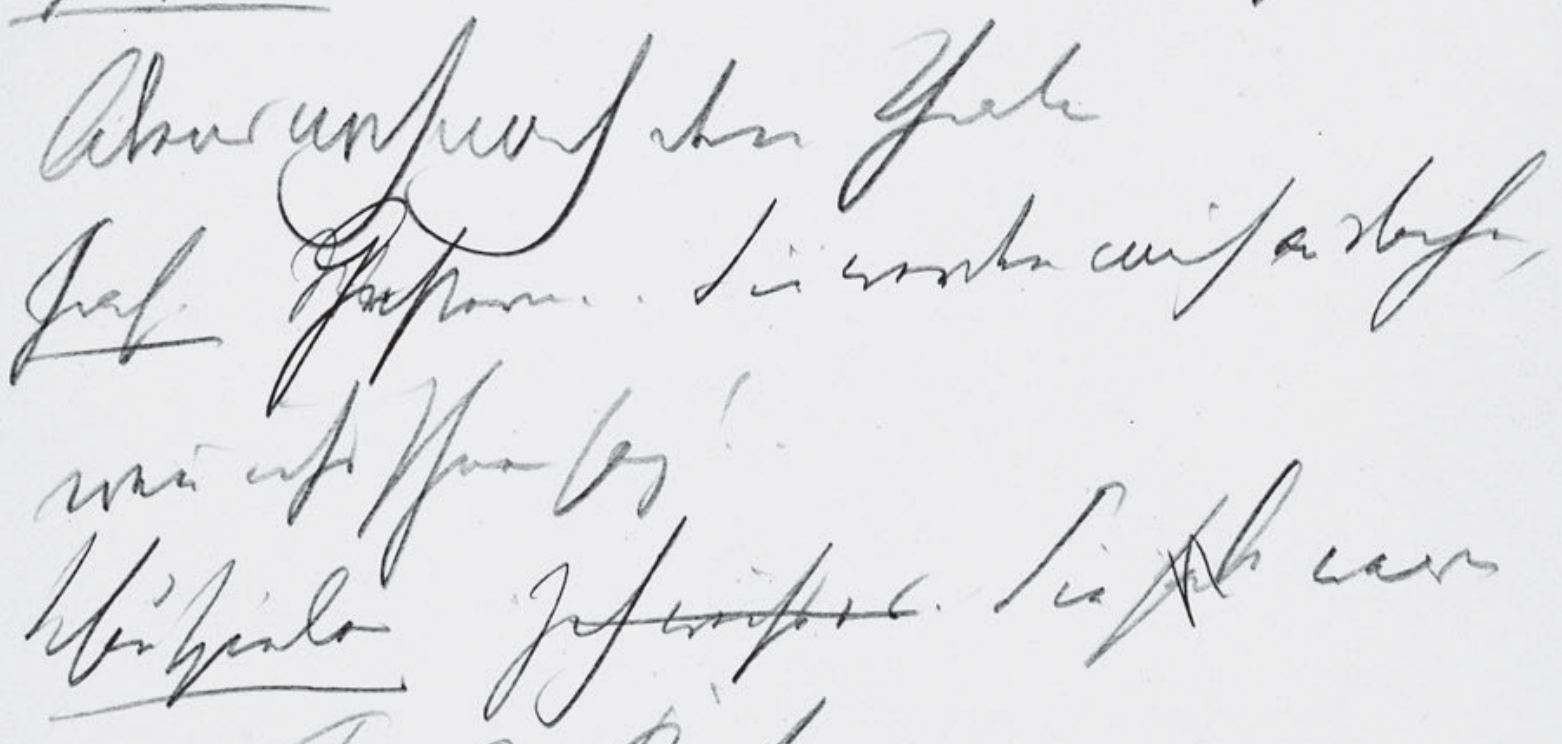

unt trines contro.

Gret Ohifoled for de cur....'.

688 
meinen .. Weil ich ${ }^{\S}$ sie kenn, die

kleine Birken! . Gott, man ken̄t

so viele; .. das ist ja gar nicht anders

möglich! .

$5 \quad$ Schauspieler . Wo waren Sie denn gestern

Abend noch nach dem Theater

Graf. ${ }^{W_{\ominus}}$ Gestern .. Sie werden mich auslachen,

weñ ichs Ihnen sag! .

Schauspieler Ich weiss es. Sie habe waren

mit Fräulein Birken.

Graf. Wie fallt Ihnen das nur ein! . 
H'Sz9 [17]

Handschriften und Typoskript

Aingiby

Y

prumet iffar h

sfongiats
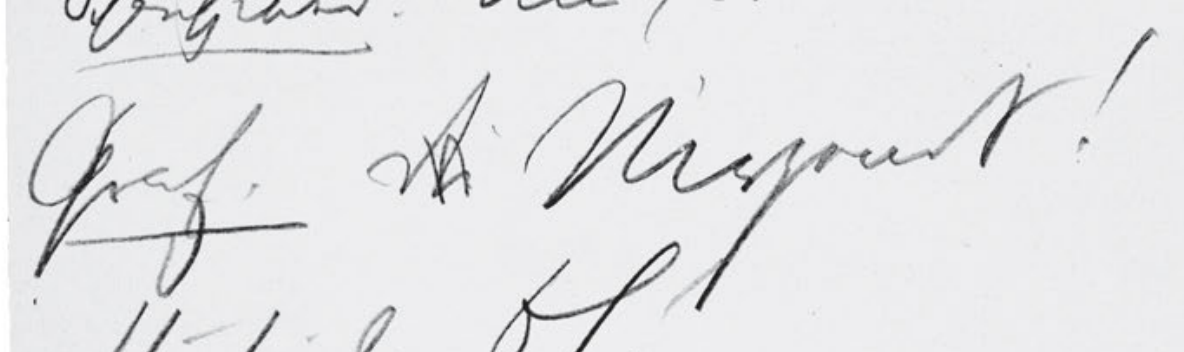

homil
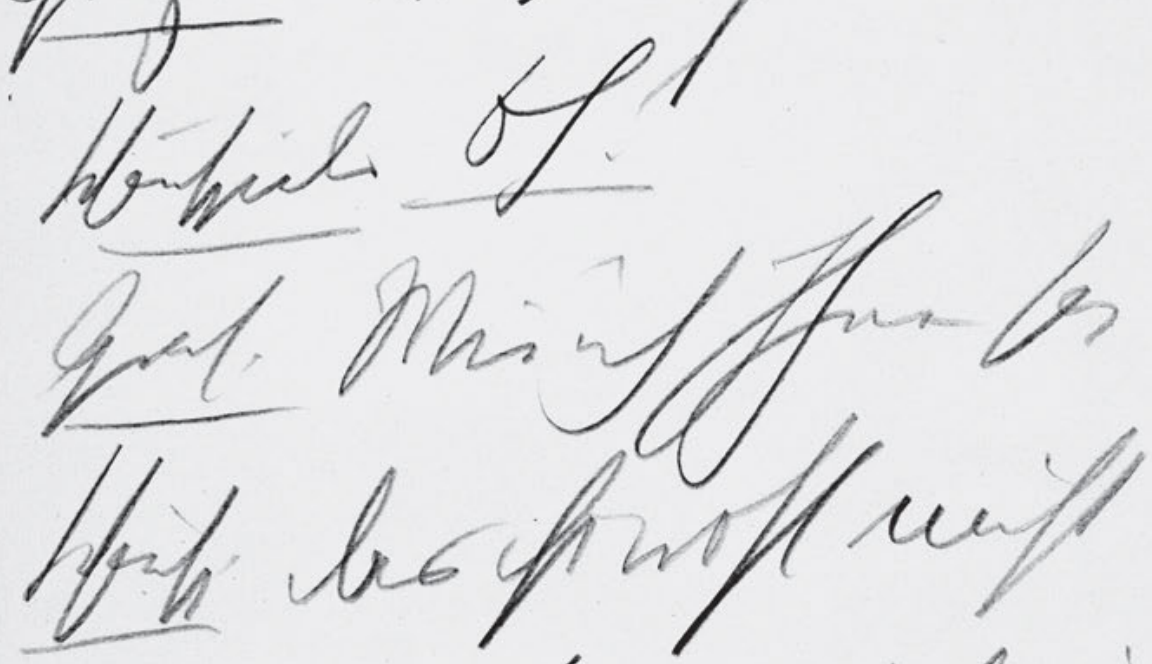

minil

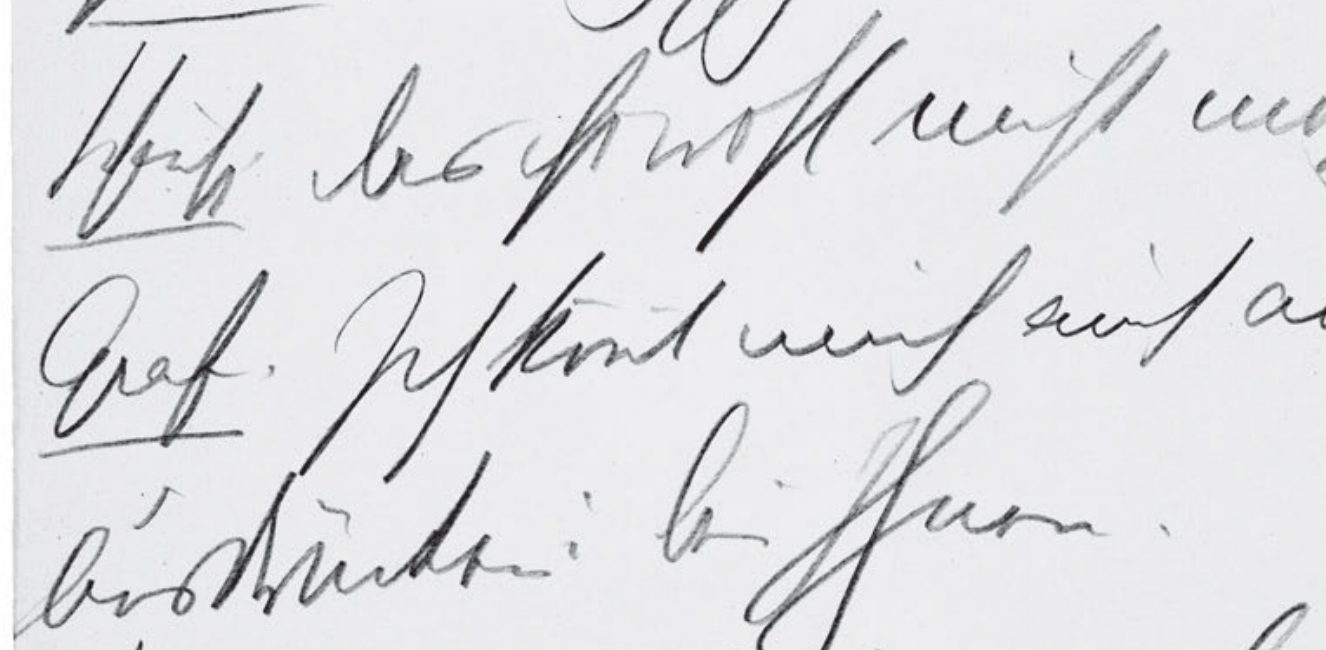

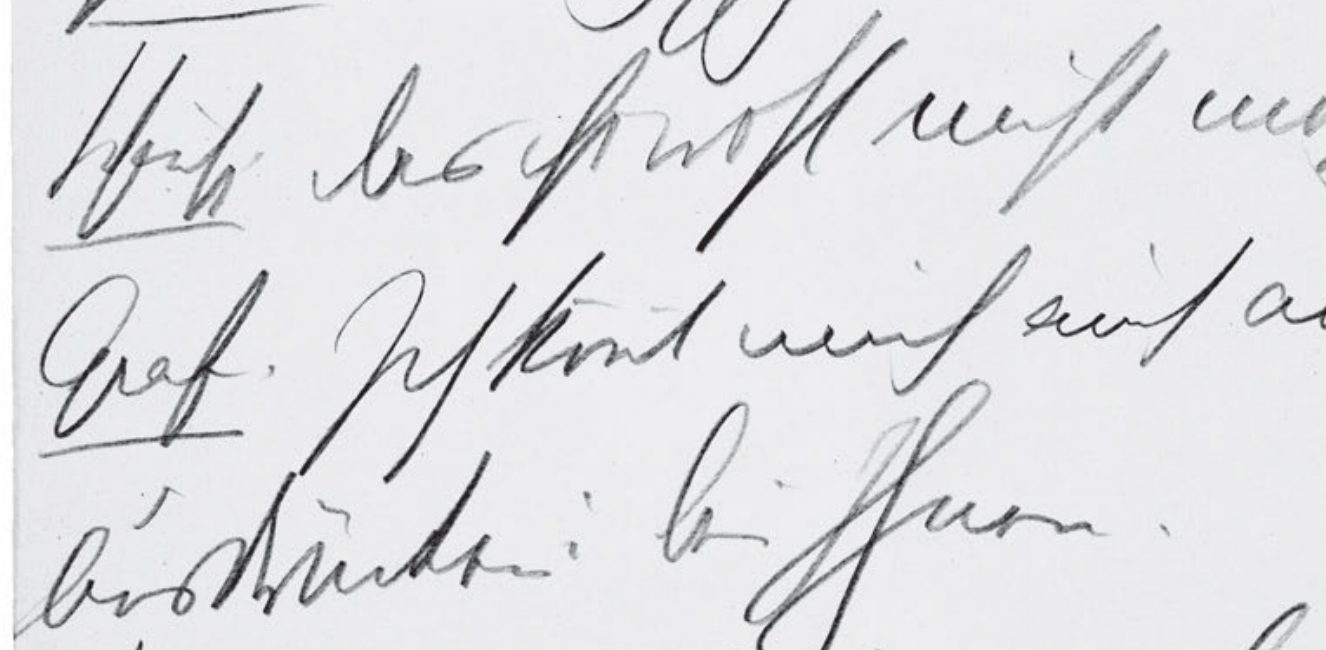

foncialon

Iy fabingent

funets

690 
Mein heilige Ehrenwort . . ich whab die Birken überhaupt nicht gsehn ..

Schauspieler. Nun, wo waren Sie?

Graf. Die Nirgends!

$5 \quad$ Schauspieler Oh!

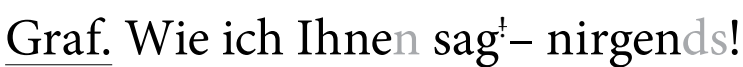

Schausp. Das ist wohl nicht möglich! .

Graf. Ich kön̄t mich auch anders

ausdrücken: bei Ihnen.

10 Schauspielerin Ich habe nichts bemerkt 
H'Sz9 [18]

Handschriften und Typoskript

Wal Marifh hff: mitifun
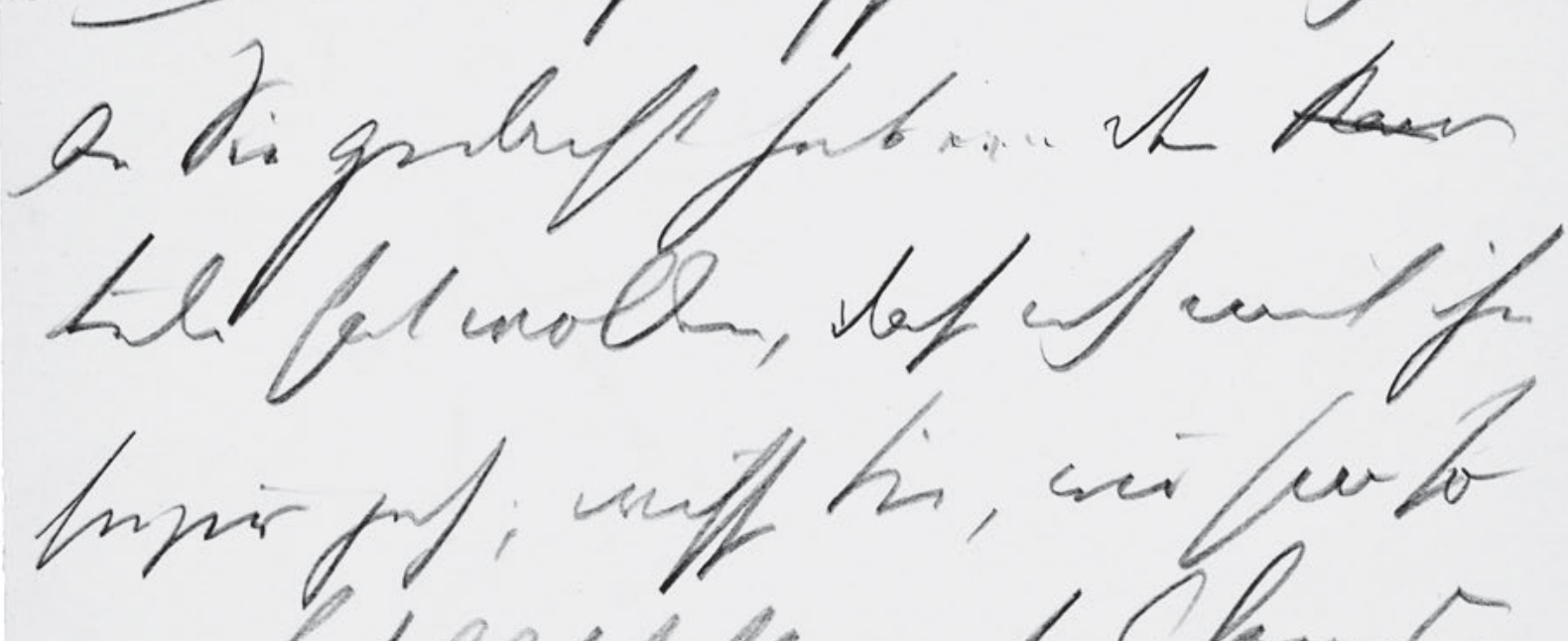

ner

ui lonin

ol esin'. un

, him nog

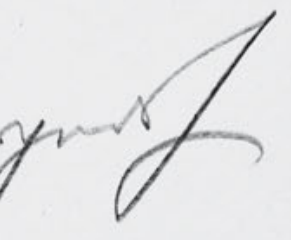

pen

Gifugator.

Qref

692 
Graf. Und es ist doch so: weil ich nur

an Sie gedacht hab ..... der Baron

Lulu hat wollen, dass ich mit ihm

soupire geh; wissen Sie, wir sind so

$5 \quad$ eine Gesellschaft jeden Abend..

und dañ in Club . . ich hab aber

${ }^{g}$ gsagt - nein ... und bin nirgendshin

gegangen .

Schauspieler . Aber wohin . .

10 Graf. Sehen S, Fräulein ... wen̄ ich von 
H'Sz9 [19]

Handschriften und Typoskript

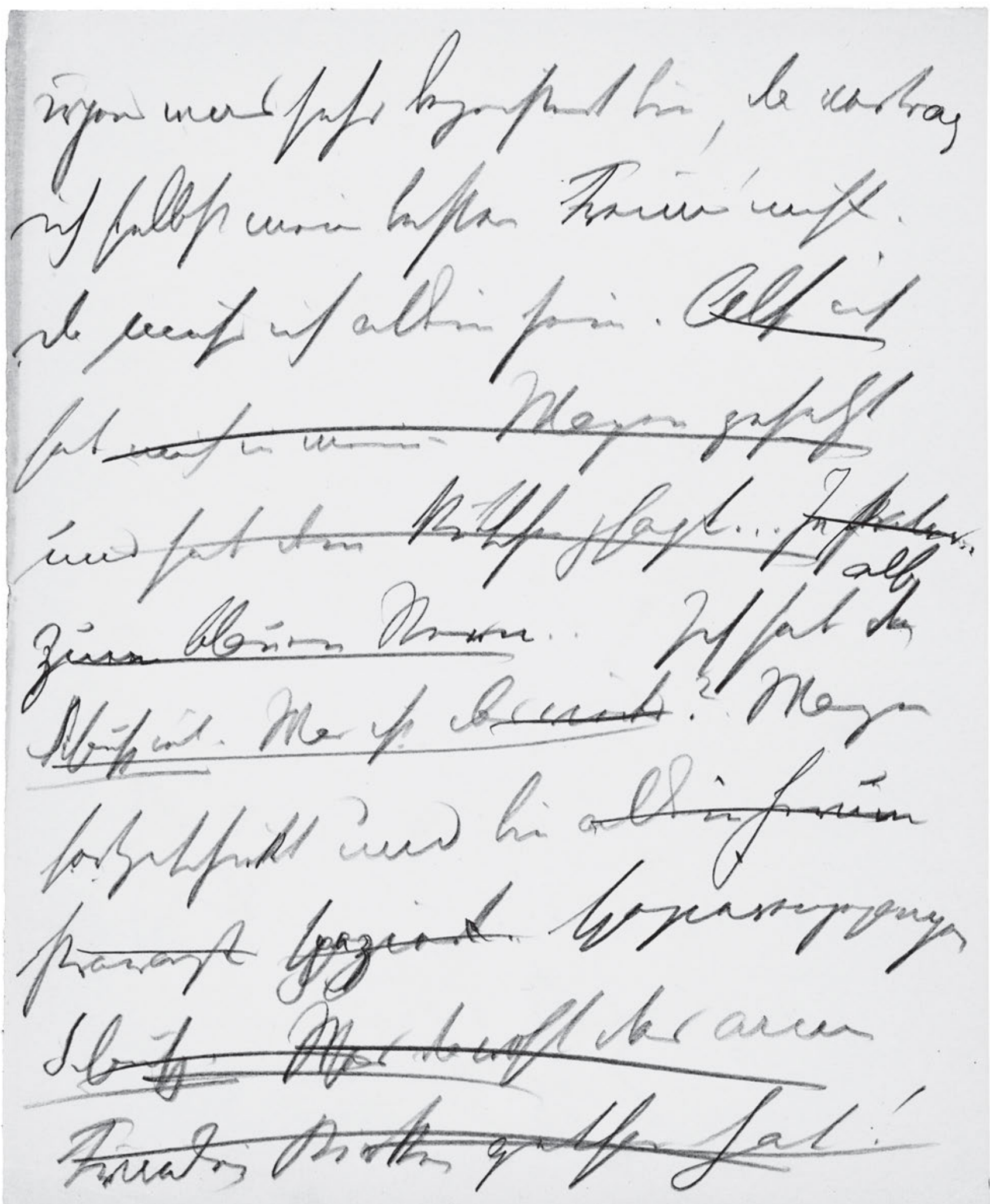

694 
irgend was sehr begeistert bin, dan vertrag ich selbst meinen besten Freund nicht.

Da muss ich allein sein. Als $\odot$ ich hab mich in meinen Wagen gesetzt und hab dem Kutscher gsagt ... In Prater ... also

zZum blauen Stern.. $\quad$ Ich hab den

Schauspiel. Was ist das wieder? . Wagen fortgeschickt und bin allein herum strawanzt ?gang? spaziert . . spazierengegangen

10 Schausp. Was da wohl das arme

Fräulein Birken gethan hat! 
H'Sz9 [20]

Handschriften und Typoskript
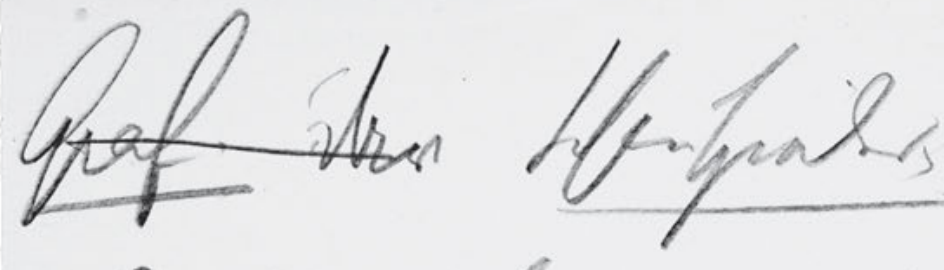

Say altinis
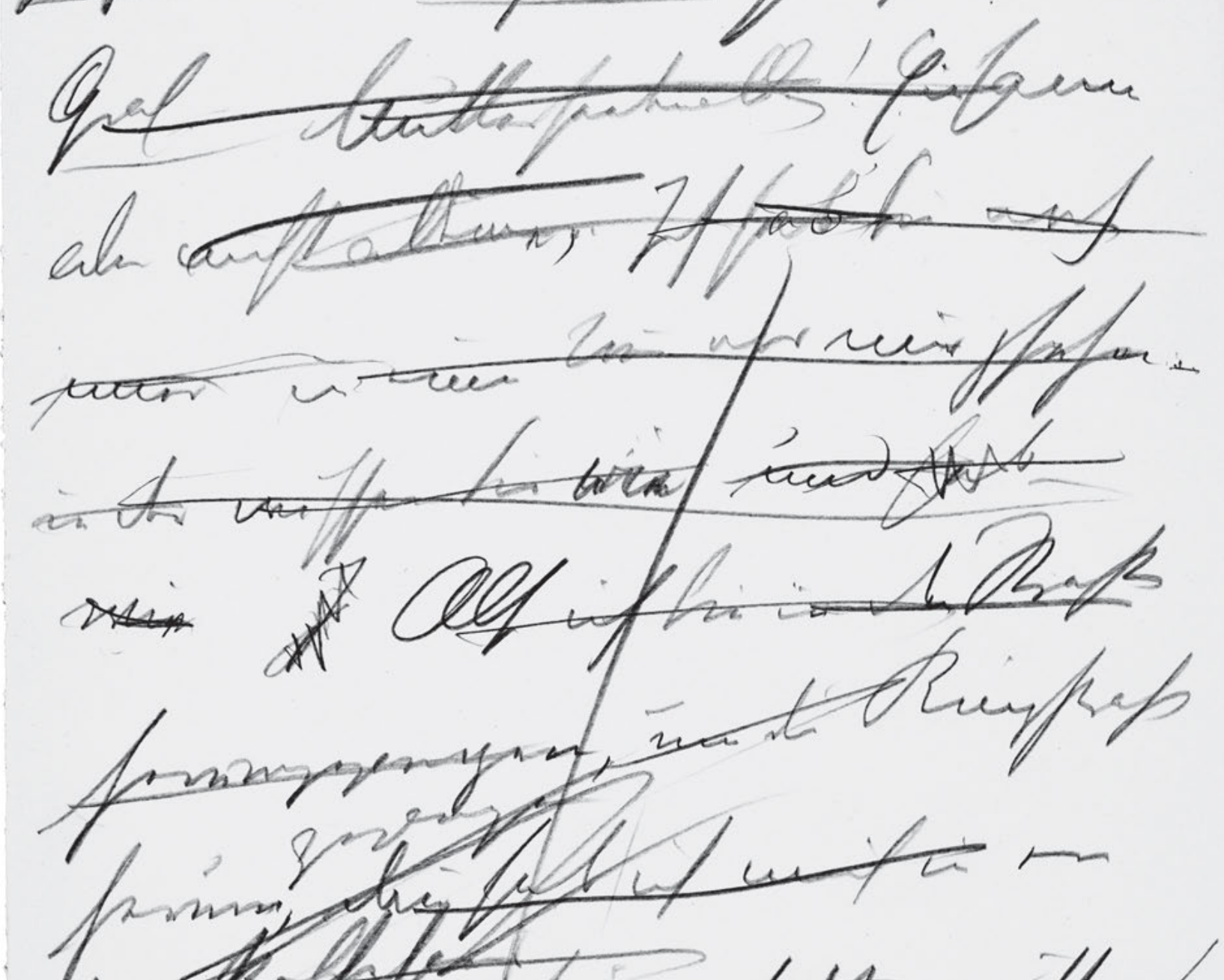

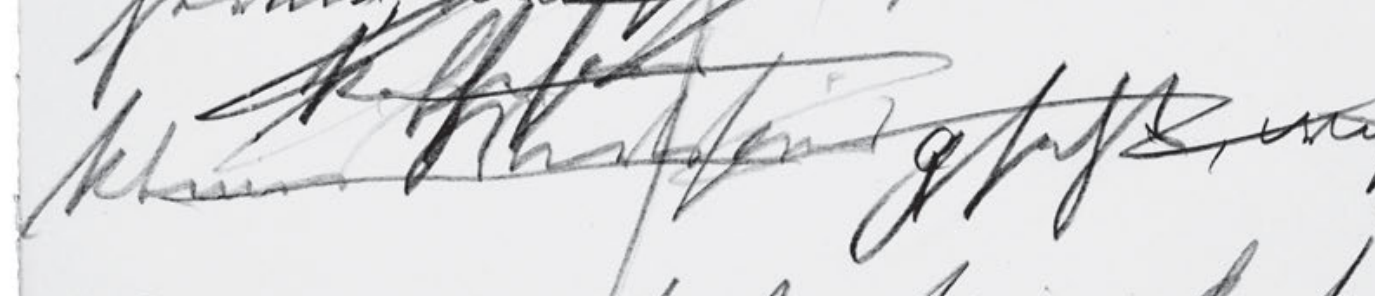

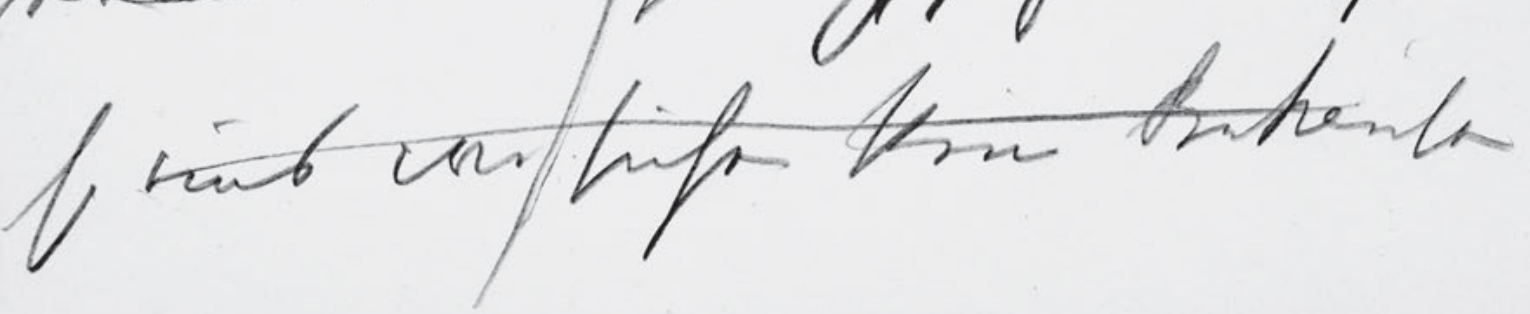


Graf. ${ }^{[?]}$ dar Schauspielerin Ganz allein?

Graf. Mutterseelenallein! Einsam aber nicht alleine*, Ich hab sie noch im̄er in einem Traum vor mir gsehn …

5 in der wissen Sie wie und hab wie 'f? Als ich bin in den Straßen

herumgegangen, um die Ringstraß gegangen

herum, dan habich mich in ein Kaffehaus

kleines Wirtshaus gsetzt, wissen S so eins wo/sicher keine Bekanten 
H'Sz9 [21]

Handschriften und Typoskript

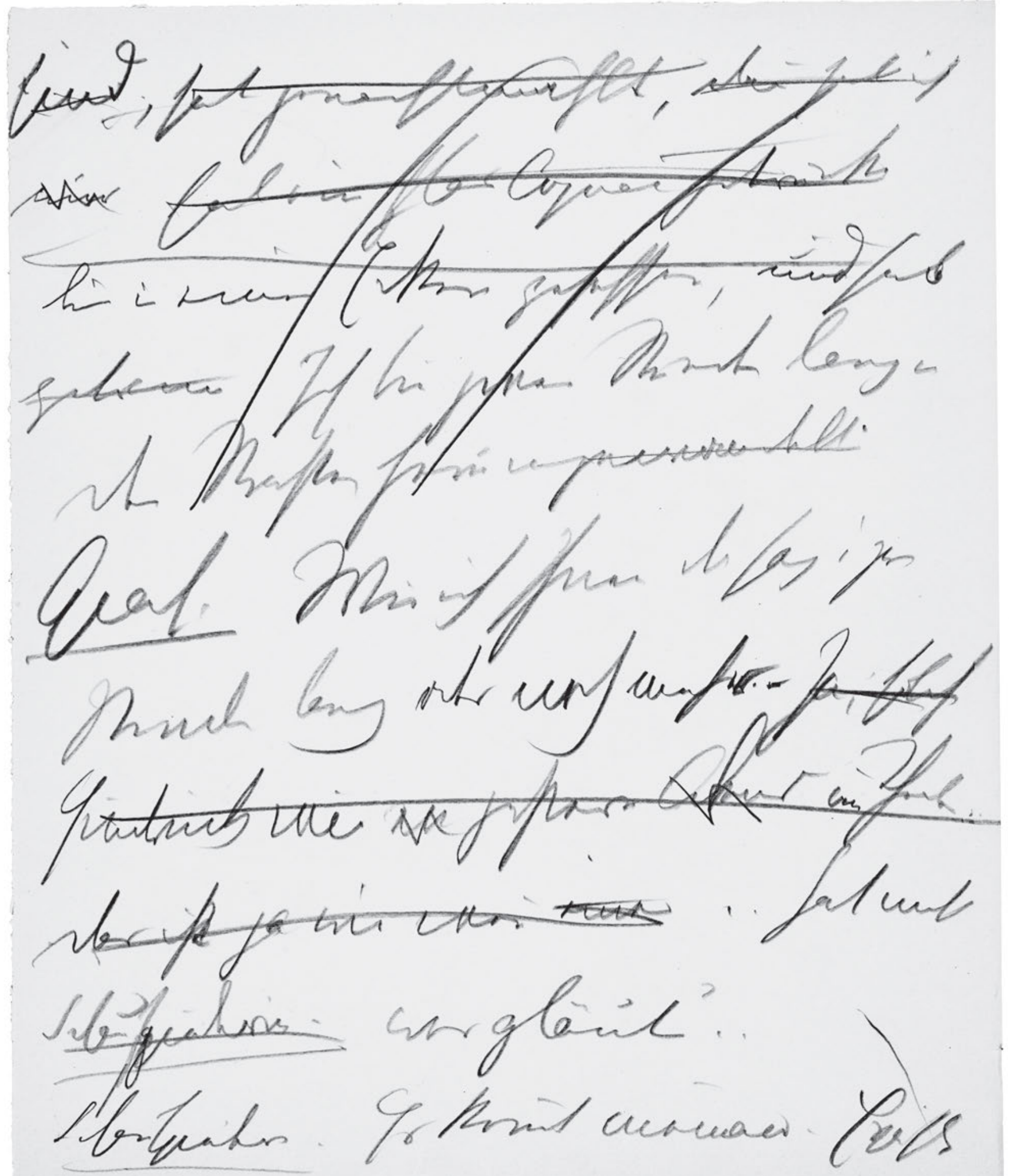

698 
sind; hab genachtmahlt, dañ habe ich ?nur? hab ein Glas Cognacgetrunken bin in einer Ecken gesessen, und hab getraum Ich bin zwei Stunden lang in

5 den Straßen herumgewandelt.

Graf. Wie ich Ihnen do sag: zwei

Stunden lang oder noch mehr. - Ja: solch

Eindrücke wie ?ein? gestern Abend im Theater..

das ist ja wie weñ einer . . hat nicht

$10 \quad$ Schauspielerin. wer gläute? .

Schauspielerin. Es kō̄t niemand. Erzählen

11 Bleistiftspuren über Erzählen nicht bedeutungstragend. 
H'Sz9 [22]

Handschriften und Typoskript

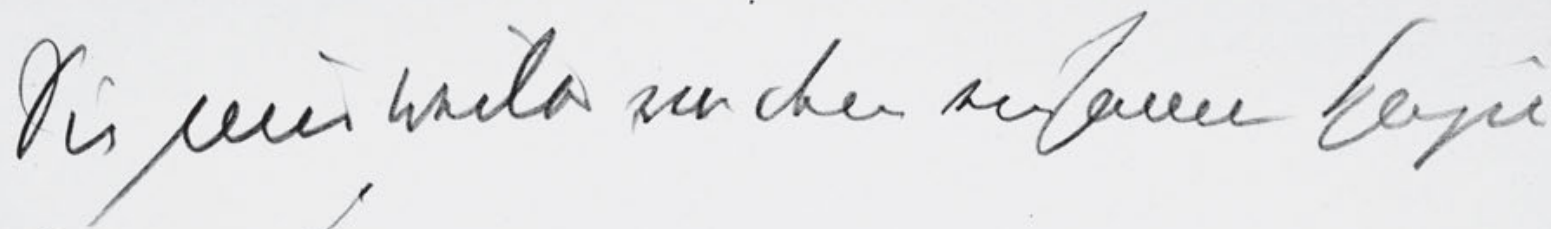
fory.

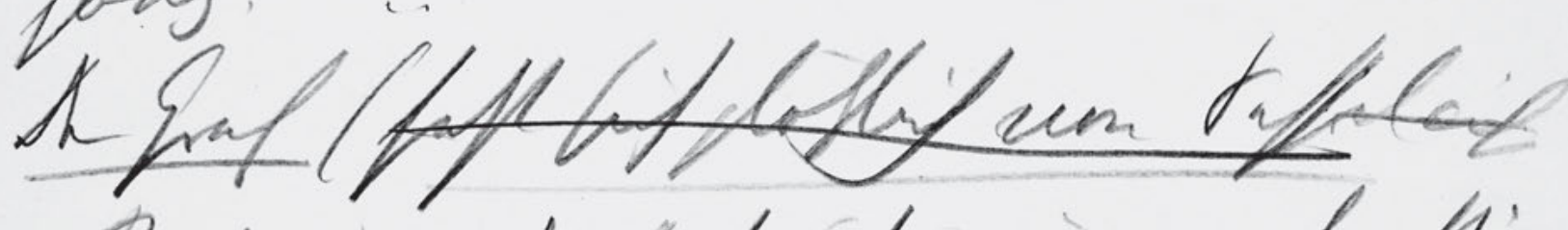

Difigitur

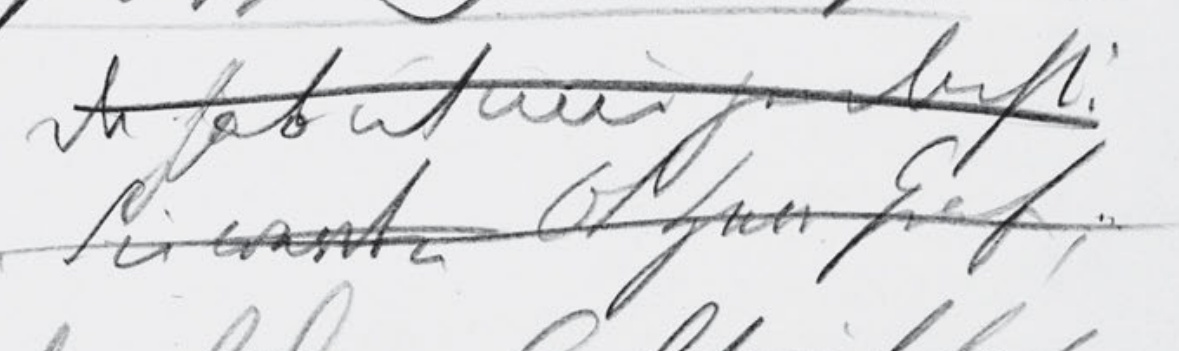

werpto hith.

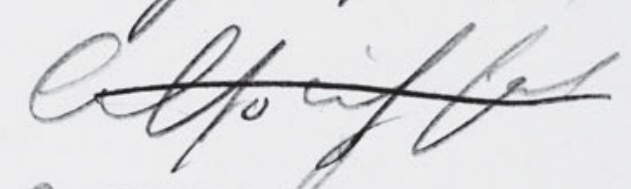

jue to sh faaf. Ssirimbell pa...

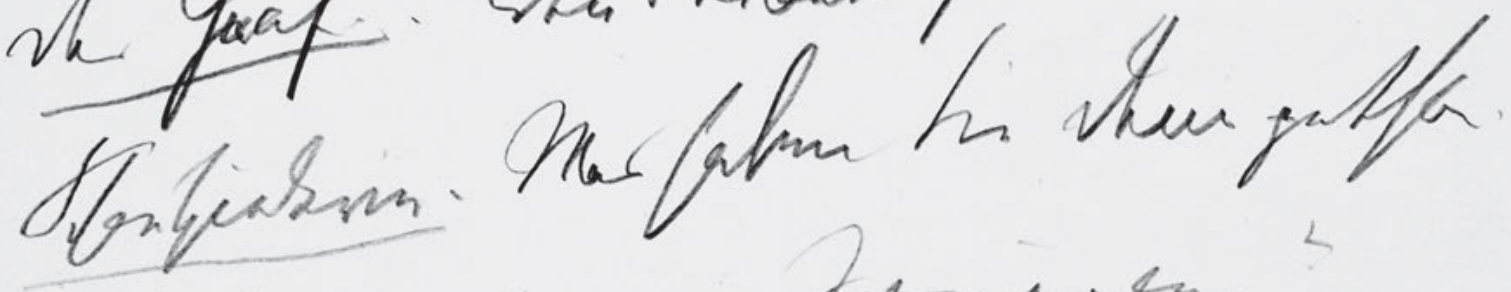

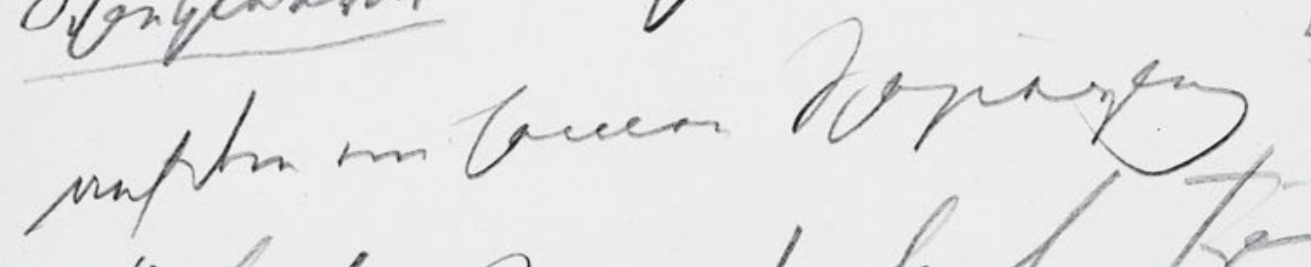
thent rimont beg, trent

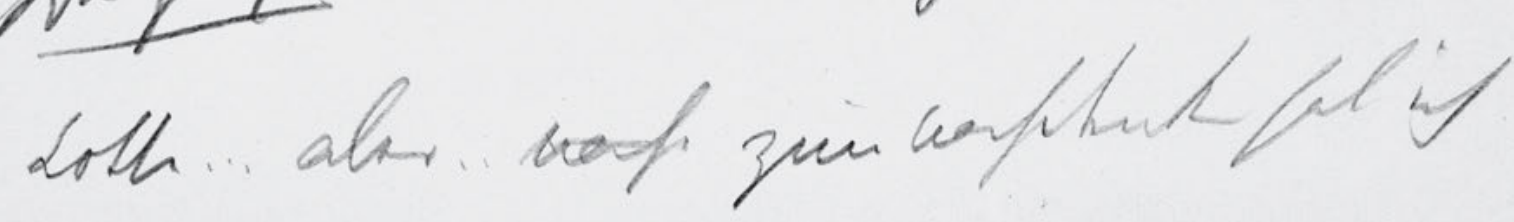

700 
Sie mir weiter von dem einsamen Spazie gang! .

Der Graf (setzt sich plötzlich vom Sessel aufs

Bett) $\mathrm{D}_{\mathrm{a}}$ hab ich mir gedacht:

5 Schauspieler. . Sie werden Oh Herr Graf,..

was ist das Leben. Also ich hab

zum nach?dendken? angefangen . .

Der Graf. . Wen̄’s erlaubt ist ... .

Schauspielerin. Was haben Sie denn gethan,

nach dem einsamen Spaziergang?

Der Graf. Sie werden lachen, Fräulein

Lotte ... aber .. nach zum nachdenken hab ich 
H'Sz9 [23]

Handschriften und Typoskript

Aafauyon.

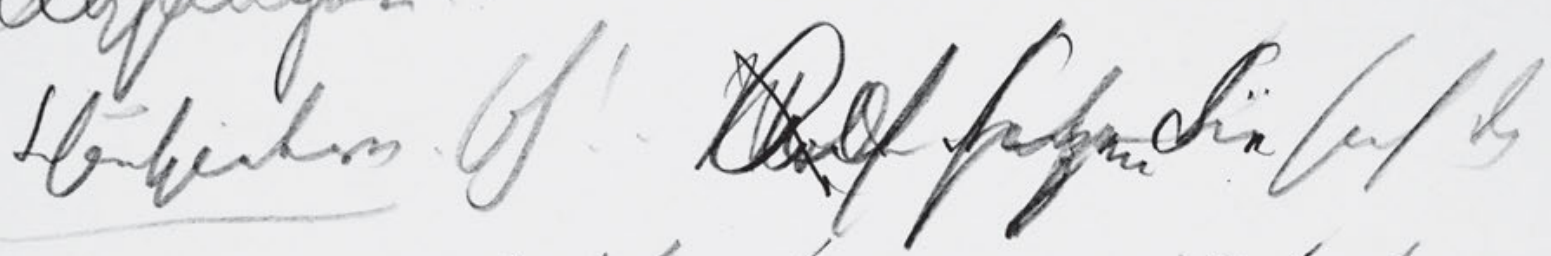

nufor - Do ka is re re me tofo

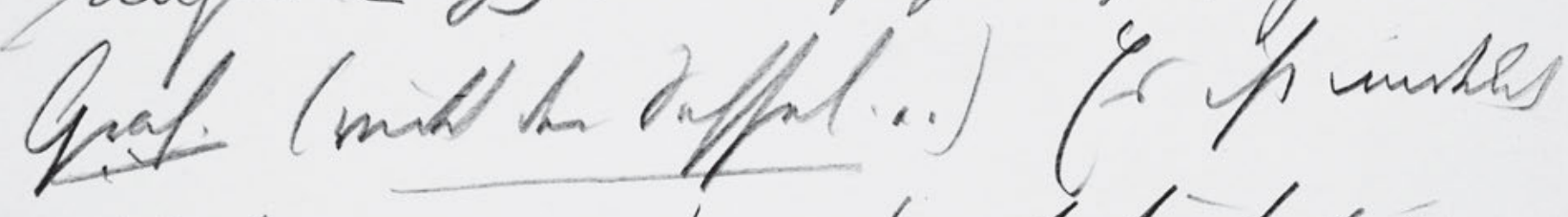

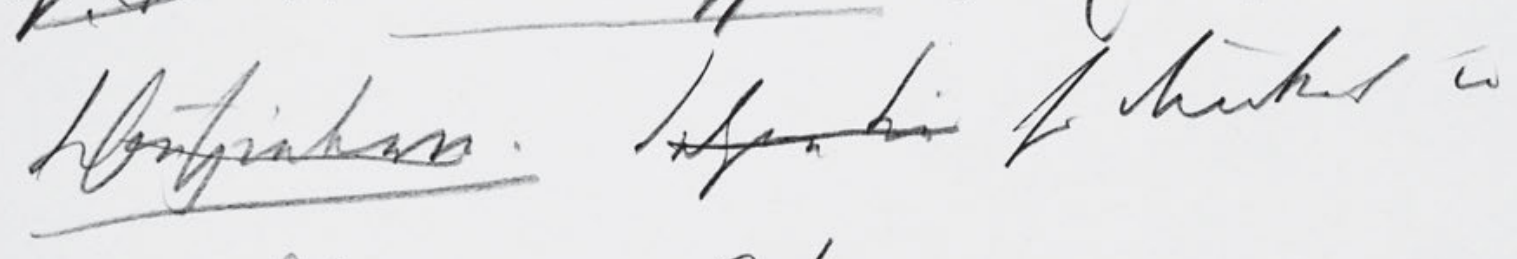

Sh jimun... tot

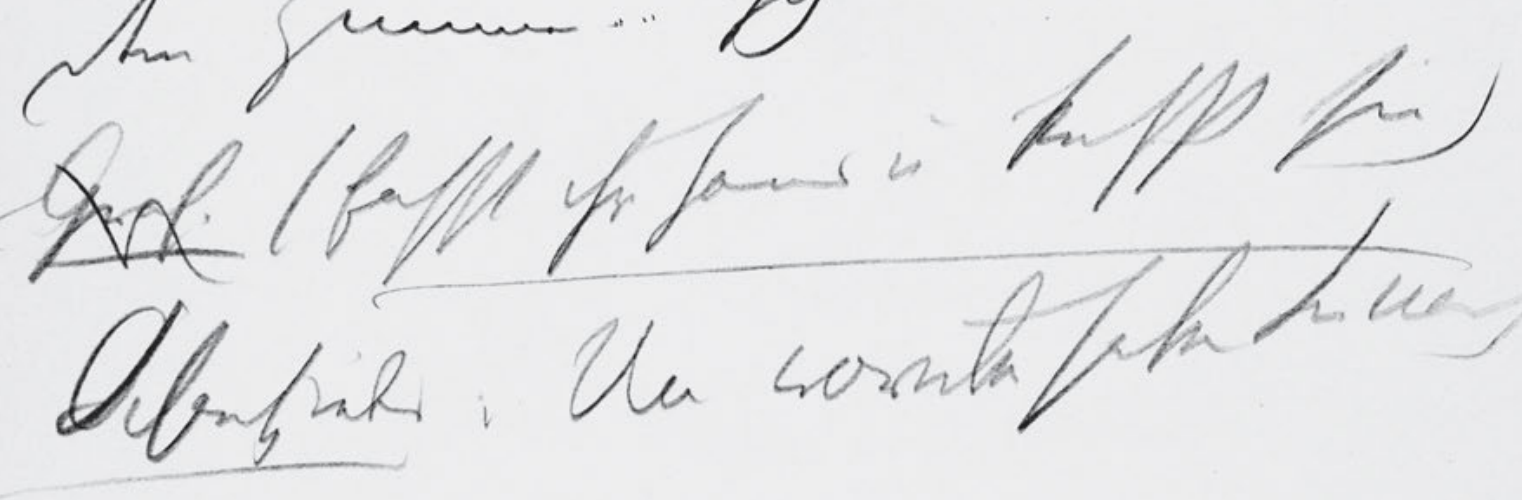

pashefs?

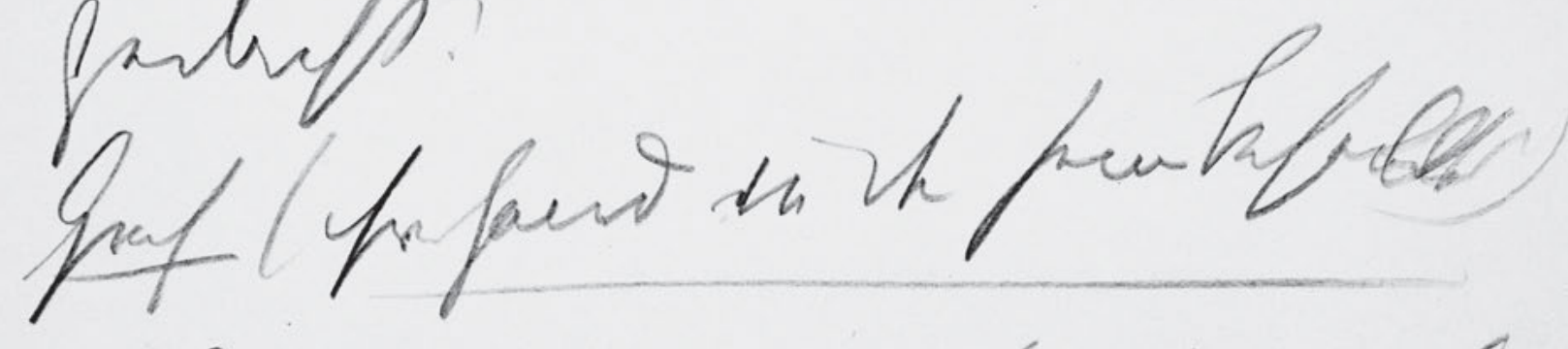

Wh alt milng fontherfy wh

702 
angfangen . .

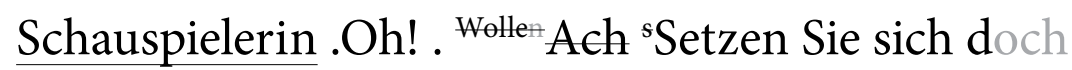

näher . - Ich kan̄ Sie ja gar nicht sehen

“Graf. (rückt den Sessel ... ) Es ist wirklich

5 Schauspielerin. Setzen Sie so dunkel in

dem Zimmer .... Ich

Graf. (fasst ihre Hand u kusst sie)

${ }^{\ominus}$ Schauspieler; Und worüber haben Sie nach

gedacht?

10 Graf (ihre Hand in der seinen beha ${ }^{\text {?nde? }}$ lt)

Über alles möglich . . hauptsächlich ube 
H'Sz9 [24]

Handschriften und Typoskript

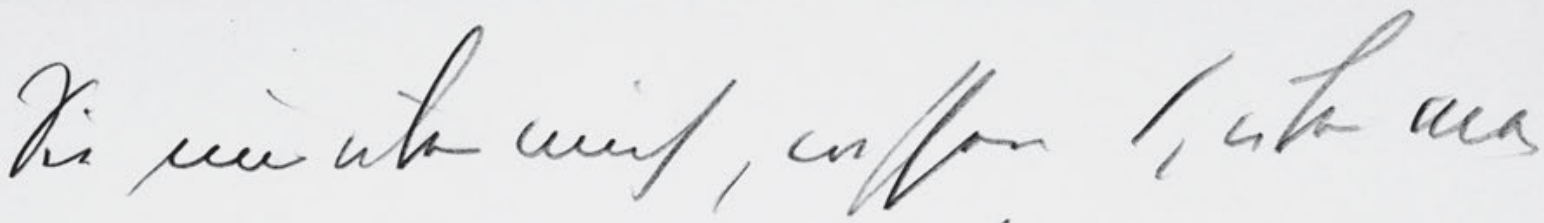
Lakn... Mpif

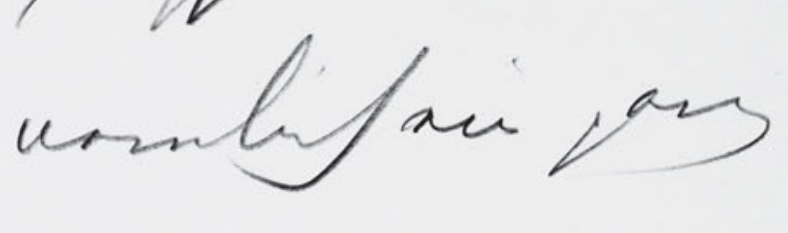

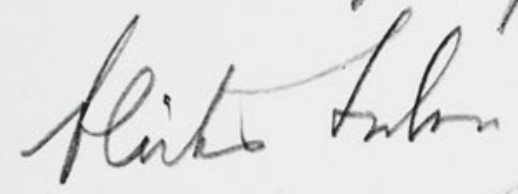

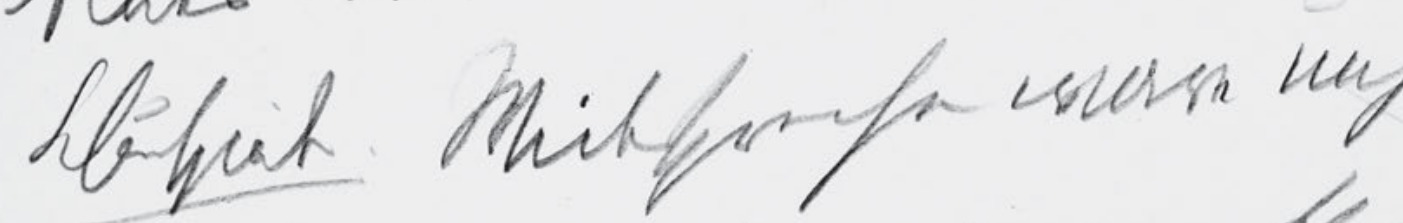

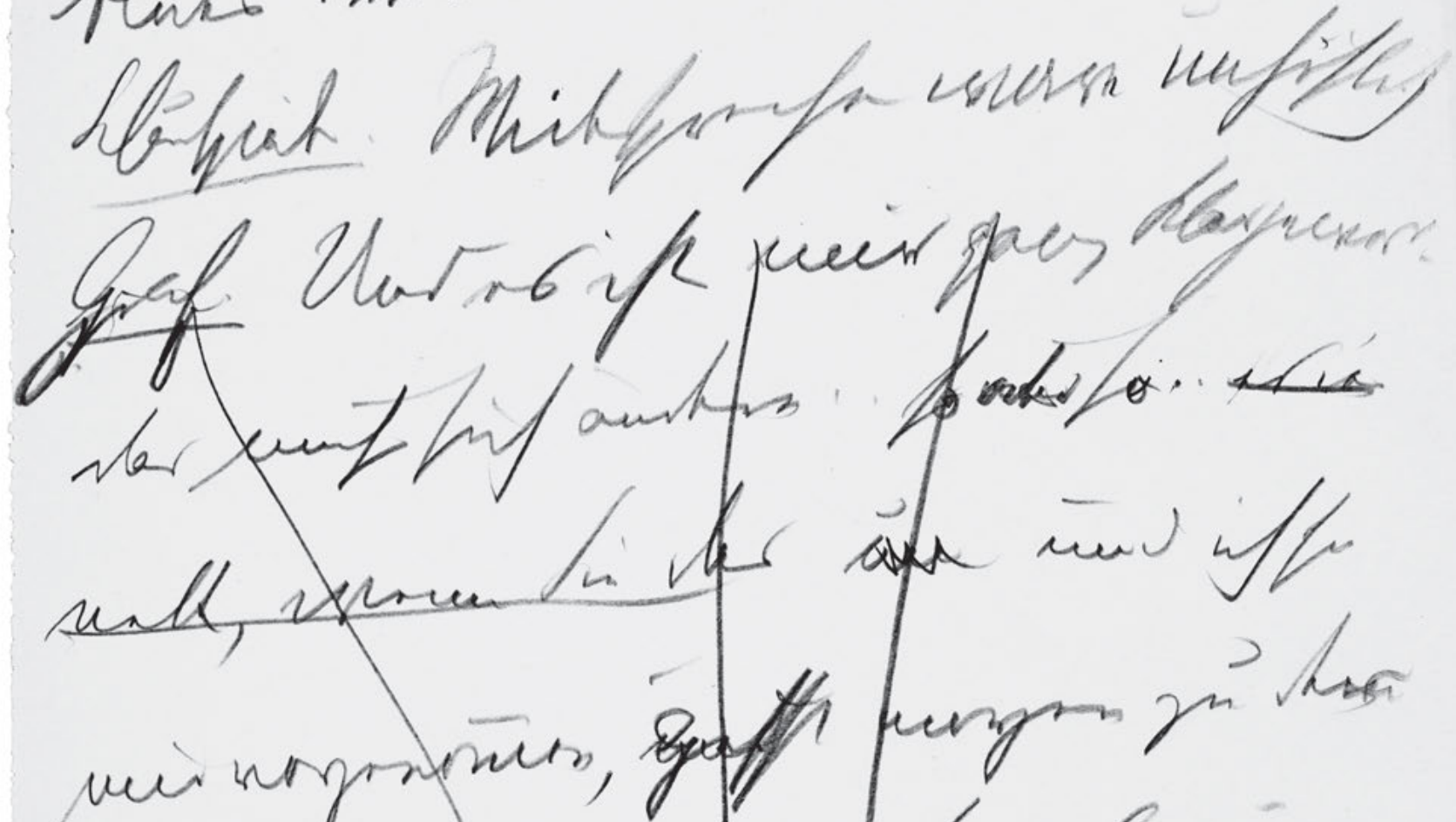

veir morpous,
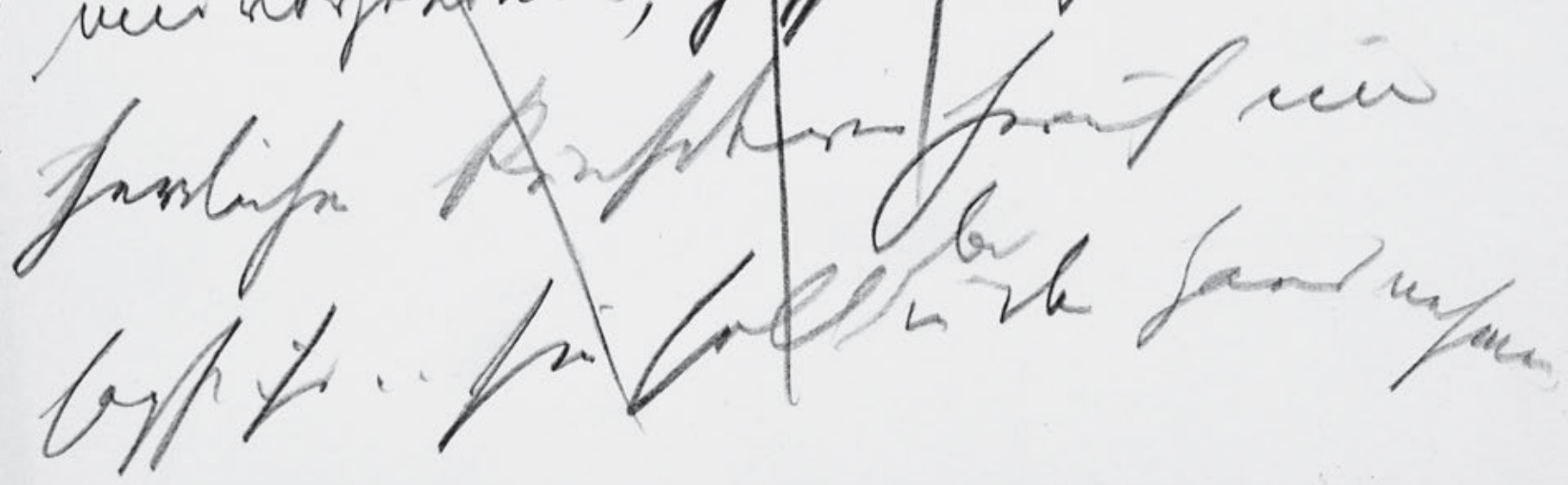

704 
Sie und über mich, wissen $\mathrm{S}$, über mein

Leben ... Ich führ nemlich ein ganz

blödes Leben . .

Schauspieler. Widersprechen ware unhöflich

5 Graf. Und es ist mir ganz klar geword,

das muss sich ändern . . so ?und? oder so . . es wär

nett, wenn Sie das und und ich ha

mir vorgenomen, ?mor? gehst morgen $\mathrm{zu} \mathrm{de}^{\mathrm{m}} \mathrm{r}$

herrlichen Künstlerin herauf und

das

10

sagst ihr . . sie soll/in die Hand nehmen, 
H'Sz9 [25]

Handschriften und Typoskript
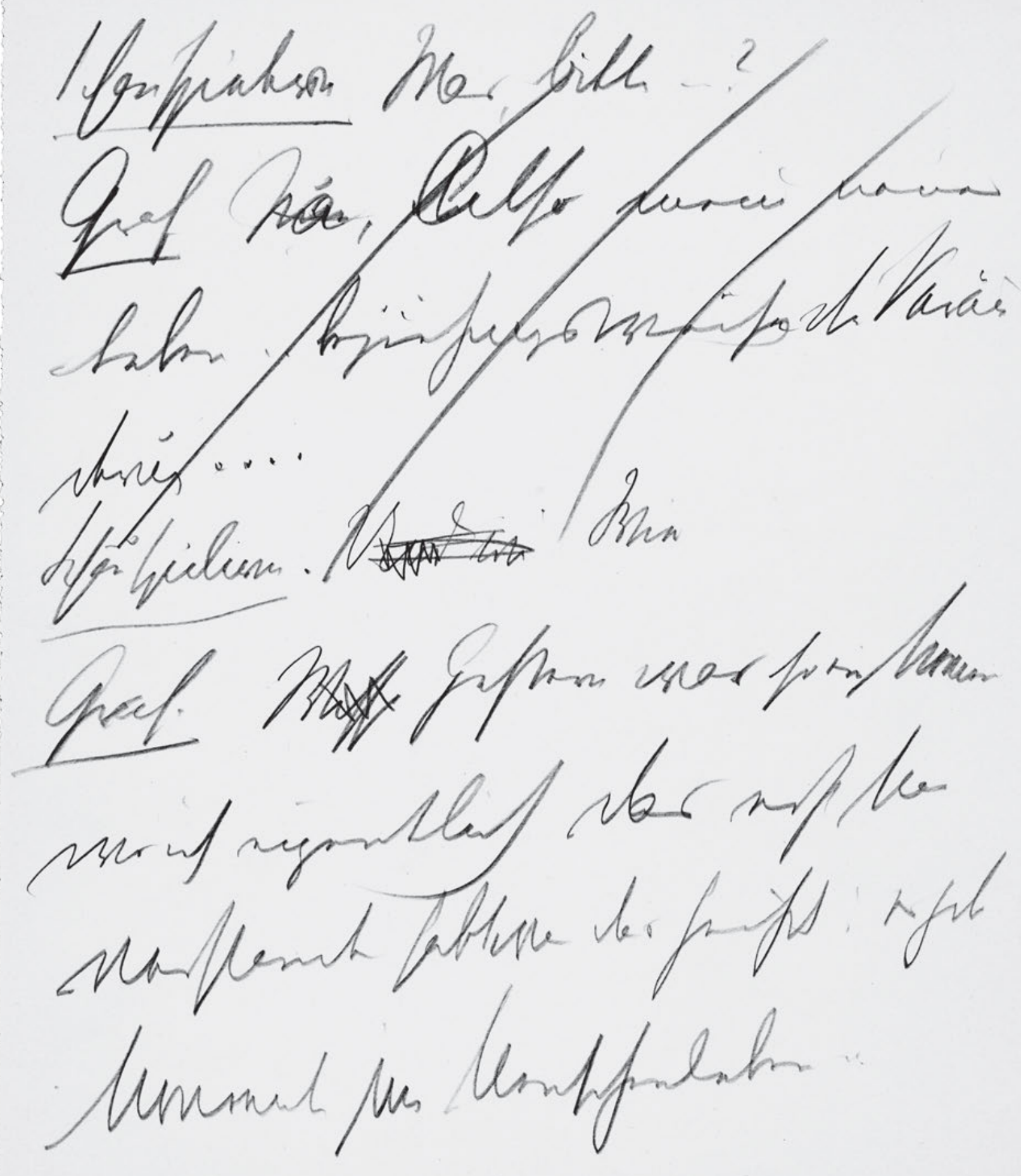

706 
Schauspielerin Was, bitte .. ?

Graf $N^{\mathrm{Hn}} \mathrm{a},{ }^{\mathrm{d}}$ Also mein neues

Leben . . beziehungsweise die Verän-

derung....

Schauspielerin. Ind wie Wie

Graf. Wisse Gestern war so ein Moment

wo ich eigentlich das erst $\mathrm{Ma}$

verstanden hab?t? was das heißt: es gib

Momente im Menschenleben ... 
H'Sz9 [26]

Handschriften und Typoskript

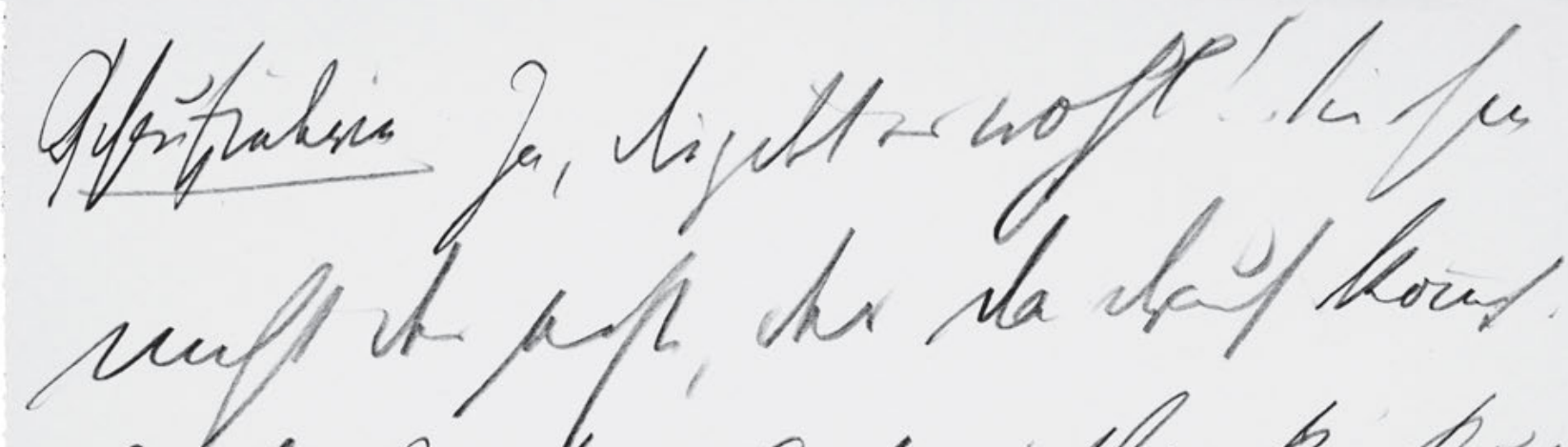

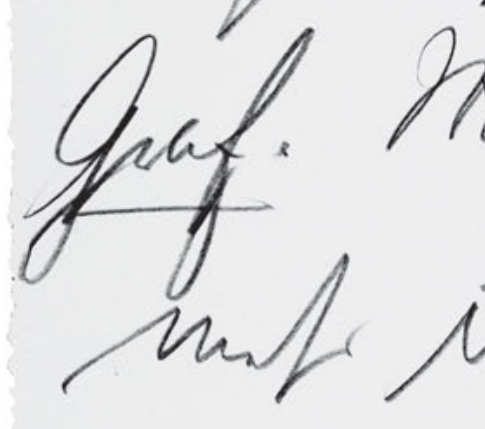

unf jur

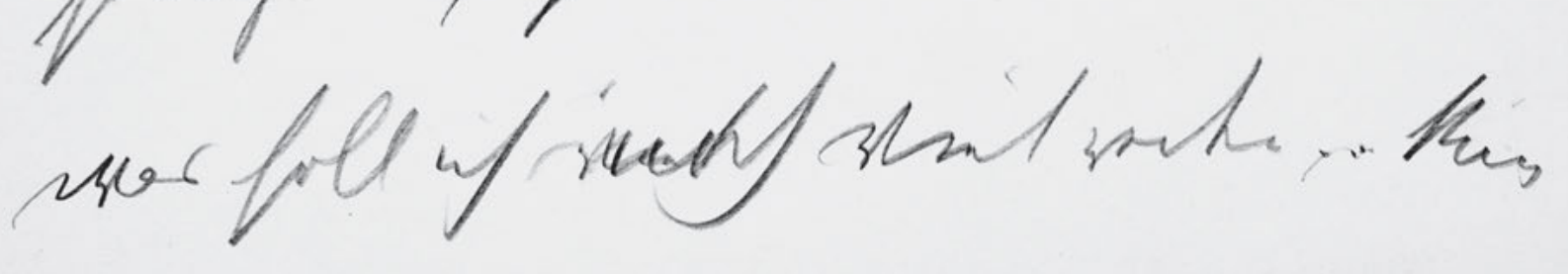

708 
${ }^{G}$ Schauspielerin Ja, die gibt es wohl! . Sie sind

nicht der erste, der da drauf kō̄t.

Graf. Woher Also ich bin ja kei Bub

mehr und hab schon manches

5 mitgmacht, was wirklich kein Spass

war - aber so entzückt wie ich gestern

vo Ihnen war . . was sag ich gestern -

so entzückt, so voll Bewunderung - also

was soll ich viel noch viel reden ... kurz 
H'Sz9 [27]

Handschriften und Typoskript

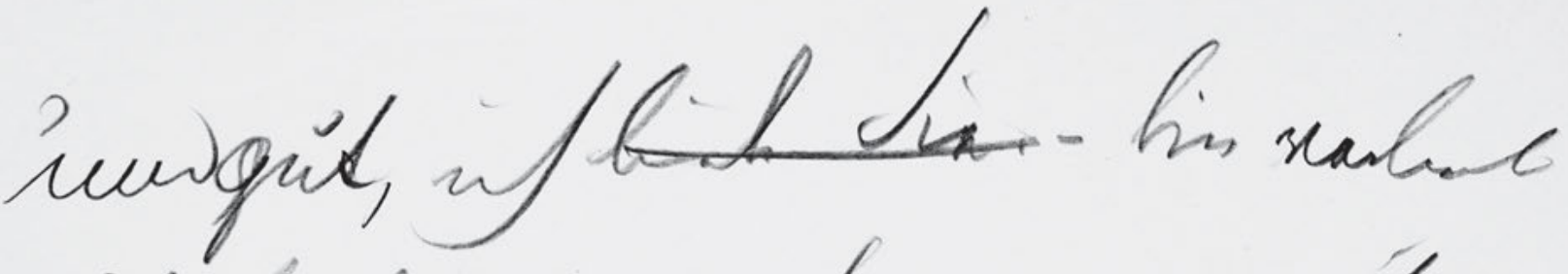

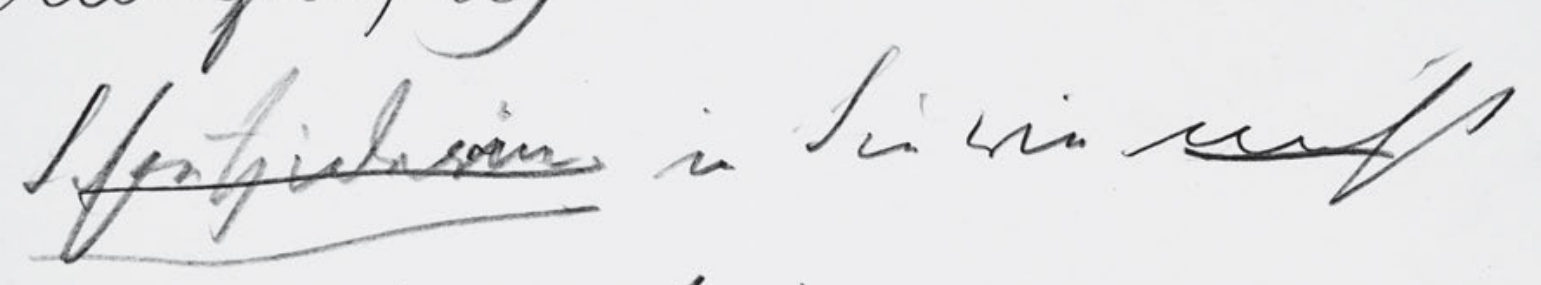

Appiat. ift is monum fors tha niff garafa his.

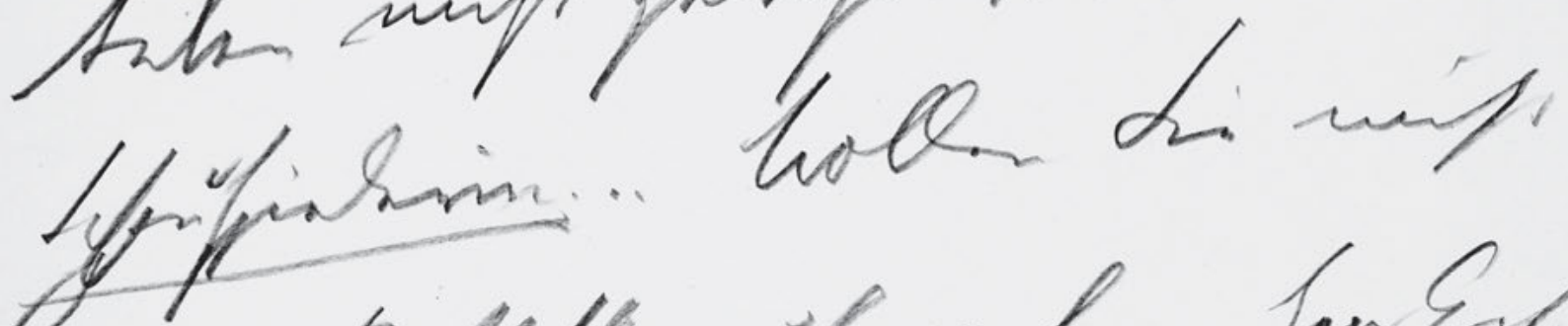

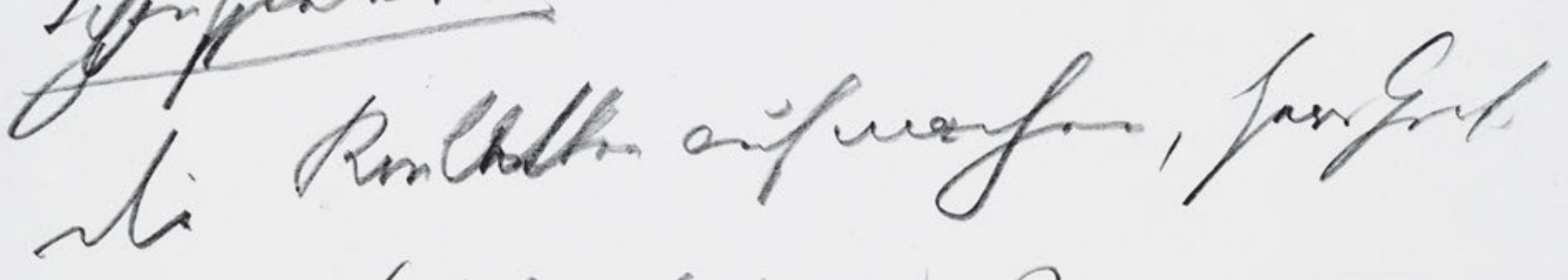

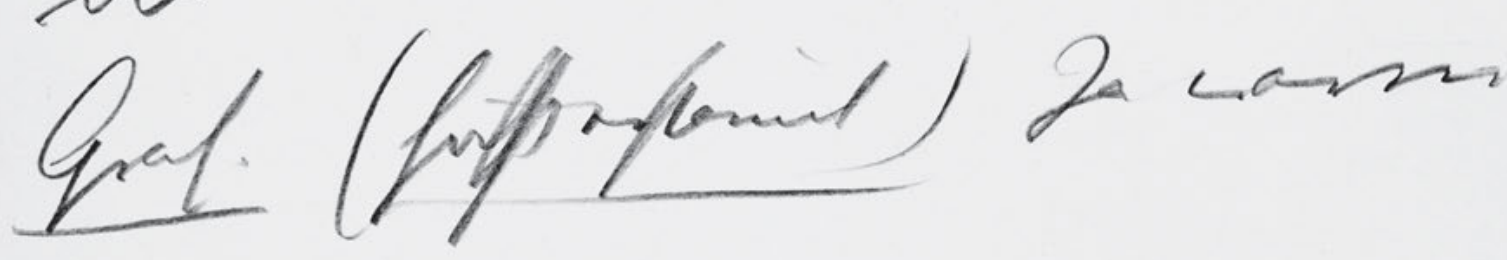

strm?

bigin ming pog

withol.

710 
und gut, ich liebe Sie. - bin verliebt

Schauspielerin. in Sie wie nicht

gscheidt. ichs in meinem ganzen

Leben nicht gewesen bin . .

$5 \quad$ Schauspielerin... Wollen Sie nicht

die Roul ${ }^{\text {let }}$ etten auf machen, Herr Graf.

Graf. (höchst erstaunt) Ja warum

denn?

Schauspielerin. Nun, es ist ja hier

10 so dunkel. 
H'Sz9 [28]

Handschriften und Typoskript

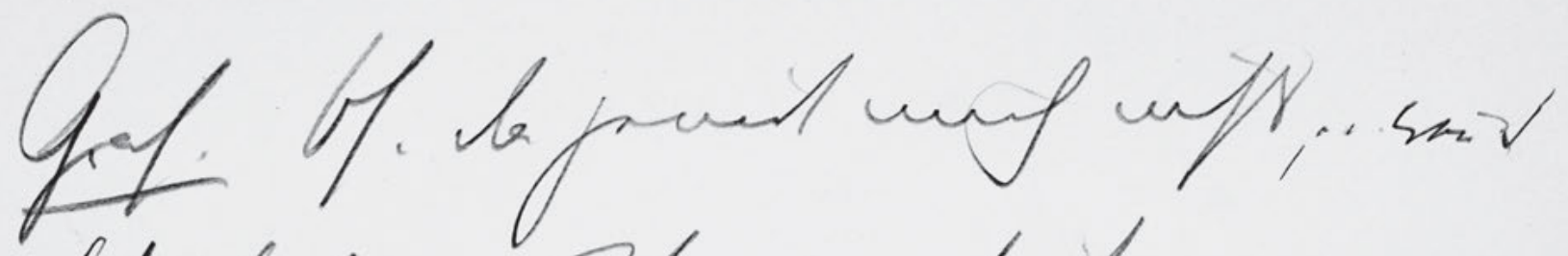
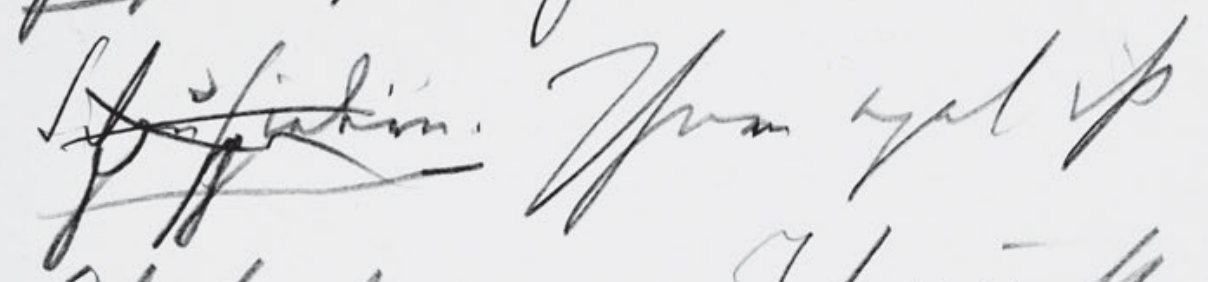

Sifipintini.

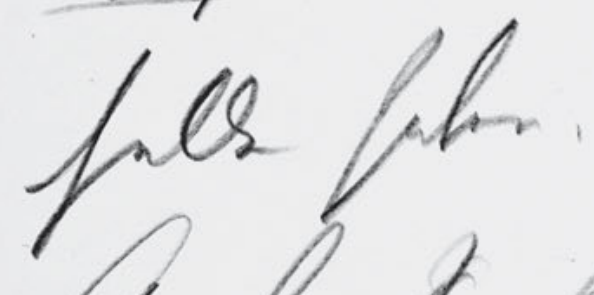

If mingturus

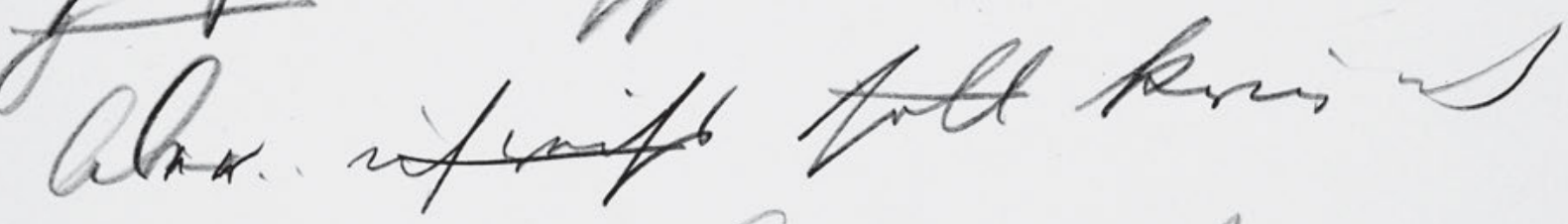

thii onils

Aluntant

fortyith.

Jis for wifum

affort?

oret fah is is cuptheurbs

712 
Graf. Oh, da genirt mich nichts'... weñ S

Schauspielerin. Ihnen egal ist.

Schauspielerin. Ich möchte es 'nic?

heller haben. Ich hasse die Sonne.

5 Graf. So lassen wirs, wie's ist.

Aber .. ich weiss soll krieg ich

keine andre Antwort auf -

Schauspielerin. Sie haben mich etwas

gefragt?

10 Graf. Haben Sie d?as? nicht bemerkt 
H'Sz9 [29]

Handschriften und Typoskript

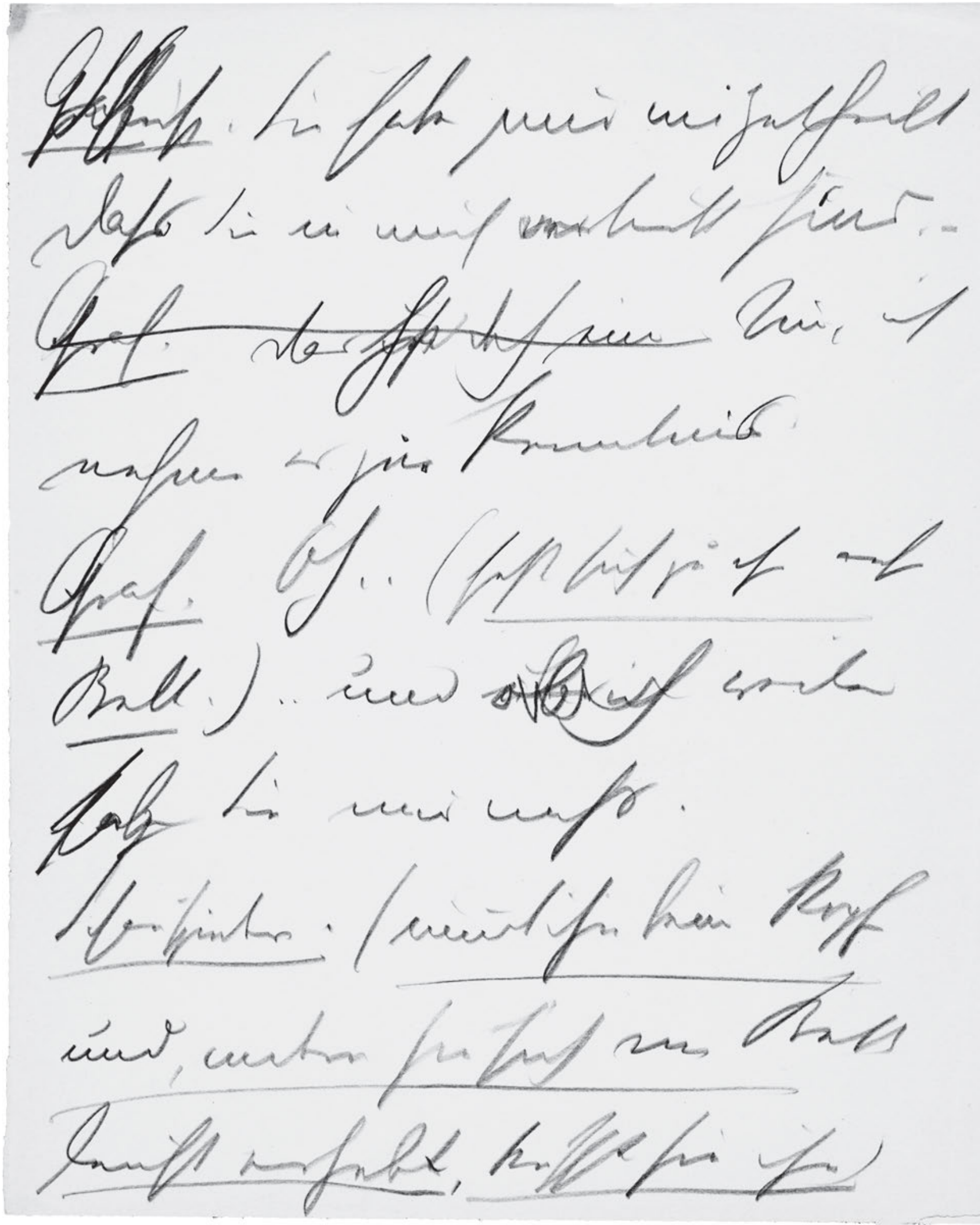

714 


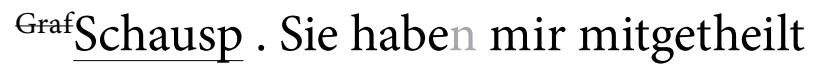

dass Sie in mich verliebt sind. -

Graf. Das ist?heis? doch eine Nun, ich

nehme es zur Kenntnis.

${ }_{5} \quad$ Graf. Oh .. (setzt sich zu ihr aufs

Bett.) .. und über ob ich weiter

${ }^{\text {haben }}$ sagen Sie mir nichts.

Schauspielerin . (nī̄t ihn beim Kopf

und, indem sie sich im Bett

10 leicht erhebt, küsst sie ihn) 
H'Sz9 [30]

Handschriften und Typoskript
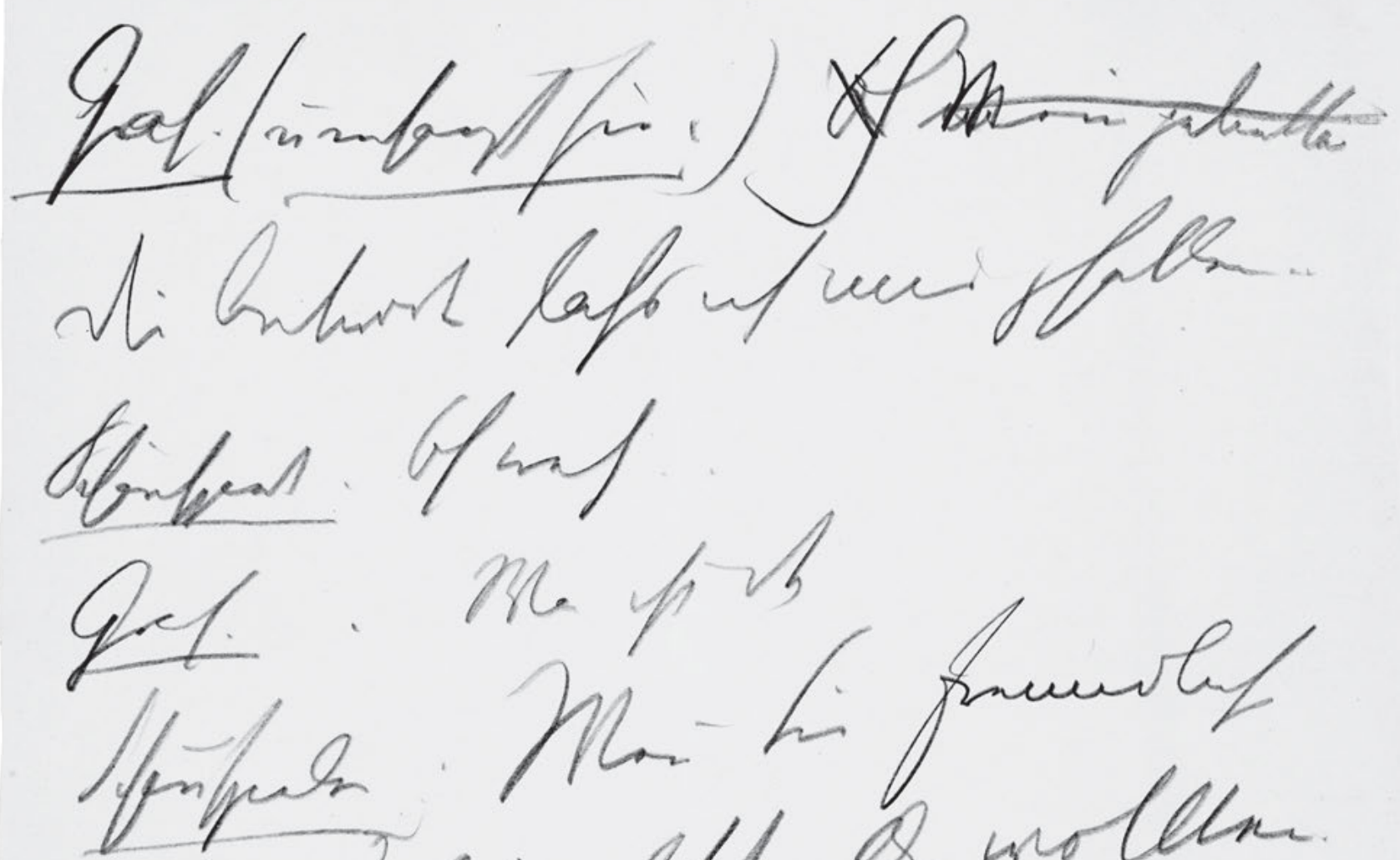

Ma pis

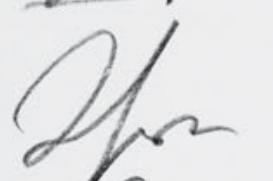

rabl

all

pal.

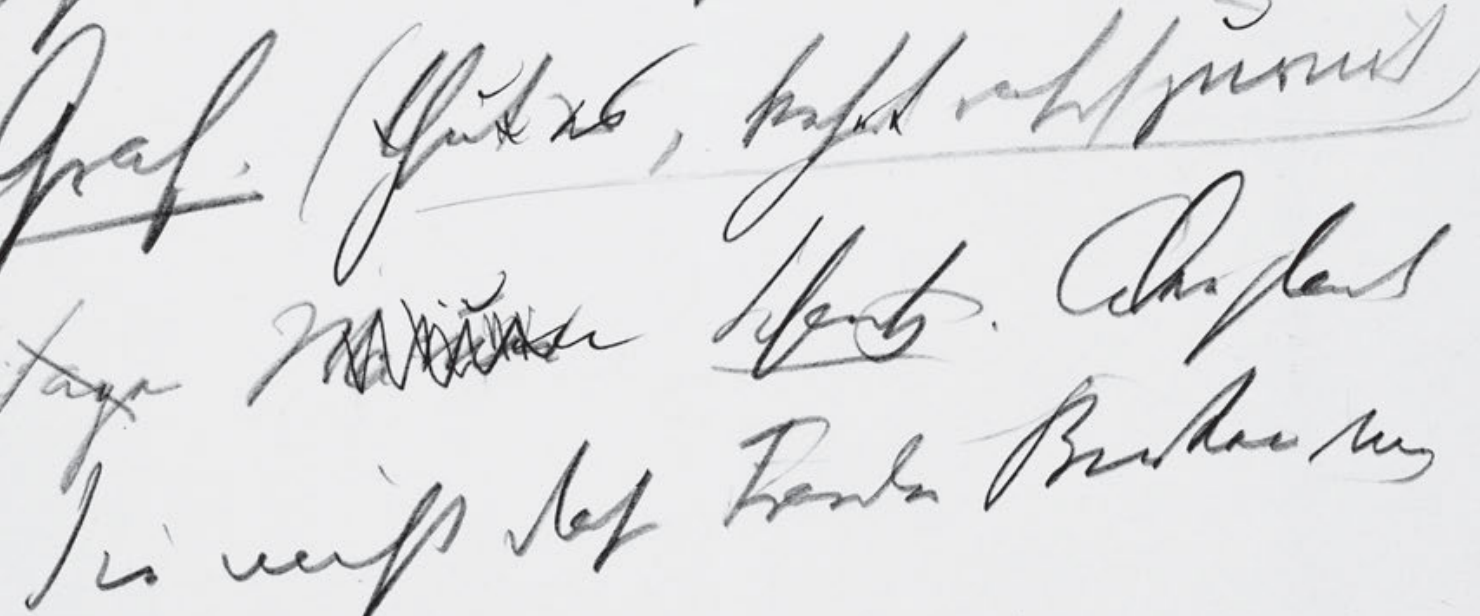

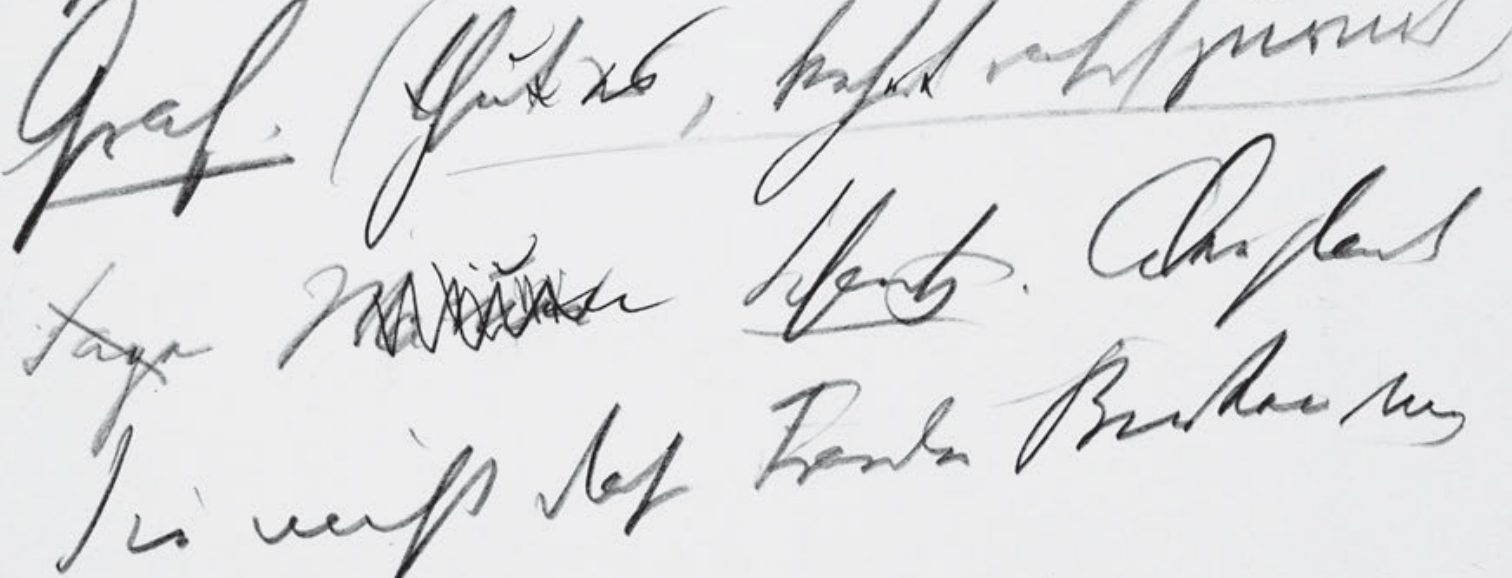

falk pon nowert?

716 
Graf. (umfängt sie.) $\mathrm{Oh}{ }^{\mathrm{m}}$ Mein geliebte

Die Antwort lass ich mir gfallen . .

Schauspiel. Oh weh..

Graf. . Was ist den

5 Schauspieler. Weñ Sie freundlichs

Ihren Säbel abschnallen wollten.

Graf. (thut es, kehrt rasch zurück)

Sagen Warum Schausp. Aber glaub

Sie nicht dass Fraulein Birken ung

$10 \quad$ halten sein wird - ? 
H'Sz9 [31]

Handschriften und Typoskript

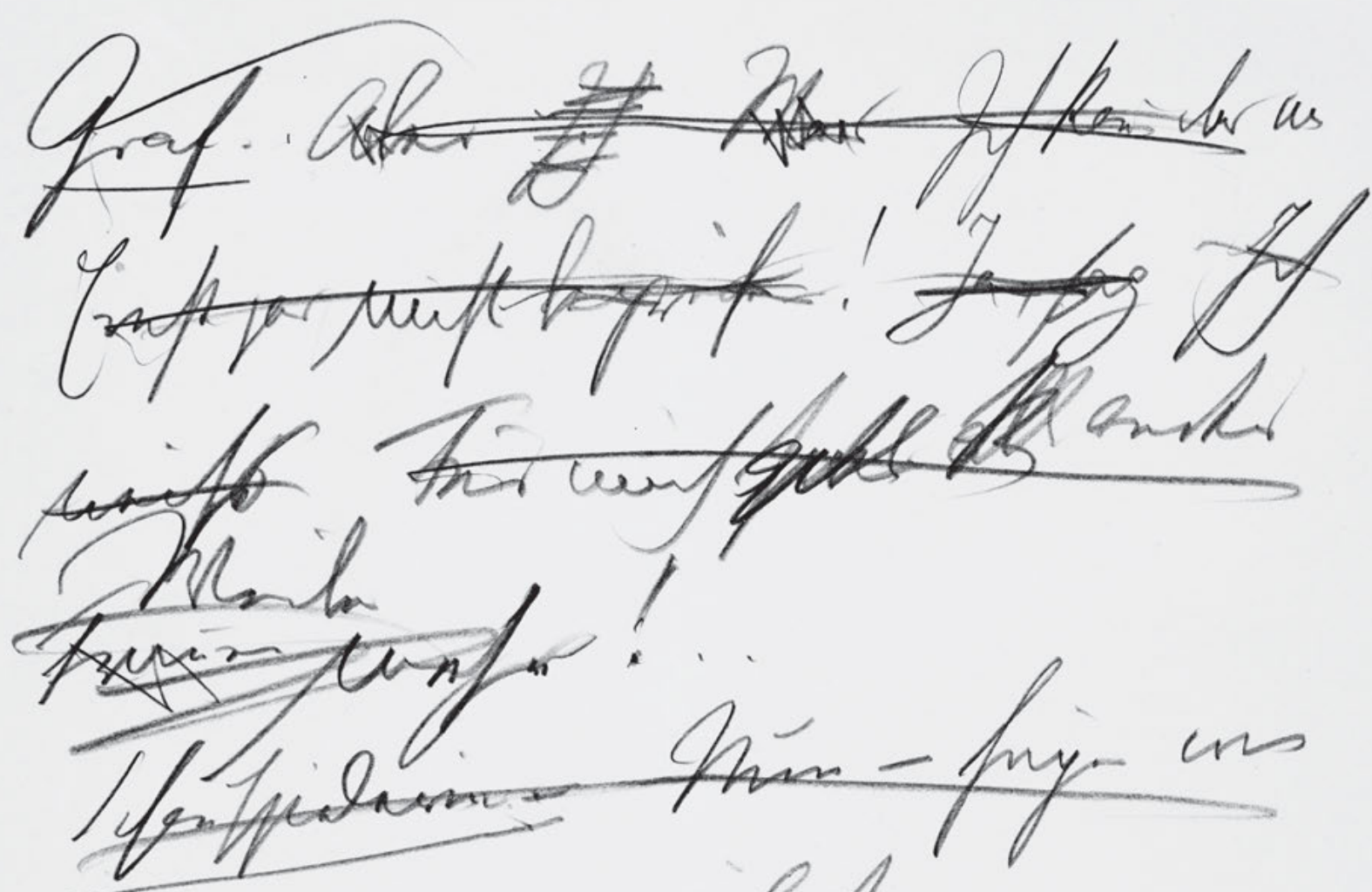

ons hat

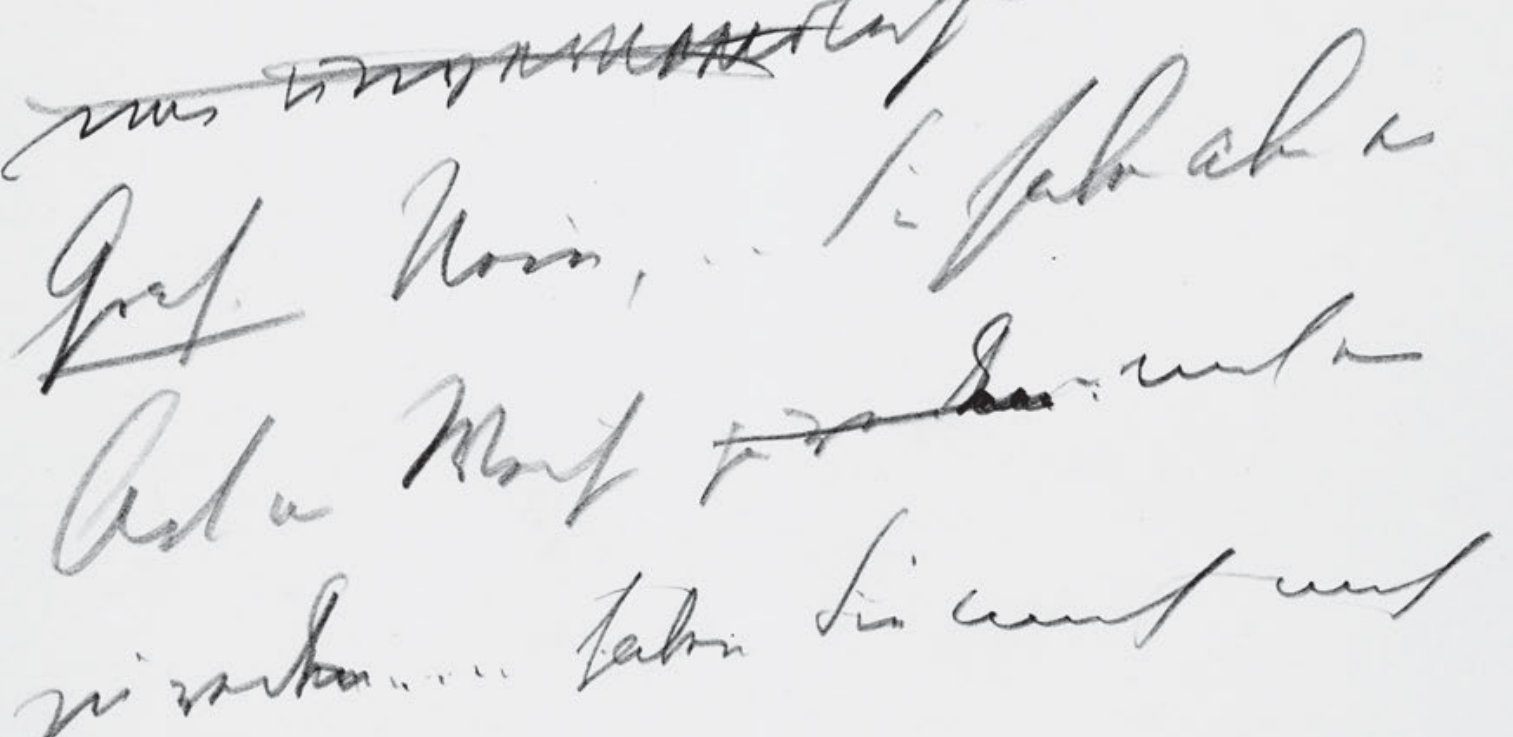
sare gah

718 
Graf. . Aber Ich Was Ich kañ das im

Ernst gar nicht begreifen! Ja, sag Ich

weiss Für mich ${ }^{\sin t}$ gibts allekein ander

Weiber

Frauen mehr! . .

5 Schauspielerin. - Nun - fügen wir

uns unvermeidliche

Graf. Nein, .. Sie haben aber ei

Art un Weise zu reden- mit ein

zu reden ...... haben Sie mich nich

10

grad geküsst ... 
H'Sz9 [32]

Handschriften und Typoskript

Agutiation. to tom bf!

Art (unfoft fiphirgarthy)

Sopint. Tuga an ment men unitiol

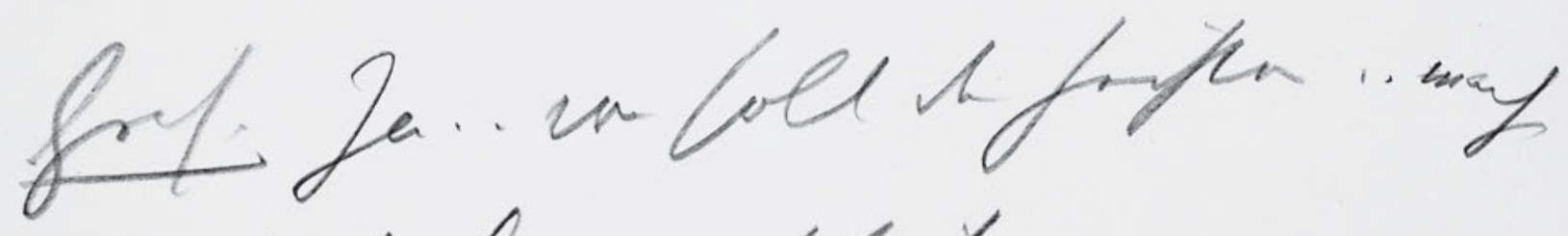
hifuint mif lops
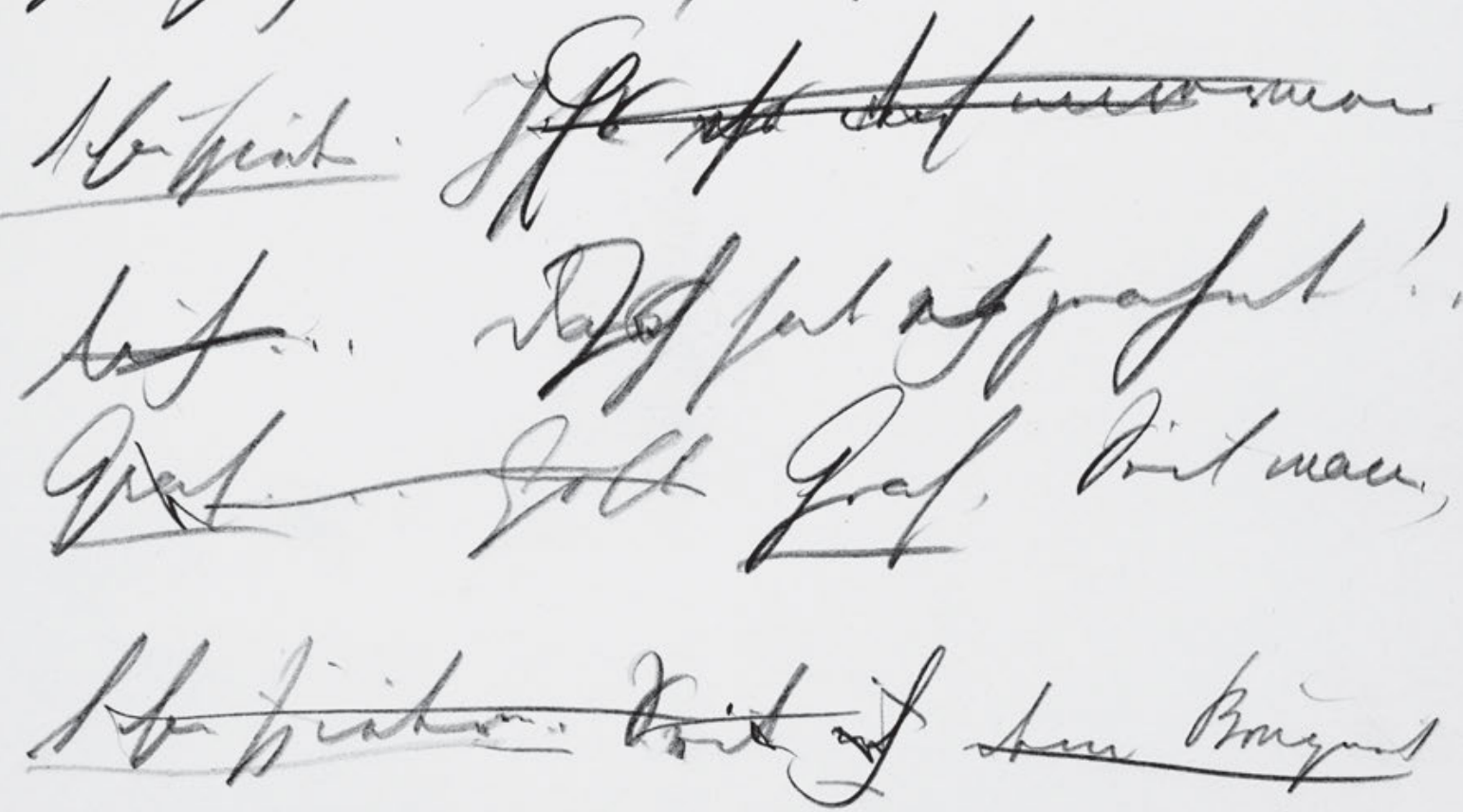

720 
Schauspielerin. So kō̄ doch! .

Graf (umfasst siè, wird zärtlich)

Schauspiel. Fügen wir uns ins unv

meidlich

5 Graf. Ja .. was soll das heißen .. machen

Sie sich über mich lust $\mathrm{g}$ -

Schauspielerin. ${ }^{\text {stes ein }}$ Es ist ?doch? unvermeid-

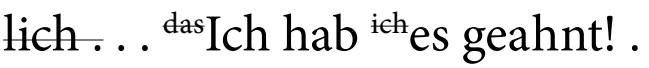

Graf. .. Gott Graf. Seit wann,

10 Schauspielerin. Seit ich dem Bouquet . 
H'Sz9 [33]

Handschriften und Typoskript

Sogipatos..

Gftrom...

zotaris df.

lef hisump

alyou

tefor

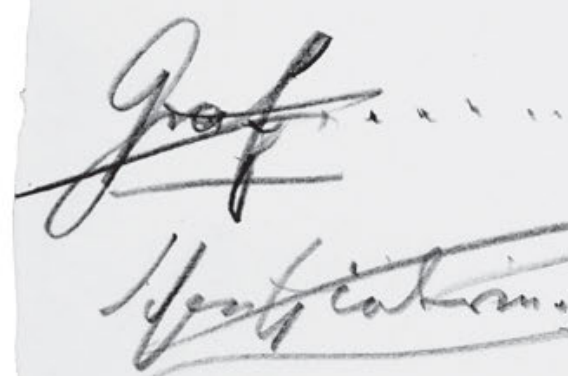

1 fof.... of

exporjarads hogala....

fef $x$

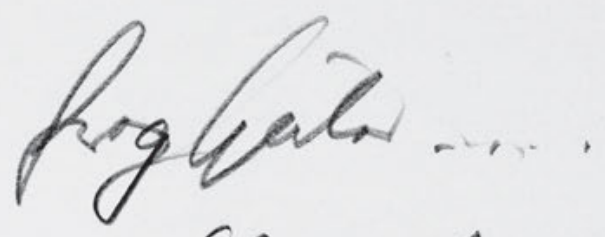

1 Jabt.

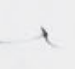

(1) 
Schauspielerin .. Oh kō̄ .. frag später ......

..... . So kom doch ... Es ist $\mathrm{d} h$

gut, dass du wenigstens den Säbel.

abgelegt hast .... oh ...

(lachend)

$5 \quad$ Graf... en plein parade oh..

Schauspielerin. Sei nicht so frivol! .

Graf............... - -

Schauspielerin. Herr Graf..

10 Graf. Du bist das herrlichste Geschöpf

das mir in meinem gan [?] 
H'Sz9 [34]

Handschriften und Typoskript

Iferater

Is bet s/th mon.

thipf

Aaf en pein perare

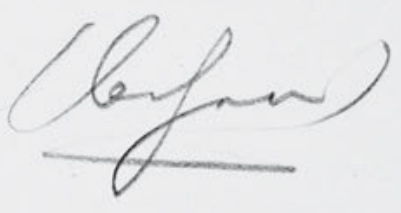

Jefpich...

$\frac{\text { qraf..... }}{\text { tnnil }}$

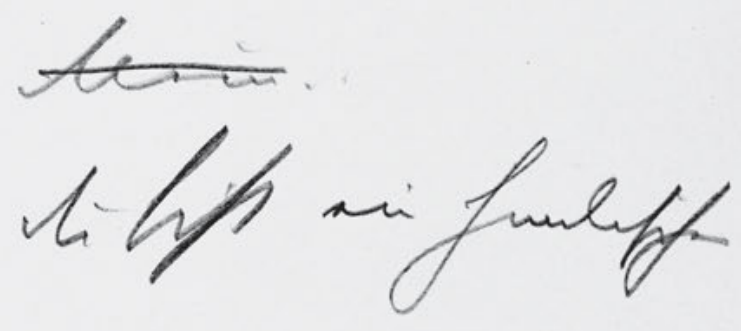

syifintin...

meep nfort ho

Qraf. Ra/sm

songutm:

quife...

Qrat.

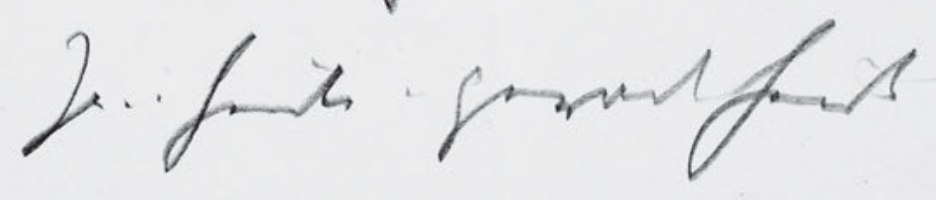

724 
Schauspieler . So bleib doch bei mir . .

du bist so schön .... . in Uniform . .

Graf. en plein parade (lachend)

Schauspielerin .......... Mein . .

${ }_{5} \quad$ Graf. $-\ldots$. Ah .. du bist ein himlisches

.. Weib .

Schauspielerin ... Willst du heut Abend

zu mir komen . .

Graf. Nach dem Theater . .

10 Schauspielerin :. Gewiss .....

Graf. Ja . . heute . gerade heute .. wird 
H'Sz9 [35]

Handschriften und Typoskript

der mift wilnt for Jyaifunt Marcie, son
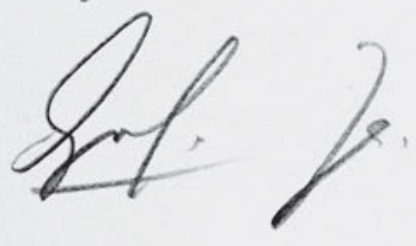
w)
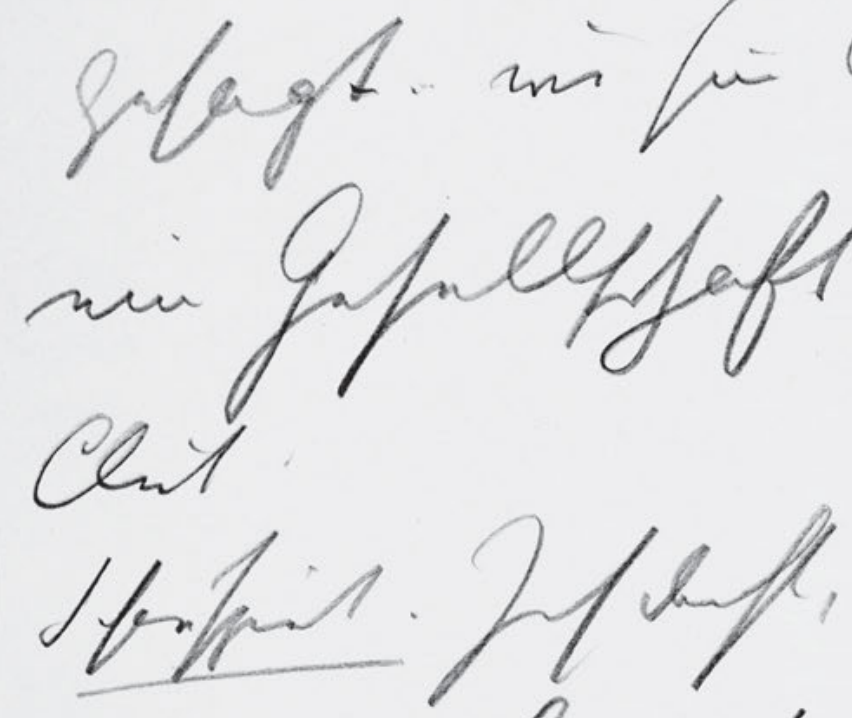

Li wobla a

unar tih asfory, lf tragf bl 
das nicht möglich sein.

Schauspieler. Warum, wen ich frag darf -

Graf. Ja, ich hab dir ja schon früher

gesagt ... wir sind Abend immer so

5 eine Gesellschaft . . un dā̄ geh ich in

Club.

Schauspiel. Ich dachte, Sie wollten ein

neues Leben anfangen, Her Graf

Graf Das hab ich j grad gethan.

10 Schauspieler. Ah, Sie ${ }^{\text {meinen }}$ denken, 


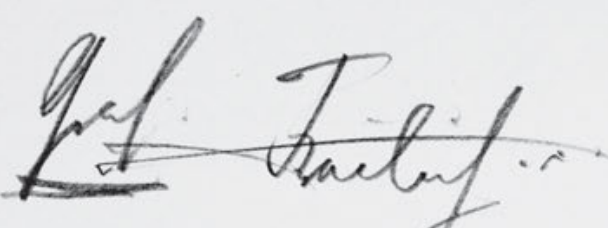

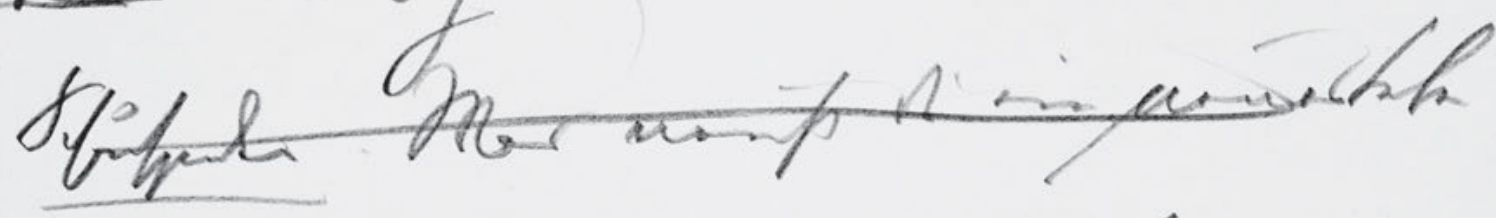
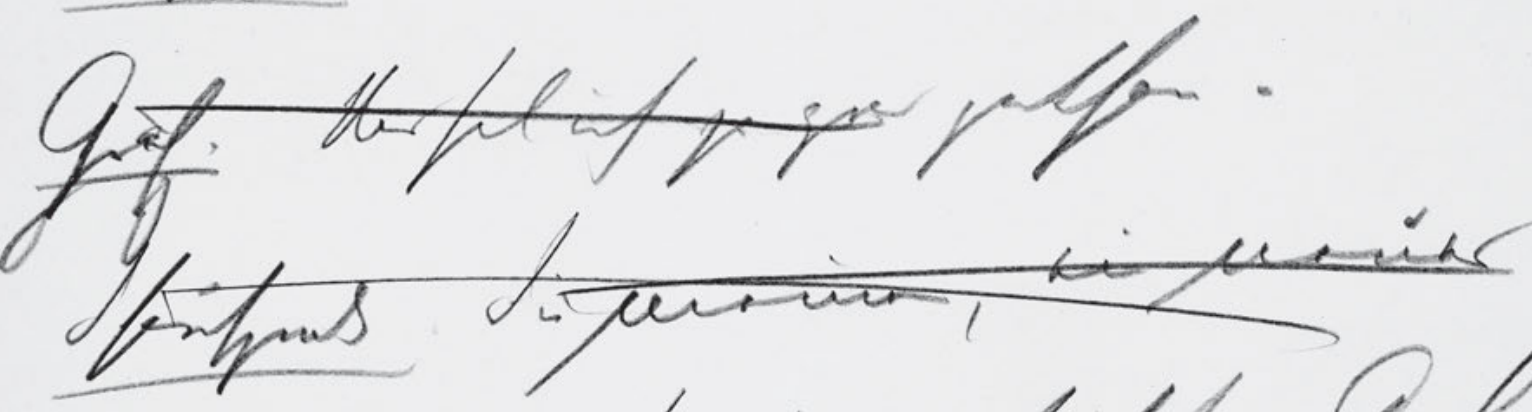

Mutpotare

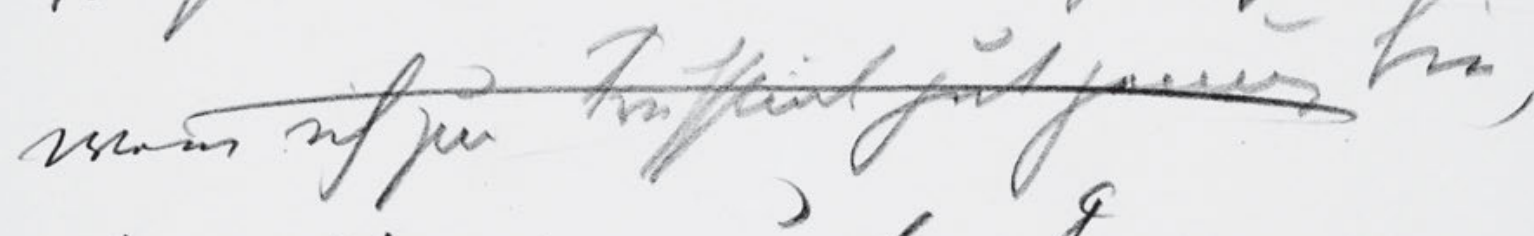

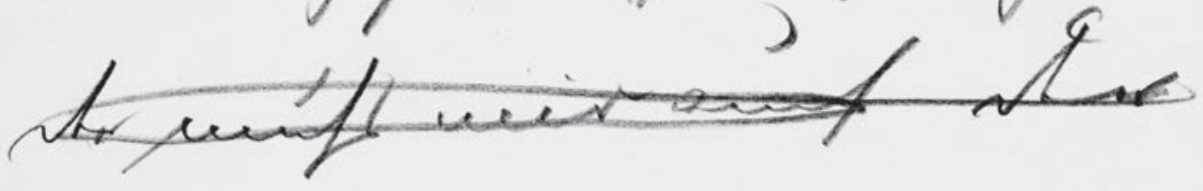

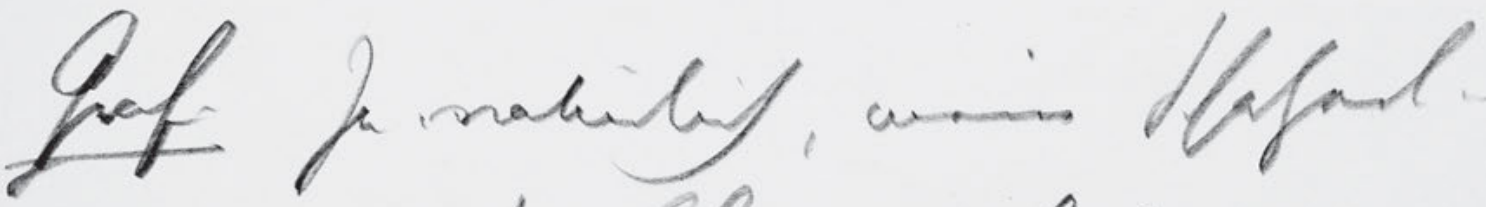

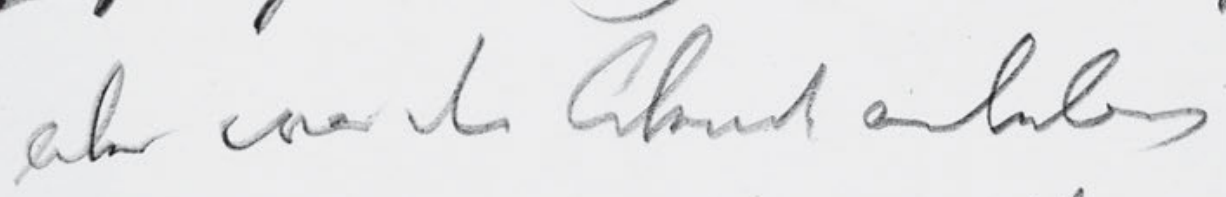

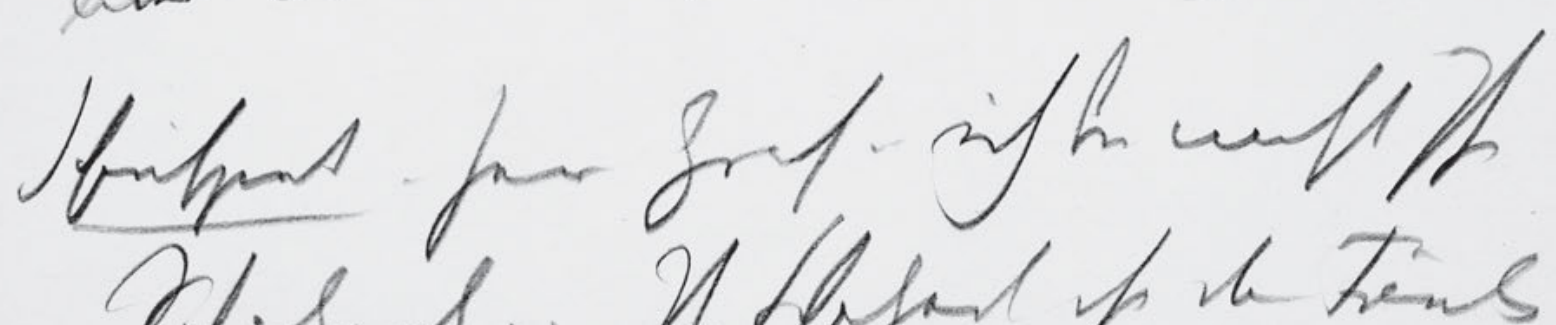

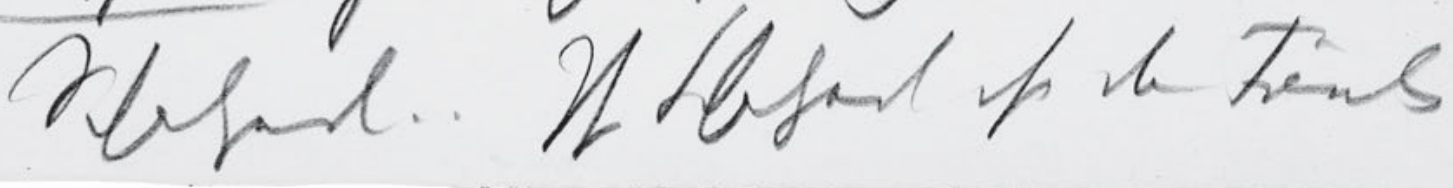


Graf. Freilich....

Schauspieler. Was neñst du ein neues Leben

Graf. Das hab ich ja grad gethan.

Schauspiel. Sie meinen, ein neues

$5 \quad$ Verhaltnis Sie irren sich Herr Graf.

wem ich zum Frühstück gut genug bin,

der muss mir auch der

Graf. Ja “natürlich, mein Schatzerl . .

aber was die Abende anbelang

Schauspiel . Herr Graf . ich bin nicht Ihr

Schatzerl . . Ihr Schatzerl ist das Fräulein 
H'Sz9 [37]

Handschriften und Typoskript
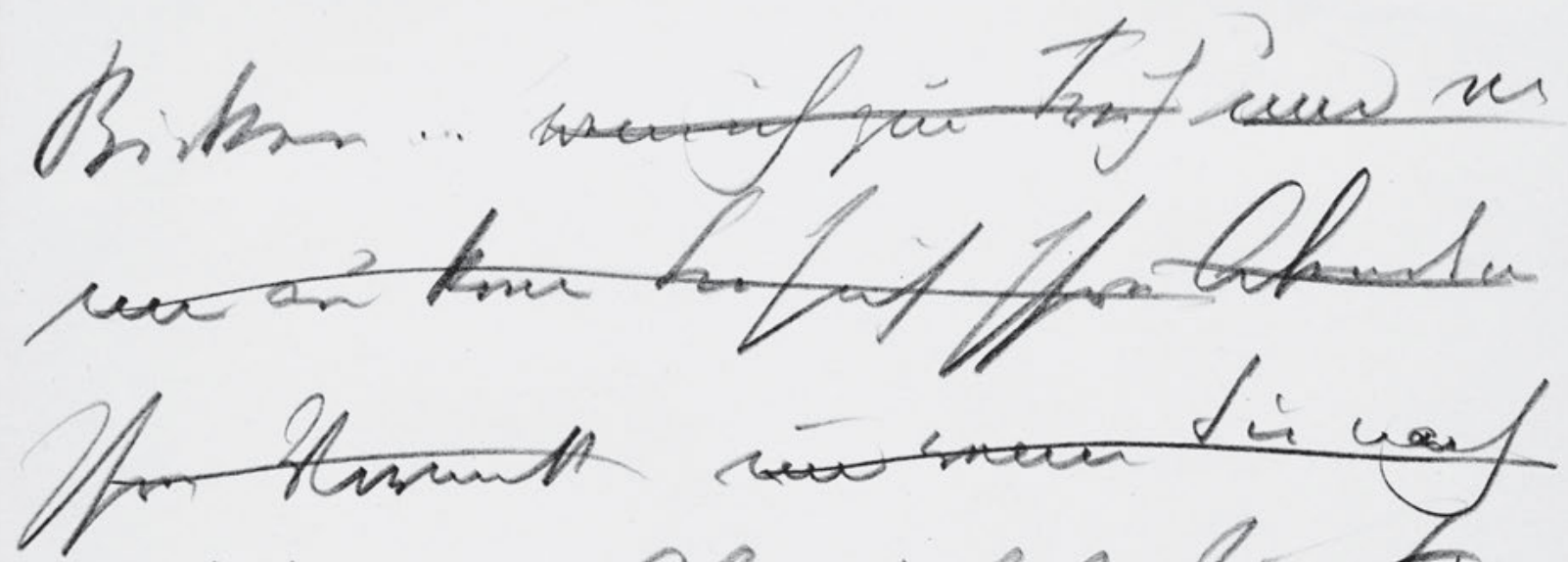

if hi

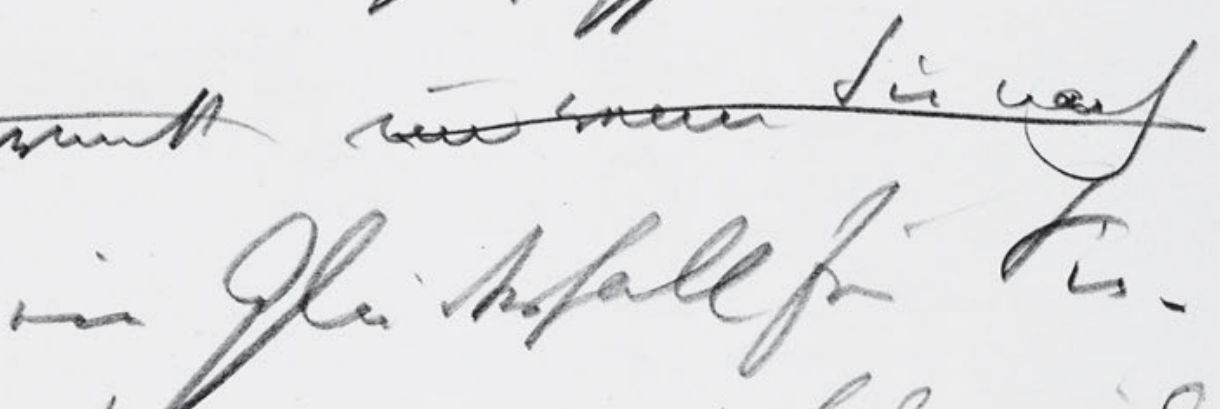

soont hif un un

pert.

Ala

if

Ak

Lin

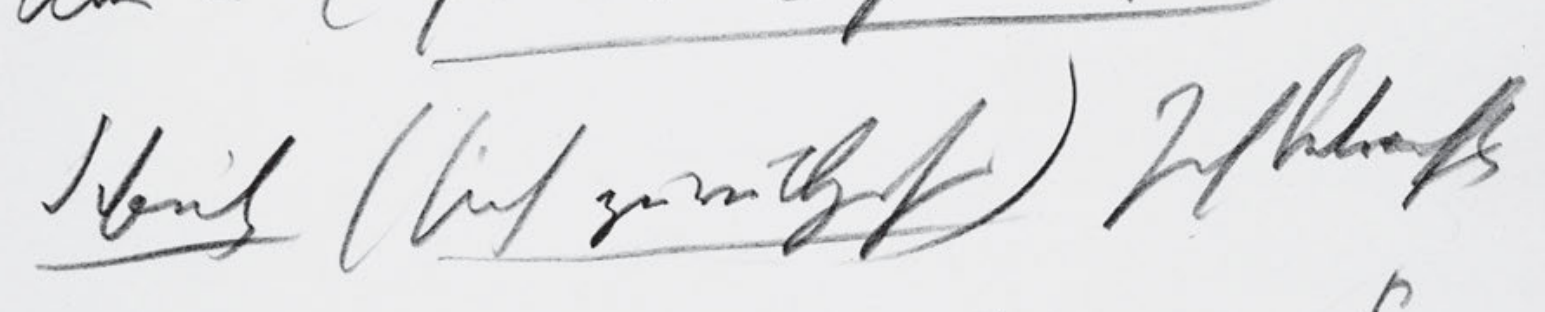

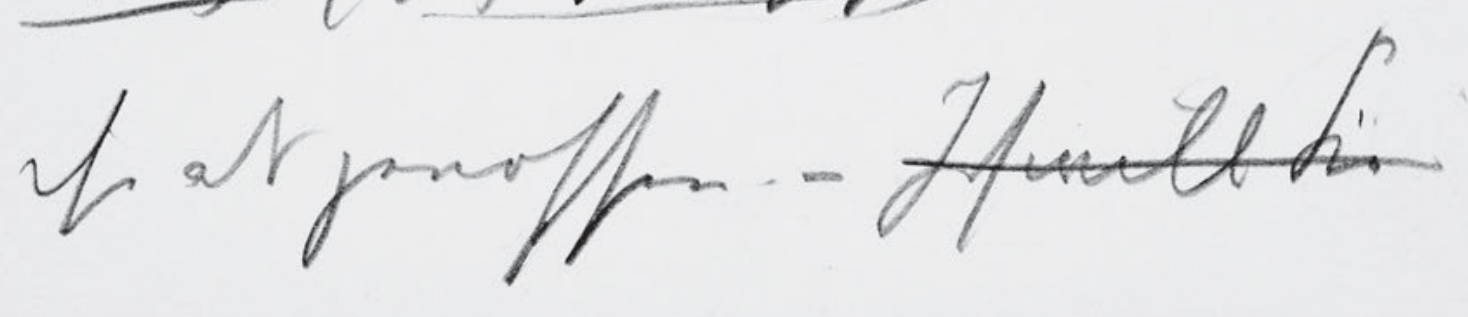

730 
Birken .... wem ich zur Früh und vo

mir aus konen Sie sich Ihre Abend un

Ihre Vernunft und wenn Sie nach

ich bin ein Glücksfall für Sie -

5 und der sich nicht wiederholen wird,

Graf. Aber was ist dē̄ ... was hab

ich dē̄ für ein Verbrechen begangen . .

Aber .. (Er will sie küssen)

Schausp (sich zurückziehend) Ich betrachte

$10 \quad$ ?hhn? als genossen. - Ich will Sie 
H'Sz9 [38]

Handschriften und Typoskript

Gel affltif.)

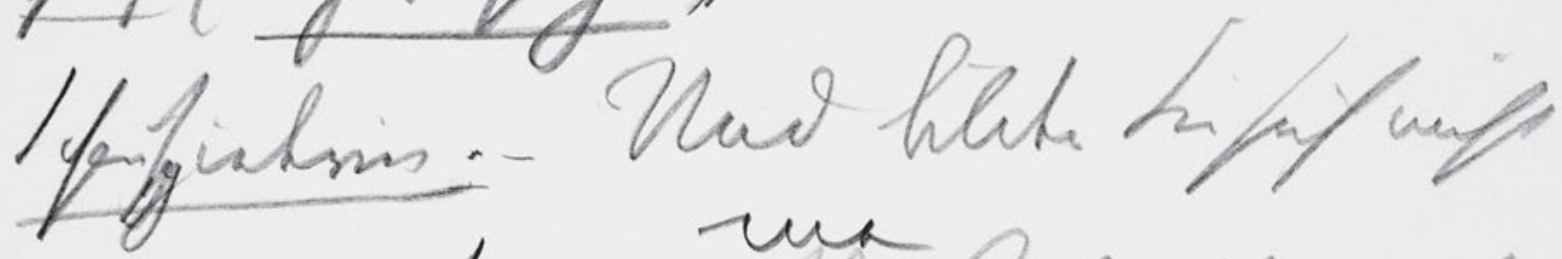

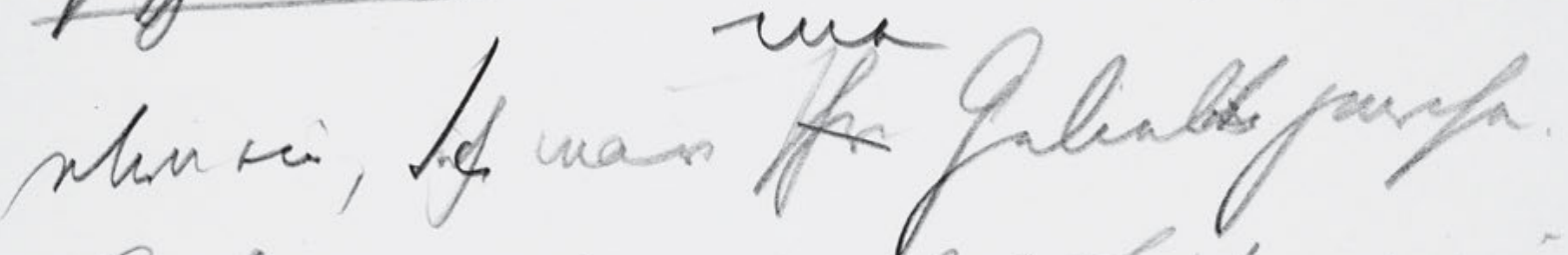
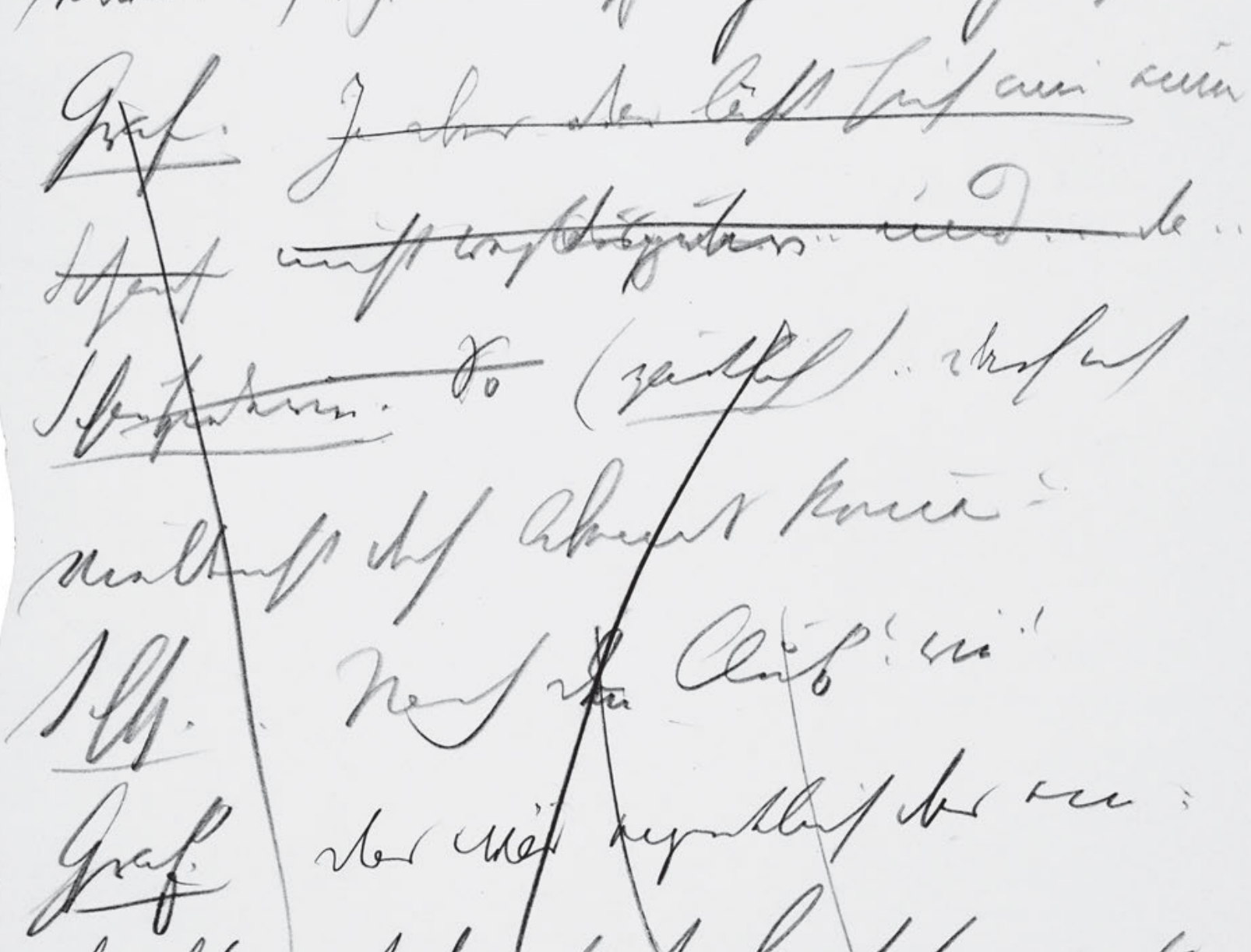

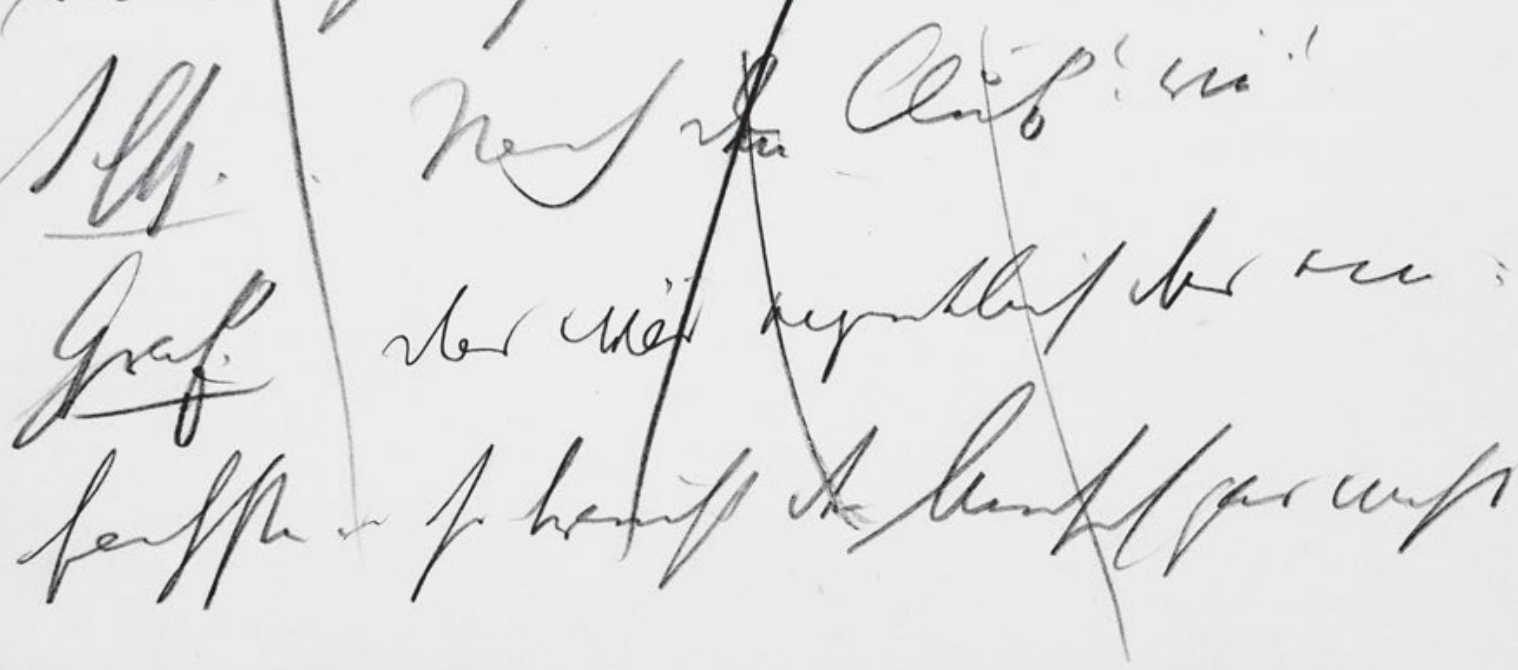

732 
Graf (erhebt sich.)

Schauspielerin. - Und bilden Sie sich nicht mein

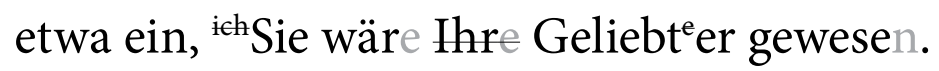

Graf. Ja aber - ‥das läßt sich nun einm

5 Schaus nicht wegä̈nnen disputiren .. und ... da . .

Schauspielerin. So (zärtlich) .. Darf ich

vielleicht doch Abends komen?

Schsp. Nach dem Club? wie?

Graf. Das wär' eigentlich das ein=

10 fachste.. so braucht der Mensch gar nichts 
H'Sz9 [39]

Handschriften und Typoskript

invariens:-

政
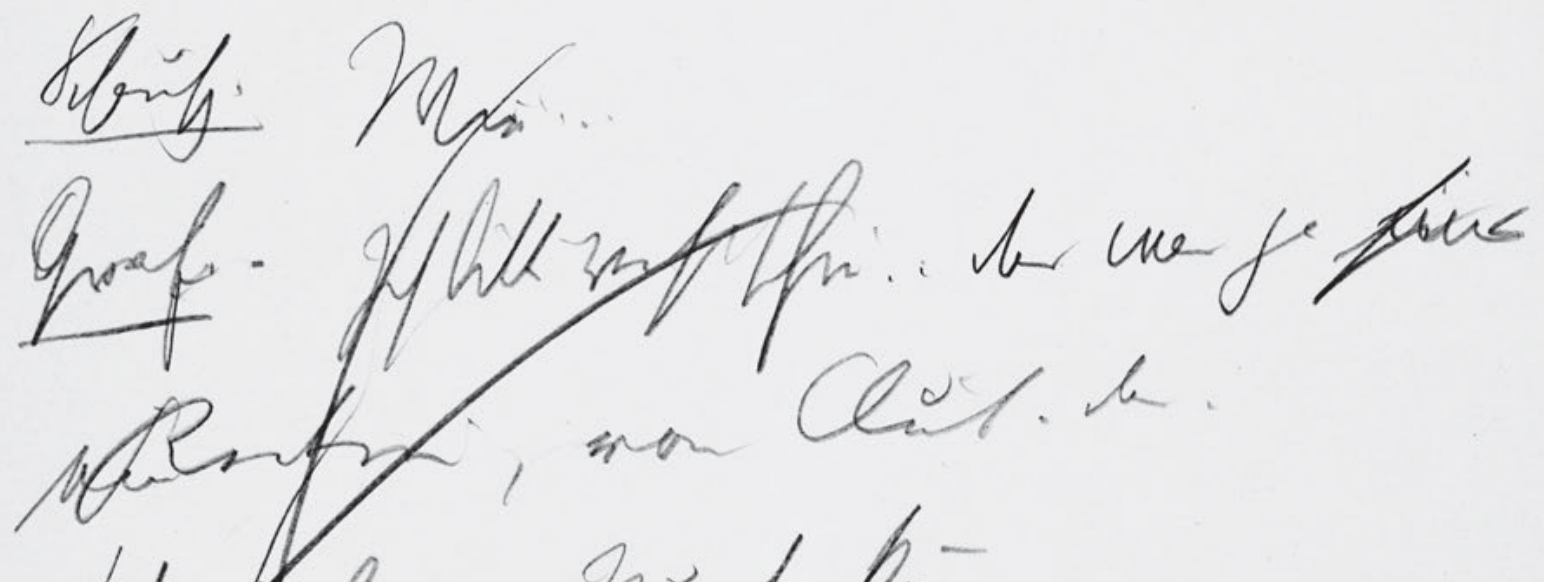

vaifgition

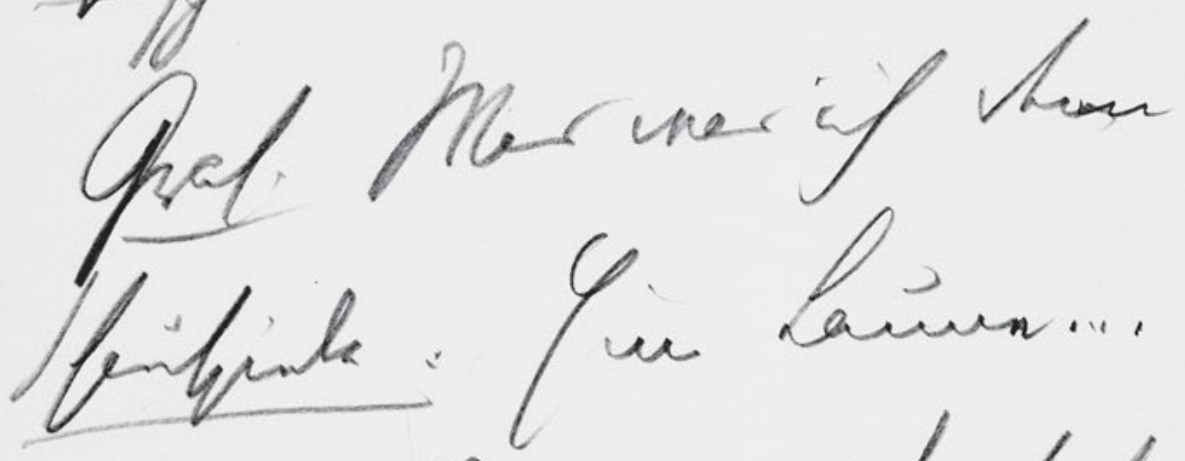

pal War min, tifis

(Yor taff pitathe

fallis.)

734 
zu versäumen. -

Schausp. Wie....

Graf. - Ich bitte recht schön . . das war ja ${ }^{\text {se? }}$ nur?

5

${ }^{\text {eine }}$ Rederei, vom Club . das .

Schauspielerin . Nun so kō̄m . .

Graf. Was war ich denn?

Schauspiele : Eine Laune ....

Graf. Aber eine, die sich wiederhol

10 wird . (Er geht zu ih u küsst sie

heftig.) 
H'Sz9 [40]

Handschriften und Typoskript

Ifing

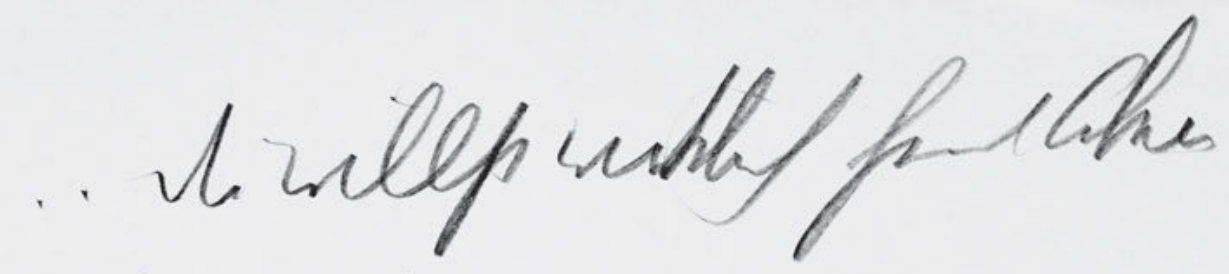
cueft thma s-

cal.. ald af ung

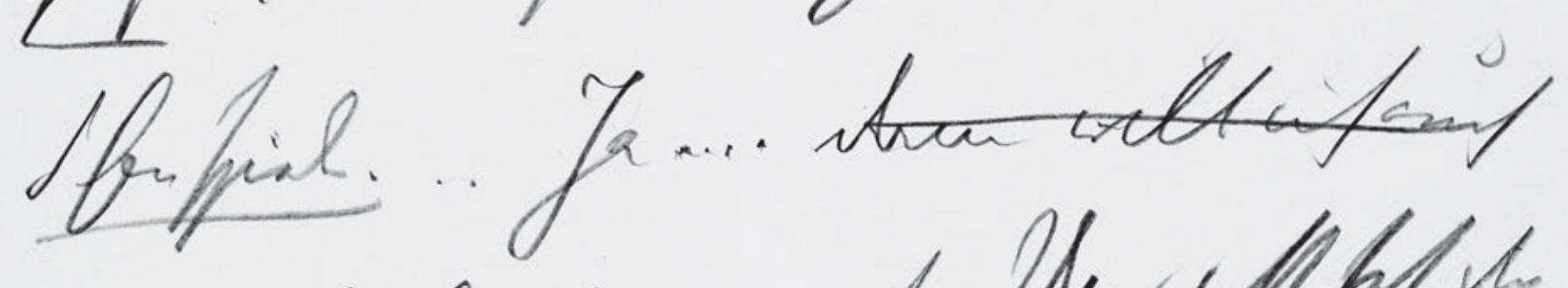

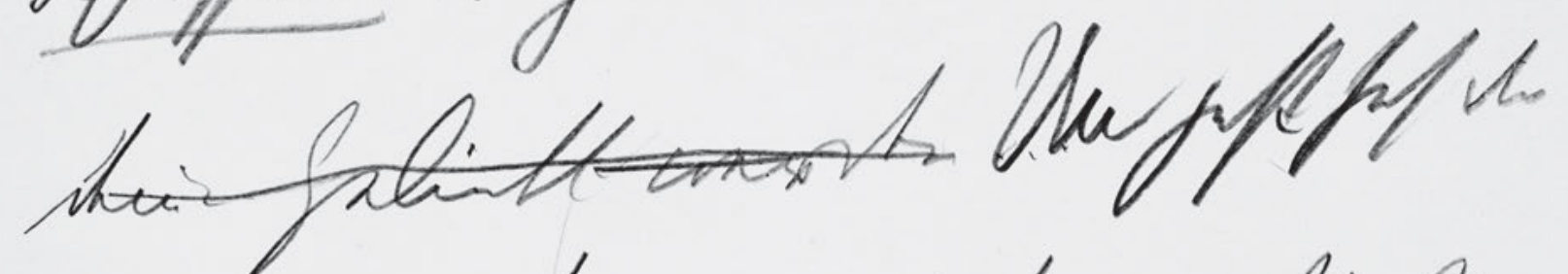

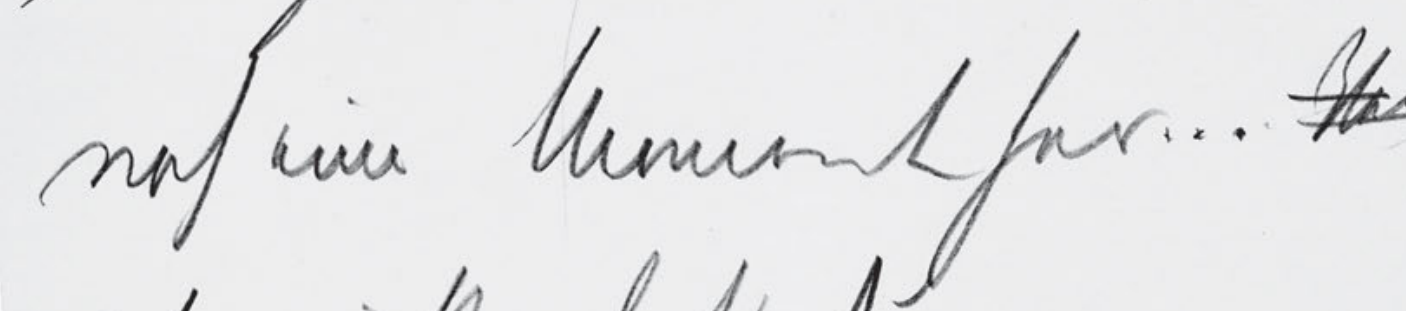

sitf wift, boft do

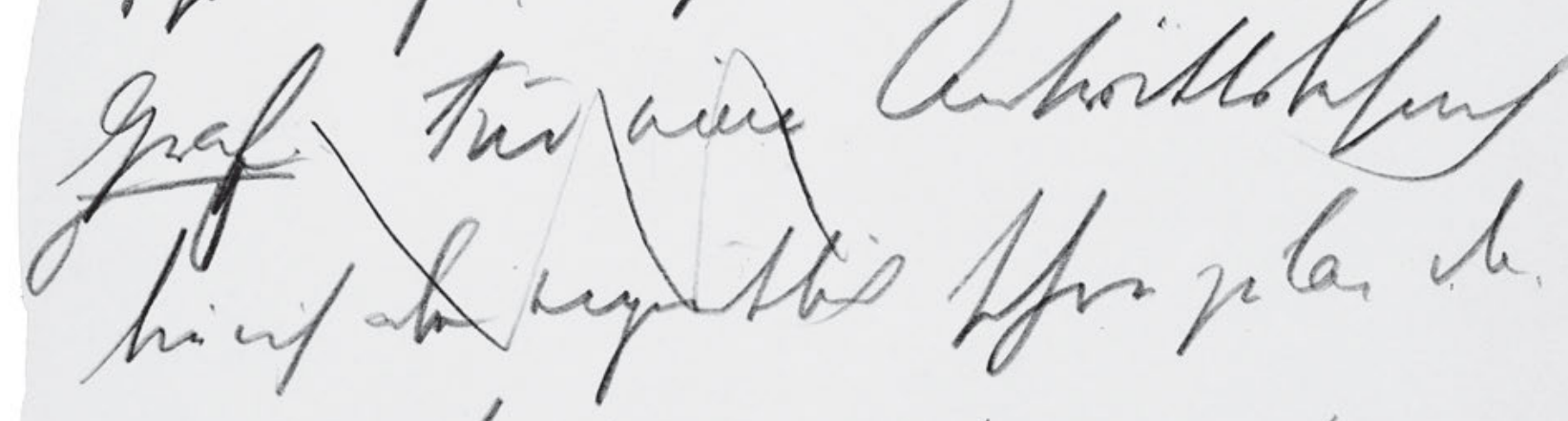

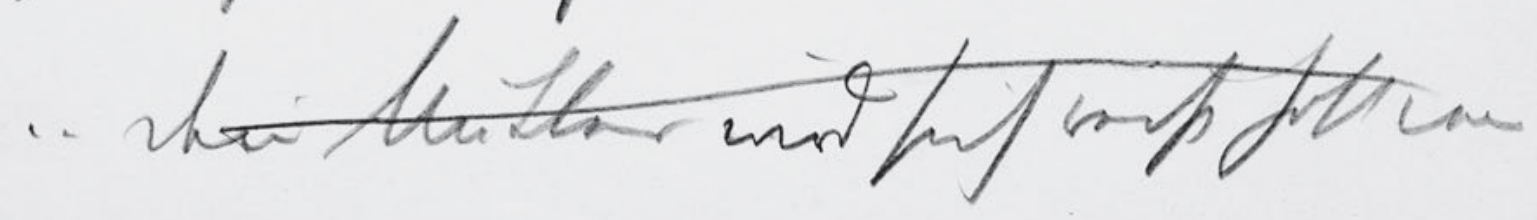

736 
Schausp. .. Du willst wirklich heute Abend

- nicht komen? -

Graf. .. Darf ich noch . .

Schauspieler. .. Ja ... dann will ich auch

5 deine Geliebte werden ' ${ }^{*}$ Und jetzt setz dic

noch einen Moment her .... Ver Ver

giss nicht, dass du

Graf. Für/einen Antrittsbesuch

bin ich aber eigentlich schon zu lang da.

10 .. deine Mutter "wird sich weiß Gott was 
H'Sz9 [41]

Handschriften und Typoskript

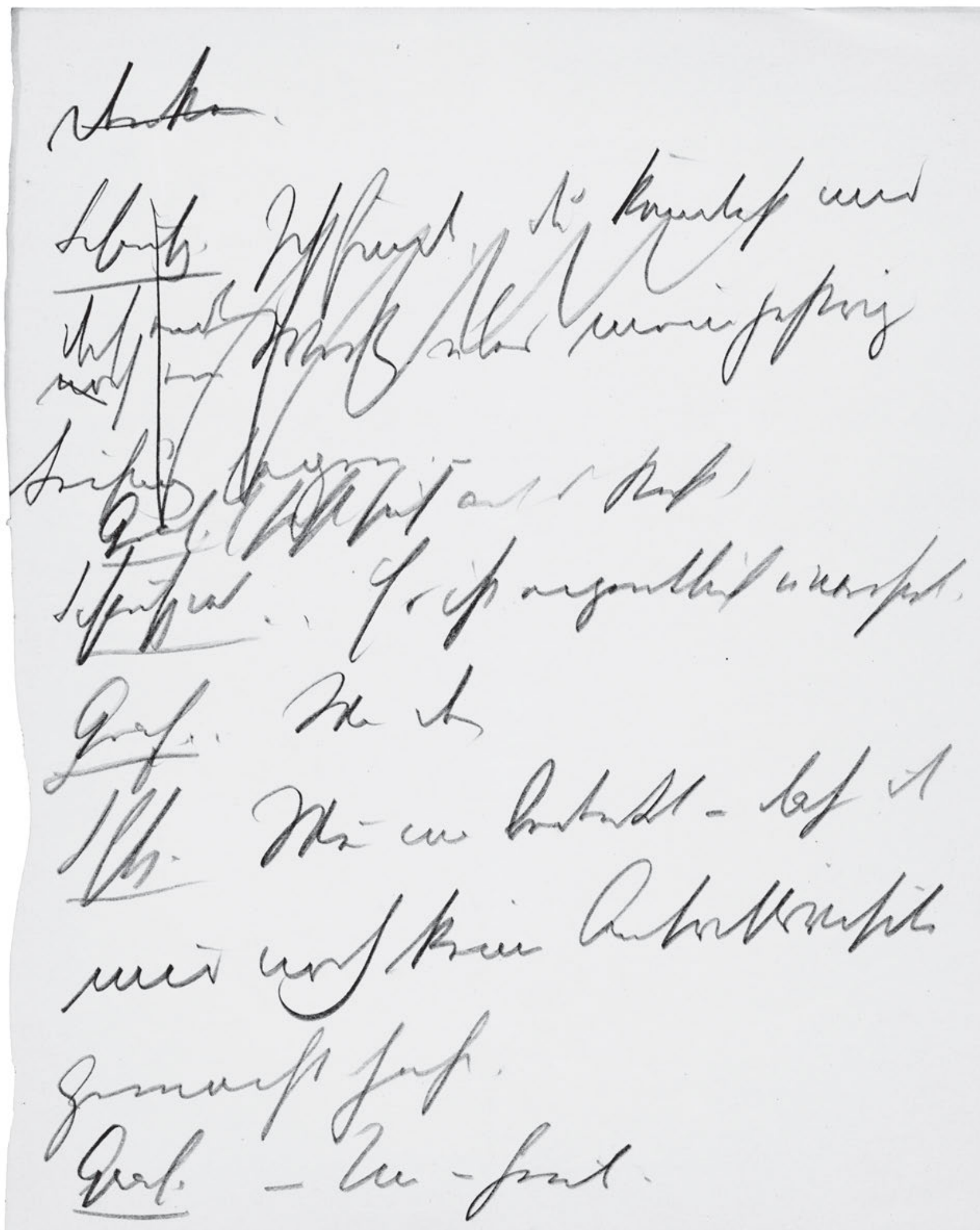

738 
denken.

Schausp. Ich finde, du könntest mir

doch end

noch ein Wort über meine gestrige

Leistung sagen. -

Graf. (setzt sich auf d Bett)

$5 \quad$ Schauspiel .. Es ist eigentlich 'unerhort?,

Graf. . Was denn

Shsp. Wen̄ ma bedenkt - dass d

mir noch keine Antrittsvisite

gemacht hast.

10 Graf. - Nun - heute. 


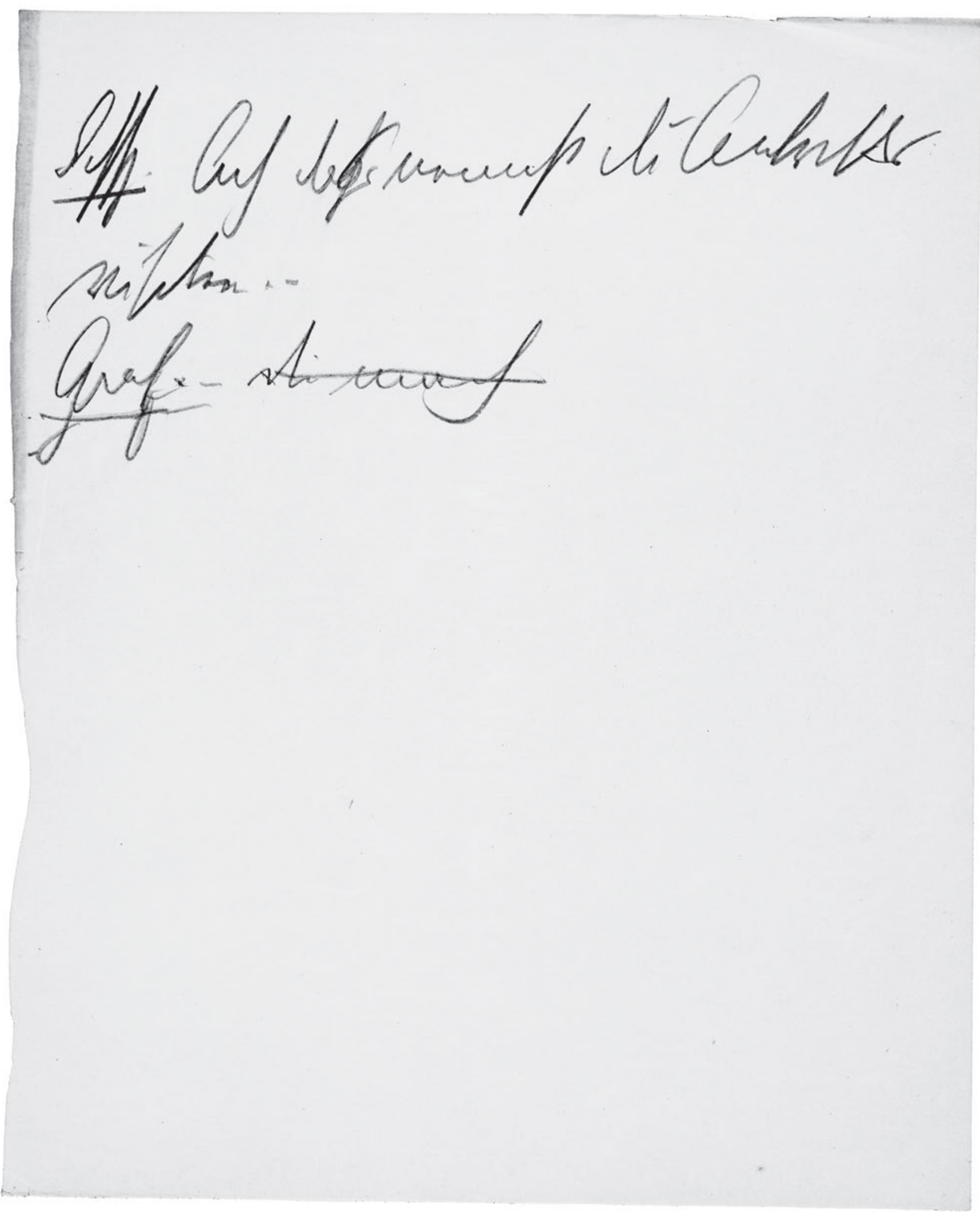


Schsp. Ach $\mathrm{da}^{\mathrm{ss}}$ s nennst du Antritts

visiten. -

Graf. - Die mach 
HSz9 303

Handschriften und Typoskript

303
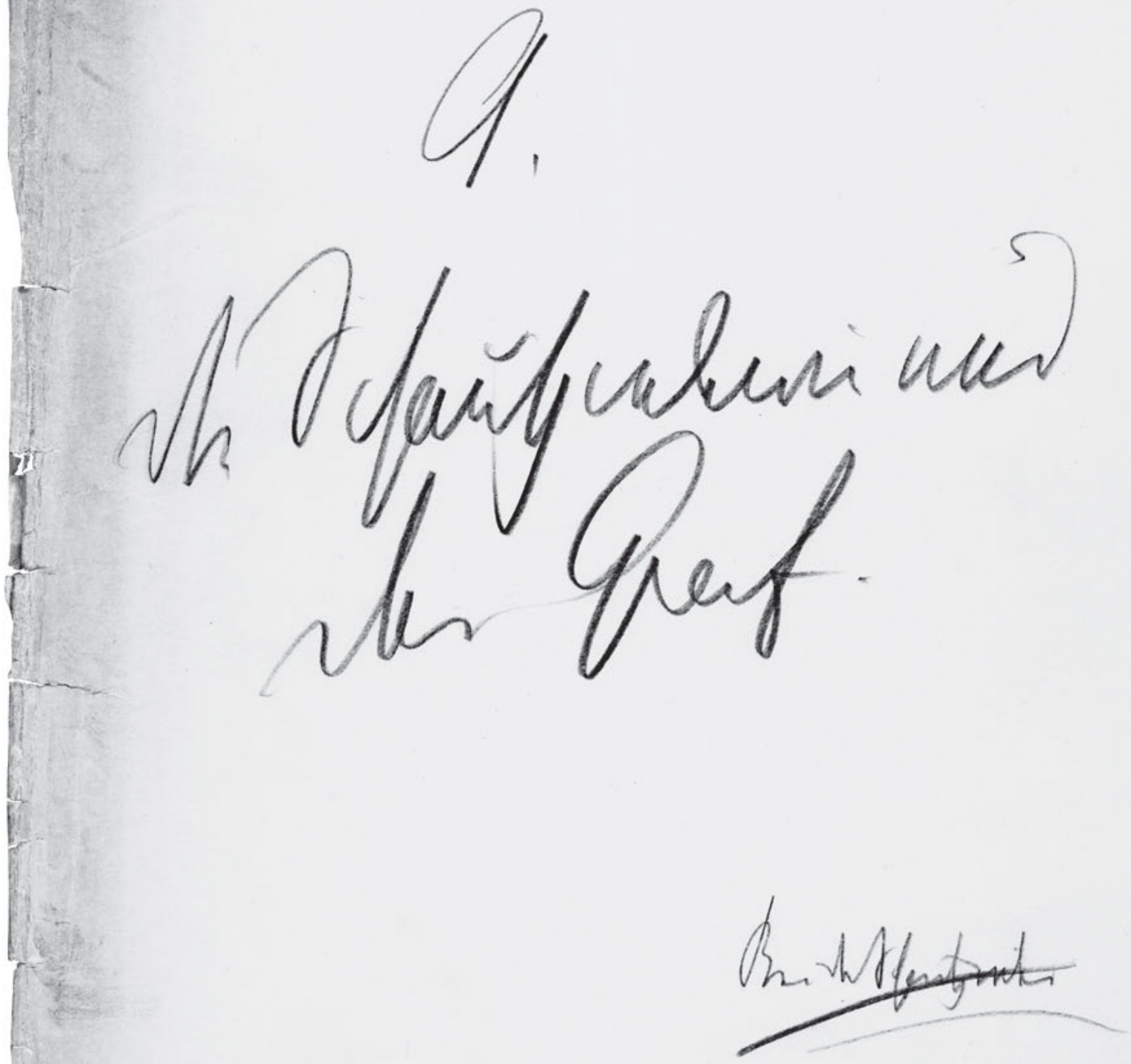

742 
303

9.

Die Schauspielerin und

der Graf. 
HSz9 304

Handschriften und Typoskript

304

Pret Afleffermin $h$

Pfortialeme

inforyis niyanifhs.

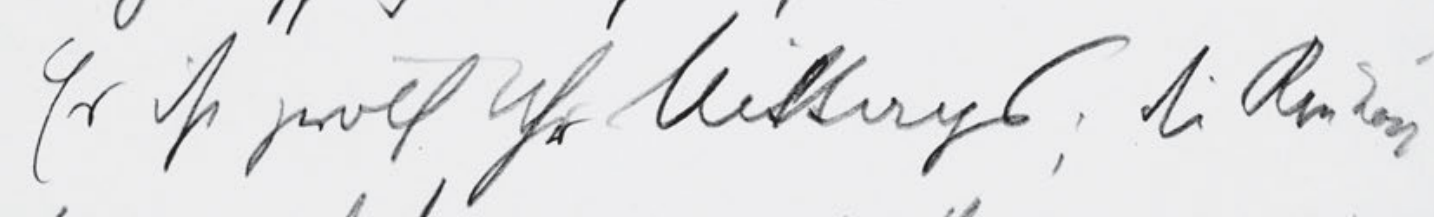

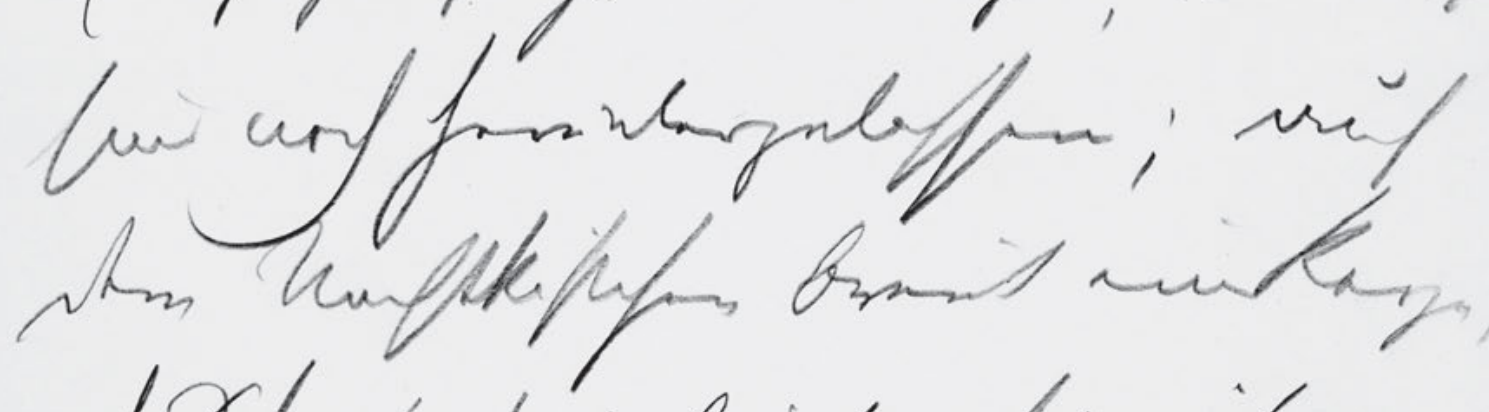

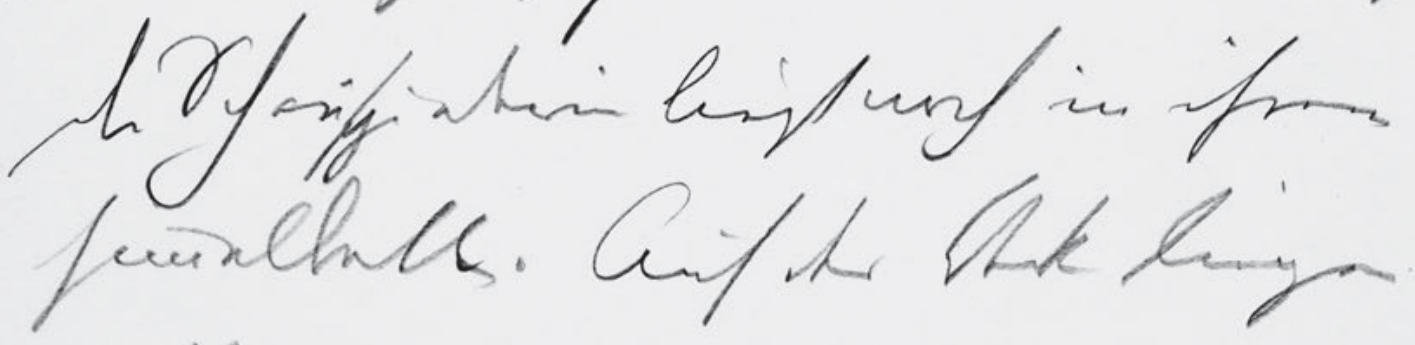
valling Pranym

st Gruf tritk in, in Anfor

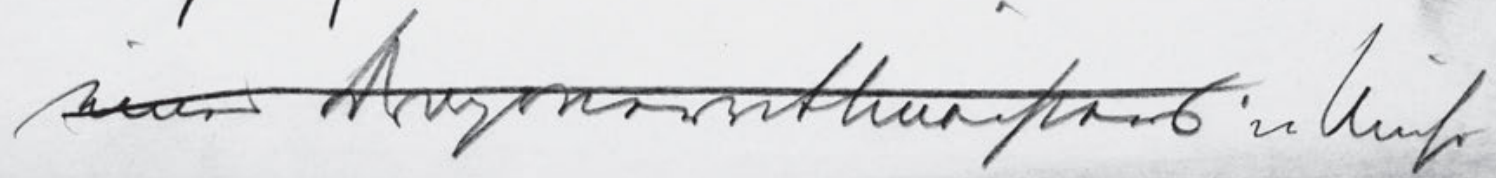

744 
304

Das Schlafzimmer der

Schauspielerin.

Sehr üppig eingerichtet.

$5 \quad$ Es ist zwölf Uhr Mittags; die Rouleaux

sind noch heruntergelassen; auf

dem Nachtkästchen bren̄t eine Kerze;

die Schauspielerin liegt noch in ihrem

Himelbett. Auf der Decke liegen

10 zahlreiche Zeitungen.

Der Graf tritt ein, in Uniform

eines Dragonerrittmeisters in Unifor 
HSz9 305

Handschriften und Typoskript

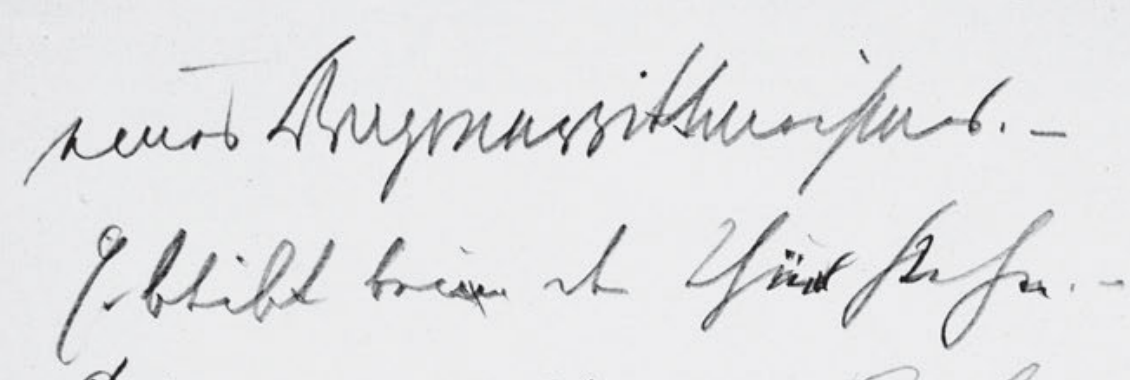

305

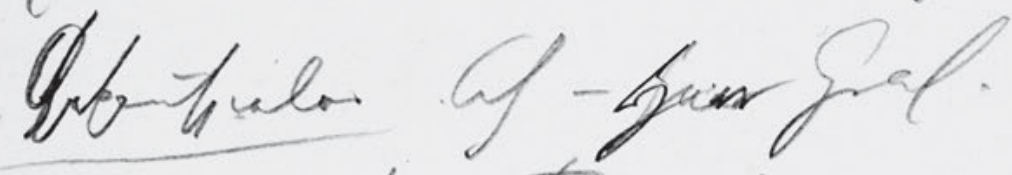

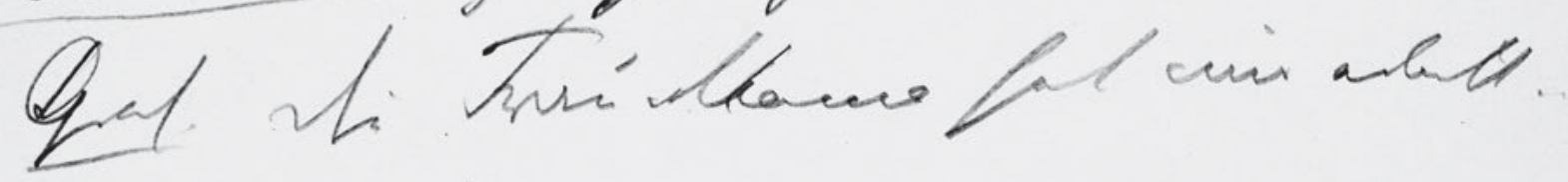

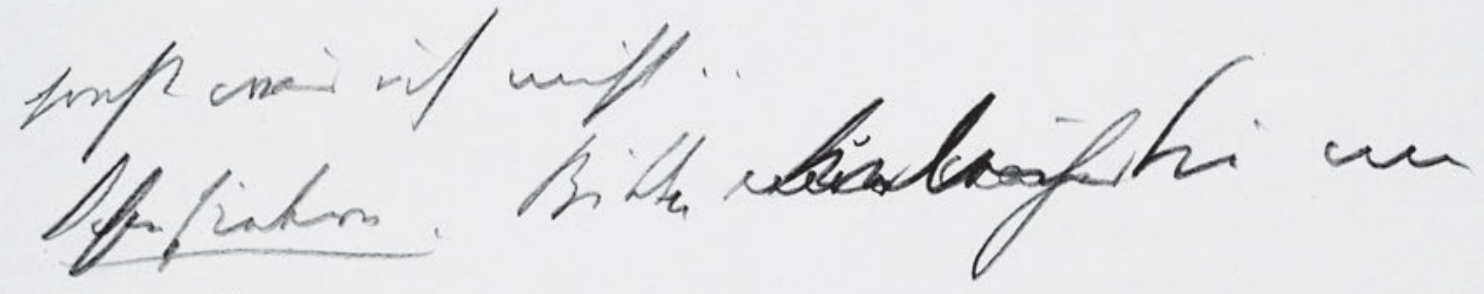
unfe

geat kiffel fores..purto - wo manfor un th trafer fromin homunt...

if If nombif not wifes

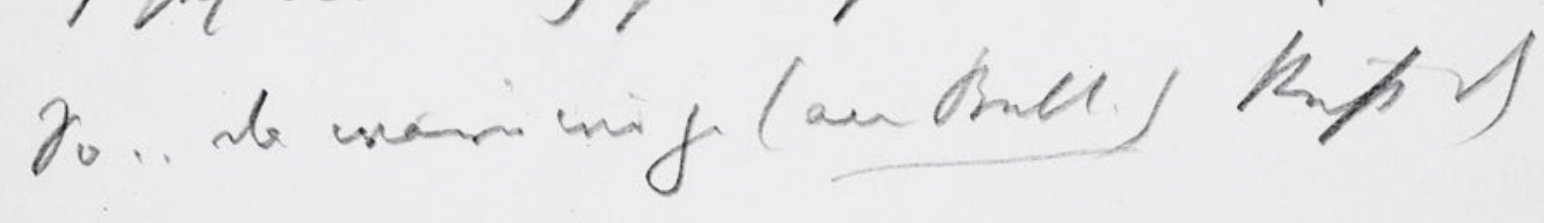
far $r$

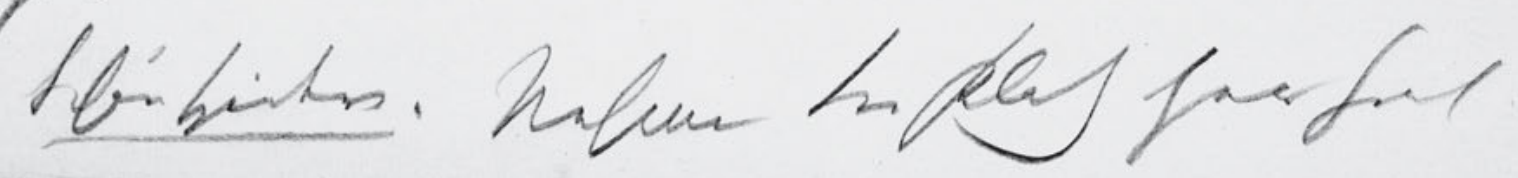

746 


\section{5}

eines Dragonerrittmeisters. -

Er bleibt beim der Thür stehen. -

${ }^{\text {GSchauspieler } . A h ~-~ H e r r ~ G r a f . ~}$

${ }^{5}{ }^{5}$ Graf. Die Frau Mama hat mir erlaubt . .

sonst wär ich nicht . .

Schauspielerin. Bitte ${ }^{\text {nur näher }}$ treten Sie nur

näher.

Graf. Küß die Hand . . Pardon - wenn

10 man her von der Straßen herein kommt ....

ich seh nemlich gar nichts noch nichts. -

So . . da wären wir ja (am Bett.) Küß die

Hand . .

Schauspielerin. Nehmen Sie Platz Herr Graf. 
HSz9 306

Handschriften und Typoskript
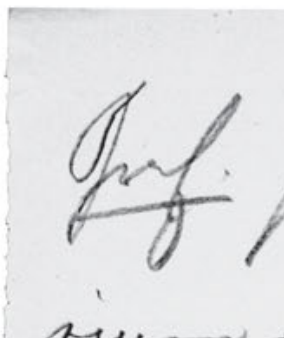

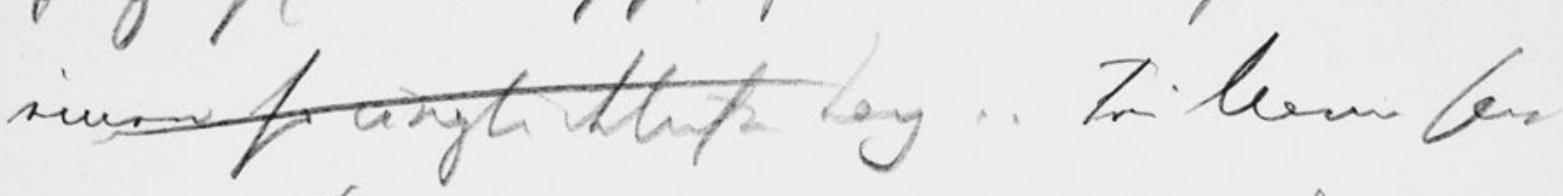

mi',

7

306

hafin Iffrothy w

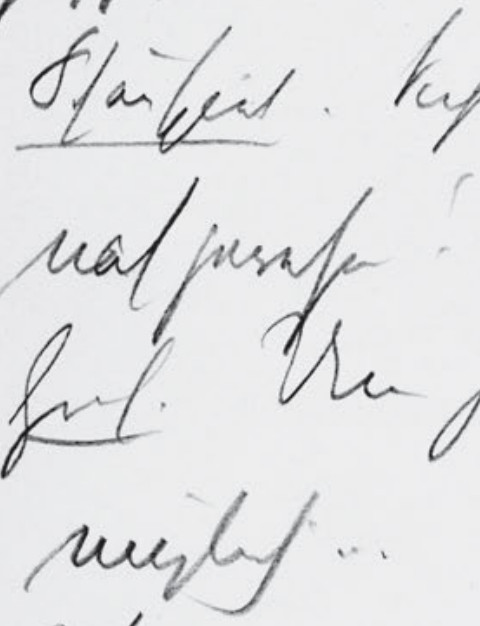

refiguter.

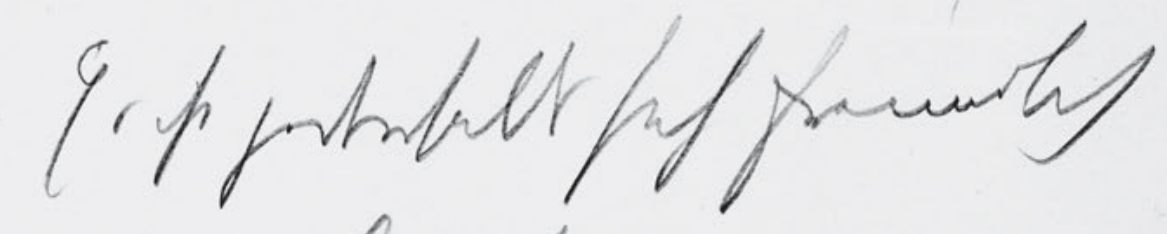

Jo hing

ful. 


\section{6}

Graf. Ich bedaure sehr, für meinen ersten Besuch einen so unglücklichen Tag . . Frau Mama sagt mir, Fräulein sind unpäßlich . . Wird doch

5 hoffentlich nichts ernstes sein.

Schauspiel . Nichts ernstes? Ich bin dem Tode de[?] nah gewesen! Graf. Um Gotteswillen ... wie ist den̄ das möglich ...

10 Schauspieler. Es ist jedenfalls seh freundlich dss Sie sich zu mir bemühen. Graf. Dem Tode sin Sie nah . . Und gestern Abend haben Sie noch gespielt wie ${ }^{\text {. jawie }}$ eine Göttin . . 
HSz9 [306a]

Handschriften und Typoskript

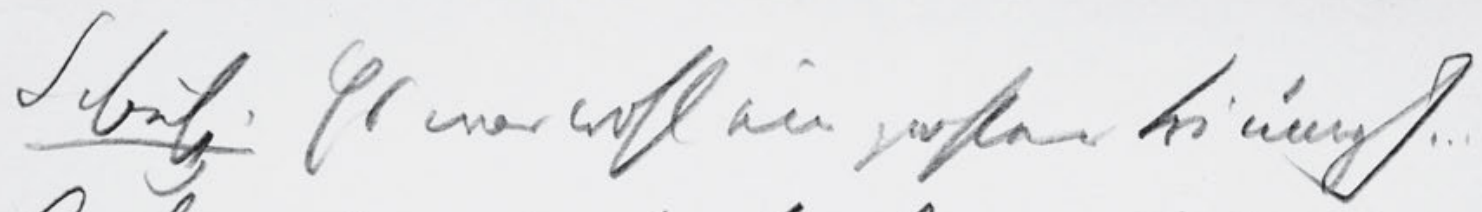

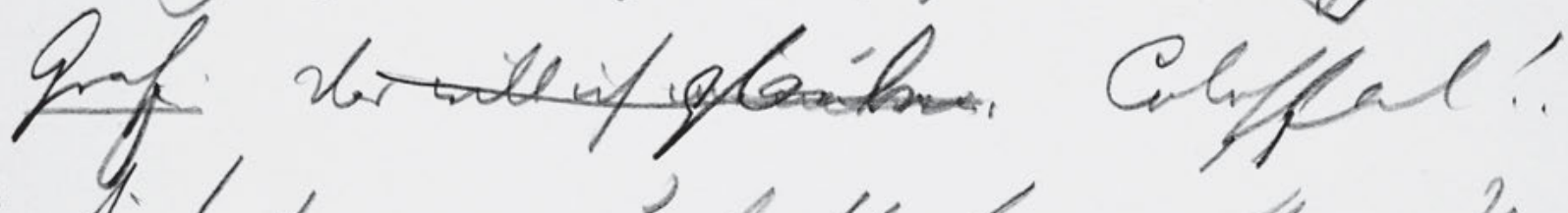

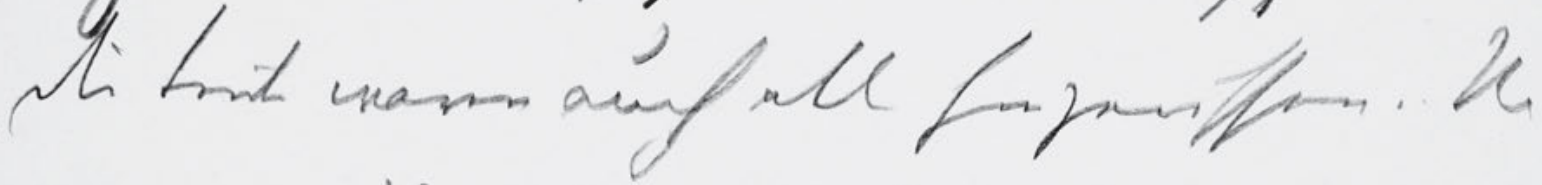
me peivill iff mift instin.

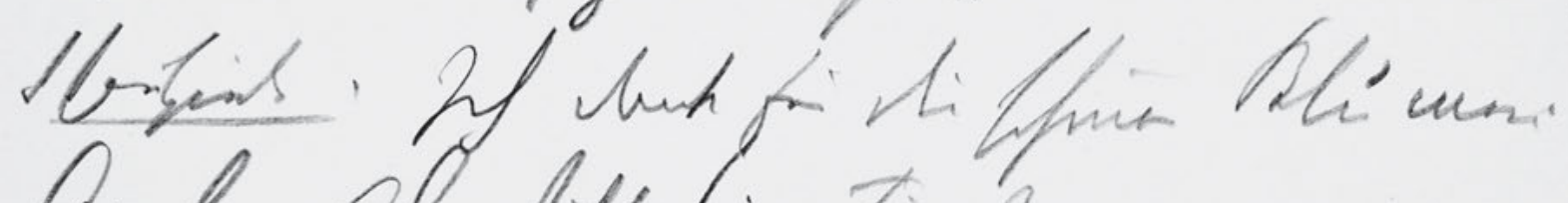

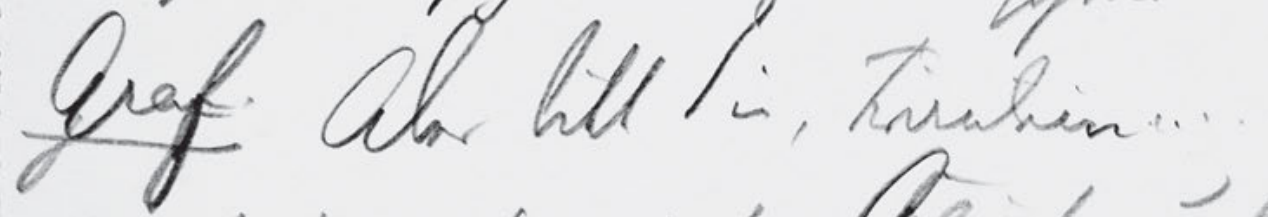

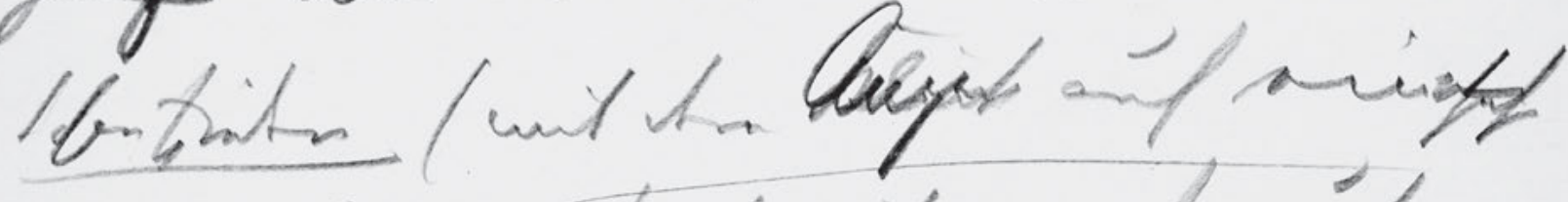

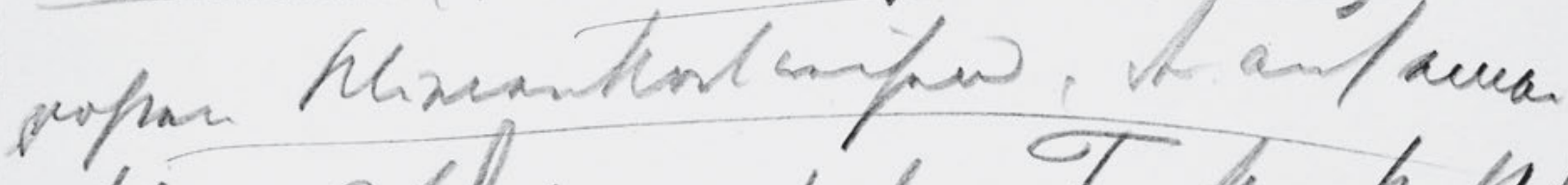

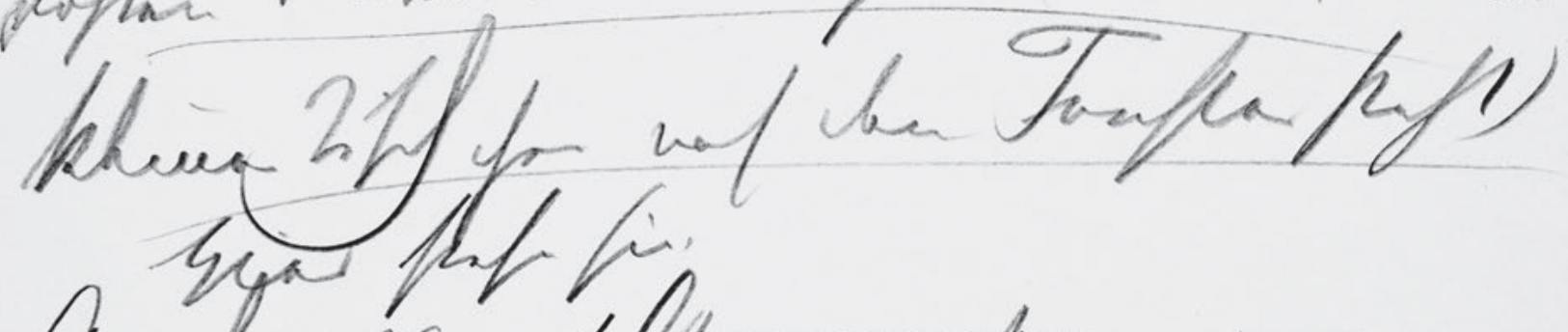

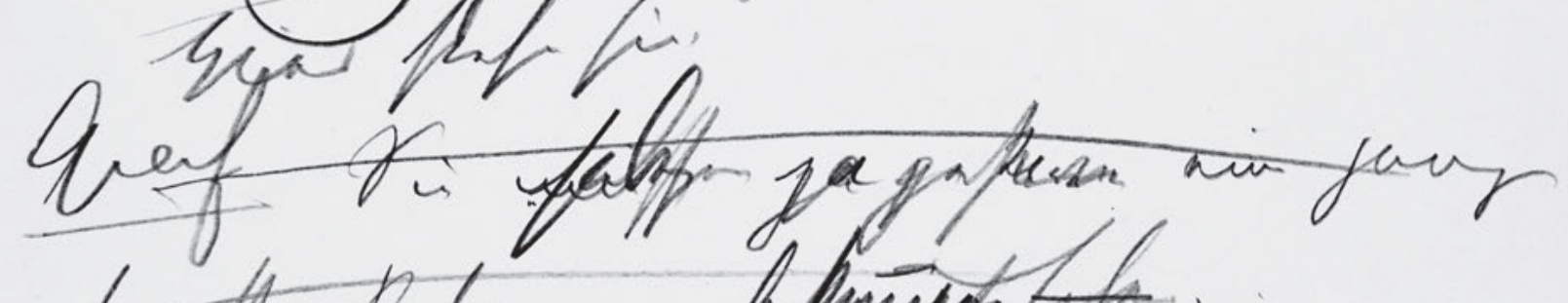
leaff BL

750 
Schausp. Es war wohl ein großer Triumph...

Graf. Das will ich ?menen? glauben. Colossal! .

Die Leute waren auch alle hingerissen .. Na

von mir will ich gar nicht reden.

$5 \quad$ Schauspiele. Ich dank für die schönen Blumen.

Graf. Aber bitt Sie, Fräulein .....

Schauspieler (mit de ${ }^{\mathrm{m}} \mathrm{n}{ }^{\text {Blick }}$ Augen auf einen sehr

großen Blumenkorb weisend, der auf einem

kleinen Tischchen nah dem Fenster steht)

Hier stehen sie.

Graf Sie $e^{\left[f_{\text {mitssen }}\right.}$ haben ja gestern eine ganze

Masse Blumen sekriegtbekomen haben . .

Schauspiel 
HSz9 307

Handschriften und Typoskript

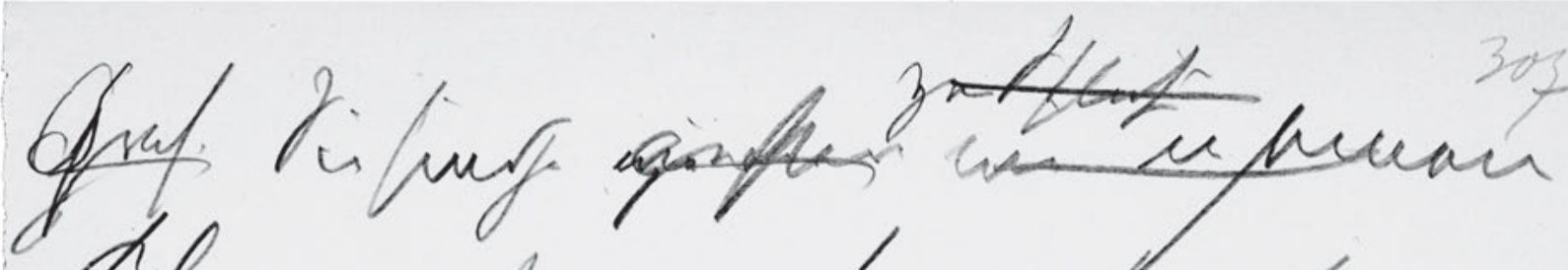

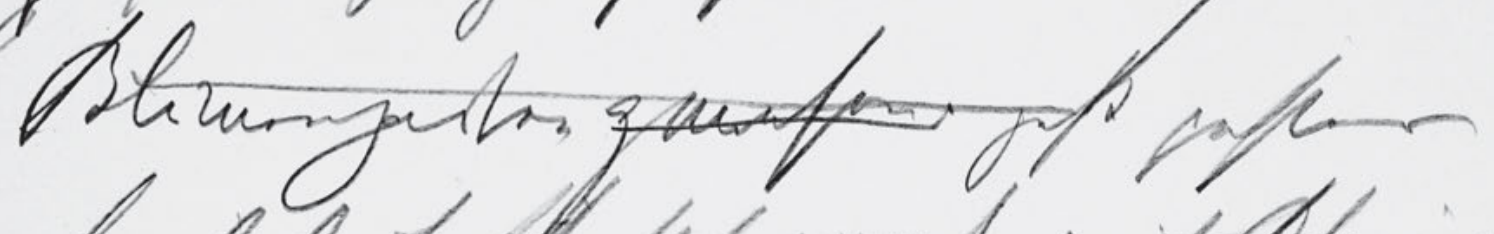

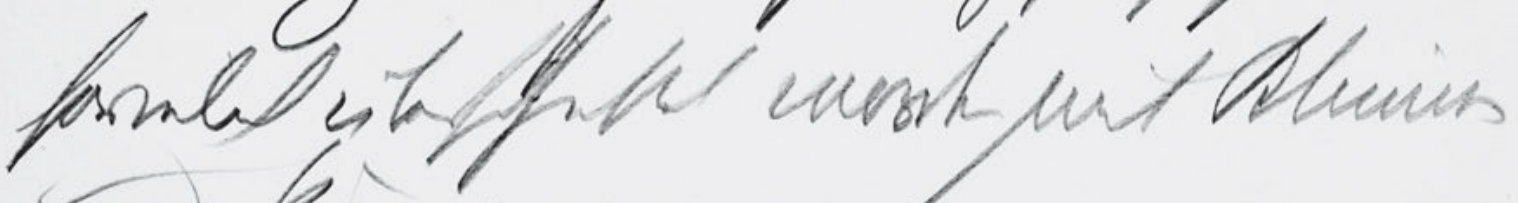
nue tarigen.

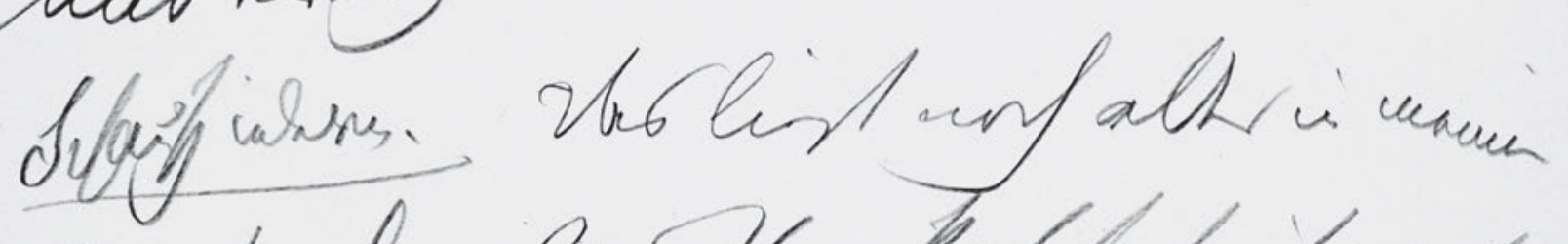

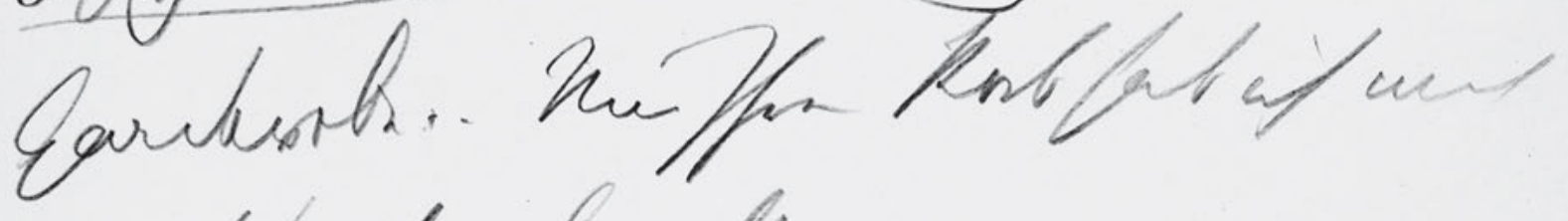
nat finf prouff.

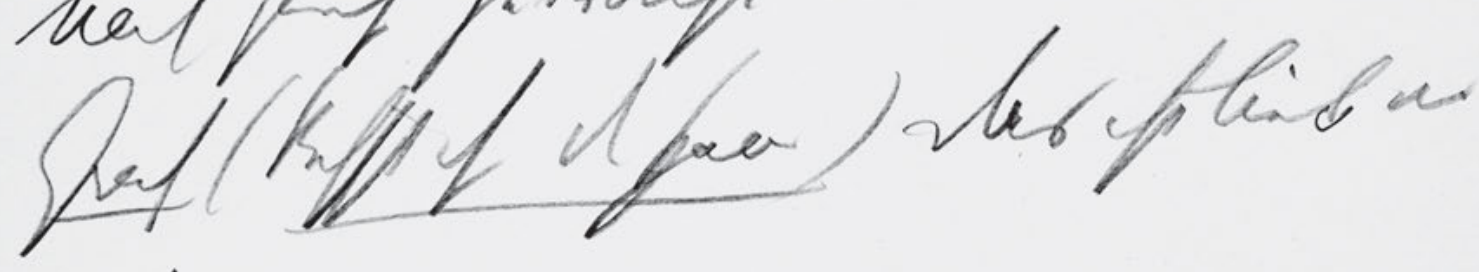

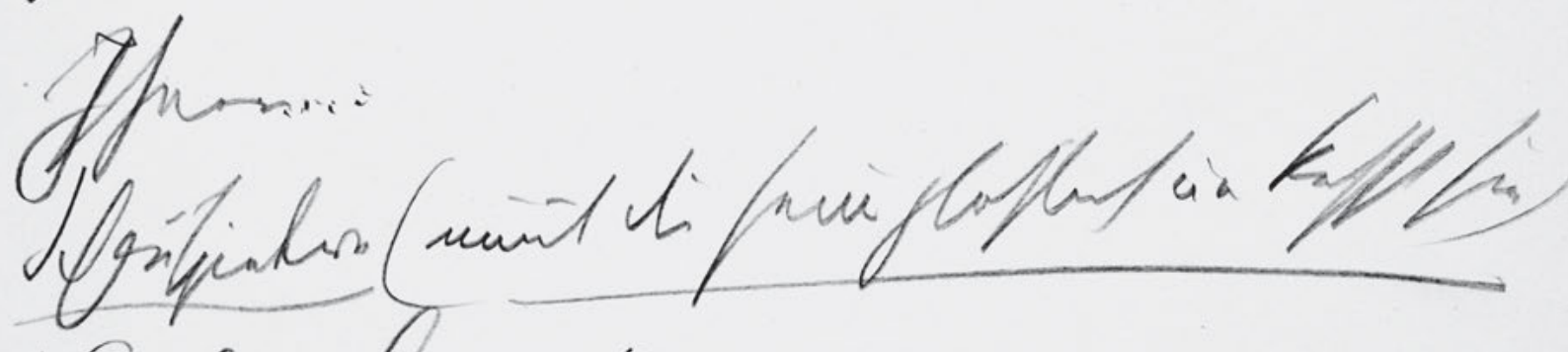

Paf. Akr.. Buision...

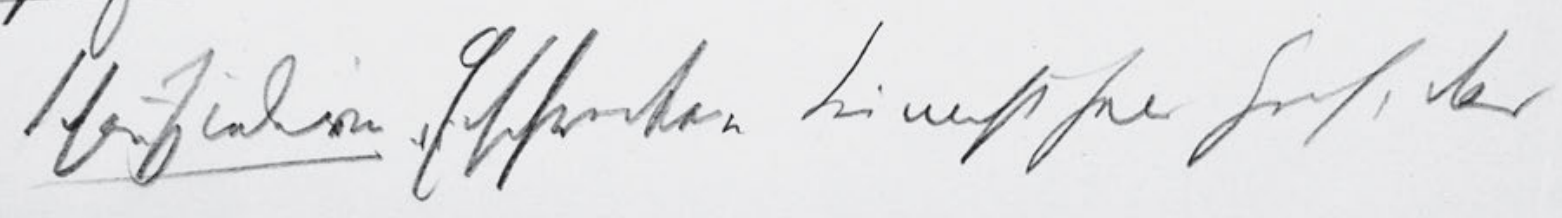

752 


$$
\text { zum Schluss } 307
$$

${ }^{\mathrm{s}} \mathrm{Graf}$. Sie sind ja wie?ein? gestern wie in einem

Blumengarten gewesen. gest gestern

formlich überschuttet worden mit Blumen

5 und Kränzen . .

Schauspielerin. Das liegt noch alles in meiner

Garderobe .. Nur Ihren Korb hab ich mit

nach hause gebracht.

Graf (küsst ihr die Hand) Das ist lieb vo

$10 \quad$ Ihnen ........

Schauspielerin (nim̄t die seine plötzlich un kusst sie)

Graf. Aber . . Fräulein ...

Schauspielerin ${ }^{[?]}$ Erschrecken Sie nicht Herr Graf, das 
HSz9 308

Handschriften und Typoskript

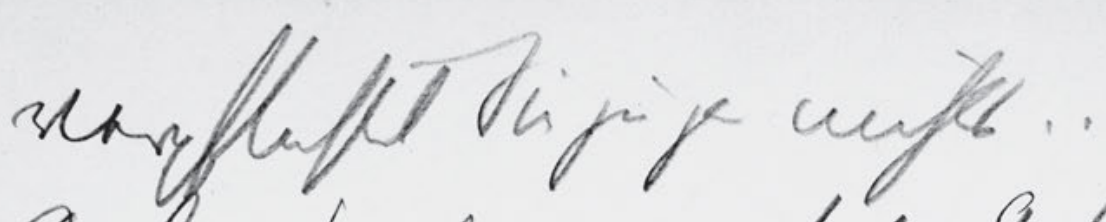

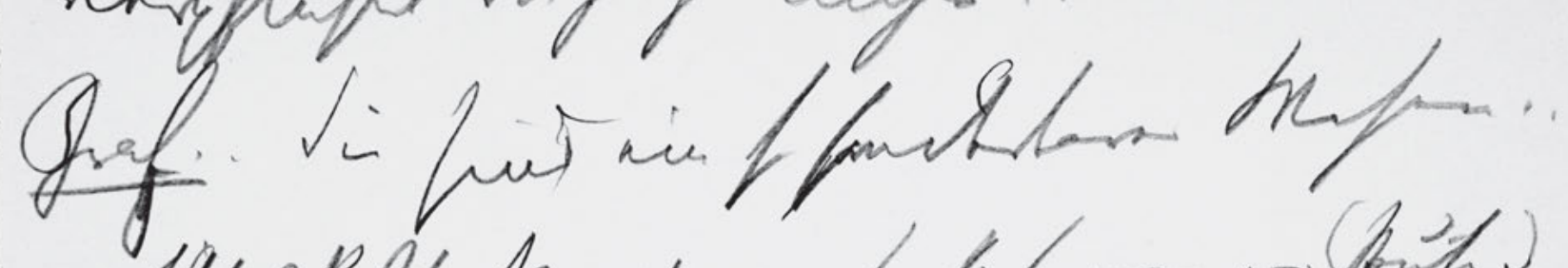

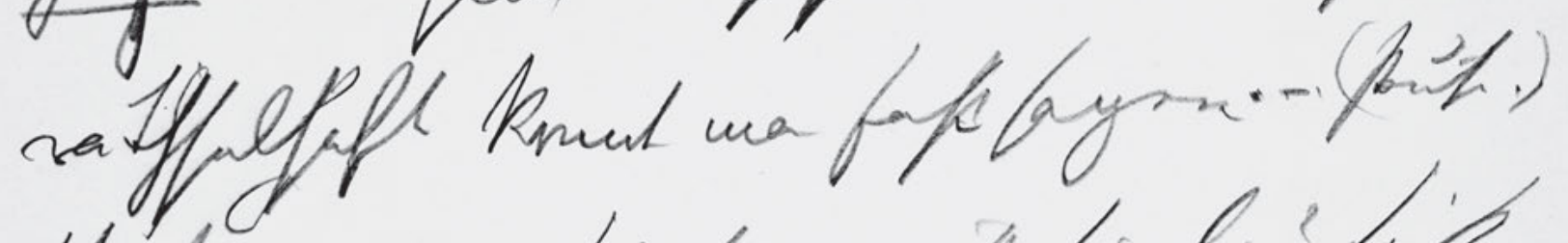

sarticiarin...

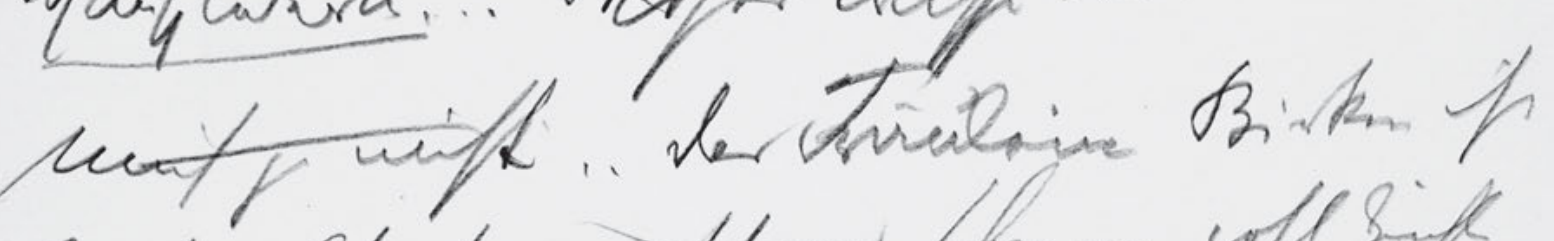

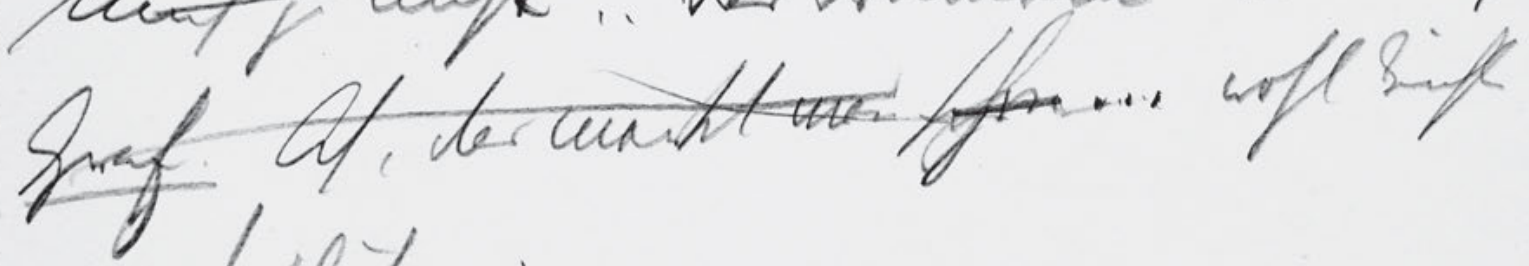
cupilite

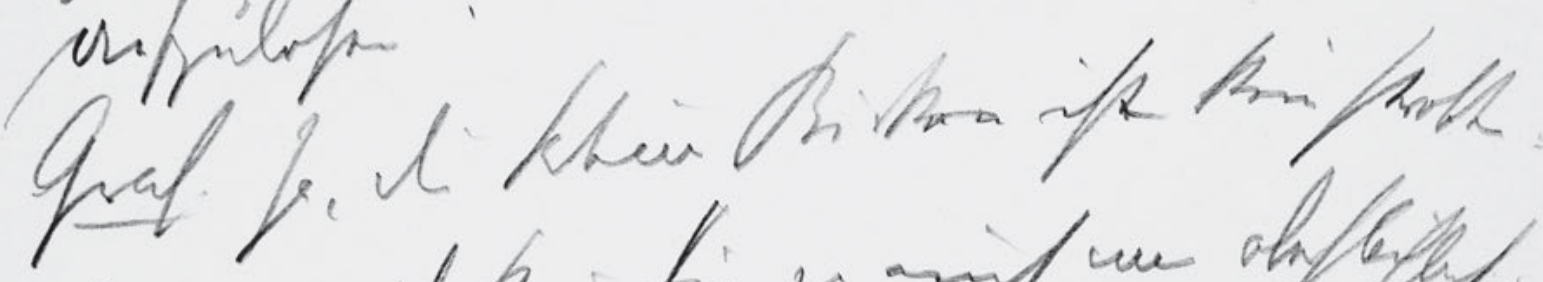

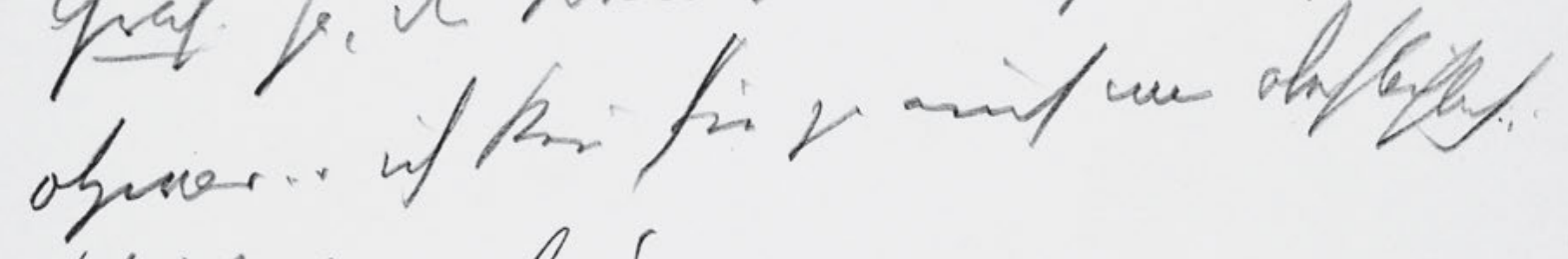
Sorfial ba!

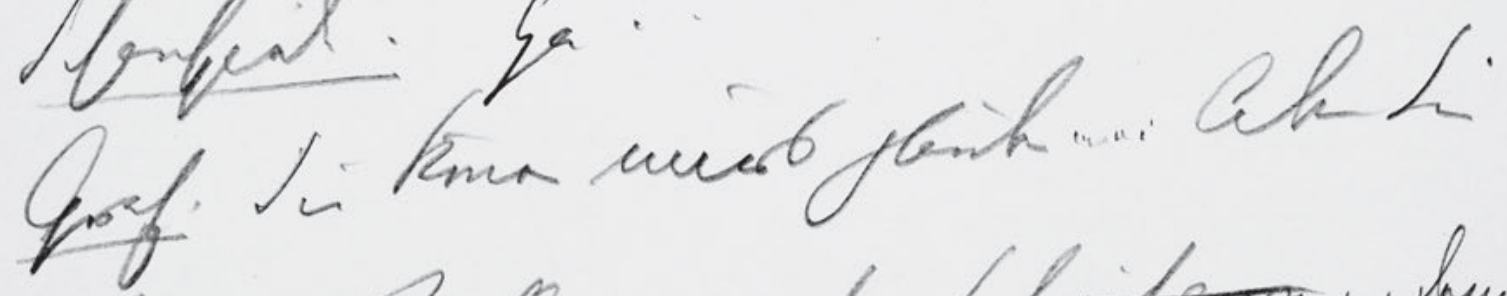

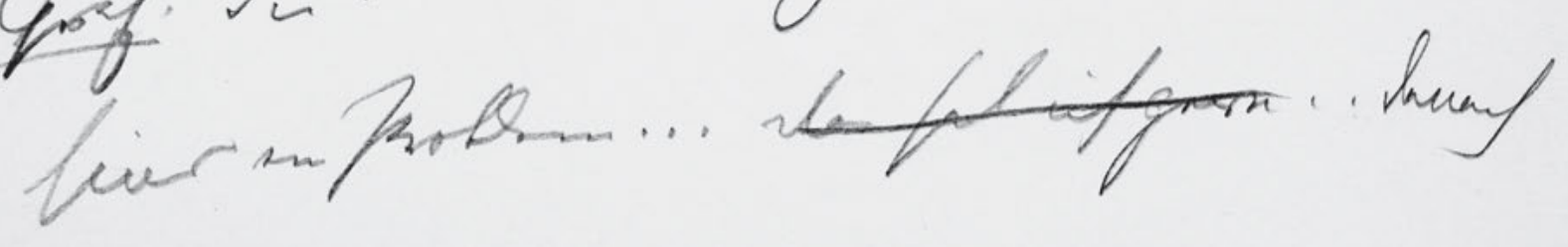

754 
308

verpflichtet Sie zu gar nichts ..

Graf. . Sie sind ein so sonderbares Wesen . .

räthselhaft konnte man fast sagen. “- (Pause.)

5

Schauspielerin. .. Woher wissen Sie das? Sie keñen

mich ja nicht. . Das Fräulein Birken ist

Graf. Ah, das merkt man schøn .... . wohl leichter

aufzulösen.

Graf. Ja, die kleine Birken ist kein Problem:

10 obzwar . . ich ken̄ sie ja auch nur oberflächlich ...

Schauspiele. Ha! .

Graf. Sie kön̄en mirs glauben ...... Aber Sie

sind ein Problem ... das hab ich gern .. danach 


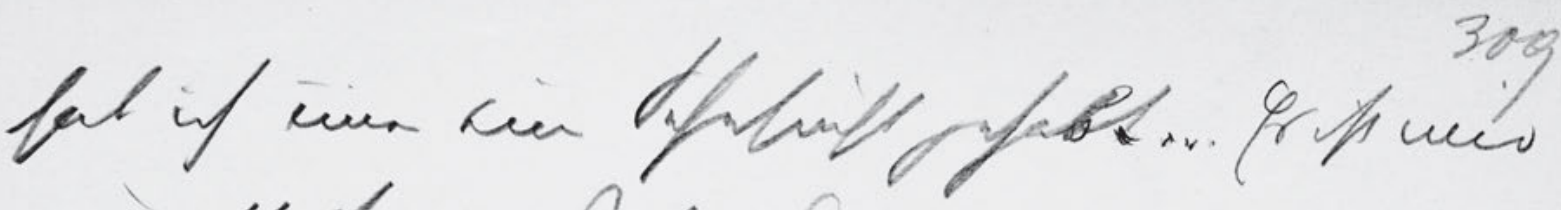

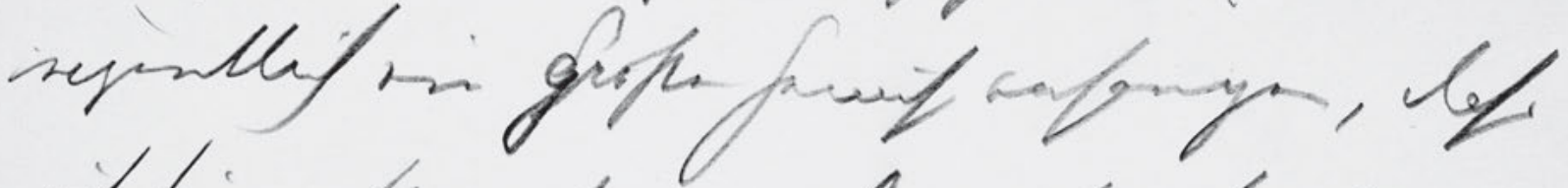

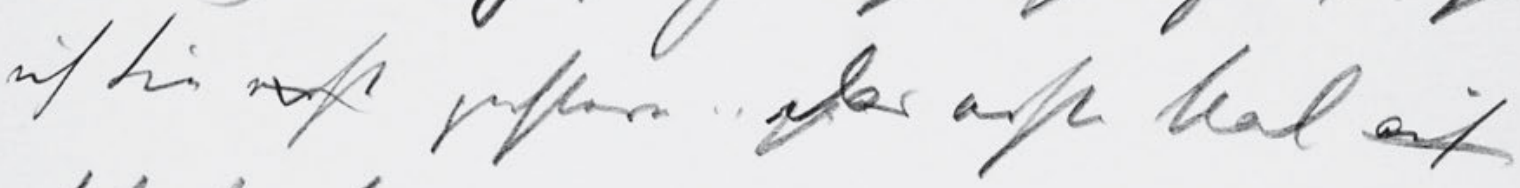

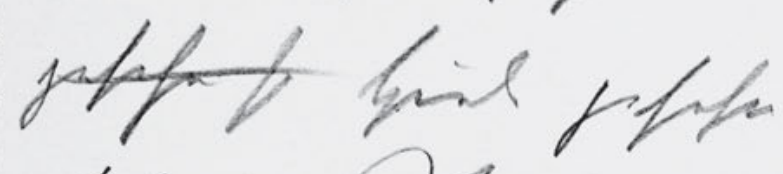

hanty ar curbl

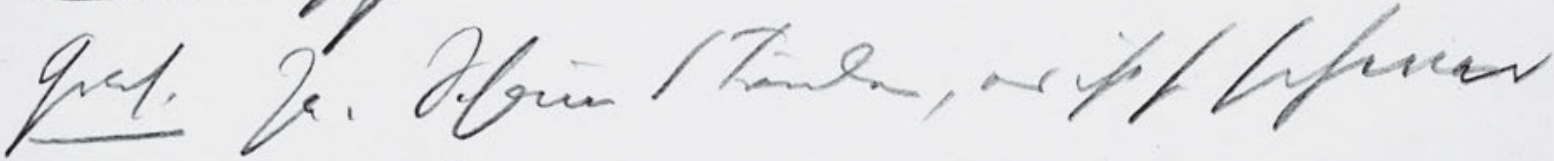

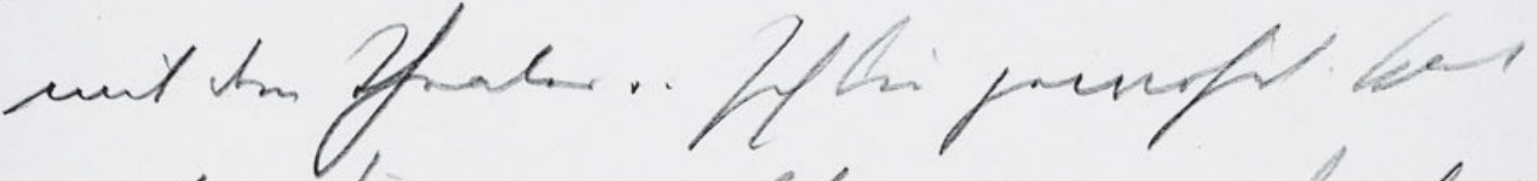

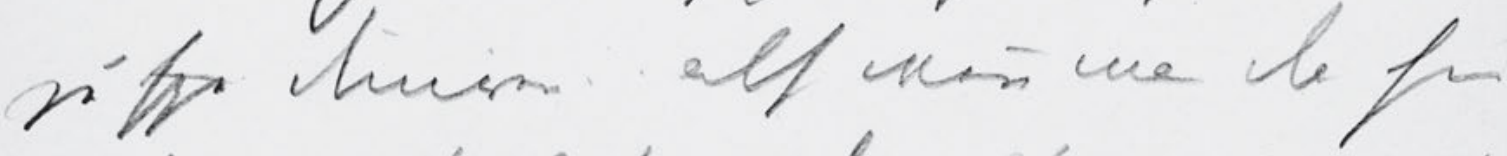

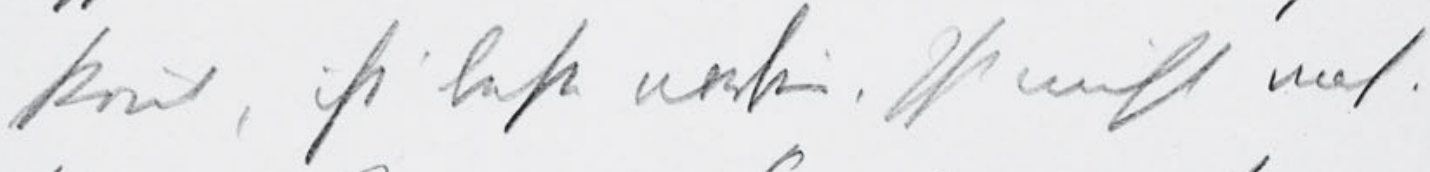

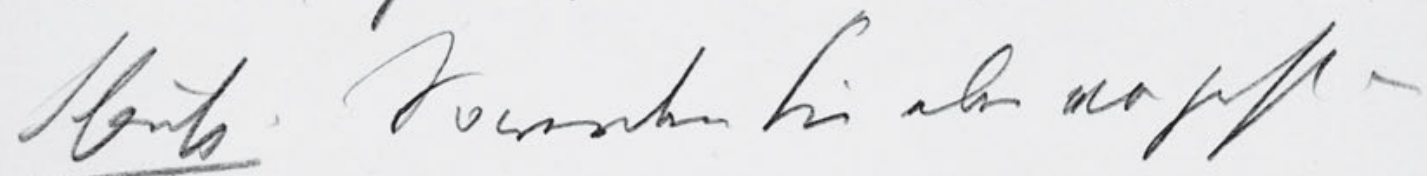
timfa uffa

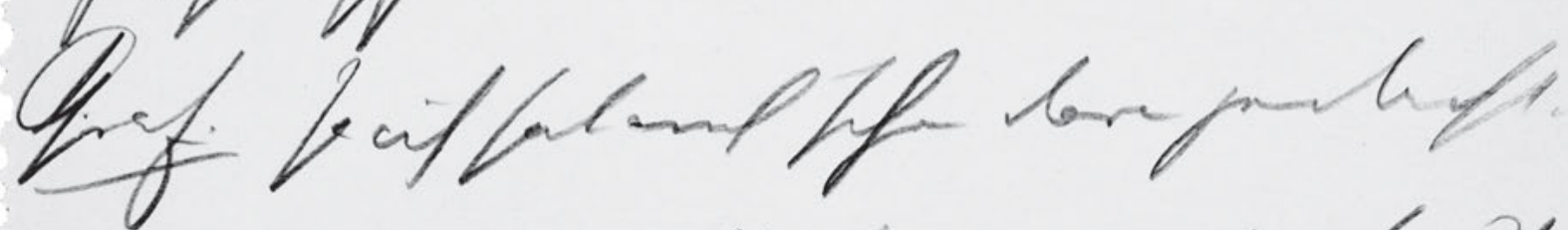

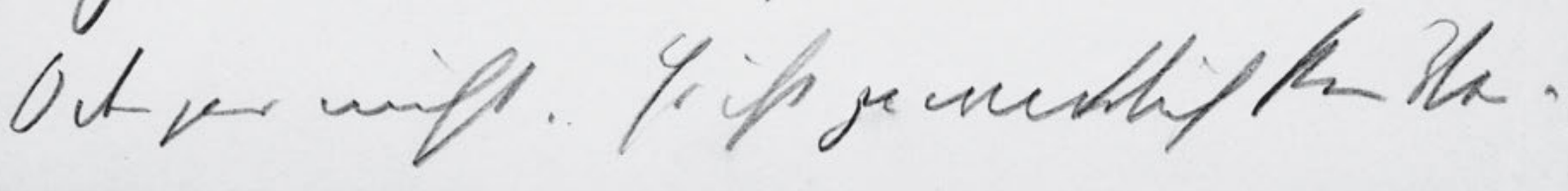


hab ich imer eine Sehnsucht gehabt ..... Es ist mir eigentlich ein ${ }^{G}$ großer Genuss entgangen, dass ich sie erst gestern . . ${ }^{\text {jad }}$ das erste Mal auf

5 gesehen ha spiele gesehe hab -

Schausp Ist das moglich

Graf. Ja. Schaun S Fräulein, es ist so schwer

mit dem Theater . . Ich bin gewöhnt . spat

zu spe diniren . . also weñ man da hin

10 kō̄t, ist' beste vorbei. Ist nicht wah.

Schausp. So werden Sie eben von jetzt an

früher essen.

Graf. Ja ich hab auch schon daran gedacht.

Oder gar nicht. Es ist ja wirklich kein Ver- 
HSz9 310

Handschriften und Typoskript

veuis, cles hiver

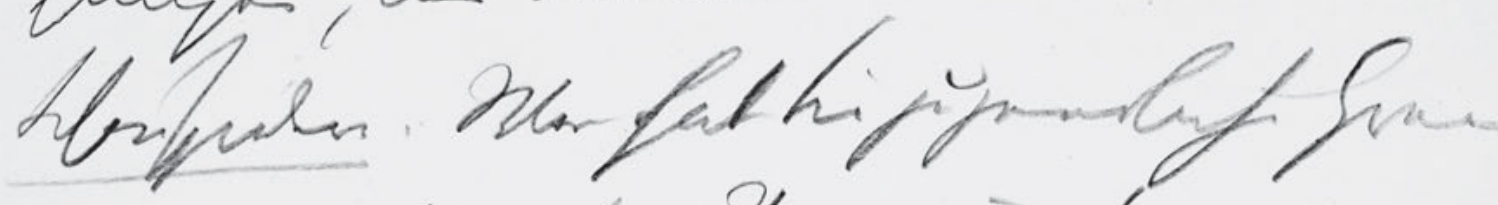
asontext unfe Hopmis

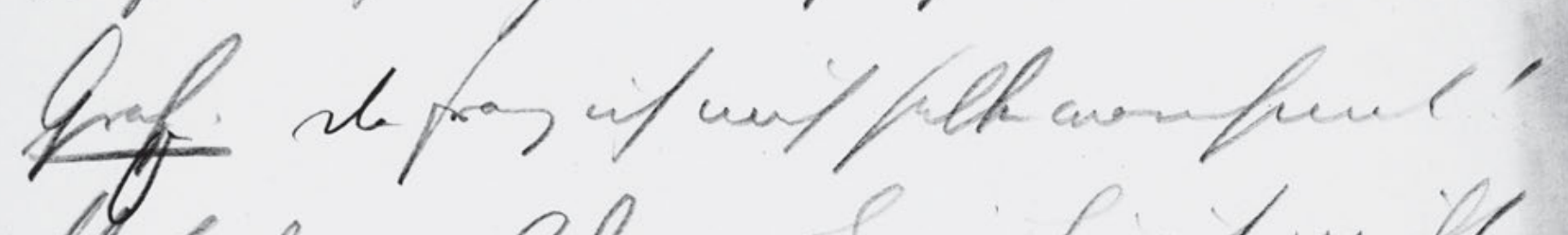

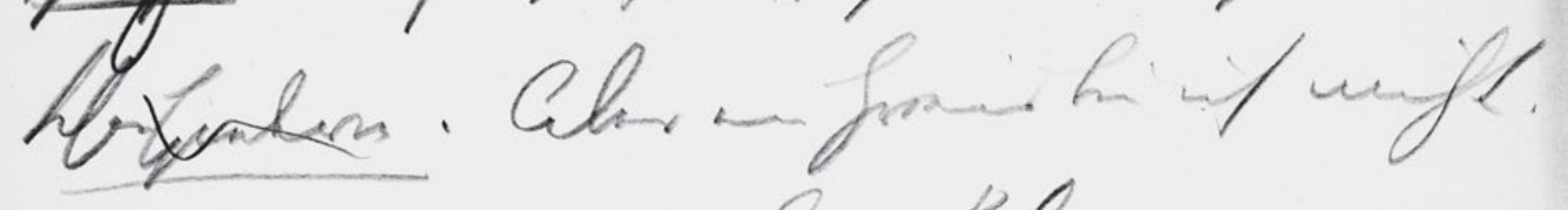
Er wit wienstr froun falmon.

Iff bant hi:

vrat ta. ch Lien bot havart

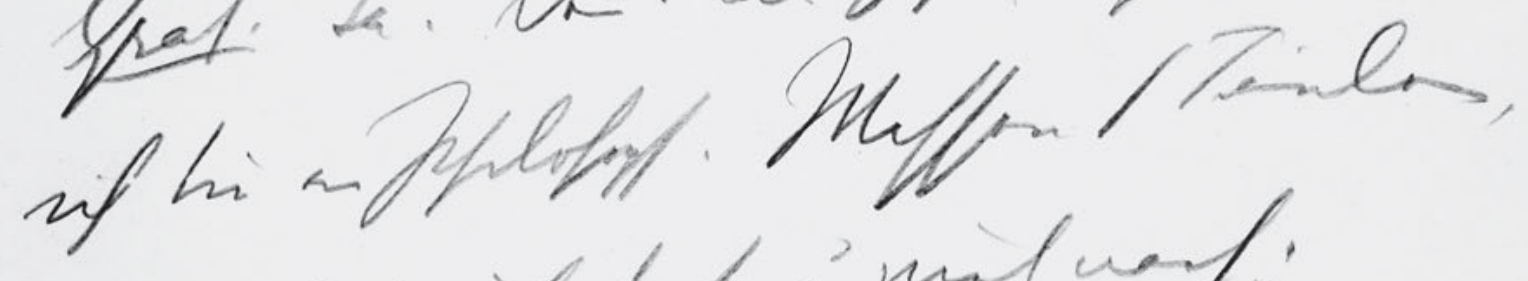
or cumint, if tht pinat way.

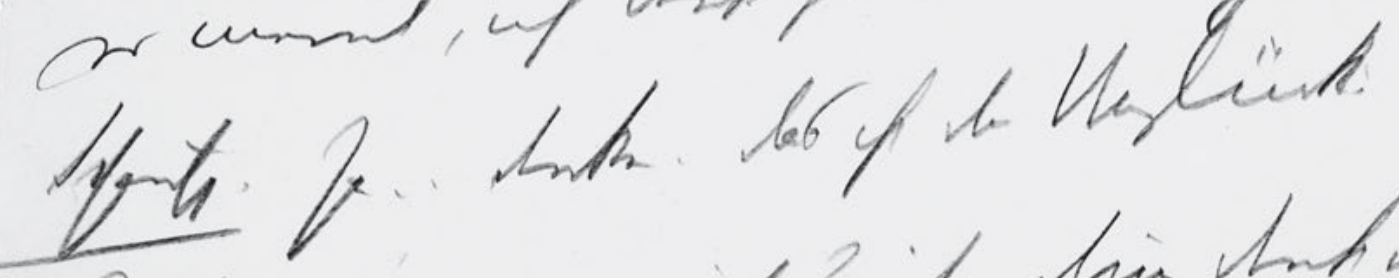

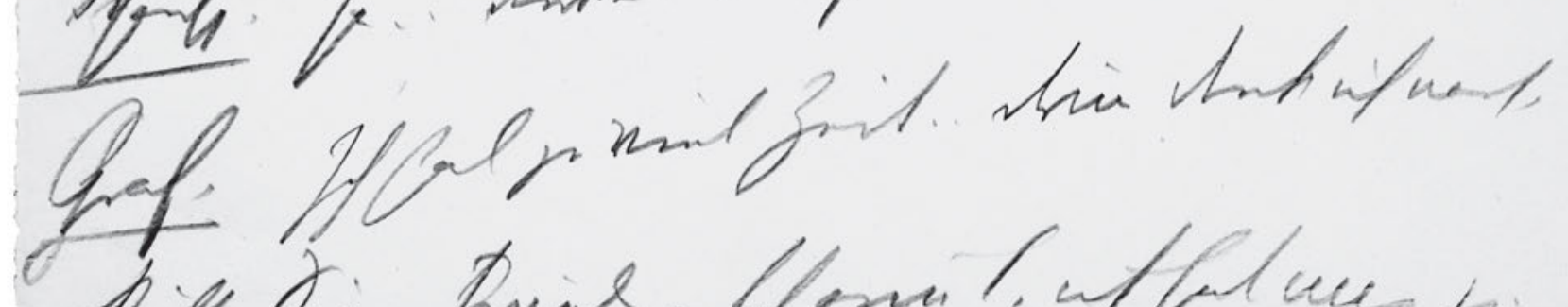

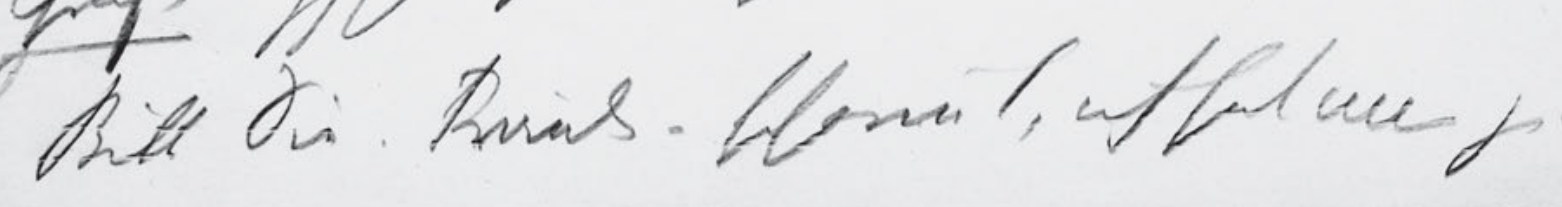

758 
310

gnügen, das Diniren.

Schauspielerin .. Woran haben Sie jugendlicher Greis eigentlich noch ein Vergnügen!

$5 \quad$ Graf. Das frag ich mich selber manchmal!

Schauspielerin . Aber ein Greis bin ich nicht.

Es muss ein andern Grund haben.

Graf.Schsp Glaub Sie?

Graf. Ja. Der Lulu sagt beispielsweise:

10 ich bin ein Philosoph. Wissen S Fräulein,

er meint, ich denk zu viel nach.

Schausp. Ja . . denken . das ist das Unglück.

Graf. Ich hab zu viel Zeit .. drum denk ich nach,

Bitt Sie . Fräulein - schaun S, ich hab mir ge- 
HSz9 311

Handschriften und Typoskript

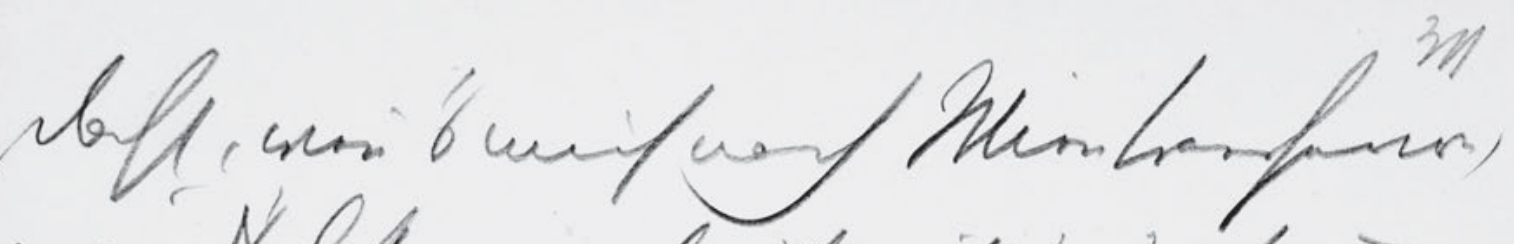

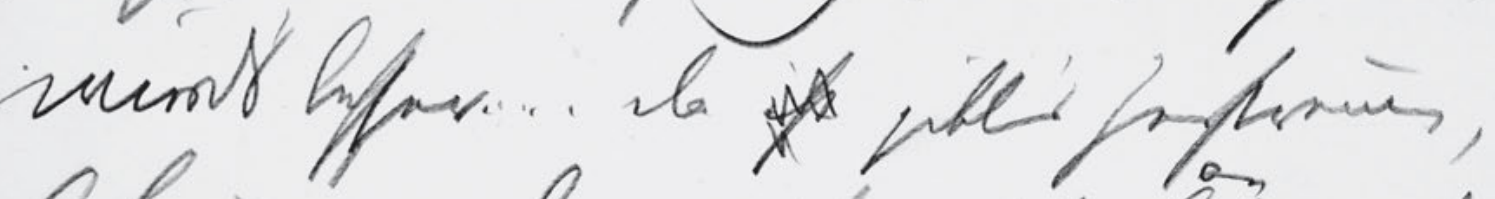
anforing ah wrik mifle el da in Sniend iff inflamber of 1 oh

lemings. Mo pra oh

Geat ha banto miffe l, treach.

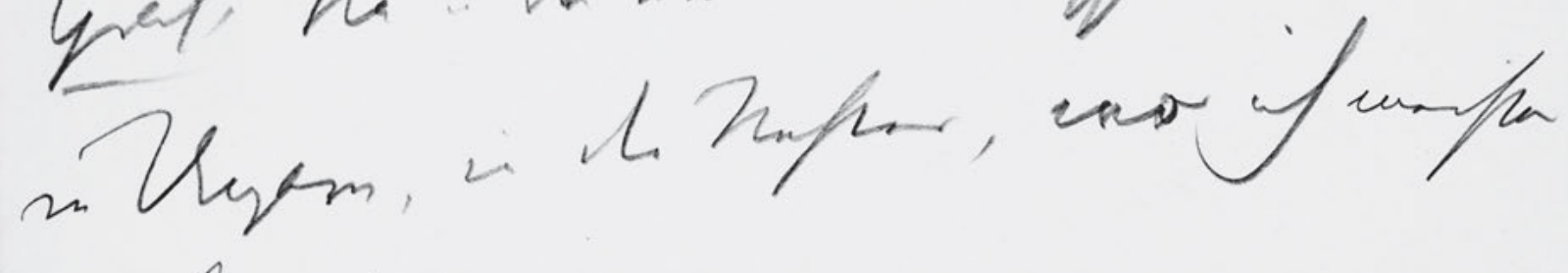
si fauifos uner....

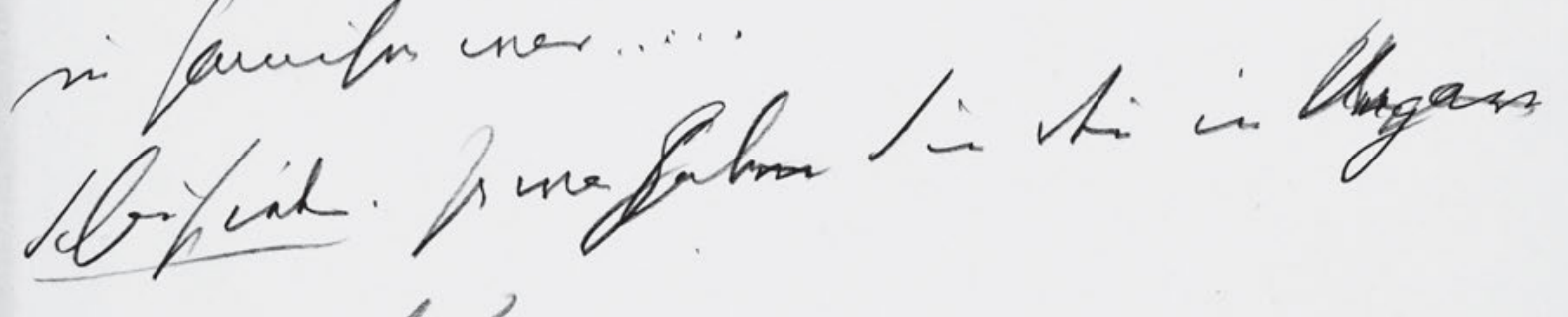
groments.

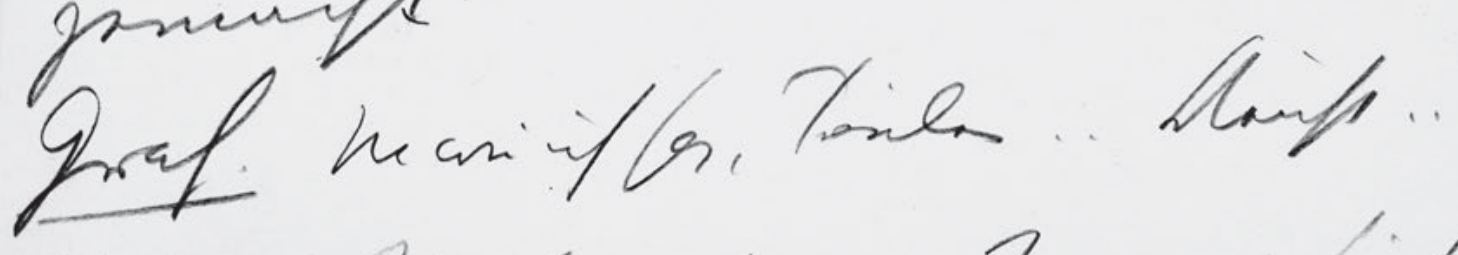

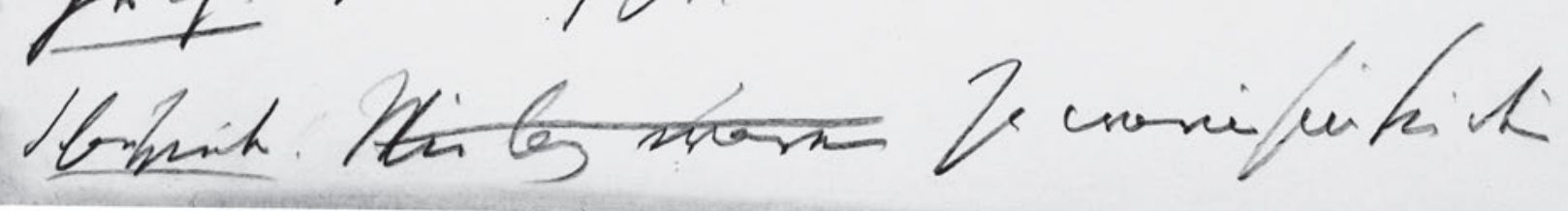

760 


\section{1}

dacht, weñ 's mich nach Wien transferirn, wird's besser .... da ist gibt's Zerstreuung, an Aufregung . . aber es ist nicht besser, als

$5 \quad$ da im Grund doch nicht anders als d oben.

d.

Schauspiel. Wo ist denn oben.

Graf. Na . . da unten . . wissen S, Fraulei

in Ungarn, in die Nester, wo ich meistens

in Garnison war ......

Schauspieler. Ja was ${ }^{\mathrm{H}}$ haben Sie deñ in Ungarn

gemacht?

Graf. Na wie ich sag, Fräulein .. Dienst . .

Schauspieler. Wie lang ${ }^{\left[{ }^{[t]}\right.}$ waren Ja warum sind Sie den̄ 
HSz9 312

Handschriften und Typoskript

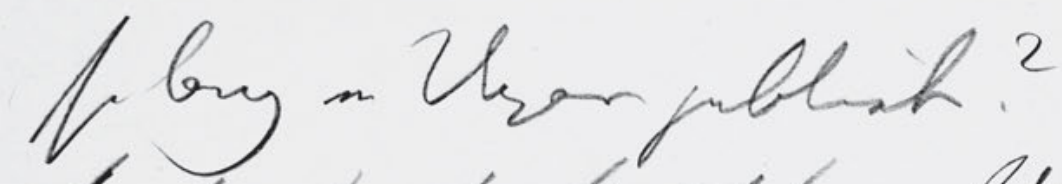

32

frat a der hinit fo... Qtave

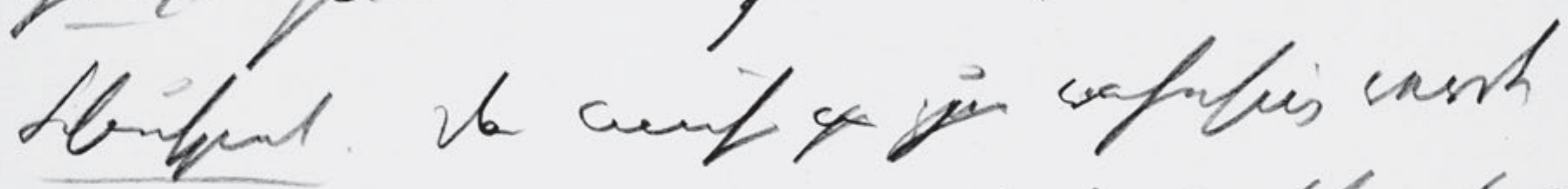

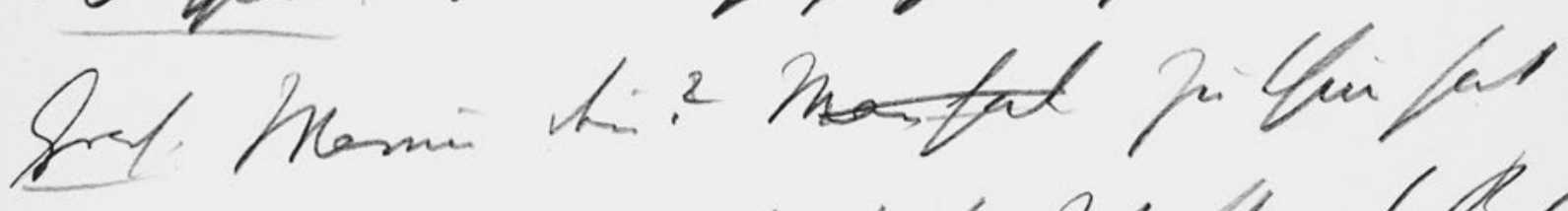

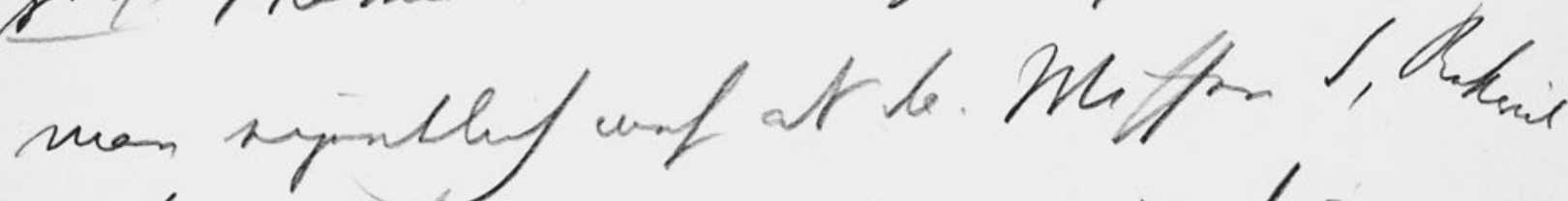

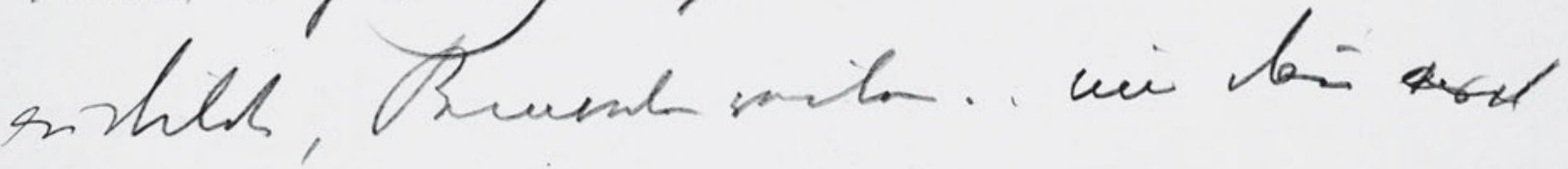

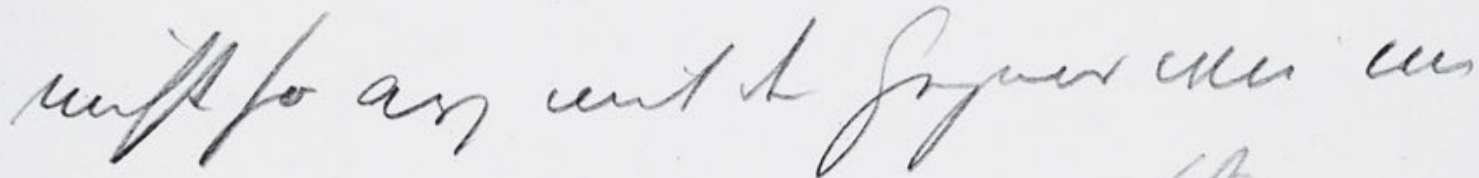

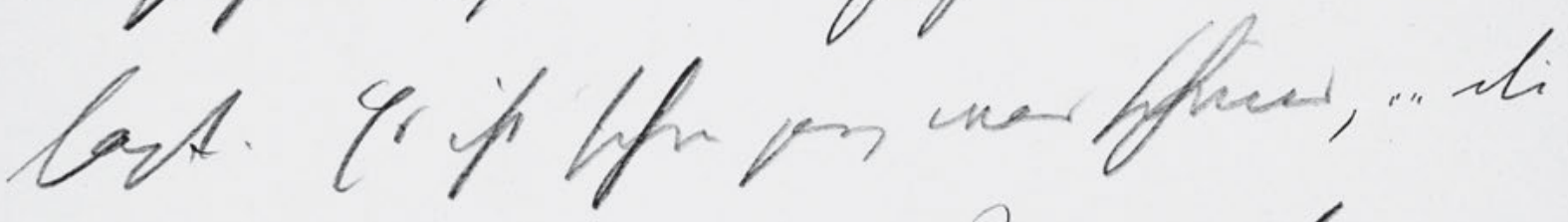

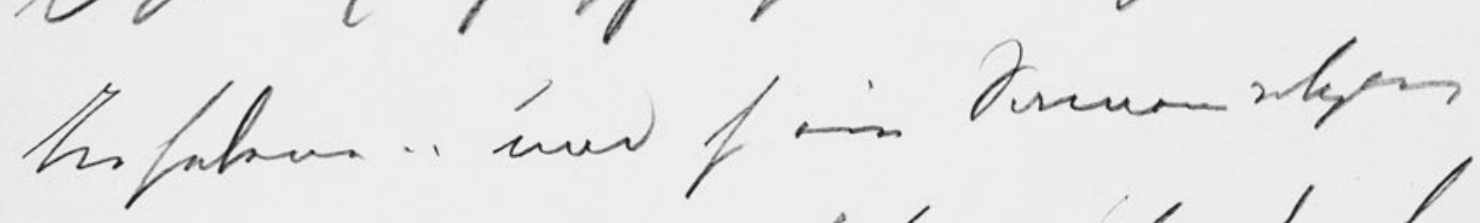

sofitfer, lefe of thin teach hi:

iiffl cur cuarsfinal profte tha

if tor that ine tertifs waln

762 
so lang in Ungarn geblieben?

Graf. Ja - das kō̄t so ... Und

Schauspiel. Das muss ${ }^{\mathrm{ja}} \mathrm{m}{ }^{\mathrm{zum}} \mathrm{ja}$ wahnsing werden

5 Graf. Warum den̄? Man hat Zu thun hat

man eigentlich mehr als da. Wissen S, Rekrut

ausbilden, Remonten reiten .. und dañ ${ }^{\text {?at? }}$ es 'is?

nicht so arg mit der Gegend wie ma

sagt. Es ist schon ganz was schönes, . . . . die

10 Tiefebene... und so ein Sonnenuntergang .

es ist schad, dass ich kein Maler bin.

+ich hab mir manchmal gedacht, wen

ich ein Maler wär, thät ichs malen. 
HSz9 313

Handschriften und Typoskript

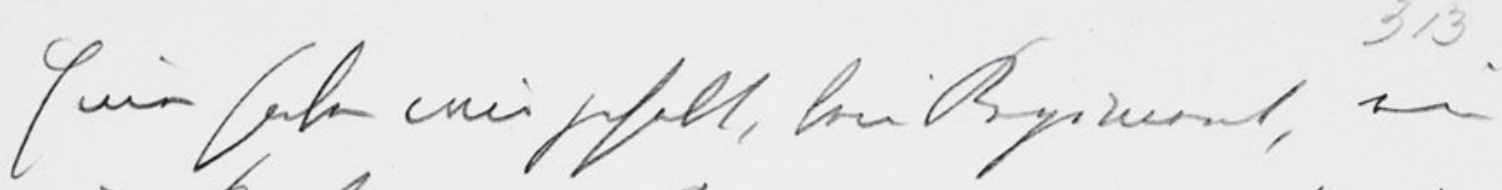

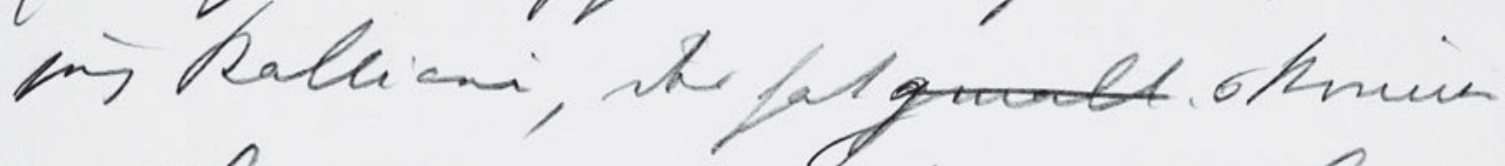
"Ahr mar moll neffer. erfefor Sthefs, Tinen..

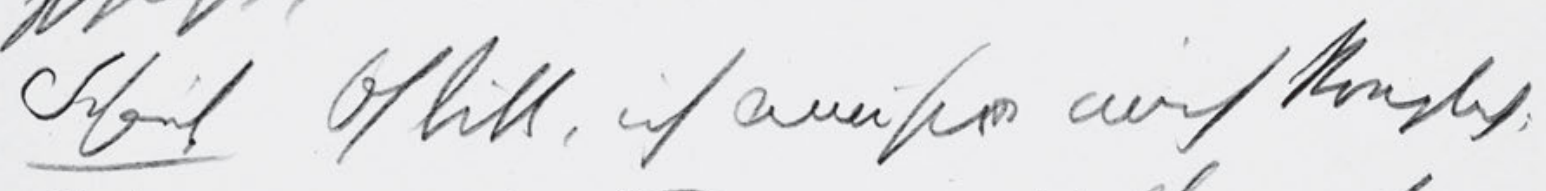

qref Ariffe Times, witfun the

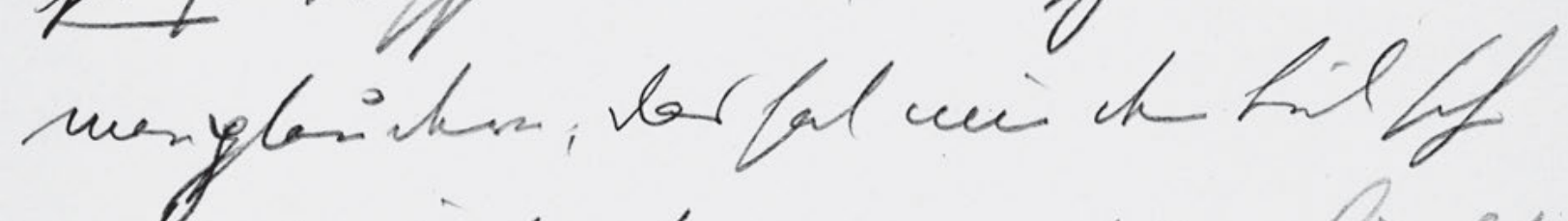

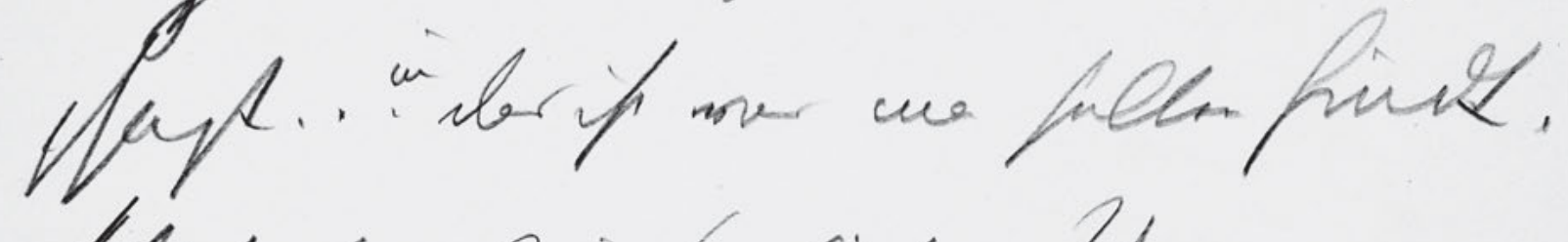

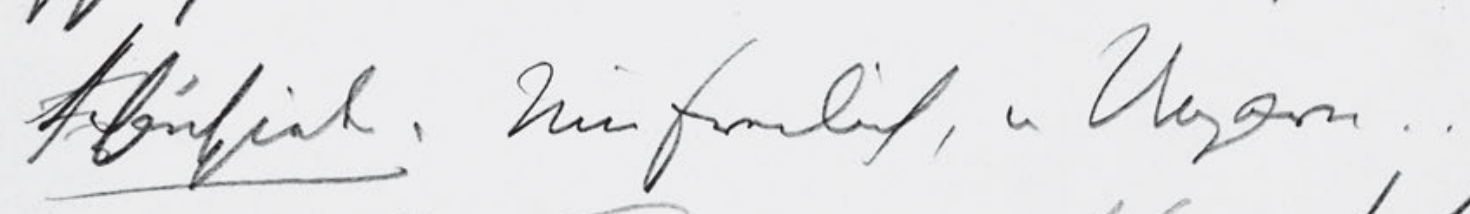

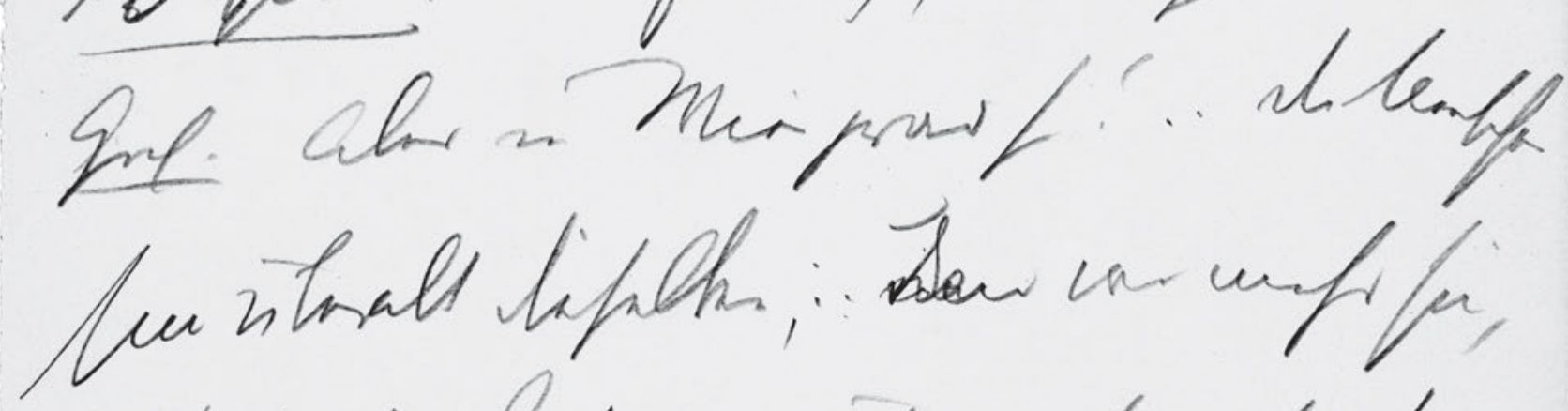

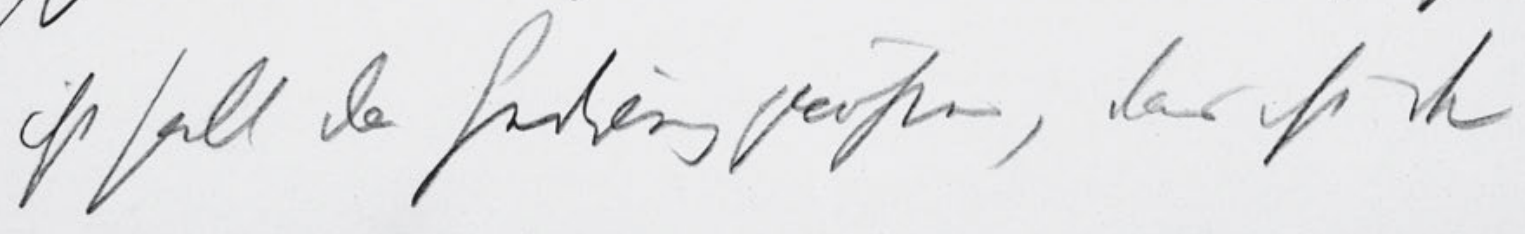

764 


\section{3}

Einen haben wir gehabt, beim Regiment, einen jung Kalliani, der hat gemalt. s können

.. Aber was erzähl ich Ihnen dasfur fad

5 Gschichtn, Fräulein . .

Schausp Oh bitte, ich amüsire mich koniglich;

Graf. Wissen S Fräulein, mit Ihnen kan̄ man plaudern; das hat mir der Lul scho un gsagt ... das ist was man selten findt.

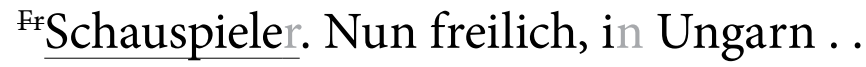

Graf. Aber in Wien grad so! . . Die Menschen sind überall dieselben; . . ${ }^{\text {?w? }}$ ?ur da wo mehr sin, ist halt das Gedräng größer, das ist der 
HSz9 314

Handschriften und Typoskript

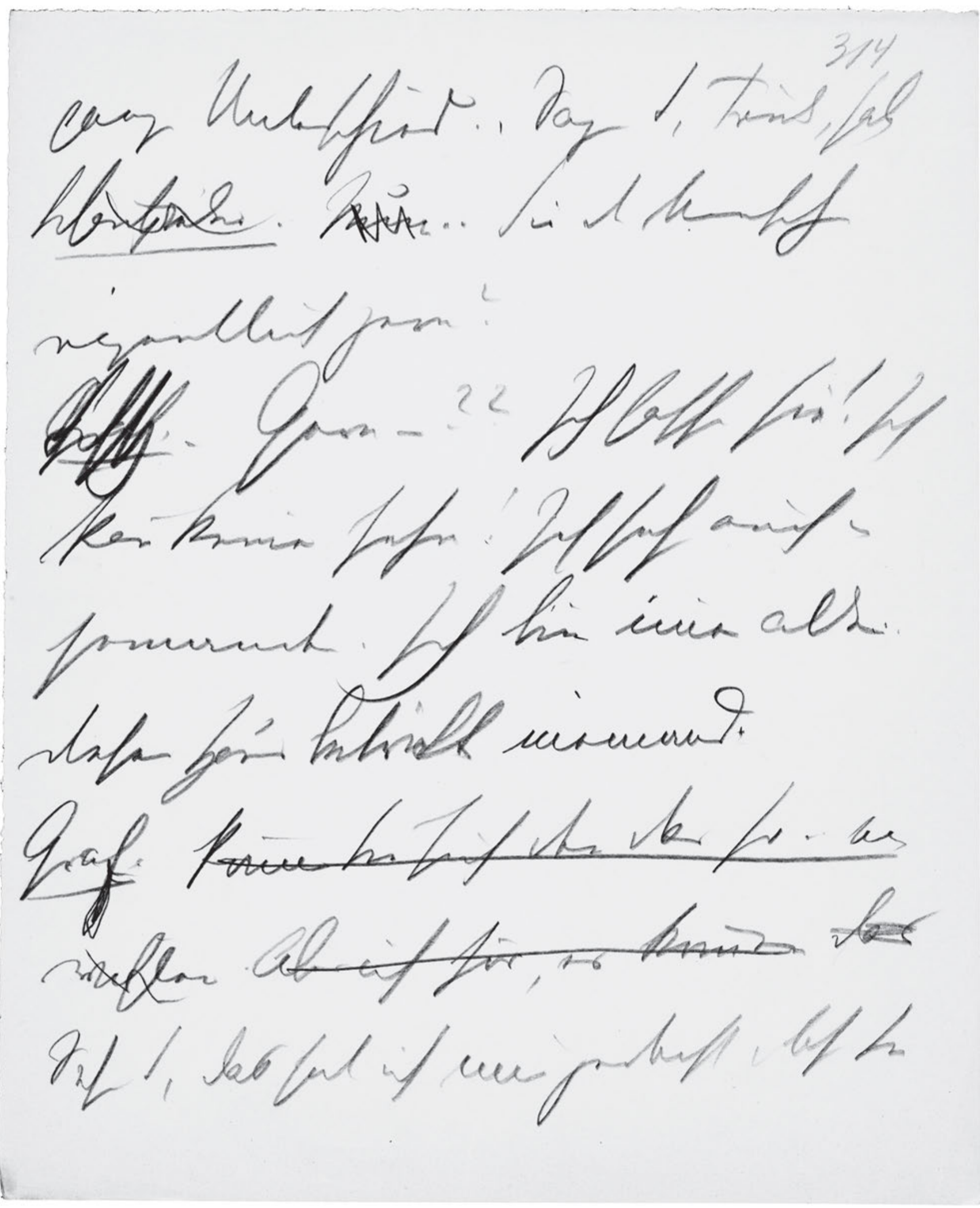

766 


\section{4}

ganze Unterschied ., Sagen S, Fräulein, haben

Schauspieler. Nun .. Sie die Menschen

eigentlich gern?

5

Graf.Schsp. Gern - ? ? Ich hasse sie! Ich

kan̄ keinen sehn! Ich sehe auch ' $n$ ?

jemanden. Ich bin imer allein ...

diese Haus betr ${ }^{[?]}$ itt niemand.

Graf. Können Sie sich den das so . . ein

10 richten .Aber ich hör, es kom̄en das

Sehn S, das hab ich mir gedacht, dass Sie 
HSz9 315

Handschriften und Typoskript

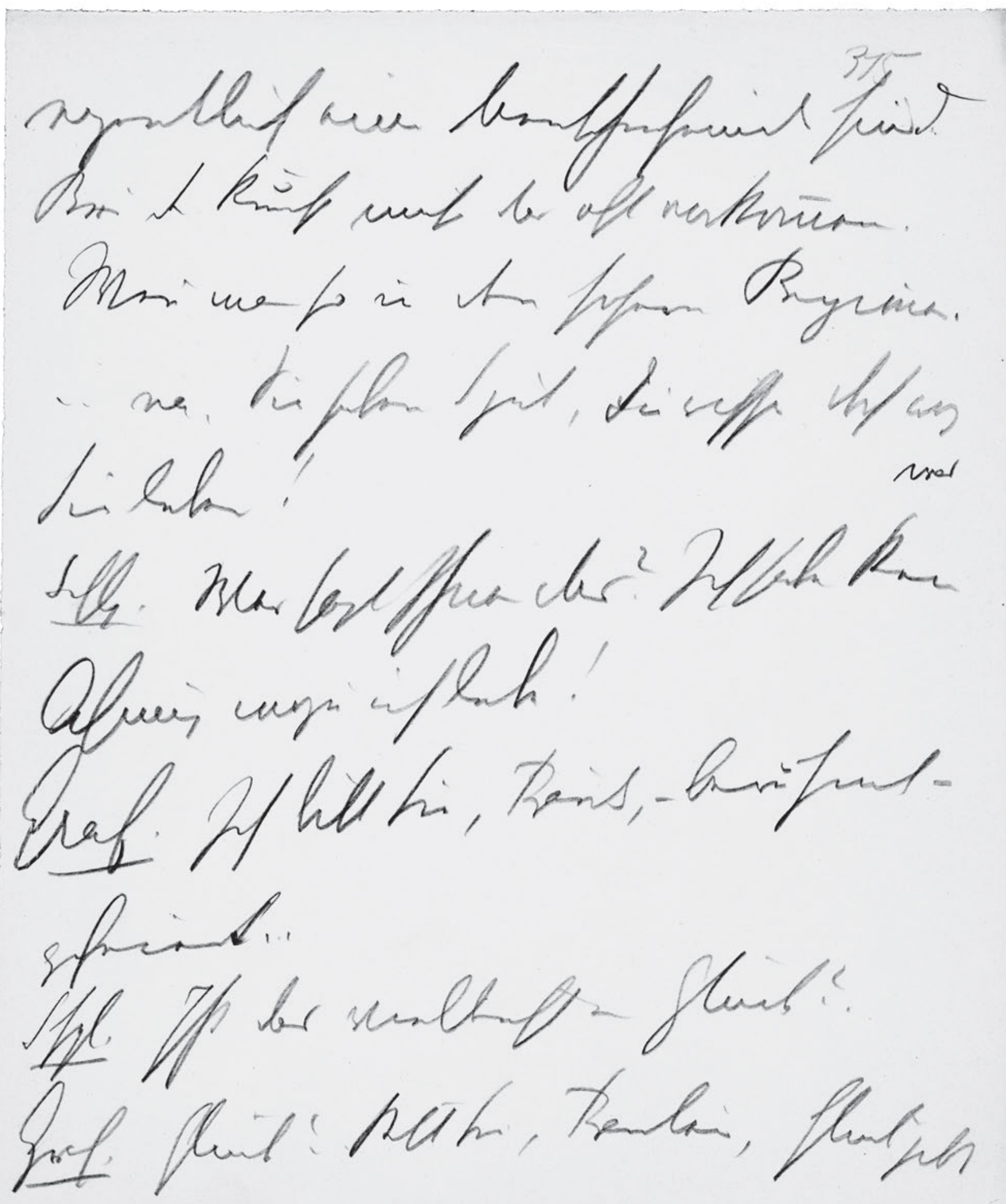

768 


\section{5}

eigentlich eine Menschenfeind sind . .

Bei der Kunst muss das oft vorkōmen.

Weñ man so in den hohern Regionen.

5 .. na . Sie haben S gut, Sie wisse doch weg

was

Sie leben!

Schsp. Wer sagt Ihnen das? Ich habe keine

Ahnung wozu ich lebe!

Graf. Ich bitt Sie, Fräulein, - berühmt -

10 gefeiert. .

Shpl. Ist das vielleicht ein Glück? .

Graf. Glück? Bitt Sie, Fraulein, Glück gibt 
HSz9 316

Handschriften und Typoskript

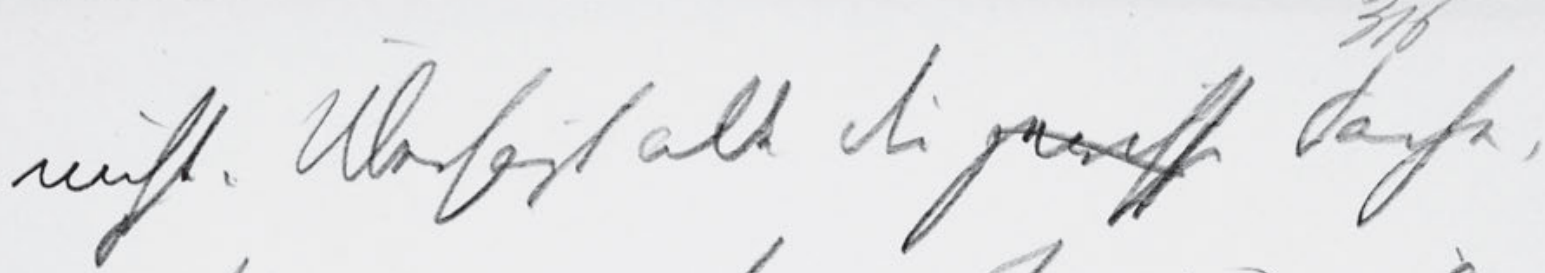

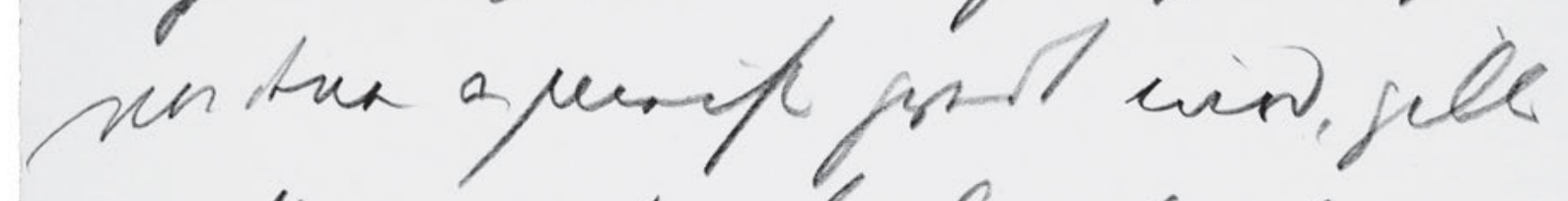
mift.

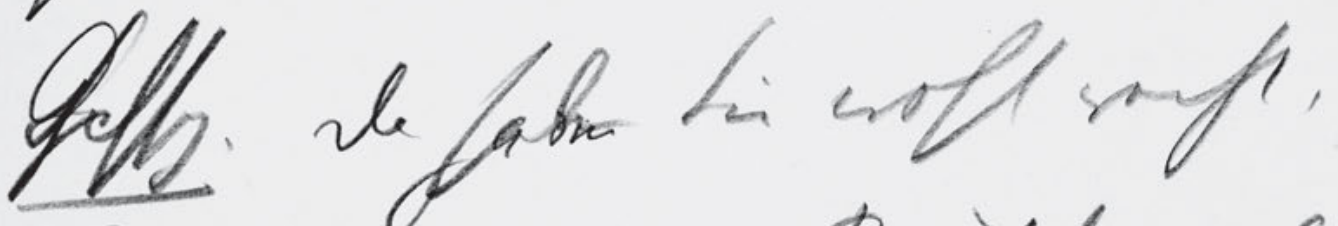

Arfe Grumft.. Banth. at jit,

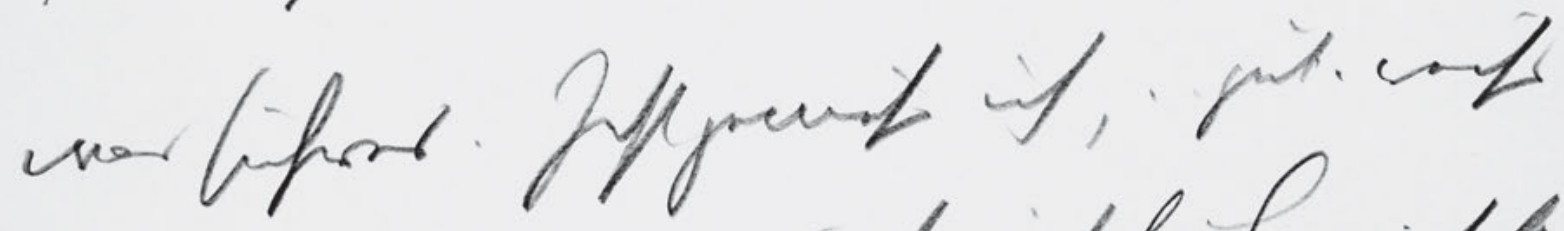
ct, if grunt ort it hismith.

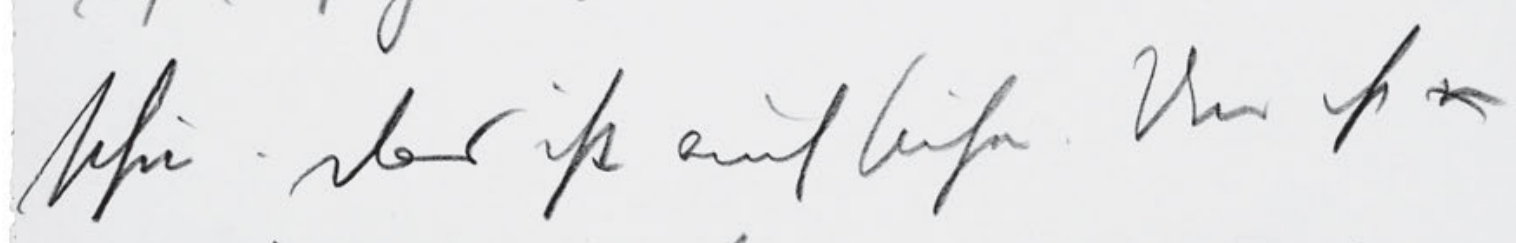
untri, firmon:

770 


\section{6}

nicht. Überhaupt alle die gewisse Sachen, von denen am meisten gredt wird, gibts nicht.. Z. B. Liebe . das ist auch

5 So was.

${ }^{G r}$ Schsp. Da haben Sie wohl recht, Graf. Genuss . . Rausch . . also gut, da laßt sich nichts sagen . . das ist was sichres. Jetzt geniess ich, .. gut . weiss

10 ich, ich geniess. Oder ich bin berauscht. schön . das ist auch sicher. Und ist es vorbei, ist vorbei. . . 
HSz9 317

Handschriften und Typoskript

gral.

Uf rink

3

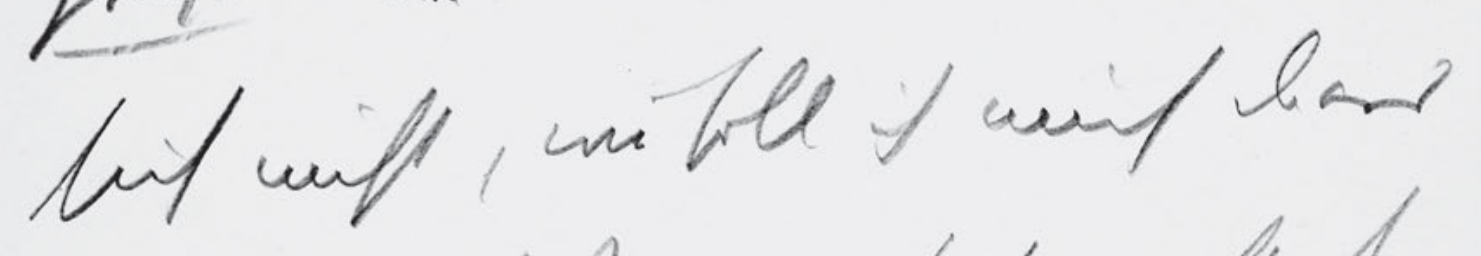

lsink

colar we lis unf

L

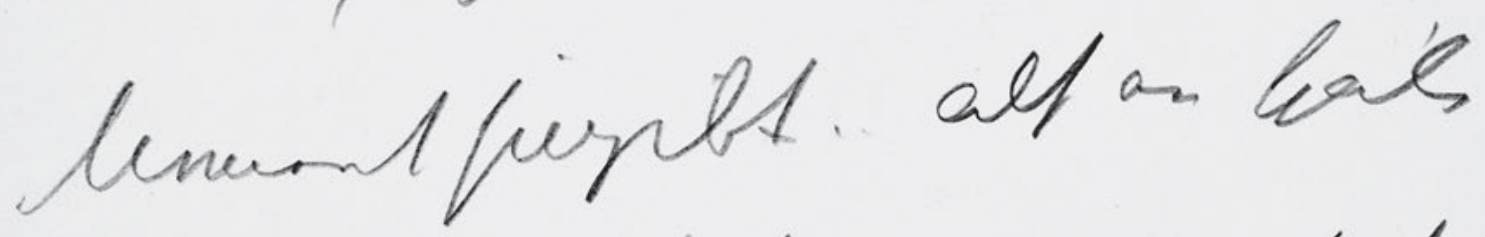

buht ruh a profe... no, ifh iff

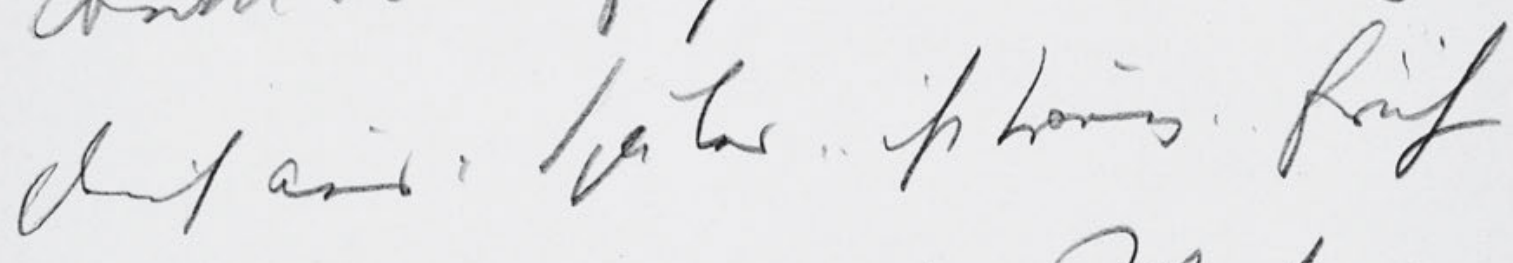
singunte... unt - Most... an

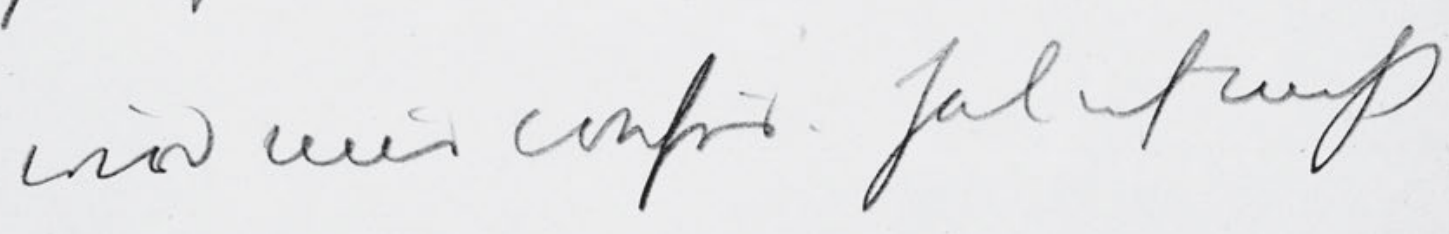
Ruf?

772 
Schsp. Es ist vorbei! .

Graf. Aber . . Alles, was Aber sobald man

sich nicht, wie soll ich mich da aus

drücken, sobal man sich nicht dem

5 Moment hingibt . . also an später

denkt oder an früher... na, ist doch

gleich aus: Später . . ist traurig . . früher

ist ungewiss .... mit ein Wort .. ma

wird nur confus. Hab ich nicht

$10 \quad$ Recht? 
HSz9 318

Handschriften und Typoskript

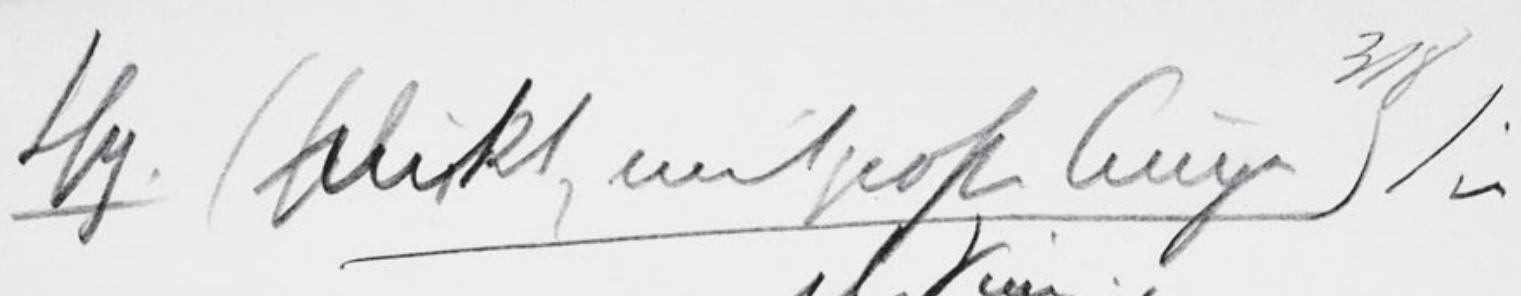

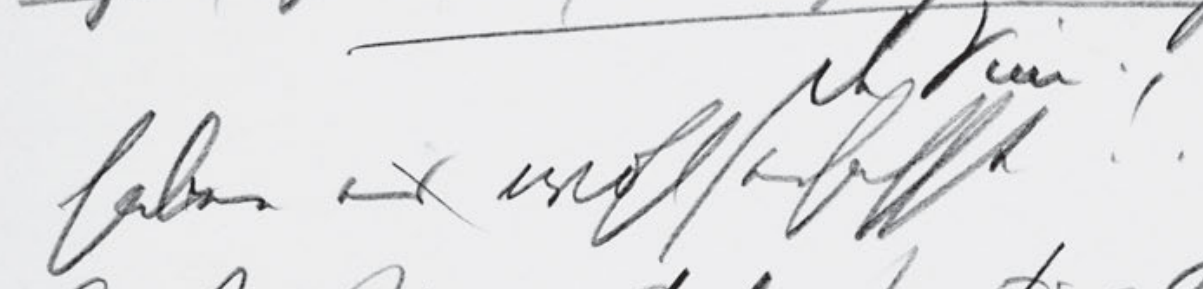

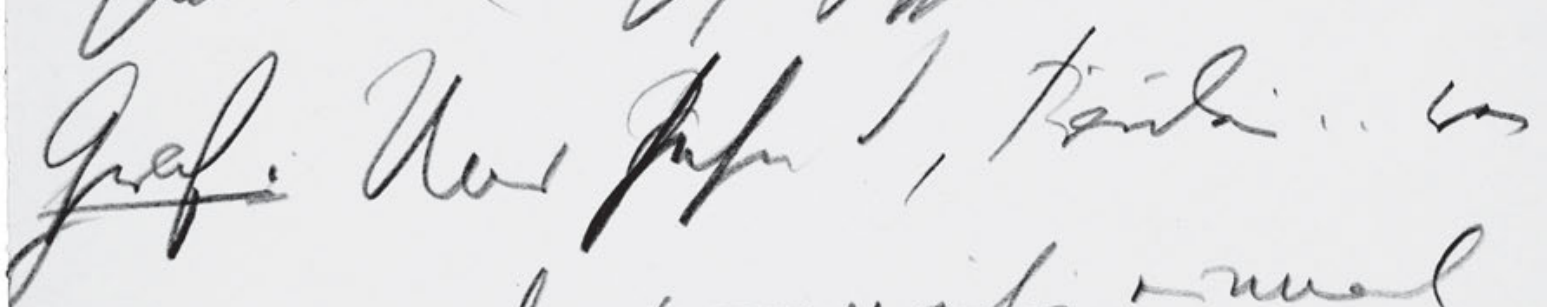

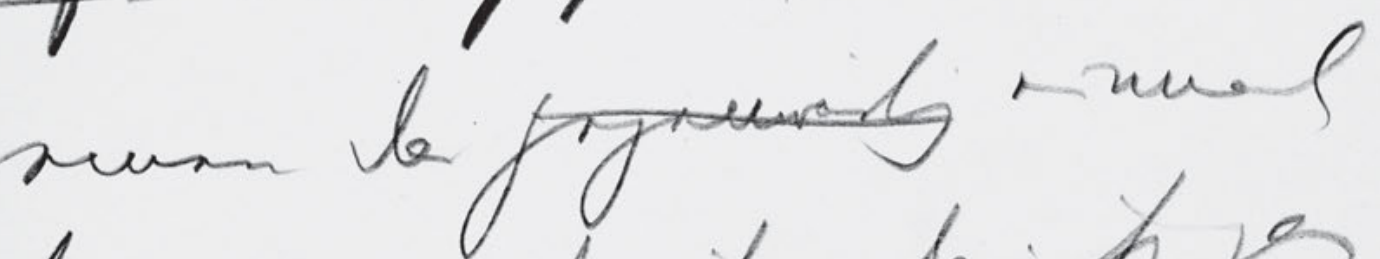
kla jummon ip, ba jos ryat, of wa ame hthrs

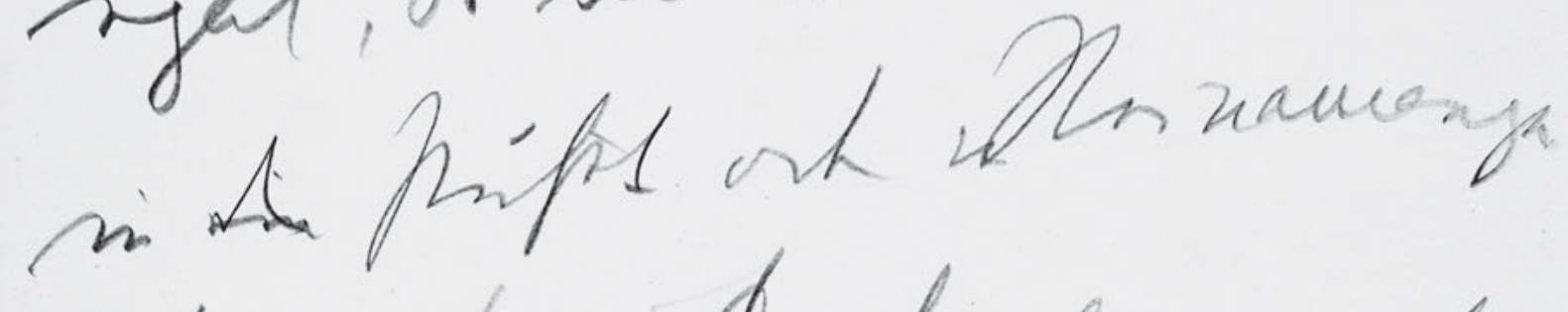

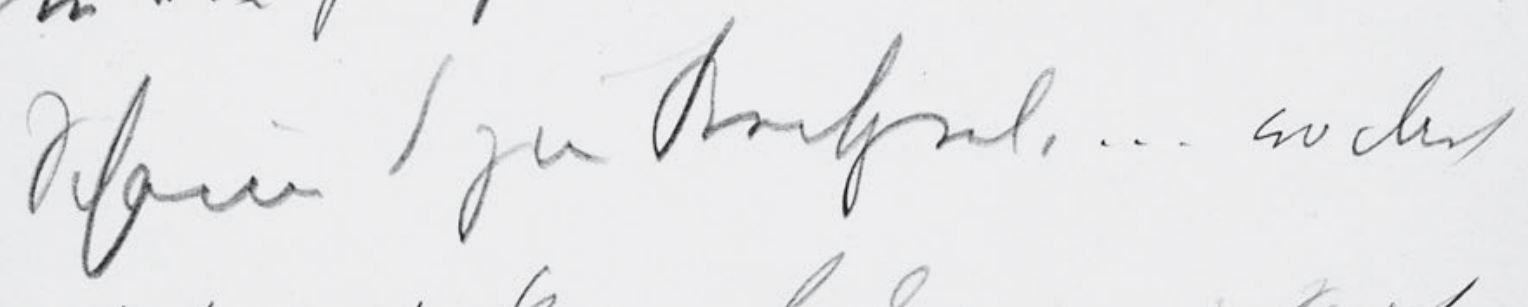

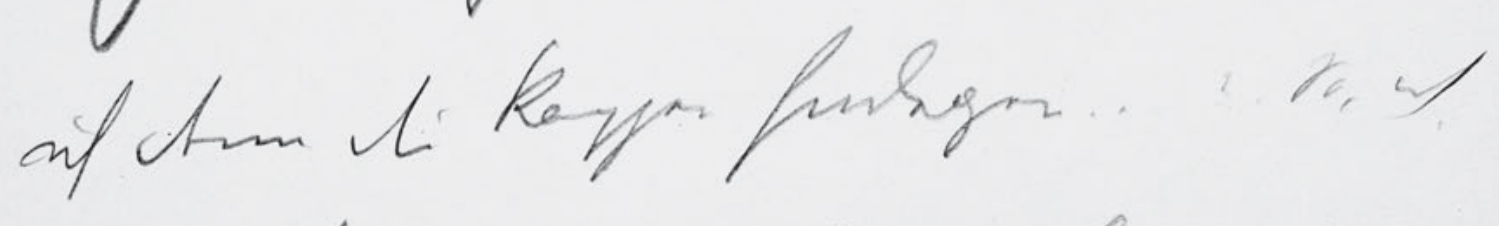

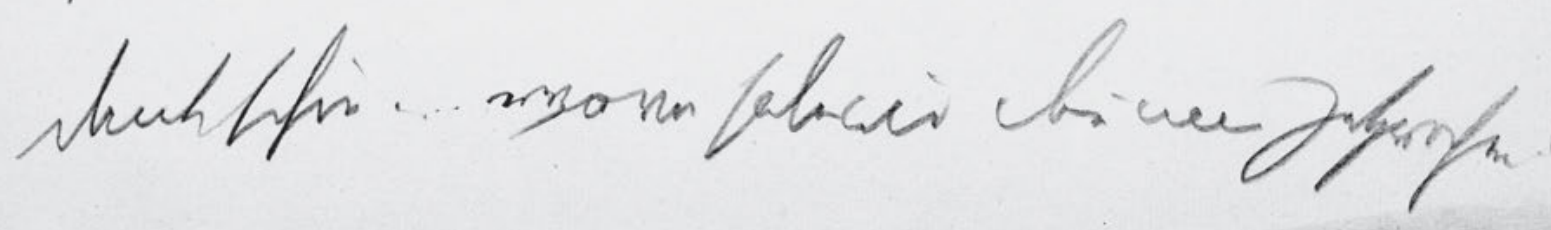

774 


\section{8}

Shp. ('sch?nickt, mit großen Augen) Sie den Sinn.

haben es wohl/erfasst! .

Graf. Und ${ }^{\mathrm{s}}$ sehn S, Fräulein . . wen

5 einem das gegenwärtig einmal

klar geworden ist, dan̄ ist ganz

egal, ob ma in Wien lebt oder

in ${ }^{\text {ein }}$ der Pußt oder in Steinamanger

Schaun S zum Beispiel, ... wo darf

10 ich denn die Kappen hinlegen ... ? . So, ich

dank schön .... wovon haben wir den̄ nur gesprochen? 
HSz9 319

Handschriften und Typoskript

Sory Her Desinameny.

Arent. Biflij. Celf mi if ay,

30

underir if

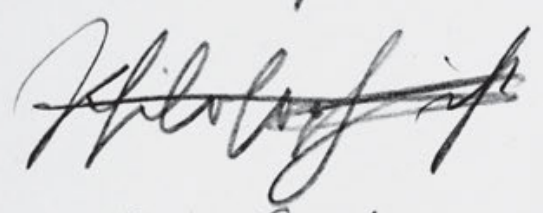

Mufan

Qher

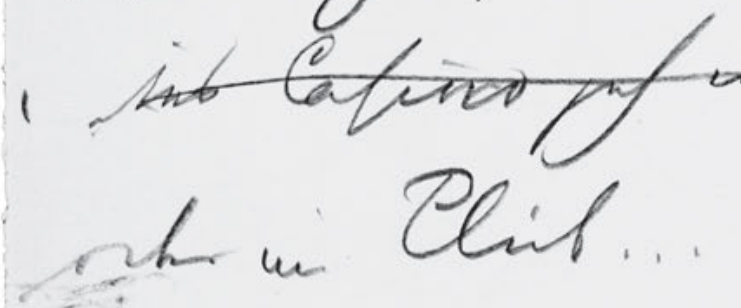

are

40
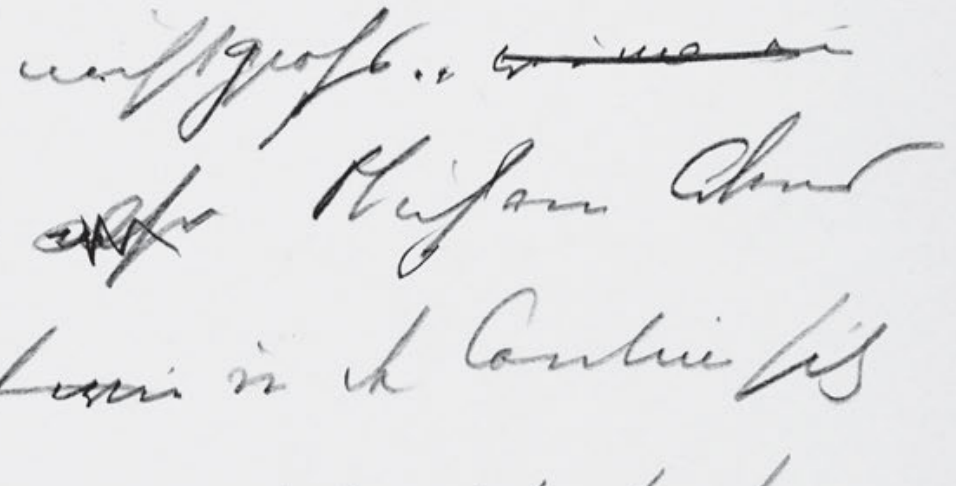

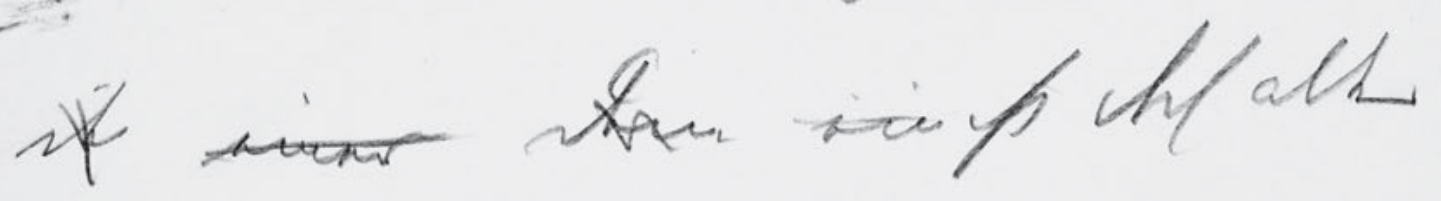

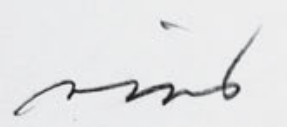

Ifonpiton. Pas.

Mut uin sarfere

hif thi her wat the hilfis

qaf.

Alsin wen to patt. It in

776 
319

Schausp. Von Steinamanger -

Graf. Richtig. Also wie ich sag, der

Unterschied ist nicht gross . . we $\bar{n}$ man ein

5 Philosoph ist ... ?w? alse Ob ich am Abend

ins Casino geh wie in der Cantine sitz

oder im Club ... ob ich mit der d'ann?

?de? einer denn ein ist doch alles

eins.

10 Schauspielerin. Sagen Und wie verhalt

sich deñ das mit der Liebe

Graf. Wen̄ man dran glaubt . . ist ī̄mer 
HSz9 320

Handschriften und Typoskript

min $h$,

L.

300

$\theta$

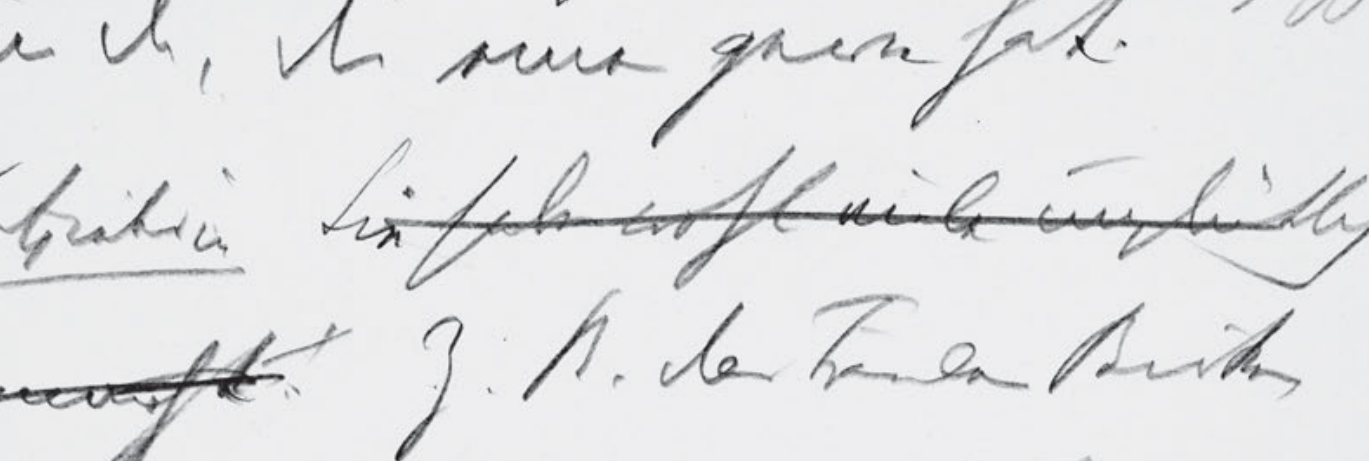

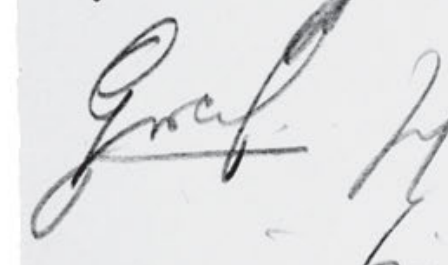

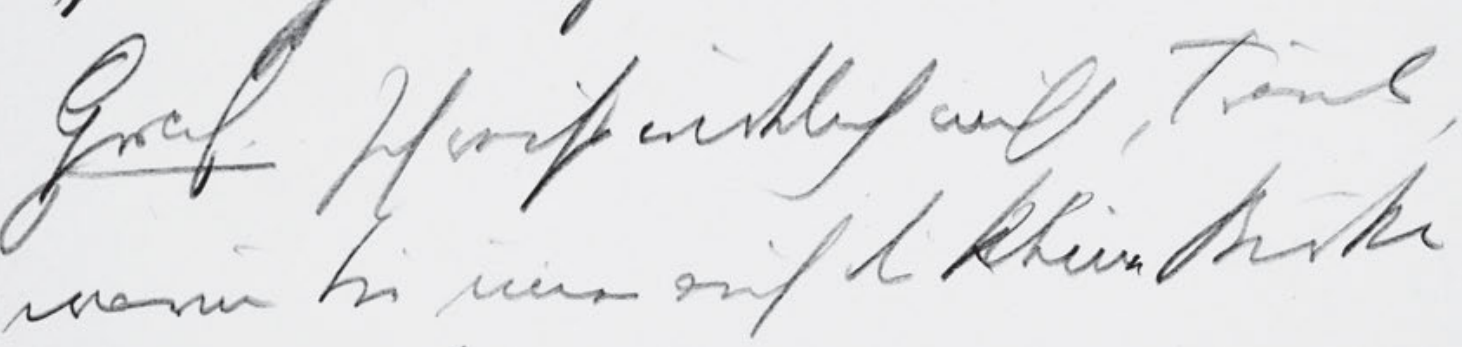

girste hañm.

Senterabion. Mr ff

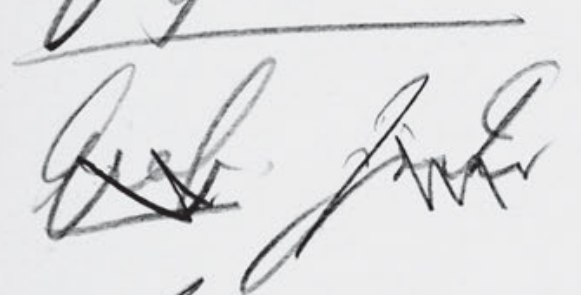
Ear

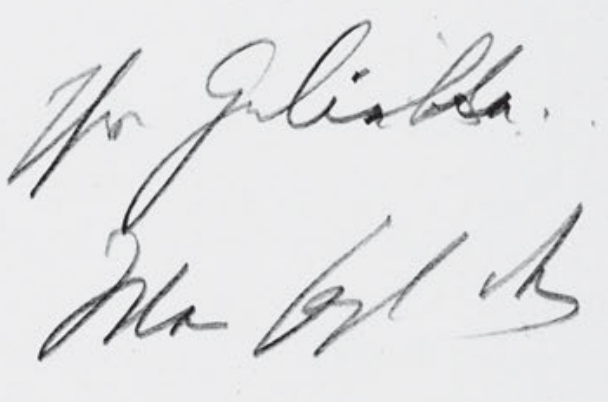

ofiguarin. b.

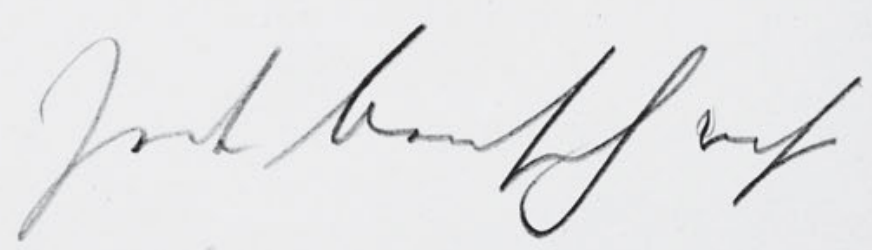

778 
320

eine $\mathrm{da}$, die einen gern hat.

Schauspielerin Sie haben wohl viele unglücklich

gemacht.! Z. B. das Fräulein Birken

5 Graf. Ich weiss wirklich nicht, Fräulein,

warum Sie imer auf die kleine Birken

zu reden komenen.

Schauspielerin. Das ist ja Ihre Geliebte...

Graf. Jeder Graf. Wer sagt denn

10 das.

Schauspielerin. Jeder Mensch weiss

das. 
HSz9 321

Handschriften und Typoskript

Srel.
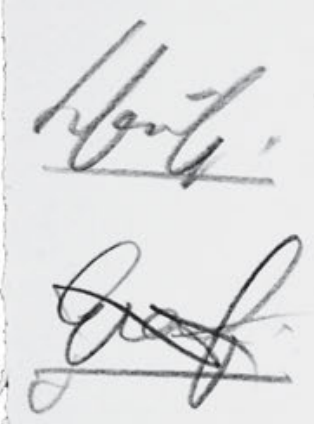

\& isfula
whil jufubt!
Graf. Hibsuf!

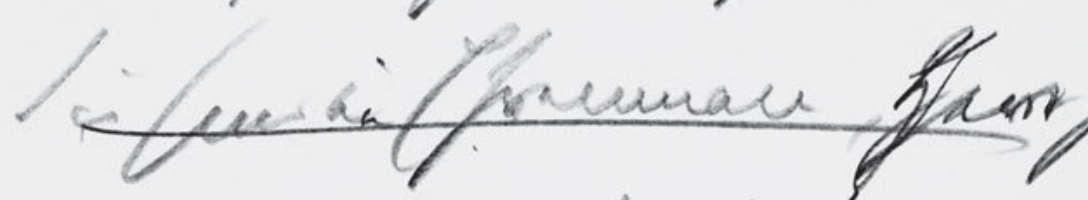

32

$\checkmark$

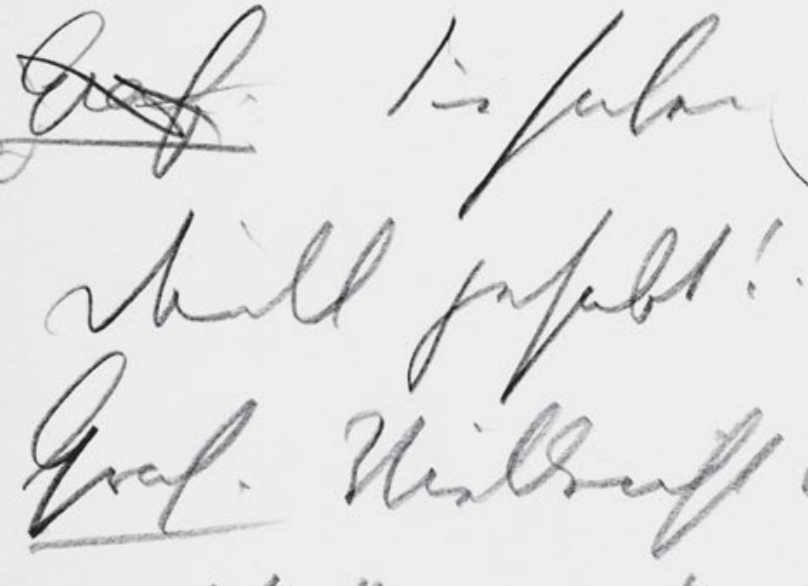

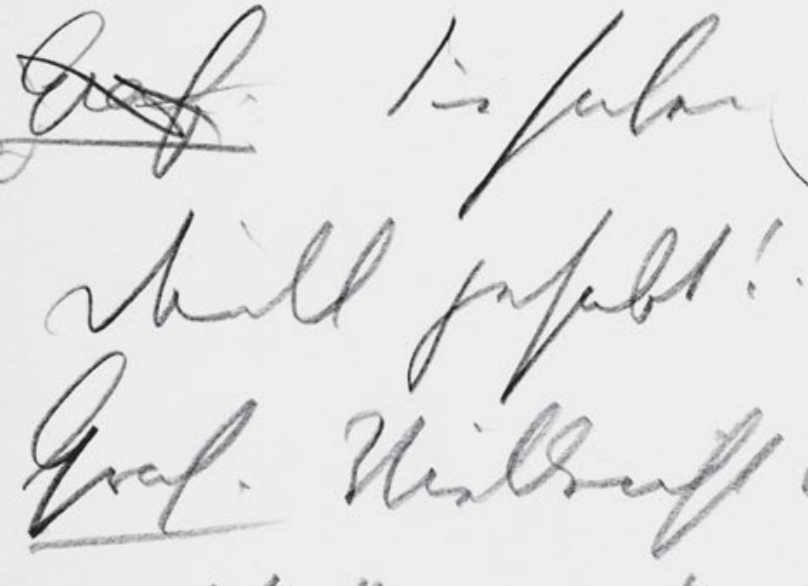

relofla werna c.

Bing frum

tom

youl.

Gift hi tip

Phis

lig

gifs
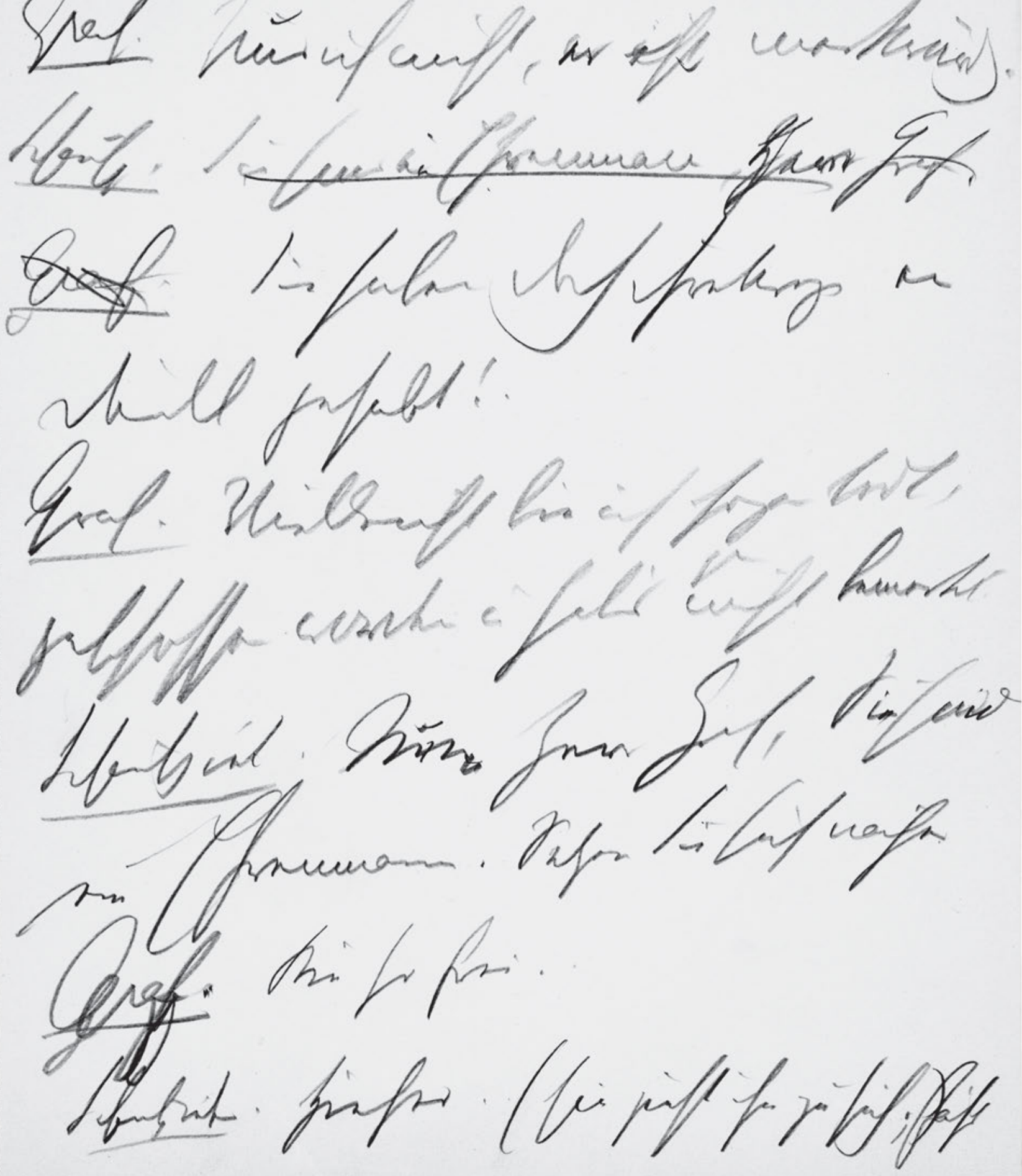

780 


\section{1}

Graf. Nur ich nicht, es ${ }^{[?] i s t}$ merkwürdig.

Schausp. Sie sind ein Ehrenmann, Herr Graf.

Graf. Sie haben doch ihretwegen ein

$5 \quad$ Duell gehabt! .

Graf. Vielleicht bin ich sogar todt,

$$
\text { gar }
$$

geschossen worden u hab's nicht bemerkt.

Schauspiel . Nun Herr Graf, Sie sind

ein Ehrenmann. Setzen Sie sich näher.

$10 \quad$ Graf. Bin so frei .

Schauspieler. Hieher . . (sie zieht ihn zu sich`; fährt 
HSz9 322

Handschriften und Typoskript
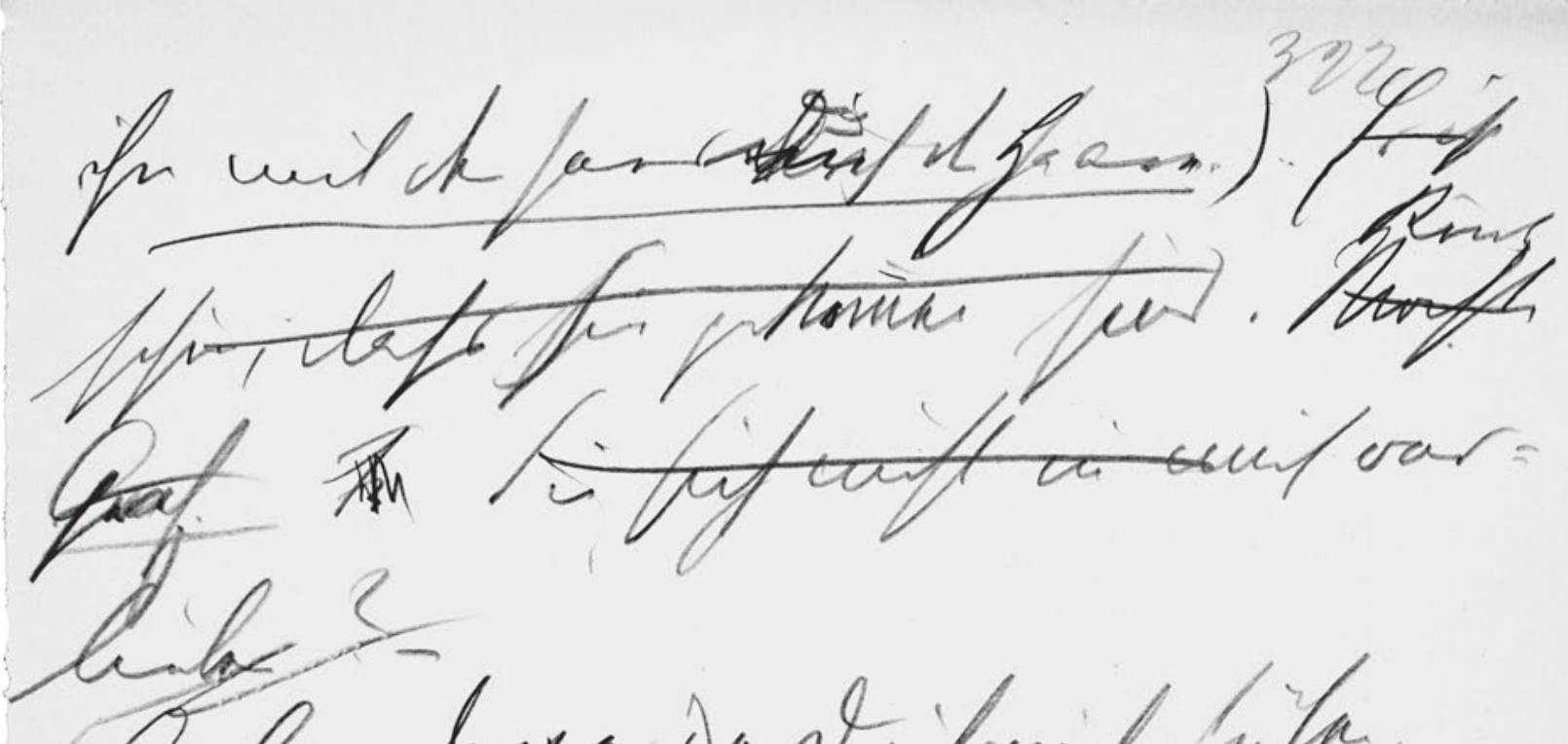

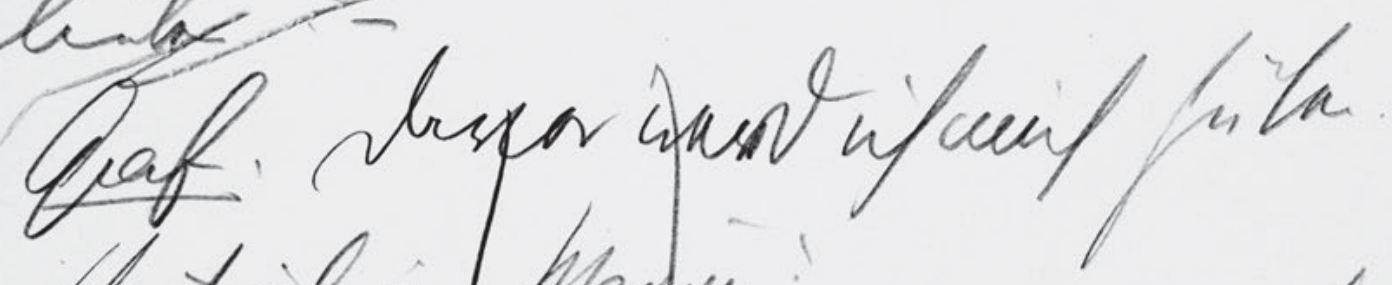

Genty inlior Maanien!

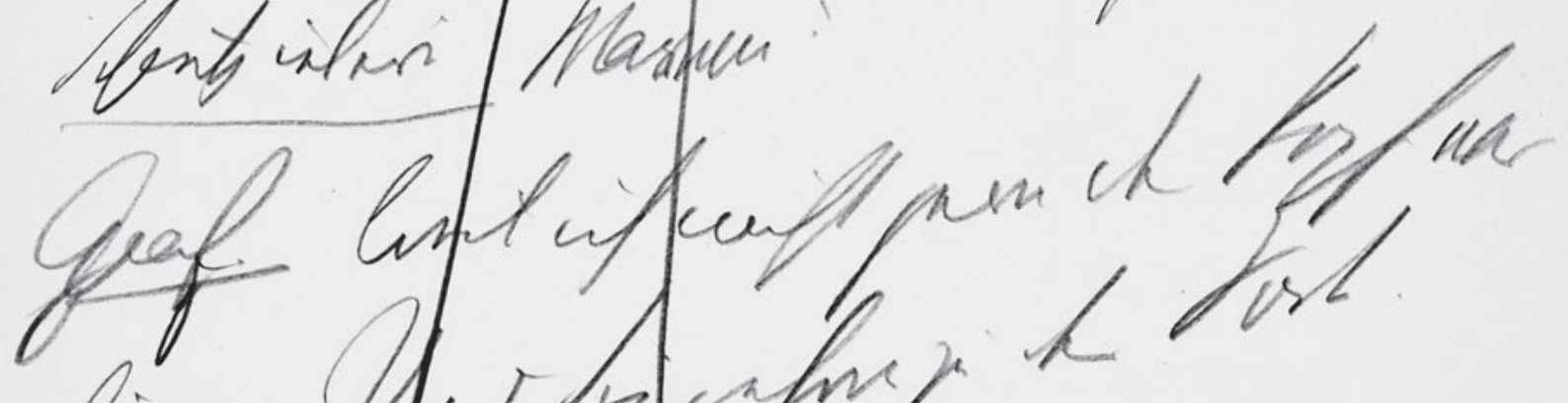

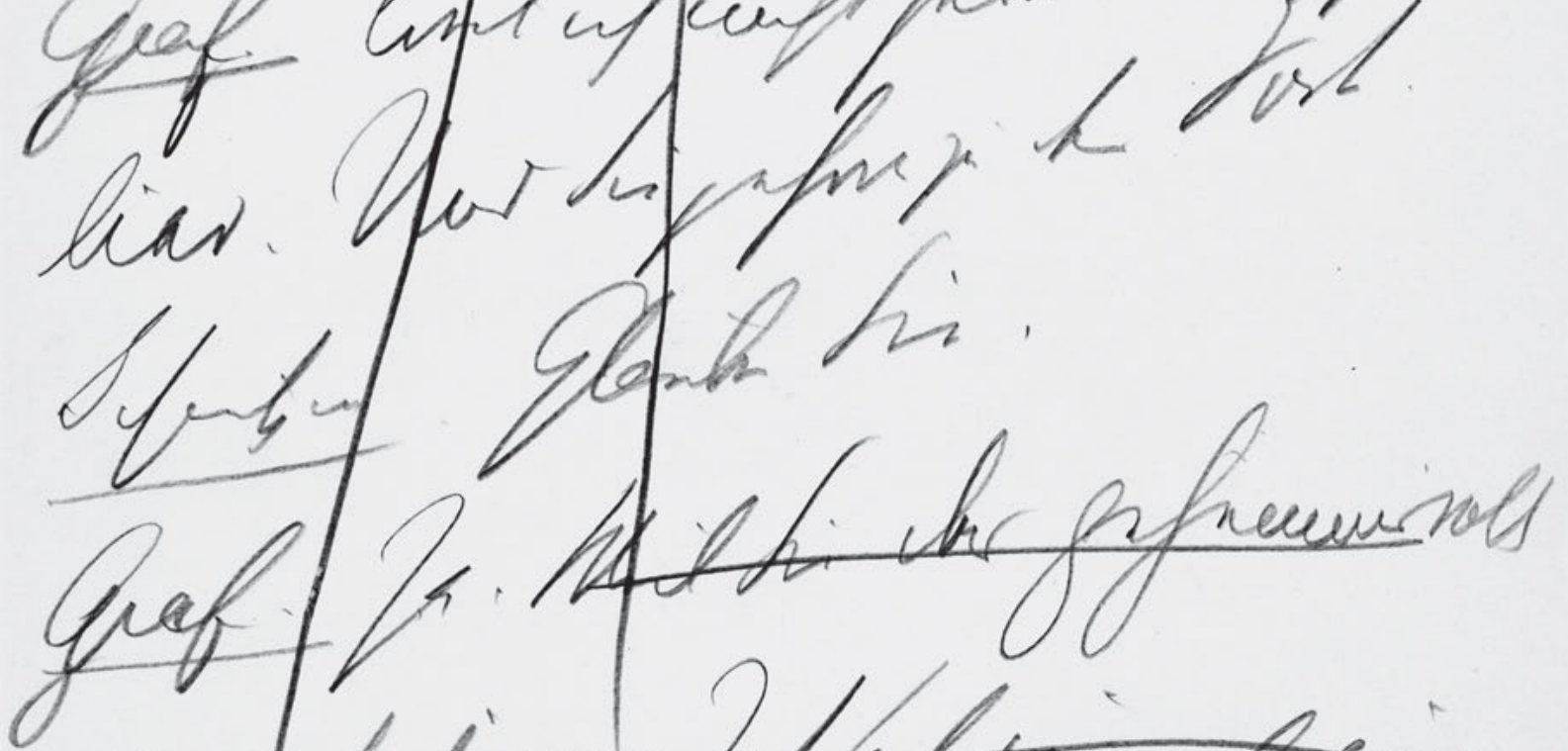

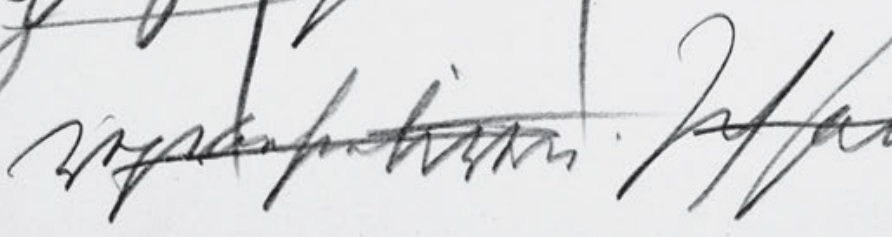

782 
322

ihm mit der Hand ${ }^{[?]_{\text {dureh }}}$ in die Haare.) . . Es ist

Könt

schön, dass ${ }^{s}$ Sie gekomen sind. Mocht

Graf. Fr Sie sich nicht in mich ver=

5 lieben? -

Graf. Davor werd ich mich hüten.

Schauspielerin Warum?

Graf. Weil ich nicht gern den Kopf ver

lier. Und Sie gehore zu der Sorte.

10 Schauspie. Glauben Sie.

Graf. Ja. Weil Sie das geheimnisvolle

reprłesentiren. Ich hab einmal eine 
HSz9 323

Handschriften und Typoskript

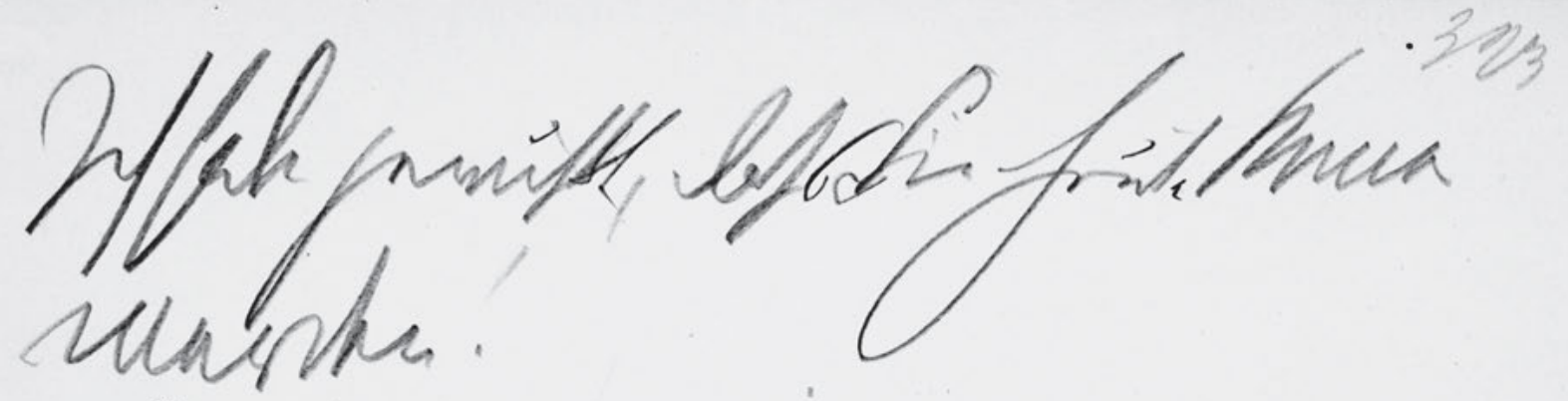

Guaf. An

if chais?

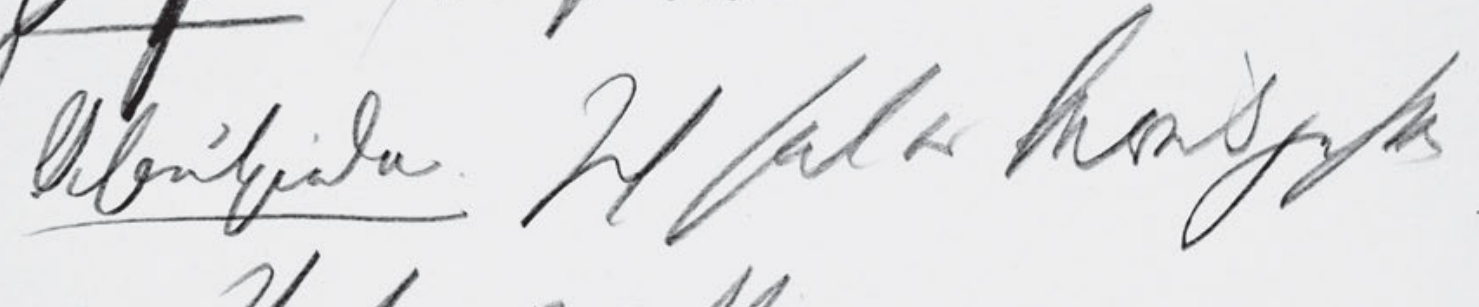

mo thate sel tar

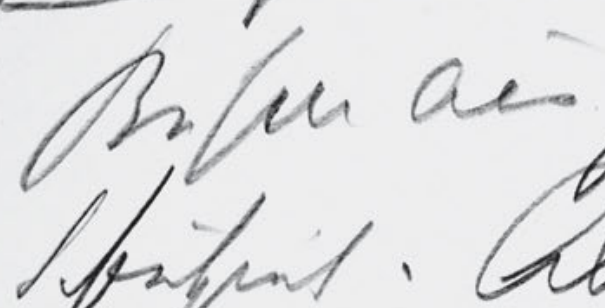

rinif the un th 
Ich habe gewußt, dass Sie heute komen

werden!

Graf. Wieso deñ? -

$5 \quad$ Schauspieler. Ich hab es bereits gestern

im Theater gewußt -

Graf. Haben Sie mich deñ von der

Buhne aus gesehn

Schauspiel . Aber Mann! Haben

10 Sie den nicht bemerkt, dass

ich nur für Sie gespielt habe. 
HSz9 324

Handschriften und Typoskript

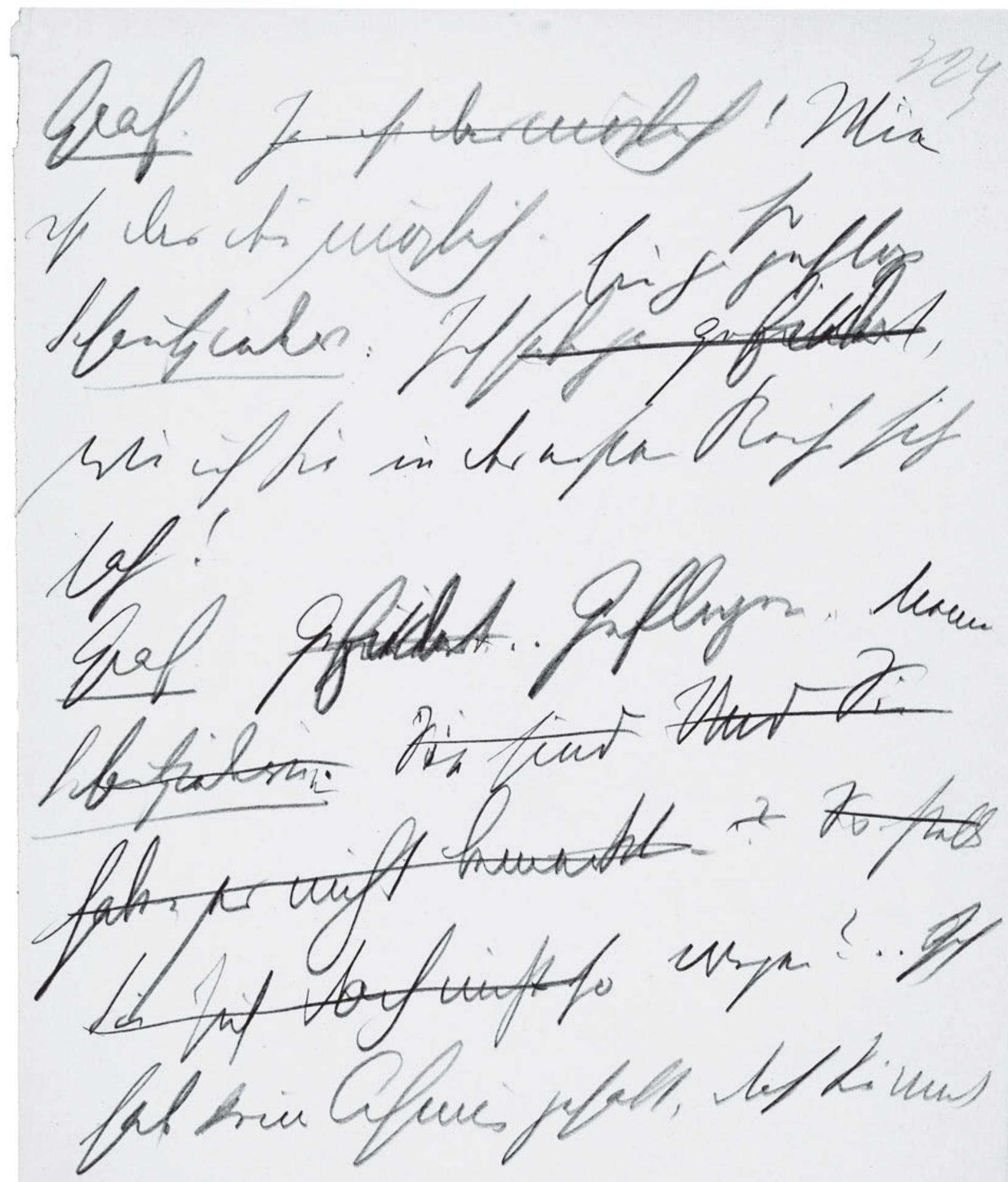

786 


\section{4}

Graf. Ja - ist das möglich! Wie

ist das den̄ möglich.

so

bin ja geflogen

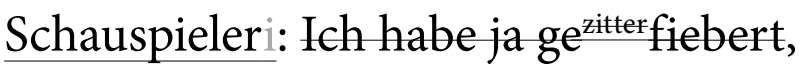

5 wie ich Sie in der ersten Reihe sitze

sah!

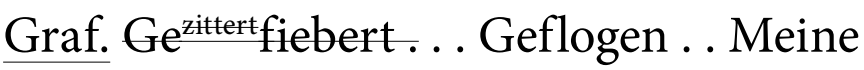

Schauspielerin. Sie sind Und Sie

haben es nicht bemerkt - ? So stellen

Sie sich doch nicht so wegen? . . "G? Ich

hab keine Ahnung gehabt, dass Sie mich 
HSz9 325

Handschriften und Typoskript

freunation!

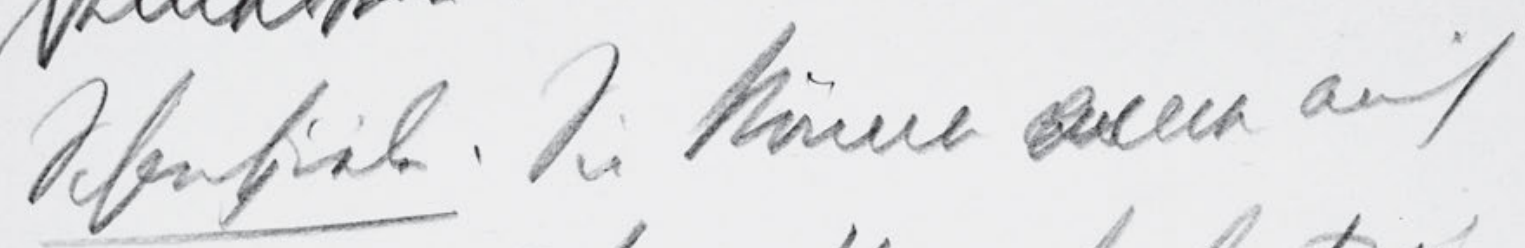

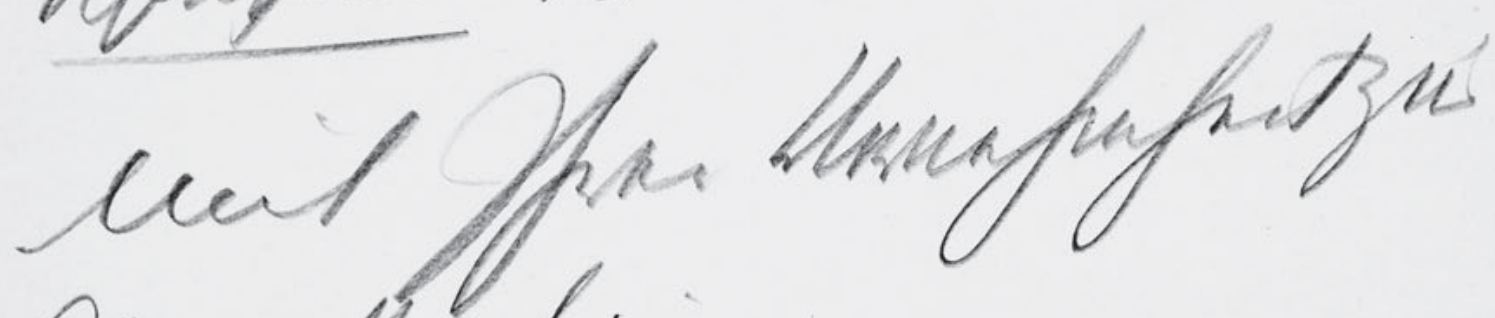
Amprifluin hinigne.

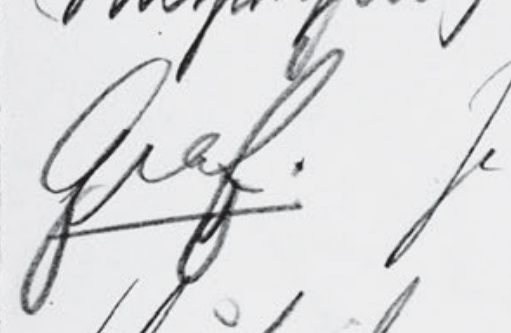

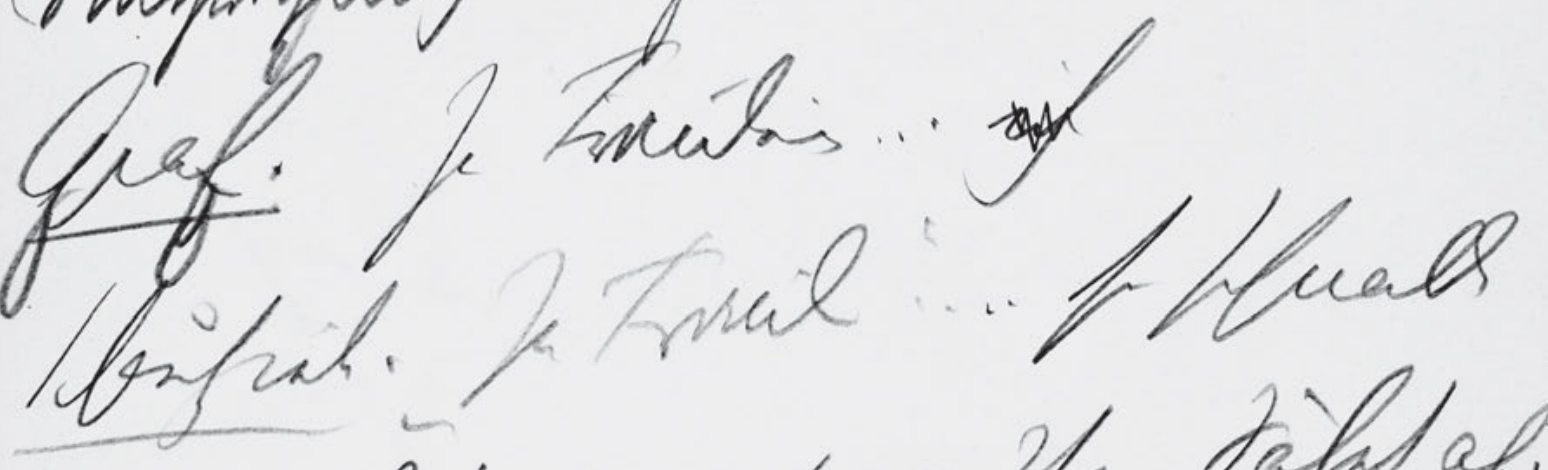

2. h/ wouptor for talat af.'

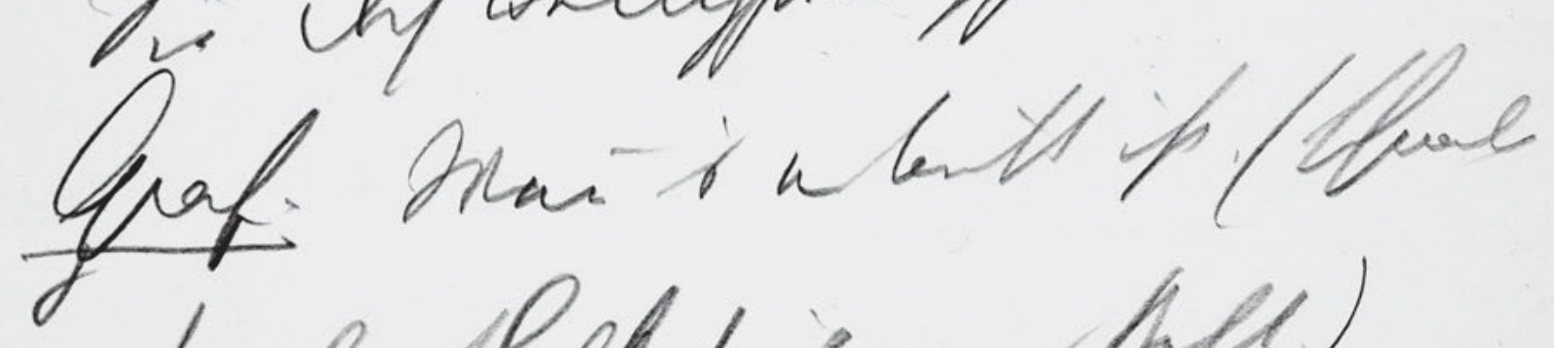
fiab, flatfet if ar thet) Iforpions. Horty the pebcei

788 


\section{5}

bemerken!

Schauspieler. Sie können ${ }^{\text {at }}$ einen auch

mit Ihrer Vornehmheit zur

$5 \quad$ Verzweiflung bringen.

Graf. Ja Fräulein ... i ich

Schauspiele. „Ja Fräulein“. . . . so schnall

Sie doch wenigstens Ihren Säbel ab!

Graf. Weñ's erlaubt ist. (schnall

$10 \quad$ ihn ab, stelltehnt ihn ans Bett.)

Schauspielerin. Und jetzt Und gib mir 
HSz9 326

Handschriften und Typoskript

novlif wurkit!

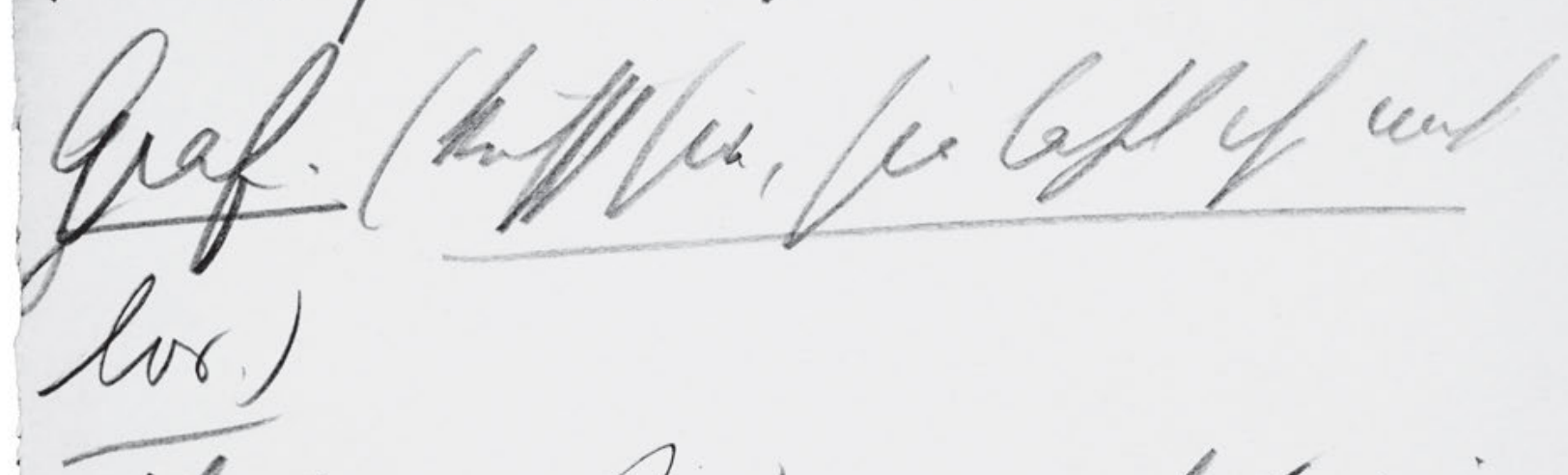

Heficater

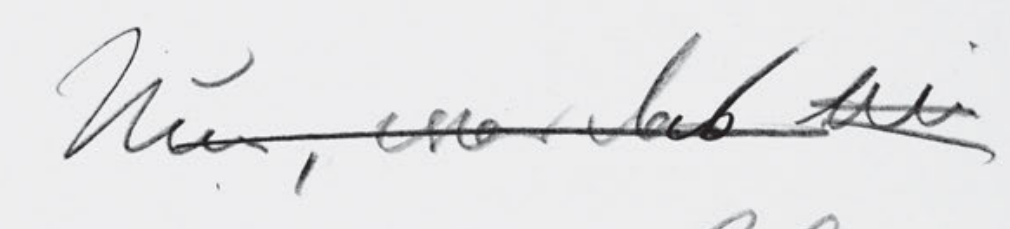

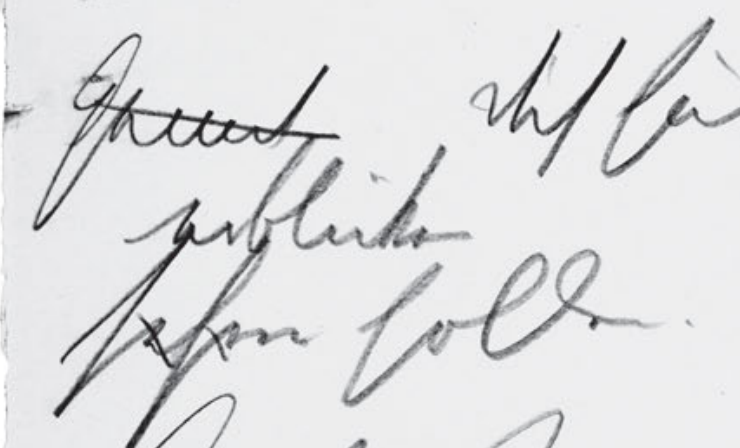

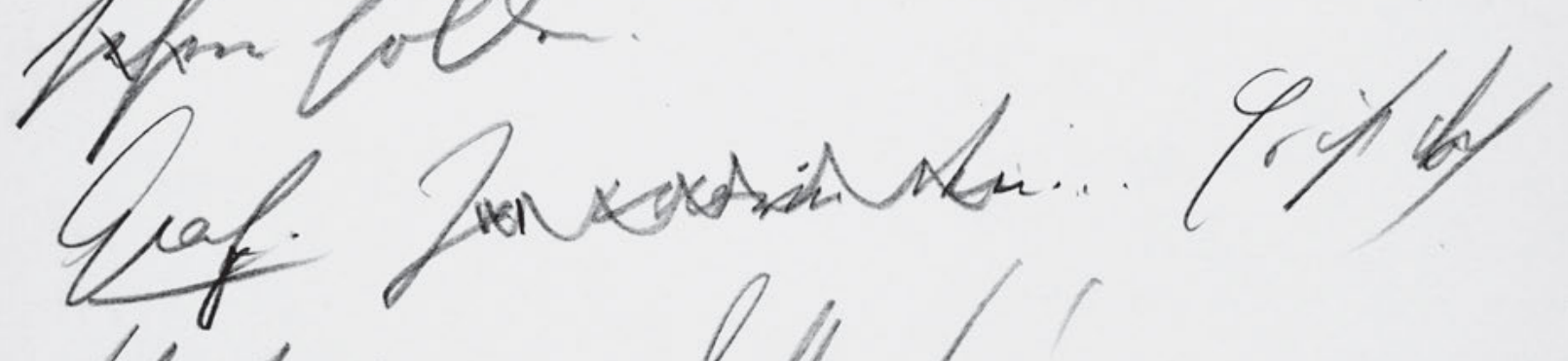

Etitipilom.

blfor.t.

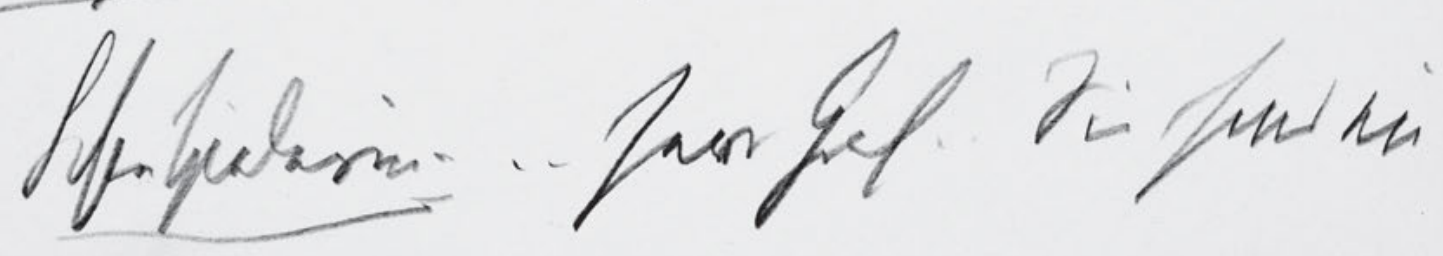

790 


\section{6}

endlich einen Kuss!

Graf. (küsst sie, sie laßt ihn nicht

los.)

5 Schauspieler. Nun, war das ein

Grund Dich hätt ich auch lieber nie

erblicken

sehen sollen.

Graf. Ja warum deñ . . . Es ist doch

Schauspielerin. besser so! -

${ }_{10}$ Schauspielerin. .. Herr Graf .. Sie sind ein 
HSz9 327

Handschriften und Typoskript

Mrfour!

304

lyaf 2 - wasnim thi

Ufitinhom.

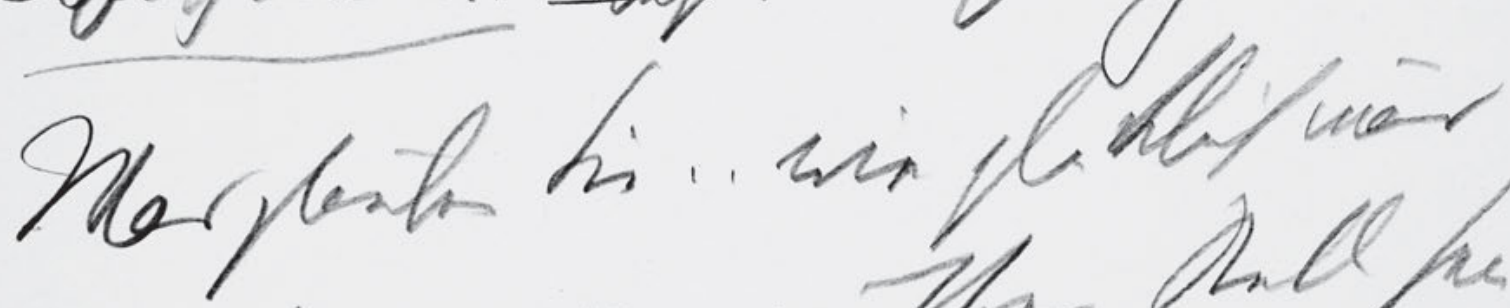

munifor, monis a Pfor thall fue

thifh.
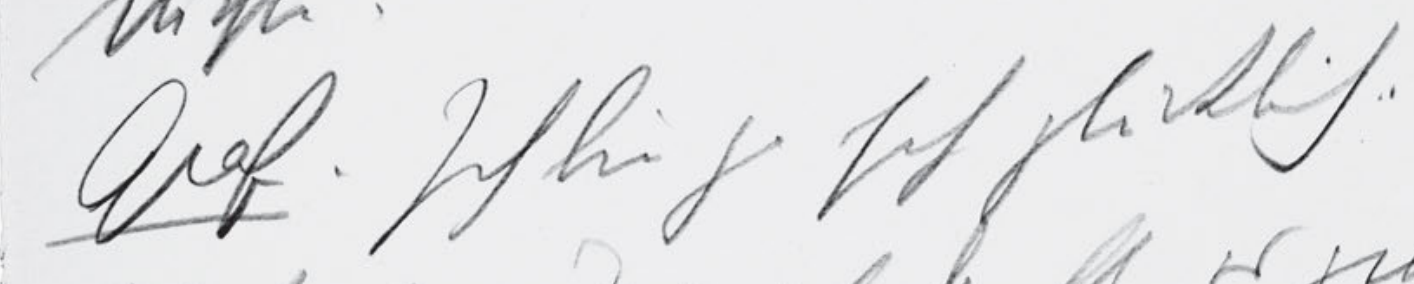

Ifsipish. his of buft, rget

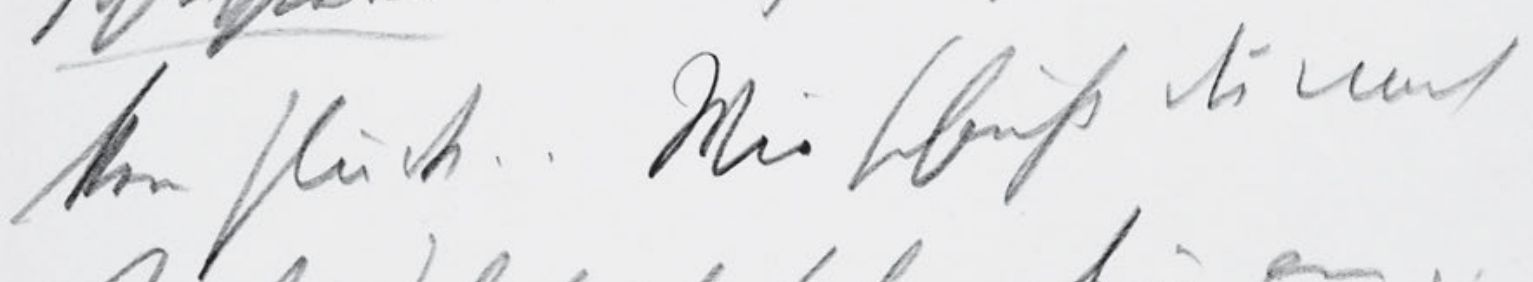
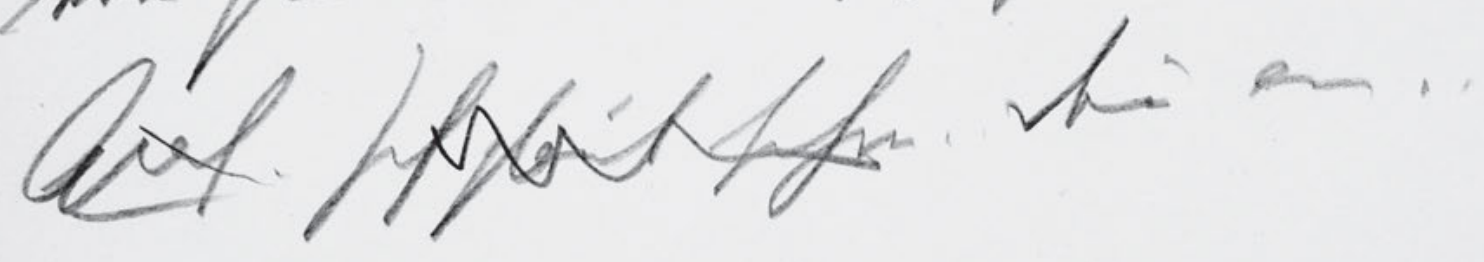

792 
Poseur ${ }^{2} !-$

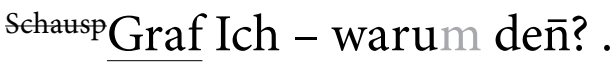

Schauspielerin. . Diese Blasirtheit...

5 Was glauben Sie .. wie glïcklich wär

mancher, weñ er an Ihrer Stelle sein

dürfte!

Graf. Ich bin ja sehr glücklich . .

Schauspieler. Nun ich dacht, es gibt

${ }_{10}$ kein Glück. . Wie schaust du mich

Graf. Ich glaub schon . . den̄ an . . 
HSz9 328

Handschriften und Typoskript

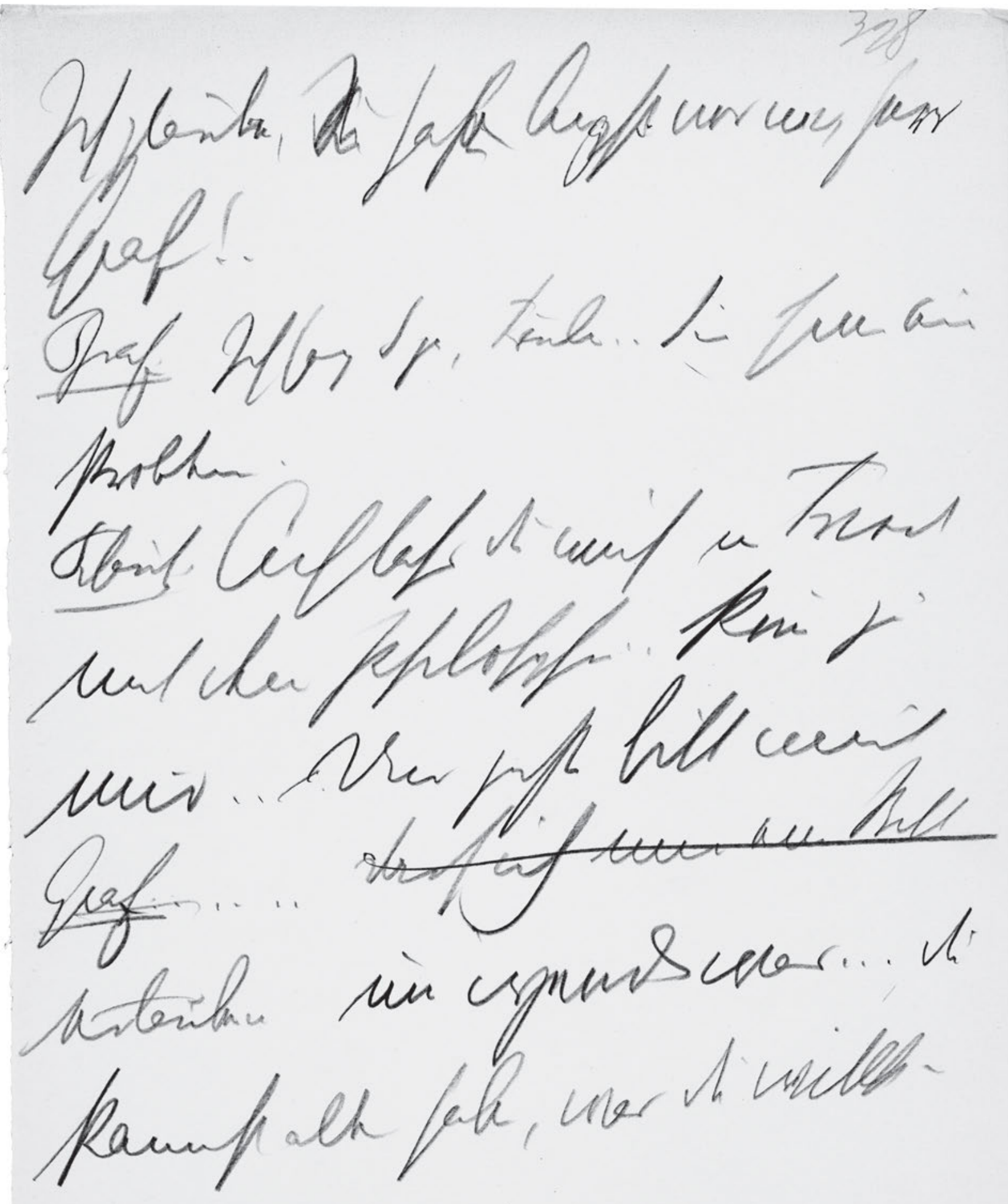

794 
328

Ich glaube, ${ }^{\text {du }}$ Sie ha ${ }^{\text {stt }}$ ben Angst vor mir, Herr

Graf! .

Graf. Ich sag S ja, Fräulei .. Sie sind ein

5 Problem.

Schaus. Ach lass du mich in Fried

mit dein Philosophie. . kō̄ zu

mir . . ${ }^{[?]}$ Und jetzt bitt mich

Graf: : . . . Darf ich mir eine Bitt

10 erlauben um irgend was ... du

kannst alles haben, was du willst - 
HSz9 329

Handschriften und Typoskript

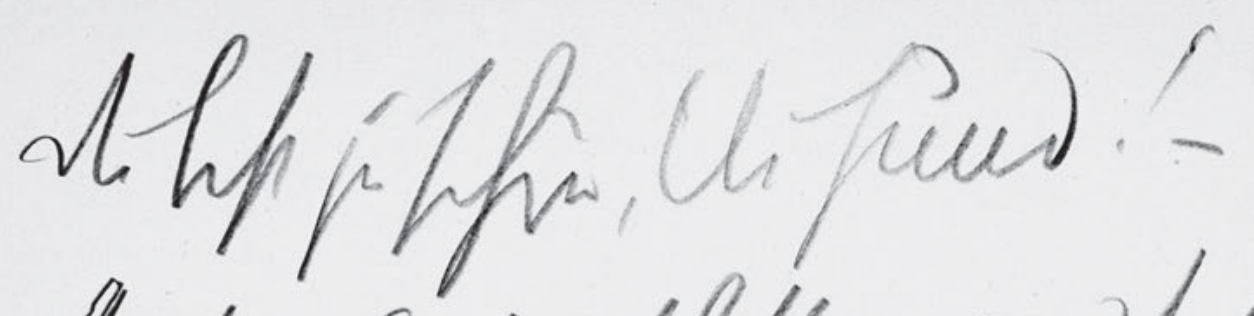

32
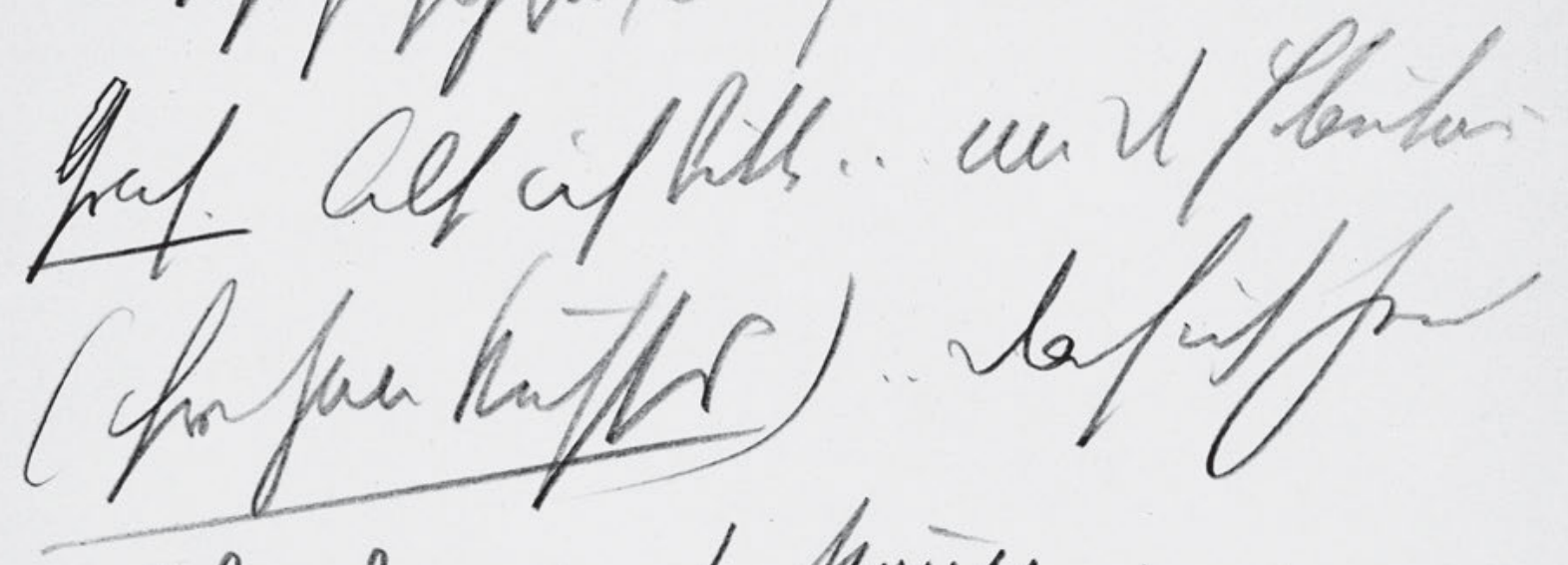

Shat ini
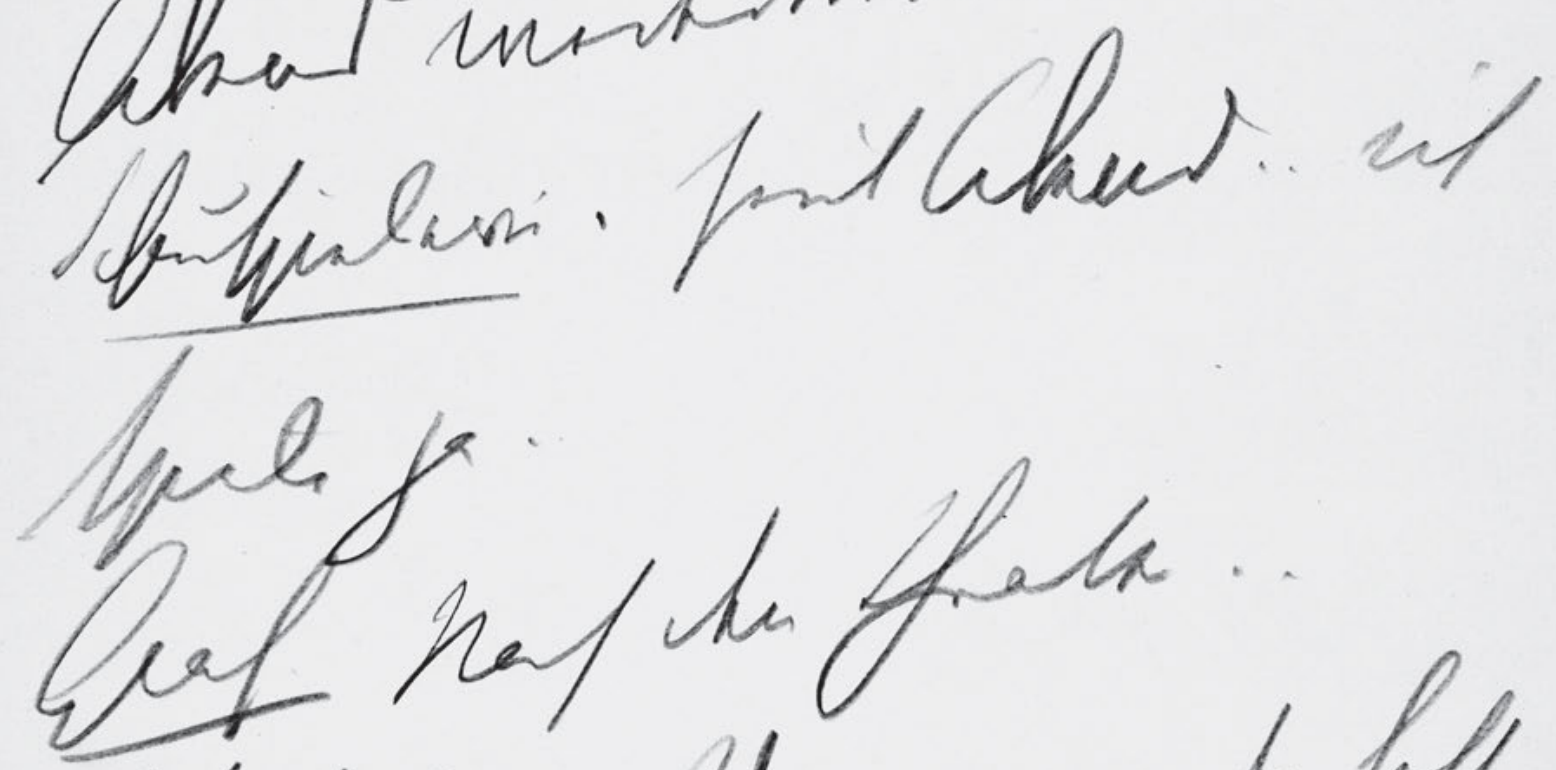

Ifingilas

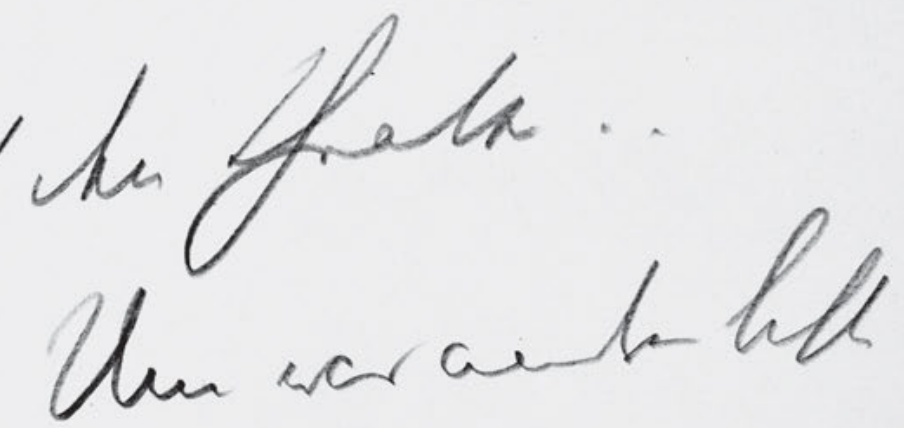

dicuff.

796 


\section{9}

du bist zu schön, ?du Hund?! -

Graf. Also ich bitte ... um die Erlaubnis -

(ihre Han küssend) . . dass ich heut

5 Abend wiederkōmen ..

Schauspielerin . Heut Abend . . ich

spiele ja . .

Graf. Nach dem Theater. .

Schauspieler. . Um was andres bitte

10 du nicht. . 
HSz9 330

Handschriften und Typoskrip

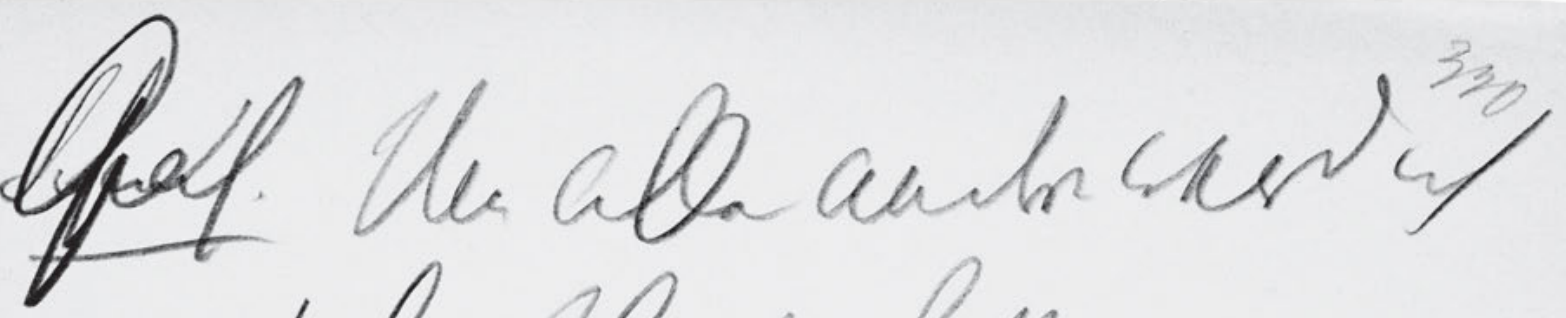
neaf ha Ifols htm....

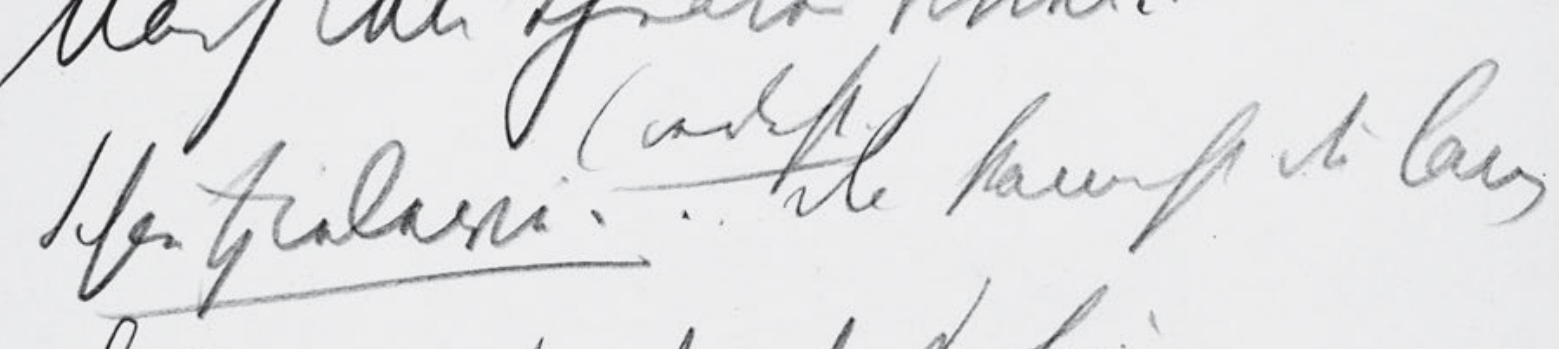
Sillow.. stiaturt fifioi.

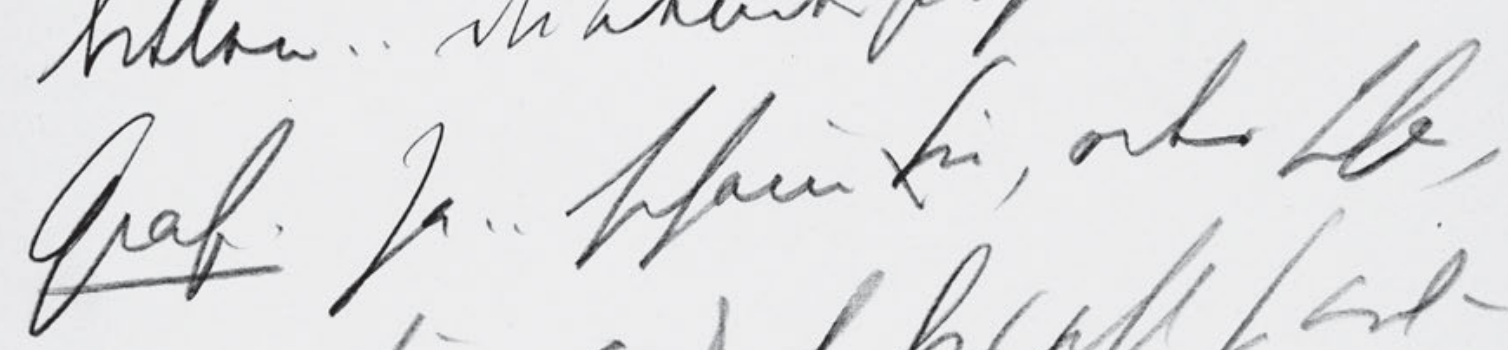
mifur It hofff far sulf went th puspon... iffai to alt unilffiris ae Cha

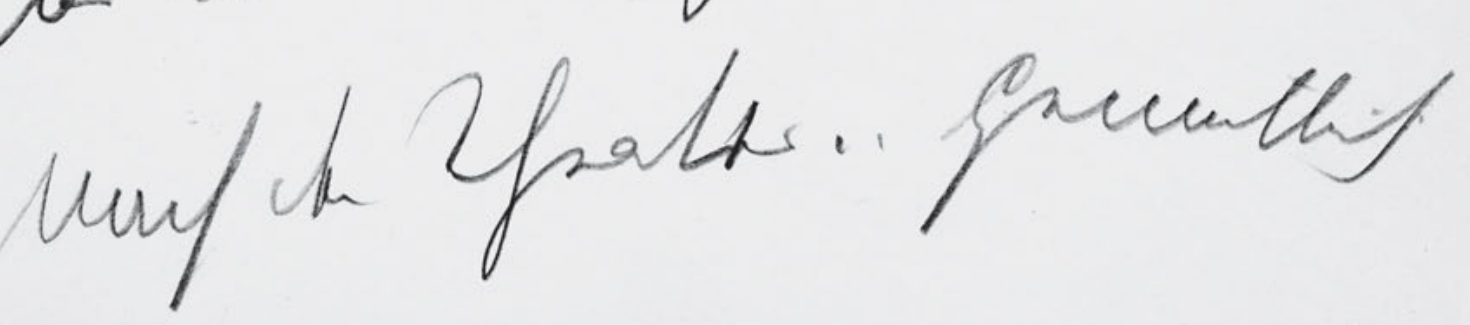

798 
${ }^{\text {Schats }}$ Graf. Um alles andre werd ich

nach dem Theater bitten ....

(verletzt.)

Schaupielerin. .. da kannst du lang

5 bitten .. du elender Poseur.

Graf. Ja .. schaun [?]Sie, oder schau, wir sind doch bis jetzt so auf-

richtg mit ?dir? gewesen . . . ich fänd

das alles viel schöner am Abend

10

nach dem Theater .. gemütlich 
HSz9 331

Handschriften und Typoskript

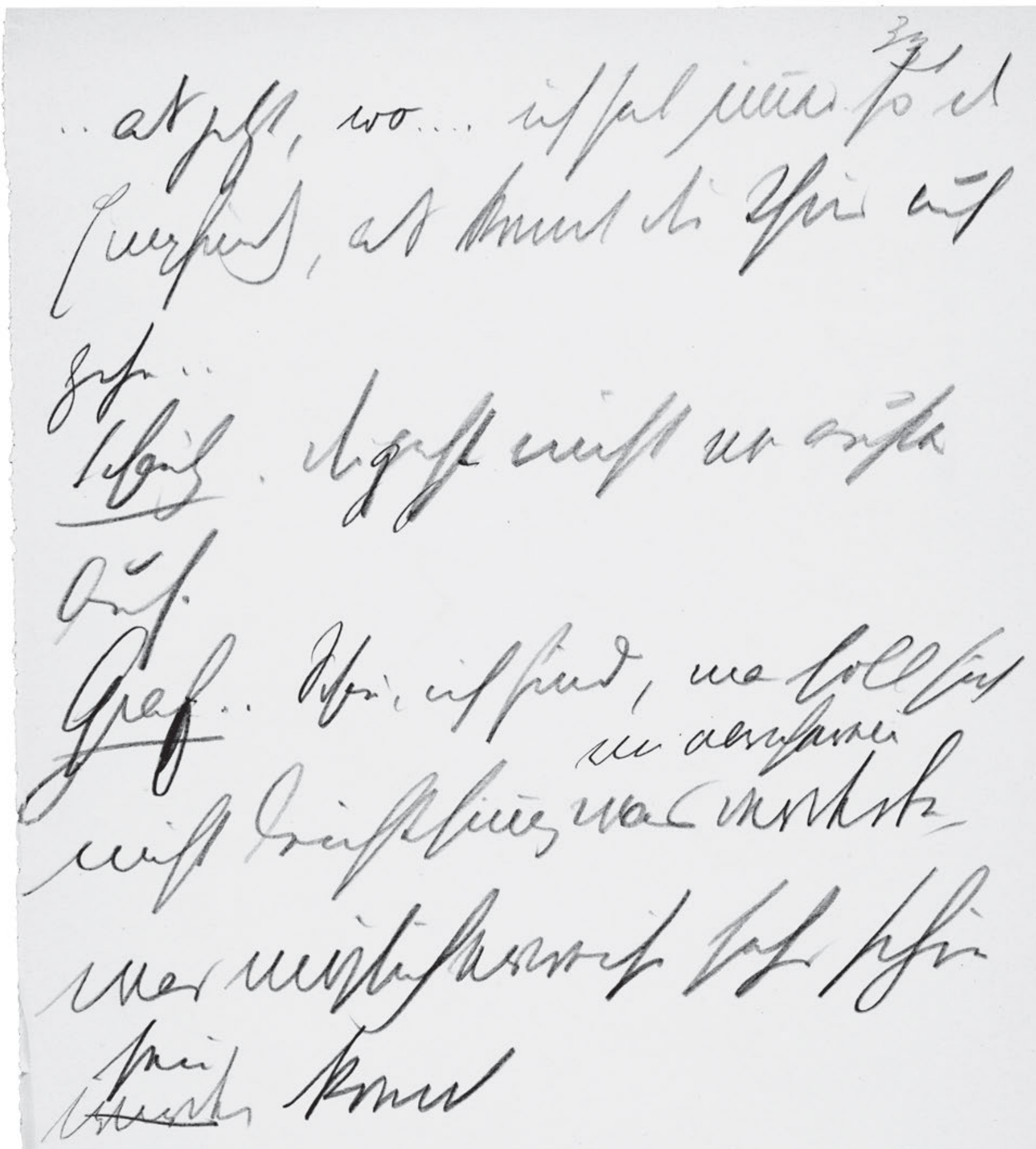

800 


\section{1}

. . als jetzt, wo . . . . ich hab imer so $\mathrm{d}$

Empfindg, als konnt die Thür auf

gehn ..

$5 \quad$ Schausp. Die geht nicht vo außen

auf.

Graf. . Schau, ich find, man soll sich

'von? vornherein

nicht leichtsin̄ig was verderben,

was möglicherweise sehr schön

sein

werden konnt 
HSz9 332

Handschriften und Typoskript

$\frac{\text { Leny. }}{\text { Hiaf }}$

Niplufurefef

332
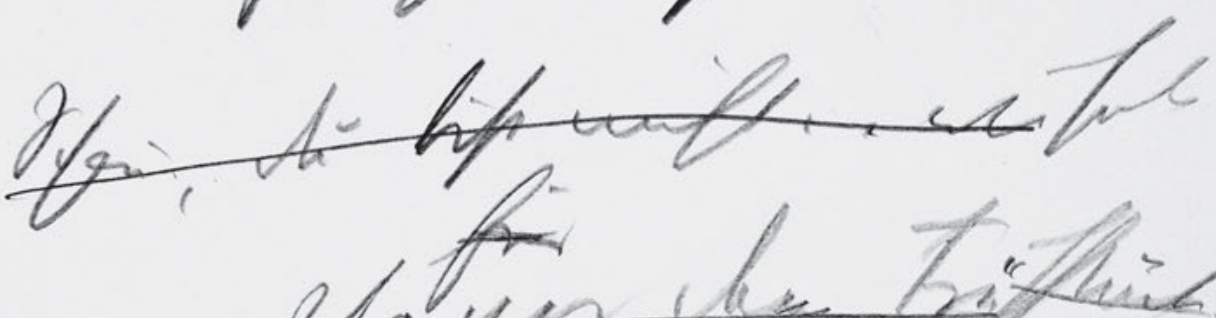

iftays

les

Laitger

fent.

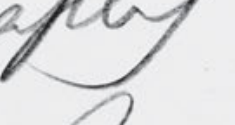

$7 n$

sar w/

funisp, u

a tol fin

fisite. 


\section{2}

Schausp . Möglicherweise!....

Graf. Schau, du bist nicht .. wie sol]

für

ich sagen . . also vor dem Frühstück..

5 das Ich bin ein ${ }_{5}^{[?]}$ Feind von Bruta=

litäten. In der früh, wē̄ ich

die Wahrheit sagen soll, find ich di

Liebe gräßlich. Am Abend

Schausp. Nun - du bist wohl das irr-

10

sinnigste, was mir je vor

gekommen ist! 
HSz9 333

Handschriften und Typoskript

Graf.-

33

chliahys شurujū̄ass...

u algmumin ify a jal Alur

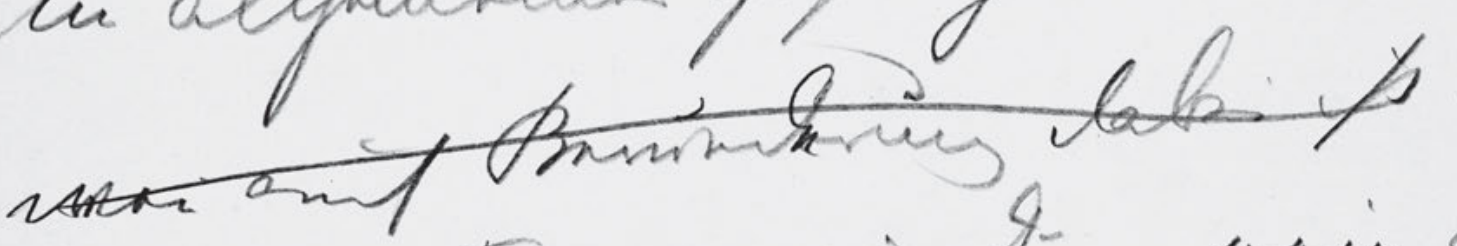

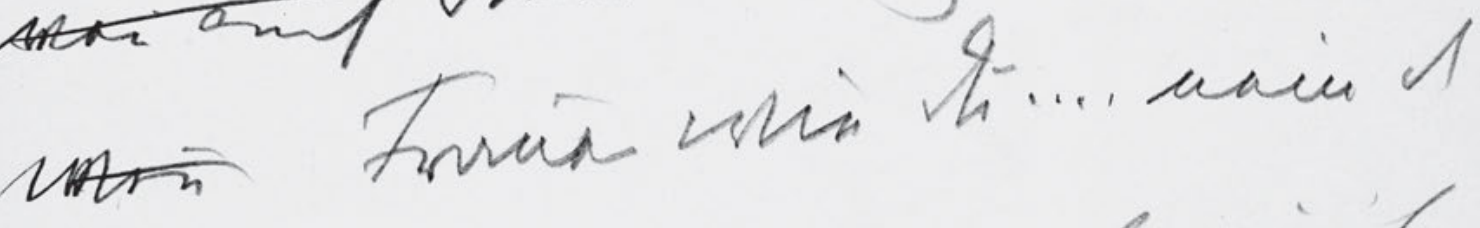

Kamp wit frint tued wis tears

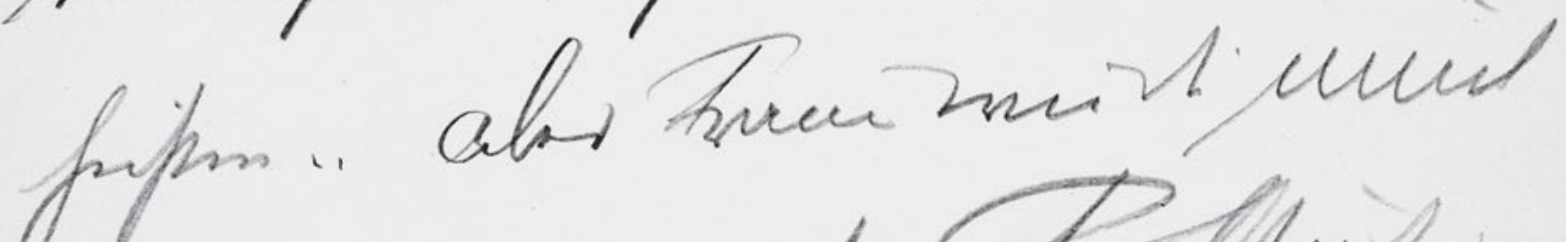

veres enforth th

804 


\section{3}

Graf. . - Das ist Ich red ja nicht von

'x'beliebigen Frauenzimern ... schlieslic

im allgemeinen ist' ja egal. Aber

5 weñ auch Bewunderung dabei ist. .

wen̄ Frauen wie du .... nein d

kannst mich hundertmal ein Narren

heißen . . aber Frauen wie du nī̄t

man nicht vor dem Frühstück zu

10 sich. Und so . . weißt . . so . .

Schausp. Gott .. was bist du süss. 
HSz9 334

Handschriften und Typoskript
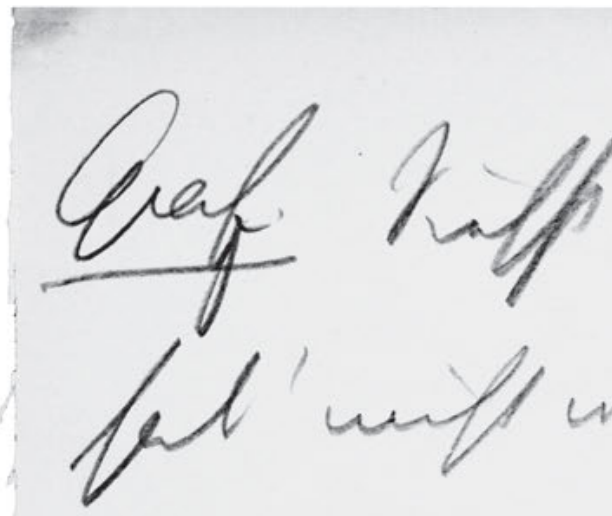

334
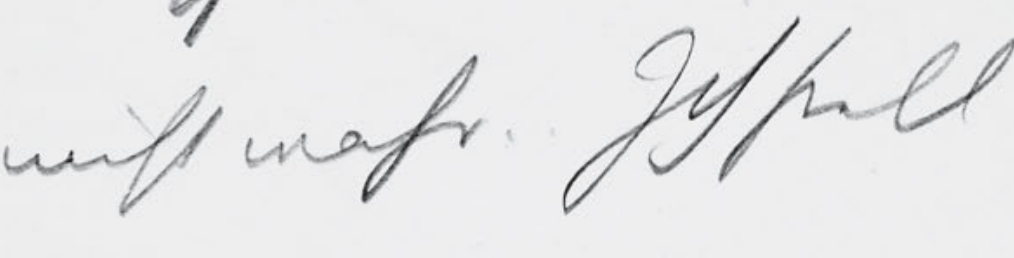

$$
\text { un th }
$$

Prin.

Parienarari

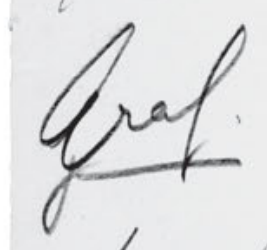

If thath wir.... if meat ve

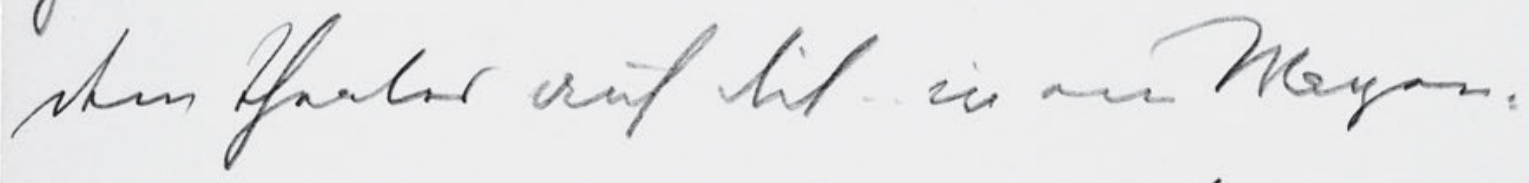

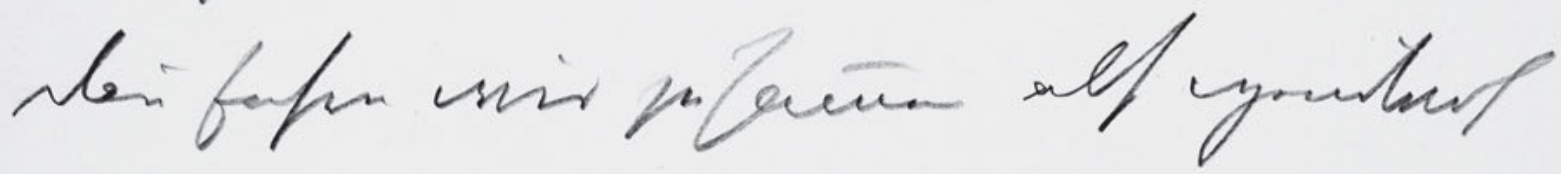
finizims.

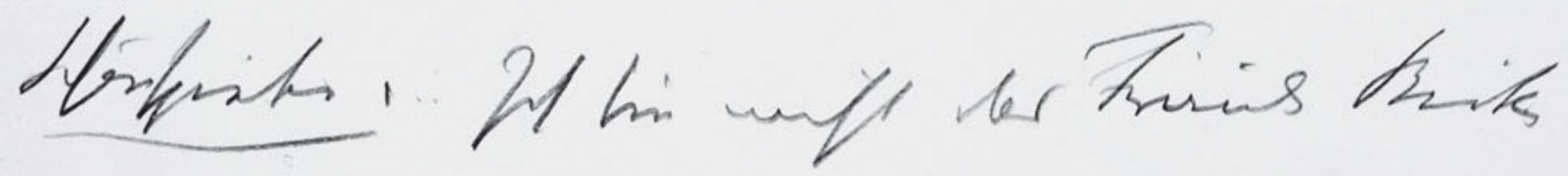
Eaf. ber fat ity and wift suber at

806 
334

Graf. Siehst du das ein, was ich gsagt

hab' nicht wahr .. Ich stell mir das

so vor . .

$5 \quad$ Schauspielerin. Nun, wie stellst du dir

das vor'!

Graf. Ich denk mir .... ich wart nach

dem Theater auf dich .. in ein Wagen:

dā̄ fahrn wir zusā̄en also irgendwoh

10 soupiren ..

Schauspieler ,.. Ich bin nicht das Fräulei Birken

Graf. . Das hab ich ja auch nicht gesagt .... Ich 
HSz9 335

Handschriften und Typoskript

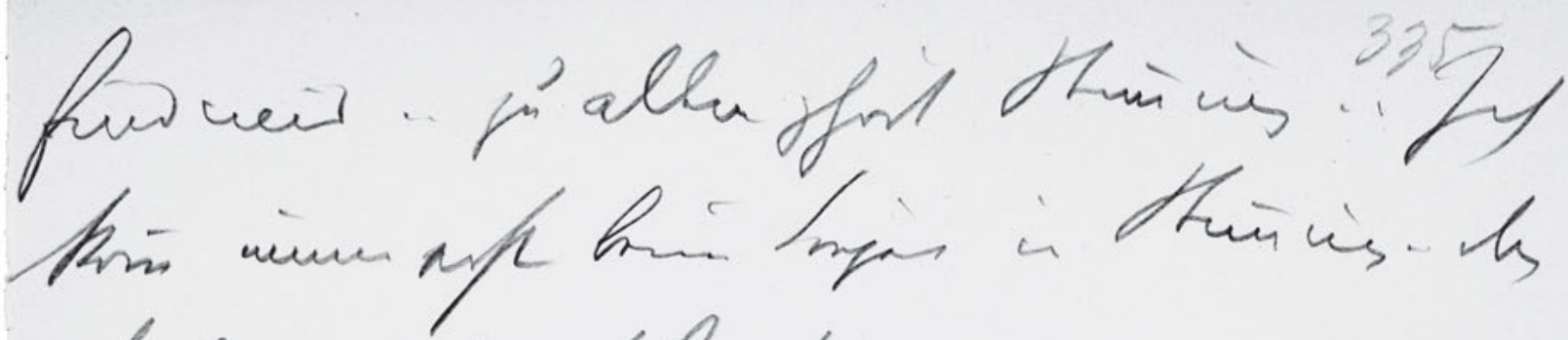

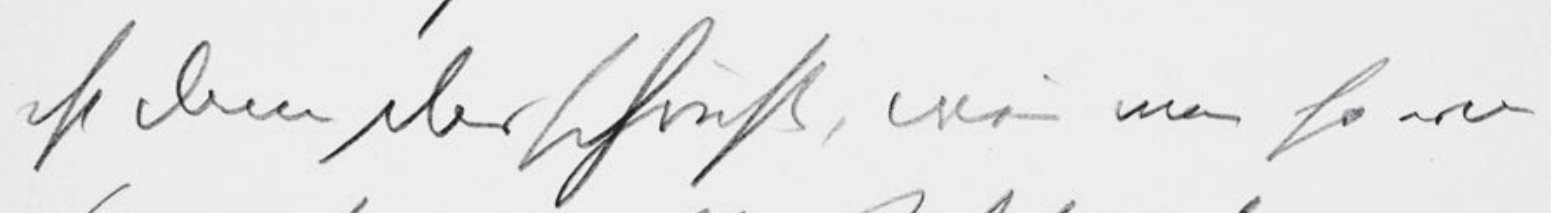
Iripr piaci

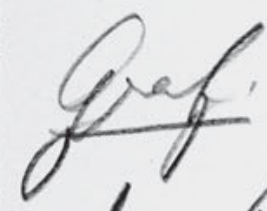

Qlf hi

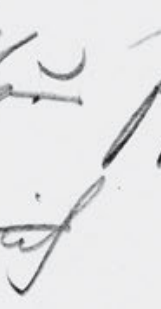

foft. his

$$
\text { hlerifs tum.? }
$$

tr thing ...

tertingmi. If lif h/ unfo

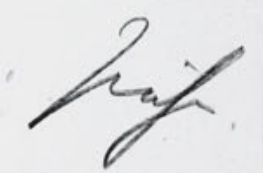

Wef

(anfe hall Giffowe.

for tont

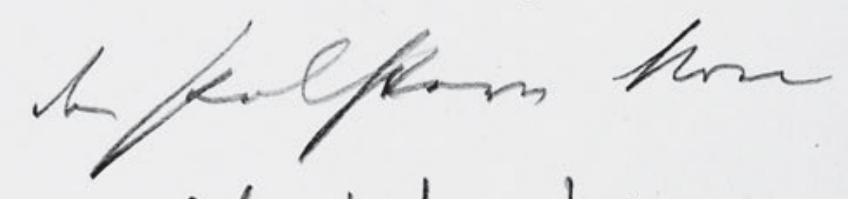

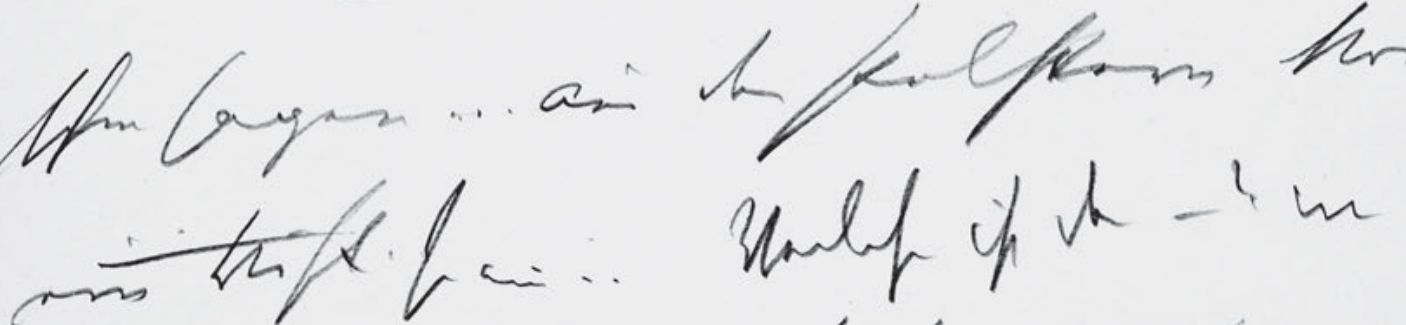

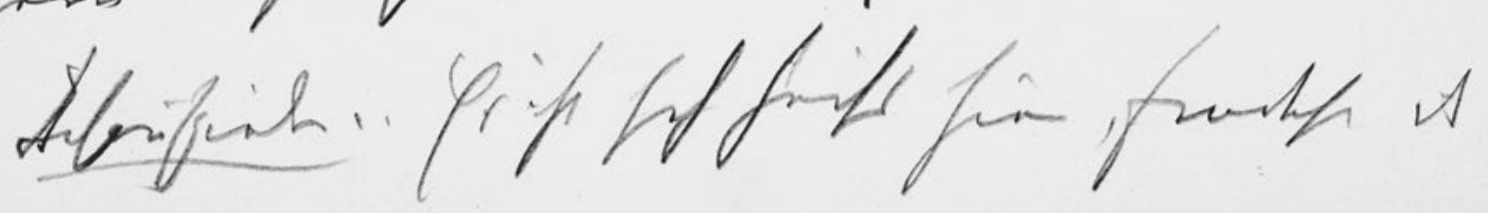

808 


\section{5}

find nur . . zu allem ghört Stī̄ung . . Ich

kō̄ immer erst beim Souper in Stī̄ung . . das

ist dann das schönste, we $\bar{n}$ man so ?vom?

5 Souper zusā̄ nach haus fahrt ... dan̄

Schauspieler. Nun ich Was ist dann . ?

Graf. Als $\circ$ dan̄ . . liegt das in der Entwickl

der Dinge ......

Schauspielerin. . Setz dich doch näher. Näher.

$10 \quad$ Graf. (auf's Bett sich setzend) .. Ich mus

schon sagen .... aus den Polstern komt

ein Duft . so ein .. Veilchen ist das - ? [???]

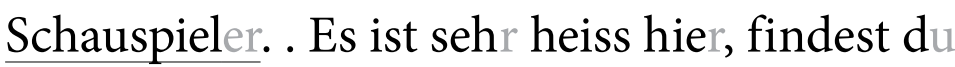


HSz9 336

Handschriften und Typoskript

ah enfl

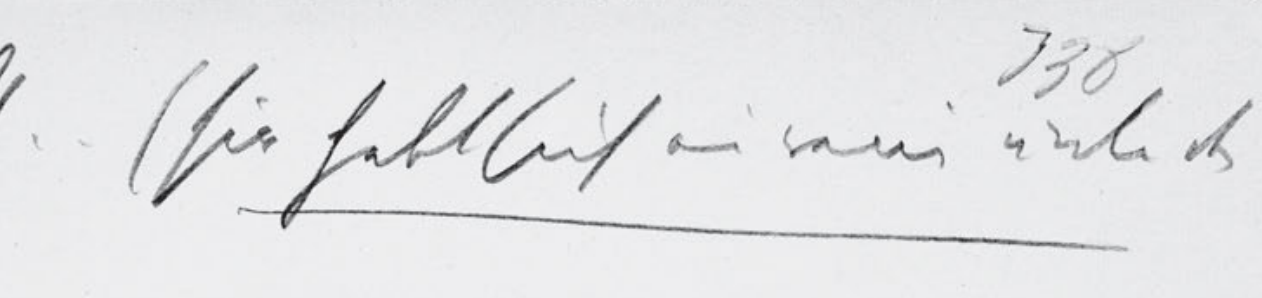

thit.

Eaf:

con

Serfint.

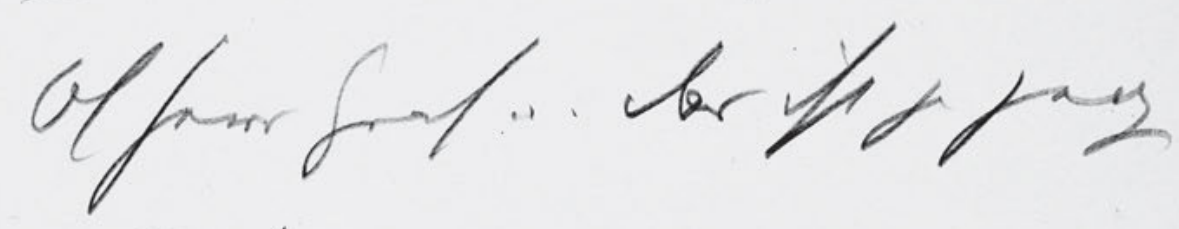

Pfogen

lol

Mard

Saler

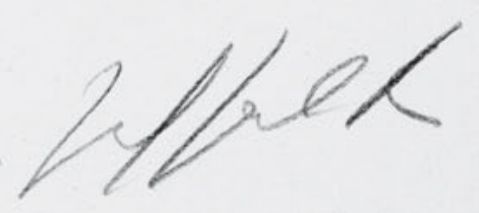

ropacion...

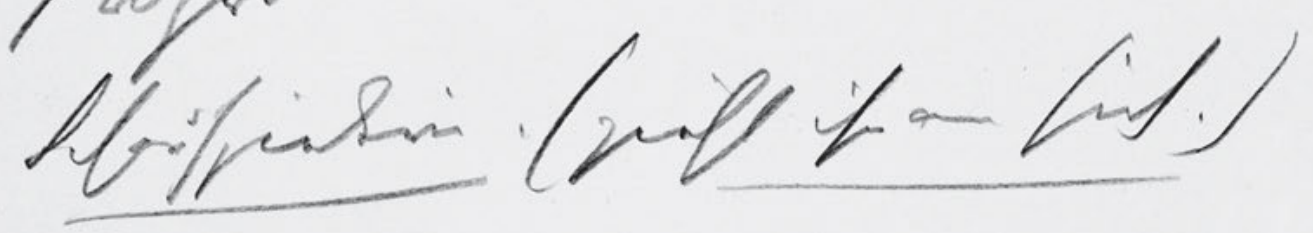

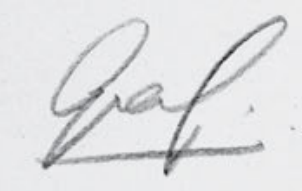

ty

tontiation.
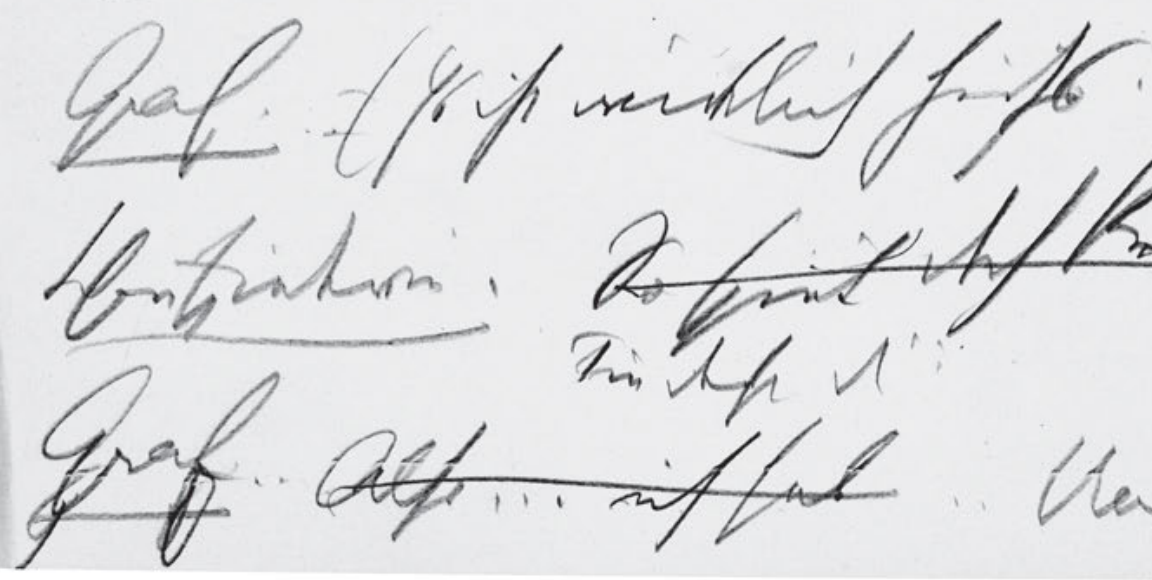

Tim 1 h 1
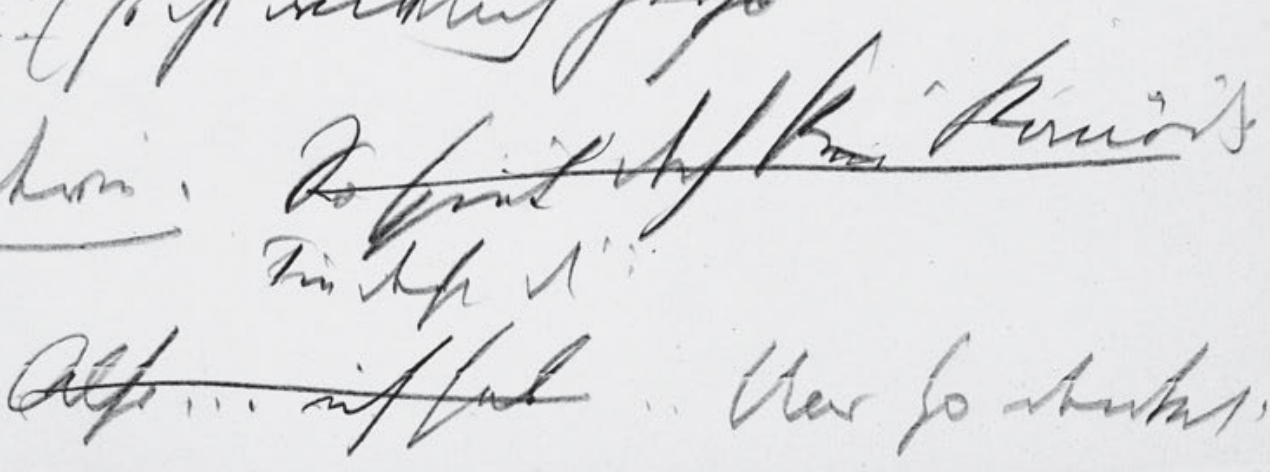

810 


\section{6}

du nicht. . (sie hebt sich ein wenig unter der

Decke.)

Graf. (neigt sich un küsst ihr Hals .. )

$5 \quad$ Schauspieler. Oh Herr Graf ... das ist ja gegen

Ihr Progrā̄!

Graf. Wer sagt den̄ das .. Ich hab ?kei?

Programm ....

Schauspielerin .(zieht ihn an sich.)

10 Graf. . (Es ist wirklich heiss.

Schauspielerin. So spiel' doch kein Komödie. Findest $\mathrm{d}$...

Graf. . Also ... ich hab . . Und so dunkel, 
HSz9 337

Handschriften und Typoskript

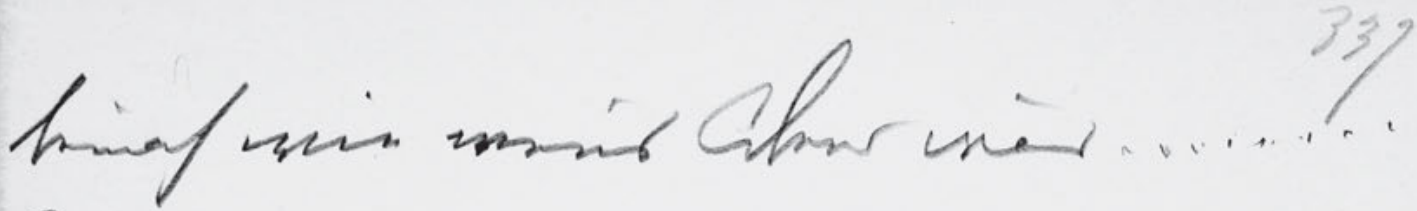

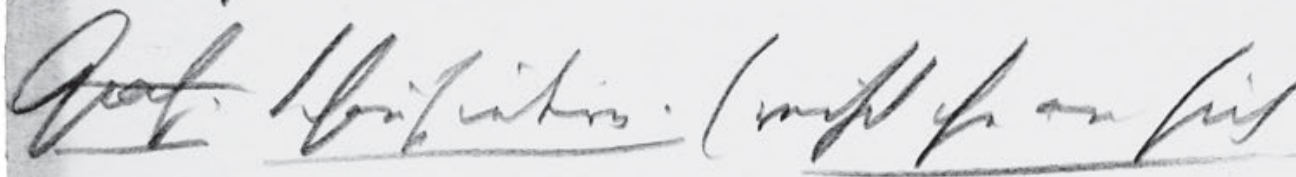

Q

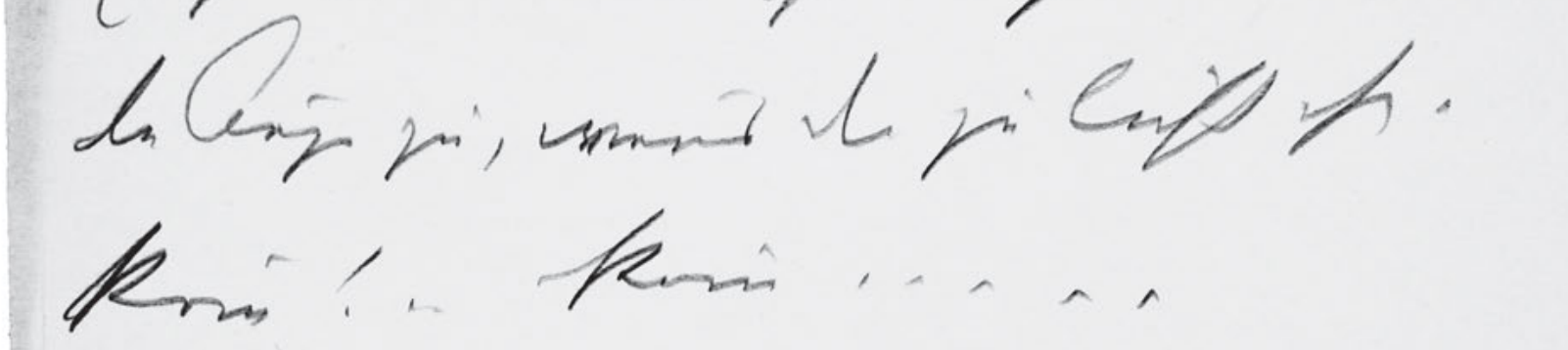

for

creeft but mett unfts

is marfi... loo

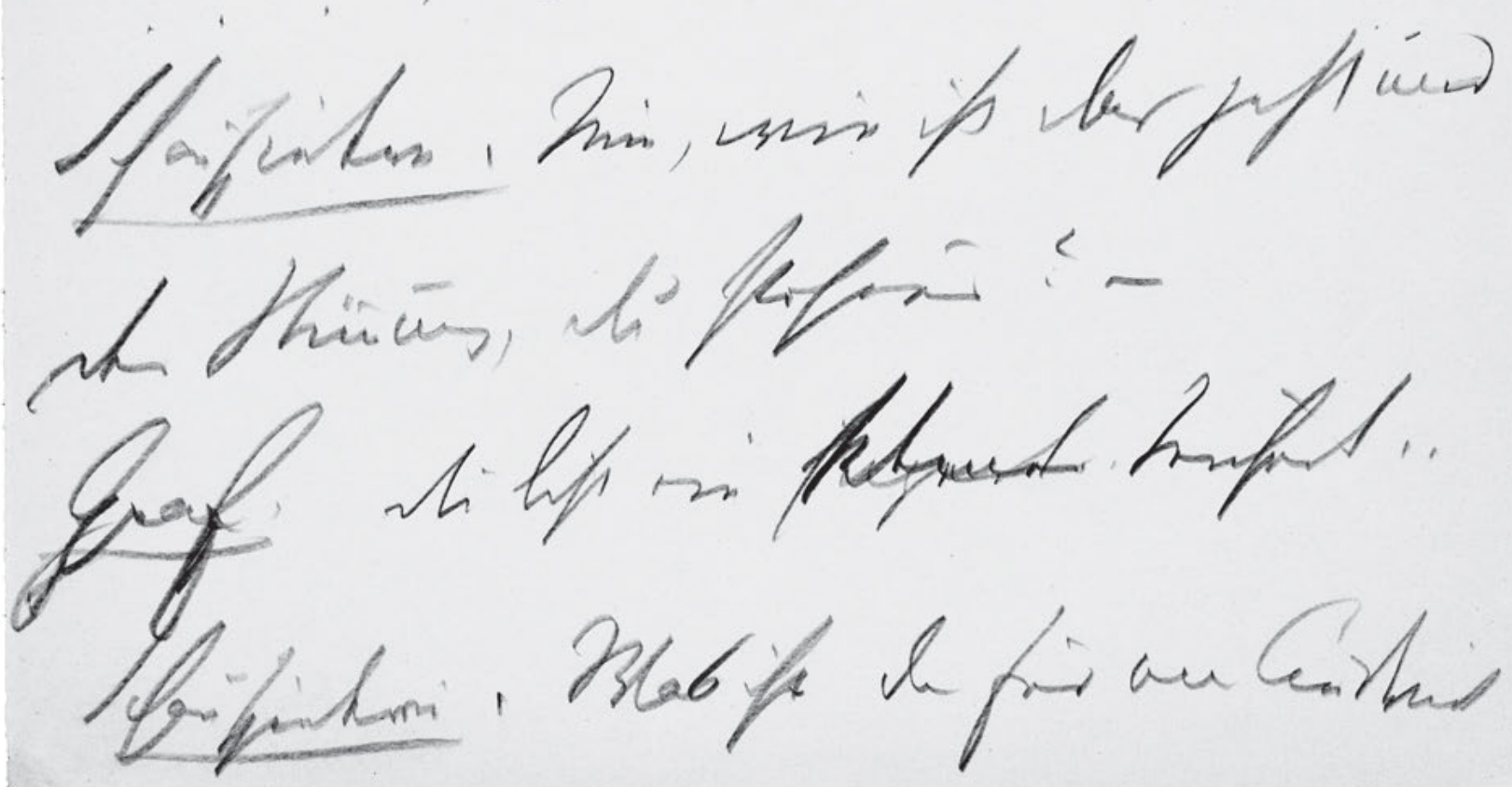

812 
beinah wie wen̄s Abend wär ..........

Graf. Schauspielerin. (reißt ihn an sich.) . .

Es ist Abend . . es ist Nacht ... Mach

5 die Augen zu, wen̄s dir zu licht ist.

Kōm ! . Kō̄ . . . . .

Graf. (wehrt sich nicht mehr.)

Schauspielerin . Nun, wie ist das jetzt mit

10 der Stī̄ung, du Poseur? -

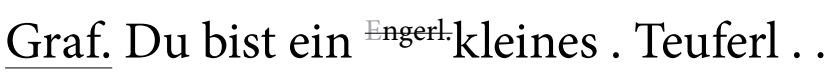

Schauspielerin. Was ist das für eine Ausdruck 
HSz9 338

Handschriften und Typoskript

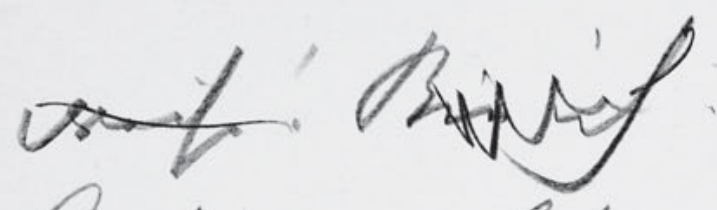

338

Graf." ha, ity alf hon Yyot.

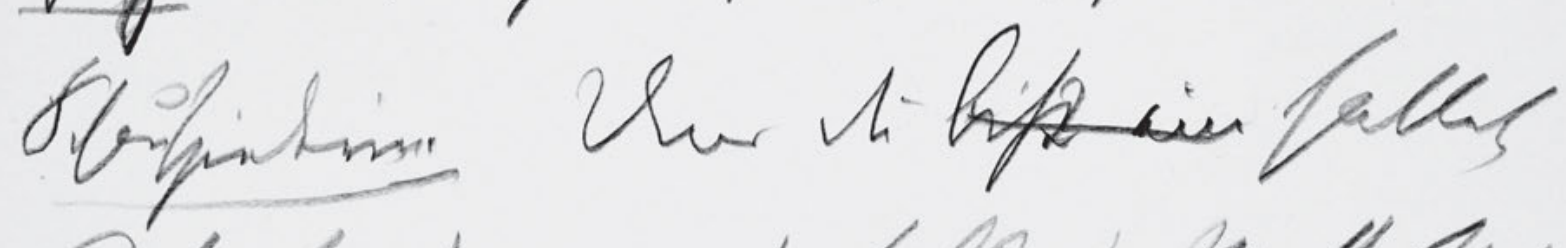

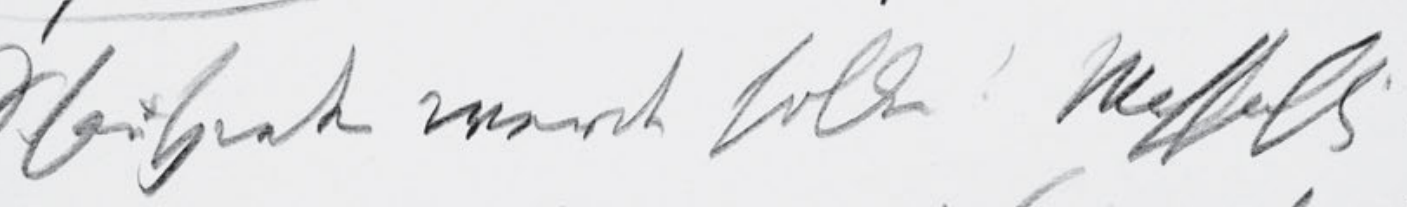
Cunafa botis

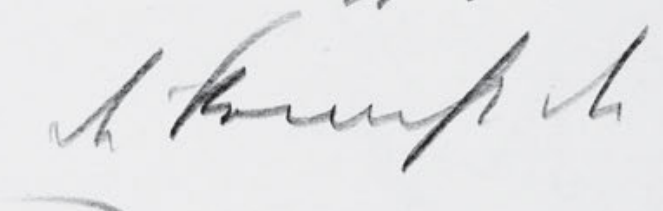

Tumiz... tifff li suer if peff thin mont:

Gral an:

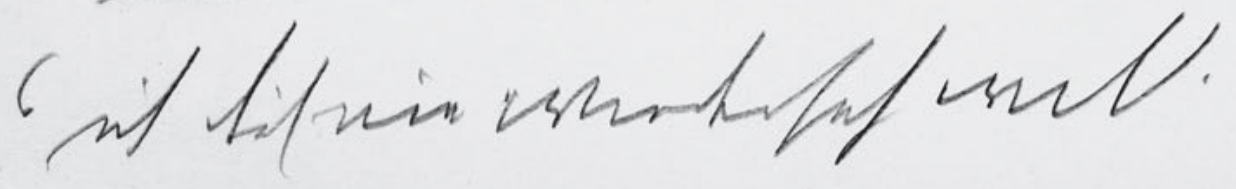

814 


\section{8}

weise! Bin ich . .

Graf. . Na, bist also bist ein Engerl.

Schauspielerin. Und du bist ein hattest

5 Schauspieler werden sollen! Wahhaftig!

Ein Verführer bist du. Du kennst die

Frauen! . . Du hast gewußt, wie es?man?

dir es anstellt ‘ ein Weib Und weißt

du was ich jetzt thun werde?

$10 \quad$ Graf. Nun?

Schauspiel. Ich werde dir sagen, dass

[?] ich dich nie wiedersehen will. 
HSz9 339

Handschriften und Typoskript

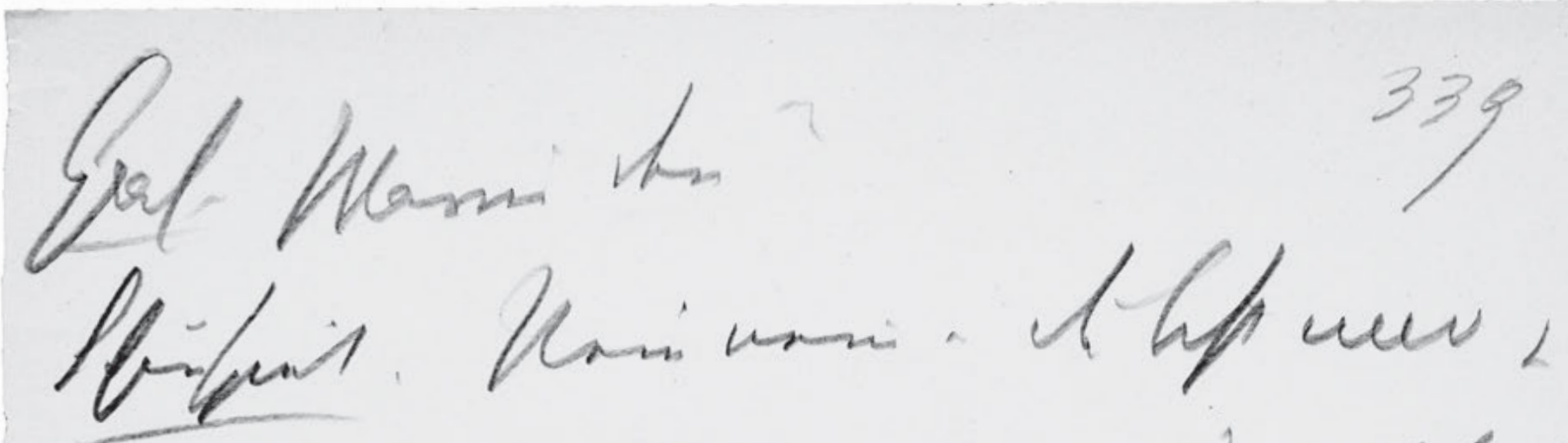

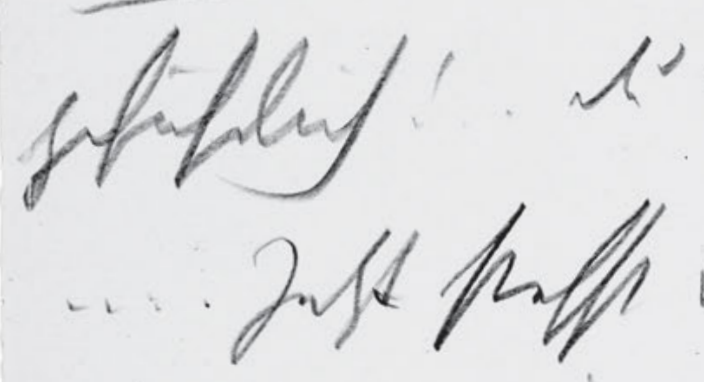

splofler/ ur an, orvar wift

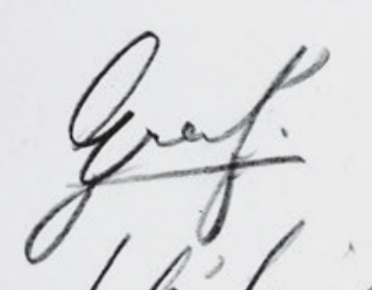

abla...

bifinto. M

Gral.

if

hin fink

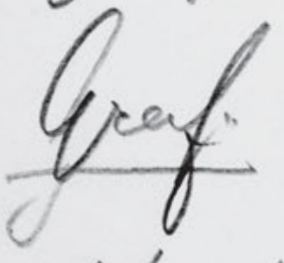

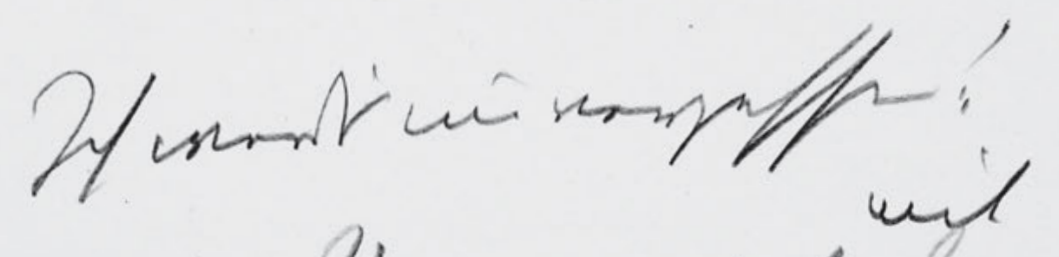

1 . 
339

Graf. Warum den?

Schauspiel. Nein nein - du bist mir zu

gefährlich! . Du machst ja ein Weib toll ....

${ }_{5} \quad$... Jetzt stehst du plötzlich vor mir,

als war nichts geschehn ...

Graf. Aber...

Schauspielerin. Ich bitte sich zu erinnern Her

Graf . ich bin soeben ihre Geliebte gewesen.

10 Graf. . Ich werd's nie vergessen"!

mit

Schauspielerin. Und wie ist das heut Aben? 
HSz9 340

Handschriften und Typoskript

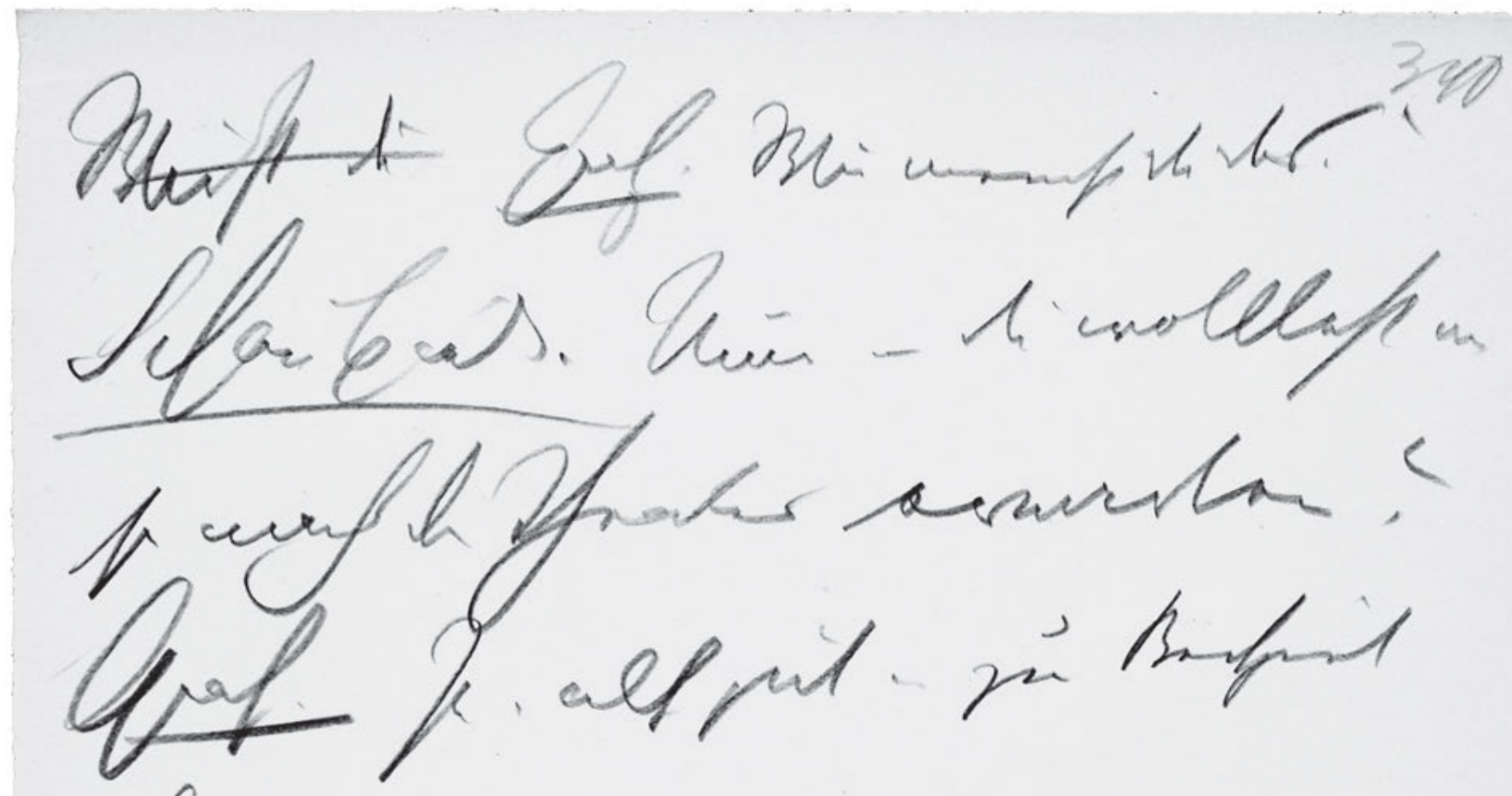

stanceoyr
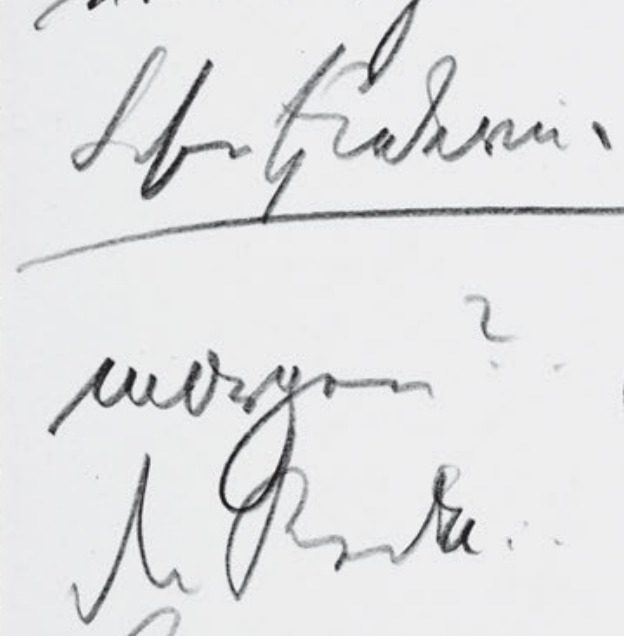
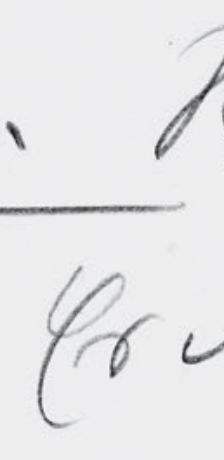

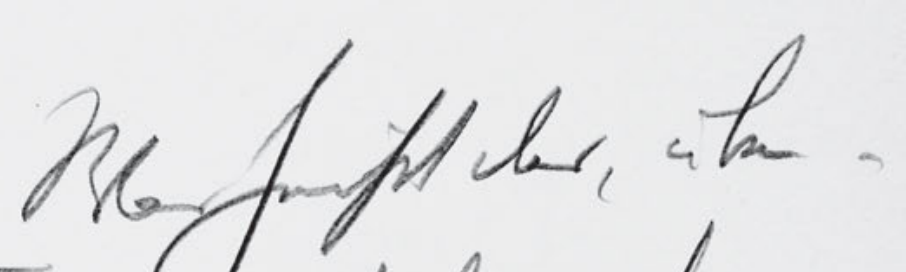


Wirst du Graf. Wie meinst du das?

Schauspiel. Nun - du wolltest mi

'ja? nach dem Theater erwarten?

$5 \quad$ Graf. Ja . also gut - zum Beispiel

übermorgen.

Schauspielerin. Was heißt das, über-

morgen? . Es war doch von heut

die Rede...

10 Graf. .. Das hätt . . kein rechten Sinn.

Schauspieler. Du .. Greis! . 
HSz9 341

Handschriften und Typoskript

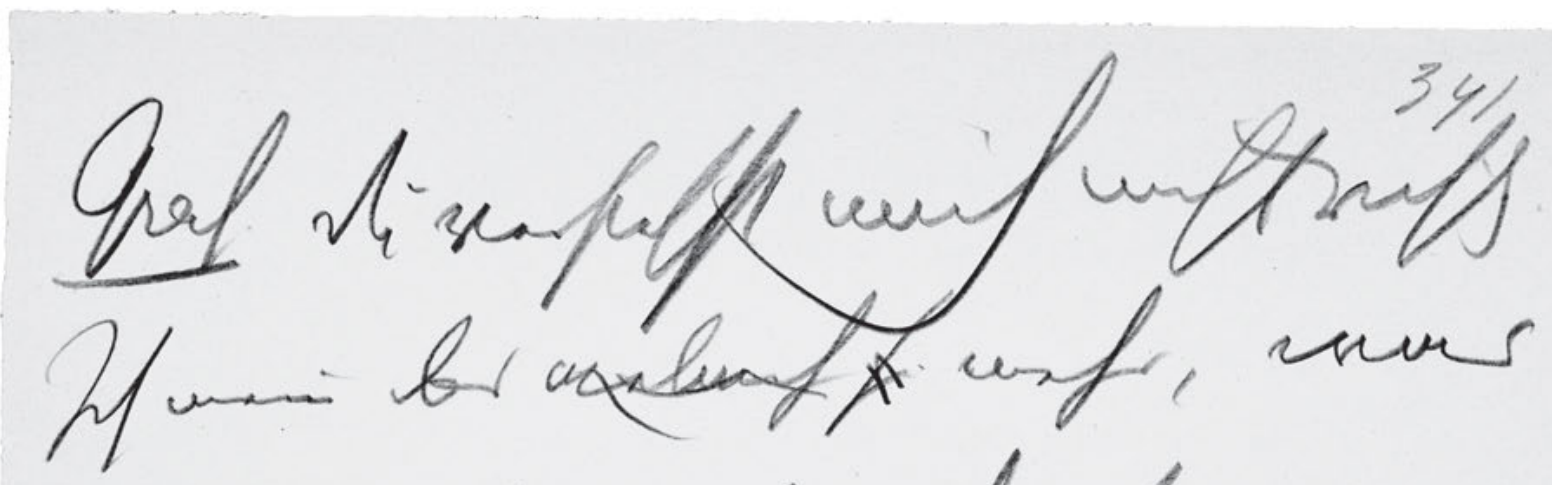
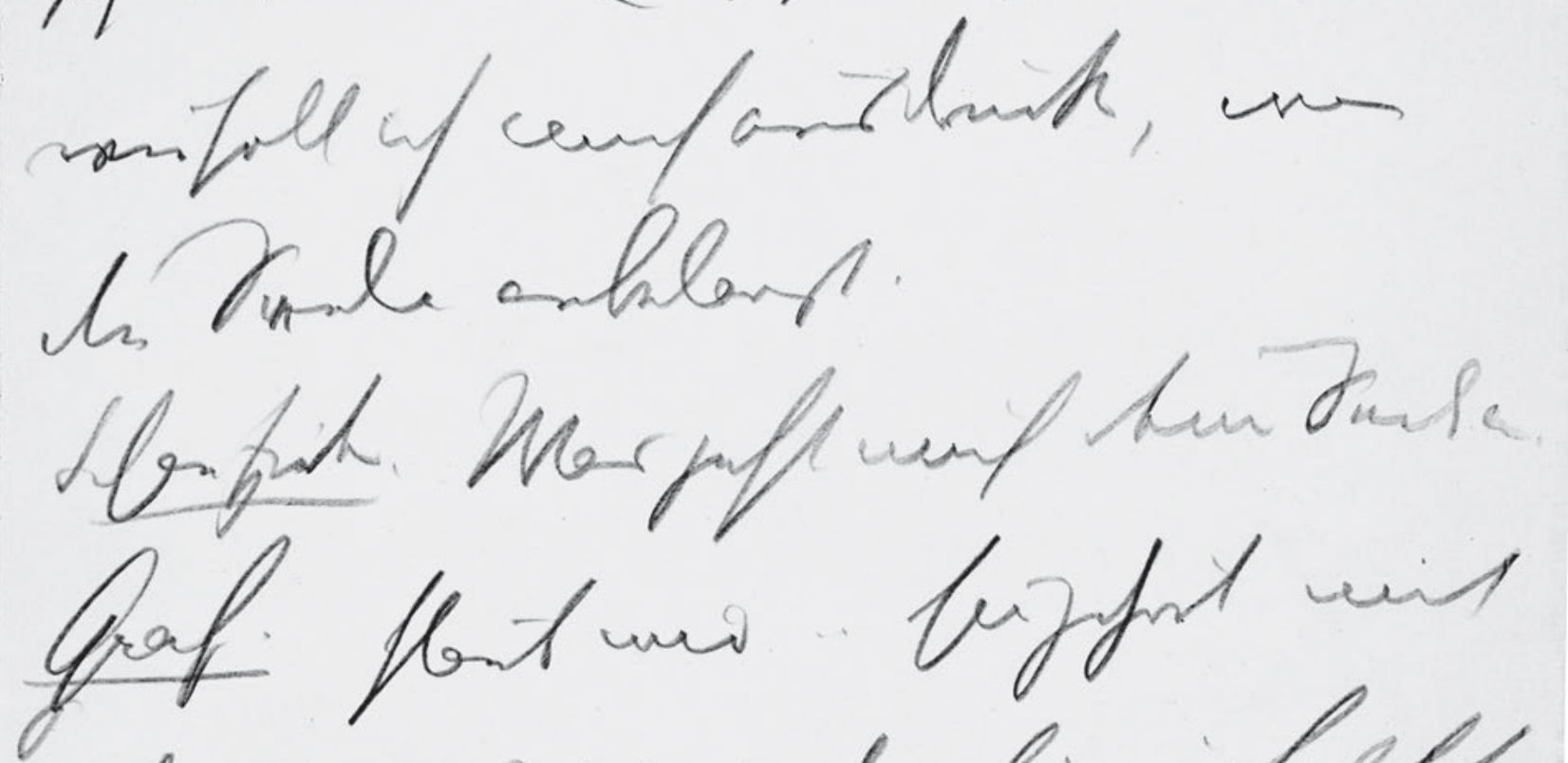

$$
\text { flat mo }
$$

bryi.

hy

befím ber

hront

Gonfins

Lafo mus mit himplief/

820 


\section{1}

Graf. Du verstehst mich nicht richtig.

Ich mein das vielmeh $s \ominus$ mehr, was

wie soll ich mich ausdrücken, was

5 die Seele anbelangt.

Schauspieler. Was geht mich deine Seel an.

Graf. Glaub mir . . sie gehört mit

dazu ... Ich halt das für eine falsch

Ansicht .. dass man das so von einand

10 tren̄t.

Schauspiel . Lass mich mit deine Philosphie 
HSz9 3411/2

Handschriften und Typoskript

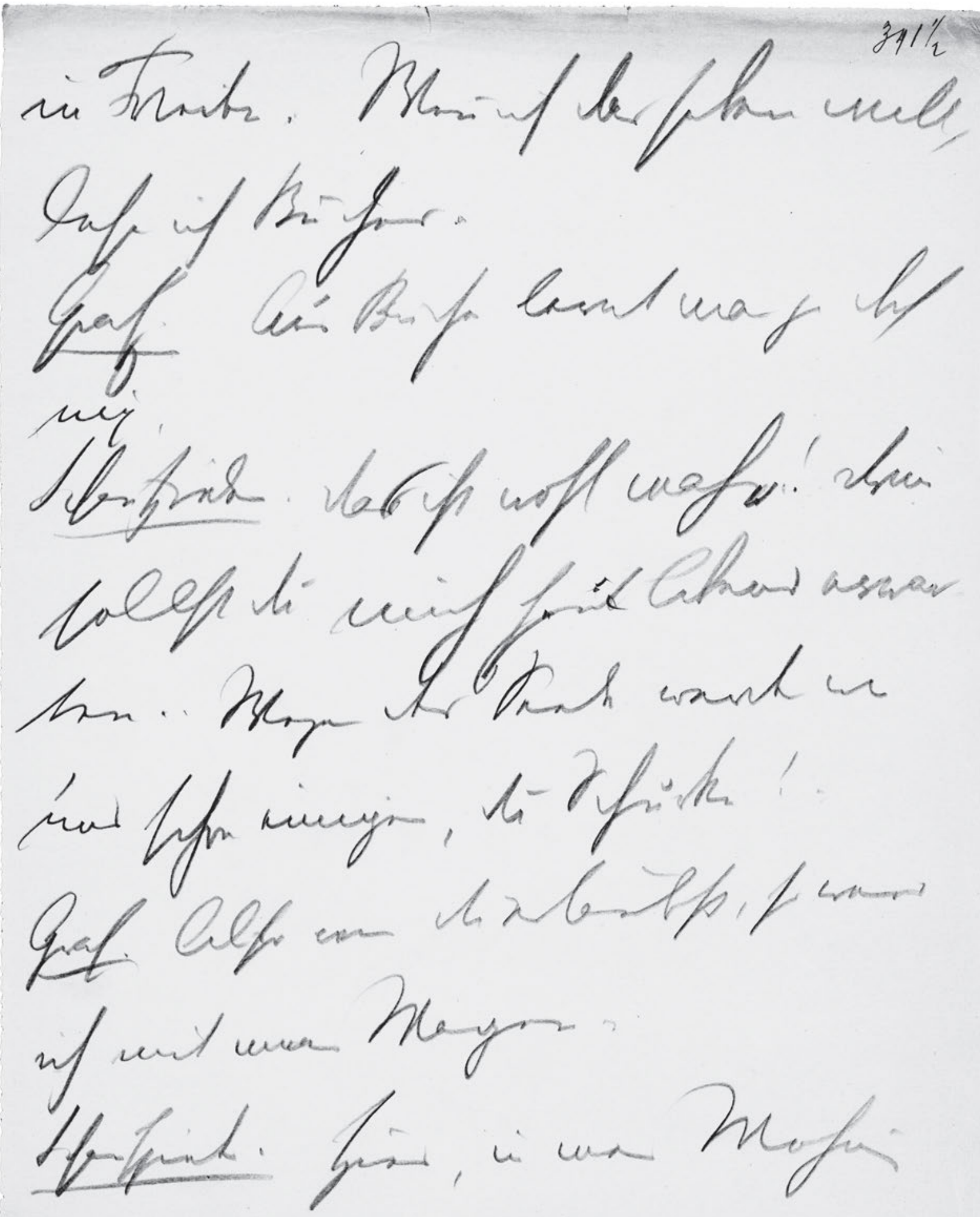




\section{$341^{1 / 2}$}

in Frieden. Wen̄ ich das haben will,

lese ich Bücher.

Graf. Aus Bücher lernt man ja doch

$5 \quad$ nix.

Schauspieler. Das ist wohl wahr. ! Drum

sollst du mich heut Abend erwar-

ten .. Wegen der Seele werden wir

uns schon einigen, du Schurke! -

10 Graf. Also wen du erlaubst, so werd

ich mit einem Wagen . .

Schauspieler. Hier, in mein Wohnung

1 Paginierung in Tinte. 
HSz9 342

Handschriften und Typoskript

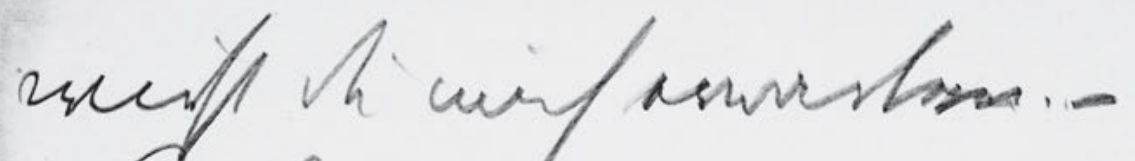

342

Oforialini

har/ $/$

Ifrala.

kadiesh
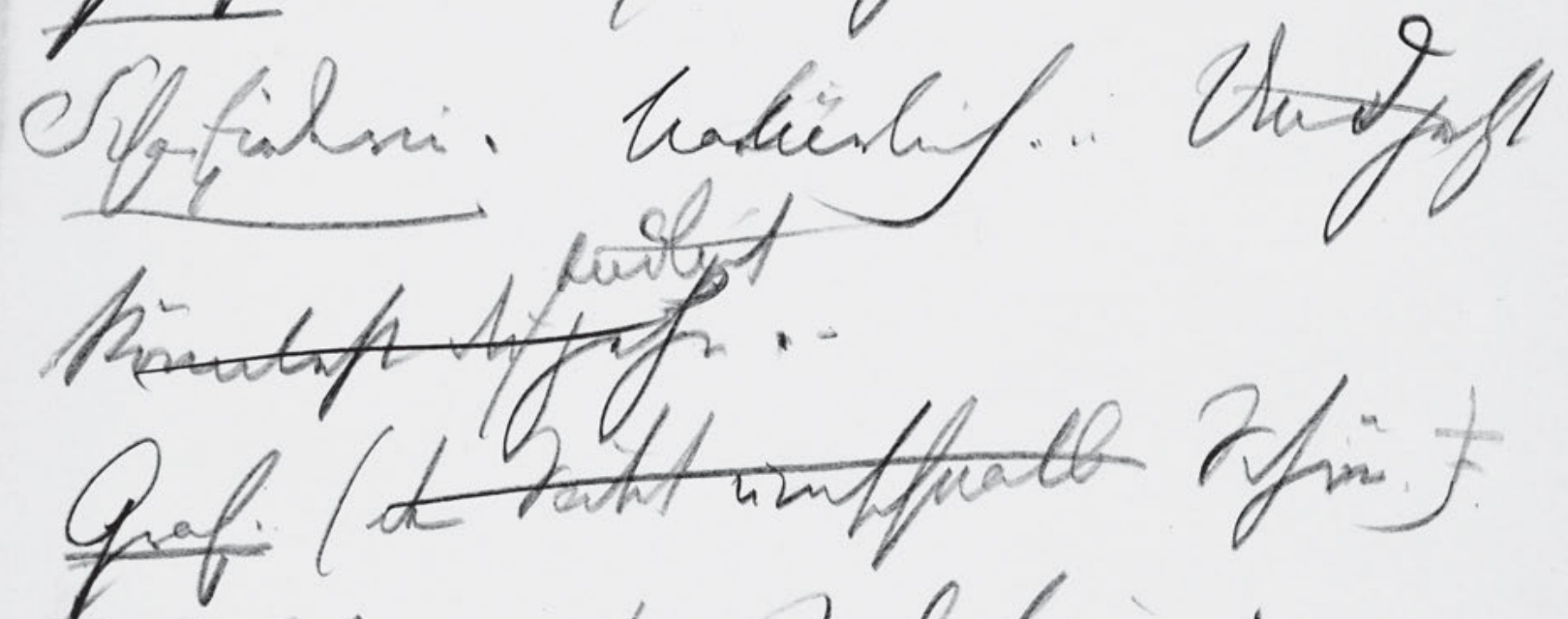

Poging

\%

ipar.

tahluin)

Pess. Pror wir

this b.:
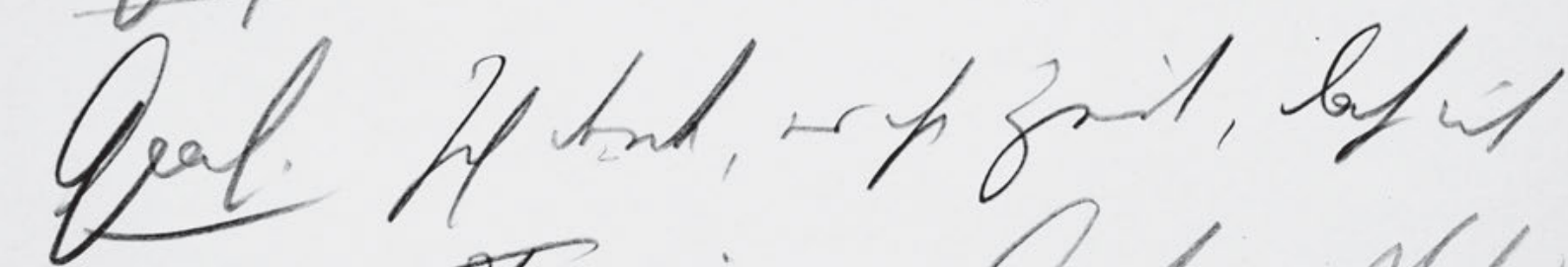

Oin mins

Cafferm thang

his if spursonst

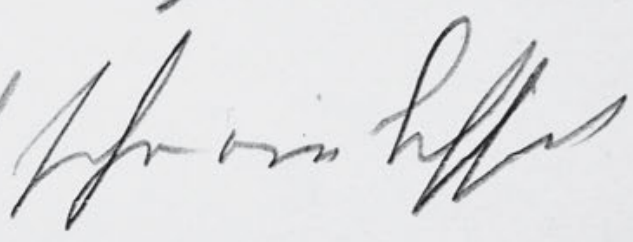

824 
wirst du mich erwarten .. -

Graf. .. Nach dem Theater.

Schauspielerin. Natürlich .... Und jetzt endlich

$5 \quad$ könntest du gehn. -

Graf. (den Säbel umschnalle Schön.)

(Er schnallt den Sabel um)

Schauspielerin. Was machst du den̄ da?

Graf. Ich denk, es ist Zeit, dass ich

10 geh ... Für einen Anstandsbesuch

bin ich doch eigentlich schon ein bissel 
HSz9 343

Handschriften und Typoskript

lon pablina Sertialen:

solemprom

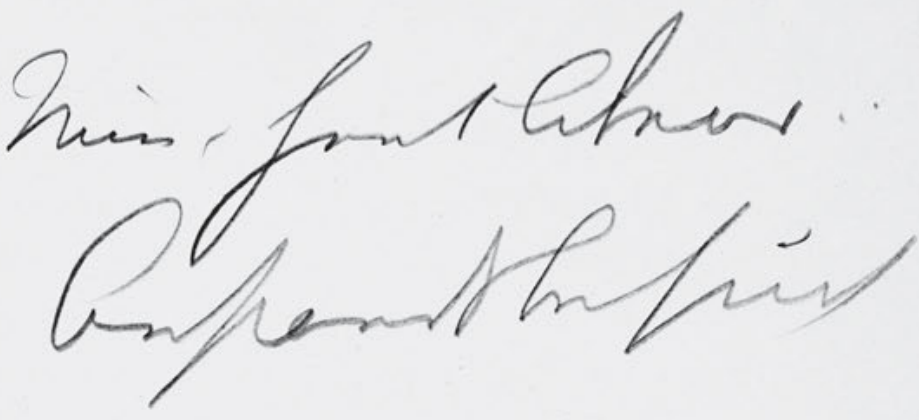

veresta.

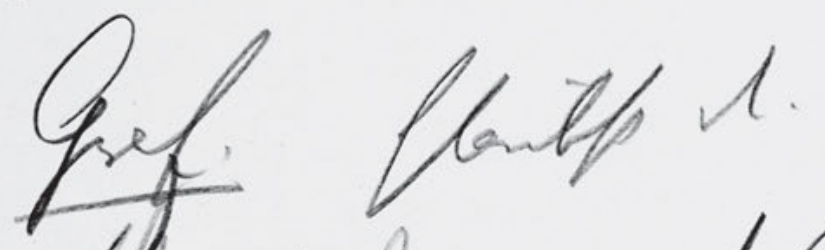

fory in

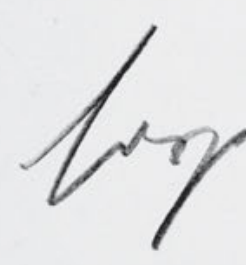

mpref.

Afilolig...

qu Norfifion

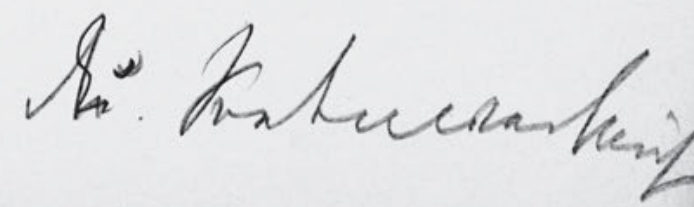

826 


\section{3}

lang geblieben . .

Schauspielerin. Nun, heut Abend . .

soll es kein Anstandsbesuch

5 werden . .

Graf. Glaubst du.

Schauspielerin. Dafur lass nur mi

sorgen .. Und jetzt gib mir ? ${ }^{n}{ }^{?}$

ein Kuss, mein philø kleiner

${ }_{10}$ Philosoph .. So . . du Verführer,

du . . süßes Kind, du Seelenverkäufer.

11 punktförmige Verschmutzung zwischen du und Seelenverkäufer. 


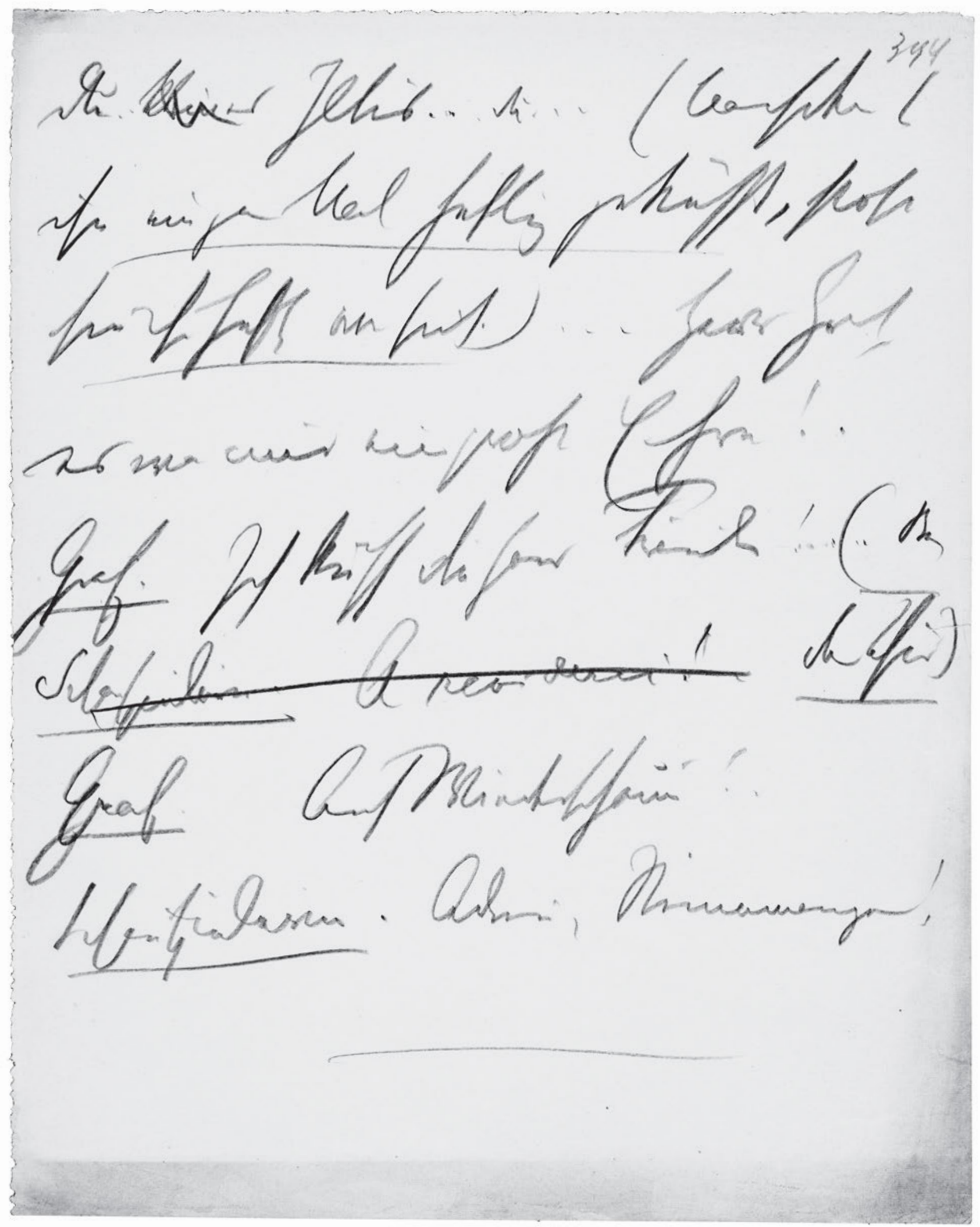


Du . . kleiner Iltis . . du . . . (Nachdem s

ihn ein paar Mal heftig geküsst, stoßt

sie ihn heft $\mathrm{v}$ von sich.) ... Herr Graf,

${ }_{5} \quad$ es war mir eine große Ehre! .

Graf. Ich küss die Hand Fräulei! .. . “ (Bei

Schauspielerin. A reviderci!. $\quad$ der Thür)

Graf. Auf Wiederschaun! .

Schauspielerin . Adieu, Steinamanger! 
H'Sz10 [1]

Handschriften und Typoskript

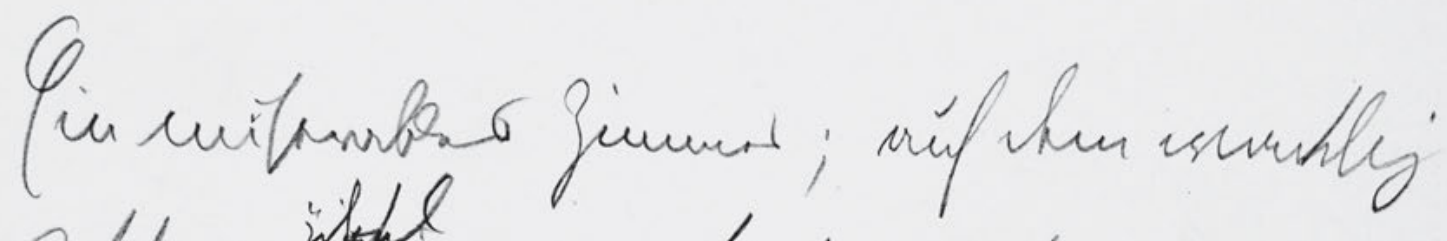

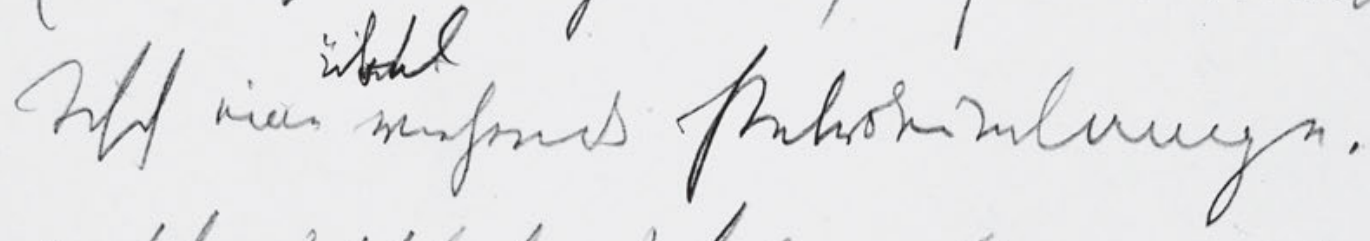

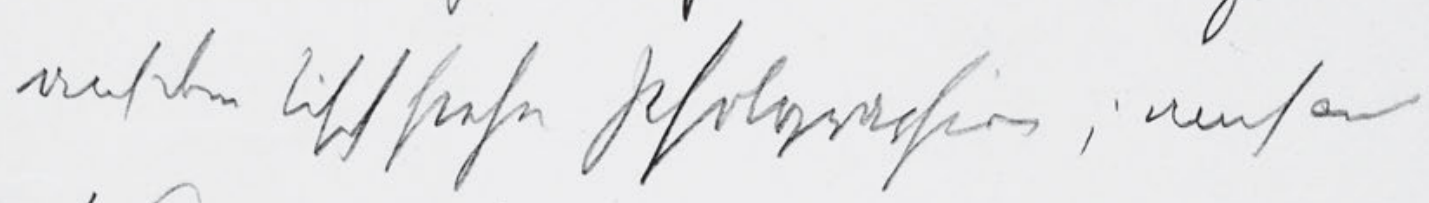

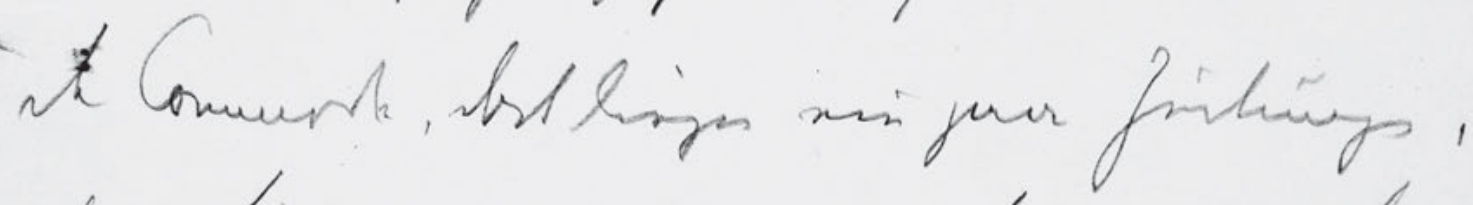

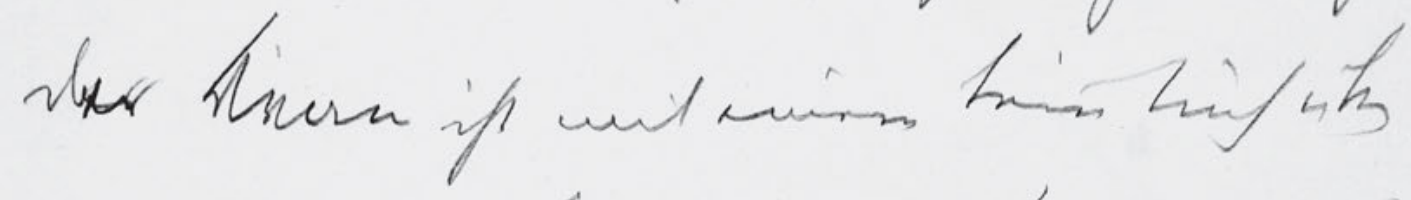

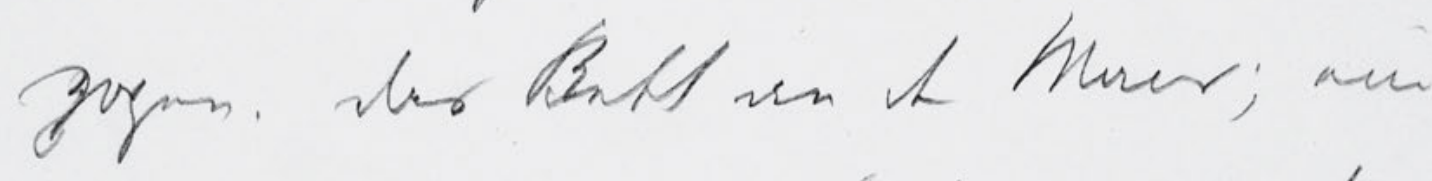

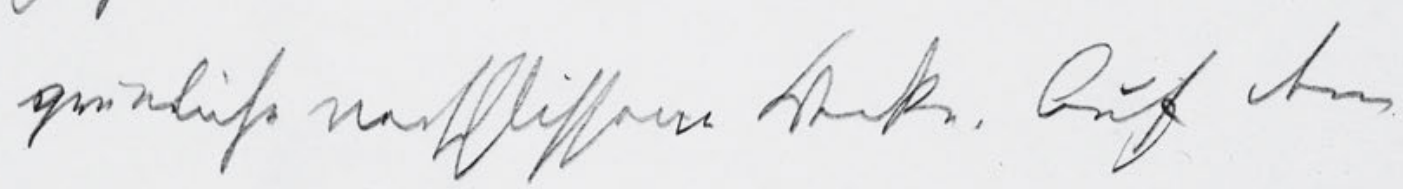

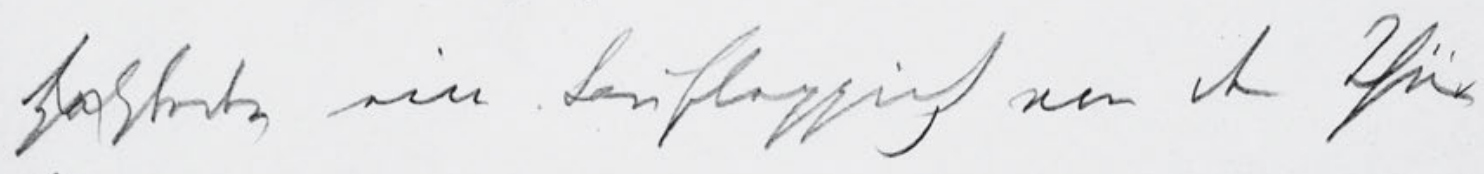

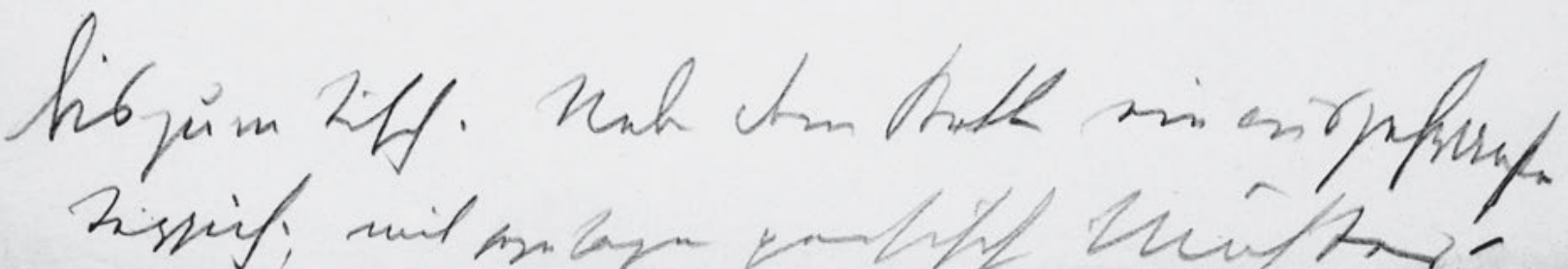

830 
Ein miserables Zimmer; auf dem wacklige

übel

Tisch eine riechende Petroleumlampe.

auf dem Tisch stehen Photographien; auch auf

der Commode, dort liegen ein paar Zeitungen,

${ }_{5} \quad d^{\text {as }}$ er Divan ist mit einem Leintuch über-

zogen. Das Bett an der Wand; eine

grünliche verschlissene Decke. Auf dem

Holzboden ein Laufteppich von der Thür

bis zum Tisch. Neben dem Bett ein ausgefranster

10

Teppich; mit sozusagen persischem Muster -

4 Verschmutzung des Papiers am linken Blattrand und am Zeilenbeginn. 
H'Sz10 [2]

Handschriften und Typoskript

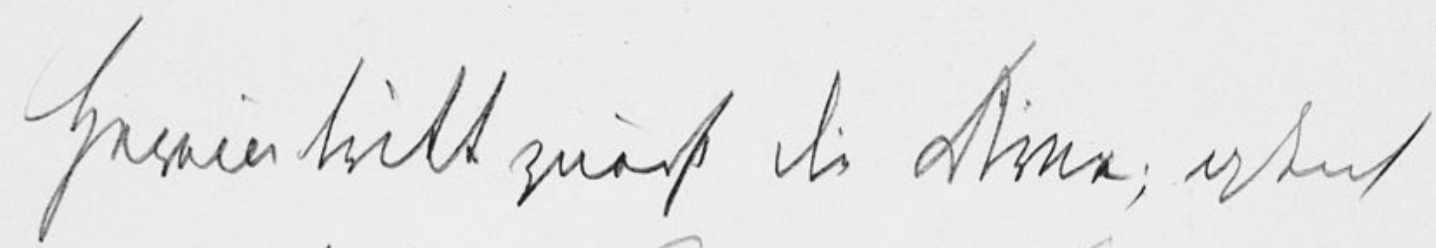

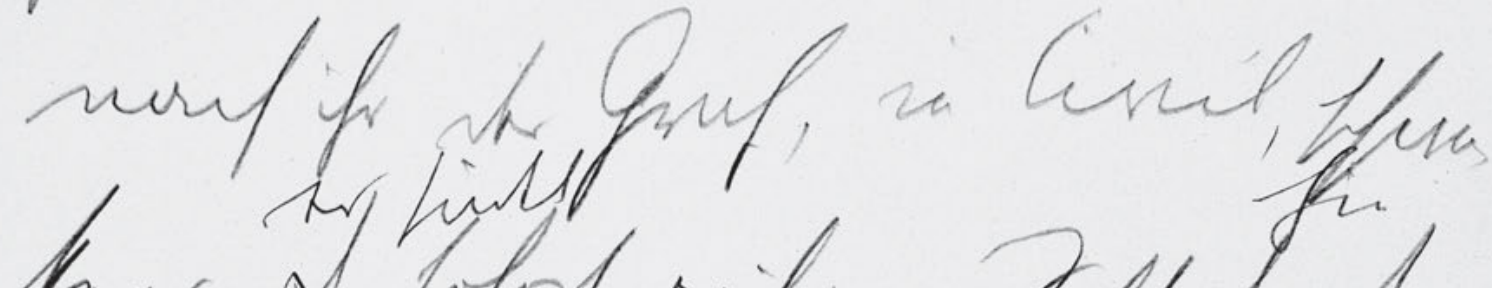

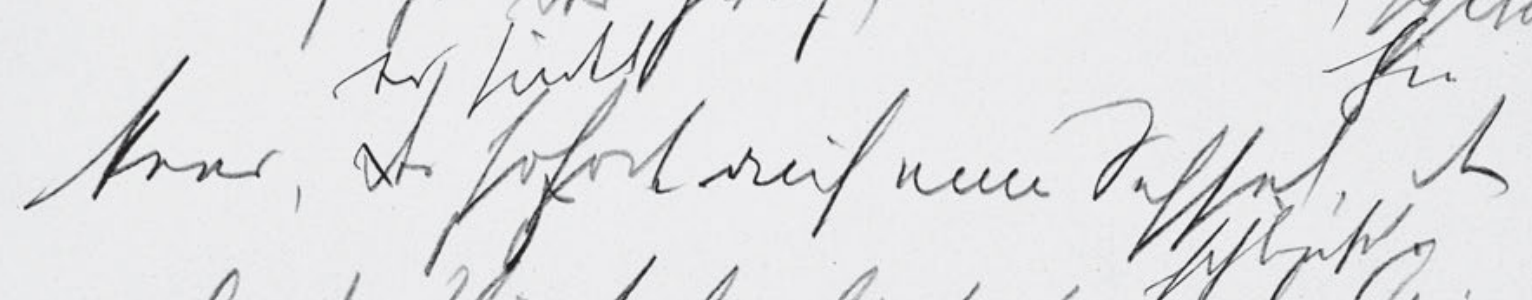

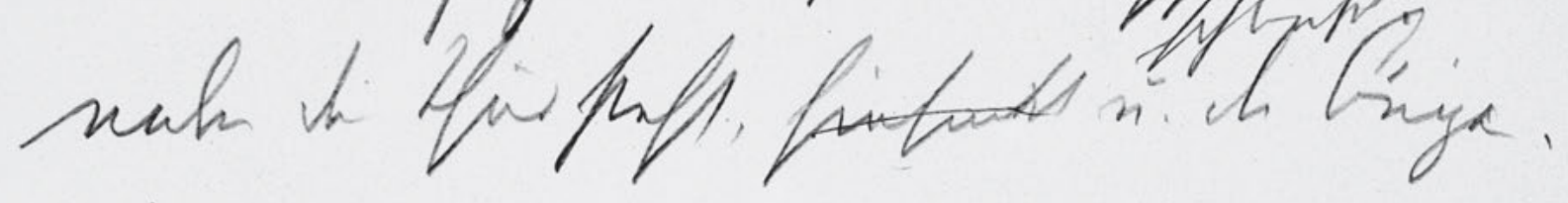
Sthift.

Anis kfai usui, buypul fift Mer mis homint.

Grat lage

Shrin (saft us Mrpiume, na in for

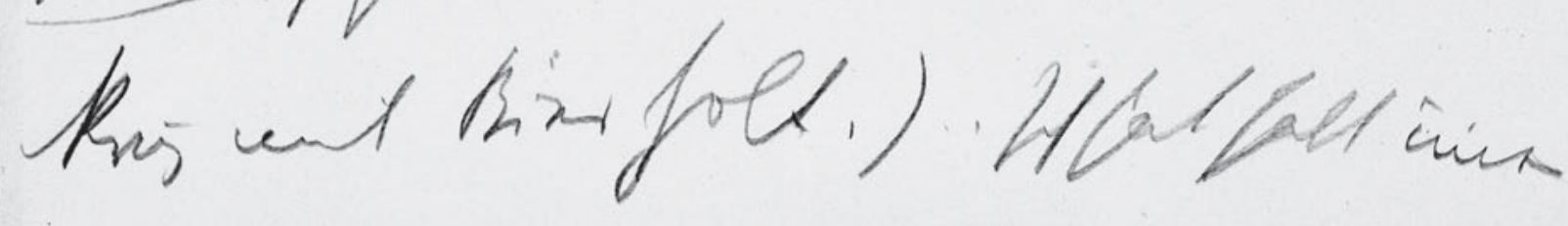

832 
Herein tritt zuerst die Dirne; gleich nach ihr der Graf, in Civil, schwaner sinkt hend, der sofort auf einen Sessel, der
kin schließt neben der Thür steht, hinsinkt u. die Augen . 5 schließt.

Dirne. Da sein wir, ${ }^{\text {h} H e r z e r l ~ . ~ ' . J e t z t ~ W a r t ' ~}$ ein Moment.

Graf. Ja ja . .

Dirne (geht ins Vorzimmer, von wo sie ein

$10 \quad$ Krug mit Bier holt.) .. Ich hab halt imer 
H'Sz10 [3]

Handschriften und Typoskript

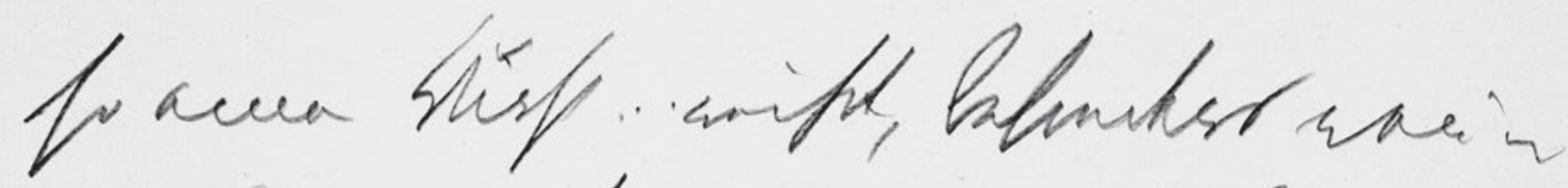

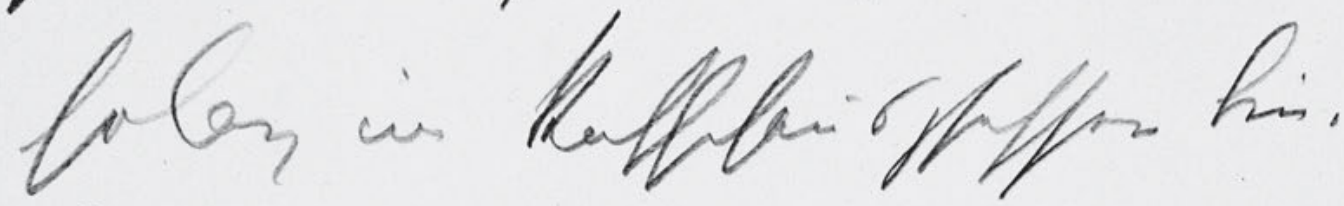

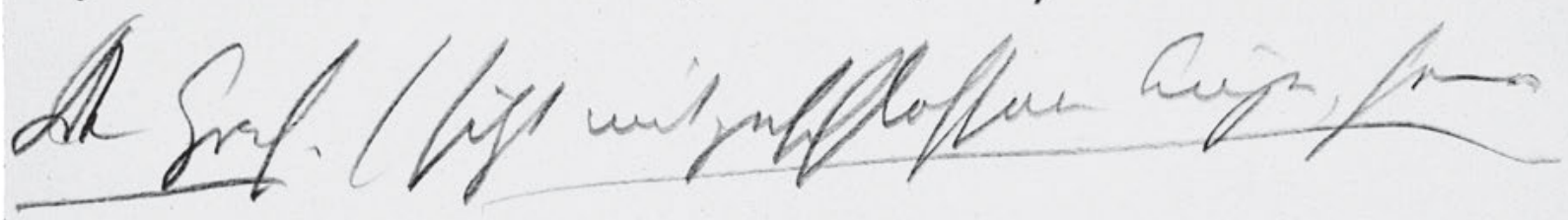
Resf pprsuruth.)

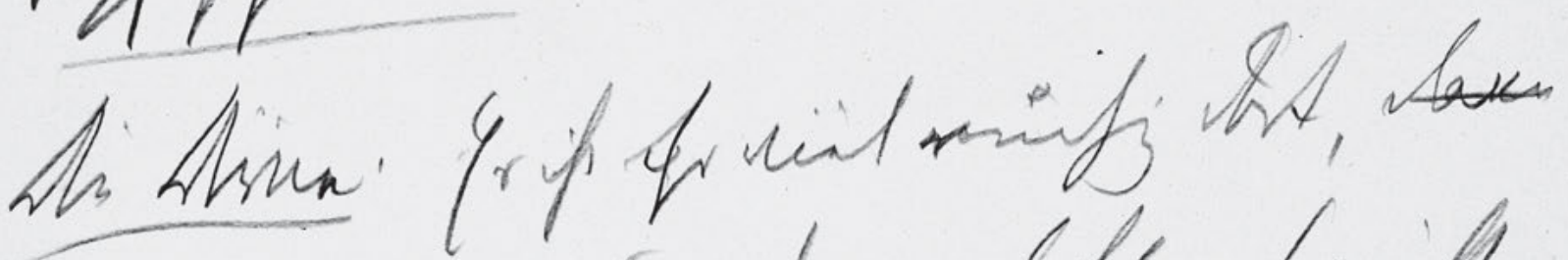

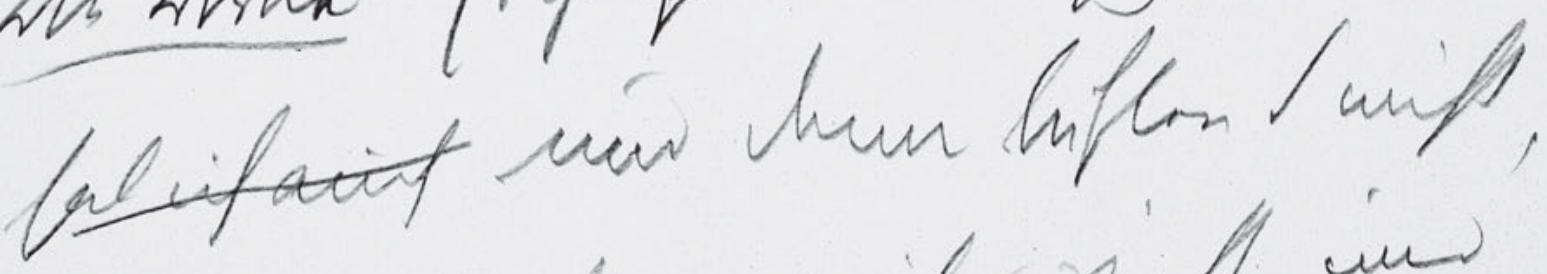
spaftant wiff urit pift in Gofpala ant inaf, wents giè, ifth

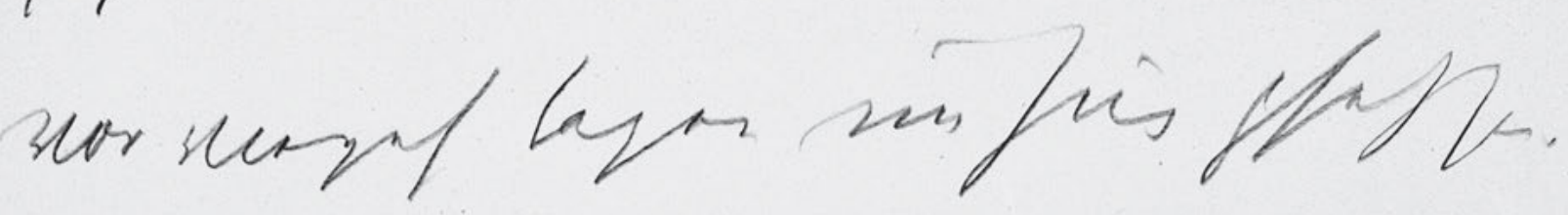

834 
so einen Durst ... weißt, besonders wen̄ ich

solang im Kaffehaus gsessen bin.

tDer Graf. (sitzt mit geschlossenen Augen, sein

Kopf schwankt.)

${ }_{5} \quad$ Die Dirne. Es ist ${ }^{[?]}$ so viel rauchig dort, davo

hab ich auch und dann lüften S nicht,

s geht auch nicht, weil s zieht und

heutzutag furcht sich alles vor dem Zug.

Es ist aber auch wahr, mit dem Zug, ich bin

$10 \quad$ vor vierzehn Tagen im Zug gsessen. 
H'Sz10 [4]

Handschriften und Typoskript

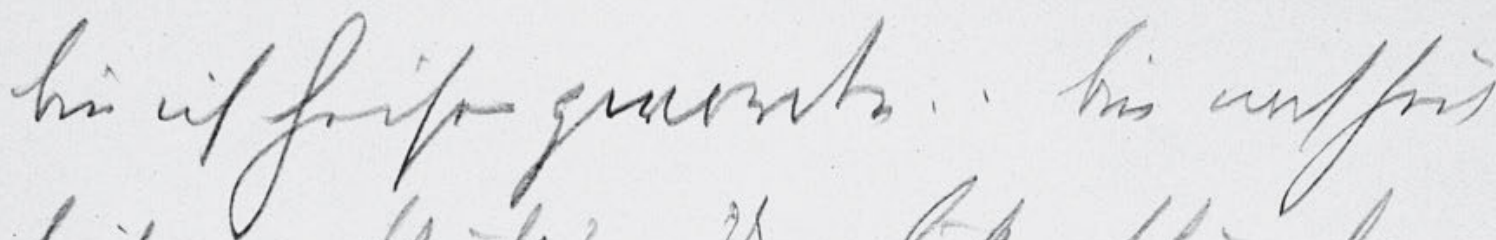

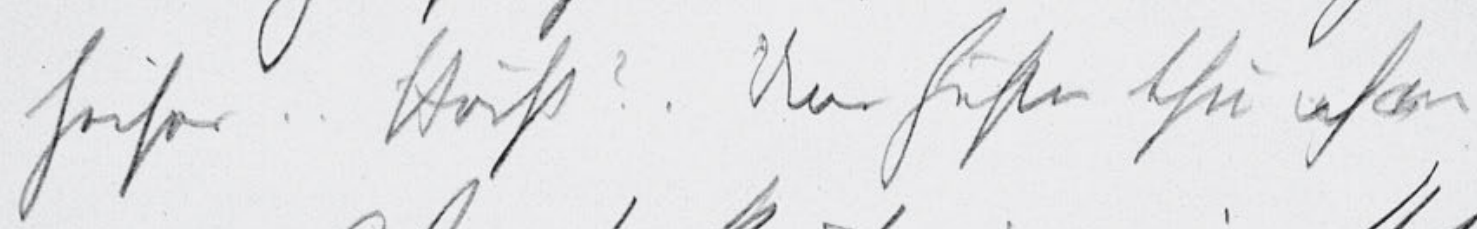

no. Alar de Borit rix in thes

w thalfafer nom derumin hitat,

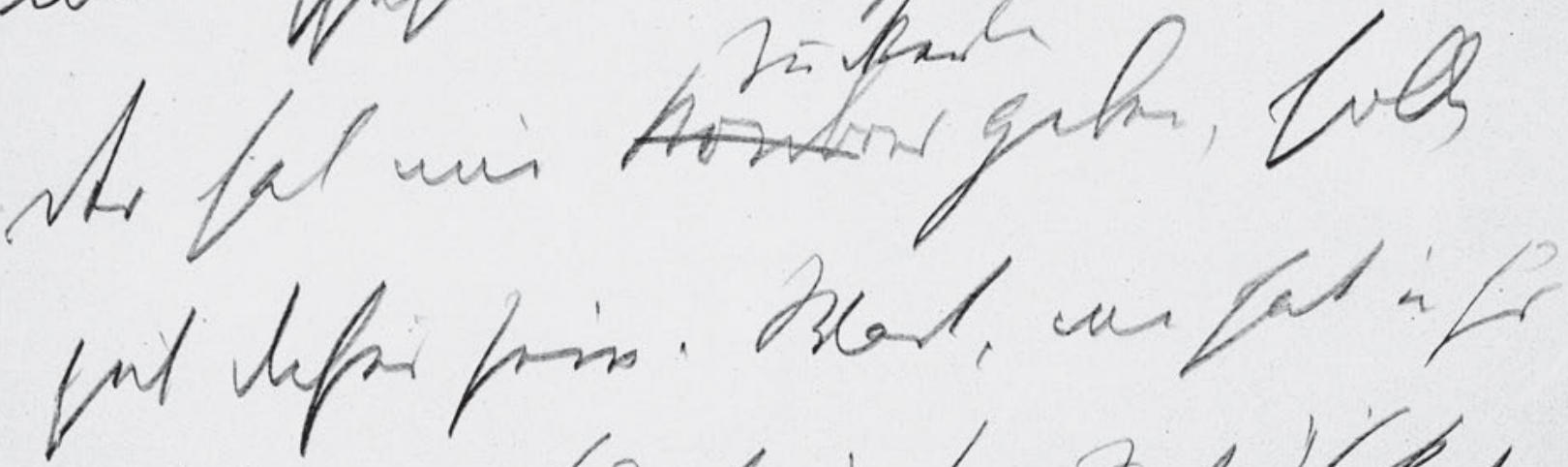

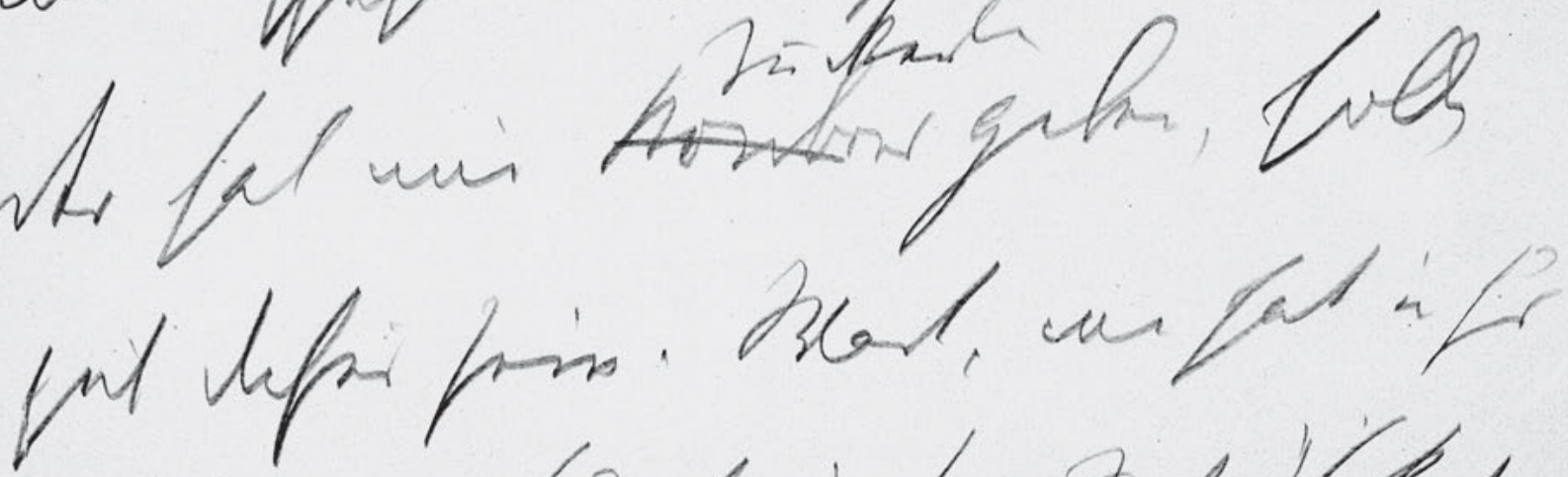

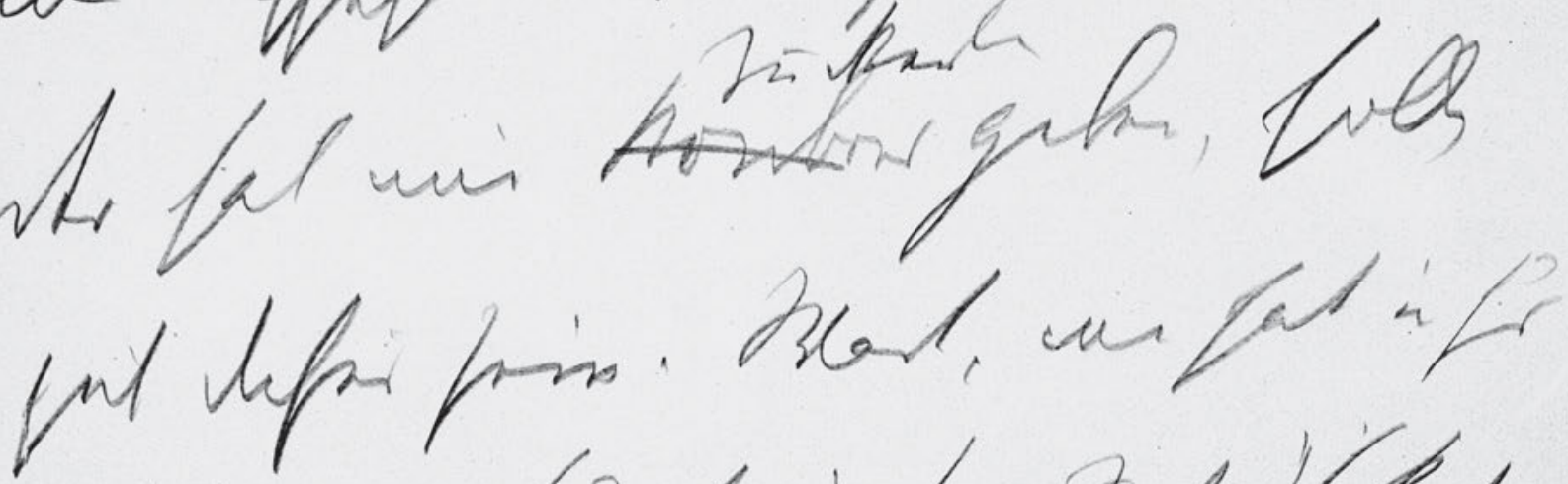

tim ?...... (omf)

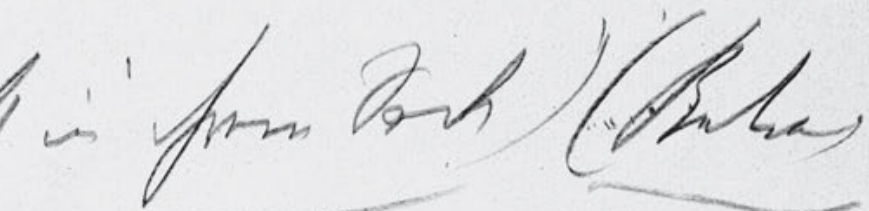

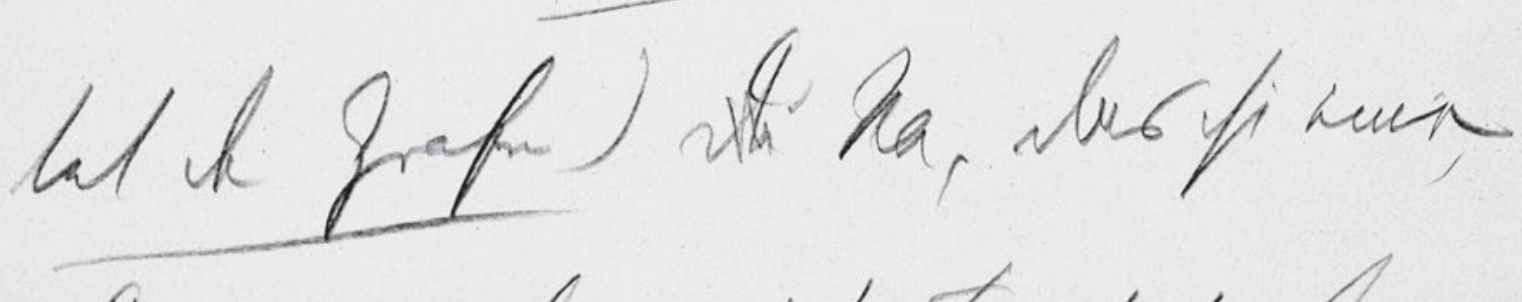

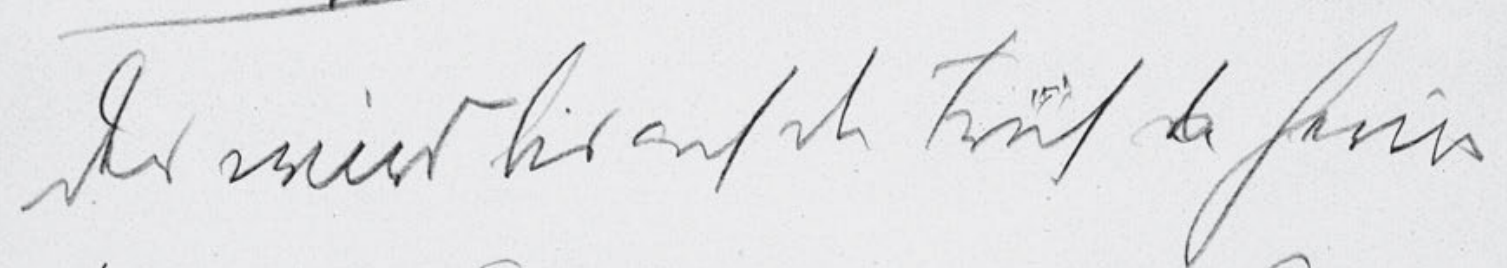

theolym... Edopit.

836 
bin ich heiser gworden . . bin noch heut

heiser . . Hörst? . Und husten thu ich ${ }^{\text {a? }} \mathrm{im}$ ?

no .. Aber da kō̄t imer ein Doktor

ins Kaffehaus vom allgemeinen Spital,

Zuckerln

5 der hat mir Bonbons geben, sollen

gut ?dafür? ?sein?. Wart, wo hab ich's

denn ?...... (Sucht in ihrem Sack) ${ }^{\cdots \cdots}$ (Betrach

tet den Grafen) $\mathrm{Du} \mathrm{Na}$, das ist einer,

der wird bis auf die Früh ${ }^{\text {ada herum }}$

10

knotzen ... . Es ist gut, Ich bin ?ime? . . Na, ein 
H'Sz10 [5]

Handschriften und Typoskript

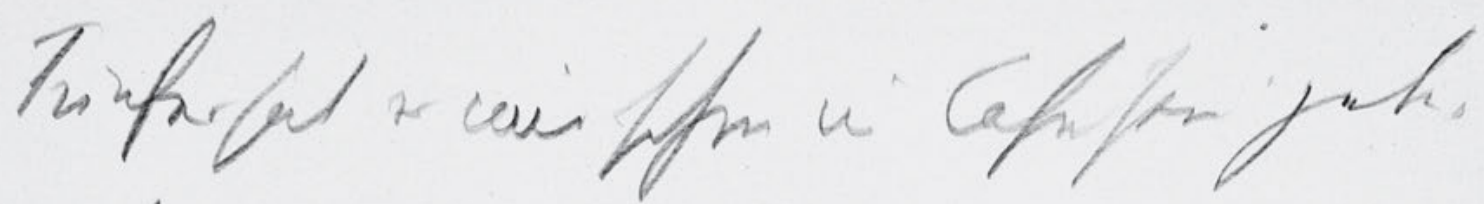

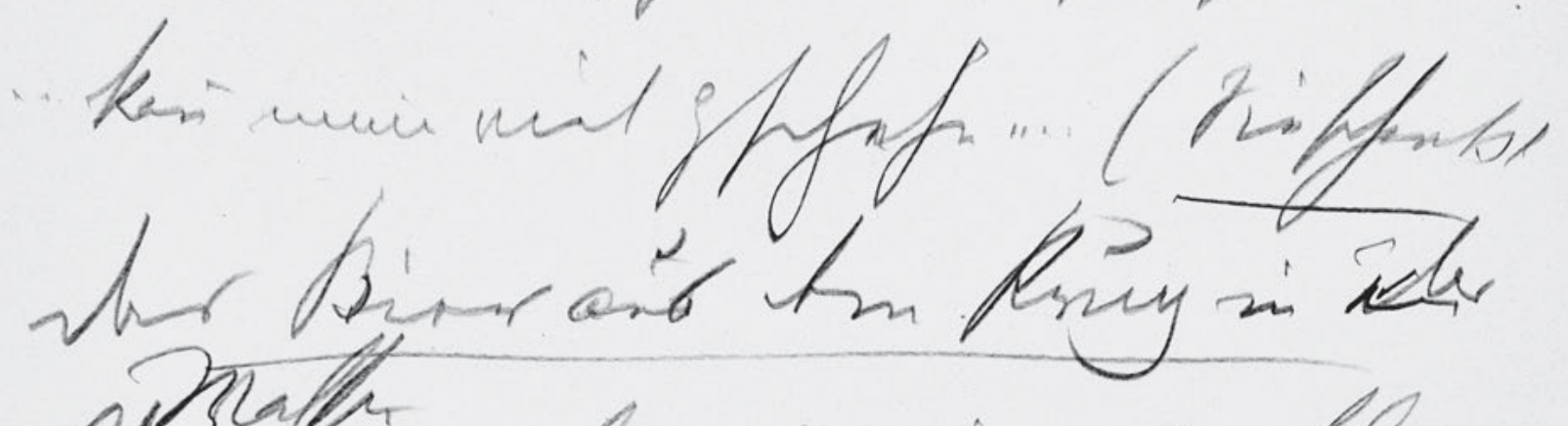
Slar van, lar ens mi nerhas nerftkape piafi.)

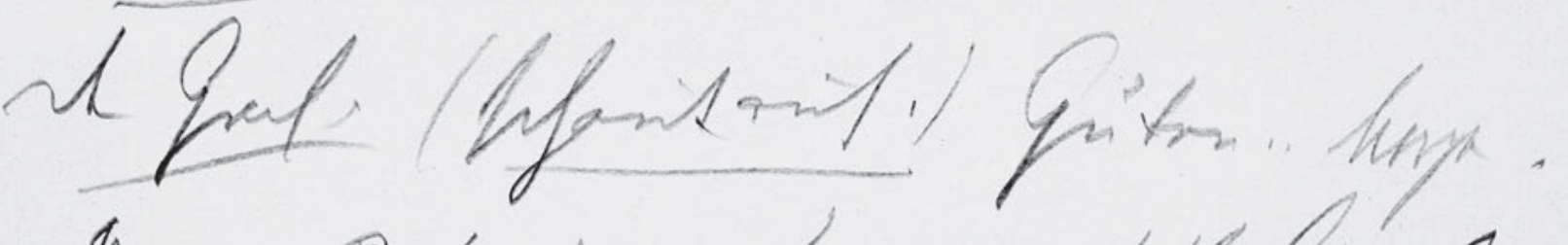

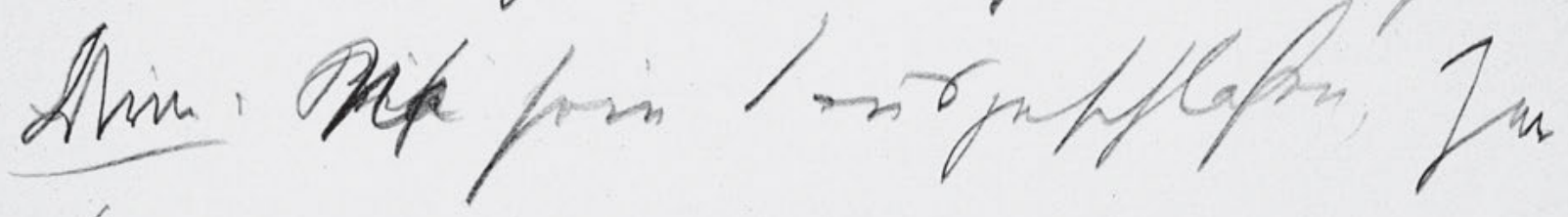
Rason?

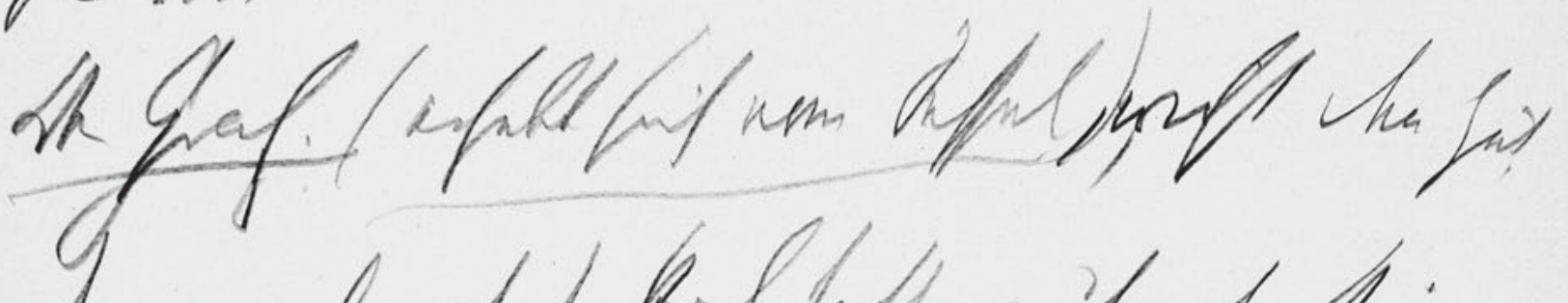

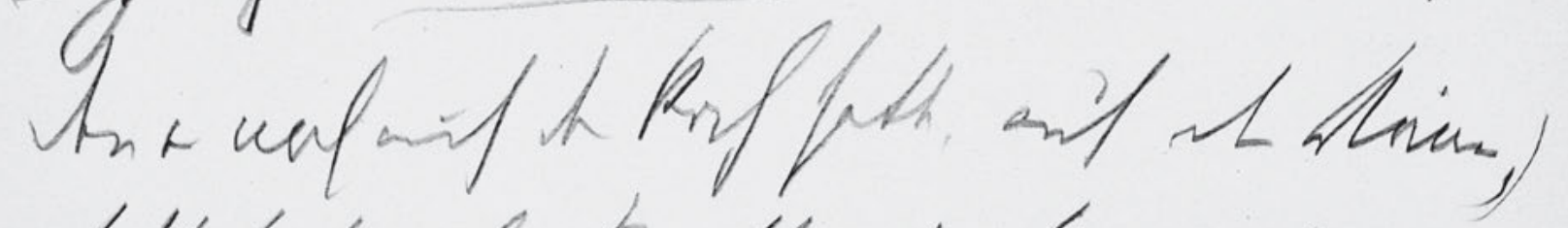

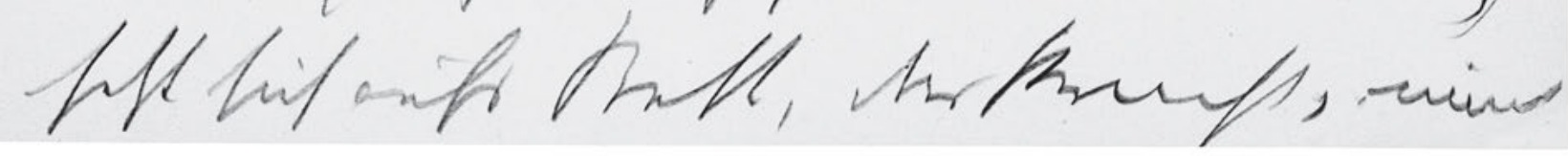

838 
Fünfer hat er mir schon im Cafehaus geben.

.. kan̄ nimer viel gschehn .... (Sie schenkt

das Bier aus dem Krug in ${ }^{\text {das }}$ ein

Wasser

Glas ${ }^{\text {att }}$ ein, das auf einem wacklig

$5 \quad$ Nachtkastl steht.)

Der Graf. (schaut auf.) Guten .. Morgen.

Dirne. ${ }^{\text {Bist }} \mathrm{Na}$ sein $\mathrm{S}$ ausgeschlafen, Herr

Baron? .

Der Graf. (erhebt sich vom Sessel's, wirft den Hut,

10 den er noch auf dem Kopf hatte, auf den Divan’,

setzt sich aufs Bett, das kracht, nimt 
H'Sz10 [6]

Handschriften und Typoskript

Mi Shin min ti Railes, fffefinat

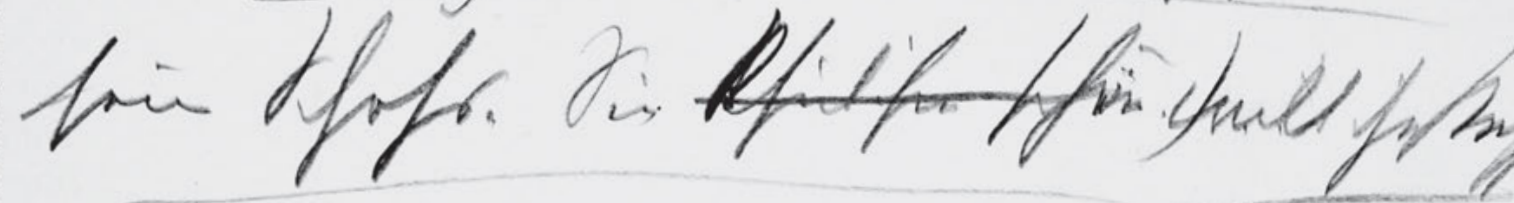

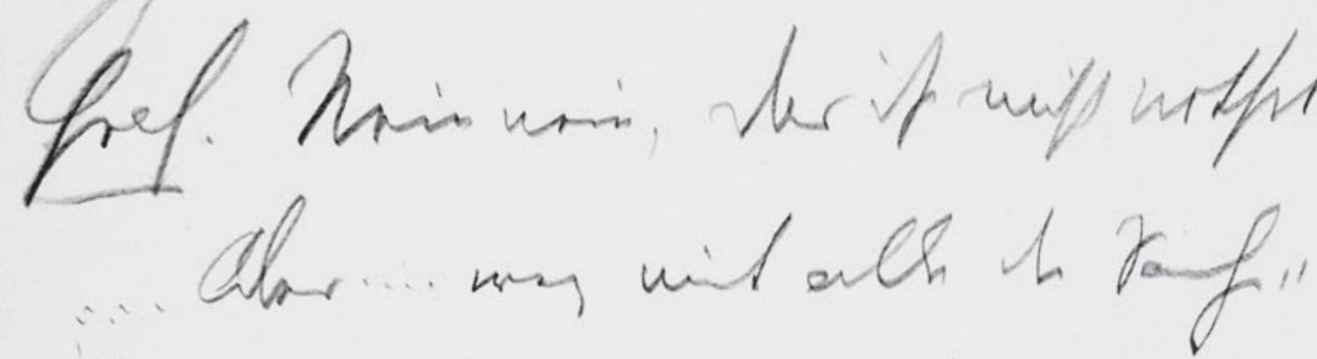

Lims he ued, th folet Mifa, uns Aprould albo do hi uni gnf

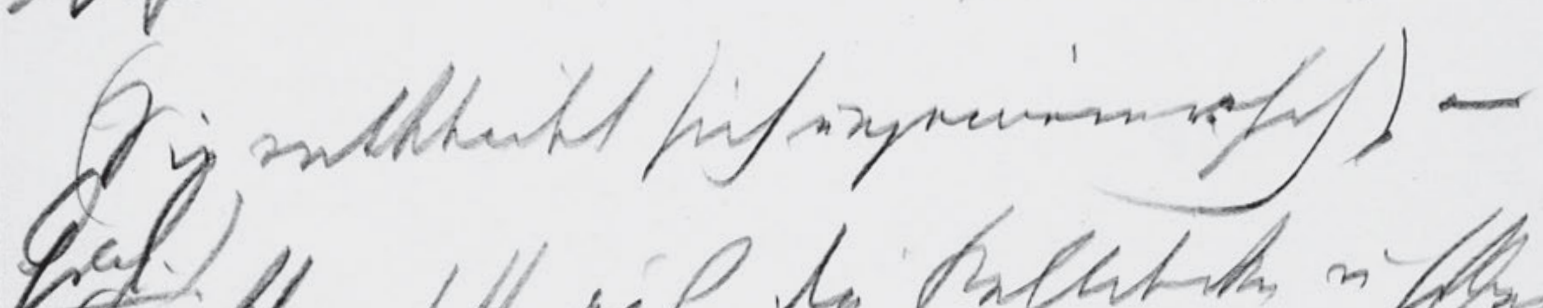

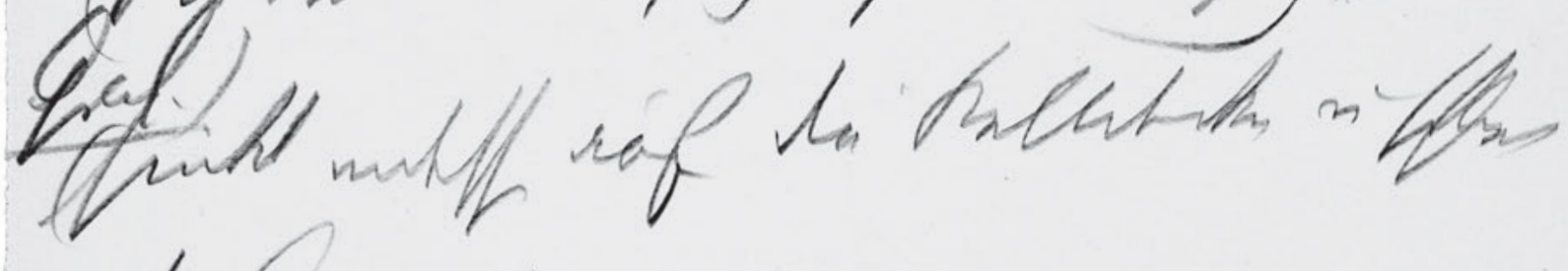
disinge.)

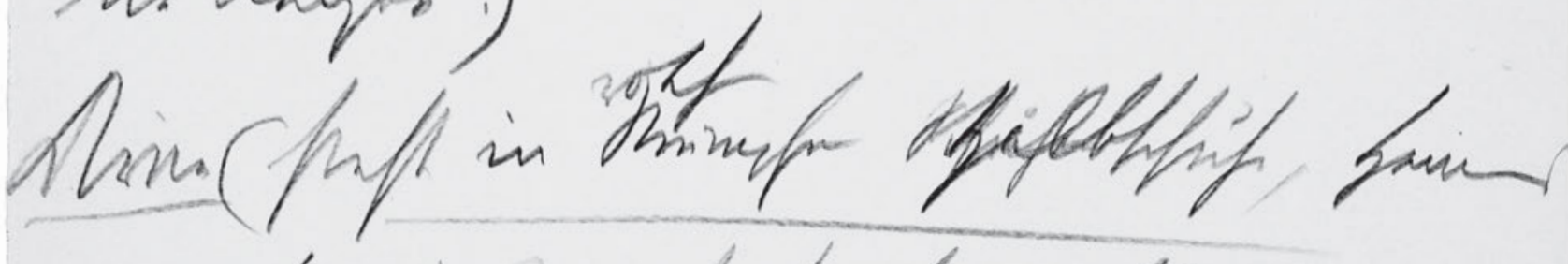

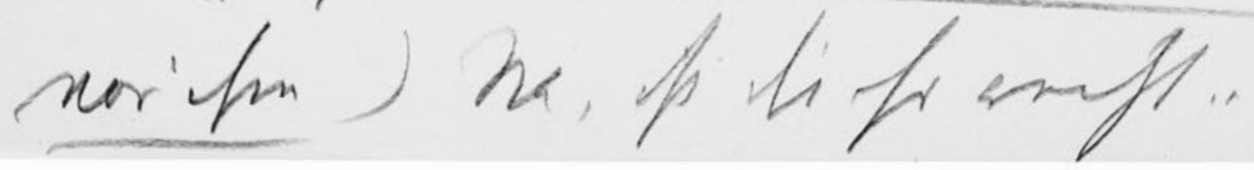

840 
die Dirne um die Taille, setzt sie auf seinen Schoss. Sie ${ }^{k}$ thut ihm schön ${ }^{\cdots 7}$ will ihn küssen)

Graf. Nein nein, das ist nicht nothwendig . .

...... Aber .... weg mit alle die Sachen . .

$5 \quad$ Dirne. Na wart, du sollst spitzn, wie

schnell all's das ${ }^{[?]}$ bei mir geht.

(Sie entkleidet sich ungemein rasch') er Graf.)

(sinkt indessen ?auf? die Bettdecke u schließ

die Augen.)

rothen

Dirne (steht in Strümpfen ${ }^{\text {Schuhen Halbschuhen, Hemd }}$

vor ihm) $\mathrm{Na}$, ist dir so recht . . 
H'Sz10 [7]

Handschriften und Typoskript

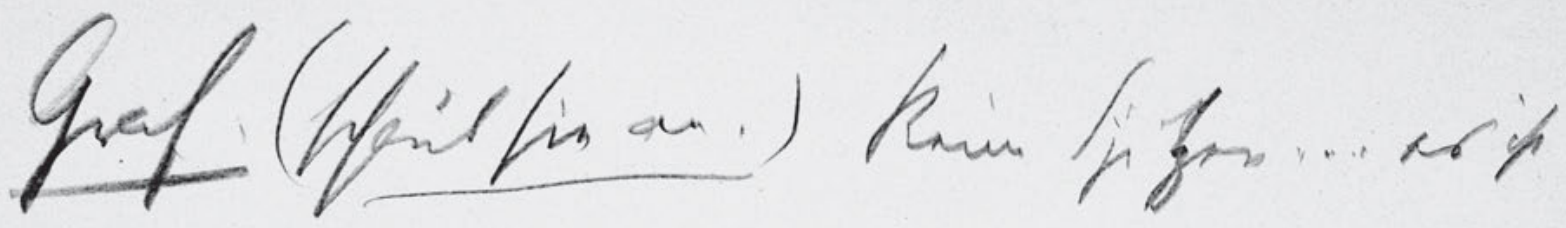

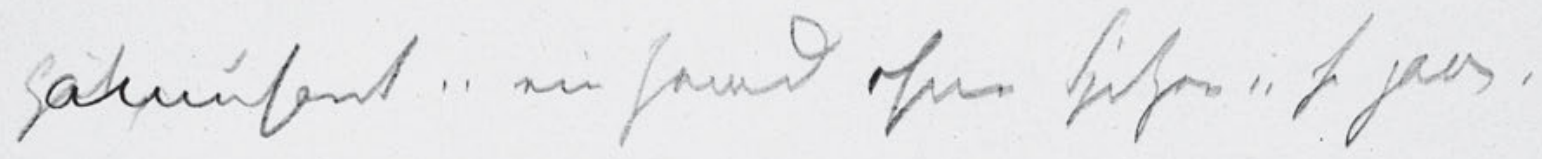

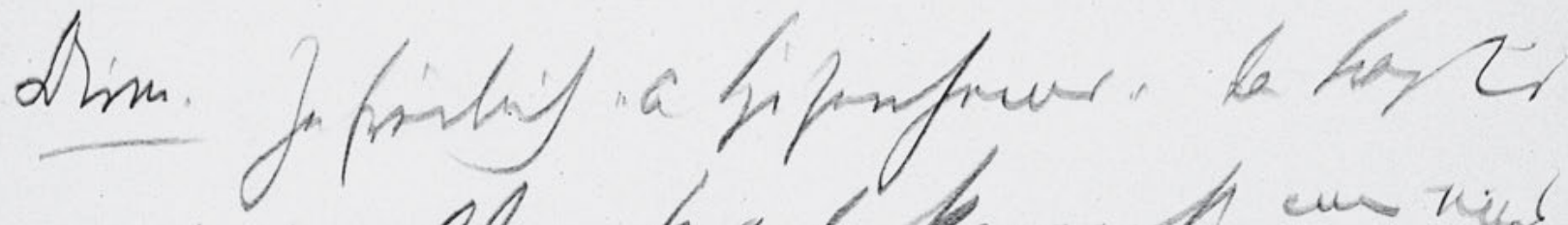
ment

- Mrapt fas hor liels dis unt

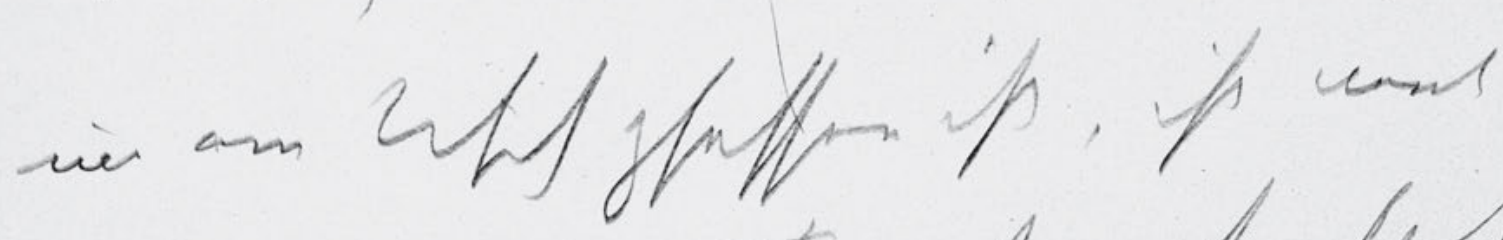

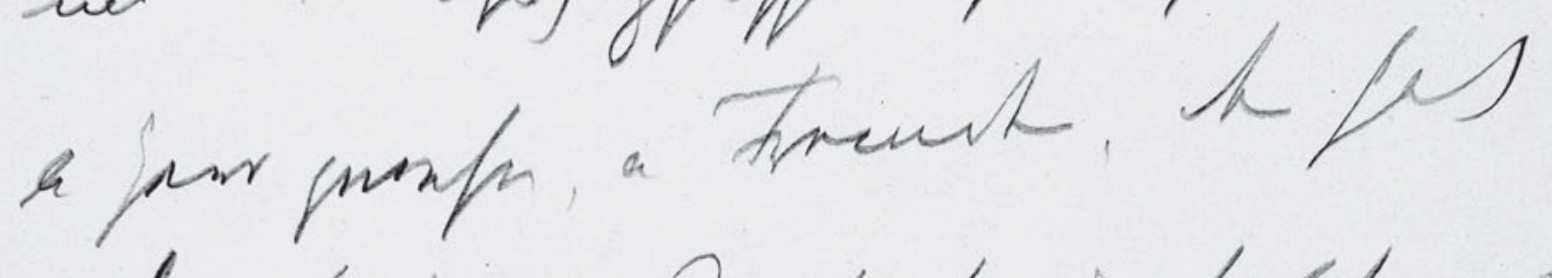

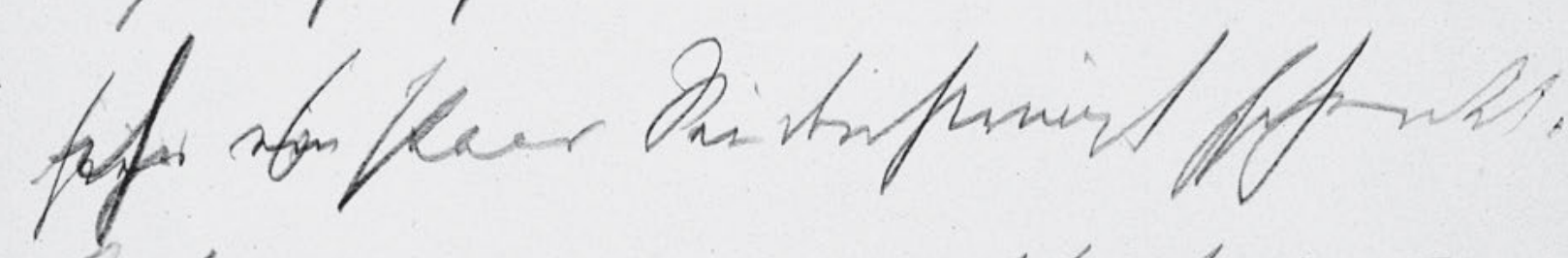

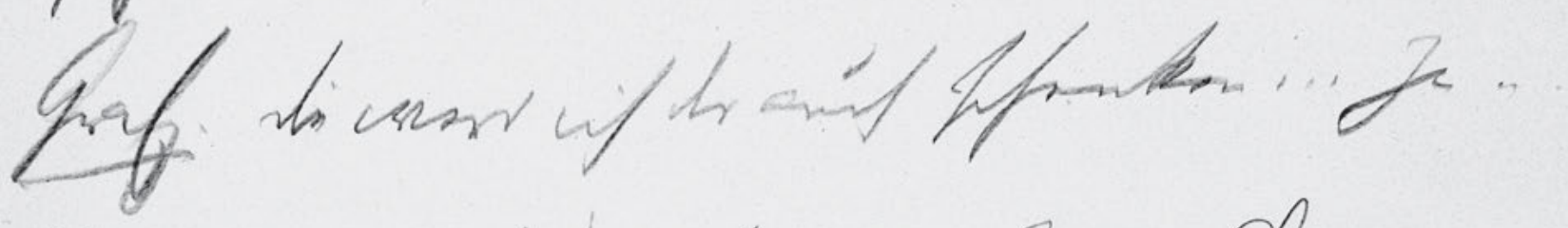

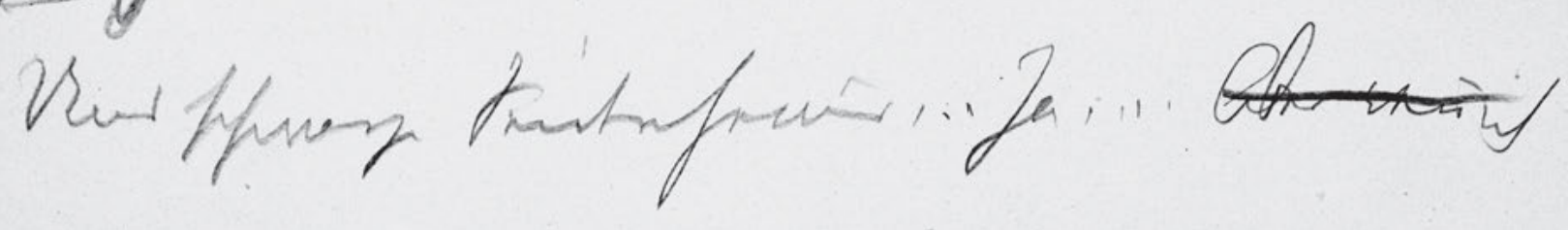

842 
Graf. (schaut sie an.) Keine Spitzen ...... es ist

?gut,?amüsant . . ein Hemd ohne Spitzen . . so ganz.

Dirne. Ja freilich „a Spitzenhemd“ das tragt's

nicht! . . Aber kaufen kannst mir eins.

$5 \quad$. . Weißt, bei der Milli, die mit

mir am Tisch gsessen ist, ist neuli

a Herr gwesn, a Fremder, der hat

${ }^{\text {hierihr }}{ }^{s \theta}$ ein Paar Seidenstrümpf gschenkt.

Gra $^{z}$ f. Die werd ich dir auch schenken ... Ja . . .

10 Und schwarze Seidenhemd .... Ja .... Aber weñ ich 
H'Sz10 [8]

Handschriften und Typoskript

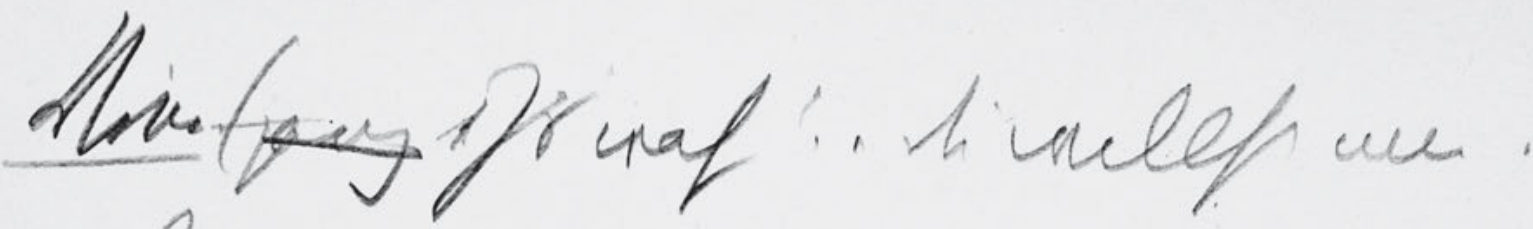

abra.

unf $x$

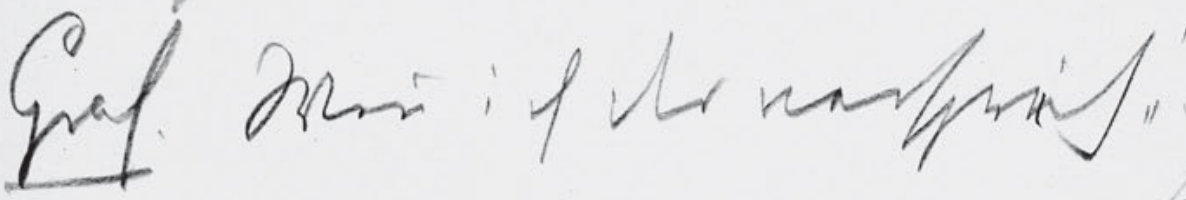

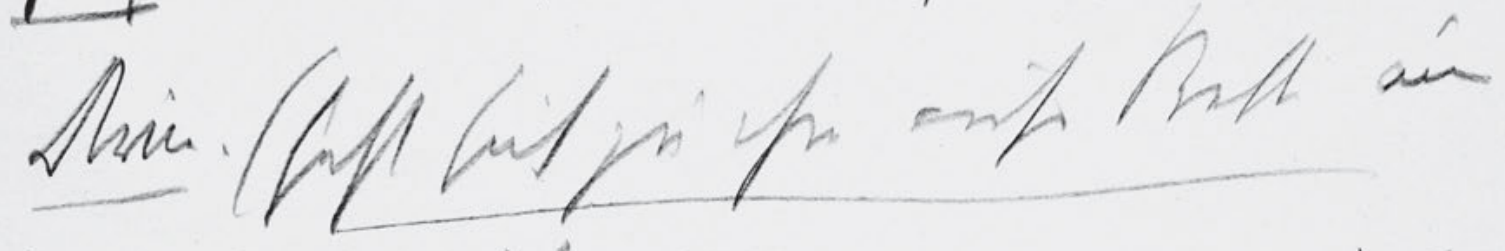

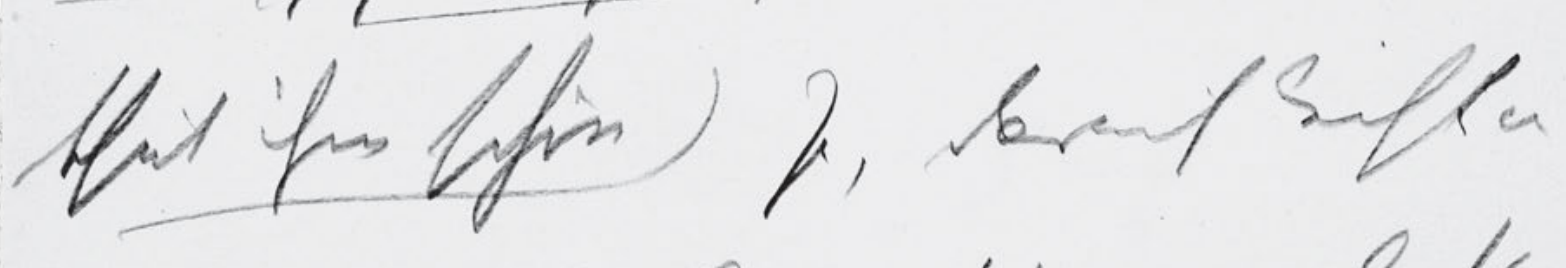

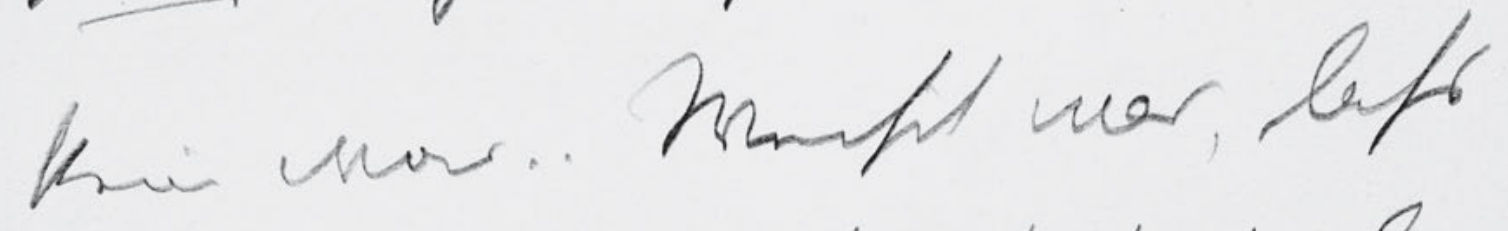

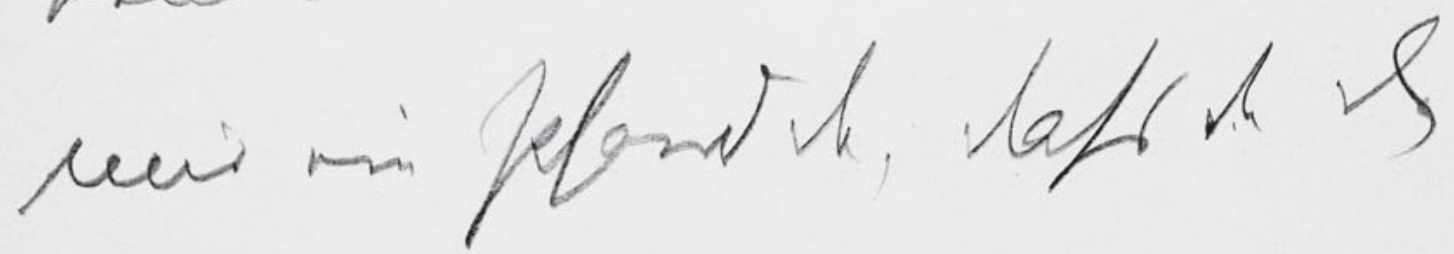

mont falesf..

quef.

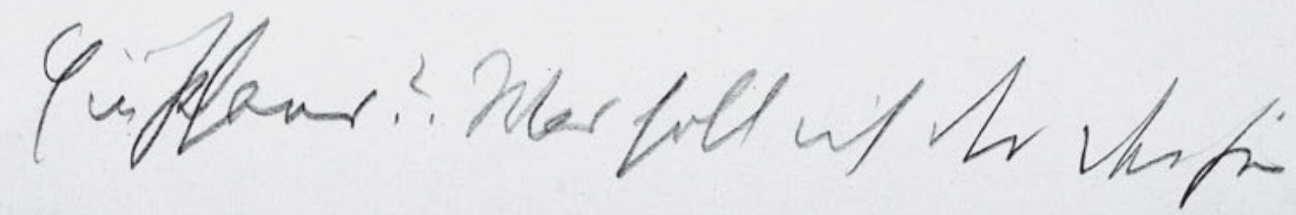

844 
Dirne (ganz [?]Is wahr? . Du willst mir .

Aber du haltst ja sicher thust ja siche

nicht . . ? $\mathrm{N}$ ?

Graf. Weñ ich dir verspriech’.... (

5 Dirne. (setzt sich zu ihm aufs Bett und

thut ihm schön) Ja, darauf leiht ein

keine was .. Weißt was, lass

mir ein Pfand da, dass 'du d'ein?

veWort haltst . .

10 Graf ... Ein Pfand?. Was soll ich dir den für 
H'Sz10 [9]

Handschriften und Typoskript

mi plawgrh.

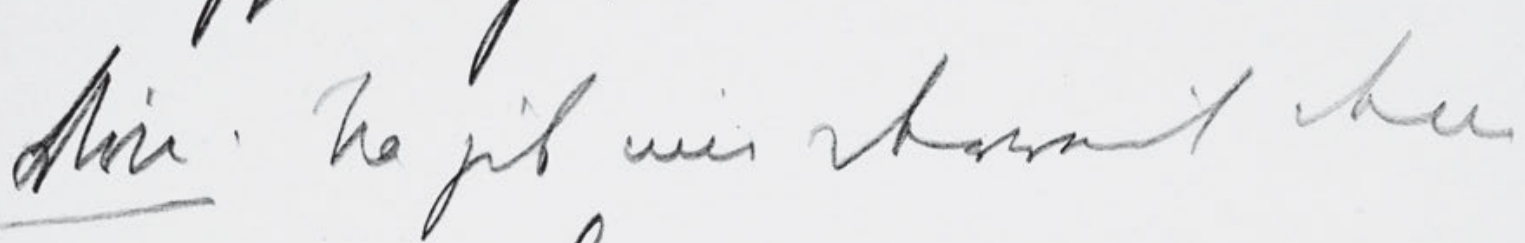

gohh

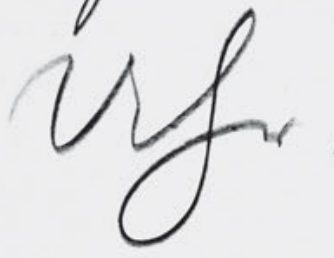

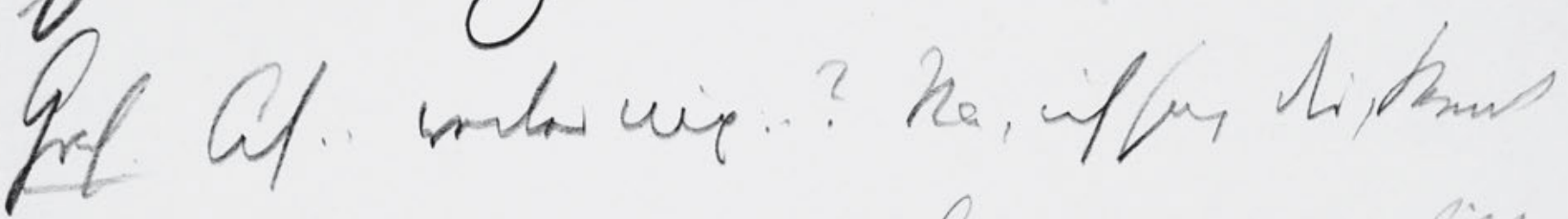

stif tomp unberfor...

Whr mavius nulles

to vet tonfor... Hifs

Cingreis.

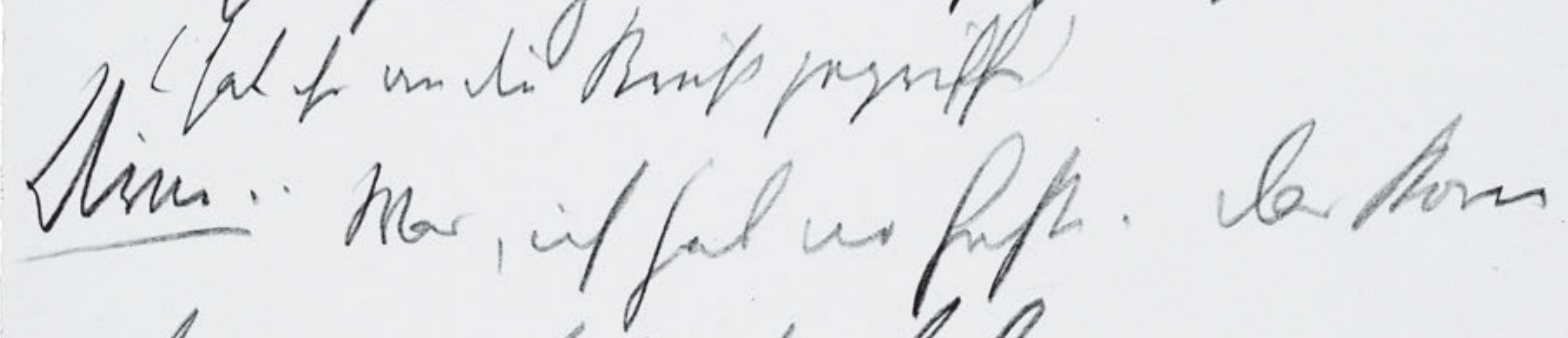

fall um foict Labm.

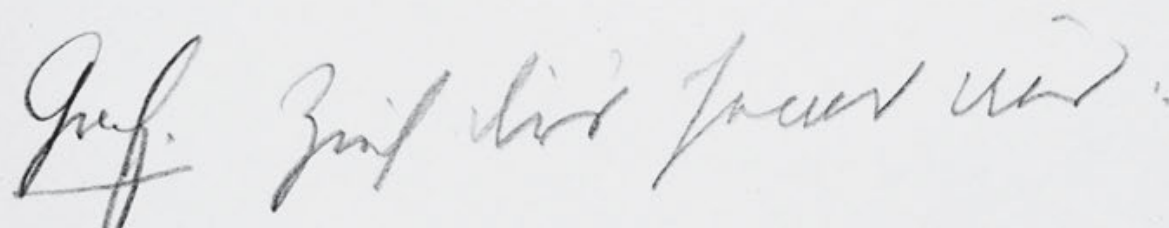

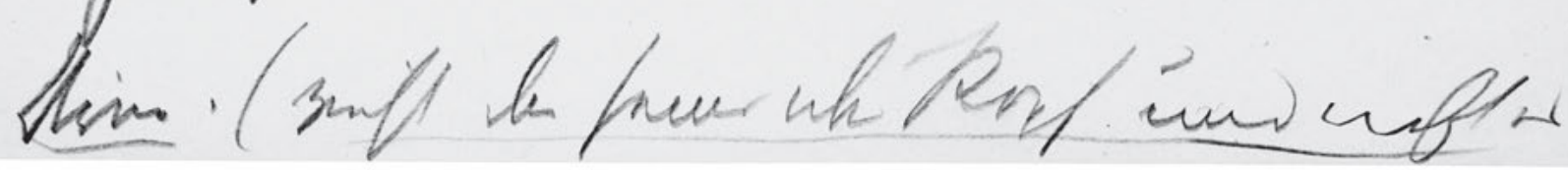

846 
ein Pfand geben.

Dirne. Na gib mir derweil deine

goldne Uhr.

Graf. Ah . . weiter nix . . ? Na, ich sag dir, kanns

5 dich drauf verlassen .... A Aber warum wills

den̄ solche Sachen ... Bist so schön genug.

(hat ihr an die Brust gegriffen)

Dirne.. Was, ich hab no feste. Das kom

halt vom soliden Leben . .

Graf. Zieh dir's Hemd aus . .

10 Dirne . (zieht das Hemd über Kopf und wirft es 
H'Sz10 [10]

Handschriften und Typoskript

reif L houts.

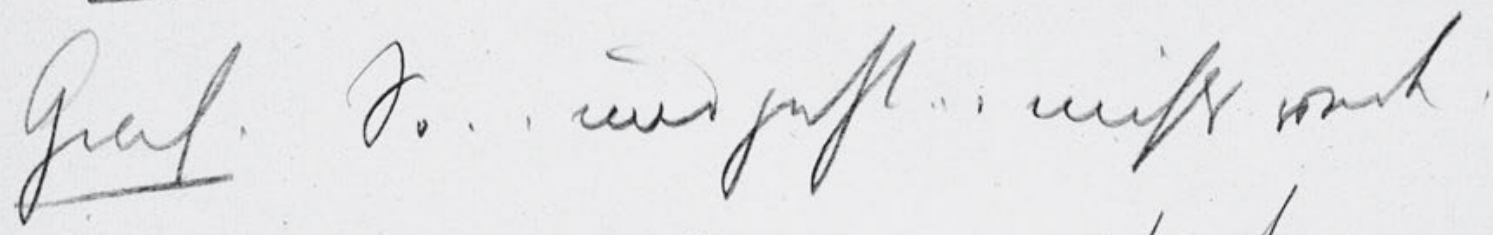

wi mifN engaho.. un ip hi no

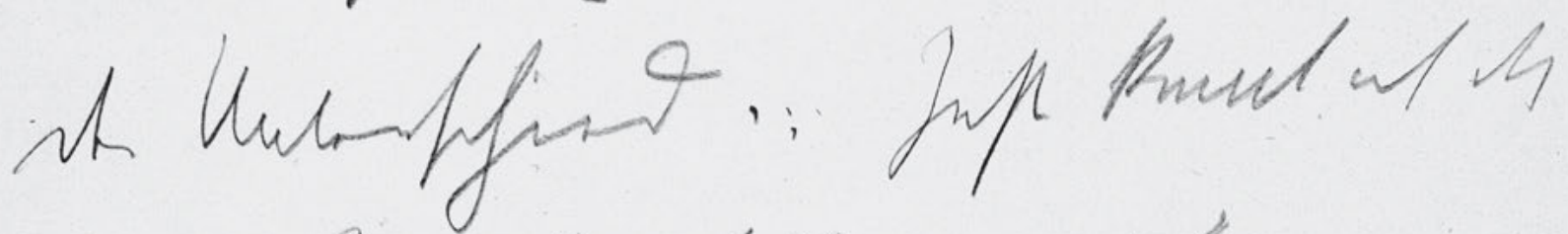

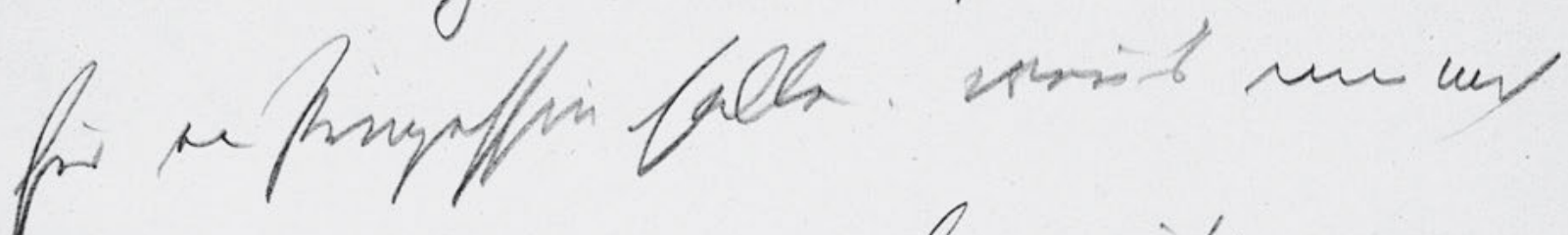

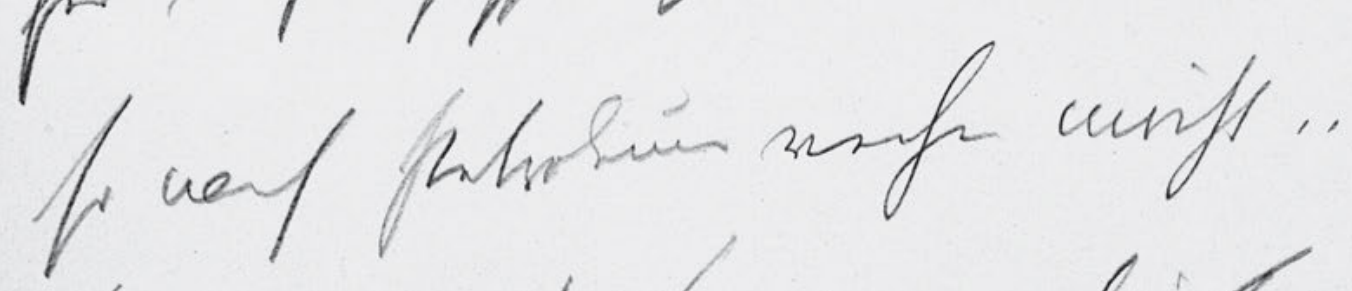

Dims. Pli Lavign, hio w

nerp Ifrall

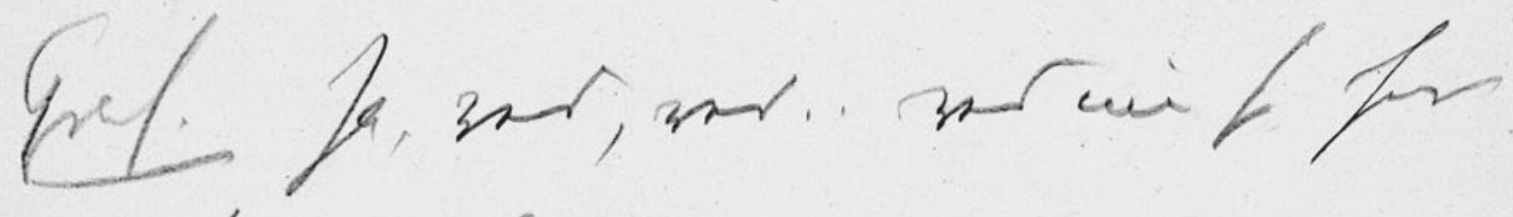

.. If un link ... wi pat.

848 
auf den Boden.)

Graf. So . . und jetzt ... nichts reden,

und nichts anhaben .. wo ist dañ noch

der Unterschied ... . Jetzt konnt ich dh

5 für ein Prinzessin halten, wen̄’s nur nich

so nach Petroleum riechen möcht . .

Dirne. Ja die Lampen, die ist ein

ewiges Gfrett . .

Graf. Ja, red, red . . red nur so fort

$10 \quad$. . ist mir lieber . . . . erzähl mir . 'und? geh . . 
H'Sz10 [11]

Handschriften und Typoskript
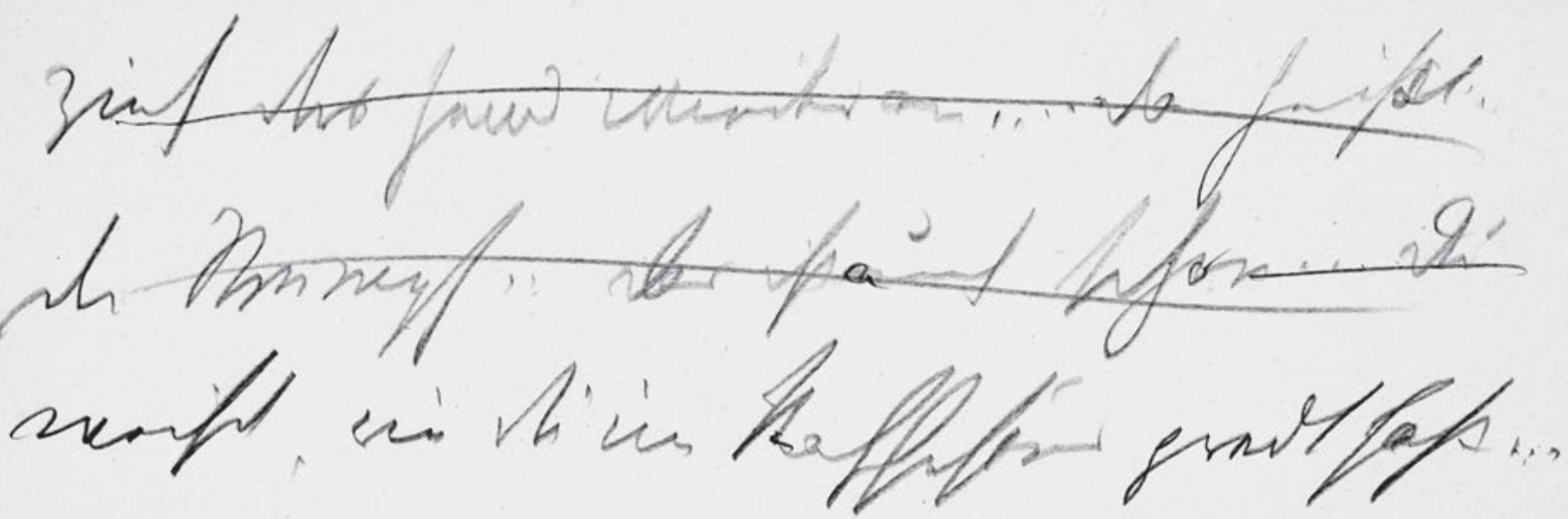

main thin. Jar wen heil.

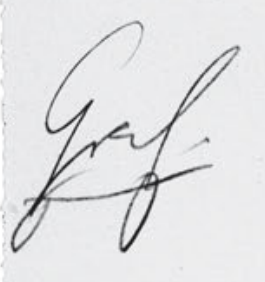

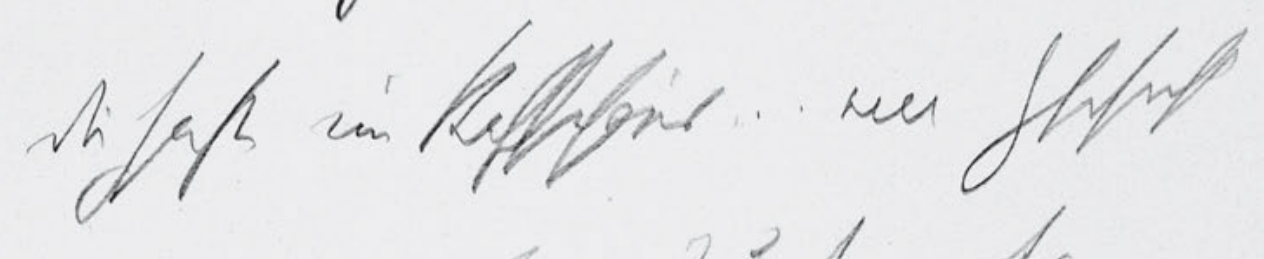

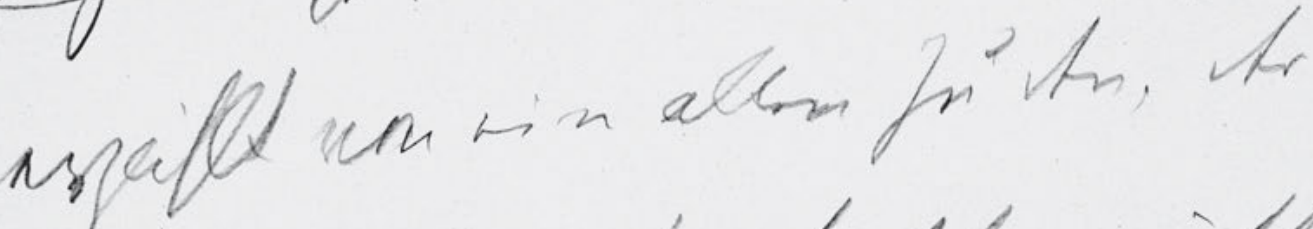

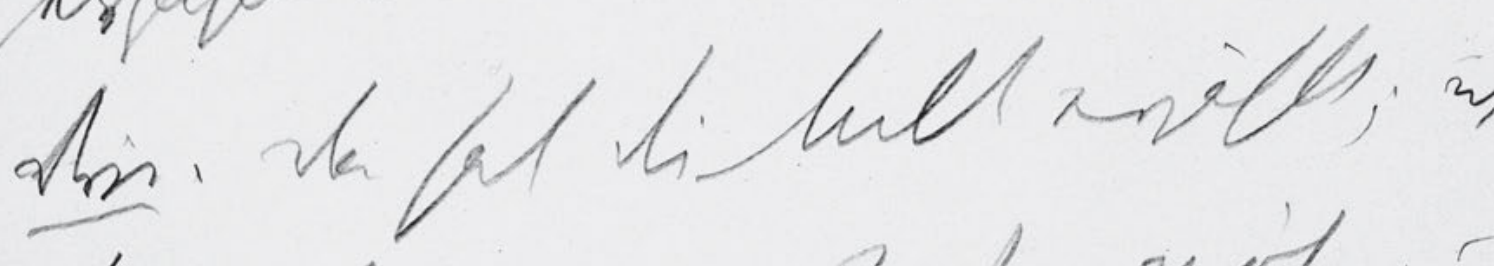
hompthain ale fich wit.. In veer thine ueir ffin. Linit.

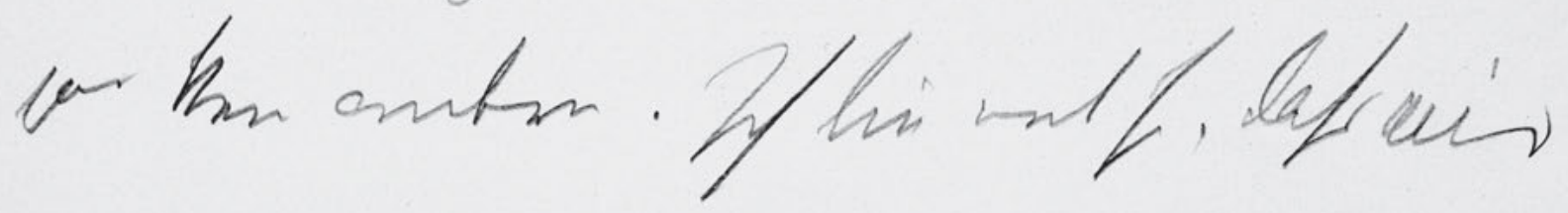

850 
zieh das Hemd wieder an ...ंdas heißt...

die Strumpf.. das ist auch schon... Du

weißt, wie du im Kaffehaus gredt hast...

wie Du. Dirne. I red ī̄er gleich.

5 Graf. Du hast im Kaffehaus . . . ein Gschicht

erzählt von ein alten Juden, der

Dirne. Das hat die Mill erzählt; ich

brauch keine alten Juden ?nöt? . . Zu

mir kō̄en nur schöne Leut. I nehm

10 gar kein andern. Ich bin net so, dass mir 
Par

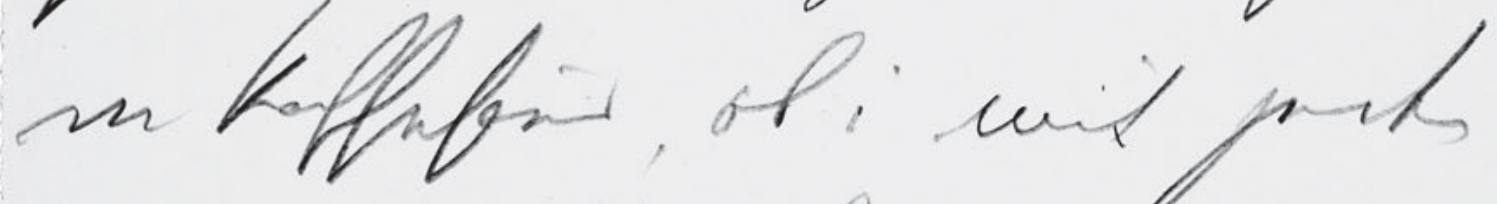
$2 \operatorname{los} 2$

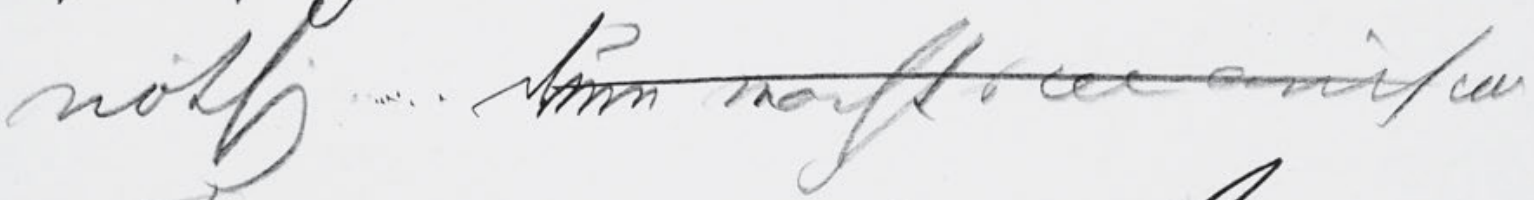

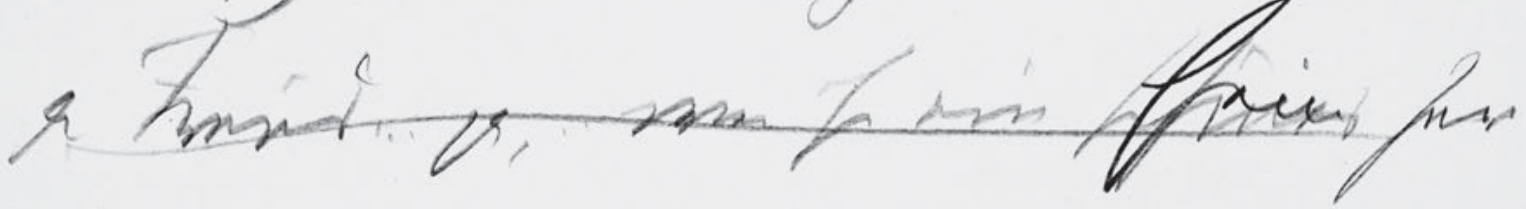

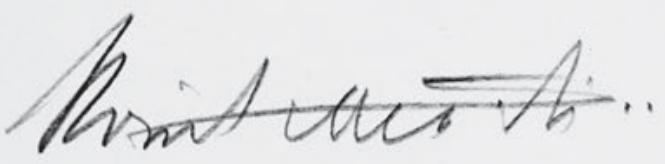

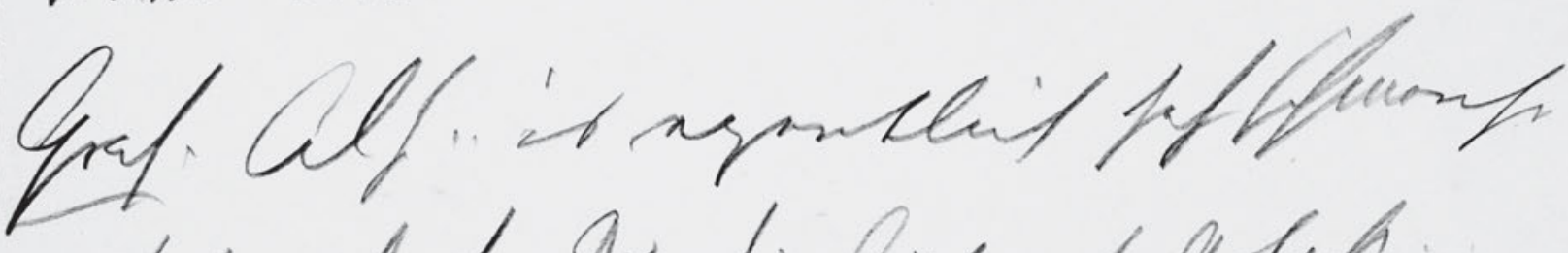

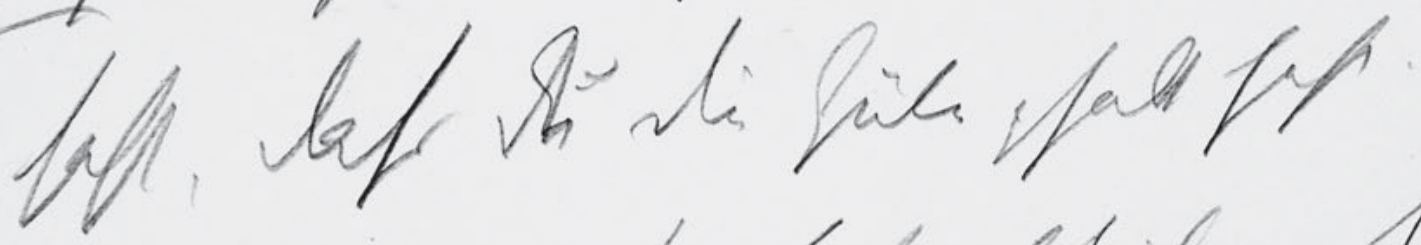

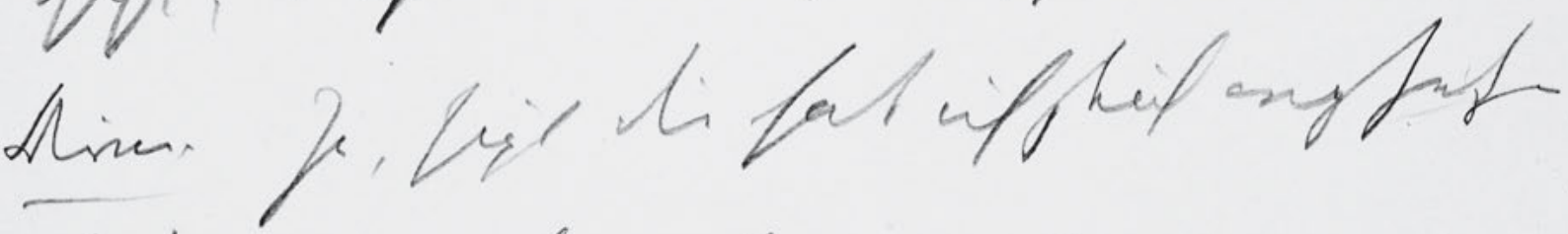

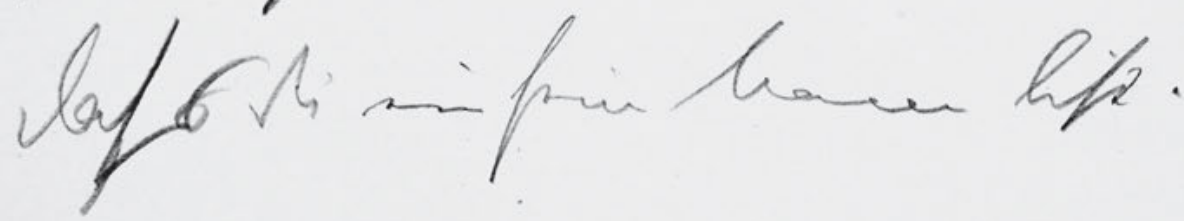


jeder recht ist .. Oh nein . . frag nur

im Kaffehaus, ob i mit jedem

zhaus geh ..... ich hab's ja auch net

nöthig ...... drum machts mir auch noc

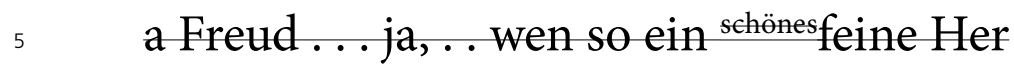

kō̄t wie du . .

Graf. Als . . is eigentlich sehr schmeiche

haft, dass du die Güte ghabt hast . .

Dirne. Ja, ?sigs? dir hab ich gleich angsehen

10 dass du ein feiner Mann bist.. 
H'Sz10 [13]

Handschriften und Typoskript

iner.

Heir y ti gale

Mine of ure

Spe

in haffor

stert

ifo gint

1 phoming thens

$$
\text { res a }
$$

nar.

Aref

Qraf

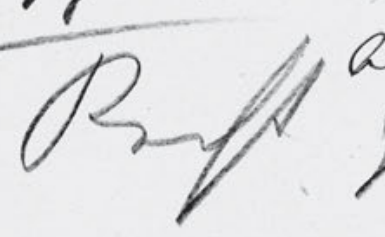

altint

that:

thine 
Graf. Wie ich dir s Geld geben hab .. was?

Dirne. Oh nein, wie du herein komenen

schwarzen

ist 'ins Kaffehaus mit dein Freund: ;

hab ichs gleich zu die ander Mädeln

5 gsagt .. Gebt's acht, das ist ein Baron.

Was, du bist ja ein Baron .. Na, und 'sigs?,

Graf Ich schau so aus, was? wie ich

als ich

Dirne. Recht ghabt hab.

Graf Ja warum glaubst du denn das eigen-

$10 \quad$ tlich?

Dirne. Aber bitt dich ... das ken̄t 'ma? ein' doch 
H'Sz10 [14]

Handschriften und Typoskript

an...

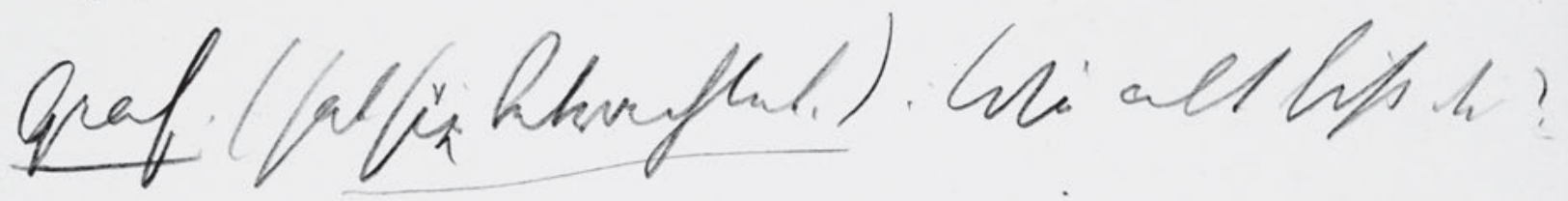

Alim, ha saff!

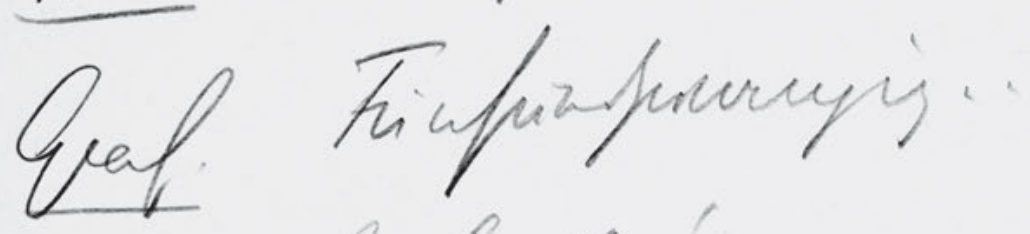

Qnim

Um Gefrem hiv

Qreat Ati... Haw bof th

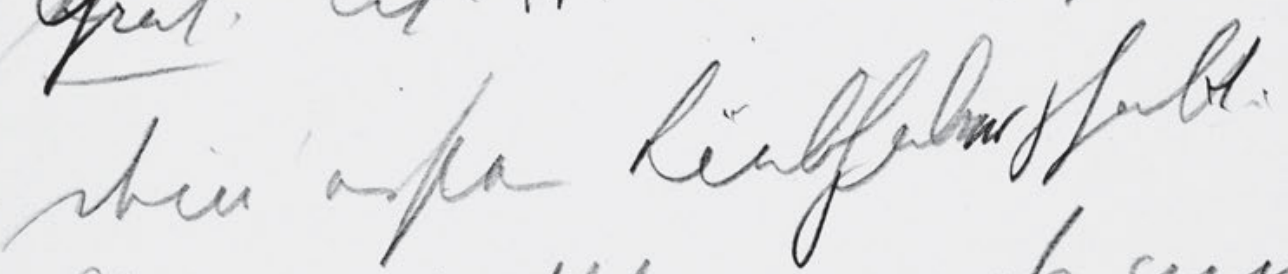

Mine hiffalos a do cur

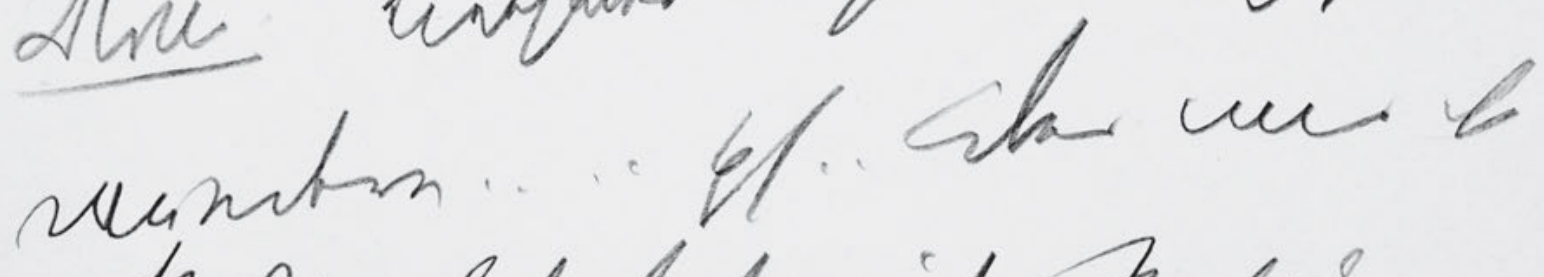
kall.. Snt latrwitu bals as

856 
an ...

Graf. (hat sie betrachtet.). Wie alt bist du?

Dirne. Na rath! .

Graf. Fünfundzwanzig . .

$5 \quad$ Dirne. Ja freili!..

Graf. Na? .

Dirne. Achtzehn bin ich . . Aber mit

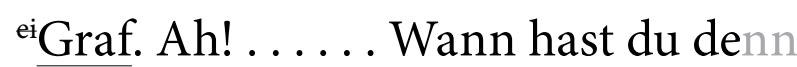

dein' ersten Liebhaber ghabt . .

10 Dirne. Liebhaber... ja da möchst d

wundern .... ? pf? . A Aber mir ist

kalt . . Geh, lass mich ins Bett legen 
H'Sz10 [15]

Handschriften und Typoskript

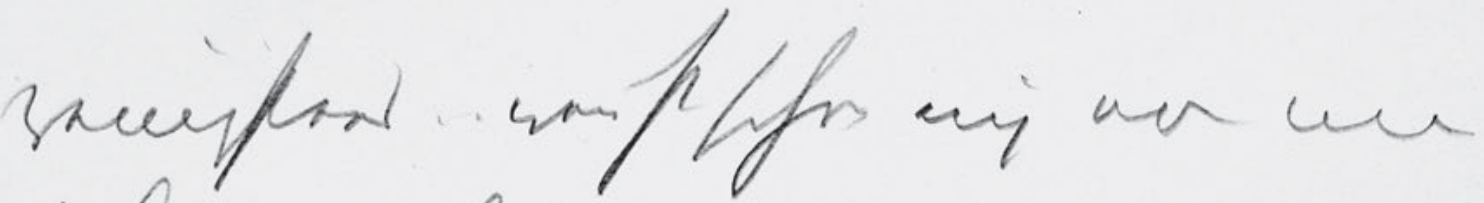
cabm usilek.

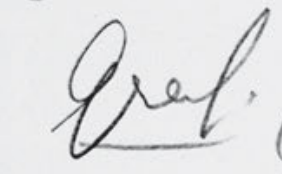

Arin

(pifian'

if. Sultar

shleforinlori,

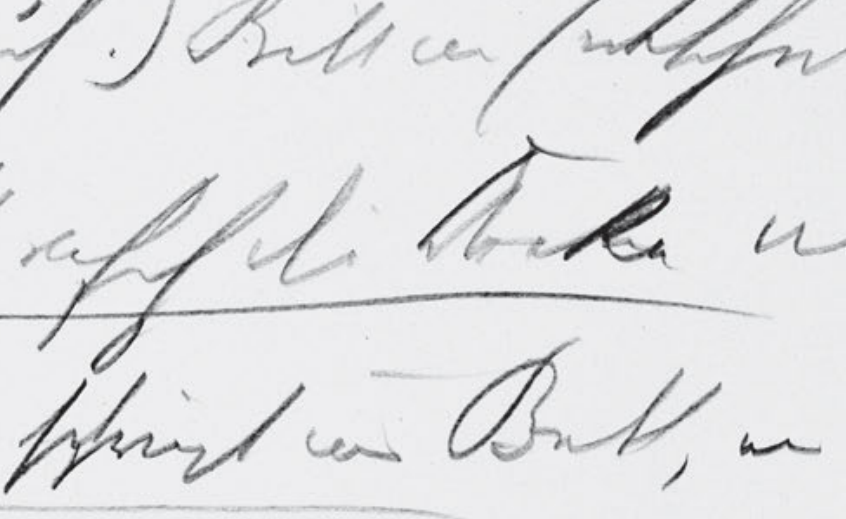

quaf.

bu

(taph aif

4n

fart 1 lisur

la ning 
wenigstens .. wen̄st schon nix von mir

haben willst.

Graf. (steht auf.) Bitt um Entschuldg

.Dirne (wirft rasch die Decke vom

$5 \quad$ Bett herunter; $s^{\text {eth }}$ pringt ins Bett, un

deckt sich zu.)

Graf. (setzt sich auf den Divan und zund

sich über der Petroleumlampe ein Cigaret

an).. Wovon haben wir nur grad gredt? .

10 Ja . . ich möcht mich wundern .. wan

du deinen ersten Liebhaber

4 punktförmige Verschmutzung zwischen Dirne und (wirft. 
H'Sz10 [16]

Handschriften und Typoskript

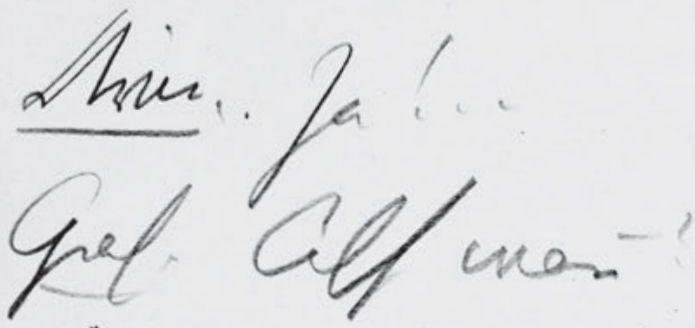

thin whe ifgrer in fathi fof

Geaf Mer hiph high thum?

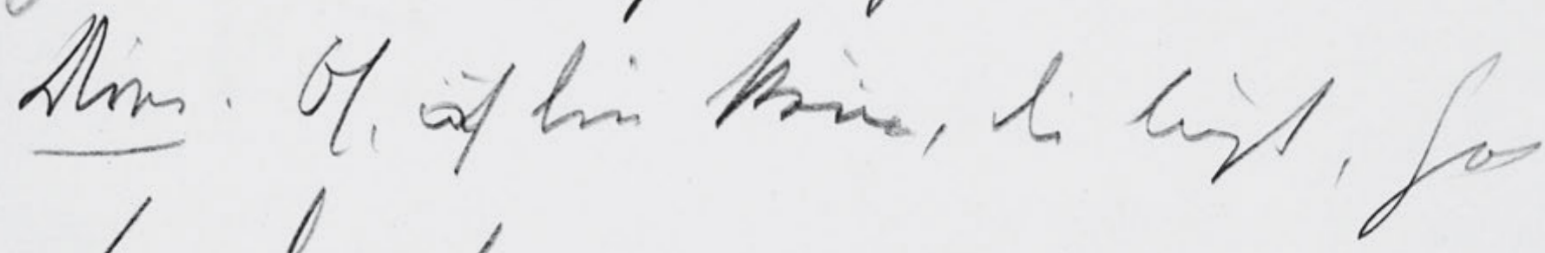

fa buht.

Araf

Le ahar. nie borff lav

rlf ha

thine

zer fof

Quft ha alf.

860 
Dirne. . Ja! . .

Graf. Also wan̄? .

Dirne. Das ist grad ein halb's Jah.

Graf. Was lügst den̄ so dumm? . .

5 Dirne. Oh, ${ }^{\text {ich }}$ bin keine, die lügt, Got

sei Dank. .

Graf. Ja aber .. wie langst lang

gehst den schon in das Kaffehaus . . da in

das..

10 Dirne. Zwei Jahr.

Graf. Na also . . 
H'Sz10 [17]

Handschriften und Typoskript

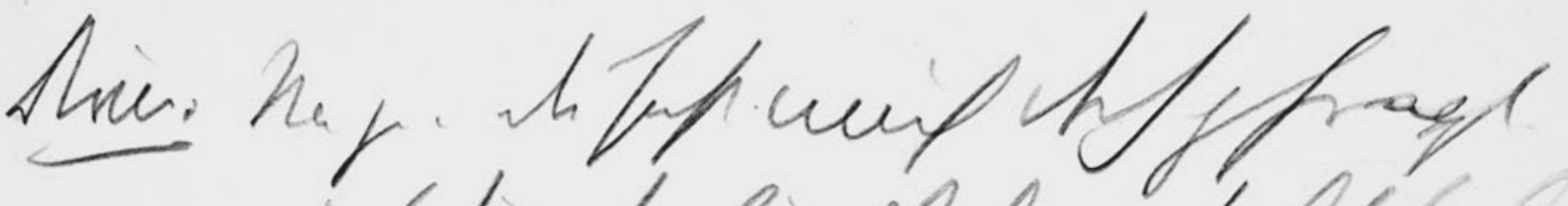

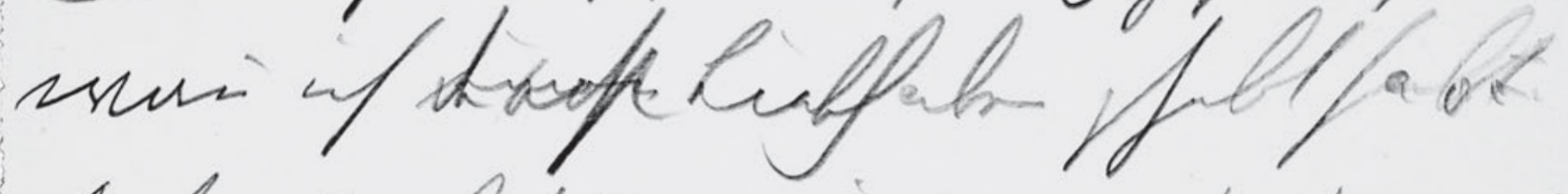
saf ha hifs monbriff at fiuigh

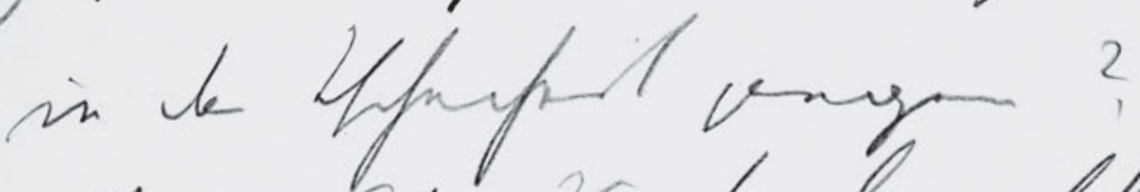

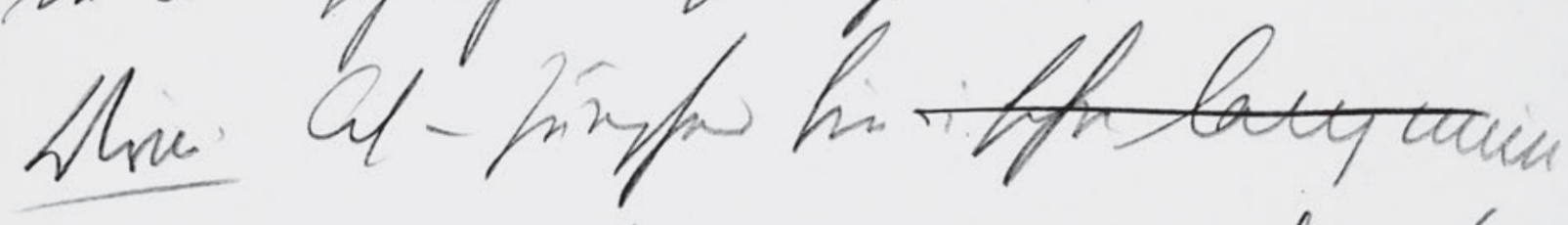

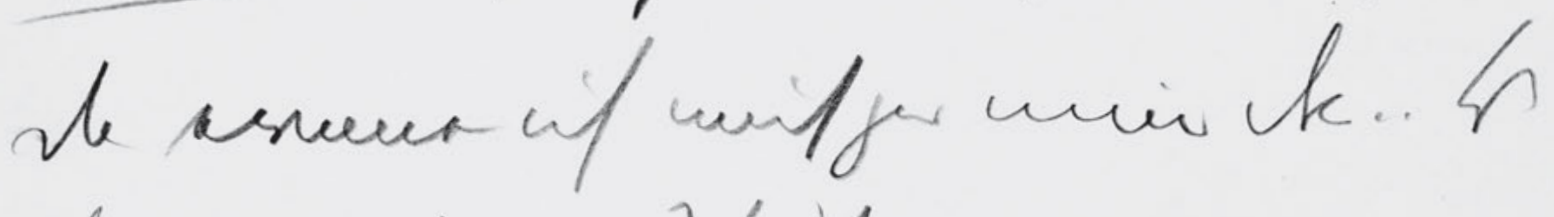
his if ung is 1 ofit ganys...

Gal Cefo mer mon li frafh, m

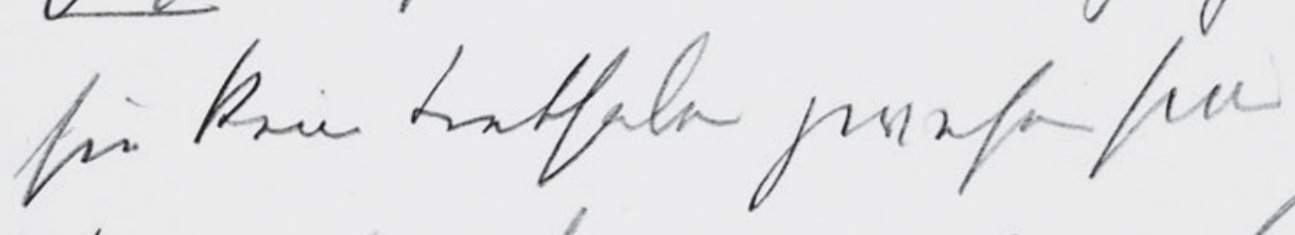
the he, hacum felt... Hón ver plentfe in laus fige, lef

862 
Dirne. Na ja , du hast mich doch gfragt,

wañ ich einen den ersten Liebhaber ghabt habt.

Graf. Na bist du vielleicht als Jungfer

in das Tschecherl gangen?

$5 \quad$ Dirne. Ah - Jungfer bin i schon lang nime

da erinner ich mich gar nime dra.. Da

bin ich noch in $\mathrm{d}$ Schul gangen ....

Graf. Also was warn die früher, wē̄

sie keine Liebhaber gwesen sind

10 Dirne. Na, Männer halt ..... Liebhaber.

${ }^{z u ?}{ }^{?}$ ? was glaubst wie lang ist her, dass

5 punktförmige Verschmutzung zwischen i und schon. 
H'Sz10 [18]

Handschriften und Typoskript

if we tulfok wh falk

hel

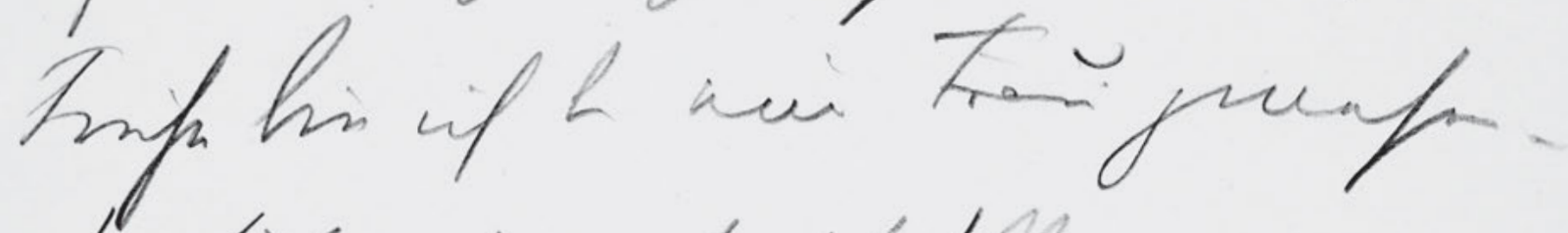

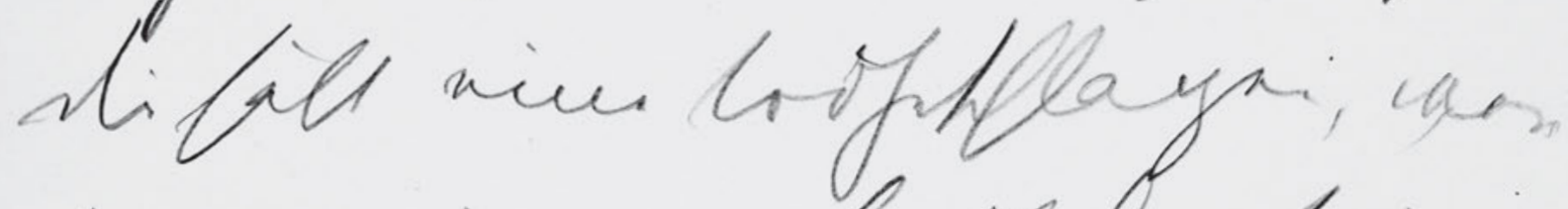

firsur nien me Linfferbigfold noriforr bists, we fat knew

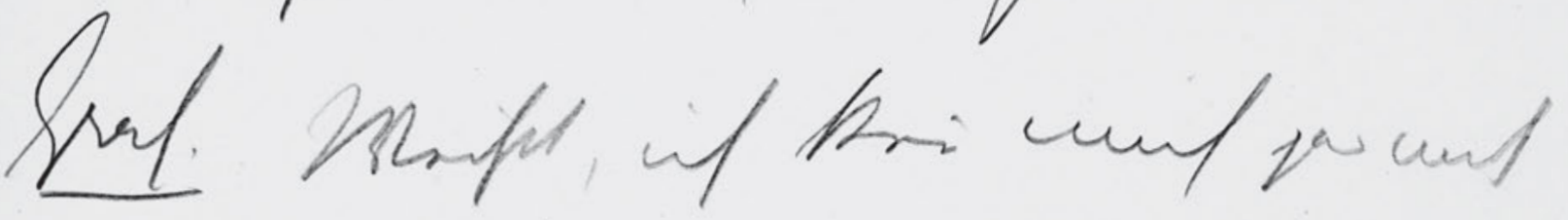

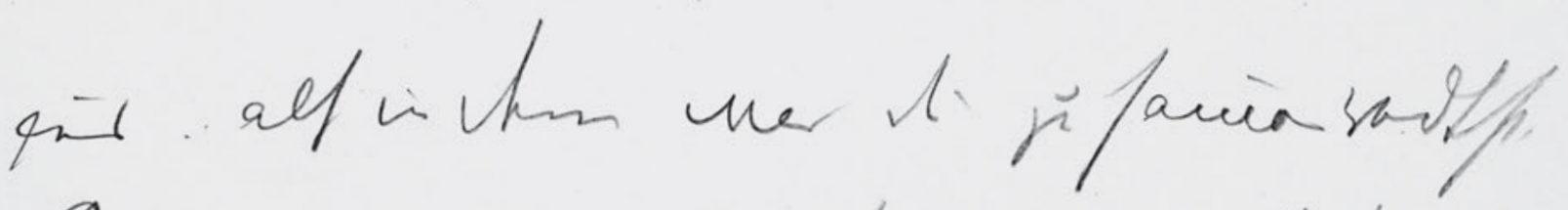
Min... Ne nuerts its mpollht us

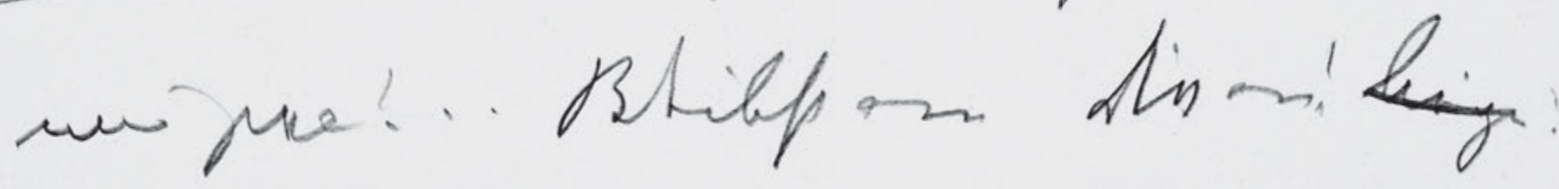

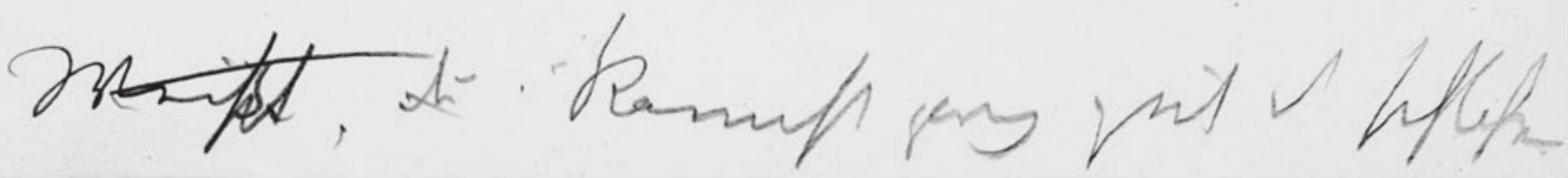

864 
ich ein Liebhaber habe halten haben durfen

Frühe bin ich bei eine Frau gwesen -

die hätt eine todtgeschlagen, wen̄

sie ein eine ein Liebhaber ghabt[?]

${ }_{5}$ hätt. . Na ja, die Herren is ${ }^{[?]}$ es auch

meistens lieber, man hat keinen

Graf. Weißt, ich ken̄ mich gar nich

aus . . also in dem was du zusā̄en redtst.

Dirn. . . Na was ist deñ eigentlich mi

10 uns zwa? .. Bleibst am Divan? liegen?

Weißt, du . - Kannst ganz gut d schlafen 
H'Sz10 [19]

Handschriften und Typoskript

amefinlef, wh of bif a ij

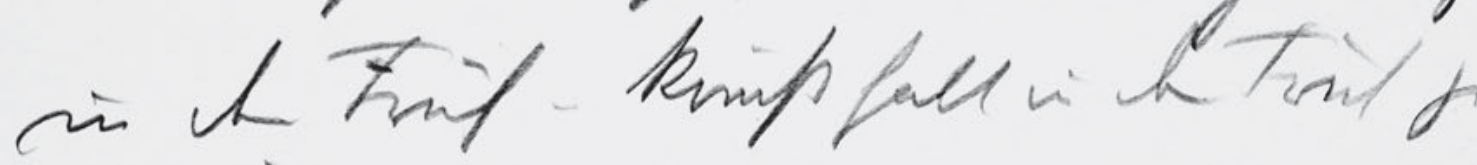
quef.

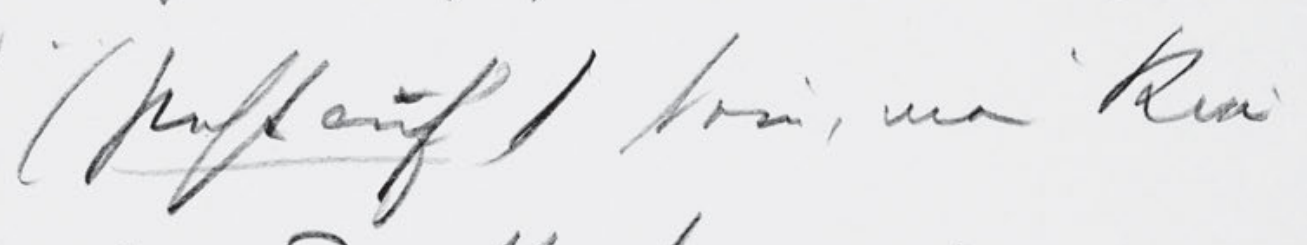
af w mas pefte... an

the pipiun

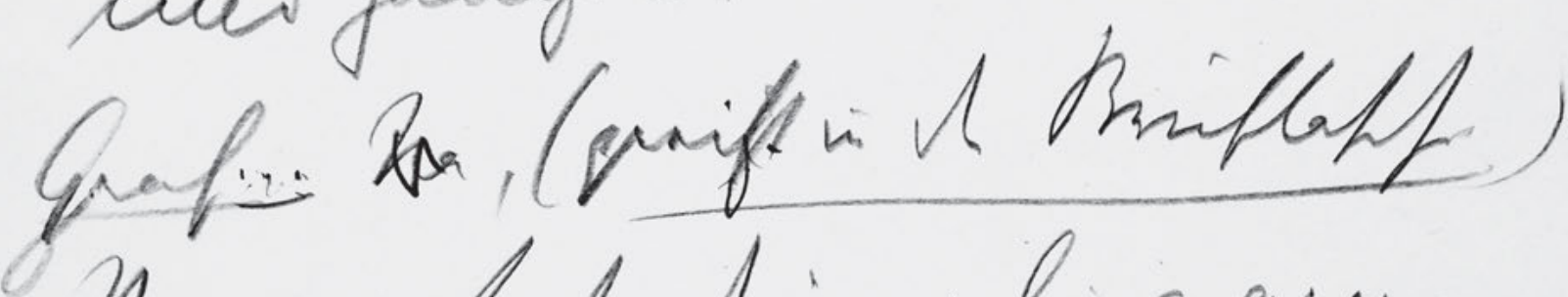
Mim. Lapp Sin, i hi a aver leart, ah

$$
\text { pritont }
$$
fabtuglest, munf
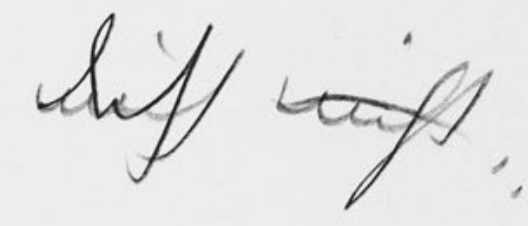
xer mei granth

866 
wennst willst, weck ich dich auf

in der Früh - kōmst halt in der Früh zu

mir..

Graf.. (steht auf) Nein, mein Kind,

also .. ich werd jetzt gehn ... und.

${ }_{5} \quad$ Dirne. Ja, zu was bist deñ du mit

mir gangen ..

Graf. .. Na, (greift in die Brieftasche)

Dirne. Laß drin, i bin a arms

Madl, aber i pfeif auf den

10 Guldenzettel, wennst ${ }^{\text {mieh }}$ dich nicht...

vor mir graust 
H'Sz10 [20]

Handschriften und Typoskript

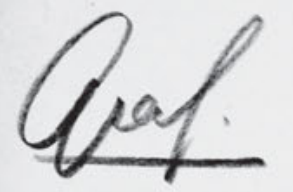

inf

Anim

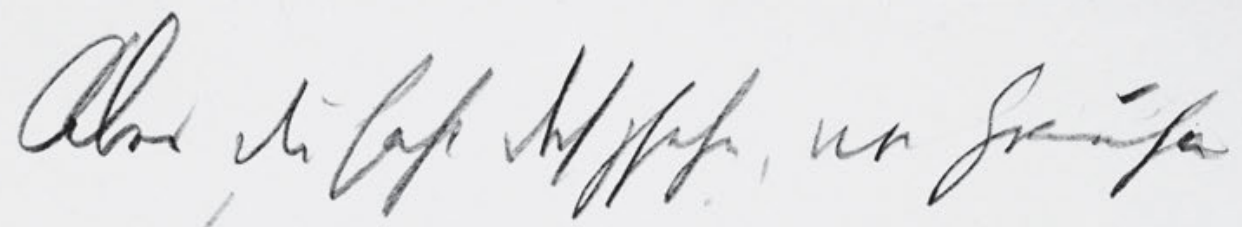

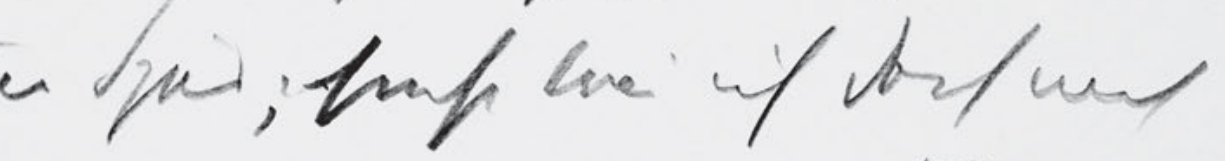

int li nat fonlyay.

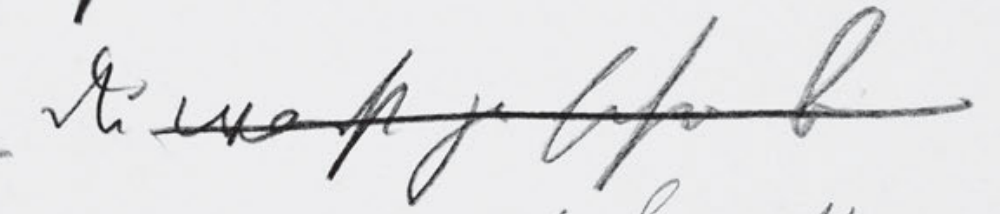

he

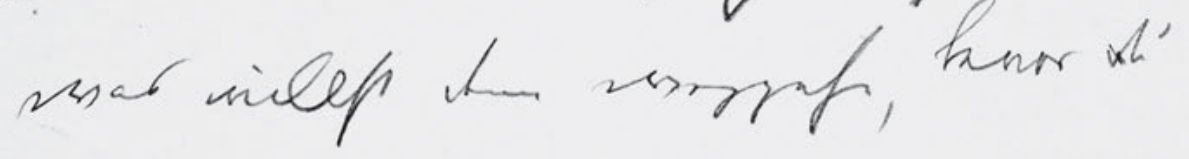

868 
Graf. Aber du hast doch gsehn, von Grausen ist keine Spur; sonst wär ich doch nich vom Tschecherl mit dir nach Haus gangen. Dirne. Du warst ja schon b Na ${ }_{5} \quad$ was willst denn weggehn, bevor ${ }^{[?]} \mathrm{du}$ 
N

Handschriften und Typoskript

the fol vever af th hir,

dilin ciptals.

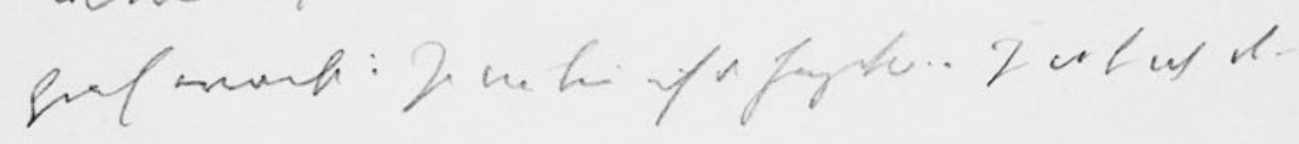

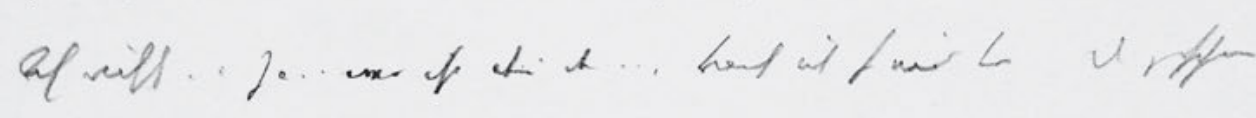

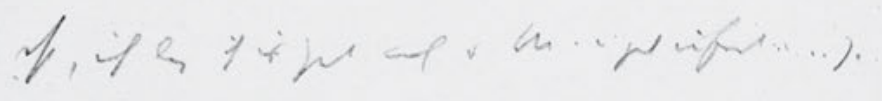

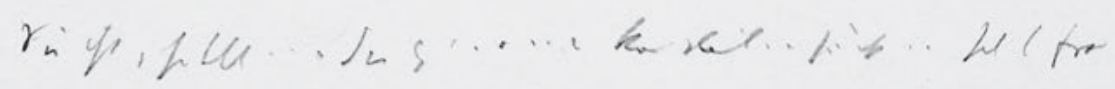

Yoth we wist froter a.

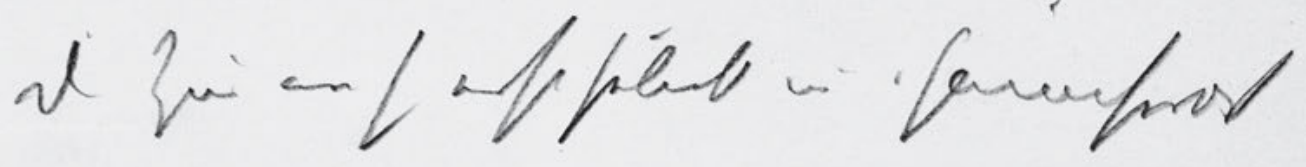

lifelg. in the remat.

Top befithif..

thery or tab ite fe

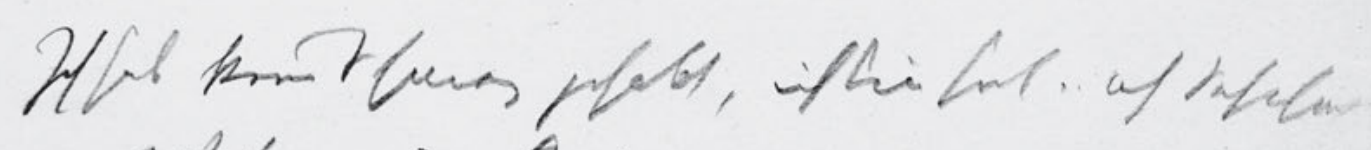

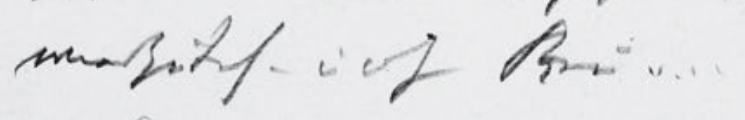

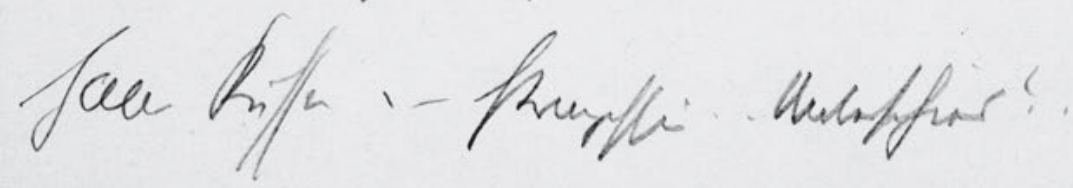

870 
Der Graf schläft auf dem 'Divan?,

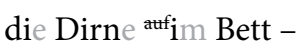

Graf erwacht: Ja ? wie? bin ich d 'hergeko? . Ja ? $\mathrm{w}^{?}$ b ich d -

Ah richtg. . . Ja ....wer ist deñ ?die? .., ?Darf? 'ich? ?so? ?einer? [?] d 'gesehen?

ist, ich leg ih ${ }^{\text {es }}$ ' Gel auf $d{ }^{?} \mathrm{~N} a$ ? . u geh einfach . . . . . Ja ... .

Sie ist, sollt ... ? $\mathrm{Sie}^{?}$ ? $\mathrm{g}$ ? . . . . . . kom gleich . . sie ist . . Ich b froh

Erzähl 'mir? "wie" ich "'hegkom? bin .

die ?Hur? an s erst Geliebt in [?] Garnisonort

die selbst in ein kl Slovak. .

Fast das hübscheste. .

Was ist das Leben? Es ist [???]

Ich hab keine Schmerz gehabt, ich bin 'sich? . . 'ah? Sehnsuch

wiedzukeh - u ohne Reu .....

?Hand? 'Küsse? - - Prinzessin . . Unterschied? . 
HSz10 345

Handschriften und Typoskript

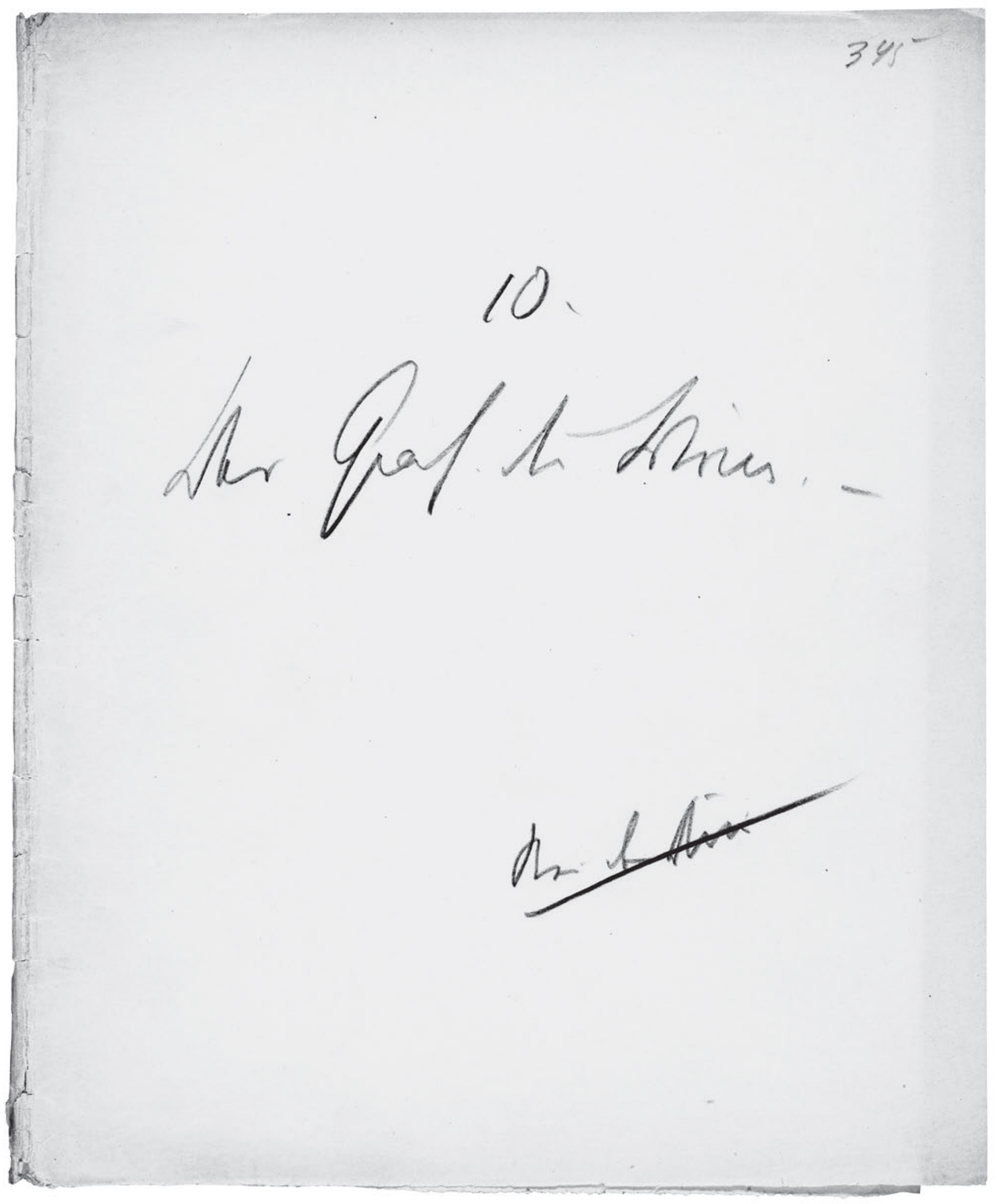

872 
10.

Der Graf. Die Dirne. -

Bei der Dirne 


\section{6}

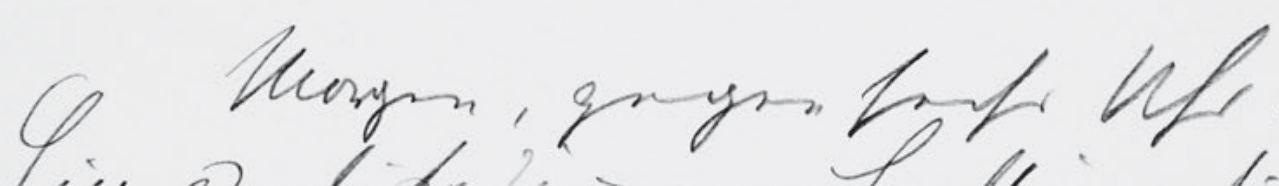

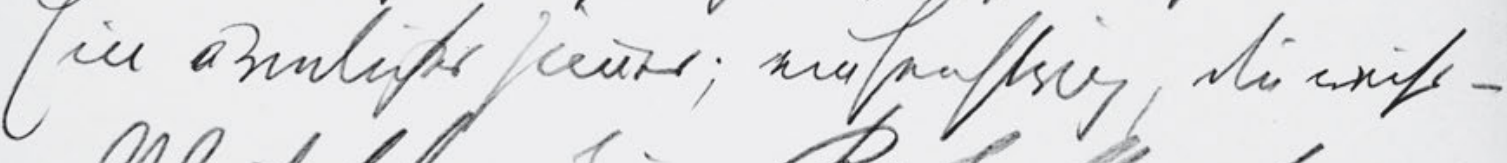
salblit Afuentios Anchlon feer

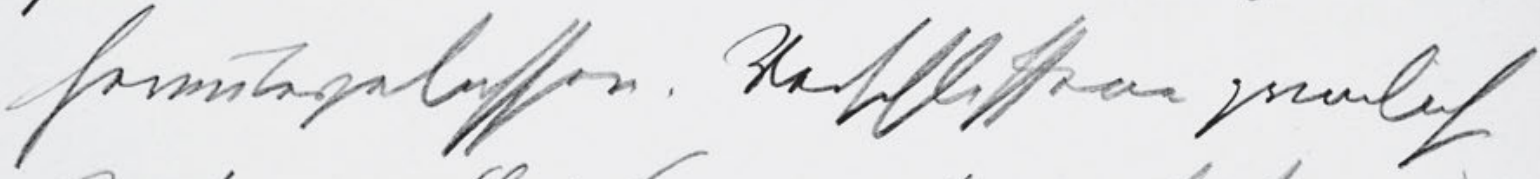

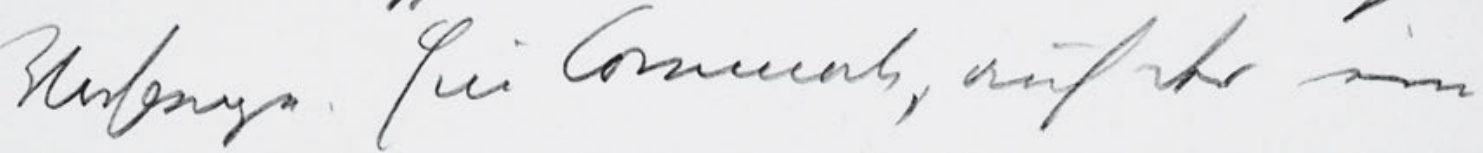

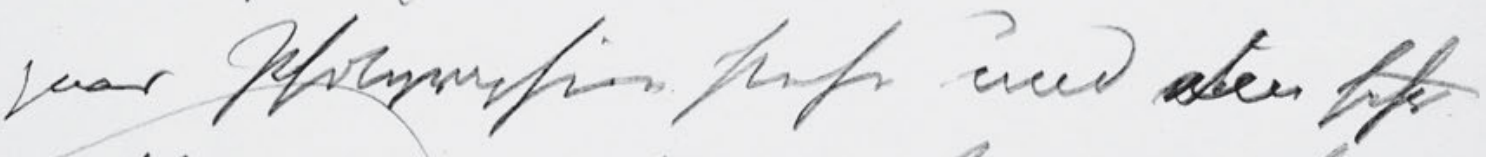

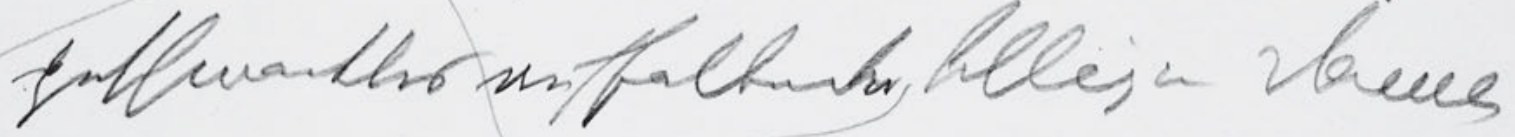
fothigh. juter th livgl hllivani

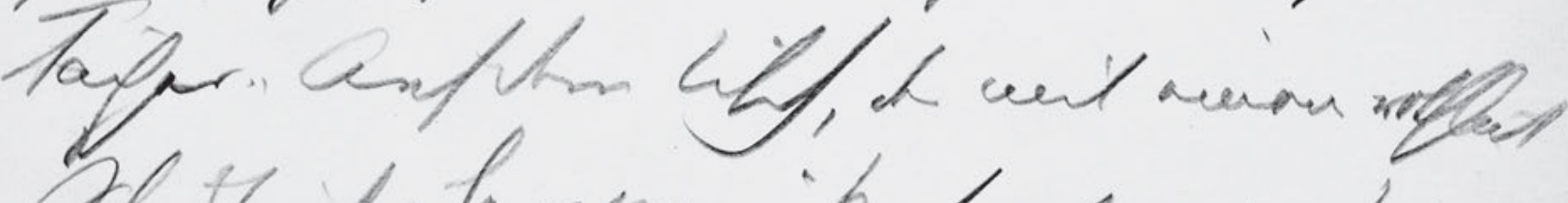

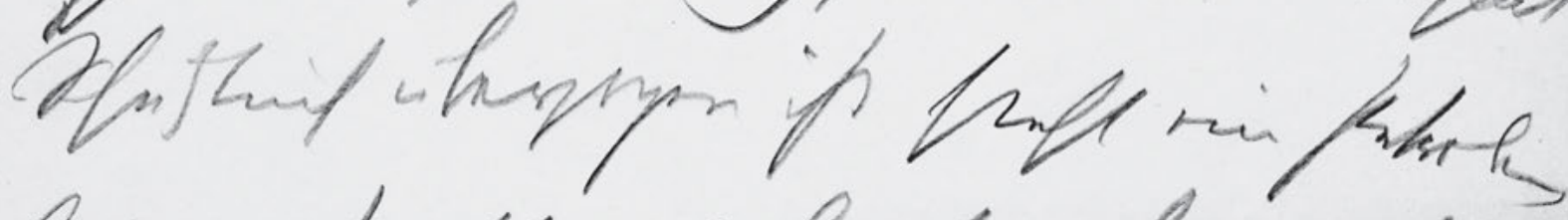

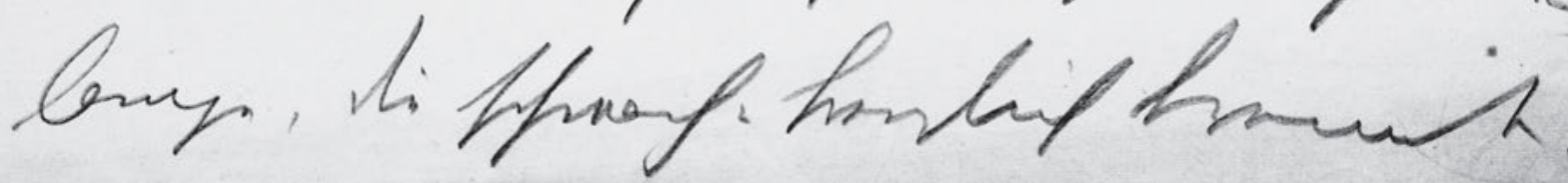




\section{6}

Morgen, gegen sechs Uhr.

Ein ärmliches Zim̄er; einfenstrig, die weissgelblich schmutzigen Rouletten sind

5 heruntergelassen. Verschlissene grunliche

Vorhange. Eine Commode, auf der ein paar Photographien stehn und ${ }^{\text {de }}$ ein sehr geschmacklos auffallender billiger Damen hut liegt. Hinter dem Spiegel billige japanis

10 Fächer .. Auf dem Tisch, der mit einem rothlich

Schutztuch überzogen ist steht eine Petroleum-

lampe, die schwach u brenzlich brennt; 
HSz10 347

Handschriften und Typoskript

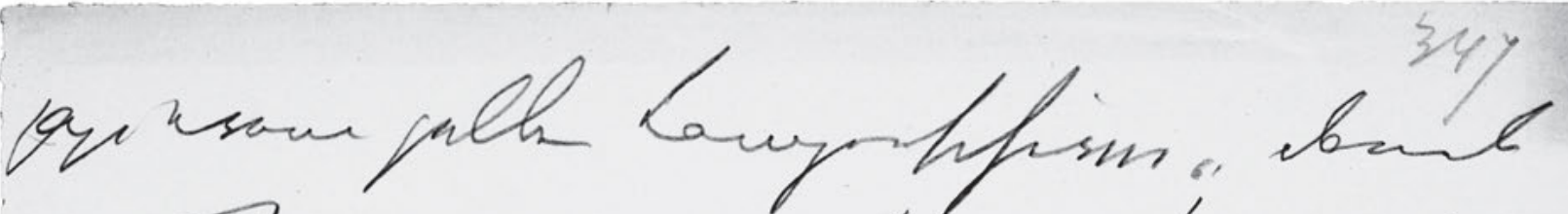

ne Bus,

Sit tin Butn

Bhum hov

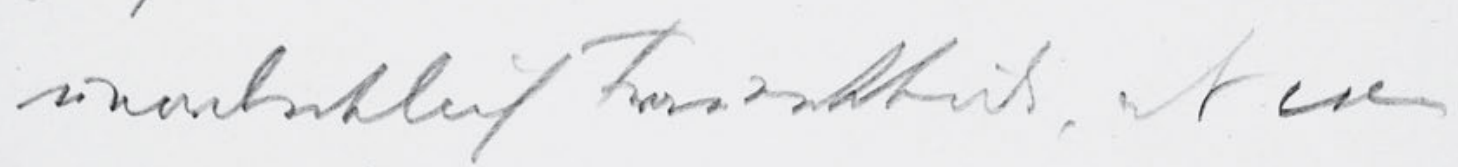
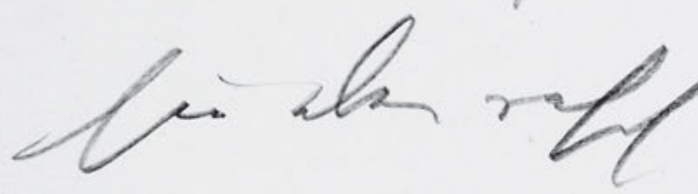

agampors.

vuiss

ins

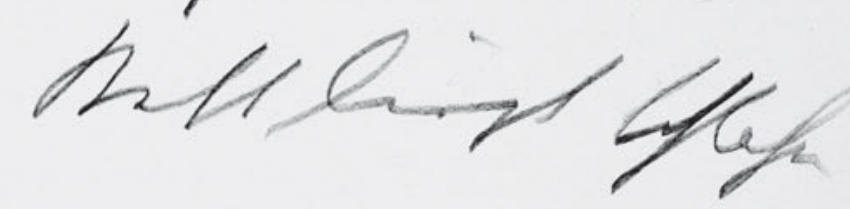

wi Sima; fer atfeund nefis.-

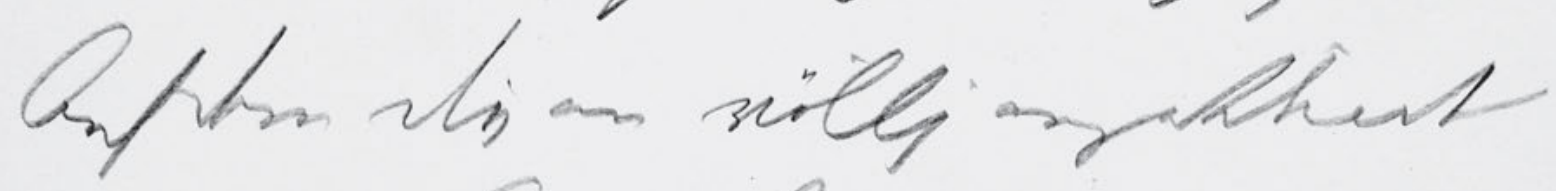

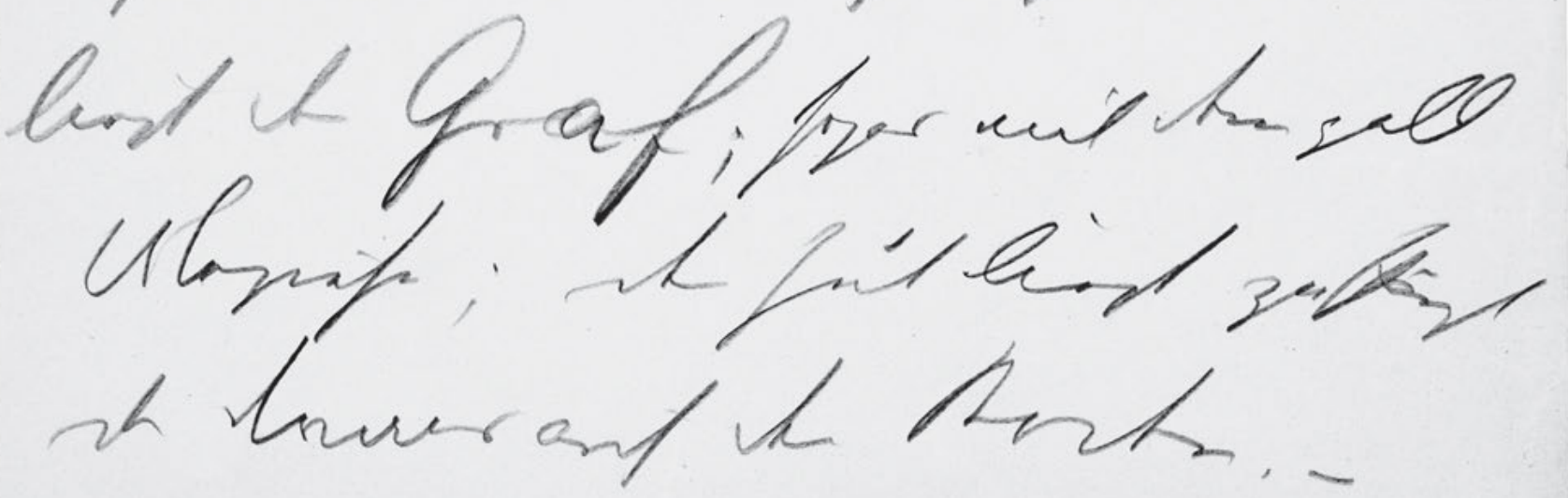

876 
papierener gelber Lampenschirm; daneb ein Krug, in dem ein Rest vo Bier ist, daneben ein halbgeleertes Glas. :-

$5 \quad$ Auf dem Boden neben dem Bett lieg unordentlich Frauenkleider, als wenn sie eben rasch abgeworfen worden wären. Im Bett liegt schlafen die Dirne; sie athmet ruhig. 10 Auf dem Divan völlig angekleidet liegt der Graf; sogar mit dem gelb Überziehe; der Hut liegt zu Häupt des Divans auf dem Boden. - 
HSz10 348

Handschriften und Typoskript

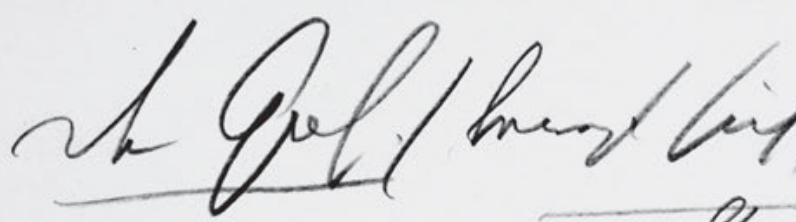

348

spbtifipl

, molltarye

Disibin if theen.

ale hivit mifl

Truia

zемersma...

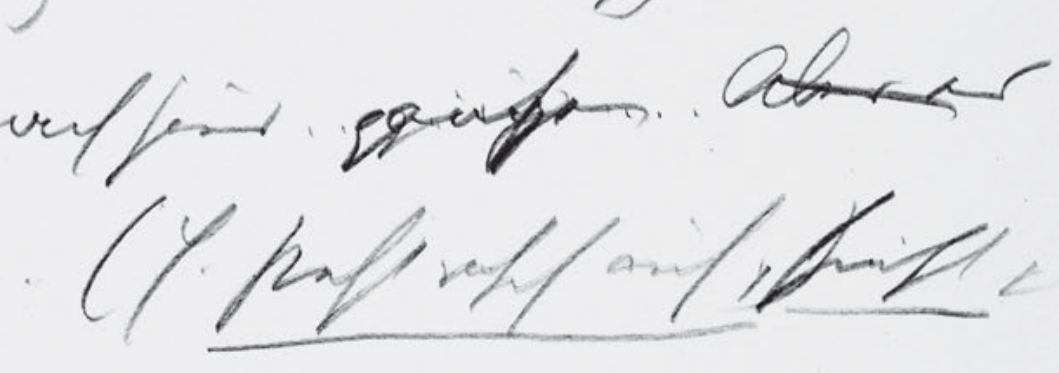

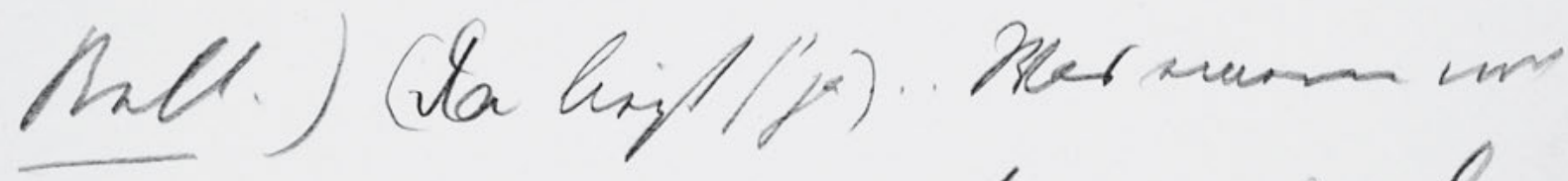

aller is min Gle vifin Lam...

hath

. 


\section{8}

Der Graf.(bewegt sich, reibt die Augen,

bleibt sitzen

erhebt sich rasch, schaut um sich . .)

Ja wie bin ich denn .. Ah so .... . Also ?doch?-

${ }_{5} \quad$ Also bin ich richtig mit dem Mensch Frauen

zimmer ... nach haus . . ${ }^{\text {zuihr }_{\text {ing }}}$ gangen .. Aber es

ist wie wenn . . (Er steht rasch auf ${ }^{\dagger}$, sieht zum

Bett.) (Da liegt s' ja') . . Was einem noch

alles in mein Alter passiren kann .... . Ja aber

10 wie bin ich dē̄ her komen .. Ich hab kein

Idee . . Haben s mich da herauf getragen.

Nein ... ich habs ja gesehn ... ? b?ekom ?das? 
HSz10 349

Handschriften und Typoskript

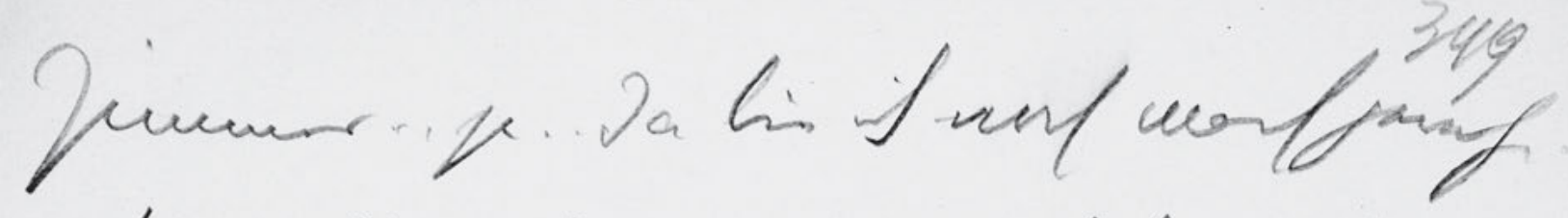

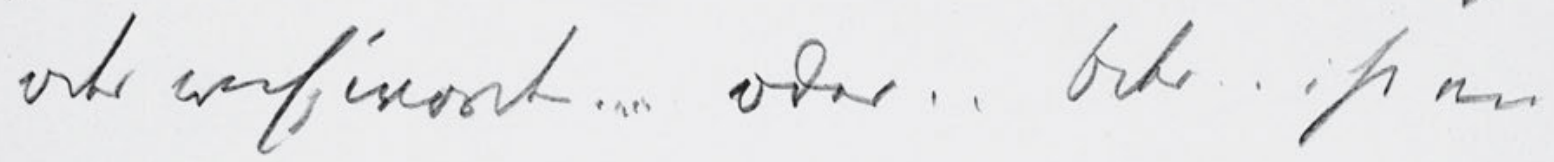

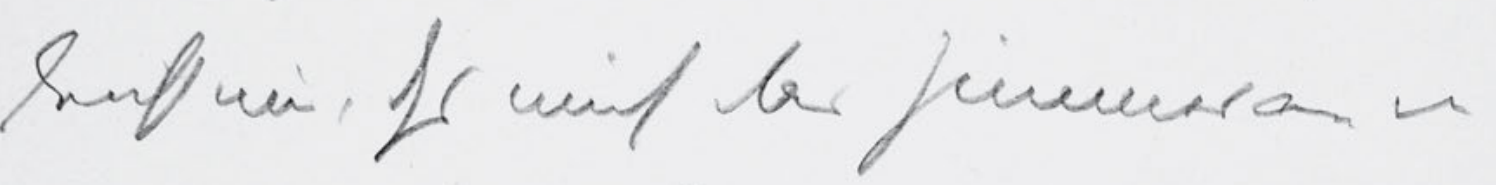

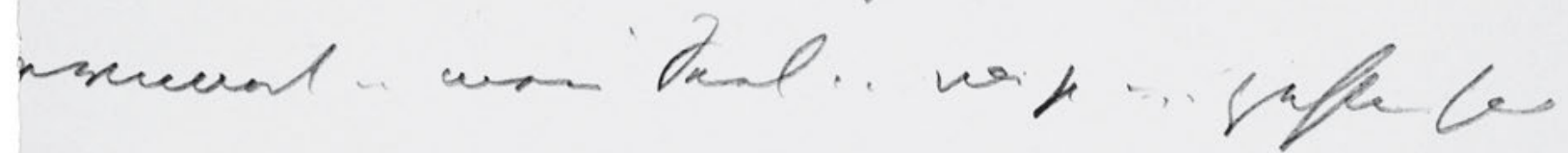

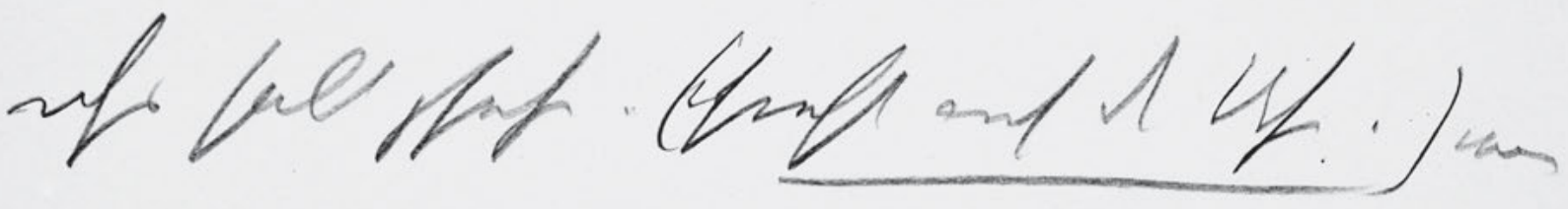

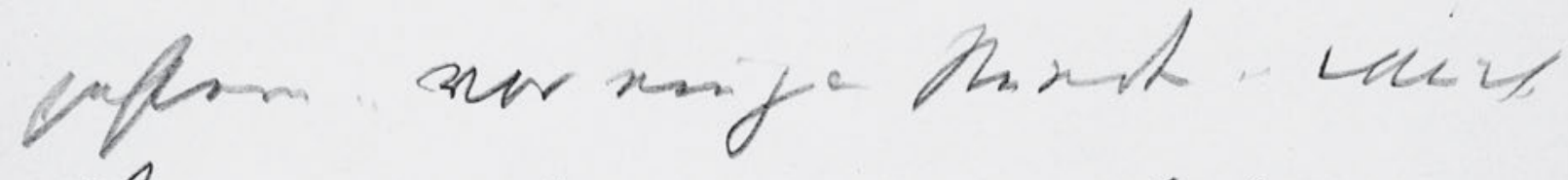
Ahr.. if fatio puritt... laf we

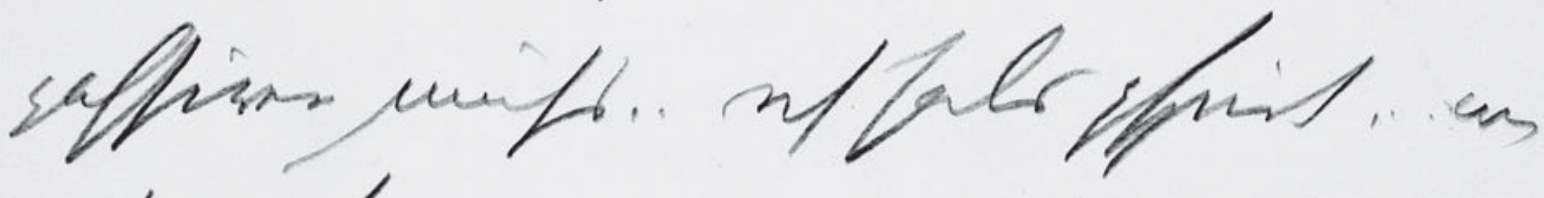

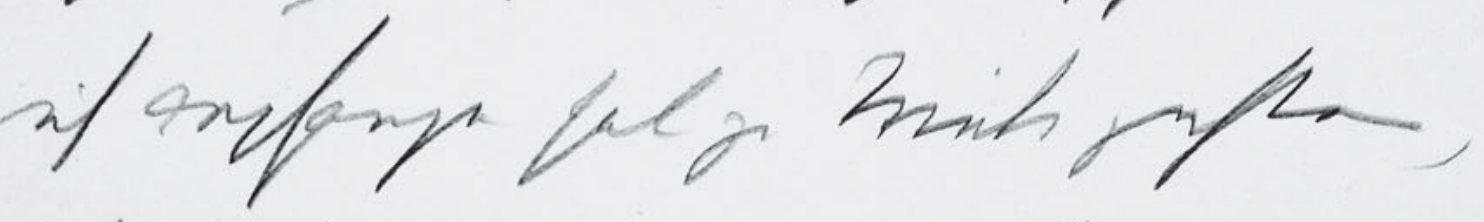

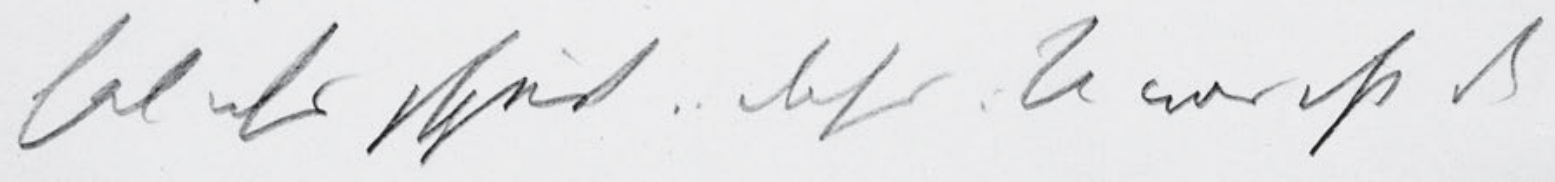

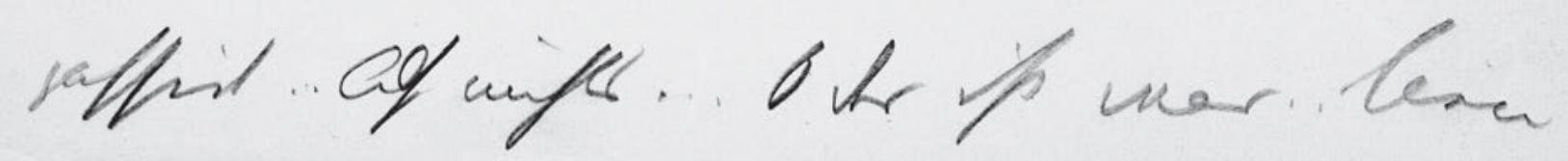

880 
349

Zimmer . . ja . . Da bin ich noch wach gewesen .. oder wachg'worden . . . . oder . . Oder . . ist vie leicht nur, dss mich das Zimmer an $\mathrm{w}$

$5 \quad$ erinnert .. mein Seel .. na ja .... gestern hab ichs halt gsehn .. ( ${ }^{[?]}$ sieht auf die Uhr.) was gestern .. vor ein paa Stunden .. wie ?ich?, Aber .. ich hab's gwußt ....... dass was passiren muss .. ich habs gspürt ... wie 10 ich angfangen hab zu trink gestern, hab ichs gspürt . . dass: $\mathrm{N}$ was ist $\mathrm{d}$ passirt... Also nichts ... Oder ist was .. Meine 
HSz10 350

Handschriften und Typoskript

358

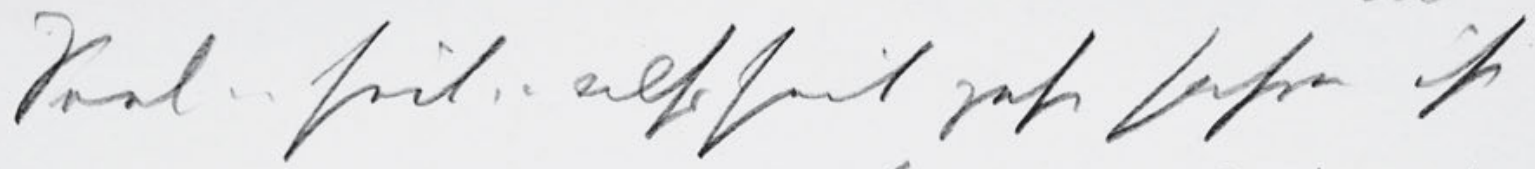
neiv to ner wiff nothinis, bef of wit

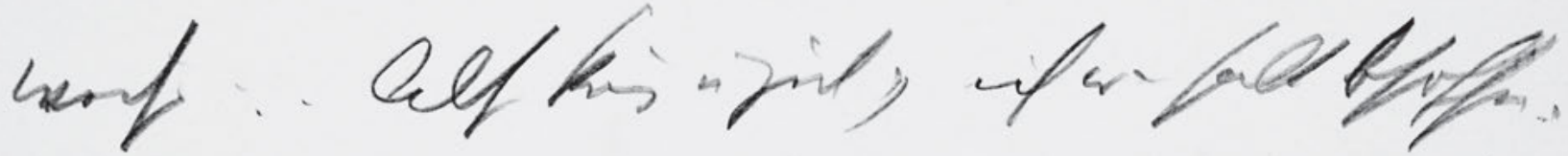

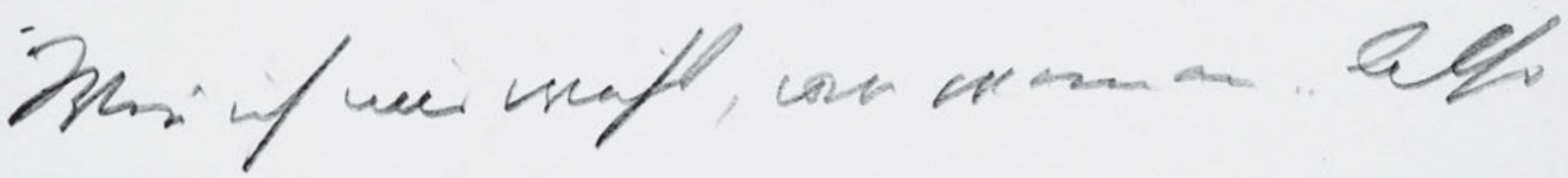

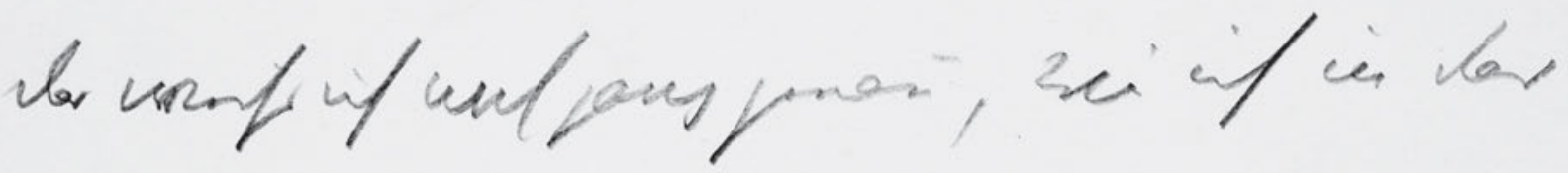

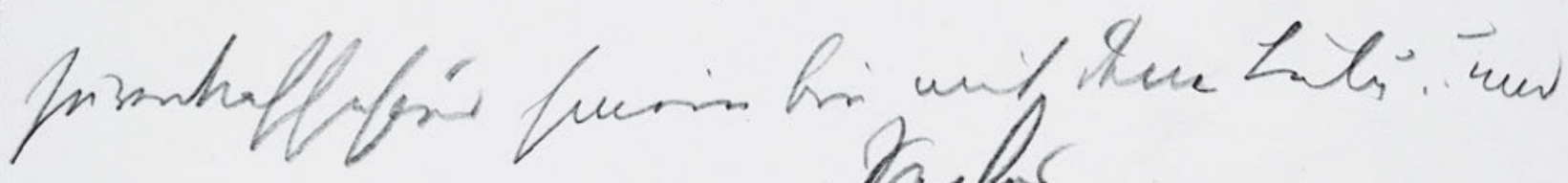

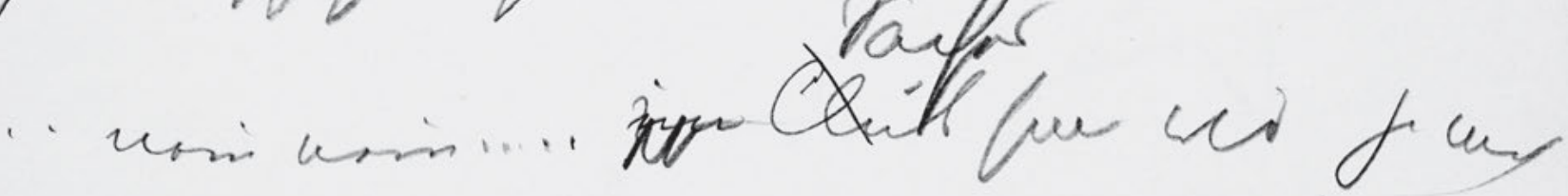

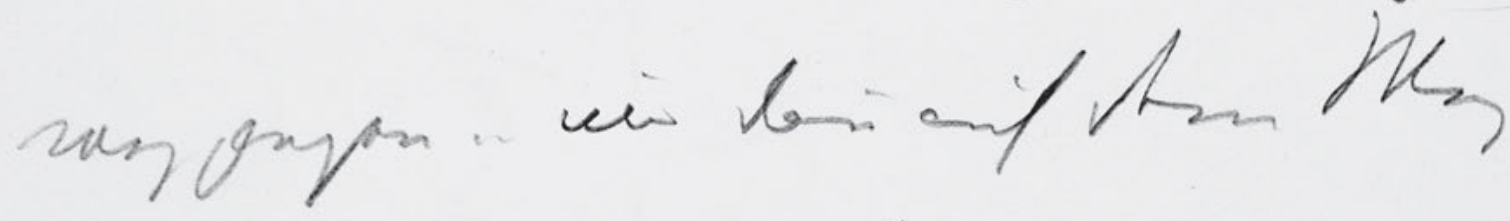

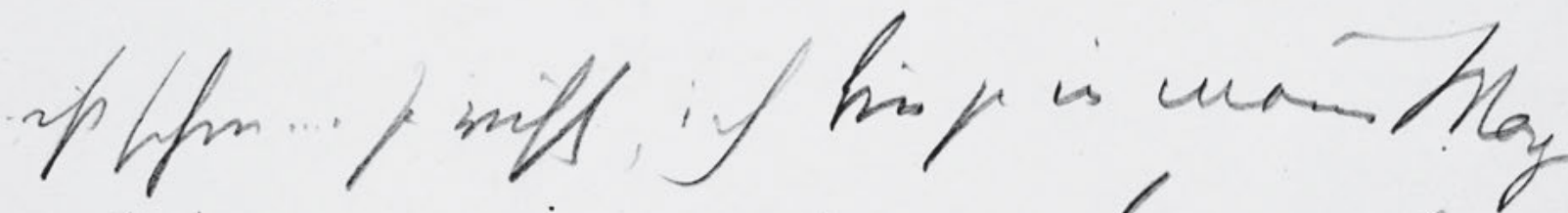

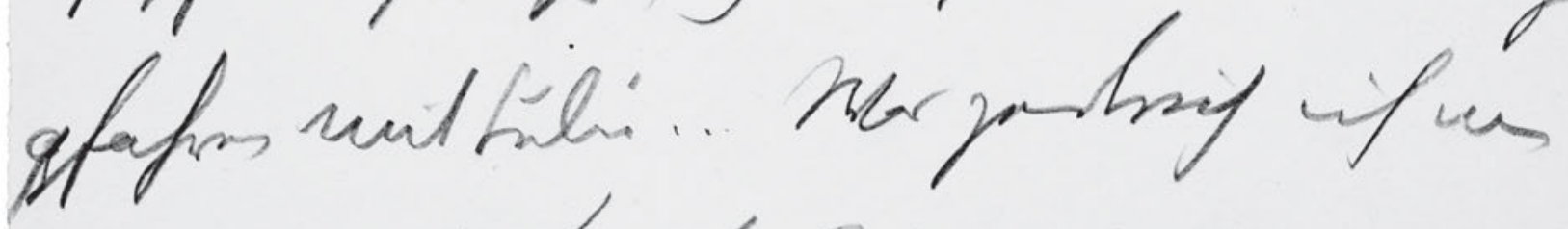

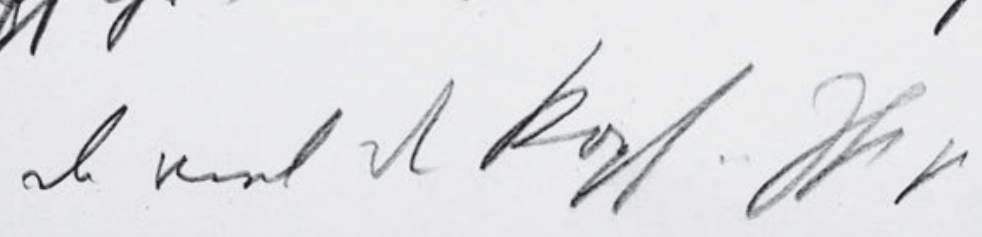
yat." Refon in

882 
Seel . . seit . . also seit zehn Jahren ist mir so was nicht vorkomen, dass ich nih weiss ... Also kurz u gut, ich war halt bsoffen . .

$5 \quad$ Weñ ich nur wüßt, von wann an .. Also das weiss ich noch ganz genau, wie ich in das Hurenkaffehaus hinein bin mit dem Lulu .. und Sacher . nein nein .... . ?im? vo Club sind wir ja noch weg gangen .. und dā̄ auf dem Weg .ist schon ... . Ja richtg, ich bin ja in meinem Wagen gfahren mit Lulu ... Was zerbrich ich mir da viel den Kopf . . Ist ja egal . . . Schau’n wir 


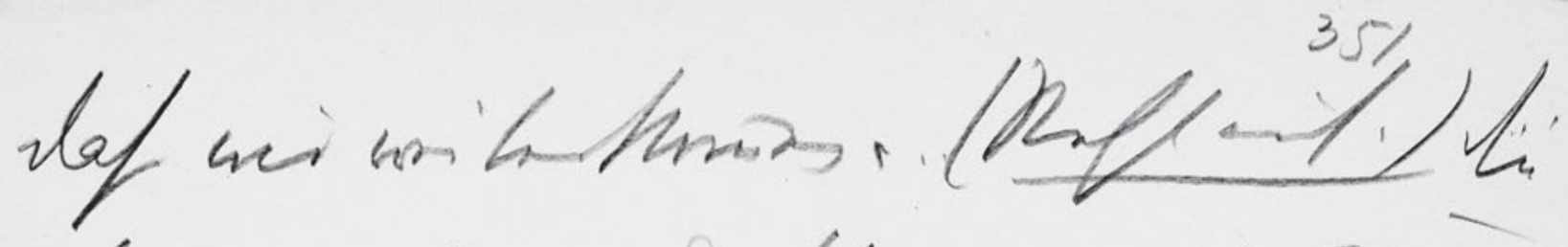

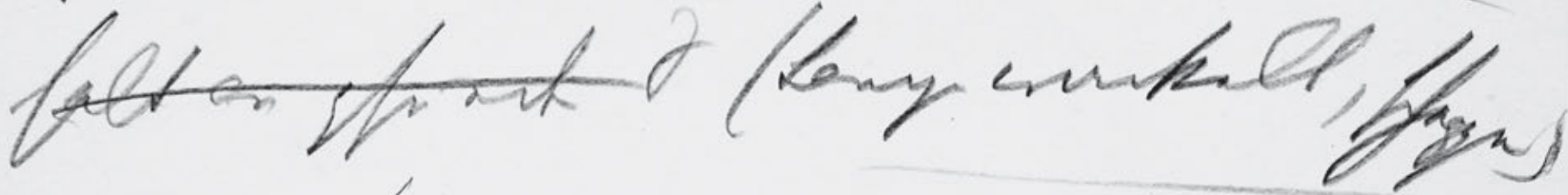

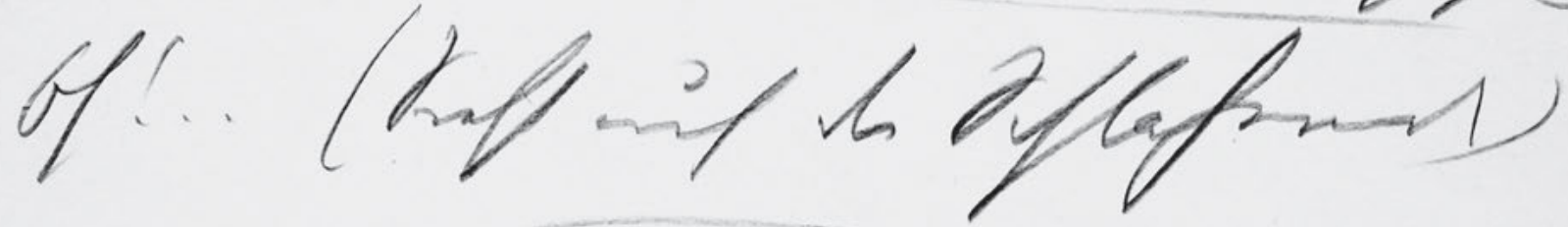

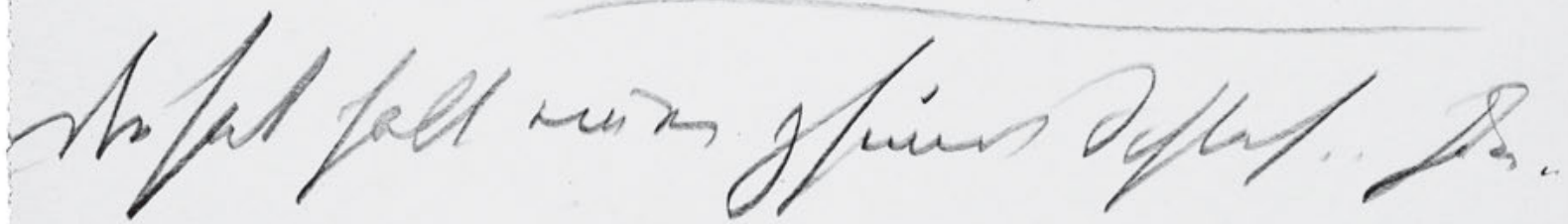
Hefth fanther

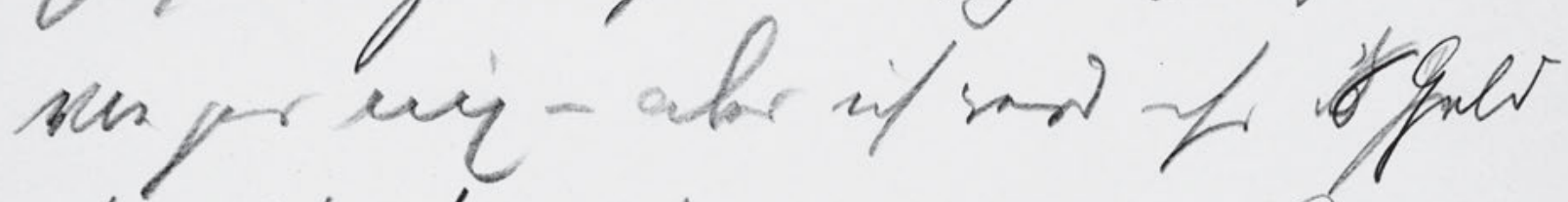

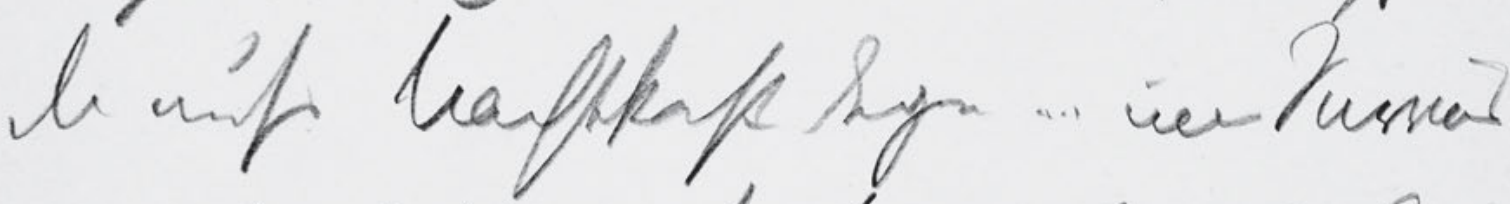

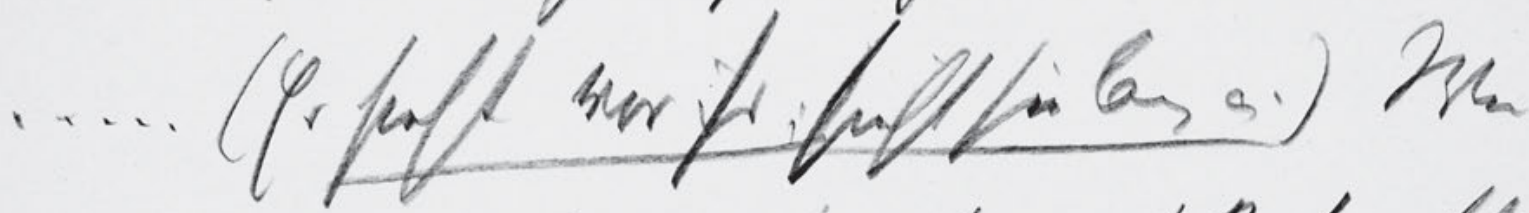

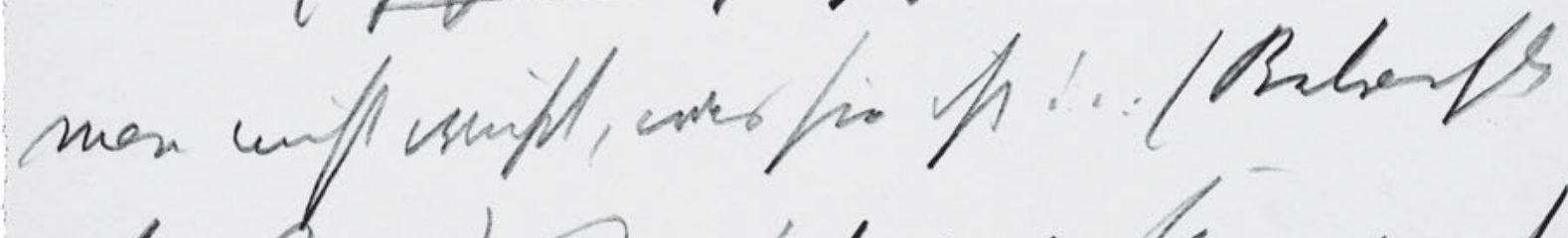
sinces Natsinat tannt Li 
351

dass wir weiterkomen ...(Steht auf.) Die

halt an gsunden $S$ (Lampe wackelt, scheppert)

Oh! . (Sieht auf die Schlafend)

5 Die hat halt einen gsund Schlaf.. Ja ?de? .

Schlaf der Gerechten ... Ich weiss zwa

von gar nix - aber ich werd ihr ${ }^{\text {'s }}$ s Geld

da aufs Nachtkast legen .... und Servus . .

.... (Er steht vor ihr; sieht sie lang an.) Wen

${ }_{10}$ man nicht wüßt, was sie ist! . . (Betrachtet

sie lang) Ich hab viel kannt, die 
HSz10 352

Handschriften und Typoskript

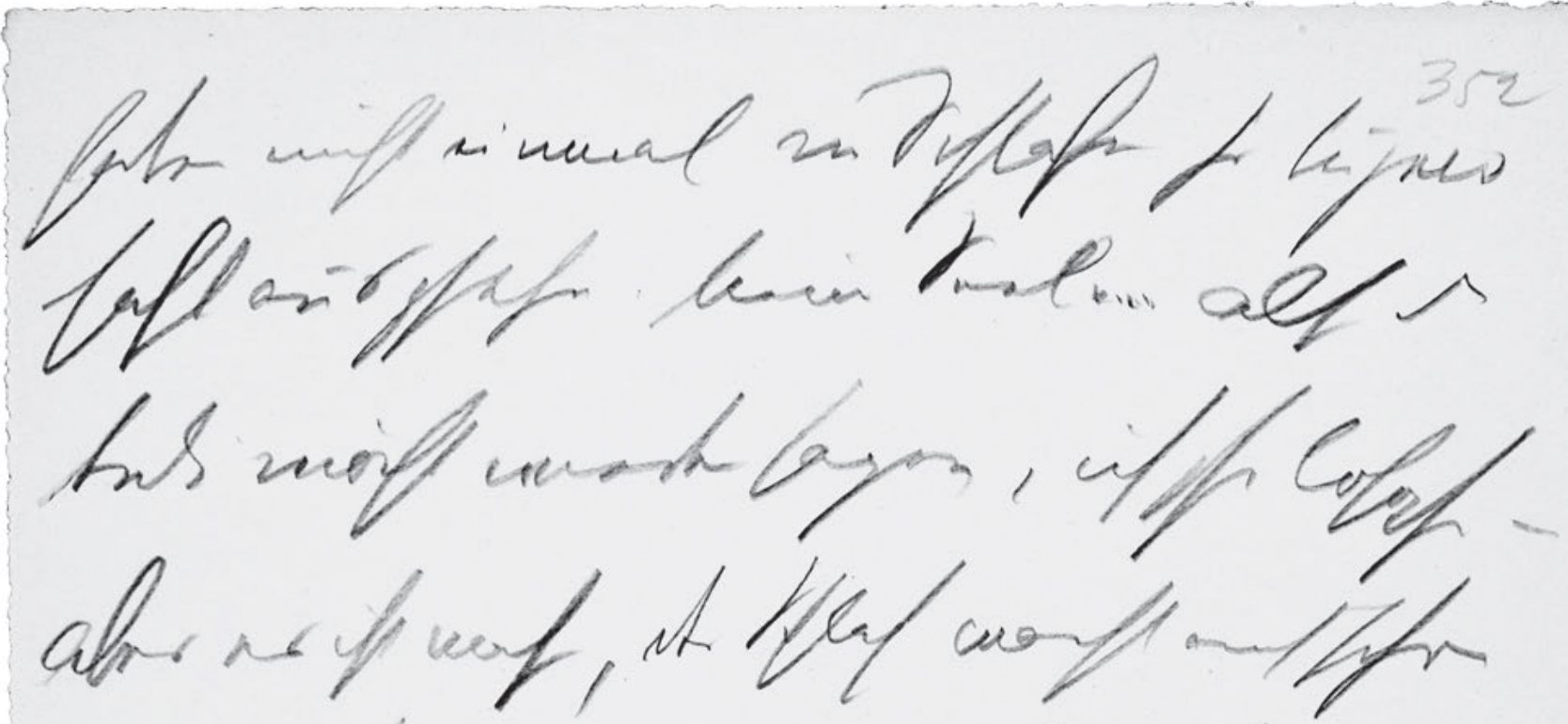

ipoif fomit wein nor alf wis hass

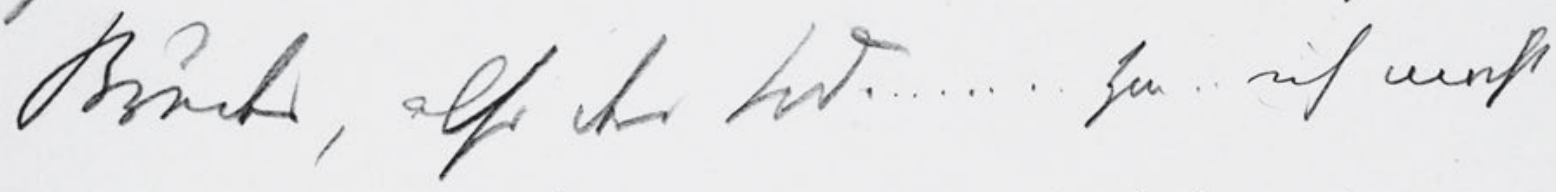

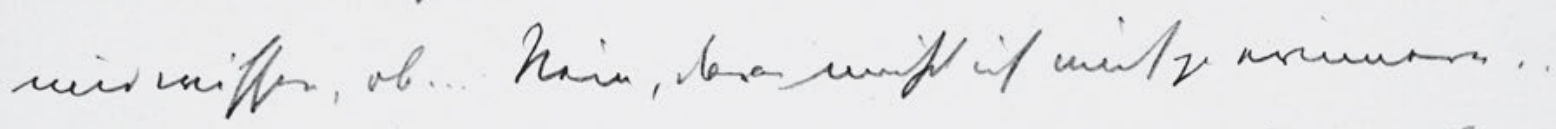

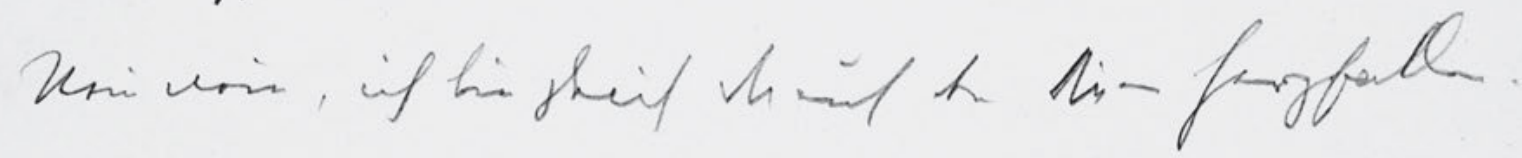

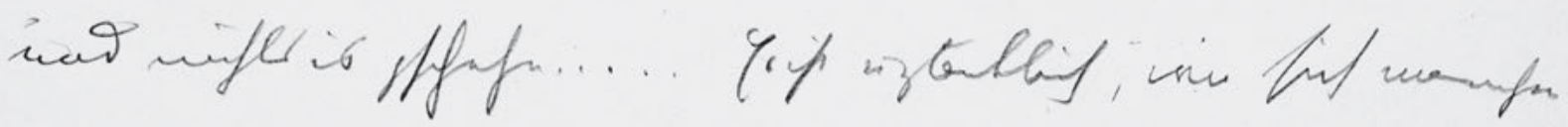

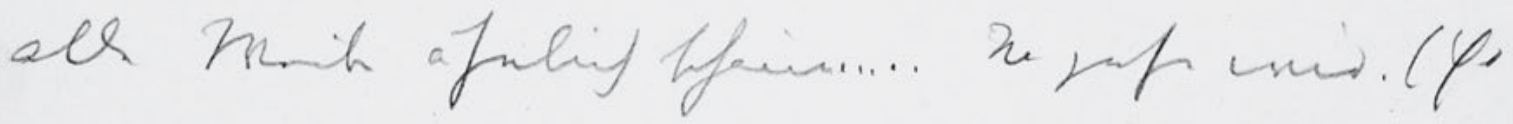

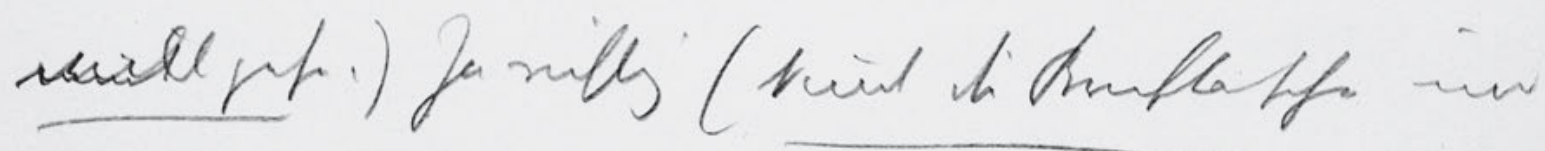

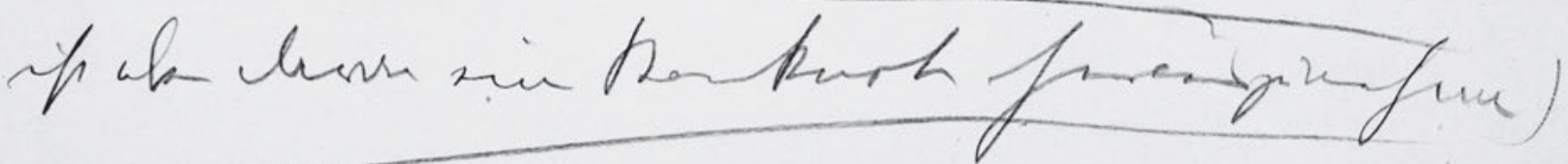

886 
haben nicht einmal im Schlafen so tugend

haft ausgsehn. Mein Seel ...... also d

Lulu möcht wieder sagen, ich philosophir aber es ist wahr, der Schlaf macht auch schon

[?] gleich, kō̄t mir vor, als wie der Herr

Bruder, also der Tod ........ Hm .. ich möcht

nur wissen, ob ... Nein, daran müßt ich mich ja erinnern . .

Nein nein, ich bin gleich da auf den Divan hergfallen ..

10 und nichts is gschehn ..... Es ist unglaublich, wie sich manch $m$

alle Weiber ähnlich schaun ..... Na gehn wir. (Er

${ }^{\text {nimmmt }}$ will gehn.) Ja richtig (Nim̄t die Brieftasche und

ist eben daran eine Banknote heraus zu nehmen) 
HSz10 353

Handschriften und Typoskript

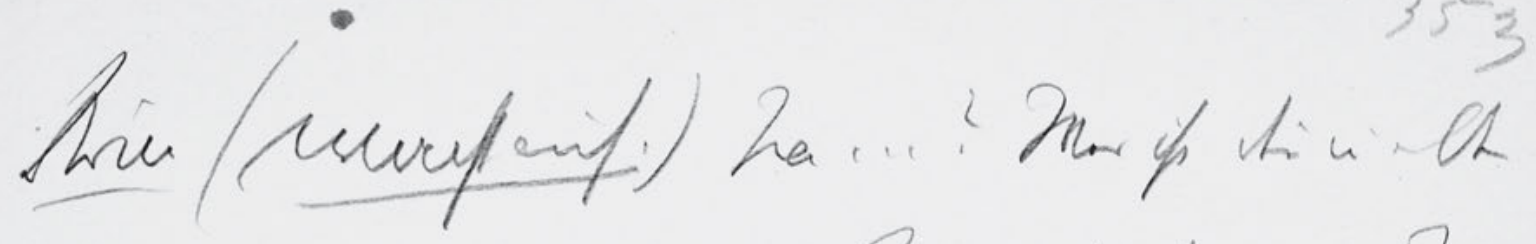

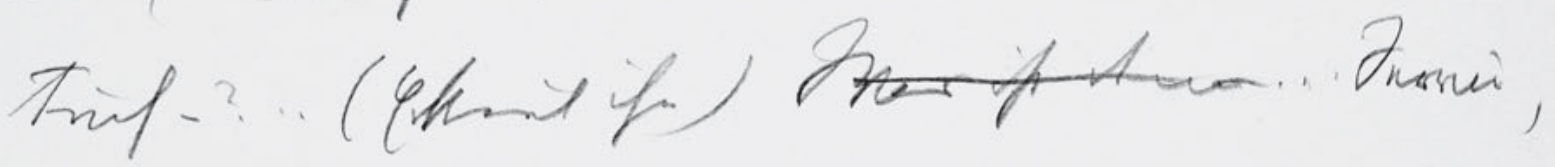
dzon sink

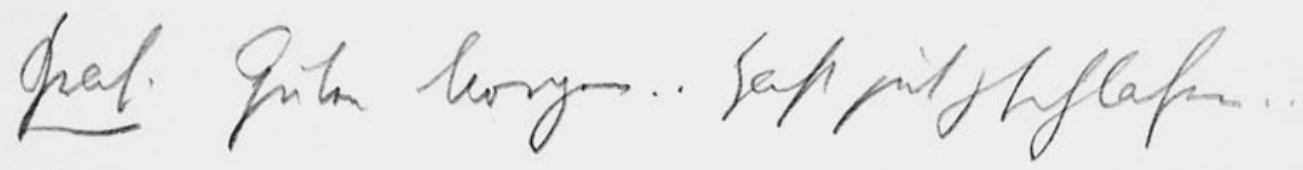

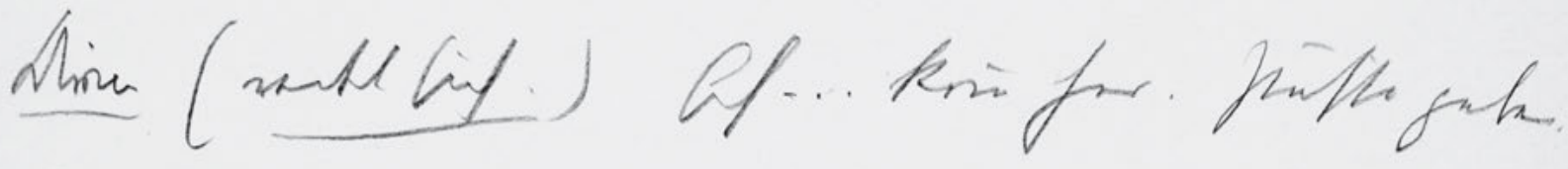

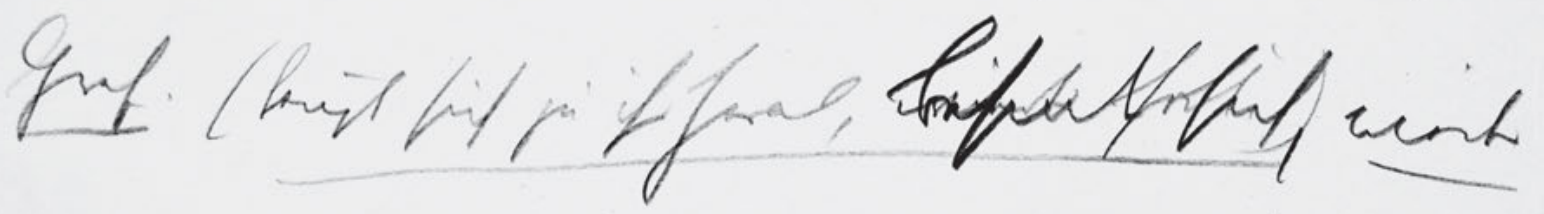

fort I Affue per firgof nollm...

Nive: Thitup.

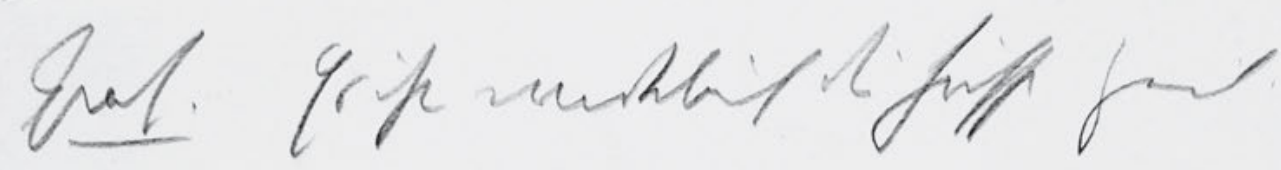

Ahis. Do uniets font of ?

Graf: (fopromenge) 2...

888 
Dirne (wacht auf.) $\mathrm{Na} .$. ? ? Was ist deñ in aller

Früh - ? . . (Erken̄t ihn) Was ist denn ... . Servus,

Baron .. Bubi.

5 Graf. Guten Morgen .. Hast gut gschlafen ..

Dirne (reckt sich.) Ah ... kom her. Pussi geben.

Graf. (beugt sich zu ihr herab, wieder fort)besint sich, wieder

fort) Ich hab grad fortgehen wollen . .

Dirne . Fortgehn - ?

10 Graf. Es ist wirklich die höchst Zeit.

Dirne. So willst fort gehen?...

Graf. ('afast verlegen) So . . 
HSz10 354

Handschriften und Typoskript

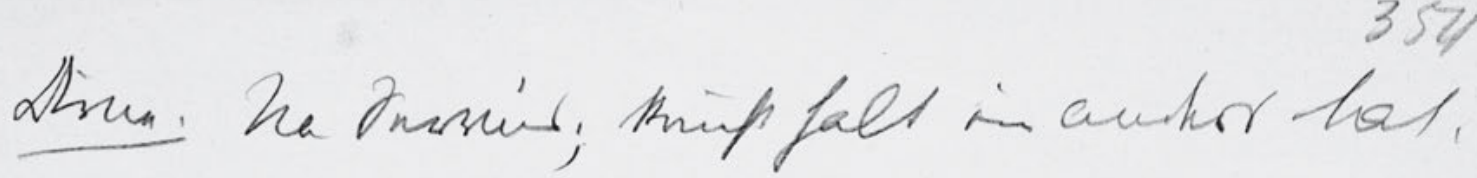

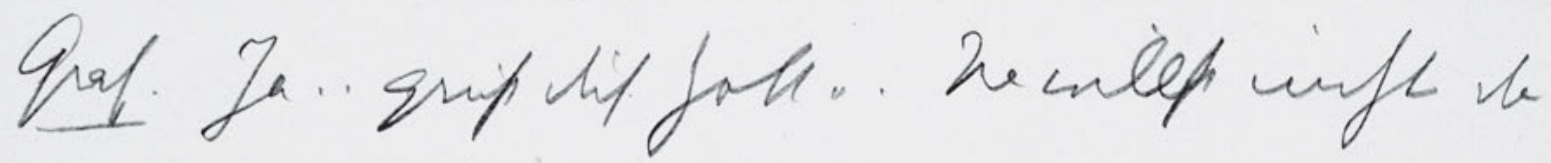
pertal gabo

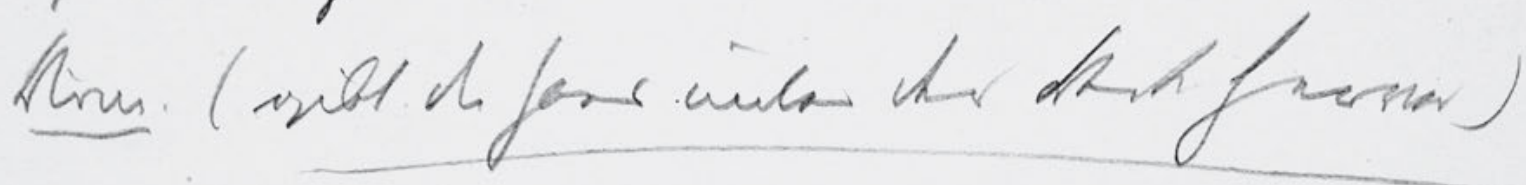

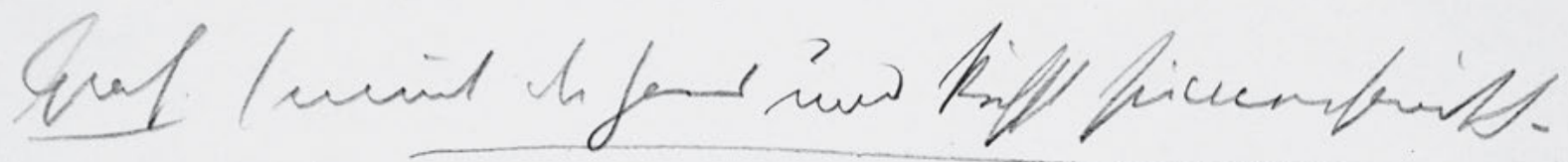

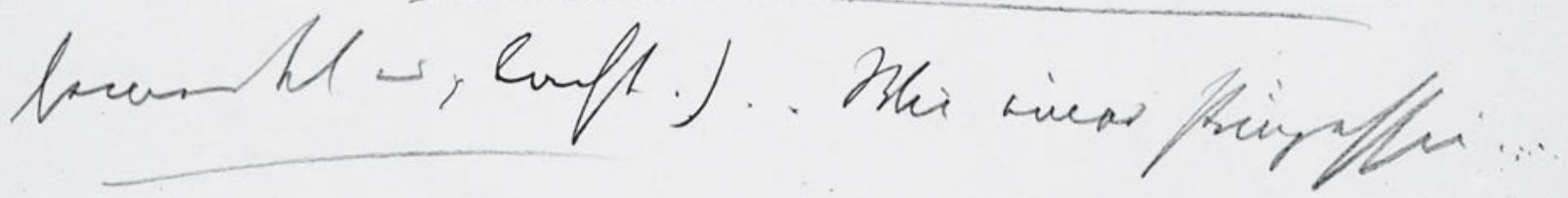

Uhipr, cansive wir.

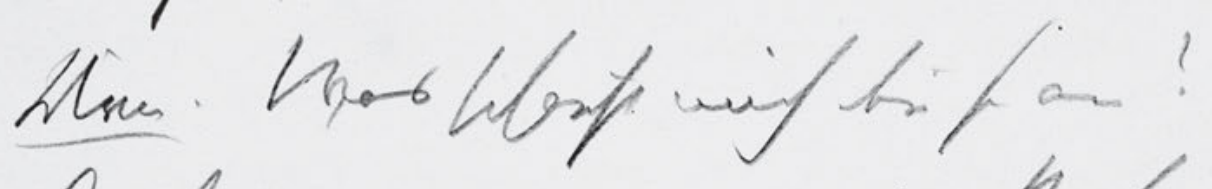

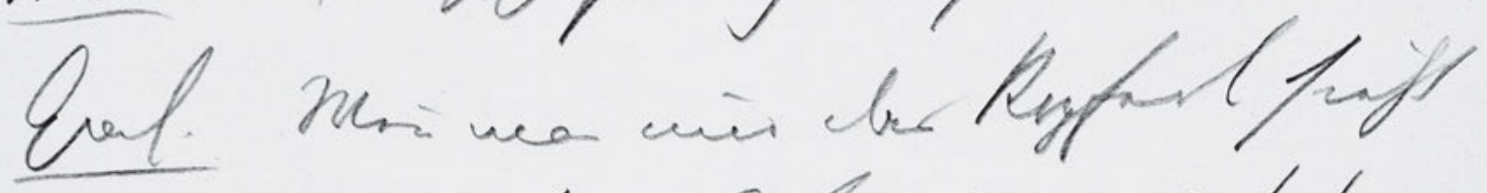

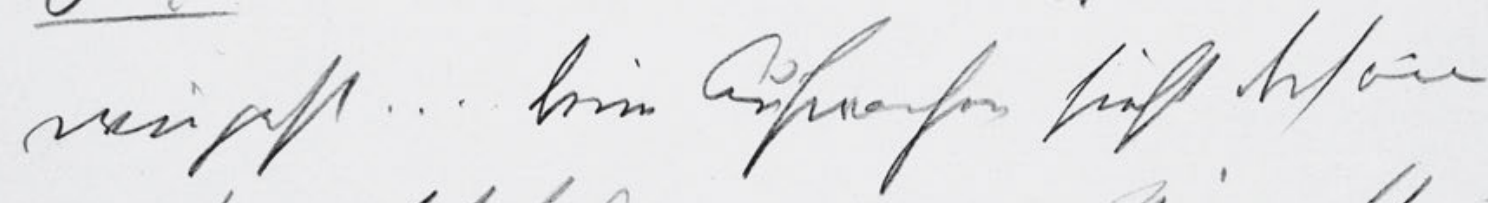

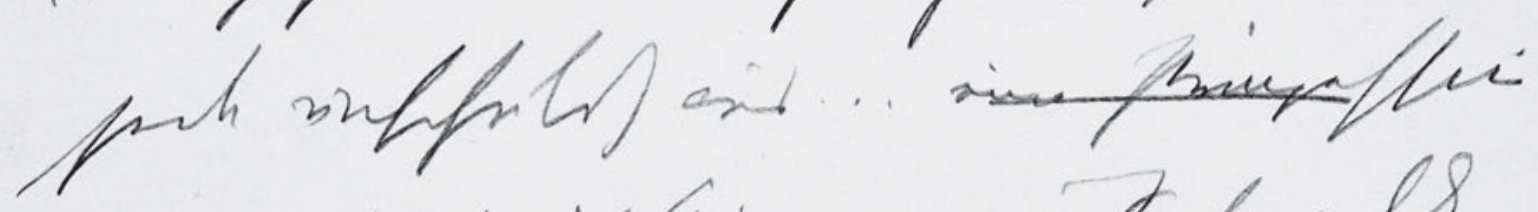

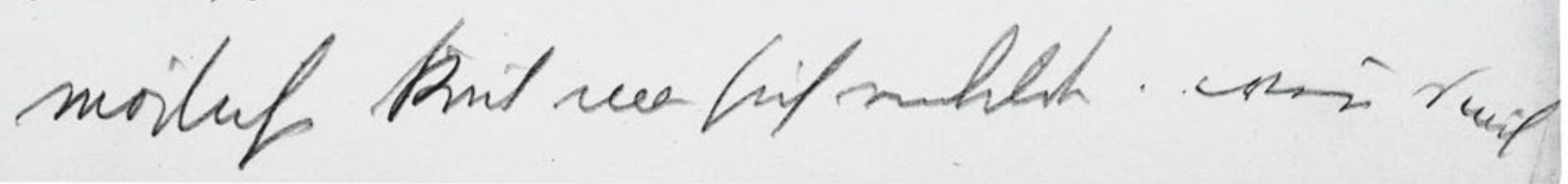

890 
354

Dirne. Na Servus; kō̄st halt ein anders Mal.

Graf. Ja . . grüß dich Gott ... Na willst nicht das

Handerl geben?

$5 \quad$ Dirne. (gibt die Hand unter der Decke hervor)

Graf. (nim̄t die Hand und küsst sie mechanisch bemerkt es, lacht.) .. Wie einer Prinzessin ...... . Ubrigens, wen̄ man nur . .

Dirne. Was schaust mich den̄ so an?

Graf. Weñ man nur das Kopferl sieht wie jetzt .... beim Aufwachen sieht doch eine jede unschuld g aus ... eine Prinzessin könt schließlich kein . . meiner Seel . . alles mögliche kön̄t man sich einbilden .. weñ s nich 
HSz10 355

Handschriften und Typoskript

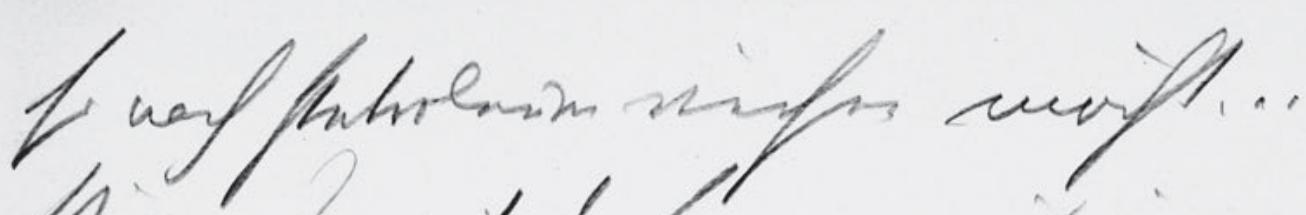

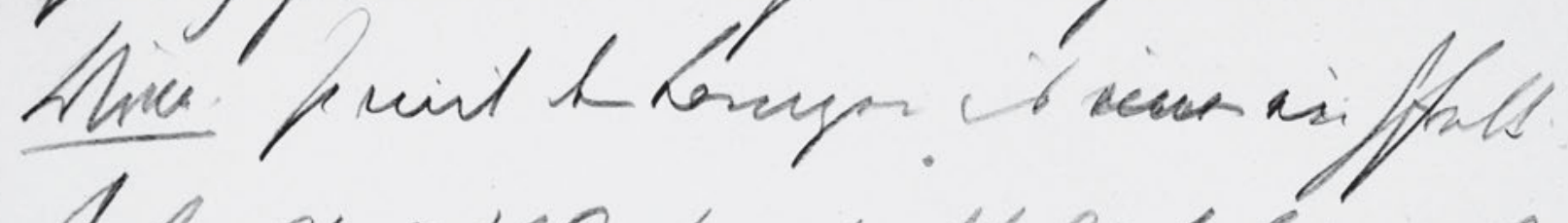

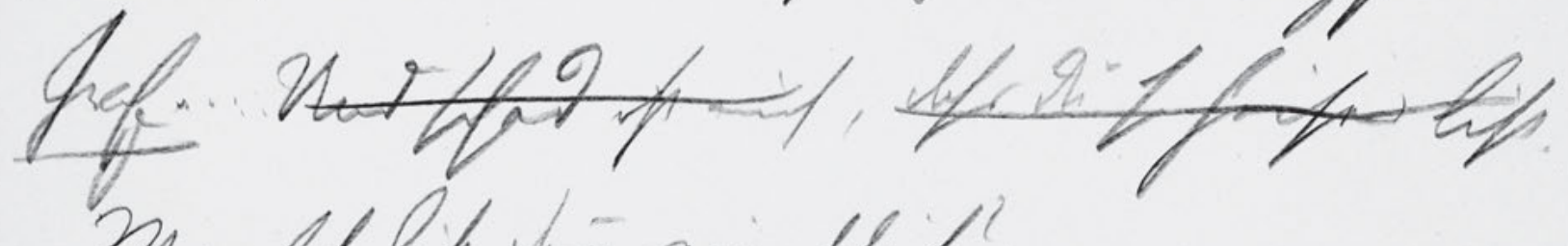

Ini alt hip this mintliy?

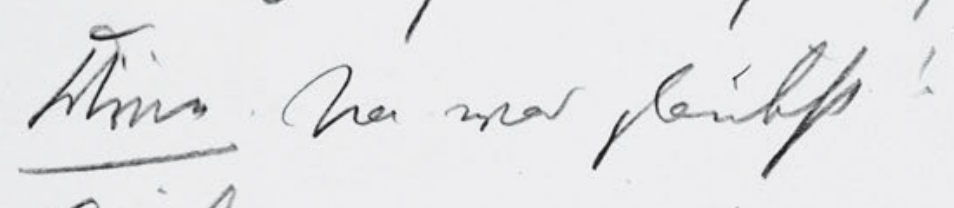

Quef thirnimpors

thim...

at reprin

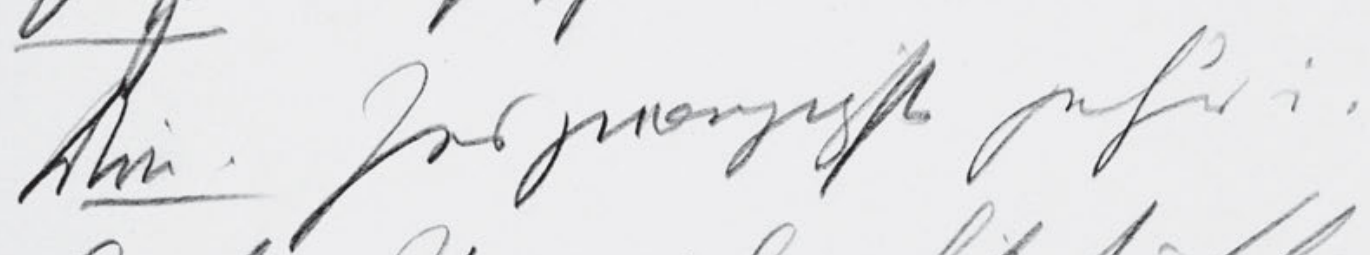

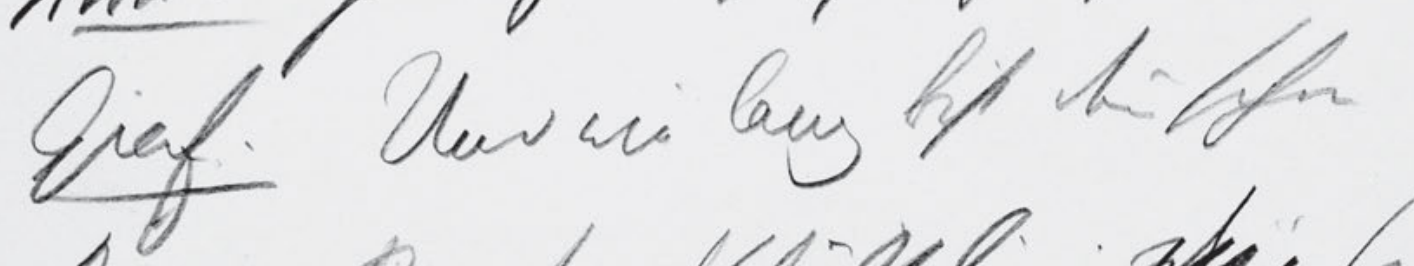

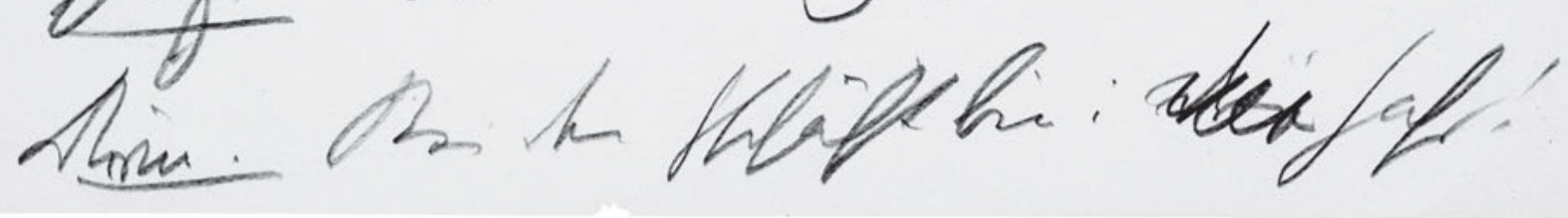

892 


\section{5}

so nach Petroleum riechen möcht ...

Dirne. Ja mit der Lampen is ?ein?imer ein Gfrett.

Graf. ... . Und schad ist auch, dass Du so heiser bist.

$5 \quad$ Wie alt bist den eigentlich?

Dirne . Na was glaubst?

Graf. Vierundzwanz

Dirne. . JaWär net schlecht! . Neunzehn . .

Graf. Ja freilich! .

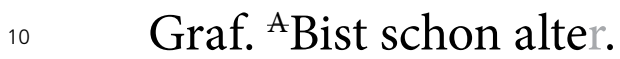

Dirne. Ins zwanzigste geh'r i.

Graf. Und wie lang bist den̄ schon ..

Dirne. Bei dem Gschäft bin i ${ }^{\text {drei }}$ ein Jahr! 
HSz10 [355a]

Handschriften und Typoskript

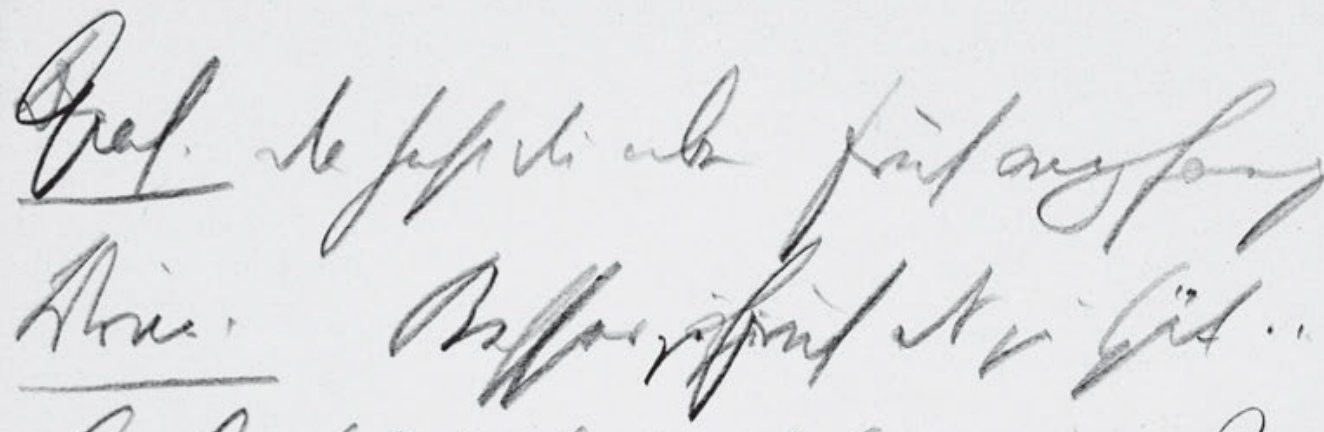

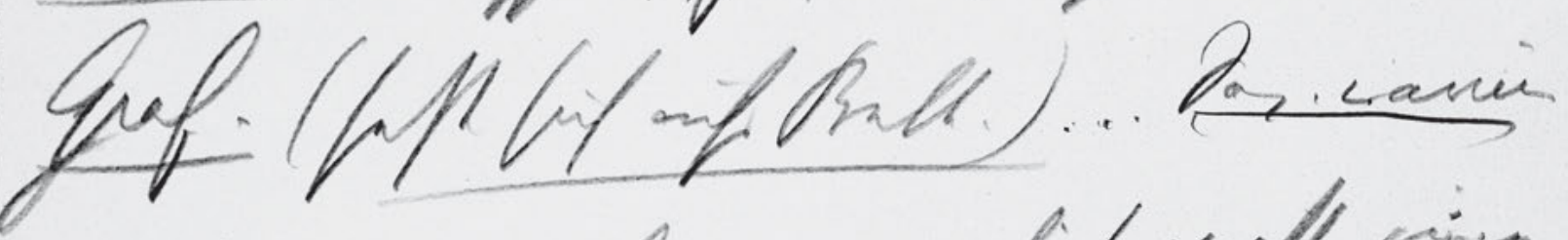
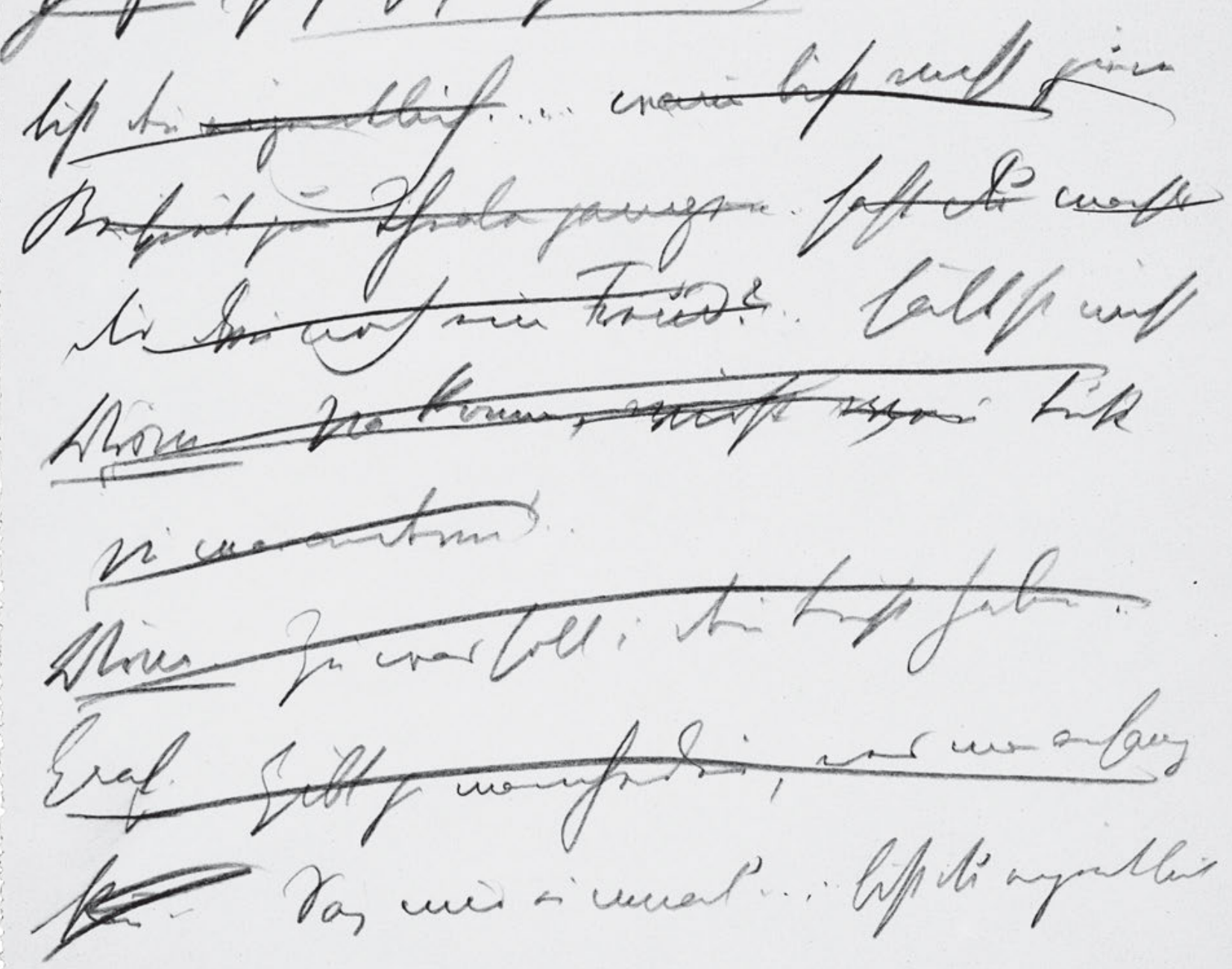
glinhlul

894 


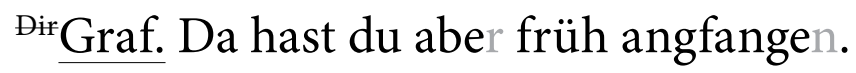

Dirne. Besser ${ }^{z "} z u$ früh als zu spät ...

Graf. (setzt sich aufs Bett.) ... Sag . warum

bist du eigentlich. . . . . warum bist nicht zum

5 Beispiel zum Theater gangen . . hast du machts

dir den̄ noch eine Freud? . . hättst nicht

Dirne Na komm, wirst w'eñ ${ }^{?}$ Lust

zu was anderm? . .

Dirne. Zu was soll i deñ Lust haben ..

$10 \quad$ Graf. Gibt ja mancherlei, was man anfang

$\mathrm{ka} \overline{\mathrm{n}}$ - Sag mir einmal . . . . bist du eigentlich

glücklich. 
HSz10 356

Handschriften und Typoskript

Mine ther?

356

Grat olf y wrin.. qafler hi gat?

this. Of weigft altinil git

Quaf J.... las if hi m/ uin arifate

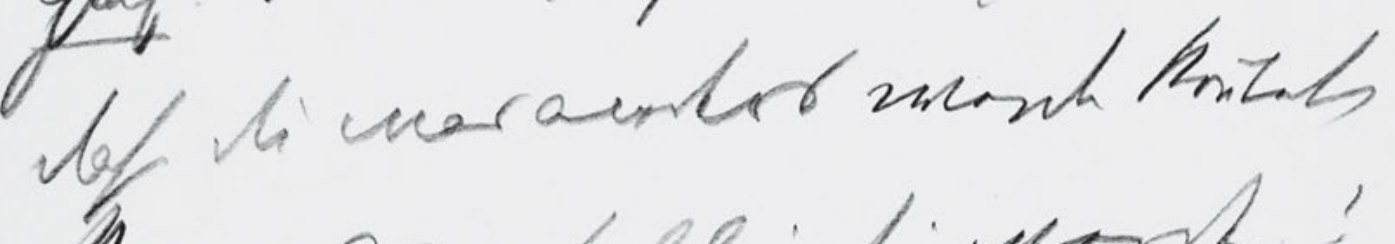

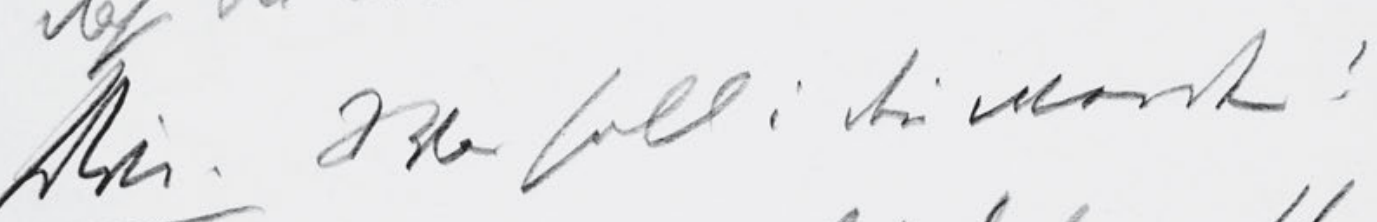

Gat Gef sh if thop withita

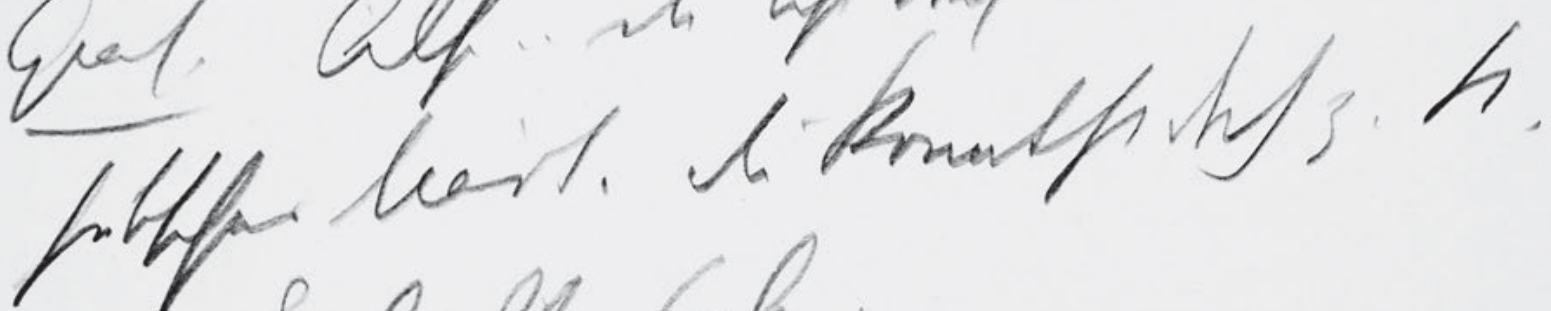
nue fabik Gh.

$\frac{\text { Alin. }}{\text { Prin. }}$

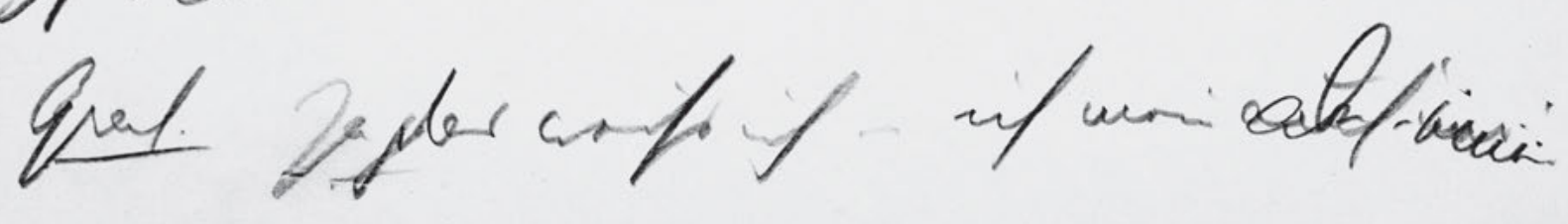

896 


\section{6}

Dirne. Was? . .

Graf. Also ich mein .. geht's dir gut? .

Dirne. Oh mir gehts alleweil gut.

5 Graf. So ... Sag, ist dir noch nie eingfalln,

dass du was anders werden kön̄test

Dirne. Was soll i deñ werden?

Graf. Also . . du bist ${ }^{\text {ein }}$ doch wirklich ein

hübsches Mädl. Du konntst doch z. B.

einen Geliebten haben.

Dirne. Meinst vielleicht, ich hab

kein! . .

Graf. Ja ${ }^{j}$ das weiss ich - ich mein ${ }^{\text {auch }}$ aber $-{ }^{\text {nur einen }}$ 
HSz10 357

Handschriften und Typoskript

nenft rimse, ho hif

$35 \%$

di wef

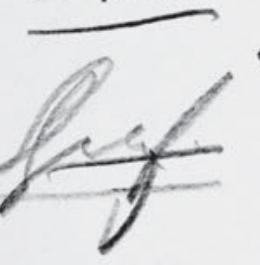

follf buba,

ber foul inntas

qual.

Anien

th

an fuir cin.

Dim. he,

t

ver/ lyman.
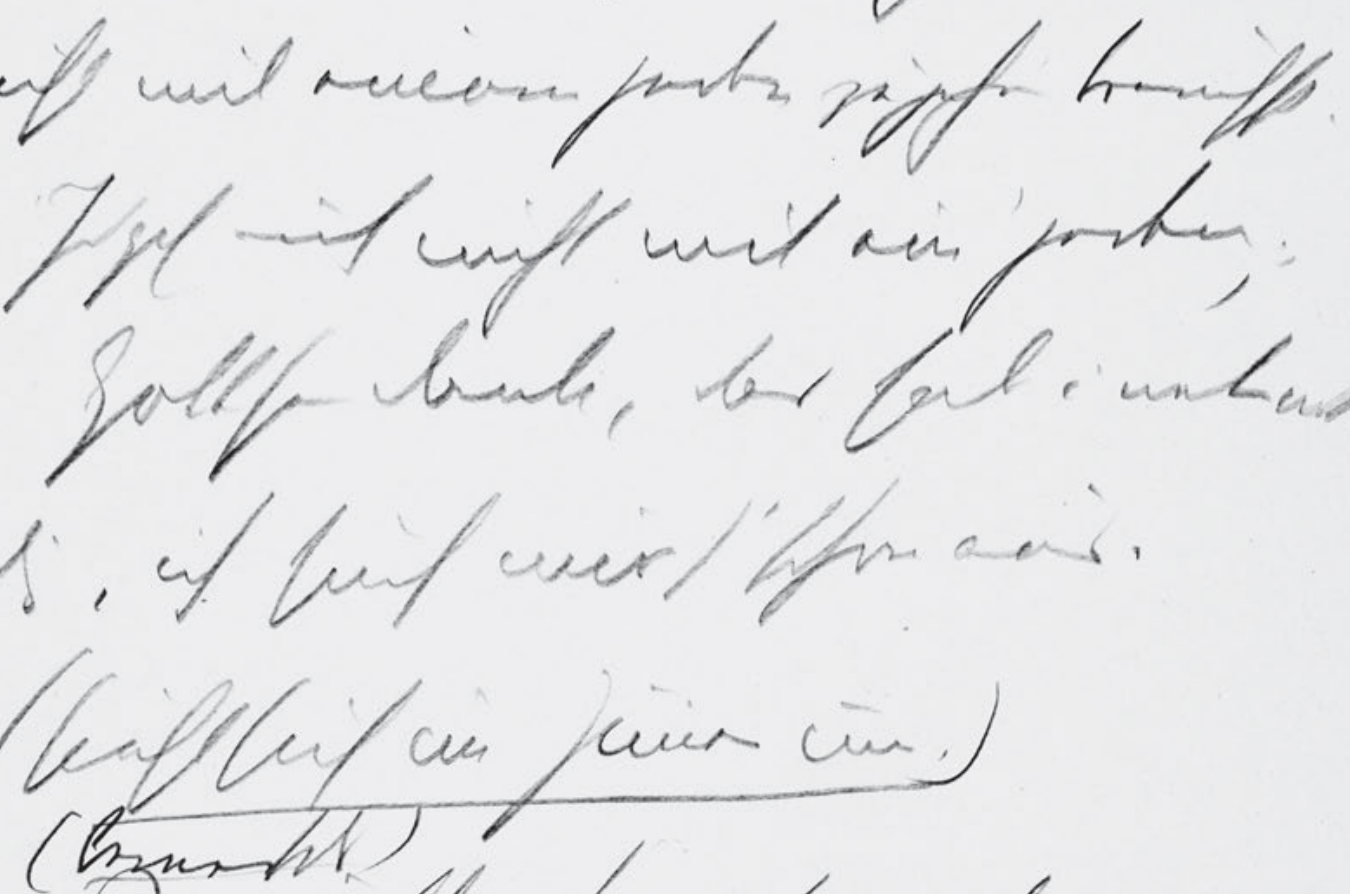


\section{7}

weißt einen, der dich halt aushalt: . . dass

du nicht mit einem jeden zu gehen brauchst.

Dirne. Ich geh auch nicht mit ein' jeden;

$5 \quad$ Graf Gott sei Dank, das hab i net not-

wendig, ich such mir s' schon aus.

Graf. (sieht sich im Zimer um.)

(bemerkts)

Dirne. Im nächsten Monat ziehn wir in

die Stadt, in die Spiegelgasse

Graf. Wir . . ? Wer den

Dirne. Na, die Frau, und die 'zwei? and

Madeln, die noch da wohnen.

Graf. Da wohnen noch solche. . 
HSz10 358

Handschriften und Typoskript

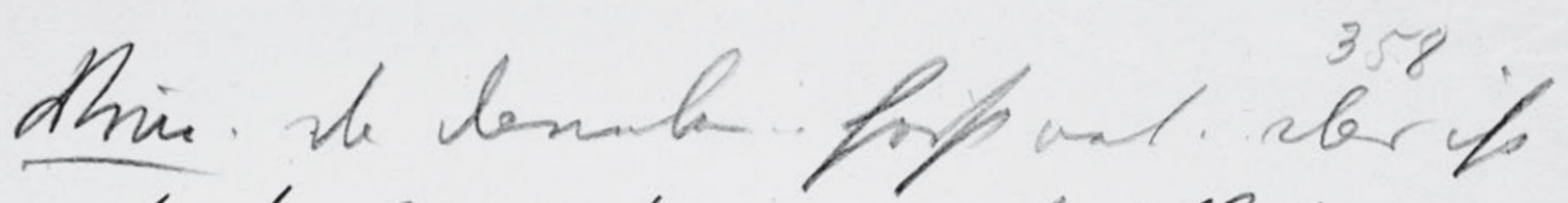

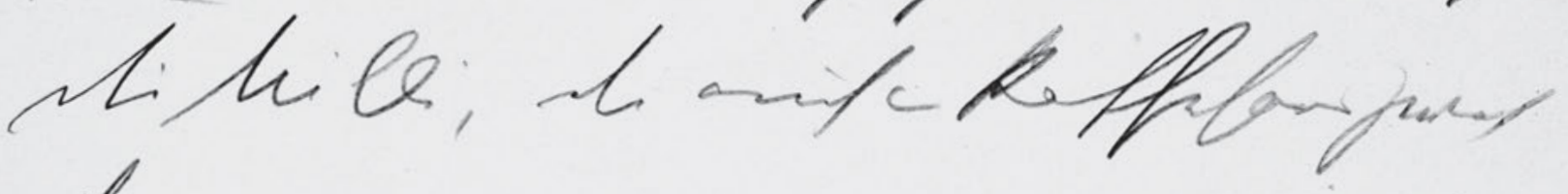
If.

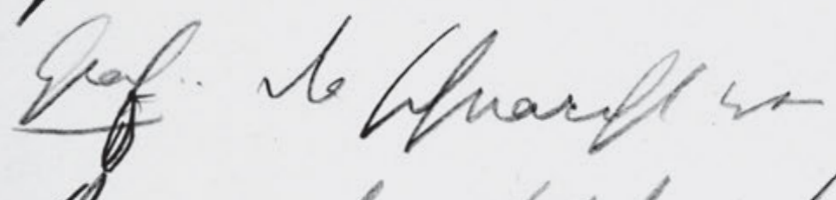

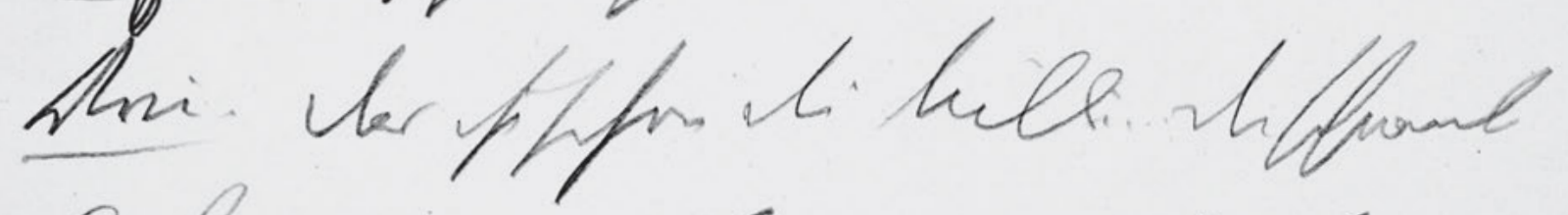

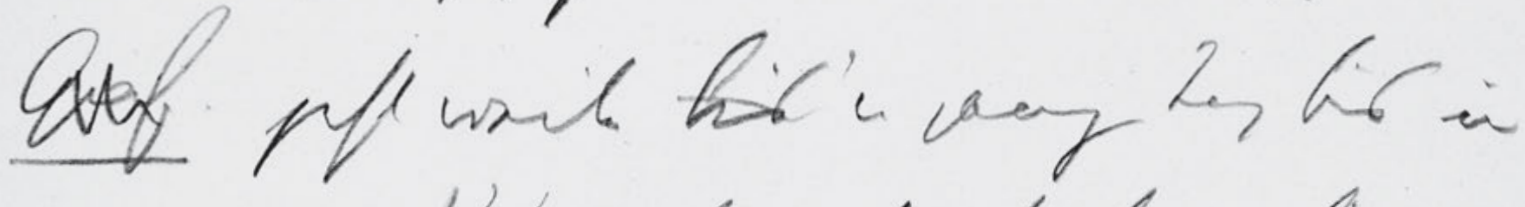

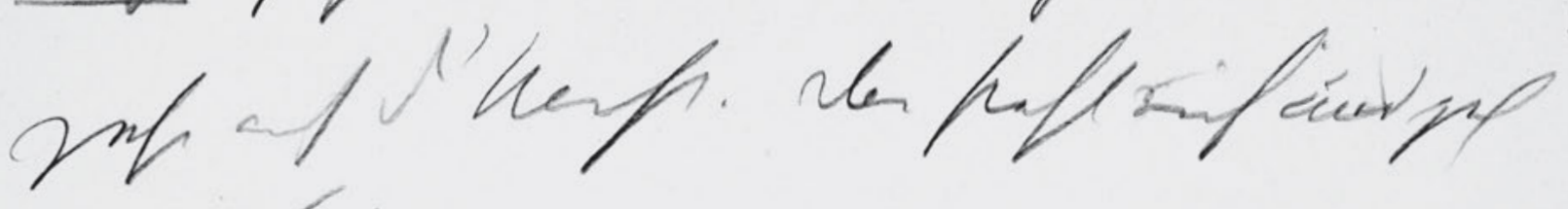
us hefres.

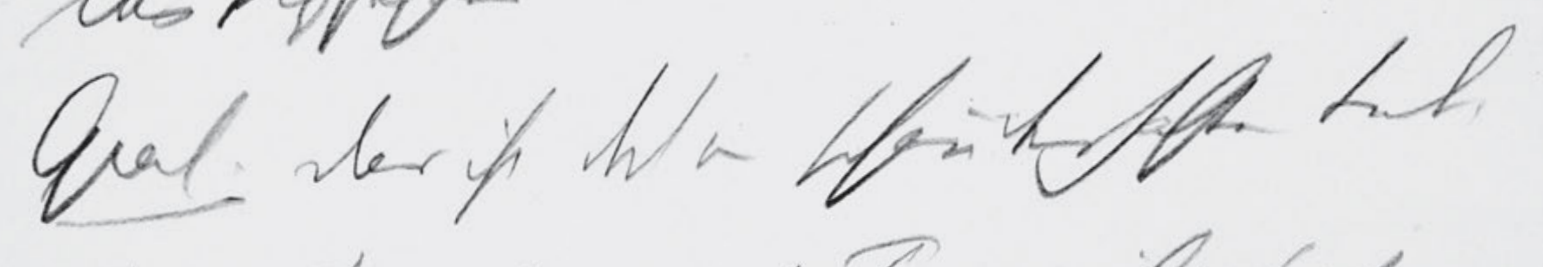

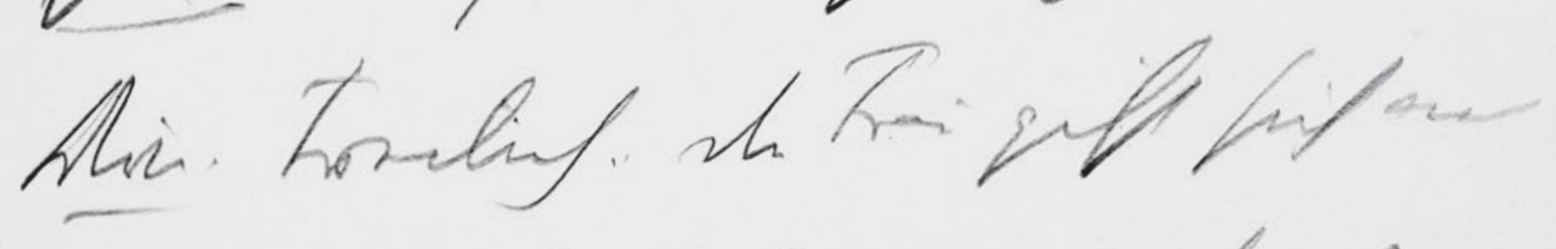
jous. If his Ifor mi milf: lal nie aif d Galfon: rifterern,

900 


\section{8}

Dirne . Da daneben . . hörst net . . das ist

die Milli, die auch im Kaffehaus gwes ist ...

$5 \quad$ Graf. . Da schnarcht wer.

Dirne. Das ist schon die Milli ... die schnarcht

Graf. jetzt weiter bis 'n ganzen Tag bis um

zehn auf d'Nacht. Dan steht s auf und geh

ins Kaffehaus.

10 Graf. Das ist doch ein schauderhaftes Leben

Dirne. Freilich .. die Frau gift sich auch

genug. Ich bin schon um zwölfe Mit

imer auf d Gassen: s gibt Herrn, 
HSz10 359

Handschriften und Typoskript

Gral her waffe the in 12

359

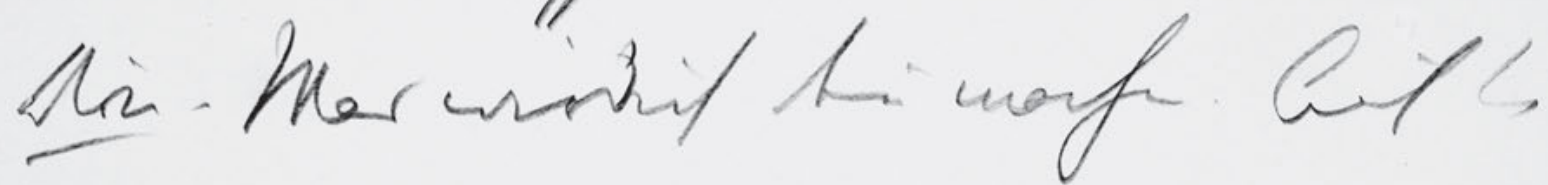

Thrif uf if fall.

lraf Aff... unturlif.. (thaff arifthinit

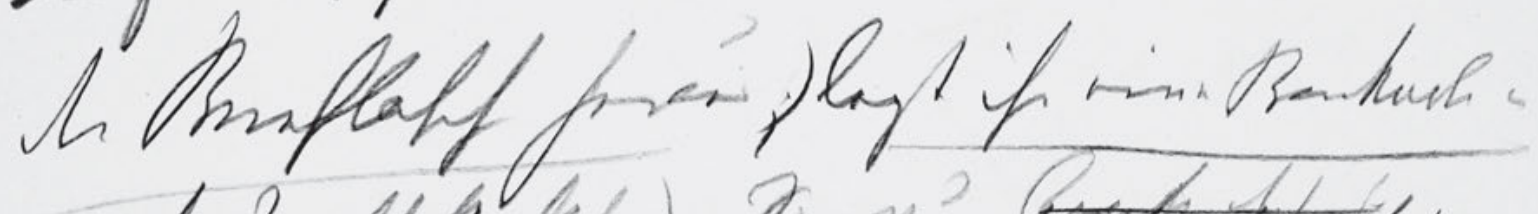

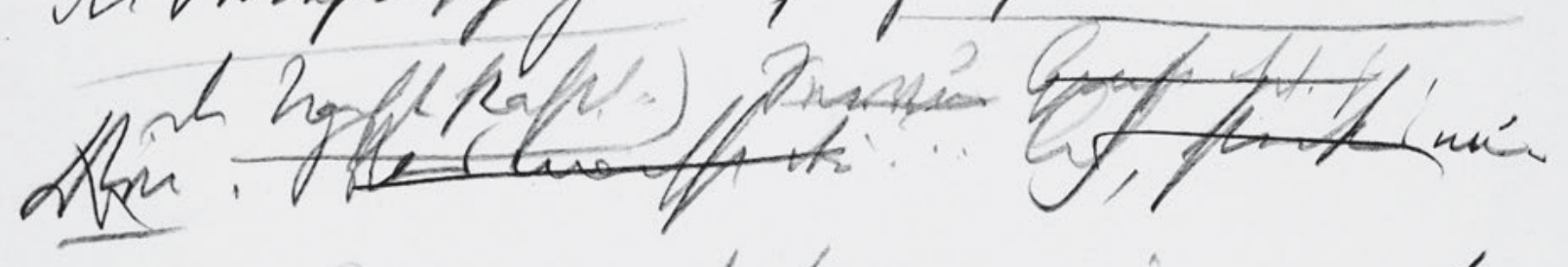

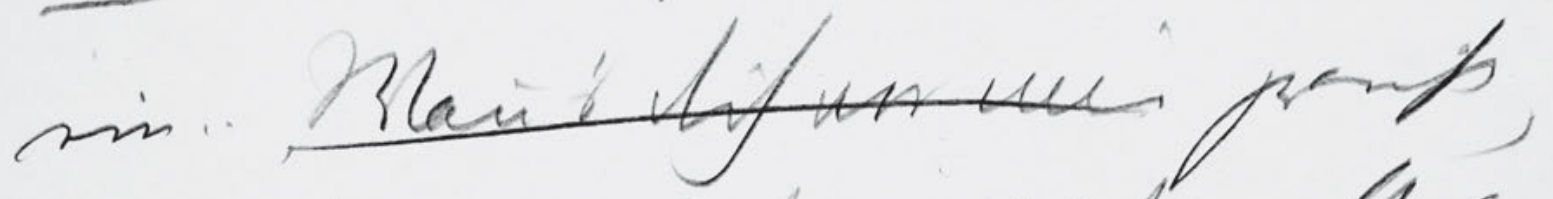

paft af this jithuguth.

Qfef... Alf Cinin.

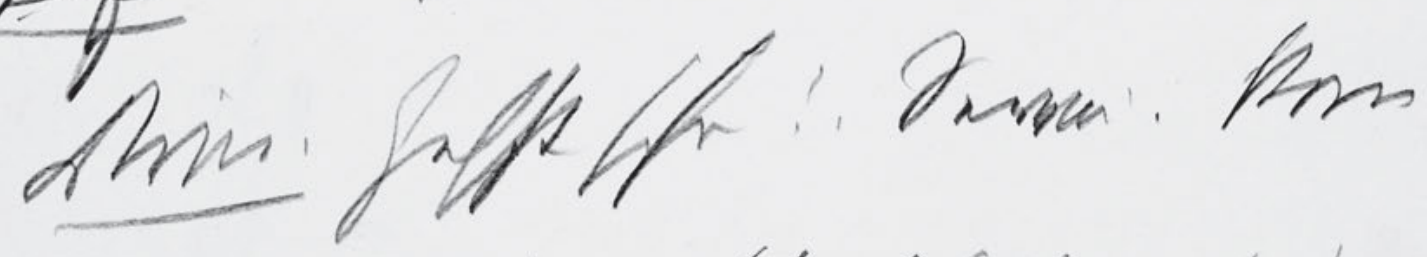

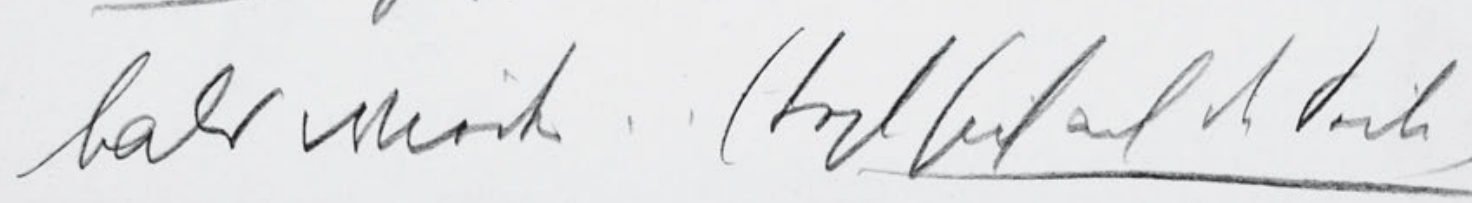

902 


\section{9}

Graf. Was machst dē̄ . um 12

Dirne. Was ?'werd? ich deñ machen. Auf den

Strich geh ich halt.

$5 \quad$ Graf. Ah so ... natürlich ... (Steht auf. ${ }^{\circ}{ }^{\circ} \mathrm{Ni} \overline{\mathrm{m}} \mathrm{t}$

die Brieftasche heraus'; legt ihr eine Banknote a

das Nachtkastl. .) Servus Gruß dich. ? $s \theta^{\text {? }}$

Dirne. Was machst deñ . . . Ah, steck's nur

ein .. Wañ's dich vor mir graust,

'brau? pfeif i auf dein Guldenzettel -

Graf. . . . Also Adieu! .

Dirne. Gehst schon? . Servus. Kom

bald wieder . . (legt sich auf die Seite.) 
HSz10 360

Handschriften und Typoskript

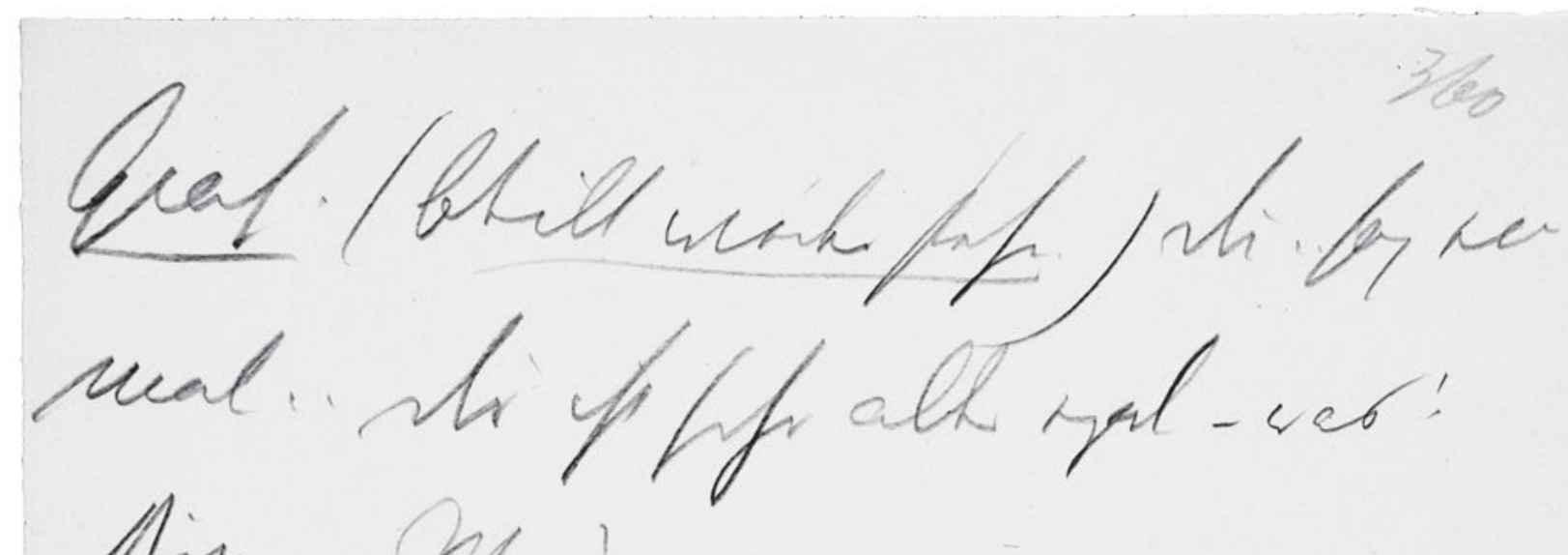

Sim.

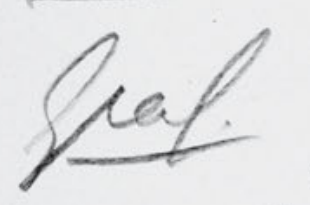

h

wran .... Liv werfer him true

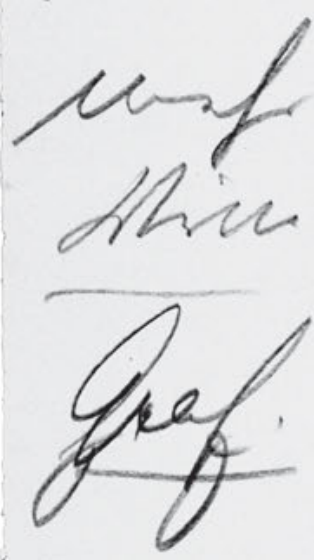

Aes

Almi.

"vafitis flesf

st of miar. 
360

Graf . (bleibt wieder stehn.) Du .. sag ein

mal .. dir ist scho alles egal - was!

Dirne. Was?

$5 \quad$ Graf. Ich mein .... dir machts keine Freud

mehr....

(gähnt.)

Dirne. Ein' Schlaf hab ich.

Graf. Dir ist alles eins .... ob einer

jung ist oder alt . . oder ob einer . .

${ }_{10} \quad$ Dirne. Was fragst ${ }^{\text {ein }}$ den $\bar{n}^{!}$? . Dich grausts doch

eh.. ? vor mir - ?

Graf. .. Also . (plötzlich auf etw komend) 
HSz10 [360a]

Handschriften und Typoskript

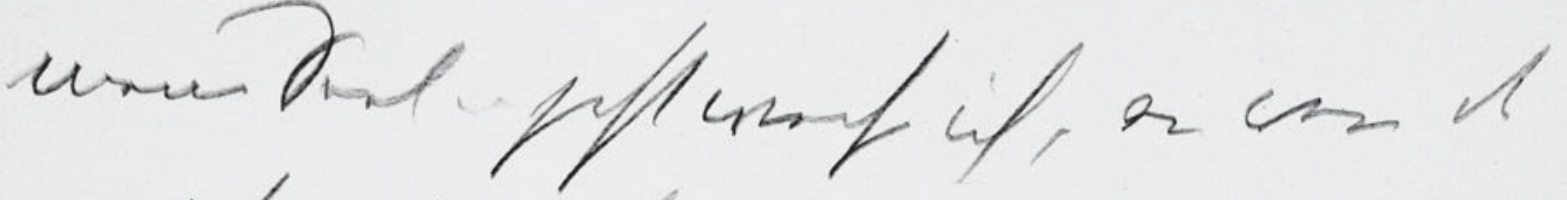
mifmerimerfe. ber fe...

Lim Peri monghat

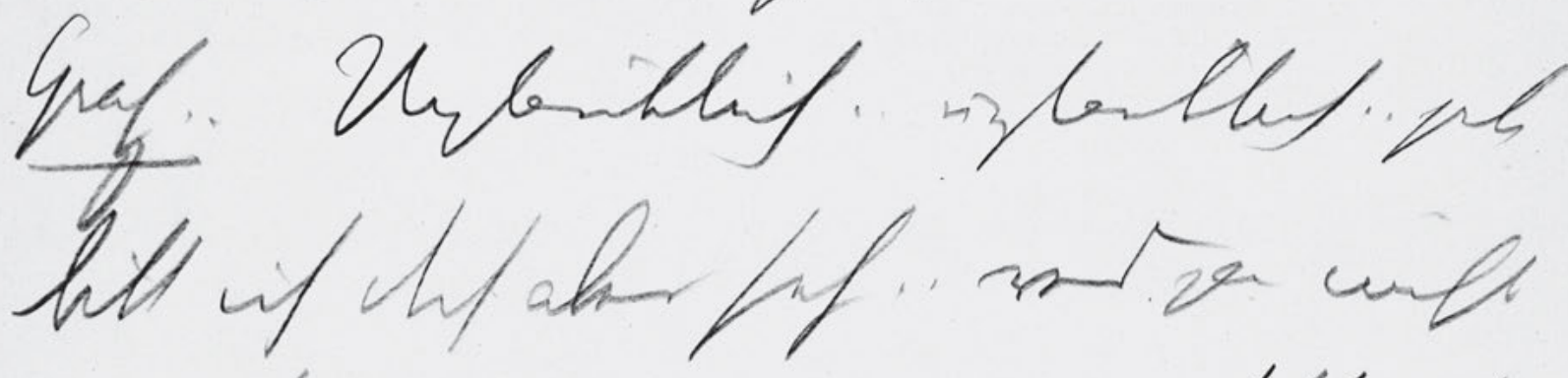

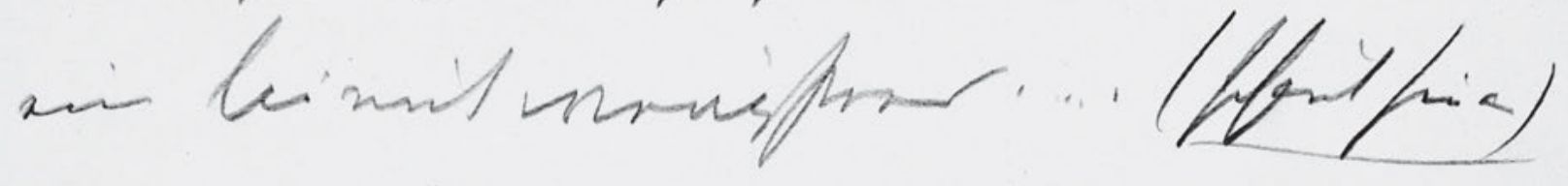

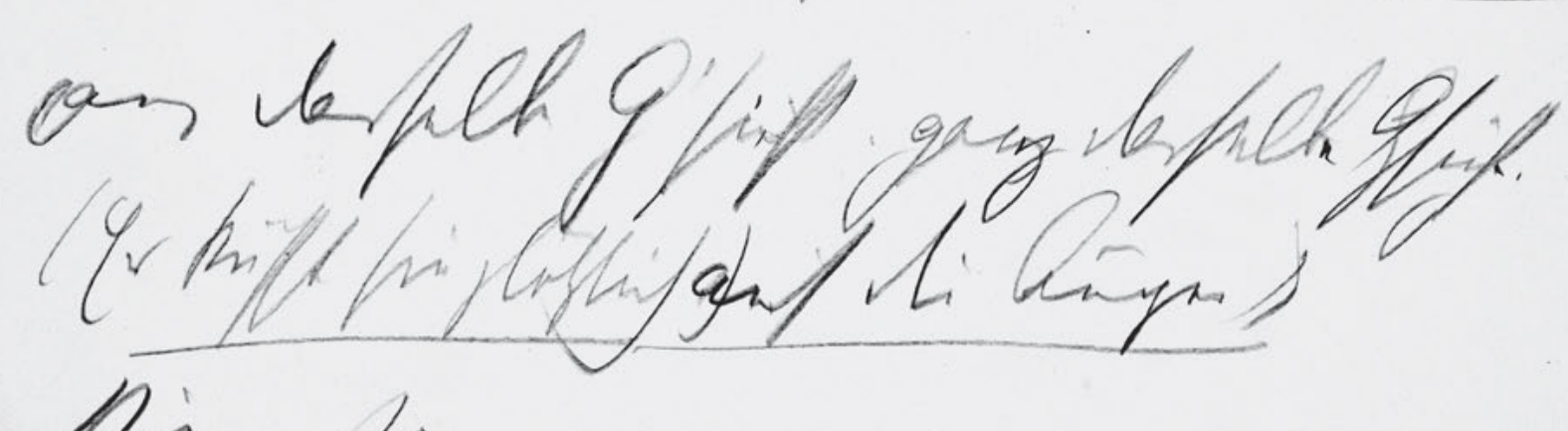

Ahime ha..
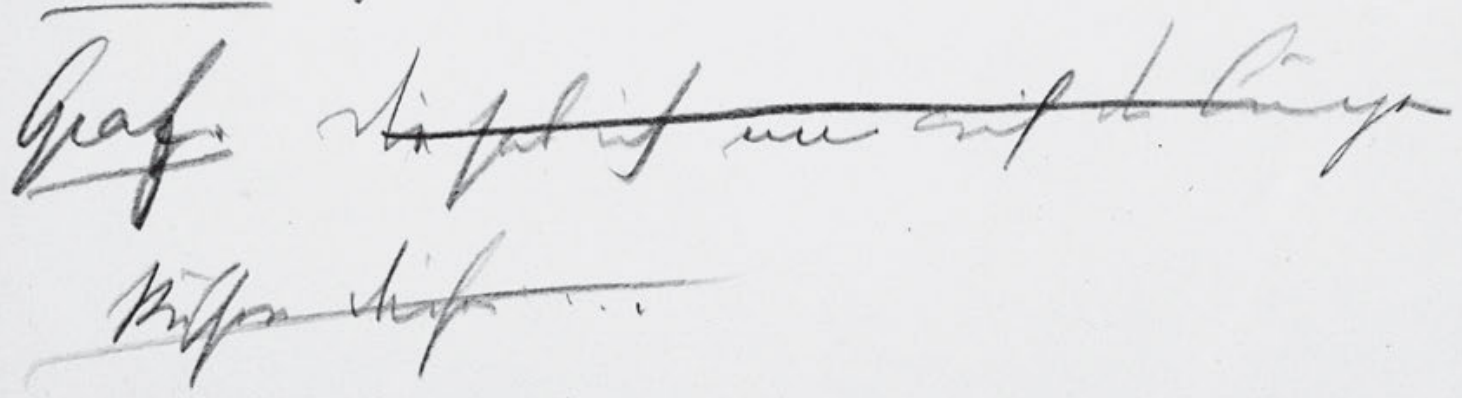

906 
meine Seel . . jetzt weiss ich, an wen du

mich erinnerst .. das ist .... .

Dirne. Schau i wem gleich?

Graf. . Unglaublich . . unglaublich . . jetz?

5 bitt ich dich aber seh $r$. red gar nicht

ein Minut wenigstens .... . (schaut sie an)

ganz dasselbe G’sicht . ganz dasselbe Gsicht. -

(Er küsst sie plötzlich ’auf die Augen)

Dirne. $\mathrm{Na}$. .

$10 \quad$ Graf. Die hab ich nur auf die Augen

küssen dürfen... . 


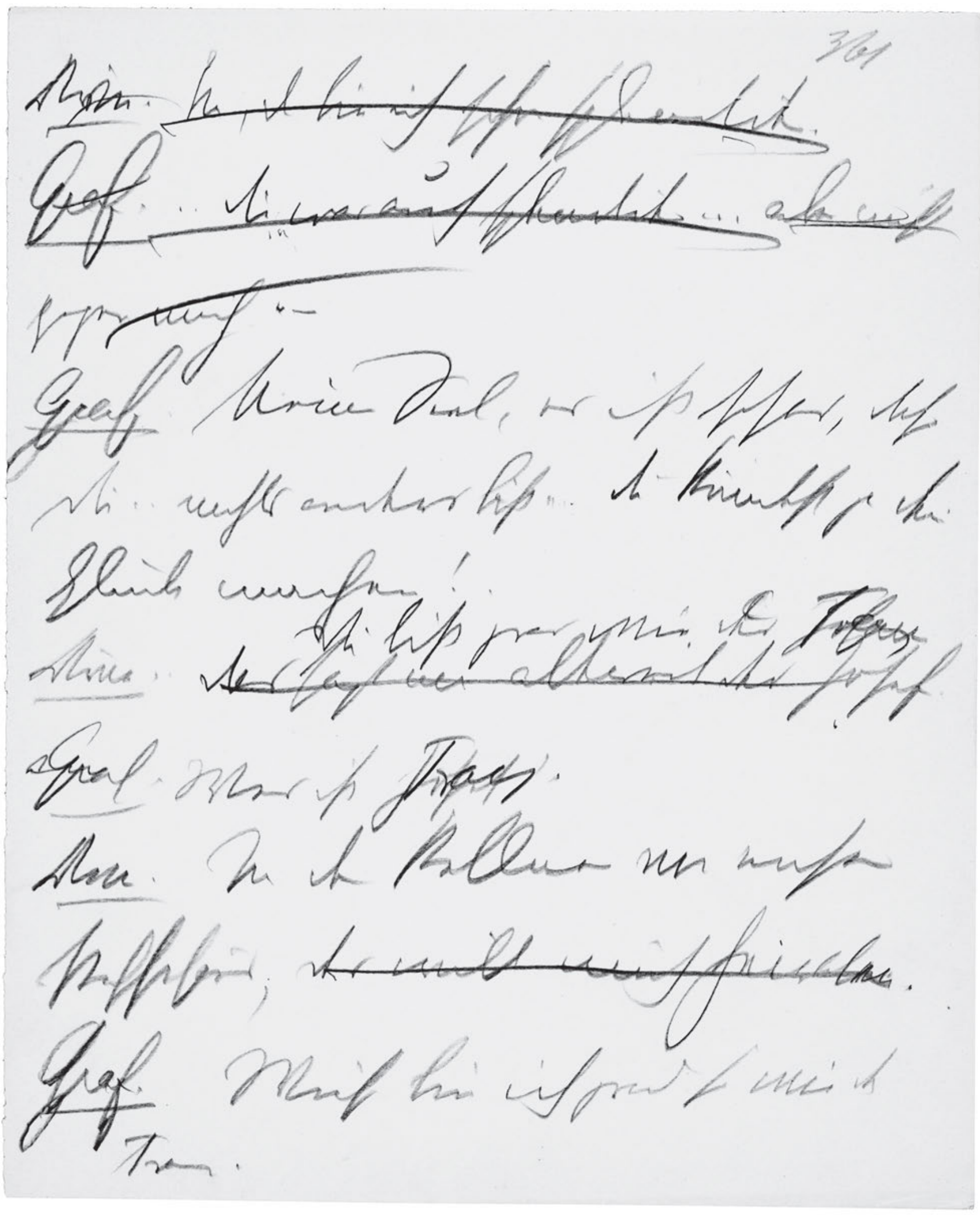


361

Dirne. $\mathrm{Na}$, da bin ich schon splendider.

Graf. .. Die war auch splendider ... aber nicht gegen mich. -

5 Graf. Meiner Seel, es ist schad, dass

du . . nichts anders bist ... du könntest ja dein

Glück machen! .

Du bist grad wie der ${ }^{\text {Johan }}$ Franz

Dirne .. Das sagt mi alleweil der Josef.

${ }^{\text {ate }}$ Graf. Wer ist Josef? Franz.

Dirne. Na der Kellner von unser

Kaffehaus; der will mich heiraten.

Graf. Wieso bin ich grad so wie der

Franz. 
HSz10 362

Handschriften und Typoskript

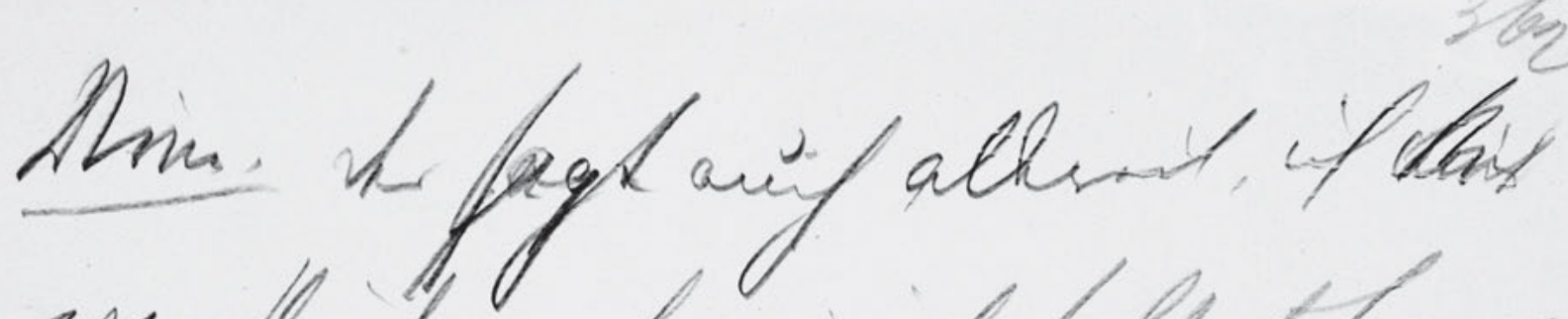

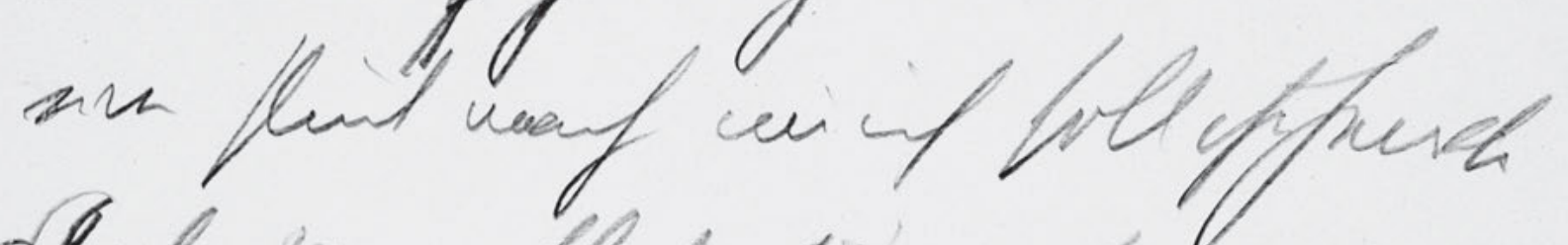
ofrel nave the he uf.

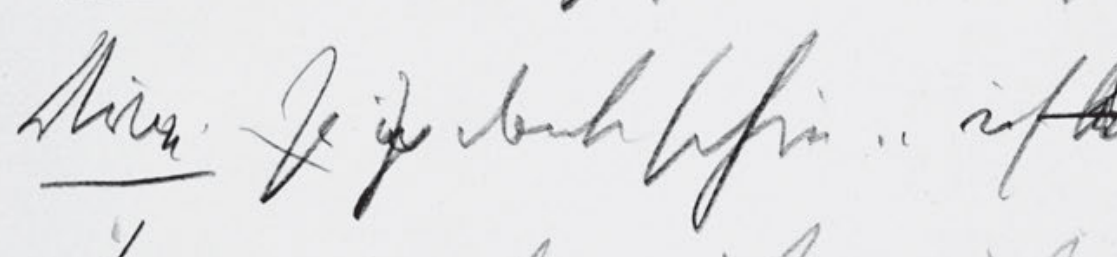
hom of unif uiff ticialik

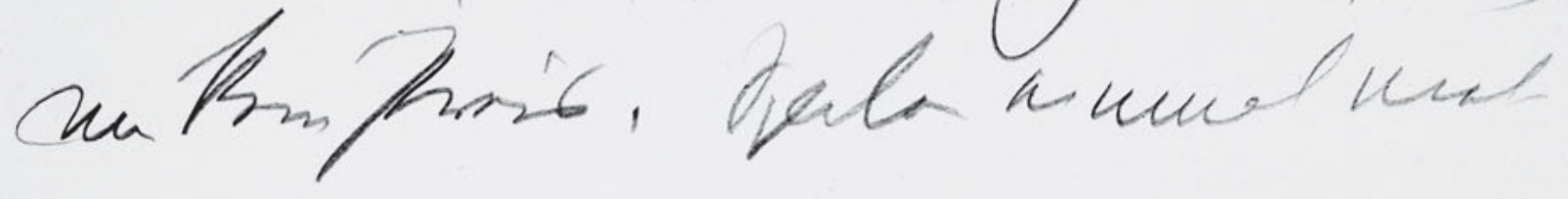
liviff.

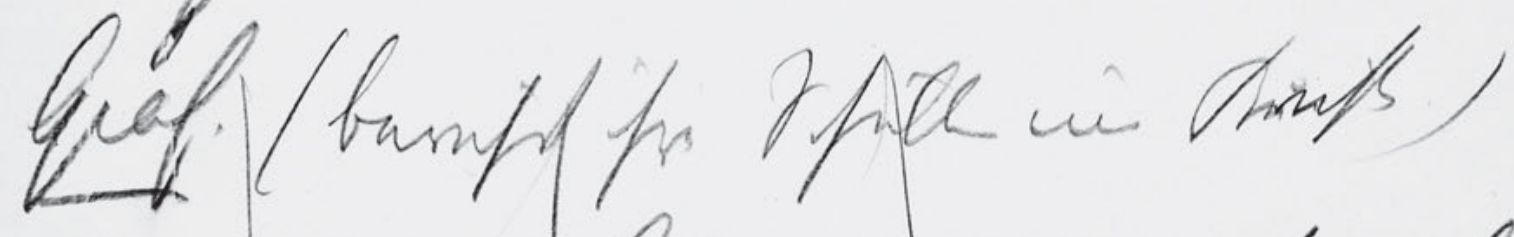

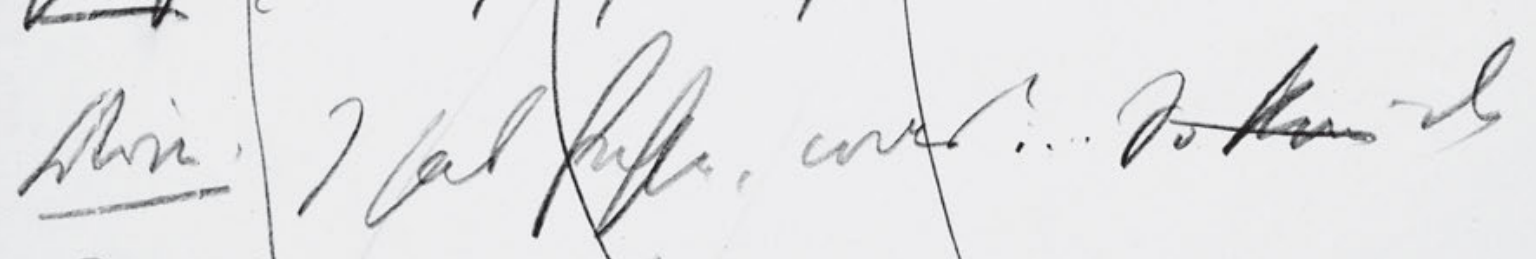
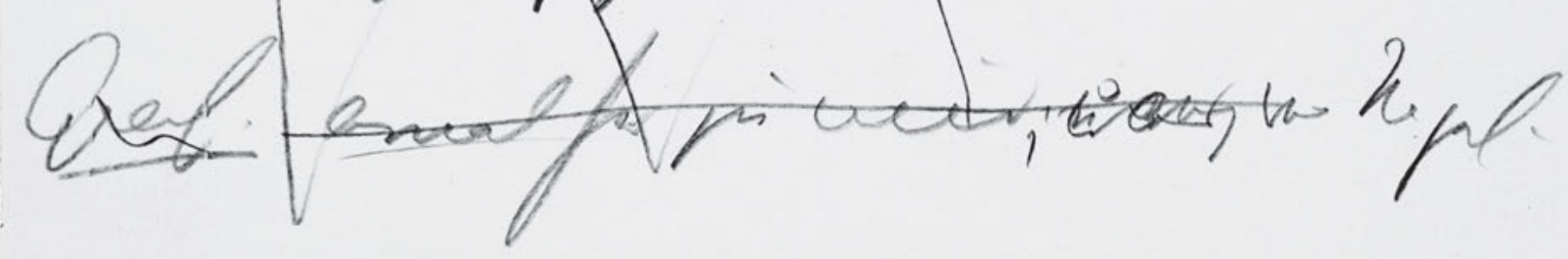

910 


\section{2}

Dirne. Der sagt auch alleweil, ich ?möch?kön

mein Glück machen un ich soll ihn heirate

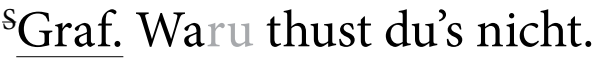

5 Dirne. Ja ${ }^{\text {?ie? }}$ Ic dank schön .. ich ${ }^{\text {bin }{ }_{\text {werde }}}$ brauch ${ }^{\text {ekeine }}$

Mann . ich möcht nicht heirat, nein,

um keine Preis. Spater einmal viel-

leicht.

Graf. (berührt ihre Schulter und Brüste.)

Dirne. I hab feste, was.... So kō̄ $\mathrm{d} h$

Graf. amal her zu mir; ${ }^{\text {reg }}$ was ver $\mathrm{Na}$ geh - 
HSz10 363

Handschriften und Typoskript
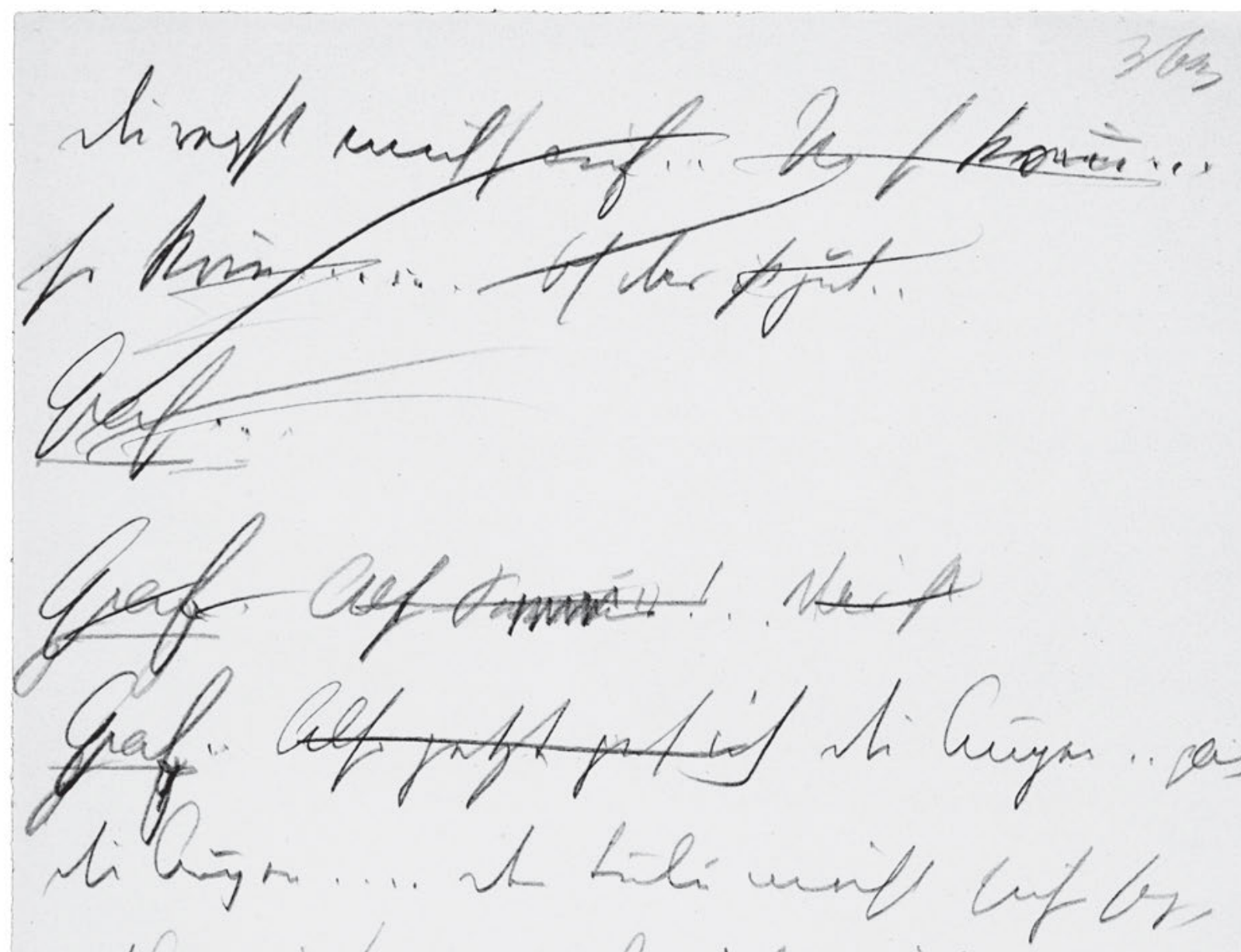

whir haver-ab if will win

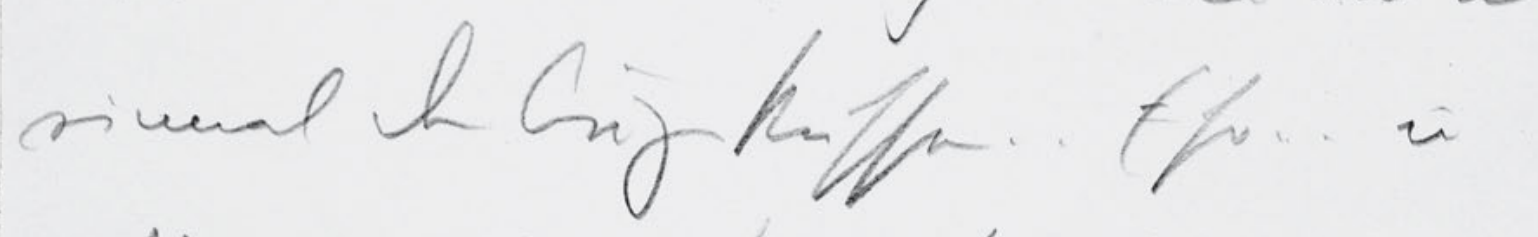
pli. suph
Din. Jusur qual (hilkin.) Sh... Gor... muntol de

912 
363

du regst mich so auf... Na so kō̄m. . .

so $k \bar{m}_{\ldots} \ldots . .$. Oh das ist gut. .

Graf...

$5 \quad$ Graf. Als $\odot$ - Servus! . ? Das' ist

Graf. ... Also jetzt geh ich Die Augen . . ganz

die Augen .... der Lulu möcht sicher sagen,

ich bin ein Narr - aber ich will nur no

einmal die Augen küssen . . (so . . un

jetzt . . grüß dich Gott, jetzt geh ich ... .

Dirne. Servus ...

Graf. (bei der Thür.) Du ... sag ... wundert dich 
HSz10 364

Handschriften und Typoskript

der ver wen ....

364

Shrue Merk:

Gral. vafo if unft won divill

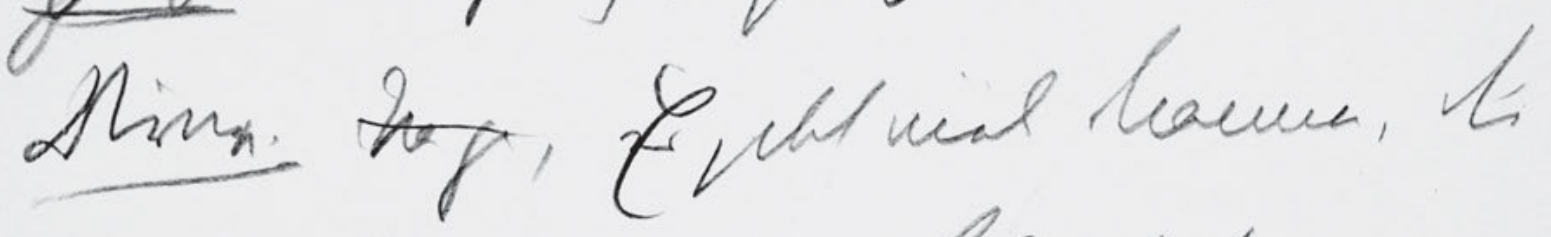
sich prif unlfarblot fin.

Qeal hag. Ri himen, b/ ifwet

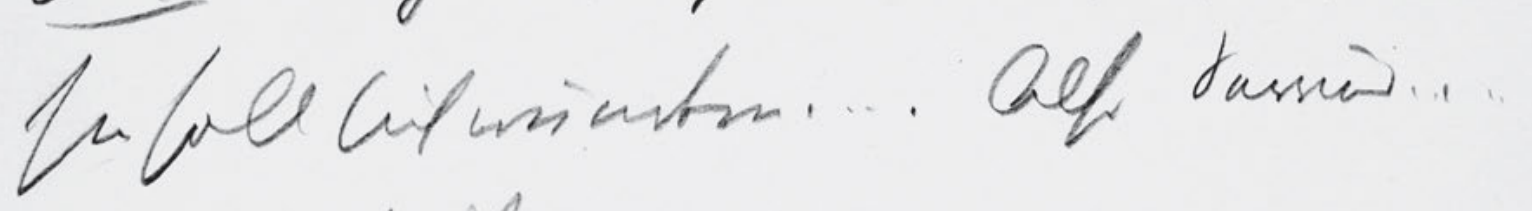

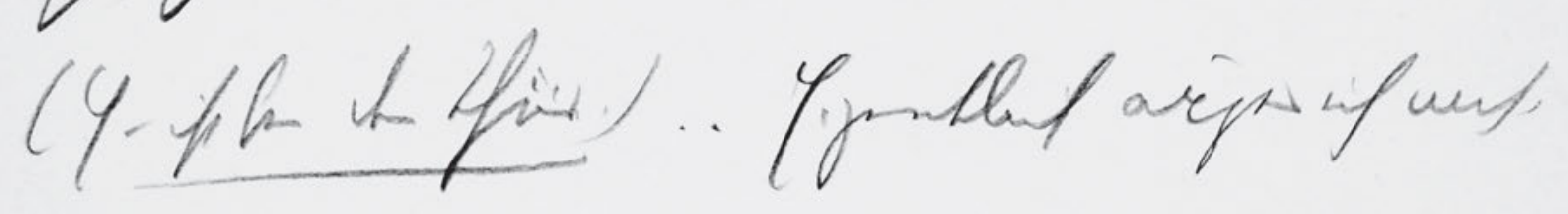

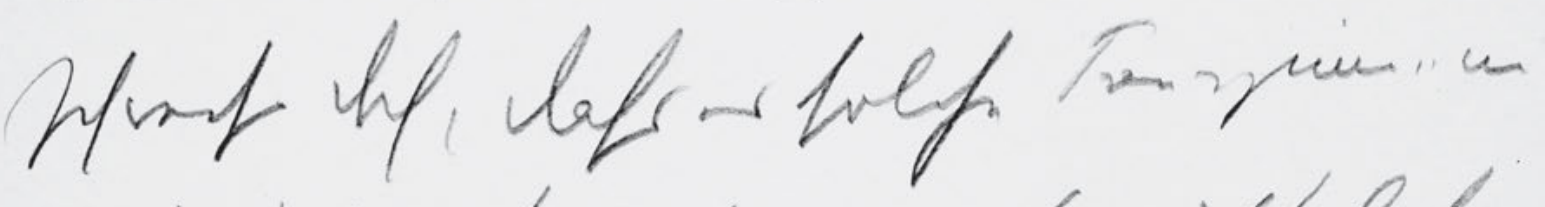

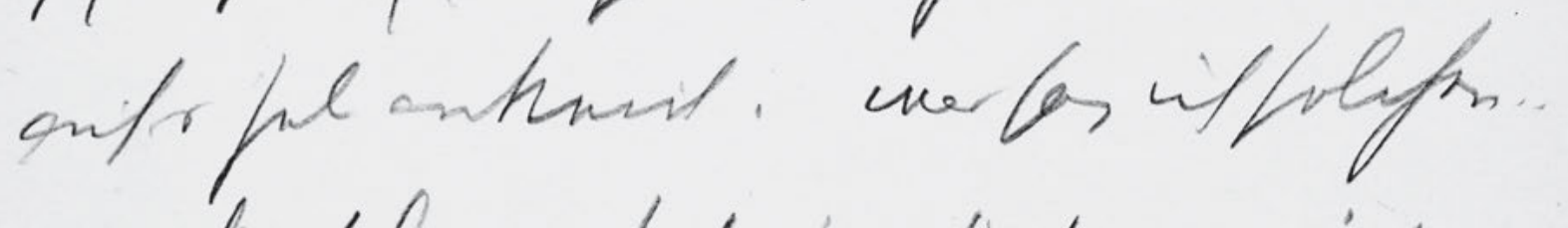

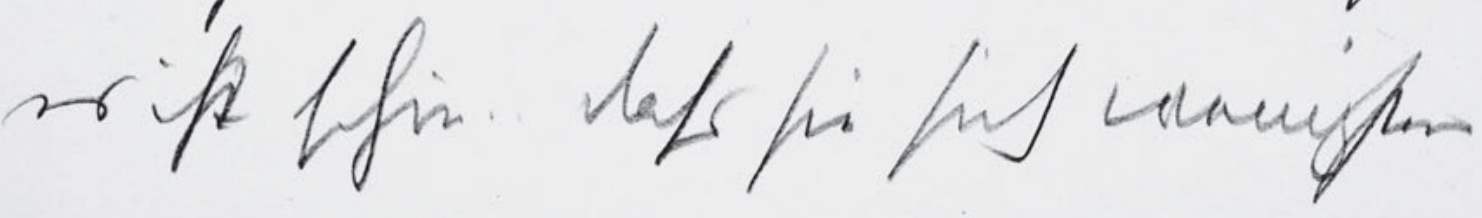

914 


\section{4}

das gar nicht....

Dirne Was denn?

Graf. . . Dass ich nichts von dir will . .

$5 \quad$ Dirne. Na ja, ${ }^{e}$ Es gibt viel Manner, die in der früh nicht aufglegt sind.

$$
\text { (F.s.) }
$$

Graf. Na ja ... Zu dumm, dass ich will sie soll sich wundern .... Also Servus .....

(Er ist bei der Thür.) . . Eigentlich ärger ich mich, Ich weiss doch, dass es solche Frauenzime .. nu aufs Gel ankō̄t . was sag ich solchen . . es ist schön . . dass sie sich wenigstens 
HSz10 365

Handschriften und Typoskript

wof ingplet bor foles muin up fomin ti unget if thei nuffers wert gi $L$..

Anin (ofut pifflopur biy n)

that

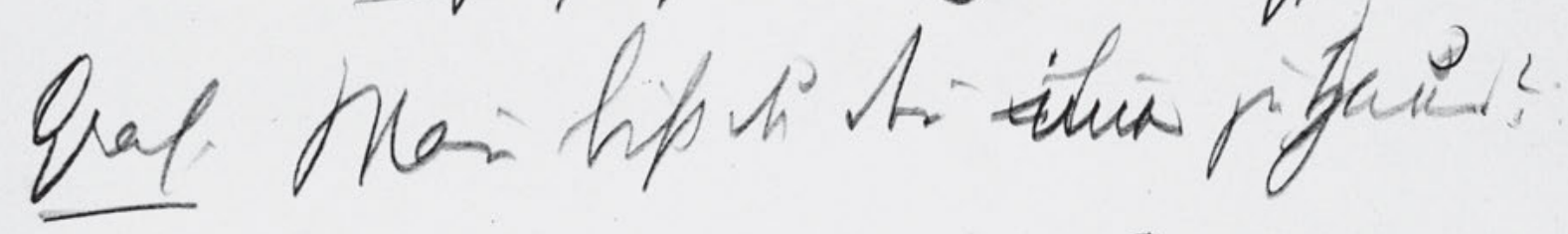

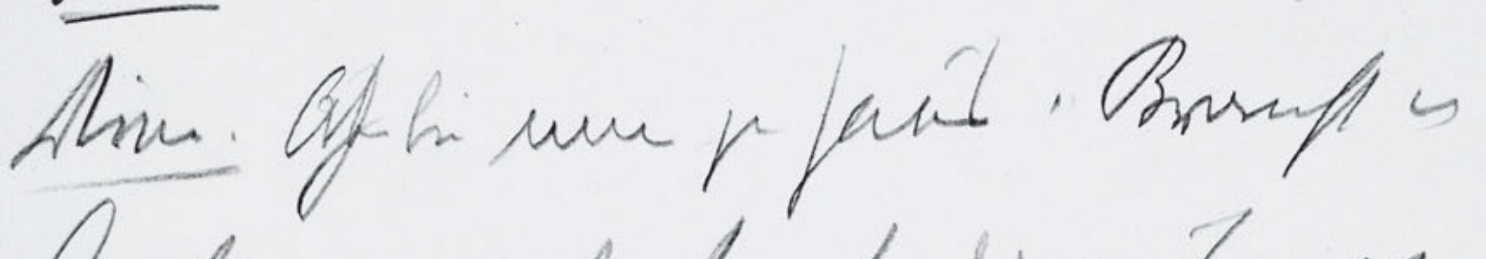
xey vel h trokativ faya. Epat. Lroparta. Dfin alf pus lifoll. (sinichis)?

Affere

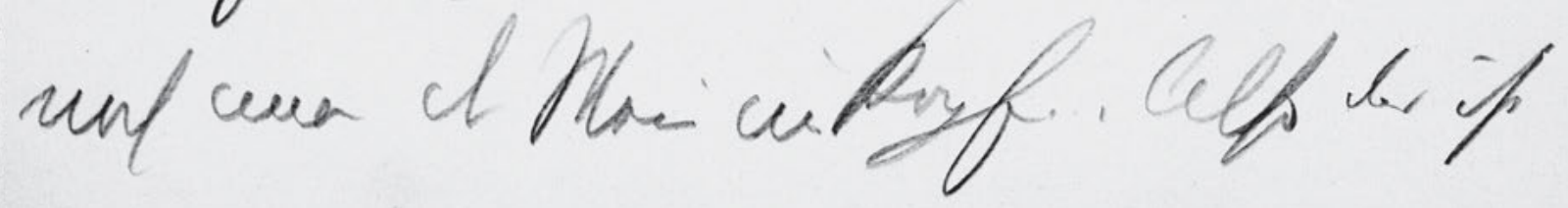

916 
365

nicht verstellt . . das sollt einen

eher freun .. du . . weißt, ich kō̄

nachstens wieder zu dir . .

$5 \quad$ Dirne (sie ${ }^{\left({ }^{2}\right.}$ it geschlossnen Augen) ${ }^{\text {Schon }}$ Gut.

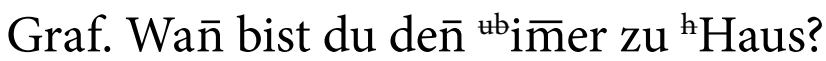

Dirne. ${ }^{\text {Abe }}$ Ic bin imer zu haus .. Brauchst ${ }^{?}$ ?

Graf. nach der Leokadia zu fragen.

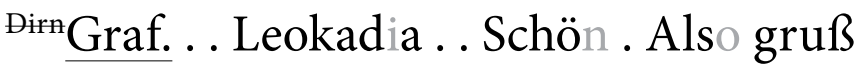

dich Gott. (Bei der Thür ${ }^{\dot{5}}$ Ich hab do

noch imer den Wein im Kopf . . . Also das ist 
HSz10 366

Handschriften und Typoskript

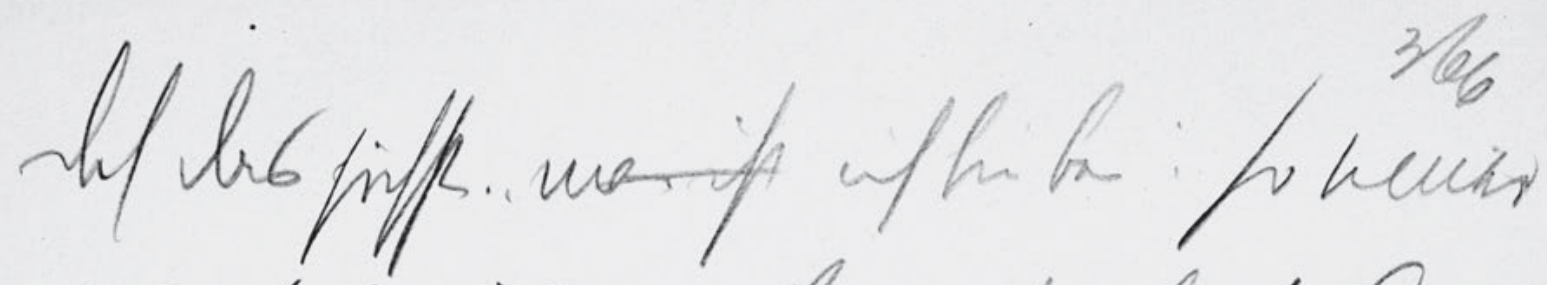

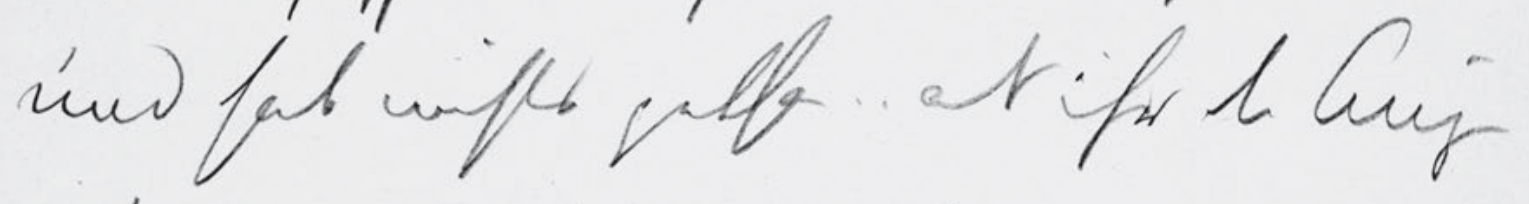
phiff unitfis mif an usen ancicia fert...... (Mondelfitpife) 1

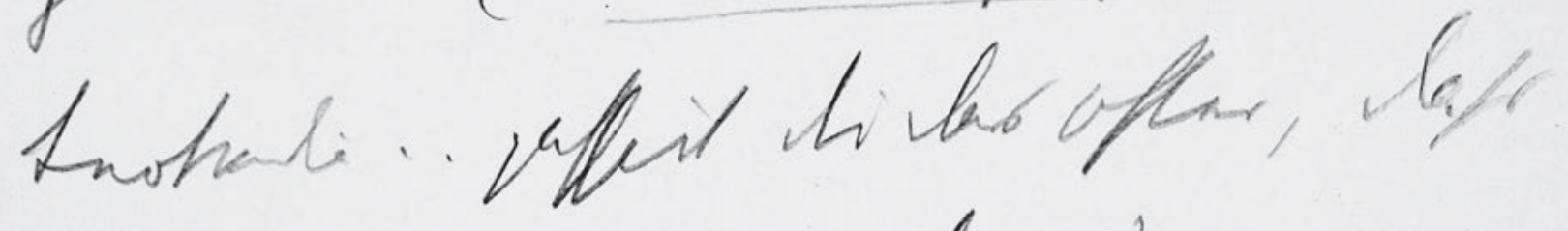
men of ungfl um lin.? Mni Mis hee.

Gal to wint.

this protif!

fral nisi... of rftefor an

918 
366

doch das höchste . . was ist ich bin bei : so einer

und hab nichts gethan .. als ihr die Augen

geküsst . . weil sie mich an wen erinner

5 hat ........ (Wendet sich zu ihr $\left.{ }^{*}\right) . d u$

Leokadia . passirt dir das ofter, dass

man so weggeht von dir - ?

Dirne. Wie denn.

Graf. So . . wie ich.

$10 \quad$ Dirne. In der früh?

Graf. Nein ... ob oft schon einma 
HSz10 367

Handschriften und Typoskript

markiline-L ceifrum nollefer

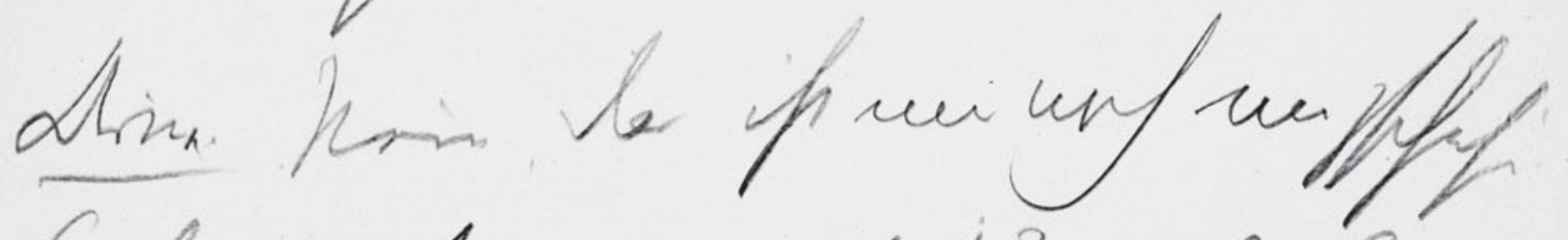

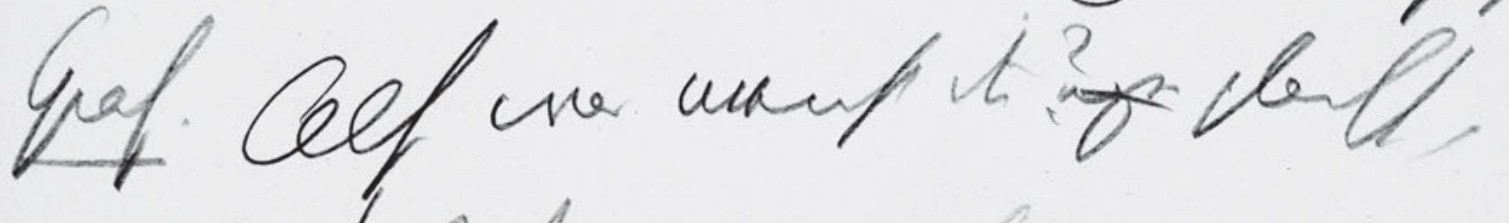
si sisfallf me unf.

thin Nerntollig th th we

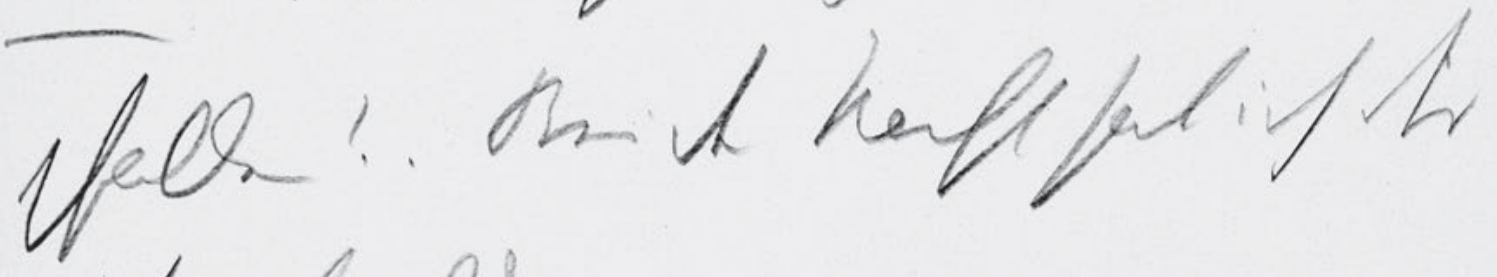
spraferes

Gef di sfelle wa anty this. Ala hist herffatif

920 


\section{7}

wer bei dir war - der nichts von dir

wollen hat.

Dirne. Nein, das ist mir noch nie gschehn!

$5 \quad$ Graf. Also was meinst du eige? glaubs, du du gfallst mir nicht.

Dirne. Warum soll ich dir den nich

gfallen? . Bei der Nacht hab ich dir

schon gfallen ..

$10 \quad$ Graf. Du gfallst mir auch jetzt -

Dirne. Aber bei der Nacht hab ich 
HSz10 368

Handschriften und Typoskript

Lis infol.

$$
\text { telt } 368
$$

Mines. ha, we troph hifotien',

Geef.

di. L her

Ans.

Mavir bentf dile.' 


\section{8}

dir besser gfallen.

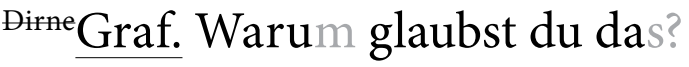

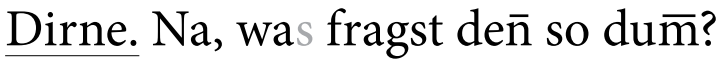

$5 \quad$ Graf. Bei der Nacht ... ja .. sag . . bin ich dē̄ nicht gleich am Divan hingfallen.

Dirne. . Na freilich ... mit mir zusam.

Graf. Mit dir ...

Dirne. . Ja weißt den̄ du das nī̄er.

$10 \quad$ Graf. Ich hab dich . . wir sind zusamen ..

....ja. . 
HSz10 369

Handschriften und Typoskript

the Celar gaf

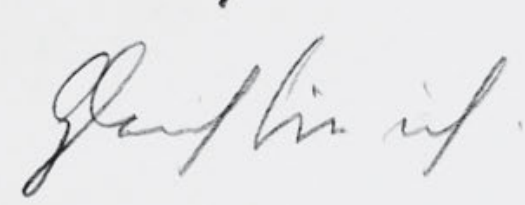

ar!

Arma.

Ja, Jik Geal...

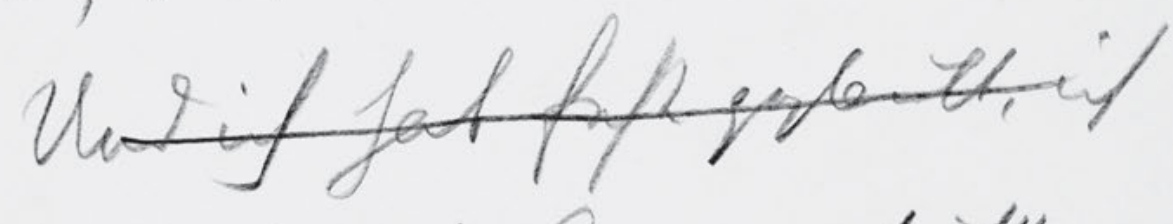

Hew

zo..... - Vart hy

aspliffrit.

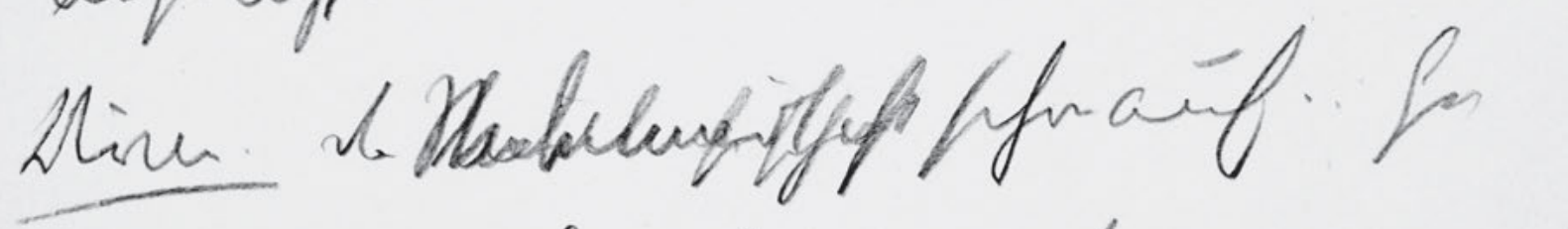

pit fr wer. An fi waingl

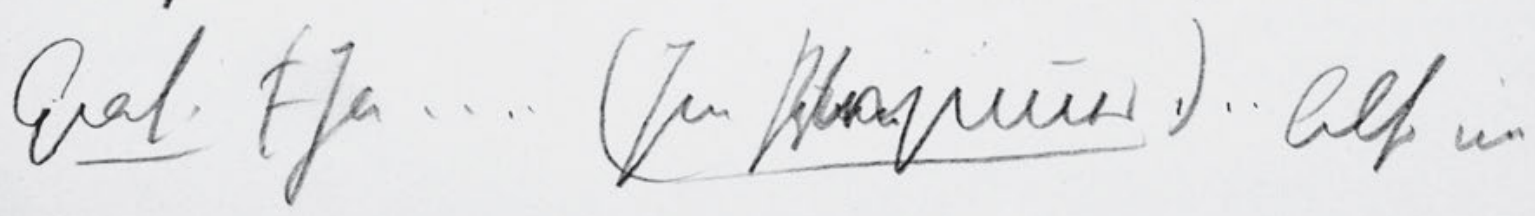

924 
Dirne . Aber gleich drauf bist du eingschlafen ..

Graf. Gleich bin ich . . So . . Also so war das? $!$.....

5 Dirne. Ja, Bubi.

Graf. ... Und ich hab fest geglaubt, ich

hab dich nur auf die Augen geküsst . .

So ....... Und doch ..... es ist eine entfernt

(Lärm)

Aehnlichkeit .... . Servus ...... Was ist den̄ ?los??

10 Dirne. Das Mädl list schon Stubenmädl ist schon auf . . Geh

gib ihr was . . beim hinausgeh.

Graf. (Ja .... (Im ${ }^{\text {Zimer }}{ }^{2}$ orzim̄er $\left.{ }^{\circ}\right)$. Also im 
HSz10 370

Handschriften und Typoskript
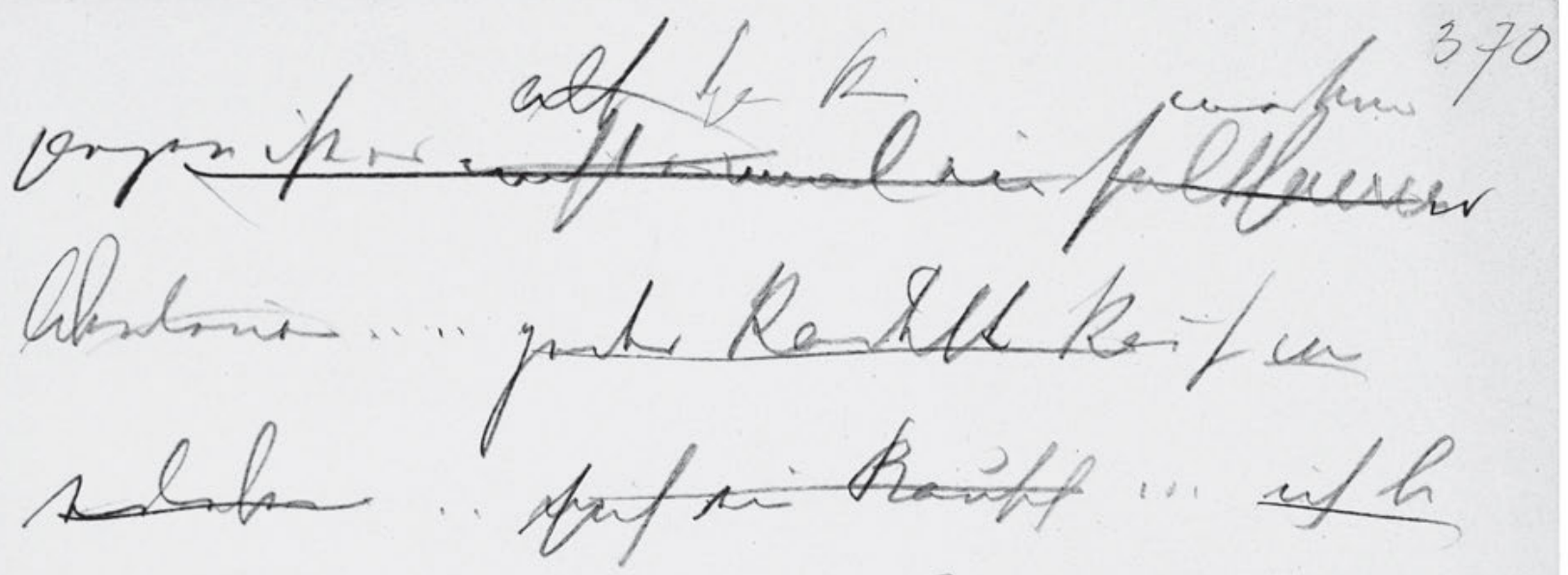

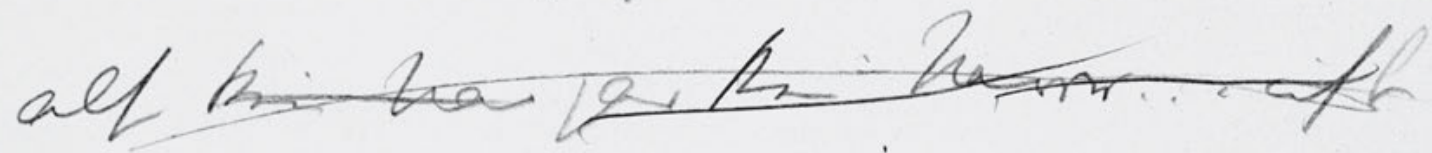

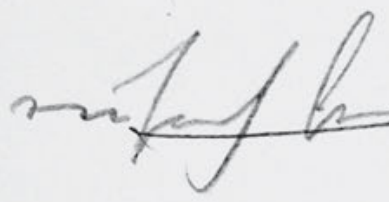

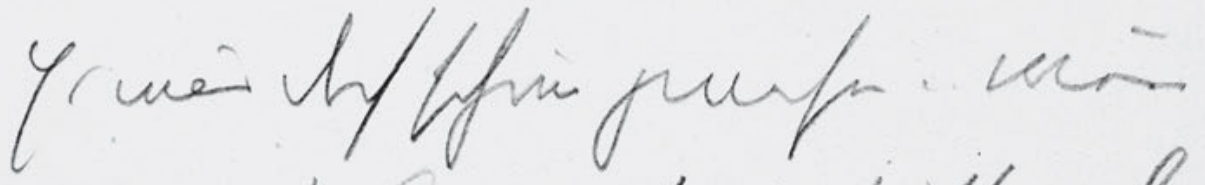

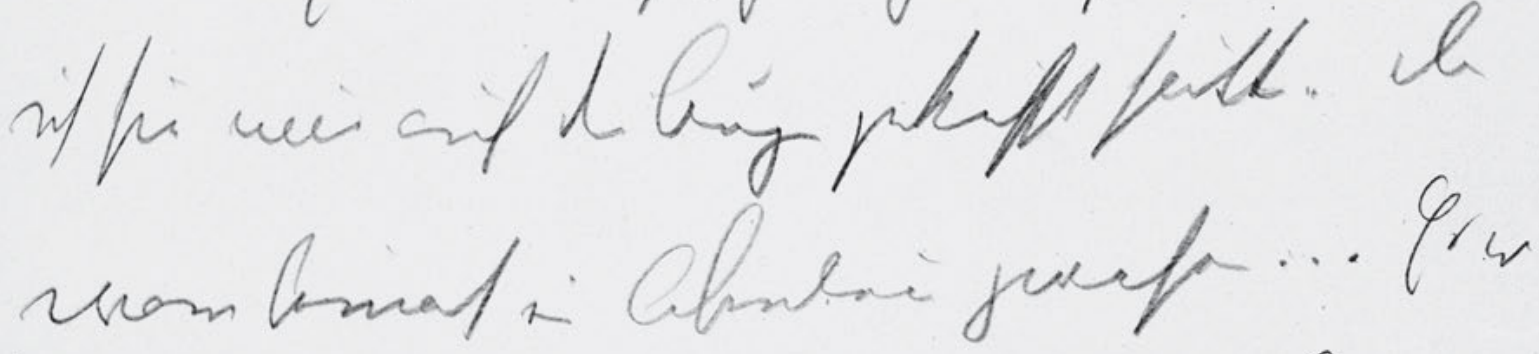
mi Goll ueffifticuent.

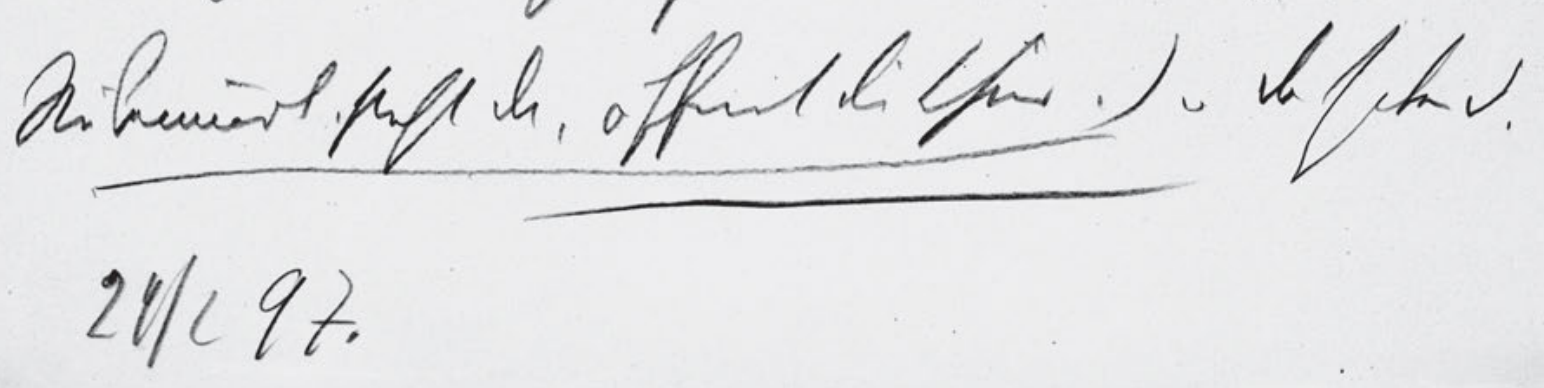

926 


$$
\text { als } \ominus \text { sgar kein merkwur } 370
$$

ganzen ist es nicht einmal ein seltsames

Abenteuer .... . jeder Kadett kan̄ so wa

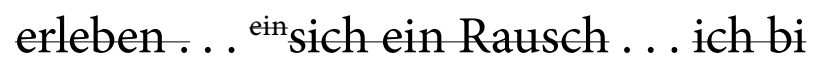

als $\odot$ kein Nar gar kein Narr... ich bin

einfach bei eine ${ }^{\mathrm{r}} \mathrm{m}$ Frauenzimer gwesen ..

- - Es wär doch schön gwesen .. wen̄

ich sie nur auf die Augen geküsst hätt . . das

ware beinah ein Abenteu gwesen ... Es w

Stubenmädl`steht da, öffnet die Thür.) .. da haben S.

24/2 97.

10f. Zuerst schien eine Replik des Stubenmädls geplant gewesen zu sein; dann wurde jedoch der entsprechende Punkt durch Nebentext überschrieben; schließlich wurde zur Vervollständigung nachträglich Das (Z 10) eingefügt. Davon unabhängig ist die Rede des Grafen: ah - - da haben S. (Z 10a/11). 

2. Drucktext 

'Reigen.

Zehn Dialoge.

\title{
Personen:
}

\author{
Die Dirne. \\ Der Soldat. \\ Das Stubenmädchen. \\ Der junge Herr. \\ Die junge Frau. \\ Der Ehegatte. \\ Das süße Mädel. \\ Der Dichter. \\ Die Schauspielerin. \\ Der Graf.
}


Soldat

(kommt pfeifend, will nach Hause.)

Dirne.

Komm', mein schöner Engel.

\section{Soldat}

(wendet sich um und geht wieder weiter).

Dirne.

Willst Du nicht mit mir kommen?

Soldat.

Ah, ich bin der schöne Engel?

Dirne.

Freilich, wer denn? Geh', komm zu mir. Ich wohn' gleich in der Näh'.

\section{Soldat.}

Ich hab' keine Zeit. Ich muß in die Kasern'!

Dirne.

In die Kasern' kommst' immer noch zurecht. Bei mir is besser.

'Soldat (greift nach ihr.)

Das ist schon möglich.

\section{Dirne.}

Pst. Jeden Moment kann ein Wachmann kommen.

\section{Soldat.}

Lächerlich! Wachmann! Ich hab' auch mein Seiten= g'wehr!

\section{Dirne.}

Geh', komm' mit.

\section{Soldat.}

Laß mich in Ruh. Geld hab' ich eh kein's. 
Dirne.

Ich brauch' kein Geld.

Soldat (bleibt stehen. Sie sind bei einer Laterne.)

Du brauchst kein Geld? Wer bist denn Du nachher?

Dirne.

Zahlen thun mir die Civilisten. So einer wie $\mathrm{Du}$ kann's immer umsonst bei mir haben.

\section{Soldat.}

Du bist am End' die, von der mir der Huber er= zählt hat. -

Dirne.

Ich kenn' kein' Huber nicht.

\section{Soldat.}

Du wirst schon die sein. Weißt - in dem Kaffee $=$ 'haus in der Schiffgassen - von dort ist er mit Dir nach Haus gangen.

\section{Dirne.}

Von dem Kaffeehaus bin ich schon mit gar vielen nach Haus gangen .... oh! oh! -

\section{Soldat.}

Also gehn wir, gehn wir.

Dirne.

Was, jetzt hast's eilig?

\section{Soldat.}

$\mathrm{Na}$, worauf soll'n wir noch warten? Und um zehn muß ich in der Kasern' sein.

Dirne.

Wie lang dienst' denn schon?

\section{Soldat.}

Was geht denn das Dich an? Wohnst weit?

Dirne.

Zehn Minuten zum gehn.

\section{Soldat.}

Das ist mir zu weit. Gieb mir ein Pussel.

Soldat (bleibt stehen. Sie] Soldat bleibt stehen. (Sie JSV

Du] du, EA JSV

nach Haus] z' Haus EA JSV BHV SFV

nach Haus] z' Haus EA JSV BHV SFV

gangen .... . gangen ... EA JSV BHV 
Dirne. (Sie küßt ihn.)

Das ist mir eh das liebste, wenn ich einen gern hab!

Soldat.

Mir nicht. Nein, ich geh' nicht mit Dir, es ist mir zu weit.

'Dirne.

Weißt was, komm morgen am Nachmittag.

Soldat.

Gut is. Gieb mir Deine Adresse.

Dirne.

Aber Du kommst am End' nicht.

\section{Soldat.}

Wenn ich Dir's sag!

\section{Dirne.}

$\mathrm{Du}$, weißt was, - wenn's Dir zu weit ist heut abend zu mir — da ... da ... (weist auf die Donau).

\section{Soldat.}

Was ist da?

Dirne.

Da ist auch schön ruhig.... geht jetzt kein Mensch.

\section{Soldat.}

Ah, das ist nicht das rechte.

\section{Dirne.}

Bei mir is immer das rechte. Geh', bleib jetzt bei mir. Wer weiß, ob wir morgen noch's Leben haben.

\section{Soldat.}

So komm - aber g'schwind!

Dirne.

Gieb obacht, da ist so dunkel. Wennst ausrutscht, liegst in der Donau.

\section{'Soldat.}

Wär' eh das beste.

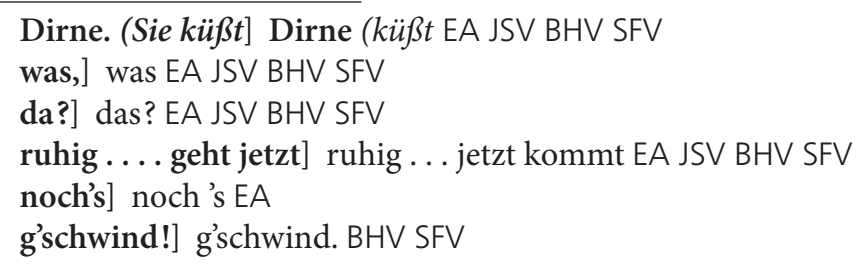


Dirne.

Pst, so wart nur ein bissel. Gleich kommen wir zu einer Bank.

\section{Soldat.}

Kennst Dich da gut aus.

Dirne.

So einen wie Dich möcht' ich zum Geliebten.

\section{Soldat.}

Ich thät' Dir zu viel eifern.

Dirne.

Das möcht' ich Dir schon abgewöhnen.

\section{Soldat.}

$\mathrm{Ha}-$

Dirne.

Nicht so laut. Manchmal is doch, daß sich ein

Wachter her verirrt. Sollt' man glauben, daß wir da mitten in der Wiener Stadt sind?

\section{Soldat.}

Daher komm', daher.

Dirne.

Aber, was fällt Dir denn ein, wenn wir da aus= rutschen, liegen wir im Wasser unten.

Soldat hat sie gepackt.

$\mathrm{Ah}, \mathrm{Du}-$

'Dirne.

Halt Dich nur fest an.

\section{Soldat.}

Hab kein' Angst..... oh .....

Dirne.

Auf der Bank wär's schon besser gewesen.

\section{Soldat.}

Da oder da .... Na, krall' aufi.

$\begin{array}{ll}127 & \text { Wiener Stadt] Wienerstadt EA JSV BHV SFV } \\ 131 & \text { Aber,] Aber EA JSV BHV SFV } \\ 138 & \text { Angst .... oh..... . Angst.... EA JSV BHV Angst ... SFV } \\ 139 & --------------- \text { ] fehlt SFV } \\ 143 & \text { aufi.] aufi! BHV SFV }\end{array}$


Dirne.

Was laufst denn so -

Soldat.

Ich muß in die Kasern', ich komm' eh schon zu spät.

Dirne.

Geh', Du, wie heißt' denn?

Soldat.

Was interessiert Dich denn das, wie ich heiß?

Dirne.

Ich heiß Leocadia.

\section{Soldat.}

Ha! - So an' Namen hab' ich auch noch nie gehört.

Dirne.

Du, ich werd Dir 'was sagen ... so gut .... so

.... oh .... so .... geh', komm' zu mir.

Soldat.

Jetzt? . . . Jetzt?? -

'Dirne.

$\mathrm{Du}$ !

\section{Soldat.}

$\mathrm{Na}$, was willst denn?

Dirne.

Geh, ein Sechserl für'n Hausmeister gieb mir wenigstens! -

\section{Soldat.}

Ha! . . . Glaubst, ich bin Deine Wurzen .... .

Servus! Leocadia . .

Dirne.

Strizzi! Fallott! -

(Er ist verschwunden.)

156-158 Dirne. Du, [...] mir.] fehlt EA JSV BHV SFV

159f. Soldat. Jetzt? ... . Jetzt?? -] fehlt EA JSV BHV SFV

$169 \mathrm{Ha}$..... Ha!... EA JSV BHV

Wurzen .... .] Wurzen ... EA JSV BHV

Leocadia .. .] Leocadia.... EA JSV BHV 
'Prater. Sonntag Abend.

Ein Weg, der vom Wurstelprater aus in die dunkeln Alleen führt.

Aus der Ferne hört man noch die wirre Musik des Wurstelpraters; auch

die Klänge vom Fünfkreuzertanz; eine ordinäre Polka, von Bläsern gespielt. Der Soldat. Das Stubenmädchen.

\section{Stubenmädchen.}

Jetzt sagen S' mir aber, warum S’ durchaus schon haben fortgehen müssen.

\section{Soldat}

(lacht verlegen, dumm.)

Stubenmädchen.

Es ist doch so schön gewesen. Ich tanz' so gern.

\section{Soldat.}

(faßt sie um die Taille).

Stubenmädchen (läßt's geschehen.)

Jetzt tanzen wir ja nimmer. Warum halten S' mich so fest?

Soldat.

Wie heißen S'? Kathi?

\section{Stubenmädchen.}

Ihnen ist immer eine Kathi im Kopf.

'Soldat.

Ich weiß, ich weiß schon ... . Marie.

\section{Stubenmädchen.}

Sie, da ist aber dunkel. Ich krieg so eine Angst.

\section{Soldat.}

Wenn ich bei Ihnen bin, brauchen S' Ihnen nicht zu fürchten. Gott sei Dank, mir sein mir!

\section{Stubenmädchen.}

Aber wohin kommen wir denn da? Da ist ja kein

Mensch mehr. Kommen S', geh’n wir zurück! — Und so dunkel!

Aus der Ferne [...] des Wurstelpraters;] Hier hört man noch die wirre Musik aus dem Wurstelprater; EA JSV Hier hört man noch die wirre Musik aus dem Wurstelprater, BHV SFV Fünfkreuzertanz;] Fünfkreuzertanz, EA JSV BHV SFV 
Soldat (zieht an seiner Virginierzigarre, daß das rote Ende leuchtet.) 's wird schon lichter! Haha! Oh, Du Schatzerl!

Stubenmädchen.

Ah, was machen S' denn. Wenn ich das gewußt hätt'.

\section{Soldat.}

Also der Teufel soll mich holen, wenn eine heut beim Swoboda mollerter gewesen ist als Sie, Fräul'n Marie.

\section{Stubenmädchen.}

Haben S' denn bei allen so probiert?

\section{Soldat.}

Was man so merkt, beim Tanzen. Da merkt man gar viel! Ha!

\section{Stubenmädchen.}

Aber mit der blonden mit dem schiefen Gesicht haben $S$ ' doch mehr 'tanzt als mit mir.

'Soldat.

Das ist eine alte Bekannte von einem meinigen

Freund.

Stubenmädchen.

Von dem Korporal mit dem auf'drehten Schnurrbart?

\section{Soldat.}

Ah nein, das ist der Civilist gewesen, wissen S', der im Anfang am Tisch mit mir g'sessen ist, der so heis'rig red't.

\section{Stubenmädchen.}

Ah, ich weiß schon. Das ist ein kecker Mensch.

\section{Soldat.}

Hat er Ihnen 'was 'than? Dem möcht' ich's zeigen!

Was hat er Ihnen 'than?

\section{Stubenmädchen.}

Oh nichts - ich hab nur geseh'n, wie er mit die andern ist.

\section{Soldat.}

Sagen S', Fräulein Marie .... .

\section{Stubenmädchen.}

Sie werden mich verbrennen mit Ihrer Cigarr'n.

$\begin{array}{ll}208 & \text { lichter!] lichter. SFV } \\ 210 & \text { denn.] denn? EA denn? JSV BHV SFV } \\ 211 & \text { hätt'.] hätt'! EA hätt'! JSV BHV SFV } \\ 240 & \text { Marie..... . Marie ... . EA JSV BHV }\end{array}$


Soldat.

Pahdon! - Fräul'n Marie. Sagen wir uns Du.

Stubenmädchen.

Wir sein noch nicht so gute Bekannte. -

\section{Soldat.}

Es können sich gar viele nicht leiden und sagen doch

Du zu einander.

'Stubenmädchen.

's nächste Mal, wenn wir . . . Aber Herr Franz -

Soldat.

Sie haben sich meinen Namen g'merkt?

Stubenmädchen.

Aber Herr Franz . . . .

Soldat.

Sagen S’ Franz; Fräulein Marie.

\section{Stubenmädchen.}

So sein S' nicht so keck - aber pst, wenn wer kommen thät!

Soldat.

Und wenn schon einer kommen thät, man sieht ja nicht zwei Schritt' weit.

\section{Stubenmädchen.}

Aber um Gotteswillen, wohin kommen wir denn da?

\section{Soldat.}

Seh'n S', da sind zwei g'rad wie mir.

\section{Stubenmädchen.}

Wo denn? Ich seh' gar nichts.

\section{Soldat.}

Da ... vor uns.

\section{Stubenmädchen.}

Warum sagen S' denn: zwei wie mir? -

\section{Soldat.}

$\mathrm{Na}$, ich mein' halt, die haben sich auch gern.

\footnotetext{
251 nächste Mal] nächstemal EA JSV BHV SFV

Aber] Aber, EA JSV BHV SFV

255 Aber] Aber, EA JSV BHV SFV

Franz .... Franz ... BHV

257 Franz;] Franz, EA JSV BHV SFV
} 
'Stubenmädchen.

Aber geben S' doch acht, was ist denn da, jetzt wär' ich beinah' g'fallen.

Soldat.

$\mathrm{Ah}$, das ist das Gatter von der Wiesen.

\section{Stubenmädchen.}

Stoßen S' doch nicht so, ich fall' ja um.

\section{Soldat.}

Pst, nicht so laut.

\section{Stubenmädchen.}

Sie, jetzt schrei' ich aber wirklich. - Aber was

machen S' denn .... aber -

\section{Soldat.}

$\mathrm{Da}$ ist jetzt weit und breit keine Seel'.

\section{Stubenmädchen.}

So geh'n wir zurück, wo Leut' sein.

\section{Soldat.}

Wir brauchen keine Leut', was Marie, wir brauchen .... dazu ... . haha.

\section{Stubenmädchen.}

Aber Herr Franz bitt' Sie, Franz, um Gotteswillen, schau'n S', wenn ich das .... gewußt .... oh .... oh .... komm! ... .

Soldat (selig.)

Herrgott noch einmal .... ah ....

'Stubenmädchen.

... . Ich kann Dein G'sicht gar nicht seh'n.

\section{Soldat.}

Ah was - G'sicht.....

$\begin{array}{ll}287 & \text { denn ... . .] denn ... EA JSV BHV } \\ 291 & \text { Leut'] Leute BHV SFV } \\ 293 & \text { was] was, EA JSV BHV SFV } \\ 296 & \text { Aber] Aber, EA JSV BHV SFV } \\ & \text { Franz] Franz, EA JSV BHV SFV } \\ & \text { Sie, Franz,] Sie, EA JSV BHV SFV } \\ 298 & \text { komm! .. . . komm! . . JSV BHV } \\ 305 & \text { Ah] A EA JSV BHV SFV } \\ & \text { G'sicht .... . . G'sicht ... . JSV BHV }\end{array}$




\section{Soldat.}

Ja, Sie, Fräul'n Marie, da im Gras können S' nicht liegen bleiben.

\section{Stubenmädchen.}

Geh, Franz, hilf mir.

\section{Soldat.}

$\mathrm{Na}$, komm zugi.

\section{Stubenmädchen.}

Oh Gott, Franz.

Soldat.

$\mathrm{Na}$ ja, was ist denn mit dem Franz.

\section{Stubenmädchen.}

Du bist ein schlechter Mensch, Franz.

\section{Soldat.}

Ja, ja. Geh', wart ein bissel.

\section{Stubenmädchen.}

Was laßt' mich denn aus?

\section{Soldat.}

$\mathrm{Na}$, die Virginier werd' ich mir doch anzünden dürfen.

\section{Stubenmädchen.}

Es ist so dunkel.

Soldat.

Morgen früh ist schon wieder licht.

\section{Stubenmädchen.}

Sag' wenigstens, hast mich gern?

Soldat.

$\mathrm{Na}$, das mußt doch g’spürt haben, Fräul'n Marie, ha!

\section{Stubenmädchen.}

Wohin gehn wir denn?

Soldat.

$\mathrm{Na}$, zurück.

\section{Stubenmädchen.}

Geh', bitt' Dich, nicht so schnell!

\section{Soldat.}

$\mathrm{Na}$ was ist denn? Ich geh nicht gern in der finstern. 


\section{Stubenmädchen.}

Sag', Franz, hast mich gern?

Soldat.

Aber grad' hab' ich's g'sagt, daß ich Dich gern hab!

\section{Stubenmädchen.}

Geh', willst mir nicht ein Pussel geben.

Soldat gnädig.

Da .... Hörst, - jetzt kann man schon wieder die Musik hören.

\section{Stubenmädchen.}

Du möchtst am End' gar wieder tanzen gehn.

Soldat.

$\mathrm{Na}$ freilich, was denn?

\section{Stubenmädchen.}

Ja, Franz, schau', ich muß zu Haus geh'n. Sie werden eh schon schimpfen, mei' Frau ist so eine .... die möcht' am liebsten, man ging' gar nicht fort.

\section{Soldat.}

$\mathrm{Na}$ ja, geh' halt zu Haus.

Stubenmädchen.

Ich hab' halt 'dacht, Herr Franz, Sie werden mich z'hausführen.

\section{Soldat.}

Z’hausführen? Ah!

Stubenmädchen.

Geh'n S', es ist so traurig, allein z'haus gehn.

Soldat.

Wo wohnen S' denn?

Stubenmädchen.

Es ist gar nicht so weit - in der Porzellangasse.

geben.] geben? EA geben? JSV BHV SFV

gehn.] geh'n? EA geh'n? JSV BHV SFV

z'hausführen] z' Haus führen BHV SFV

Z'hausführen] Z' Haus führen BHV SFV

z'haus] z' Haus BHV SFV 


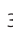

\section{Soldat.}

So? Ja, da haben wir ja einen Weg .... aber jetzt ist's mir zu früh ... jetzt wird noch 'draht, heut' hab' ich über Zeit .... vor 12 brauch i nicht in der Kasern zu sein. I geh' noch tanzen.

\section{Stubenmädchen.}

Freilich, ich weiß schon, jetzt kommt die blonde mit dem schiefen Gesicht dran!

\section{'Soldat.}

Ha! - Der ihr G’sicht ist gar nicht so schief.

\section{Stubenmädchen.}

Oh Gott, sein die Männer schlecht. Was, Sie machen's sicher mit einer jeden so.

\section{Soldat.}

Das wär' z’ viel! -

\section{Stubenmädchen.}

Franz, bitt' schön, heut nimmer, - heut bleiben S' mit mir, schau'n $S^{\prime}-$

\section{Soldat.}

Ja ja, ist schon gut. Aber tanzen werd' ich doch noch dürfen.

\section{Stubenmädchen.}

Ich tanz' heut mit kein' mehr!

\section{Soldat.}

Das ist er ja schon . .

\section{Stubenmädchen.}

Wer denn?

\section{Soldat.}

Der Swoboda! Wie schnell wir wieder da sein.

.... Also wannst auf mich warten willst, so führ' ich

Dich z'haus .... wenn nicht ... Servas -

\section{Stubenmädchen.}

Ja, ich werd' warten.

Zeit....] Zeit.....EA

i] ich EA JSV BHV SFV

z'viel] z'viel EA JSV BHV SFV

Ja] Ja, EA JSV BHV SFV

Das] Da EA JSV BHV SFV

da:] das ... EA JSV BHV SFV

z'haus.... z' z' Haus.... BHV z' Haus... SFV 
(Sie treten in den Tanzsaal ein.)

'Soldat.

Wissen S', Fräul'n Marie, ein Glas Bier lassen S'

Ihnen geben. ( $\mathrm{Zu}$ einer blonden sich wendend, die eben mit einem

Burschen vorbeitanzt, sehr hochdeutsch:) Mein Fräulein, darf ich bitten? -

\section{'Das Stubenmädchen und der junge Herr.}

PD [29] - EA [31]

\section{${ }^{\top}$ Heißer Sommernachmittag. - Die Eltern sind schon auf dem Lande.} Die Köchin hat Ausgang. - Das Stubenmädchen schreibt in der Küche einen Brief an den Soldaten, der ihr Geliebter ist. Es klingelt aus dem Zimmer des jungen Herrn. Sie steht auf und geht in's Zimmer des jungen Herrn.

Der junge Herr liegt auf dem Divan, raucht, und liest einen französischen Roman.

Das Stubenmädchen.

Bitt' schön, junger Herr?

\section{Der junge Herr.}

Ah ja, Marie, ah ja, ich hab’ geläutet, ja ... was hab' ich nur .... ja richtig, die Rouletten lassen $S$ herunter, Marie ... . Es ist kühler, wenn die Rouletten unten sind .... ja....

(Das Stubenmädchen geht zum Fenster und läßt die Rouletten herunter.)

Der junge Herr (liest weiter.)

Was machen S' denn, Marie? Ach ja. Jetzt sieht man aber gar nichts zum lesen.

\section{Das Stubenmädchen.}

Der junge Herr ist halt immer so fleißig.

$\begin{array}{ll}408 & \text { lassen S'] lassen's EA JSV BHV SFV } \\ 413 & \text { Lande.] Lande. - EA JSV BHV SFV } \\ 418 & \text { raucht, ] raucht SFV } \\ 423 & \text { ja ... . ja ... . JSV BHV } \\ 424 & \text { nur .... . nur . . EA JSV BHV } \\ 425 & \text { Marie ... . . Marie . . EA JSV BHV } \\ 429 & \text { Ach] Ah EA JSV BHV SFV } \\ 430 & \text { lesen] Lesen EA JSV BHV SFV }\end{array}$


'Der junge Herr (überhört das vornehm.)

So, ist gut.

(Marie geht.)

Der junge Herr

(versucht weiter zu lesen; läßt bald das Buch fallen, klingelt wieder.)

Das Stubenmädchen.

(erscheint.)

Der junge Herr.

Sie, Marie .... ja was ich habe sagen wollen

... . ja . . . . ist vielleicht ein Cognac zu Haus?

Das Stubenmädchen.

Ja, der wird eingesperrt sein.

Der junge Herr.

$\mathrm{Na}$, wer hat denn die Schlüssel?

Das Stubenmädchen.

Die Schlüssel hat die Lini.

Der junge Herr.

Wer ist die Lini?

Das Stubenmädchen.

Die Köchin, Herr Alfred.

Der junge Herr.

$\mathrm{Na}$, so sagen S' es halt der Lini.

Das Stubenmädchen.

Ja, die Lini hat heut Ausgang.

Der junge Herr.

So .....

'Das Stubenmädchen.

Soll ich dem jungen Herrn vielleicht aus dem Kaffee= haus....

Der junge Herr.

Ah nein .... es ist so heiß genug. Ich brauch' keinen Cognac. Wissen S', Marie, bringen Sie mir ein Glas Wasser. Pst, Marie - aber laufen lassen, daß es recht kalt ist. -

(Das Stubenmädchen ab.) 
Der junge Herr

(sieht ihr nach, bei der Thür wendet sich das Stubenmädchen nach ihm um; der junge Herr schaut in die Luft. - Das Stubenmädchen dreht den Hahn der Wasserleitung auf, läßt das Wasser laufen. Während dem geht sie in ihr kleines Kabinet, wäscht sich die Hände, richtet vor dem Spiegel ihre Schneckerln. Dann bringt sie dem jungen Herrn das Glas Wasser. Sie tritt zum Divan.)

Der junge Herr (richtet sich zur Hälfte auf, das Stubenmädchen giebt ihm das Glas in die Hand, ihre Finger berühren sich).

Der junge Herr.

So, danke. - Na, was ist denn? - Geben Sie acht; stellen Sie das Glas wieder auf die Tasse .... (Er legt sich hin und streckt sich aus.) Wie spät ist's denn? -

Das Stubenmädchen.

Fünf Uhr, junger Herr.

Der junge Herr.

So, fünf Uhr. - Ist gut. -

'Das Stubenmädchen (geht; bei der Thür wendet sie sich um; der junge Herr hat ihr nach= geschaut; sie merkt es und lächelt).

Der junge Herr

(bleibt eine Weile liegen, dann steht er plötzlich auf. Er geht bis zur

Thür, wieder zurück, legt sich auf den Divan. Er versucht wieder zu lesen. Nach ein paar Minuten klingelt er wieder).

\section{Das Stubenmädchen}

(erscheint mit einem Lächeln, das sie nicht zu verbergen sucht).

Der junge Herr.

Sie, Marie, was ich Sie hab' fragen wollen. War heut' Vormittag nicht der Doktor Schüller da?

\section{Das Stubenmädchen.}

Nein, heut Vormittag war niemand da.

\footnotetext{
4711. Während dem] Währenddem BHV SFV

472 Kabinet] Kabinett EA JSV BHV SFV

480 acht; ] acht, BHV SFV

481 denn? -] denn? BHV SFV

487 geht; ] geht, BHV SFV

um;] um, BHV SFV 
Der junge Herr.

So, das ist merkwürdig. Also der Doktor Schüller war nicht da? Kennen Sie überhaupt den Doktor Schüller?

\section{Das Stubenmädchen.}

Freilich. Das ist der große Herr mit dem schwarzen

Vollbart.

Der junge Herr.

Ja. War er vielleicht doch da?

Das Stubenmädchen.

Nein, es war niemand da, junger Herr.

Der junge Herr (entschlossen.)

Kommen Sie her, Marie.

'Das Stubenmädchen (tritt etwas näher.)

Bitt' schön.

Der junge Herr.

Näher ... . so . . . ah . . . ich hab' nur ge $=$ glaubt.....

\section{Das Stubenmädchen.}

Was haben der junge Herr?

Der junge Herr.

Geglaubt .... geglaubt hab' ich - Nur wegen Ihrer

Blusen .... Was ist das für eine .... Na, kommen

S’ nur näher. Ich beiß' Sie ja nicht.

Das Stubenmädchen (kommt zu ihm.)

Was ist mit meiner Blusen? G'fallt sie dem jungen

Herrn nicht?

Der junge Herr (faßt die Bluse an, wobei er das Stubenmädchen zu sich herabzieht.)

Blau? Das ist ganz ein schönes Blau. (Einfach.)

Sie sind sehr nett angezogen, Marie.

Das Stubenmädchen.

Aber junger Herr ....

Der junge Herr.

$\mathrm{Na}$, was ist denn?... (er hat ihre Bluse geöffnet.

Sachlich): Sie haben eine schöne weiße Haut, Marie.

Das Stubenmädchen.

Der junge Herr thut mir schmeicheln.

5155. geglaubt..... .] geglaubt .... BHV

533 denn?....] denn?..... BHV 
'Der junge Herr (küßt sie auf die Brust.)

Das kann doch nicht weh thun.

Das Stubenmädchen.

Oh nein.

Der junge Herr.

Weil Sie so seufzen! Warum seufzen Sie denn?

Das Stubenmädchen.

Oh, Herr Alfred ....

Der junge Herr.

Und was Sie für nette Pantoffeln haben .....

Das Stubenmädchen.

.... Aber .... junger Herr .... wenn's

draußen läut' -

Der junge Herr.

Wer wird denn jetzt läuten?

Das Stubenmädchen.

Aber junger Herr . . . . schaun S’ . . . es ist so licht....

\section{Der junge Herr.}

Vor mir brauchen Sie sich nicht zu genieren. Sie brauchen sich überhaupt vor niemandem .... wenn man so hübsch ist. Ja, meiner Seel', Marie, Sie sind . . . Wissen Sie, Ihre Haare riechen sogar angenehm.

Das Stubenmädchen.

Herr Alfred ....

Der junge Herr.

Machen Sie keine solchen Geschichten, Marie .... .

'ich hab' Sie schon anders auch gesehn. Wie ich neulich in der Nacht nach Haus gekommen bin, und mir Wasser geholt hab; da ist die Thür zu Ihrem Zimmer offen gewesen.... na....

Das Stubenmädchen (verbirgt ihr Gesicht.)

Oh Gott, aber das hab ich garnicht gewußt, daß der Herr Alfred so schlimm sein kann.

\footnotetext{
542 seufzen!] seufzen. BHV SFV

546 haben ..... . haben .... EA JSV BHV

558 Seel',] Seel'; EA JSV BHV SFV

sind .... sind .... EA JSV BHV

Marie.... .] Marie... JSV

bin,] bin SFV

hab;] hab', BHV SFV

garnicht] gar nicht EA JSV BHV SFV
} 
Der junge Herr.

Da hab' ich sehr viel gesehen .... das ... und das .... und das .... und -

\section{Das Stubenmädchen.}

Aber, Herr Alfred!

Der junge Herr.

Komm, komm .... daher ... . so, ja, so ....

Das Stubenmädchen.

Aber wenn jetzt wer läutet -

Der junge Herr.

Jetzt hören Sie schon einmal auf . . . . macht man

höchstens nicht auf ... .

(Es klingelt.)

Der junge Herr.

Donnerwetter .... Und was der Kerl für einen

Lärm macht. - Am End hat der schon früher geläutet und wir habens nicht gemerkt.

'Das Stubenmädchen.

Oh, ich hab' alleweil aufgepaßt.

Der junge Herr.

$\mathrm{Na}$, so schaun S' endlich nach — durchs Guckerl. -

\section{Das Stubenmädchen.}

Herr Alfred ... . Sie sind aber .... nein ....

so schlimm.

Der junge Herr.

Bitt' Sie, schaun S' jetzt nach ....

LDas Stubenmädchen (geht $a b$.)

Der junge Herr (öfnet rasch die Rouleaux.)

Das Stubenmädchen (erscheint wieder.)

Der ist jedenfalls schon wieder weggangen. Jetzt ist niemand mehr da. Vielleicht ist es der Doktor Schüller gewesen.

Der junge Herr (ist unangenehm berührt)

Es ist gut.

Das Stubenmädchen (nähert sich ihm.)

577 ja,] ja EA JSV BHV SFV

so....] so ... EA JSV BHV

587 geläutet] geläutet, SFV

599 Rouleaux] Rouleaus BHV SFV 
Der junge Herr entzieht sich ihr.

- Sie, Marie, - ich geh' jetzt in's Kaffeehaus.

Das Stubenmädchen zärtlich.

Schon .... Herr Alfred.

Der junge Herr (streng.)

Ich geh' jetzt in's Kaffeehaus. Wenn der Doktor

Schüller kommen sollte -

'Das Stubenmädchen.

PD [39]

Der kommt heut nimmer.

Der junge Herr (noch strenger.)

EA 44

Wenn der Doktor Schüller kommen sollte, ich, ich

... . ich bin - im Kaffeehaus. - (Geht ins andere Zimmer.)

(Das Stubenmädchen nimmt eine Cigarre vom Rauchtisch, steckt sie ein und geht $a b$.)

\section{${ }_{\llcorner}$Der junge Herr und die junge Frau.}

PD [41] - EA [45] der Schwindgasse.

Der junge Herr ist eben eingetreten, zündet, während er noch den Hut auf dem Kopf und den Überzieher an hat, die Kerzen an. Dann öfnet er die Thür zum Nebenzimmer und wirft einen Blick hinein. Von den Kerzen des Salons geht der Lichtschein über das Parquet bis zu einem Himmelbett, das an der abschließenden Wand steht. Von dem Kamin, in einer Ecke des Schlafzimmers, verbreitet sich ein rötlicher Lichtschein auf die Vorhänge des Bettes. - Der junge Herr besichtigt auch das Schlafzimmer. Von dem Trumeau nimmt er einen Spray= apparat und bespritzt die Bettpolster mit feinen Strahlen von Veilchen= parfüm. Dann geht er mit dem Sprayapparat durch beide Zimmer und drückt unaufhörlich auf den kleinen Ballon, so daß es bald überall nach Veilchen riecht. Dann legt er Überzieher und Hut ab. Er setzt sich auf das blausammtene Fauteuil, zündet sich eine Cigarette an und raucht. Nach einer kleinen Weile erhebt er sich wieder und ver= gewissert sich, daß die grünen Jalousien geschlossen sind. Plötzlich geht

\footnotetext{
624 Der junge Herr] Der junge Herr EA JSV BHV

627 Parquet] Parkett EA JSV BHV SFV

629 Kamin,] Kamin EA JSV BHV SFV

Schlafzimmers,] Schlafzimmers EA JSV BHV SFV

blausammtene] blausamtene BHV SFV
} 
er wieder in's Schlafzimmer, öffnet die Lade des Nachtkästchens. Er fühlt hinein und findet eine Schildkrothaarnadel. Er sucht nach einem Ort, sie zu verstecken und giebt sie endlich in die Tasche seines Über= ziehers. Dann öffnet er einen Schrank, der im Salon steht, nimmt eine silberne Tasse mit einer Flasche Cognac und zwei Liqueurgläschen heraus, stellt alles auf den Tisch. Er geht wieder zu seinem Überzieher, aus dem er jetzt ein kleines weißes Päckchen nimmt. Er öffnet es und legt es zum Cognac; geht wieder zum Schrank, nimmt zwei kleine Teller 'und Eßbestecke heraus. Er entnimmt dem kleinen Paket eine glacierte Kastanie und ißt sie. Dann schenkt er sich ein Glas Cognac ein und trinkt es rasch aus. Dann sieht er auf seine Uhr. Er geht im Zimmer auf und ab. - Vor dem großen Wandspiegel bleibt er eine Weile stehen, richtet mit seinem Taschenkamm das Haar und den kleinen Schnurr= bart. - Er geht nun zur Vorzimmerthür und horcht. Nichts regt sich. Dann zieht er die blauen Portièren, die vor der Schlafzimmerthür an= gebracht sind, zusammen. Es klingelt. Der junge Herr fährt leicht zusammen. Dann setzt er sich auf den Fauteuil und erhebt sich erst, als die Thür geöfnet wird und die junge Frau eintritt. -

Die junge Frau dicht verschleiert, schließt die Thür hinter sich, bleibt einen Augenblick stehen, indem sie die linke Hand auf's Herz legt, als müsse sie eine gewaltige Erregung bemeistern.

Der junge Herr tritt auf sie zu, nimmt ihre linke Hand und drückt auf den weißen, schwarz tamburierten Handschuh einen Kuß. Er sagt leise. Ich danke Ihnen.

Die junge Frau.

Alfred - Alfred!

Der junge Herr.

Kommen Sie, gnädige Frau .... Kommen Sie,

Frau Emma ....

Die junge Frau.

Lassen Sie mich noch eine Weile — bitte .... oh

bitte sehr, Alfred!

(Sie steht noch immer an der Thür.)

Der junge Herr (steht vor ihr, hält ihre Hand.)

Die junge Frau.

Wo bin ich denn eigentlich?

'Der junge Herr.

Bei mir. 


\section{Die junge Frau.}

Dieses Haus ist schrecklich, Alfred.

Der junge Herr.

Warum denn? Es ist ein sehr vornehmes Haus.

Die junge Frau.

Ich bin zwei Herren auf der Stiege begegnet.

Der junge Herr.

Bekannte?

\section{Die junge Frau.}

Ich weiß nicht. Es ist möglich.

\section{Der junge Herr.}

Pardon, gnädige Frau - aber Sie kennen doch

Ihre Bekannten.

\section{Die junge Frau.}

Ich habe ja gar nichts gesehen.

Der junge Herr.

Aber wenn es selbst Ihre besten Freunde waren, sie können ja Si e nicht erkannt haben. Ich selbst ... wenn ich nicht wüßte, daß Sie es sind .... dieser

Schleier - .

Die junge Frau.

Es sind zwei.

Der junge Herr.

Wollen Sie nicht ein bischen näher? ... . Und

Ihren Hut legen Sie doch wenigstens ab!

'Die junge Frau.

Was fällt Ihnen ein, Alfred? Ich habe Ihnen ge= sagt: Fünf Minuten ... . Nein, länger nicht . . . . ich schwöre Ihnen -

Der junge Herr.

Also den Schleier -

Die junge Frau.

Es sind zwei.

Der junge Herr.

Nun ja, beide Schleier - ich werde Sie doch wenig= stens sehen dürfen.

Die junge Frau.

Haben Sie mich denn lieb, Alfred? 
Der junge Herr (tief verletzt.)

Emma - Sie fragen mich ....

Die junge Frau.

Es ist hier so heiß.

Der junge Herr.

Aber Sie haben ja Ihre Pelzmantille an - Sie

werden sich wahrhaftig verkühlen.

Die junge Frau (tritt endlich in's Zimmer, wirft sich auf den Fauteuil) Ich bin totmüd.

Der junge Herr.

Erlauben Sie: (Er nimmt ihr die Schleier ab; nimmt die

Nadel aus ihrem Hut, legt Hut, Nadel, Schleier beiseit).

Die junge Frau (läßt es geschehen).

'Der junge Herr (steht vor ihr, schüttelt den Kopf).

Die junge Frau.

Was haben Sie?

Der junge Herr.

So schön waren Sie noch nie.

Die junge Frau.

Wieso?

Der junge Herr.

Allein .... allein mit Ihnen - Emma -

(Er läßt sich neben ihrem Fauteuil nieder, auf ein Knie, nimmt ihre

beiden Hände und bedeckt sie mit Küssen.)

Die junge Frau.

Und jetzt .... lassen Sie mich wieder gehen. Was

Sie von mir verlangt haben, hab' ich gethan.

Der junge Herr (läßt seinen Kopf auf ihren Schoß sinken).

Die junge Frau.

Sie haben mir versprochen, brav zu sein.

Der junge Herr.

Ja.

Die junge Frau.

Man erstickt in diesem Zimmer.

totmüd] todmüd' JSV BHV todmüd SFV

Sie:] Sie. JSV BHV SFV

die Schleier] den Schleier JSV BHV SFV

$a b$;] $a b, \mathrm{BHV}$ SFV

beiseit] beiseite EA JSV BHV SFV 
Der junge Herr (steht auf.)

Noch immer haben Sie Ihre Mantille an.

Die junge Frau.

Legen Sie sie zu meinem Hut.

'Der junge Herr (nimmt ihr die Mantille ab und legt sie gleichfalls auf den Divan).

Die junge Frau.

Und jetzt - adieu -

Der junge Herr.

Emma - ! - Emma! —

Die junge Frau.

Die fünf Minuten sind längst vorbei.

Der junge Herr.

Noch nicht eine! -

Die junge Frau.

Alfred, sagen Sie mir einmal ganz genau, wie spät es ist.

\section{Der junge Herr.}

Es ist punkt viertel sieben.

Die junge Frau.

Jetzt sollte ich längst bei meiner Schwester sein.

Der junge Herr.

Ihre Schwester können Sie oft sehen ....

Die junge Frau.

Oh Gott, Alfred, warum haben Sie mich da z u verleitet.

Der junge Herr.

Weil ich Sie .... anbete, Emma.

Die junge Frau.

Wie vielen haben Sie das schon gesagt?

'Der junge Herr.

Seit ich Sie gesehen, niemandem.

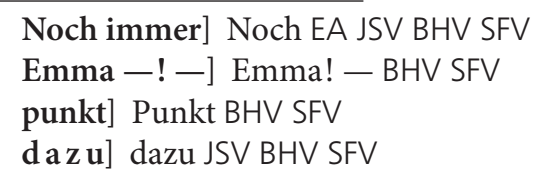


Die junge Frau.

Was bin ich für eine leichtsinnige Person! Wer mir das vorausgesagt hätte .... noch vor acht Tagen ... noch gestern ....

Der junge Herr.

Und vorgestern haben Sie mir ja schon versprochen ...

Die junge Frau.

Sie haben mich so gequält. Aber ich habe es nicht thun wollen. Gott ist mein Zeuge - ich habe es nicht thun wollen .... Gestern war ich fest entschlossen ... Wissen Sie, daß ich Ihnen gestern Abends sogar einen langen Brief geschrieben habe?

Der junge Herr.

Ich habe keinen bekommen.

\section{Die junge Frau.}

Ich habe ihn wieder zerrissen. Oh, ich hätte Ihnen lieber diesen Brief schicken sollen.

Der junge Herr.

Es ist doch besser so.

Die junge Frau.

Oh nein, es ist schändlich .... von mir. Ich begreife mich selber nicht. Adieu, Alfred, lassen Sie mich.

Der junge Herr (umfaßt sie und bedeckt ihr Gesicht mit heißen Küssen).

'Die junge Frau.

So .... halten Sie Ihr Wort....

Der junge Herr.

Noch einen Kuß - noch einen.

Die junge Frau.

Den letzten. (Er küßt sie; sie erwidert den Kuß; ihre Lippen

bleiben lange aneinandergeschlossen).

Der junge Herr.

Soll ich Ihnen etwas sagen, Emma? Ich weiß jetzt erst, was Glück ist.

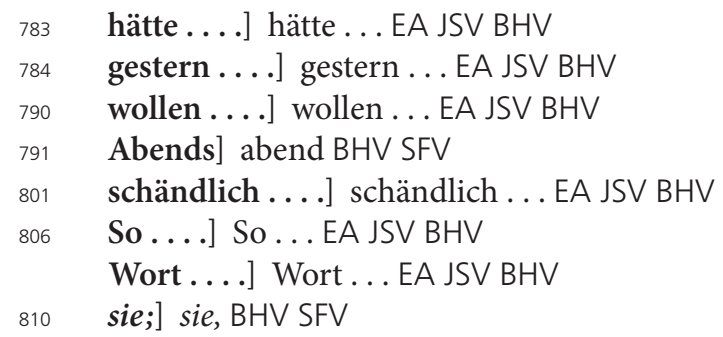


Die junge Frau (sinkt in den Fauteuil zurück).

Der junge Herr (setzt sich auf die Lehne, schlingt einen Arm leicht um ihren Nacken).

... oder vielmehr, ich weiß jetzt erst, was Glück sein könnte.

Die junge Frau (seufzt tiefauf).

Der junge Herr (küßt sie wieder).

Die junge Frau.

Alfred, Alfred, was machen Sie aus mir!

Der junge Herr.

Nicht wahr - es ist hier gar nicht so ungemütlich ... Und wir sind ja hier so sicher! Es ist doch tausend= mal schöner als diese Rendezvous im freien ....

Die junge Frau.

Oh, erinnern Sie mich nur nicht daran.

'Der junge Herr.

Ich werde auch daran immer mit tausend Freuden denken. Für mich ist jede Minute, die ich an Ihrer Seite verbringen durfte, eine süße Erinnerung.

Die junge Frau.

Erinnern Sie sich noch an den Industriellenball?

Der junge Herr.

Ob ich mich daran erinnere .... ? Da bin ich ja während des Soupers neben Ihnen gesessen, ganz nahe neben Ihnen. Ihr Mann hat Champagner ... .

Die junge Frau (sieht ihn klagend an).

Der junge Herr.

Ich wollte nur vom Champagner reden. Sagen Sie Emma, wollen Sie nicht ein Glas Cognac trinken?

Die junge Frau.

Einen Tropfen, aber geben Sie mir vorher ein Glas Wasser.

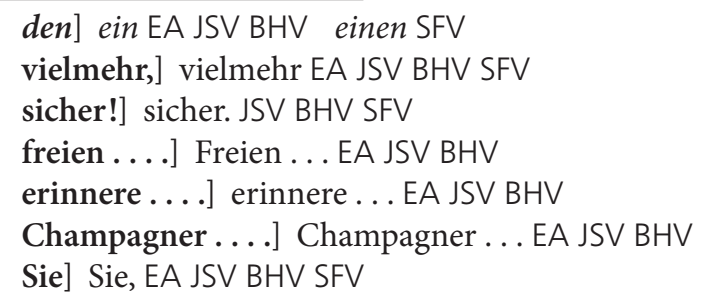


Der junge Herr.

Ja .... Wo ist denn nur - ach ja .... (Er

schlägt die Portière zurück und geht in's Schlafzimmer).

Die junge Frau (sieht ihm nach).

Der junge Herr (kommt zurück mit einer Karaffe Wasser und zwei Trinkgläsern).

Die junge Frau.

Wo waren Sie denn?

Der junge Herr.

Im .... Nebenzimmer. (Schenkt ein Glas Wasser ein).

'Die junge Frau.

Jetzt werde ich Sie etwas fragen, Alfred - und

schwören Sie mir, daß Sie mir die Wahrheit sagen werden.

Der junge Herr.

Ich schwöre. -

Die junge Frau.

War in diesen Räumen schon jemals eine andere Frau?

Der junge Herr.

Aber Emma - dieses Haus steht schon zwanzig

Jahre! -

\section{Die junge Frau.}

Sie wissen, was ich meine, Alfred .... Mit Ihnen!

Bei Ihnen!

Der junge Herr.

Mit mir - hier — Emma! — Es ist nicht schön, daß Sie an so etwas denken können.

Die junge Frau.

Also, Sie haben .... wie soll ich .... Aber nein, ich will Sie lieber nicht fragen. Es ist besser, wenn ich nicht frage. Ich bin ja selbst schuld. Alles rächt sich.

Der junge Herr.

Ja, was haben Sie denn? Was ist Ihnen denn?

Was rächt sich?

848 Ja .... J Ja ... EA JSV BHV

ja.... ja... EA JSV BHV

${ }_{856}$ Im .....] Im ... EA JSV BHV

861 schwöre.] schwöre JSV BHV SFV

869 Alfred .....] Alfred... EA JSV BHV

875 Also,] Also EA JSV BHV SFV 
Die junge Frau.

Nein, nein, nein, ich darf nicht zum Bewußtsein

'kommen .... Sonst müßte ich vor Scham in die Erde sinken.

Der junge Herr (mit der Karaffe Wasser in der Hand, schüttelt traurig den Kopf).

Emma, wenn Sie ahnen könnten, wie weh Sie mir thun.

Die junge Frau (schenkt sich ein Glas Cognac ein).

Der junge Herr.

Ich will Ihnen etwas sagen, Emma. Wenn Sie

sich schämen, hier zu sein — wenn ich Ihnen also gleich= giltig bin - wenn Sie nicht fühlen, daß Sie für mich alle Seligkeit der Welt bedeuten — - so geh'n Sie lieber. -

Die junge Frau.

Ja, das werd' ich auch thun.

Der junge Herr (sie bei der Hand fassend).

Wenn Sie aber ahnen, daß ich ohne Sie nicht leben kann, daß ein Kuß auf Ihre Hand für mich mehr be= deutet, als alle Zärtlichkeiten, die alle Frauen auf der ganzen Welt .... Emma, ich bin nicht wie die anderen jungen Leute, die den Hof machen können - ich bin vielleicht zu naiv .... ich ....

Die junge Frau.

Wenn Sie aber doch sind wie die anderen jungen

Leute?

Der junge Herr.

Dann wären Sie heute nicht da - denn Sie sind nicht wie die anderen Frauen.

'Die junge Frau.

Woher wissen Sie das?

Der junge Herr (hat sie zum Divan gezogen, sich nahe neben sie gesetzt).

Ich habe viel über Sie nachgedacht. Ich weiß, Sie sind unglücklich.

Die junge Frau (erfreut). Ja. 


\section{Der junge Herr.}

Das Leben ist so leer, so nichtig - und dann, -

so kurz - so entsetzlich kurz! Es giebt nur e in Glück

.... einen Menschen finden, von dem man geliebt wird -

Die junge Frau (hat eine kandierte Birne vom Tisch genommen, nimmt sie in den Mund).

Der junge Herr.

Mir die Hälfte! (Sie reicht sie ihm mit den Lippen).

Die junge Frau (faßt die Hände des jungen Herrn, die sich zu verirren drohen).

Was thun Sie denn, Alfred .... Ist das Ihr

Versprechen.

Der junge Herr (die Birne verschluckend, dann kühner).

Das Leben ist so kurz.

Die junge Frau (schwach).

Aber das ist ja kein Grund -

Der junge Herr (mechanisch).

Oh ja.

'Die junge Frau (schwächer).

Schauen Sie, Alfred, und Sie haben doch versprochen, brav .... Und es ist so hell ....

Der junge Herr.

Komm', komm', Du einzige, einzige .... (Er hebt sie vom Divan empor).

Die junge Frau.

Was machen Sie denn?

Der junge Herr.

Da drin ist es gar nicht hell.

Die junge Frau.

Ist denn da noch ein Zimmer?

Der junge Herr (zieht sie mit).

Ein schönes .... und ganz dunkel.

Die junge Frau.

Bleiben wir doch lieber hier.

Der junge Herr (bereits mit ihr hinter der Portière, im Schlaf= zimmer, nestelt ihr die Taille auf).

ein] ein BHV SFV

Versprechen.] Versprechen? BHV SFV

Sie,] Sie EA JSV

hell .... .] hell ... JSV BHV 
Die junge Frau.

Sie sind so .... oh Gott, was machen Sie aus

mir! - Alfred!

Der junge Herr.

Ich bete Dich an, Emma!

Die junge Frau.

So wart' doch, wart' doch wenigstens ... (Schwach.)

Geh .... ich ruf' Dich dann.

'Der junge Herr.

Laß mir Dich - laß Dir mich (er verspricht sich) ...

laß ... mich - Dir - helfen.

\section{Die junge Frau.}

Du zerreiß't mir ja alles.

Der junge Herr.

Du hast kein Mieder an.

Die junge Frau.

Ich trag' nie ein Mieder. Die Odilon trägt auch

keines. Aber die Schuh' kannst Du mir aufknöpfeln.

Der junge Herr (knöpfelt die Schuhe auf, küßt ihre Füße).

Die junge Frau (ist in's Bett geschlüpft).

Oh mir ist kalt.

Der junge Herr.

Gleich wird's warm werden.

Die junge Frau (leise lachend).

Glaubst Du?

Der junge Herr (unangenehm berührt, für sich).

Das hätte sie nicht sagen sollen. (Entkleidet sich im

Dunkel.)

Die junge Frau (zärtlich).

Komm', komm', komm!

Der junge Herr (dadurch wieder in besserer Stimmung).

Gleich - -

Die junge Frau.

Es riecht hier so nach Veilchen. 
'Der junge Herr.

Das bist Du selbst ... . Ja (zu ihr) Du selbst.

Die junge Frau.

Alfred .... Alfred!!!!

Der junge Herr.

Emma....

Der junge Herr.

Ich habe Dich offenbar zu lieb ... . ja ... . ich bin wie von Sinnen.

Die junge Frau ......

Der junge Herr.

Die ganzen Tage über bin ich schon wie verrückt.

Ich hab' es geahnt.

Die junge Frau.

Mach dir nichts draus.

Der junge Herr.

Oh gewiß nicht. Es ist ja geradezu selbstverständ= lich, wenn man ....

Die junge Frau.

Nicht ... . nicht ... . Du bist nervös. Beruhige

Dich nur....

Der junge Herr.

Kennst Du Stendhal?

Die junge Frau.

Stendhal?

'Der junge Herr.

Die psychologie de l' amour.

Die junge Frau.

Nein, warum fragst Du mich?

Der junge Herr.

Da kommt eine Geschichte drin vor, die sehr be= zeichnend ist.

Die junge Frau.

Was ist das für eine Geschichte? 


\section{Der junge Herr.}

Das ist eine ganze Gesellschaft von Kavallerieoffizieren zusammen. -

\section{Die junge Frau.}

So.

\section{Der junge Herr.}

Und die erzählen von ihren Liebesabenteuern. Und jeder berichtet, daß ihm bei der Frau, die er am meisten, weißt Du, am leidenschaftlichsten geliebt hat .... daß ihn die, daß er die - also kurz und gut, daß es jedem bei dieser Frau so gegangen ist, wie jetzt mir.

Die junge Frau.

Ja.

Der junge Herr.

Das ist sehr charakteristisch.

Die junge Frau.

Ja.

'Der junge Herr.

Es ist noch nicht aus. Ein einziger behauptet ...

es sei ihm in seinem ganzen Leben noch nicht passiert, aber, setzt Stendhal hinzu - das war ein berüchtigter Bramarbas.

Die junge Frau.

So. -

Der junge Herr.

Und doch verstimmt es einen, das ist das Dumme, so gleichgiltig es eigentlich ist.

Die junge Frau.

Freilich. Überhaupt weißt Du .... Du hast mir ja versprochen, brav zu sein.

Der junge Herr.

Geh', nicht lachen, das bessert die Sache nicht.

Die junge Frau.

Aber nein, ich lache ja nicht. Das von Stendhal ist wirklich interessant. Ich habe immer gedacht, daß nur

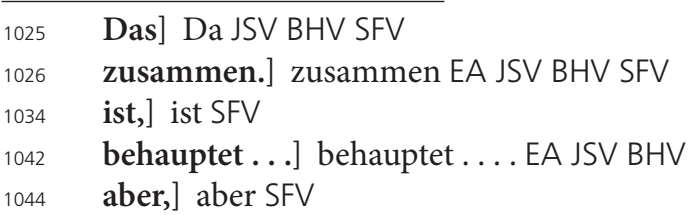


bei älteren . . . . oder bei sehr . . . . weißt Du, bei

Leuten, die viel gelebt haben ....

Der junge Herr.

Was fällt Dir ein. Das hat damit gar nichts zu thun. Ich habe übrigens die hübscheste Geschichte aus dem Stendhal ganz vergessen. Da ist einer von den Kavallerieoffizieren, der erzählt sogar, daß er drei Nächte oder gar sechs .... i ich weiß nicht mehr, mit der Frau zusammen war, die er durch Wochen hindurch verlangt 'hat - desirée - verstehst $\mathrm{Du}$ - und die haben alle diese Nächte hindurch nichts gethan als vor Glück geweint .... beide ....

Die junge Frau.

Beide?

Der junge Herr.

Ja. Wundert Dich das? Ich find' das so begreif= lich - gerade wenn man sich liebt.

\section{Die junge Frau.}

Aber es giebt gewiß viele, die nicht weinen.

Der junge Herr (nervös).

Gewiß ... das ist ja auch ein exceptioneller Fall.

Die junge Frau.

$\mathrm{Ah}-\mathrm{ich}$ dachte, Stendhal sagte, alle Kavallerie= offiziere weinen bei dieser Gelegenheit.

Der junge Herr.

Siehst Du, jetzt machst Du Dich doch lustig.

\section{Die junge Frau.}

Aber was fällt Dir ein! Sei doch nicht kindisch, Alfred!

\section{Der junge Herr.}

Es macht nun einmal nervös . . . . Dabei habe ich

die Empfindung, daß Du ununterbrochen daran denkst.

Das geniert mich erst recht.

Die junge Frau.

Ich denke absolut nicht daran.

\footnotetext{
1059 älteren .... .] älteren ... JSV BHV

$1068 \mathrm{Du}-\mathrm{d} \mathrm{du}-$, SFV

die] sie JSV BHV SFV 
'Der junge Herr.

Oh ja. Wenn ich nur überzeugt wäre, daß Du

mich liebst.

\section{Die junge Frau.}

Verlangst Du noch mehr Beweise?

Der junge Herr.

Siehst Du .... immer machst Du Dich lustig.

Die junge Frau.

Wieso denn? Komm, gieb mir Dein süßes Kopferl.

Der junge Herr.

Ach das thut wohl.

Die junge Frau.

Hast Du mich lieb?

Der junge Herr.

Oh ich bin ja so glücklich.

Die junge Frau.

Aber Du brauchst nicht auch noch zu weinen.

Der junge Herr (sich von ihr entfernend, höchst irritiert.)

Wieder, wieder. Ich hab Dich ja so gebeten ....

Die junge Frau.

Wenn ich Dir sage, daß Du nicht weinen sollst ...

Der junge Herr.

Du hast gesagt: Auch noch zu weinen.

Die junge Frau.

Du bist nervös, mein Schatz.

'Der junge Herr.

Das weiß ich.

Die junge Frau.

Aber Du sollst es nicht sein. Es ist mir sogar lieb, daß es .... daß wir sozusagen als gute Kameraden ...

\section{Der junge Herr.}

Schon wieder fangst Du an.

Die junge Frau.

Erinnerst Du Dich denn nicht! Das war eines

\begin{tabular}{ll}
\hline 1100 & Du.... . du ... EA JSV BHV \\
1104 & Ach] Ach, EA JSV BHV SFV \\
1108 & Oh] Oh, EA JSV BHV SFV \\
1114 & sollst ... . sollst . . . BHV \\
1123 & es ... . es . . . JSV BHV
\end{tabular}


unserer ersten Gespräche. Gute Kameraden haben wir sein wollen; nichts weiter. Oh das war schön ..... das war bei meiner Schwester, im Jänner auf dem großen Ball, während der Quadrille .... Um Gotteswillen ich sollte ja längst fort sein .... meine Schwester erwartet mich ja - was werd' ich ihr denn sagen .... Adieu, Alfred -

Der junge Herr.

Emma - ! so willst Du mich verlassen!

Die junge Frau.

Ja - so! -

Der junge Herr.

Noch fünf Minuten .... .

Die junge Frau.

Gut. Noch fünf Minuten. Aber Du mußt mir versprechen .... Dich nicht zu rühren? ... Ja? ... Ich will Dir noch einen Kuß zum Abschied geben .... . 'Pst ... ruhig .... nicht rühren, hab' ich gesagt, sonst steh' ich gleich auf, Du mein süßer . . . süßer ...

Der junge Herr.

Emma .... meine ange.......

Die junge Frau.

Mein Alfred -

Der junge Herr.

Ah; bei Dir ist der Himmel.

Die junge Frau.

Aber jetzt muß ich wirklich fort.

Der junge Herr.

Ach laß Deine Schwester warten.

Oh] Oh, EA JSV BHV SFV

schön .....] schön .... BHV

1131 Gotteswillen] Gotteswillen, EA JSV BHV Gottes willen, SFV

sagen .... . sagen ...... EA JSV BHV

versprechen ....] versprechen ... BHV

geben ..... geben ...... EA JSV

süßer ....] süßer ... EA JSV BHV

Ah;] Ah, EA JSV BHV SFV

Ach] Ach, EA JSV BHV SFV 
Die junge Frau.

Nach Haus muß ich. Für meine Schwester ist's längst zu spät. Wie viel Uhr ist es denn eigentlich?

\section{Der junge Herr.}

Ja, wie soll ich das eruieren?

Die junge Frau.

Du mußt eben auf die Uhr sehen.

\section{Der junge Herr.}

Meine Uhr ist in meinem Gilet.

Die junge Frau.

So hol' sie.

'Der junge Herr (steht mit einem mächtigen Ruck auf.) Acht.

Die junge Frau (erhebt sich rasch.)

Um Gotteswillen .... Rasch, Alfred, gieb mir

meine Strümpfe. Was soll ich denn nur sagen? Zu

Hause wird man sicher schon auf mich warten . . . acht

Uhr....

Der junge Herr.

Wann seh' ich Dich denn wieder?

Die junge Frau.

Nie.

Der junge Herr.

Emma! Hast Du mich denn nicht mehr lieb?

Die junge Frau.

Eben darum. Gieb mir meine Schuhe.

Der junge Herr.

Niemals wieder? Hier sind die Schuhe.

Die junge Frau.

In meinem Sack ist ein Schuhknöpfler. Ich bitt

Dich, rasch ....

Der junge Herr.

Hier ist der Knöpfler.

Die junge Frau.

Alfred, das kann uns beide den Hals kosten.

Der junge Herr (höchst unangenehm berührt.)

Wieso? 
'Die junge Frau.

Ja, was soll ich denn sagen? Wenn er mich fragt:

Woher kommst Du?

Der junge Herr.

Von der Schwester.

Die junge Frau.

Ja, wenn ich lügen könnte.

Der junge Herr.

$\mathrm{Na}, \mathrm{Du}$ mußt es eben thun.

Die junge Frau.

Alles für so einen Menschen. Ach, komm her ...

laß Dich noch einmal küssen. (Sie umarmt ihn.) - Und jetzt - - laß mich allein, geh' in's andere Zimmer.

Ich kann mich nicht anziehen, wenn Du dabei bist.

Der junge Herr (geht in den Salon, wo er sich ankleidet. Er ißt etwas von der Bäckerei, trinkt ein Glas Cognac. Nach einer Weile ruft

Die junge Frau.

Alfred!

Der junge Herr.

Mein Schatz.

\section{Die junge Frau.}

Es ist doch besser, daß wir nicht geweint haben.

Der junge Herr (lächelnd).

Wie kann man so frivol reden? -

Die junge Frau.

Wie wird das jetzt nur sein - wenn wir uns zu= fällig wieder einmal in Gesellschaft begegnen?

'Der junge Herr.

Zufällig - einmal .... Du bist ja morgen

sicher auch bei Lobheimers?

Die junge Frau.

Ja. Du auch?

Der junge Herr.

Freilich. Darf ich Dich um den Cotillon bitten?

sagen? Wenn] sagen, wenn EA JSV BHV SFV

her....] her.... EA JSV BHV

Cognac. Nach einer Weile ruft] Cognac). EA Kognak). JSV BHV SFV

Frau.] Frau (ruft nach einer Weile). EA JSV BHV SFV

Herr] Herr (nicht ohne Stolz EA JSV BHV SFV 
Die junge Frau.

Oh, ich werde nicht hinkommen. Was glaubst $\mathrm{Du}$ denn? - Ich würde ja .... (sie tritt völlig angekleidet in den Salon, nimmt eine Chokoladebäckerei) in die Erde sinken.

Der junge Herr.

Also morgen bei Lobheimer, das ist schön.

Die junge Frau.

Nein, nein .... ich sage ab; bestimmt -

Der junge Herr.

Also übermorgen .... hier.

Die junge Frau.

Was fällt Dir ein?

Der junge Herr.

Um $6 \ldots$

Die junge Frau.

Hier an der Ecke stehen Wagen, nicht wahr? -

Der junge Herr.

Ja - soviel Du willst. Also übermorgen hier um 6.

So sag' doch ja, mein geliebter Schatz.

'Die junge Frau.

... D Das besprechen wir morgen beim Cotillon.

Der junge Herr (umarmt sie).

Mein Engel.

Die junge Frau.

Nicht wieder meine Frisur ruinieren.

Der junge Herr.

Also morgen bei Lobheimers und übermorgen in meinen Armen.

Die junge Frau.

Leb wohl ....

Der junge Herr (plötzlich wieder besorgt).

Und was wirst $\mathrm{Du}$ - ih m heut sagen? -

Die junge Frau.

— Frag' nicht .... frag' nicht ... . es ist zu schrecklich. - Warum hab' ich Dich so lieb! - Adieu.

ja.... j ja...EA JSV BHV

Chokoladebäckerei] Schokoladebäckerei JSV BHV SFV

Ja - soviel] Ja, so viel EA JSV BHV SFV

hier] hier, JSV BHV SFV

Frau. - ] Frau. EA JSV BHV SFV 
- Wenn ich wieder Menschen auf der Stiege begegne, trifft mich der Schlag. — Pah! -

Der junge Herr (küßt ihr noch einmal die Hand).

Die junge Frau (geht).

Der junge Herr (bleibt allein zurück).

(Er betrachtet sich im Spiegel. Dann setzt er sich auf den Divan. Er lächelt vor sich hin und sagt zu sich selbst).

Also jetzt hab ich ein Verhältnis mit einer an= ständigen Frau.

'Ein behagliches Schlafgemach.

Es ist halb elf Uhr Nachts. Die junge Frau liegt zu Bette und liest.

Der Gatte tritt eben, im Schlafrock, in's Zimmer.

Die junge Frau (ohne aufzuschauen).

Du arbeitest nicht mehr?

\section{Der Gatte.}

Nein. Ich bin zu müde. Und außerdem ....

Die junge Frau.

Nun? -

\section{Der Gatte.}

Ich hab mich an meinem Schreibtisch plötzlich so ein= sam gefühlt. Ich habe Sehnsucht nach Dir bekommen.

Die junge Frau (schaut auf).

Wirklich?

Der Gatte (setzt sich zu ihr auf's Bett).

Lies heute nicht mehr. Du wirst Dir die Augen verderben.

Die junge Frau (schlägt das Buch zu).

Was hast Du denn?

Der Gatte.

Nichts, mein Kind. Verliebt bin ich in Dich! Das weißt Du ja!

\footnotetext{
1268f. zurück). (Er betrachtet sich im Spiegel.] zurück. EA JSV BHV SFV

1275 Die junge] Die EA JSV BHV SFV

1280 außerdem .... .] außerdem ... EA JSV BHV

1294 Dich!] dich. BHV SFV
} 
'Die junge Frau.

Man könnte es manchmal fast vergessen.

Der Gatte.

Man muß es sogar manchmal vergessen.

Die junge Frau.

Warum?

Der Gatte.

Weil die Ehe sonst etwas unvollkommenes wäre.

Sie würde .... wie soll ich nur sagen .... sie würde ihre Heiligkeit verlieren.

Die junge Frau.

Oh....

\section{Der Gatte.}

Glaube mir - es ist so .... Hätten wir in den

fünf Jahren, die wir jetzt miteinander verheiratet sind, nicht manchmal vergessen, daß wir ineinander verliebt sind - wir wären es wohl gar nicht mehr.

Die junge Frau.

Das ist mir zu hoch.

Der Gatte.

Die Sache ist einfach die: wir haben vielleicht schon zehn oder zwölf Liebschaften miteinander gehabt ..... Kommt es Dir nicht auch so vor?

\section{Die junge Frau.}

Ich hab' nicht gezählt! -

\section{Der Gatte.}

Hätten wir gleich die erste bis zum Ende durch= 'gekostet, hätte ich mich von Anfang an meiner Leiden= schaft für Dich willenlos hingegeben, es wäre uns gegangen wie den Millionen von anderen Liebespaaren. Wir wären fertig mit einander.

Die junge Frau.

Ah .... so meinst Du das?

Der Gatte.

Glaube mir - Emma - in den ersten Tagen unserer Ehe hatte ich Angst, daß es so kommen würde.

Die junge Frau.

Ich auch. 
Der Gatte.

Siehst Du? Hab' ich nicht recht gehabt? Darum ist es gut, immer wieder für einige Zeit nur in guter Freundschaft mit einander hinzuleben.

Die junge Frau.

Ach so.

Der Gatte.

Und so kommt es, daß wir immer wieder neue nie drauf ankommen lasse, die Flitterwochen ....

\section{Die junge Frau.}

$\mathrm{Zu}$ Monaten auszudehnen.

\section{Der Gatte.}

Richtig.

Die junge Frau.

Und jetzt .... scheint also wieder eine Freundschafts= periode abgelaufen zu sein -?

'Der Gatte (sie zärtlich an sich drückend).

Es dürfte so sein.

\section{Die junge Frau.}

Wenn es aber . . . . bei mir anders wäre.

\section{Der Gatte.}

Es ist bei Dir nicht anders. Du bist ja das klügste und entzückendste Wesen, das es giebt. Ich bin sehr glücklich, daß ich Dich gefunden habe.

Die junge Frau.

Das ist aber nett, wie Du den Hof machen kannst

- von Zeit zu Zeit.

Der Gatte (hat den Schlafrock abgeworfen und sich auch zu Bett begeben).

Für einen Mann, der sich ein bischen in der Welt umgesehen hat - geh', leg den Kopf an meine Schulter - der sich in der Welt umgesehen hat, bedeutet die Ehe eigentlich etwas viel geheimnisvolleres als für Euch junge Mädchen aus guter Familie. Ihr tretet uns rein und .... wenigstens bis zu einem gewissen Grad unwissend 
entgegen und darum habt Ihr eigentlich einen viel klareren Blick für das Wesen der Liebe als wir.

Die junge Frau (lachend).

Oh!

\section{Der Gatte.}

Gewiß. Denn wir sind ganz verwirrt und unsicher geworden durch die vielfachen Erlebnisse, die wir not= gedrungen vor der Ehe durchzumachen haben. Ihr hört ja viel und wißt zu viel und lest ja wohl eigentlich auch zu viel, aber einen rechten Begriff von dem, was wir Männer in der That erleben, habt Ihr ja doch nicht. Uns wird das, was man so gemeinhin die Liebe nennt, recht gründlich widerwärtig gemacht, denn was sind das schließlich für Geschöpfe, auf die wir angewiesen sind!

Die junge Frau.

Ja, was sind das für Geschöpfe?

Der Gatte (küßt sie auf die Stirn.)

Sei froh, mein Kind, daß Du nie einen Einblick in diese Verhältnisse erhalten hast. Es sind übrigens meist recht bedauernswerte Wesen - werfen wir keinen Stein auf sie.

\section{Die junge Frau.}

Bitt' Dich - dieses Mitleid - Das kommt mir da gar nicht recht angebracht vor.

Der Gatte (mit schöner Milde).

Sie verdienen es. Ihr, die Ihr junge Mädchen aus guter Familie wart, die ruhig unter Obhut Euerer Eltern auf den Ehrenmann warten könnt, der Euch zur Ehe begehrt; - Ihr kennt ja das Elend nicht, das die meisten von diesen armen Geschöpfen der Sünde in die Arme treibt.

\section{Die junge Frau.}

So verkaufen sich denn alle?

\section{Der Gatte.}

Das möchte ich nicht sagen. Ich mein' ja auch nicht 'nur das materielle Elend. Aber es giebt auch — ich möchte sagen - ein sittliches Elend; eine mangelhafte 
Auffassung für das, was erlaubt und insbesondere für das, was edel ist.

Die junge Frau.

Aber warum sind die zu bedauern? - Denen geht's

ja ganz gut?

\section{Der Gatte.}

Du hast sonderbare Ansichten, mein Kind. Du darfst nicht vergessen, daß solche Wesen von Natur aus bestimmt sind, immer tiefer und tiefer zu fallen. Da giebt es kein Aufhalten.

Die junge Frau (sich an ihn schmiegend).

Offenbar fällt es sich ganz angenehm.

Der Gatte (peinlich berührt).

Wie kannst Du so reden, Emma. Ich denke doch, daß es gerade für Euch anständige Frauen nichts wider= wärtigeres geben kann, als alle diejenigen, die es nicht sind.

Die junge Frau.

Freilich, Karl, freilich. Ich hab' ja auch nur so gesagt.

Geh' erzähl weiter. Es ist so nett, wenn Du so redst.

Erzähl' mir 'was.

Der Gatte.

Was denn? -

Die junge Frau.

Nun, - von diesen Geschöpfen.

'Der Gatte.

Was fällt Dir denn ein?

\section{Die junge Frau.}

Schau ich hab' Dich schon früher, weißt Du, ganz

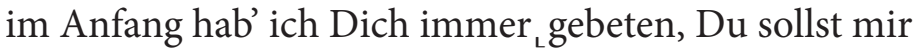
aus Deiner Jugend 'was erzählen.

\section{Der Gatte.}

Warum interessiert Dich denn das?

erlaubt] erlaubt, EA JSV BHV SFV

die] sie JSV BHV SFV

Euch] euch, EA JSV BHV SFV

Frauen] Frauen, EA JSV BHV SFV

kann,] kann SFV

hab'] hab's EA JSV BHV SFV

Geh'] Geh', EA JSV BHV SFV

Nun,] Nun BHV SFV

Schau] Schau, EA JSV BHV SFV 
Die junge Frau.

Bist Du denn nicht mein Mann? Und ist das nicht geradezu eine Ungerechtigkeit, daß ich von Deiner Ver= gangenheit eigentlich gar nichts weiß? -

Der Gatte.

Du wirst mich doch nicht für so geschmacklos halten, daß ich - Genug, Emma ... . das ist ja wie eine Entweihung.

Die junge Frau.

Und doch hast $\mathrm{Du} . .$. wer weiß wie viel andere Frauen so in den Armen gehalten wie jetzt mich.

Der Gatte.

Sag’ doch nicht „Frauen“. Frau bist Du.

Die junge Frau.

Aber eine Frage mußt Du mir beantworten ... sonst .... sonst .... sonst . . . . ist's nichts mit den Flitterwochen.

'Der Gatte.

Du hast eine Art zu reden .... denk' doch, daß

Du Mutter bist ... . daß unser Mäderl da drin liegt ... .

Die junge Frau (an ihn sich schmiegend).

Aber ich möcht auch einen Buben.

Der Gatte.

Emma!

Die junge Frau.

Geh', sei nicht so .... freilich bin ich Deine Frau

... aber ich möchte auch ein bissel ... . Deine $\mathrm{Ge}=$

liebte sein.

Der Gatte.

Möchtest Du? ... .

Die junge Frau.

Also - zuerst meine Frage.

Der Gatte (gefügig).

Nun?

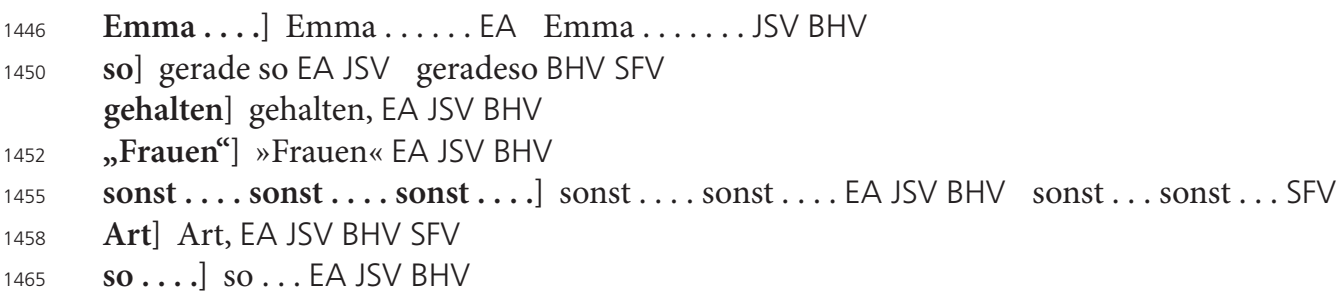


wie] Wie BHV SFV

Du.... d du...EA JSV BHV

Ja] Ja, BHV SFV irgend einer] irgendeiner SFV sie... .] sie .... EA JSV BHV

Die junge Frau.

War .... eine verheiratete Frau - unter ihnen?

Der Gatte.

Wieso? - wie meinst Du das?

Die junge Frau.

Du weißt schon.

Der Gatte (leicht beunruhigt).

Wie kommst Du auf diese Frage?

\section{Die junge Frau.}

Ich möchte wissen, ob es . . . . das heißt - es

'giebt solche Frauen .... das weiß ich. Aber ob

Der Gatte (ernst).

Kennst Du eine solche Frau?

Die junge Frau.

Ja, ich weiß das selber nicht.

\section{Der Gatte.}

Ist unter Deinen Freundinen vielleicht eine solche

Frau?

Die junge Frau.

Ja wie kann ich das mit Bestimmtheit behaupten

- oder verneinen?

\section{Der Gatte.}

Hat Dir vielleicht einmal eine Deiner Freundinen

... Man spricht über gar manches, wenn man so -

die Frauen unter sich - hat Dir eine gestanden - ?

Die junge Frau (unsicher).

Nein.

\section{Der Gatte.}

Hast Du bei irgend einer deiner Freundinen den Ver= dacht, daß sie ...

Die junge Frau.

Verdacht..... oh ..... Verdacht.

\section{Der Gatte.}

Es scheint. 
Die junge Frau.

Gewiß nicht Karl. Nein Karl, sicher nicht. Wenn

ich mir's so überlege - ich trau' es doch keiner zu.

'Der Gatte.

Keiner?

Die junge Frau.

Von meinen Freundinen keiner.

\section{Der Gatte.}

Versprich mir etwas, Emma.

Die junge Frau.

Nun.

Der Gatte.

Daß Du nie mit einer Frau verkehren wirst, bei der

Du auch nur den leisesten Verdacht hast, daß sie ......

kein ganz tadelloses Leben führt.

Die junge Frau.

Das muß ich Dir erst versprechen?

Der Gatte.

Ich weiß ja, daß Du den Verkehr mit solchen Frauen nicht suchen wirst. Aber der Zufall könnte es fügen, daß $\mathrm{Du}$.... . Ja, es ist sogar sehr häufig, daß gerade solche Frauen, deren Ruf nicht der beste ist, die Gesell= schaft von anständigen Frauen suchen, teils um sich ein Relief zu geben, teils aus einem gewissen .... . wie soll ich sagen .... . aus einem gewissen Heimweh nach der Tugend.

\section{Die junge Frau.}

So.

\section{Der Gatte.}

Ja. Ich glaube, daß das sehr richtig ist, was ich

'da gesagt habe. Heimweh nach der Tugend. Denn daß diese Frauen alle eigentlich sehr unglücklich sind, das kannst Du mir glauben.

\section{Die junge Frau.}

Warum?

Gewiß nicht] Gewiß nicht, BHV SFV

Karl. Nein Karl,] Karl, EA JSV BHV SFV auch nur] auch EA JSV BHV SFV gewissen ..... . gewissen .... EA JSV BHV sagen ..... s sagen .... JSV BHV

Denn] Denn, EA JSV BHV 
Der Gatte.

Du fragst, Emma? - Wie kannst Du denn nur fragen? - Stell' Dir doch vor, was diese Frauen für eine Existenz führen! Voll Lüge, Tücke, Gemeinheit und voll Gefahren.

Die junge Frau.

Ja freilich. Da hast Du schon Recht.

\section{Der Gatte.}

Wahrhaftig - sie bezahlen das bischen Glück .... .

das bischen ....

Die junge Frau.

Vergnügen.

\section{Der Gatte.}

Warum Vergnügen? Wie kommst Du darauf, das

Vergnügen zu nennen?

\section{Die junge Frau.}

Nun, - etwas muß es doch sein - ! Sonst thäten

sie's ja nicht.

\section{Der Gatte.}

Nichts ist es .... . ein Rausch.

Die junge Frau (nachdenklich).

Ein Rausch.

'Der Gatte.

Nein, es ist nicht einmal ein Rausch. Wie immer

- teuer bezahlt, das ist gewiß!

Die junge Frau.

Also .... Du hast das einmal mitgemacht nicht wahr?

Der Gatte.

Ja, Emma. - Es ist meine traurigste Erinnerung.

Die junge Frau.

Wer ist's? Sag'! Kenn' ich sie?

\section{Der Gatte.}

Was fällt Dir denn ein?

Recht] recht JSV BHV SFV

Glück..... .] Glück.... JSV BHV

bischen .... .] bischen ..... EA

Nun,] Nun BHV SFV

es..... es es.... JSV BHV

Also .... . Also ..... EA 
Die junge Frau.

Ist's lange her? War es sehr lang, bevor Du mich geheiratet hast?

\section{Der Gatte.}

Frag' nicht. Ich bitt Dich, frag' nicht.

Die junge Frau.

Aber Karl.

Der Gatte.

Sie ist tot.

Die junge Frau.

Im Ernst?

Der Gatte.

Ja .... es klingt fast lächerlich, aber ich habe die Empfindung, daß alle diese Frauen jung sterben.

Die junge Frau.

Hast Du sie sehr geliebt?

'Der Gatte.

Lügnerinen liebt man nicht.

Die junge Frau.

Also warum ..... -

Der Gatte.

Ein Rausch ....

Die junge Frau.

Also doch?

Der Gatte.

Sprich nicht mehr davon .... ich bitt' Dich. Alles das ist lang vorbei. Geliebt hab' ich nur eine - das bist Du. Man liebt nur, wo Reinheit und Wahrheit ist.

Die junge Frau.

Karl!

\section{Der Gatte.}

Oh wie sicher, wie wohl fühlt man sich in solchen Armen. Warum hab' ich Dich nicht schon als Kind ge= kannt? Ich glaube, dann hätt' ich andere Frauen über= haupt nicht angesehen.

Karl.] Karl! EA JSV BHV SFV

Ja.... Ja J.... EA

Lügnerinen] Lügnerinnen EA JSV BHV SFV

warum .... - ] warum.... EA JSV BHV warum... SFV

davon.... .] davon EA davon, JSV BHV SFV

Oh] Oh, EA JSV BHV SFV 
Die junge Frau.

Karl!

Der Gatte.

Und schön bist Du! ... . schön! ... . Oh komm . . (Er löscht das Licht aus).

Die junge Frau.

Weißt Du, woran ich heute denken muß?

'Der Gatte.

Woran, mein Schatz?

Die junge Frau.

An .... an .... an Venedig.

Der Gatte.

Die erste Nacht ....

Die junge Frau.

Ja.... so ....

Der Gatte.

Was denn - ? So sag's doch!

Die junge Frau.

So lieb hast Du mich heut.

Der Gatte.

Ja, so lieb.

Die junge Frau.

Ah .... Wenn Du immer .....

Der Gatte (in ihren Armen).

Wie?

Die junge Frau.

Mein Karl.

Der Gatte.

Was meintest Du? Wenn ich immer....

Die junge Frau.

Nun ja.

\section{Der Gatte.}

Nun, was wär denn, wenn ich immer .....?

\footnotetext{
1616 komm ..] komm'.... EA JSV BHV

1636 immer..... immer.... EA JSV BHV

1640 Karl.] Karl! EA JSV BHV SFV

1642 immer .... .] immer...? JSV BHV SFV

1646 immer..... ?] immer... ? EA immer... JSV BHV SFV
} 
'Die junge Frau.

Dann wüßt ich immer, daß Du mich lieb hast.

Der Gatte.

Ja. Du mußt es aber auch so wissen. Man ist nicht immer der liebende Mann, muß auch zuweilen hin= aus in's feindliche Leben, muß kämpfen und streben!

Das vergiß nie, mein Kind! Alles hat seine Zeit in der Ehe - das ist eben das schöne. Es giebt nicht viele, die sich noch nach fünf Jahren an - ihr Venedig erinnern.

Die junge Frau.

Freilich!

Der Gatte.

Und jetzt.... gute Nacht, mein Kind.

Die junge Frau.

Gute Nacht.

Ein Cabinet particulier im Riedhof. Behaglich, mäßige Elegance.

Der Gasofen brennt. -

Der Gatte. Das süße Mädel.

Auf dem Tisch sind die Reste einer Mahlzeit zu sehen; Obersschaum= baisers, Obst, Käse. In den Weingläsern ein ungarischer weißer Wein.

Der Gatte (raucht eine Havannahcigarre, er lehnt in der Ecke des Divans).

Das süße Mädel (sitzt neben ihm auf dem Sessel und löffelt aus einem Baiser den Obersschaum heraus, den sie mit Behagen schlürft).

Der Gatte.

Schmeckt's?

ich] ich eben EA JSV BHV SFV

Mann,] Mann, man EA JSV BHV SFV

Kind.] Kind! BHV SFV

Nacht.] Nacht! EA JSV BHV SFV

Cabinet] Kabinet EA Kabinett JSV BHV SFV

Behaglich] Behagliche EA JSV BHV SFV

Elegance] Eleganz EA JSV BHV SFV

sehen;] sehen, BHV SFV

Havannahcigarre] Havannazigarre EA JSV BHV SFV 
Das süße Mädel (läßt sich nicht stören).

Oh.

Der Gatte.

Willst Du noch eins?

Das süße Mädel.

Nein, ich hab so schon zu viel gegessen.

\section{Der Gatte.}

Du hast keinen Wein mehr. (Er schenkt ein).

Das süße Mädel.

Nein ... . aber schaun' S', ich laß ihn ja eh' stehen.

'Der Gatte.

Schon wieder sagst Du Sie.

Das süße Mädel.

So? - Ja wissen S', man gewöhnt sich halt so schwer.

\section{Der Gatte.}

Weißt D u.

Das süße Mädel.

Was denn?

\section{Der Gatte.}

Weißt D u, sollst Du sagen; nicht wissen S'. -

Komm, setz' Dich zu mir.

Das süße Mädel.

Gleich ... . bin noch nicht fertig.

Der Gatte (steht auf, stellt sich hinter den Sessel und umarmt das süße Mädel, indem er ihren Kopf zu sich wendet).

Das süße Mädel.

$\mathrm{Na}$, was ist denn?

Der Gatte.

Einen Kuß möcht' ich haben.

Das süße Mädel (giebt ihm einen Kuß).

Sie sind .... oh pardon, Du bist ein kecker Mensch.

\section{Der Gatte.}

Jetzt fällt Dir das ein?

Das süße Mädel.

Ah nein, eingefallen ist es mir schon früher.... schon auf der Gassen. - Sie müssen -

Oh.] Oh! EA JSV BHV SFV

D u] du BHV SFV

D u] du BHV SFV 
Das süße Mädel.

Du mußt Dir eigentlich was schönes von mir denken.

\section{Der Gatte.}

Warum denn?

\section{Das süße Mädel.}

Daß ich gleich so mit Ihnen in's chambre separée gegangen bin.

Der Gatte.

$\mathrm{Na}$, gleich kann man doch nicht sagen.

Das süße Mädel.

Aber Sie können halt so schön bitten.

\section{Der Gatte.}

Findest Du?

\section{Das süße Mädel.}

Und schließlich, was ist denn dabei?

\section{Der Gatte.}

Freilich.

Das süße Mädel.

Ob man spazieren geht oder -

Der Gatte.

Zum spazieren gehen ist es auch viel zu kalt.

Das süße Mädel.

Natürlich ist zu kalt gewesen.

Der Gatte.

Aber da ist es angenehm warm; was? (Er hat sich Seite).

Das süße Mädel (schwach).

$\mathrm{Na}$.

\section{Der Gatte.}

Jetzt sag' einmal ... . Du hast mich schon früher bemerkt gehabt, was?

Das süße Mädel.

Natürlich. Schon in der Singerstraßen. 
Der Gatte.

Nicht heut, mein' ich. Auch vorgestern und vorvor= gestern, wo ich Dir nachgegangen bin.

\section{Das süße Mädel.}

Mir gehn gar viele nach.

Der Gatte.

Das kann ich mir denken. Aber ob Du mich be= merkt hast.

Das süße Mädel.

Wissen $S^{\prime}$.... ah . ... weißt, was mir neulich passiert ist? Da ist mir der Mann von meiner Cousine nachg'stiegen in der Dunkeln und hat mich nicht 'kennt.

Der Gatte.

Hat er Dich angesprochen?

Das süße Mädel.

Aber was glaubst denn? Meinst, es ist jeder so keck wie Du?

'Der Gatte.

Aber es kommt doch vor.

Das süße Mädel.

Natürlich kommt's vor.

Der Gatte.

$\mathrm{Na}$, was machst $\mathrm{Du}$ da?

Das süße Mädel.

Na nichts - Keine Antwort geb' ich halt.

Der Gatte.

$\mathrm{Hm}$.... mir hast Du aber eine Antwort gegeben.

Das süße Mädel.

$\mathrm{Na}$, sind S' vielleicht bös?

Der Gatte (küßt sie heftig).

Deine Lippen schmecken noch nach dem Obersschaum.

Das süße Mädel.

Oh, die sind von Natur aus süß.

wo] wie EA JSV BHV SFV

1756 Cousine] Kusine JSV BHV SFV

$1770 \mathrm{Na}] \mathrm{Na}$, EA JSV BHV SFV

nichts] nichts. BHV SFV

$1774 \mathrm{Na}$,] Na EA JSV BHV SFV

1776 schmecken noch] schmecken EA JSV BHV SFV 
Der Gatte.

Das haben Dir schon viele gesagt?

Das süße Mädel.

Viele!! Was Du Dir wieder einbildest!

Der Gatte.

$\mathrm{Na}$, sei einmal ehrlich. Wie viele haben den Mund

da schon geküßt?

Das süße Mädel.

Was fragst mich denn? Du möch'st mir's ja doch nicht glauben, wenn ich Dir's sag'!

'Der Gatte.

Warum denn nicht?

Das süße Mädel.

$\mathrm{Na}$, rat einmal.

\section{Der Gatte.}

$\mathrm{Na}$, sagen wir, - aber Du darfst nicht bös sein?

Das süße Mädel.

Warum sollt ich denn bös sein?

Der Gatte.

Also ich schätze .... zwanzig.

Das süße Mädel (sich von ihm losmachend).

$\mathrm{Na}$ - warum nicht gleich hundert?

Der Gatte.

Ja ich hab' eben geraten.

Das süße Mädel.

Da hast Du aber nicht gut geraten.

\section{Der Gatte.}

Also zehn.

Das süße Mädel.

Freilich. Eine, die sich auf der Gassen anreden läßt und gleich mitgeht in's chambre separée!

Der Gatte.

Sei doch nicht so kindisch. Ob man auf der Straßen herumläuft oder in einem Zimmer sitzt ... . Wir sind doch da in einem Gasthaus. Jeden Moment kann der 
'Kellner hereinkommen — da ist doch wirklich gar nichts dran .....

Das süße Mädel.

Das hab ich mir eben auch gedacht.

Der Gatte.

Warst Du schon einmal in einem chambre separée?

Das süße Mädel.

Also wenn ich die Wahrheit sagen soll: ja.

Der Gatte.

Siehst Du, das g'fallt mir, daß Du doch wenigstens

aufrichtig bist.

Das süße Mädel.

Aber nicht so - wie Du Dir's wieder denkst. Mit einer Freundin und ihrem Bräutigam bin ich im chambre separée gewesen, heuer im Fasching einmal.

Der Gatte.

Es wär' ja auch kein Malheur, wenn Du einmal

- mit Deinem Geliebten -

Das süße Mädel.

Natürlich wär's kein Malheur. Aber ich hab' kein’

Geliebten.

Der Gatte.

Na geh'.

Das süße Mädel.

Meiner Seel', ich hab' keinen.

Der Gatte.

Aber Du wirst mir doch nicht einreden wollen, daß

ich ....

'Das süße Mädel.

Was denn? ... . Ich hab' halt keinen — schon

seit mehr als einem halben Jahr.

Der Gatte.

Ah so .... Aber vorher? Wer war's denn?

Das süße Mädel.

Was sind S' denn gar so neugierig?

Der Gatte.

Ich bin neugierig, weil ich Dich lieb hab'.

dran ..... d dran .... EA JSV BHV

Also] Also, EA JSV BHV SFV

$\mathrm{Na}$ ] Na, JSV BHV SFV

war's] war's EA JSV BHV SFV 
Das süße Mädel.

Is' wahr?

Der Gatte.

Freilich. Das mußt Du doch merken. Erzähl' mir also. (Drückt sie fest an sich.)

Das süße Mädel.

Was soll ich Dir denn erzählen?

Der Gatte.

So laß Dich doch nicht so lang bitten. Wer's ge= wesen ist, möcht' ich wissen.

Das süße Mädel (lachend).

$\mathrm{Na}$ ein Mann halt.

\section{Der Gatte.}

Also - also - wer war's?

Das süße Mädel.

Ein bissel ähnlich hat er Dir gesehen.

'Der Gatte.

So.

Das süße Mädel.

Wenn Du ihm nicht so ähnlich schauen thätst -

Der Gatte.

Was wär' dann?

Das süße Mädel.

$\mathrm{Na}$ also frag' nicht, wennst schon siehst, daß ... .

Der Gatte (versteht).

Also darum hast Du Dich von mir anreden lassen.

Das süße Mädel.

$\mathrm{Na}$ also ja.

Der Gatte.

Jetzt weiß ich wirklich nicht, soll ich mich freuen oder soll ich mich ärgern.

Das süße Mädel.

$\mathrm{Na}$ ich an Deiner Stell' thät' mich freuen.

Der Gatte.

$\mathrm{Na}$ ja. 
Das süße Mädel.

Und auch im Reden erinnerst Du mich so an ihn .... und wie Du einen anschaust....

\section{Der Gatte.}

Was ist er denn gewesen?

Das süße Mädel.

Nein, die Augen -

'Der Gatte.

Wie hat er denn geheißen?

Das süße Mädel.

Nein, schau mich nicht so an, ich bitt' Dich.

Der Gatte (umfängt sie. Langer, heißer Kuß).

Das süße Mädel (schüttelt sich, will aufstehen).

Der Gatte.

Warum gehst $\mathrm{Du}$ fort von mir?

Das süße Mädel.

Es wird Zeit zum Z’hausgehn.

Der Gatte.

Später.

Das süße Mädel.

Nein, ich muß wirklich schon zu Haus gehen. Was glaubst denn, was die Mutter sagen wird.

\section{Der Gatte.}

Du wohnst bei Deiner Mutter?

Das süße Mädel.

Natürlich wohn' ich bei meiner Mutter. Was hast denn geglaubt?

Der Gatte.

So - bei der Mutter. Wohnst Du allein mit ihr?

Das süße Mädel.

Ja freilich, allein! Fünf sind wir! zwei Buben und noch zwei Mädeln.

'Der Gatte.

So setz' Dich doch nicht so weit fort von mir. Bist

Du die älteste? 
Das süße Mädel.

Nein ich bin die zweite. Zuerst kommt die Kathi;

die ist im G'schäft, in einer Blumenhandlung, dann komm' ich.

Der Gatte.

Wo bist $\mathrm{Du}$ ?

Das süße Mädel.

$\mathrm{Na}$ ich bin zu Haus.

Der Gatte.

Immer?

Das süße Mädel.

Es muß doch eine z'haus sein.

\section{Der Gatte.}

Freilich. Ja, - und was sagst Du denn eigentlich

Deiner Mutter, wenn Du - so spät nach Haus kommst?

Das süße Mädel.

Das ist ja so eine Seltenheit.

\section{Der Gatte.}

Also heut' zum Beispiel. Deine Mutter fragt Dich

doch?

\section{Das süße Mädel.}

Natürlich fragt s' mich. Da kann ich Obacht geben so viel ich will - wenn ich nach Haus komm', wacht s' auf.

\section{Der Gatte.}

Also was sagst Du ihr da?

'Das süße Mädel.

$\mathrm{Na}$, im Theater werd' ich halt gewesen sein.

\section{Der Gatte.}

Und glaubt sie das?

Das süße Mädel.

$\mathrm{Na}$, warum soll s' mir denn nicht glauben? Ich geh' ja oft in's Theater. Erst am Sonntag war ich in der Oper mit meiner Freundin und ihrem Bräutigam und mein' ältern Bruder.

Der Gatte.

Woher habt Ihr denn da die Karten? 
Das süße Mädel.

Aber mein Bruder ist ja Friseur.

Der Gatte.

Ja, die Friseure ... ah, wahrscheinlich Theater= friseur.

Das süße Mädel.

Was fragst mich denn so aus?

Der Gatte.

Es interessiert mich halt. Und was ist denn der andere Bruder?

Das süße Mädel.

Der geht noch in die Schul'. Der will ein Lehrer werden. Nein .... so was!

\section{Der Gatte.}

Und dann hast Du noch eine kleine Schwester?

'Das süße Mädel.

Ja, die ist noch ein Fratz, aber auf die muß man schon heut so aufpassen. Hast Du denn eine Idee, wie die Mädeln in der Schule verdorben werden! Was glaubst! Neulich hab' ich sie bei einem Rendezvous er= wischt.

\section{Der Gatte.}

Was?

\section{Das süße Mädel.}

Ja! mit einem Buben von der Schul'vis-a-vis ist sie Abends um halber acht in der Strozzigasse spazieren gegangen. So ein Fratz!

Der Gatte.

$\mathrm{Na}$ was hast Du gemacht?

Das süße Mädel.

$\mathrm{Na}$, Schläg' hat s' kriegt!

\section{Der Gatte.}

So streng bist $\mathrm{Du}$ ?

\footnotetext{
1959 Aber] Aber, EA JSV BHV SFV

Friseur.] Friseur! JSV BHV SFV

1961 Friseure .... .] Friseure ...... EA JSV BHV

1982 mit] Mit BHV SFV

$\boldsymbol{v} \boldsymbol{i s}-\boldsymbol{a}$ - $\boldsymbol{v i s}]$ vis-à-vis EA JSV SFV vis=à $=v i s \mathrm{BHV}$

1983. spazieren gegangen] spazierengegangen SFV

$1986 \mathrm{Na}$ Und, EA JSV Und BHV SFV

Du] du da EA JSV BHV SFV
} 
Das süße Mädel.

$\mathrm{Na}$ wer soll's denn sein? Die Ältere ist im G'schäft, die Mutter thut nichts als raunzen; - kommt immer alles auf mich.

Der Gatte.

Herrgott, bist Du lieb! (Küßt sie und wird zärtlicher.)

Du erinnerst mich auch an wen.

Das süße Mädel.

So - an wen denn?

'Der Gatte.

An keine bestimmte ... . an die Zeit .... . na halt an meine Jugend. Geh, trink', mein Kind!

Das süße Mädel.

Ja, wie alt bist Du denn? ... . Du ... . ja

... . ich weiß ja nicht einmal, wie Du heißt.

Der Gatte.

Karl.

\section{Das süße Mädel.}

Ist's möglich! Karl heißt Du?

Der Gatte.

Er hat auch Karl geheißen?

Das süße Mädel.

Nein, das ist aber schon das reine Wunder .... das ist ja - Nein die Augen .... Das G'schau ... (schüttelt den Kopf).

Der Gatte.

Und wer er war - hast Du mir noch immer nicht gesagt.

\section{Das süße Mädel.}

Ein schlechter Mensch ist er gewesen - das ist g'wiß, sonst hätt' er mich nicht sitzen lassen.

Na] Na, EA JSV BHV SFV

Ältere] ältere EA JSV BHV SFV

Zeit ..... Ze Zeit.... EA JSV BHV

na] na, EA JSV BHV SFV

2004f. ja ....] ja ... EA JSV BHV

2013 Wunder.....] Wunder... EA JSV BHV

2014 Nein] nein EA JSV nein, BHV SFV

G'schau.... G'schau.... EA JSV BHV

war -] war, BHV SFV 
Der Gatte.

Hast ihn sehr gern g'habt?

Das süße Mädel.

Freilich hab' ich ihn gern g'habt.

'Der Gatte.

Ich weiß, was er war, Lieutenant.

Das süße Mädel.

Nein, beim Militär war er nicht. Sie haben ihn nicht genommen. Sein Vater hat ein Haus in der ... Aber was brauchst Du das zu wissen?

Der Gatte (küßt sie).

Du hast eigentlich graue Augen, manchmal hab ich gemeint, sie sind schwarz.

Das süße Mädel.

Na sind s' Dir vielleicht nicht schön genug?

Der Gatte (küßt die Augen).

Das süße Mädel.

Nein nein — das vertrag' ich schon gar nicht... oh bitt' Dich - oh Gott . . . . oh Gott .... nein, laß mich aufstehn . . . . nur für einen Moment bitt' Dich.

Der Gatte (immer zärtlicher).

Oh nein.

Das süße Mädel.

Aber ich bitt' Dich, Karl ....

Der Gatte.

Wie alt bist $\mathrm{Du} ?-18$, was?

Das süße Mädel.

Neunzehn vorbei.

\section{Der Gatte.}

Neunzehn .... und ich -

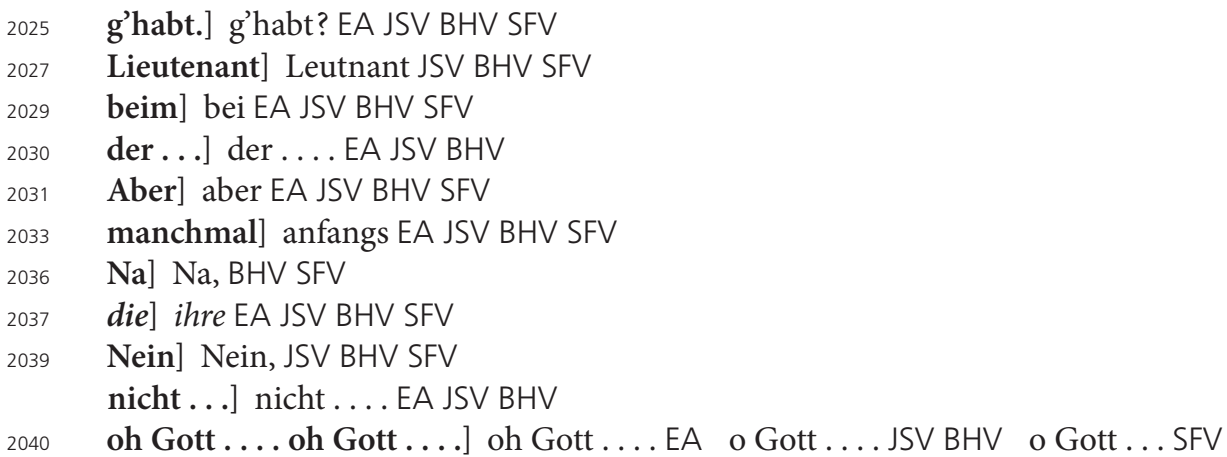


'Das süße Mädel.

Du bist dreißig ....

Der Gatte.

Und einige drüber. - Reden wir nicht davon.

Das süße Mädel.

Er war auch schon zweiunddreißig, wie ich ihn kennen gelernt hab'.

\section{Der Gatte.}

Wie lang ist das her?

Das süße Mädel.

Ich weiß nimmer .... . Du in dem Wein muß 'was drin gewesen sein.

\section{Der Gatte.}

Ja, warum denn?

\section{Das süße Mädel.}

Ich bin ganz .... weißt - mir dreht sich alles.

\section{Der Gatte.}

So halt' Dich fest an mich. So .... (Er drückt sie

an sich und wird immer zärtlicher, sie wehrt kaum ab.) Ich werd'

Dir 'was sagen, mein Schatz, wir könnten jetzt wirklich geh'n.

\section{Das süße Mädel.}

Ja .... nach Haus.

Der Gatte.

Nicht grad' nach Haus .... .

Das süße Mädel.

Was meinst denn? ... . oh nein, oh nein ....

ich geh' nirgends hin, was fallt Dir denn ein -

'Der Gatte.

Also hör' mich nur an, mein Kind, das nächste Mal, wenn wir uns treffen, weißt Du, da richten wir das so ein, daß .... (Er ist zu Boden gesunken, hat seinen Kopf in ihrem Schoß.) Das ist angenehm, oh das ist angenehm.

Du] Du, BHV SFV

denn?] denn. BHV SFV

könnten] können SFV

denn?...oh] denn? ... Oh EA denn? ... O JSV BHV SFV

nein .... .] nein ... EA JSV BHV

wir das] wir uns das EA JSV BHV SFV

daß....] daß...EA JSV BHV

oh] oh, EA JSV BHV SFV 
Das süße Mädel.

Was machst denn? (Sie küßt seine Haare.) ... . Du in dem Wein $\mathrm{mu} ß$ 'was drin gewesen sein - so schläf= rig .... Du, was g'schieht denn, wenn ich nimmer auf= stehn kann? Aber, aber, schau, aber Karl .... und wenn wer hereinkommt .... ich bitt Dich ..... der Kellner.

Der Gatte.

Da .... kommt sein Lebtag.... kein Kellner

.... herein ....

Das süße Mädel (lehnt mit geschlossenen Augen in der Divanecke).

Der Gatte (geht in dem kleinen Raum auf und ab, nachdem er sich eine Cigarette angezündet).

Längeres Schweigen.

Der Gatte (betrachtet das süße Mädel lange, für sich).

Wer weiß, was das eigentlich für eine Person ist

— Donnerwetter ... . So schnell ... . War nicht sehr

vorsichtig von mir ....Hm ....

Das süße Mädel (ohne die Augen zu öffnen).

In dem Wein muß was drin gewesen sein.

'Der Gatte.

Ja warum denn?

Das süße Mädel.

Sonst....

Der Gatte.

Warum schiebst Du denn alles auf den Wein? ...

Das süße Mädel.

Wo bist denn? Warum bist denn so weit? Komm doch zu mir.

Der Gatte (zu ihr hin, setzt sich).

Das süße Mädel.

Jetzt sag' mir, ob Du mich wirklich gern hast. 


\section{Der Gatte.}

Das weißt Du doch .... (Er unterbricht sich rasch.)

Freilich.

\section{Das süße Mädel.}

Weißt .... es ist doch .... Geh, sag' mir die

Wahrheit, was war in dem Wein?

Der Gatte.

Ja, glaubst Du ich bin ein . . . . ich bin ein Gift= mischer?

\section{Das süße Mädel.}

Ja, schau, ich versteh's halt nicht. Ich bin doch nicht so .... Wir kennen uns doch erst seit .... Du ich bin nicht so .... . meiner Seel' und Gott, - wenn Du das von mir glauben thätst -

'Der Gatte. Ja - was machst Du Dir denn da für Sorgen.

Ich glaub' gar nichts schlechtes von Dir. Ich glaub' halt, daß Du mich lieb hast.

Das süße Mädel.

Ja....

\section{Der Gatte.}

Schließlich, wenn zwei junge Leut' allein in einem

Zimmer sind, und nachtmahlen und trinken Wein ....

es braucht gar nichts drin zu sein in dem Wein.

\section{Das süße Mädel.}

Ich hab's ja auch nur so g'sagt.

\section{Der Gatte.}

Ja warum denn?

Das süße Mädel (eher trotzig).

Ich hab' mich halt g'schämt.

Der Gatte.

Das ist lächerlich. Dazu liegt gar kein Grund vor.

Umsomehr als ich Dich an Deinen ersten Geliebten er= innere.

Das süße Mädel.

Ja.

Du] du, BHV SFV

Du] Du, EA JSV BHV SFV

thätst - ] tät'st. - BHV tät'st. - SFV

sind,] sind SFV

Umsomehr] Um so mehr JSV BHV Um so mehr, SFV 
Der Gatte.

An den ersten.

Das süße Mädel.

Na ja....

'Der Gatte.

Jetzt möcht' es mich interessieren, wer die anderen waren.

Das süße Mädel.

Niemand.

Der Gatte.

Das ist ja nicht wahr, das kann ja nicht wahr sein.

Das süße Mädel.

Geh' bitt' Dich, sekir' mich nicht. -

Der Gatte.

Willst eine Cigarette?

Das süße Mädel.

Nein, ich dank' schön.

Der Gatte.

Weißt Du, wie spät es ist?

Das süße Mädel.

$\mathrm{Na}$ ?

Der Gatte.

Halb zwölf.

Das süße Mädel.

So!

Der Gatte.

$\mathrm{Na}$.... und die Mutter? Die ist es gewöhnt, was?

Das süße Mädel.

Willst mich wirklich schon z'haus schicken?

Der Gatte.

Ja, Du hast doch früher selbst -

'Das süße Mädel.

Geh', Du bist aber wie ausgewechselt. Was hab' ich Dir denn gethan? 
Der Gatte.

Aber Kind, was hast Du denn, was fällt Dir

denn ein?

\section{Das süße Mädel.}

Und es ist nur Dein G'schau gewesen, meiner Seel', sonst hättst Du lang .... haben mich schon viele ge= beten, ich soll mit ihnen in's chambre separée.

\section{Der Gatte.}

$\mathrm{Na}$, willst $\mathrm{Du}$.... bald wieder mit mir hieher

.... oder auch wo anders -

Das süße Mädel.

Weiß nicht.

Der Gatte.

Was heißt das wieder: Du weißt nicht.

Das süße Mädel.

Na wenn Du mich erst fragst?

\section{Der Gatte.}

Also wann? Ich möcht Dich nur vor allem aufklären, daß ich nicht in Wien lebe. Ich komm' nur von Zeit zu Zeit auf ein paar Tage her.

Das süße Mädel.

Ah geh', Du bist kein Wiener?

Der Gatte.

Wiener bin ich schon. Aber ich lebe jetzt in der Nähe....

\section{'Das süße Mädel.}

Wo denn?

Der Gatte.

Ach Gott, das ist ja egal.

Das süße Mädel.

$\mathrm{Na}$, fürcht' Dich nicht, ich komm' nicht hin.

Der Gatte.

Oh Gott, wenn es Dir Spaß macht, kannst Du auch hinkommen. Ich lebe in Graz.

Das süße Mädel.

Im Ernst?

separée.] separée gehen. EA JSV BHV SFV

Du..... du ....EA JSV BHV

wo anders] woanders SFV

$\mathrm{Na}$ ] $\mathrm{Na}$, EA JSV BHV SFV 
Der Gatte.

$\mathrm{Na}$ ja, was wundert Dich denn daran?

Das süße Mädel.

Du bist verheiratet, wie?

Der Gatte (höchst erstaunt).

Ja, wie kommst Du darauf?

\section{Das süße Mädel.}

Mir ist halt so vorgekommen.

Der Gatte.

Und das würde Dich gar nicht genieren?

Das süße Mädel.

Na lieber ist mir schon, Du bist ledig. - Aber Du bist ja doch verheiratet! -

Der Gatte.

Ja, sag' mir nur, wie kommst Du denn da darauf?

'Das süße Mädel.

Wenn einer sagt, er lebt nicht in Wien, und hat nicht immer Zeit -

\section{Der Gatte.}

Das ist doch nicht so unwahrscheinlich.

Das süße Mädel.

Ich glaub's nicht.

\section{Der Gatte.}

Und da möchtest Du Dir gar kein Gewissen machen, daß Du einen Ehemann zur Untreue verführst?

Das süße Mädel.

Ah was, Deine Frau machts sicher nicht anders als Du.

Der Gatte (sehr empört).

$\mathrm{Du}, \mathrm{d}$ a s verbiet' ich mir. Solche Bemerkungen -

Das süße Mädel.

Du hast ja keine Frau, hab' ich geglaubt.

\section{Der Gatte.}

Ob ich eine hab' oder nicht - man macht keine

\begin{tabular}{ll}
\hline 2237 & Na] Na, EA JSV BHV SFV \\
2240 & denn da] denn JSV BHV SFV \\
2242 & Wien,] Wien EA JSV BHV SFV \\
2255 & verbiet'] verbitt' JSV BHV SFV \\
& Bemerkungen -] Bemerkungen. JSV BHV SFV
\end{tabular}


solchen Bemerkungen.

(Er ist aufgestanden).

Das süße Mädel.

Karl, na Karl, was ist denn? Bist bös? Schau, ich hab's ja wirklich nicht gewußt, daß Du verheiratet bist. Ich hab' ja nur so g'redt. Geh' komm und sei wieder gut.

'Der Gatte (kommt nach ein paar Sekunden zu ihr).

Ihr seids wirklich sonderbare Geschöpfe, Ihr ....

Weiber. (Er wird wieder zärtlich an ihrer Seite).

Das süße Mädel.

Geh' ... . nicht .... es ist auch schon so spät. -

Der Gatte.

Also jetzt hör' mir einmal zu. Reden wir einmal im Ernst miteinander. Ich möcht Dich wieder sehen, öfter wiedersehen.

Das süße Mädel.

Is wahr?

Der Gatte.

Aber dazu ist notwendig .... also verlassen muß ich mich auf Dich können. Aufpassen kann ich nicht auf Dich.

Das süße Mädel.

Ah, ich pass' schon selber auf mich auf.

Der Gatte.

Du bist ... . na also, unerfahren kann man ja

nicht sagen - aber jung bist Du — und — die Männer sind im allgemeinen ein gewissenloses Volk.

Das süße Mädel.

Oh jeh!

Der Gatte.

Ich mein' das nicht nur in moralischer Hinsicht. $\mathrm{Na}, \mathrm{Du}$ verstehst mich sicher. -

solchen] solche EA JSV BHV SFV

Geh'] Geh', JSV BHV SFV

seids] seid EA JSV BHV SFV

Geh'.... .] Geh'..... EA JSV BHV

nicht..... nicht.....EA JSV BHV 
Das süße Mädel.

Ja, sag' mir, was glaubst Du denn eigentlich von mir?

'Der Gatte.

Also - wenn Du mich lieb haben willst - nur mich - so können wir's uns schön einrichten - wenn ich auch für gewöhnlich in Graz wohne. Da wo jeden Moment wer hereinkommen kann, ist es ja doch nicht das rechte.

Das süße Mädel (schmiegt sich an ihn).

\section{Der Gatte.}

Das nächste Mal .... werden wir wo anders $\mathrm{zu}=$ sammen sein, ja?

Das süße Mädel.

Ja.

Der Gatte.

Wo wir ganz ungestört sind.

Das süße Mädel.

Ja.

Der Gatte (umfängt sie heiß).

Das andere besprechen wir im Nachhausfahren.

(Steht auf, öffnet die Thür.) Kellner ... . die Rechnung!

'Ein kleines Zimmer, mit behaglichem Geschmack eingerichtet. Vorhänge,

Wand.

Das süße Mädel. Der Dichter. -

Sie kommen eben zusammen herein. Der Dichter schließt zu.

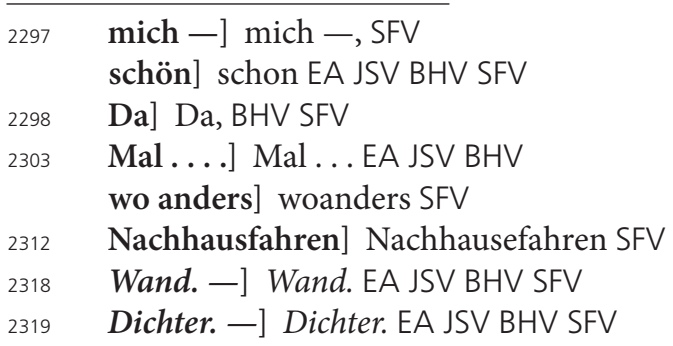




\section{Der Dichter.}

So mein Schatz. (Küßt sie).

Das süße Mädel (hat noch Hut und Mantille an).

Ah! Da ist aber schön! Nur sehen thut man nichts!

\section{Der Dichter.}

Deine Augen müssen sich an das Halbdunkel ge= wöhnen. - Diese süßen Augen (küßt sie auf die Augen).

Das süße Mädel.

Dazu werden die süßen Augen aber nicht Zeit genug haben.

Der Dichter.

Warum denn?

Das süße Mädel.

Weil ich nur eine Minuten dableib’.

'Der Dichter.

Den Hut leg' ab, ja?

Das süße Mädel.

Wegen der einen Minuten?

Der Dichter (nimmt ihr die Nadel aus ihrem Hut und legt den

Hut fort.) Und die Mantille -

Das süße Mädel.

Was willst denn? - Ich muß ja gleich wieder fortgehen.

\section{Der Dichter.}

Aber Du mußt Dich doch ausruh'n! Wir sind ja drei Stunden gegangen.

Das süße Mädel.

Wir sind gefahren.

Der Dichter.

Ja nach Haus - aber in Weidling am Bach sind wir doch drei volle Stunden herumgelaufen. Also setz' Dich nur schön nieder, mein Kind .... Wohin Du willst; - hier an den Schreibtisch; - aber nein, das ist nicht bequem. Setz' Dich auf den Divan. - So.

So] So, EA JSV BHV SFV

Schatz. (Küßt] Schatz (küßst EA JSV BHV SFV

Mädel (hat noch Hut und Mantille an).] Mädel (mit Hut und Mantille). EA JSV BHV SFV nimmt ihr] nimmt EA JSV BHV SFV

Ja] Ja, BHV SFV

Wohin] wohin EA JSV BHV SFV

So. (Er] So (er JSV 
(Er drückt sie nieder.) Bist Du sehr müd', so kannst Du Dich auch hinlegen. So. (Er legt sie auf den Divan). Da das Kopferl auf den Polster.

Das süße Mädel (lachend).

Aber ich bin ja gar nicht müd!

'Der Dichter.

Das glaubst Du nur. So - und wenn Du schläf= rig bist, kannst Du auch schlafen. Ich werde ganz still sein. Übrigens kann ich Dir ein Schlummerlied vor= spielen .... von mir .... (Geht zum Pianino).

Das süße Mädel.

Von Dir?

\section{Der Dichter.}

Ja.

Das süße Mädel.

Ich hab' glaubt, Robert, Du bist ein Doktor.

\section{Der Dichter.}

Wieso? Ich hab' Dir doch gesagt, daß ich Schrift= steller bin.

Das süße Mädel.

Die Schriftsteller sind doch alle Dokters.

\section{Der Dichter.}

Nein; nicht alle. Ich z. B. nicht. Aber wie kommst

Du jetzt darauf.

Das süße Mädel.

Na, weil Du sagst, das Stück, was Du da spielen thust, ist von Dir.

\section{Der Dichter.}

Ja ... . vielleicht ist es auch nicht von mir. Das ist ja ganz egal. Was? Überhaupt wer's gemacht hat, das ist immer egal. Nur schön muß es sein — nicht wahr?

'Das süße Mädel.

Freilich .... schön muß es sein — das ist die

Hauptsach'! -

Der Dichter.

Weißt Du, wie ich das gemeint hab'?

\footnotetext{
2363f. vorspielen .... vorspielen ..... EA

2383 Ja ....] Ja ... EA JSV BHV
} 
Das süße Mädel.

Was denn?

Der Dichter.

$\mathrm{Na}$, was ich eben gesagt hab'.

Das süße Mädel (schläfrig).

$\mathrm{Na}$ freilich.

Der Dichter (steht auf; zu ihr, ihr das Haar streichelnd).

Kein Wort hast Du verstanden.

Das süße Mädel.

Geh', ich bin doch nicht so dumm.

Der Dichter.

Freilich bist Du so dumm. Aber gerade darum hab' ich Dich lieb. Ah, das ist so schön, wenn Ihr dumm seid. Ich mein' in der Art wie Du.

Das süße Mädel.

Geh', was schimpfst denn?

Der Dichter.

Engel, kleiner. Nicht wahr, es liegt sich gut auf dem weichen, persischen Teppich?

Das süße Mädel.

Oh ja. Geh' willst nicht weiter Klavier spielen?

'Der Dichter.

Nein, ich bin schon lieber da bei Dir. (Streichelt sie).

Das süße Mädel.

Geh' willst nicht lieber Licht machen?

Der Dichter.

Oh nein .... Diese Dämmerung thut ja so wohl.

Wir waren heute den ganzen Tag wie in Sonnenstrahlen gebadet. Jetzt sind wir sozusagen aus dem Bad gestiegen und schlagen .... die Dämmerung wie einen Badmantel (lacht) ah nein - das muß anders gesagt werden .... . Findest Du nicht?

Das süße Mädel.

Weiß nicht.

Der Dichter (sich leicht von ihr entfernend). Göttlich, diese Dummheit. (Nimmt ein Notizbuch und schreibt ein paar Worte hinein).

Geh'] Geh', EA JSV BHV Geh, SFV

Geh'] Geh', EA JSV BHV Geh, SFV

Badmantel] Bademantel JSV BHV SFV

Dummheit.] Dummheit! EA JSV BHV SFV 
Das süße Mädel.

Was machst denn? (Sich nach ihm umwendend.) Was schreibst Dir denn auf?

Der Dichter (leise).

Sonne, Bad, Dämmerung, Mantel .... so . . . .

(steckt das Notizbuch ein. Laut.) Nichts ... . Jetzt sag' ein= mal, mein Schatz, möchtest Du nicht etwas essen oder trinken?

Das süße Mädel.

Durst hab' ich eigentlich keinen. Aber Appetit.

'Der Dichter.

Hm . . . . mir wär' lieber, Du hättest Durst.

Cognac hab' ich nämlich zu Haus, aber Essen müßte ich erst holen.

Das süße Mädel.

Kannst nichts holen lassen?

Der Dichter.

Das ist schwer, meine Bedienerin ist jetzt nicht mehr da - na wart' - ich geh' schon selber ... . was magst Du denn?

Das süße Mädel.

Aber es zahlt sich ja wirklich nimmer aus, ich muß ja so wie so zu Haus.

Der Dichter.

Kind, d a von ist keine Rede. Aber ich werd' Dir 'was sagen: wenn wir weggehn, geh'n wir zusammen wohin nachtmahlen.

Das süße Mädel.

Oh nein. Dazu hab' ich keine Zeit. Und dann, wohin sollen wir denn. Es könnt uns ja 'wer Bekannter seh'n.

Der Dichter.

Hast Du denn gar so viel Bekannte?

Das süße Mädel.

Es braucht uns ja nur Einer zu sehn, ist's Malheur schon fertig.

\begin{tabular}{ll}
\hline 2453 & d a von] davon JSV BHV SFV \\
2458 & denn.] denn? EA JSV BHV SFV \\
2461 & viel] viele BHV SFV \\
2463 & Einer] einer JSV BHV SFV
\end{tabular}


Der Dichter.

Was ist denn das für ein Malheur?

'Das süße Mädel.

$\mathrm{Na}$, was glaubst, wenn die Mutter 'was hört ...

Der Dichter.

Wir können ja doch irgend wohin gehen, wo uns niemand sieht, es giebt ja Gasthäuser mit einzelnen Zimmern.

Das Mädel (singend).

Ja beim Souper im chambre separée.

Der Dichter.

Warst Du schon einmal in einem chambre separée?

Das süße Mädel.

Wenn ich die Wahrheit sagen soll — ja.

Der Dichter.

Wer war der glückliche?

Das süße Mädel.

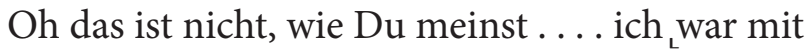
meiner Freundin und ihrem Bräutigam. Die haben mich mitgenommen.

\section{Der Dichter.}

So. Und das soll ich Dir am End glauben?

Das süße Mädel.

Brauchst mir ja nicht zu glauben!

Der Dichter (nah bei ihr).

Bist Du jetzt rot geworden? Man sieht nichts mehr!

Ich kann Deine Züge nicht mehr ausnehmen. (Mit seiner

Hand berührt er ihre Wangen.) Aber auch so erkenn' ich Dich.

'Das süße Mädel.

Na, paß' nur auf, daß Du mich mit keiner andern

verwechselst.

Der Dichter.

Es ist seltsam, ich kann mich nicht mehr erinnern, wie Du aussiehst.

hört ...] hört .... EA JSV

irgend wohin] irgendwohin BHV SFV

Ja] Ja, EA JSV BHV SFV separée.] separée! EA JSV BHV SFV

Oh] Oh, BHV SFV

glauben?] glauben! BHV SFV

paß'] pass' EA JSV BHV SFV 


\section{Das süße Mädel.}

Dank'schön!

Der Dichter (ernst).

Du, das ist beinah' unheimlich, ich kann mir Dich nicht vorstellen - In einem gewissen Sinne hab' ich dich schon vergessen - Wenn ich mich auch nicht mehr an den Klang Deiner Stimme erinnern könnte . . . . was wärst Du da eigentlich? - Nah und fern zugleich . . . un un= heimlich.

Das süße Mädel.

Geh', was redst denn -?

Der Dichter.

Nichts, mein Engel, nichts. Wo sind Deine Lippen .... (Erküßt sie).

Das süße Mädel.

Willst nicht lieber Licht machen.

Der Dichter.

Nein .... (Er wird sehr zärtlich.) Sag', ob Du mich lieb hast.

Das süße Mädel.

Sehr.... oh sehr.

'Der Dichter.

Hast Du schon irgendwen so lieb gehabt wie mich?

Das süße Mädel.

Ich hab' Dir ja schon gesagt nein.

Der Dichter.

Aber.... (er seufzt).

Das süße Mädel.

Das ist ja mein Bräutigam gewesen.

\section{Der Dichter.}

Es wär' mir lieber, Du würdest jetzt nicht an ihn denken.

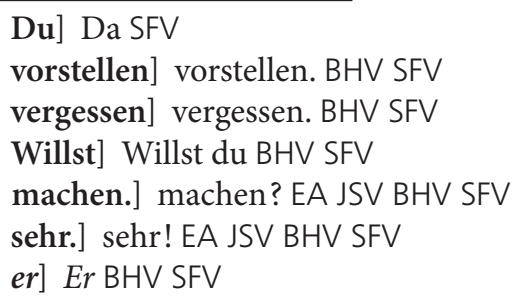


Das süße Mädel.

Geh' ... . was machst denn .... schau ....

Der Dichter.

Wir können uns jetzt auch vorstellen, daß wir in einem Schloß in Indien sind.

Das süße Mädel.

Dort sind s' gewiß nicht so schlimm wie Du.

Der Dichter.

Wie blöd! Göttlich — Ah wenn Du ahntest, was

Du für mich bist....

Das süße Mädel.

$\mathrm{Na}$ ?

Der Dichter.

Stoß mich doch nicht immer weg; ich thu' Dir ja

nichts - vorläufig.

'Das süße Mädel.

$\mathrm{Du}$, das Mieder thut mir weh.

Der Dichter (einfach).

Zieh's aus.

Das süße Mädel.

Ja. Aber Du darfst deswegen nicht schlimm werden.

\section{Der Dichter.}

Nein.

Das süße Mädel (hat sich erhoben und zieht in der Dunkelheit ihr Mieder aus).

Der Dichter (der währenddessen auf dem Divan sitzt). Sag', interessiert's Dichs denn gar nicht, wie ich mit dem Zunamen heiß'?

Das süße Mädel.

Ja, wie heißt Du denn?

\section{Der Dichter.}

Ich werd' Dir lieber nicht sagen, wie ich heiß, sondern wie ich mich nenne.

Das süße Mädel.

Was ist denn da für ein Unterschied?

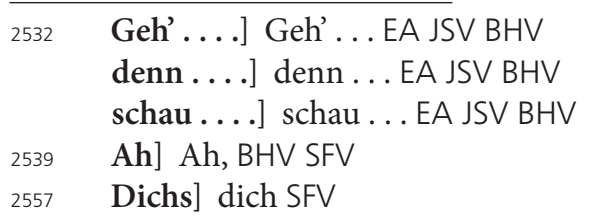

2557 Dichs] dich SFV 


\section{Der Dichter.}

$\mathrm{Na}$, wie ich mich als Schriftsteller nenne.

Das süße Mädel.

Ah, Du schreibst nicht unter Deinem wirklichen Namen?

Der Dichter (nah zu ihr).

'Das süße Mädel.

Ah ....geh!.... nicht.

Der Dichter.

Was einem da für ein Duft entgegensteigt. Wie süß. (Er küßt ihren Busen).

Das süße Mädel.

Du zerreißt ja mein Hemd.

\section{Der Dichter.}

Weg .... weg .... alles das ist überflüssig.

(Er entkleidet sie rasch).

Das süße Mädel.

Aber Robert.

Der Dichter.

Und jetzt komm' in unser indisches Schloß.

Das süße Mädel.

Sag' mir zuerst, ob Du mich wirklich lieb hast.

Der Dichter.

Aber ich bete Dich ja an. (Hat sie auf den Divan nieder= gedrückt - küßt sie heiß.) Ich bete Dich ja an, mein Schatz, mein Frühling .... mein ....

Das süße Mädel.

Robert.... Robert....

\section{Der Dichter.}

Das war überirdische Seligkeit .... Ich nenne mich ....

'Das süße Mädel.

Robert, oh mein Robert!

überflüssig. (Er entkleidet sie rasch).] überflüssig. EA JSV BHV SFV

Robert.] Robert! EA JSV BHV SFV

an. (Hat sie auf den Divan niedergedrückt $-k \ddot{i} \beta t]$ an. (Küßt EA JSV BHV SFV

Frühling .... . Frühling ... EA JSV BHV

mein .... .] mein ... EA JSV BHV

Robert.... Robert.... R Robert.... Robert...! JSV Robert.... Robert....! BHV

Robert ... Robert ... ! SFV 


\section{Der Dichter.}

Ich nenne mich Biebitz.

Das süße Mädel.

Warum nennst Du Dich Biebitz?

Der Dichter.

Ich heiße nicht Biebitz — ich nenne mich so ....

nun, kennst Du den Namen vielleicht nicht?

Das süße Mädel.

Nein.

Der Dichter.

Du kennst den Namen Biebitz nicht. Ah — göttlich!

Wirklich? Du sagst es nur, daß Du ihn nicht kennst, nicht wahr?

Das süße Mädel.

Meiner Seel' ich hab' ihn nie gehört.

Der Dichter.

Gehst Du denn nie in's Theater?

Das süße Mädel.

Oh ja - ich war erst neulich mit einem - weißt

mit dem Onkel von meiner Freundin und meiner Freundin sind wir in der Oper gewesen bei der Cavalleria.

\section{Der Dichter.}

$\mathrm{Hm}$, also ins Burgtheater gehst Du nie.

'Das süße Mädel.

Da krieg ich nie Karten geschenkt.

\section{Der Dichter.}

Ich werde Dir nächstens eine Karte schicken.

Das süße Mädel.

Oh ja! aber nicht vergessen! Zu 'was lustigem aber.

\section{Der Dichter.}

Ja ... lustig . . . zu was traurigem willst $\mathrm{Du}$

nicht gehn?

Das süße Mädel.

Nicht gern.

nicht.] nicht? EA JSV BHV SFV

Seel'] Seel', EA JSV BHV SFV

gehört.] gehört! EA JSV BHV SFV

2618 weißt] weißt, EA JSV BHV SFV

2630 Ja .... Ja ..... EA JSV

lustig .... .] lustig ..... EA JSV 


\section{Der Dichter.}

Auch wenn's ein Stück von mir ist?

Das süße Mädel.

Geh' - ein Stück von Dir? Du schreibst für's

Theater?

\section{Der Dichter.}

Erlaube, ich will nur Licht machen. Ich habe Dich noch nicht gesehen, seit Du meine Geliebte bist. - Engel! (Er zündet eine Kerze an.)

Das süße Mädel.

Geh' ich schäm' mich ja. Gieb mir wenigstens eine Decke.

Der Dichter.

Später! (Er kommt mit dem Licht zu ihr, betrachtet sie lang.)

Das süße Mädel (bedeckt ihr Gesicht mit den Händen).

Geh', Robert!

'Der Dichter.

Du bist schön, $\mathrm{Du}$ bist die Schönheit, $\mathrm{Du}$ bist viel= leicht sogar die Natur, Du bist die heilige Einfalt.

Das süße Mädel.

Oh weh, Du tropfst mich ja an! Schau, was giebst denn nicht acht.

Der Dichter (stellt die Kerze weg).

Du bist das, was ich seit lange gesucht habe. Du liebst nur mich, Du würdest mich auch lieben, wenn ich Schnittwaarencommis wäre. Das thut wohl. Ich will Dir gestehen, daß ich einen gewissen Verdacht bis zu diesem Moment nicht losgeworden bin. Sag' ehrlich, hast Du nicht geahnt, daß ich Biebitz bin?

Das süße Mädel.

Aber geh', ich weiß gar nicht, was Du von mir willst. Ich kenn' ja gar kein' Biebitz.

\section{Der Dichter.}

Was ist der Ruhm! Nein, vergiß, was ich gesagt habe, vergiß sogar den Namen, den ich Dir gesagt hab'. Robert bin ich und will ich für Dich bleiben. Ich hab' auch nur gescherzt. (Leicht). Ich bin ja nicht Schrift=

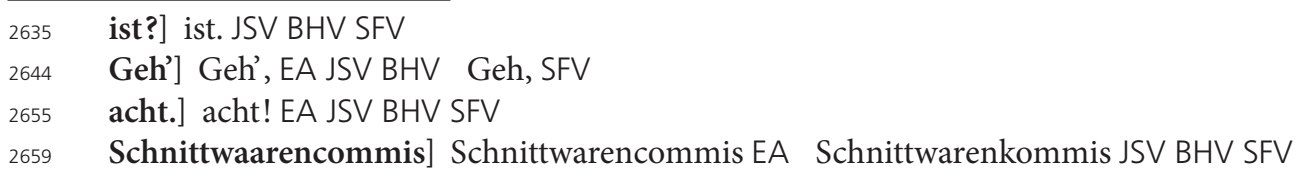


steller, ich bin Commis und am Abend spiel' ich bei Volks= sängern Klavier.

Das süße Mädel.

Ja, jetzt kenn' ich mich aber nicht mehr aus .... nein, und wie Du einen nur anschaust. Ja, was ist denn, ja, was hast denn?

'Der Dichter.

Es ist sehr sonderbar - was mir beinah' noch nie passiert ist, mein Schatz, mir sind die Thränen nah. Du ergreifst mich tief. Wir wollen zusammen bleiben, ja? Wir werden einander sehr lieb haben.

Das süße Mädel.

$\mathrm{Du}$, ist das wahr mit den Volkssängern?

\section{Der Dichter.}

Ja, aber frag' nicht weiter. Wenn Du mich lieb hast, frag' überhaupt nichts. Sag' kannst Du Dich auf ein paar Wochen ganz frei machen?

Das süße Mädel.

Wieso ganz frei?

Der Dichter.

Nun, vom Hause weg?

Das süße Mädel.

Aber!! Wie kann ich das! Was möcht' die Mutter sagen? Und dann, ohne mich ging' ja alles schief zu Haus.

Der Dichter.

Ich hatte es mir schön vorgestellt, mit Dir zusammen, allein mit Dir, irgendwo in der Einsamkeit draußen, im Wald, in der Natur ein paar Wochen zu leben. Natur ... . in der Natur. Und dann, eines Tages Adieu von einander gehen, ohne zu wissen wohin.

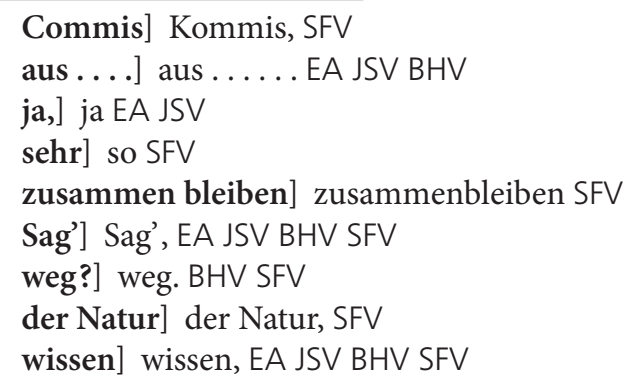


'Das süße Mädel.

Jetzt redst schon vom Adieu=sagen! Und ich hab' gemeint, daß Du mich so gern hast.

\section{Der Dichter.}

Gerade darum - (Beugt sich zu ihr und küßt sie auf die

Stirn.) Du süßes Geschöpf!

Das süße Mädel.

Geh', halt mich fest, mir ist so kalt.

\section{Der Dichter.}

Es wird Zeit sein, daß Du Dich ankleidest. Warte, ich zünde Dir noch ein paar Kerzen an.

Das süße Mädel (erhebt sich).

Nicht herschauen.

Der Dichter.

Nein. (Am Fenster.) Sag' mir, mein Kind, bist Du glücklich?

Das süße Mädel.

Wie meinst das?

Der Dichter.

Ich mein' im Allgemeinen, ob Du glücklich bist?

\section{Das süße Mädel.}

Es könnt' schon besser gehen.

\section{Der Dichter.}

Du mißverstehst mich. Von Deinen häuslichen Ver= hältnissen hast Du mir ja schon genug erzählt. Ich weiß, daß Du keine Prinzessin bist. Ich mein', wenn Du von 'alledem absiehst, wenn Du Dich einfach leben spürst. Spürst Du Dich überhaupt leben?

Das süße Mädel.

Geh', hast kein' Kamm.

Der Dichter (geht zum Toilettetisch, giebt ihr den Kamm, betrachtet das süße Mädel).

Herrgott, siehst Du so entzückend aus!

Das süße Mädel.

$\mathrm{Na}$.... nicht. 


\section{Der Dichter.}

Geh', bleib' noch da, bleib' da, ich hol' was zum

Nachtmahl, und ....

Das süße Mädel.

Aber es ist ja schon viel zu spät.

\section{Der Dichter.}

Es ist noch nicht neun.

Das süße Mädel.

Na sei so gut, da muß ich mich aber tummeln.

\section{Der Dichter.}

Wann werden wir uns denn wiedersehen?

Das süße Mädel.

$\mathrm{Na}$, wann willst mich denn wiedersehen?

\section{Der Dichter.}

Morgen.

Das süße Mädel.

Was ist denn morgen für ein Tag?

'Der Dichter.

Samstag.

Das süße Mädel.

Oh da kann ich nicht, da muß ich mit meiner kleinen Schwester zum Vormund.

Der Dichter.

Also Sonntag .... hm .... Sonntag ... am

Sonntag .... jetzt werd' ich Dir 'was erklären. -

Ich bin nicht Biebitz, aber Biebitz ist mein Freund. Ich werd' Dir ihn einmal vorstellen. Aber Sonntag ist das Stück von Biebitz; ich werd' Dir eine Karte schicken und werde Dich dann vom Theater abholen. Du wirst mir sagen, wie Dir das Stück gefallen hat; ja?

Das süße Mädel.

Jetzt, die G'schicht' mit dem Biebitz — da bin ich schon ganz blöd. 


\section{Der Dichter.}

Ganz werd' ich Dich erst kennen, wenn ich weiß, was Du bei diesem Stück empfunden hast.

Das süße Mädel.

So .... ich bin fertig.

Der Dichter.

Komm', mein Schatz!

(Sie gehen). Mond; die Fenster stehen offen.

Große Stille.

Der Dichter und die Schauspielerin treten ein; wie sie hereintreten, ver= löscht das Licht, das der Dichter in der Hand hält.

\section{Dichter.}

$\mathrm{Oh} . .$. .

\section{Schauspielerin.}

Was ist denn?

\section{Dichter.}

Das Licht. - Aber wir brauchen keins. Schau', es ist ganz hell. Wunderbar!

Schauspielerin (sinkt am Fenster plötzlich nieder, mit gefalteten Händen).

\section{Dichter.}

Was hast Du denn?

Schauspielerin (schweigt).

Dichter (zu ihr hin).

Was machst Du denn?

'Schauspielerin (empört). 
Dichter.

Glaubst Du an Gott?

Schauspielerin.

Gewiß, ich bin ja kein blasser Schurke.

Dichter.

Ach so.

\section{Schauspielerin.}

Komm' doch zu mir, knie Dich neben mich hin.

Kannst wirklich auch einmal beten. Wird Dir keine Perle aus der Krone fallen.

Dichter (kniet neben sie hin und umfasst sie).

Schauspielerin.

Wüstling! - (Erhebt sich). Und weißt Du auch, zu wem ich gebetet habe?

Dichter.

$\mathrm{Zu}$ Gott, nehm' ich an.

Schauspielerin. (Großer Hohn.)

Jawohl! zu Dir hab' ich gebetet.

\section{Dichter.}

Warum hast Du denn da zum Fenster hinaus= geschaut?

\section{Schauspielerin.}

Sag' mir lieber, wo Du mich da hingeschleppt hast, Verführer!

'Dichter.

Aber Kind, das war ja Deine Idee. Du wolltest ja auf's Land - und gerade hieher.

Schauspielerin.

Nun, hab' ich nicht Recht gehabt?

\section{Dichter.}

Gewiß; es ist ja entzückend hier. Wenn man be= denkt, zwei Stunden von Wien - und die völlige Ein= samkeit. Und was für eine Gegend! 
Schauspielerin.

Was? Da könntest Du wohl manches dichten, wenn

Du zufällig Talent hättest.

\section{Dichter.}

Warst Du hier schon einmal?

\section{Schauspielerin.}

Ob ich hier schon war? Ha! Hier hab' ich Jahre

lang gelebt!

\section{Dichter.}

Mit wem?

\section{Schauspielerin.}

Nun, mit Fritz natürlich.

\section{Dichter.}

Ach so!

\section{Schauspielerin.}

Den Mann hab' ich wohl angebetet! -

\section{Dichter.}

Das hast Du mir bereits erzählt.

'Schauspielerin.

Ich bitte - ich kann auch wieder gehen, wenn ich

Dich langweile!

\section{Dichter.}

Du mich langweilen? ... Du ahnst ja gar nicht was Du für mich bedeutest . . . Du bist eine Welt für sich . . . Du bist das Göttliche, Du bist das Genie . . . Du bist . . . Du bist eigentlich die heilige Einfalt ... Ja, Du .... Aber Du solltest jetzt nicht von Fritz reden.

\section{Schauspielerin.}

Das war wohl eine Verirrung! $\mathrm{Na}$ ! -

\section{Dichter.}

Es ist schön, daß Du das einsiehst.

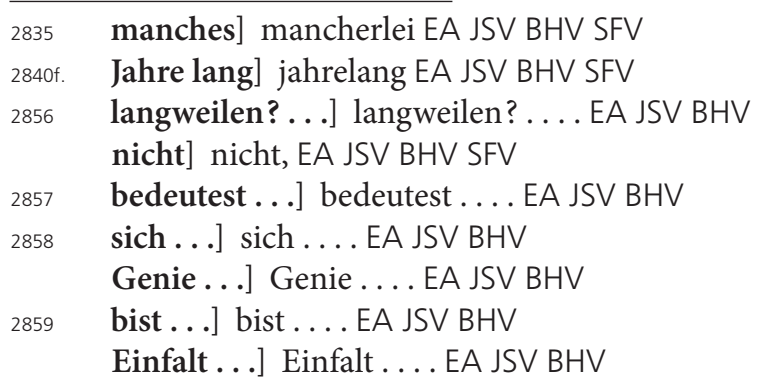


Schauspielerin.

Komm her, gieb mir einen Kuß!

Dichter (küßt sie).

\section{Schauspielerin.}

Jetzt wollen wir uns aber gute Nacht sagen! Leb'

wohl, mein Schatz!

Dichter.

Wie meinst Du das?

\section{Schauspielerin.}

Nun, ich werde mich schlafen legen!

Dichter.

Ja - das schon, aber was das Gute Nacht sagen anbelangt .... Wo soll denn ich übernachten?

'Schauspielerin.

Es giebt gewiß noch viele Zimmer in diesem Haus.

Dichter.

Die anderen haben aber keinen Reiz für mich. Jetzt werd' ich übrigens Licht machen, meinst Du nicht?

\section{Schauspielerin.}

Ja.

Dichter (zündet das Licht an, das auf dem Nachtkästchen steht).

Was für ein hübsches Zimmer .... und fromm sind die Leute hier. Lauter Heiligenbilder ... Es wäre interessant, eine Zeit unter diesen Menschen zu verbringen .... doch eine andre Welt. Wir wissen eigentlich so wenig von den andern.

\section{Schauspielerin.}

Rede keinen Stiefel und reiche mir lieber diese Tasche vom Tisch herüber.

\section{Dichter.}

Hier, meine einzige!

Schauspielerin (nimmt aus dem Täschchen ein kleines Marienbildchen, stellt es auf das Nachtkästchen).

\section{Dichter.}

Was ist das?

aber] aber eine EA JSV BHV SFV

Ja] Ja, EA JSV BHV SFV

Gute Nacht sagen] gute Nacht sagen EA JSV BHV Gutenachtsagen SFV

Heiligenbilder .... Heiligenbilder .... EA JSV BHV

kleines Marienbildchen] kleines, gerahmtes Bildchen EA JSV BHV SFV 


\section{Schauspielerin.}

Das ist die Madonna.

Dichter.

Die hast Du immer mit?

Schauspielerin.

Die ist doch mein Talisman. Und jetzt geh', Robert!

Dichter.

Aber was sind das für Scherze? Soll ich Dir nicht helfen?

\section{Schauspielerin.}

Nein, Du sollst jetzt gehn.

Dichter.

Und wann soll ich wiederkommen?

\section{Schauspielerin.}

In zehn Minuten.

Dichter (küßt sie).

Auf Wiedersehen!

\section{Schauspielerin.}

Wo willst Du denn hin?

\section{Dichter.}

Ich werde vor dem Fenster auf und abgehen. Ich liebe es sehr, Nachts im Freien herumzuspazieren. Meine besten Gedanken kommen mir so. Und gar in Deiner Nähe, von Deiner Sehnsucht sozusagen umhaucht .... in Deiner Kunst webend.

Schauspielerin.

Du redest wie ein Idiot....

Dichter (schmerzlich).

Es giebt Frauen, welche vielleicht sagen würden ... wie ein Dichter.

'Schauspielerin.

Nun geh endlich. Aber fang mir kein Verhältnis mit der Kellnerin an. -

Dichter (geht).

Schauspielerin (kleidet sich aus. Sie hört, wie der Dichter über die Holztreppe hinuntergeht und hört jetzt seine Schritte unter dem Fenster. 
Sie geht, wie sie ausgekleidet ist, zum Fenster, sieht hinunter, er steht da; sie ruft flüsternd hinunter).

Komm!

Dichter (kommt rasch herauf; stürzt zu ihr, die sich unterdessen in's Bett gelegt und das Licht ausgelöscht hat; er sperrt ab).

\section{Schauspielerin.}

So, jetzt kannst Du Dich zu mir setzen und mir 'was erzählen.

Dichter (setzt sich zu ihr auf's Bett).

Soll ich nicht das Fenster schließen? Ist Dir nicht kalt?

\section{Schauspielerin.}

Oh nein.

Dichter.

Was soll ich Dir denn erzählen?

Schauspielerin.

Nun, wem bist Du in diesem Moment untreu?

Dichter.

Ich bin es ja leider noch nicht.

\section{Schauspielerin.}

Nun tröste Dich, ich betrüge auch jemanden.

'Dichter.

Das kann ich mir denken.

\section{Schauspielerin.}

Und was glaubst $\mathrm{Du}$, wen?

Dichter.

Ja Kind, davon kann ich keine Ahnung haben.

\section{Schauspielerin.}

Nun, rate.

Dichter.

Warte.... Na, Deinen Direktor.

Schauspielerin.

Mein Lieber, ich bin keine Choristin.

\footnotetext{
2937 wie] sobald EA JSV BHV SFV

$2938 d a ;] d a$, BHV SFV

2941 hat; ] hat, BHV SFV

2949 nein.] nein! EA JSV BHV

2957 Nun] Nun, EA JSV BHV SFV
} 
Dichter.

Nun, ich dachte nur.

Schauspielerin.

Rate noch einmal.

\section{Dichter.}

Also Du betrügst Deinen Kollegen ... Benno -

\section{Schauspielerin.}

Ha! Der Mann liebt ja überhaupt keine Frauen

.... weißt Du das nicht? Der Mann hat ja ein Ver= hältnis mit seinem Briefträger!

Dichter.

Ist das möglich! -

\section{Schauspielerin.}

So gieb mir lieber einen Kuß!

'Dichter (umschlingt sie).

\section{Schauspielerin.}

Aber was thust Du denn?

\section{Dichter.}

So quäl' mich doch nicht so.

\section{Schauspielerin.}

Höre, Robert, ich werde Dir einen Vorschlag machen.

Leg' Dich zu mir in's Bett.

\section{Dichter.}

Angenommen.

\section{Schauspielerin.}

Komm' schnell, komm' schnell.

\section{Dichter.}

Ja ... . wenn es nach mir gegangen wäre, wär' ich schon längst ... . Hörst $\mathrm{Du}$....

Schauspielerin.

Was denn?

\section{Dichter.}

Draußen zirpen die Grillen.

\section{Schauspielerin.}

Du bist wohl wahnsinnig, mein Kind, hier giebt es ja keine Grillen. 
Dichter.

Aber Du hörst sie doch.

Schauspielerin.

Nun so komm endlich!

'Dichter.

Da bin ich. (Zu ihr).

\section{Schauspielerin.}

So, jetzt bleib' schön ruhig liegen ... . Pst ....

nicht rühren.

Dichter.

Ja was fällt Dir denn ein?

Schauspielerin.

Du möchtest wohl gerne ein Verhältnis mit mir haben?

\section{Dichter.}

Das dürfte Dir doch bereits klar sein.

\section{Schauspielerin.}

Nun, das möchte wohl mancher ....

Dichter.

Es ist aber doch nicht zu bezweifeln, daß in diesem Moment ich die meisten Chancen habe.

\section{Schauspielerin.}

So komm', meine Grille! Ich werde Dich von nun an Grille nennen.

Dichter.

Schön ....

\section{Schauspielerin.}

Nun, wen betrüg' ich?

Dichter.

Wen?... . Vielleicht mich ....

'Schauspielerin.

Mein Kind, Du bist schwer gehirnleidend.

\section{Dichter.}

Oder einen .... den Du selbst nie gesehen ....

\footnotetext{
3009 Nun] Nun, BHV SFV

3013 liegen .... .] liegen ..... EA JSV BHV

Pst.... . Pst..... EA JSV BHV

3016 Ja] Ja, EA JSV BHV SFV

3039 einen ..... einen ..... EA JSV BHV

gesehen .... g. gesehen ..... EA JSV BHV
} 
einen, den Du nicht kennst, einen - der für Dich be= stimmt ist und den Du nie finden kannst....

Schauspielerin.

Ich bitte Dich, rede nicht so märchenhaft blöd.

\section{Dichter.}

... Ist es nicht sonderbar, .... auch $\mathrm{Du}$ - und man sollte doch glauben - Aber nein, es hieße Dir Dein bestes rauben, wollte man Dir . . komm, komm - - komm Schauspielerin.

Das ist doch schöner, als in blödsinigen Stücken spielen .... was meinst Du?

Dichter.

Nun, ich mein', es ist gut, daß Du doch zuweilen auch in vernünftigen zu spielen hast.

\section{Schauspielerin.}

Du arroganter Hund meinst gewiß wieder das

Deine?

Dichter.

Jawohl!

Schauspielerin (ernst).

Das ist wohl ein herrliches Stück!

'Dichter.

Nun also.

\section{Schauspielerin.}

Ja, Du bist ein großes Genie, Robert.

\section{Dichter.}

Bei dieser Gelegenheit könntest Du mir übrigens sagen, warum Du vorgestern abgesagt hast. Es hat Dir doch absolut gar nichts gefehlt.

Schauspielerin.

Nun, ich wollte Dich ärgern.

\footnotetext{
3044f. Dichter. ... .] Dichter. .... EA JSV BHV

3046 glauben] glauben. EA JSV BHV SFV

3047 Dir ...] dir . . . EA JSV BHV

komm,] komm' JSV

komm -] komm. - JSV SFV komm. - BHV blödsinigen] blödsinnigen EA JSV BHV SFV zuweilen auch] zuweilen EA JSV BHV SFV also.] also! EA JSV BHV SFV

Robert.] Robert! EA JSV BHV SFV
} 
Dichter.

Ja warum denn? Was hab' ich Dir denn gethan?

Schauspielerin.

Arrogant bist Du gewesen.

Dichter.

Wieso?

\section{Schauspielerin.}

Alle im Theater finden es.

\section{Dichter.}

So.

\section{Schauspielerin.}

Aber ich hab' ihnen gesagt: Der Mann hat wohl ein Recht, arrogant zu sein.

Dichter.

Und was haben die anderen geantwortet?

'Schauspielerin.

Was sollen mir denn die Leute antworten? Ich rede ja mit keinem.

\section{Dichter.}

Ach so.

\section{Schauspielerin.}

Sie möchten mich am liebsten alle vergiften. Aber das wird ihnen nicht gelingen.

\section{Dichter.}

Denke jetzt nicht an die anderen Menschen. Freue

Dich lieber, daß wir hier sind und sage mir, daß Du mich lieb hast.

\section{Schauspielerin.}

Verlangst Du noch weitere Beweise?

\section{Dichter.}

Bewiesen kann das überhaupt nicht werden.

\section{Schauspielerin.}

Das ist aber großartig! Was willst Du denn noch?

Dichter.

Wie vielen hast Du es schon auf diese Art beweisen wollen .... hast Du alle geliebt?

\section{Schauspielerin.}

Oh nein. Geliebt hab ich nur einen.

\begin{tabular}{ll}
\hline 3097 & sind] sind, BHV SFV \\
3107 & wollen ... . . w wollen .... . EA JSV
\end{tabular}


Dichter (umarmt sie).

Mein ....

Schauspielerin.

Fritz.

'Dichter.

Ich heiße Robert. Was bin denn ich für Dich, wenn Du jetzt an Fritz denkst?

\section{Schauspielerin.}

Du bist eine Laune.

\section{Dichter.}

Gut, daß ich es weiß.

Schauspielerin.

Nun sag', bist Du nicht stolz?

Dichter.

Ja, weshalb soll ich denn stolz sein.

\section{Schauspielerin.}

Ich denke, daß Du wohl einen Grund dazu hast.

\section{Dichter.}

Ach deswegen.

\section{Schauspielerin.}

Jawohl, deswegen, meine blasse Grille! — Nun, wie ist das mit dem Zirpen? Zirpen sie noch?

\section{Dichter.}

Ununterbrochen. Hörst Du's denn nicht?

\section{Schauspielerin.}

Freilich hör' ich. Aber das sind Frösche, mein Kind.

\section{Dichter.}

Du irrst Dich; die quaken.

\section{Schauspielerin.}

Gewiß quaken sie.

'Dichter.

Aber nicht hier, mein Kind, hier wird gezirpt.

\section{Schauspielerin.}

Du bist wohl das eigensinnigste, was mir je unter= gekommen ist. Gieb mir einen Kuß, mein Frosch!

\section{Dichter.}

Bitte sehr, nenn' mich nicht so. Das macht mich direkt nervös. 


\section{Schauspielerin.}

Nun, wie soll ich Dich denn nennen.

Dichter.

Ich hab doch einen Namen: Robert.

Schauspielerin.

Ach, das ist zu dumm.

\section{Dichter.}

Ich bitte Dich aber, mich einfach so zu nennen, wie ich heiße.

Schauspielerin.

Also Robert, gieb mir einen Kuß .... Ah! (Sie

küßt ihn.) Bist Du jetzt zufrieden, Frosch? Hahahaha.

\section{Dichter.}

Würdest Du mir erlauben, mir eine Cigarette an= zuzünden?

\section{Schauspielerin.}

Gieb mir auch eine.

Er nimmt die Cigarettentasche vom Nachtkästchen, entnimmt ihr zwei Cigaretten, zündet beide an, giebt ihr eine.

'Schauspielerin.

Du hast mir übrigens noch kein Wort über meine gestrige Leistung gesagt.

\section{Dichter.}

Über welche Leistung?

\section{Schauspielerin.}

Nun.

\section{Dichter.}

Ach so. Ich war nicht im Theater.

Schauspielerin.

Du beliebst wohl zu scherzen.

\section{Dichter.}

Durchaus nicht. Nachdem Du vorgestern abgesagt hast, habe ich angenommen, daß Du auch gestern noch nicht im Vollbesitze Deiner Kräfte sein würdest, und da hab' ich lieber verzichtet. 


\section{Schauspielerin.}

Du hast wohl viel versäumt.

Dichter.

So.

\section{Schauspielerin.}

Es war sensationell. Die Menschen sind blaß ge= worden.

\section{Dichter.}

Hast Du das deutlich bemerkt?

\section{Schauspielerin.}

Benno sagte: Kind, Du hast gespielt wie eine Göttin.

'Dichter.

$\mathrm{Hm}$ ! . . . Und vorgestern noch so krank.

\section{Schauspielerin.}

Jawohl; ich war es auch. Und weißt Du warum?

Vor Sehnsucht nach Dir.

\section{Dichter.}

Früher hast Du mir erzählt, Du wolltest mich ärgern, und hast darum abgesagt.

\section{Schauspielerin.}

Aber was weißt Du von meiner Liebe zu Dir.

Dich läßt das ja alles kalt. Und ich bin schon Nächte= lang im Fieber gelegen. 40 Grad!

\section{Dichter.}

Für eine Laune ist das ziemlich hoch.

\section{Schauspielerin.}

Laune nennst Du das? Ich sterbe vor Liebe zu

Dir, und Du nennst es Laune - ?!

Dichter.

Und Fritz .... ?

\section{Schauspielerin.}

Fritz? ... . Rede mir nicht von diesem Galeeren= sträfling! -

\footnotetext{
$3195 \mathrm{Hm}$.....] Hm!.... EA JSV BHV

3200 ärgern,] ärgern EA JSV BHV SFV

3204 läßt das] läßt JSV BHV SFV

32044. Nächtelang] nächtelang BHV SFV

3210 Dir,] dir EA JSV

3214 Fritz?.... .] Fritz? .... EA JSV BHV
} 
${ }_{2}$ Das Schlafzimmer der Schauspielerin. Sehr üppig eingerichtet. auf dem Nachtkästchen brennt eine Kerze, die Schauspielerin liegt noch in ihrem Himmelbett. Auf der Decke liegen zahlreiche Zeitungen.

Der Graf tritt ein in Uniform eines Dragonerrittmeisters.

Er bleibt an der Thür stehen. -

\section{Schauspielerin.}

Ah, Herr Graf.

\section{Graf.}

Die Frau Mama hat mir erlaubt, sonst wär' ich nicht -

\section{Schauspielerin.}

Bitte, treten Sie nur näher.

\section{Graf.}

Küss' die Hand. Pardon - wenn man von der

Straßen hereinkommt .... . ich seh' nämlich noch rein gar nichts. - So ... da wären wir ja (am Bett) Küss' die Hand.

\section{Schauspielerin.}

Nehmen Sie Platz, Herr Graf.

\section{Graf.}

Frau Mama sagte mir, Fräulein sind unpäßlich . . .

Wird doch hoffentlich nichts ernstes sein.

'Schauspielerin.

Nichts ernstes? Ich bin dem Tode nahe gewesen!

Graf.

Um Gotteswillen, wie ist denn das möglich?

\section{Schauspielerin.}

Es ist jedenfalls sehr freundlich, daß Sie sich zu mir bemühen. in] in der EA JSV BHV SFV nichts. - ] nichts. EA JSV BHV SFV So .... So .... EA JSV BHV 
Graf.

Dem Tode nahe! Und gestern Abend haben Sie noch gespielt wie eine Göttin.

Schauspielerin.

Es war wohl ein großer Triumph.

Graf.

Kollossal! ... . Die Leute waren auch alle hin= gerissen. Und von mir will ich gar nicht reden.

Schauspielerin.

Ich danke für die schönen Blumen.

Graf.

Aber bitt' Sie, Fräulein.

Schauspielerin (mit den Augen aufeinen großen Blumenkorb weisend, der auf einem kleinen Tischchen auf dem Fenster steht).

Hier stehen sie.

Graf.

Sie sind gestern förmlich überschüttet worden mit Blumen und Kränzen.

'Schauspielerin.

Das liegt noch alles in meiner Garderobe. Nur Ihren Korb habe ich mit nach hause gebracht.

Graf (küßt ihr die Hand).

Das ist lieb von Ihnen.

Schauspielerin (nimmt die seine plötzlich und küßt sie).

Graf.

Aber Fräulein.

\section{Schauspielerin.}

Erschrecken Sie nicht, Herr Graf, das verpflichtet

Sie zu gar nichts.

Graf.

Sie sind ein sonderbares Wesen ... . räthselhaft

könnte man fast sagen. - (Pause).

Schauspielerin.

Das Fräulein Birken ist wohl leichter aufzulösen. 
Graf.

Ja, die kleine Birken ist kein Problem, obzwar . . . ich kenne sie ja auch nur oberflächlich.

\section{Schauspielerin.}

Ha!

Graf.

Sie können mir's glauben. Aber Sie sind ein

Problem. Danach hab' ich immer Sehnsucht gehabt.

Es ist mir eigentlich ein großer Genuß entgangen, dadurch, daß ich Sie gestern ... . das e rste Mal spielen ge= sehen habe.

'Schauspielerin.

Ist das möglich?

Graf.

Ja. Schauen Sie, Fräulein, es ist so schwer mit dem Theater. Ich bin gewöhnt, spät zu dinieren .... also wenn man dann hinkommt, ist's beste vorbei. Ist's nicht wahr?

\section{Schauspielerin.}

So werden Sie eben von jetzt an früher essen.

Graf.

Ja, ich hab' auch schon daran gedacht. Oder gar

nicht. Es ist ja wirklich kein Vergnügen, das Dinieren.

Schauspielerin.

Was haben Sie jugendlicher Greis eigentlich noch

für ein Vergnügen?

Graf.

Das frag' ich mich selber manchmal! Aber ein Greis

bin ich nicht. Es muß einen andern Grund haben.

\section{Schauspielerin.}

Glauben Sie?

Graf.

Ja. Der Lulu sagt beispielsweise, ich bin ein Philo= soph. Wissen Sie, Fräulein, er meint, ich denk' zu viel nach.

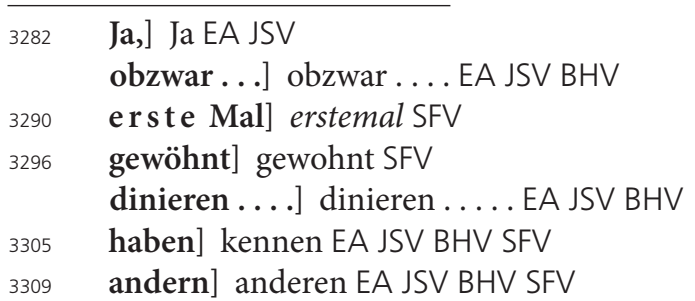




\section{Schauspielerin.}

Ja .... denken, das ist das Unglück.

Graf.

Ich hab' zu viel Zeit, drum denk' ich nach. Bitt'

'Sie, Fräulein, schauen S', ich hab' mir gedacht, wenn nicht anders als da oben.

\section{Schauspielerin.}

Wo ist denn das da oben?

Graf.

$\mathrm{Na}$, da unten, wissen S’ Fräulein, in Ungarn, in die Nester, wo ich meistens in Garnison war.

\section{Schauspielerin.}

Ja, was haben Sie denn in Ungarn gemacht?

Graf.

$\mathrm{Na}$, wie ich sag', Fräulein, Dienst.

\section{Schauspielerin.}

Ja warum sind Sie denn so lang in Ungarn ge= blieben?

\section{Graf.}

Ja, das kommt so.

\section{Schauspielerin.}

Da muß man ja wahnsinnig werden.

Graf.

Warum denn? Zu thun hat man eigentlich mehr wie da. Wissen S' Fräulein, Rekruten ausbilden, $\mathrm{Re}=$ monten reiten .... und dann ist's nicht so arg mit der Gegend, wie man sagt. Es ist schon ganz was schönes, die Tiefebene - und so ein Sonnenuntergang, es ist 'schade, daß ich kein Maler bin, ich hab' mir manchmal gedacht, wenn ich ein Maler wär', thät' ich's malen. Einen haben wir gehabt beim Regiment, einen jungen Splany, der hat's können. - Aber was erzähl' ich Ihnen da für fade G’schichten, Fräulein.

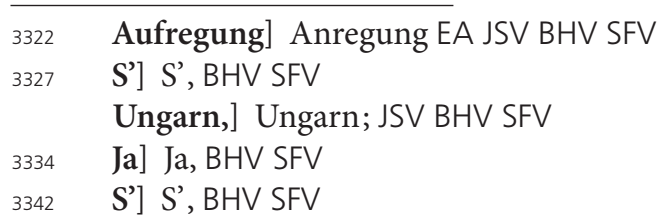




\section{Schauspielerin.}

Oh bitte, ich amüsire mich königlich.

Graf.

Wissen S' Fräulein, mit Ihnen kann man plaudern, das hat mir der Lulu schon g'sagt, und das ist's was man selten find't.

\section{Schauspielerin.}

Nun freilich, in Ungarn.

Graf.

Aber in Wien grad' so! Die Menschen sind überall dieselben; da wo mehr sind, ist halt das Gedräng' größer, das ist der ganze Unterschied. Sagen S’ Fräulein, haben Sie die Menschen eigentlich gern?

\section{Schauspielerin.}

Gern - ? ? Ich hasse sie! Ich kann keine sehn! Ich seh' auch nie jemanden. Ich bin immer allein, dieses Haus betritt niemand.

Graf.

Seh'n S', das hab' ich mir gedacht, daß Sie eigent= lich eine Menschenfeindin sind. Bei der Kunst muß das oft vorkommen. Wenn man so in den höheren Regionen .... na, Sie haben 's gut, Sie wissen doch wenigstens, warum Sie leben!

Schauspielerin.

Wer sagt Ihnen das? Ich habe keine Ahnung, wo= zu ich lebe!

Graf.

Ich bitt' Sie, Fräulein, — berühmt — gefeiert -

Schauspielerin.

Ist das vielleicht ein Glück?

Graf.

Glück? Bitt' Sie, Fräulein, Glück giebts nicht.

Überhaupt alle die Sachen, von denen am meisten g'redt

\begin{tabular}{|c|c|}
\hline & S'] S', BHV SFV \\
\hline & ist's] ist's, EA JSV BHV SFV \\
\hline & $\begin{array}{l}\text { man] man so JSV BHV SFV } \\
\text { da] da, BHV SFV }\end{array}$ \\
\hline & $\left.S^{\prime}\right]$ S', BHV SFV \\
\hline & haben 's] haben's JSV BHV SF \\
\hline & $\begin{array}{l}\text { Sie,] Sie EA JSV } \\
\text { alle] gerade EA JSV BHV SFV }\end{array}$ \\
\hline
\end{tabular}


wird, giebt's nicht ... z. B. Liebe. Das ist auch so 'was.

\section{Schauspielerin.}

Da haben Sie wohl recht.

Graf.

Genuß ... . Rausch .... also gut, da läßt sich

nichts sagen .... das ist 'was sicheres. Jetzt genieße ich, ... gut, weiß ich, ich genieß'. Oder ich bin be= rauscht, schön. Das ist auch sicher. Und ist vorbei, ist vorbei.

Schauspielerin (groß).

Es ist vorbei!

Graf.

Aber sobald man sich nicht, wie soll ich mich denn ausdrücken, sobald man sich nicht dem Moment hingiebt, also an später denkt oder an früher .... na, ist doch gleich aus. Später . . . . ist traurig . . . . früher ist rungewiß .... mit einem Wort .... man wird nur confus. Hab' ich nicht recht?

Schauspielerin (nickt mit großen Augen).

Sie haben wohl den Sinn erfaßt.

Graf.

Und sehen S', Fräulein, wenn einem das einmal klar geworden ist, ist's ganz egal, ob man in Wien lebt oder in der Pußta oder in Steinamanger. Schaun S' zum Beispiel ... . wo darf ich denn die Kappen hin= legen? So, ich dank' schön .... wovon haben wir denn nur gesprochen?

\section{Schauspielerin.}

Von Steinamanger.

Graf.

Richtig. Also wie ich sag', der Unterschied ist nicht groß. Ob ich am Abend in der Kantin' sitz' oder im Klub, ist doch alles eins. 
Schauspielerin.

Und wie verhält sich denn das mit der Liebe?

Graf.

Wenn man dran glaubt, ist immer eine da, die einen gern hat.

\section{Schauspielerin.}

Z. B. das Fräulein Birken.

Graf.

Ich weiß wirklich nicht, Fräulein, warum Sie immer auf die kleine Birken zu reden kommen.

'Schauspielerin.

Das ist doch Ihre Geliebte.

Graf.

Wer sagt denn das?

\section{Schauspielerin.}

Jeder Mensch weiß das.

Graf.

Nur ich nicht, es ist merkwürdig.

\section{Schauspielerin.}

Sie haben doch ihretwegen ein Duell gehabt!

Graf.

Vielleicht bin ich sogar tot geschossen worden und hab's gar nicht bemerkt.

\section{Schauspielerin.}

Nun, Herr Graf, Sie sind ein Ehrenmann. Setzen

Sie sich näher.

Graf.

Bin so frei.

Schauspielerin.

Hierher (sie zieht ihn zu sich, fährt ihm mit der Hand durch

die Haare).

Ich hab' gewußt, daß Sie heute kommen werden!

Graf.

Wieso denn?

Schauspielerin.

Ich hab' es bereits gestern im Theater gewußt. 
'Graf.

Haben Sie mich denn von der Bühne aus gesehen?

Schauspielerin.

Aber Mann! Haben Sie denn nicht bemerkt, daß

ich nur für Sie gespielt habe?

Graf.

Wie ist das denn möglich?

Schauspielerin.

Ich bin ja so geflogen, wie ich Sie in der ersten

Reihe sitzen sah!

Graf.

Geflogen? Meinetwegen? Ich hab' keine Ahnung gehabt, daß Sie mich bemerken!

\section{Schauspielerin.}

Sie können einen auch mit Ihrer Vornehmheit zur

Verzweiflung bringen.

Graf.

Ja Fräulein ....

\section{Schauspielerin.}

"Ja Fräulein“! . . . so schnallen Sie doch wenig= stens Ihren Säbel ab!

Graf.

Wenn es erlaubt ist. (Schnallt ihn ab, lehnt ihn ans Bett).

Schauspielerin.

Und gieb mir endlich einen Kuß.

Graf (küßt sie, sie läßt ihn nicht los).

Schauspielerin.

Dich hätte ich auch lieber nie erblicken sollen.

Graf.

Es ist doch besser so! -

Schauspielerin.

Herr Graf, Sie sind ein Poseur!

\footnotetext{
3458 gespielt habe] spiele EA JSV BHV SFV

3460 das denn] denn das BHV SFV

3471 Ja] Ja, JSV BHV SFV

3473 „Ja] »Ja JSV »Ja, BHV „Ja, SFV

Fräulein“!] Fräulein«! JSV BHV Fräulein!“ SFV

so] So EA JSV BHV SFV 
Graf.

Ich - warum denn?

\section{Schauspielerin.}

Was glauben Sie, wie glücklich wär' mancher, wenn er an Ihrer Stelle sein dürfte!

Graf.

Ich bin sehr glücklich.

\section{Schauspielerin.}

Nun, ich dachte, es giebt kein Glück. Wie schaust

Du mich denn an? Ich glaube Sie haben Angst vor mir, Herr Graf!

Graf.

Ich sag's ja, Fräulein, Sie sind ein Problem.

\section{Schauspielerin.}

Ach laß' Du mich in Frieden mit der Philosophie ... komm' zu mir. Und jetzt bitt' mich um irgend 'was .... Du kannst alles haben, was Du willst. Du bist zu schön.

Graf.

Also ich bitte um die Erlaubnis (ihre Hand k küssend,) daß ich heute abends wiederkommen darf.

'Schauspielerin.

Heut Abend .... ich spiele ja.

Graf.

Nach dem Theater.

\section{Schauspielerin.}

Um was anderes bittest Du nicht?

Graf.

Um alles andere werde ich nach dem Theater bitten.

Schauspielerin (verletzt).

Da kannst Du lange bitten, Du elender Poseur.

Graf.

Ja schauen Sie, oder schau, wir sind doch bis jetzt so aufrichtig mit einander gewesen .... Ich fände das

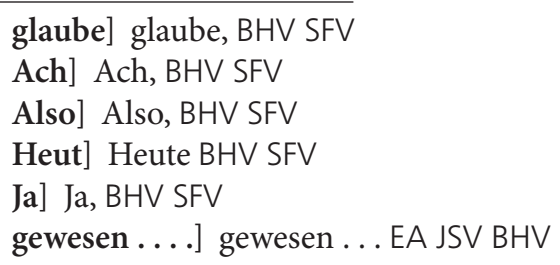


alles viel schöner am Abend nach dem Theater .... gemütlicher als jetzt, wo . . . . ich hab immer so die

Empfindung, als könnte die Thür aufgehn ....

\section{Schauspielerin.}

Die geht nicht von außen auf.

Graf.

Schau' ich find', man soll sich nicht leichtsinnig von

vornherein was verderben, was möglicherweise sehr schön sein könnte.

\section{Schauspielerin.}

Möglicherweise! ....

Graf.

In der Früh, wenn ich die Wahrheit sagen soll, find' ich die Liebe gräßlich.

'Schauspielerin.

Nun - Du bist wohl das irrsinnigste, was mir je vorgekommen ist!

Graf.

Ich red' ja nicht von beliebigen Frauenzimmern . . . schließlich im allgemeinen ist's ja egal. Aber Frauen wie $\mathrm{Du}$.... nein, Du kannst mich hundertmal einen Narren heißen. Aber Frauen wie Du . . . . nimmt man nicht vor dem Frühstück zu sich. Und so . . . . weißt . . . . so ....

\section{Schauspielerin.}

Gott, was bist $\mathrm{Du}$ süß!

Graf.

Siehst Du das ein, was ich g'sagt hab', nicht wahr.

Ich stell mir das so vor -

Schauspielerin.

Nun, wie stellst Du Dir das vor?

Graf.

Ich denk' mir .... ich wart nach dem Theater auf

Dich in ein' Wagen, dann fahren wir zusammen also irgendwohin soupieren -

Theater..... .] Theater... EA JSV BHV

wo .... .] wo ... EA JSV BHV

Schau'] Schau', BHV SFV

Frauenzimmern ... .] Frauenzimmern .... EA JSV BHV

Du.... d du... EA JSV BHV

mir....] mir.....EA JSV 


\section{Schauspielerin.}

Ich bin nicht das Fräulein Birken.

Graf.

Das hab' ich ja nicht gesagt. Ich find' nur, zu allem g'hört Stimmung. Ich komm' immer „erst beim Souper in Stimmung. Das ist dann das schönste, wenn man so vom Souper zusamm' nach Haus fahrt, dann ....

\section{Schauspielerin.}

Was ist $\mathrm{d}$ an $\mathrm{n}$ ?

Graf.

Also dann ... . liegt das in der Entwicklung der

Dinge.

\section{Schauspielerin.}

Setz' Dich doch näher. Näher.

Graf (sich aufs Bett setzend).

Ich muß schon sagen, aus den Polstern kommt so ein .... Reseda ist das - nicht?

\section{Schauspielerin.}

Es ist sehr heiß hier, findest Du nicht?

Graf (neigt sich und küßt ihren Hals).

\section{Schauspielerin.}

Oh Herr Graf, das ist ja gegen Ihr Programm.

Graf.

Wer sagt denn das? Ich hab' kein Programm.

Schauspielerin (zieht ihn an sich).

Graf.

Es ist wirklich heiß.

\section{Schauspielerin.}

Findest Du? Und so dunkel, wie wenn's Abend wär' ...... (reißt ihn an sich.) Es ist Abend .... es 'ist Nacht ... . Mach' die Augen zu, wenn's Dir zu licht ist. Komm! . . . Komm! . . . .

Graf (wehrt sich nicht mehr).

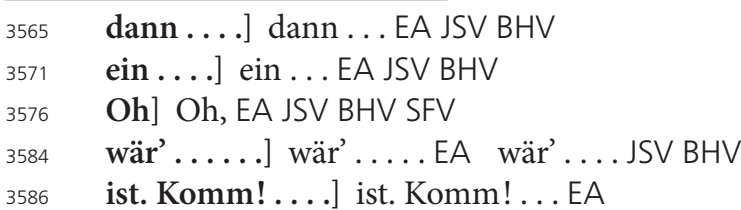




\section{Schauspielerin.}

Nun, wie ist das jetzt mit der Stimmung, Du Poseur?

Graf.

Du bist ein kleiner Teufel.

\section{Schauspielerin.}

Was ist das für ein Ausdruck?

Graf.

$\mathrm{Na}$, also bist ein Engel.

\section{Schauspielerin.}

Und Du hättest Schauspieler werden sollen! Wahr= haftig! Du kennst die Frauen! Und weißt Du, was ich jetzt thun werde?

Graf.

Nun?

\section{Schauspielerin.}

Ich werde Dir sagen, daß ich Dich nie wieder= sehen will.

Graf.

Warum denn?

\section{Schauspielerin.}

Nein, nein. Du bist mir zu gefährlich! Du machst ja ein Weib toll. Jetzt stehst Du plötzlich vor mir, als wär' nichts gescheh'n.

'Graf.

Aber.....

Schauspielerin.

Ich bitte sich zu erinnern, Herr Graf, ich bin soeben Ihre Geliebte gewesen.

Graf.

Ich werd's nie vergessen!

\section{Schauspielerin.}

Und wie ist das mit heute Abend?

Graf.

Wie meinst Du das?

\section{Schauspielerin.}

Nun - Du wolltest mich ja nach dem Theater er= warten?

\footnotetext{
3596 also bist] also EA JSV BHV SFV

3613 Aber...... Aber.... JSV BHV

3616 gewesen.] gewesen! BHV SFV
} 
Graf.

Ja, also gut, zum Beispiel übermorgen.

Schauspielerin.

Was heißt das, übermorgen? Es war doch von heute die Rede.

Graf.

Das hätte keinen rechten Sinn.

Schauspielerin.

Du Greis!

Graf.

Du verstehst mich nicht recht. Ich mein' das mehr, was, wie soll ich mich ausdrücken, was die Seele an= belangt.

\section{Schauspielerin.}

Was geht mich Deine Seele an?

'Graf.

Glaub' mir, sie gehört mit dazu. Ich halte das für eine falsche Ansicht, daß man das so von einander trennen kann.

\section{Schauspielerin.}

Laß mich mit Deiner Philosophie in Frieden. Wenn ich das haben will, lese ich Bücher.

Graf.

Aus Büchern lernt man ja doch nie.

\section{Schauspielerin.}

Das ist wohl wahr! Drum sollst Du mich heut Abend erwarten. Wegen der Seele werden wir uns schon einigen, Du Schurke!

Graf.

Also wenn Du erlaubst, so werde ich mit meinem

Wagen ....

\section{Schauspielerin.}

Hier in meiner Wohnung wirst Du mich erwarten -

Graf.

.... Nach dem Theater.

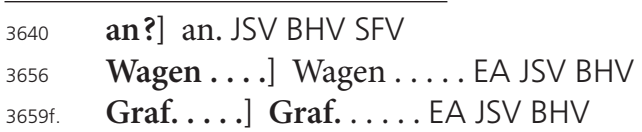




\section{Schauspielerin.}

Natürlich.

(Er schnallt den Säbel um).

\section{Schauspielerin.}

Was machst Du denn da?

Graf.

Ich denke, es ist Zeit, daß ich geh'. Für einen

'Anstandsbesuch bin ich doch eigentlich schon ein bissel lang geblieben.

Schauspielerin.

Nun, heut Abend soll es kein Anstandsbesuch werden.

Graf.

Glaubst Du?

Schauspielerin.

Dafür laß nur mich sorgen. Und jetzt gieb mir noch einen Kuß, mein kleiner Philosoph. So, Du Verführer, Du . . . . süßes Kind, Du Seelenverkäufer, Du Iltis .... Du .... (Nachdem sie ihn ein paar Mal heftig geküßt, stößt sie ihn heftig von sich). Herr Graf, es war mir eine große Ehre!

Graf.

Ich küss' die Hand, Fräulein! (Bei der Thür). Auf

Wiederschaun'.

Schauspielerin.

Adieu, Steinamanger! 
${ }_{L}$ Morgen, gegen sechs Uhr.

Ein ärmliches Zimmer; einfenstrig, die wei $\beta=$ gelblich schmutzigen Rouletten sind heruntergelassen. Verschlissene, grünliche Vorhänge. Eine Kommode, auf der ein paar Photographien stehen und ein auffallend geschmackloser billiger Damenhut liegt. Hinter dem Spiegel billige, japanische Fächer. Auf dem Tisch, der mit einem rötlichen Schutztuch überzogen ist, steht eine Petroleumlampe, die schwach brenzlich brennt; papierener, gelber Lampenschirm, daneben ein Krug, in dem ein Rest von Bier ist, daneben ein halb geleertes Glas. Auf dem Boden neben dem Bett liegen un= ordentlich Frauenkleider, als wenn sie eben rasch abgeworfen worden wären. Im Bett liegt schlafend die Dirne; sie atmet ruhig. - Auf dem Divan, völlig angekleidet, liegt der Graf; sogar mit dem gelben Überzieher; der Hut liegt zu Häupten des Divans auf dem Boden. Graf (bewegt sich, reibt die Augen, erhebt sich rasch, bleibt sitzen, schaut um sich).

Ja wie bin ich denn .... Ah so .... Also bin ich richtig mit dem Frauenzimmer nach haus.... (Er steht rasch auf, sieht ihr Bett.) Da liegt s' ja ..... Was einem noch alles in meinem Alter passieren kann. Ich hab' keine Idee, haben s' mich da herauf getragen? Nein .... ich hab' ja gesehen, - ich komm' in das Zimmer ... ja ... da bin ich noch wach gewesen oder wach 'worden .... oder .... oder ist vielleicht nur, daß 'mich das Zimmer an was erinnert .... . meiner Seel'

Zimmer;] Zimmer, BHV SFV

einfenstrig,] einfenstrig; BHV SFV

wei $\beta=$ gelblich schmutzigen $]$ gelblich-schmutzigen EA BHV SFV gelblich=schmutzigen JSV

Verschlissene,] Verschlissene EA JSV BHV SFV

geschmackloser] geschmackloser, EA JSV BHV SFV

billige,] billige EA JSV BHV SFV

ist, daneben] ist, und EA JSV BHV SFV

Graf; sogar mit dem gelben Überzieher] Graf, im Drapp-Überzieher EA SFV Graf, im

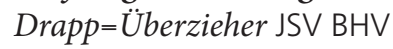

Boden. - ] Boden. EA JSV BHV SFV

Ja] Ja, EA JSV BHV SFV

haus ..... Haus ... JSV BHV

ja..... ja....EA JSV BHV

herauf getragen] heraufgetragen EA JSV BHV SFV

gesehen,] geseh'n EA JSV BHV SFV

erinnert.....] erinnert?.... EA JSV BHV erinnert?... SFV

meiner Seel'] Meiner Seel', EA JSV BHV SFV 
na ja .... gestern hab' ich's halt g'sehn ... (sieht auf die Uhr) was! gestern, vor ein paar Stunden - Aber ich hab's g'wußt, daß 'was passieren muß ....... ich hab's g'spürt .... wie ich ang'fangen hab zu trinken gestern, hab' ich's g'spürt, daß ... . Und was ist denn passiert?. . Also nichts ... oder ist was ... ? Meiner Seel' ... . seit .... also seit zehn Jahren ist mir so was nicht vor'kommen, daß ich nicht weiß ..... Also kurz und gut, ich war halt b'soffen. Wenn ich nur wüßt', von wann an .... Also das weiß ich noch ganz genau, wie ich in das Hurenkaffeehaus hinein bin mit dem Lulu und .... nein, nein ... . vom Sacher sind wir ja noch weg'gangen .... und dann auf dem Weg ist schon ... Ja richtig, ich bin ja in meinem Wagen g'fahren mit 'm Lulu .... Was zerbrich ich mir denn viel den Kopf. Ist ja egal. Schau'n wir, daß wir weiterkommen. (Steht auf. Die Lampe wackelt.) oh!..... (Sieht auf die Schlafende.) Die hat halt einen g'sunden Schlaf. Ich weiß zwar von gar nix - aber ich werd' ihr's Geld auf's Nachtkastel legen .... und Servus .... (Er steht vor ihr, sieht sie lange an.) Wenn man nicht wüßt', was sie ist! (Betrachtet sie lang.) Ich hab' viel kennt, die haben nicht einmal im Schlafen so tugendhaft ausg'sehn. Meiner Seel' . . . also der Lulu möcht' wieder sagen, ich philo= sophir', aber es ist wahr, der Schlaf macht auch schon gleich, kommt mir vor; - wie der Herr Bruder, also der Tod .... Hm, ich möcht nur wissen, ob . . . . Nein 'daran müßt ich mich ja erinnern .... Nein nein, ich bin gleich da auf den Divan herg'fallen .... . und nichts is g'schehn .... Es ist unglaublich, wie sich manchmal

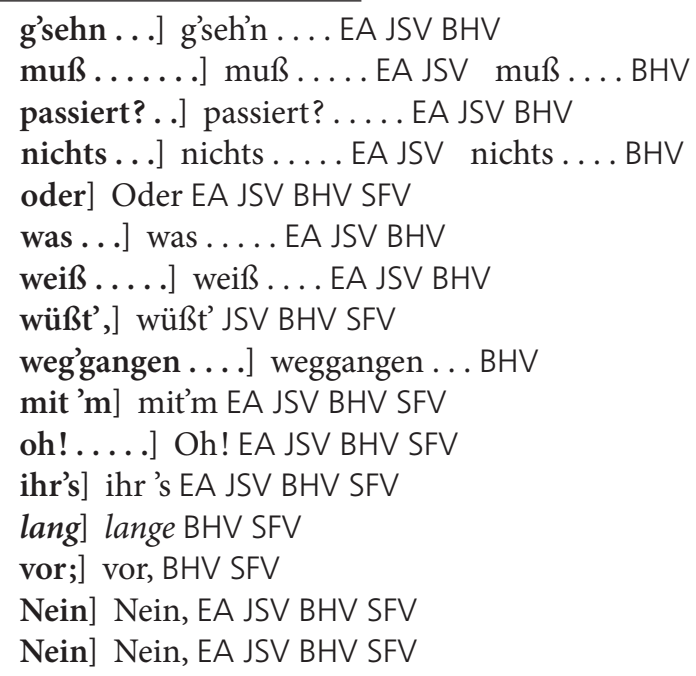


alle Weiber ähnlich schauen .... Na gehn wir. (Er will gehen). Ja richtig. (Er nimmt die Brieftasche und ist eben daran, eine Banknote herauszunehmen).

Dirne (wacht auf).

$\mathrm{Na} . .$. wer ist denn in aller Früh - ? (Erkennt

ihn). Servus, Bubi!

Graf.

Guten Morgen. Hast gut g'schlafen.

Dirne (reckt sich).

Ah, komm' her. Pussi geben.

Graf (beugt sich zu ihr herab, besinnt sich, wieder fort).

Ich hab' grad fortgehen wollen ....

Dirne.

Fortgehn?

Graf.

Es ist wirklich die höchste Zeit.

Dirne.

So willst Du fort gehn?

Graf (fast verlegen).

So....

Dirne.

$\mathrm{Na}$ Servus; kommst halt ein anderes Mal.

Graf.

Ja, grüß’ Dich Gott. Na, willst nicht das Handerl geben?

'Dirne (giebt die Hand aus der Decke hervor).

Graf (nimmt die Hand und küßt sie mechanisch, bemerkt es, lacht).

Wie einer Prinzessin. Übrigens, wenn man nur ...

Dirne.

Was schaust mich denn so an?

Graf.

Wenn man nur das Kopferl sieht, wie jetzt .... .

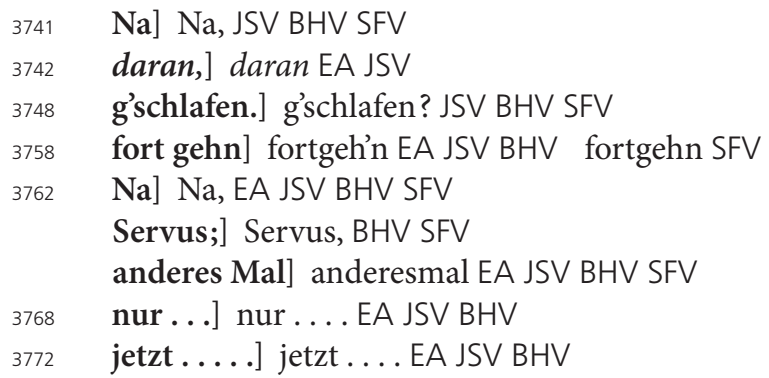


beim Aufwachen sieht doch eine jede unschuldig aus ... meiner Seel', alles mögliche könnt' man sich einbilden, wenn's nicht so nach Petroleum stinken möcht' ... .

Dirne.

Ja mit der Lampen ist immer ein Gfrett.

Graf.

Wie alt bist denn eigentlich?

Dirne.

$\mathrm{Na}$, was glaubst?

Graf.

Vierundzwanzig.

Dirne.

Ja freilich.

Graf.

Bist schon älter?

Dirne.

In's zwanzigste geh' i.

Graf.

Und wie lang' bist Du schon ....

Dirne.

Bei dem G’schäft bin i ein Jahr!

'Graf.

Da hast Du aber früh ang'fangen.

Dirne.

Besser zu früh als zu spät.

Graf (setzt sich auf's Bett).

Sag' mir einmal, bist Du eigentlich glücklich?

Dirne.

Was?

Graf.

Also ich mein', geht's Dir gut?

Dirne.

Oh, mir geht's alleweil gut.

Graf.

So .... Sag', ist Dir noch nie eing'fallen, daß

Du was anderes werden könntest? 
Dirne.

Was soll i denn werden?

Graf.

Also ... . Du bist doch wirklich ein hübsches Mädel.

Du könntest doch z. B. einen Geliebten haben.

Dirne.

Meinst vielleicht, ich hab' kein?

\section{Graf.}

Ja, das weiß ich - ich mein' aber einen, weißt e in en, der Dich halt aushalt, daß Du nicht mit einem jeden zu gehn brauchst.

'Dirne.

I geh' auch nicht mit ein' jeden. Gott sei Dank, das hab' i net notwendig, ich such mir s' schon aus.

Graf (sieht sich im Zimmer um).

Dirne (bemerkt das).

Im nächsten Monat zieh'n wir in die Stadt, in die Spiegelgasse.

Graf.

Wir? Wer denn?

\section{Dirne.}

$\mathrm{Na}$, die Frau, und die paar anderen Mädeln, die noch da wohnen.

Graf.

Da wohnen noch solche -

\section{Dirne.}

Da daneben .... hörst net ... . das ist die Milli, die auch im Kaffeehaus g'wesen ist.

Graf.

Da schnarcht wer.

Dirne.

Das ist schon die Milli, die schnarcht jetzt weiter 'n ganzen Tag bis um zehn auf d' Nacht. Dann steht s' auf und geht in's Kaffeehaus.

Graf.

Das ist doch ein schauderhaftes Leben.

\begin{tabular}{ll}
\hline 3817 & weißt] weißt, JSV BHV SFV \\
3818 & Dich halt] dich EA JSV BHV SFV \\
3830 & Frau, ] Frau SFV \\
3835 & net.... . net.... . JSV
\end{tabular}


'Dirne.

Freilich. Die Frau gift' sich auch genug. Ich bin schon um zwölfe Mittag immer auf der Gassen.

Graf.

Was machst denn um zwölf auf der Gassen?

Dirne.

Was werd' ich denn machen? Auf den Strich geh' ich halt.

Graf.

Ah so .... natürlich ... (Steht auf, nimmt die Brief= tasche heraus, legt ihr eine Banknote auf das Nachtkastel.) Adieu!

\section{Dirne.}

Gehst schon .... Servus .... Komm bald wieder.

(Legt sich auf die Seite).

Graf (bleibt wieder stehen).

$\mathrm{Du}$, sag' einmal, Dir ist schon alles egal — was?

\section{Dirne.}

Was?

Graf.

Ich mein', Dir macht's gar keine Freud' mehr.

Dirne (gähnt).

Ein' Schlaf hab' ich.

Graf.

Dir ist alles eins ob einer jung ist oder alt oder ob einer....

Dirne.

Was fragst denn?

${ }_{\mathrm{L}}^{\mathrm{G}} \mathrm{raf}$.

... Also (plötzlich auf etwas kommend) meiner Seel', jetzt weiß ich, an wen Du mich erinnerst, das ist ....

Dirne.

Schau i wem gleich?

Graf.

Unglaublich, unglaublich, jetzt bitt ich Dich aber sehr, red' gar nichts, eine Minute wenigstens ... (schaut sie an)

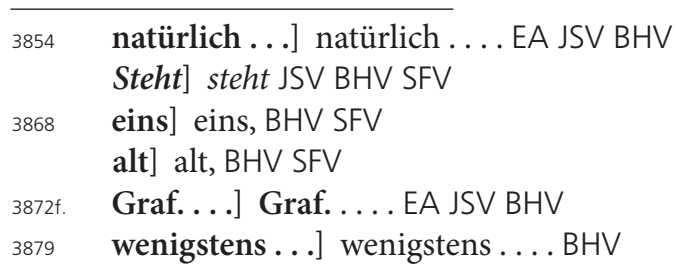


ganz dasselbe G'sicht, ganz dasselbe G'sicht. (Er küßt sie plötzlich auf die Augen).

Dirne.

$\mathrm{Na} . .$.

Graf.

Meiner Seel', es ist schad', daß Du . . . . nichts

andres bist ... . Du könntst ja Dein Glück machen!

Dirne.

Du bist grad wie der Franz.

Graf.

Wer ist Franz?

Dirne.

Na der Kellner von unserm Kaffeehaus .... .

Graf.

Wieso bin ich grad' so wie der Franz?

Dirne.

Der sagt auch alleweil, ich könnt mein Glück machen und ich soll ihn heiraten.

Graf.

Warum thust Du's nicht?

'Dirne.

Ich dank schön .... ich möcht' nicht heiraten, nein, um keinen Preis. Später einmal vielleicht.

Graf.

Die Augen .... ganz die Augen .... Der Lulu

möcht' sicher sagen, ich bin ein Narr — aber ich will Dir noch einmal die Augen küssen .... so .... und jetzt grüß Dich Gott, jetzt geh' ich.

\section{Dirne.}

Servus....

Graf (bei der Thür).

$\mathrm{Du}$... sag' ... wundert Dich das gar nicht...

Dirne.

Was denn?

Graf.

Daß ich nichts von Dir will.

\begin{tabular}{ll}
\hline 3896 & machen] machen, SFV \\
3904 & die Augen .... . die Augen ... EA JSV \\
3911 & Du.... Du ... . JSV BHV \\
& sag'.... sag'... . JSV BHV
\end{tabular}


Dirne.

Es giebt viel Männer, die in der Früh' nicht auf= gelegt sind.

Graf.

$\mathrm{Na} \mathrm{ja} \mathrm{...} \mathrm{(Für} \mathrm{sich.)} \mathrm{Zu} \mathrm{dumm,} \mathrm{daß} \mathrm{ich} \mathrm{will,} \mathrm{sie}$ soll sich wundern ... Also Servus ... (Er ist bei der Thür.)

Eigentlich ärger' ich mich. Ich weiß doch, daß es solchen Frauenzimmern nur auf's Geld ankommt ... was sag ich - solchen ... . es ist schön ... daß sie sich wenig= stens nicht verstellt, das sollte einen eher freuen ... Du, — weißt, ich komm' nächstens wieder zu Dir.

'Dirne (mit geschlossenen Augen).

Gut.

Graf.

Wann bist Du immer zu Haus?

Dirne.

Ich bin immer zu Haus. Brauchst nur nach der Leokadie zu fragen.

Graf.

Leokadie .... Schön - Also grüß Dich Gott.

(Bei der Thür.) Ich hab doch noch immer den Wein im

Kopf. Also das ist doch das höchste ... ich bin bei so einer und hab' nichts gethan als ihr die Augen geküßt, weil sie mich an wen erinnert hat... (Wendet sich $z u$ ihr.)

$\mathrm{Du}$, Leokadie, passiert Dir das öfter, daß man so weg= geht von Dir?

\section{Dirne.}

Wie denn?

Graf.

So wie ich?

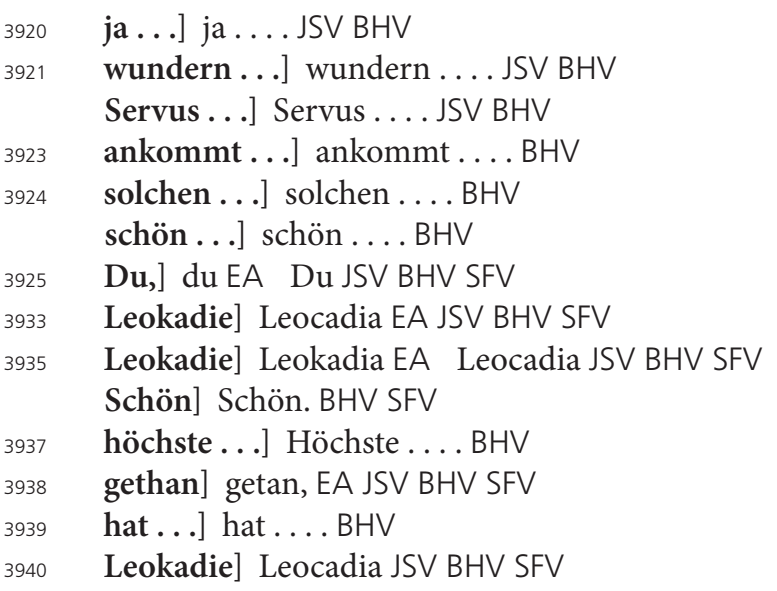


Dirne.

In der Früh?

Graf.

Nein ... ob ob schon manchmal wer bei Dir war, - und nichts von Dir wollen hat?

Dirne.

Nein, das ist mir noch nie g'schehn.

Graf.

Also was meinst denn? Glaubst, Du g'fallst mir nicht?

'Dirne.

Warum soll ich Dir denn nicht g'fallen? Bei der Nacht hab' ich Dir schon g'fallen.

Graf.

Du g'fallst mir auch jetzt.

Dirne.

Aber bei der Nacht hab' ich Dir besser g'fallen.

Graf.

Warum glaubst Du das?

Dirne.

$\mathrm{Na}$, was fragst denn so dumm?

Graf.

Bei der Nacht ... ja, sag' bin ich denn nicht gleich am Divan hing'fallen?

Dirne.

$\mathrm{Na}$ freilich .... mit mir zusammen.

Graf.

Mit Dir?

Dirne.

Ja weißt denn Du das nimmer?

Graf.

Ich hab .... wir sind zusammen .... ja ... .

$3954 \quad$ Also] Also, EA JSV BHV SFV

3962 g'fallen.] g'fallen? BHV SFV

3968 Nacht...] Nacht.... BHV

sag'] sag', EA JSV BHV SFV

3971 freilich .....] freilich ... EA JSV

3975 Ja] Ja, EA JSV BHV SFV

3977 hab.... hab'.....EA JSV hab'.... BHV

zusammen.... zusammen...... EA JSV zusammen....... BHV 
Dirne.

Aber gleich bist eing'schlafen.

Graf.

Gleich bin ich ... So ... Also so war das!...

'Dirne.

Ja, Bubi. Du mußt aber ein ordentlichen Rausch g'habt haben, daß Dich nimmer erinnerst.

Graf.

So .... - Und doch .... es ist eine entfernte

Ähnlichkeit ... Servus ... (Lauscht.) Was ist denn los?

Dirne.

Das Stubenmädl ist schon auf. Geh', gieb ihr was beim Hinausgehn. Das Thor ist auch offen, ersparst den Hausmeister.

Graf.

Ja. (Im Vorzimmer.) Also . . . Es wär' doch schön gewesen, wenn ich sie nur auf die Augen geküßt hätt'. Das wäre beinahe ein Abenteuer gewesen ... Es war mir halt nicht bestimmt. (Das Stubenmädel steht da, öffnet die Thür). Ah — da haben S' ... Gute Nacht. -

Stubenmädchen.

Guten Morgen.

Graf.

Ja freilich ... guten Morgen ... guten Morgen.

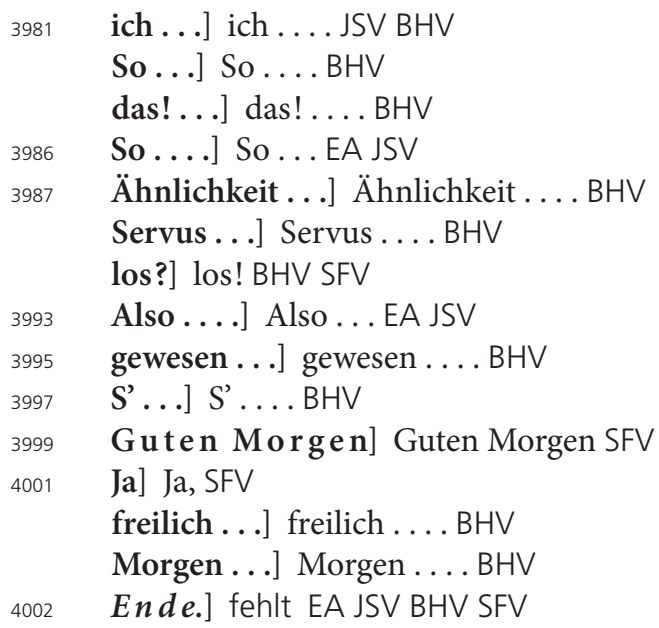





\subsection{Herausgebereingriffe}

Die Vorlage für den edierten Text D ist der Privatdruck PD, dessen orthographische Eigenheiten bewahrt werden (vgl. Vorbemerkung, S. 24). Nur bei offenkundigen Satzund Druckfehlern wurde gegenüber der Textgestalt von PD eingegriffen:

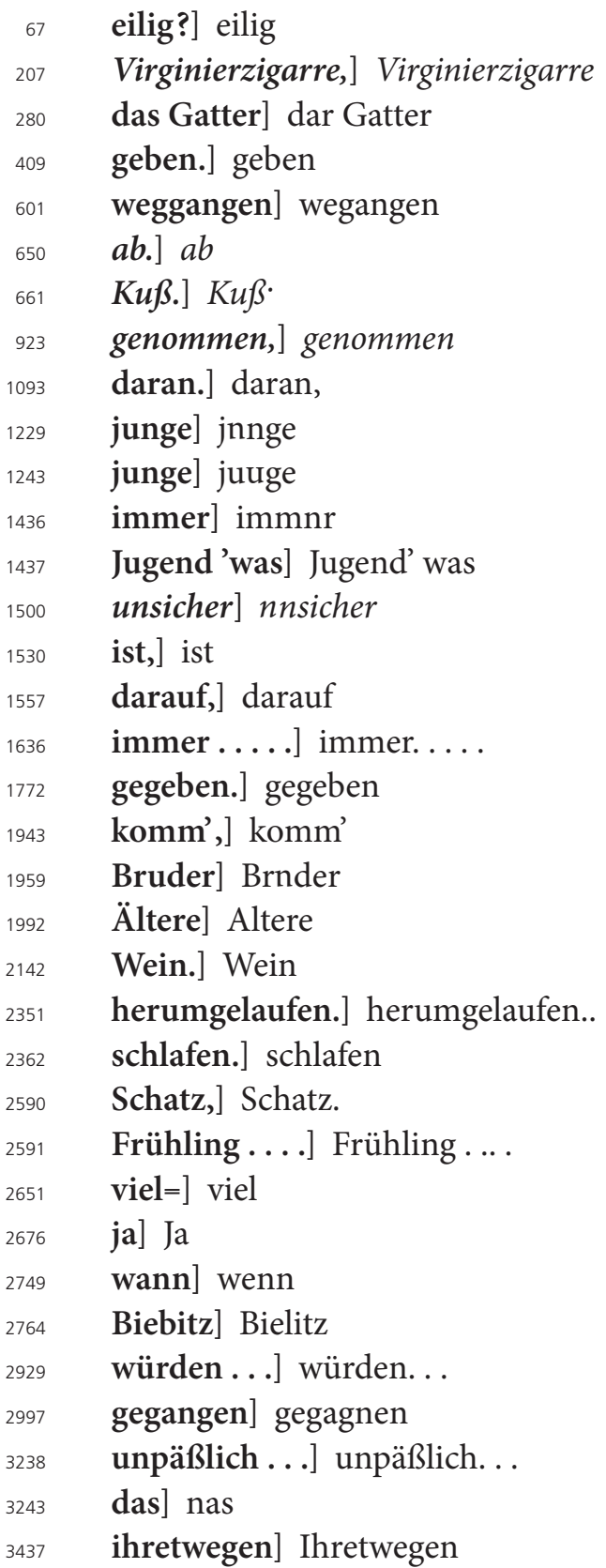




$\begin{array}{ll}3516 & \text { bitten] bittten } \\ 3538 & \text { Frauenzimmern ... .] Frauenzimmern. . . } \\ 3561 & \text { nach] na } \\ 3700 & \text { sitzen,] sitzen } \\ 3741 & \text { ähnlich] ählich } \\ 3766 & \text { hervor).] hervor. } \\ 3857 & \text { wieder.] wieder } \\ 3977 & \text { hab ....] hab. ... }\end{array}$


3. Kommentar 

A reviderci: arrivederci: (ital.) auf Wiedersehen.

Absteige / Absteigquartier: kostengünstiges (Stunden-)Hotel; auch: zu erotischen Zwecken angemietete Wohnung.

alleweil: (bes. öst.) immer.

allgemeinen Spital: allgemeines Spital: Mit der Errichtung erster Spitalsgebäude auf dem Areal im heutigen 9. Wiener Gemeindebezirk wurde bereits 1693 begonnen; unter Joseph II. kam es zu einer größeren Umstrukturierung und zur Eröffnung des ,Allgemeinen Krankenhauses' 1784. Heute wird der Baukomplex als Universitätscampus genützt.

amal: (mundartl.) einmal.

Antrittsbesuch / Antrittsvisite: der Vorstellung dienender Höflichkeitsbesuch.

aufdrehten: aufdrehen: hier: nach oben drehen, aufzwirbeln.

aufknöpfeln: (öst.) aufknöpfen; $\rightarrow$ Schuhknöpfler.

aufzulösen: auflösen: hier: enträtseln, entwirren, verstehen.

Augartenbrücke: Brücke über den Donaukanal ( $\rightarrow$ Donau), die den 2. mit dem 1. und dem 9. Wiener Gemeindebezirk verbindet.

aushalt: jemanden aushalten: (ugs.) den Lebensunterhalt für jemanden bezahlen; oft auch abwertend.

ausnehmen: hier: sehen, erkennen, wahrnehmen.

Bäckerei: hier: (öst., süddt.) Kleingebäck.

Ballon: hier: Ballonpumpe für einen Parfumzerstäuber; $\rightarrow$ Sprayapparat.

Bettpolster: $\rightarrow$ Polster.

Bouquet: (frz.; dt. ,Bukett') größerer, gebundener Blumenstrauß.

Brambarbas / Bramarbas: Bramarbas: Aufschneider, Prahlhans.

Burgtheat / Burgtheater: eine der bedeutendsten Sprechbühnen Europas; 18741888 nach Plänen von Gottfried Semper (1803-1879) und Carl von Hasenauer (18331894) im Stil der Neorenaissance als k.k. Hofburgtheater im 1. Wiener Gemeindebezirk errichtet.

Cabinet particulier: (frz.) separater Raum in Restaurants, der diskretes und ungestörtes Zusammensein erlaubt; $\rightarrow$ Chambre separé.

Cavalleria: Cavalleria rusticana: Oper in einem Akt von Pietro Mascagni (1863-1945), UA 1890.

Cavallerieoffizieren: $\rightarrow$ Kavallerieoffizieren.

Chambre separé / separée / separéè / separee: Chambre séparée: Pseudoentlehnung aus dem Französischen für einen abgetrennten Raum in Restaurants, der diskretes und ungestörtes Zusammensein erlaubt; $\rightarrow$ Cabinet particulier.

Chanpagner: Champagner.

Chocolad Bäckerei / Chokoladebäckerei: $\rightarrow$ Bäckerei. 
Commis: (frz.; dt. ,Kommis') Angestellter, Gehilfe.

Cotillon: von frz. „cotillon”: Unterrock; auch: Kotillon; zu Beginn des 18. Jahrhunderts in Frankreich entstandener Gesellschaftstanz.

dem Mensch: das Mensch: (mundartl.) Mädchen, auch: Dienstbotin; oft abfällig gebraucht.

der Blumen Rache: Der Blumen Rache: Ballade (1838) von Ferdinand Freiligrath (1810-1876), in der eine Schlafende von geisterhaft belebten Blumen zur Strafe für das Abpflücken getötet wird.

der liebende Mann [...] muß kämpfen und streben: leicht abgewandeltes Zitat aus Friedrich Schillers Ballade Das Lied von der Glocke (1799): „Der Mann muß hinaus / In's feindliche Leben, / Muß wirken und streben / Und pflanzen und schaffen, / Erlisten, erraffen, / Muß wetten und wagen/ Das Glück zu erjagen."

der Schlaf macht $[. .$.$] gleich [...] wie der Herr Bruder, also der Tod: zurückgehend$ auf die griechische Mythologie, in der der Tod (Thanatos) als Bruder des Schlafes (Hypnos) gilt.

desirée: désirée: (frz.) begehrt.

die Finstern / der finstern: die Finstern: (mundartl.) Dunkelheit, Finsternis.

die Frau: hier: Inhaberin, Dienstgeberin (HSz10, 357,11; HSz10, 358,11; D 3830; D 3846).

diniren / das Diniren / dinieren / das Dinieren: dinieren: von frz. „dîner": zu Abend essen.

Divan: veralt. Schreibweise für: Diwan: Liegesofa.

Donau: in der ersten Szene wird als Schauplatz mehrmals das Ufer der Donau genannt; aufgrund des ersten Treffpunkts der Dirne und des Soldaten $(\rightarrow$ Augartenbrücke) und der weiteren Beschreibungen muss aber der Donaukanal gemeint sein. Dieser entstand in den 1870er-Jahren während der Regulierung der Donau. Er trennt - von Nord nach Süd - die Wiener Gemeindebezirke 20 und 2 von 19, 9, 1, 3 und 11.

Dragonerrittmeisters: Dragonerrittmeister: Kommandant eines Reiterregiments.

draht / 'draht: drahn: (mundartl.) ausgehen, ausgiebig feiern, tanzen.

Drapp-Überzieher: (veralt., öst.) sandfarbener Mantel; $\rightarrow$ Überzieher.

Duellkodex: Regelwerk für die Abhaltung eines Duells, das Rechte und Pflichten des Beleidigten bzw. des Beleidigenden sowie der Sekundanten ( $\rightarrow$ Sekundant) und die möglichen Abläufe (u. a. mit Pistole, Säbel, Degen) regelt. Es gab mehrere Kodifikationen, z. B. jene Franz von Bolgárs; $\rightarrow$ Man übergibt dem Gegner.

in der Dunkeln: (mundartl.) in der Dunkelheit.

eifer / eifern: (veralt.) eifersüchtig sein, missgünstig sein.

eilf: (veralt.) elf.

Ein' Schlaf hab' ich.: einen Schlaf haben: (mundartl.) müde sein. 
Emma: Der Name verweist auf die Protagonistin von Gustave Flauberts Ehebruchsroman Madame Bovary (1857); $\rightarrow$ Karl.

en plein parade: en pleine parade: (frz.) in voller Parade.

Fallott: der Falott: (öst., ugs.) Schuft, Gauner, Betrüger.

Fauteul / Fauteuil: fauteuil: (frz.) Lehnsessel, gepolstertes Sitzmöbel mit Armlehnen.

Francillon: Francillon. Pièce En Trois Actes: Schauspiel von Alexandre Dumas, fils (1824-1895), UA 1887. Am 24. 9. 1894 hatte Schnitzler Adele Sandrock in der Titelrolle am Deutschen Volkstheater gesehen (vgl. Tb II,89). Im Spielwinter 1896/97 gastierte sie in diesem Stück am Stadttheater Baden.

Fratz: der Fratz: (öst., süddt.) Bezeichnung für ein kleines (HSz6, 183,4; D 1974) oder unartiges (HSz6, 184,8; D 1984) Kind.

Fünfer: Münze im Wert von fünf Kreuzern; ein Kreuzer bzw. Neukreuzer war nach der Einführung der österreichischen Guldenwährung $(\rightarrow$ Guldenzettel; $\rightarrow$ Sechserl für'n Hausmeister) der hundertste Teil eines Guldens; $\rightarrow$ Fünfkreuzertanz.

Fünfkreuzertanz: billige Tanzgelegenheit in Gaststätten und Lokalen (z. B. $\rightarrow$ Swoboda); wurde in kleinen Wirtshäusern am Stadtrand und im $\rightarrow$ Prater veranstaltet, wobei anfangs kein Eintritt, aber für jeden Tanz fünf Kreuzer ( $\rightarrow$ Fünfer) eingehoben wurden.

gangen: (mundartl.) gegangen.

Garnison: von frz. „garnison“: Besatzung, Truppenstandort.

Garnisonort: $\rightarrow$ Garnison.

Gatter: Latten- bzw. Gitterzaun oder -tor.

geh'r i: (mundartl.) gehe ich. Der Sprosskonsonant "r" verhindert das Zusammentreffen zweier Vokale (das "h" bleibt stumm).

gemeine Soldat: der Gemeine: einfacher Soldat ohne Dienstgrad.

Gfrett: das Gfrett: (mundartl.) Ärger, Plage.

gift sich / gift' sich: sich giften: (ugs.) sich ärgern, böse sein.

Gilèt / Gilet: (frz.) gilet: (ärmellose) Weste.

gleichgiltig: gleichgiltig: (veralt.) gleichgültig.

Grisette: in der Literatur des 19. Jahrhunderts junges (Pariser) Mädchen, oft Näherin oder Putzmacherin; häufig in der Rolle der unverheirateten Geliebten eines Künstlers.

Gschau / G’schau: (mundartl.) Aussehen, Gesichtsausdruck, charakteristische Mimik einer Person.

Guckerl: (öst.) Guckloch, Türspion.

Guldenzettel: Banknote. Die österreichische Guldenwährung war 1857 ( $\rightarrow$ Sechserl für'n Hausmeister) eingeführt worden und wurde 1892 durch die Krone ersetzt, blieb aber bis 1900 gültig; $\rightarrow$ Fünfer. 
gute Kameraden: möglicherweise Anspielung auf Paul Heyses (1830-1914) Novelle Gute Kameraden (1883), die im Briefwechsel mit Olga Waissnix (1862-1897) zitiert wird (vgl. u. a. Br I,11/184).

hab’ ich über Zeit: über Zeit haben: (mundartl.) Zeit übrig haben, mehr Zeit haben.

halber acht: (mundartl.) halb acht Uhr; hier: 19 Uhr 30.

Havannahcigarre: Havannazigarren: aus Kuba stammende Zigarrenmarken; im Gegensatz zur in Österreich produzierten $\rightarrow$ Virginiercigarre als exklusiv geltend.

heilige Einfalt: (lat.) sancta simplicitas. Die Wendung stammt aus spätlateinischen Quellen und wurde v. a. durch das betreffende Zitat in Johann Wolfgang von Goethes Faust I (1808; Vs. 3037) populär.

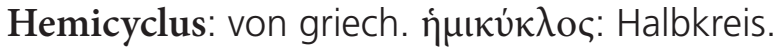

herum knotzen: (öst., ugs.) lümmeln.

heuer: (öst., schweiz., süddt.) dieses Jahr, in diesem Jahr.

hieher: (öst., süddt., sonst veraltet) hierher.

I / i: (mundartl.) Ich / ich.

Industriellenball: Ball der Wiener Industriellenvereinigung, der jährlich zur Faschingszeit abgehalten wurde. Zur Entstehungszeit von Reigen fand er im Wiener Musikverein im 1. Wiener Gemeindebezirk statt.

is / I'ss' / Is' / Is: (mundartl.) ist (es).

Jänner: (öst.) Januar.

Kabinet: das Kabinett: (öst.) kleines, einfenstriges Zimmer.

Kadett: von frz. „cadet": Offiziersanwärter; Zögling einer Kadettenanstalt, einer internatsähnlichen Einrichtung, die auf eine Laufbahn als Berufsoffizier vorbereitete.

Kalliani: vermutlich Anspielung auf den Namen Joseph Kalliany de Kallian (Name existiert in unterschiedlichen Schreibweisen; ?-1859); ab 1845 General-Major des k.k. Infanterie-Regiments Nr. 41; kämpfte während der Ungarischen Revolution 1848/49; 1852 Freiherrenstand.

Karl: Der Name verweist auf Gustave Flauberts Roman Madame Bovary (1857). Charles Bovary wird von seiner Ehefrau $(\rightarrow$ Emma) mehrfach betrogen.

Kasern: Da der Soldat einen ähnlichen (HSz2, 31,11f.) bzw. den gleichen Heimweg (D 373) hat wie das Stubenmädchen, das in der Porzellangasse ( $\rightarrow$ Porzellangassen) wohnt, handelt es sich vermutlich um die Rossauer Kaserne im 9. Wiener Gemeindebezirk. Als Kronprinz-Rudolph-Kaserne wurde sie 1870 eröffnet.

Kavallerieoffizieren: Kavallerie: Reiterregiment. Offizier: militärische Rangstufe, die die Dienstgrade von Lieutenant bis General umfasst.

Kodex: $\rightarrow$ Duellkodex.

kommst' immer noch zurecht: zurechtkommen: hier: rechtzeitig, zur rechten Zeit kommen. 
Korporal: niedrigster Dienstgrad eines Unteroffiziers.

krall' aufi: auffi kralln: (mundartl.) hinauf klettern.

licht, lichter: (öst.) hell, heller.

Lieutenant: (frz.) Stellvertreter; militärischer Dienstgrad, niederster Offiziersrang.

Maht: die Mahd: das Abgemähte, die (Heu-)Ernte.

Man übergibt dem Gegner [...] die gerichtliche Verfolgung einzuleiten: Fast wörtlich übernommenes Zitat aus dem Kapitel "Pistolenduell - nur ein Lauf geladen“ in Franz von Bolgárs (1851-1923) Die Regeln des Duells (1880; dt. 1884), einem der bekanntesten Duellkodizes; $\rightarrow$ Duellkodex. Bolgár wird auch in Briefen von und an Richard Beer-Hofmann (1866-1945) erwähnt (Brief v. Beer-Hofmann an Schnitzler v. 7. 9. 1894; Brief v. Schnitzler an Beer-Hofmann v. 9. 9. 1894, beide: Beer-HofmannBw 58f.).

Mantille: (frz.) mantille: (veralt.) Damenmantel; hier auch: aus Pelz oder mit Pelzbesatz; $\rightarrow$ Pelzmantille.

mei' Frau: meine Frau: hier (HSz2, 30,8; D 357) in der Bedeutung von: $\rightarrow$ die Frau. meinig / meinigen: meinig: (veralt.) mein.

Mied / Miede / Mieder: das Mieder: eng geschnürtes Oberteil.

Mir sein mir / mir sein mir: (öst. süddt.) wir sind wir. Diese beispielsweise in Bayern auch heute noch beliebte Tautologie - "mir san mir" bzw. „mia san mia” - findet sich als Ausdruck der Identitätsvergewisserung etwa auch in einem Lied Carl Michael Ziehrers aus dem Repertoire der Hoch- und Deutschmeister: Mir san mir - von Num'ro 4. Satirisch eingesetzt wird sie in Karl Kraus' Drama Die letzten Tage der Menschheit (1922) in der Ansprache des „Wieners" (1. Akt, 1. Szene).

mit die andern: in der Mundart gebräuchliche Verwendung des Akkusativs statt des Dativs: mit den anderen.

mollerter: Komparativ von: mollert: (öst., süddt.) mollig, dicklich.

nachher: hier: (mundartl.) dann, denn.

Nachtkästchen / Nachtkastchen / Nachtkast / Nachtkastl / Nachtkastel: Nachtkästchen / Nachtkastl: (öst., süddt.) Nachttisch.

nachtmahlen / Nachtmahl: (öst.) zu Abend essen / das Abendessen.

Nah und fern zugleich: möglicherweise Anspielung auf Johann Wolfgang von Goethes Faust II (1832); Helena sagt dort zu Faust: „Ich fühle mich so fern und doch so nah, / Und sage nur zu gern: da bin ich! Da!"

Nester: das Nest: hier: (ugs.) kleiner, abgelegener Ort.

net: (mundartl.) nicht.

nimmer: (öst., süddt.) nicht mehr.

Obacht / obacht: (süddt.) Vorsicht, Achtung; Obacht geben: aufpassen, vorsichtig sein. 
Oberschaumbaisers / Obersschaumbaisers: Obersschaumbaiser: mit geschlagener Sahne gefülltes Schaumgebäck aus Eischnee und Zucker; Obers: (bes. ostöst., süddt.) süße Sahne; Baiser: von frz. „baiser”: küssen.

Odilon: Helene Odilon (1865-1939): Schauspielerin, die ab 1891 am Deutschen Volkstheater in Wien engagiert war.

ordinäre: ordinär: hier eher: (veralt.) alltäglich, gewöhnlich.

Pãdon / Pahdon: Verballhornungen von: $\rightarrow$ Pardon.

Pardon / pardon: (frz.) Bitte um Nachsicht, Verzeihung.

Parquet: (frz.); hier: Parkettfußboden.

Pelzmantille: $\rightarrow$ Mantille.

Perser / persischen Teppich: Perserteppich; schwerer, kunstvoll gewebter Teppich; urspr. aus den Gebieten des ehemaligen Perserreiches (bes. Iran).

Polster: hier: der Polster: (öst.) Kissen.

Portiéren / Portière / Portièren: portière: (frz.) Tür; Gardinen oder Vorhänge an türlosen Eingängen, üblicherweise aus schweren Stoffen wie Brokat, Plüsch oder Samt.

Porzellangassen: Porzellangasse: Straße im 9. Wiener Gemeindebezirk.

Poseur: (frz.) Angeber, Wichtigtuer, Person, die sich in Szene setzt.

Prater: weitläufiges Augebiet an der Donau im 2. Wiener Gemeindebezirk; beliebtes Freizeitareal.

psychologie de l'amour: De l'Amour: 1822 erschienene essayistische Abhandlung von $\rightarrow$ Stendhal, in der eine ,Theorie der Liebe' entworfen wird. In Sz4, 94,4-99 bzw. D 1012-1082 bezieht sich "Der junge Herr' auf das Kapitel "Vom Fiasko".

Pussel / Pussi: alternative Schreibungen von: Busserl: (öst., süddt.) Kuss.

Pußt / Pußta: Puszta (eingedeutscht: Pußta): Steppenlandschaft / Weideland im heutigen Ungarn, dem heutigen Ostösterreich und Teilen der heutigen Slowakei; $\rightarrow$ Tiefebene.

Quadrille: Gruppentanz für vier Paare.

Rauchtisch: kleiner, runder Tisch (meist mit Metallplatte) für Rauchutensilien.

raunzen: (öst., süddt.) weinerlich klagen, unzufrieden nörgeln.

Rede keinen Stiefel: einen Stiefel zusammenreden: (ugs.) Unsinn sprechen.

Remonten: die Remonte: von frz. "cheval de remonte”: junges Militärpferd, das für den Dienst in einem Reiterregiment ausgebildet wird.

Reseda: Pflanze mit länglichen Blättern und in Trauben oder Ähren stehenden kleinen, duftenden Blüten von weißer oder gelblicher Farbe.

Riedhof: Restaurant im 8. Wiener Gemeindebezirk, das ab 1850 von dem Restaurator Johann Benedickter (1851/52?-1931) geführt wurde und ein beliebter Treffpunkt für Aristokratie und Bürgertum war.

Riesenbouquet: $\rightarrow$ Bouquet. 
Riesensucces: von frz. "succès": Erfolg.

Ringstraß: Ringstraße, Ring: Wiener Prachtstraße, die nach der 1857 von Kaiser Franz Joseph I. angeordneten Schleifung der Festungsmauern und Basteien rund um die Innenstadt angelegt wurde und an der man in den 1860er- bis 1880er- Jahren zahlreiche Repräsentationsbauten errichtete.

Rouleaux: frz. Plural von: Rouleau; $\rightarrow$ Rouletten.

Rouletten / Roulett / Roulette: die Roulette: von frz. "roulette de suspension": Gardinenröllchen; veralt. Bezeichnung für: (frz.) Rouleau: Rollvorhang aus Gewebe, der über eine oben am Fenster angebrachte Walze nach unten gezogen wird; $\rightarrow$ Rouleaux.

Sacher: Café Sacher: bekanntes Kaffeehaus im 1. Wiener Gemeindebezirk.

Sack: hier: (öst., schweiz., süddt.) (Hand-)Tasche.

saubrer: Komparativ von: sauber: hier: (öst., schweiz., süddt.) ansehnlich, hübsch; oft auf Mädchen und Frauen bezogen.

Schau i wem gleich?: jemandem gleichschauen: (bes. öst.) jemandem ähnlichsehen.

Schiffgassen: Große Schiffgasse: Straße im 2. Wiener Gemeindebezirk; aufgrund der topographischen Zuordnungen ( $\rightarrow$ Augartenbrücke) kann nicht die Kleine Schiffgasse gemeint sein, die bis $1919 \mathrm{im}$ 4. Wiener Gemeindebezirk verlief.

Schildkrothaarnadel: Schildkrot (Schildpatt): Material aus dem Rückenschild von bestimmten Meeresschildkrötenarten; häufig verwendet u. a. für hochwertige Kämme, Haarschmuck und Dosen.

Schlaf der Gerechten: den Schlaf der Gerechten schlafen: scherzhafte Redewendung, im Sinne von "ruhig und fest schlafen".

Schneckerln: (öst.) Löckchen.

Schnittwaarencommis: Handlungsgehilfe, kaufmännischer Angestellter in einem Geschäft, das geschnittene Ware (z. B. Textilien, Holz) vertreibt; $\rightarrow$ Commis.

Schuhknöpfler: auch: Stiefelknöpfler/-knöpfer; Gerät, das zum Zuknöpfen der Schuhe verwendet wurde; Haken an einem langen Schaft mit Griff, der durch die Öse/das Knopfloch geführt wurde.

Schwindgasse: Straße im 4. Wiener Gemeindebezirk.

Sechserl für'n Hausmeister: auch: Sperrsechserl: Entgelt für den Hausmeister, wenn dieser nach der Sperrstunde (zumeist 21 oder $22 \mathrm{Uhr}$ ) noch das Haustor öffnen musste. Es gab nur eine Hausglocke, die mit der Hausmeisterwohnung verbunden war; erst nach dem Zweiten Weltkrieg erhielten auch die Mieter Haustorschlüssel. Ein Sechserl bezeichnete ursprünglich den sechsten Teil eines Guldens (60 Kreuzer) und damit die 10-Kreuzer-Münze. Die Begriffe "Sechserl" oder "Sperrsechserl" blieben auch noch erhalten, als die österreichische Guldenwährung mit dem Wiener Münzvertrag von 1857 eingeführt wurde, bei der einem Gulden 100 Kreuzer entsprachen, und schließlich auch noch nach der Einführung der österreichischen Krone 1892 (einer Krone entsprachen 100 Heller); $\rightarrow$ Fünfer; $\rightarrow$ Guldenzettel. 
Seitengewehr / Seiteng'wehr: Stichwaffe, die an der Seite getragen oder wie ein Bajonett am Gewehr montiert („aufgepflanzt“) werden kann.

seki / sekir': sekkieren: (öst., sonst veraltet) belästigen, quälen.

Sekundant: Zeuge eines Duells, der vom jeweiligen Duellanten nach festgelegten Kriterien ausgewählt werden musste und darauf zu achten hatte, dass der $\rightarrow$ Duellkodex eingehalten wurde. In der Regel musste jeder Duellant zwei Sekundanten haben.

Servas: mundartl. Variation von: $\rightarrow$ Servus.

Servus: (öst., süddt.) freundschaftlicher Gruß beim Abschied oder zur Begrüßung; von lat. "servus": (dein) Diener.

sich ein Relief zu geben: sich Relief geben: (veralt.) sich Bedeutung, Kontur verleihen. sigs: sigst: (mundartl.) Siehst du!

Singerstraßen: Singerstraße: Straße im 1. Wiener Gemeindebezirk.

Soupers / soupèr / soupiren / Souper / soupire / soupieren: soupieren: von frz. "souper": zu Abend essen / das Abendessen.

Spiegelgasse: Straße im 1. Wiener Gemeindebezirk.

spitzn: spitzen: (öst.) aufmerken, sich wundern.

splendider: splendid: (veralt.) freigebig, großzügig.

Sprayapparat: hier: (veralt.) Parfumzerstäuber mit Ballonpumpe; $\rightarrow$ Ballon.

Steinamanger: Szombathely: ungarische Stadt an der Grenze zu Österreich; lag zentral im Gebiet der k.u.k. Monarchie und war ein wichtiger Eisenbahnknotenpunkt sowie ein Leichtindustriezentrum.

Stendhal: franz. Schriftsteller: eig. Marie-Henri Beyle (1783-1842); $\rightarrow$ psychologie de l'amour.

Stengelglas: Weinglas.

Stiege: (öst., süddt.) Treppe.

strawanzt: strawanzen: (öst., süddt.): sich herumtreiben, umherstreifen.

Strizi / Strizzi: der Strizzi: (öst., süddt.) leichtsinniger, leichtfertiger, durchtriebener Bursche, auch: Zuhälter.

Strozzigassen: Strozzigasse: Straße im 8. Wiener Gemeindebezirk.

Swoboda: um 1900 bekanntes Lokal im $\rightarrow$ Prater, in dem bis zu seiner Schließung 1927 der $\rightarrow$ Fünfkreuzertanz angeboten wurde.

Taille: Bereich zwischen Brust und Hüfte (HSz1, 18,4; H'Sz10, [6],1; D 188); enganliegendes Oberteil (HSz4, 90,8; HSz8, 277,4; D 954). Hier nicht zu verstehen als $\rightarrow$ Mieder, da ,Die junge Frau' kein solches trägt (vgl. HSz4, 91,9f.; D 969/971).

tamburirten / tamburierten: tamburieren: mit Tamburierstich (Kettenstich) besticken.

Tasse: hier: (öst., veralt.) Untertasse, Tablett. 
Tatzen: auch: Tazen: (mundartl.) Untertasse, Tablett.

thut ihm schön: jemandem schöntun: jemandem schmeicheln, den Hof machen.

Tiefebene: Die kleine ungarische Tiefebene (auch: Tiefland) liegt im Nordwesten Ungarns - mit Ausläufern bis nach Österreich und in die Slowakei; $\rightarrow$ Pußt. Die große ungarische Tiefebene befindet sich im Zentrum, Süden und Osten Ungarns und reicht bis nach Serbien, Rumänien und in die Ukraine.

Toilett: von frz. "toilette": hier: Kleidung.

Toilettentisch / Toilettetisch: Schminktisch; oft mit Spiegel und zahlreichen Schubfächern versehen.

transferirn / transferiren: transferieren: (öst. Amtssprache) versetzen.

Trumeau: (frz.) trumeau: Fensterpfeiler, manchmal mit Wandspiegel und Ablagetisch oder -schränkchen.

Tschecherl: (öst.) kleines, einfaches Gast- oder Kaffeehaus.

tummeln: sich tummeln: hier: (öst.) sich beeilen.

Überzieher: Herrenmantel; $\rightarrow$ Drapp-Überzieher.

viertel sieben: (mundartl.) Viertel nach sechs, hier: 18 Uhr 15.

Virginiercigarre / Virgin / Virginierzigarre / Virginier: Virginia-Zigarre; (öst.) Virginier: lange, dünne Zigarre mit Mundstück. In Österreich wurde sie ab 1844 hergestellt und war im Gegensatz zu den Havannas ( $\rightarrow$ Havannahcigarre) kostengünstiger; sie galt als typisch wienerisch und zum städtischen Leben gehörend.

vis à vis: (frz.) gegenüber.

Volkssanger / Volkssängern: Volkssänger: im 19. Jh. v. a. in Städten als Bezeichnung für Unterhalter der mittleren und unteren Schichten; im 20. Jh. generell im Sinne von "Sänger aus dem Volk/für das Volk" (Wienerlied).

Vormund: jemand, der eine minderjährige oder entmündigte Person vertritt. Im Allgemeinen Bürgerlichen Gesetzbuch von 1811 wurde die Großjährigkeit mit Vollendung des 24. Lebensjahres festgelegt (§ 21), erst ab 1919 wurde diese Altersgrenze sukzessive heruntergesetzt. Ein Vormund wurde dann bestimmt, wenn die betroffene Person nicht durch den Vater versorgt wurde (§ 187).

Wachter: (mundartl.) Wächter, Wachmann.

wannst: (mundartl.) wenn du.

Weidling am Bach: Weidling: Wienerwaldort nordwestlich von Wien; im 19. Jahrhundert beliebtes Sommerfrischeziel.

wie mir: (mundartl.) wie wir.

wie nicht gscheidt: wie nicht gscheit: (öst. Redewendung) wie verrückt, ohne Maß und Ziel.

wie sie ausgekleidet ist: (mundartl.) als sie ausgekleidet ist.

Wird dir keine Perle aus der Krone fallen: Redewendung: Das ist nicht zu viel verlangt, nicht unter jemandes Würde. 
Wurstelprater: gängige Bezeichnung für den Volksprater, einen Vergnügungspark im 2. Wiener Gemeindebezirk, Teil des Praters ( $\rightarrow$ Prater); die Bezeichnung „Wurstelprater" geht zurück auf eine Figur des Volkstheaters, den Hanswurst.

Wurzn / Wurzen: die Wurzen: (mundartl.) jemand, der sich ausnützen lässt.

zhaus / zu Haus / Z haus / z'haus / Zhaus / z Haus / zuhaus / Z' Haus: hier: (mundartl.) nach Hause.

Zuckerln: das Zuckerl: (öst., süddt.) Bonbon.

zugi: (mundartl., veralt.) hinzu, herbei, her.

zum blauen Stern: gemeint sein könnte das gleichnamige Haus in der Praterstraße $64 \mathrm{im}$ 2. Wiener Gemeindebezirk oder das Gasthaus Zum blauen Stern in der Adlerstraße 164; die Adlerstraße verlief zwischen Rotenturmstraße und Laurenzerberg im 1. Wiener Gemeindebezirk; nach den Zerstörungen im Zweiten Weltkrieg wurde sie 1954 aus dem Straßenkataster gestrichen.

zwa: (mundartl.) zwei (H'Sz10 [18],10).

Zwischenakt: Zeitspanne zwischen zwei Akten einer Aufführung (in Theater oder Oper), die z. B. mit Musik oder Ballett ausgefüllt wird. 
4. Anhang 



\subsection{Schenkungsblatt}
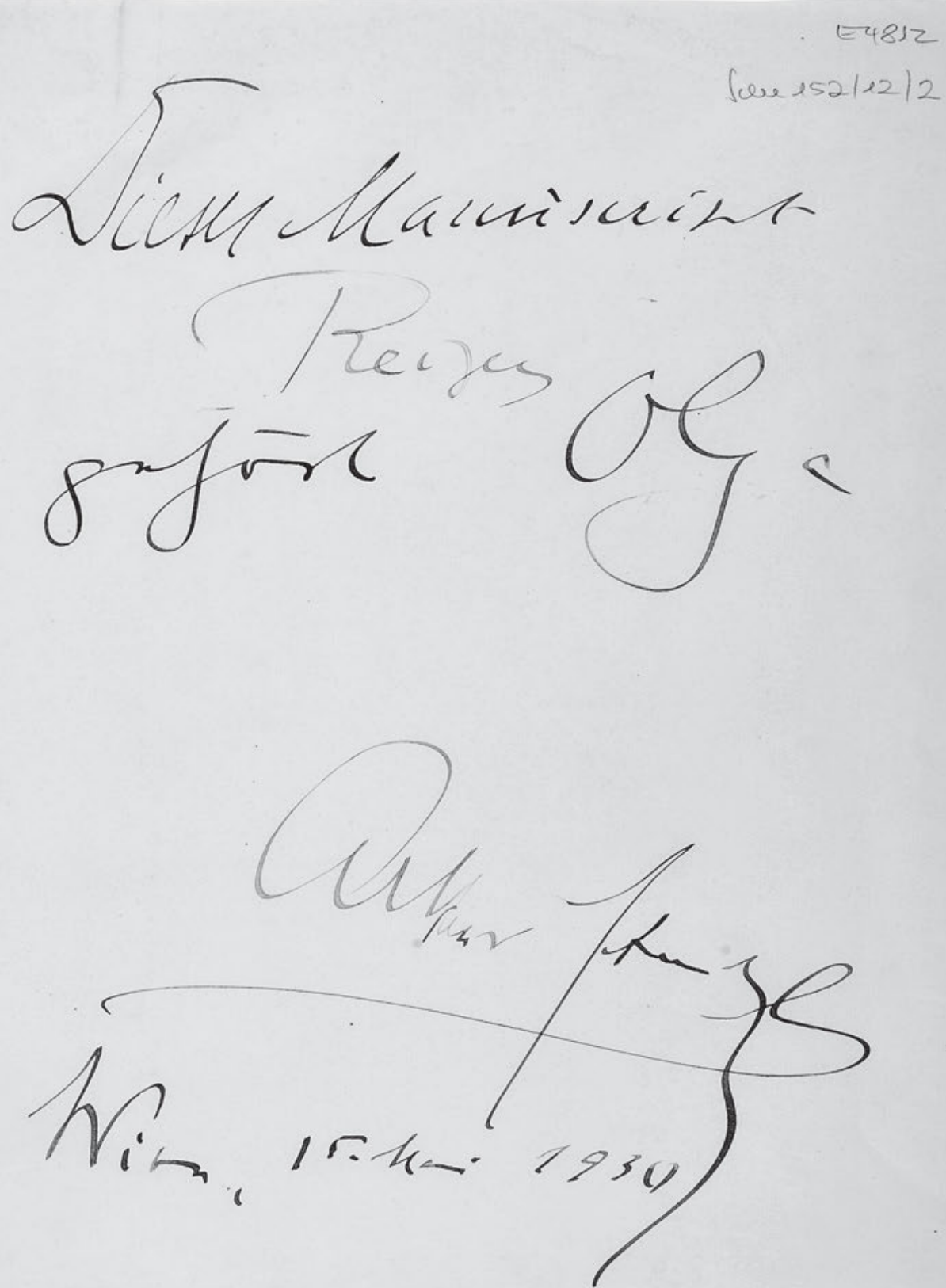

„Dieses Manuscript / Reigen / gehört Olga / Arthur Schnitzler / Wien, 15. Mai 1930“

Bestätigung der Schenkung des Reigen-Manuskripts an Olga Schnitzler durch Arthur Schnitzler Originalmaße 16,7 x 20,5 cm

KHM-Museumsverband, Theatermuseum Wien (HS_Schn_152_12,2) 


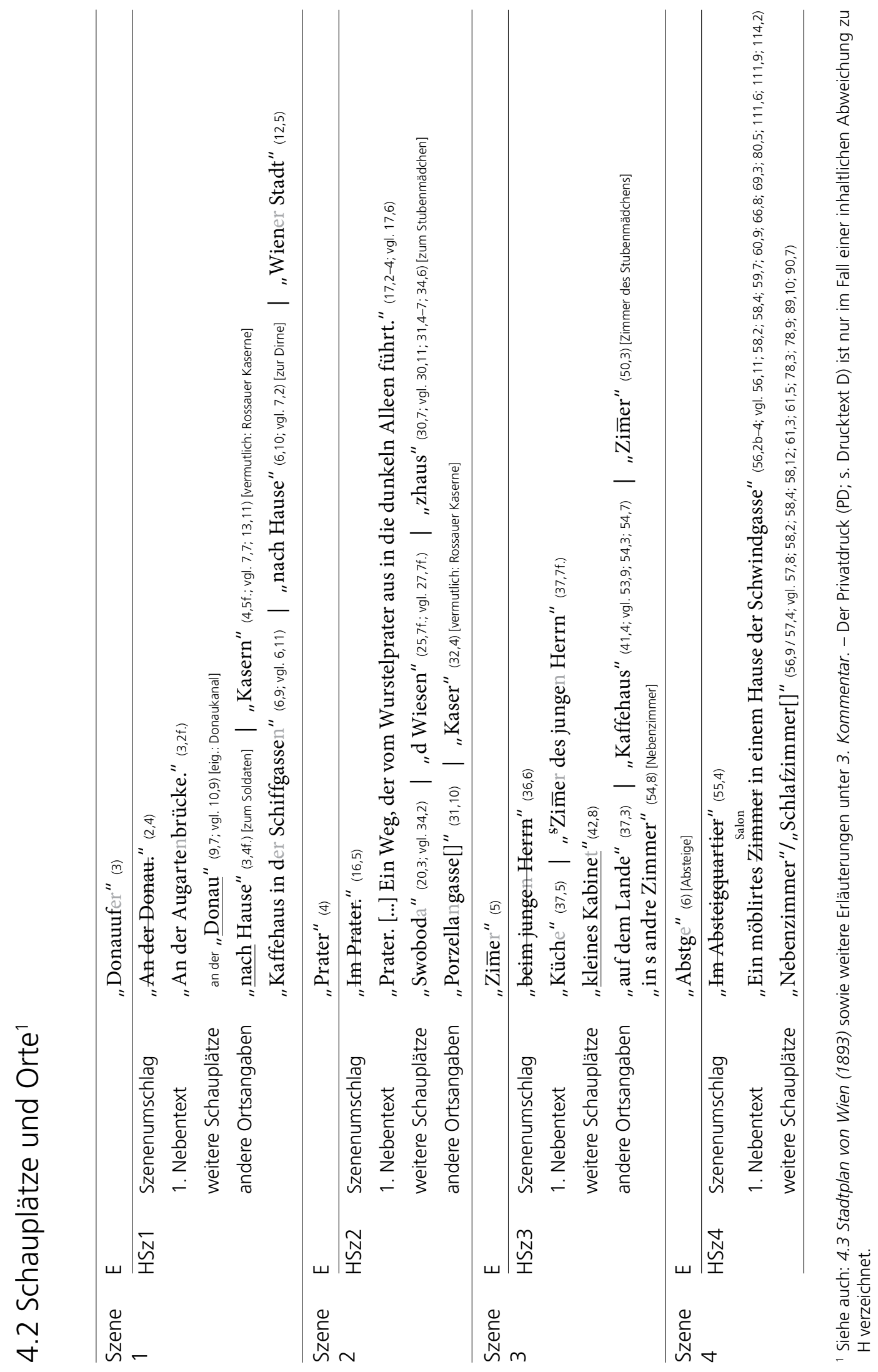




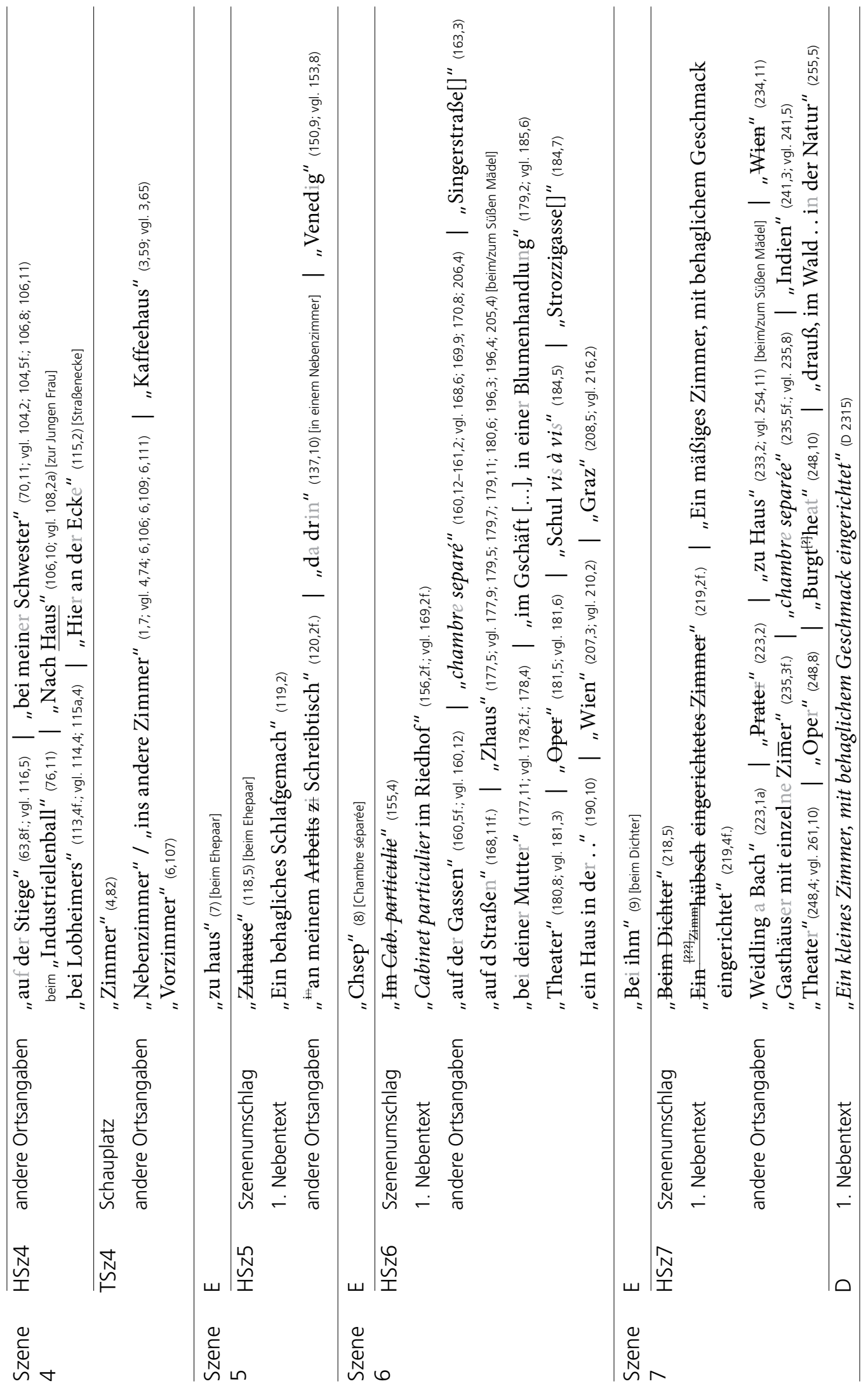




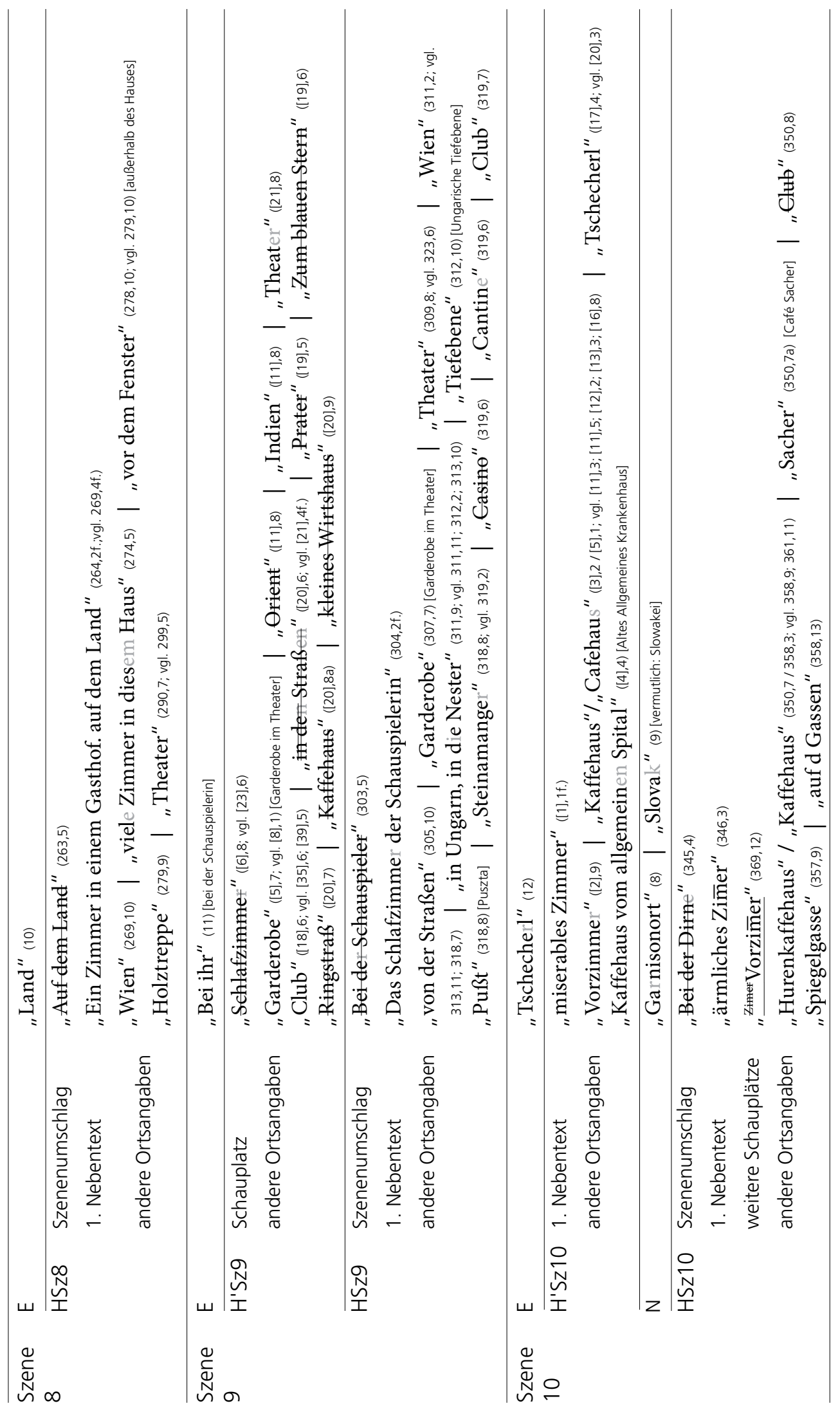




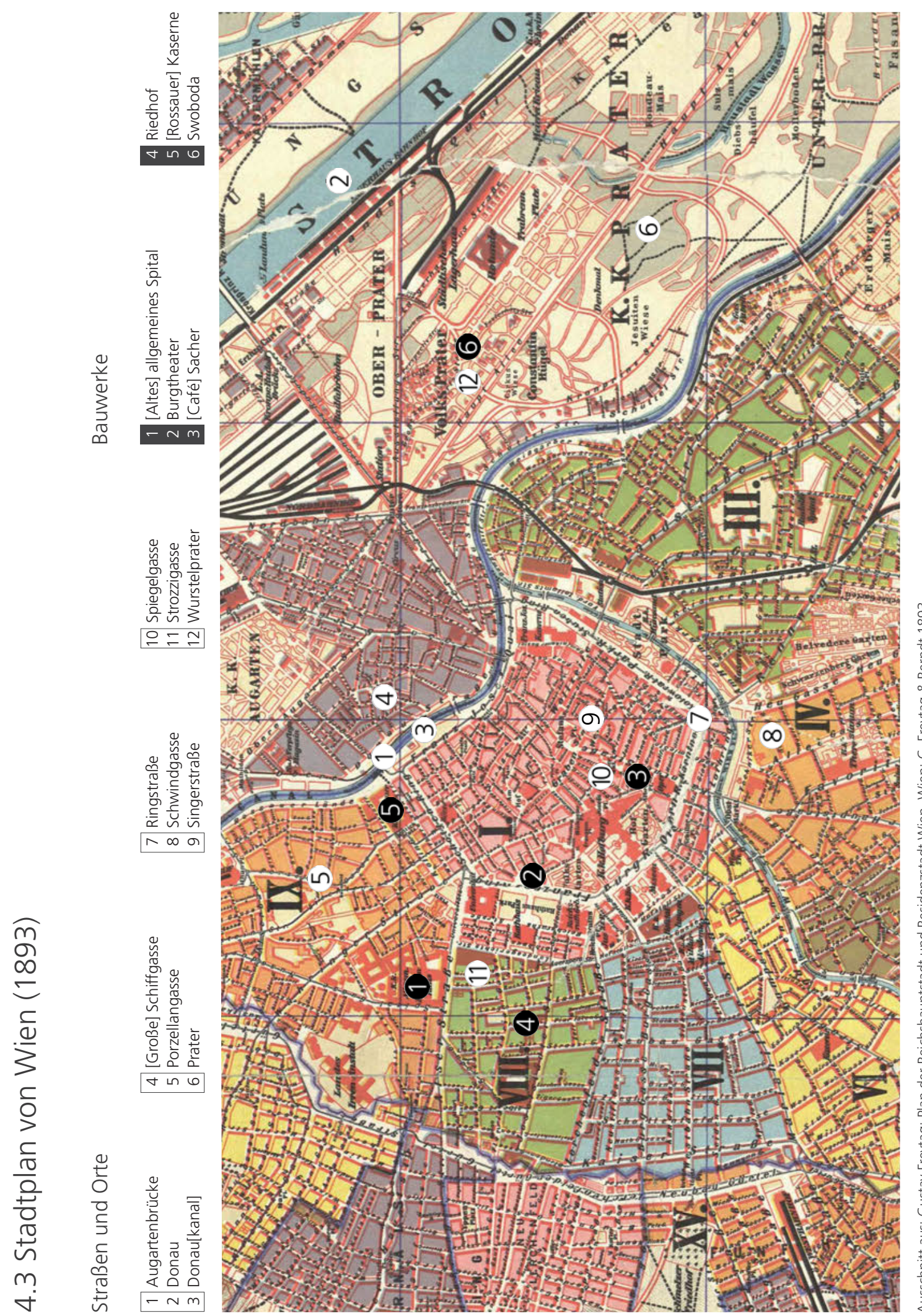




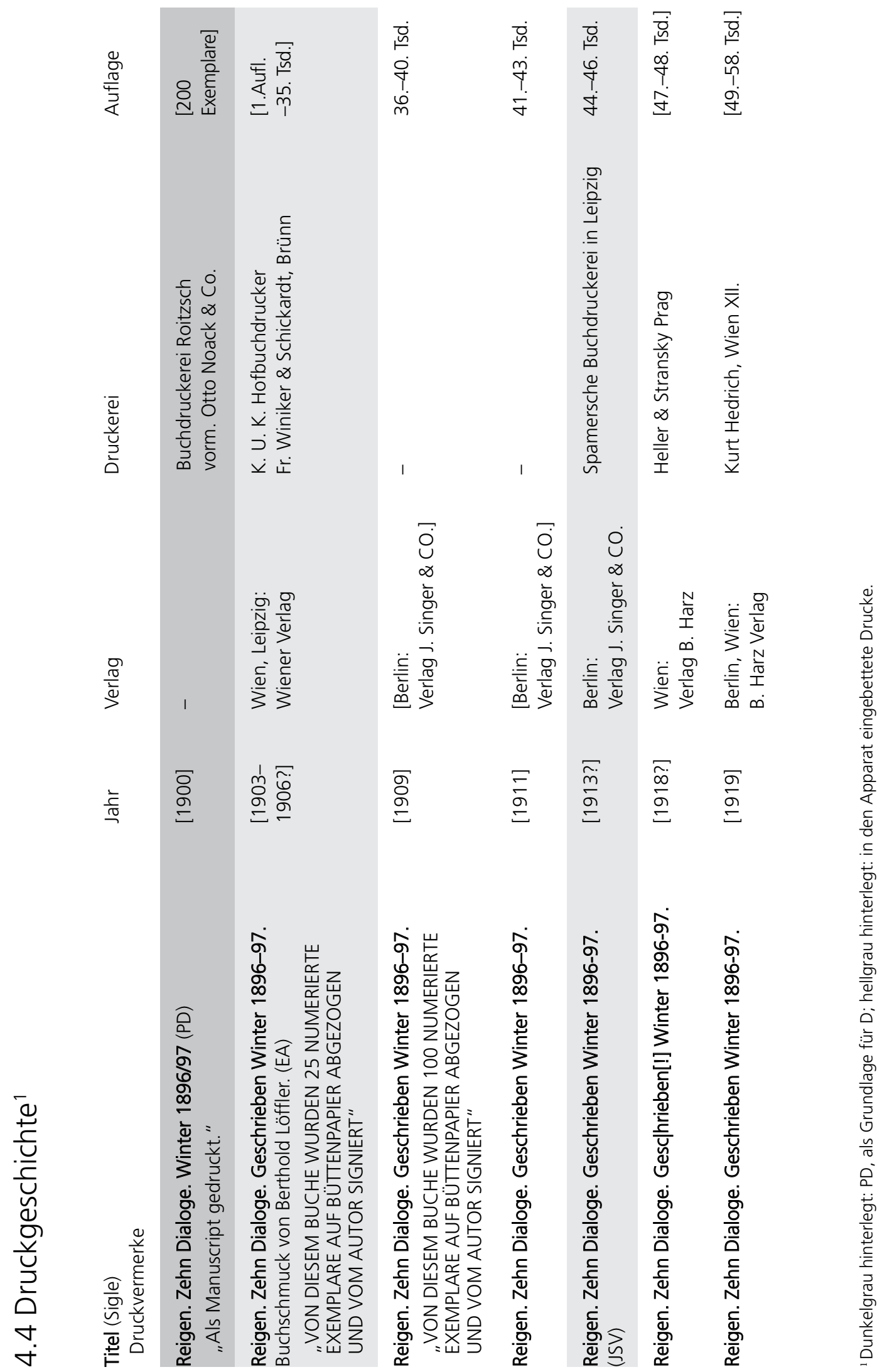




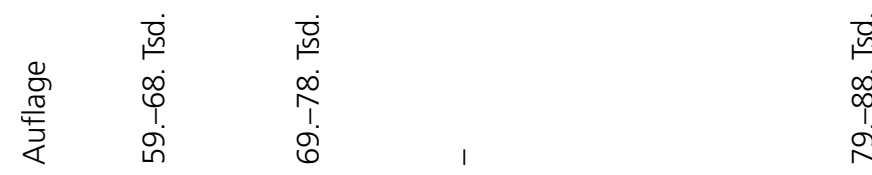

$\dot{0}$
$\infty$
$\infty$
$\infty$
$\infty$
$\infty$
$\infty$
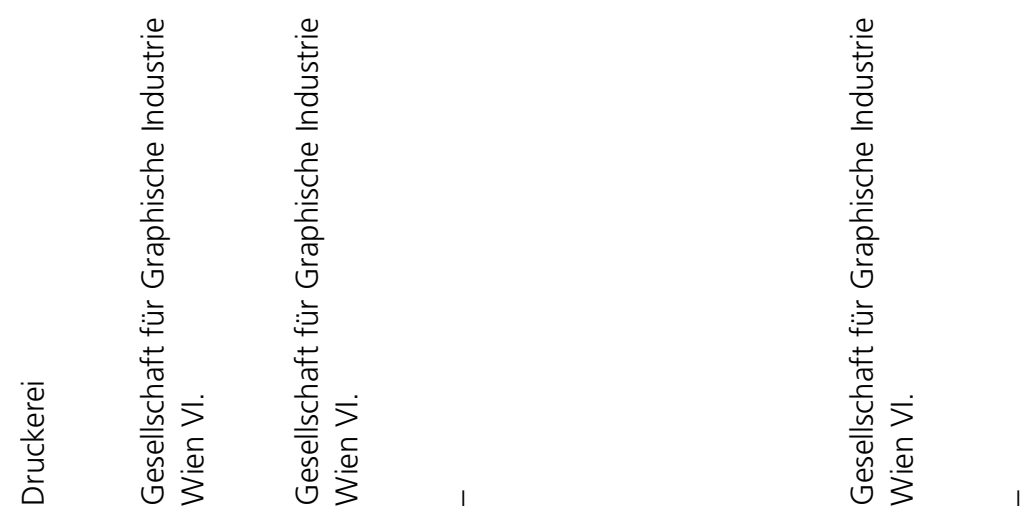

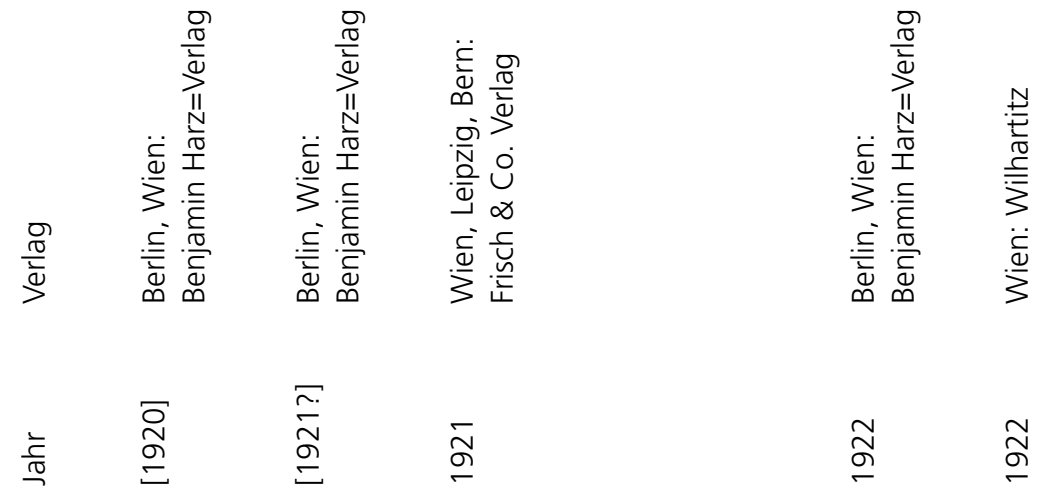

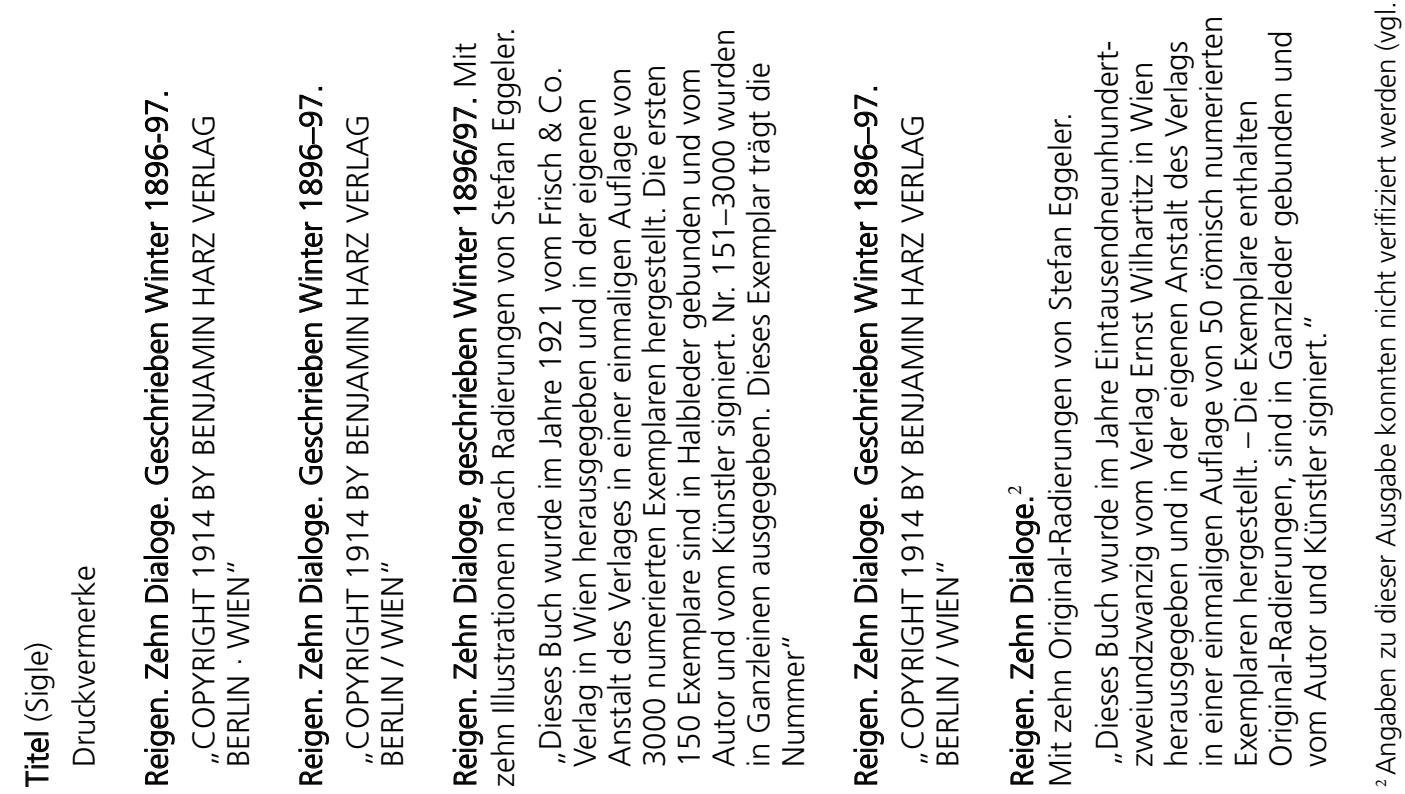




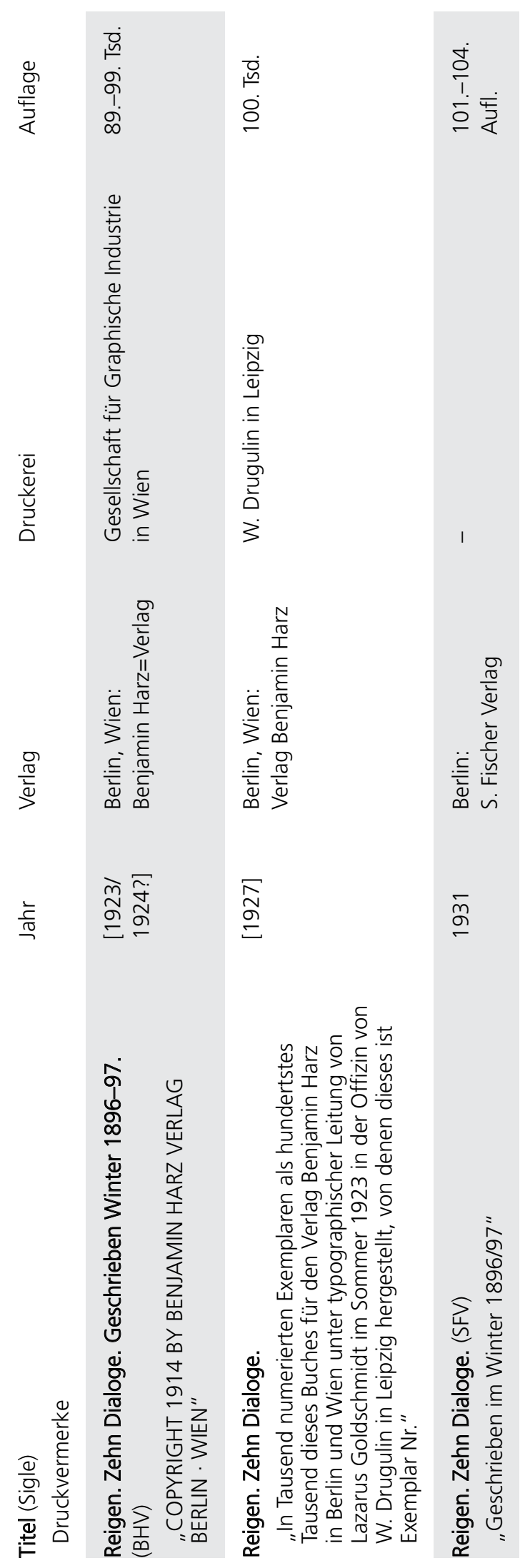




\subsection{Beispielseiten aus dem Privatdruck}

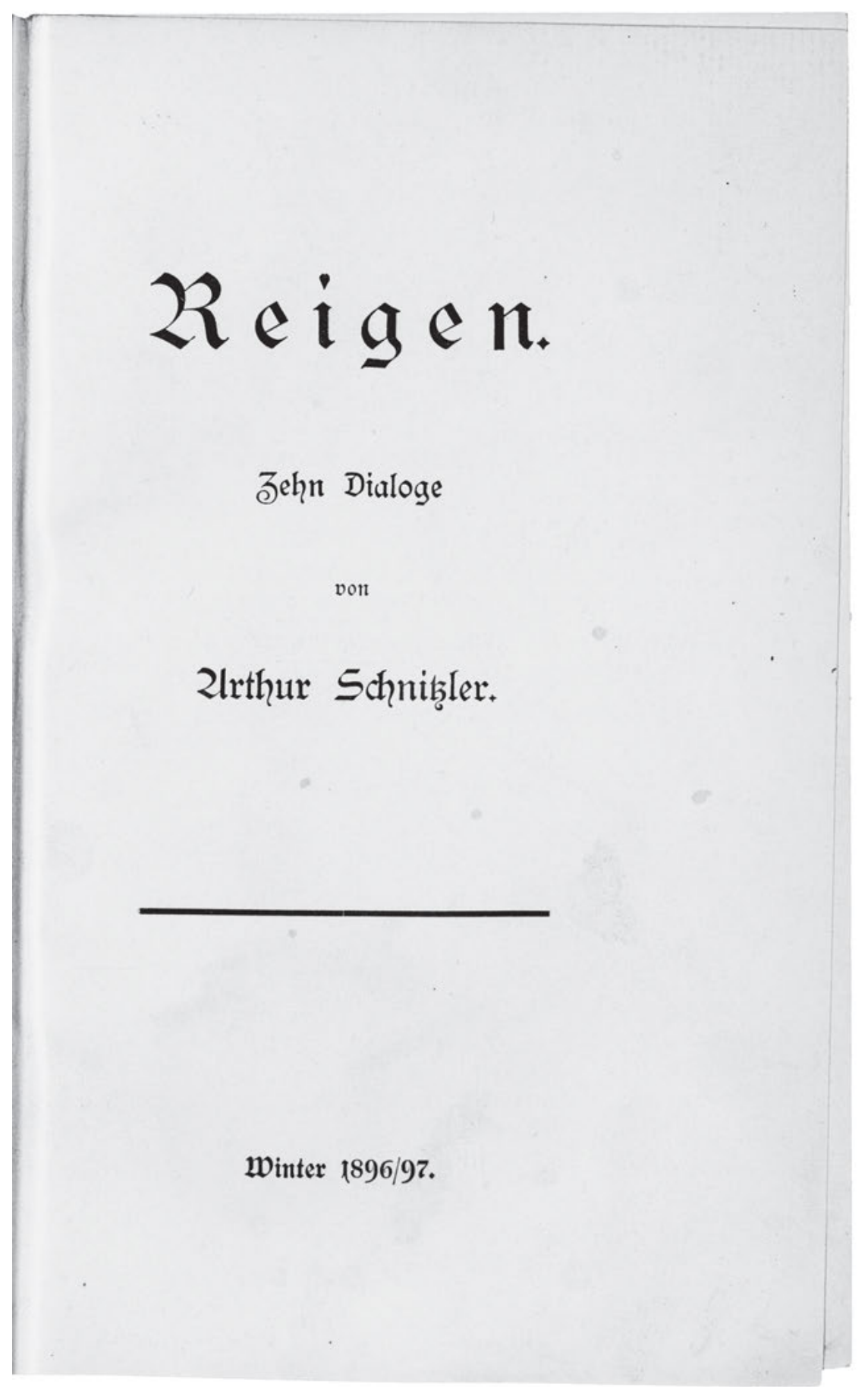

Privatdruck (PD): Reigen. Zehn Dialoge. Winter 1896/97. Als Manuscript gedruckt. Buchdruckerei Roitzsch vorm. Otto Noack \& Co. [1900].

Wienbibliothek im Rathaus (MA 9) 


\section{a 12,3706}

AI8 Manuicript gebrudt.

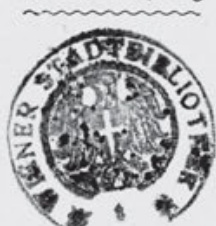

$3 N 168490$ 
Anhang

Beispielseiten Privatdruck

Sh.tz.

becunntushn

Lev kenying

Ein (Erideinten ber nadyfolgenden Scenen ift bor= läufig auछgejdlofien. Să habe fie num als Manu= fcript in Drut gegeben; Denn idf) glaube, ihr $\mathfrak{B}$ ert

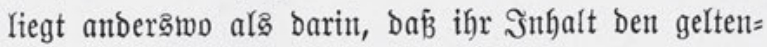
Den Begriffen nach) bie Beröffentlichung z̆t verbieten icheint. Da jeobd) Dummbeit und böfer $2 B i l l e$ immer

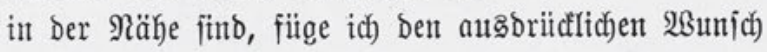
bei, dá̉ meine Freunde, Denent ich biefes Manufcript gelegentlid) übergeben werbe, es burdaus in biejem Sinne behandeln und als ein beideeibenes, ifnen per=

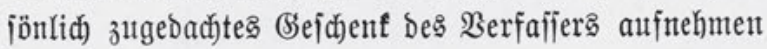
mögen.

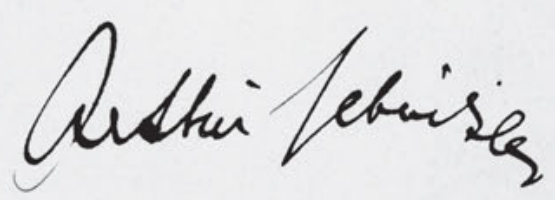

Man lasi 900 .

1077 


\section{Zieigen.}

Jehn Dialoge.

\section{Perionen :}

Die Dirnte.

Der Evlbat.

Då Stutbenutäbdjett.

Der juttge $\mathfrak{b e r r}$.

Die jutge જraut.

Der Erfegatte.

Då jüî̉e Miäber.

Der Didjter.

Die Edjaujpielerin.

Der Girạ́. 
Die Dirne und der Soldat. 


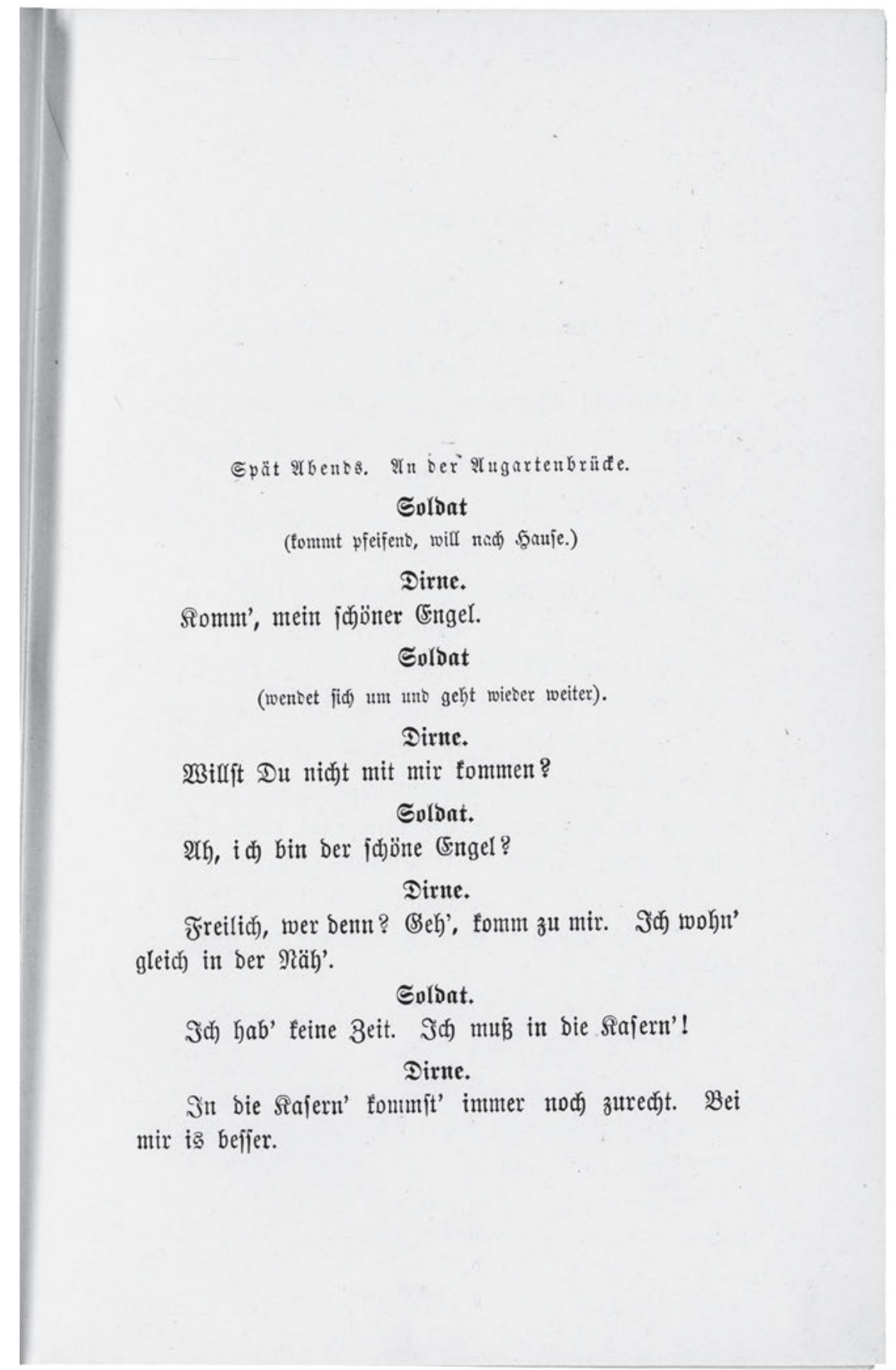


Solbat (greift nad ibr.)

Daకి ijt jớ)on niöglid).

Dirne.

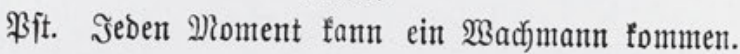

Solbat.

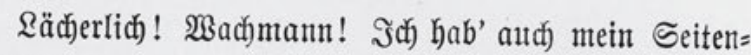
g'wehr!

$$
\begin{aligned}
& \text { Seh', fomm' mit. } \\
& \text { Solbat. }
\end{aligned}
$$

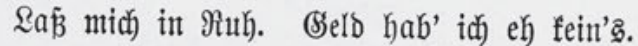

Dirnte.

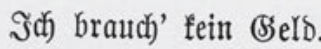

Solbat (bleibt fteben. Cie fint bei einer Saterne.)

Du braudjift fein Beld? Wer bijt Dent Dut nachber?

Dirne.

Bahlen thun mir bie Sibilifiten. So einer wie Dut fann's immer umionit bei mir haben.

Solbat.

Du bij̈t am End' die, bon ber mir ber Suber er= zählt hat. -

\section{Dirnte.}

Э̧c) fenn' fein' \$ुuber nicht.

Solbat.

Du wirît idjon bie jein. Weis̄t - in bem faffee= 
hauts in ber Sdjiffgaifen - von bort ift er mit Dir nad Şatı gangent.

Dirute.

Bon bem Saffeebaus bin id fdon mit gar vielen nach) Şaus gangen .... oh ! oh ! -

Solbat.

2rljo gehn wir, gehn wir.

Dirnte.

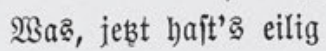

Solbat.

গa, worauf foll'n wir nod) warten? Utto um zehn mús id) in ber Sajern' jein.

Dirnte.

Wie lang bienft' benn fdon?

Golbat.

Waa geht benn bas Didh an? Wohnjt weit?

Dirnte.

3ehn Minuten zum gehn.

Solbat.

Dab ift mir zu weit. S5ieb mir ein \$ruffel.

Dinute. (હie füßt ifn.)

Das ijt mir eh bas liebite, wenn idh einen gern hab!

Soldat.

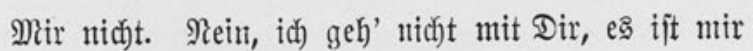
孔 weit. 
Dirute.

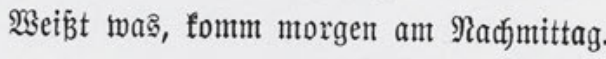

Soldat.

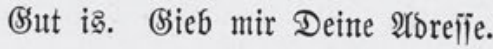

Dirne.

Áter Dut fommit am (End' nicht.

\section{Solbat.}

Wenn id) Dir's jag!

Dirne.

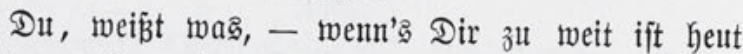
abend zu mir $-\delta a \ldots \delta a \ldots$ (weift anf sie Dorau).

\section{Soldont.}

$\mathfrak{W a}$ ift $b a ?$

Dirne.

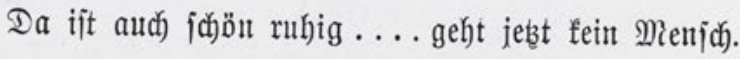
Solbat.

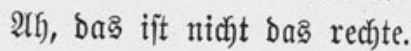

Dirne.

Bet mir is immer bas red)te. (3Seh', bleib jekst bei mir. Wer weiß̄, ob wir morgen nod's \&eben haben.

Soldat.

So fomm - aber g'idfinito!

Dirne.

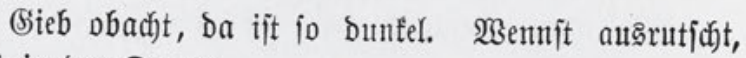
liegft in Der Donaut. 


\section{Enldat.}

Wär' eh bą bejte.

Dirute.

\$it, jo wart nur ein bifijel. BSleid) fommen wir zu einer $\mathfrak{B a n t}$.

\section{Sploat.}

Siennit Didj ba gut aแติ.

Dirute.

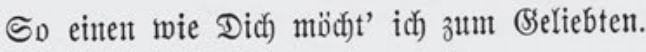

Soldat.

Эch thät' Dir zut viel eifern.

Dirnte.

Dą möd)t' id Dir fidjon abgewöhnen.

Golbat.

Şa -

Dirne.

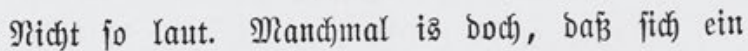
Waat)ter her verirrt. Sollt' man glauben, dá̉ wir ba mitten in ber $\mathfrak{S i e n t e r}$ Stabt fint?

\section{Solbat.}

Daher fomm', baher.

Dirne.

2્રber, was fällt Dir benn ein, wenn wir ba auts= rutichen, liegen wir im $\mathfrak{B a j f e r}$ unten.

Soldont hat fie gepadt.

2(F), Du- 
Dirne.

Şalt Didy mur fejt an.

Solbat.

ફ̧ab fein' $\mathfrak{A}$ ngĩt . . . . of . . . . .

Dirne.

2uf ber Bant wär's jđon befijer getwejen.

Soloat.

Da ober ba .... গ⿰a, frall' aufi.

Dirne.

Was Iauffit benn jo -

Solbat.

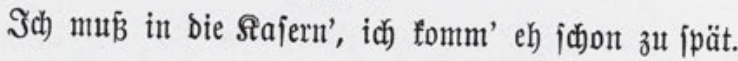
Dirne.

(Seh', Dut, wie heiñt' benn?

Solbat.

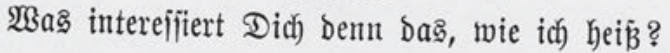

Dirnte.

Э̊ch) Keí̄ Reocabia.

Solbat.

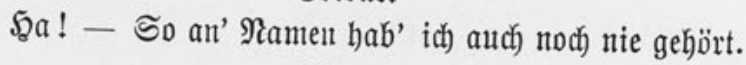

Dirnte.

Dut, idf werd Dir 'was jagen . . . io gut . . . . io $\ldots . \mathrm{of} \ldots$. . 10 . . geh', fomm' zit mir.

Solbat.

Jeķt? . . . Jekst? ? - 
Dirne.

Du!

Solbat.

Na, was willft benn?

Dirnte.

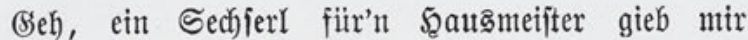
wenigitens! -

Eoldont.

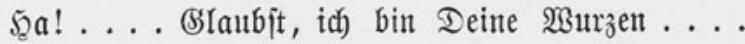
Serbus! Reocadia..

Dirute.

Strizzi! Fallott! -

(Er ift veridfwumten.) 


\subsection{Siglenverzeichnis}

Ausgaben

BHV Reigen. Zehn Dialoge. Geschrieben Winter 1896-97. 89.-99. Tausend. Berlin, Wien: Benjamin Harz=Verlag [1923/1924?].

EA Reigen. Zehn Dialoge. Geschrieben Winter 1896-97. Buchschmuck von Berthold Löffler. Wien, Leipzig: Wiener Verlag 1903.

JSV Reigen. Zehn Dialoge. Geschrieben Winter 1896-97. 44.-46. Tausend. Berlin: Verlag J. Singer \& CO. [1913?].

PD Reigen. Zehn Dialoge. Winter 1896/97. Als Manuscript gedruckt. Buchdruckerei Roitzsch vorm. Otto Noack \& Co. [1900].

SFV Reigen. Zehn Dialoge. 101.-104. Aufl. Berlin: S. Fischer Verlag 1931.

Edierte Texte

$\begin{array}{ll}\text { D } & \text { Drucktext (Grundlage: PD) } \\ \text { E } & \text { Entwurfskizze } \\ \text { H } & \text { Finale Textstufe; umfasst HF, HSz1-HSz10 } \\ \text { HF } & \text { Figurenliste } \\ \text { HSz1 } & \text { Szene 1 } \\ \text { HSz2 } & \text { Szene 2 } \\ \text { HSz3 } & \text { Szene 3 } \\ \text { HSz4 } & \text { Szene 4 } \\ \text { HSz5 } & \text { Szene 5 } \\ \text { HSz6 } & \text { Szene 6 } \\ \text { HSz7 } & \text { Szene 7 } \\ \text { HSz8 } & \text { Szene 8 } \\ \text { HSz9 } & \text { Szene 9 } \\ \text { HSz10 } & \text { Szene 10 } \\ \text { H'Sz9 } & \text { Textstufe zu Szene 9 } \\ \text { H'Sz10 } & \text { Textstufe zu Szene 10 } \\ \text { N } & \text { Notiz } \\ \text { TSz4 } & \text { Typoskript zu Szene 4 } \\ \text { U } & \text { Umschlag }\end{array}$


Unveröffentlichtes

NB

Notizbuch (CUL, A 193,2)

Zitierte Literatur

BI-HKA Arthur Schnitzler: Blumen. Historisch-kritische Ausgabe. Hrsg. v. Isabella Schwentner. Berlin, Boston: De Gruyter 2018 (Werke in historisch-kritischen Ausgaben).

BDB Börsenblatt für den deutschen Buchhandel.

Br I Arthur Schnitzler: Briefe 1875-1912. Hrsg. v. Therese Nickl u. Heinrich Schnitzler. Frankfurt a. M.: S. Fischer 1981.

Br II Arthur Schnitzler: Briefe 1913-1931. Hrsg. v. Peter Michael Braunwarth, Richard Miklin, Susanne Pertlik u. Heinrich Schnitzler. Frankfurt a. M.: S. Fischer 1984.

de Mendelssohn Peter de Mendelssohn: S. Fischer und sein Verlag. Frankfurt a. M.: S. Fischer 1970.

FBG-HKA Arthur Schnitzler: Frau Bertha Garlan. Historisch-kritische Ausgabe. Hrsg. v. Gerhard Hubmann u. Isabella Schwentner. Unter Mitarbeit v. Anna Lindner u. Martin Anton Müller. Berlin, Boston: De Gruyter 2015 (Werke in historisch-kritischen Ausgaben).

Fischer-Bw Samuel Fischer u. Hedwig Fischer: Briefwechsel mit Autoren. Hrsg. v. Dierk Rodewald u. Corinna Fiedler. Mit einer Einführung v. Bernhard Zeller. Frankfurt a. M.: S. Fischer 1989.

Hall Murray G. Hall: Der "Törleß"- und "Reigen"-Verleger. In: MusilForum 9 (1983), S. 129-149.

Heine $\quad$ Der Kampf um den Reigen. Vollständiger Bericht über die sechstägige Verhandlung gegen Direktion und Darsteller des Kleinen Schauspielhauses Berlin. Hrsg. und mit einer Einleitung v. Wolfgang Heine. Berlin: Rowohlt 1922.

Janz Rolf-Peter Janz: Zum Sozialcharakter des "süßen Mädels”. In: Ders. u. Klaus Laermann: Arthur Schnitzler: Zur Diagnose des Wiener Bürgertums im Fin de siècle. Stuttgart: Metzler 1977, S. 41-54; Ders.: "Reigen“. In: ebd., S. 55-75.

L-HKA Arthur Schnitzler: Liebelei. Historisch-kritische Ausgabe. Hrsg. v. Peter Michael Braunwarth, Gerhard Hubmann u. Isabella Schwentner. 2 Bde. Berlin, Boston: De Gruyter 2014 (Werke in historisch-kritischen Ausgaben).

LG-HKA Arthur Schnitzler: Lieutenant Gustl. Historisch-kritische Ausgabe. Hrsg. v. Konstanze Fliedl. Berlin, New York: De Gruyter 2011.

Pfoser I Alfred Pfoser, Kristina Pfoser-Schewig, Gerhard Renner: Schnitzlers ,Reigen'. Zehn Dialoge und ihre Skandalgeschichte. Analysen und Dokumente. Bd. 1: Der Skandal. Frankfurt a. M.: Fischer 1993. 
Pfoser II

Reinhardt-Bw

Rovagnati 2001

Rovagnati 2004

Schinnerer 1931

Schinnerer

1932/33

Schneider

St-HKA

Tb II

Tb III

Tb IV
Alfred Pfoser, Kristina Pfoser-Schewig, Gerhard Renner: Schnitzlers ,Reigen'. Zehn Dialoge und ihre Skandalgeschichte. Analysen und Dokumente. Bd. 2: Die Prozesse. Frankfurt a. M.: Fischer 1993

Der Briefwechsel Arthur Schnitzlers mit Max Reinhardt und dessen Mitarbeitern. Hrsg. v. Renate Wagner. Salzburg: Otto Müller 1971 (= Publikationen der Max-Reinhardt-Forschungsstätte II).

Gabriella Rovagnati: Arthur Schnitzler (1862-1931), Reigen'. In: Spiegel der Welt. Handschriften und Bücher aus drei Jahrtausenden. Eine Ausstellung der Fondation Martin Bodmer Cologny in Verbindung mit dem Schiller-Nationalmuseum Marbach und der Stiftung Museum Bärengasse Zürich. Hrsg. v. Martin Bircher in Zusammenarbeit mit Elisabeth Macheret-van Daele u. Hans-Albrecht Koch. Bd. 1. Cologny: Fondation Martin Bodmer u. Marbach: Deutsche Schillergesellschaft 2001 (= Marbacher Kataloge 55), S. 374-378.

Arthur Schnitzler: Ein Liebesreigen. Die Urfassung des "Reigen". Hrsg. v. Gabriella Rovagnati. Frankfurt a. M.: S. Fischer 2004.

Otto P. Schinnerer: The History of Schnitzler's Reigen. In: PMLA 46 (1931), 3, S. 839-859.

Otto P. Schinnerer: Systematisches Verzeichnis der Werke von Arthur Schnitzler. In: Jahrbuch deutscher Bibliophilen und Literaturfreunde 18/19 (1932/33), S. 94-121.

Gerd K. Schneider: Die Rezeption von Arthur Schnitzlers Reigen. 1897-1994. Text, Aufführungen, Verfilmungen, Pressespiegel und andere zeitgenössische Kommentare. Riverside: Ariadne 1995 (= Studies in Austrian Literature, Culture and Thought).

Arthur Schnitzler: Sterben. Historisch-kritische Ausgabe. Hrsg. v. Gerhard Hubmann. Berlin, Boston: De Gruyter 2012 (Werke in historisch-kritischen Ausgaben).

Arthur Schnitzler: Tagebuch 1893-1902. Unter Mitwirkung von Peter Michael Braunwarth, Konstanze Fliedl, Susanne Pertlik u. Reinhard Urbach hrsg. v. der Kommission für literarische Gebrauchsformen der Österreichischen Akademie der Wissenschaften, Obmann: Werner Welzig. Wien: Verlag der Österreichischen Akademie der Wissenschaften 1995.

Arthur Schnitzler: Tagebuch 1903-1908. Unter Mitwirkung von Peter Michael Braunwarth, Susanne Pertlik u. Reinhard Urbach hrsg. v. der Kommission für literarische Gebrauchsformen der Österreichischen Akademie der Wissenschaften, Obmann: Werner Welzig. Wien: Verlag der Österreichischen Akademie der Wissenschaften 1991.

Arthur Schnitzler: Tagebuch 1909-1912. Unter Mitwirkung von Peter Michael Braunwarth, Richard Miklin, Maria Neyses, Susanne Pertlik, Walter Ruprechter u. Reinhard Urbach hrsg. v. der Kommission für literarische Gebrauchsformen der Österreichischen 
Tb V

Tb VI

Tb VII

Tb IX

Tb $X$

TS-HKA

Urbach

Institutionen

CUL

DLA

NÖLA

TMW
Akademie der Wissenschaften, Obmann: Werner Welzig. Wien: Verlag der Österreichischen Akademie der Wissenschaften 1981. Arthur Schnitzler: Tagebuch 1913-1916. Unter Mitwirkung von Peter Michael Braunwarth, Richard Miklin, Susanne Pertlik, Walter Ruprechter u. Reinhard Urbach hrsg. v. der Kommission für literarische Gebrauchsformen der Österreichischen Akademie der Wissenschaften, Obmann: Werner Welzig. Wien: Verlag der Österreichischen Akademie der Wissenschaften 1983.

Arthur Schnitzler: Tagebuch 1917-1919. Unter Mitwirkung von Peter Michael Braunwarth, Richard Miklin, Susanne Pertlik u. Reinhard Urbach hrsg. v. der Kommission für literarische Gebrauchsformen der Österreichischen Akademie der Wissenschaften, Obmann: Werner Welzig. Wien: Verlag der Österreichischen Akademie der Wissenschaften 1985.

Arthur Schnitzler: Tagebuch 1920-1922. Unter Mitwirkung von Peter Michael Braunwarth, Susanne Pertlik u. Reinhard Urbach hrsg. v. der Kommission für literarische Gebrauchsformen der Österreichischen Akademie der Wissenschaften, Obmann: Werner Welzig. Wien: Verlag der Österreichischen Akademie der Wissenschaften 1993.

Arthur Schnitzler: Tagebuch 1927-1930. Unter Mitwirkung von Peter Michael Braunwarth, Susanne Pertlik u. Reinhard Urbach hrsg. v. der Kommission für literarische Gebrauchsformen der Österreichischen Akademie der Wissenschaften, Obmann: Werner Welzig. Wien: Verlag der Österreichischen Akademie der Wissenschaften 1997.

Arthur Schnitzler: Tagebuch 1931. Gesamtverzeichnisse 1879-1931. Unter Mitwirkung von Peter Michael Braunwarth, Susanne Pertlik u. Reinhard Urbach hrsg. v. der Kommission für literarische Gebrauchsformen der Österreichischen Akademie der Wissenschaften, Obmann: Werner Welzig. Wien: Verlag der Österreichischen Akademie der Wissenschaften 2000.

Arthur Schnitzler: Die Toten schweigen. Historisch-kritische Ausgabe. Hrsg. v. Martin Anton Müller. Unter Mitarbeit v. Ingo Börner, Anna Lindner u. Isabella Schwentner. Berlin, Boston: De Gruyter 2016 (Werke in historisch-kritischen Ausgaben).

Reinhard Urbach: Schnitzler-Kommentar zu den erzählenden Schriften und dramatischen Werken. München: Winkler 1974.

\section{Cambridge University Library}

Deutsches Literaturarchiv, Marbach a. N.

Niederösterreichisches Landesarchiv, St. Pölten

Theatermuseum, Wien 